\title{
The development of the building envelope using Welsh-grown timber: A study through prototyping
}

Steven John Coombs BSc (Hons) BArch DipArch RIBA

A dissertation submitted in The Welsh School of Architecture,

Cardiff University

In candidature for the degree of Philosophiae Doctor, Cardiff University 
The development of the building envelope using Welsh-grown timber: A study through prototyping

Steven John Coombs

\section{Declaration}

This work has not been submitted in substance for any other degree or award at this or any other university or place of learning, nor is being submitted concurrently in candidature $p$ r any degree or other award.

sones Shem

Date 22.04 .2016

Statement 1

This thesis is being submitted in partial fulfillment of the requirements for the degree of $\mathrm{PhD}$.

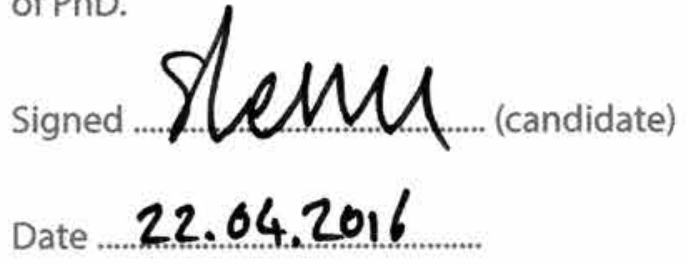

Statement 2

This thesis is the result of my own independent work/ investigation, except where otherwise stated. Other sources are acknowledged by explicit references. The views expressed are my own.

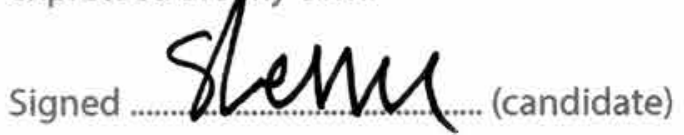

Statement 3

Thereby give consent for my thesis, if accepted, to be available for photocopying and for inter-library loan, and for the title and summary to be made available to outside organisations.

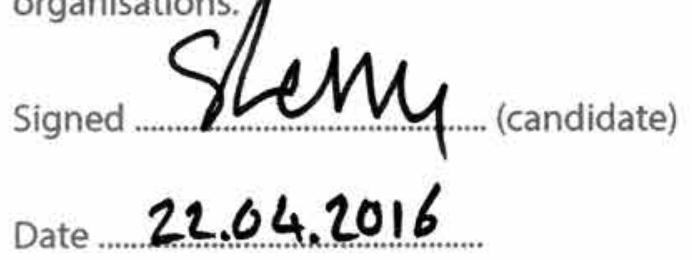





\section{Abstract}

This thesis tests the use of Welsh-grown timber in the building envelope, through the prototyping of a series of live design projects with a focus on species, technology and tectonic form. Projects are clustered under 4 headings identified as significant to the Welsh timber industry: hardwoods, engineered timber, timber board products and the complete timber envelope.

The Welsh timber industry relies heavily on the importation of sawnwood, timber board products and innovative, engineered timber systems to meet an increasing demand to improve construction efficiency and the environmental performance of the building envelope. Compared to Northern and Central Europe and regions such as the Vorarlberg, Austria, Wales is perceived as having an underdeveloped and underperforming timber construction industry with only $15 \%$ forest cover to supply a variety of timber sectors.

This thesis analyses the properties of Welsh-grown soft and hardwoods, the technical and skill limitations and opportunities of the industry and highlights the impact of the use of timber on the tectonic form of the building envelope. These evaluations inform the observations and reflections of 12 architectural prototype projects to demonstrate potential to exploit the Welsh-grown timber crop in the design and construction of the architectural building envelope.

The research demonstrates that it is possible to use Welsh-grown timber for a variety of modular superstructure, cladding and external joinery systems. The conclusions identify limitations, such as a lack of research and development investment, from government and business, and a lack of knowledge and focused direction across the industry. However, the prototype projects show that the unique properties of timber, sustainably grown, managed and processed in Wales can be innovatively manufactured and assembled into prefabricated, components for the design and construction of the low-energy architectural building envelope. Furthermore, the properties, technology and skills available have informed an additive tectonic approach that is specific to Welsh-grown timber. 
In memory of

David Jenkins MBE

(1952 - 2015) 


\section{Contents}

Abstract

Contents

Acknowledgements

List of Illustrations

Preface

Introduction

1.1 Context

2 Problem

1.3 Aim and Objectives

Hypothesis

Method

Structure

2.1 Introduction

2.2 A history

2.3 Wood and timber properties

2.3.1 Qualities of wood

2.3.2 Woodland management

2.3.3 Certification

2.3.4 Classification of trees and wood

2.3.5 Anatomy of wood

2.3.6 Processing wood

2.3.7 Mechanical properties of timber

2.3.8 Durability of timber

2.4 Welsh woodlands and trees

2.4.1 Welsh woodland

2.4.2 Welsh-grown tree species

2.4.3 Identification of useable Welsh-grown timber species

$2.5 \quad$ Findings

2.5.1 Woodlands and trees

2.5.2 Timber properties

2.5.3 Findings to take forward 
3.1 Introduction

3.2 Political and advisory context

3.3 Import v homegrown

3.3.1 UK and Wales production

Timber procurement and supply chain

Forest owners and harvesting

Primary processing

Secondary processing

3.8 Timber construction

3.8.1 Timber construction in Wales

3.8.2 A Way Forward

3.9 Findings

3.9.1 Woodland supply and primary processing

3.9.2 Secondary processing and construction

3.9.3 Findings to take forward

The Building Envelope

4.1 Introduction

4.2 The building envelope

4.2.1 Building elements

4.2.2 Performance requirements

4.2.3 Low-energy envelope

4.2.4 Modern Methods of Construction

4.3 The timber building envelope

4.3.1 Superstructure and infil

4.3.2 External cladding and finishes

4.3.3 External joinery

4.3.4 Other

4.4 Best practice precedent

4.5 Findings

4.5.1 Findings to take forward

Introduction

Hypothesis

Aim

Objectives

Scope and limitations

Framework for evaluation 
5.6.1 Welsh-grown timber, species and adaptation

5.6.2 Building envelope

5.6.3 Technology and skills

5.6.4 Tectonic form

5.6.5 Prototype studies

5.6.6 Evaluation matrix

5.7 Research Method

5.7.1 The role of the author

5.7.2 Design process

5.7.3 Design research

5.7.4 Prototype

5.7.5 Reflection

5.7.6 Next steps

6.1 Introduction

6.1.1 Research aim

6.1.2 Limitations

6.2 Context and precedent

6.2.1 Rainscreen claddings

6.2.2 'Green' structures

6.2.3 Bedales School Olivier Theatre

6.2.4 Darwin College study centre

6.3 The beach hut

6.3.1 Design

6.3.2 Prototype

6.3.3 Observations and reflections

6.4 Findings on hardwoods

7.0 Engineered timber

7.1 Introduction

7.1.1 Research aim

7.1.2 Limitations

7.2 Context and precedent

7.2.1 What is engineered timber?

7.2.2 Glue laminated components

7.2.3 Cross-laminated timber

7.2.4 Brettstapel

7.2.5 Bridge building

7.2.6 The Hiili Cafe, Helsinki, Finland 
319

7.3.3 Observations and Reflections 331

7.4 Stress-lam construction

7.4.1 Design

7.4.2 Prototype

7.4.3 Observations and Reflections

7.5 Findings on engineered timber

8.1 Introduction
8.1.1 Research aim
8.1.2 Limitations

8.2 Context and precedent

8.2.1 Timber board products

8.2.2 Furniture houses, Shigeru Ban

8.2.3 Everyday materials

8.3 Eisteddfod pavilion

$$
\text { 8.3.1 Design }
$$

8.3.2 Prototype

8.4 Cardiff Castle kiosk

8.4.1 Introduction

8.4.2 Brief

8.4.3 Site

8.4.4 Planning

8.4.5 Detailed design

8.5 Observations and Reflections

8.5.1 Species performance and adaptation

8.5.2 Building envelope

8.5.3 Technology and skills

8.5.4 Tectonic form

8.6 Findings on timber board products 
9.2.2 Affordable housing in rural Wales

9.2.3 Timber prefabrication

9.2.4 Precedents

9.3 Sitka spruce construction system

9.3.1 Feasibility

9.3.2 Primary structure

9.3.3 Secondary structure

9.3.4 Prototype structure

9.3.5 Observations and reflections

9.4 Smithsonian pavilion

9.4.1 Design

9.4.2 Prototype

9.4.3 Observations and reflections

9.5 Environmental Resource Centre

9.5.1 Design

9.5.2 Prototype

9.5.3 Observations and reflections

9.6 Welsh Longhouse

9.6.1 Design

9.6.2 Prototype

9.6.3 Observations and reflections

9.7 Findings on the complete timber envelope

Findings

10.1 Introduction

10.2 Firmitas

10.2.1 Welsh-grown timber and adaptation

10.2.2 Material efficiency

10.2.3 Fabrication and construction

10.2.4 Collaborative design

10.3 Utilitas

10.3.1 Superstructure

10.3.2 Claddings, finishes and joinery

10.3.3 Integrated envelope

10.3.4 Fire protection

10.4 Venustas

10.4.1 Rules, grids and systems

601

10.4.2 Composition and form 


\section{Glossary of terms}




\section{Acknowledgements}

This research would not have been possible without the support, guidance and assistance of others. I would like to thank:

Professor Wayne Forster, my supervisor, for his guidance and encouragement throughout my time in DRUw and with this research.

Professor Chris Tweed, my second supervisor, for his support with my career.

My colleagues within the Welsh School of Architecture, Cardiff University for all their support through my education and ongoing teaching and research. In particular past and present members of the Design Research Unit Wales: Rhian, Mat, Amanda, Caroline, Heidi, Rob, Amy, Richard, Monica, Alex, Sam, Ed and Jon who I have enjoyed working with and learnt a lot from.

Coed Cymru: David, Gareth, Nigel, Tabitha and Dylan who introduced me to Welsh timber and industry contacts, allowing me to find my feet and continue this research.

There are a wide number of vital collaborators, including clients, funding bodies, engineers, foresters, joiners, carpenters, contractors and other specialists that are too numerous to name, but without their professional guidance and contributions this practice-based research would not have been possible.

Finally, I would like to thank my patient and supportive family, my parents, Vicky and Woody through this lengthy research and period of bad health. 


\section{List of illustrations}

All illustrations and photographs are copyright property of the author or Design Research Unit Wales if not otherwise stated.

\section{Preface}

Fig. i Expressed roof structure of Sogn Benedetg chapel, Peter Zumthor ....

Fig. ii Expressed detailing and tectonic elements of Shadowbox house

Olson Kundig

Source: http://buildipedia.com/at-home/design-remodeling/camping-influences-

home-design [accessed 25th March 2014]

Fig. iii Standardised and prefabricated Bagsværd church, Jørn Utzon ...................xlii Source: <https://en.wikipedia.org/wiki/Bagsværd_Church> [accessed 25th March 2014]

Fig. iv Demountable chair by Jean Prouvé ................................. xlii Source: <http://jergreene.tumblr.com/image/82838724024> [accessed 25th March 2014]

Fig. $v \quad$ Restoration of MG Midget MkIII, $1997 \ldots \ldots$

Fig. vi 1:20 model of BArch thesis primer for a beach rescue station on the Gower peninsula, $2000 \ldots$....

ig. vii 1:20 modular model of social housing scheme made in DRUw, $2001 \ldots$

\section{Chapter 1}

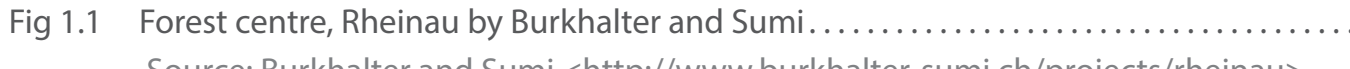
Source: Burkhalter and Sumi <http://www.burkhalter-sumi.ch/projects/rheinau> [accessed 3rd September 2015]

Fig 1.2 School sports hall, Mehrzweckhalle, Vrin by Gion Caminada ................. Source: <http://www.dezeen.com/2014/04/16/gion-a-caminada/> [accessed 3rd September 2105]

Fig 1.3 Private house, Schaffhausen by Hermann Kaufmann ........................ Source: Architekten Hermann Kaufmann <http://www.hermann-kaufmann.at/ index.php?pid=2\&kid=2\&prjnr=05_29\&lg=en> [accessed $3 r d$ September 2015]

Fig 1.4 PhD structure diagram.....

\section{Chapter 2}

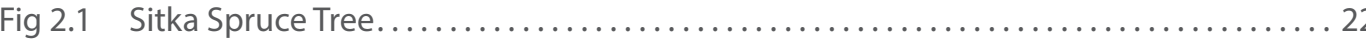

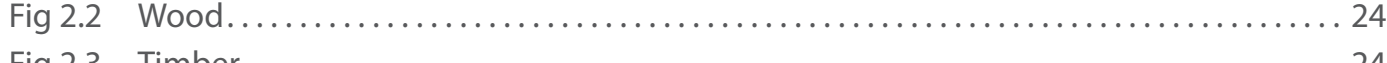

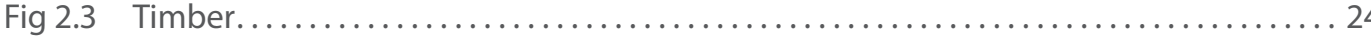

Fig 2.4 Ancient forest, Abergavenny .......................................... 24

Fig 2.5 Deciduous woodlands of the Wye Valley, Symonds Yat....................... 24 Source: Forestry Commission

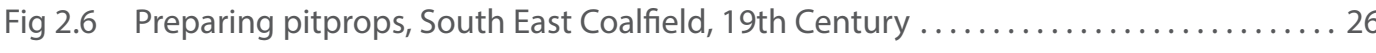
Source: Amgueddfa Cymru — National Museum Wales

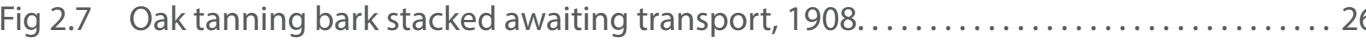
Source: Amgueddfa Cymru — National Museum Wales

Fig 2.8 Timber species commercially available as lumber around the world............... 26 Source: Nick Gibbs, The Real Wood Bible (London: Firefly Books Ltd, 2005) p.38

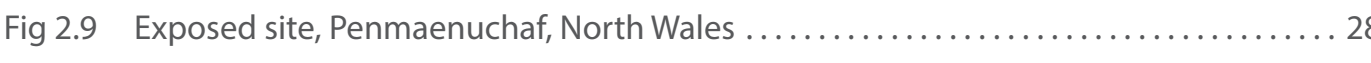
Credit: Guthrie Whitby 
Fig 2.10 Site adjacent to water, River Wye ..... Source: <http://www.ggat.org.uk/cadw/historic_landscape/wye_valley/images hlc001 lrg.gif > [accessed 31st August 2015]

Fig 2.11 Steeply sloping site, North Wales .... Source: <http://www.woodlands.co.uk/blog/practical-guides/creating-a-campsite/> [accessed 31st August 2015]

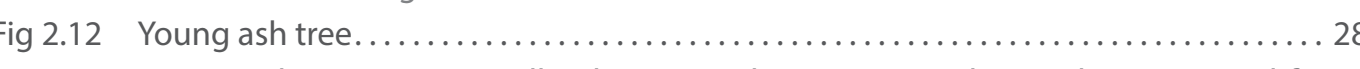
Source: <http://www.woodlandtrust.org.uk/visiting-woods/wood/4401/pound-farm/> [accessed 31st August 2015]

Fig 2.13 Tall, mature Douglas fir tree ............................................ 28 Source: <http://www.woodlandtrust.org.uk/visiting-woods/wood/26817/styal-estate/> [accessed 31st August 2015]

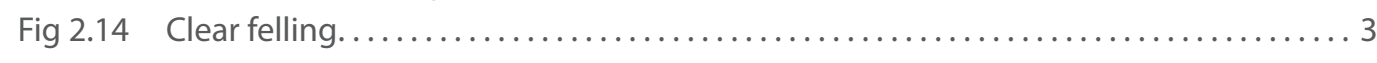
Source: <http://www.telegraph.co.uk/news/earth/environment/forests/10896910 Too-few-trees-planted-to-protect-woodland.html> [accessed 31st August 2015]

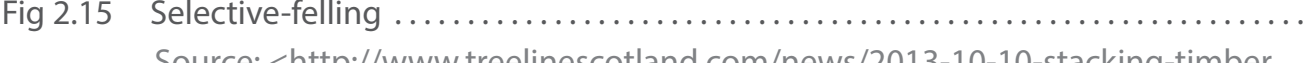
Source: $<$ http://www.treelinescotland.co into-the-sunset/> [accessed 31st August 2015]

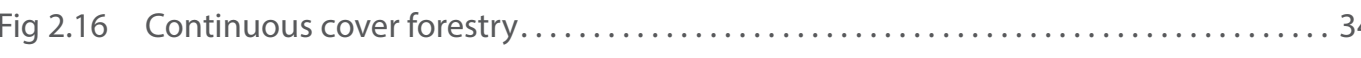
Source: <http://www.forestry.gov.uk/fr/infd-94lcmr> [accessed 30th August 2015.

Fig 2.17 Thinning. .... Source: <http://www.woodlandtrust.org.uk/visiting-woods/wood/4704 georges-wood/> [accessed 31st August 2015]

Fig 2.18 Coppicing Source: <https://www.woodlandtrust.org.uk/visiting-woods/wood/4293/views wood-the-williams-wood/> [accessed 31st August 2015]

Fig 2.19 Pruning Source: <http://surrey-tree-surgeons.co.uk/tree-pruning/> [accessed 31 August 2015]

Fig 2.20 Certification logos for sustainable forestry as applied to felled roundwood ........ 36 Source: <www.fsc-uk.org> / <www.pefc.org> laccessed 30th August 2015]

Fig 2.21 Functions of a sustainable forest ..

Source: Forestry Commission, Forestry Facts and Figures Sustainable Forest Management (Edinburgh: Forestry Commission, 2002) p.3

Fig 2.22 Areas of FSC certified woodland .... Source: Forestry Commission, Forestry Statistics 2014 (Edinburgh: Foresty Commission, 2014) p.9, 13

Fig 2.23 Sitka spruce timber swatch....

Fig 2.24 Needles and cones.

Source: John White, Jill White and S. Max Walters Trees: A feld guide to the thes of Britain and Northern Europe (New York: Oxford University Press, 2005) p.77

Fig 2.25 English oak timber swatch ......................................... 40 Fig 2.26 Wide leaves and seed $\ldots \ldots \ldots \ldots \ldots \ldots \ldots \ldots \ldots \ldots \ldots \ldots \ldots \ldots \ldots \ldots \ldots \ldots \ldots$
Source: $<$ http://www.ccfg.org.uk/about/about.html> [accessed 30 August 2015]

Fig 2.27 Softwood and Hardwood species in Wales........................... Commission, 2014)

Fig 2.28 Tree Anatomy Source: <http://dickeytree.com/injection.htm> [accessed 30th August 2015]

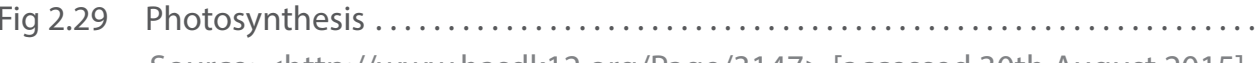
Source: <http://www.hasdk12.org/Page/3147> [accessed 30th August 2015]
Fig 2.30 Transverse section of softwood.

Source: <http://www.sbs.utexas.edu/mauseth/weblab/webchap15wood 15.3-2.htm> [accessed 30th August 2015

Fig 2.31 Late/early wood in tree trunk ....

Fig 232 Anatomy of a tree trunk

Source: CV Y Chong, Properties of materials (Plymouth: MacDonald and Evans Limited, 1977) p.1078\&

Fig 2.33 Cross-sections to show the differences in softwood (left) and hardwood (right) ... 44 Source: WPK Findlay, Timber: Properties and Uses (Herts: Granada Publishing Limited, 1978) p.13

Fig 2.34 Live knot

Source: <http://www.trada.co.uk/images/onlinebooks/981519E1-AA46-4C59 AAC5-295CFDB987FD/> [accessed 31st August 2015]

Fig 2.35 Intergrown knot Source: <http://www.popularwoodworking.com/projects/knots accessed 31st August 2015]

Fig 2.36 Dead knots....

Source: <https://en.wikipedia.org/wiki/Wood> [accessed 31st August 2015]

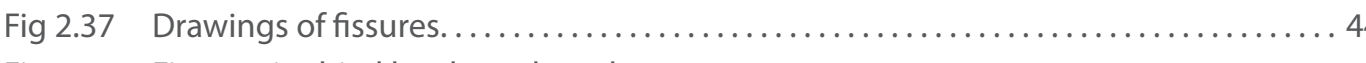

Fig 2.38 Fissures in dried hardwood trunk................................... 44 Source: <http://www.hobbithouseinc.com/personal/woodpic figureandgrainterms.htm $>$ [accessed 31st August 2015]

Fig 2.39 Roundwood ......................................................... 46

(a) Source: http://www.railwaysleeper.com/KFtelegraphpoles.htm [accessed 31 August 2015]

(b) Source: http://fencepanelss.net/round-wood-fence/ [accessed 01 September 2015] (c) Source: Naomi Stungo, The New Wood Architecture (London: Laurence King Publishing, 2001) p.13

Fig 2.40 Sawmilling

(d) Source: <http//wwwelectro-gid ru/frm_goods/3684/> [accessed 2nd May 2013] (f) Source: $<$ http.//www.coppiceandcleave.co. $\mathrm{k} /$ moroto laccessed 31st August 2015]

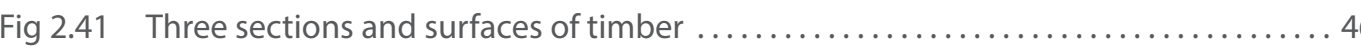

Fig 2.42 Tree cutting diagrams.

Fig 2.43 Distortion of boards on drying..... Source: WPK Findlay, Timber: Properties and Uses (Herts: Granada Publishing Limited, 1978) p. 191

Fig 2.44 Timber use and moisture content .................... 48

Fig 2.45 Air drying (left) and kiln dried (right) timber . . . . . . . . . . . . . . . . . . . . . . 50

Fig 2.46 Standard sawn softwood sizes table............................ 50 Source: TRADA, Wood Information Sheet: Softwood sizes WIS 2-3/37 (Buckinghamshire: TRADA Technology Ltd, January 2015)

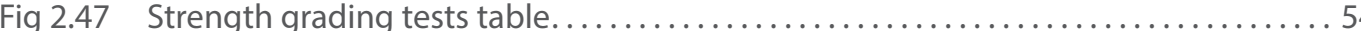

Fig 2.48 BMTRADA Certification grade mark on visually graded timber .......................56 56 Source: Trada, Dry-graded structural softwood (UK, Trada, 2002) p.3

Fig 2.49 Welsh-grown timber strength grades............................... 56 Source: Ivor Davies, Sustainable Construction Timber: Sourcing and specifying loca timber (Edinburgh: Forestry Commission Scotland, 2009) p.15

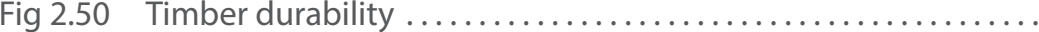

Source: Alan Everett, Mitchell's Materials 5th Edition (Longman Group UK Ltd: fourth impression, 1997) . 44 . . .

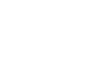


Fig 2.51 Cross section through glue laminated timber beam after 30 minutes and 60 minutes exposure to fire Source: Wolfgang Ruske, Timber Construction for Trade, Industry, Administration

Source: $<$ http://www.lunerouge.org/spip/article.php3?id_article $=950>$ [accessed 1st September 2015]

Fig 2.53 Durability and use classes.... Source: I. Davies, P. Walker, J. Pendlebury, Timber Cladding in Scotland (Edinburgh: ARCA Publications Ltd, 2002) pp. 32-33

Fig 2.54 Treatment classes...

Source: British Standards Institution, BS EN 350-2: 1994, Durability of wood and wood-based products - Natural durability of solid wood, Part 2: Guide to the natural durability and treatability of selected wood species of importance in Europe (London: BSI, 1994)

Fig 2.55 Indigenous and introduced tree species in Wales ........................... Source: The Woodland Trust, British Trees: native and non-native trees, $<\mathrm{http}: / / \mathrm{ww}$. woodlandtrust.org.uk/visiting-woods/trees-woods-and-wildlife/british-trees/> [accessed 17th August 2015]

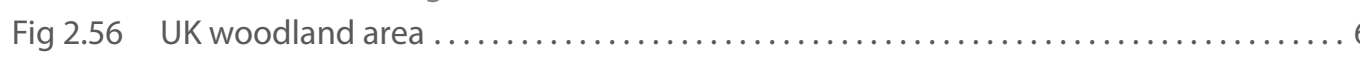
Source: Forestry Commission, Forestry Statistics 2014 (Edinburgh: Forestry Commission, 2014), p.9 \& 13

Fig 2.57 Map of Woodland in Wales....

Fig 2.58 International woodland areas . Source: Foresty Commission, Fonesty Facts and Fino.......................... Commission, 2010) p.145

Fig 2.59 Coniferous and broadleaf tree areas in Wales . Source: Forestry Commission, National Inventory of Woodlands and trees: Wales (Edinburgh: Foresty Commission, 2002) / Forestry Commission, NFI 2011 Woodland Map Wales: National Forest Inventory Report (Edinburgh: Foresty Commission, 2011)

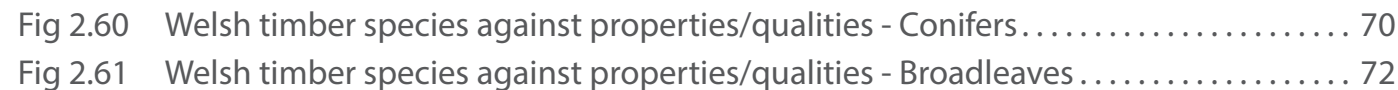

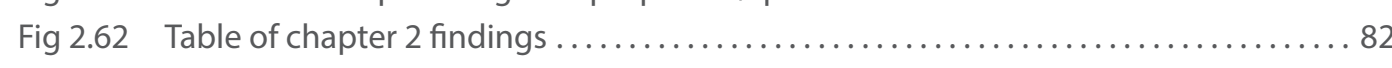

\section{Chapter 3}

Fig 3.1 Woodland for Wales key indicators chart.....

Source: Forestry Commission Wales, Woodlands for Wales: The Welsh Assembly Government's Strategy for woodlands and trees (Cardiff: Welsh Assembly Government, 2009), p.9

Fig 3.2 Volumes and values of imported wood and wood products .... Source: Forestry Commission, Forestry Commission Statistics 2014 (Edinburgh: Forestry Commission 2014) tables 3.2, 3.4 and 3.6, p.80-82

Fig 3.3 Businesses by main source of timber and quantity of timber used by source ....... 98 Source: Forestry Commission Wales survey of woodland enterprises

Fig 3.4 Origin of wood imports into the UK .............................. 100 Source: Forestry Commission, Forestry Commission Statistics 2014 (Edinburgh: Forestry Commission 2014) table 3.8, p.95-6

Fig 3.5 UK apparent consumption of wood and wood products..... Source: Forestry Commission, Forestry Commission Statistics 2014 (Edinburgh: Forestry Commission 2014) table 3.2, p.89 \& tables 2.5, 2.6 \& 2.7, p.52-55
Fig 3.6 Turnover of Manufacturing Industries in the UK $2012 \ldots \ldots \ldots \ldots \ldots \ldots \ldots \ldots \ldots . \ldots \ldots$ Source: Timber Trade Federation, Statistical Review 2014 (London: TTF 2014) p.29

Fig 3.7 Welsh timber supply chain from forest to end-user ......................... 110

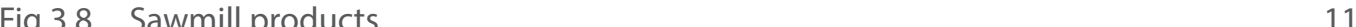
Source: Dennis Jones, Review of the Welsh Timber Resource

(Port Talbot: BRE Wales, 2011) p.30

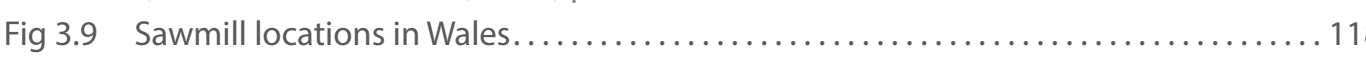

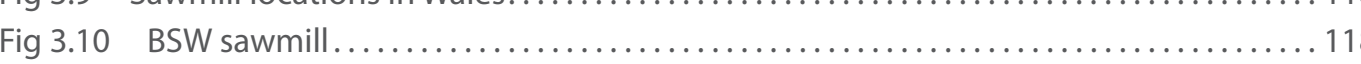
Credit: Aaron Sneddon

Fig 3.11 Aerial view of Wentwood Timber Store ................................. 118 Source: "Wentwood" $51^{\circ} 38^{\prime} 39.30^{\prime \prime} \mathrm{N}$ and 2 $2^{\circ} 49^{\prime} 47.68^{\prime \prime} \mathrm{W}$ Google Earth. [accessed 26th August 2015]

Fig 3.12 Wales and UK production of softwood sawnwood and other product markets .... 120 Source: Forestry Commission, Forestry Commission Statistics 2014 (Edinburgh: Forestry Commission 2014) tables 2.14 \& 2.15, p.62-64 \& tables 2.17 \& 2.18, p.66-67

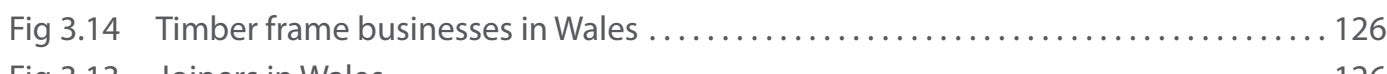

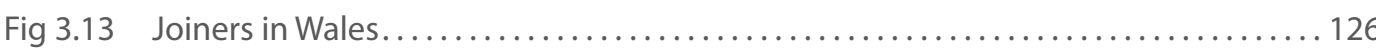

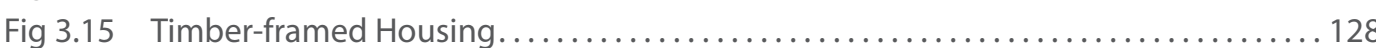
Source: Timbertrends, Market Report 2012 (Alloa: Structural Timber Association, 2012) p.5

Fig 3.16 Main uses of UK grown timber Source: Ivor Davies, Sustainable Construction Timber: Sourcing and specifying local timber (Edinburgh: Forestry Commission Scotland, 2009) p.7 \& 8

Fig 3.17 Construction products made of UK grown timber....................... Source: Ivor Davies, Sustainable Construction Timber: Sourcing and specifying local timber (Edinburgh: Forestry Commission Scotland, 2009) p.9

Fig 3.18 Table of Technology and skills findings ...

\section{Chapter 4}

Fig 4.1 Building element performance requirements ... Source: Peter Rich \& Yvonne Dean, Principles of Element Design (Oxford: Butterworth Heinemann, 1999); Derek Osbourn, Mitchell's Building Series: Introduction to Building (Harlow: Addison Wesley Longman Ltd, 1997); Robin Lancashire and Lewis Taylor, Timber Frame Construction: designing for high performance, (High Wycombe: TRADA Technology Ltd, 2011) Ted J. Kesik, 'Building Enclosure Design Principles and Strategies, Whole Building Design Guide, (Toronto: National Institute of Building Sciences, 2014)

Fig 4.2 Diagram of the building envelope performance requirements................. 152 Source: Derek Osbourn, Introduction to Building (Harlow: Addison Wesley Longman Limited, 1997) p.5

Fig 4.3 Objectives of Good Design Source: Welsh Government, Technical Advice Note 12 (2014) p.7

Fig 4.4 Diagram of the elemental and layered building envelope .......................... 154

Fig 4.5 Energy Hierarchy Diagram. .................. 154 Source: Welsh Government, Technical Advice Note 12 (2014) p.30

Fig 4.6 Timeline to zero carbon housing................................... 156

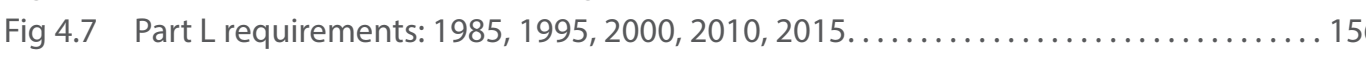
Source: Building Regulations Approved Document Part L

Fig 4.8 Definitions of Modern Methods of Construction........................... 158

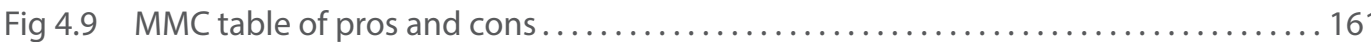
Source: Design Research Unit Wales, MMC Wales Executive Summary (Cardiff:WSA 2008 
Fig 4.10 Key national and international developments of prefabrication and Modern Methods of Construction Source: Design Research Unit Wales, MMC Wales : Achieving Modern Methods of

Construction in Wales (Cardiff: Welsh School of Architecture, 2008) p.4 - 5

Fig 4.11 Programme comparison of Modern Methods of Construction types ............. 162 Source: Design Research Unit Wales, MMC Wales Executive Summary (Cardiff: WSA, 2008)

Fig 4.12 Cost comparison of Modern Methods of Construction types .................. 162 Source: National Audit Office, Using modern methods of construction to build homes more quickly and efficiently (London: National Audit Office, 2005) p.14

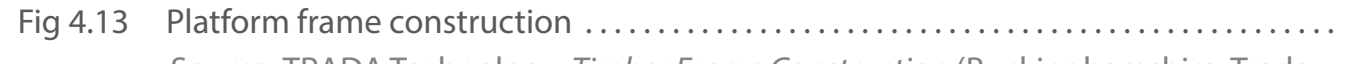
Source: TRADA Technology, Timber Frame Construction (Buck. Technology Limited, 2008) p.17

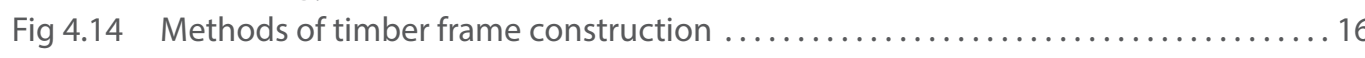
Source: Wolfgang Rushke, Timber Construction for Trade, Industry, Administratio (Basel: Birkhauser, 2004) p.20-1

Fig 4.15 Volumetric construction ..... Technology Limited, 2008) p.19

Fig 4.16 Horizontal boarding profiles .......................... 170 Source: Patrick Hislop, External Timber Cladding (Buckinghamshire: Trada Technology Limited, 2008) p.49

Fig 4.17 Profiles suitable for vertical boarding ..... Source: Patrick Hislop, External Timber Cladding (Buckinghamshire: Trada Technology Limited, 2008) p.50

Fig 4.18 Sogn Benedetg Chapel, Sumvitg, Switzerland, $1988 \ldots \ldots \ldots \ldots \ldots \ldots . \ldots 175$

Fig 4.19 Summer sauna, Mikkeli ............................................. 175 Source: Pekka Heikkinen, Jari Laiho, Jussi Tiainen, Wood Works (Tampere: Parvs Publishing, 2007) p.17

Fig 4.20 Karsamaki Church, Finland, 2004 Source: <www.oopeaa.com/project/karsamaki-shingle-church> [accessed 4th September 2015]

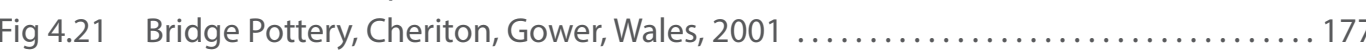
Source: Dean Hawkes, 'Necessity and Poetry: David Lea's Bridge Pottery', ARQ, 6 (2002), 131-143 (p.135)

Fig 4.22 Pfarrhaus, Krumbach, Vorarlberg, Austria, 2013 .......................... 177 Source: <www.hermann-kaufmann.at/index.php?pid=2\&kid=\&prjnr=11_12\&lg=en> [accessed 4th September 2015]

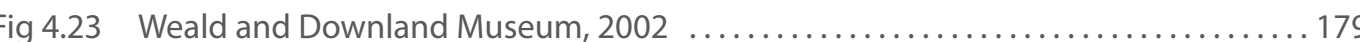

Fig 4.24 Kupla - Observation Tower at Korkeasaari Zoo, Helsinki ......................... 179 Source: Pekka Heikkinen, Jari Laiho, Jussi Tiainen, Wood Works (Tampere: Parvs Publishing, 2007) p.38

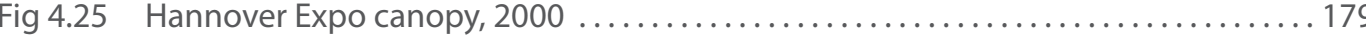
Source: <www.kubuildingtech.org/sarcweb/Assemblages00/dieste/htmlfiles/related htmlfiles/related.htm> / http://archidialog.com/tag/metropol-parasol-sevilla> [accessed 4th September 2015]

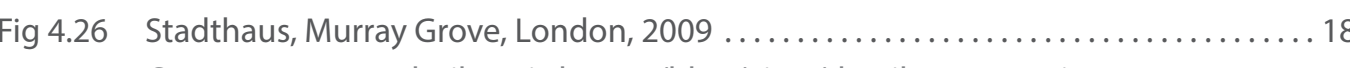
Source: <www.techniker.oi-dev.org/blog/view/detail-green-saving-120-tonnesof-co2 $>/<$ www.proholz.at/zuschnitt/33/holz-in-the-city $>$ [accessed 4th September 2015]

Fig 4.27 Graz Impulse Centre, Graz, 2004 .................... 181

Fig 4.28 Serpentine Pavilion ............................................. 183

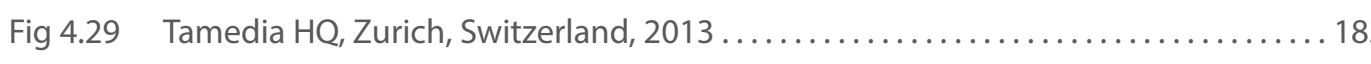
Source: <www.enraiza.es/2015/03/otra-manera-de-entender-la-arquitectura> <www.surfingbird.ru/surf/f-rTcD64c\#.VerUizReJOc> [accessed 4th September 2015]

Fig 4.30 LlfeCycle Tower, Dorbirn, Vorarlberg, Austria, 2012 ...

Source: Christian Schittich, Best of Detail: Holz/ Wood (München: Institut fü international Architektur-Dokumentation GmbH \& Co. KG, 2014) p.77/ <www.hermann-kaufmann.at/index.php?pid=2\&kid=\&prjnr=10_21\&lg=en> [accessed 4th September 2015]

Fig 4.31 Brockholes Visitor Centre, Preston, UK, $2011 \ldots$ Source: Christian Schittich, Best of Detail: Holz/Wood (München: Institut für international Architektur- Dekumentation GmbH \& Co. KG 2014) p.126

Fig 4.32 Mount Stuart Visitor Centre, Isle of Bute, Scotland, 2001 ..................... 185 Source: <www.sleepeatenjoy.com/2015/03/23/mount-stuart-visitor-centre-isleof-bute> [accessed 4th September 2015

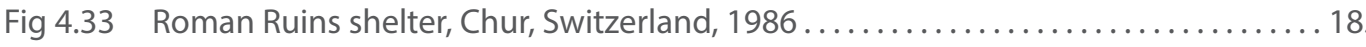

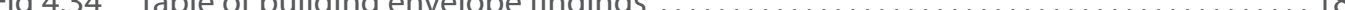

\section{Chapter 5}

Fig 5.1 Timber adaptation for evaluation ..................................... 198

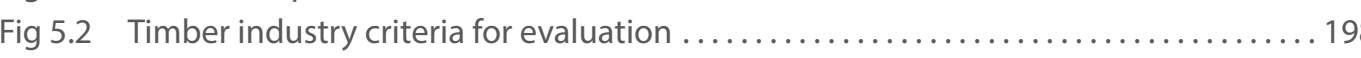

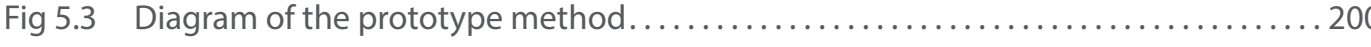

Fig 5.4 Framework for evaluation matrix ........................................ 202

Fig 5.5 Tradition and Innovation Tijbaou Cultural Centre, Noumea, Renzo Piano.......... 208 Source: <www.rpbw.com/project/41/jean-marie-tjibaou-cultural-center/\#> [accessed 5th September 2015]

Fig 5.6 Originally conceived as a new community that harmonized with its environment The Sea Ranch, California, Charles Moore ... Source: <www.greatbuildings.com/buildings/Sea_Ranch_Condominium.html> [accessed 5th September 2015]

Fig 5.7 Concrete walls extend into the sea and around existing rock formations to embed the pools within their context, Leça Swimming Pools, Porto, Alvaro Siza .......... 208 Source: <www.e-architect.co.uk/portugal/leca-swimming-pools > [accessed 5th September 2015]

Fig 5.8 The cladding reflects the changing landscape surrounding the building, Chameleon House, Lake Michigan, Anderson Anderson Architecture ..................... 210 Source: <www.designboom.com/architecture/anderson-anderson-architecturechameleon-house/> [accessed 5th September 2015

Fig 5.9 The act of making and craft, Tom Kundig............................. 210 Source: <www.dwell.com/profiles/article/man-steel> [accessed 5th September 2015]

Fig 5.10 The corporeal experience, Swiss Pavilion, Peter Zumthor .................... 210 Source: <www.brainport.bwk.tue.nl/?page_id=78> [accessed 5th September 2015]

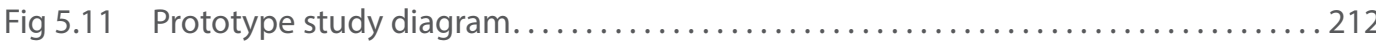

Fig 5.12 Design research method definitions ...................................... 214

Fig 5.13 Prototype study project details........................................ 216

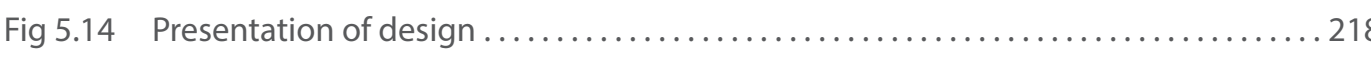

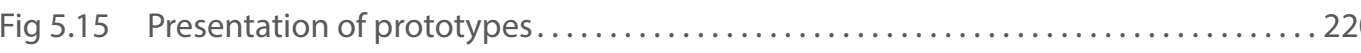

Fig 5.16 Wood Thinnings, Thinnings Teahouse, Rural Studio........................ 220 Source: <www.ruralstudio.org/projects/lions-park-scouts > [accessed 5th September 2015]

Fig 5.17 The act of making, projects by Assemble..................... 222 Source: <www.assemblestudio.co.uk> [accessed 5th September 2015] 
Fig 5.18 Models and 1:1 Prototype, Jean-Marie Tjibaou Cultural Center, Renzo Piano Building Workshop 222 Source: <www.fondazionerenzopiano.org/project/85/jean-marie-tjibaoucultural-center/models/page/1/> [accessed 5th September 2015]

Fig 5.19 Learning by doing, The Wood Program, Helsinki ..... Source: Pekka Heikkinen, Jari Laiho, Jussi Tiainen, Wood Works (Tampere: Parvs Publishing, 2007) p.2

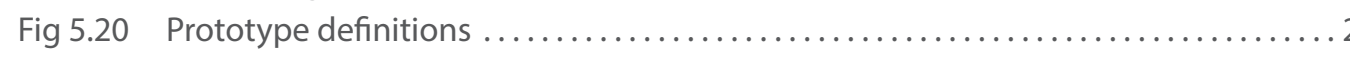
Source: Della Thompson (ed.), The Pocket Oxford Dictionary (Oxford: Clarendon Press 8th edition, 1992)

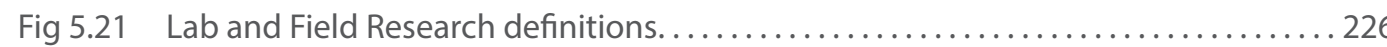
Source: Illpo Koskinen, John Zimmerman, et al, Design Research Through Practice: From the lab, _eld and showroom, (Elsevier, 2011

Fig 5.22 Interpretation of Houde and Hill Prototype Model ........................ 226

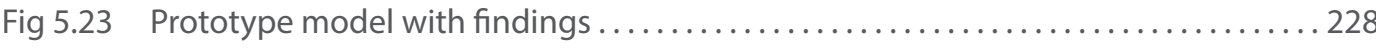

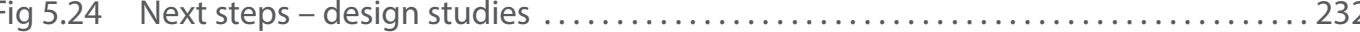

\section{Chapter 6}

Fig 6.1 Pressure equa 238

Source: Canadian Wood Council,'Durability by Design: Wall Types for Water Control' <http://cwc.ca/design-with-wood/durability/durability-solutions/ durability-by-design/> [accessed 13th September 2015]

Fig 6.2 Green oak cladding, River and Rowing Museum, Henley-on-Thames, David Chipperfield.

Fig 6.3 Cladding detail, River and Rowing Museum .................................. 240 Source: Wayne Forster, 'Tradition and innovation: timber as rainscreen cladding', Architectural Research Quarterly, 2 (1997) p.54-63

Fig 6.4 Green oak hardwood costs table..... Source: Peter Ross, Christopher Mettem, Andrew Holloway, Green Oak in Construction (High Wycombe: TRADA Technology Ltd 2007) p.20

Fig 6.5 Great Coxwell Barn, Oxfordshire ....................................... 242

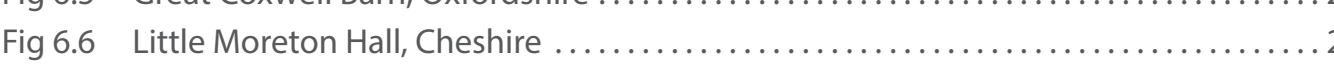
Source: <http://www.architecturalhistory.co.uk/news/item/case_studies/littlemoreton-hall-cheshire> [accessed 13th September 2015]

Fig 6.7 Greenstead-juxta-Ongar church, Essex.....

Source: <https://www.flickr.com/photos/ianvisits/7281120854> [accessed 13th September 2015]

Fig 6.8 Weobley, Hertfordshire............................................ 242 Source: <http://www.geograph.org.uk/photo/150532> [accessed 13th September 2015

Fig 6.9 Traditional framing joints. Source: Peter Ross, Christopher Mettem, Andrew Holloway, Green Oak in Construction (High Wycombe: TRADA Technology Ltd 2007) p.48-50

Fig 6.10 Green oak truss detail with steel wedges and pins ................. 246 Source: Naomi Stungo, The New Wood Architecture (London: Laurence King Publishing, 2001) p.119

Fig 6.11 Olivier theatre foyer green oak post and beam structure ..................... 246 Source: Naomi Stungo, The New Wood Architecture (London: Laurence King Publishing, 2001) p.115
Fig 6.12 Exterior oak clad roof of Olivier theatre Source: Naomi Stungo, The New Wood Architecture (London: Laurence King Publishing, 2001) p.116

Fig 6.13 Details of innovative oak connections .............................. 246 Source: Barrie Evans, 'Theatre in the frame', Architect's Journal, 1 (1996), pp.35-44 (p.40)

Fig 6.14 Section through cantilevered study bay ..................248 Source: Götz Gutdeutsch, Building in Wood: Construction and Details (Basel: Birkhäuser, 1996) p.14

Fig 6.15 Detail of double beam bolts Source: Götz Gutdeutsch, Building in Wood: Construction and Details (Basel: Birkhäuser, 1996) p.17

Fig 6.16 Green oak posts and double beam structure. Source: Peter Carolin, 'Natural selection: Jeremy Dixon in Cambridge', Architecture Today, 49 (1994), $24-29$ (p.29)

Fig 6.17 Oak clad exterior to river..... Source: Peter Carolin, 'Natural selection: Jeremy Dixon in Cambridge, Architecture Today, 49 (1994), 24-29 (p.24)

Fig 6.18 Exploded isometric to explore the functional and performative needs for the beach

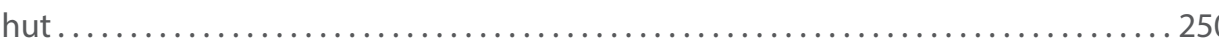

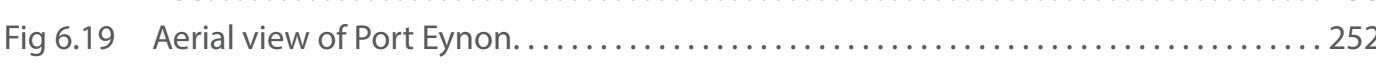

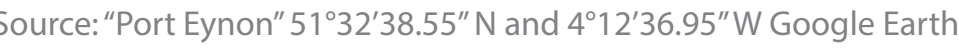
accessed 12th September 2015

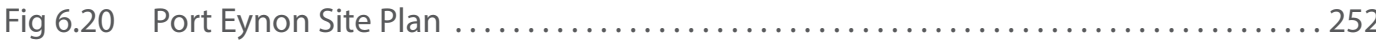

Fig 6.21 View of Port Eynon........................................... 252

Fig 6.22 Preferred option plan and model for site location ........................ 254

Fig 6.23 Sketches investigating function and form ............................ 254

Fig 6.24 Langland Bay beach huts ........................................ 256 Source: $<$ http://www.gowerpenthouse.com/photos.asp> [accessed 12th September 2015]

Fig 6.25 Working fisherman huts in Rye, Sussex .............................2 256 Source: <https://ekgroup.wordpress.com/2012/01/31/the-curate-series-benjaminlucraft-2-references/eric-de-mare-skyscraper-001/> [accessed 4th August 2014]

Fig 6.26 Modular development sketches of a flexible timber 'cube'. ....................256

Fig 6.27 Various configurations of the GucklHupf, in Mondsee, Austria.... Source: Phyllis Richardson, XS: Big Ideas, Small Buildings (London: Thames \& Hudson Ltd, 2001) p.44

Fig 6.28 Floor plans ......................................... 258

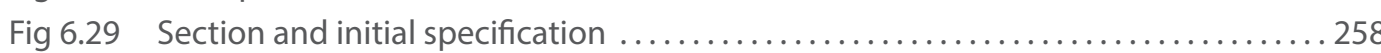

Fig 6.30 Rendered section and elevation ................................... 258

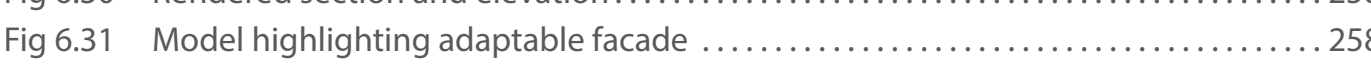

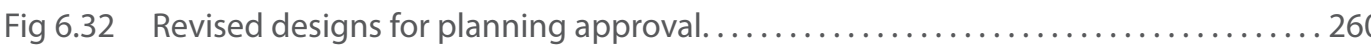

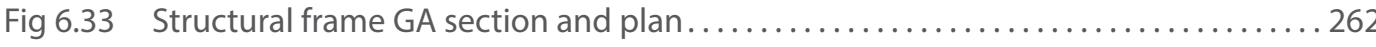

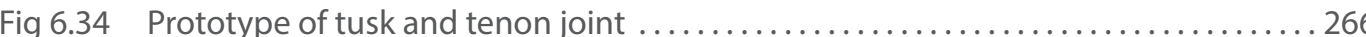

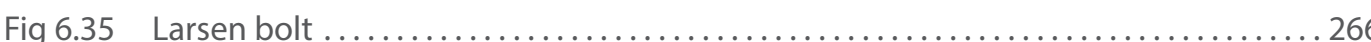
Source: <http://www.carl-ras.dk/e-shop/befaestigelse/bolte/oejeboltetrappebolte/ larsenboltmeddorn/> [accessed 20th July 2015]

Fig 6.36 Larsen bolt detail ..... September 2015]

Fig 6.37 Proposed bolting details by structural engineers........................ 266 Source: Ove Arup \& Partners - consulting engineers on the design of the beach hut

Fig 6.38 Floor panel assembly detail ..................................... 269 
Fig 6.39 Fixed wall panel assembly detail. ....

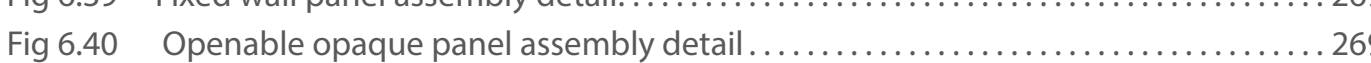

Fig 6.41 Openable panel over window assembly detail .......................... 271

Fig 6.42 Openable bi-panel over door assembly detail.......................... 271

Fig 6.43 Laminated hardwood casement window assembly detail ....................271

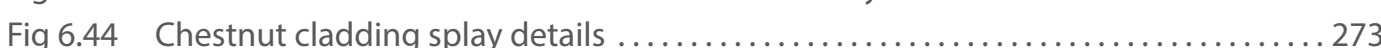

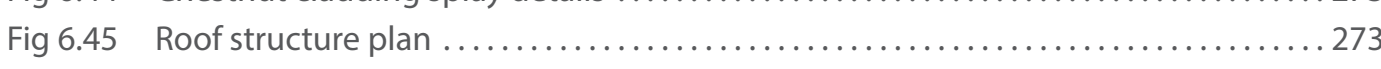

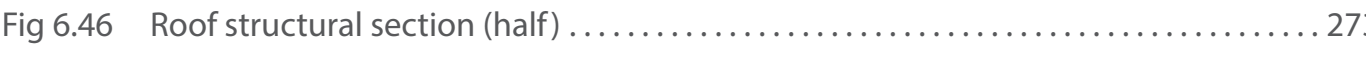

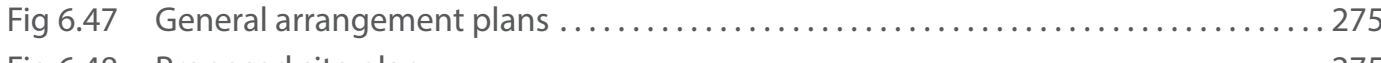

Fig 6.48 Proposed site plan .................................................... 275

Fig 6.49 Proposed Section AA (top) ........................................ 275

Fig 6.50 Proposed Section BB (bottom) ...................................... 275

Fig 6.51 Proposed detailed elevations........................................... 276

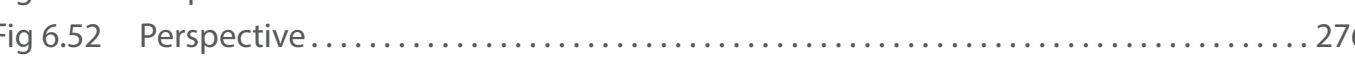

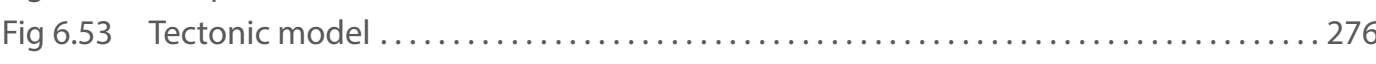

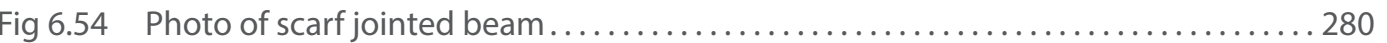
Source: <http://www.castleringoakframe.co.uk/scarfed-joint/> [accessed 31 August 2015]

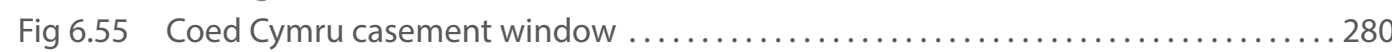

Fig 6.56 Olivier Theatre glazing panel detail to overcome movement in green oak with Source: Barrie Evans, 'Theatre in the frame', Architect's Journal, 1 (1996), pp.35-44 (p.42)

Fig 6.57 Modulhaus in Olching ..................................................... 286 Source:'Review of Architecture: Timber Construction', Detail, January/ February 2000, p.42

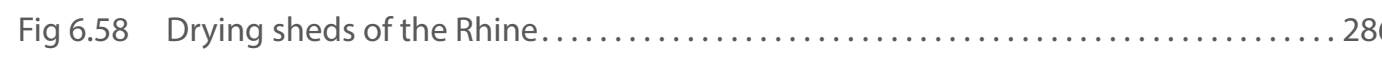
Source: Heike Werner, 'Modern Aspects of Traditional Construction: Timber Facades of Drying Sheds', Detail, January/February 2000, p.26

Fig 6.59 Matrix of hardwood findings

\section{Chapter 7}

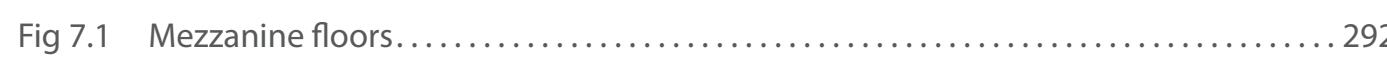

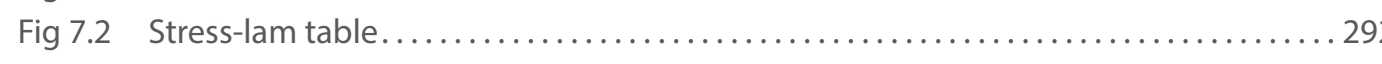

Fig 7.3 Adhesive types used in glue laminated manufacturing ..................... 294 Source: Christian Müller, Holzleimbau: Laminated Timber Construction (Basel: Birkhäuser, 2000) p.37

Fig 7.4 The Glu-laminating Process........................................... 296 Source: <http://www.woodsolutions.com.au/Wood-Product-Categories/Glulam> <http://www.timber-technologies.com> [accessed 8th September 2015

Fig 7.5 Advantages and Disadvantages of CLT construction.....................
Source: Andy Sutton, Daniel Black, Pete Walker, Cross-laminated Timber: An introduction to low impact building materials (Watford: BRE Trust, 2011),

Fig 7.6 Site construction sequence: wall and floor panels ............ Source: Trada, Case Study: Stadthaus, Murray Grove, London, (Buckinghamshire: Trada Technology, 2009) p. 5

Fig 7.7 Simple fixing details. Source: <http://www.slideshare.net/jeffranson/stadthaus-murray-grove-case-studypresentation> [accessed 8th September 2015]

Fig 7.8 Welsh made Brettstapel panel, Coed-y-Brenin, Architype ....
Fig 7.9 Stress laminated bridge slabs made up of glulam beams on Mattisdammen (top) and Daleråsen bridges (bottom), Norway

Source: Tormod Dyken, Otto Kleppe, Norwegian Public Roads Administration,

The Norwegian approach to modern timber bridge design, (Norway) pp. 6 and 10

Fig 7.10 Hiili Cafe, Helsinki, Finland constructed from exposed and charred CLT panels..... 302 Source: Pekka Heikkinen, Jari Laiho, Jussi Tiainen, Puusta Tehty: Wood Works, (Tampere: Parvs Publishing, 2007) p.30

Fig 7.11 Reclaimed timber beams with M12mm threaded bars drilled through ......... 302 Source: <http://remadeincornwall.co.uk/buy-hairpin-legs-online/six-layer-boltedtimbers-with-300mm-hairpin-legs/> [accessed 19th July 2013]

Fig 7.12 Plywood table with bolt connection for flexibility of form .................... 302

Fig 7.13 Completed Mezzanine floors, East side of studio .......................... 304

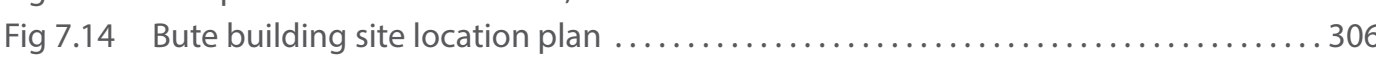

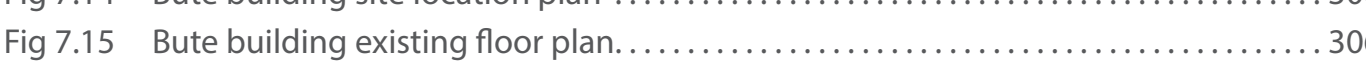

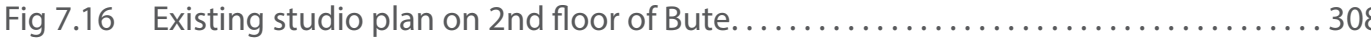

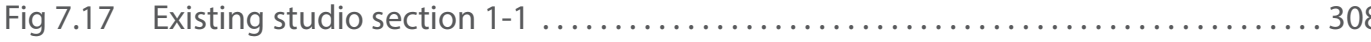

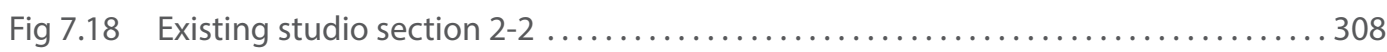

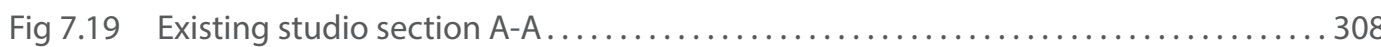

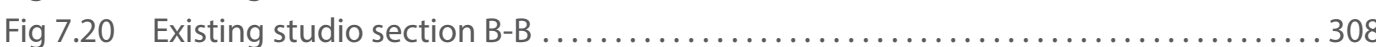

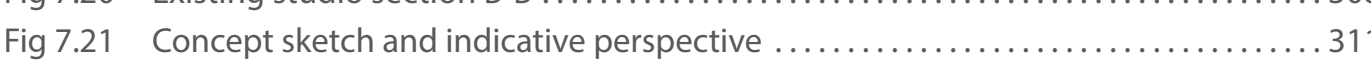

Fig 7.22 Photos of existing studio spaces...................................... 31

Fig 7.23 Print Gallery with workshop, London, Mikhail Riches, $2000 \ldots \ldots \ldots \ldots \ldots \ldots \ldots . \ldots 311$ Source:<https://www.architecture.com/FindAnArchitect/ArchitectPractices/ MikhailRiches/Projects/LondonPrintStudio-71065.aspx> [accessed 6th September 2015]

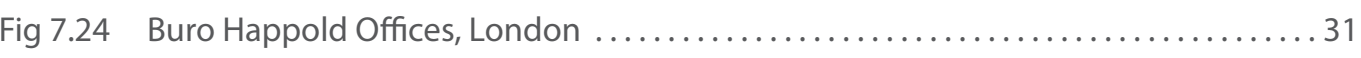

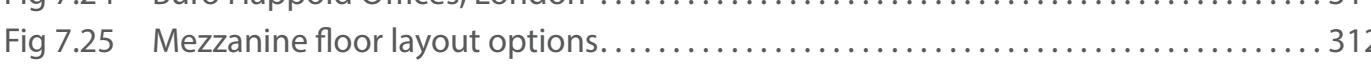

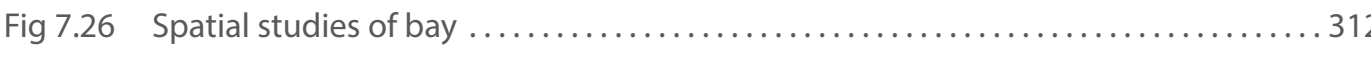

Fig 7.27 Working model of mezzanine floors including sliding screens ................. 314

Fig 7.28 Proposed section: Mezzanine connected to existing wall.................... 314

Fig 7.29 Proposed section: Mezzanine separated from wall as standalone structure........ 314

Fig 7.30 Plan of proposed generic bay at mezzanine level . . . . . . . . . . . . . . . . . . . . . 316

Fig 7.31 Elevation of proposed mezzanines ....................................316

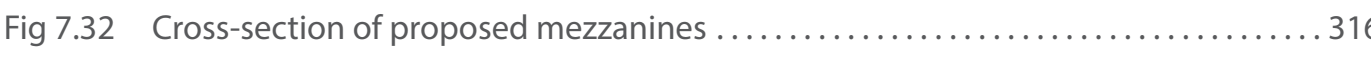

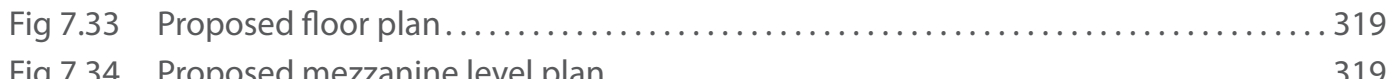

Fig 7.34 Proposed mezzanine level plan......................................... 319

Fig 7.35 Proposed elevation of mezzanine structure .............................. 319

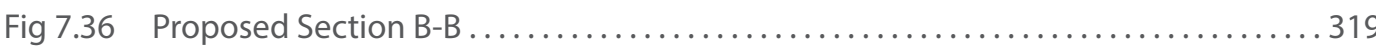

Fig 7.37 Exploded detail axonometric of 1 bay of the mezzanine structure ............. 320

Fig 7.38 Structural details of typical bay connections .............................. 320

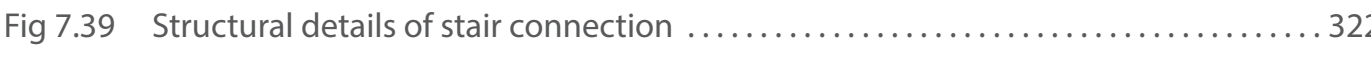

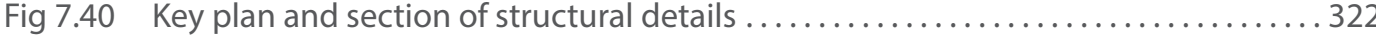

Fig 7.41 Photos of mezzanine construction sequence ….......................... 325

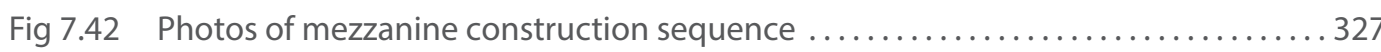

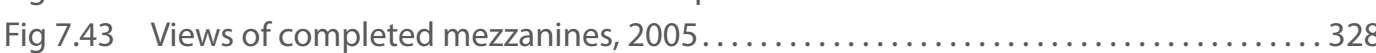

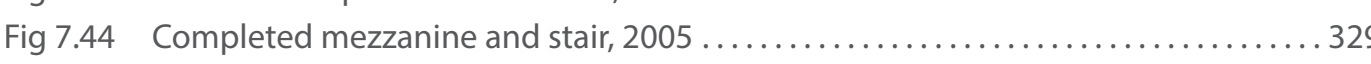

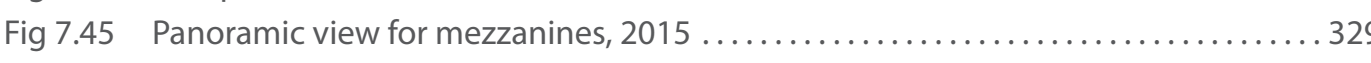

Fig 7.46 Shrinkage has caused gaps between boards and a warping of the end of unsupported boards, April 2015

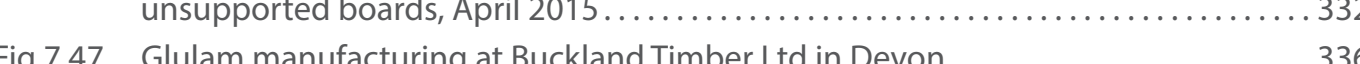

Fig 7.48 Relationship between mezzanines and existing fabric...................... 338 


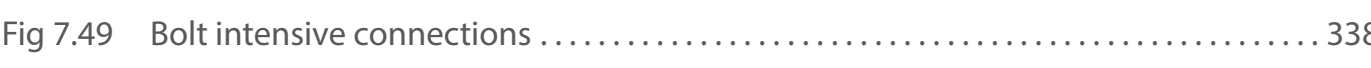

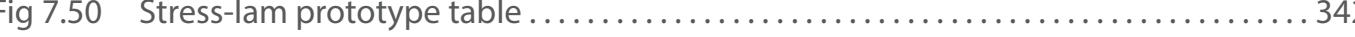

Fig 7.51 Location plan for stress-lam table within Bute building....................... 344

Fig 7.52 Existing floor plan where table will be located ........................... 344

Fig 7.53 Concept sketches of table and stress-lam construction system ................ 346

Fig 7.54 Early development model......................................... 346

Fig 7.55 Sample of a Brettstapel wall panel........................................... 348 Source: James Henderson, 'Brettstapel: An Investigation into the Properties and Merits of Brettstapel Construction' (unpublished Masters thesis, University of Strathclyde, 2009) p.26

Fig 7.56 Final tectonic model .............................................. 350

Fig 7.57 General arrangement plan and elevation highlighting bolting positions.......... 351

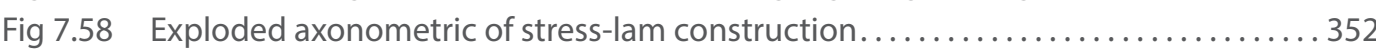

Fig 7.59 Timber species: Douglas fir and Sycamore ................................ 352

Fig 7.60 Fabrication drawing of lamella types .................................... 354

Fig 7.61 Model testing rotational movement of single bolt through finger jointed lamella . 356

Fig 7.62 Dogtooth washer

Source: <http.//www tradecounterdirectcom/fixing-security/nuts-bolts-screws/ washers/forgefix-dog-tooth-washers-zinc-plated-boxed_50-x-50-x-10mm-boxwashers/forgefix-dog-tooth-washers-2ing
of-100.html> [accessed 26 July 2013]

Fig 7.63 Dogtooth washer between lamella to provide rotation resistance ............. 356 Source: <http://www.itraveltimor.com/fasteners.html> [accessed 26 July 2013]

Fig 7.64 Exploded section through lamella .................................. 356

Fig 7.65 Fabrication process photos at workshop in Builth Wells ...................... 358

Fig 7.66 Installation sequence photos in Bute building .......................... 360

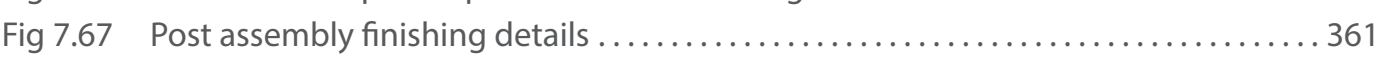

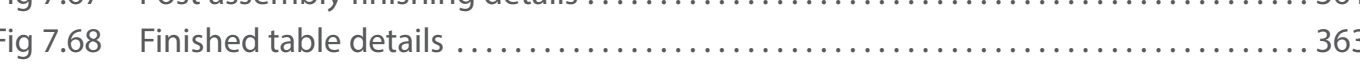

Fig 7.69 End view of table highlighting finger jointed connection of leg and top ......... 363

Fig 7.70 Completed $4.3 \mathrm{~m}$ of table............................................. 363

Fig 7.71 Table supported while the bolts were re-tightened, cut to the new length and the top re-planed to take out unevenness created by the movement. ............... 364

Fig 7.72 Corner detail of table in 2015 highlighting movement due to shrinkage around

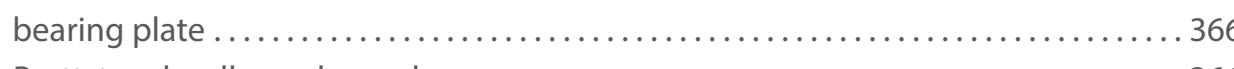

ig 7.73 Brettstapel wall panel sample ....................................... 366 Source: <https://projectsustainablehome.wordpress.com/tag/brettstapel/> [accessed 5th September 2015]

Fig $7.74 \quad$ KLH board with timber services routed in ............................. 368 Source: <http://www.klhuk.com/product-.aspx> [accessed 5th September 2015]

Fig 7.75 CNC routing, FACIT Homes ........................................ 370 Source: <http://facit-homes.com/made-with-intelligence/precision-manufacturing> [accessed 7th September 2015]

Fig 7.76 Assembly of on-site prefabricated components, FACIT Homes.................. 370 Source: <http://facit-homes.com/made-with-intelligence/clean-build $>$ [accessed 7th September 2015]

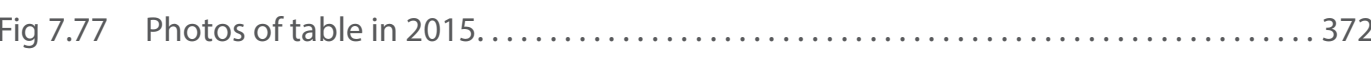

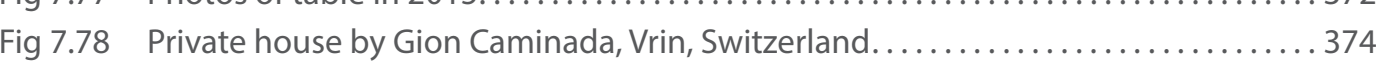
Source: <http://www.dezeen.com/2014/04/16/gion-a-caminada/> [accessed 31st August 2015]

Fig 7.79 Kingsdale school sports hall by dRMM, London .......................... 374 Source: <http://www.promolegno.com/materialegno/05/imparare-dal-legno/> [accessed 31st August 2015]

Fig 7.80 Matrix of engineered timber findings.

\section{Chapter 8}

Fig 8.1 UK Consumption by Volume, by Product and Source 2013 ..................... 382 Source: Timber Trade Federation, Statistical Review 2014: Industry Facts and Figures for the Year 2013, (London: TTF 2014) p.8

Fig 8.2 UK Imports of Timber and Panel Products 2013, by Volume ................... Source: Timber Trade Federation, Statistical Review 2014: Industry Facts and Figures for the Year 2013, (London: TTF 2014) p.15

Fig 8.3 Percentage Volume Change in Timber and Panel Products Imports 2013/2012 382 Source: Timber Trade Federation, Statistical Review 2014: Industry Facts and Figures for the Year 2013, (London: TTF 2014) p.16

Fig 8.4 UK Production of Timber and Panel Products 2013, by Volume................. 38 Source: Timber Trade Federation, Statistical Review 2014: Industry Facts and Figures for the Year 2013, (London: TTF 2014) p. 20

Fig 8.5 Swatches of different plywood grades ................................ 384 Source: Wood For Good, The Builder's Guide to Plywood (London: Wood For Good)

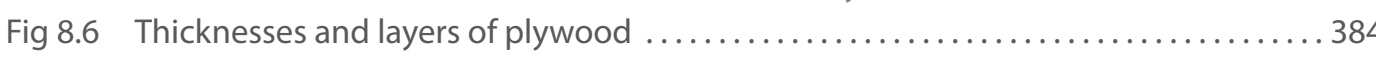
Source: Ibid, p.4-5

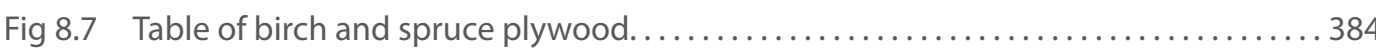
Source: Ibid

Fig 8.8 Laminated-strand timber, Oriented-Strand Board, Chipboard . Source: Borimir Radovic, 'Composite Wood Products and Their Use in Building' Detail, 1 (2000), 91-98 (p. 97)

Fig 8.9 Hardwood fibreboard, Medium-density wood-fibreboard, Soft wood-fibreboard ... 386 Source: Borimir Radovic, 'Composite Wood Products and Their Use in Building', Detail, 1 (2000), 91-98 (p. 98)

Fig 8.10 Furniture House 1, Lake Yamanaka, Japan, Shigeru Ban, 1995 ................... 388 Source: Matilda McQuaid, Shigeru Ban, (London: Phaidon, 2003) p.166-167, 169

Fig 8.11 Semper's primitive hut model . . . . Source: $<$ https://www.studyblue.com/notes/note/n/arch/deck/752409> [accessed 9th September 2015]

Fig 8.12 Simple and inexpensive material and construction detailing, Latapie House, Floirac,

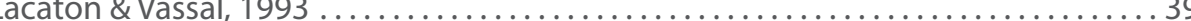
Source: Monica Gili, SL, 2G: Lacaton \& Vassal, (Barcelona: Editorial Gustavo Gili, 2006) p. 26, 30

Fig 8.13 East End Sawmills, Glasgow by NORD with timber structure constructed entirely from material sourced within the adjacent warehouse ...................... Source: Northern Office for Research and Design, East End Sawmills, <http:// nordarchitecture.com/projectseast-end-sawmills/> [accessed 6th August 2013]

Fig 8.14 Royal Welsh College of Music and Drama, Cardiff by BFLS uses birch faced plywood cladding in main auditorium

Source: <http://pursuitist.com/surprising-modern-conservatoire-royal-welshcollege-of-music-and-drama/> [accessed 8th September 2015]

Fig 8.15 Casa da Musica, Oporto, OMA with plywood fixed to the two flanking walls to balance the acoustic requirements of the two glazed ends .... Source: <http://www.archdaily.com/619294/casa-da-musica-oma> [accessed 8th September 2015]

Fig 8.16 Completed Eisteddfod Pavilion, 2004 .................................... 396

Fig 8.17 Aerial view of site, Tredegar Park .......................................... 398 Source: "Tredegar Park" 51 $1^{\circ} 33^{\prime} 52.68^{\prime \prime} \mathrm{N}$ and 3०01'50.02" W Google Earth. [accessed 8th September 2015] 82

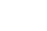
. .

\section{0}


Fig 8.18 Eisteddfod Site Plan - site marked with red boundary .................... 398

Fig 8.19 Design strategies ..............

Fig 8.20 Grid options to explore standard timber board arrangements .................. 404

Fig 8.21 Final floor layout grid arrangement.................................... 404

Fig 8.22 Pavilion zoning plan .............................................. 406

Fig 8.23 Pavilion openings strategy to separate elements and establish visual links....... 406

Fig 8.24 Early concept model with separated structure and enclosure.................408

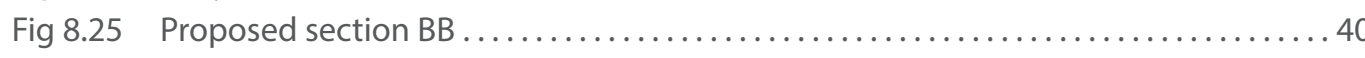

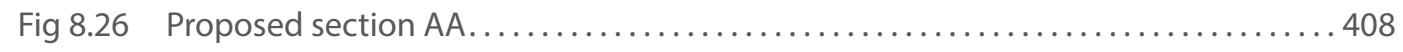

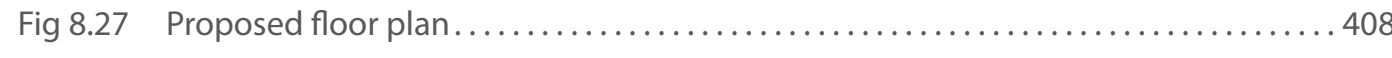

Fig 8.28 Proposed front elevation.......................................... 408

Fig 8.29 Sequence of construction demonstrated using a 1:20 tectonic model ..........410

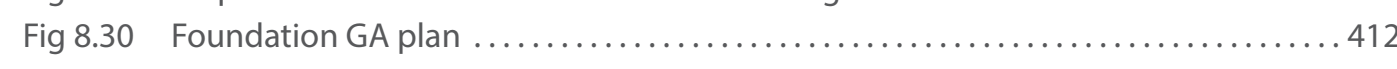

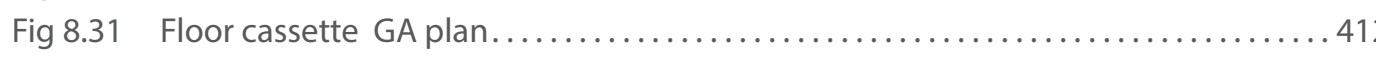

Fig 8.32 Floor deck GA plan................................................ 412

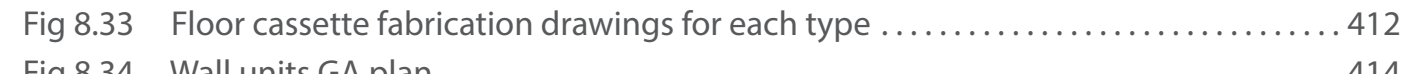

Fig 8.34 Wall units GA plan ......

Fig 8.35 Wall unit fabrication drawings of different types highlighting stud frame, plywood

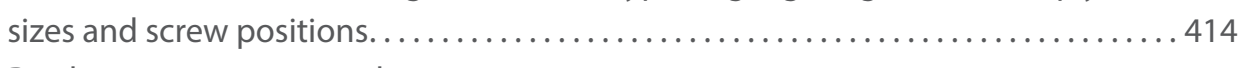

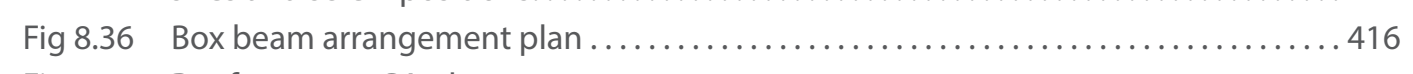

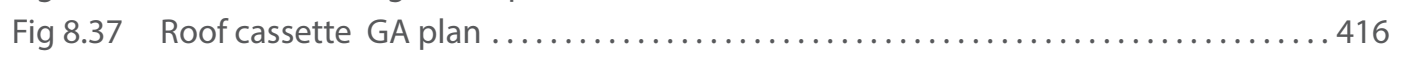

Fig 8.38 Diaphragm roof deck GA plan....................................... 416

Fig 8.39 Roof cassette fabrication drawings for each type.........................4 416

Fig 8.40 Setting out and foundations ......................................... 419

Fig 8.41 Floor cassettes assembly ......................................... 419

Fig 8.42 Wall unit fabrication .............................................. 419

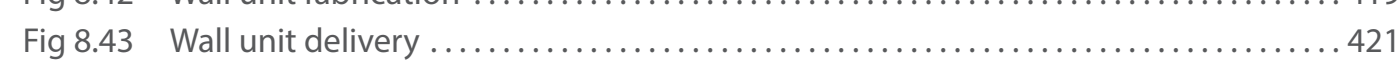

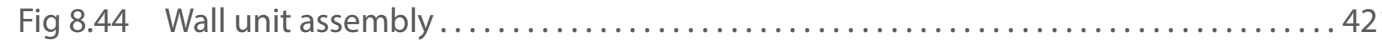

Fig 8.45 Ply box fabrication and installation ................................... 421

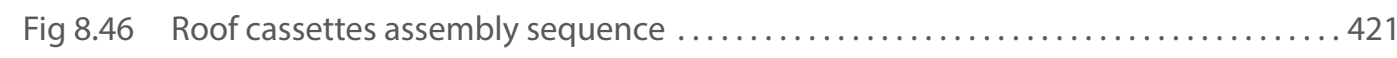

Fig 8.47 Installation of wall cladding rails................................... 423

Fig 8.48 Installation of roof firring and rainscreen................................ 423

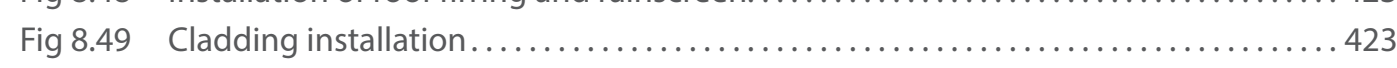

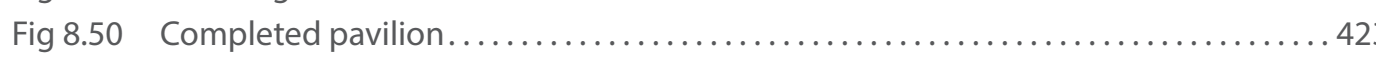

Fig 8.51 Interior views with direct connection to natural light and the outside.......... 424

Fig 8.52 Cube stools in the AV space; cross pavilion views; end wall of exhibition space. ... 424

Fig 8.53 Exterior view of pavilion during the Eisteddfod festival. .................... 424

Fig 8.54 Project details summary ........................................... 426

Fig 8.55 Expoloded axo and wall unit typology .............................. 426

Fig 8.56 Aerial photo of site, Cardiff Castle and Bute Park ....................... 42 Source: "Cardiff Castle" $51^{\circ} 28^{\prime} 53.01^{\prime \prime} \mathrm{N}$ and $3^{\circ} 10^{\prime} 51.39^{\prime \prime} \mathrm{W}$ Google Earth [accessed 10th September 2015]

Fig 8.57 Existing location plan with site marked in red.......................... 429

Fig 8.58 Photos of the moat and Castle wall prior to installation........................ 429

Fig 8.59 Montage of Eisteddfod pavilion in moat to the east of the main Castle entrance .. 429

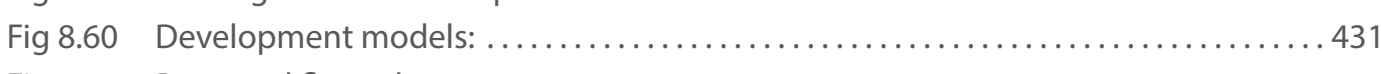

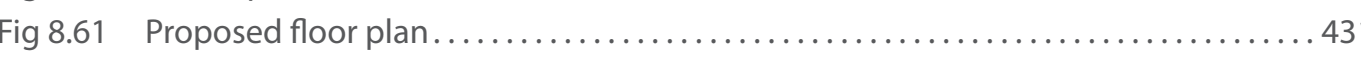

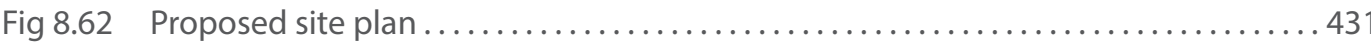

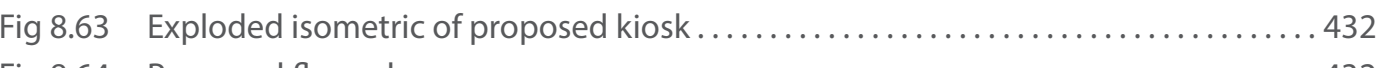

Fig 8.64 Proposed floor plan.............................

Fig 8.65 Exploded isometric of a typical $1220 \times 610 \times 2440 \mathrm{~mm}$ wall unit with display shelving 435

Fig 8.66 Proposed Section AA .............................................. 435

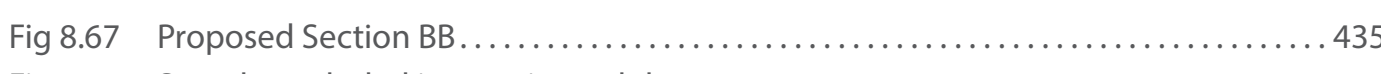

Fig 8.68 Sample exploded isometric modules ................................. 435

Fig 8.69 Detail of furniture unit, Sagaponac House, New York, Shigeru Ban, 2004 .......... 438 Source: Matilda McQuaid, Shigeru Ban, (London: Phaidon, 2003) p.179 .

Fig 8.70 Axonometric of Nine-square grid house, Hadano Japan by Shiger Ban demonstrating the flexibility of the open plan arrangement with furniture houses 440 Source: Matilda McQuaid, Shigeru Ban, (London: Phaidon, 2003) p.173

Fig 8.71 Closed timber panel construction complete with external joinery and membranes 440

Fig 8.72 Matrix of timber board product findings ................................ 450

\section{Chapter 9}

Fig 9.1 Sitka spruce forest .458

Fig 9.2 Sitka spruce properties... 460

Fig 9.3 The General Panel System ... Source: Konrad Wachsmann, Building the Wooden House: Technique and Design (Basel: Birkhäuser, 1995)

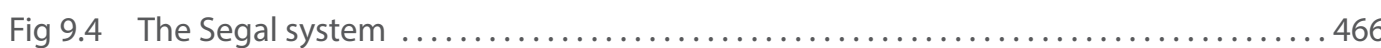
Source: Jon Broome, 'The Segal Method', Architect's Journal, 183 (1986), 31-68

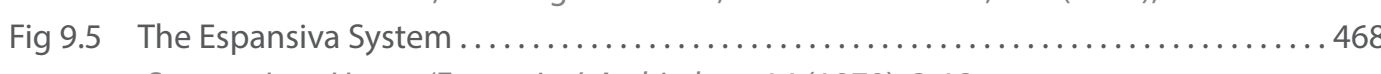
Source: Jørn Utzon, 'Espansiva', Architektur, 14 (1970), 3-12

Fig 9.6 Module elements and arrangement types based on Espansiva system ........... 470

Fig 9.7 Spatial configuration concept of room modules leaving space for circulation . ..... 470

Fig 9.8 Fabricating the box sections........................................ 472

Fig 9.9 End grain bolted connection detail .................. 474

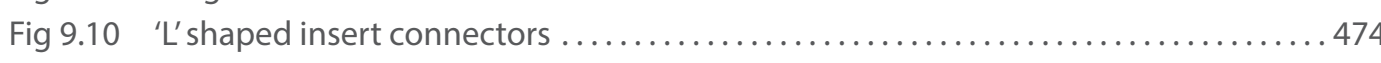

Fig 9.11 Box section beam testing at Cowley Timberwork ....................... 476

Fig 9.12 Box beam sizes and loadings table prepared by Burroughs................. 478 Source: Burroughs, Technical Assessment of the Ty Unnos System (Cardiff: Burroughs, 2009) p.18

Fig 9.13 Completed prototype portal frame using end grain bolting .................. 478

Fig 9.14 Infill panel development studies .................................... 478

Fig 9.15 Sequence of installing initial proposal for prefabricated infill box sections within a mono pitched portal frame

Fig 9.16 Ladder beam panel development .......................................... 480

Fig 9.17 Ladder beam structural testing at Glamorgan University ................... 482

Fig 9.18 Structurat engineer's sketch ofladder beam options ..........................4.482 Source: Burroughs

Fig 9.19 Box section and ladder cassette connection assembly with t\&g spruce lapping top of box section and bearing batten fixed to side of box beam ....

Fig 9.20 Constructing a 1:1 prototype of $2.4 \times 2.4 \times 2.4 \mathrm{~m}$ pavilion module with box section frames and ladder infill panels.

Fig 9.21 Exploded isometric of $2.4 \times 2.4 \times 2.4 \mathrm{~m}$ pavilion module ......................... Source: Rob Thomas

Fig 9.22 Generic house type plans ........................................ 486

Fig 9.23 Single storey 'slipped plan' house type for rural Wales as 3B6P and 2B4P based on room modules

Fig 9.24 Proposed perspective of rural house type. ................................... 486

Fig 9.25 Twisted $47 \times 225 \mathrm{~mm}$ Sitka spruce boards prior to drying highlighting typical properties of Welsh spruce.

Fig 9.26 Typical spans and centres for the principal Ty Unnos components . . . . . . . . . . ... 488 Source: Burroughs, Ty Unnos Component Toolkit, (Cardiff: Burroughs, 2011) p.5 
Fig 9.27 Smithsonian project details table........

Fig 9.28 Completed Smithsonian Pavilion on the Mall, Washington DC ................... 494 Source: Kenton Jones Joinery

Fig 9.29 Aerial view of The Mall, Washington ....

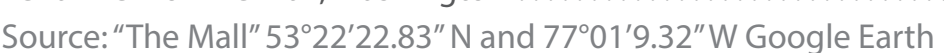
[accessed 10th September 2015]

Fig 9.30 Welsh longhouse, Museum of Welsh Life, St Fagans ....................... 496

Fig 9.31 Proposed axonometric and plan of demonstration house type ............... 498

Fig 9.32 Marie Short house, New South Wales, Australia by Glenn Murcutt ............. 498 Source: <http://www.wallpaper.com/gallery/architecture/glenn-murcutt-architect> [accessed 11th September 2015]

Fig 9.33 Reduced pavilion arrangement to meet budget and limited prefabricated components......

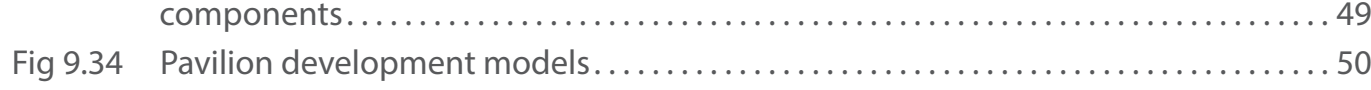

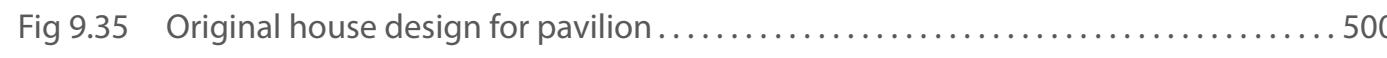

Fig 9.36 Exploded isometric of exhibition pavilion................................ 502

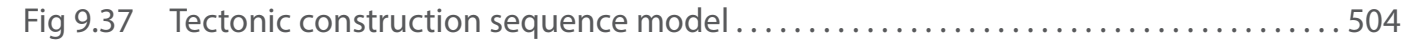

Fig 9.38 Floor cassette fabrication drawing ................................. 504

Fig 9.39 Section AA incorporating floor, wall and roof cassettes...................... 504

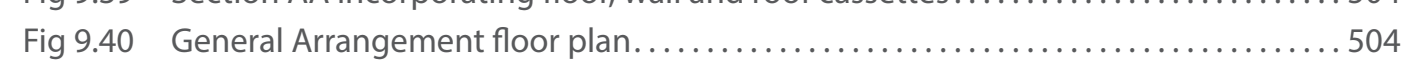

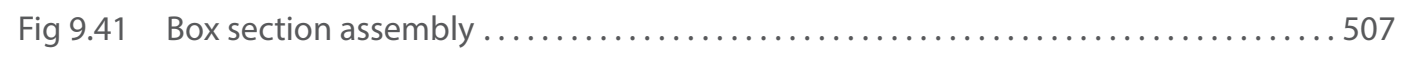

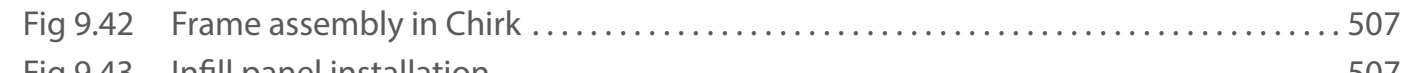

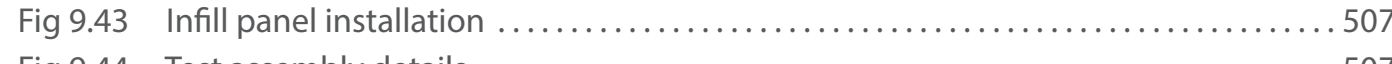

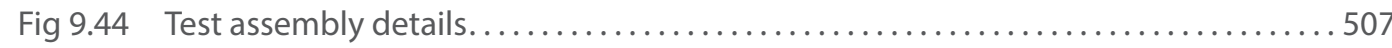

Fig 9.45 Smithsonian frame assembly on The Mall, Washington DC ................... 509 Source: Kenton Jones Joinery

Fig 9.46 Infill panel assembly .............
Source: Kenton Jones Joinery Source: Kenton Jones Joinery

Fig 9.47 Roof assembly ................ Wall panel and screen assembly Source: Kenton Jones Joinery Source: Kenton Jones Joinery

Fig 9.50 Interior of completed pavilion Source: Kenton Jones Joinery

Fig 9.52 Proposed

across reedbeds ............................ 516 Source: "The Works, Ebbw Vale" $51^{\circ} 46^{\prime} 11.20^{\prime \prime} \mathrm{N}$ and $3^{\circ} 11^{\prime} 57.13^{\prime \prime} \mathrm{W}$ Google Earth [accessed 10th September 2015]

Fig 9.54 Existing photos of pumphouse and surrounding site.....................518

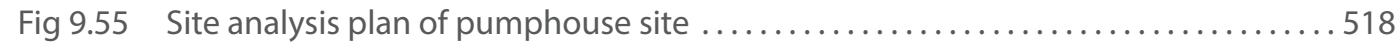

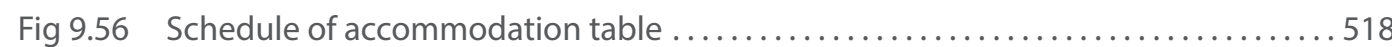

Fig 9.57 Site option studies for classroom positioning . .......................... 520

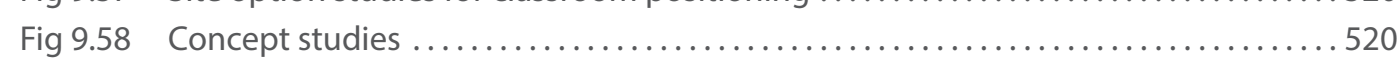

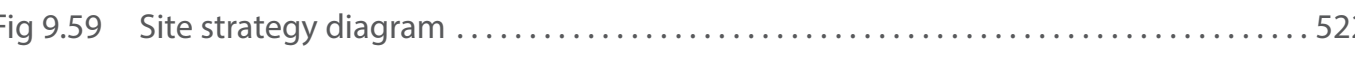

Fig 9.60 Ty Unnos module studies .......................................... 522

Fig 9.61 Design development plans and sections................................ 524

Fig 9.62 Layered murals and cladding....................................... 524

Fig 9.63 Charred timber studies............................................ 524

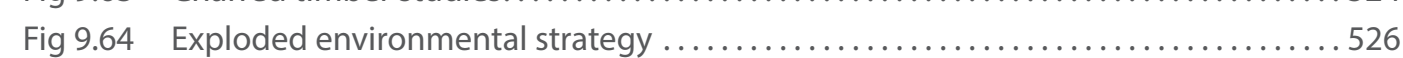

xxxiv

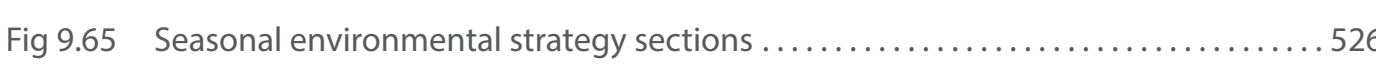

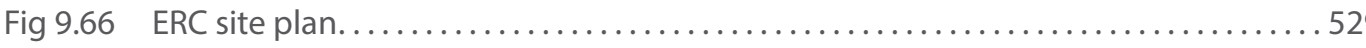

Fig $9.67 \quad 1: 200$ site study model of ERC adjacent to ponds........................... 529

Fig 9.68 Proposed ERC perspective across ponds ................................. 529

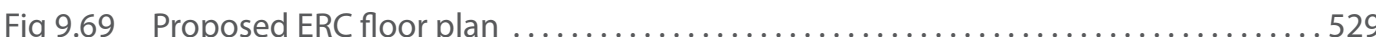

Fig 9.70 1:20 exploded ERC model highlighting conceptual elements: spaces, murals, cladding, storage wall, oversailing roof................................ 529

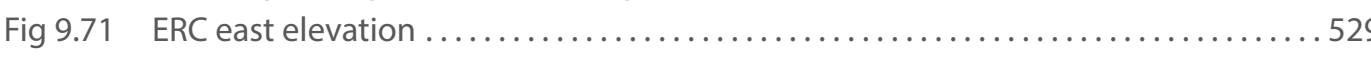

Fig 9.72 Detail section through east elevation and storage wall .................... 530

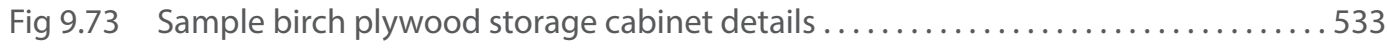

Fig 9.74 Coed Derwen Joinery top-hung, outward opening window .................. 533

Fig 9.75 Coed Cymru laminated window details .................................. 533

Fig 9.76 Sample charred cladding prefabricated panel drawing ...................... 533

Fig 9.77 ERC proposed construction sequence model ........................... 534

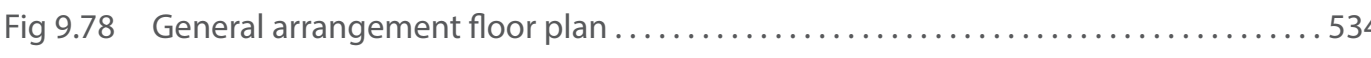

Fig 9.79 General arrangement short section................................... 534

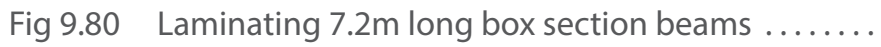

Fig $9.81210 \times 270 \mathrm{~mm}$ box sections ........................................... 536

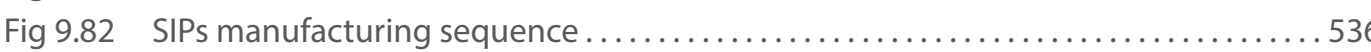

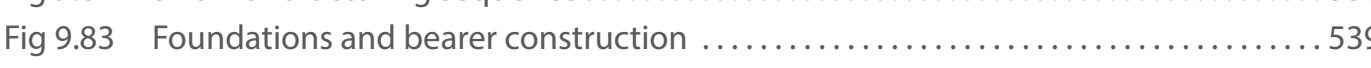

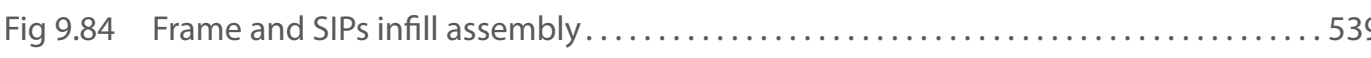

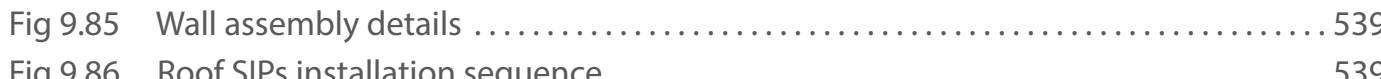

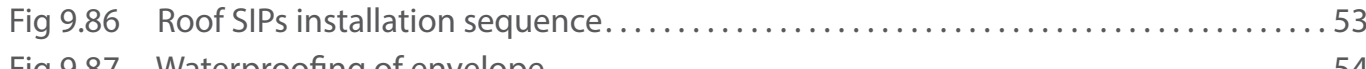

Fig 9.88 Outer cladding installation............................................ 54

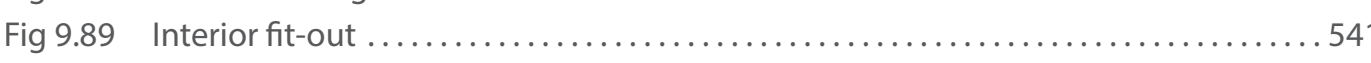

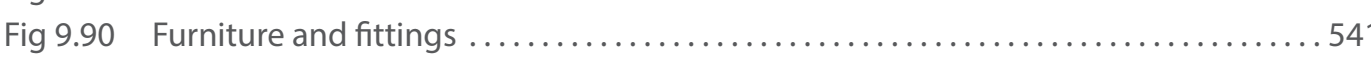

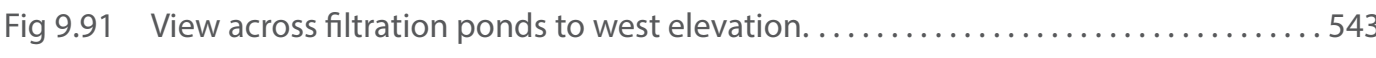

Fig 9.92 View on arrival from south-east with solar hot water panel entrance screen. ......543

Fig 9.93 Northern view of charred cladding over murals and hidden door to office.. . . . ....543

Fig 9.94 View of boardwalk and vertical charred timber shutters at night. ............... 543

Fig 9.95 Entrance view at night........................................... 543

Fig 9.96 View from entrance deck down circulation spine............................... 543

Fig 9.97 View of glazed screen looking across reed beds and Green Valley. . . . . . . . . . . 543

Fig 9.98 Rear storage wall with pin board doors across empty classroom. ...............54

Fig 9.99 Birch plywood toilet doors......................................... 543

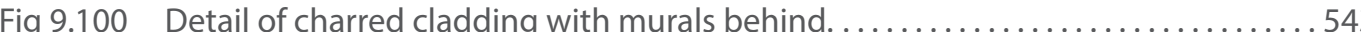

Fig 9.101 Enclosed scaffolding tent over construction site ....................... 544

Fig 9.102 Zoning grid of ERC............................................. 552

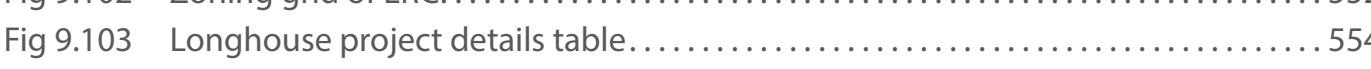

Fig 9.104 Proposed perspective of Longhouse south elevation .................... 554

Fig 9.105 Original 3 bedroom, 5 person, competition design proposal ................ 557

Fig 9.106 Aerial photograph of The Works during land remediation ...........................559 Source: <http://www.theworksebbwvale.co.uk/home/the-image-gallery.aspx> [accessed 13th October 2008]

Fig 9.107 Oblique aerial photo of Welsh Future Homes site during construction .......... 559 Source: <http://www.theworksebbwvale.co.uk/home/the-image-gallery.aspx> [accessed 18th February 2011]

Fig 9.108 The Works masterplan. The housing site is labelled RES J...................... 559 Source: <http://www.blaenau-gwent.gov.uk/education/19993.asp> [accessed 18th February 2011]

Fig 9.109 Longhouse concept strategy 
Fig 9.110 Vernacular longhouse - Cilewent Farmhouse

Source: <https://www.museumwales.ac.uk/stfagans/buildings/cilewent/> [accessed 20th October 2009]

Fig 9.111 Simple forms - St David's Church, Gaufron, Powys.....

Source: Alasdair Ogilvie <http//wwwtintabernacles.co.uk/alasdair_ogilvie_st_

davids_church_gaufron_powys_wales.html> [accessed 31st July 2009]

Fig 9.112 Composition ................................................ 560

Fig 9.113 Traditional Ty Unnos - The 'Ugly' house near Betws y Coed......................... 560 Source: <http://www.britishlistedbuildings.co.uk/wa-3182-ty-hyll-the-uglyhouse-capel-curig/photos\#.VgaEDbReJOc> [accessed 30th April 2009]

Fig 9.114 Map of material sources and suppliers used in the Longhouse construction...... 560

Fig 9.115 Ty Unnos modules arranged as a 2-storey longhouse................... 562

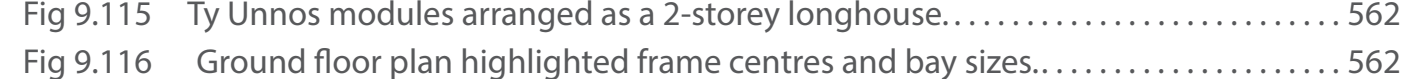

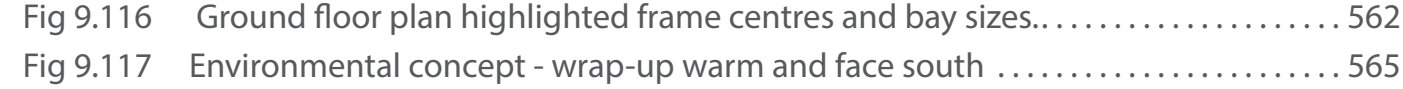

Fig 9.118 Exploded diagram of competition house design and intended environmental

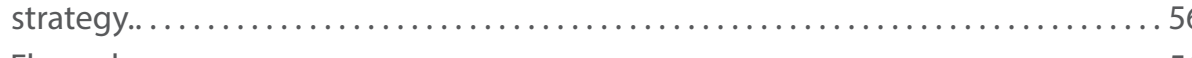

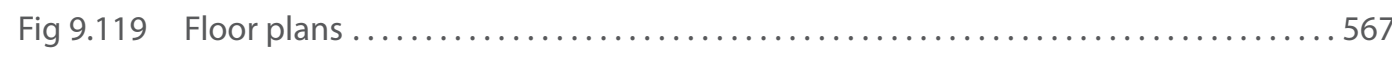

Fig 9.120 Perspective of longhouse from north-east. .......................... 567

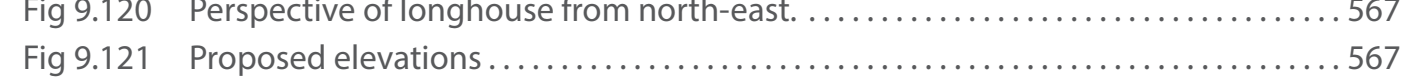

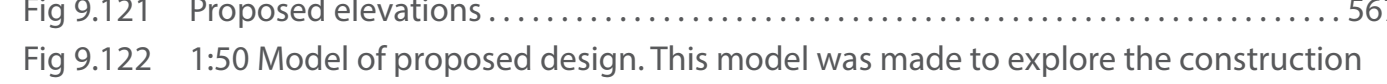
process and layering ............................................ 567

Fig 9.123 Exploded isometric of the construction of one 2-storey longhouse bay. ........ 568

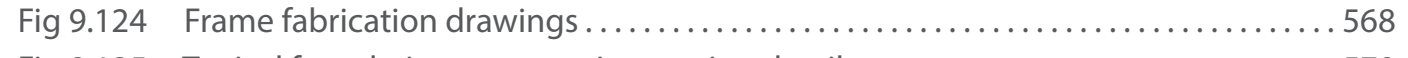

Fig 9.125 Typical foundation construction section details ....................... 570

Fig 9.126 Sample frame panel fabrication drawing .............................. 570

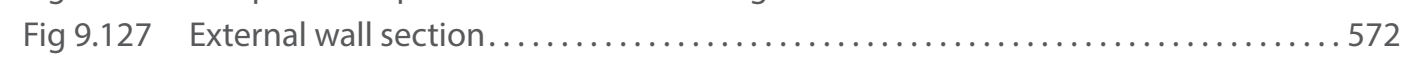

Fig 9.128 Thermal bridging modelling of corner and intermediate floor ............... 572

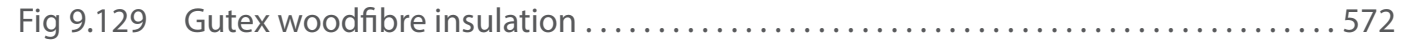

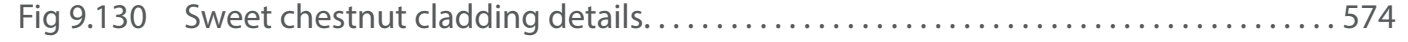

Fig 9.131 Cladding arrangement around windows ............................ 574

Fig 9.132 Cladding fixing details ........................................ 574

Fig 9.133 Details of bespoke low-energy window developed by Vintage Joinery. . . . . . . . 577 Source: Vintage Joinery

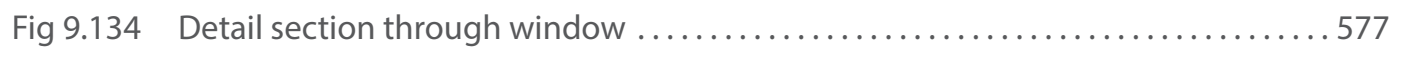

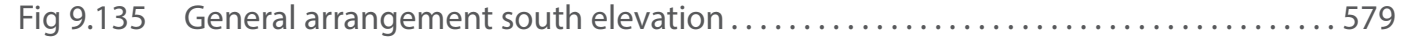

Fig 9.136 General arrangement section through dining bay ....................... 579

Fig 9.137 General arrangement section through kitchen........................... 579

Fig 9.138 Ground floor plan .............................................. 579

Fig 9.139 First floor plan..................................................... 579

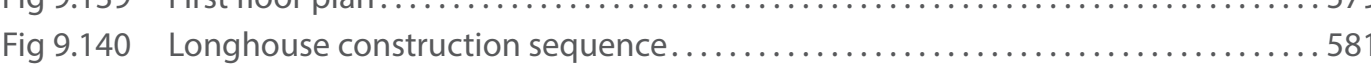

Fig 9.141 Galvanised steel angle bracket fixing box section post to concrete kerb. ........58

Fig 9.142 Open frame panels were installed from the exterior and sheathe internally with $\mathrm{OSB} / 3$.

Fig 9.143 Ladder beam panels were tested internally to use more poor quality spruce. ....58

Fig 9.144 Exposed tie-beam across master bedroom............................. 581

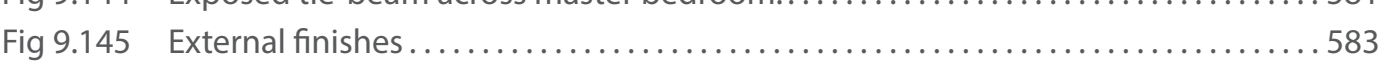

Fig 9.146 Welsh chestnut low energy windows and doors are installed, lapped and taped

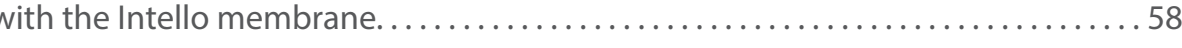

Fig 9.147 Internal layering of envelope........................................ 583

Fig 9.148 South garden elevation.......................................... 585

Fig 9.149 West elevation with entance and drive ............................ 585

Fig 9.150 North elevation with dining bay. ................................. 585
Fig 9.151 Detail of south elevation bedroom windows....................... 585

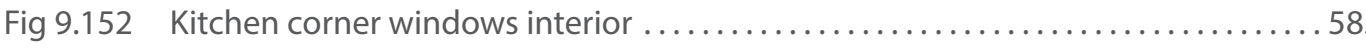

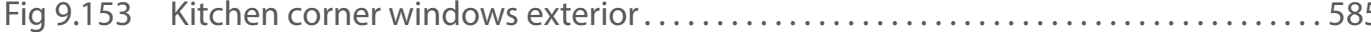

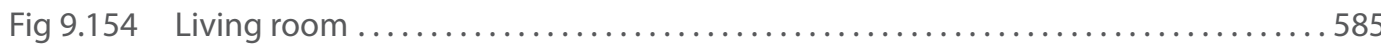

Fig 9.155 Master bedroom with exposed tie-beam ............................ 585

Fig 9.156 Master bedroom with mezzanine void to living room below ................ 585

Fig 9.157 Photos of oak cladding stained from interaction with ferrous metals ............ 588

Fig 9.158 Detail of wall panel and box section post ........................... 590

Fig 9.159 Movement in sycamore floor at first floor ............................... 590

Fig 9.160 Cost appraisal of Longhouse project …................................ 592

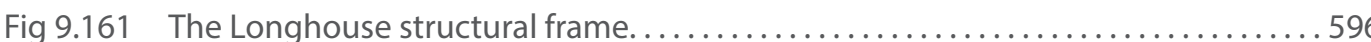

Fig 9.162 Matrix of complete timber envelope findings .......................... 598

\section{Chapter 10}

Fig 10.1 Routemap diagram of thesis structure ................................6 602

Fig 10.2 Completed framework for evaluation as a checklist of tested objectives..........604

Fig 10.3 Photographs of chippings and sawdust produced during roundwood processing at

BSW sawmills at Newbridge-on-Wye .....................................612

Fig 10.4 Elemental, modular and layered tectonic typologies ......................6 630

Fig 10.5 Cyclical diagram of timber standardisation ............................ 632

Fig 10.6 Table of potential Welsh-grown species against appropriate uses, exposure and

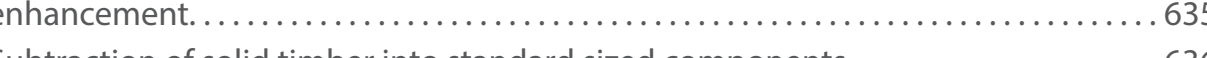

Fig 10.7 Subtraction of solid timber into standard sized components . .

Fig 10.8 Additive process of engineered timber to exploit the use of Welsh-grown timber .638

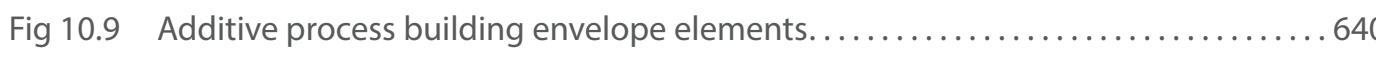

Fig 10.10 Exhibition installation for Reflecting Wales $09: 09 \ldots \ldots \ldots \ldots \ldots \ldots \ldots \ldots . \ldots 64$

Fig $10.11600 \mathrm{~mm}$ layout grid coordinated with the following ...................... 642 

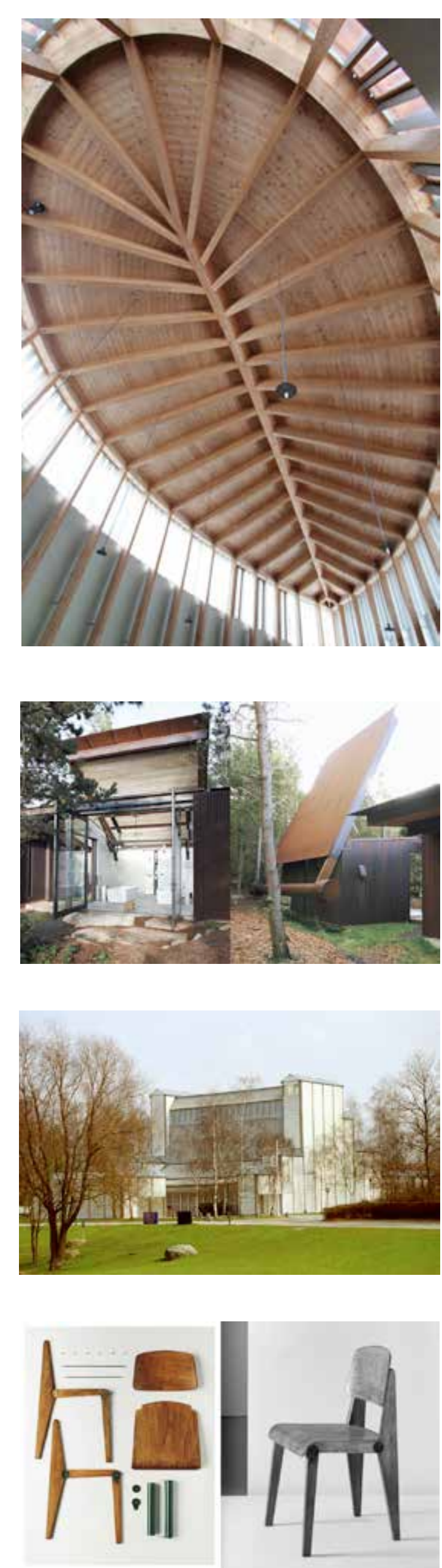

xxxviii
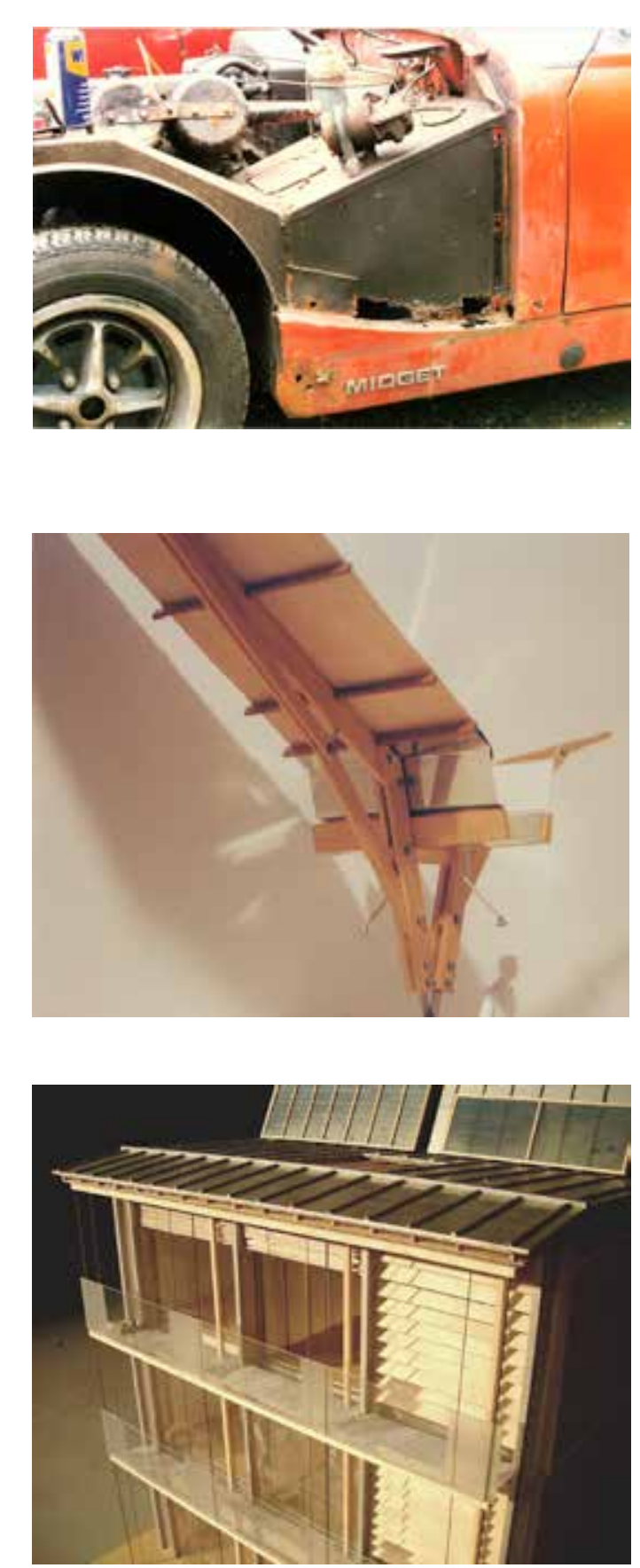

LEFT (top - bottom)

Fig. $i$ Expressed roof structure of Sogn Benedetg chapel, Peter Zumthor

Fig. ii Expressed detailing and tectonic elements of Shadowbox house, Olson Kundig

Fig. iii Standardised and prefabricated

Bagsværd church, Jørn Utzon

Fig. iv Demountable chair by Jean Prouvé

ABOVE

Fig. v Restoration of MG Midget MkIII, 1997

Fig. vi 1:20 model of BArch thesis primer for a beach rescue

Fig. vii 1:20 modular model of social housing scheme made in DRUw, 2001

\section{Preface}

This thesis has emerged from the author's personal interests in materials, making and tectonic form

Since a young age I have grown up around mechanical engineering, a principle of DIY and an inquisitive approach to how things work whether this be a piece of furniture, a broken CRT television or a car. Disassembly, repairing and making were therefore a vital part of my education with BMX bikes transformed annually into entries for the local carnival, school projects often incorporated a made output or a study of processes and the restoration of an MG Midget. Design and Technology projects led to 1:1 physical prototypes to test appearance, ergonomics or function that has subsequently informed my approach to designing and making

During my architectural education, materials and making informed design decisions, culminating in my BArch thesis project focussed on tectonic form and culture as a juxtaposition of heavy and light construction composition, tradition and innovation and the detail. Inspiration was drawn from the work of Tom Kundig, Renzo Piano Building Workshop, Jørn Utzon, Jean Prouvé, Peter Zumthor, Glenn Murcutt and Rural Studio and more recently Anderson Anderson, Thomas Heatherwick and Assemble Studio.

Since joining the Design Research Unit Wales, Welsh School of Architecture at Cardiff University, in 2002, I have been able to further investigate an interest in the 'architect as maker' through live design research projects in collaboration with other architects, researchers, engineers, clients and industry. My projects have been informed through interrogation of local materials, construction methods, modules and grids in relation to context, function and experience. It is within this field of interest that this research area emerged combining a passion for prototyping as a means to investigate material usage and tectonic form. The use of local timber is uniquely integrated with history, culture, climate, the environment and social wellbeing. The properties of timber encompass this history but through the relative ease of working with timber provide a tangible connection between nature and man that is less evident with other materials. The projects included in this thesis therefore consider the way materials go together and the poetry of this expression as an honest tectonic where timber and detail are expressed to provide a corporeal atmosphere appropriate for the client, function and context. 

CHAPTER 1

Introduction 
The sensuous, environmental and working properties of timber are well known from foresters to consumers. Construction industry literature and guidance prepared by regulatory and promotional bodies regularly highlight the renewable properties of timber grown to store carbon; managed to replace and expand woodlands; and processed, recycled, re-used and downcycled to store carbon within the building envelope. Designers and clients often reference the diverse visual and physical properties available from hardwoods and softwoods through the phenomenological attributes of colour, grain, smell, texture, a connection to nature and improved internal environments. As a result of these properties joiners, carpenters, artists, craftsmen and DIY enthusiasts use timber for a diverse range of products and functions from tools and toys to instruments and boats. Within architecture, timber is often used for structures, cladding, window frames, doors, finishes, furniture and fuel.

While once the UK was covered in dense forestry, the majority of UK woodlands and forests were depleted and cleared for agriculture and ship building by the 17th century. ' With the onset of the industrial revolution and the development of new contemporary materials for construction, timber in the UK had almost disappeared as an architectural construction material for the best part of the nineteenth century. Timber was regarded as a secondary material for fuel in the production of steel and energy and as pit props in coal mining. ${ }^{2}$

Despite research and development by the Timber Trade Federation (TTF), Building Research Establishment (BRE), the Timber Research and Development Association (TRADA) and a few private sector experiments into new timber framing techniques, the use of timber in architecture, through the first three quarters of the 20th century, was restricted to low-cost imported softwoods for components such as floor joists and roof trusses in house-building. Even when volume house builders developed new timber framing and panelling techniques in the 1970's and 1980's, technical failure through poor building techniques almost precluded further development. ${ }^{3}$ Throughout this period, British forestry management failed to develop timber and associated products at the same rate as some other materials, and clear felling and the replacement of the varied native forest with quick growing softwoods severed the connection between local forest and building. The use of local hardwoods in construction was limited to conservation work, ecological or self-building and traditional craft technologies.

1 William Linnard, Welsh Woods and Forests: A history (Llandysul: Gomer Press, 2000) p.74 2 ibid, p.134

3 Julian Owen, Kit and Modern Timber Frame Homes: The Complete Guide (Marlborough: The Crowood Press, 2007) p.16 
Over the last 30 years in the UK, there has been a revival in the use of timber, or what has been called a timber renaissance. ${ }^{4}$ This steady reintroduction of timber into British architecture has reset many of the negative images that had become attached in previous years. As well as coinciding with many national and international initiatives aimed at creating more sustainable construction practices, a number of other factors have contributed to a growing interest in wood building - efficient and fast building techniques, prefabrication, regionalism, environmental performance, the local versus the global and perhaps crucially a growing interest in the tectonic - materiality. The renewable properties of timber are well known, the problem until recently has been how to use the material without imitating traditions, using it as decoration or purely for environmental reasons. This is not to say lessons have not been learnt from traditional carpentry or from environmental best practice, but for the renaissance to continue the industry must compete with steel, concrete and plastic developments in the twenty-first century, as a legitimate and honest material in its own right.
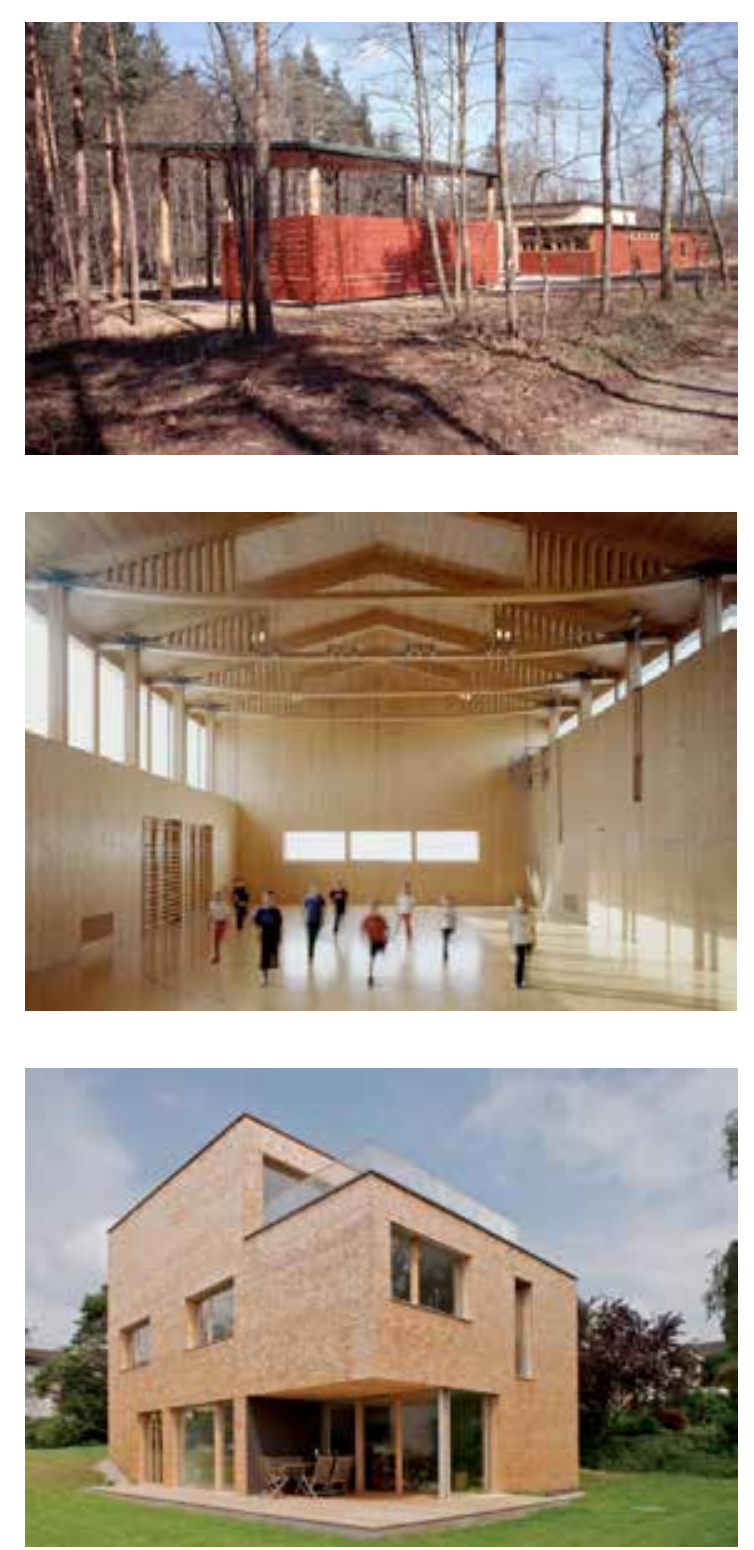

Fig 1.1 Forest centre, Rheinau by Burkhalter

Fig 1.2 School sports hall, Mehrzweckhalle, Vrin by Gion Caminada

Fig 1.3 Private house, Schaffhausen by Hermann Kaufmann
The UK wood revolution owes a lot to the influence of the unbroken tradition of architectural development of timber construction in Scandinavia, the Alpine countries, Japan and North America. The publication of the work of architects, such as Burkhalter and Sumi, Gion Caminada, Hermann Kaufmann and Peter Zumthor who have reclaimed their regional culture through the use of new wood building techniques, has begun to inspire architects in other European countries. The tradition of timber development in regions like the Graubünden, Switzerland, and the Vorarlberg, Austria combine tradition with new engineered solutions and prompt a number of questions about how timber may be employed in contemporary architecture. In the UK architects such as FCB Studios, David Chipperfield and Edward Cullinan have made progress in finding new ways of using local timber and finding a balance between traditional craft and contemporary engineering. While de Rijke Marsh Morgan (dRMM), Waugh Thistleton Architects and Karakusevic Carson Architects have designed and used imported innovative, engineered structural systems for large span and high-rise timber structures. However the volume house builders and prefabrication industry use the largest volume of, predominantly imported, timber in the UK. The sustainability, speed and ease in which timber can be worked has meant that many housing developments in the UK now have a prefabricated timber structure with increased thermal performance, often wrapped in a masonry skin. In 2009, $25 \%$ of all new housing starts in the UK were timber framed, using a combination of open panel construction and trussed roofs. ${ }^{5}$

4 Andrew Lawrence, 'Timber renaissance', The Engineer 2012 (London: Centaur Communications Ltd) $<$ http://www.theengineer.co.uk/home/blog/guest-blog/timber-renaissance/1013772.article> [accessed 5th September 2015]

5 Dennis Jones and Nick Tune, 'Sustainable construction with timber in Wales', WoodKnowledge Wales report (Machynlleth: Wales Forest Business Partnership: 2010) p.1 
While there may be a need to conduct research into the use of UK-grown timber in architecture, this thesis is focused on the Welsh woodland industries from the properties of the Welsh-grown timber, through the processing industries to construction. This has allowed for a focused study of a national timber industry within the context of its political, social, economic and environmental influences. Wales also has a strong culture and identity in which to understand the context, design and technical opportunities and constraints that influence the use of homegrown timber.

As can be seen in the UK, Welsh woodlands and forests are under resourced, under valued and in some opinions not managed for the future demands of both the ecology and economy. ${ }^{6}$ The timber and knowledge is available and there would appear to be a political, social and industry will to use local timber, as encouraged by the Welsh Government that states:

'Wales will be known for its high-quality woodlands that enhance the landscape, are appropriate to local conditions and have a diverse mixture of species and habitats. These will:

- provide real social and community benefits, both locally and nationally;

- $\quad$ support thriving woodland-based industries; and

- contribute to a better quality environment throughout Wales."

Many timber businesses in Wales are willing to use homegrown timber and develop their product range and technology for new, innovative uses. This has been influenced by an increasing emphasis on sustainable, standardised, efficient construction methods. However, the small scale of the UK and Welsh timber industry and an apparent lack of communication and structure between different parts of the supply chain has resulted in a lack of investment from both the public and private sector. ${ }^{8}$

There are approximately 306000 hectares, comprised of an almost even split between broadleaf and coniferous woodland, covering $15 \%$ of the total land area of Wales. ${ }^{9}$ The Woodland Trust website lists 63 native and non-native species commonly

6 Jaakko Pöyry Consulting, Welsh Forest Industry: Mapping and Benchmarking the Forest Industry, Final Report (Executive Summary Only) (London: Jaakko Pöyry Consulting, 2004) p. 5-13 7 Forestry Commission Wales, Woodlands for Wales: The Welsh Assembly Government's Strategy for Woodlands and Trees (Cardiff: Welsh Assembly Government, 2009), p.8

8 Gary Newman, Graham Hilton and Geraint Williams, Scoping a Roadmap for Delivering Sustainability and Growth of Welsh Woodlands (Machynlleth: Wales Forest Business Partnership 2015) p.8

9 Forestry Commission, Forestry Statistics 2014 (Edinburgh: Foresty Commission, 2014) p.9 
growing in the UK and available, in varying quantities and properties, for use. ${ }^{10}$ However this forest cover is considerably lower than other parts of Europe (45\% average), Japan (69\%), Canada (34\%) and the United States of America (33\%) that have developed forestry and adapted to changing demands. ${ }^{11}$ Meanwhile, the UK and Wales has seen a decline in the sourcing, specification and use of timber and timber products using the local crop. As a result the construction industry in Wales, relies heavily on the importation of both sawnwood and innovative timber products.

In contrast, current production of Welsh-grown timber is stable, meeting the demands of a number of established supply chains and market demands. However, the crop is considered by many in the industry to have limited commercial value and use, often seen as waste for processing as pulp and wood fibre for paper, wood-based panels, pallets and fuel. As a result of a publicly subsidised woodland management system, $65 \%$ of felled Welsh-grown softwood is delivered to Welsh sawmills for processing, however this only contributes $42 \%$ of the softwood consumed used by a range of sectors, of which $22 \%$ is construction. On the other hand, $86 \%$ of hardwood, predominantly from private, un-managed woodland, is used for fuel and fencing with only $14 \%$ processed at sawmills for a variety of end uses. ${ }^{12}$

To date, the use of local timber remains minimal compared to the volume of imported softwoods and timber products, for small-scale cladding and timber framing, from Scandinavia and North America. This is further supplemented by the importation of tropical hardwoods and board products from South America, China and Malaysia with high levels of deforestation. The UK has well-managed and certified forests and woodlands, with chain of custody from forest to product, ${ }^{13}$ although limited in size and drastically under valued and used. If a UK architectural timber renaissance is to continue, architects and other designers must either rely on increased importation of timber and timber products or increase the specification of local timber to promote further research and development. In order for the latter to happen, there needs to be an understanding of the forests and species available through to the sizes, properties, uses and detailing of timber in practice.

Currently in Wales, and the UK, there is a lack of innovative design precedent compared to regions such as the Vorarlberg in Austria where the technological and engineering enhancement contributes towards a tectonic timber architecture

10 Woodland Trust, British Trees (Grantham: Woodland Trust) <http://www.woodlandtrust.org.uk visiting-woods/trees-woods-and-wildlife/british-trees/> [accessed 6th September 2015]

11 Food and Agriculture Organization of the United Nations, 'Global Forest Resources Assessment Main Report' (Rome: FAO, 2010) p.224-228

2 Forestry Commission, p.52-53

13 ibid, p.13 
using the timber available locally for each project. ${ }^{14} \mathrm{As}$ a result the social, cultural and ecological history of the locality, often contained within the ancient woodlands, can be reflected in the application and use of the timber in the architecture from the outset. This would reflect a return to the historical way of building, where an understanding of the local environmental, social and economic parameters that form society can be fully appreciated.

Currently there is a gap in the knowledge of and designing with, Welsh-grown timber. This research therefore develops on initial technical studies on the properties and detailing of UK timber conducted by Napier University, TRADA, BRE and WKW and on the innovative research into timber design in Northern and Central Europe to test approaches to designing and constructing the contemporary building envelope with Welsh-grown timber.

\section{Aim and objectives}

It is the aim of this thesis to investigate and demonstrate the potential to use and innovate with sustainable local, Welsh-grown timber and timber products in the design of contemporary architecture. For the scope of this study, the use of timber will be limited to the external building envelope and in particular the most common uses of timber in Wales: Superstructure, including frames, walls and roofs; external claddings and finishes; and joinery. This aim will be delivered through consideration of the following objectives:

1. Can Welsh-grown timber species be used effectively in the design and construction of the contemporary and sustainable building envelope?

2. Can the performance of Welsh-grown timber species be improved through innovation?

3. Can value be added, to Welsh-grown timber through innovation?

4. What, if any, results may emerge related to the 'tectonic' qualities of the resulting architectural prototypes?

\section{$1.4 \quad$ Hypothesis}

There is potential to exploit the Welsh-grown timber crop in the design and construction of the architectural building envelope. 
It is proposed that the aims and objectives of this study be explored through the design and prototyping of live architectural projects to test the use of Welsh-grown timber based on an evaluation of the timber industry in Wales. This thesis will therefore be conducted in two parts that are informed by established models for research by design, and in particular practice-based research.

First, a comprehensive evaluation of the Welsh timber industry from woodland and timber properties to the use of the timber in the construction industry is conducted. This will be based on first hand experience of working collaboratively with the industry, limited literature and reports on the history, properties and developments of using Welsh-grown timber.

The second stage incorporates a series of live design studies to design, develop and prototype a range of approaches, products and techniques of using Welshgrown timber in the building envelope as identified, in the previous industry evaluation. Four overlapping themes are identified each with a cluster of projects with a particular focus that lead to observations and reflections that inform the performance of timber technically, functionally and tectonically.

Principally this thesis will follow a model of practice-based research that typically involves 'an original investigation...in order to gain new knowledge partly by means of practice and the outcomes of that practice, ${ }^{15}$ including a substantial contextualisation of the design studies. The role of physical prototypes and timber innovation places an increased emphasis on the artefact as a means to test, analyse and demonstrate research findings. In this sense, the thesis is seen as performative research in that the prototypes are both the nature of the research and the primary outcomes. ${ }^{16}$

The prototype projects are therefore seen as outcomes of the research, with findings presented on the reflections on the industry, design and making processes and the finished prototype.

15 Linda Candy, 'Practice Based Research: A Guide', Creativity \& Cognition Studios 1 (Sydney: University of Technology, 2006), p.1

16 Daniel Fallman, 'Design-oriented Human-Computer Interaction', Proceedings of CH12003, Conference on HUman Factors in Computing Systems, Vol.5, Issue No.1 (New York, NY: ACM Press), pp.225-232 (p.231) 

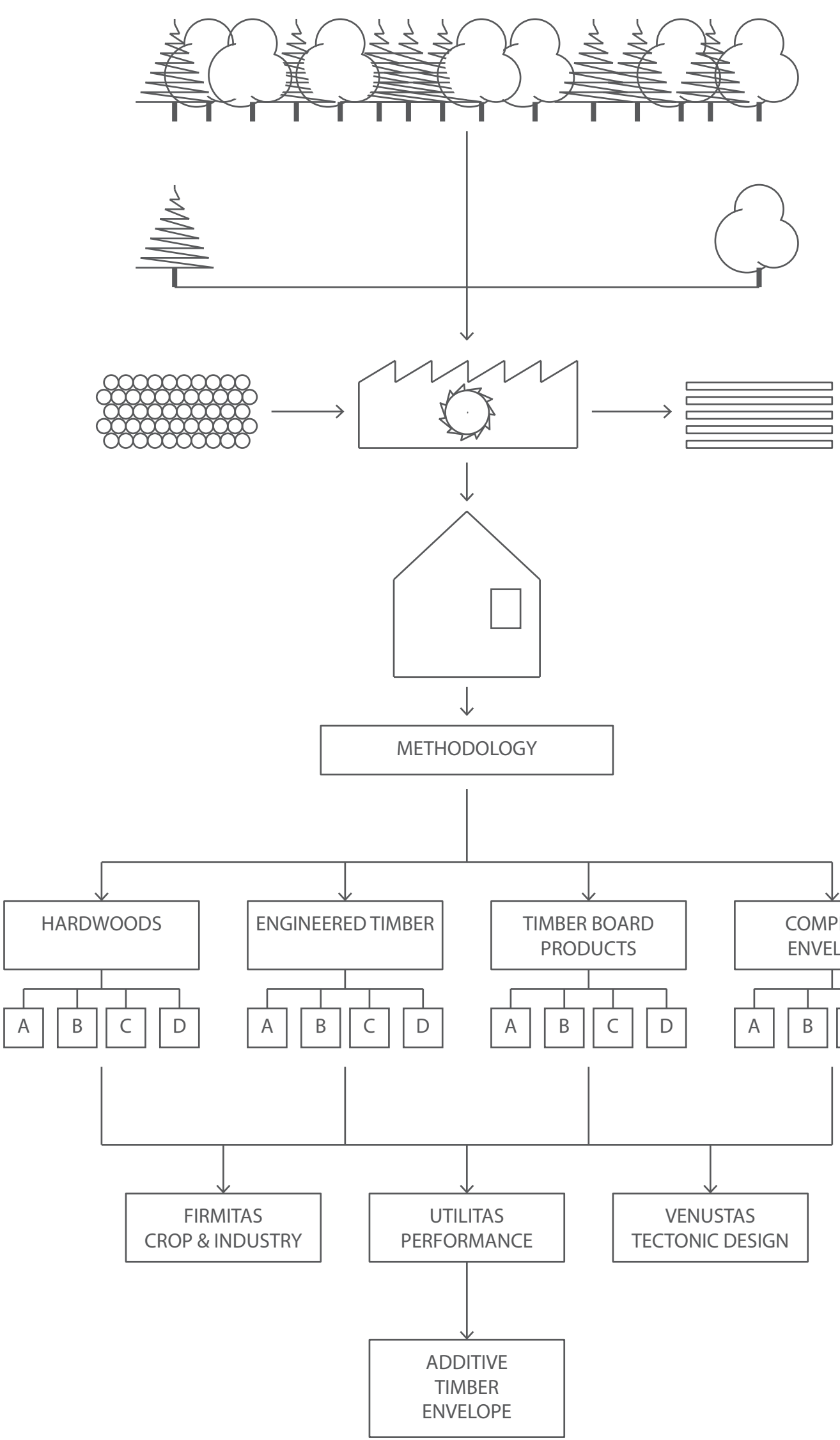

Chapter 2

Chapter 4

Chapter 5

Chapter 3

\section{Chapters 6-9}

\section{Structure}

Following the methods described above the research is structured as follows:

Chapter 1 introduces the thesis context, problem, aims and objectives and an overview of the method and structure.

Chapter 2, is the first of three industry review chapters with a focus on Welsh woodlands and trees. The chapter begins with a brief history of Welsh woodlands, the key developments in woodland management and uses for timber to provide a context to the state of the industry today. This is followed by a review of the general properties of wood and timber from the tree to processed timber highlighting specific qualities of Welsh-grown timber where appropriate. This provides the basis of the terms, properties and constraints that will inform the design and detailing of the prototype projects. These include: an evaluation of woodland management methods and global certification schemes such as FSC and PEFC; the growth of a tree and the consequence of this on specific properties that affect the performance of timber;

the processing of timber in relation to cut sizes, grain and seasoning; the mechanical properties of strength and durability.

The next section focuses on Welsh woodlands and tree species in relation to areas and proportions of different species that leads to an identification of 6 species that are identified in relation to their properties and availability for further consideration in the building envelope. It should be noted, that these species are not selected for specific study in the prototype projects, but to be incorporated as and when appropriate for the needs of the project. The chapter ends with findings on the species and properties that may inform the design and construction of the prototypes.

Chapter 3 provides a review of the timber industry in Wales. The review begins with the political and advisory context that legislates and informs on targets and developments within the timber industry. This is followed by an appraisal of the significance of imported and Welsh production of timber in the context of environmental, economic and social sustainability. The review includes a summary of the scale of importation in comparison to other sectors of wood products, source locations and an evaluation of the perceived obstacles for using Welsh-grown softwood compared to imported equivalents.

A review of the supply chain and procurement follows highlighting the current ability, opportunities and limitations within the following sectors of the industry: forest owners and harvesting; primary processing; and secondary processing. A 
number of previous reports and studies of the industry are referenced and further evaluated to provide an overview of the available technology and skills that affect the opportunities to innovate with Welsh-grown timber. A final section on timber construction provides a review of current and potential applications with Welshgrown timber to highlight the lack of innovation and possible diversity and range of opportunities to exploit Welsh-grown timber.

Findings are then presented to take forward for consideration in the development of the prototype projects.

Chapter 4 draws on the reviews in the previous chapters to evaluate the incorporation of Welsh-grown timber in the design and construction of the external building envelope. The chapter includes a summary of the principal building envelope elements and performance characteristics that have an impact on timber use. Two significant concerns within UK construction are then discussed in relation to the impact and opportunities that Welsh-grown timber may offer: the low energy building envelope and modern methods of construction (MMC). The use of timber within the building envelope is contextualised with performance requirements under four elements that provide the focus for the prototypes: superstructure, external claddings and finishes, external joinery and other opportunities.

16 precedent projects from around the world are presented with a focus on innovative solutions incorporating a low-energy envelope, prefabrication and a clear tectonic strategy as a best-practice approach to demonstrate the use of timber across a wide variety of building products, components and elements that meet a range of technical and design aspirations. The chapter ends with a summary of findings to take forward for evaluation in the prototype studies.

Chapter 5, the research methodology, provides a description of the criteria for evaluation and methodological approach to a series of live design projects and prototype outputs. The aim and objectives are focussed in reflection of the industry review findings to form a framework for evaluation that guides and benchmarks the prototype projects under four themes and four objectives.

The method is vital to the process and reflection of the prototype projects as research through making to test the performance and outcome of Welsh-grown timber in the building envelope. The significance of tectonic form is presented along with a review of prototyping as a model for research that lead to a selection of projects undertaken within the Design Research Unit Wales and the structure for presenting the studies. 
Chapters $\mathbf{6}$ - 9 comprise the four prototype studies clustered under four headings: hardwoods, engineered timber, timber board products and the complete timber envelope. Each chapter is presented in a similar format using drawings, diagrams and photographs of the designs and prototype process and outcome, in parallel with the descriptive text. The studies start with the research aim and objectives for that particular study which is followed by a contextualisation of the theme sourced from literature, previous projects, precedents and best-practice guidance.

Firstly the design is presented from brief to a planning application or equivalent presenting the key design decisions in relation to context, functional needs and use of timber. The second part focuses on the prototyping as process from detailed design, through fabrication to on-site construction or assembly as appropriate for the project. Each prototype study ends with substantial observations and reflections in relation to the four objectives highlighted in the framework for evaluation. These are often sub-divided into further categories that are identified as significant in the design and making with timber.

Where more than one project is presented, the structure of the chapter repeats, before ending with findings on the overall theme to take forward to the thesis findings in chapter 10.

Chapter 10 brings together the observations and reflections of the prototype studies to analyse further into findings and a conclusion on a tectonic timber architecture.

Chapter $\mathbf{1 1}$ is the bibliography separated into journals, books, reports and electronic data. 


\section{CHAPTER 2}

Welsh Woodland and Trees 


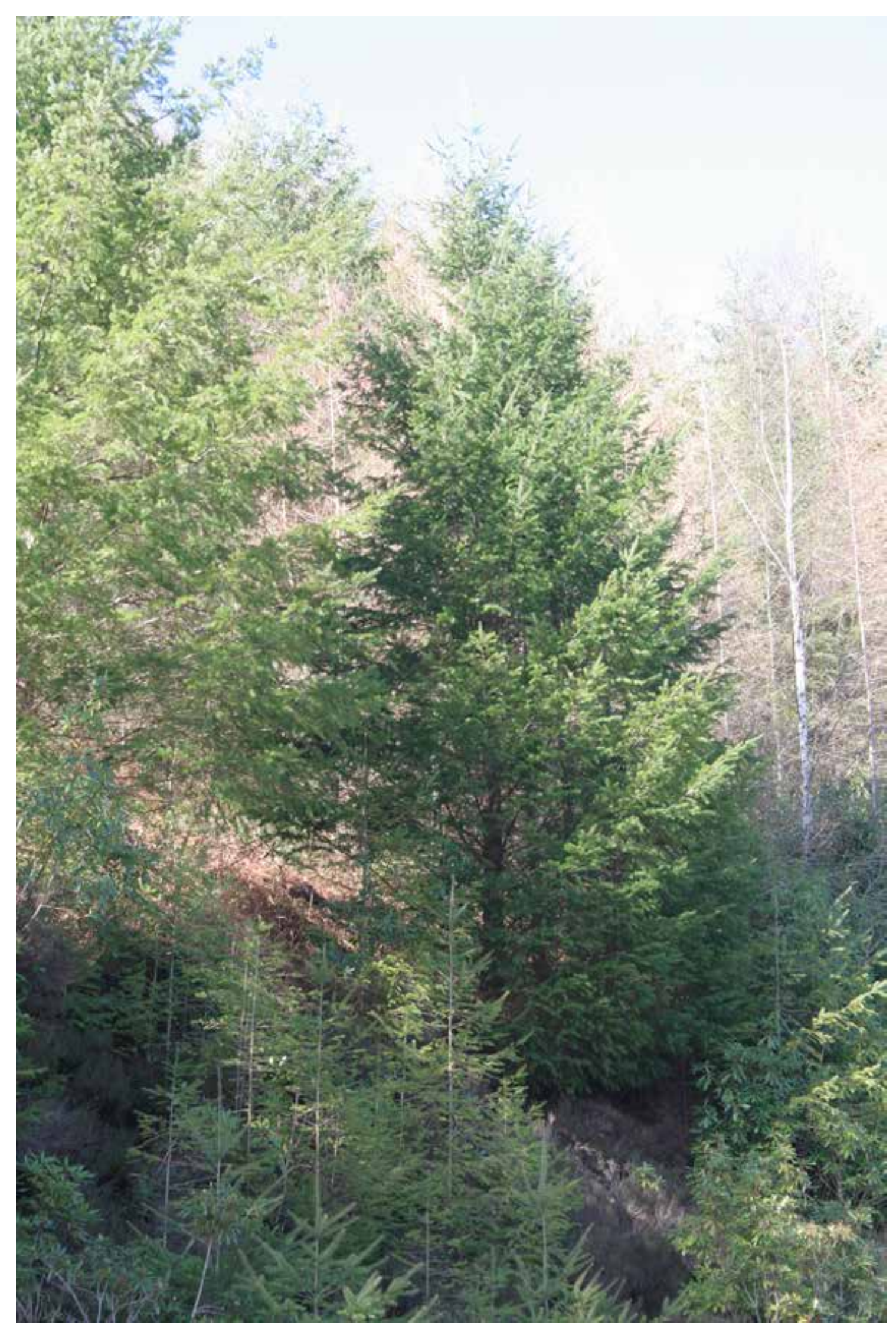

\section{Introduction}

In this chapter the Welsh woodlands and forests are evaluated to highlight the properties, limitations and considerations that affect the timber specification process for use in architecture. The enquiry starts with a brief history of the Welsh woodlands, forests and historical timber uses to provide the context behind the woodlands, species and properties that forms the basis of the contemporary timber industry in Wales.

In the second section, the qualities of wood, woodland management techniques and the physical properties of timber that directly affect the characteristics of the use of timber in the architectural building envelope are discussed. Definitions of tree classification, certification schemes and wood anatomy are provided to contextualise this thesis before highlighting the main parameters of sizing, mechanical properties and durability. This forms the basis of timber knowledge that is critical in understanding the Welsh woodlands, tree species and eventually designing, specifying and making with Welsh-grown timber.

The third section provides an overview and analysis of the current state of Welsh forestry with particular reference to large-scale plantation woodlands grown specifically with an end-use in mind as well as the small-scale indigenous woodlands, predominantly of hardwoods. As such this will limit the research to the tree species found in public and private woodlands and forests of over 2 hectares in size, as listed in the Forestry Commission for Wales National Inventory. This is not to class trees in smaller woodlands as not usable or viable, but that as the majority of these trees are in private ownership or hedgerows and gardens they are not generally felled and therefore not available on the commercial market to work with. Welsh forest stocks are analysed with the objective of identifying the area of woodland and volumes of useable crop available for use and to suggest a number of species that show potential to be used in the contemporary building envelope and which will be investigated further.

The chapter ends with a summary of critical properties to consider when specifying timber and key findings relating to the Welsh forest stocks and species identified for further study and potential use within the construction of the contemporary building envelope. 


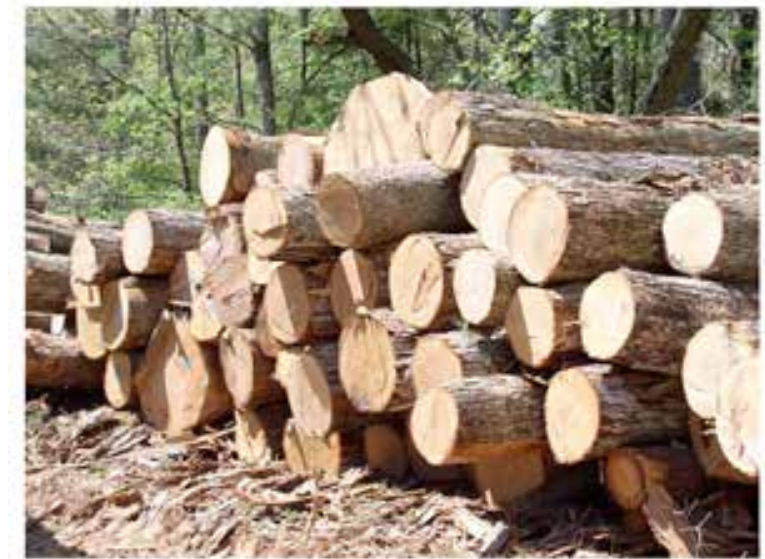

Fig 2.2 Wood

The hard, fibrous substance composing most of the stem and branches of a tree, or the raw material of a tree before being processed for use in construction

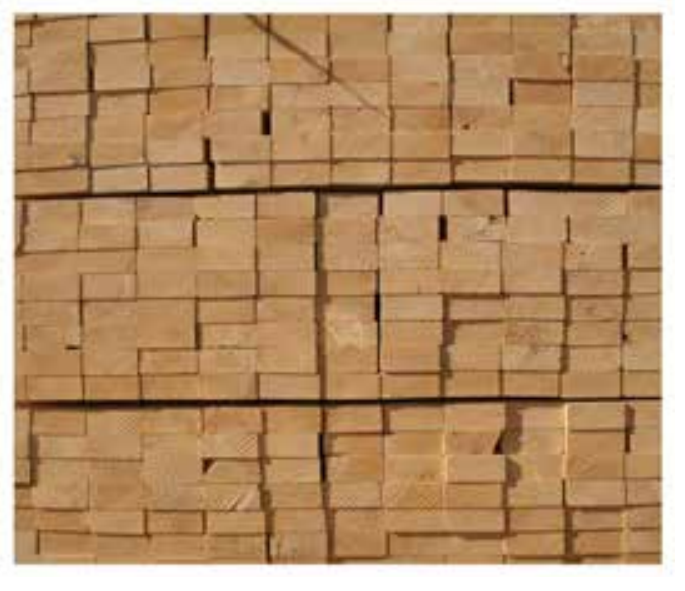

Fig 2.3 Timber

The wood of growing trees suitable for structural uses, or the wood after processing ready to be used as a construction material.

The Welsh woodland has changed dramatically over the last six thousand years. Following the last glacial period, the first species to colonise the Welsh woodlands were birches and Scots pine. Over time hazel, elm and oak began to establish with oak becoming the dominant native tree until 19th and 20th centuries. In the 12th and 13th century, woodland areas had begun to be cleared to make way for agricultural land. By the 16th and 17th centuries forest coverage in Wales was reduced to under $10 \%$ of the land area' while non-native species were being introduced on private estates as ornaments.

This period also corresponded with the high demand for four main products developed by forest based industries: charcoal, ship timber, tan bark and pitwood. Whole woods were bought for the purpose of pitwood leaving the homegrown supply insufficient to meet the demands of the industry. Records as early as 1775 show imports of coniferous pitwood into Wales. To meet the demand evidence shows increased planting of conifers on private estates on a semi commercial scale. ${ }^{2}$ This included European conifers such as Scots pine, Norway spruce and European larch. However, the deforestation continued in the 1800 s reducing the area of woodland in Wales to approximately $4 \%{ }^{3}$ By 1914 , over $90 \%$ of wood supplies were imported.

In 1917, the newly appointed Forestry Sub-Committee ${ }^{4}$ recommended the adoption of a suitable Forest Policy including the implementation of a long term state afforestation programme and creation of an appropriate state forest service. In 1919 the Forestry Commission (FC) was established with the objective of creating 'reserves of standing timber sufficient to meet the essential requirements of the nation over a limited period of three years in time of war or national emergency. ${ }^{5}$ Between 192021 the Forestry Commission planted 640 acres across Gwydyr, Llanover, Llantrisant and Margam consisting primarily of Douglas fir, Scots and Corsican pine, European and Japanese larch, as well as Norway and Sitka spruce. FC's acquisition of lands and planting rate continued to increase from 1,128 acres in 1922 to 4,200 acres in 1930. ${ }^{6}$ Following the second World War the FC was devolved to provide national committees. Wales now had its own director of forestry and by 1962250,000 acres of woodland had been planted in Wales.

In 1958 the objective of FC was revised to 'the commercial production of timber for

1 William Linnard, Welsh Woods and Forests: A history (Llandysul: Gomer Press, 2000), p.74 2 ibid, p.134

3 ibid, p. 182
4 ibid, p. 189

4 ibid, p.189

6 ibid, p.193

$\begin{array}{ll}\text { Fig 2.4 Ancient forest, Abergavenny } \\ \text { Fig 2.5 } & \text { Deciduous woodlands of th }\end{array}$ Wye Valley, Symonds Yat. 


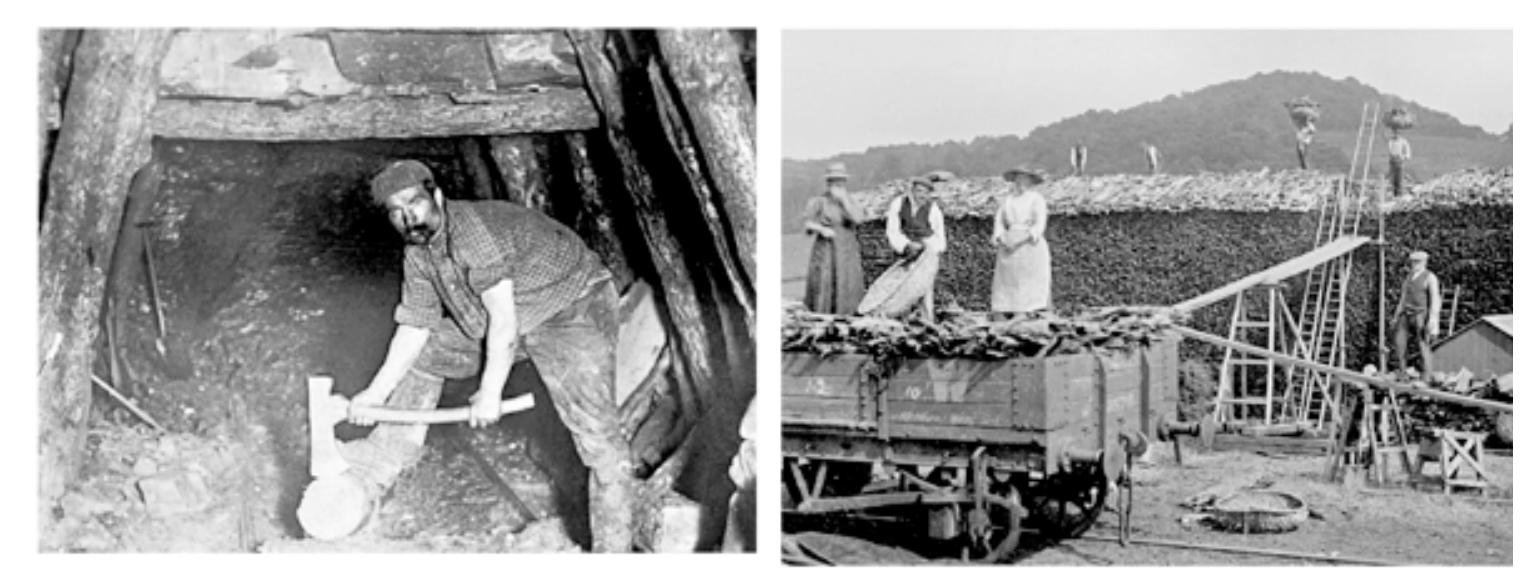

ABOVE

Fig 2.6 Preparing pitprops, South East Coalfield 19th Century

Fig 2.7 Oak tanning bark stacked awaiting

BELOW

Fig 2.8 Timber species commercially available as lumber around the world

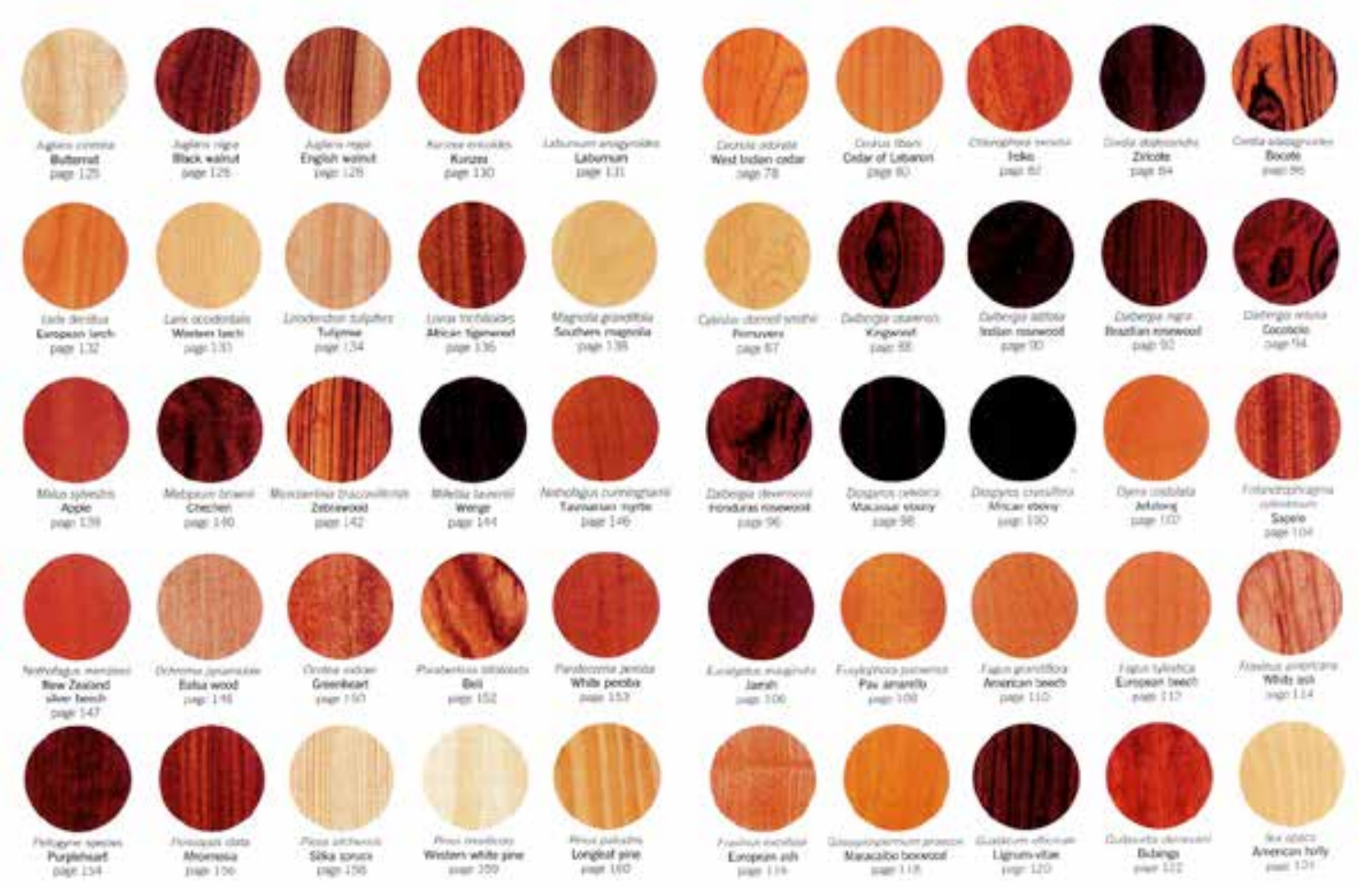

industry'. FC censuses in 1979-82 showed that the proportion of coniferous forest in Wales had increased from 33\% in 1947 to $70 \%$ in 1980 predominantly in large monospecies woodlands. The total area of FC plantations in Wales peaked in 1982/83 at 136,849 hectares. By 1995 this had fallen to 118,863 hectares and new planting had ceased although restocking of felled areas increased steadily. ${ }^{8}$ The Welsh woodlands today are left mainly comprised of un-needed mining timber. This has left a a stock of low value, non-native softwood most suited to sawlogs, pulpwood and boardmill material. This disparity between supply, properties and industry demand is a key driver in the research aims for this thesis.

Since 1989, Coed Cymru have been working alongside the Forestry Commission, in County Councils and National Parks, to heighten awareness of native woodlands, providing help, advice and training on the sensitive and sustainable management of Welsh broadleaf woodland. ${ }^{9}$ Coed Cymru have worked collaboratively with woodland owners, contractors and timber users to develop timber products and markets that ensures broadleaf woodlands have a firm economic base to ensure continued management.

\section{Wood and timber properties}

In order to work with any material a designer must understand how the material was made, its properties, how it performs and how it will last in order to design, detail and construct appropriately. As a living material, constantly changing with the climate, timber is highly complex in nature and therefore less well known today than its counterparts masonry and steel. ${ }^{10}$ The general properties of trees, wood and timber are discussed to provide definitions and meanings that will be associated with terminology used throughout this thesis. It is the intention to give a broad overview of the parameters involved in the growing of trees, the properties of wood that will ultimately affect the performance and use of timber in Wales.

\section{Qualities of wood}

The qualities, whether this is aesthetic, experiential, physical or performance related are all determined by the species ${ }^{11}$ and, as a naturally living and growing organism, the genetics of the tree.

$\begin{array}{ll}7 & \text { ibid, p.209 } \\ 8 & \text { ibid, p.213 }\end{array}$

9 Coed Cymru, Objectives and Targets, <http://www.coedcymru.org.uk/objectives.html> [accessed 17th August 2015]

10 CVY Chong Properties of materials (Plymouth: MacDonald and Evans Limited, 1977) p.105

11 Nick Gibbs, The Real Wood Bible (London,;Firefly Books Ltd, 2005) p.6 

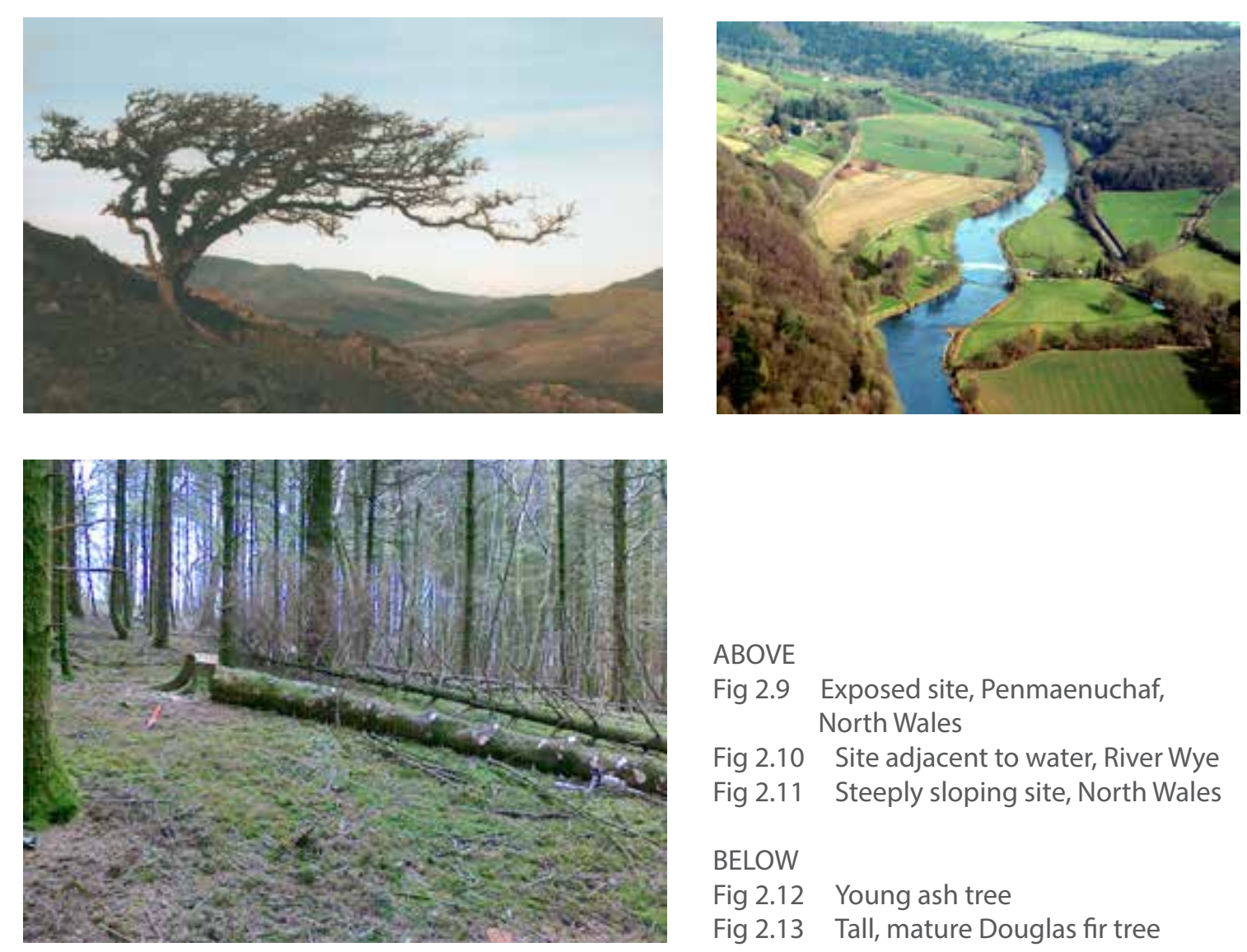

ABOVE

Fig 2.9 Exposed site, Penmaenuchaf, North Wales

Fig 2.10 Site adjacent to water, River Wye Fig 2.11 Steeply sloping site, North Wales

BELOW

Fig 2.12 Young ash tree

Fig 2.13 Tall, mature Douglas fir tree
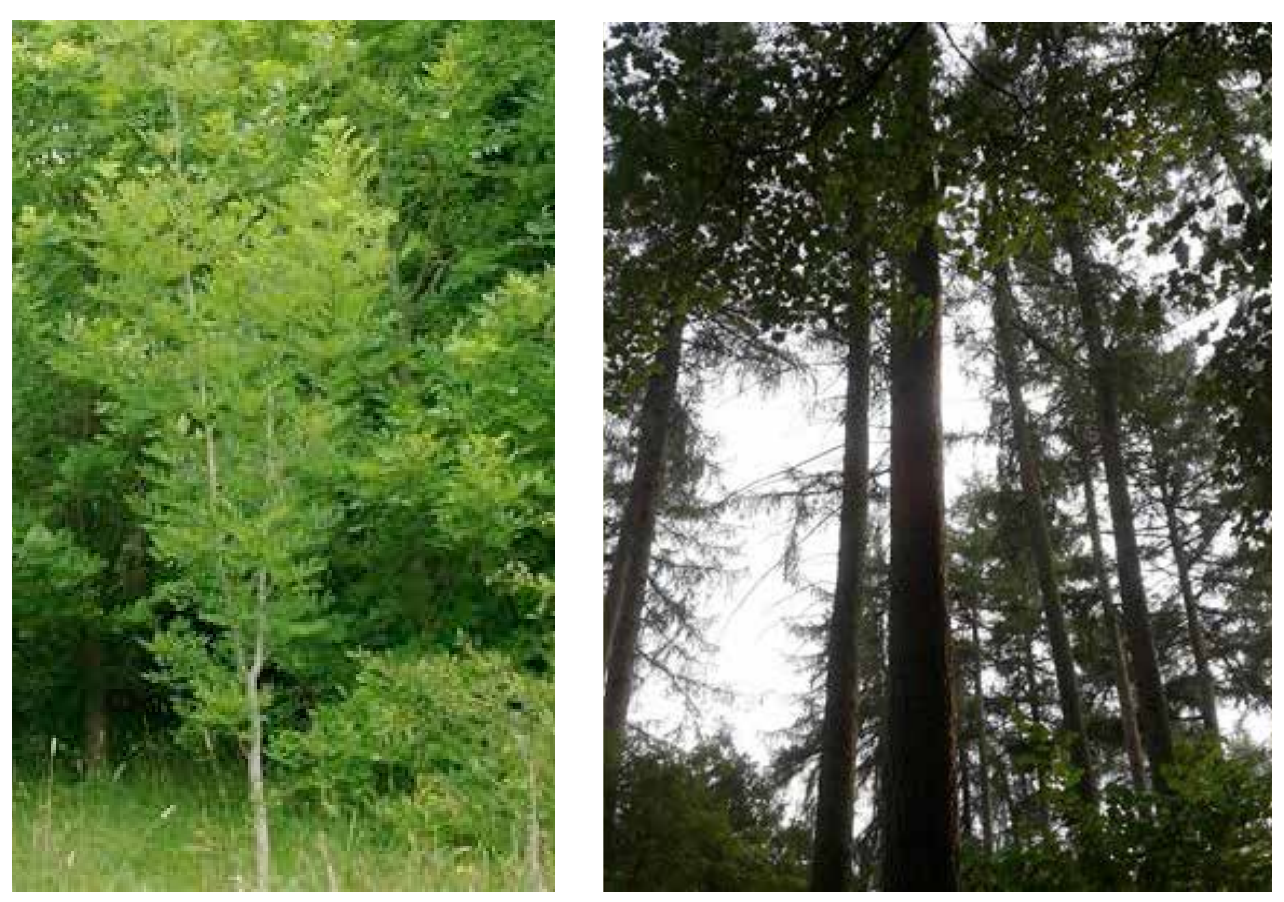

The primary selection decisions by most architects is generally first aesthetic and experiential followed by the physical performance, however this is what can commonly lead to mistakes in timber usage. Not all timbers can be used for every purpose. According to the World Resources Institute there are estimated to be 100 000 species $^{12}$ of tree globally, each with varying qualities including colours, textures, grain patterns and smells. In the UK there are only around 400 of these species of which there are only 50 native trees and approximately 60 species commonly known and used.

If the tree species is the primary influencing factor over the qualities, then the location ${ }^{13}$ in which the tree grows will have a major impact on the shape, size and length of timber taken from the tree. Location refers here to both its macro and micro location and therefore climate. A tree located within a large forest will be very different to the same species of tree located at the edge of the forest or isolated on its own due to the climatic conditions and available nutrients. A tree in the centre of a forest is likely to compete with its surroundings for light and survival, as such neighbouring trees and other plants will grow taller and wider to reach for the light, creating tall and straight trunks with less branches, although the tree may grow fairly quickly to reach the required height creating larger growth rings and earlywood. Trees towards the edge of a forest, or isolated, are likely to be vulnerable to exposure and will typically be shorter with curved trunks and/ or with the majority of branches on one side leading to eccentric growth rings. Equally the same tree species located near to or far from water and nutrients or in differing soil conditions will show different qualities in size and strength.

The age of a tree is critical in determining the quality and size of wood that can be processed. However, the life of a tree and yield will vary greatly from species to species and its location and climate. Typically coniferous trees will grow faster than broadleaf trees, meaning that softwood timber, such as spruce, is generally available after around 20 years of growth while hardwoods, such as oak, are not available until after 100 years, ${ }^{14}$ however a faster growing tree does not always produce good quality timber. A faster growing tree is likely to have larger growth rings, a larger proportion of sapwood and will generally not be as strong as a slower grown alternative, as typically evident in the mild, wet Welsh climate. A slower grown tree or hardwood timber will typically have less sapwood and tighter growth rings achieving higher strength grades. ${ }^{15}$

12 United Nations Development Programme, United Nations Environment Programme, World Bank, World Resources Institute, A Guide to World Resources 2000-2001: People and Ecosystems: The Fraying Web of Life (Washington: World Resources Institute, 2000) p.100

13 WPK Findlay, Timber: Properties and Uses (Herts: Granada Publishing Limited, 1978) p.3

14 ibid, p.2

15 ibid, p.14 
The combination of tree species, climate and age culminates in the management and eventual processing of the tree to create usable timber lengths and sections. The quality of the wood will determine how the tree is cut and the optimum lengths and section sizes, which in turn will determine the structural performance, durability, cost and other properties discussed later.

\section{Woodland management}

Sustainable forestry management, at a global level, has been a concern for over thirty years. These concerns are represented from two different view-points: that of the environmentalist, who cares about the quality of trees and wood, and the timbertrader, who cares about the quantity of timber: each with widely differing values, points of view and contradictory theories. In recent years there has been progress toward a consensus. ${ }^{16}$ With an increased interest in sustainable design, forestry practice is becoming critical for the building designer/specifier as the sustainable credentials of timber and timber products are founded in the sources and sourcing of the material.

In 1997 the Food and Agricultural Organisation (FAO) of the United Nations published a report on the status of the world's forests. It revealed that while the extraction of timber to meet demand was rising, the area of the world's forests was also increasing. Environmentalists claim that this increase masks a worldwide loss of quality forests, with the industry definition of 'sustainability' rejected by environmentalists as it is based on 'sustainable yield'. This can be represented by the replacement planting in a forest of one fast growing species, such as conifer or eucalyptus, very closely spaced. Environmentalists would argue that this strategy destroys the original bio-diversity of that forest. ${ }^{17}$ There are a number of reasons for the replacement planting of lowgrade timber. Primarily by the large demand for pulp and chips for paper and the processed timber industry.

For some, timber is considered as a by-product of the forest's primary function: sustaining biological diversity and maintaining long term ecological health. ${ }^{18}$ In this way foresters should, as far as possible, mimic natural disturbance patterns within a given eco-system. In the meantime the conservation of species and the genetic variation available in nature is shared as a critically important goal for current stability

16 Sustainable Forest Management and the Ecosystem Approach (Warsaw: Ministerial Conference on the Protection of Forests in Europe, 2005) p.2

17 Food and Agriculture Organization of the United Nations, State of the World's Forests 2007 (Rome Electronic Publishing Policy and Support Branch - Communication Division - FAO, 2007), p.8

18 Sustainable Forest Management and the Ecosystem Approach (Warsaw: Ministerial Conference on the Protection of Forests in Europe, 2005) p.3 

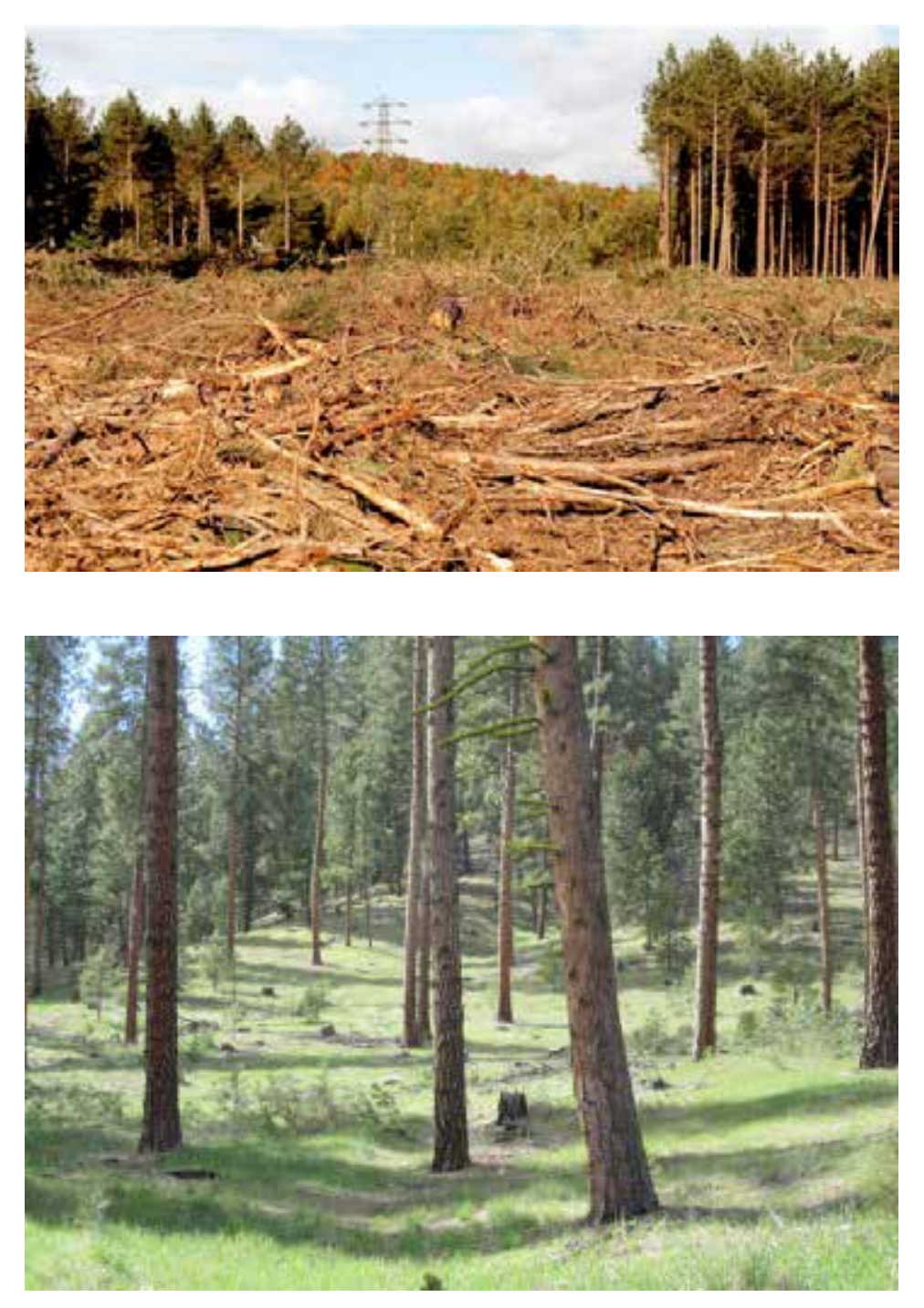

\section{Fig 2.14 Clear felling}

is generally an economic strategy and results in large areas being felled and the area then being 'brushed off' in order to vegetation. Then non-native, fast growing (sometimes genetically engineered) species, such as spruce are planted instead creating mono-culture often followed by the use of chemicals to combat diseases and pests and the acidification of the soili?

\section{Fig 2.15 Selective-felling}

is the process of removing selected individual or groups of trees be whived through thinning This method is auld normally natural regrowth of woodland species by creating space and light but also helps to diversify the forest structure and age range. ${ }^{2}$

1 Nigel Dudley, Jean-Paul Jeanrenaud and Frances Sullivan, Bad Harvest? The timber trade and the degradation of the world's forests (London, Earthscan Publications Limited, 1996) p.41

2 ibid, p.41
The main tension between timber traders and environmentalists, in forest management, is in the method of felling. There are two primary commercial methods of felling: clear-felling and selective-felling.

Environmentalists prefer selective felling, while the industry prefers to clear-fell. Some argue that selective felling is the only way of achieving sustainable forests, while others argue that both ways can potentially be sustainable, depending on the situation. Good practice suggests that the eco-system should be re-generated and replenished as happens naturally. The problem with clear-felling is that the sustainability of the forest is decided in the aftermath of felling. ${ }^{19}$ Seeds and dead, or dying, trees are left allowing the forest to regenerate providing a mixture of trees and thus an ideal habitat for animals and plants or in the worst case clear-felling results in the destruction of the forest.

As such, most countries now restrict the area of clear-felling, in Finland ${ }^{20}$ less than 2 hectares is clear-felled, and other governments in Europe recommend that clearfelled sites should not be left devoid of trees. As a result, selective felling is promoted as the most sustainable way of managing the forest. An example of this is the continuous cover forestry method practiced and promoted by Coed Cymru ${ }^{21}$, in Wales.

Continuous cover forestry is defined as an alternative'silvicultural [system] whereby the forest canopy is maintained at one or more levels without clear felling.'22 It is believed to have a less negative impact on the forest landscape than clear felling and provide a more diverse ecosystem within the forest. The approach is based on the principle that trees in the forest provide the framework for the wider forest ecosystem. Therefore when and how a tree is removed is monitored against the effect their removal will have on the wider ecosystem. In general this will only allow small, dispersed felling sites within the forest. The process then relies on natural regeneration to repopulate, in order to ensure that the species most appropriate to that context will be cultivated. In this way the variation in site conditions within the forest provides a source of species diversity.

19 Nigel Dudley, Jean-Paul Jeanrenaud and Frances Sullivan, Bad Harvest? The timber trade and the degradation of the world's forests (London, Earthscan Publications Limited, 1996), p.47

20 Ministry of Agriculture and Forestry <http://www.mmm.fi/en/index/frontpage/forests/legis/ation $\mathrm{html}>$ [Accessed 12th August 2015]

21 Coed Cymru, Innovation, <http://www.coedcymru.org.uk/innovation.html> [Accessed 10th July 2015]

22 Bill Mason, Gary Kerr, James Simpson, What is Continuous Cover Forestry? (Edinburgh: Forestry Commission, 1999), p.1 


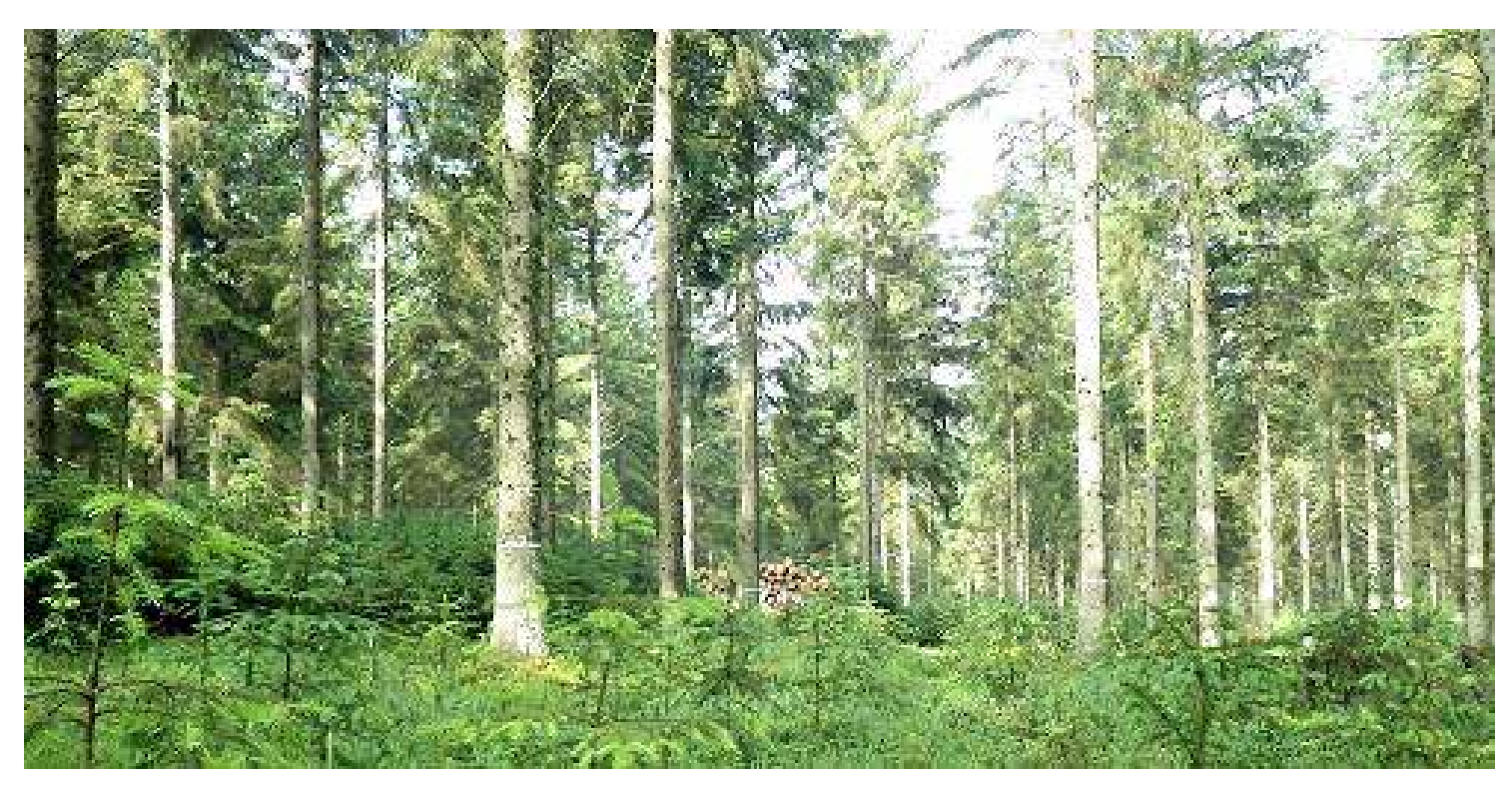

ABOVE

Fig 2.16 Continuous cover forestry

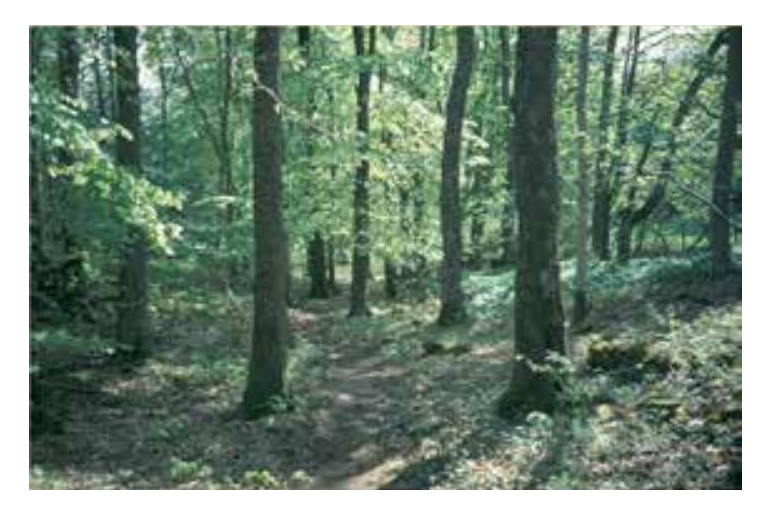

LEFT

Fig 2.17 Thinning

is the process of selectively removing trees,

primarily to improve the growth rate or health of the remaining trees allowing more light to the forest floor and allowing the trees to grow talle and wider;

Fig 2.18 Coppicing

is a traditional woodland management process which takes advantage of new growth from a stump or root when cut down. This process often occurs repeatedly, with new shoots growing for a number of years before being harvested on rotation around the woodland. Coppicing maintains a tree at juvenile stage and therefore never dies of old age. Common species coppiced include birch, oak, hazel, ash and willow;

Fig 2.19 Pruning

is usually the process of removing lower branches of a growing broadleaf tree. Trees are pruned to shape the tree from a young age to encourage the tree to grow straight and upwards without developing low-level, large branches or forking that will reduce the quality of the future timber. Conifers will usually self-prune as they grow, while the longest harvested species such as oak and ash greatly benefit from pruning during their juvenile years.

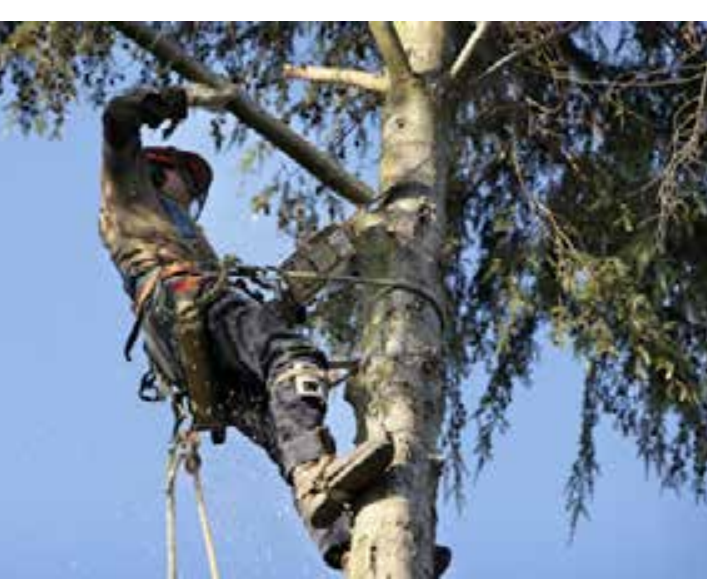

1 Forestry Commission Wales, Woodlands for Wales: The Welsh Assembly Government's Strategy for woodlands and trees (Cardiff: Welsh Assembly Government, 2009) p.57
Coed Cymru propose that crooked young and medium growth trees (diameter $+/$ $15 \mathrm{~cm}$ ) in the woodland are selected for felling. These trees, which previously were used as firewood, are proposed for use in construction, often with the aid of glues. The remaining straight trees are left to keep growing, and not cut for the immediate supply of timber, thus developing a mature growth forest, and a supply of hi-grade, large section, quality timber for future generations. This is often employed on private woodlands such as on the Llysdinam Estate in mid-Wales.

Whether or not a particular forest environment is suitable for continuous cover forestry depends on a number of factors. This includes the light requirement of the species within the forest, the intended rotation period of the trees, the soil conditions and the exposure of the site. Natural regeneration also relies on the existing tree stock being mature enough to start to reseed regularly. There is, however, 'general agreement' ${ }^{23}$ that continuous cover forestry incurs higher costs due to trees being maintained beyond their financial rotation. It is believed however that these costs may be offset against other income generated by the multipurpose forest. Also if natural regeneration is successful this should avoid the cost of replanting.

To further improve the forest or woodland biodiversity and quality of trees, there are a range of management techniques used to improve tree growth, forest floor light levels and quality of future timber. These techniques are usually carried out over decades, producing small scale timber quantities, while the woodland develops and matures prior to an eventual final felling. Three common management techniques used in Wales are: thinning, coppicing and pruning.

It seems obvious to recommend that timber should only be sourced from well managed forests so that species and genetic variation in nature will be sustained. In practical terms this means that it is preferable to source timber from forests where selective felling is practiced. In summary, it should be the sustainability of the individual forest that is critical when selecting any timber.

2.3.3

\section{Certification}

Certification has become increasingly important in the protection of the worlds forests as well as for society. The purpose of certification is to ensure the environmental, social and economic integrity of forest management is maintained and verified. This differs from sustainable forestry which is not measured or tested by a third-party source as the definition of what is sustainable is open to interpretation

23 Bill Mason, Gary Kerr, James Simpson, p.5 
and can therefore be applied differently. However, it is easier for the consumer to identify a 'label' that approves forestry methods rather than seek sustainable proof from other non-certified sources. The volume of certified forest products grew fourfold in two years, from 7.3million m3 to 29.8 million $\mathrm{m} 3$ in 1999, and according to research carried out by Price Waterhouse Coopers, the demand for certified forest products will continue to grow between $100 \%$ and $150 \%$ per year. While in Western Europe certified forest products have reached $5 \%$ levels in market penetration. (Forestworld, website).

Certification allows a timber specifier to be sure that the material will come from a 'well managed' forest, and ultimately 'encourage' sustainable forestry. It is clear that by specifying certified timber or timber products, the public can have a further influence on the 'sustainability' of forestry. However, some claim that the area of certified forest is too small, and that for smaller landowners and third-world countries certification is a difficult and costly exercise. Currently there are several certification schemes recognised both in the UK and globally with each scheme offering an

Fig 2.20 Certification logos for sustainable forestry as applied to felled roundwood

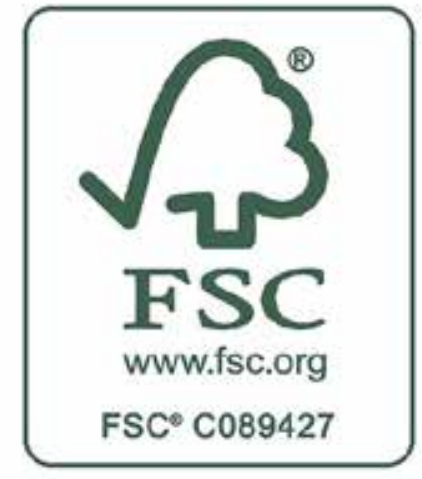

The mark of responsible forestry
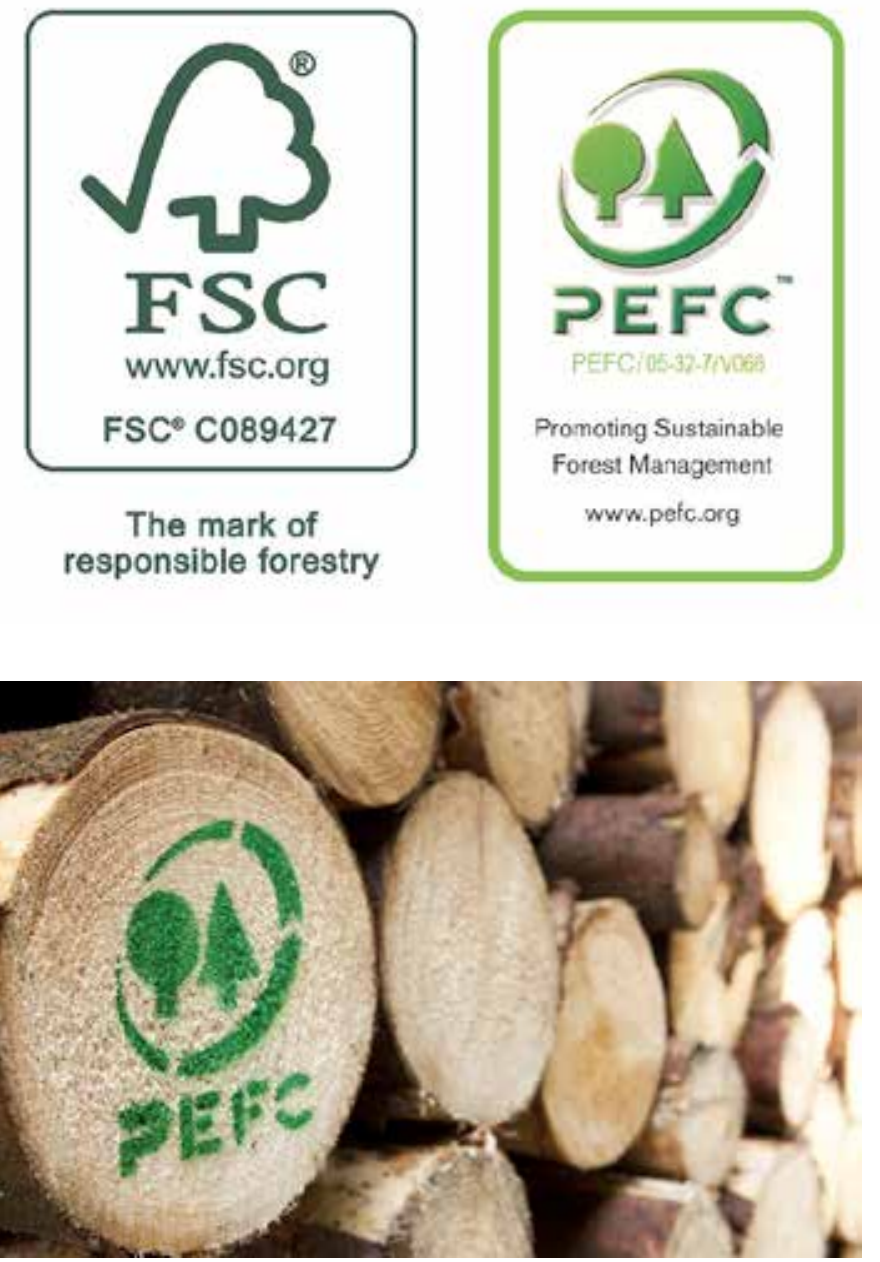

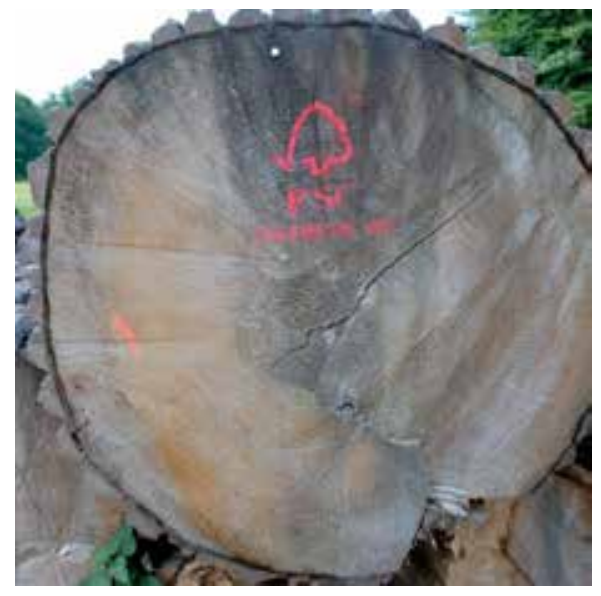

interpretation of what 'sustainable' forestry means. Two schemes are discussed here:

\section{- Forest Stewardship Council (FSC)}

The FSC was the first and only world-wide organisation offering certification for all types of forest with support from the WWF, Friends of the Earth, National Trust, Greenpeace and The Woodland Trust. Their aim is to promote'...environmentally appropriate, socially beneficial and economically viable management of the world's forests. ${ }^{\prime 24}$ At present the FSC has certified 50 million hectares in over 60 countries, with over 10000 timber products carrying the FSC trademark in the UK. The key to sustainable forests is in understanding all aspects of forestry life from the jobs they create to the habitats within and communities that may be based around them.

The 10 FSC principles for forest stewardship are based on: environmental issues and maintaining the biodiversity, productivity and ecological processes; social issues to ensure local communities will sustain the forests resources; and economic issues to create structure and add value without affecting the previous two. In order for a forest organisation to sell timber, as FSC certified, they must have Chain of Custody certification that provides a guarantee about the production from processing to distribution.

\section{- Pan European Forest Certification (PEFC)}

The PEFC has become the world's largest umbrella organisation for national forest certification. It covers 30 European independent schemes and other inter-

24 Forest Stewardship Council, Our Mission (FSC) <http://www.fsc-uk.org/our-mission-and vision.8.htm > [Accessed 10th 27th June 2013] 


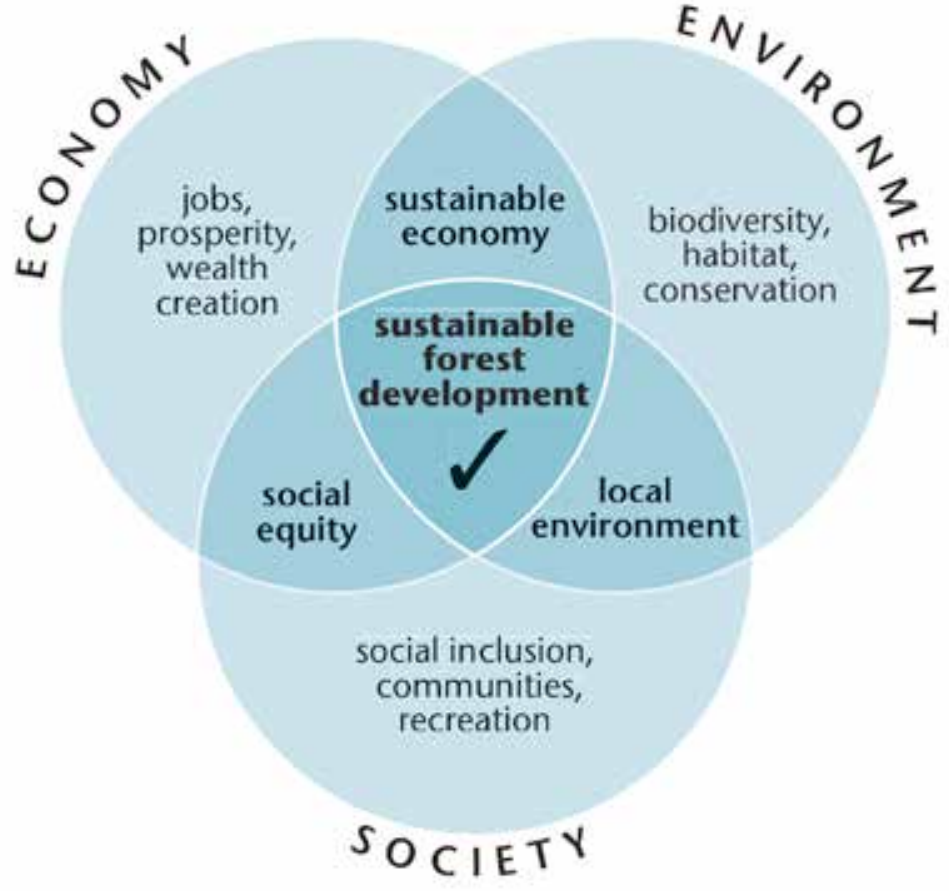

Fig 2.21 Functions of a sustainable forest governmental processes for sustainable forest management around the world accounting for over 220million hectares of forest. The PEFC is similar to the FSC in that it is an independent, non-profit, non-governmental organisation using a performance-based scheme with third party certification. However, unlike the FSC it does not use a one standard approach to certification. It offers a framework for the mutual recognition of different national forest certification schemes which is governed by representatives of national governing bodies, in turn organised by national forest owners' associations. The standards are defined at national/regional level, requiring endorsement by the PEFC council.

The common goal of both certification schemes is that they seek to assure the public that the participating companies or landowners are committed to 'good' forest stewardship leading to a sustainable chain of businesses through the supply chain from forest to consumer. The PEFC scheme is aimed at and is therefore more appropriate for small to medium sized forest owners, who claim that FSC certification is time consuming and overly expensive although the FSC do have a system of group-certification to groups who belong to a single association or whose forests are managed by the same consulting foresters. The PEFC, on the other hand, is opposed by European environmental groups who prefer the credentials of the FSC scheme.

It is difficult for a consumer or specifier to know which certificate to demand or to know what they stand for. This is especially true for the national certification schemes. Furthermore, doubts could be raised whether the schemes really represent 'sustainable' forestry management. According to Coed Cymru, (Jenkins, 2000) a FSC certificate is the only way to be assured that the obtained timber comes from a wellmanaged, sustainable resource: the standards and criteria are very good, known and can be easily checked throughout the world - in contrast to national schemes.

An alternative, sometimes proposed as a complimentary system, is ISO 14000. It is used in Brazil, Canada, Indonesia, Finland, South Africa, Sweden, New Zealand and the US as a system applying third-party certification, but as opposed to the FSC and PEFC schemes, it does not assess environmental field performance. Instead it assesses a company's environmental performance in order to implement continual improvement. It is not forest-specific, and thus does not apply any forest management standards and no product labelling is allowed. Many people think that this provides an opportunity to avoid practical forestry matters, and as such, it should not be used instead of a performance based system such as FSC and PEFC.

Certification is a crucial tool in achieving sustainable forestry worldwide. Although there are a lot of international, national and regional certification schemes, for the 


\begin{tabular}{|c|c|c|c|c|c|c|c|c|c|}
\hline \multirow[b]{4}{*}{ Country } & \multicolumn{9}{|c|}{ Areas of FSC certified woodland } \\
\hline & \multicolumn{9}{|c|}{ Woodland ownership (in thousands of hectares) } \\
\hline & \multicolumn{3}{|c|}{ Publicly owned - Forestry Commisssion } & \multicolumn{3}{|c|}{ Privately owned } & \multicolumn{3}{|c|}{ Total woodland areas } \\
\hline & Total area & Area certified & $\%$ & Total area & Area certified & $\%$ & Total area & Area certified & $\%$ \\
\hline England & 215 & 215 & 100 & 1087 & 135 & 12 & 1302 & 350 & 27 \\
\hline Scotland & 477 & 477 & 100 & 942 & 344 & 37 & 1392 & 821 & 59 \\
\hline Wales & 117 & 117 & 100 & 189 & 24 & 13 & 306 & 141 & 46 \\
\hline N. Ireland & 62 & 62 & 100 & 50 & 3 & 6 & 112 & 65 & 58 \\
\hline TOTAL UK & 871 & 871 & 100 & 2268 & 491 & 22 & 3112 & 1377 & 44 \\
\hline
\end{tabular}
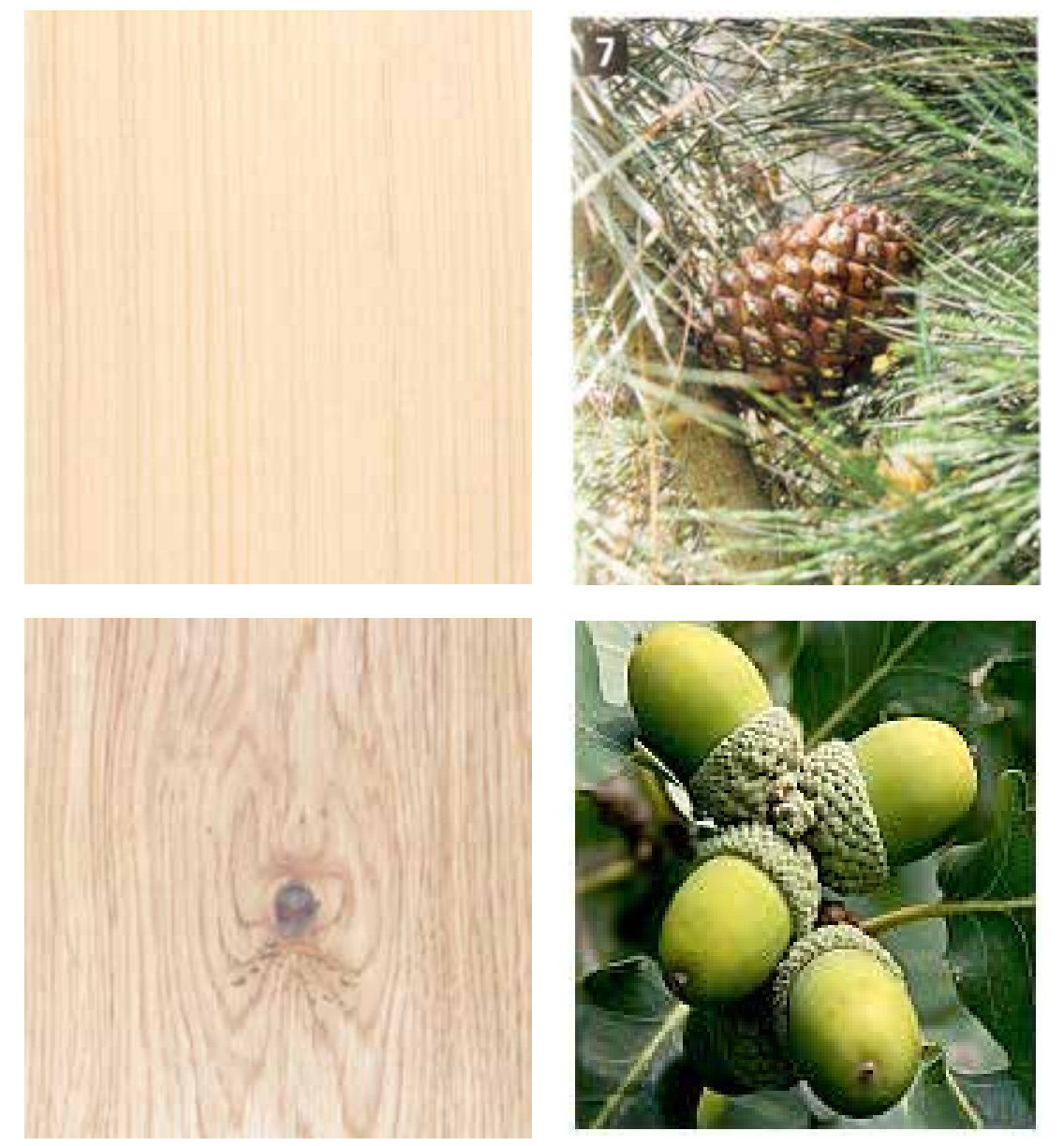

TOP

Fig 2.22 Areas of FSC certified woodland

Fig 2.23 Sitka spruce timber swatch

Fig 2.24 Needles and cones

Fig 2.25 English oak timber swatch

Fig 2.26 Wide leaves and seed timber consumer and specifier, the matter can probably be reduced to just whether the FSC and/ or PEFC logos are present.

In the UK, all 117000 hectares of publicly-owned, Forestry Commission for Wales managed, woodland is certified by the FSC. $89 \%$ of this is of conifers with an ever decreasing area of broadleaf woodland.

\section{Classification of trees and wood}

There are a couple of classifications that have been used so far to describe the different types of tree species and timber properties: coniferous and broadleaf; and softwood and hardwood. These terms are very different but are often confused in the description of timber. The first are terms used to describe the type of tree by the type of foliage it has and relates indirectly to the pattern of retaining or losing its foliage during the seasons:

- Coniferous trees are part of the botanical family of gymnosperms, which comprise a further 12 types of tree. The term conifers is used to describe any tree that has needle-like leaves and has cone-shaped seeds. Typical conifer trees include cedars, Douglas firs, pines, spruces, firs, larches and yews among others. They are generally evergreen trees, in that they keep there leaves all year round, but some, such as the larch family, lose their needles in the autumn.

- Broadleaf trees are from the botanical family of angiosperms and is any tree that has wide leaves rather than needles. Most broadleaf trees are deciduous, in that they lose their leaves in the autumn, such as oak, beech and birch however there are also some evergreen broadleaf trees such as live oak and holly.

The second terms relate to non-botanical, generalised descriptions of the wood or timber from either coniferous or broadleaf trees. It does not scientifically refer to the actual hardness of the wood, although often this is the case:

- Softwoods are generally derived from coniferous trees, which are grown in the northern temperate zones. ${ }^{25}$ Not all softwoods are low density, such as yew which is strong and durable. Softwood and coniferous trees provide the source of $80 \%$ of the World's production timber.

- Hardwoods are derived from broad leaf trees ${ }^{26}$ and are grown in both the temperate and tropical zones, leading to temperate hardwoods such as oak, 


\begin{tabular}{|c|c|}
\hline $\begin{array}{c}\text { Softwood species } \\
\text { in Wales } \\
\text { Conifers }\end{array}$ & $\begin{array}{c}\text { Hardwood species } \\
\text { in Wales } \\
\text { Broadleaves }\end{array}$ \\
\hline Douglas fir & Alder \\
\hline European larch & Ash \\
\hline Japanese larch & Beech \\
\hline Scots pine & Birch \\
\hline Corsican pine & Elm \\
\hline Lodgepole pine & Hazel \\
\hline Sitka spruce & Oak \\
\hline Norway spruce & Sweet cheestnut \\
\hline Western Hemlock & Sycamore \\
\hline & White poplar \\
\hline Source: Forestry Commission, Forestry Statistics 2014 (Edinburgh: Foresty
\end{tabular}

Fig 2.27 Softwood and Hardwood species in Wales

BELOW (Left - Righ

Fig 2.28 Tree Anatomy

Fig 2.29 Photosynthesis

Fig 2.30 Transverse section of softwoo

Fig 2.31 Late/early wood in tree trunk

Fig 2.32 Anatomy of a tree trunk

A tree is a complex plant or vegetab

organism that uses salts and water

from the soil and carbon dioxide from

the air to manufacture food through

photosynthesis or the action of sunlight

on chlorophyl. To do a his the tree

extends upwards to reach the best light,

some Douglas fir trees in North

some Douglas tree consists of lonitudina tubiform that carry the nutrients up and down the tree as it grows. The cell walls are made up of cellulose and lignin which combine in different species of tree, eventually
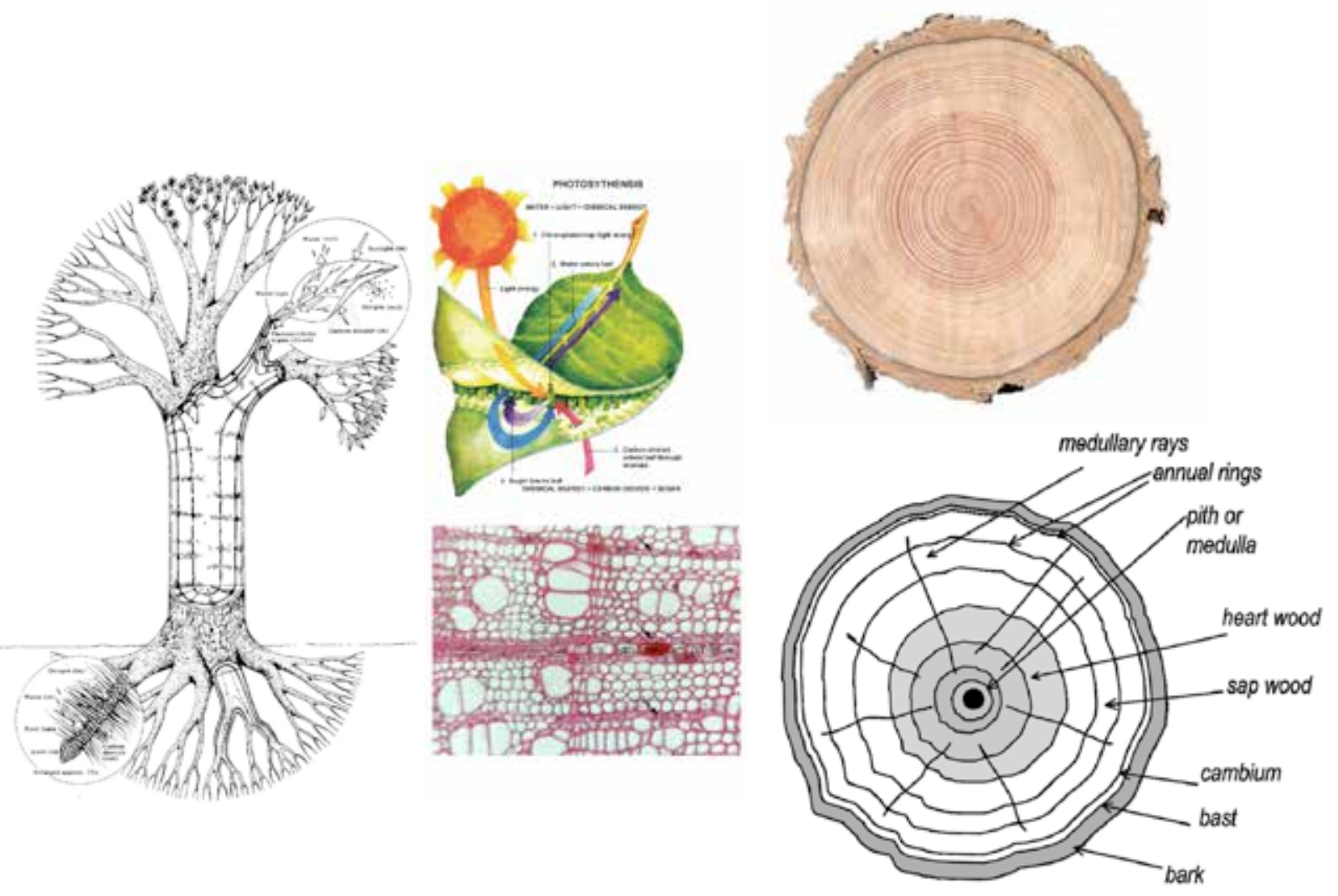

beech, ash, western red cedar, chestnut and sycamore and tropical hardwoods such as iroko, mahogany, sapeli, meranti and jelutong. Not all hardwoods are high density such as the tropical hardwood balsa which is softer than most softwoods.

In terms of actual 'hardness', density or mechanical strength, the softwoods overlap the hardwoods with the hardest softwoods being harder than the softest hardwoods. The average hardness for hardwoods is greater than the average hardness of softwoods. For the purpose of this thesis, the table opposite identifies the softwood and hardwood trees widely growing in Wales:

\section{Anatomy of wood}

Further clarity in the differences between softwood and hardwood can be seen in the anatomy of trees and wood and more specifically in the way in which the trees grow that ultimately defines the characteristics of the timber.

A young tree develops from a leading shoot that becomes the centre of the mature tree, or the pith. The tree grows in annual phases between April and September (in the Northern hemisphere) creating growth rings. The production of the cells in each ring occurs in the cambium, a microscopic layer of cells on the out side of the tree, just under the protective bark. During the first stages of growth each year large-pored cells are formed, known as early-wood, transporting large quantities of nutrients. In the later stages of growth more solid, thick-walled cells are produced known as late-wood. As the tree grows, a new growth ring around the pith is produced approximately each year creating the primary growing zone of the tree known as the xylem. Each ring differs in its early/ late wood proportion reflecting the climate and or other influential conditions with the balance of early-wood and latewood over several years determining the strength of the wood. ${ }^{27}$

As the tree matures and further rings are formed, the nutrients, such as starch, stored in previous rings are extracted along medullary rays, cells that cross the rings from the centre towards the bark, causing these rings to dry and become more durable and resistant to insect and fungal attack. This is known as the heartwood due to its central location. Heartwood is generally darker in colour than sapwood. Sapwood can typically vary between $25-150 \mathrm{~mm}$ with the centre left as heartwood. ${ }^{28}$

While the above description of wood anatomy is generally true for both softwoods 

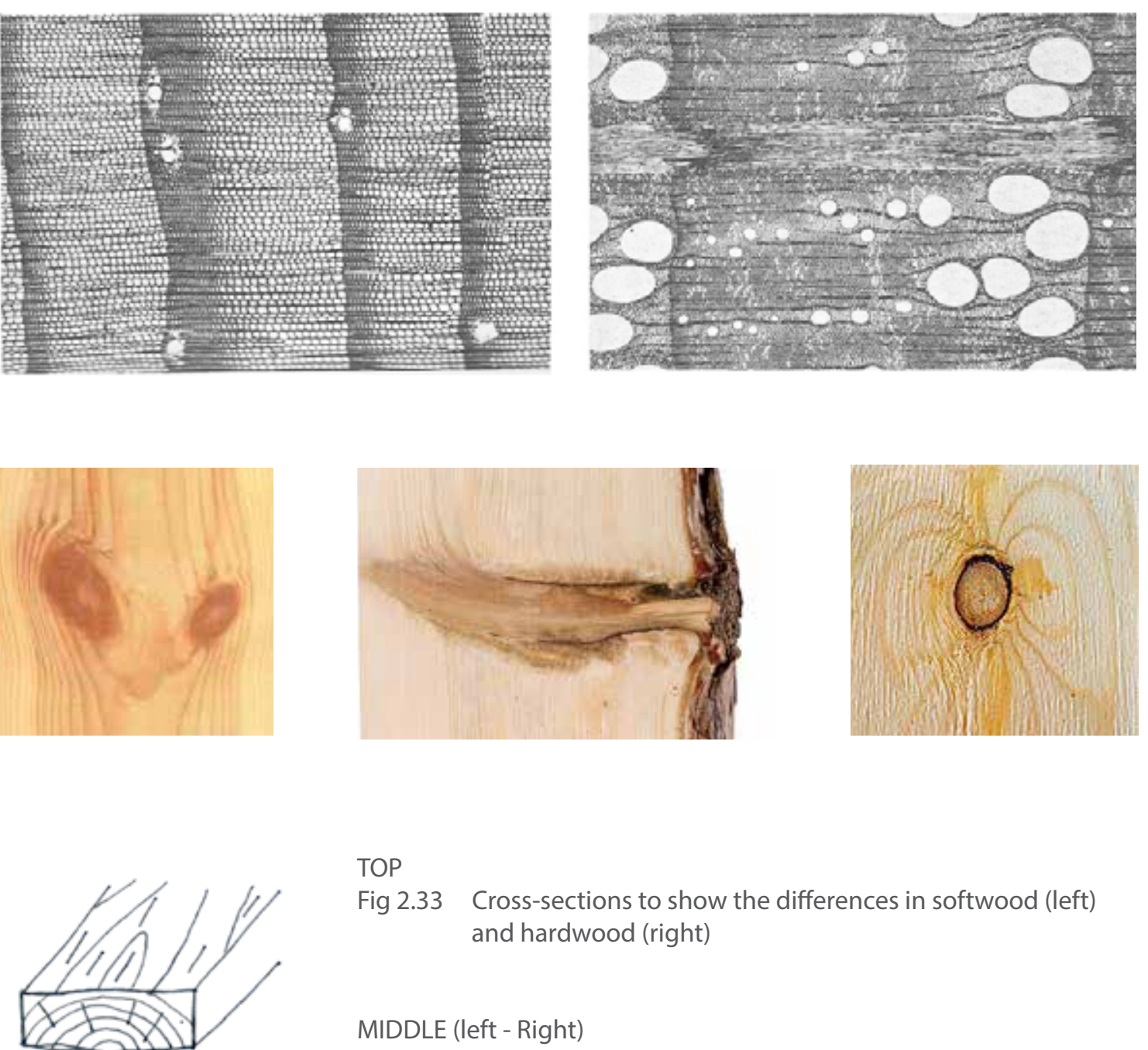

Fig 2.33 Cross-sections to show the differences in softwood (left) and hardwood (right)

MIDDLE (left - Right)

Fig 2.34 Live knot

where a branch is fully connected into the fibres of the xylem where all growth rings within the tree join the growth rings within the

branch. These knots will be part of the timber when cut.

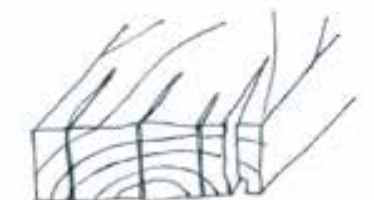

Fig 2.35 Intergrown knot

formed where a branch has died or been removed in the past leaving a short stub that has been engulfed by the tree as it continues to grow. The knot will be attached to the xylem at the base but loose where the tree has grown around it; and

Fig 2.36 Dead knots

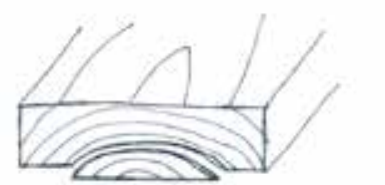

occur where are branch has died and been removed and/ or decayed leaving it separated from the fibres of the xylem. This type of knot is likely to be loose and will fall out during processing, therefore educing the strength of the timber.

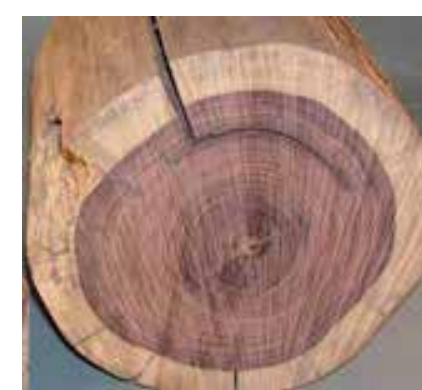

LEFT (Top - Bottom)

ig 2.37 Drawings of fissures

The typical shakes that appear are:

a. radial shakes where the tree has shrunk circumferentially leaving a

radial split;

b. ring shakes where the tree has split between growth rings;

c. a heart shake where the pith or heartwood has dried and shrunk

becoming either partially or completely separated from the sapwood.

Fig 2.38 Fissures in dried hardwood trunk and hardwoods, there are some primary differences in the the microscopic features of the two:

- Softwoods, when cut, generally show a uniform division of cells with a slight variation between the early- and latewood density that shows up as the growth rings. These cells are known as tracheids and are needle-shaped units between 2-5mm long, tightly packed together making up the bulk of wood. ${ }^{29}$

- The hardwood structure is more complex than that of softwood. The conduction of sap is through long tubular vessels, seen on the end grain, while the mechanical strength is provided for by fibres. 'Diffuse porous' trees, such as beech, form similar sized vessels throughout the growing period giving a relatively uniform growth pattern whereas 'ring porous' trees, such as oak, grow more similarly to softwoods with earlywood vessels much wider than latewood vessels. Hardwood rays vary in cell width often leading to a significant figure to the wood, but are more prone to splitting along the grain..$^{30}$

As the tree grows, branches are produced that spread out radially, diminishing in cross sectional area as they fork out to produce leaves. Classed as an imperfection in the resultant timber, the start of these branches in the xylem are known as knots. Depending on the state of a branch and the age of the tree, three differing types of knot can be found in timber: live, intergrown and dead knots. ${ }^{31}$

Other imperfections in timber, caused by the natural growing of a tree are:

- Fissures - cracks or splits that occur due to shrinkage as moisture is lost Shrinkage can happen while the tree is still alive, after it is felled or during the processing of timber;

- Reaction wood - occurs when a tree grows in an unusual manner, such as sideways out of a steep bank before bending to grow vertically, or when subjected to continually strong winds in coastal locations. Reaction wood is often referred to as either compression wood in softwoods or tension woods in hardwoods. Both types of reaction wood are problematic to work with in commercial timbers, but can be used for specialist purposes. ${ }^{32}$ 

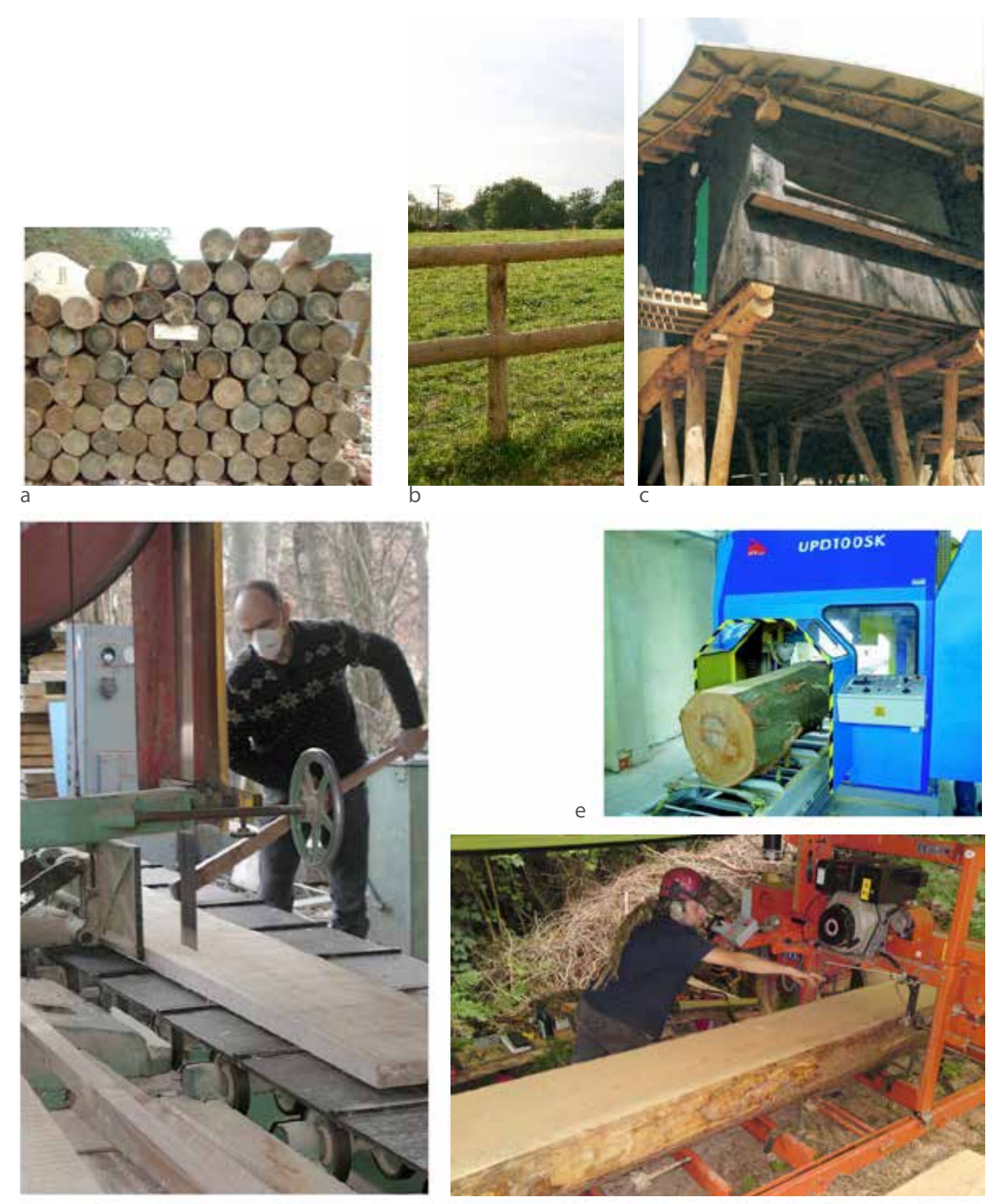

d

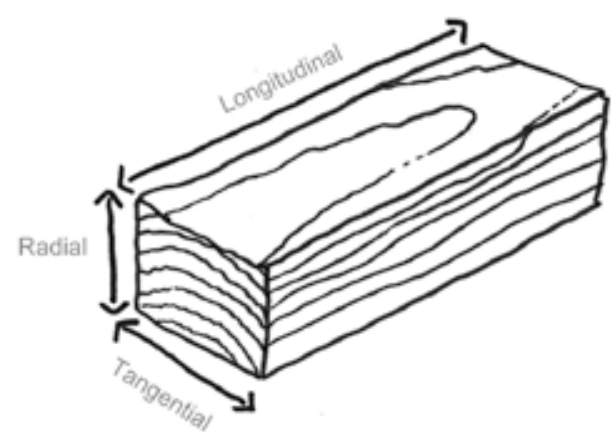
Radial section with vertical grain parallel to the edges of the cut;

Cross (or transverse) section with the growth rings visible usually perpendicular to the edge of the cut; and Tangential section with the grain diagonally and/ or wavy across the face often culminating in arcs as the
2.3.6

Processing wood

The conversion of trees and wood into timber involves a number of processes that are determined either by the properties of the tree, the intended use of the timber or a combination of the two. Typically a tree with diameter less than $230 \mathrm{~mm}$ is used as roundwood ${ }^{33}$ and is cross cut rather than sawn to be used in the past as pit props and telegraph poles, while in the UK today the narrow trees and thinnings are usually pulped for the use of paper making, board products, such as chipboard or MediumDensity-Fibreboard (MDF) or used as fuel. ${ }^{34}$ Sometimes the round-section wood is used in construction for traditional log on log type constructions or in bespoke designs either as a conscious design choice or where local timber has been used where limited processing skills and machinery were available.

Prior to the mechanisation of timber processing in the late eighteenth-century all other useable timber was processed from a log by hand through hewing, cleaving, slicing, peeling and sawing. Unless, specifically required to use traditional methods, all construction timber today is processed either at the forest with a portable bandsaw or at a sawmill to generate various section sizes and lengths. The wood is cut in two ways, cross cut to reduce the length of the log and longitudinally cut to specific section sizes. ${ }^{35}$ Furthermore there are two types of longitudinal cut: a tangential cut, that crosses the growth rings but never through the heart; and a radial cut, perpendicular to the growth rings through the heart.

While these types of cut have different aesthetic qualities with the grain they are also fundamental to the types of timber section that will be processed, and its resultant properties for use.

A log can be sawn into boards and planks in a variety of ways, but only in the tangential or radial direction. The simplest way is to cut down the length of the log from one end to the other. This will generate a number of tangentially cut boards with one radial cut board including the heart of the tree. This is known as plain-sawn or flat-sawn timber. An alternative is to cut the log to maximise from the better quality radially cut boards by dividing the log into quarters. This can be done in a number of ways shown in the drawings, but the objective is to cut perpendicular to the growth rings so as to ensure that the angle between ring and edge of board is no more than 45 degrees. This is known as quarter-sawn timber. Plain-sawn timber is usually cheaper to produce but there are increased chances of undesirable

33 Ibid, p.17

34 Forestry Commission, Forestry Facts and Figures (UK, Forestry Commission, 2014) 35 Findlay, p. 18-2 


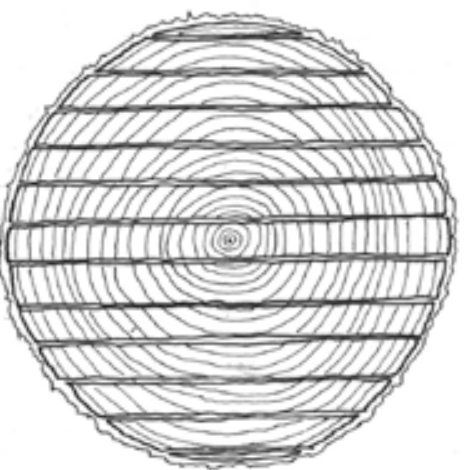

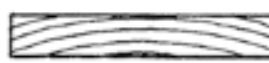

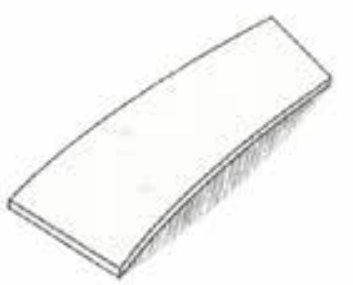

Bow

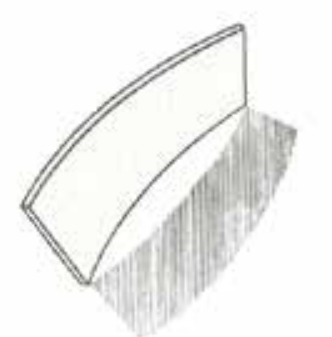

Spring

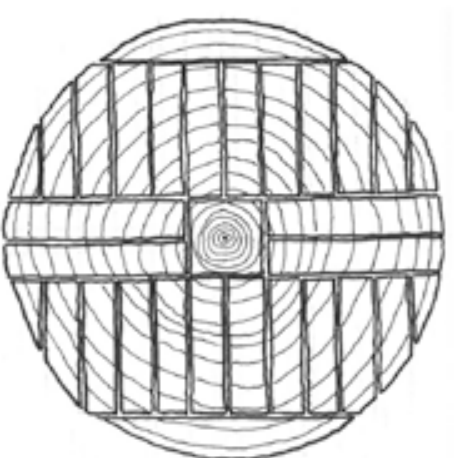

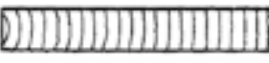
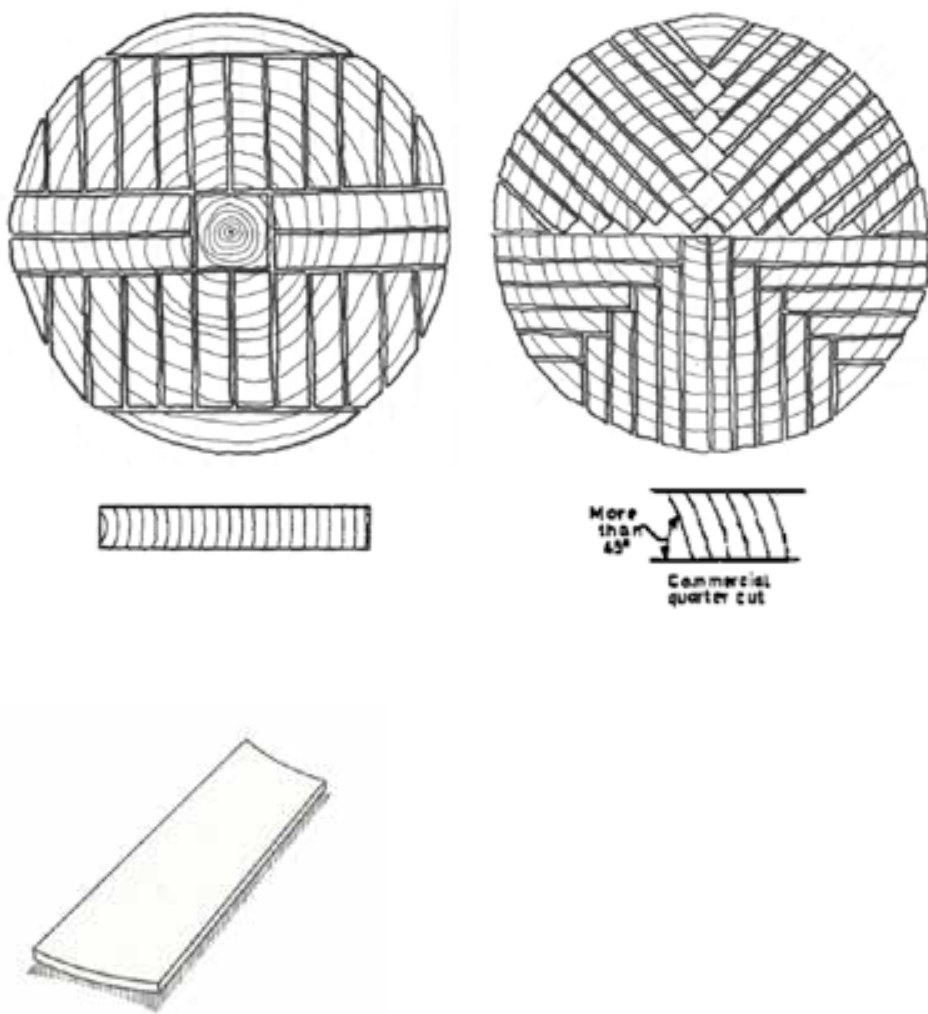

Cup

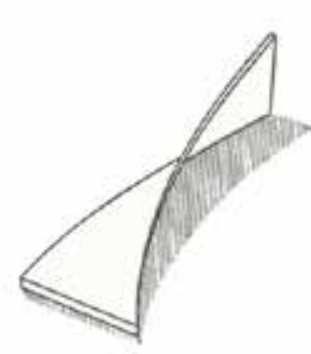

Twist

Fig 2.42 Tree cutting diagrams

LEFT

ig 2.43 Distortion of boards on drying

BOTTOM

Fig 2.44 Timber use and moisture content

\begin{tabular}{|c|c|c|}
\hline \multirow[b]{2}{*}{ Moisture content } & \multicolumn{2}{|c|}{ Timber use and moisture content } \\
\hline & BS EN 942: 2007 & Experienced rule of thumb \\
\hline \multicolumn{3}{|l|}{$\begin{array}{l}\text { Green } \\
>30 \%\end{array}$} \\
\hline \multirow{3}{*}{$\begin{array}{l}\text { Semi-dry } \\
>20 \%-<30 \%\end{array}$} & \multirow{3}{*}{ External joinery (12 - 19\%) } & Carcassing timber $(22-25 \%)$ \\
\hline & & External cladding $(18 \%)$ \\
\hline & & High-class carpentry $(18-20 \%)$ \\
\hline \multirow{3}{*}{$\begin{array}{l}\text { Dry } \\
<20 \%\end{array}$} & unheated internal use $(10-16 \%)$ & General joinery (15\%) \\
\hline & $\begin{array}{l}\text { internal use heated between } 12-21^{\circ} \mathrm{C} \\
(9-13 \%)\end{array}$ & Internal flooring and panelling $(10-12 \%)$ \\
\hline & $\begin{array}{l}\text { internal use heated over } 21^{\circ} \mathrm{C} \\
(6-10 \%)\end{array}$ & $\begin{array}{l}\text { Internal use in low air tightness buildings } \\
(5-10 \%)\end{array}$ \\
\hline
\end{tabular}

movement as the boards dry, especially in lower quality timbers such as Sitka spruce. In some trees the central heartwood of the tree is weaker and less durable than the rest of the heartwood, so it is sometimes desirable to 'box the heart' and use this core wood for lower value applications. ${ }^{36}$

\subsubsection{1}

\section{Seasoning}

As a living tree has a very high moisture content, wood is naturally a hygroscopic material with the ability to both lose and absorb moisture according to ambient conditions. Wood, once cut, will begin to shrink as it loses moisture. This movement can be significant with up to $10 \%$ in the tangential plane and up to $5 \%$ across the radial cuts, however the longitudinal shrinkage is usually negligible at around $0.1 \%$. As a rule of thumb timber generally will move $1 \%$ across the grain with every $4 \%$ change in moisture content. ${ }^{37}$ This can have a significant effect on the type of boards cut leading to bowing, springing, cupping and/ or twisting if not carefully seasoned and processed..$^{38}$

This basic ability is the primary influencing factor of almost all the physical properties of timber and must be understood in both design and construction. Sometimes it may be possible to specify ' $g r e e n$ ' timber with a moisture content over $30 \%$, but this requires careful detailing to allow for the movement that will occur as it continues to lose moisture to below $20 \%$, or 'dry' ${ }^{\prime 39}$ Due to the influence of moisture on performance, once a log has been primary cut into boards and planks it must be seasoned, regardless of species, to:

- Minimise shrinkage in use;

- be more resistant to fungal decay, staining and insect attack

- Reduce its weight for transport

- Make it less corrosive to metals

- Make it more absorbent of preservative fluids; and

- Make it suitable to receive paints, varnishes and stains.

There are two main methods of seasoning: natural, air drying and artificial, kiln drying. Until around 80 years ago air drying was the principal way to dry timber. The rough sawn boards are stacked evenly, with a continuous space between all boards in a well ventilated but sheltered space for up to a year per $25 \mathrm{~mm}$ thickness of board. In the UK the moisture content will drop to about $18 \%$ to match the relative humidity

36 Ibid, p.67-68

37 Building Research Establishment, The Movement of Timbers, Technical Note 38 (Watford: BRE 1982) 38 Findlay, p.67-68

39 These figures of the moisture content of wood are expressed as a percentage of the 'dry' weight compared to its original 'wet' weight rather than the actual volume of water within the timber. 

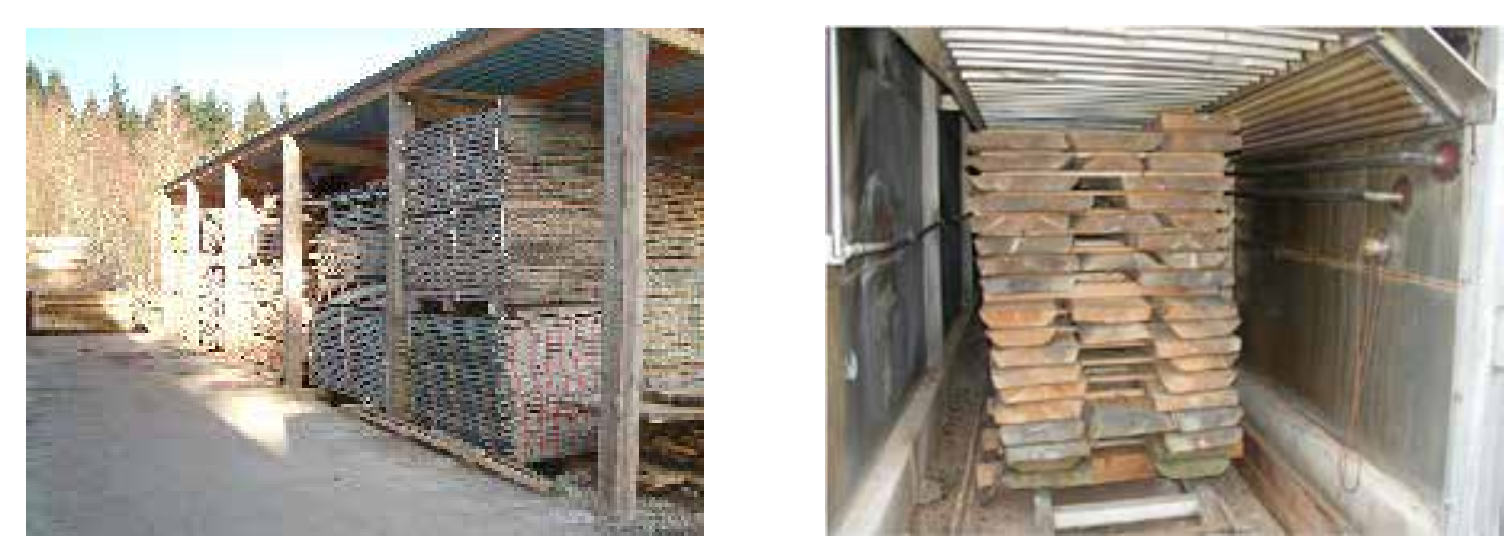

TOP

Fig 2.45 Air drying (left) and kiln dried (right) timber

BELOW

Fig 2.46 Standard sawn softwood sizes table of the surrounding atmosphere. Due to the length of time required, air-drying is now mainly used as a primer for hardwoods to reduce the initial moisture content before kiln drying which helps to reduce energy and cost and to avoid excessive movement in the kiln. ${ }^{40}$

Kiln drying was developed in the 1920 s to accelerate the seasoning process, reduce storage space and reduce the risk of fungal or insect attack during seasoning. The temperature and humidity levels are carefully controlled and often adapted to suit the nature of a batch being dried. The kiln environment is set with a high humidity and low temperature which is slowly reversed over several days or weeks heating the timber to evaporate moisture, while also reducing the humidity. Typical moisture content levels, shown in the tables, for different purposes are defined in slightly differing ways by different trade bodies and standards, however all would agree that the moisture content required should be based on intended use. ${ }^{41}$

Sizes

While some softwood boards are left rough sawn and sold for use in general construction the majority of softwood is planed on either two sides or all four sides (also known as CLS - Canadian Lumber Sizes) to provide smooth edges for more accurate construction or joinery. The processing of seasoned plain- and quarter-sawn boards into marketable and useable sizes is split into two types: structural timber from the heartwood and falling boards cut from the sapwood around the edge of the tree. The falling boards are generally plain-sawn and will often result in cupping requiring planing to produce a square section, but typically of small cross-section than the more stable structural timber. A full range of approved sizes for structural softwood timber are listed in BS EN 1313-1:201042 and BS EN 336:2003. The section sizes, in the UK, are often based on previous imperial measurements with widths in multiples of $25 \mathrm{~mm}$, however a metric range of sizes influenced by European markets are emerging but still less common. Standard lengths are often cut in increments of $300 \mathrm{~mm}$ between $2400 \mathrm{~mm}$ and $5400 \mathrm{~mm}$. It should be noted that while these sizes are highlighted as the full range of available structural softwood, not all these sizes are processed in every sawmill or as standard practice in Wales. Typically, with a smaller turnover of planed softwood, the Welsh sawmills produce a limited supply of the most popular sizes based on $47 \mathrm{~mm}$ and $75 \mathrm{~mm}$ thicknesses.

Hardwood is less commonly produced ${ }^{43}$ and used in a standardised way than

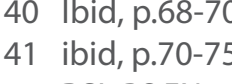

42 BSI, BS EN 1313-1:2010-Round and sawn timber. Permitted deviations and preferred sizes. Softwood sawn timber (Chiswick: BSI Standards Limited, 2010)

43 Welsh Economy Research Unit, Welsh Institute for Rural Studies, School of Agriculture and Forest 
softwood, therefore there are less standard hardwood options and sizes available. A range of approved sizes and increments for cutting hardwood are listed in BS EN 1313-2:1999, although the tables are less specific than for softwood instead recommending preferred thicknesses, widths and lengths. Instead, hardwood is generally treated as specific for each project and specified and sized according to the requirements. A more specific parameter on the sizes of hardwood available in Wales is related to the method by which hardwood is cultivated. As hardwoods take longer to grow and reach their optimum felling size, less hardwood is readily available. While it is possible to source large section hardwood, it is considered better practice for foresters, sawmills and specifiers to use Welsh-grown hardwoods more resourcefully and more efficiently. By using small sections and lengths it may be possible to reengineer components and/ or conceive constructions differently so that the product of thinning, coppicing and pruning the hardwood forests can be used to reduce the impact of selective and clear felling of the hardwood, and often indigenous woodland.

\section{Mechanical properties of timber}

In this section the mechanical properties are examined with a focus on two significant parameters on use of timber in structures: density and strength.

\subsubsection{Density}

As previously discussed, the density of timber is primarily affected by the species, moisture content and the rate of growth of a tree: Green timber will have a higher density than seasoned timber ${ }^{44}$ due to the higher moisture content; hardwoods will generally be more dense than softwoods, with exceptions, due to the higher amount of cell-wall substance; and the proportion of earlywood and latewood in trees of the same species can differ significantly due to the climate and location of the growing tree. In comparison to other building materials, timber is far less dense making it generally a lightweight building material. The table shows the densities of a range of global timber species against general building materials, however it can be seen that in the UK, the mainstream timbers available range between the low density (spruce at $450 \mathrm{Kg} / \mathrm{m3}$ ) and medium density (European oak at $730 \mathrm{Kg} / \mathrm{m3}$ ) in comparison with some of the tropical hardwoods. This has an effect on the physical properties of timber in two ways: thermally and strength.

The low density of timber with the high volume of air trapped inside the cells means 
Strength grading tests

\section{Bending loads}

Important for floor joists that have to take dead loads and variably imposed loads

Stiffness (modulus of elasticity)

Important for floor joists to resist bending and avoid

movement cracks as well as determining the

strengths of long columns

Tensile strength

Important for timbers that are to be curved into a permanent shape

- Impact bending

The ability to resist a sudden load

Compressive strength

Tested for loads that are applied parallel to the grain, such as columns

Hardness

Useful for floor finishes that need to resist indentation

\section{Cleavability}

Measure the resistance to being pulled apart that

may determine whether the timber can intentionally

be split, such as in shingle making

Shearness

Measure the resistance to the timber splitting when under torsional loadings, such as in floor joists or wall studs providing racking resistance in a building. that timber is generally a good insulator with a low thermal conductivity, compared to masonry, steel and concrete, although this will vary slightly with moisture content. This makes timber ideally suited when combined with other thermal insulating materials to the construction of external walls to reduce heat losses through the fabric. However with low thermal conductivity comes a lower thermal storage capacity than that of masonry or concrete. For example the thermal storage coefficient of spruce is approximately $350 \mathrm{Wh} / \mathrm{m} 3 \mathrm{~K}$, whereas concrete is $660 \mathrm{Wh} / \mathrm{m} 3 \mathrm{~K}$. This makes it typically difficult to control the thermal compensation of a timberframed building in the extremes of summer or winter.

2.3.7.2

\section{Strength}

The density and moisture content of timber will greatly affect the mechanical strength properties and are therefore the primary considerations when specifying the correct timber species for load-bearing situations. As timber dries, its ability to withstand compressive forces gradually increases, for example dry timber with less than $12 \%$ moisture content may be able to carry twice the load of unseasoned timber, although as the timber dries its toughness may decrease making it more brittle. However, the density of timber is directly correlational with strength: ${ }^{45}$ the higher the density the higher its compression strength, bending strength and hardness. Therefore the strongest timbers are dry and high density.

Unlike many building materials, timber has the ability to absorb both compressive and tensile forces to an equal extent, but timber is also an anisotropic material in that its strength differs according to the direction the stress is applied. Therefore when referring to the strength properties of timber it is important to specify whether the stress is across or parallel to the grain. Parallel to the grain, timber can absorb approximately four times as much compressive force than across the grain. Therefore square section timber will be much better as a post and rectangular section timber better as a beam. Furthermore, dense hardwoods, such as oak, will be more suitable for compressive loads, while the long-fibre softwoods, such as Sitka spruce, will be more capable of dealing with bending loads. There are eight strength test ${ }^{46}$ used to classify timber each with a different significance depending on what the timber will be used for, as shown in the table opposite.

As each piece of timber will be unique, due to the irregularities of nature, the expected strength cannot be guaranteed. Timber is therefore graded either visually or mechanically according to a number of characteristics that effect the strength of any section of timber. The stress grading of all timbers involves a study of the

Fig 2.47 Strength grading tests table $\quad 45$ ibid, p.25 


$\begin{gathered}\text { Certification body } \\ \text { or logo mark }\end{gathered}$
$\begin{gathered}\text { Company } \\ \text { reference }\end{gathered}$

TOP

Fig 2.48 BM TRADA Certification grade mark on visually graded timber

BELOW

Fig 2.49 Welsh-grown timber strength grades

\begin{tabular}{|c|c|c|c|c|c|c|c|c|c|c|c|c|c|}
\hline \multicolumn{14}{|c|}{ Welsh-grown timber strength grades } \\
\hline \multicolumn{2}{|c|}{$\begin{array}{l}\text { Characteristic value in bending } \\
\qquad\left(\mathrm{N} / \mathrm{mm}^{2}\right)\end{array}$} & & & & & & & & & & 50 & 60 & 70 \\
\hline \multirow{2}{*}{$\begin{array}{l}\text { Strength } \\
\text { classes }\end{array}$} & Coniferous & C14 & $\mathrm{C} 16$ & C18 & $\mathrm{C} 22$ & C24 & C27 & С30 & C35 & C40 & & & \\
\hline & Deciduous & & & & & & & D30 & D35 & D40 & D50 & D60 & D70 \\
\hline \multirow[t]{5}{*}{ softwoods } & Sitka spruce & GS & & ss & & & & & & & & & \\
\hline & Norway spruce & GS & & ss & & & & & & & & & \\
\hline & larchs & & GS & & & ss & & & & & & & \\
\hline & Douglas fir & GS & & ss & & ss & & & & & & & \\
\hline & pines & GS & & & ss & & & & & & & & \\
\hline \multirow[t]{2}{*}{ hardwoods } & oak & & & & & & & $\begin{array}{l}\text { TH1 } \\
\text { THB }\end{array}$ & THA & & & & \\
\hline & sweet chestnut & & & & & & & $\mathrm{TH} 1$ & & & & & \\
\hline \multicolumn{14}{|c|}{ zone of strength grades achievable with Welsh-grown timber } \\
\hline & rength $\mathrm{g}$ & & timbe & & & & & & & & & & \\
\hline
\end{tabular}

following characteristics: size, knots, slope of grain, rate of growth, wane, fissures, resin/ bark pockets, distortion and biological defects from insects and fungi. However, the methods and grading of softwood and hardwood are different.

The mechanical testing of softwood is generally restricted to the larger sawmills. The testing requirements, for machine tested softwood, are defined by BS EN 14081 but are the same as listed above, however the machine processes the relationship between strength and stiffness by applying physical loads to the test piece and measuring the deformation. ${ }^{47}$ The visual testing requirements, ${ }^{48}$ which often also follow the machine testing are defined by BS 4978: 2007. In both methods the softwood that passes the test is graded, and marked, either dry or wet and as General (GS) or Special (SS) structural, for structural use depending on where the timber will be used. A strength grade is applied based on all the above data with a $\mathrm{C}$ (conifer) class between C14 and C40, defined by BS EN 338. In the UK, homegrown softwood is typically graded to a maximum of C16, although C24 is possible but with larger rejected quantities of timber and is therefore uneconomical. BSW, in Newbridge,

have carried out research ${ }^{49}$ that shows that structural grades are often over specified with a typical domestic span achieved using a C24, 45×170×3600 joist, that could be achieved at comparable cost with a homegrown C16, 45×195×3600 joist. However the Bridging the Gap report identified that Welsh sawmills currently only produce C16 timber in $47 \mathrm{~mm}$ thickness, while many timber frame manufacturers prefer to use $38 \mathrm{~mm}$ thickness on cost grounds. A mix of timber species usually makes up the Welsh-grown C16 softwood market, collectively known as whitewood. This predominantly consists of Sitka spruce, but will often include Douglas fir, Norway spruce, larch and pine. While the strength characteristics are the same for these species, other properties may often differ, possibly with undesirable results.

Hardwood stress grading is guided by BS 5756: 2007. As the supply and demand for structural hardwood in the UK is lower than that of softwood, the hardwoods are generally visually graded on request, but it is also possible to machine grade. The grading of hardwoods is split into the imported tropical hardwoods that are stamped with ' $\mathrm{HS}$ ' and the temperate hardwoods, grown in the UK, that are stamped with either ' $\mathrm{TH} 1$ ' and ' $\mathrm{TH} 2$ ', for general structural use, or 'THA' and ' $\mathrm{THB}$ ', for heavy use. ${ }^{50}$ Both are graded in dry and wet states that will be dependent on where they will be used. The strength class of hardwoods is also defined by BS EN 338 and is marked accordingly with a D (deciduous) grade between D18 and D70. In the UK, the primary

47 TRADA Technology Ltd, 'Dry graded structural softwood', Wood Information 4-29 (2002)

48 John Moore, Wood properties and used of Sitka spruce in Britain (Edinburgh: Forestry Commission, 2011) p.29-30

British Grown C16 Timber, (Earlston: BSW Timber 2013), p.16

50 THA and THB grades require a cross-sectional area greater than $200000 \mathrm{~mm} 2$ and a thickness of $100 \mathrm{~mm}$ or more. 


\begin{tabular}{|c|c|c|c|c|c|}
\hline & \multicolumn{3}{|c|}{ Timber durability } & & \\
\hline & \multicolumn{2}{|r|}{ Cause } & Effect & & \\
\hline Fire & & & charring & & \\
\hline \multirow{3}{*}{ Mechanical } & \multicolumn{2}{|c|}{ excessive loads } & fracture & & \\
\hline & \multicolumn{2}{|c|}{ abrasion } & \multirow{2}{*}{ loss of surface } & & \\
\hline & erosion by $r$ & ain, dust and sand & & & \\
\hline \multirow{2}{*}{ Water } & \multicolumn{2}{|c|}{ flowing water } & $\begin{array}{l}\text { leaching of soluble colour } \\
\text { erosion of surface }\end{array}$ & & \\
\hline & \multicolumn{2}{|c|}{ wetting and drying } & $\begin{array}{l}\text { expansion and contraction } \\
\text { causing mechanical failure in } \\
\text { forms of cracks }\end{array}$ & & \\
\hline Sunlight & & & $\begin{array}{l}\text { fading of colour } \\
\text { embrittlement of surface }\end{array}$ & & \\
\hline Chemicals & & & $\begin{array}{l}\text { discoloration } \\
\text { complete disintegration }\end{array}$ & & \\
\hline Bacteria & & & superficial discoloration & & \\
\hline \multirow{4}{*}{ Fungi } & \multirow{2}{*}{$\begin{array}{l}\text { in moist } \\
\text { conditions }\end{array}$} & moulds & superficial discoloration & & \\
\hline & & dry rot & $\begin{array}{l}\text { complete disintegration } \\
\text { (in advanced stages) }\end{array}$ & & \\
\hline & \multirow{2}{*}{$\begin{array}{l}\text { in wet } \\
\text { conditions }\end{array}$} & roots & \multirow{2}{*}{$\begin{array}{l}\text { complete disintegration } \\
\text { (in advanced stages) }\end{array}$} & \multirow{2}{*}{$\begin{array}{l}\text { LEFT } \\
\text { Fig } 2.50\end{array}$} & \multirow{2}{*}{ Timber durability } \\
\hline & & wet rot & & & \\
\hline Marine borers & & & tunnels & \multirow{3}{*}{$\begin{array}{l}\text { BELOW } \\
\text { Fig } 2.51\end{array}$} & \\
\hline \multirow{2}{*}{ Insects } & \multicolumn{2}{|c|}{ Termites } & $\begin{array}{l}\text { irregular honeycombing or } \\
\text { wide channels }\end{array}$ & & \multirow{3}{*}{$\begin{array}{l}\text { Cross section through glue } \\
\text { laminated timber beam } \\
\text { after } 30 \text { minutes and } 60 \\
\text { minutes exposure to fire } \\
\text { Charred wood }\end{array}$} \\
\hline & \multicolumn{2}{|c|}{ Beetles } & & & \\
\hline Source: Ev & tchell's $M$ & & & Fig 2.52 & \\
\hline
\end{tabular}
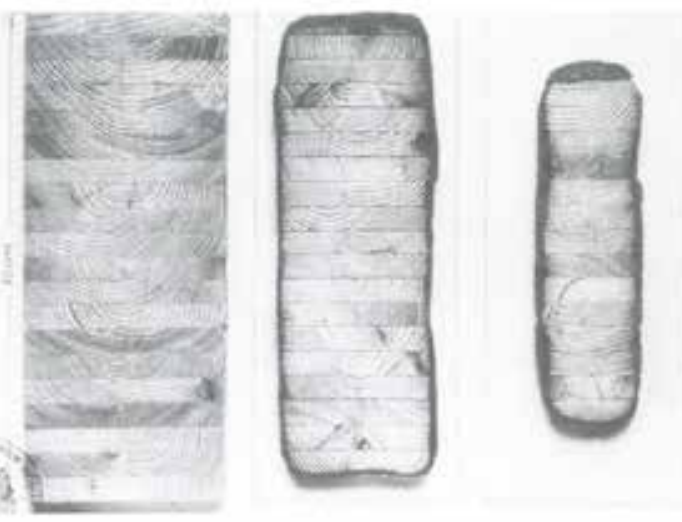

structural hardwood species is oak, predominantly graded at D30 in all classes. It is common that a larger volume of Welsh-grown hardwoods will instead be appearance graded $^{51}$ for non-structural use, such as for internal joinery and finishes.

\subsection{8}

2.3.8.1

\section{Durability of timber}

Directly influenced by the growth and properties of the tree, durability is a major consideration in timber selection. Timber is a naturally durable material which should not change with age, however unlike the mineral materials, such as masonry and concrete, wood is organic and susceptible to damage by fire, vegetal and animal pests and the weather/ climate. Any damage caused by these will almost certainly affect the mechanical strength and appearance. ${ }^{52}$ The table opposite outlines the cause and effect of the main issues of timber durability.

Fire

Wood, in its natural state, is a flammable material. However, this is not always problematic in construction. Timber will always burn on the surface from the outside in unless there are any shrinkage cracks or fissures that will accelerate the rate of burning. Due to the biological structure of different timber species, softwoods will burn at approximately $0.6-0.8 \mathrm{~mm} / \mathrm{min}$, whereas hardwoods will burn at approximately $0.4 \mathrm{~mm} / \mathrm{min}$. This generally means that the larger the cross-sectional area the slower and more evenly it will burn. The charcoal that forms on the surface provides protection to the inner timber, acting as an insulant. Unless extinguished the fire will of course continue, but the slowness of larger sections to burn means that the the timber will maintain its structural integrity until the timber section has been reduced below its load-bearing capacity. ${ }^{53}$ This means that in timber-framed buildings it is, in theory, possible to size the structure to allow for charring, providing time for occupants to escape and possibly the preservation of the building structure itself.

Conversely, in situations where there is a large surface area of timber exposed, the natural fire resistance decreases as there is a larger area of the timber surface to burn. It is in these situations where the building regulations affect the detail and exposure of timber more. The behaviour of building components in fires are determined by two stages: ignition and growth or spread. In the initial phase it is the combustibility of a material that is important, in the second stage fire resistance

51 I. Davies and G. Watt, Making the Grade: A guide to appearance grading UK grown hardwood timber (Edinburgh: ARCA Media 2005)

52 Findlay, p. 88

53 Structural Timber Engineering Bulletin, Fire safety in timber buildings, Structural Timber Association, p.4 
Durability and use classes to BS EN 460:1994

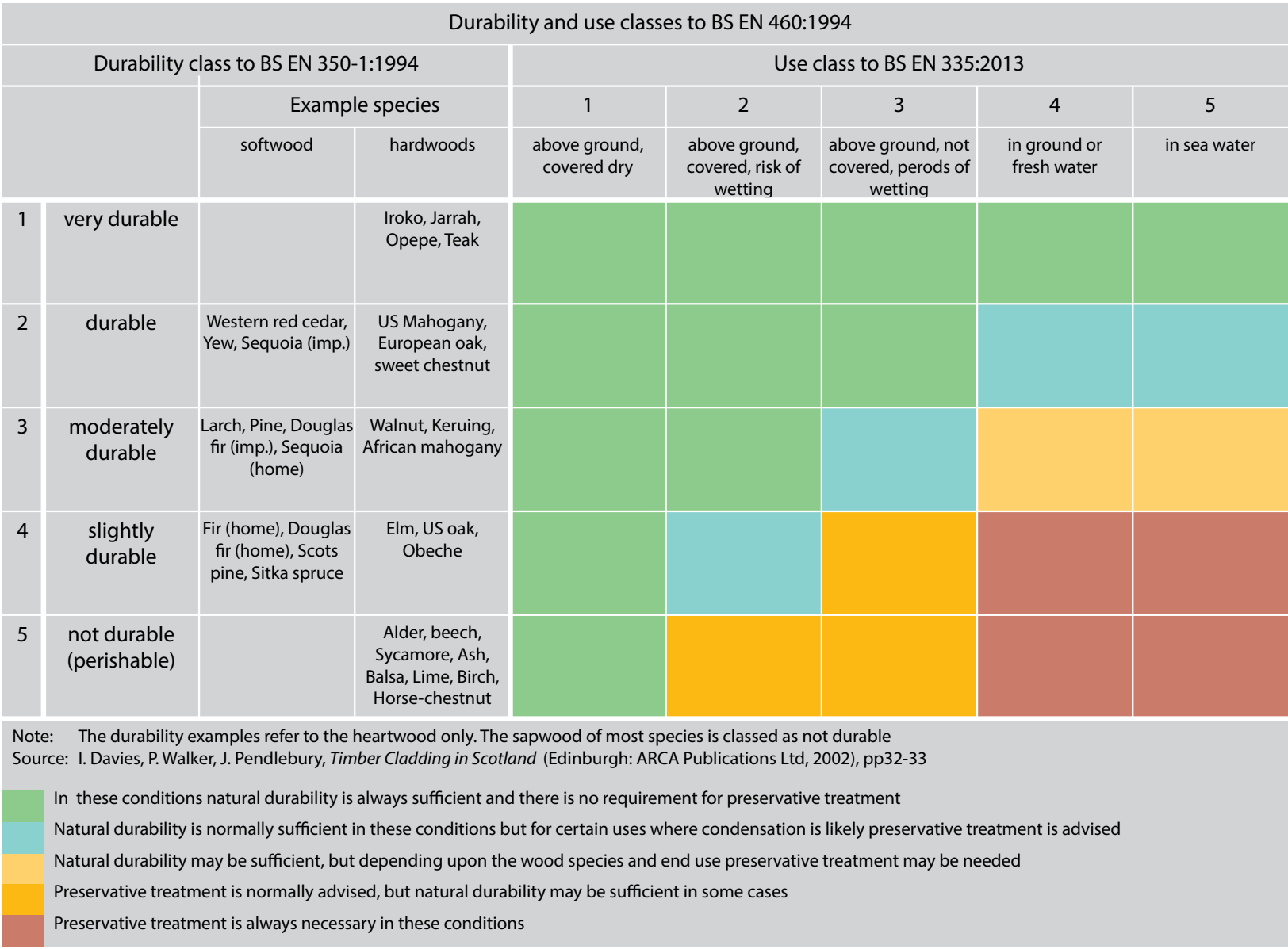

\begin{tabular}{|c|c|}
\hline \multicolumn{2}{|r|}{ Treatment classes } \\
\hline & Treatability \\
\hline Class & BS EN 350-2: 1994 \\
\hline 1 & $\begin{array}{l}\text { Easy to treat } \\
\text { (permeable) }\end{array}$ \\
\hline 2 & $\begin{array}{l}\text { Moderately easy to treat } \\
\text { (moderately resistant) }\end{array}$ \\
\hline 3 & $\begin{array}{l}\text { Difficult to treat } \\
\text { (resistant) }\end{array}$ \\
\hline 4 & $\begin{array}{l}\text { Extremely difficult to treat } \\
\text { (Extremely resistant) }\end{array}$ \\
\hline $\begin{array}{l}\text { Source } \\
1994, \\
\text { produc } \\
\text { Guide } \\
\text { treatal } \\
\text { Europe }\end{array}$ & $\begin{array}{l}\text { Standards Institution, BS EN 350-2: } \\
\text { yof wood and woodd-based } \\
\text { yral duarbility of solid wood, Part 2: } \\
\text { tural durability and } \\
\text { ulacted wood species of importance in } \\
\text { on: BSI, 1994) }\end{array}$ \\
\hline
\end{tabular}

Fig 2.53 Durability and use classes

LEFT

Fig 2.54 Treatment classes

becomes important. It is at this second stage that fire will spread over the surface of combustible materials. Therefore, this timber will require treating with a fire retardant or intumescent coating to one of three classes from 0 to 3 depending on the size, escape times and type of building. It is worth noting that only retardants can be used with timber as there is not treatment that will make timber non-combustible. ${ }^{54}$

\subsubsection{2}

\section{Biological decay}

Apart from fire, the main natural cause of serious timber degradation, leading to structural failure, is from damp conditions which will bring about the decomposition processes from fungi and insects. As such, the classification of timber durability, in BS EN 350-1:1994, refers directly to how resistant the timber species is naturally to fungal and insect attack in the heartwood and therefore its ability to cope in different levels of moisture. The sapwood of all timber species is assumed as'not durable'. BS EN 350-2:1994 refers to the classes of timber to accept treatment.

Fungi are forms of plant life that do not possess chlorophyll to generate organic materials, instead they obtain their nutrients from other living (parasitic) or dead (saprophytic) organic matter. In general it is the saprophytes that are more problematic, as the tree is no longer living when used in construction. However some parasitic fungi are becoming extremely relevant and important to the timber and construction industries such as: Dutch Elm disease, caused by Ophiostoma novo-ulmi; ash dieback, caused by Chalara fraxinea; and Phytophthora ramorum in European, Japanese and hybrid larch..$^{55}$ While any defects caused by these parasitic fungi are dealt with, removed and not allowed to enter the market if there is a risk of spread or poor quality timber within the construction industry, the fungi is capable of spreading fast throughout the woodlands and forests, without any known cure. This is resulting in large volumes of infected or potentially infected trees being felled to reduce spread, leading to a surge in specific timber species available for use. More often than not the infected timber is burnt to reduce the risk of spread, however it may still be possible to use the uninfected timber for construction.

There are two types of saprophytic fungi: non-destructive fungi feeding off of the dampness, starch, and sugar in the sapwood but critically not the cell walls; and destructive fungi which leads to discolouring and a softening of the wood leading to a loss of strength. Destructive saprophytic fungi can be further broken down into wet and dry rot.

54 HM Government, The Building Regulations 2010: Approved Document Part B Volumes 1 \& 2 55 Natural Resources Wales, Woodlands for Wales Indicators 2013-14 (Cardiff: Welsh Government, 2014), pp.20-23 
Both wet and dry rot fungi will cause loss of strength, but the rate of decay will depend on temperature, moisture content and degree of natural resistance. Dry is more likely to persist with its pores more likely to survive even if the timber is dried to below $20 \%$ moisture content.

\section{Insect attack}

Insect attack on timber is not normally as destructive as fungi rot and is more easily identified by the presence of bore holes on the surface. Unlike with fungi, the timber does not need to be wet and is usually confined to sapwood only. In the UK, insect attack is limited to a variety of different beetles including the furniture, the house longhorn, ambrosia and the infamous deathwatch beetle. While each beetle has its own distinctive mark on timber, all beetles follow a similar lifecycle which leads initially to aesthetic damage, but in long untreated attacks over many years can potentially lead to loss of strength. ${ }^{56}$ 


\section{Welsh woodlands and trees}

The following section will focus on the woodland and trees that are currently grown in Wales, however not all of these are indigenous to Wales or even the UK. While this is not necessarily significant to the timber available to use in construction today and will not prejudice the selection of one timber over another, it does go someway to explain the varied, and sometimes challenging, properties of the now primary species available.

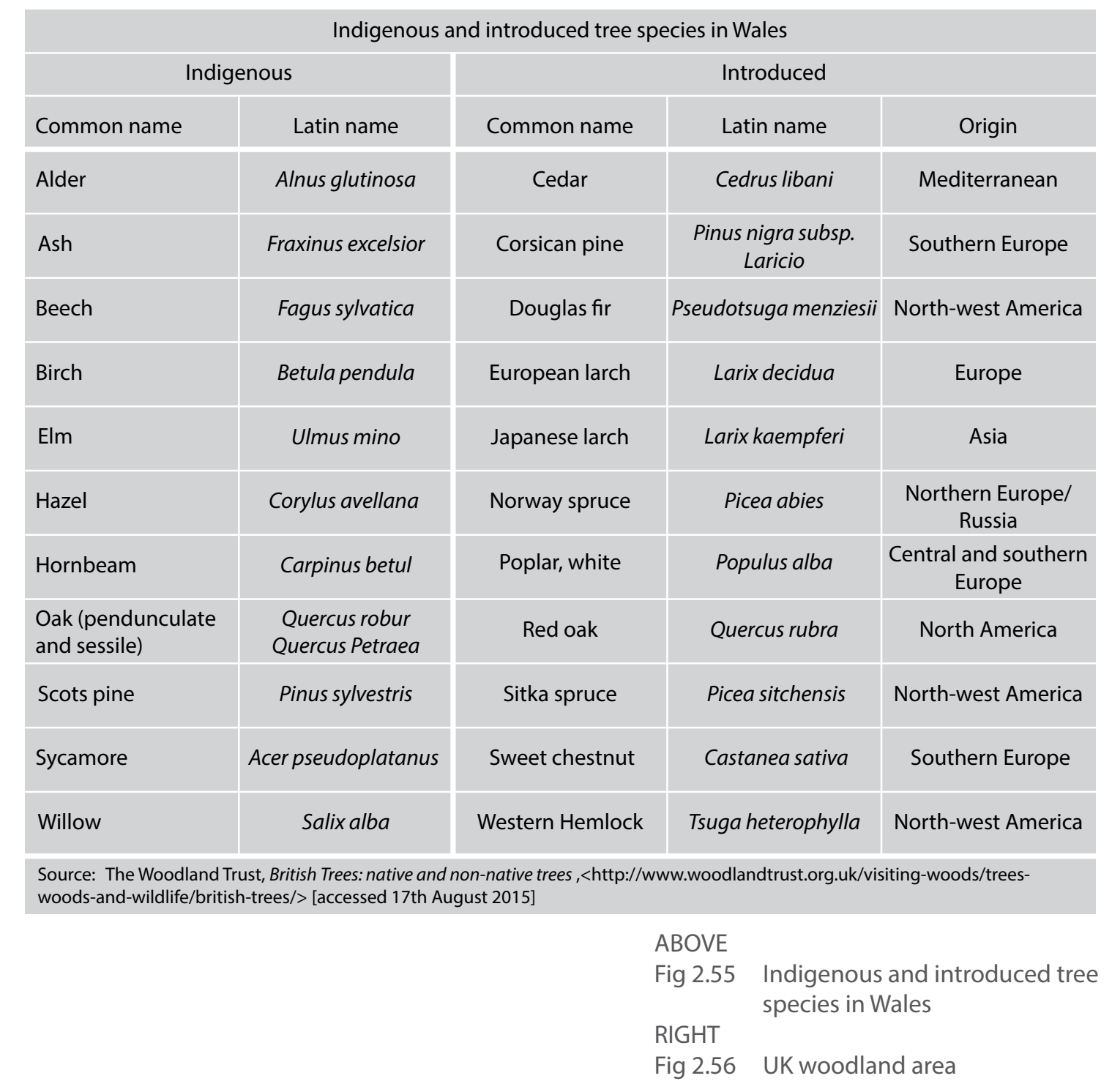

\section{Welsh woodland}

Wales has 34000 hectares of ancient and semi natural woodland, that is woodland that has existed continuously since 1600 with predominantly native species and wildlife. There is a further 28000 hectares of plantation timber on ancient sites but without a semi-natural environment.

The Forestry Commission have been surveying and recording the woodland and forest stocks in the UK and its constituent countries and regions since 1924. The last data recorded in the National Inventory of Woodlands and Trees $^{57}$ (NIWT) in 2002, based on a survey conducted between 1995-99, was limited to all woodland and forest areas over 2 hectares in size due to limitations at that time on surveying smaller woodlands. However, the Forestry Commission are currently revising this data with the National Forest Inventory ${ }^{58}$ (NFI), which began in 2009 and finalised in 2014, focusing on all woodlands and forests of area over 0.5 hectares with more accuracy. For the purposes of this thesis, the latest interim data available from the NFI, based on the Forestry Statistics and Facts and Figures published in $2014^{59}$, will be used

\begin{tabular}{|c|c|c|c|c|c|c|c|c|c|c|c|}
\hline \multirow[b]{4}{*}{ Country } & \multicolumn{11}{|c|}{ UK woodland area } \\
\hline & \multicolumn{9}{|c|}{ Woodland area (in thousands of hectares) } & \multirow{3}{*}{$\begin{array}{l}\text { Woodland } \\
\text { totals a s \% } \\
\text { land area }\end{array}$} & \multirow{3}{*}{$\begin{array}{l}\text { Woodland } \\
\text { f totals hal per } \\
100 \text { population }\end{array}$} \\
\hline & \multicolumn{3}{|c|}{ Coniferous } & \multicolumn{3}{|c|}{ Broadleaves } & \multicolumn{3}{|c|}{ Total } & & \\
\hline & $\mathrm{FC}$ & non-FC & $\%$ & FC & non-FC & $\%$ & FC & non-FC & Total & & \\
\hline England & 151 & 188 & 26 & 64 & 899 & 74 & 215 & 1087 & 1302 & 10 & 2.5 \\
\hline Scotland & 438 & 614 & 74 & 39 & 328 & 26 & 477 & 942 & 1419 & 18 & 26 \\
\hline Wales & 98 & 53 & 49 & 19 & 136 & 51 & 117 & 189 & 306 & 15 & 10 \\
\hline N. Ireland & 56 & 11 & 60 & 6 & 39 & 40 & 62 & 50 & 112 & 7 & 5 \\
\hline TOTAL UK & 742 & 866 & 51 & 129 & 1402 & 49 & 870 & 2268 & 3138 & 13 & 5 \\
\hline
\end{tabular}

57 Forestry Commission, National Inventory of Woodlands and Trees: Wales, (Edinburgh: Forestry Commission, 2002)

58 Forestry Commission, NFI 2011 Woodland Map Wales: National Forest Inventory Report (Edinburgh: Foresty Commission, 2011)

59 Forestry Commission, Forestry Statistics 2014 (Edinburgh: Forestry Commission 2014) 


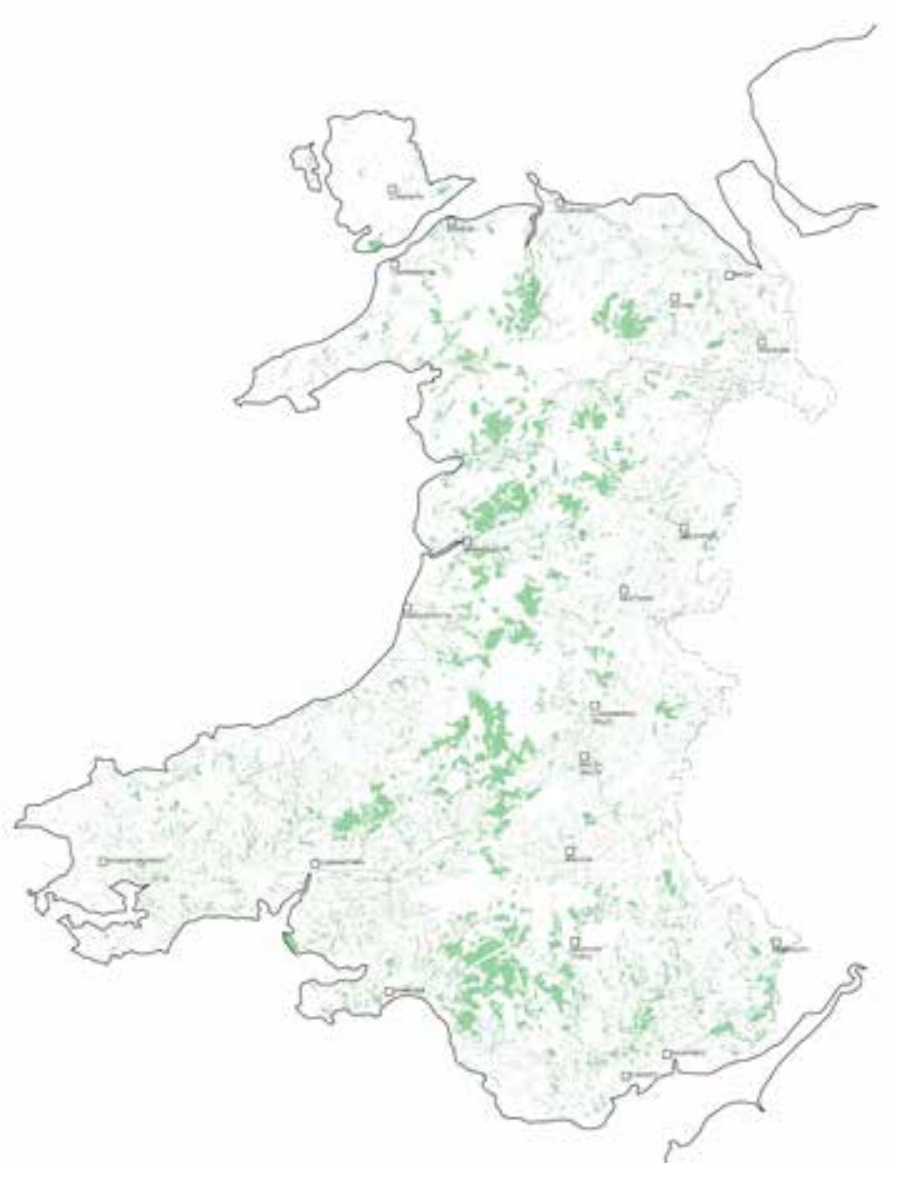

\begin{tabular}{|c|c|c|c|c|}
\hline \multirow[b]{2}{*}{ Country } & \multicolumn{4}{|c|}{ International woodland areas } \\
\hline & $\begin{array}{l}\text { Forest areaa } \\
\text { (million ha) }\end{array}$ & $\begin{array}{l}\text { Total land area } \\
\text { (million ha) }\end{array}$ & $\begin{array}{l}\text { Forest a s\% of of } \\
\text { land area }\end{array}$ & $\begin{array}{l}\text { Forest thal pe } \\
100 \text { population }\end{array}$ \\
\hline Europe & 1005 & 2215 & 45 & 137 \\
\hline United Kingdom & 3 & 24 & 13 & 5 \\
\hline Finland & 22 & 30 & 73 & 418 \\
\hline France & 16 & 55 & 29 & 26 \\
\hline Germany & 11 & 35 & 32 & 13 \\
\hline Italy & 9 & 29 & 31 & 15 \\
\hline Spain & 18 & 50 & 36 & 41 \\
\hline Sweden & 28 & 41 & 69 & 306 \\
\hline Other EU & 49 & 154 & 32 & 29 \\
\hline Total EU-27 & 157 & 419 & 37 & 32 \\
\hline Russian Federation & 809 & 1638 & 49 & 572 \\
\hline Africa & 674 & 2974 & 23 & 68 \\
\hline Asia & 593 & 3091 & 19 & 15 \\
\hline North and Central America & 705 & 2135 & 33 & 132 \\
\hline Oceania & 191 & 849 & 23 & 548 \\
\hline South America & 864 & 1746 & 49 & 225 \\
\hline World & 4033 & 13011 & 31 & 60 \\
\hline
\end{tabular}

In 2014, the UK has an estimated 3.1 million hectares of woodland and forest, covering $13 \%$ of the land area $^{60}$ while Wales has a slightly higher forest area, covering $15 \%$ of the country. In comparison to international forest areas, and especially those in Europe, the UK and Wales forest coverage is very low and explains in some part why the UK relies heavily on imported timber to meet demand. Further key findings from the latest NFI data with a focus on Wales are:

- There is a total mapped woodland of 303572 hectares in Wales;

- The total coniferous woodland area is 151000 hectares:

- The total broadleaf woodland area is 153000 hectares;

- The total woodland owned or managed by the Forestry Commission is 117000 hectares or $38 \%$;

- The total certified woodland in both the public and private sectors is 140000 hectares or $45 \%$;

- $100 \%$ of Forestry Commission owned or managed woodland is FSC certified;

- 700 hectares of new woodland were created between 2011-12 mostly of broadleaved species;

- 2000 hectares of woodland were restocked between 2011-12 mostly with coniferous species; and

- 253 sites were issued with a Statutory Plant Health Notice in 2013 resulting in 3300 hectares of felled woodland that has not necessarily been restocked. The majority of this is related to disease spreading through the larch trees. ${ }^{61}$

\subsection{2}

\section{Welsh-grown tree species}

The Forestry Commission have published NFI data for Wales, specific to the coniferous and broadleaf species. The areas of stocked ${ }^{62}$ woodland types and species differ to the latest statistics, however it provides a good basis to appraise the main species and proportion available in Wales. The data still confirms an approximate 50:50 split between the overall quantities of coniferous and broadleaf woodland, but there are some significant differences within the numbers of tree species within these classifications that are worth noting:

- The majority of coniferous woodland is in public ownership at $62 \%$;

60 ibid, p.9

61 ibid, p.39

62 Stocked areas are calculated through field studies and differ to the mapped woodland areas that are based on high resolution aerial photography. NFI Field studies sample a selection of woodlands and use statistics to integrate the results from both the mapping and fieldwork 
Coniferous and broadleaf tree areas in Wales

\begin{tabular}{|l|l|l|l|}
\hline Area of species within high forest $(>2 \mathrm{ha})$ & Area of species within woodland $(>0.5 \mathrm{ha})$ \\
\hline
\end{tabular} National Inventory of woodland and trees, Wales 2002 NFF estimates of coniferous and broadleaf species in Wales, 2011

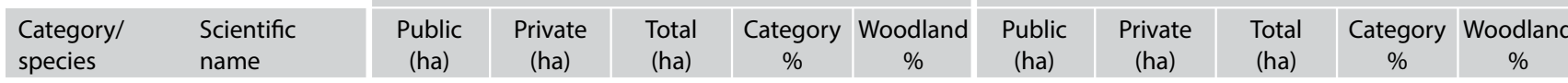

\begin{tabular}{|c|c|c|c|c|c|c|c|c|c|c|c|}
\hline \multirow{2}{*}{\multicolumn{12}{|c|}{\begin{tabular}{|l} 
species \\
Conifers
\end{tabular}}} \\
\hline & & & & & & & & & & & \\
\hline Scots pine & Pinus sylvestris & 2544 & 1944 & 4488 & 3 & 2 & 2000 & 1700 & 3700 & 3 & 1 \\
\hline Corsican pine & $\begin{array}{l}\text { Pinus nigra subsp. } \\
\text { laricio }\end{array}$ & 2622 & 728 & 3350 & 2 & 2 & 1900 & 800 & 2700 & 2 & 2 \\
\hline Lodgepole pine & Pinus contorta & 4024 & 2107 & 6131 & 4 & 2 & 2600 & 1600 & 4200 & 3 & 2 \\
\hline Sitka spruce & Piceasitchensis & 55322 & 25993 & 81315 & 56 & 33 & 49500 & 28000 & 77500 & 59 & 30 \\
\hline Norway spruce & Picea abies & 7165 & 3886 & 11051 & 8 & 4 & 5200 & 1600 & 6800 & 5 & 3 \\
\hline European larch & Larix decidua & 194 & 393 & 587 & 0.4 & 0 & \multicolumn{5}{|c|}{ included in Japanese/ hybrid larch data } \\
\hline $\begin{array}{l}\text { Japanese/ } \\
\text { hybrid larch }\end{array}$ & Larix keempferi & 11805 & 9729 & 21534 & 15 & 9 & 12300 & 8600 & 20900 & 16 & 8 \\
\hline Douglas fir & $\begin{array}{l}\text { Psendodtosuga } \\
\text { menziesil }\end{array}$ & 5458 & 5357 & 10815 & 7 & 4 & 5000 & 4600 & 9600 & 7 & 4 \\
\hline Other conifers & & 3932 & 2319 & 6251 & 4 & 3 & 2900 & 2900 & 5800 & 4 & 2 \\
\hline Total conifers & & 93066 & 52456 & 145522 & & 58 & 81400 & 49800 & 131200 & & 51 \\
\hline \multicolumn{12}{|l|}{ Broadleaves } \\
\hline Oak & Quercus robur & 4389 & 33703 & 38092 & 37 & 15 & 2400 & 22500 & 24900 & 20 & 10 \\
\hline Beech & Fagus sylvatica & 2269 & 5100 & 7369 & 7 & 3 & 1700 & 6100 & 7800 & 6 & 3 \\
\hline Sycamore & $\begin{array}{l}\text { Acer } \\
\text { pseudoplatanus }\end{array}$ & 205 & 5919 & 6124 & 6 & 2 & 100 & 9900 & 10000 & 8 & 4 \\
\hline Ash & Fraxinus excelsior & 1196 & 16985 & 18181 & 17 & 7 & 400 & 17200 & 17600 & 14 & 7 \\
\hline Birch & Betula pendula & 2399 & 8414 & 10813 & 10 & 4 & 1100 & 10300 & 11400 & 9 & 4 \\
\hline $\begin{array}{l}\text { White poplar/ } \\
\text { Aspen }\end{array}$ & $\begin{array}{l}\begin{array}{l}\text { Populus albal } \\
\text { Populus tremula }\end{array} \\
\text { a }\end{array}$ & 52 & 516 & 568 & 1 & 0.2 & \multicolumn{5}{|c|}{ included in other broadleaf data } \\
\hline Sweet chestnut & Castanea sativa & 130 & 402 & 532 & 1 & 0.2 & 0 & 400 & 400 & 0 & 0.2 \\
\hline Elm & Ulmus minor & 0 & 123 & 123 & 0.1 & 0 & \multicolumn{5}{|c|}{ included in other broadleaf data } \\
\hline Hazel & Corylus avellana & \multicolumn{5}{|c|}{ included in other broadleaf data } & 0 & 12800 & 12800 & 10 & 5 \\
\hline Hawthorn & Crataegus spp. & \multicolumn{5}{|c|}{ included in other broadleaf data } & 0 & 5400 & 5400 & 4 & 2 \\
\hline Alder & Alnussp. & \multicolumn{5}{|c|}{ included in other broadleaf data } & 100 & 9000 & 9100 & 7 & 4 \\
\hline Willow & Salixspp. & \multicolumn{5}{|c|}{ included in other broadleaf data } & 0 & 8900 & 8900 & 7 & 3 \\
\hline \multicolumn{2}{|c|}{ Other broadleaves } & 3032 & 19406 & 22438 & 22 & 9 & 7800 & 10400 & 18200 & 14 & 7 \\
\hline \multicolumn{2}{|c|}{ Total broadleaves } & 13672 & 90568 & 104240 & & 42 & 13600 & 112900 & 126500 & & 49 \\
\hline \multicolumn{2}{|l|}{ Woodland totals } & 106738 & 143024 & 249762 & & 100 & 95000 & 162700 & 257700 & & 100 \\
\hline \multicolumn{2}{|c|}{ \% woodland cover } & & & 13.8 & & & & & 13.8 & & \\
\hline
\end{tabular}

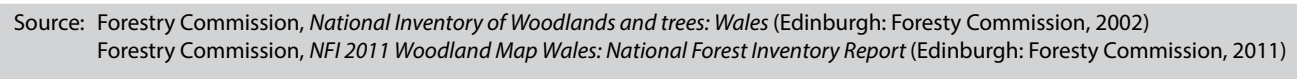

Fig 2.59 Coniferous and broadleaf tree areas in Wales
- The majority of the broadleaf woodland is in private ownership at 89\%;

- $30 \%$ of the Welsh woodland area and $59 \%$ of coniferous woodland consists of Sitka spruce at 77500 hectares with 64\% in FC ownership;

- $10 \%$ of the Welsh woodland and $20 \%$ of the broadleaves are oak

- $21 \%$ of the Welsh woodland is made up by the $3 \mathrm{rd}$ and 4 th abundant species but is also potentially affected by the spread of disease, with larch accounting for $8 \%$ of the total woodland and $16 \%$ of coniferous trees and ash making up $14 \%$ of the total woodland and $7 \%$ of broadleaves;

- $25 \%$ of the broadleaf woodland is aged between $21-40$ years, $18 \%$ between 41-60 years, while the remainder is evenly distributed between 0-20 and 60 $100+$ years;

- $85 \%$ of the total standing coniferous volume is between 20 and 60 years old, highlighting a large volume of timber that is ready or soon to be ready for felling;

- The comparison between the NIWT and NFI data also reveals a significant change in the broadleaf statistics with $5 \%$ less oak and the addition of reasonable areas of hazel, hawthorn, alder and willow.

Historical precedence and the increase in the spread of diseased larch trees suggests that the Forestry Commission are likely to continue with the restocking of Sitka spruce and therefore maintain the dominance of Sitka spruce in Wales.

The following table sets out the Welsh-grown timber species that have been identified in the NFI and NIWT surveys as contributing to over $1 \%$ of the area of woodland and forest in the woodlands over 0.5 hectares. Poplar and elm have been included without quantity figures as they were included in the NIWT survey but are now within the 'other' species categories in the NFI survey. Sweet chestnut has been included, in spite of the very low quantities, due to it being one of only two durable timbers grown in Wales. It should also be noted that the strength characteristics of the species have not been included as most of the species are capable of being structural in either their natural state or after an adjustment process such as glulam. The key information that is highlighted by the table is summarised as follows:

- The top six dominant species, by area, in order of abundance are: Sitka spruce $(30 \%)$, oak (10\%), larch (8\%), ash (7\%), hazel (5\%) and Douglas fir and alder (4\%);

- Despite an almost even split in the areas of coniferous and broadleaf woodland, there is clearly a larger supply of softwood for use in construction than hardwood with Sitka spruce leading the way;

- There are only two durable species - oak and sweet chestnut offering 


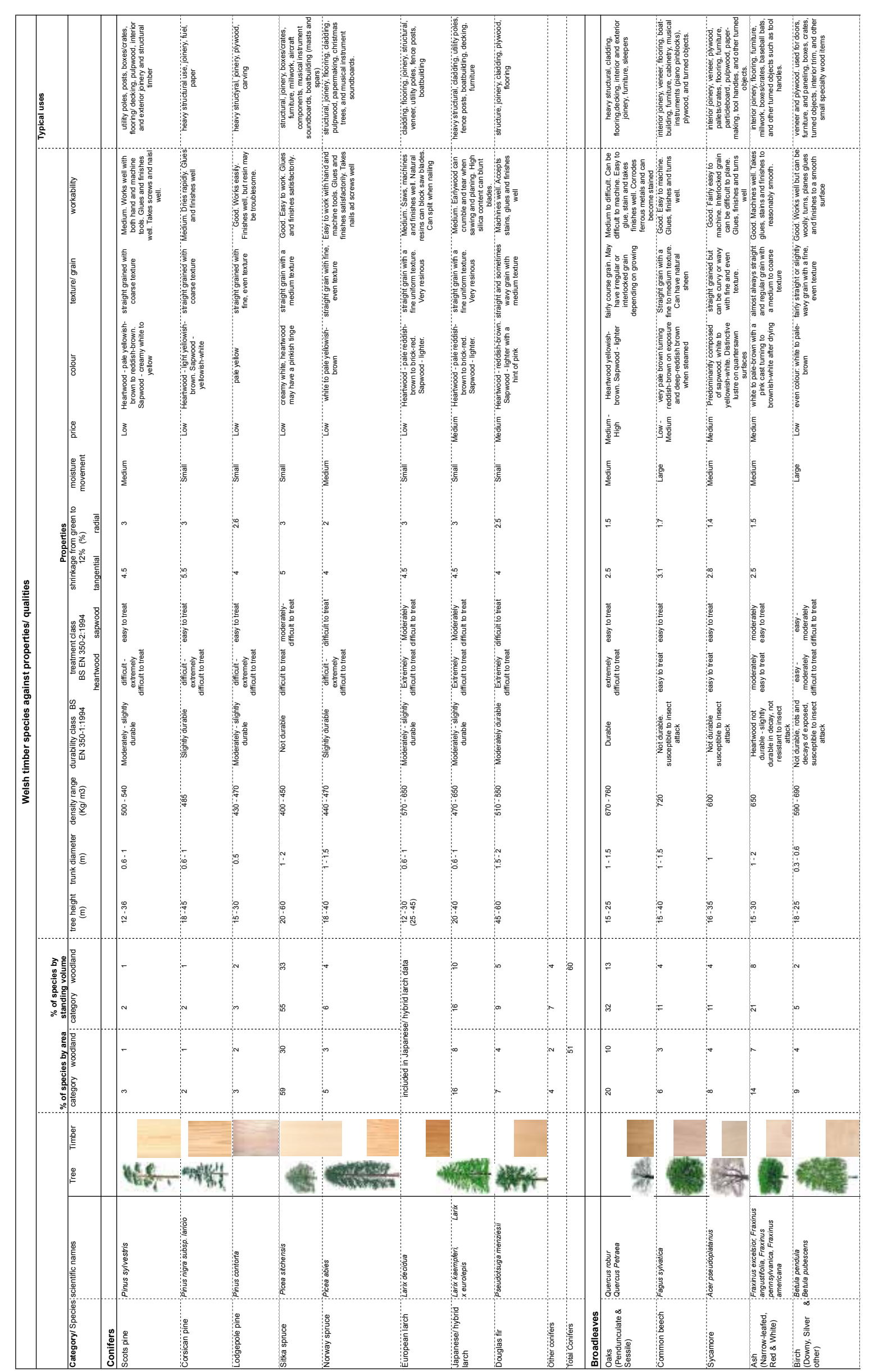

Fig 2.60 Welsh timber species against properties/ qualities - Conifers immediate potential for external use in exposed locations. These are also the only hardwoods above the 'not durable' classification:

- There is very little sweet chestnut grown, with all in the private woodlands, despite its durable classification. This suggests the species must be used very carefully to maximise its potential;

- The pine, larch and Douglas fir are all classed as moderately - slightly durable offering potential for use externally, subject to exposure and location;

- Sitka spruce is classed as not durable but is also difficult to apply treatments;

- While not indicated in the table it is thought that the majority of the hawthorn, hazel and willow are found in the smaller woodlands below 2 hectares, suggesting that these are not normally harvested for their timber;

- hazel and willow are generally used for specific purposes such as weaving fences and baskets;

- All the species are classed as 'easy to glue and finish well' suggesting that lamination may be possible and that most will be good for joinery.

\section{Identification of useable Welsh-grown timber species}

On analysing this table further, it is clear that there are some species that are more useable in construction than others and as such provide a typical set of natural Welsh-grown timber properties by which to use in the design and specification of architecture. Five species will be selected that best represent the general characteristics and properties of Welsh-grown timber. It is not the intention to select five species to 'test' or only ever use, but to select five species that are immediately available to use, but that also demonstrate the properties available in other species of lower quantity or of alternative strength, durability etc therefore suggesting that these timbers could also be used in certain circumstances. When a performance property does not exist in the Welsh-grown species, a process of innovation may be required to achieve the intended design.

Firstly it should be noted that there are wide range of species that are too long to list here, that grow in Wales but contribute to under $1 \%$ of the total woodland area. In many cases these species demonstrate good properties for specific uses in construction, but their limited stocks does not make them particularly viable for anything more than bespoke projects. These include the coniferous species Grand fir, Noble fir, western red cedar and redwoods and the broadleaf species lime, cherry, London plane and walnut. All these species have been used in a variety of designs and/ or technical innovations, in the past, specific to the aesthetics, workability and performance of the species. ${ }^{63}$

63 Tom Jenkins, Justin Gilbert, Ewan Mackie, Robert Matthews, Tree Species: A document listing the tree 


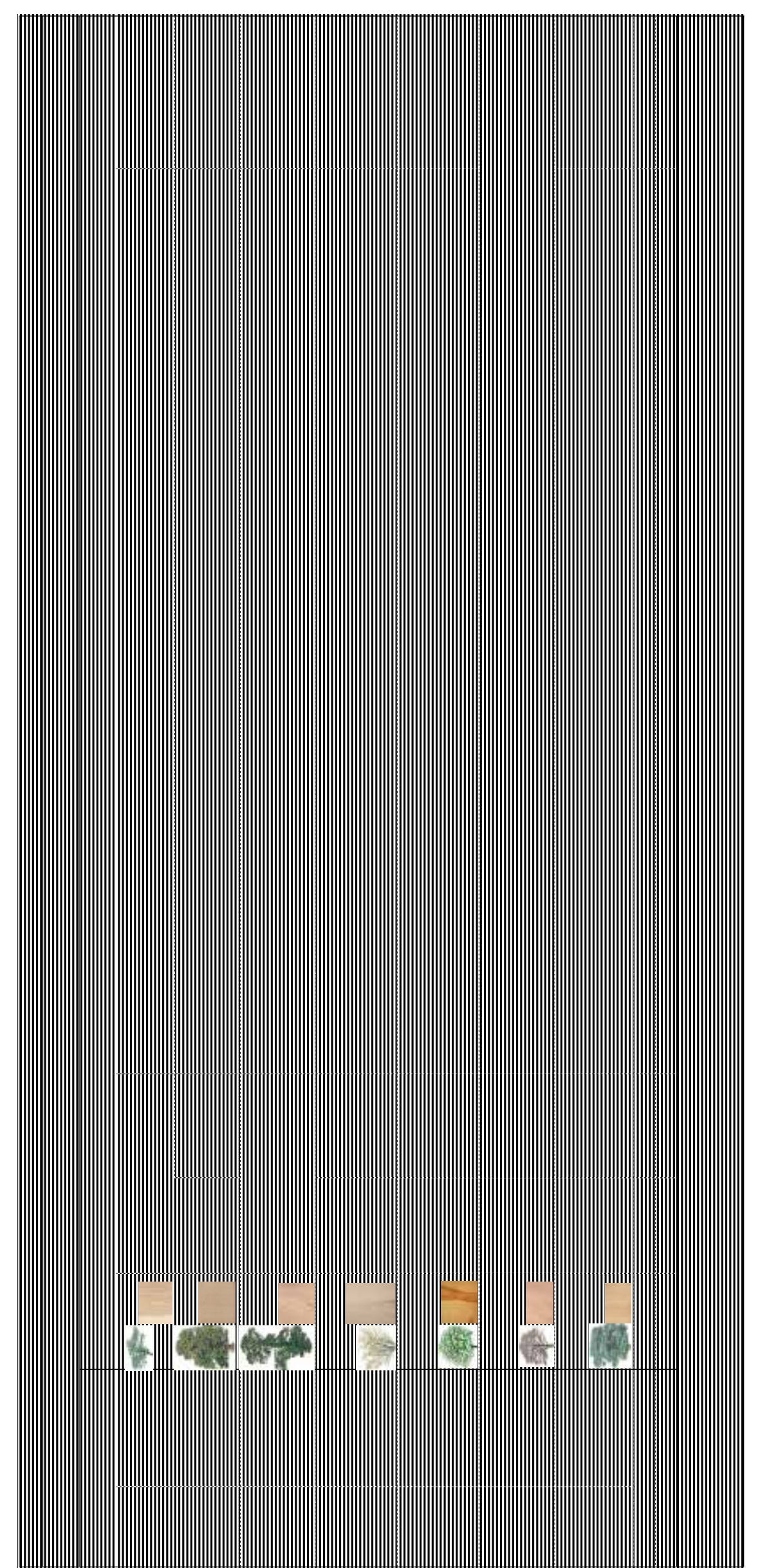

Fig 2.61 Welsh timber species against properties qualities - Broadleaves
Of the twenty species listed as contributing to over $1 \%$ of the woodland area in either the NIWT or NFI surveys, hazel, hawthorn, elm and willow will not be considered further, despite the relatively large areas of willow and hazel, as these species are generally found in specific locations for a functional or ornamental purpose such as hedgerows. They are not generally used in construction and are used for specific purposes such as weaving fences and baskets.

The hardwoods alder, poplar, aspen, birch, sycamore and beech are classed as not durable or suffer from too much moisture movement to be used within the external envelope and are also in relatively low quantities to be seriously considered as a structural option. However, they are well suited to interior joinery, internal flooring and furniture which is outside the scope of this thesis.

Three of the softwoods are types of pine, but only contribute to $4 \%$ of the area when combined. These, along with Norway spruce, also demonstrate very similar properties in terms of appearance, strength and moisture movement as Sitka spruce. If Sitka can be used then so can the lesser quantities of Scots pine, Corsican pine, Lodgepole pine and Norway spruce that contribute to the classification of whitewood. In some cases the slightly-moderately durable pines may offer a better choice than spruce.

This therefore leaves the following species as representative of Welsh-grown timber to be studied further through design and prototyping. The qualities and properties of each of these species are summarised in the following tables:

- $\quad$ Sitka spruce (including other species categorised as whitewood)

- European, Japanese \& hybrid larch (classified together due to the very low quantities of European larch and affected by disease);

- Douglas fir;

- Oak (pendunculate and sessile);

- Sweet chestnut - low quantity but durable; and

- Common ash - affected by disease. 


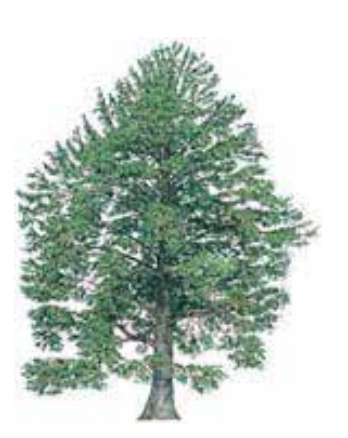

Origin: Sitka Spruce is named after the old Russian capital of Alaska on Baranof Island, called Sitka, although its natural range is all along the coast of NW America. It was introduced to Britain in 1831."

Site: Adapted to a maritime climate with high atmospheric moisture. Sites with less than $1000 \mathrm{~mm}$ rainfall per year should be avoided unless the soil is moist. This is a pioneer or early successional species of and air pollution It grows best on soils of poor or medium nutrient stats with good misture spring frosts will tolerate drained peats and gleys. Sensitive to heather check on very poor soils, where it should be grown in mixture with pine or larch. Because of its liking for the Welsh mild, wetclimate and its ability to establish in peaty upland solis Welsh spruce grows much faster than in its native origin producing timber

Pests: In some years, Sitka spruce can suffer very heavy defoliation by the green spruce aphid (Elatobium) with a significant impact on growth. The spruce bark beetle, Dendroctonus micans, has become established in Britain and atlacks Stika spruce although the host-spectic predatory beetie, Rhizophagus grandis, controls this. Heterobasidion (Fomes root and butt rot) affects Sitka spruce, although in this growing on peaty soils, especially under conditions of high rainfall, is low.

Prov

6. Height: $20-60 \mathrm{~m}$

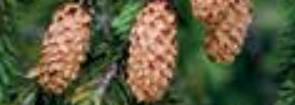

Tes: $3 \mathrm{~cm}$ Straight flattened and very spiny need

Cone - green then pale brown when ripe.

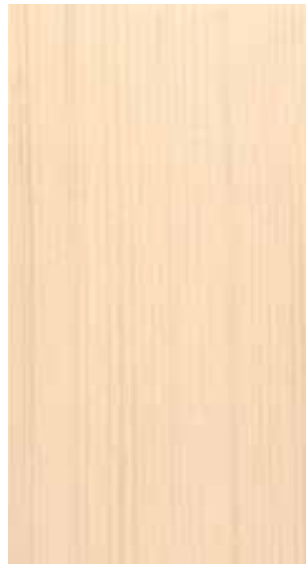

Timber: There is little difference in colour between sapwood and heartwood, the wood generally being a creamy white, but the heartwood usually has a pinkish tinge. It usually has a very straight grain, but occasionally this may be spiral, while the texture is medium but dependent on the rate of growth, although on non-tainting, light in weight when dried, and showing a silvery lustre on planed surfaces. ${ }^{3}$

Drying: Dries rapidly and quite well, but care is needed if warping, spliting and loosening of knots is to be kept to a reasonable level. ${ }^{3}$

The 政

Class: Typically graded at a maximum of C16 with larch, Douglas fir and pine.

Working Good - It is easily worked, and provided cutting edges are kept sharpened, finishes very cleanly. It can

qualities: be nailed, screwed, glued, stained, polished and painted satisfactorily

Use: $\quad$ structural, joinery, boxes/crates, furniture, millwork, aircraft components, musical instruments.

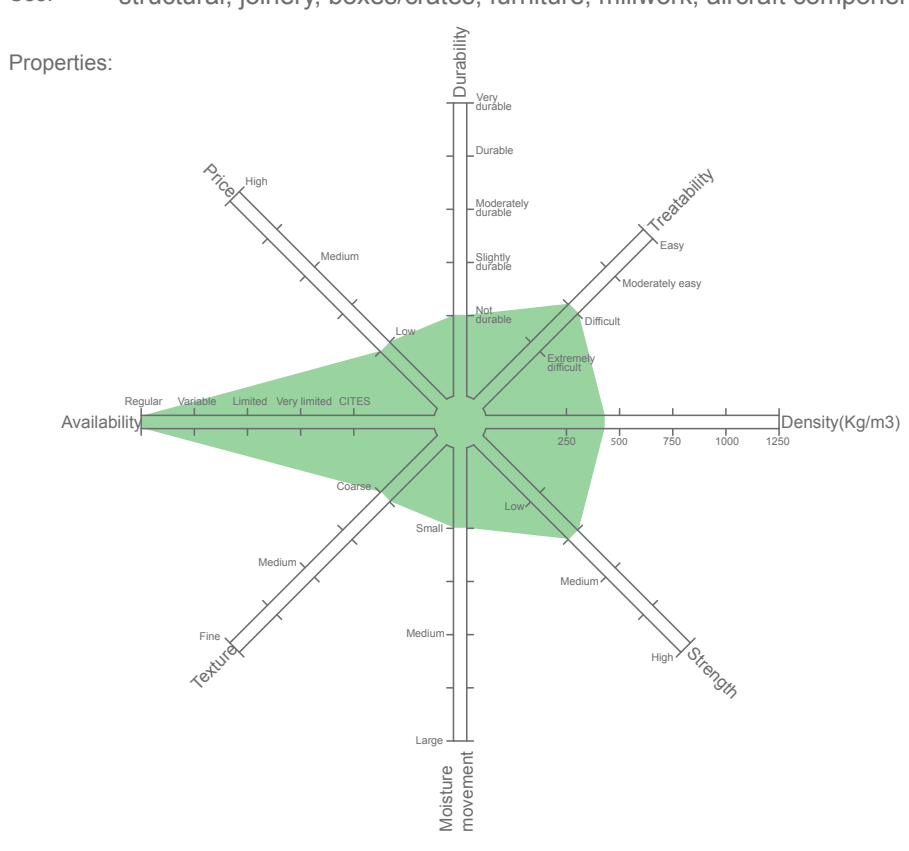

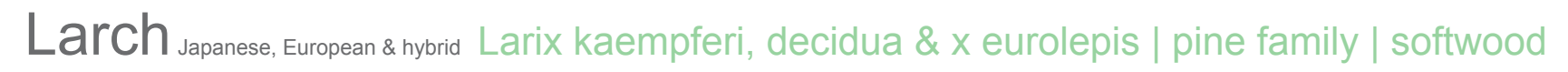
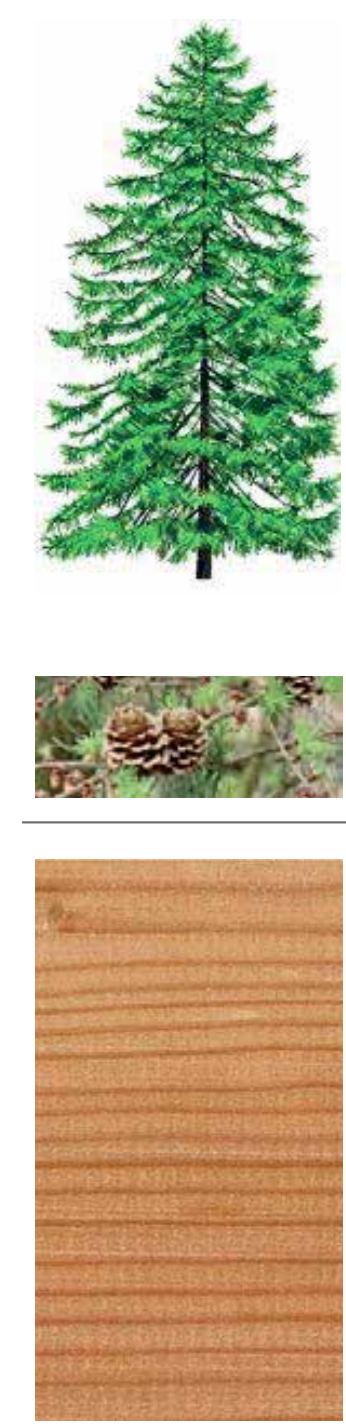

Origin: Japanese larch is a deciduous tree introduced from its native Japan in the early 1860 s by the well known plant enthusiast JG Veitch. The European larch is the only deciduous conifer native to Europe and was introduced to Britain sometime around 1620 for its timber. Hybrid larch is a cross between Japanese and European larch.

Site: A light demanding pioneer species which needs more than $1000 \mathrm{~mm}$ of rainfall for good growth. Cold hardy and withstands moderate exposure (unlike European larch), atthough stem form can be poor or more fertile sites. Vulnerable to spring and autumn frosts. Best suited to poor soils and on better drained

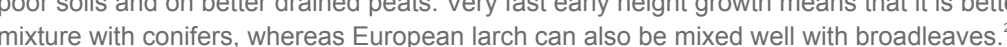

Pests: European and hybrid larch is susceptible to the fungal disease, larch canker (Lachnellula willkommii) which causes perennial cankers that girdle or distort branches and stems with frosty sites particularly at risk. European larch can also occasionally suffer striking defoliation by the needle cast fungus Meria pathogen Phytophthora ramorum, which is causing wides has been altacked, by he introduced western parts of Britain.

$\begin{array}{ll}\text { Height: } & 20-40 \mathrm{~m} \\ \text { Trunk: } & 0.6-1 \mathrm{~m}\end{array}$

Ceaves: Gross Seeds: straw coloured cones.

Timber: The colour of all three larches (European, Japanese and hybrid) is reddish-brown with clearly marked annual rings. Japanese larch growth is often fairly rapid, resulting in a generally lighter weight than tha of European larch.

Drving: Dries fairly rapidly but with a tendency to warp, split and check. ${ }^{3}$ crumble and tear durng sawing and planing. Cutting edges must be kept shar pened, when a clean finish can be obtained. The wood can be stained, varnished and painted, but care is needed in nailing to

Strength: Japanese larch is about 30 per cent softer, and 20 per cent less stiff than European larch.

Class: Typically graded at C16 with spruce, fir and pine but has potential to be graded up to C24.

Use: structural, cladding, utility poles, fence posts, boatbuilding, decking, furniture

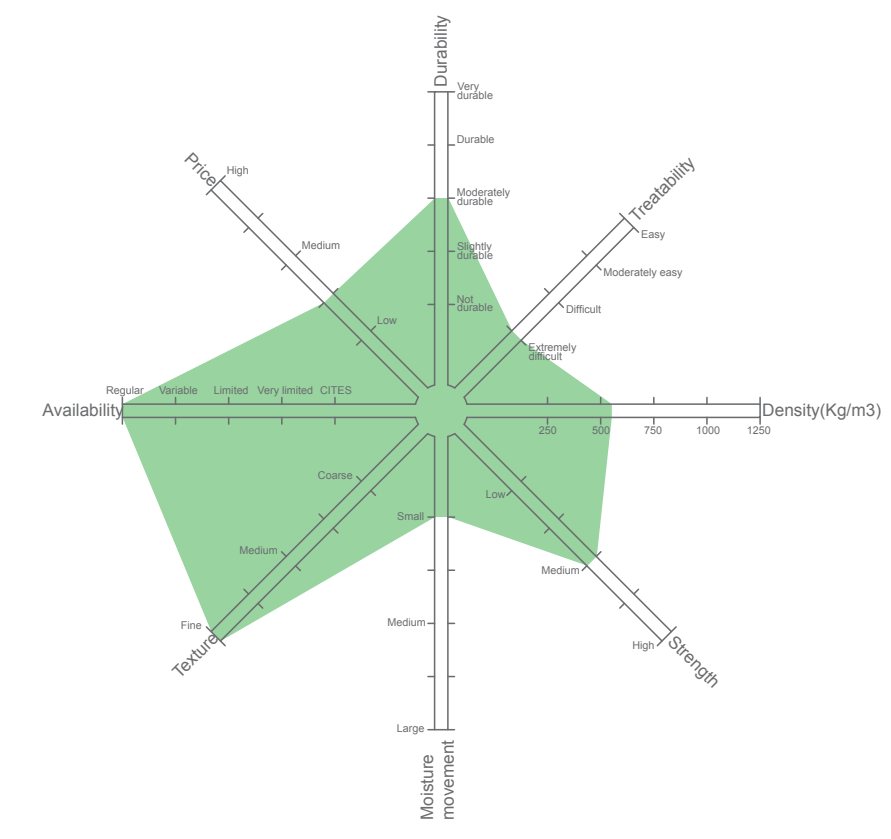


Douglas fir

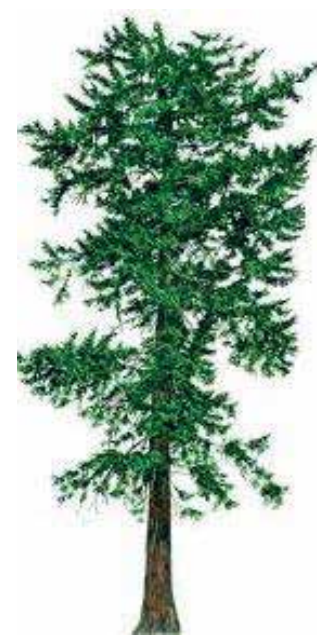

ลे

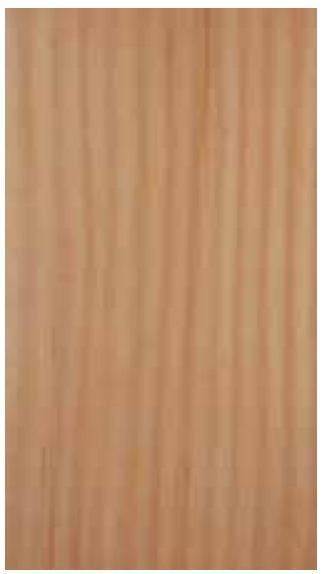

Origin: Named after David Douglas who introduced the tree to Europe from its natural habitat in N.W America where it can grow to $120 \mathrm{~m}$

Site: This is a high yielding early successional species of intermediate shade tolerance which produces a high quality timber. It is best suited to areas of high humidity with $750-2000 \mathrm{~mm}$ of rainfiall but it can als sheltered areas such as lower to middle valley sides. It is damaged by late spring frosts and young trees can be prone to toppling. It grows well on mineral soils of poor to medium fertility but requires adequate moisture and good soil aeration. It will not grow well on waterlogged or calcareous sites, or in

competition with heather,

Pests: Douglas fir is usually considered moderately resistant to Heterobasidion (Fomes root and butt rot) as it attack by Heterobasidion. It is also affected by the fungal disease Swiss needle cast, Phaeocryptopus gaeumannii, which is widespread but relatively insignificant although climate change predictions susceptible to infection by Phytophthora ramorum, although only when grown in close proximity to other infected plants which are a major source of spores.

Height: $\quad 45-60 m$

Leaves: $3 \mathrm{~cm}$ green n

Imber: The heartwood is light reddish-brown in colour, usually quite distinct from the lighter coloured sapwood The abrupt change and contrast in colour between early-wood and late-wood bands, produce a prominent growth ring figure which is a feature of plain-sawn surfaces and of rotary-cut veneer. The UK

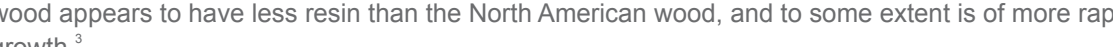

Drying: Care is required when drying from green, particularly because of the generally high preponderance o nnots which are hard, often loose, and which encourage a more wavy grain."

Strength: Compared with European redwood, it is some 60 per cent stiffer, 40 per cent harder and more resistant suddenly apolied loads, and 30 per cent stronger in bending and in compression along the grain.

Class: Typically graded at C16 with spruce, larch and pine but can be graded up to C24.

Use: $\quad$ structure, internal and external joinery, cladding, plywood, flooring.

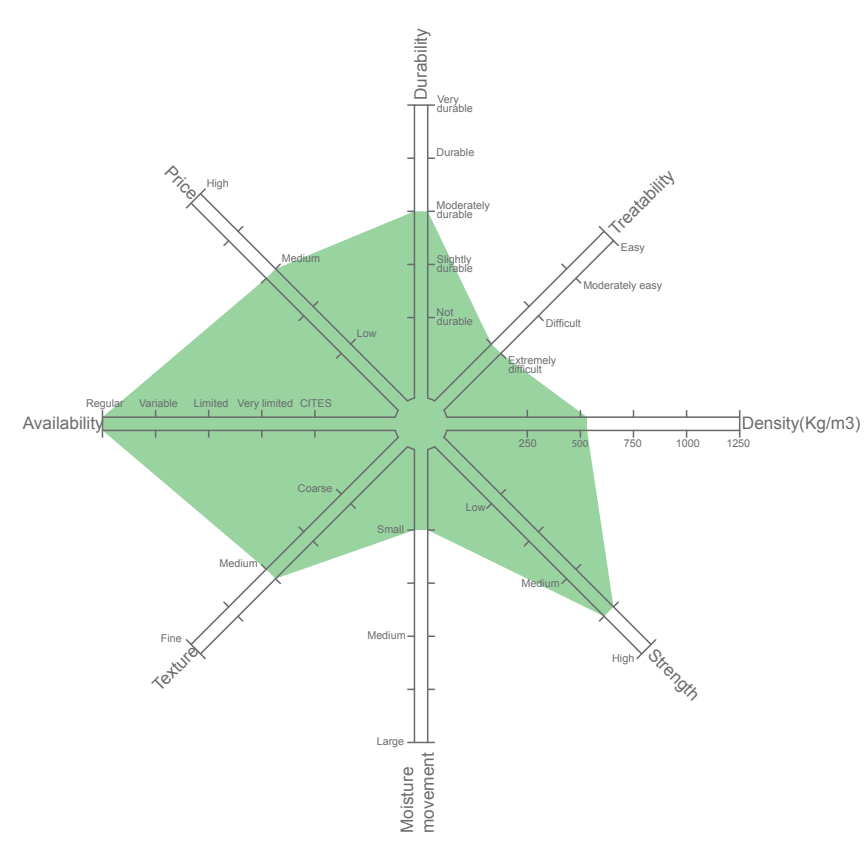

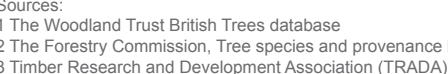

Oak Pendunculate \& Sessile

Quercus robur \& petraea

beech family

hardwood
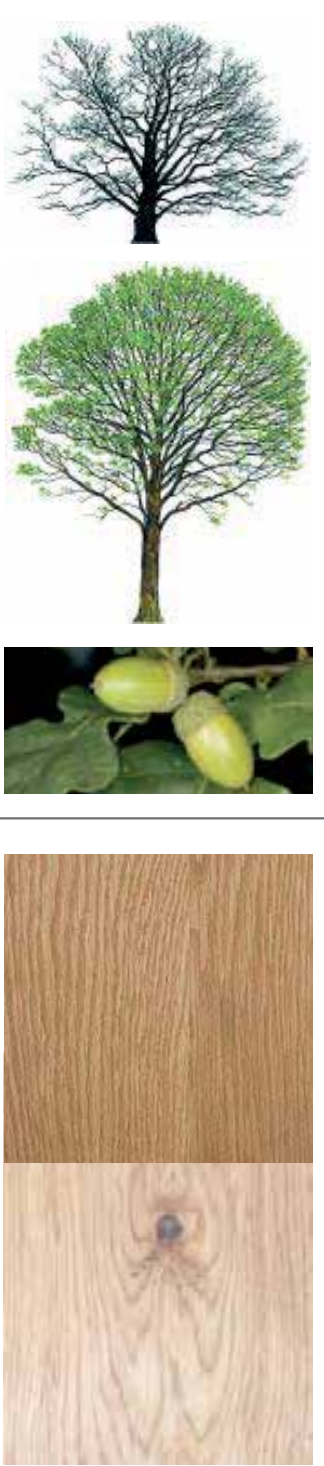

Origin: Both types are native to the British Isles. In Britain sessile tends to have a more westerly and upland distribution than ped
previous centuries.

The oak is the largest of the UK native broad-leaved trees and regarded as "kings of the forest". Oaks are sturdy, tall with domed crowns. The broad rounded canopy has wide spreading thick lower
branches

Site: Pendunculate is considered to be more light demanding than sessile oak. Both are windfirm and cold hardy but are susceptible to damage by late spring frost at young age. They prefer moist and heary slightly drier soils but is not suited to compacted or wet soils, Its ability to root in to heavier soils is ecologically valuable for its structure-improving and drainage effects.

Pests: Unlike pendunculate that suffers from chronic decline over decades, sessile oak is rarely afflicted by oak mortality Both are affected by the oak processionary moth as a major defolitorid while the acond pedunculate oak are often affected by knopper gall leading to acorn deformation and abortion?

$\begin{array}{lll} & & \\ \text { Height: } & 15-25 m \\ \text { Trunk: } & 1-1.5 m\end{array}$

Leaves: Dark green, shallow leaves. On the underneath of the leaf the main veins tend to be hairy.

(atkin developing into an acorn.'

Tmber- There is no difference in the appearance of the wood of either species. The sapwood is $25 \mathrm{~mm}$ to $50 \mathrm{~mm}$ wide and lighter in colour than the heartwood which is yellowish-brown. Quarter-sawn surfaces show a distinct silver-grain figure due to broad rays. The rings are clearly marked by alternating zones of great extent: for exament in slowly grown wood the proportion of dense latewood is redued in each annual growth ring, making the wood soft and light in weight.

Drying: Oak dries very slowly with a marked tendency to split and check in the early stages of drying. There is considerable risk of honeycombing if the drying is forced, especially in thick sizes. End and top protection must be provided to freshly sawn stock exposed to sun and drying winds. ${ }^{3}$

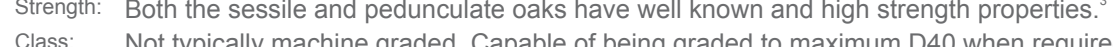

Working Medium to difficult - either machines easily or with moderate difficulty. Tool blades must be kept

qualities: sharpened, particularly where cross grain is present, and especially in planing highly-figured quarter-sawn surfaces. In general, oak finishes well and can be stained, poilshed, waxed, and glued

Use: $\quad$ Heavy structural, cladding, flooring, decking, interior and exterior joinery, furniture.

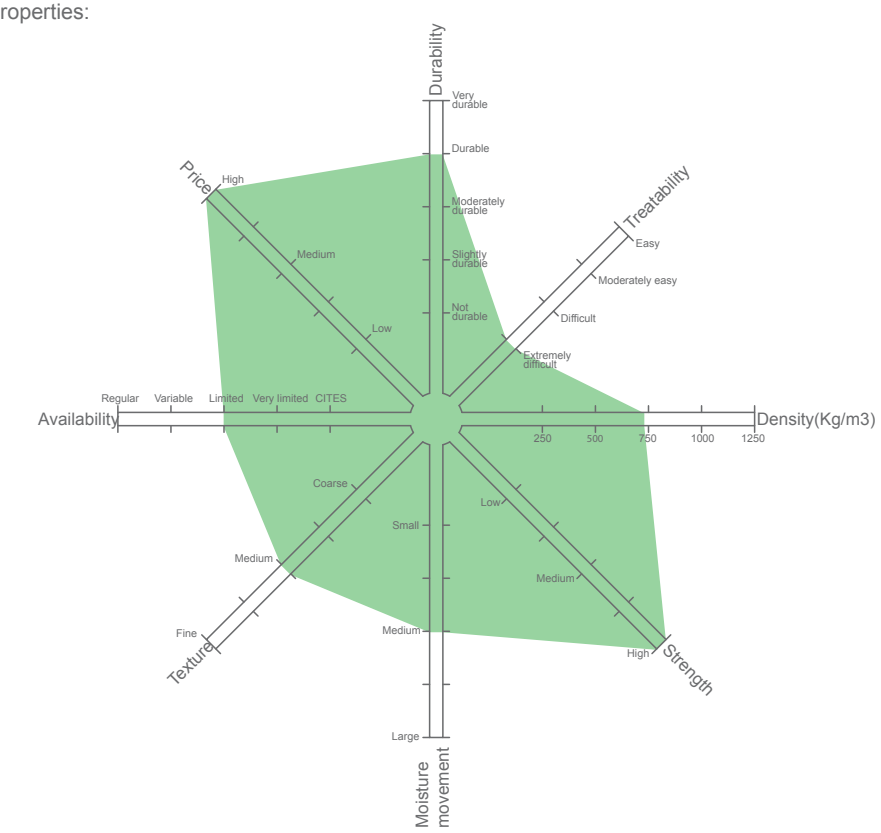

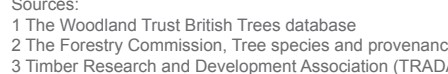


Sweet chestnut Castanea sativa | beech family | hardwood

Origin: Introduced to Britain over 2000 years ago, from southern Europe, sweet chestnuts are often considered an 'honorary' native tree.'

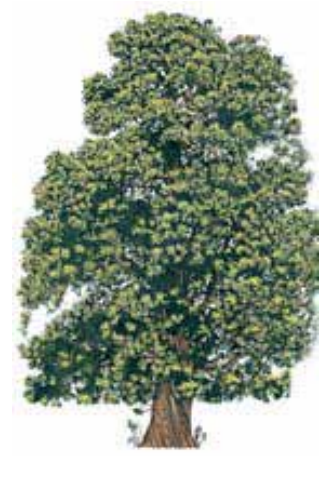

Site: The species is suited to warmer, more continental parts of Britain (i.e. $<1500 \mathrm{~mm}$ rainfall per year) on medium to poor solis of fresh or sightily dry moisture status. Ii tis hot suited to alkatine or waterlogged of exposure It is now widespread on lighter sort coppice species.

Pests: Sweet chestnut is susceptible to several root attacking species of Phytophthora, mainly P. cinnamom

cankers and girdles branches and stems, is a serious disease in parts of Europe ${ }^{2}$

\section{$\begin{array}{ll}\text { Height: } & 20-30 \mathrm{~m} \\ \text { Trunk: } & 1.5-2 \mathrm{~m}\end{array}$}

Leaves: Green $20 \mathrm{~cm}$ long, oval leaves have around 20 pairs of straight parallel veins each ending in a saw

Seeds. $\quad$ Catkin developing to a brown seed within a green spiny case.'

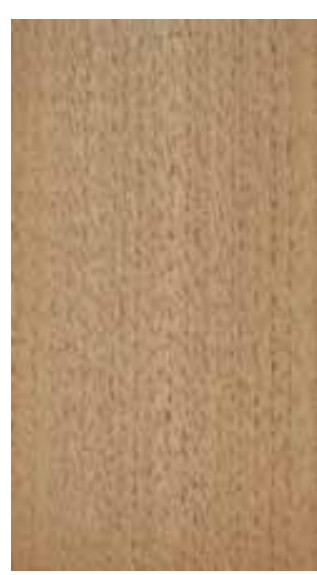

Timber: The sapwood is narrow, and distinct from the heartwood which is yellowish-brown in colour, closely resembling oak in appearance but lacking the silver-grain figure characteristic of that timber. The grain
may be straight, but is more commonly spiral, particularly in wood from old trees, while logs are liable may be straight, but is more commonly spiral, particularly in wood from old trees, while logs are liable
cup and ring-shake. On account of its somewhat acidic character chestrut tends to accelerate the cup and ring-shake. Onaccount of tits somewhat acidic character chestnut tends to accelerate the
corrosion of metals, particularly when moist. It also contains tannin, as a result of which blue-black discolourations are prone to appear on the wood when it comes into contact with iron or iron

Drying: It is rather difficult to dry, retaining its moisture in patches, and tending to collapse and honeycomb; this form of defect does not respond well to reconditioning treatments. ${ }^{3}$

Strength: Chestnut is less hard and tough, and some 20 per cent inferior in all its strength properties to oak.

Working Good, easy to work and finishes excellently. Takes nails, glue, stains and polish well.'

Qualities: $\quad$ Exterior and interior joinery, cladding.

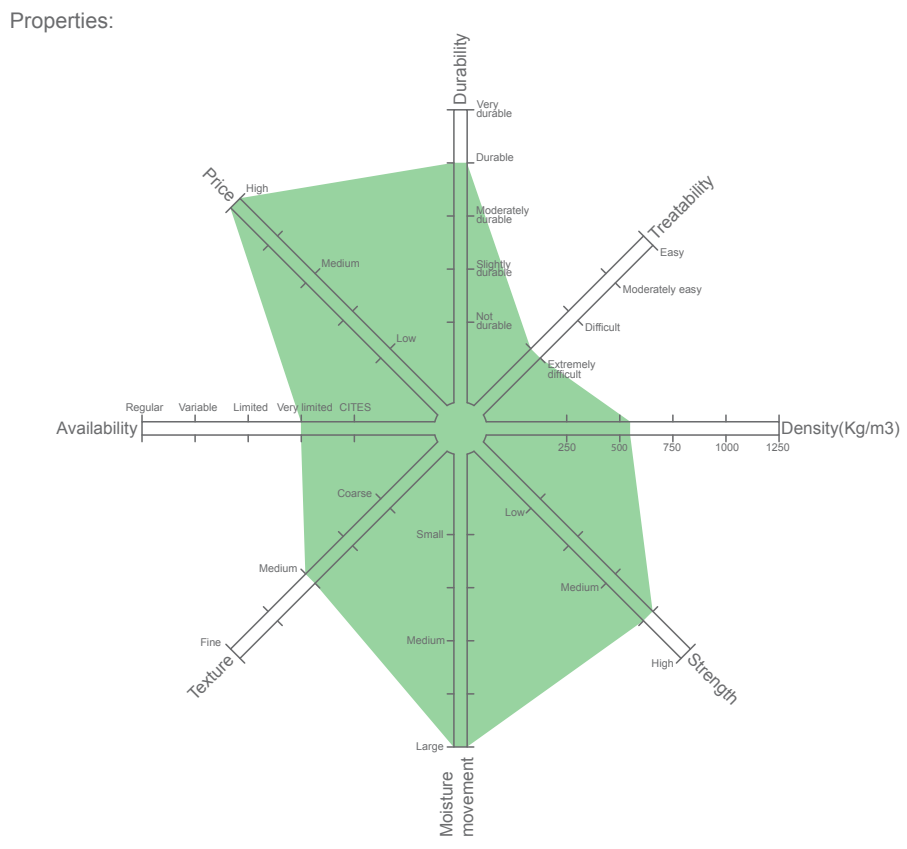

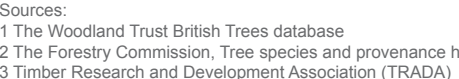

\section{Common ash}

Fraxinus excelsior

ash family

hardwood

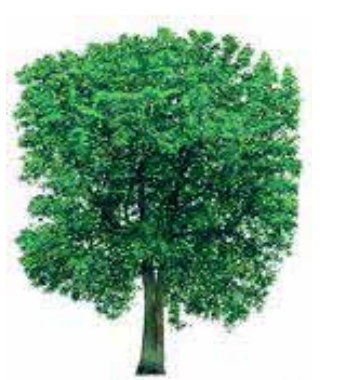

Origin: Native to the British Isles and much of western Europe except the far north.

Varants: Narrow-leafed ash (Fraxinus angustifolia); Red ash (Fraxinus pennsylvanica); and white ash (Fraxinus americana).

Site: Ash has intermediate shade tolerance when young but needs early thinning for good growth. The species is cold hardy and moderately tolerant of exposure, but is susceptible to late frost damage which
can cause forking. This is a very site demanding species. Grows best on moist, well-drained deep and rich solis with a high nitrogen content, and often overlying calcareous bedrock; requires $\mathrm{pH}$ values of 5 or above. Nutrient poor dry and waterlogged soils should be avoided

Pests: Ash trees can suffer from a variety of root and butt rots that can cause late flushing, thinning foliage and death of scattered twigs, branches or limbs, especially in the eastern drier parts of the country. It is commonly affected by ash bud moth (Prays fraxinella), which causes wilt and dieback of some small

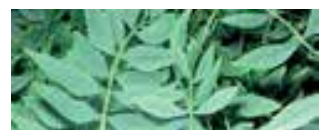
species of fungal pathogen, Chalara fraxinea.

19.2. $\begin{array}{cc}\text { Height: } & 15-30 \mathrm{~m} \\ \text { Trunk: } & 1-2 \mathrm{~m}\end{array}$

Trunk:
Leaves:
Seeds:

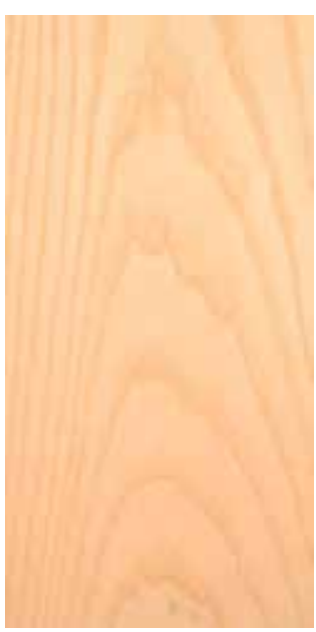

Timber: There is usually no distinction in colour between sapwood and heartwood, freshly cut wood being Whitish to pale brown with a pink cast, turning to a slightly brownish-white after drying. In some logs, a irregular dark brown or black heartwood is found, but this is not necessarily a defect, as the timber is decritive nature of the wood which is krow as alve ast?

Drying: Dries at a fairly rapid rate without excessive surface checking and splitting, but under the influence of severe temperatures, there is a tendency to distort and for end splititing to occur. Distorted stock responds well to reconditioning kin treatment.

Class: Not typically machine graded

Working Good, although tough, ash works and machines quite well, and finishes to a reasonably smooth finish. It qualities: can be glued, stained, and polished.

Use: Interior joinery, flooring, furniture, millwork, boxes/crates and other turned objects such as tool handles. Properties:

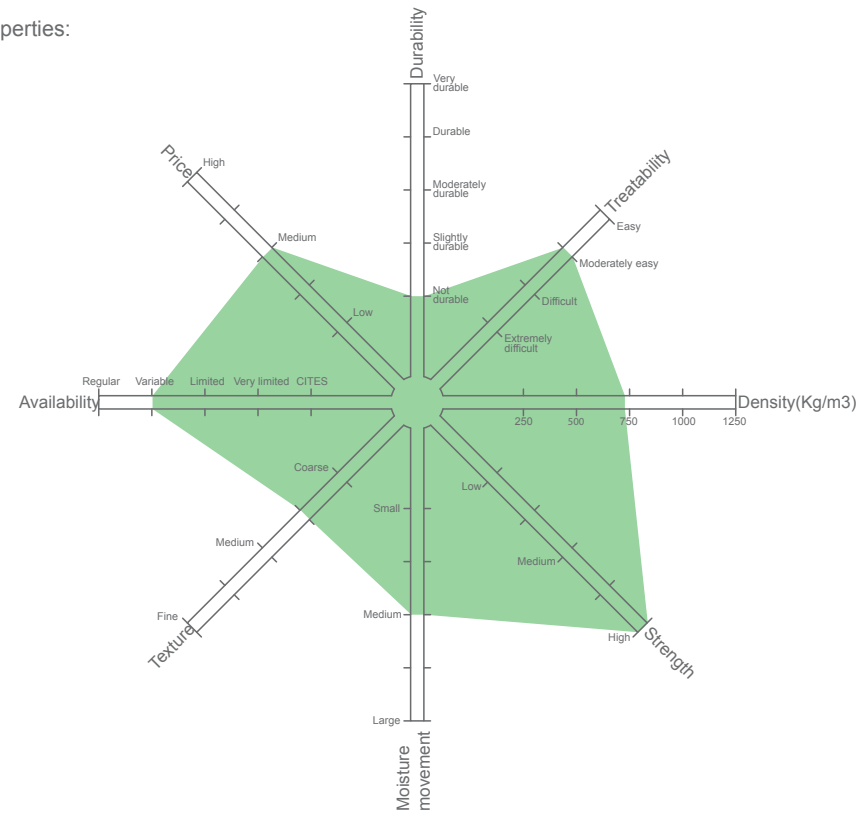




\section{Findings}

This chapter has highlighted that in general the Welsh woodlands are well managed, certified and capable of providing sustainable construction timber, but the volumes available are not likely to meet the demands of the whole industry.

\section{Woodlands and trees}

- Woodland management ultimately determines the sustainability of the woodland and therefore quality of the timber. It is vital that all timber used by the construction industry is sustainably sourced. Welsh woodlands are comprised of an almost 50:50 split between coniferous and broadleaf species with $66 \%$ of coniferous woodland and $11 \%$ of broadleaf woodland in public ownership managed by the Forestry Commission for Wales.

- $100 \%$ FC managed, publicly owned, woodland (approx. 117000 hectares) is FSC certified ensuring the forest is well managed and appropriately felled of which $85 \%$ is softwood species.

- Only $11 \%$ of the privately owned woodland is FSC certified. This does not mean that the woodland is badly managed however, care needs to be taken in the sourcing of timber from non-certified woodland to ensure it is effectively managed. In particular, the $89 \%$ of the broadleaf woodland, producing hardwood, that is within private ownership. All timber should ideally be sourced from certified woodland or selectively felled, thinned or coppiced as part of a continuous cover forest strategy. This is likely to result in limited volumes, section sizes and lengths of hardwood for use.

- With the predominant softwood species having an average yield class between 10-24 cubic metres per hectare per year, the Welsh woodlands are predominantly supplying certified softwood.

- The lower yield class of the hardwoods, with sweet chestnut achieving a yield class of 8 cubic metres per hectare per year ${ }^{64}$ and oak achieving 4 cubic metres per hectare per year ${ }^{65}$, along with the lower evidence of certification suggests that careful specification is required to ensure the longer term management and sustainability of broadleaf woodland. 


\section{Timber properties}

The sections on the physical properties highlighted key performance properties of timber that must be considered in the design, specification and making of the contemporary building envelope in relation to each species:

- Processing of timber: in respect to the proportions of early- and late-wood and the incorporation of heartwood. This may affect durability, strength grading and movement.

- Moisture content and seasoning: to allow for, or control the movement of timber post processing and in use to reduce risks of cupping, warping,

twisting and bowing. It is to be expected that all timber is likely to shrink and expand in response to the relative humidity.

- Imperfections: knots and fissures in relation to the appearance, strength and workability of each species.

- Density: is a given of each species, although growth rate may slightly alter the ange of densities available for specific purposes. This will directly relate to strength and may offer beneficial thermal bridging performance.

- Strength and structural grading: in general the softwood has a low grade strength class across all species ranging from C16 to limited volumes of C24. This is to be accepted as a parameter of Welsh-grown timber.

\begin{tabular}{|c|c|c|c|}
\hline \multirow{15}{*}{$\begin{array}{l}\text { Welsh-grown } \\
\text { Timber }\end{array}$} & \multirow[t]{7}{*}{ species } & \multicolumn{2}{|l|}{ Sitka spruce } \\
\hline & & \multicolumn{2}{|c|}{ European, Japanese \& hybrid larch } \\
\hline & & \multicolumn{2}{|l|}{ Douglas fir } \\
\hline & & \multicolumn{2}{|l|}{ Common oak } \\
\hline & & \multicolumn{2}{|l|}{ Common ash } \\
\hline & & \multicolumn{2}{|c|}{ Sweet chestnut } \\
\hline & & \multicolumn{2}{|l|}{ other } \\
\hline & \multirow{9}{*}{ adaptation } & \multirow{2}{*}{ untreated } & 'green’ \\
\hline & & & dried \\
\hline & & \multirow{2}{*}{ modified } & heat \\
\hline & & & chemical \\
\hline & & \multirow{2}{*}{ engineered } & timber only \\
\hline & & & composite \\
\hline & & \multirow[t]{3}{*}{ standardised } & short lengths \\
\hline & & & small sections \\
\hline A & & & structural grading \\
\hline
\end{tabular}

Fig 2.62 Table of chapter 2 findings
2.5 .3

- Durability: will determine the suitability of timber species for different uses within the external envelope. Only the hardwoods oak and sweet chestnut, grown in Wales, are classed as durable with larch the only softwood rated as moderately durable. All other species will require some form of chemical or heat based modification to improve their durability.

\section{Findings to take forward}

- Only use FSC-certified timber (predominantly coming from FC managed woodland) or timber from woodlands that can demonstrate a commitment to continuous cover forest management.

- Selection of Sitka spruce, larch, Douglas fir, oak, sweet chestnut and/ or ash as a range of Welsh-grown timber species with properties that have potential for use. It is not intended that these species are individually tested in the building envelope but incorporated as and when appropriate for the specific needs of individual projects.

- Use small sections and lengths of hardwoods

- The forest industry is primarily focussed on the growing of high-yield softwood species which are limited to C16 and limited C24 strength grade classes 
Consider the affect or control of the moisture content in use

Consider the modification of timber to improve durability characteristics

- Consider the engineering of timber to improve structural capabilities allowing a wider range of species to be used

These findings are now taken forward into an evaluation of the timber industry in Wales 


\section{CHAPTER 3}

Timber Industry in Wales 
In the previous chapter, an analysis of the woodlands, trees and resultant timber in Wales highlighted a number of species and properties that were worthy of further consideration in construction. In this chapter, the timber industry in Wales is analysed as the process by which the raw roundwood, and associated properties, is extracted from the woodland, and processed before being made available for market either as sawnwood or as a specific value-added product. The purpose is to illustrate the scale and role of the timber industry to ascertain the potential and barriers that exist to the use of Welsh-grown timber and timber products. Data for Wales is provided wherever possible, however where this is not available an analysis of the UK wide industry is provided as a comparable equivalent.

The chapter begins with the political context of the Welsh Government to promote and support forestry and associated industries. The purpose is to demonstrate that there is a will and a need for the forest industry to perform efficiently, environmentally, socially and economically. Key influential organisations are highlighted that are contributing to research and knowledge transfer within the industry. The next section provides further industry context with a review of the volumes of imported timber and timber products against volume of homegrown production in the UK and, where possible, Wales. The shortfalls of harvested homegrown timber available and the reliance on imported timber will highlight the potential market for timber and timber products in Wales. The section ends with a brief comparative review of homegrown and imported softwood in timber frame construction.

Following the review of the industry context, the chapter is divided into sections to focus on timber procurement and the flow of timber through the supply chain in Wales. Beginning with an analysis of the scale of the industry, the effectiveness of the supply chain as a whole is analysed to identify any barriers or opportunities that may highlight possible innovation within the industry. Sections follow, on:

- Forest harvesting - to highlight the decisions that forest owners must take when planting and harvesting in respect to rotation cycles, species yield class and a target, profitable market;

- Primary processing - to analyse the impact that sawmills have on the supply of sawnwood for use in construction with a focus on sizes, structural grading and value-added processes such as timber product manufacturing;

- Secondary processing - is analysed in relation to available use of Welsh-grown timber, technology and skills as the key part of the chain supplying construction industry products, such as timber frames and joinery 
components;

- Construction - a brief analysis on the use of timber within the UK construction industry to provide context on the extent and types of timber use, level of contractor skills and market share.

The chapter ends with findings on the political and industry 'will' to use Welsh-grown timber; the level of technology and skills available within the industry to manufacture and construct timber architecture; identification of the parameters and opportunities to work with softwood and hardwood; and the barriers that exist on innovation.

\section{Political and advisory context}

The Welsh Assembly Government (now Welsh Government), published a report with the then Forestry Commission Wales in 2009 entitled 'Woodlands for Wales', in which they set out their strategy for woodlands and trees in relation to climate, people and the economy. They stated their vision as:

'Wales will be known for its high-quality woodlands that enhance the landscape are appropriate to local conditions and have a diverse mixture of species and habitats. These will:

- provide real social and community benefits, both locally and nationally

- support thriving woodland-based industries and

- contribute to a better quality environment throughout Wales.'1

Since this report was published outlining 20 'high-level outcomes for implementation", the Forestry Commission Wales, as part of public cost saving measures, has been merged into a larger organisation with the former Countryside Council for Wales and the Environment Agency in Wales to form Natural Resources Wales. Formed in April 2013, initial reaction from members within the former Forestry Commission for Wales were mixed. Some were cynical that the merger would 'water-down' the functions of the previous three organisations reducing the ability to develop the Welsh timber industry with complex decision making processes. Others see the now shared responsibilities for the natural environment as an opportunity to work in the best interests of the environment as whole in Wales rather than on individual agendas. However, the success of the timber industry is not solely down to the management

1 Forestry Commission Wales, Woodlands for Wales: The Welsh Assembly Government's Strategy for woodlands and trees (Cardiff: Welsh Assembly Government, 2009), p.8

2 ibid, p.9 


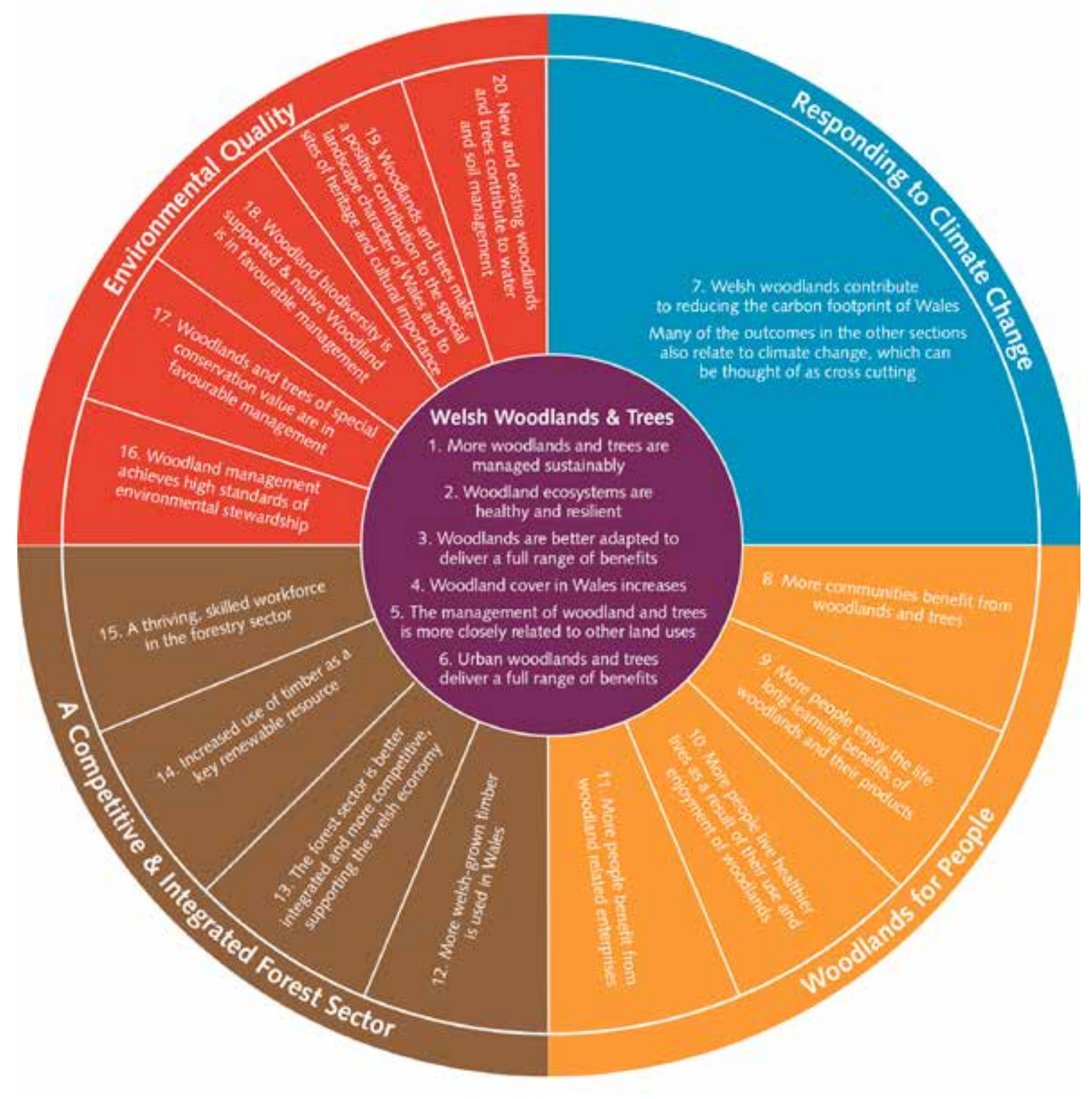

Fig 3.1 Woodland for Wales key indicators chart of the resource, but equally by the thousands of private businesses working within the supply chain who are able to shape the direction of the industry. These include sawmills, timber product manufacturers, design teams and clients/ customers/ endusers.

While all 20 outcomes highlighted in Woodlands for Wales are vital, four of these are directly relevant to the construction industry and architecture, relating to a 'competitive and integrated forest sector.' These are:

1. More Welsh-grown timber is used in Wales;

2. The forest sector is better integrated and more competitive, supporting the Welsh economy;

3. Increased use of timber as a key renewable resource; and

4. A thriving, skilled workforce in the forestry sector.

The outcomes of these themes are also influential on the design and construction of timber architecture in Wales and are therefore incorporated into the following timber industry appraisal.

In appraising the industry a range of organisations have been consulted to provide data and evaluation that have been conducted by consultants and researchers within the UK and Welsh timber industry over the last ten years. Where possible data has been selected and focused on the Welsh timber industry, however this is not always available and therefore UK wide data has been used instead. These organisations are:

- Wales Forest Business Partnership (WFBP);

- Wood Knowledge Wales (WKW);

- Wood Source Wales (WSW);

- Forestry Commission (FC)

- Natural Resources Wales (NRW)

- Building Research Establishment Wales (BRE)

- Welsh Government (previously Welsh Assembly Government);

- Timber Research and Development Association (TRADA);

- Timber Trade Federation (TTF)

Of particular note is the Wales Forest Business Partnership and its three business development initiatives: Woodknowledge Wales, Woodsource Wales and Woodfuel Wales. WFBP is an industry led group represented by businesses working in, 
influencing or influenced by the timber industry in Wales, such as foresters,

sawmills, engineers, manufacturers, designers, craft businesses, paper mills etc. The organisation is supported by the Welsh Government and was established following the 'Woodlands for Wales' report and the recommendations to establish a leadership group representing the interests of the industry from a report prepared by Jaakko Poyry Consulting in 2004 called 'Welsh Forest Industry: Mapping and Benchmarking the Forest Industry'. The objectives are to ensure Welsh forest based industries are globally competitive; expand and develop the market; encourage a wood using culture in Wales; build an innovative industry; and be recognised as a sector that contributes to the Welsh economy, environment and communities.

WKW was established to lead on industry innovation, research and development with three aims: to provide information to Welsh wood using businesses and assist in knowledge transfer; to assist in developing new products and processes; and promote research and development. The three aims of WSW are: to provide opportunities for business development; provide support for increased market exposure for businesses; and target procurement teams and individuals by raising the profile of Welsh timber as a sustainable material. Woodfuel Wales (WFW) was established more recently to bring together businesses in Wales involved with the growth and supply of wood fuel and the design, supply and installation of woodburning installations to develop, educate, advise and encourage the use of clean and efficient wood burning systems and the material source.

\section{Import v homegrown}

Although much of Europe and the USA have large forests and stocks of timber available to support a successful timber industry, the UK can currently supply only $24 \%$ of the timber it uses, with the majority of wood and wood products imported from Europe, China, Brazil and USA. In 2010, the UK was the third largest net importer of forest products behind China and Japan. ${ }^{6}$ While the overall demand for timber has reduced in the last 5 years, corresponding with a period of economic downturn, the longterm forecast is likely to continue to increase with a rise in demand for timber products to meet sustainability requirements. In 2004 the demand for forest products within Europe was expected to continue increasing until at least 2020 at

5 Jaakko Poyry Consulting, Welsh Forest Industry: Mapping and Benchmarking the Forest Industry, Final Report (Executive Summary Only), (London, 5th November 2004)

6 Forestry Commission, Forestry Statistics 2012 (Edinburgh: Forestry Commission 2012) 
approximately 1-2\% growth. ${ }^{7}$ The issue, therefore, of choosing between home-grown and imported timber on grounds of sustainability alone is a complex one.

In the life-cycle assessment of a material, a major environmental cost is the processing of the material and the transportation of the product or the raw materials. In the making of 'ecological architecture' timber appears to be an appropriate primary material. ${ }^{8}$ If this is the case it may seem obvious to argue that in order to source 'sustainable' timber it needs to come from well-managed local forests. However this does not necessarily guarantee success. Some economists argue that the concept of sustainability is self-defeating in itself. Avoiding inter-continental transport would eliminate the merits of export and import.

The environmental cost of transportation of timber remains an issue. Coed Cymru compared the environmental cost of road transport with sea transport. If a lorry carried 20 tonnes of material at 6 miles to the gallon, then it would take $2.5 \mathrm{I}$ to transport 1 tonne $100 \mathrm{~km}$. If a ship (21,000 tonne dead-weight) travels at $32 \mathrm{~km} / \mathrm{hr}$, it would consume 40 tonnes of fuel/day; which makes 0.25 I to transport 1 tonne 100 $\mathrm{km}$. The ratio is $1 / 10$. This means that transporting timber from Mid Wales to London (100 miles) is roughly equivalent to transporting timber from the Baltic coast to the London Docks (1000 miles). 9

The use of home-grown indigenous products offers several distinct advantages. The environmental cost of transportation is of little consequence when considered amongst all the other performance factors such as fitness for purpose, durability, regeneration of the local forest, ecology and socio-economic factors. In attempting to specify sustainable timber a pre-requisite is that it should be sourced from sustainable or well-managed forests. As identified in chapter 2 selective rather than clear-felling, in the local or indigenous forest, may be practised in order to protect the forest. This may mean that the size and quality of species available does not match 'traditional' standards and particular sizes. This demands innovative ways of using medium growth timbers of smaller size and section.

Despite, and as a result of, an increase in demand for timber products, a greater awareness of the environmental advantages of timber and a slow but increasing interest in using local materials, including timber, the UK is one of Europe's largest importers of wood and wood products with imports accounting for $80 \%$ of all wood

7 United Nations Economic Commission for Europe/ Food and Agriculture Organization of the United Nations, European Forest Sector Outlook Study (Geneva: United Nations, 2005)

8 Timber Trade Federation, Sustainability (London: Timber Trade Federation 2014) <http://www.ttf co.uk/sustainability.aspx> [Accessed 7th August 2015]

9 Conversation with David Jenkins, Director of Coed Cymru, 2000 
(produced and imported) in the UK and imports accounting for $89 \%$ of apparent wood consumption in the UK..$^{10}$ Although these figures are lower than the recent peak of 2007 where $96 \%$ of apparent UK consumption was met through imported timber. In relation to UK production, it should be noted that the UK exports approximately half of the timber it produces predominantly for use in board and paper making.

In 2013 the UK produced 10.8 million cubic metres of roundwood, exported 6.2 million cubic metres and imported 42.2 million cubic metres giving an apparent consumption of 46.8 million cubic metres, an $8 \%$ increase since 2012. The imports can be broken down into the following primary categories:11

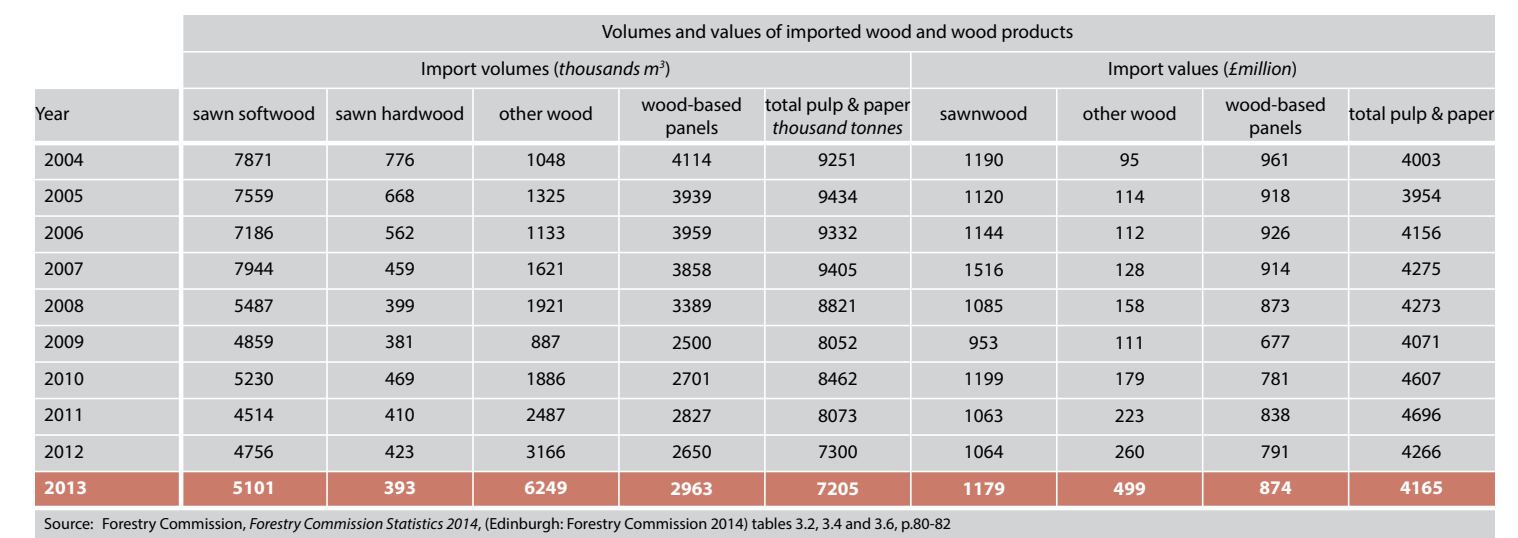

Chart 27: Businesses by main source of timber$$
100 \%
$$

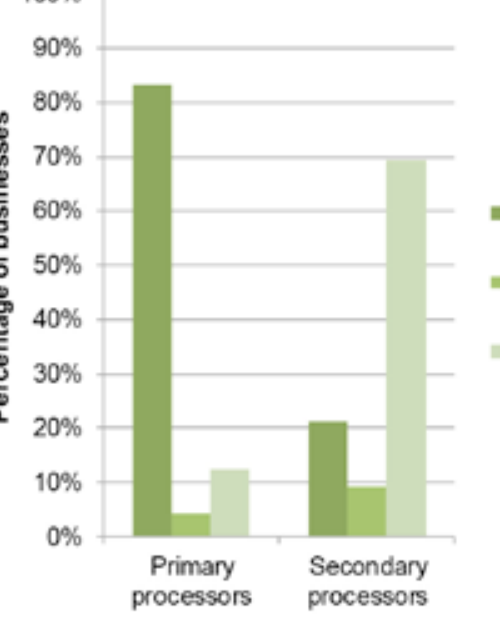

Source: Forestry Commission Wales

survey of woodland enterprises

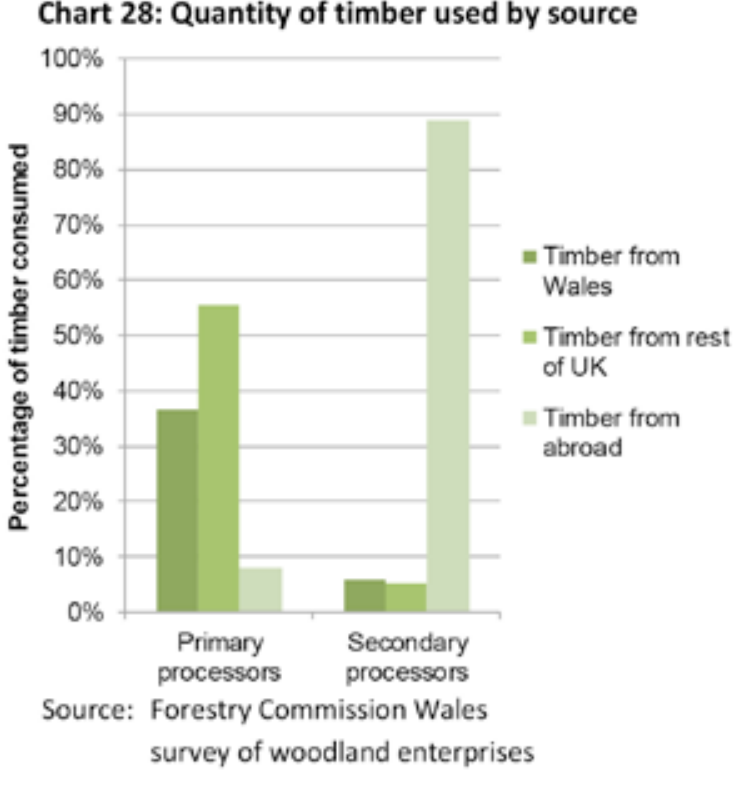

- 5.1 million cubic metres of sawn softwood, an increase of $6 \%$ from 2012 but a decrease of $36 \%$ since 2004 ;

- 393 thousand cubic metres of sawn hardwood, an increase of $12 \%$ from 2012 but a decrease of $49 \%$ since 2004

- 2.96 million cubic metres of wood-based panels, a decrease of $7 \%$ from 2012 and a decrease of $28 \%$ since 2004 ;

- 5.9 million tonnes of paper, a decrease of $3 \%$ from 2012 and a decrease of $22 \%$ since 2004;

- the total value of wood and wood product imports was $£ 6.7$ billion, of which $£ 4.2$ billion was pulp and paper. ${ }^{12}$

These figures and table show that the significant dip in the volumes and value of wood and wood product importation since the 2008 recession are beginning to increase but are significantly lower than figures 10 years ago. Contrary to this the UK production of timber has steadily increased for the last 10 years with an increase from 2004 of $23 \%$ from $8.3-10.8$ million cubic metres. ${ }^{13}$ Approximately $39 \%$, and the largest apparent consumption of wood in the UK is paper and paperboard followed by both coniferous and non-coniferous sawnwood at 37\%. $40 \%$ of the UK sawnwood market is provided for by UK production and $49 \%$ of the paper and paperboard market supplied by UK production. The UK produces no veneer, and therefore plywood, relying entirely on imports to meet demand whereas $77 \%$ of particle- and fibre-boards, such as OSB and MDF, are produced in the UK from UK grown timber.

10 Forestry Commission, Forestry Statistics 2012, p.76

Fig 3.2 Volumes and values of imported wood and wood products

Fig 3.3 Businesses by main source of timber and quantity of timber used by source

11 Forestry Commission, Forestry Statistics 2014 (Edinburgh: Forestry Commission 2014), p.87

12 ibid, p.86 


\begin{tabular}{|c|c|c|c|c|c|c|c|}
\hline & \multicolumn{7}{|c|}{ Origin of wooc } \\
\hline & sawn softwood & sawn hardwood & plywood & particle board & fibre board & wood pulp & $\begin{array}{l}\text { paper \& } \\
\text { paperboard }\end{array}$ \\
\hline & \multicolumn{7}{|c|}{ \% of total U Kimports im volume for each category } \\
\hline Sweden & 46 & 0 & 0 & 0 & 0 & 27 & 17 \\
\hline Finland & 13 & 1 & 12 & 0 & 2 & 7 & 15 \\
\hline Germany & 5 & 7 & 0 & 25 & 24 & 1 & 19 \\
\hline France & 0 & 9 & 1 & 22 & 1 & 0 & 8 \\
\hline Italy & 0 & 10 & 1 & 1 & 0 & 1 & 4 \\
\hline Netherlands & 0 & 2 & 1 & 0 & 0 & 6 & 4 \\
\hline Belgium & 1 & 3 & 0 & 10 & 8 & 0 & 2 \\
\hline Spain & 0 & 0 & 1 & 3 & 11 & 3 & 2 \\
\hline Ireland & 8 & 2 & 1 & 15 & 34 & 0 & 1 \\
\hline Latvia & 14 & 6 & 2 & 8 & 4 & 0 & 0 \\
\hline Poland & 0 & 3 & 0 & 0 & 7 & 0 & 2 \\
\hline Portugal & 0 & 0 & 0 & 10 & 1 & 4 & 2 \\
\hline Estonia & 2 & 6 & 0 & 0 & 1 & 0 & 0 \\
\hline Other EU-27 & 2 & 3 & 2 & 4 & 3 & 4 & 5 \\
\hline TOTAL EU-27 & 92 & 54 & 21 & 99 & 96 & 53 & 81 \\
\hline China & 0 & 1 & 42 & 0 & 3 & 0 & 3 \\
\hline USA & 0 & 22 & 0 & 0 & 0 & 7 & 4 \\
\hline Brazil & 0 & 0 & 15 & 0 & 0 & 26 & 2 \\
\hline Russia & 5 & 1 & 5 & 0 & 0 & 0 & 0 \\
\hline Malaysia & 0 & 5 & 9 & 0 & 0 & 0 & 0 \\
\hline Cameroon & 0 & 9 & 0 & 0 & 0 & 0 & 0 \\
\hline Other non-EU & 2 & 10 & 8 & 1 & 1 & 14 & 11 \\
\hline TOTAL non-EU & 8 & 46 & 79 & 1 & 4 & 47 & 19 \\
\hline
\end{tabular}

Fig 3.4 Origin of wood imports into the UK
Therefore the UK relies on imports for $60 \%$ of the sawnwood, $53 \%$ of the OSB and MDF and $100 \%$ of the plywood used to meet demand. With an increase in the use of homegrown wood for fuel and the ever increasing demand for paper putting further pressure on limited resources, will mean that the UK will either need to grow more timber, increase its dependency on imported products or innovate with the way timber is used.

Approximately $71 \%$ of all imported wood and wood products in the UK originate from within Europe, with $73 \%$ of sawn softwood coming principally from Sweden, Finland and Latvia. ${ }^{14}$ The latter of which has been slowly increasing its market share over the last 10 years, recovering from the collapse of the former Soviet Union. It is expected that this, alongside other former Russian states, will increase their exports leading to an increased supply of material which may depress prices and saturate the market. $^{15}$

With only a limited selection of hardwoods grown in the UK, it is not surprising that only $18 \%$ of hardwoods consumed in the UK are homegrown with $22 \%$ sourced from the USA, 54\% sourced from a range of EU countries and at least 15\% from tropical regions to acquire more durable temperate and tropical hardwoods for decorative interior joinery and furniture. However, care must be taken in the sourcing and specification of these species to ensure the sustainability credentials. The temperate hardwoods imported from within Europe are typically oak, birch, chestnut and beech to meet the lower quantities and higher costs or perceived inferior properties of the UK grown equivalents.

While the majority of particleboard (99\%) and fibreboard (96\%) is imported from Europe and the large manufacturers in Germany, France and Ireland the majority of plywood is imported from non-EU countries (79\%) such as China, Brazil and Malaysia typically supplying tropical hardwood plywood with lower cost, but often leading to over-harvesting of forests due to demand. The more commonly used spruce and birch plywoods in construction are generally imported from Finland and to a lesser extent Latvia, although Chinese manufacturers are beginning to compete with this market.

14 ibid, p.95

15 Dennis Jones, Welsh timber resources and their potential within the construction industry (Port Talbot: BRE Wales for the Forestry Commission, Report number 236-355, 2007), p.7 
The UK produced an estimated 11.5 million green tonnes of roundwood, in 2013. 11 million tonnes of this was softwood, with 0.5 million tonnes of hardwood. ${ }^{16}$ Whereas softwood deliveries to sawmills for primary processing has increased over the last 10 years, hardwood deliveries have decreased overall and remained consistent over the last 5 years. $58 \%$ of the round softwood and only $15 \%$ of the round hardwood grown in the UK are processed at sawmills producing a total of 3.6 million cubic metres of sawnwood, of which $99 \%$ was coniferous timber. 1.3 million tonnes of softwood is processed at panel sawmills providing 3 million cubic metres of panel products. The remaining $30 \%$ of soft and hardwood is delivered to pulp mills, used in the round, used for fencing, exported or used as woodfuel. The latter of which, highlights a rapidly increasing market for homegrown timber with $9 \%$ of softwood and $74 \%$ of the hardwood processed as woodfuel, an increase of $900 \%$ for softwood and $266 \%$ for hardwood in the last 10 years. This is by far the fastest increasing demand on UK grown timber.

\begin{tabular}{|c|c|c|c|c|c|c|}
\hline & \multicolumn{6}{|c|}{ UK apparent consumption of wood and wood products } \\
\hline & \multicolumn{2}{|c|}{$\begin{array}{l}\text { UK roundwood consumption } \\
\text { (thousands tonnes) }\end{array}$} & \multirow{2}{*}{$\begin{array}{l}\text { UK sawmill } \\
\text { production } \\
\text { (thousand } \mathrm{m}^{3} \text { ) }\end{array}$} & \multirow[t]{2}{*}{$\begin{array}{l}\text { Product imports } \\
\text { (thousand } \mathrm{m}^{3} \text { ) }\end{array}$} & \multirow[t]{2}{*}{$\begin{array}{c}\text { Exports } \\
\text { (thousand } \mathrm{m}^{3} \text { ) }\end{array}$} & \multirow{2}{*}{$\begin{array}{c}\text { Apparent } \\
\text { consumption } \\
\text { (thousand } \mathrm{m}^{3} \text { ) }\end{array}$} \\
\hline & UK grown & imported & & & & \\
\hline \multicolumn{7}{|l|}{ Sawnwood } \\
\hline Coniferous & 6407 & 126 & 3536 & 5101 & 146 & 8491 \\
\hline Non-coniferous & 74 & 13 & 46 & 393 & 19 & 420 \\
\hline Total & 6481 & 139 & 3581 & 5494 & 164 & 8911 \\
\hline \multicolumn{7}{|c|}{ Wood-based panels } \\
\hline Veneer sheets & - & - & 0 & 24 & 2 & 22 \\
\hline Plywood & - & - & 0 & 1374 & 58 & 1316 \\
\hline Particleboard & - & - & 1 & 790 & 229 & 2837 \\
\hline Fibreboard & - & - & 756 & 774 & 143 & 1388 \\
\hline Total & 1263 & - & 3032 & 2963 & 432 & 5563 \\
\hline \multicolumn{7}{|c|}{ Paper \& paperboard } \\
\hline Total & 465 & - & 4561 & 5921 & 1120 & 9362 \\
\hline
\end{tabular}

Fig 3.5 UK apparent consumption of wood and wood products

With a focus on sawnwood, that would generally be used in construction, in 2013 the UK produced $42 \%$ of the sawn softwood market and $11 \%$ of the sawn hardwood market. ${ }^{17}$ The total production of sawnwood from UK grown timber in the UK was $41 \%$ which can also be classed as an indicator of the self-sufficiency of the UK, as based on the calculations by Papodopoulos and Karagouni in $2002^{18}$ that listed the UK's sufficiency at $24 \%$ placing the UK 17th in a list of the $25 \mathrm{EU}$ partners. This demonstrates an improvement of $16 \%$ since 2002. Although this is still significantly lower than the overall European sufficiency rating of $93 \%$ in 2002 that was expected to reach $100 \%$ by $2030 .^{19}$

In 2004, in response to the increasing importation of softwood by the secondary processing industries, BRE undertook a study in conjunction with Stewart Milne Timber Systems Ltd, for the Forestry Commission, to compare home grown and imported softwood for the timber frame market. The study evaluated the relevant properties of the softwood and tested sample panel assemblies. The report concluded that'...UK grown timber is well-suited to timber frame panel manufacture, although economic factors and company policy may count against its uptake. ${ }^{20}$ Key findings in the comparison highlighted:

16 Forestry Commission, Forestry Statistics 2014, p.41

17 ibid, p.89

18 loannis Papadopoulos, Glykeria Karagouni, 'European Timber Trade Analysis: An Economical Overview and Regional Market Potential', International Workshop, Larnaka, Cost Action E34 "Bonding of Timber" 2007 (p.6)

19 ibid, p.9

20 Cedric Wilkins, Comparison of home grown and imported softwood for Timber Frame market Final Report, (Watford: BRE report 215-340, 2004) p.34 
- Both softwoods showed low levels of distortion, although the quantity of compression wood in the home grown sample caused a greater tendency to distort in bow and spring when drying;

- Home grown softwood had a $60 \%$ higher area of knots with an average knot size $12 \%$ larger than the imported softwood; ${ }^{21}$

- The homegrown timber was better in compression due to the higher proportion of knots, but this could cause greater nail fouling; ${ }^{22}$

- Shrinkage related to moisture content, was minimal in both samples due to the restraint offered from panel construction; ${ }^{23}$

Turnover of Manufacturing Industries in the UK 2012

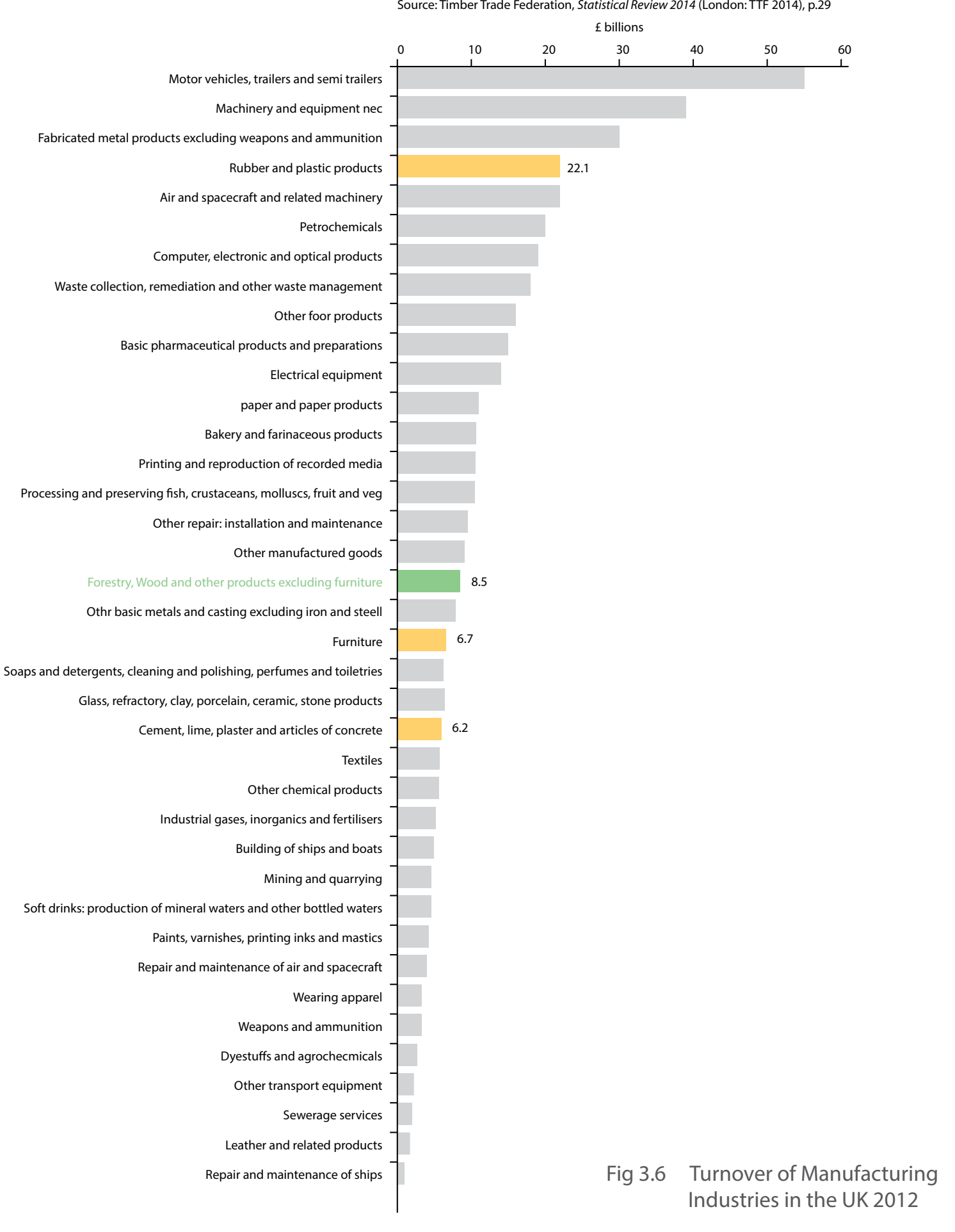

- Stewart Milne Timber Systems were not willing to fabricate panels with UK softwood in full scale structures due to current supply chain discounts on imported timber. ${ }^{24}$

\section{Timber procurement and supply chain}

The UK forestry, wood and other products industry in 2012 was increasing in line with national economic recovery and worth $£ 8.5$ billion, performing well against the rubber and plastics, furniture, cement, lime, plaster and concrete industries. ${ }^{25}$

The Welsh timber industry is a thriving sector with a wide breadth of expertise from suppliers, sawmills and manufacturers producing round timber, pulp and paper, sawn timber, low-grade products such as fencing, packaging and pallets, biomass, boards and high-value added products for construction and furniture. However, 2013 employment figures published by the Welsh Government have shown a decrease of up to $20 \%$ since 2008 now at: ${ }^{26}$

\footnotetext{
715 businesses within all sectors of the timber industry;

8500 people were employed across all sectors;

- 3200 people were employed in the primary and secondary sectors;

- 3900 people were employed within the pulp and paper sector;
}

21 ibid, p.19

22 ibid, p.34

23 ibid, p.32

25 Timber Trade Federation, Statistical Review 2014: Industry Facts and Figures for the Year 2013, (London: TTF 2014), p.27

26 Forestry Commission Wales, Woodlands for Wales Indicators 2013-14 (Cardiff: Welsh Government, 2014) 
The gross value added (GVA) for the three main sectors of the timber industry in 2013 were: ${ }^{27}$

- Forestry \& harvesting - $£ 19.9$ million

- Manufacture of wood and products of wood $-£ 147.7$ million

- manufacture of paper and paper products- $£ 288.1$ million

- Total GVA - $£ 455.7$ million

However, while the potential for the supply chain is significant the reality is that ${ }^{\prime} .$. there is a growing disconnection between the current Welsh resource and processing.'28 An example identified in a report for BRE Wales and the Low Carbon Research Institute (LCRI) highlighted that one of the largest timber wholesalers in the UK, Premier Forest Products in Newport, sells no Welsh timber, while many manufacturers also rely almost exclusively on imported timber, unless specifically specified to be Welsh.

Although the Welsh market is dominated by imported timber there is potential to increase production when considering the lower environmental impact and lower transportation costs that a homegrown supply would create. However, many producers are yet to develop long-term market strategies, while profitability within the transportation and harvesting sector leads to negative impacts and a loss of economy of scale. ${ }^{29}$ To make an effective use of the Welsh supply chain the procurement of materials and services will need to be actively sought by those making the decisions. The supply chain, with its typically small scale businesses lacks confidence from the customers, designers and specifiers with the industry often unable to guarantee long-term or large-scale supply. This problem is exacerbated by public procurement rules which prohibit the specification of a source of any products in building contracts, promoting value for money through open and fair competition within the whole European market. ${ }^{30}$ Therefore the current timber industry must demonstrate sustainable practices from forest to product, compete on cost with European counterparts and prove availability, in order to be considered.

A report prepared in 2011,'Integrated Strategies for the Welsh Timber Industry' considered the cost of C16 homegrown timber against C24 imported timber using average prices from Premier Forest Products and Welsh sawmills and suppliers. While the comparison would need further analysis, in relation to specific building

27 Forestry Commission Wales, Woodlands for Wales Indicators 2013-14 (Cardiff: Welsh Government, 2014), p.39

28 Jaakko Poyry Consulting, p.8

29 Jones, p.27

30 Ivor Davies, Sustainable Construction Timber: Sourcing and Specifying Local Timber, (Edinburgh: Forestry Commission Scotland, 2009), p.23 
typologies to generate accurate figures, it demonstrated that the imported C24

timber is generally $11 \%$ cheaper than the $\mathrm{C} 16$ homegrown timber in the construction of buildings up to $40 \mathrm{~m}^{2}$ and almost $19 \%$ cheaper for buildings between 400 $4000 \mathrm{~m}^{2} .^{31}$

In comparison with Scandinavian countries the scale of supply and processing is very small therefore a competitive advantage must be found through greater levels of innovation across the whole industry. The development of a highly integrated supply chain would utilise the strengths of individual parts of the industry and in doing so would provide a framework for innovation, enable the development of high-value products and significantly increase value along the chain. The solution is neither led bottom-up or top-down but as a combination of all sectors working within Wood Knowledge Wales. The Jaakko Poyry report summarised this through the suggestion of a 'Welsh franchise' and that 'The emerging Welsh forest industry is able to consider, over time, a highly integrated chain from resource to end-user, due to; the current strong secondary wood businesses, the opportunity to establish a high value resource, and the proximity to major markets, in particular the UK. This structure will have neither the single focus on secondary wood businesses, such as the Danish furniture, nor the predominance of primary processing such as Nordic countries, Scotland and New Zealand. It will be unique to Wales...' ${ }^{32}$

Furthermore a closer integration of the supply chain would make it possible to develop a zero wood wastage strategy, enabling the unused or recycled material from one process as raw material in another to generate value-added products. BSW at Newbridge-on-Wye, have indicated that there is a $42 \%$ wastage in the conversion of roundwood to sawnwood alone. This type of approach would ensure that all the timber is maximised passing the increased revenues back through the industry to the foresters. However, a clear approach and understanding of the entire supply chain at all sectors is required to create strategic alliances for the flow of material. Kronospan in Wrexham currently use $60 \%$ recycled fibres in the manufacture of chipboard with the capacity to increase this, but many other possibilities exist including the manufacture of wood-fibre insulation. Bere Architects and BRE Wales identified three factors to sustain a long-term integrated supply chain: ${ }^{33}$

- Increased collaboration and communication between all sectors:

- Investment in the long-term evolution of the industry; and

- Focus on adding value through the supply chain, rather than just increasing the volume of output.

31 Thomas Stoney Bryans, Integrated Strategies for the Welsh Timber Industry, (Cardiff: LCRI 2011), p.21 32 Jaakko Poyry Consulting, p.3

33 Bryans, p.16 


\section{G 7 ( \\ Wosh woodands and toress}

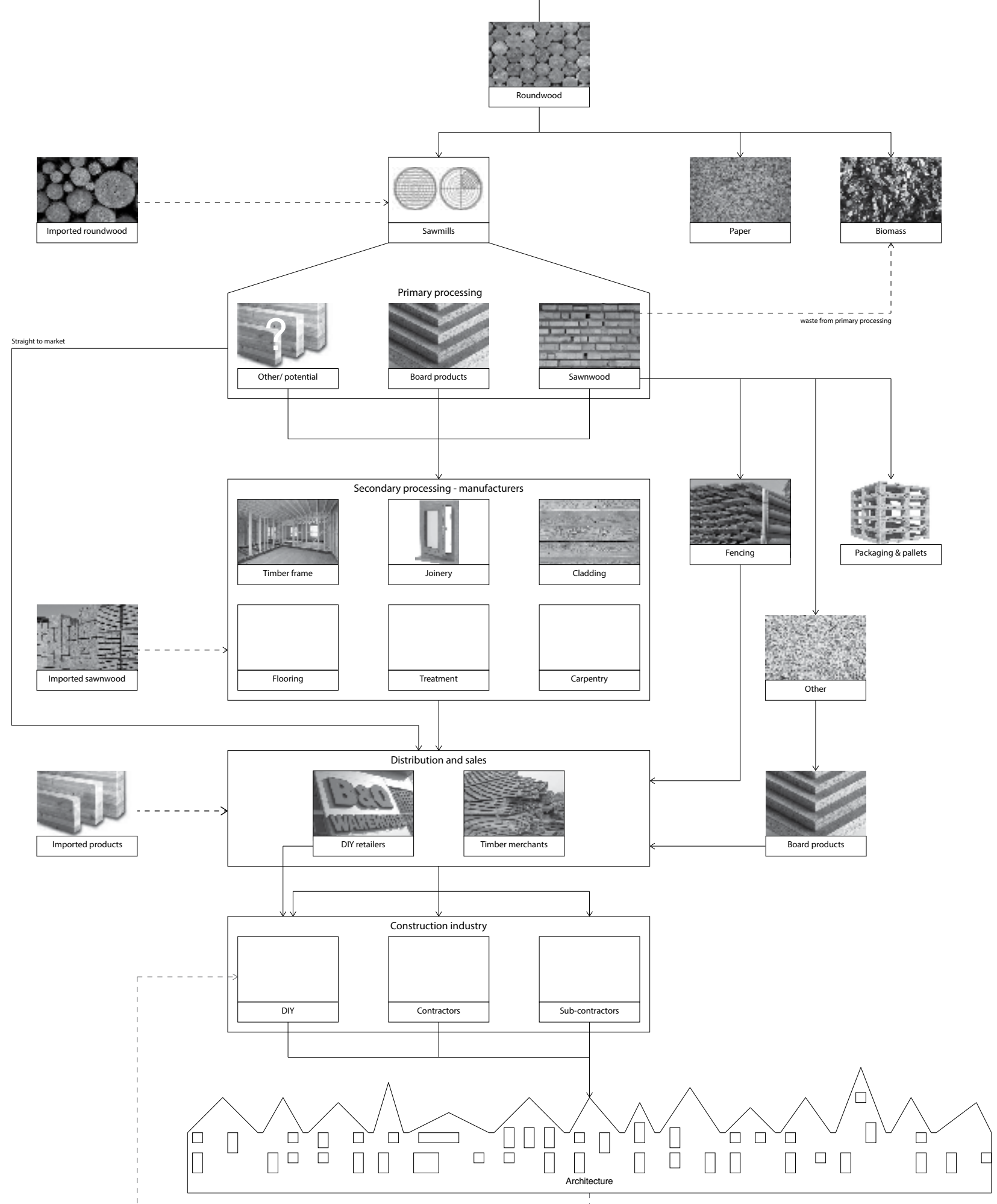

$i_{\text {nasside }}$

Fig 3.7 Welsh timber supply chain from forest to end-user
The following diagram illustrates the current flow of the Welsh timber supply chain from forest to end-user, with the focus on the primary and secondary sectors. These stages of the supply chain are described in more detail to highlight opportunities and barriers to the use of Welsh-grown timber.

\section{Forest owners and harvesting}

The Welsh forestry sector, including the forest owners, management and harvesting of timber, is characterised by long established family owned businesses with a generally rural base. However, while $62 \%$ of the total Welsh woodland and forests is in private ownership, the sector only contributes $42 \%$ of the total harvested timber delivered to sawmills for processing. Whereas the largest ownership group within Wales, the Forestry Commission is providing $58 \%$ of which $86 \%$ is coniferous timber with the privately owned contributing predominantly broadleaf species. ${ }^{34}$ The largest private owner, accounting for $25 \%$ is UPM Tilhill managing approximately 13000 hectares of woodland harvesting 120000 tonnes of roundwood per annum. Such is the current demand for Welsh grown timber, that some private owners have brought forward harvesting by one year in order to benefit from higher prices.

Whilst this represents the current understanding of timber, it does not necessarily represent the amount of material available, or used by Welsh businesses. Many of the timber species actually listed within the table represent timber species of little or no commercial value when considering potentials within the construction sector. Among these 'unsuitable' timber species are hybrid larch and lodgepole/ Corsican pine. Thus there is an immediate reduction in potential production of around $10 \%$ of the harvestable area. Further reductions may also be due to accessibility. Annually the Forestry Commission is currently harvesting 689000 green tonnes timber per annum within Wales, with an estimated 501000 tonnes available from private woodlands.

Current forecasts suggest that the volume of timber available will continue to rise until 2020 with the private sector gradually increasing its contribution to eventually providing more than the public sector. However BRE Wales in their 'Bridging the gap' study does not see a greater supply of material from the private sector becoming accessible in order to cover some of the projected shortfall in Welsh timber supply

34 Forestry Commission, Forestry Statistics 2012, p.38-9 
under present forestry practices, since many of the private resources are present in 'micro-stands', where extraction and delivery to small, local or larger, regional sawmills are financially unacceptable under present conditions. ${ }^{35}$

These provide valuable employment opportunities for local communities. Some of these enterprises are also involved in the management of the smaller and widely diverse native woodlands.

The decisions chosen by forest owners and the management of Welsh woodland and forest is largely governed by the end market for the harvested timber as much as the climatic considerations of which species grow best where. The demand for timber products can change fairly rapidly as fashions, politics and environmental agendas shift, however the speed at which the forest sector can change is limited by the yield and rotational classes for different species of tree, ie. the speed at which a tree is grown to an appropriate height and girth before it is ready for processing for use. Different uses will demand a different performance and therefore age of the tree. This is further exacerbated by forest owners understandably seeking a reliable and regular source of market to ensure that the trees they plant will still be in demand when harvested many years later. As such, long term and consistent industries such as paper, pulp, fuel and low grade construction uses such as fencing are now reliable markets for foresters to cater for. However this will also mean that specific timber species will continue to be grown even when the industry previously demanding that species ceases to require the timber. An example is the mining industry, where Sitka spruce pit props were a reliable product resulting in large Sitka spruce plantations with a reasonable yield class of 14cubic metres per hectare per year from the 1960s to date. Since the closure of the mines the growth and management of Sitka spruce has continued with the paper and pulp industries taking over the use of this species providing a reliable turnover of Sitka spruce with a higher market value found in the export of Sitka spruce wood chips and fibres by UPM Tilhill to Austria and Finland as feedstock into the paper industry. ${ }^{36}$

The Review of the Welsh Timber Resource, by BRE Wales, further highlights the biomass element to the timber processing industries that produce and process wood-based fuels from forest residues. Over time the bio-mass application of timber, with its lower carbon emissions than fossil fuels, will considerably add to the portfolio of opportunities for Welsh timber. However it is important to ensure that higher quality material capable of providing high added-value be reserved for these markets. This will mean some degree of timber selection at the forest gate. ${ }^{37}$

37 Dennis Jones, Review of the Welsh Timber Resource, (Cardiff: LCRI 2011), p.27 
Hardwoods, on the other hand, have a much longer rotation-cycle of between 80 -120 years, meaning that the decision of what to grow is not an immediate one but a generational decision. However, with only oak and sweet chestnut offering a durable timber species and as long as softwood remains the preferred structural material,

hardwoods and therefore indigenous Welsh species are likely to be marginalised. This was seen between 1930 and 1970, when hardwoods went from the leading species planted at 20000 hectares per year to just 4000 hectares per year corresponding with a rise in softwood planting from 4000 hectares per year to a peak of 38000 hectares per year.

For construction use, this reliability is made more difficult by the fluctuations of the economy. During times of economic prosperity the industry has the potential to turnover large volumes of timber for a variety of construction uses, however during periods of economic downturn, the demand for timber can virtually grind to a halt leaving the foresters out of pocket and needing to find alternative markets. The problem is therefore that the construction industry may find that the timber available, when required, does not meet the performance requirements needed and must turn to imported timber which means there is little influence on the foresters to change their practice. The timber available generally remains low value and poor quality for construction industry use. The result is often that the construction industry must adapt its processes to work with Welsh-grown timber, rather than the other way around.

While it is not the intention of this thesis to focus on and determine the business of forest management, the outcomes of which species are available to work with now, which species will be available in 10-20 years time and which species are actually best to use in construction equates to demand from the construction industry that must be put into economic perspective with the demands from other timber processing industries. Can value be added within the construction industry to provide a reliable market for the growth of specific timber species and/ or qualities? 
Primary wood processing is the most connected aspect of the supply chain. It is critical for the rest of the industry that primary wood processing is competitive and efficient as it provides the majority of the stumpages to the forest owners and produces the products that are essential for the following stages in the industry. The better the performance of this group in supplying a high quality product to the next stage, the higher the profitability.

The majority of primary wood, or roundwood, delivered to sawmills in Wales is Sitka spruce, with limited amounts of Douglas fir and Norway spruce being co-processed and marketed as 'whitewood'. Specialist processing of some of the lesser species previously listed is only undertaken by the small sawmills, for niche market/ personal use. The roundwood is processed through quarter- or plain-sawn and prepared for market as follows:

- sawn into large format boards for sale to the secondary processing industry;

- sawn and planed into standard section sizes for sale to the construction industry as structural timber;

- rough sawn as fencing grade timber;

- rough sawn for pallet making and packaging;

- kiln and/ or air dried ready for use in construction;

- strength and appearance graded.

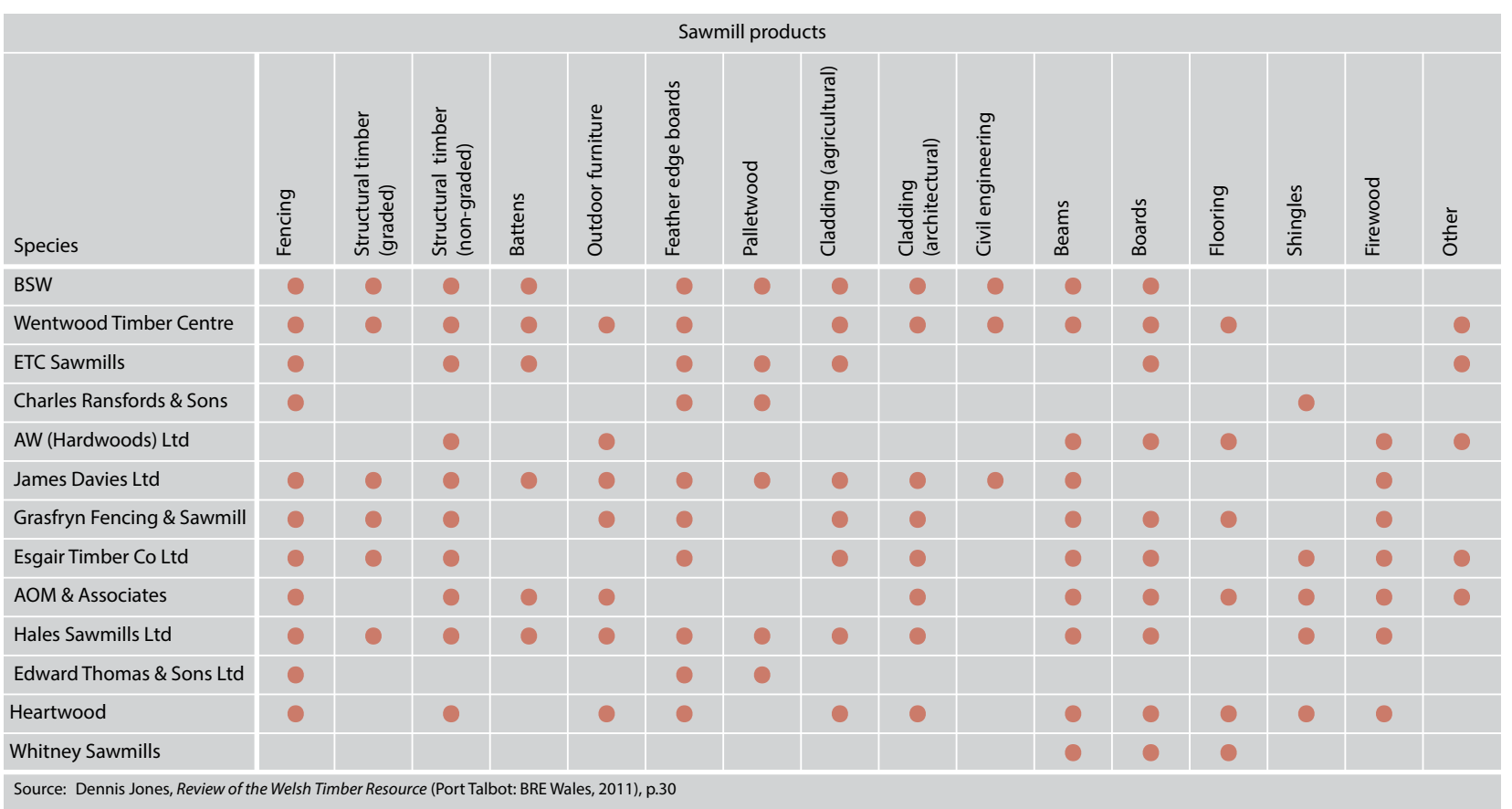

Fig 3.8 Sawmill products

Many of the sawmills also provide finished products for sale, such as exterior cladding and fencing timber. However, the sawmills have the potential to generate further channels to market with a better utilisation of Welsh-grown timber, through the production of engineered wood products, where there is a European forecast for the continual growth in the production of glue-lam, I-joists and Laminated Veneered Lumber (LVL). This competition with European whitewood imports will have an add-on cost to the timber product, which may take its sales price above that of the material currently being imported. Such actions would need to be carefully assessed when forming a business case for these new methods of processing. 'If the large mills were persuaded to invest in new processes (e.g. laminated timber) enabling them to add value to Welsh timber, there are risks: should imports become more attractive (due to a strengthening Pound) before the use of Welsh timber in construction becomes better established, the benefits to our woodland management from these technologies could be lost. ${ }^{38}$

38 Rob Marsh, Woodland Management in Wales: Recent research and implications for policy, (Wales Forest Business Partnership), p.10 

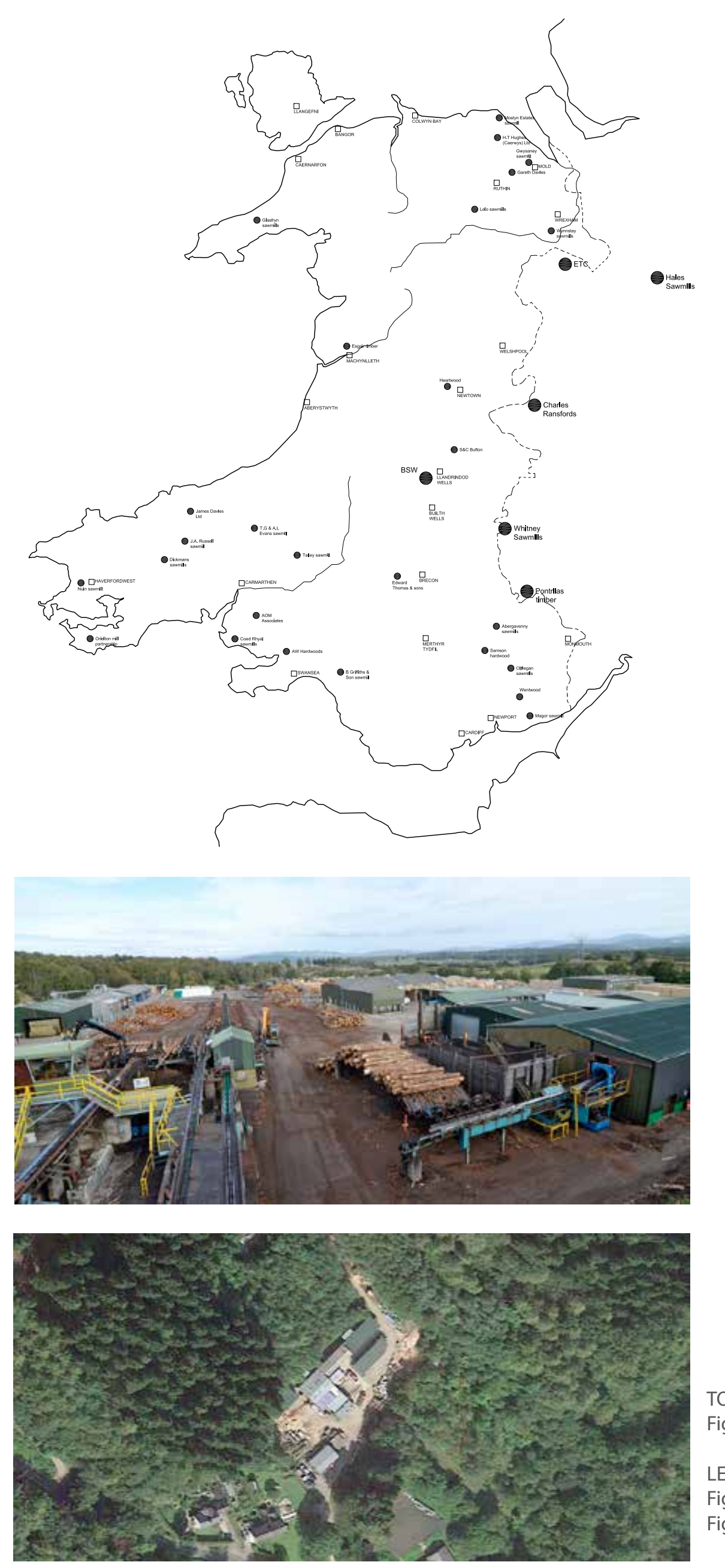

TOP

Fig 3.9 Sawmill locations in Wales

EFT

Fig 3.10 BSW sawmill

Fig 3.11 Aerial view of Wentwood Timber Store
The current scale of the Welsh sawmills varies widely from the large sawmills such as BSW, at Newbridge-on-Wye, to the small, private estate saw mills, such as Mostyn Sawmill in North Wales, producing individual crafts or more bespoke products for market. The following map identifies the majority of large and small scale sawmills currently operating in Wales and also a cluster of large sawmills on the English side of the Wales-England border which also process large quantities of Welsh-grown timber and as such have a significant impact on the processing and supply of Welsh-grown timber for the construction industry in Wales.

The map highlights that the majority of sawmills are located in rural areas, often near to the woodland and forest that the timber is sourced from. Four clusters can be identified:

- South-west small specialist sawmills;

- South-east small specialist sawmills;

- North-east small specialist sawmills; and

- The large sawmills of the border regions and mid-Wales

The location of the sawmills near to the woodlands would seem a logical location, with reduced travel distances from woodland to sawmill. The largest sawmills are evenly and strategically positioned to be within close proximity to woodlands and centres of population to supply sawnwood to the secondary processing industries. However, the majority of the smaller specialist sawmills are located long distances from the cities and major towns which, in most cases, would offer the most reliable market for their products. As highlighted by Poyry, these aspects of the industry are characterised by small, family-run companies carrying out their own deliveries with their market defined by a daily round trip of approximately 65 miles. This would explain the significantly low production and market share of these sawmills.

In the case of BSW, a strong supply chain has been established with forest owners, secondary markets and opportunities for direct marketing to the construction industry. BSW have taken the decision to concentrate on a limited range of products, such as $\mathrm{C} 16$ graded boards of $47 \mathrm{~mm}$ thickness. Based on their commitment to deliver this product, BSW have established long-term marketing strategies with major outlets, so ensuring a strong price for their product. This strong position, meets the demands of a reliable market and therefore suggests that there is no need to change the marketing policy for Welsh-grown timber. Whilst there is a strong market for $47 \mathrm{~mm}$ boards, there is also a high demand for smaller sized material, typically $38 \mathrm{~mm}$ boards. It would be possible to produce more of the smaller dimension boards from a standard volume of material, but varying the production between two differing 
dimensions may have affects on both markets, for example saturating the $38 \mathrm{~mm}$ board market, whilst limiting supply of $47 \mathrm{~mm}$ boards. ${ }^{39}$

Recent fluctuations in currency rates and rapid increases in the price of oil have led to several imported sources of timber becoming cost comparable to home-grown equivalents. This has led BSW to re-evaluate the sizes of timber produced, and to begin creating a range of 'Easi' products, as an equivalent to the Canadian Lumber Size (CLS) in ungraded and unseasoned sizes of $38 \mathrm{~mm}, 47 \mathrm{~mm}$ and $75 \mathrm{~mm}$ thicknesses for use in formwork and purlins and graded and treated finished sizes of $19 \mathrm{~mm}$, $25 \mathrm{~mm}, 38 \mathrm{~mm}, 45 \mathrm{~mm}$ and $72 \mathrm{~mm}$ for battens, studwork and decking. ${ }^{40} \mathrm{CLS}$ is one of the more commonly used sizes of timber within the construction industry, thus its manufacture within Wales should realise a greater share of the construction market for home-grown timbers.

Further to sawnwood, there is also a large wood panel business, in Chirk, that both processes small roundwood, along with recycled wood, as fibres to manufacture particleboard and MDF. This is the only wood panel business in Wales and as such is highlighted by the Jaakko Poyry report as a concept that '...should be of interest to Wales'.41 OSB and plywood are not currently manufactured in Wales.

\begin{tabular}{|c|c|c|}
\hline \multicolumn{3}{|c|}{ Wales and UK production of softwood sawnwood and other product markets } \\
\hline Product & UK & Wales \\
\hline Sawnwood production & \multicolumn{2}{|c|}{ thousand cubic metres } \\
\hline All sawmills & 3536 & 349 \\
\hline Large sawmills & 3170 & 329 \\
\hline Softwood markets & \multicolumn{2}{|c|}{$\%$ of total product markets } \\
\hline Construction & 29 & 22 \\
\hline Fencing & 34 & 27 \\
\hline Packaging/pallet & 32 & 48 \\
\hline Other & 5 & 3 \\
\hline $\begin{array}{l}\text { wood processing industries as } \\
\text { bark, wood chips \& sawdust }\end{array}$ & (61) & (78) \\
\hline bio-energy & (21) & (5) \\
\hline $\begin{array}{l}\text { other industries for bark, wood } \\
\text { chips \& sawdust }\end{array}$ & (17) & (10) \\
\hline
\end{tabular}

Fig 3.12 Wales and UK production of softwood sawnwood and other product markets
Whilst there are a range of sawmills across Wales dealing specifically with hardwoods, often these are small family-run businesses. Many of the suppliers of hardwood stock limited supplies, so there can be a considerable turn- round time for delivery on an order, given the long periods of time for air drying hardwoods. This often means that manufacturers of products from hardwood depend on imported materials. There are a few companies producing a range of products, though they often indicate difficulties in the supply chain. Groups such as Coed Cymru are active in helping regenerate and manage hardwood forests, though these are often less than 2 hectares. Through this regeneration, more hardwood is slowly becoming more available on the marketplace and thus more products are being manufactured.

The following table demonstrates the markets currently provided for, by the largest sawmills in Wales (that is sawmills producing at least 10000 cubic metres of sawnwood per year) with only $23 \%$ of the Welsh softwood processed at the largest Welsh sawmills used within the Welsh construction industry compared to a UK average of $29 \%$. The majority of Welsh sawnwood is used for fencing, packaging and pallet making.

39 Jones, 2007, p.32

40 BSW Timber Group, Easi-timber, <http://www.easi-timber.co.uk/construction/> [Accessed 10th August 2015]

41 Jaakko Poyry Consulting, p.44 
While the primary processing can be seen as a vital link between the forests and timber products in terms of underpinning the supply chain, the secondary processing adds the majority of value to wood products and is therefore the largest sector of the Welsh timber industry. The Woodlands for Wales report acknowledges that 'Wales already has a track record of investment and innovation in developing new uses for wood and acting as an early adopter for new technologies developed elsewhere. ${ }^{122}$ However, the Jaakko Poyry report, in relation to a comparison with Denmark, identifies the following targets to further improve the Welsh secondary processing industry: ${ }^{43}$

- create competitiveness;

- develop a market shift from supply push to demand pull;

- create a culture of design, possibly with the development of a 'design school':

- the creation of a leadership group to promote the industry.

Since 2004, only the leadership group (Wales Forest Business Partnership) has been established, with a demand pull slowly emerging, but meeting resistance from the supply chain or material performance which further highlights the lack of knowledge coming from the designers, specifiers and consumers. There have been a number of attempts to create and promote competition within the manufacturing sector, such as a recent attempt to promote a standard Welsh Passivhaus window, by BRE Wales, that would be manufactured by a consortium of 5 or 6 different joinery businesses. However, the industry tends to be very independent with isolated, hand-to-mouth decisions made by each business which has led to only one manufacturer making the approved Passivhaus window with little demand for it.

In relation to this thesis, the secondary processing of timber in Wales is focused primarily on the businesses involved with the conversion of sawn timber from the sawmills into end products for sale in the construction industry for use in the building envelope. That is for use in timber frame manufacturing, window and door joinery, carpentry, claddings/ finishes, floorings and furniture.

As previously identified, in $2013,65 \%{ }^{44}$ of Welsh felled conifers was processed in Wales contributing to $79 \%$ of the total roundwood processed at Welsh sawmills. $22 \%$ of the sawnwood produced is used within the Welsh construction industry,

42 Forestry Commission Wales, Woodlands for Wales: The Welsh Assembly Government's Strategy for woodlands and trees (Cardiff: Welsh Assembly Government, 2009) p.37

43 Jaakko Poyry Consulting, p.54

44 Forestry Commission Wales, Woodlands for Wales Indicators 2013-14 (Cardiff: Welsh Government, 2013) p.36 
which equates to $14 \%$ of the total Welsh timber felled. Approximately $42 \%$ of the UK turnover of sawnwood used by secondary processors was sourced within the UK, with the rest imported. The data for Wales highlights that $68 \%$ of businesses in Wales are sourcing timber from abroad with $88 \%$ of the timber used in secondary processing imported. ${ }^{45}$ Anecdotal evidence from timber frame manufacturers, joiners and general contractors suggest the reasons for this vary, including: cost, perceived quality, structural grade, long term supply chains with importers, sizes, reliability and market perception. The Wood Forest Business Partnership has reported that 'timber buyers stated that price is the main consideration when sourcing timber (52\%) followed by quality (35\%) and availability (21\%).46

In 2007, BRE Wales surveyed 26 timber frame businesses to ascertain the volumes of Welsh-grown timber sourced and the different structural grades used. The results highlighted:

- a difficulty in identifying exact levels of Welsh-grown timber due to complexities within the supply chain.

- $80 \%$ of businesses had not attempted to source Welsh-grown timber.

- The total turnover volume of softwood by all business was $64693 \mathrm{~m} 3$.

- Of the total volume of softwood used by these businesses, $51 \%$ was C16 softwood; $15 \%$ was C24 and 33\% TR26.

- A number of businesses suggested that may use Welsh-grown timber if supplied at $38 \mathrm{~mm}$ thickness rather than the $47 \mathrm{~mm}$ typically supplied by BSW and others.

Similar to the wider timber industry, the secondary processing businesses are generally small, family owned and run with a low turnover. The directors and managers are usually actively engaged in the day to day running of the business with little time to consider diversification or research and development. The businesses have a range of woodworking skills, with the medium to large scale businesses offering apprenticeship schemes that encourage new people into the industry, however the manual skills are usually basic carpentry and joinery with limited skills in the more complex traditional joinery/ craft. Whereas the small businesses often offer a high level of craftsmanship producing traditional carpentry and joinery generally to the conservation market. The craft of the larger secondary businesses, from timber frame panel manufacture to window joinery, involves a set of machine oriented processes and assembly rather than physical craft which has improved efficiency and output but has generally reduced the skill base available in Wales from which

45 Forestry Commission Wales, Woodlands for Wales: The Welsh Assembly Government's Strategy for woodlands and trees (Cardiff: Welsh Assembly Government, 2009) p.38 


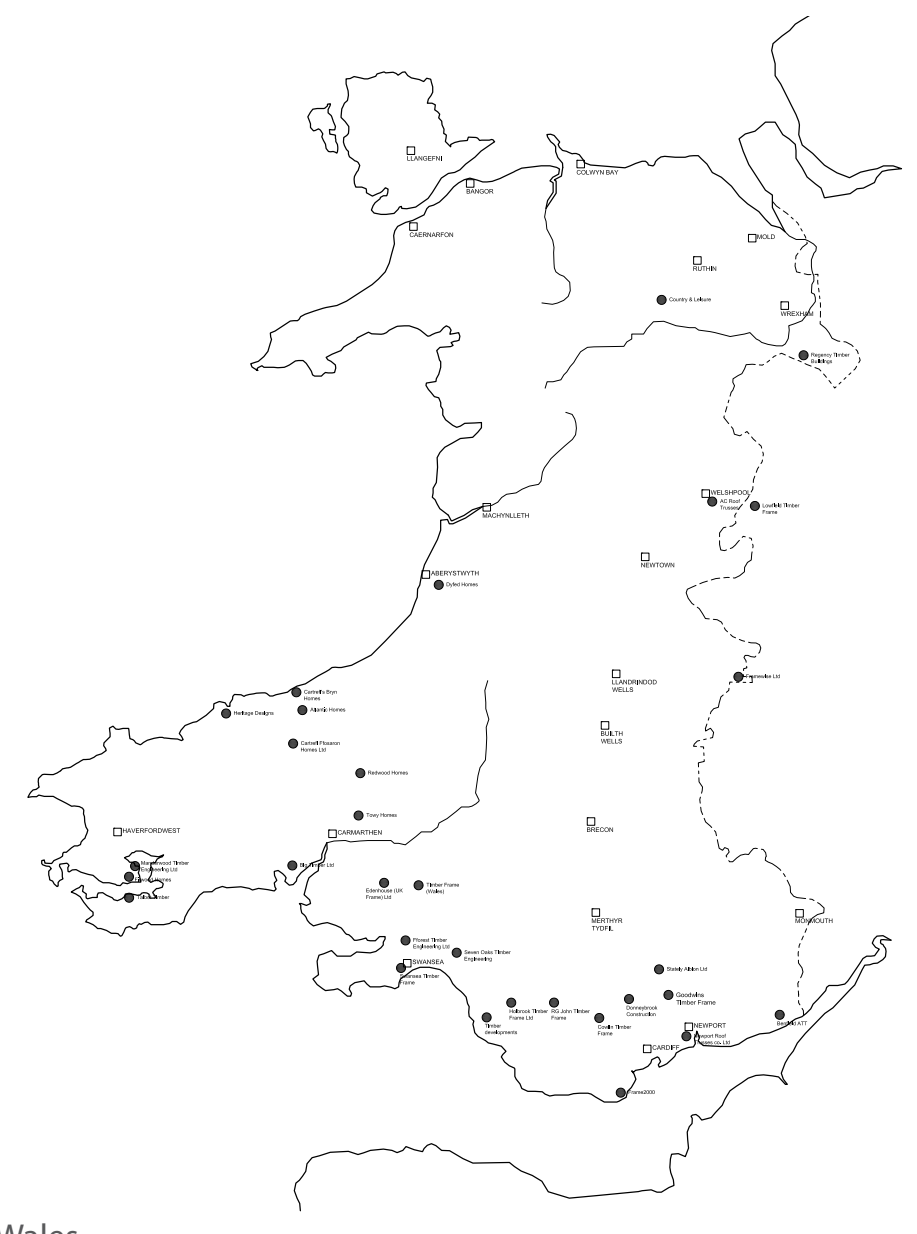

Fig 3.14 Timber frame businesses in Wales

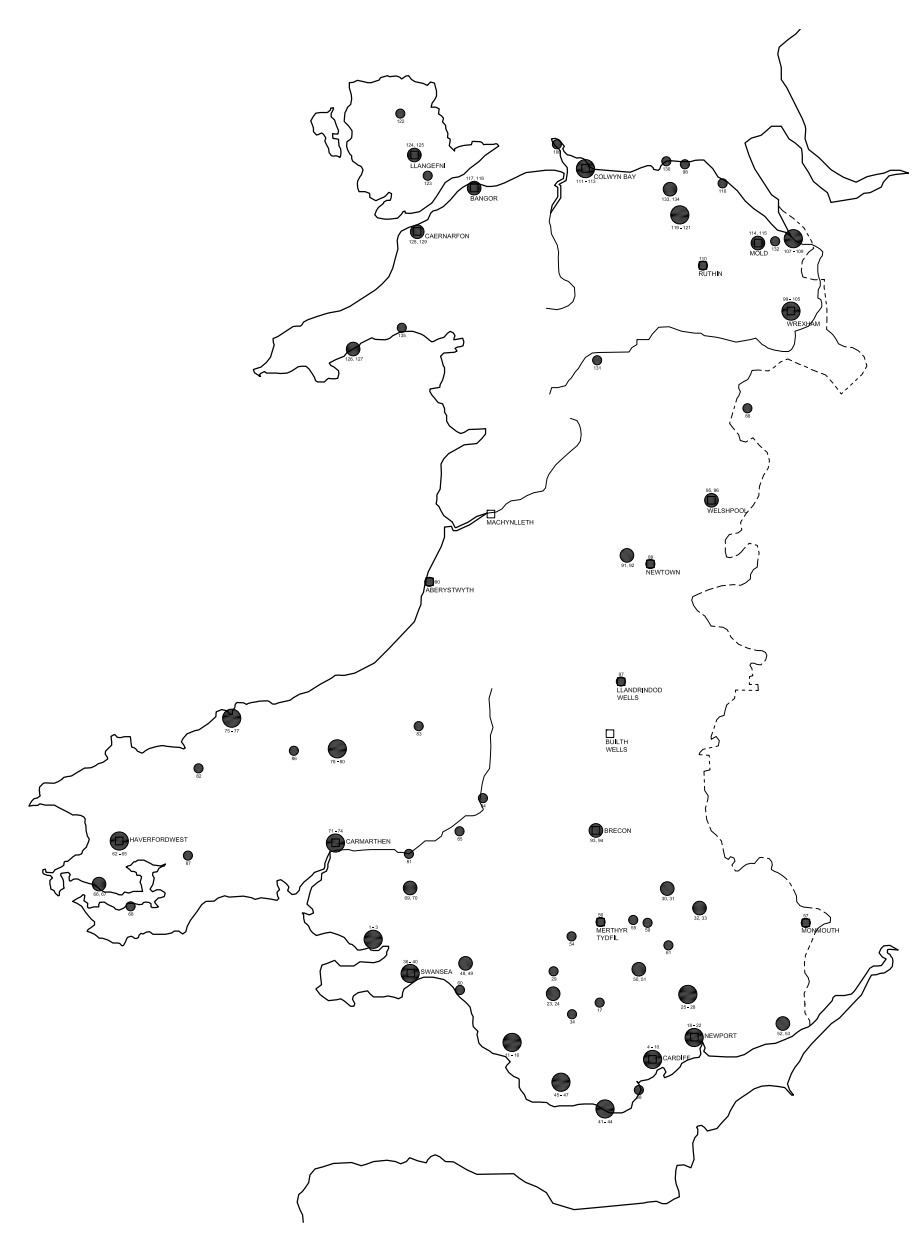

the industry developed. On the other hand, the majority of products demanded by the construction industry today are prefabricated, modular with high expected performance requirements, increased quality and reduced time which will only put further pressure on the industry to mechanise and therefore de-skill.

It could therefore be argued that the timber industry in Wales is low skilled with an increasing reliance on a low-medium level of technology/ plant in comparison to the leading timber industries in Europe. The majority of businesses have the standard machinery to cut, plane and profile timber for a wide range of uses, but only a limited number of the larger businesses also have more bespoke machinery to process, grade and cut timber for timber frame panels in large quantities. Some are considering or have begun investing in technology to enable the production of closed and advanced timber panels, while some have a small press to produce small scale laminated joinery products such as windows and doors. No businesses in Wales have the highly bespoke and costly plant readily seen across Europe to manufacture Glu-lam posts and beams, Cross-Laminated Timber (CLT), Laminated Veneer Lumber (LVL), Laminated Strand Lumber (LSL) and Brettstapel, although some businesses are investigating methods to make some of these systems as test products with Welsh timber using the limited tools available. These will not be commercially successful, though, without the investment in the specialist technology which makes the process efficient and will therefore always remain as bespoke, high-cost products for niche markets.

Alternative products that are not currently manufactured in Wales may increase the dependence on machinery and the further loss of traditional skills.

\section{Timber construction}

This section is focussed on the current uses of timber in construction, in Wales. The section begins with an overview of the background and current primary use of timber in the construction industry - timber framed housing, to identify the scale of the sector. This is followed by an evaluation of the market share timber frame has within the house building sector. This is concluded with a review of how timber is used within a typical new-build house to highlight the level of skill required and technological advancement.

In the early 1980 s, $27 \%$ of new housing in the UK was timber framed finished with an outer skin of brick. However a World in Action documentary, broadcast on ITV in 1983 , presented a critical review of timber frame construction leading to a crash in 

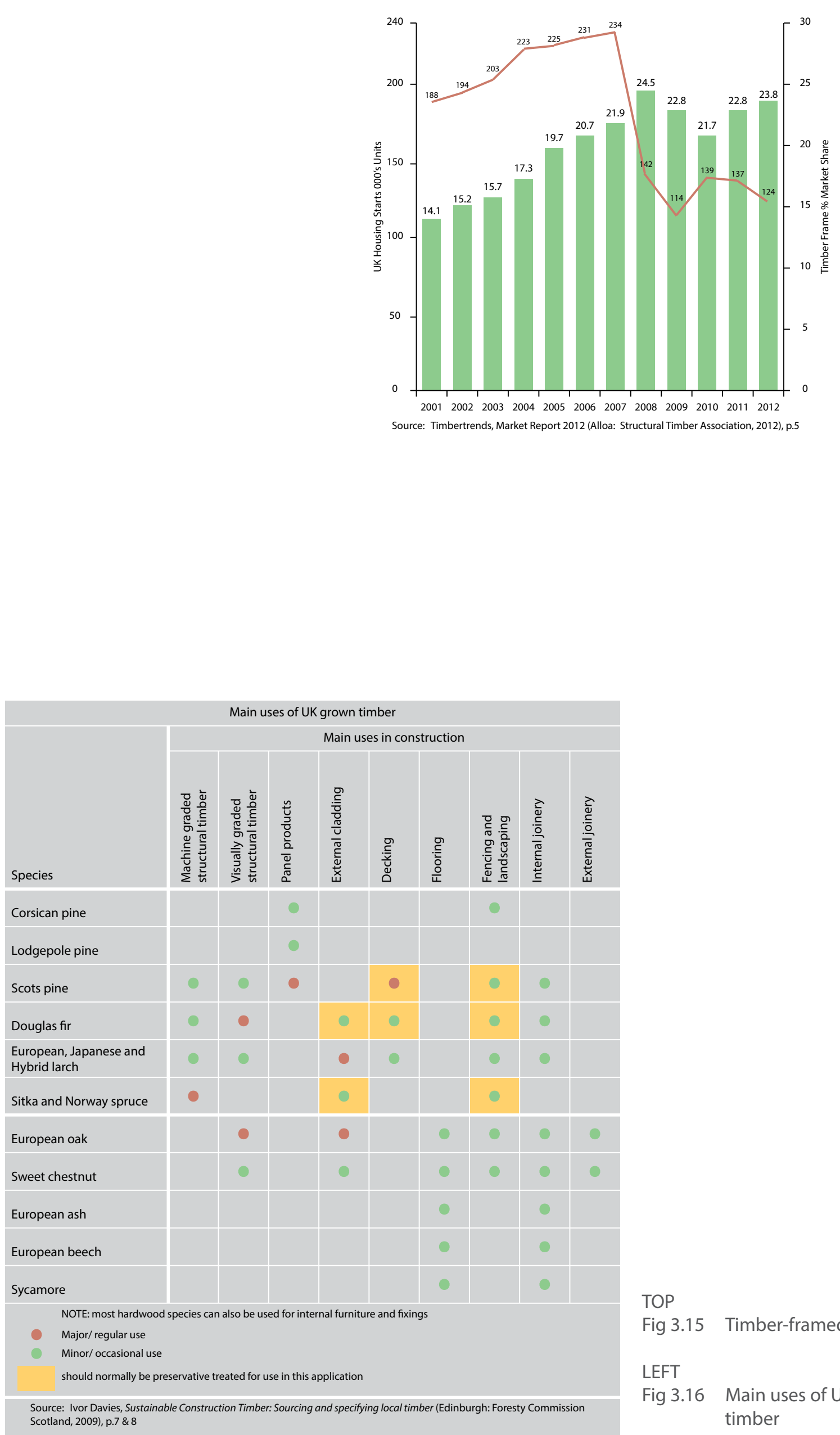

TOP

Fig 3.15 Timber-framed Housing LEFT

Fig 3.16 Main uses of UK grown timber timber-framed housing to just $3 \%{ }^{47}$ Using hidden cameras, the programme alleged poor workmanship and quality control and that '...timber-frame construction could not produce houses that would last, citing rot in the frames of nine-year-old homes on a Cornwall estate. ${ }^{\prime 48}$ It went on to also report that timber frame was at a higher fire risk than other forms of non-timber construction highlighting a fire at a Barratt home. Barratt Homes stopped using timber frame construction methods for over 20 years. ${ }^{49}$

By 1998 the market share had reached 8\%, with investment and innovation remaining slow to pick up until a number of reviews highlighting the cost and time advantages of Modern Methods of Construction and the environmental sustainability benefits of timber re-ignited interest. 2012 market share statistics, prepared by Timbertrends for the Structural Timber Association (STA), previously the UK Timber Frame Association (UKTFA), shows a significant increase in market share of new build housing with timber from $14.1 \%$ in 2001 to $24.5 \%$ before the financial crash in 2008. This is now increasing again with the economic recovery with market share in 2012 at $23.6 \% .{ }^{50}$ In Wales this stands at $26.6 \%$ with an overall growth in timber frame construction of $60 \%$ since $2008 .{ }^{51}$

\section{Timber construction in Wales}

The following tables highlight the current general uses of softwood and hardwood in the UK construction industry and a range of products manufactured with UK timber. Both could be seen as a reflection on the uses of Welsh-grown timber. The table only includes a limited selection of products, primarily produced by the sawmills, with only a few products created within the secondary processing sector. The table also demonstrates the dominance of the softwoods for use in all categories, while the hardwoods are primarily limited to interior uses due to their poor durability characteristics coupled with long yield times, limited availability and higher costs. Therefore only oak and sweet chestnut are currently used in external building envelope situations, while Sitka spruce, the larches and Douglas fir are used for almost every use.

47 Julian Owen, Kit and Modern Timber Frame Homes: The Complete Guide (Marlborough: The Crowood Press, 2007) p.16

48 Nancy Cavill,'Timber's back in the frame', Issue 31, 1999, <http://www.building.co.uk/timber8217s back-in-the-frame/4474.article> [accessed 22nd August 2015]

49 Josephine Smit,'20 years after World in Action, Barratt goes back into prefab', Issue 30, 2003, <http://www.building.co.uk/news/finance/20-years-afetr-world-in-action-barratt-goes-back-into prefab/1030087.article> [accessed 22nd August 2015]

50 Timbertrends, Market Report 2012 (Alloa: Structural Timber Association, 2012) p.6 51 ibid, p.7 
Based on these these tables and the volume of timber frame housing construction that is likely to be the primary use of timber in Wales, the following common uses of timber in construction can be identified:

- Ground and intermediate flooring - Commonly using C16 or C24 treated softwood as a suspended ground or intermediate floor with a chipboard or plywood floor surface nailed to the joists ready for the internal floor finish. Limitations on the use of Welsh timber arise when larger spans or a reduced joist depth is required. Flooring provides and ideal opportunity for the use of the Welsh-grown hardwood, especially oak, ash, sycamore and sweet chestnut which are typically impact resistant and durable.

- Timber framed walls - typically used as both load bearing and non-load bearing structure in the building envelope of housing and small commercial and public buildings. Current use is primarily limited to two different principles: high-skill, bespoke and costly post and beam structures usually of oak; and prefabricated, open softwood framed panels used in platform frame construction.

- Roof structure - timber is the preferred material for domestic scale roof construction either: erected on-site by skilled carpenters as a cut roof comprising rafters, purlins, braces and ties; or prefabricated as softwood trusses spanning up to $18 \mathrm{~m}$ using imported TR26 graded whitewood.

- Cladding - Facing brickwork and rendered blockwork account for the majority of new-build external wall finishes in Wales, often with little regard to the construction behind. Imported western red cedar has often been the first and default choice for many architects and specifiers because of its natural durability, stability benefits over oak and appearance. Oak, sweet chestnut, larch, Douglas fir and even Sitka spruce have started to be used more widely. ${ }^{52}$

- External joinery - The majority of external windows and doors fitted to buildings in Wales are manufactured from u-PVC. Until recently, the Welsh timber industry had not seized the opportunity with windows described by Pat Borer and Cindy Harris as inadequate with too small an air space between the glass panes, made from preservative treated timber and not well enough sealed to compete with imported low energy windows. ${ }^{53}$ Following research and development by Coed Cymru, there are now a few joiners manufacturing $100 \%$ Welsh-grown timber windows and doors from untreated larch, oak and sweet chestnut.

52 I. Davies, B. Walker, J. Pendlebury, Timber Cladding in Scotland, (Edinburgh: ARCA Publishing Ltd 2002)

53 Cindy Harris and Pat Borer, The Whole House Book: Ecological Building Design and Materials (Machynlleth: Centre for Alternative Technology 2005) 


\begin{tabular}{|c|c|}
\hline \multicolumn{2}{|r|}{ Construction Products made of UK Grown Timber } \\
\hline Product & Availability \\
\hline \multicolumn{2}{|l|}{ Structural timber } \\
\hline Machine graded structural timber & $\begin{array}{l}\text { Spruce (trade name whitewood) is available of the shelf graded to } C 16 \text {; no other softwoods } \\
\text { are routinely machine graded in the UK although larch, Douglas fir and Scots pine can be } \\
\text { produced as specials. hardwiod timber is not normally machine grded }\end{array}$ \\
\hline Visually graded structural timber & $\begin{array}{l}\text { Softwoods: Scots pine, whitewood, larch and Douglas fir can be visually graded to GS or SS } \\
\text { grades. } \\
\text { Hardwoods: Most hardwood timbers cannot be machine graded and so are graded by visual } \\
\text { inspection. Oak is the most common visually graded UK hardwood although others such as } \\
\text { sweet chestnut are sometimes available. }\end{array}$ \\
\hline \multicolumn{2}{|l|}{ Non structural timber } \\
\hline Carcassing & Whitewood is available off the shelf for uses such as non-loadbearing internal partitions \\
\hline Sarking, slating, laths \& battens & $\begin{array}{l}\text { Whitewood or other softwood timbers are widely available. They are normally preservative } \\
\text { treated for use where there is risk of wetting. }\end{array}$ \\
\hline Decking & $\begin{array}{l}\text { Preservative treated softwood decking is widely available. Oak and sweet chestnut can also } \\
\text { be supplied in parts of the UK. }\end{array}$ \\
\hline Windows & $\begin{array}{l}\text { Oak windows manufactured from UK timber are sometimes available. The timber used in } \\
\text { softwood windows is almost always imported. }\end{array}$ \\
\hline Flooring & $\begin{array}{l}\text { Strip flooring of oak, sweet chestnut, Iarch, Douglas fir and other timbers are available to } \\
\text { order in some parts of the UK. Endgrain flooring blocks are also available. }\end{array}$ \\
\hline External cladding and shingles & $\begin{array}{l}\text { Larch is the most common UK cladding timber although oak, sweet chestnut and western red } \\
\text { cedar can be used plus preservative treated Douglas fr, Scots pine and whitewood. } \\
\text { Availability varies. Shingles are available from a few suppliers. }\end{array}$ \\
\hline Specials eg. doors or stairs & Many other joinery components can be made as 'specials'. \\
\hline \multicolumn{2}{|l|}{ Panel products } \\
\hline MDF & $\begin{array}{l}\text { There are } 3 \text { UK manufacturers producing several products for non structural applications in } \\
\text { shop fitting, flooring, kitchen units etc. }\end{array}$ \\
\hline OSB & $\begin{array}{l}\text { There is } 1 \text { UK manufacturer producing } 4 \text { types of product. OSB is used for structural } \\
\text { applications such as sheathing, plus non structural products such as flooring. }\end{array}$ \\
\hline Particleboard & $\begin{array}{l}\text { There are } 4 \text { UK manufacturers making a range of products for flooring, kitchen units and } \\
\text { other non structural applications. }\end{array}$ \\
\hline \multicolumn{2}{|l|}{ Engineered wood products } \\
\hline I-joists & $\begin{array}{l}\text { There is one UK manufacturer of I-joists. The thin central element (the web) is made from } \\
\text { local OSB, whilst the top and bottom flanges are fabricated from imported C } 24 \text { softwood. }\end{array}$ \\
\hline Glulam & $\begin{array}{l}\text { There is currently no producer of standard glulam sections. A few will make 'specials' to order } \\
\text { using oak, sweet chestnut or other timbers. }\end{array}$ \\
\hline \multicolumn{2}{|l|}{ Other products } \\
\hline Pole rounded timber & A few firms produce pole rounded timbers for both structural and non-structural uses. \\
\hline Log buildings & Several firms make log buildings to order \\
\hline Landscaping and fencing & $\begin{array}{l}\text { Landscaping products such as bollards and acoustic barriers are produced plus fencing and } \\
\text { gates. They mainly use preservative treated softwoods. }\end{array}$ \\
\hline Bridges & $\begin{array}{l}\text { Both pedestrian and light vehicukar bridges are made from preservative treated larch, } \\
\text { Douglas fir or scots pine. Oak is also used. The designs available include beam bridges, stress } \\
\text { laminated arches and trusses. }\end{array}$ \\
\hline Civil and marine & Large section timbers are used for dock structures, canal gates etc. \\
\hline
\end{tabular}

Fig 3.17 Construction products made of UK grown timber
Skills vary from the highly skilled traditional carpenter to general contractors assembling prefabricated components.

\section{A Way Forward}

As discussed, the Welsh timber industry is diverse with a wide range, but limited level of expertise, suppliers and manufacturers through primary and secondary processing. Timber is already used for a wide range of uses both outside and within the construction industry. However, the majority of products are small-scale produced in low quantities to order with only a few businesses able to consistently manufacture on a larger-scale. The potential therefore exists, and is recommended by the Jaakko Poyry report, Wood Knowledge Wales and BRE Wales, to produced an even wider range of products, which if undertaken as part of an integrated supply chain could transform the industry and help develop a sustainable regional economy while also offering innovative products and expanding the potential use of Welshgrown timber. The range of products that could be considered are extensive, often subject to research and development, financial investment and should be considered in collaboration with end users, architects, engineers and specifiers to ensure a need and therefore demand exists.

The following table, based on research by BRE Wales, demonstrates a number of processes, products and components widely used and manufactured in Scandinavia, Germany, Switzerland, Austria and the Baltic states and often imported to the UK and Wales. As such consideration is given to the advantages, disadvantages and implications of manufacturing these in Wales. 
The analysis of the timber industry in Wales has shown a political and industry led desire to promote and develop forestry and processing for the greater good of the complete timber industry and the environmental, social and economic sustainability of Wales.

A number of barriers and opportunities have been identified that are of relevance to this thesis that may affect the use of Welsh-grown timber in the architectural building envelope. These findings, overlap and expand on those highlighted in the BRE Wales report 'Welsh timber resources and their potential within the construction industry.54

\subsubsection{Woodland supply and primary processing}

- Political drive to expand and develop forestry with a range of support from advisory, research, educational and industry-led organisations.

- There should be 'increased collaboration and communication between all sectors' of the industry. ${ }^{55}$

- The rotation cycles and yield class of varying species has a significant impact on the quality and quantity of timber available. Therefore, the decisions made by both public and private woodland owners to grow specific trees for target markets, that may not be related to the construction industry, means that the construction industry, including architects, must understand the properties of the available and forecast Welsh-grown timber to design with, construct with and add-value to.

- The current industry predominantly uses softwood led by the supply from public woodlands the processing at the dominant and largest sawmills and that used by the secondary processing industry. However, the vast majority of softwood used by the secondary processing sector is imported, with Welsh-grown softwood used for fencing, pallet making, pulp for paper and as biomass fuel.

- Current supply and production of softwood sawnwood is structurally graded at $\mathrm{C} 16$ to a range of standard sizes to maximise the potential of the crop and reduce defect cut wastage. Any deviation from these parameters will need to consider the implications on the whole supply chain to ensure value is added from woodland management to end user.

- The production and processing of Welsh-grown hardwoods has remained constantly and significantly lower than with softwoods, while the large scale 
importation of mainly tropical hardwood is increasing. Two durable hardwood timbers are grown in Wales that also offer superior structural properties. While the volume of hardwood available to use will always be limited, ${ }^{56}$ projections suggest the volume of hardwood available will increase from $20000 \mathrm{~m} 3$ to a peak of $299000 \mathrm{~m} 3$ between $2042-2046$ before starting to drop off although, this does not necessarily equate to production of hardwood which is subject to demand, management objectives and processing. This does suggest, however, a real potential to use more Welsh grown hardwood.

- $\quad 83 \%$ of primary processing businesses in Wales source their timber from within Wales. The majority of Welsh timber is used in Wales, the production of sawn softwood is increasing as is the self-sufficiency - there is demand and slowly this is being met more and more with homegrown. ${ }^{57}$

\section{Secondary processing and construction}

- The secondary processing industry imports approximately $88 \%$ of the softwood used predominantly in the manufacture of timber frame panels, roof trusses and joinery. ${ }^{58}$ This is despite demonstrable evidence that home grown timber performs as well as imported timber. Reasons given refer to costs of homegrown timber, established supply chains with import markets and perceived need to specify C24 softwood in timber frame construction.

- It has been highlighted by Jaakko Poyry Consulting that a wood panel industry should be of interest to Wales. MDF and chipboard is manufactured in Chirk, north Wales, but there are no plywood manufacturers.

- The industry is competent from hand craft skills up to the manufacture of standard mass market products, but is limited in its economic ability to further research and development into innovative timber products. Neither does the scale of the industry and level of investment available indicate that technology and training will increase to compete with European counterparts. However, this is not seen as a problem, but an opportunity to develop Welsh specific innovations.

- The secondary processing businesses are currently using low - medium technology. Any innovation will need to work with the medium level of machinery and skills currently available to ensure viability on grounds of cost, quality of workmanship, time and allow for replicability.

56 Forestry Commission, Forestry Statistics 2014, p.49

57 Forestry Commission Wales, Woodlands for Wales Indicators 2013-14 (Cardiff: Welsh Government, 2014), p.38 


\begin{tabular}{l|l|l|}
$\begin{array}{l}\text { Technology \& } \\
\text { Skills }\end{array}$ & processing & general manipulation \\
& C1 & primary \\
\hline & tools \& plant & hand crafted/ hand tools \\
\hline & C2 & operative controlled \\
\hline & fabrication \& \\
construction & on-site \\
\hline & off-site \\
\hline & low-tech (DIY) \\
\hline C & C3 & contractor (general) \\
\hline
\end{tabular}

Findings to take forward

- Add value to existing homegrown species to create a reliable demand from the construction industry that allows foresters to continue to work with a broad range of industries rather than 'putting all its eggs in one basket'. Consider the implications of timber processing throughout the supply chain.

- Any innovations with Welsh-grown softwood must work within standard sawn sizes and $\mathrm{C} 16$ or involve innovation beyond these limitations.

- Consider the use of Welsh-grown hardwood.

- Designing with wood panel products.

- Consider low-medium technology designs and innovations to ensure the use of Welsh-grown timber manufactured within Wales with medium level machinery and basic manual skills.

- $\quad$ Large parts of the secondary processing industry are set up for off-site prefabrication and timber frame manufacturing.

Having evaluated Welsh-grown timber from the woodlands and individual species to construction products, the key findings are considered, in the next chapter, in relation to the architectural building envelope. 


\section{CHAPTER 4 \\ The Building Envelope}


In the previous chapters a review of the woodland and trees and the supply chain of timber processing industries has identified: the properties of a number of Welshgrown species within the woodland crop for use in construction; a will and need to promote Welsh forestry and timber processing; and opportunities and limitations in the skills, technologies and products throughout the industry. In this chapter, the incorporation of timber in the design and construction of the architectural building envelope is reviewed.

The diversity and range of products manufactured using timber has been highlighted in chapter 3 , suggesting the building envelope offers the greatest potential for an architect to exploit the potential use of Welsh-grown timber. The inclusion of timber and timber products in the building envelope is dependent on a wide range of parameters affecting on the one hand form and composition and on the other technical performance. An identification of the principle elements of the building envelope will therefore be followed by an appraisal of the general building performance characteristics, incorporated into the Building Regulations, that all designs must comply with. The evolution of these performance characteristics are considered in the context of the use of timber to meet increased environmental and construction based performance.

Based on these performance requirements, a review of the specific use of timber within different methods of timber construction and components of the building envelope will identify where and how timber may be incorporated in architectural design.

A selection of contemporary buildings, incorporating timber as a significant part of the building envelope are presented as a source of precedent for the design and construction of innovative timber architecture. These will demonstrate the use of timber across a wide variety of building products, components and elements that meet a range of technical and design aspirations.

The chapter ends with findings on the categorisation of components to study further and the key performance requirements that may influence the selection of timber species, technologies and skills required or to be explored further. 
In this section a definition and the context of the term 'building envelope' is provided before highlighting the primary elements that will form the basis of incorporating and designing with timber in architecture.

The word envelope, derived from the French language, simply means 'wrapper, covering' and the act of envelopment is to 'wrap-up, cover and surround.' This act of covering or wrapping is a useful analogy but the effective building envelope has to deal with a set of complex requirements way beyond the literal use of the term 'envelope'. In fact the environmental dimensions of architecture places demand on the building envelope to operate as a mediator or filter between outside and inside conditions. The increasing performance requirements of buildings, the needs and expectations of building users plus the real concern for sustainability means that the design of the contemporary building envelope is more challenging than ever.

'To survive for even a few days we need air to breathe, water to drink, earth...on which to stand and, in certain countries, fire... to resist the dominance of climate over the exposed human body... A person may fulfil these functions in a building, even some form of primitive hut, which should improve the conditions of survival. The building forms a system of barriers, filters, containers - sometimes condensers - for an enormous collection of materials and energies which affect that site, that building, that person.'

The most basic performance requirement of the building envelope is to provide shelter, from the weather; security and warmth and a comfortable internal environment. 'However successful the architecture, if the roof leaks, the wind whistles through ill-fitting windows, and the interior environment is uncomfortable it has failed its primary requirements of providing shelter from the elements'.4 The local climate plays a key role in establishing the functions of the different elements of the building envelope that are necessary to meet these performance requirements. Within the context of Wales, the building envelope needs to respond to a 'temperate-oceanic' climate, the warm wet Atlantic system results in a windy country with a changeability of weather and a regular freeze thaw cycle, this can be lethal to building materials and the finishes of the external skin of the building. ${ }^{5}$

\footnotetext{
1 Della Thompson (ed.), The Pocket Oxford Dictionary, (Oxford: Clarendon Press 8th edition, 1992) p.290$$
2 \text { lbid, p.290 }
$$$$
3 \text { Steven Groak, The idea of building, (London: E \& FH Spon, 1992) p.21 }
$$$$
4 \text { William Allen, Envelope Design for Buildings, (Oxford: Architectural Press, 1997) p.ix }
$$ 
This section introduces an identification of the principle elements of the building envelope. 6 elements of the building envelope are detailed, as adopted and condensed from Principles of Element Design ${ }^{6}$ that focus on the aspects that provide structure and enclosure. These elements are based on a traditional approach to architecture as an enclosure of space that provides 'comfortable shelter, without hazard and provide an alternative environment to the outside which is health-promoting and enables a range of activities to take place. ${ }^{17}$

\section{- Foundations}

- the dead, live and wind loads of the building are transferred into the surrounding and supporting ground conditions through the foundation system.

- Foundations are primarily constructed from concrete in the forms of strip, pad, raft or piles.

\section{- Ground floors}

- must provide a level surface capable of supporting the ground floor activities and internal non-loadbearing structure whilst also preventing moisture from entering and heat being lost from the building. ${ }^{8}$

- Walls

- External walls: usually required to support the dead, live and wind loads of the roof and floor construction.

- subjected from the outside to wind and rain, as well as affected by fluctuating temperatures, noise and radiation. From inside to outside the wall has an impact on temperature gradient, air convection, sound transmission and water vapour diffusion.

- Must provide levels of thermal and acoustic insulation, as well as weather proofing and protection from fire and spread of fire.

- The material and design of the external wall will play a large part in the overal appearance of the building. ${ }^{10}$

- Internal walls: can be loadbearing or non loadbearing or acting as lateral restraint from racking depending on the overall structural strategy of the building and will be used for fixtures and fittings.

6 Peter Rich \& Yvonne Dean, Principles of Element Design (Oxford: Butter-Heinemann, 1999) 7 Ibid, p.xiii

8 Derek Osbourn, Mitchell's Building Series: Introduction to Building, (Harlow: Addison Wesley Longman Limited, 1997) p.186

9 Ludwig Steiger, Basics: Timber Construction, (Basel: Birkhauser, 2007) p.55

10 Osbourn, p.195 
provide physical space separation within a building, in turn providing privacy and security as well as providing protection against noise and fire. ${ }^{11}$

- may also need to provide sufficient thermal insulation to protect heat loss to other areas.

\section{- Intermediate floors}

- provide a level surface with strength to support the dead

and live loads of that floor. May also be required to provide lateral restraint between the external walls. ${ }^{12}$

- Will be required to provide a degree of fire, thermal and acoustic separation particularly as a party floor between spaces of different ownership or tenure.

\section{- Roof}

- $\quad$ must provide protection from the weather, wind rain and snow, as well as solar gains and insulate the building from the external environment and prevent heat loss. Defence for the occupants against fire and protect its spreading..$^{13}$

- Roof are generally flat or pitched/mono-pitched. Flat roofs can also provide additional functions such as roof terraces/gardens above. Roof can be short, medium or long span.

- Windows, Doors, Rooflights

- to provide natural light, ventilation and views in and out. Admit light, energy, fresh air and sunshine, and can change the feel and quality of a space, based on their proportions, framing materials and location. ${ }^{14}$

- Determine the accessibility of a building plan.

For the purposes of this thesis, foundations are omitted as essentially engineered structures with little potential for the use of timber and non-loadbearing walls and other internal elements are omitted as not contributing to the external performance and therefore subjecting the timber to parameters that would be demanding of the timber properties.

$$
\begin{array}{ll}
11 & \text { Steiger, p.71 } \\
12 & \text { Osbourn, p.215 } \\
13 & \text { Ibid, p.219 } \\
14 & \text { Rich \& Dean, p.150 }
\end{array}
$$




\begin{tabular}{|c|c|c|c|c|c|}
\hline & \multicolumn{5}{|c|}{ Building envelope performance requirements } \\
\hline & Requirement & Parameters & & Control approach & $\begin{array}{l}\text { Building Regulation } \\
\text { Approved Document }\end{array}$ \\
\hline 1 & Structural stability & $\begin{array}{l}\text { - Resist dead, live \& wind } \\
\text { loads } \\
\text { - Loadbearing/ } \\
\text { non-loadbearing }\end{array}$ & $\begin{array}{l}\text { - Seimic activity } \\
\text { - Thermal effects }\end{array}$ & $\begin{array}{l}\text { - substructure } \\
\text { - superstructure }\end{array}$ & Part A \\
\hline 2 & Weather proof & $\begin{array}{l}\text { - Protect from moisture } \\
\text { - Rain \& snow penetration } \\
\text { - Bulk water } \\
\text { - Capillary water }\end{array}$ & $\begin{array}{l}\text { - Vapour diffusion } \\
\text { - Air leakage }\end{array}$ & $\begin{array}{l}\text { - shedding/ rainscreen } \\
\text { - drainage } \\
\text { - storage and drying } \\
\text { - barriers/membranes }\end{array}$ & Part C \\
\hline 3 & Thermal comfort & $\begin{array}{l}\text { - Effective thermal } \\
\text { resistance } \\
\text { - Convection, conduction } \\
\text { \& radiation }\end{array}$ & $\begin{array}{l}\text { - Thermal bridging } \\
\text { - Air leakage }\end{array}$ & $\begin{array}{l}\text { - thermal insulation } \\
\text { - thermal mass } \\
\text { - radiation barrier } \\
\text { - air barriers }\end{array}$ & $\begin{array}{l}\text { Part L } \\
\text { Part J }\end{array}$ \\
\hline 4 & $\begin{array}{l}\text { Air permeability, } \\
\text { ventilation and air } \\
\text { quality }\end{array}$ & $\begin{array}{l}\text {-Stack and wind pressure } \\
\text {-Ventiation requirements }\end{array}$ & $\begin{array}{l}\text { - Trickle vents } \\
\text {-Air leakage }\end{array}$ & $\begin{array}{l}\text { - air barriers } \\
\text { - air tightness } \\
\text { - quality of workmanship } \\
\text { - opening details }\end{array}$ & $\begin{array}{l}\text { Part L } \\
\text { Part F }\end{array}$ \\
\hline 5 & $\begin{array}{l}\text { Lighting and } \\
\text { solar radiation }\end{array}$ & $\begin{array}{l}\text { - Control of sun \& day light } \\
\text {-Opacity/ emissivity } \\
\text { - Orientation }\end{array}$ & $\begin{array}{l}\text { - Control of solar gains } \\
\text { - Fenestration } \\
\text { - Shading }\end{array}$ & $\begin{array}{l}\text { - Orientation } \\
\text { - Fenestratition } \\
\text { - Shading devices } \\
\text { - Glazing properties } \\
\text { - Thermal resistance }\end{array}$ & Part L \\
\hline 6 & Fire & - Fire rating & -Combustibility & $\begin{array}{l}\text { - non-combustible } \\
\text { materials } \\
\text { - fire retadants/treatments }\end{array}$ & Part $B$ \\
\hline 7 & Acoustic & $\begin{array}{l}\text { - Airborne sound } \\
\text {-Conducted sound }\end{array}$ & -Vibration & $\begin{array}{l}\text { - acoustic insulation } \\
\text { - material selection }\end{array}$ & Part E \\
\hline 8 & Durability & $\begin{array}{l}\text { - UV degradation } \\
\text { - Corrosion } \\
\text {-Freeze/ thaw } \\
\text { - Abrasion }\end{array}$ & $\begin{array}{l}\text { - Biological attack } \\
\text { - Chemical attack } \\
\text { - Fatigue } \\
\text { - Efflorescence } \\
\text { - Instability }\end{array}$ & $\begin{array}{l}\text { - design } \\
\text { - material selection } \\
\text { - construction/detailing }\end{array}$ & $\begin{array}{l}\text { Part K } \\
\text { Part B } \\
\text { Part Q }\end{array}$ \\
\hline 9 & Security & $\begin{array}{l}\text {-Vandalism protection } \\
\text { - Blast/ballistic protection }\end{array}$ & $\begin{array}{l}\text {-Wind induced projectile } \\
\text { - Health \& Safety }\end{array}$ & $\begin{array}{l}\text {-material selection } \\
\text { - details } \\
\text {-opening design }\end{array}$ & $\begin{array}{l}\text { Part K } \\
\text { Part Q }\end{array}$ \\
\hline 10 & Cost & $\begin{array}{l}\text { - Capital cost } \\
\text { - Maintenance cost }\end{array}$ & $\begin{array}{l}\text { - Operating cost } \\
\text { - Life cycle cost }\end{array}$ & $\begin{array}{l}\text { - design } \\
\text { - material selection }\end{array}$ & - \\
\hline 11 & Appearance & $\begin{array}{l}\text {-Visual } \\
\text {-Experiential }\end{array}$ & $\begin{array}{l}\text { - Acoustic } \\
\text { - Tactile }\end{array}$ & $\begin{array}{l}\text { - design } \\
\text { - tectonic form }\end{array}$ & - \\
\hline
\end{tabular}

Fig 4.1 Building element performance requirements
'Sir Henry Wooten, a fifteenth-century humanist who adapted the writings of Vitruvius for his book, The Elements of Architecture (1624), wrote that a good building must satisfy three conditions:

Commodity: comfortable environment conditions

Firmness: stability and safety

Delight: aesthetic and psychological appeal'15

The basic requirements of the building envelope have changed very little since the earliest structures were erected to provide shelter, comfort and security. This is evident in the construction of the various buildings preserved at the St. Fagans Natural History Museum. While these do not meet contemporary requirements and regulations, careful consideration can be seen in the choice of structure, external finishes to exclude water, positioning of openings, orientation, source of heat, ventilation and details of sills, eaves, gables etc. that will have influenced and moderated internal conditions.

These considerations can be seen in the earliest attempts to regulate performance such as in the 1959 volume of Principles of Modern Building ${ }^{16}$ that identified a principle-based approach to 11 building performance characteristics in the UK. The headings of these individual performance requirements of the building envelope have changed very little over the last 50 years. However, the means and approach to the requirements have evolved, in particular those affecting climate and comfort.

The following performance requirements, therefore form the basis for considering the technical function of the building envelope: structural stability, weatherproofing, control of heat, control of lighting and solar radiation, control of ventilation and air permeability, fire protection, acoustic control, costs and durability. ${ }^{17}$ These are described further in the table opposite alongside the corresponding Building Regulation Approved Document and potential control strategies. It should be noted that they are not placed in order of importance as any one requirement may be more critical than another for a particular element, building or location. ${ }^{18}$

While all nine requirements offer guidance on the technical approach and performance of the building envelope, it is only as a collective that they are informed by and contribute to the orientation, form, composition and overall appearance of architecture. Considerations must be given to location, site context, climate,

15 Osbourn, p.4

16 Department for Research, Principles of Modern Building (London: HMSO 3rd edition, 1959) 17 Rich \& Dean, p.xi

18 Osbourn, p.4 


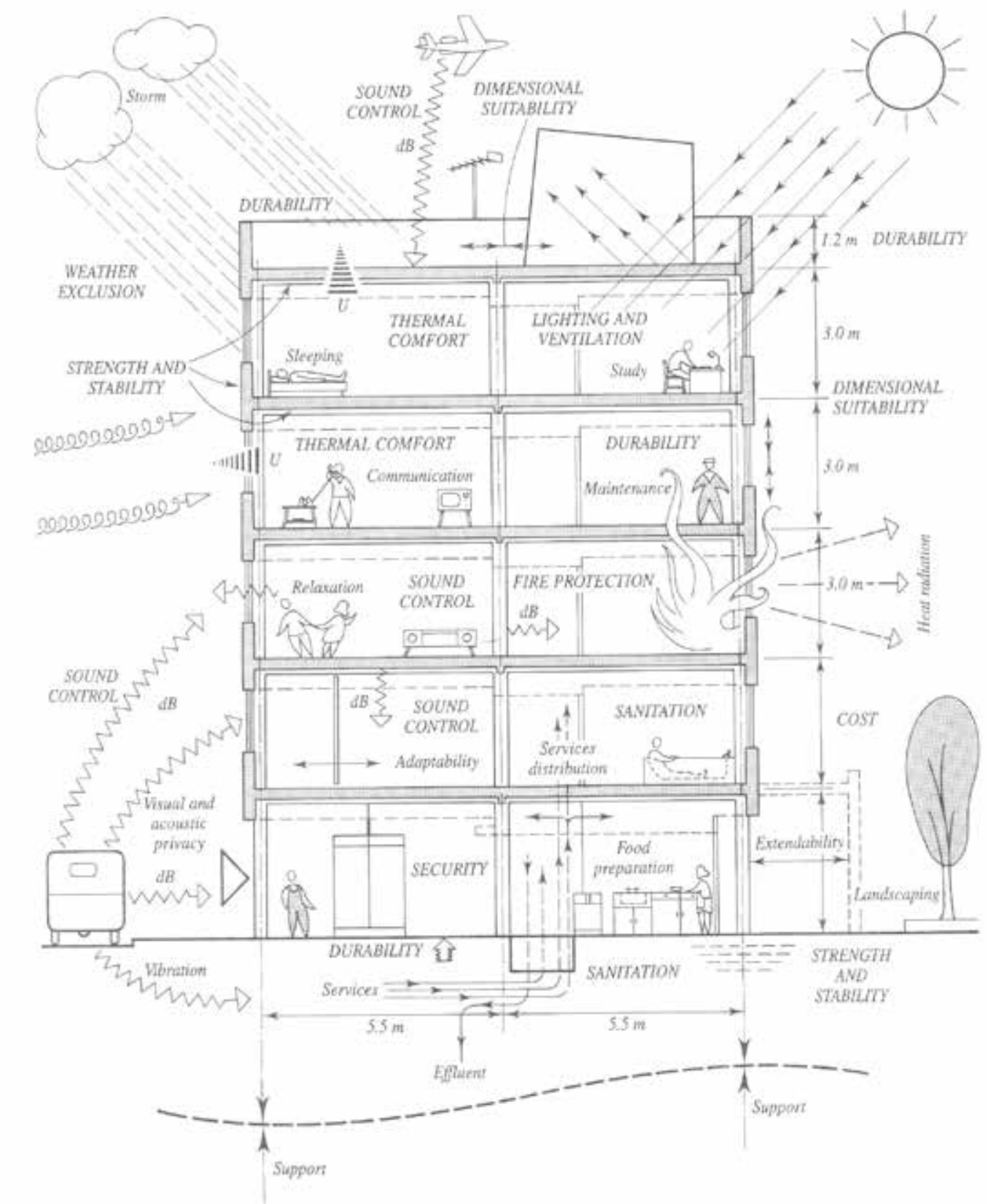

Fig 4.2 Diagram of the building envelope performance requirements culture, history, functional and experiential requirements that may influence any of the technical requirements individually but as a whole will provide a holistic response to architectural design. This was highlighted by Reyner Banham's review of the environmental performance of buildings and associated technology in an Architecture of the Well-Tempered Environment, in $1969 .{ }^{19}$ Instead of the envelope as a barrier, a holistic view was encouraged to consider the selective and adaptive skin that provided flexible environmental management.

Of these requirements, items 3, 4 and 5 in relation to environmental control, could be argued as having a significant impact on building envelope design.

The following sections highlight two developments/ movements within the UK construction industry that has had a significant impact on the design and construction of the building envelope and in particular the incorporation of timber: low - zero carbon design and Modern Methods of Construction (MMC). These could be seen as relating specifically to performance requirements $1,3,4,5,8$ and 10 .

\section{Low energy envelope}

'Climate change represents a potentially catastrophic threat, but it is within our control to address it - and address it we must 20

Over the last century, there has been a profound change between the relationship of the human world and the planet. Evidence of global warming is evident in regions al over the world, with the correlation between burning fossil fuels and global warming becoming ever more the likely cause. There have been many attempts to consider global sustainability initiatives. Perhaps the most influential was the Brundtland Commission report Our Common Future: the World Commission on Environment and Development, by the UN Environment Commission, in 1987, that introduced what is now a commonly accepted concept of a three dimensional sustainability:

- environmental;

- economic; and

- social.

The emphasis was no longer purely on energy conservation, and as such defined sustainable development as'... development that meets the needs of the present

19 Reyner Banham, Architecture of the Well-Tempered Environment (London: Architectural Press, 1969)

20 Secretary of State for Environment, Food and Rural Affairs, The UK Government Sustainable Development Strategy (London: HMSO 2005), p.3 


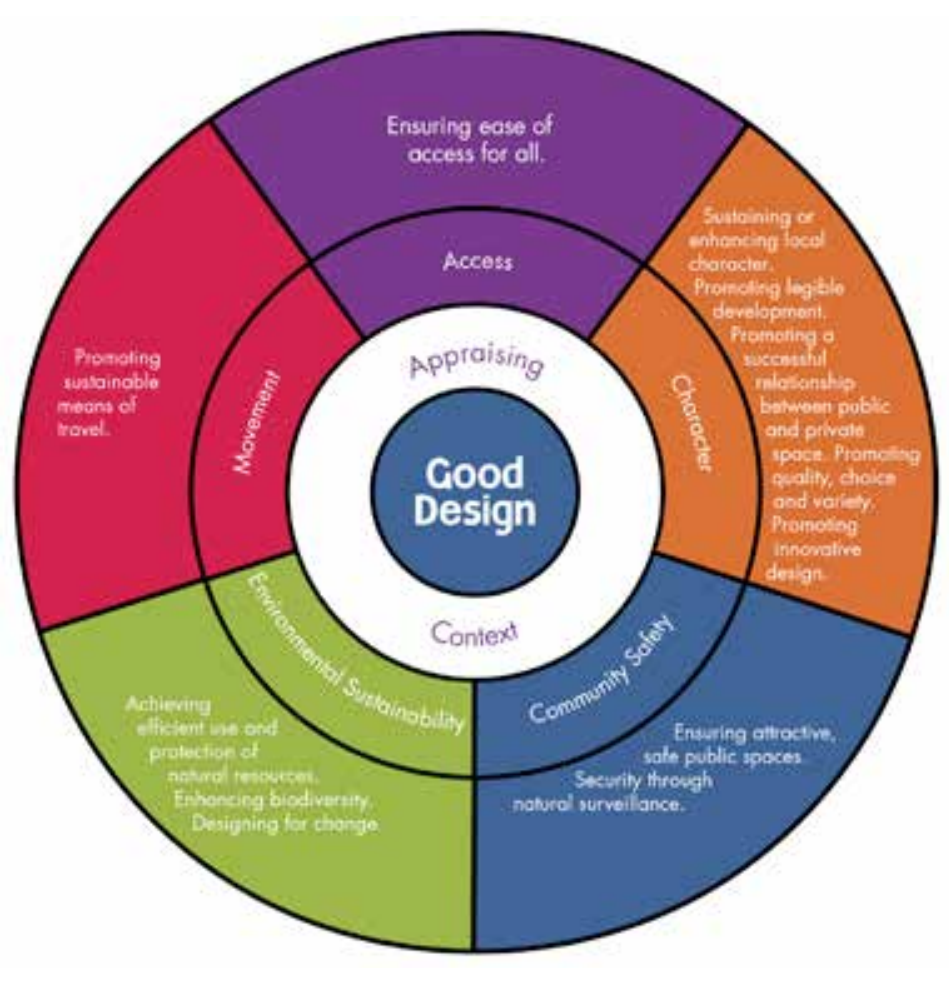

TOP - BOTTOM

Fig 4.3 Objectives of Good Design

Fig 4.4 Diagram of the elemental and layered Fig 4.5 Energy Hierarchy Diagram
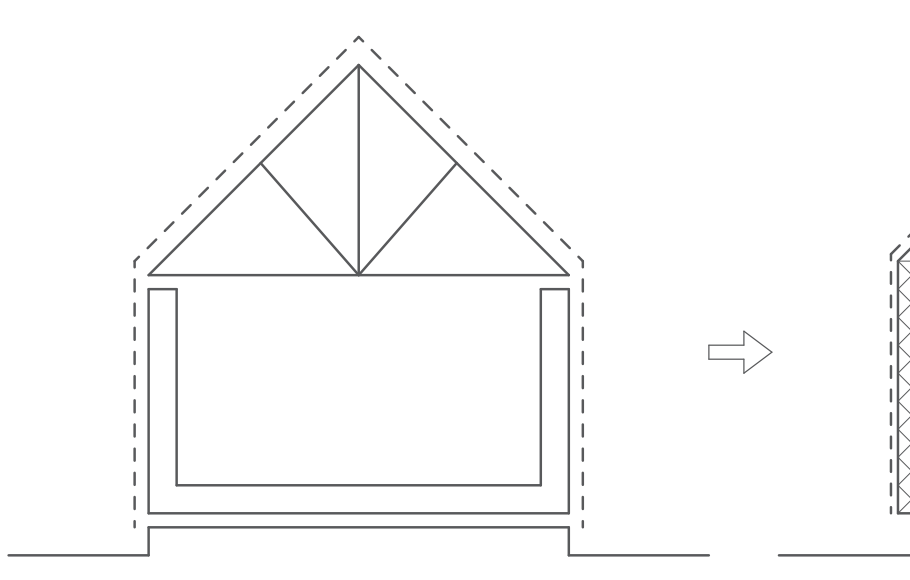

Solid walls with or without rainscreen

$$
\Rightarrow
$$

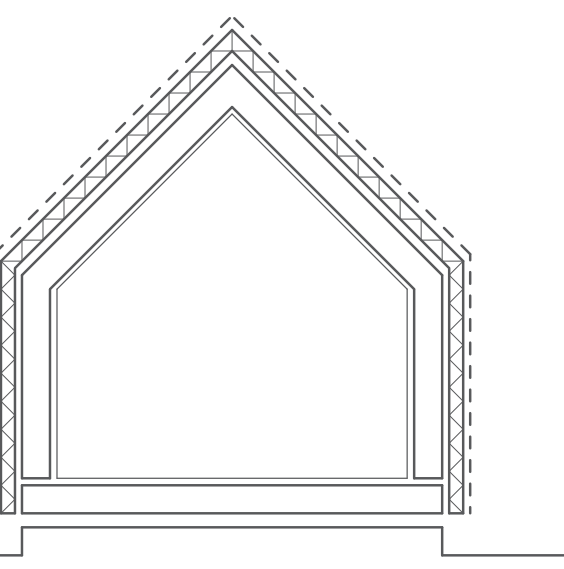

Masonry wall, timber truss roo Multi-layered, breathable,
per-insulated, air tight, low ene panels

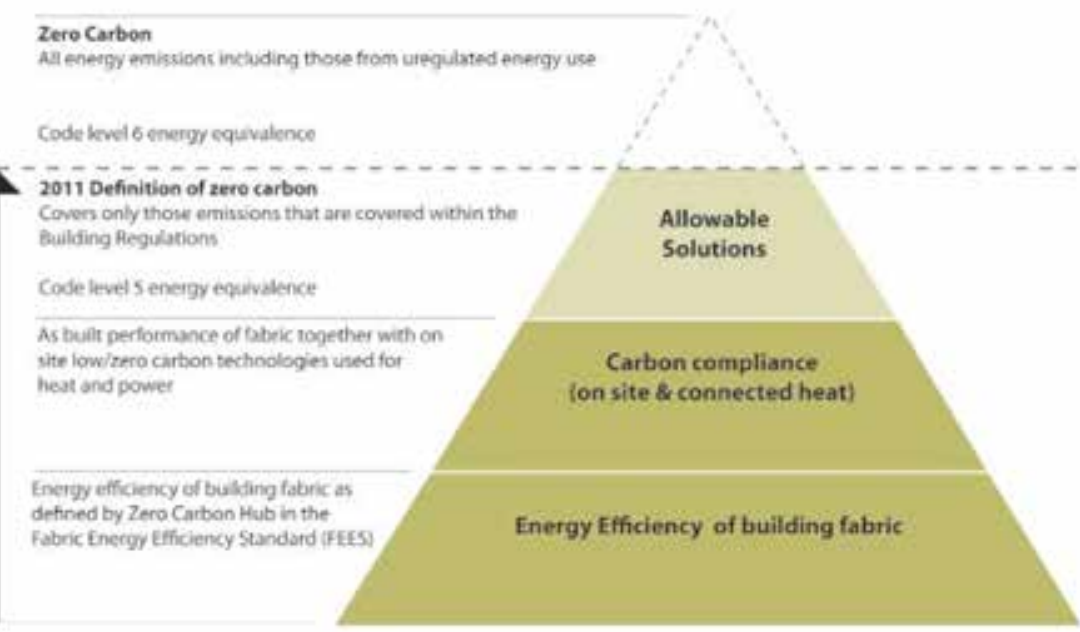

without compromising the ability of future generations to meet their own needs.'2

In the 2009 publication, of One Wales: One Planet, the Welsh Assembly Government states that:

'In Wales, sustainable development means enhancing the economic, social and environmental wellbeing of people and communities, achieving a better quality of life for our own and future generations:

- In ways which promote social justice and equality of opportunity; and

- In ways which enhance the natural and cultural environment and respect it's limits - using only our fair share of the earth's resources and sustaining our cultural legacy.'22

Chapter 4 - Sustainable Resource Use, sets a number of targets to meet a reduction in energy consumption, that have become widely accepted in Wales and embedded in the Welsh planning system through Planning Policy Wales (PPW) and Technical Advice Note (TAN) 12: Design.

- A reduction in greenhouse gas emissions by $3 \%$ a year by 2011;

- An aim to stabilise the housing ecological footprint (housing makes up $25 \%$ of the Welsh footprint) by 2020; and

- A target of all new buildings to be 'zero carbon' (with houses reaching the Code for Sustainable Homes Level 6) by 2011. (This was later scrapped and replaced with changes to the devolved Building Regulations Part L)

Over the last 30 years, there has been a significant change in the approach to the building envelope in relation to energy performance. The domestic scale building envelope has evolved from a concrete ground floor slab with masonry cavity walls, a timber trussed roof and UPVC windows to buildings comprising multiple layers with high-levels of insulation, reduced thermal bridging, increased air tightness, thermally broken triple-glazed windows and incorporating renewable technologies. Regulation and advisory bodies have continually updated their requirements to improve thermal efficiency, air tightness, ventilation, embodied carbon and carbon emissions:

- In 1985 the Building Regulations required a U-value of $0.45 \mathrm{~W} / \mathrm{m} 2 \mathrm{~K}$ for walls and ground floor;

- In 1990 BRE launched BREEAM to set best practice targets in sustainable

21 World Commission on Environment and Development, Our Common Future, (Oxford: Oxford University Press, 1987)

22 Welsh Assembly Government, One Wales: One Planet, (Cardiff: Welsh Assembly Government 2009) p.8 


\section{Energy Pertormance Certificates (EPCs)} Modelling of the energy efficiency and carbo

CLG: Definition of zero carbon consultation

ero carbon defined as regulated and unregulated

\section{Building regulations Part $\mathrm{L} 2010$}

(CSH)

\section{The Carbon Plan}

Budget 2011: A revised definition of zerocarbon

\section{Renewable Heat Incentive (RHI)}

On site renewable heat generation incentivised

\section{English Building Regulations Part L 2013}

2014

2014

English Building Regulations Part L 2016 All new housing expected to be 'zero carbon
Fabric Energy Efficiency Standard, Carbon compliance and Allowable Solutions expected to be

\section{Welsh Building Regulations Part L 2016}

regulations to reflect zero carbo expected.
WAG zero carbon aspiration
WAG announces aspiration for zero carbon homes by 2011 code for Sustainable Homes adopted in Wales, all Code 3 funded housing to achieve a minimu Planning Policy Wales Pret

\section{Planning Policy Wales} energy credits $\beta 1 \%$ imo meet CSH Code 3 plus six

\section{Building Regulations} 2012 One Wales Commitmen (1) expected, with a suggested 55\%6 reduction in energy

review of Welsh Building Regulations expected

\section{Welsh Building Regulations Part L 2013}

building design;

- In 2000 EcoHomes was introduced to consider a wider range of sustainability concerns than just the fabric energy performance which became mandatory for social housing in 2003;

- In 2007, the Code for Sustainable Homes replaced EcoHomes to cover an increased range of sustainability parameters and more stringent targets on carbon emissions related to SAP calculations;

- In 2011 the Building Regulations were devolved to Wales. The Welsh Government remained focussed on delivering zero carbon and nearly zero energy standards for new buildings;

- Welsh Government scrapped the requirement for new development to meet CfSH and BREEAM targets in 2014 in favour of a revised Building Regulations Approved Document Part $L$ that incorporated requirements on elemental U-values, thermal bridging and air tightness as well as heating source and total carbon emissions.

Over this same period, there has been an increase in the use of timber in the UK as a natural material that offers low-embodied carbon, higher levels of carbon sequestration, reduced thermal bridging and a lightweight framed structure that can accommodate high levels of insulation in between and over the frame..$^{23}$ This multi-layered construction relies on a Fabric First approach that underpins many of the Scandinavian, German and Austrian energy performance models achieved using timber construction methods such as Passivhaus ${ }^{24}$ and Activehouse. ${ }^{25}$

\begin{tabular}{|c|c|c|c|c|c|}
\hline \multicolumn{6}{|c|}{ Building envelope performance 1985 - 2014} \\
\hline Element & 1985 & 1991 & 2000 & 2010 & $\begin{array}{c}2014 \\
\text { (Wales) }\end{array}$ \\
\hline Exposed walls $\left(W / m^{2} K\right)$ & \multirow{3}{*}{0.45} & \multirow{2}{*}{0.45} & \multirow{2}{*}{0.35} & \multirow{2}{*}{0.3} & 0.21 \\
\hline Party walls $\left(\mathrm{W} / \mathrm{m}^{2} \mathrm{~K}\right)$ & & & & & 0.2 \\
\hline Ground floor $\left(\mathrm{W} / \mathrm{m}^{2} \mathrm{~K}\right)$ & & 0.35 & 0.25 & 0.25 & 0.18 \\
\hline Pitched roof $\left(\mathrm{W} / \mathrm{m}^{2} \mathrm{~K}\right)$ & \multirow{2}{*}{0.25} & \multirow{2}{*}{0.2} & $0.16-0.25$ & \multirow{2}{*}{0.2} & \multirow{2}{*}{0.15} \\
\hline Flat roof $\left(\mathrm{W} / \mathrm{m}^{2} \mathrm{~K}\right)$ & & & 0.25 & & \\
\hline Windows $\left(W / m^{2} K\right)$ & & 3.0 & $2.0-2.2$ & 2.0 & 1.6 \\
\hline Air permeability & & & & 10 & 10 \\
\hline Thermal bridging & & & & 0.08 & 0.04 \\
\hline
\end{tabular}

23 Geoffrey Pitts \& Robin Lancashire, Low-energy timber frame buildings: designing for high performance 2nd Edition (High Wycombe: TRADA Technology Ltd, 2011), p.24

24 Passivhaus Trust, The UK Passive House Organisation, <http://www.passivhaustrust.org.uk> [Accessed on 5th August 2015]

25 Activehouse, <http://www.activehouse.info> [Accessed 5th August 2015] 


\section{Modern Methods of Construction}

Prefabrication and standardisation in the building industry can be traced to long before the industrial revolution. Buildings, where individual components were prefabricated in workshops and fitted together on site can be seen throughout vernacular architecture in particular with the use of timber. Examples include timber frame housing in medieval Britain and the tatami-based modularised systems used in traditional Japanese houses. Since the industrial revolution prefabrication and modular building have been investigated as a way of providing housing on a mass scale with significant developments in prefabricated housing occurring during the nineteenth century in France, Britain and the USA.

'Modern Methods of Construction' is a recently introduced umbrella term that covers a wide variety of processes and products with an aim of improving construction industry efficiency. Often incorporating the notion of off-site construction, the term is used to denote not just innovative products, but also innovation in issues relating to people, procurement and process and as such has been defined in many ways.

In 2004, the former Office of the Deputy Prime Minister (OPDM), now the Department for Communities and Local Government (DCLG), defined MMC as'the process to produce more, better quality homes in less time ${ }^{\prime 26}$ and derived four MMC product sectors:

\section{Building Research Establishment (BRE)}

'a range of processes and technologies which involve prefabrication, offsite assembly and various forms of supply chain specifications.'

- Panelised units;

- Volumetric construction;

- Hybrid techniques of both panel and volumes; and

- Other variations of cassette type construction, sub-assemblies and M\&E systems.

\section{Welsh Government}

WAG promoted MMC through 'Better Homes for People in Wales'. While no specific targets were set, the need to raise standards in response to 'Rethinking Construction' was recognised. The focus was on raising awareness of partnering, demonstration projects, and implementing the principles of Rethinking Construction in social housing.

However, it is important to consider all of the processes involved in the manufacture and construction of these MMC systems when assessing their possible benefits and disadvantages. While each method or system has its own unique benefits, the following table provides a generic overview of the impact of using MMC.

Perhaps the most beneficial impact of MMC is the movement of construction into the more controlled environment of a factory, off-site. This reduces time lost to bad weather, can improve the quality of the product, improve environmental performance of the envelope, as well as reducing defects and snagging. Although,

26 Office of the Deputy Prime Minister: Housing, Planning, Local Government and the Regions Select Committee - Eighth Report, supplementary memorandum by the Office of the Deputy Prime Minister THC01(b)); July 2004 


\begin{tabular}{|c|c|}
\hline Advantages of MMC & Disadvantages of MMC \\
\hline $\begin{array}{c}\text { Potential for cost savings over a number of } \\
\text { repetitive units }\end{array}$ & Increased transportation requirement \\
\hline $\begin{array}{c}\text { Increased quality contorl possible due to increased } \\
\text { production under factory conditions }\end{array}$ & $\begin{array}{c}\text { Limited industry capacity: research in 2004 } \\
\text { showed that the industry was operating at } \\
70 \% \text { of max. output }\end{array}$ \\
\hline $\begin{array}{c}\text { Potential time savings on site, offering possibility of } \\
\text { up to 50\% time savings }\end{array}$ & $\begin{array}{c}\text { Decisions must be made earlier in the design } \\
\text { process due to early design freeze }\end{array}$ \\
\hline $\begin{array}{c}\text { Increased airtightness due to factory production } \\
\text { and improved tolerances }\end{array}$ & $\begin{array}{c}\text { While time on-site may be reduced, up front } \\
\text { design period may be longer }\end{array}$ \\
\hline $\begin{array}{c}\text { Improved Health and Safety } \\
\text { Perceived increase in risk due to different } \\
\text { procurement routes and earlier payment dates }\end{array}$ \\
\hline $\begin{array}{c}\text { More effective use of materials, leading to } \\
\text { reductions in waste, particularly on-site }\end{array}$ & $\begin{array}{c}\text { Cultural challenge - public perception } \\
\text { tarnished by past experiences of failed systems }\end{array}$ \\
\hline Reduced defects & \\
\hline Source: Design Research Unit Wales, MMC Wales Executive Summary (Cardiff: WSA 2008) \\
\hline
\end{tabular}

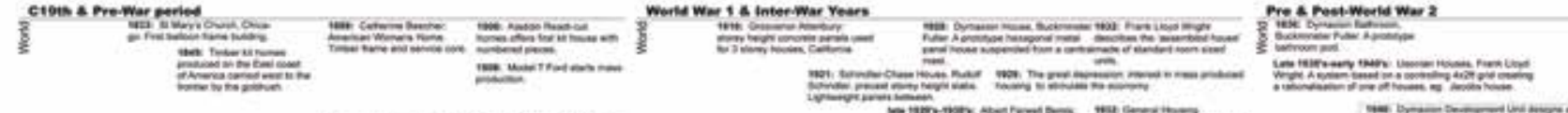

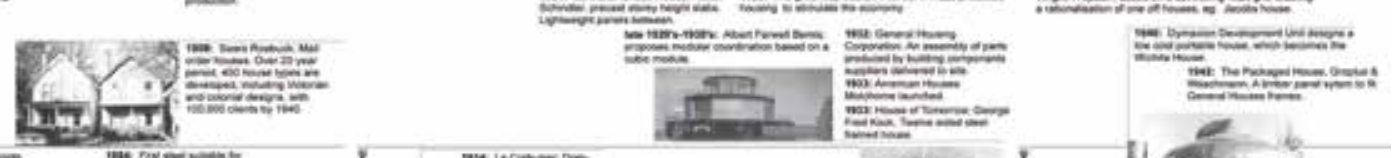
$=5$ \& $\equiv=$

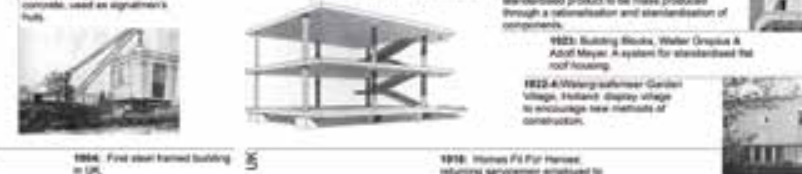

$=$

$$
\begin{aligned}
& =
\end{aligned}
$$

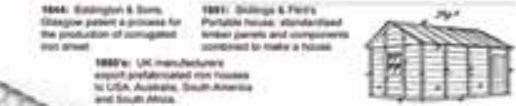

$\underline{E}=5$
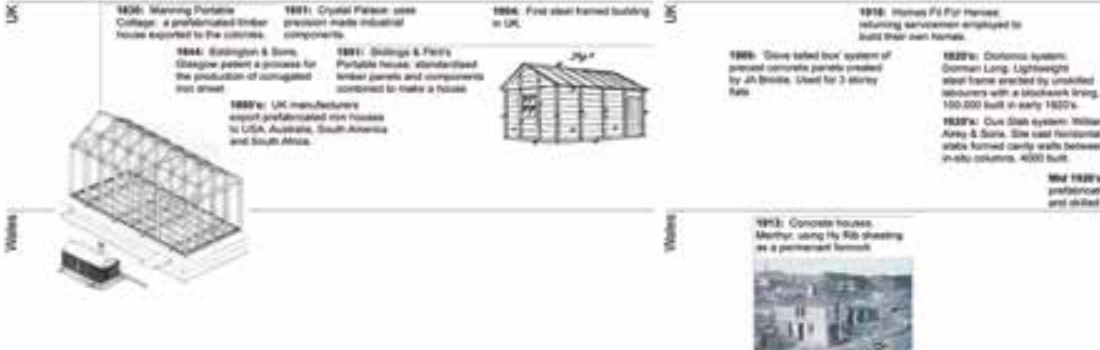

$=$

$$
\pm=
$$$$
=-1
$$

문돈

i

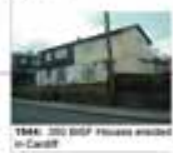

Fig 4.9 MMC table of pros and cons

Fig 4.10 Key national and international developments of prefabrication and Modern Methods of Construction

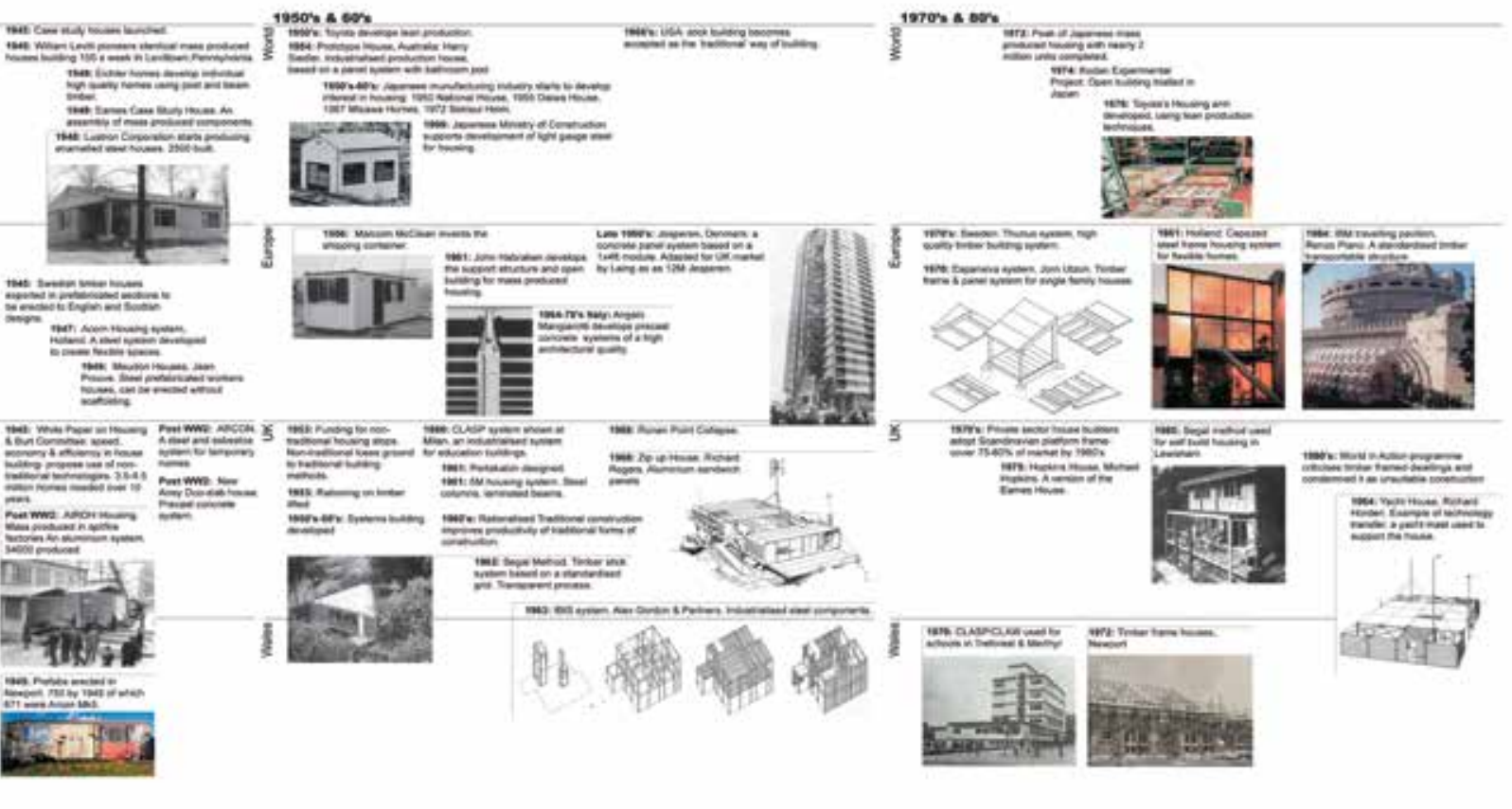




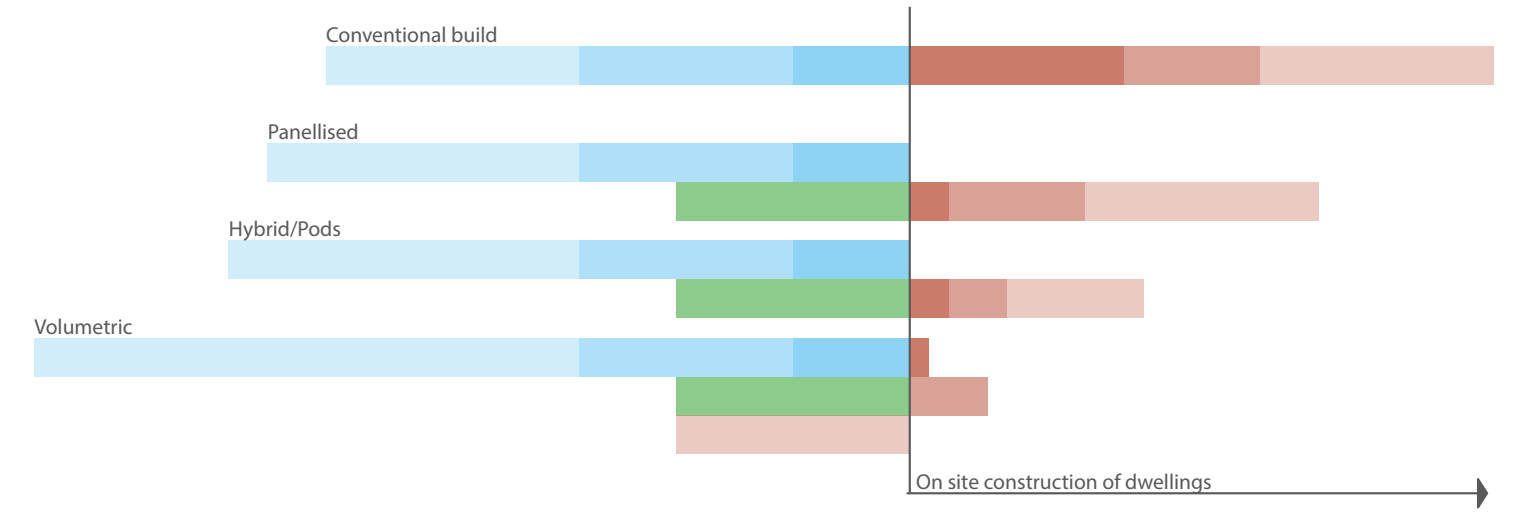

Manufacture
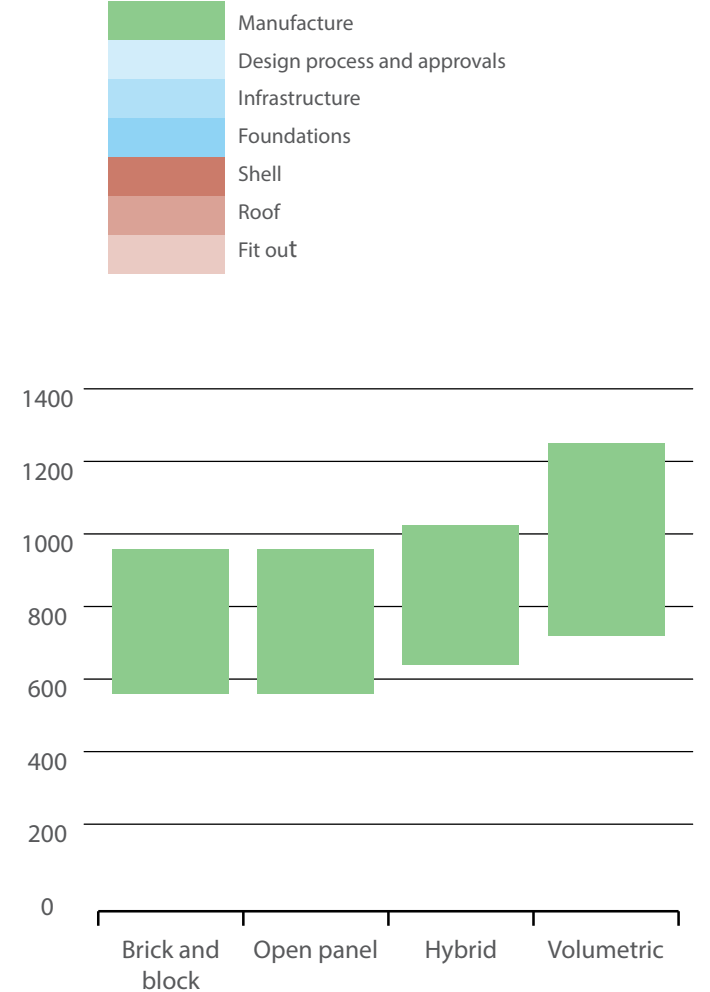

Comparison of construction costs ( $\left(\mathrm{E} / \mathrm{m}^{2}\right)$ Source: Cost calculations prepared for the National
Audit Office by the Building Cost Information Service

Fig 4.11 Programme comparison of Modern Methods of Construction types

Fig 4.12 Cost comparison of Modern Methods of Construction types the often cited cost savings are less clearly identified; in some case studies MMC costs more, but has the benefit of a shorter construction period.

The use of timber in MMC prefabricated systems has always been popular for its environmental credentials, ease of working, lightweight properties and versatility. In 2005 prefabricated timber frame construction accounted for $18.6 \%$ of new construction projects, the highest of the MMC methods, with light steel frame accounting for 3.9\%, which is predicted to increase further to $30 \%$ by $2016 .{ }^{27}$

Prefabrication, or off-site construction is defined in the 2010 TRADA publication Off-site and modern methods of timber construction: a sustainable approach as 'the manufacture and pre-assembly of components, elements or modules before installation into their final location. ${ }^{28}$ As such, timber prefabrication has arguably existed since the first timber structures were erected using pre-selected trees for their particular shape and curve, felled and processed on-site prior to assembly with all other pre-prepared parts. This was and still is most notable in the construction of cruck-framed barns and houses. The process continued through the box-framing Tudor periods where timber sections and lengths became relatively standardised for the use in house frames.

This timber practice was superseded by the use of brick as a prefabricated modular unit and developed further with the introduction of steel sections manufactured in standard sizes or fabricated to order.

Over the last 100 years, this trend towards prefabrication has developed significantly within the construction industry throughout the world. Inspired by movements and practice within the automotive industry, Le Corbusier, Mies van der Rohe, Konrad Wachsmann and others sought to rationalise and standardise the construction of housing in order to improve efficiency and quality while reducing time and cost. Early developments were limited to stick-frame building methods originating in the USA, by which houses were erected from a set of standard sized timber elements: posts, beams, braces and trusses connected together using nails and screws. As prefabrication developed in Europe, the UK industry was not in a position to offer 'home-made' prefabrication, therefore relying on importing Scandinavian, German, Austrian and Polish systems using cheaper and stronger softwood than was thought to be available in the UK.

Innovation on methods of timber construction is common across Northern and Central Europe, where there is an abundance of high quality timber. Most are

27 Clare Vokes and Jennifer Brennan, Technology and Skills in the Construction Industry: Evidence Report 74 (Rotherham: UKCES 2013), p.12

28 Dr Robert Hairstans, Off-site and modern methods of timber construction: a sustainable approach (High Wycombe: TRADA Technology Ltd 2010) 
prefabricated structural panels, that are sometimes left exposed for the interior finish, using various methods of laminating and jointing between small lengths and sections of C16, C24 or TR26 rated softwood such as spruce, and pine. The panels are generally manufactured as complete wall elements with insulation, services, exterior cladding and windows and doors pre-installed, before being mechanically manoeuvred and fixed together on-site to form a structural, weathertight envelope in 2-3 days.

While the various panel systems in Europe are an efficient and innovative solution to housing construction some are 'high-tech' requiring large and expensive factories and machinery which is difficult to transfer to another country until an established market and timber source is available. Therefore, in terms of sustainability, these systems seem best limited to high density projects and urban sites located near to distribution or fabrication warehouses or shipping ports. Currently, the Welsh MMC supply chain is immature compared to that in the rest of the UK. Many of the Welsh MMC manufacturers are receiving larger orders from hotel and fast food retailers outside Wales than from construction and housing companies within Wales. With the correct input, many of the current MMC suppliers have the potential to develop more focussed and advanced construction systems.

\section{The timber building envelope}

The previous sections identified the key building elements and associated performance requirements and established the context and use of timber within the building envelope to meet the increasing demands on performance. This section will examine the principle timber construction methods and applications within the external building envelope as appropriate to the use of timber. As 'timber construction means building elementally according to constructive logic and clear, easily understood laws', ${ }^{29}$ four headings have been identified to categorise the elemental use of timber in the building envelope that expand on the basic elements of walls, floors and roofs to incorporate the use of timber within the layered approach to the envelope:

- Superstructure and infill - to include the primary and secondary structures of walls, floors and roof and the infill components that complete the structura and weathertight envelope.

- External claddings and finishes - that focuses on the external claddings to 


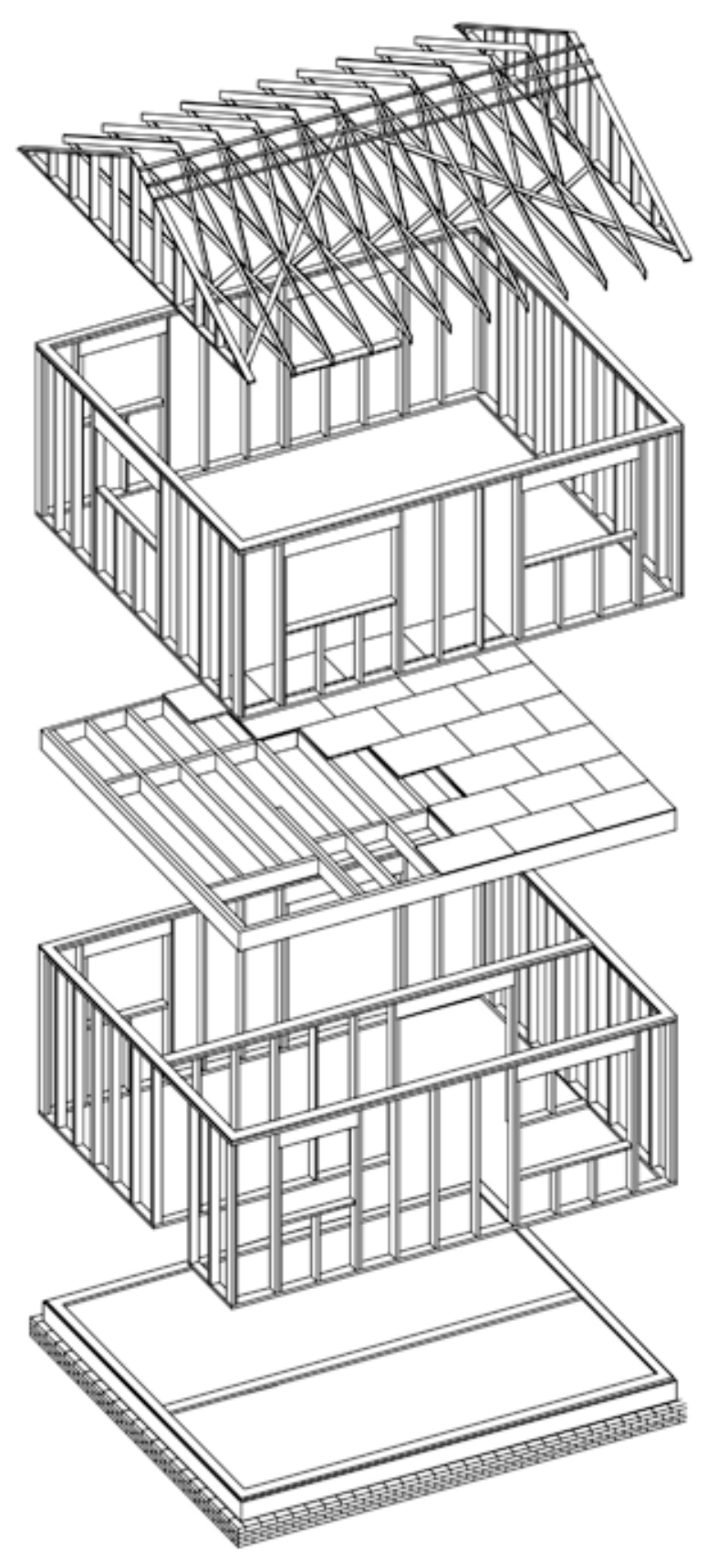

walls and roof and any other finishes to the envelope that contribute to the overall performance.

- External joinery - including windows, doors, shutters, solar shading and other integral items to the performance of the envelope.

- Other - to include individual components of the envelope that contribute to the overall performance and appearance such as insulation and internal wall, floor and ceiling finishes.

The final section will illustrate a selection of best-practice, worldwide precedents that have considered the holistic building envelope from technical performance as detailed here and the overall tectonic form.

\subsubsection{Superstructure and infil}

In the UK TRADA defines 'Timber frame as a method of construction. It is not a system of building although there are a number of well researched systems which use timber frame as a basis. Timber frame construction uses timber studs and rails, together with a structural sheathing board, to form a structural frame which transmits all vertical and horizontal loads to the foundations. ${ }^{30}$

Timber superstructures are of dry construction, generally quick to erect and dimensionally accurate. A concrete slab or precast concrete ground floor is usually constructed while the timber components are being fabricated. Alternatively a timber ground floor can be provided and constructed sequentially with the timber frame superstructure. The use of a 'dry' floor system in this way can have several advantages: reduces the time lost while screeds are drying out and avoids introducing a wet trade into an otherwise dry method of construction. ${ }^{31}$

The following headings categorise the range of traditional and current prefabricated systems available in the UK and mainland Europe:

\section{Elemental}

- Post and beam or skeleton systems use a standardised set of framing components that are assembled on-site. The load-bearing components are cut and fixed together into walls and roof trusses, linked together and sheathed both internally and externally. These large spans generally require glue laminated or other composite lumber beams to achieve the strength and 

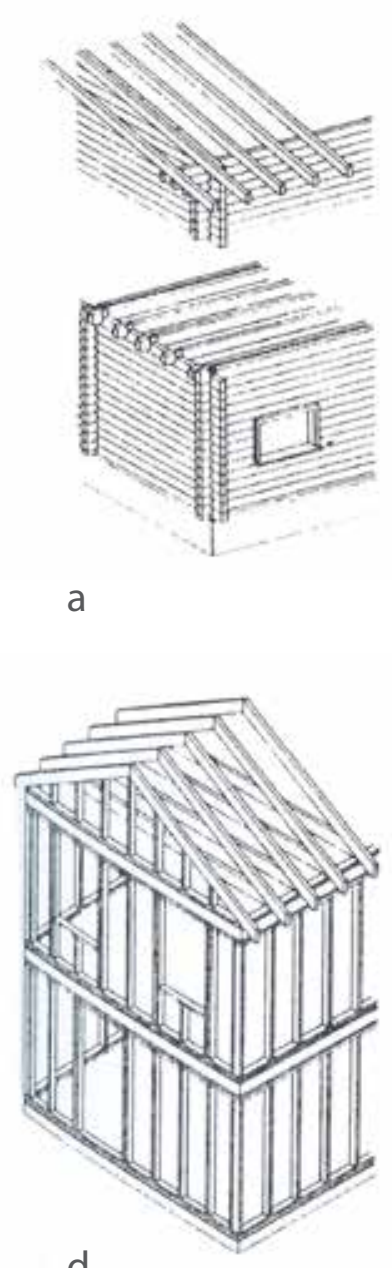

d

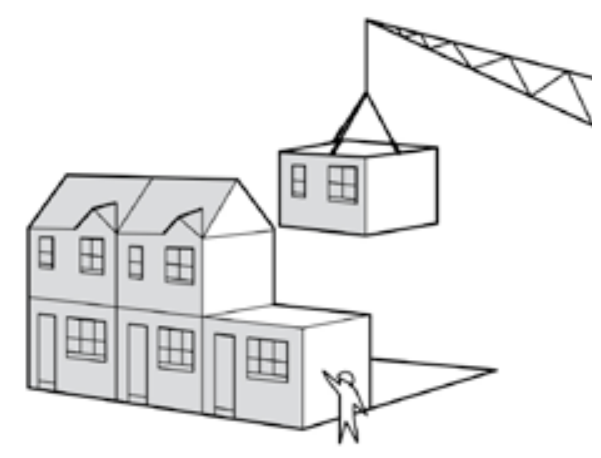

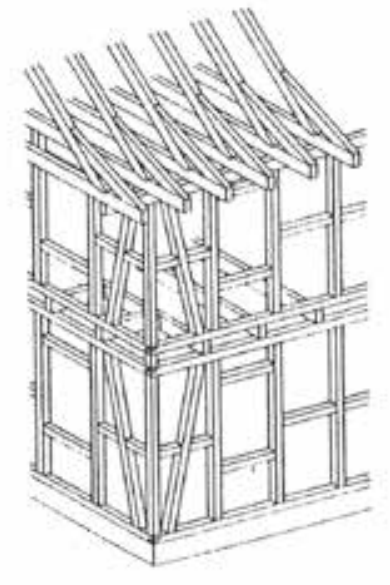

b

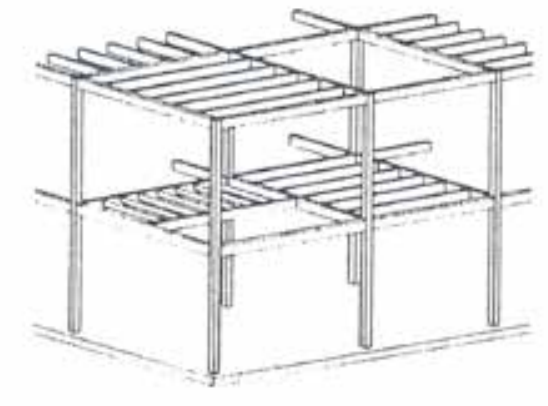

e

TOP

Fig 4.14 Methods of timber fram construction

a. Log-on-log construction

b. Box frame

c. Balloon frame

d. Platform frame

e. Post and beam

f. Panelised timber frame

LEFT

Fig 4.15 Volumetric construction

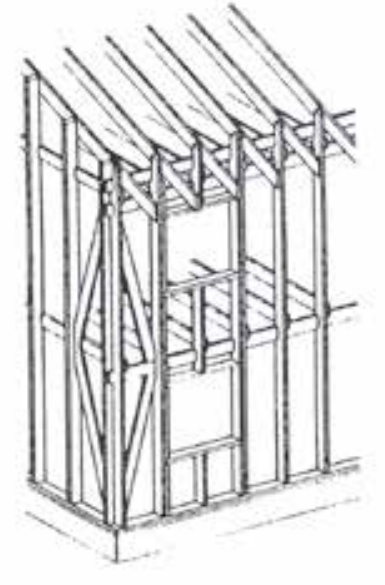

c
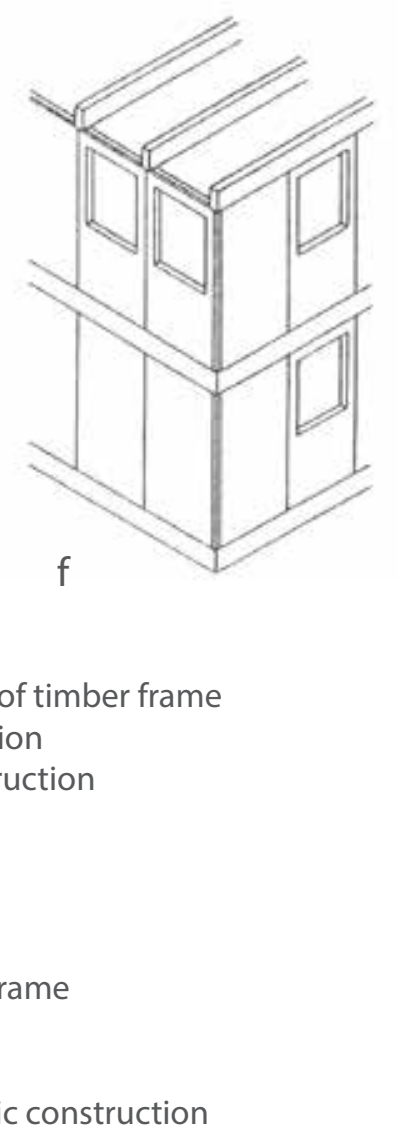

stability required.

- Log buildings have an important tradition. ${ }^{32}$ Stacked softwood beams, round or edge sawn are built up to create the walls. Historically the walls would be solid wood which could lead to issues once the wood had settled and dried out.

\section{Framed}

- Box frame - typically a traditional hardwood construction typology of braced side-wall, roof and floor frames to create a skeleton box that is then covered or infilled.

- Balloon frame - developed in Chicago, as a 2- or 3- storey full height timber frame and sheathed wall panels acting as vertical diaphragms that support internal floors and roof as horizontal diaphragms. This method is not commonly used.

- $\quad$ Platform frame - a floor-to-ceiling height frame for each storey with the intermediate floors resting on top becoming the platform for the next storey. This is the most common form of construction in North America and the UK.

\section{Panelised}

- The wall panels can be modular to make up one wall or made in one piece to make up a whole wall. Openings for windows and doors are integrated into the panels allowing quick and easy erection on site. ${ }^{33}$

- Open panel - skeletal frame enclosed on one side, produced in a factory in panels and delivered to site to be erected into a three dimensional structure.

- Closed panel - fitted in the factory with insulation, and can sometimes be fitted with windows and service voids.

- Advanced panel - fully enclosed at the factory and include fixtures and fittings such as windows, insulation and plumbing and service runs. Internal finishes are also fitted in the factory.

- SIPS - Structurally Insulated Panel systems are a form of composite panel typically of plywood and expanded polystyrene (EPS) insulation. SIPS can be used for walls and inclined roofs, and can be used for up to four storeys.

- Solid panel - Solid timber panels commonly consist of laminated softwood constructed of either glued cross laminated softwood (CLT) or of softwood lamellae fixed using bolts or rods (brettstapel).

Steiger, p.31

33 Wolfgang Rushke, Timber Construction for Trade, Industry, Administration: Basics and Projects, (Basel: Birkhauser 2004) p.23 


\section{Volumetric}

- Volumetric building systems are a step up from panelised systems. The panelised elements are constructed within the factory to create units with $3 / 4$ sides and floors and ceilings already complete. The whole unit is then delivered to site and connected to other blocks to form the overall building. ${ }^{34}$ The construction follows one of 4 approaches:

- Framed modules - Framed modules are created through structural elements located at the corners of the modules. This allows any sized openings to be located anywhere in the side panels.

- Monocoque modules - Monocoque is a form of shell construction, where load is shared across the entire skin of the module. This form of module is commonly produced in steel frame.
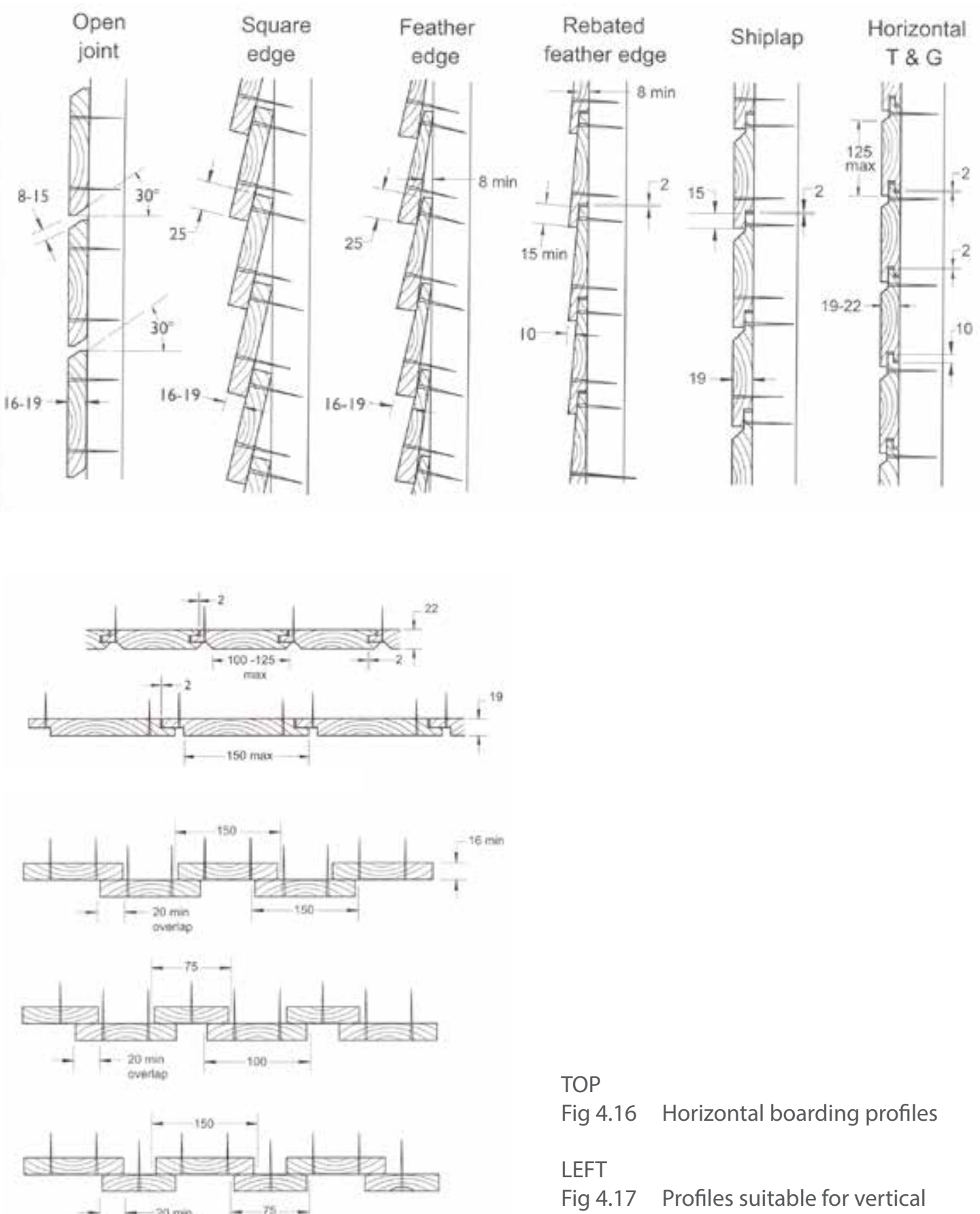

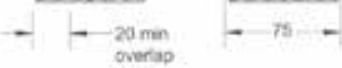
boarding

Panellised modules - Modules are created from pre-constructed panels which are similar to advanced or closed panels, either in timber or steel.

- Pods - Highly repeatable areas of buildings, such as kitchens and bathrooms, manufactured as volumetric modules that are fitted out in the factory with services and finishes to 'plug-in' to the building on-site.

4.3.2

The main functions of the cladding on a timber frame building are to provide weather resistance and create the external appearance required. ${ }^{35}$

- Timber cladding is designed on a rainscreen principle which assumes some water will penetrate the cladding. A vertical cavity should always be included behind the cladding to allow for the drainage of any water away and a breather membrane protects the main structure from water penetration. ${ }^{36}$

- The main performance requirements to consider are: control of moisture; allowance for moisture movement; durability to resist insect attack, rot and UV; and fixing detail especially in relation to hardwoods and at junctions and around openings.

- Timber cladding is most commonly fixed as vertical or horizontal boarding but also as diagonal cladding, shingles, shakes and wood based panels. ${ }^{37}$

- The choice of species for cladding may depend on the environmental qualities, whether they are sustainably grown and certified, imported or home-grown. ${ }^{38}$

34 Ibid, p.23

35 Lancashire \& Taylor, p.159

36 Patrick Hislop, External Timber Cladding, (High Wycombe: TRADA Technology Ltd 2nd edition, 2007), p.43

37 Lancashire \& Taylor, p.175

38 Ibid, p.175 
- Timber cladding can be coated with an applied finish or left unfinished to weather and bleach naturally, depending on the species and specification of the timber. ${ }^{39}$

\subsubsection{External joinery}

Both softwood and hardwood are used to manufacture the frames and components for windows and doors, as well as additional external joinery items such as shutters,

solar shading, balustrades. The most common is painted softwood either imported o manufactured in Wales using imported softwood.

- Windows are usually double glazed and either fixed pane, or top-, bottom- or side-hung casement.

- A key benefit of timber frame windows is that they do not have a requirement to be thermally broken as this is inherent to the nature of the material, although to improve thermal efficiency, European manufactures are producing Passivhaus standard timber windows that are thermally broken with insulation, double sealed and triple-glazed.

- Windows and doors can also be manufactured in a hybrid/composite system. For instance in exposed scenarios where an external aluminium skin is fixed to the timber frame with the internal surface painted.

- In conjunction with the cladding design solid timber elements can also be used to provide solar shading or shutters.

There are also other possibilities to utilise timber in the building envelope that have less demands on the timber performance but contribute to supplementary 'layers' of the building envelope:

- Insulation: wood fibre insulation is manufactured in Switzerland and Austria using spruce wood pulp and fibres.

- Boards: OSB, plywood, chipboard and MDF are often used for internal wall and floor linings beneath the proposed wall and floor finishes and for decorative mouldings.

- Finishes: Some projects also choose to let the functional, internal boarded skin be read as the finished covering within the completed building. As long as the correct coatings are applied to ensure fire protection all timber boards can be used to create an internal finished face. This applies to floors as well as floors where boards can also be used in lieu of an additional layer of floor finish above. 
In this section precedent projects, built over the last 30 years, are presented from around the world to highlight the holistic design thinking about the use of timber within the external building envelope. In all cases the buildings, have been widely published and have won awards for the architectural design. The projects have been selected to highlight a range of uses, that is not technology led, or primarily about incorporating the use of timber, but are designed and constructed/ assembled to use the best materials and systems appropriate for the overall design intent. The resultant tectonic form is therefore based on holistic design decisions that combine spatial design with structural resolution, technical performance with experiential qualities and detail design with durability and quality.
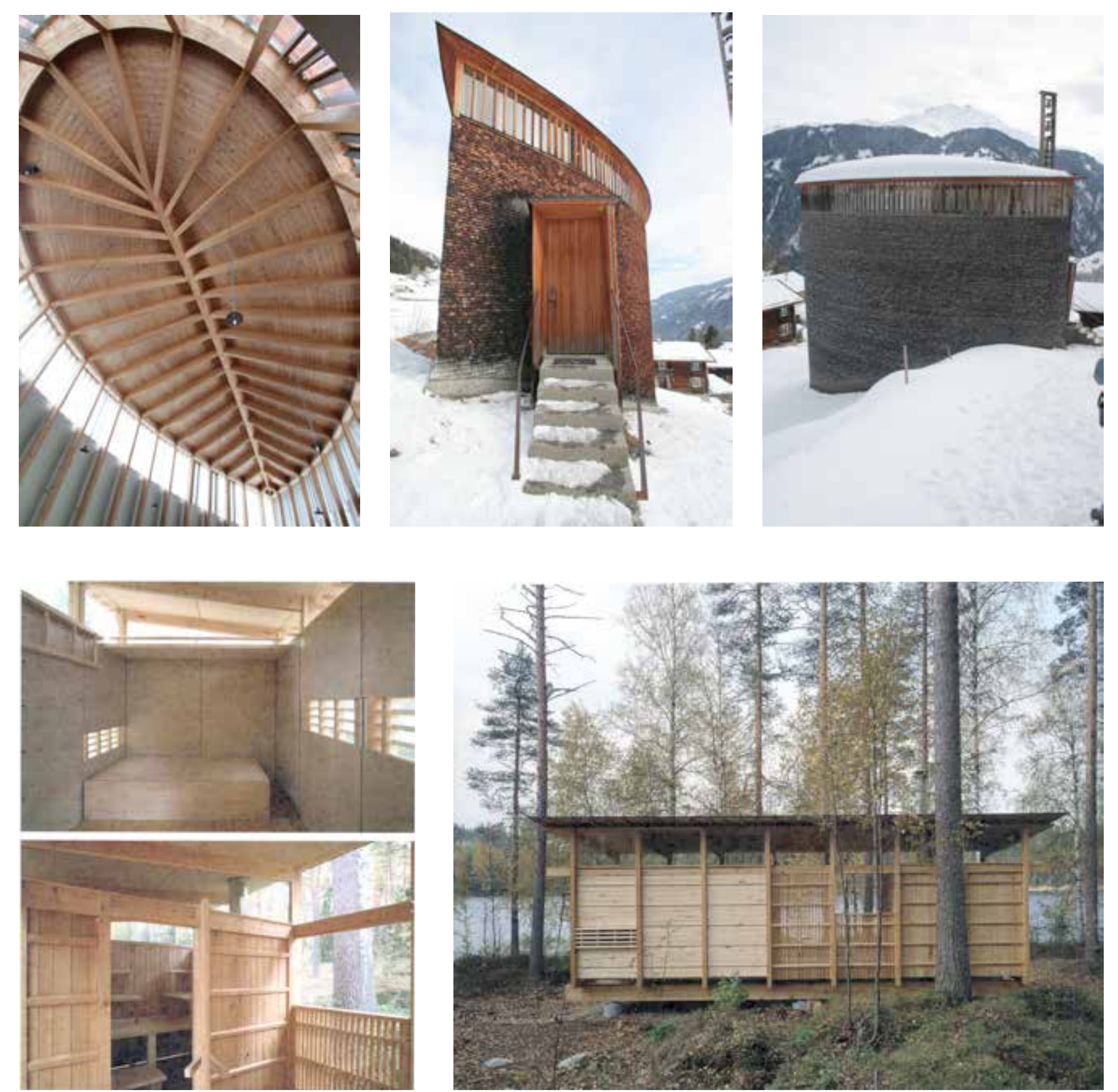

Fig 4.18 Sogn Benedetg Chapel, Sumvitg, Switzerland, 1988 by Peter Zumthor

\section{Species: Larch, Pine}

Technology: Glulam timber elements were provided by Blumer AG in Waldstatt, Hand crafted details built on site, plywood internal finish.

Envelope: Freestanding solid pine vertical timber pillars provide the bearing structure with the structural lines continuing across the ceiling into the timber roof bearers. The external walls are connected to the vertical structure by metal rods. The ceiling deck above the roof structure is pine. The primary roof beam has been cut three dimensionally, tapering off at the plan's most westerly point. The walls, are externally clad with hand split larch strips like shingles. The larch has been burned black on the sun facing side, while the north façade has faded to a silvery grey. Internally the walls are clad in plywood panels which have been primed, sanded, and treated with resin, chalk and paint.

Source: Daniel Schönbächler, Saint Benedict Chapel Architecture and Symbolism: Thoughts and Images, (Sumvitg: Cussegl da fundazin, 2013)

\section{Fig 4.19 Summer sauna, Mikkeli}

by Wood Program, Helsinki

Species: Pine, Alder, Aspen, Larch

Technology: Glulam pine structure, plywood internal finish.

Envelope: The walls that infill between the glulam pine structure are a combination of solid alder in some areas and plywood elements covered within aspen boards in others. The internal finish on the ceiling is plywood with wood fibre insulation above, the floor finish is larch and the external cladding is aspen. 

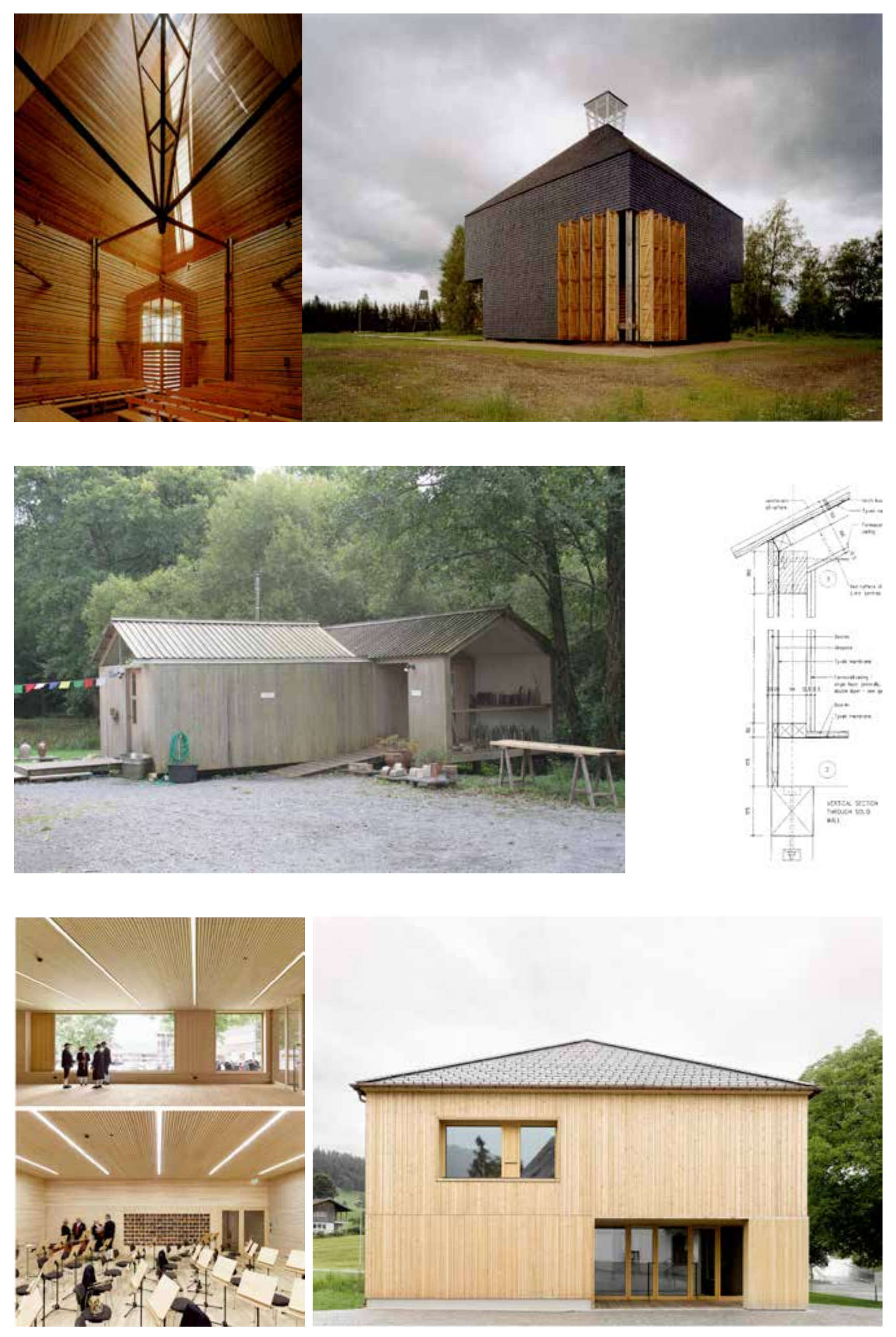

Karsamaki Church, Finland, 2004

by OOPEAA

Species: Pine, Aspen

Technology: Built using traditional methods but with a modern interpretation of the detailing.

Envelope: Log on log pine core structure with $125 \times 125 \mathrm{~mm}$ rough sawn pine framed structure.

External cladding is aspen shingles, coated in tar for weather resistance. Internally the walls are finished in roughsawn pine boards.

Fig 4.21 by David Lea

Species: Oak, larch

Technology: Low tech, hand built, hand crafted

Envelope: The platform of the gallery has oak pile foundations and ground beams, The $150 \times 150 \mathrm{~mm}$ piles are tiled together by $175 \times 150 \mathrm{~mm}$ edge beams that support the floor structure. The structural post and beam frame is of Welsh larch. Larch is also used to clad the walls and roof and is used as the internal floor finish.

Source: Dean Hawkes, 'Necessity and Poetry: David Lea's Bridge Pottery', ARQ, 6 (2002), 131-143

\section{Fig 4.22 Pfarrhaus, Krumbach, Vorarlberg, Austria, 2013} by Hermann Kaufmann

Species: Fir, pine, oak, undefined whitewood species

Technology: The building uses wood grown in local community-owned forests. The building uses simple detailing

Envelope: Prefabricated whitewood CLT structure, rough sawn silver fir cladding, planed white fir internal finish, oak floorboards. The windows are made of pine. 

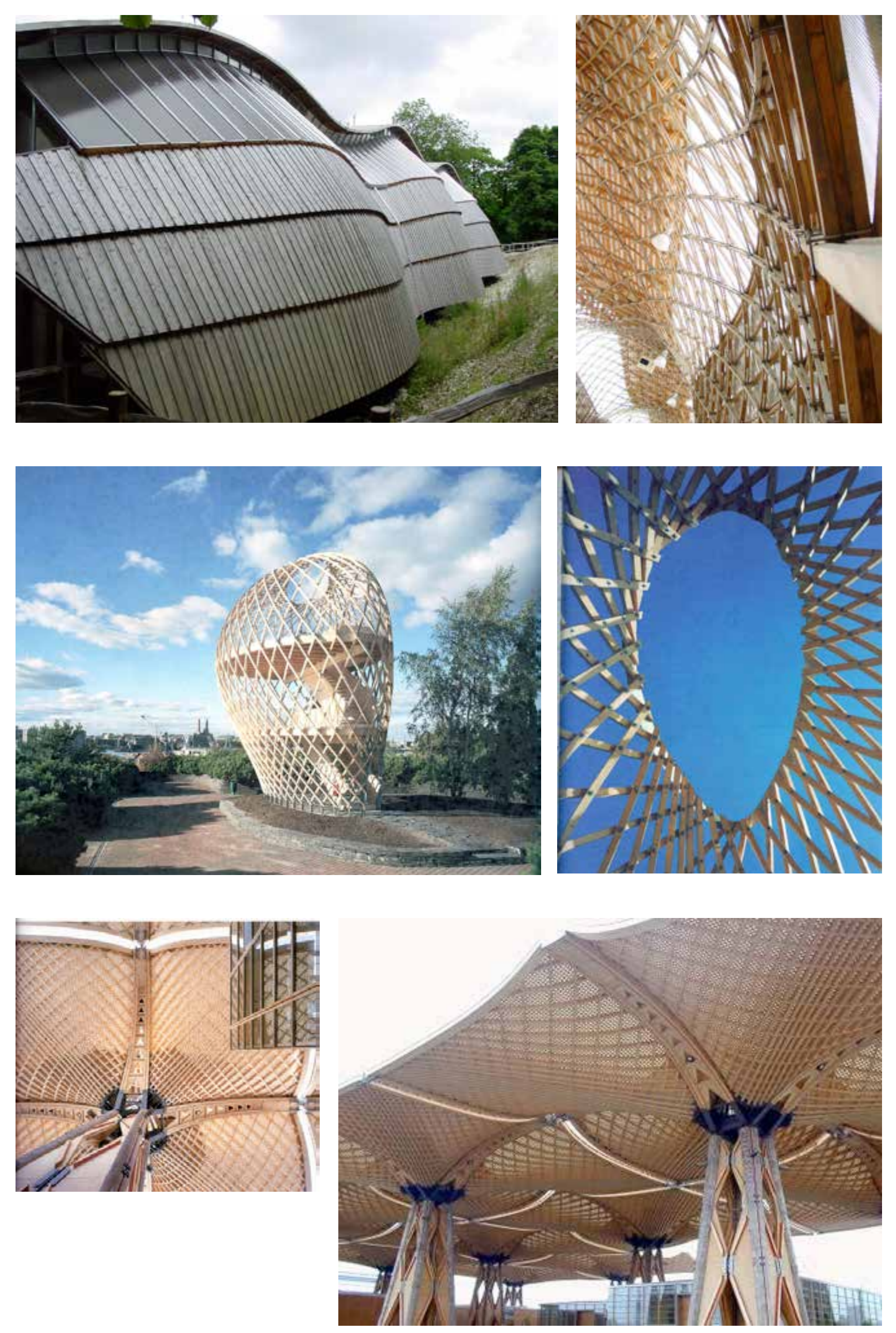

Weald and Downland Museum, 2002

by Edward Cullinan Architects

Species: Oak, cedar, fir

Technology: First double layer timber gridshell in the UK. Green oak was used because high moisture content enabled flexibility required for the forming process. Once the laths were in position natural drying strengthened their structure The oak had to be imported as no adequate supplies locally and and the shorter lengths were then reconnected using finger joints

Envelope: Doubly curved gridshell made from green oak laths, clad using locally grown untreated red cedar with a support frame of fir below. Laminated dry oak arches at either end of the building.

Source: Ruth Slavid, Wood Architecture (London: Laurence King Publishing, 2005), pp. 30-33

Fig 4.24 Kupla - Observation Tower at Korkeasaari Zoo, Helsinki by Wood Program, Helsink

Species: Pine

Technology: Timber members glued of four $15 \mathrm{~mm}$ lamellas. Members were bent to shape on site by steaming. Structure treated with linseed-based wood balm that evens variations in moisture content in timber.

Envelope: Mesh structure made out of $60 \times 60 \mathrm{~mm}$ bent pine timber members, fixed to each other with bolted joints

Source: Pekka Heikkinen, Jari Laiho, Jussi Tiainen, Puusta Tehty: Wood Works, (Tampere: Parvs Publishing, 2007), p.37

\section{Fig 4.25 Hannover Expo canopy, 2000}

by Thomas Herzog

Species: Silver fir, undefined whitewood species

Technology: Round timber, sawn timber, timber board, glued timber and laminated veneer lumber lattice. Steel connections.

Envelope: The vertical structure is composed of 4 no columns stabilised by triangular timber frames between. Each 'tower' is made up of a single 200 year old silver fir trunks. The triangular frame between is made using glulam planks with LVL. The frame is connected to the columns by bolts and dowels. The shell above is constructed of ribs made up of 8-10 boards with a cross section of 30/160mm each. At the intersection of the ribs the layers run through alternatively. 

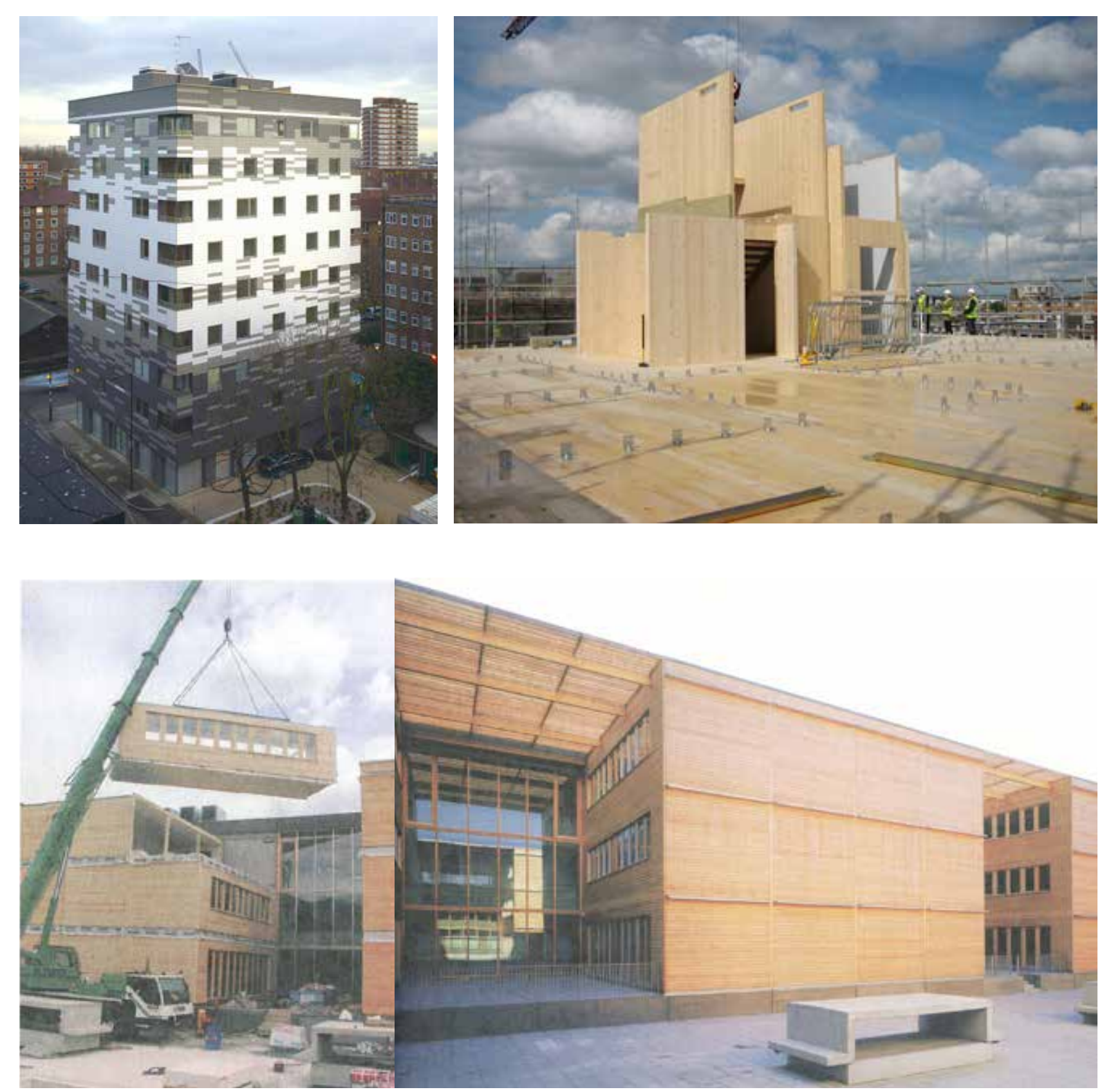

\section{Stadthaus, Murray Grove, London, 2009}

by Waugh Thistleton Architects

Species: Spruce

Technology: CLT panels form a cellular structure for floor, walls and core.

Envelope: All vertical load bearing and lateral resistance is provided by wooden walls and cores. The lift core, stair walls and cellular spaces above ground floor are all CLT construction. Close grain timber specified on the faces of panels significantly improved their fire resistance. Where possible floor panels designed to span in two directions or cantilever if support removed and wall panels can span laterally if support beneath is removed. Nail reinforcement strengthens junctions between wall and floor

Source: Techniker, 'Tall Timber Buildings: The Stadthaus, Hoxton, London' < http://www.techniker.oidev.org/blog> [accessed 13th September 2015]

Fig 4.27 Graz Impulse Centre, Graz, 2004

by Hubert Riess

Species: Larch, undefined whitewood species

Technology: Prefabricated, volumetric modules using CLT walls and floors.

Envelope: Boxes made of solid KLH engineered wood walls, lined internally with plasterboard with an external insulation layer and rear ventilated larch cladding. Prototypes/models made to test fire safety and properties of thermal and sound insulation.

Source: Hermann Kaufmann and Winfried Nerdinger, Building with timber: Paths into the Future, (Munich: Prestel Publishing Ltd., 2011) p.48 

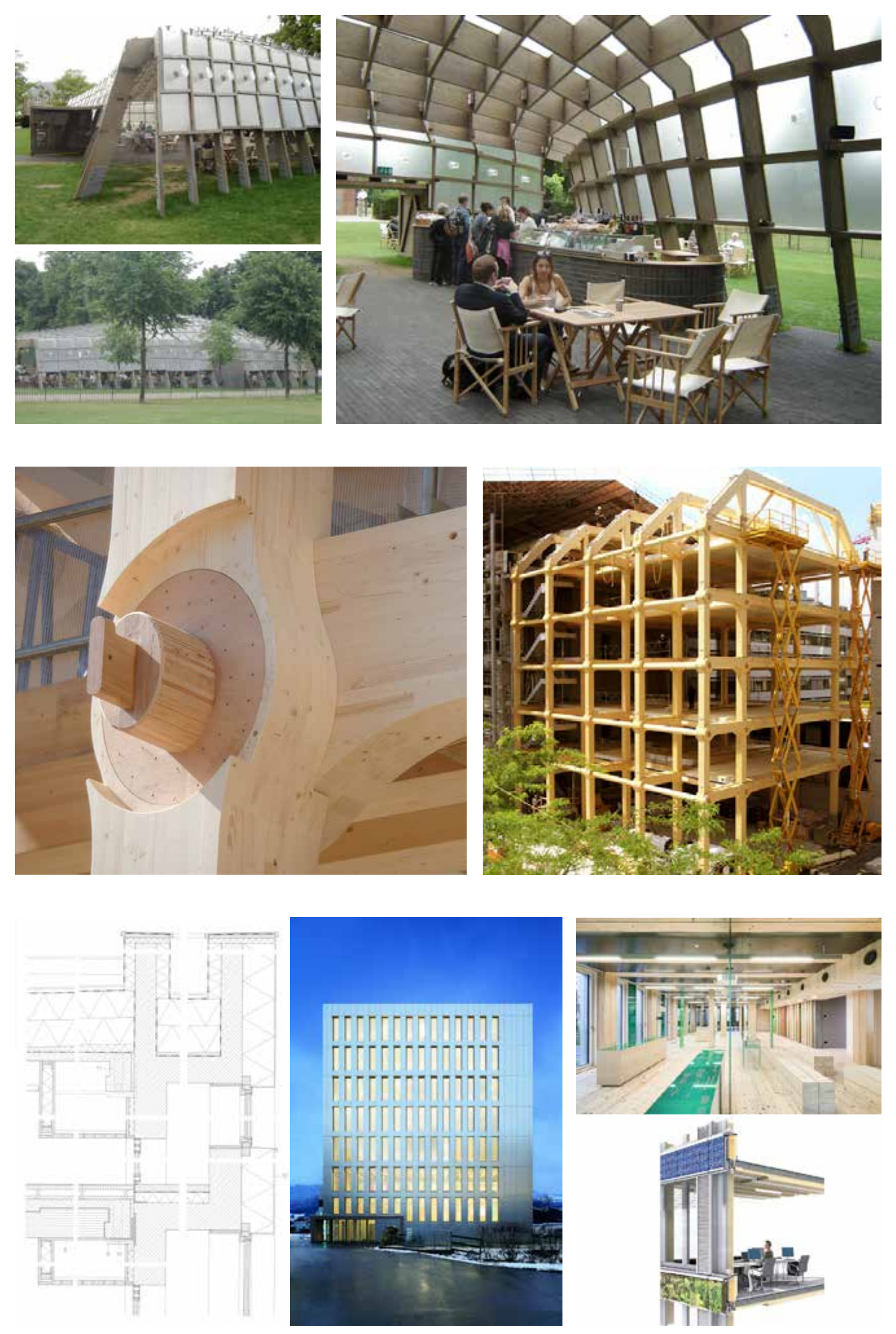

Fig 4.28

Serpentine Pavilion

by Alvaro Siza \& Eduardo Souta de Moura

Species: Undefined softwood

Technology: Low tech construction method with mortise and tenon joints between each plank, but highly precise computing and engineering to inform the design. Laminated veneer lumber, made in Finland.

Envelope: LVL planks are stained to match the oak trees adjacent to the site. Short planks form a grid for the roof and fold down at the edges to form the walls. Panes of polycarbonate fill in the squares of the ground. Gaps are left unfilled between the planks at ground level.

Source: 2005 Serpentine Gallery <http://alvarosizavieira.com/2005-serpentine-gallery> [accessed 13th September 2015]

Fig 4.29 Tamedia HQ, Zurich, Switzerland, 2013

by Shigeru Ban

Species: Spruce, Beech

Technology: Slow grown spruce glulam post and beam structure with laminated beech peg connections. CNC-milled construction and assembles on site. All connections are nail, screw and bolt free.

Envelope: Loadbearing structure consists of full height columns, beam pairs and girders. Each column is made of 3no glue-laminated block-bonded timber components. Columns and beams are attached using beech plywood pegs. Roof slabs made of $45 \mathrm{~mm}$ three-ply panels stabilize the structure. The production of the timber construction included the primary structure and manufacturing of the ceiling elements - hollow core ceiling units infilled with sand and insulation.

Source: Christian Schittich, Best of Detail: Holz/Wood (München: Institut für international ArchitekturDokumentation GmbH \& Co. KG, 2014) p.60-61

Fig 4.30 LIfeCycle Tower, Dorbirn, Vorarlbrg, Austria, 2012 by Architekten Hermann Kaufmann

Species: Undefined softwood

Technology: Timber hybrid.

Envelope: Prefabricated façade elements, $240 \times 240 \mathrm{~mm}$ glulam columns prefabricated into wall panel with windows. Composite intermediate floors made using glulam softwood beams and concrete ribbed floor. Concrete as separating material between floors allowed timber board to be exposed internally on the walls without fire protection. 


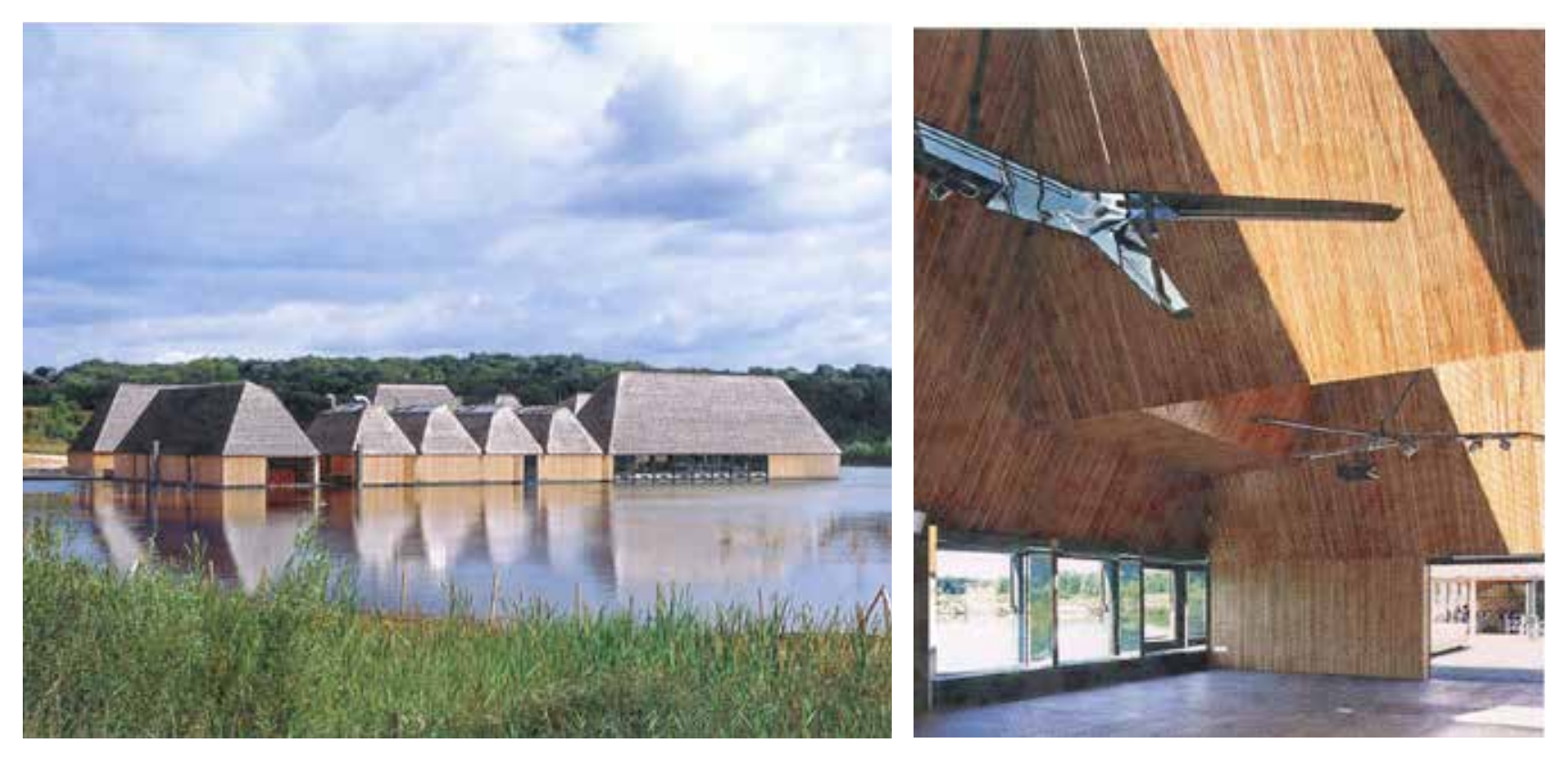

Brockholes Visitor Centre, Preston, UK, 2011

by Adam Khan Architects

Species: Oak, larch, birch

Technology: Prefabricated panels, Laminated timber rafters

Envelope: Oak vertical cladding on walls, split oak shingles on roof Oak posts frame support the

structure that spans over the windows. The window frames are oak with triple glazing Oak strips

provide the internal lining to walls and roof. Larch and birch linings and fittings used internally.

Prefabricated wall and roof panels are used structurally to avoid the needs for cross bracing or purlins.
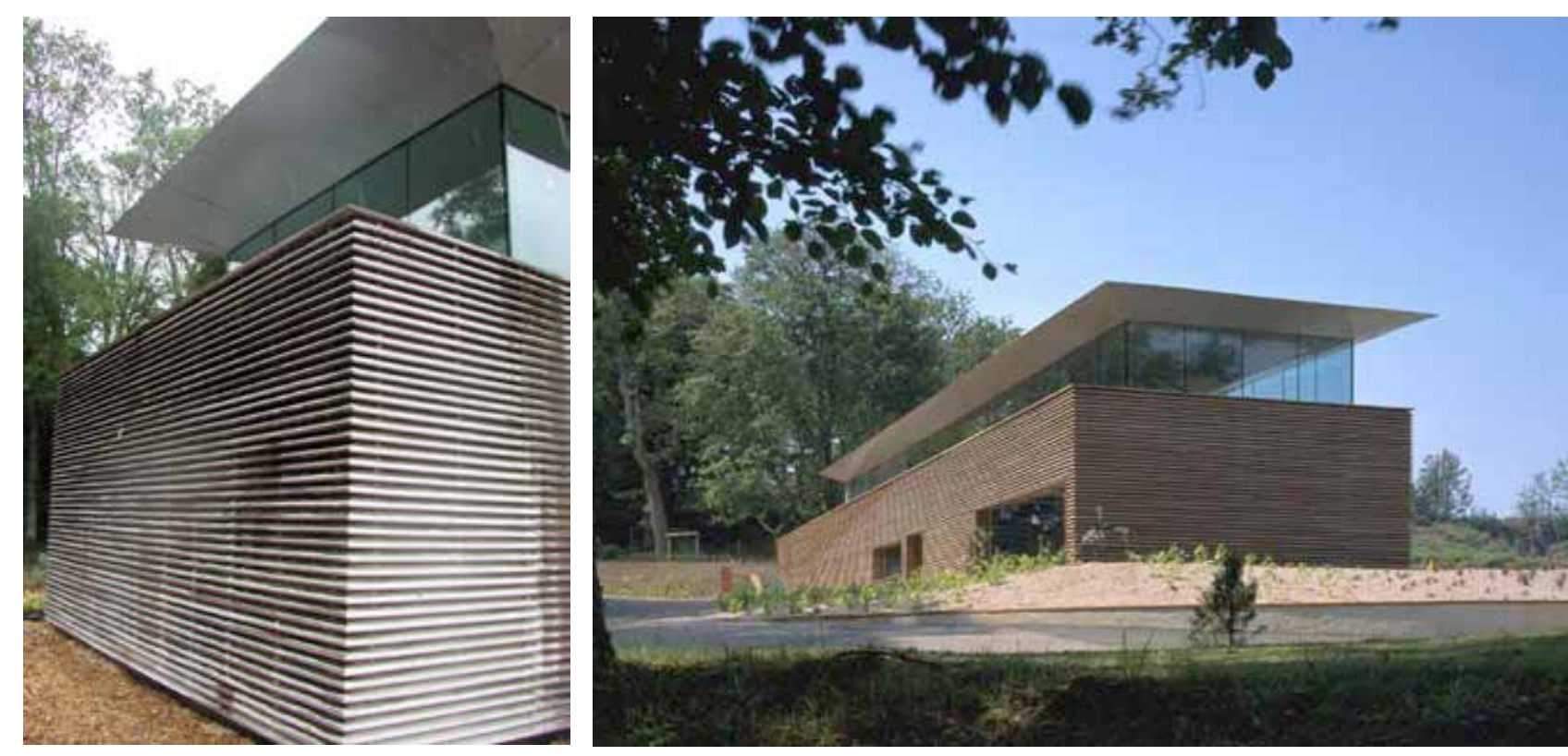

Source: Christian Schittich. Best of Detail: Holz/ Wood (München: Institut für international ArchitekturDokumentation GmbH \& Co. KG, 2014) p.125

Mount Stuart Visitor Centre, Isle of Bute, Scotland, 2001

by Munkenbeck and Marshall Architects

Species: Iroko

Technology: Specialist carpenter

Envelope: Iroko rainscreen cladding. Stressed-skin plywood roof with metal cladding above. Timber

floor to the balconies

Source: Kenneth Powell, It's a Bute', Architects' Journal, 214 (2001), 30-39 (p.37)
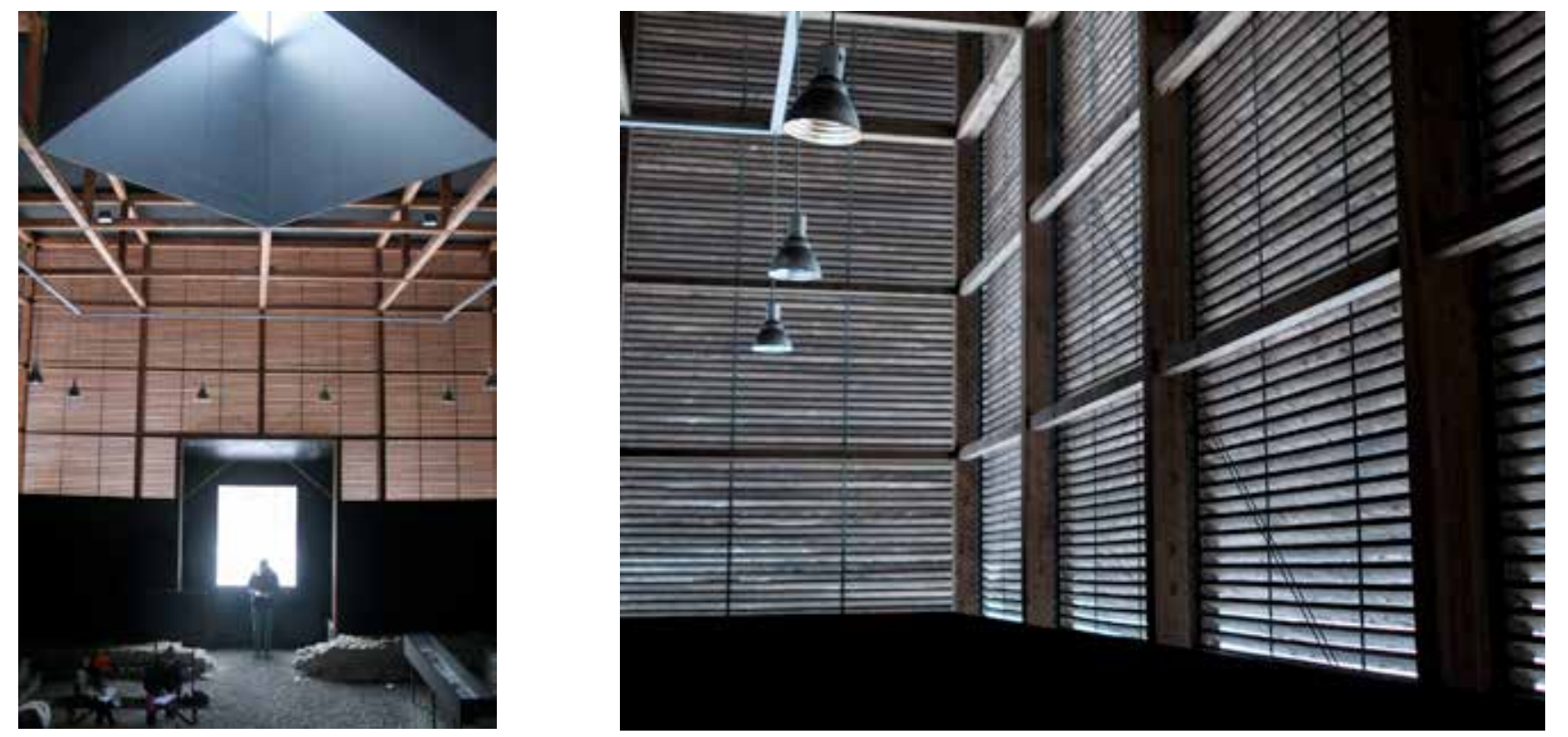

Roman Ruins shelter, Chur, Switzerland, 1986

by Peter Zumthor

Species: Unknown - lamella believed to be larch

Technology: Timber lamella shelters

Envelope: Open slatted cladding to provide weather protection but also allow ventilation, provides

the external skin to the vertical timber and steel support structure. The roof structure above is steel

reinforced timber trusses. The timber beams and steel members are crafted with the joints concealed.

Source: Swisher, Shawn. 'What Makes Us Human: Reactions to the Shelters for Roman Archaeological Site.'ArchDaily, 2010 <http://www.archdaily.com/76796/what-makes-us-human-reactions-to-theshelters-for-roman-archaeological-site> [accessed 13th September 2015] 
As the form and functions of buildings have developed so too have the requirements of the building envelope. This chapter has highlighted the performance requirements of the elements of the building envelope and demonstrated that timber, as seen in the precedent studies, has huge potential to be used within the envelope to improve construction efficiency and environmental performance. 'Without a doubt, timber delivers sustainable and energy efficient solutions - low embodied carbon, a choice of insulation performance, minimal waste, speed of construction, solutions without needing renewables, and off-site manufacture in a quality controlled environment. ${ }^{40}$

Timber is used within primary and secondary structures that contribute to the methods and systems of the walls, floors and roof. The structure can be finished with high performance claddings, joinery and insulated with woodfibre. The current use in Wales is relatively standard using basic tried and tested methods that have not evolved over the last 30 years. To do this the industry relies on imported softwood to manufacture low-tech components. When an innovative solution is required,

an appropriate system is imported that further demonstrates processes and opportunities for the use of Welsh-grown timber.

The timber industry, and UK reports evaluating MMC and energy performance, suggest timber is the primary material to provide innovation and dominate the market using engineered solutions such as glulam, CLT and SIPs. This innovation, with locally grown timber, is evident in the best-practice precedents, highlighting a significant gap between the levels and qualities of technology and design in Wales and areas such as the Vorarlberg region, Austria.

\begin{tabular}{|c|c|c|}
\hline \multirow{11}{*}{$\begin{array}{l}\text { Building } \\
\text { envelope } \\
\text { component }\end{array}$} & \multirow[t]{5}{*}{ superstructure } & post and beam \\
\hline & & framed panels \\
\hline & & solid timber \\
\hline & & volumetric \\
\hline & & hybrid \\
\hline & B1 & boards \\
\hline & \multirow{3}{*}{$\begin{array}{l}\text { cladding \& } \\
\text { finishes }\end{array}$} & external cladding \\
\hline & & interior wall \\
\hline & & interior floor \\
\hline & \multirow[t]{3}{*}{ external joinery } & windows \\
\hline & & doors \\
\hline B & & shutters etc. \\
\hline
\end{tabular}

Fig 4.34 Table of building envelope findings

\subsubsection{Findings to take forward}

- Timber has potential to be exploited within the external building envelope achieving high performance characteristics.

- Timber can play a crucial role in the design of low energy/ zero carbon buildings.

- Timber construction is increasingly becoming an off-site fabrication process involving significant levels of standardisation and modularisation.

- The following categories will be used to refer to elements of the timber building envelope: superstructure method (walls, floors and roofs), claddings and external joinery. Other components will also be considered but in

40 Andrew Carpenter, Building in Timber, (Heathfield: Architects Datafile, NetMAGMedia, 2014) $<$ http:/www.architectsdatafile.co.uk/news/building-in-timber> [Accessed 20th August 2015] 
conjunction with these categories.

- The tectonic form of the envelope must consider the holistic design

requirements, from technical aspects to architectural consideration such as

spatial, functional, contextual and compositional requirements and responses. 
CHAPTER 5

Methodology 
The findings from the previous three chapters have highlighted key Welsh woodland statistics, identified timber species, highlighted timber properties, demonstrated that there is a will and means to use Welsh-grown timber in construction, identified technological barriers and opportunities within the industry and reviewed the application of timber within the building envelope.

In this chapter, the findings are used to propose a hypothesis and re-consider the aim and objectives before formulating a framework for evaluation that will be used as a check-list to test the use of Welsh-grown timber in the design and construction of the building envelope against five study themes that have emerged from the previous reviews.

A research method is proposed, highlighting the format and structure of the design studies. This includes a description of the role of the author, as a practicing architect interested in tectonic form and making, to establish the context in which the

research is oriented. It is established that to test the use of Welsh-grown timber in the building envelope this thesis will be conducted by design and will involve a mixedmethod approach to considering both quantitative and qualitative information and processes. ${ }^{1}$ A brief review of design research methodologies will establish a rigorous process to design as a means to evaluate research aims. The section concludes with a selection of the design projects and the structure for conducting the design appraisal of each of the studies.

The research method is further developed, through a review and contextualisation of the role of making as a means to physically test components, structures and buildings that are considered within this research to be prototypes that represent both a performative method and an outcome of research. As such the role of prototyping and a model for evaluating different forms of prototype are discussed as a means to test, deliver and reflect on both the quantitative and qualitative research objectives.

\subsection{Hypothesis}

That there is potential to exploit the Welsh-grown timber crop in the design and construction of the architectural building envelope. 
The aim of this thesis is to test the use of Welsh-grown timber in the external building envelope through the design and construction of a series of prototype projects.

\section{Objectives}

The aim will be addressed through the following objectives that have been highlighted in chapters 2, 3 and 4:

A. Welsh-grown timber - to test the use of Welsh-grown timber species in components and elements of the building envelope.

B. Building envelope - to evaluate the use of timber in the design and construction of the 'smart' building envelope to meet low-energy performance requirements. ${ }^{2}$

C. Technology and skills - Work within the limitations and exploit opportunities that exist in the timber industry in Wales to develop ways of working with Welsh-grown timber.

D. Tectonic form - reflect on the tectonic form, through design and 1:1 prototypes to identify an architectural language integral to the use of Welsh grown timber.

These objectives directly inform the operational framework, in section 5.6 , by which the designs and parameters will be reflected on.

\subsection{Scope and limitations}

Beyond these thesis specific objectives, are a number of long established research traditions within the construction and timber industries. Forest ecology, biodiversity and science are relevant to the properties and biology of the available timber therefore affecting the design process and technology of experiments. Engineering is essential to the structural success of developed products and will critically influence decisions on sizing and connections. However, it is not an intention to directly contribute to these fields of research. The purpose is to share data from these fields to inform decisions regarding the architectural use of Welsh-grown timber in the building envelope, although, in doing so there may be reflections on forest management, timber science and structural engineering, that could inform further 
research within these fields.

This research will also be limited to or by the following:

- The projects will only focus on the components that are found within the structural, external envelope: primary, secondary and tertiary structure; internal and external finishes and claddings to the envelope; and external joinery such as windows, shutters and doors;

- This thesis will not focus on the technology or innovations with the use of Welsh-grown timber for interior uses, such as flooring and furniture as these components are not specifically related to the performance of architecture. However, they may be included in some designs as part of the wider design strategy;

- The projects included should primarily be regarded as early stage prototypes, even though some projects are completed, buildings, upon which a discussion of future development could be conducted.

\section{Framework for evaluation}

To meet the aim and objectives, the framework by which Welsh-grown timber will be tested is set out in the following sections. The framework for evaluation considers each of the objectives. The first three are primarily quantitative, leading to objective findings, whereas the fourth criteria is qualitative based on reflections on the design and construction process as well as the final prototype.

The findings, and an operational framework matrix, is then formulated to assist the evaluation of the design prototypes against the aim and objectives.

\section{Welsh-grown timber, species and adaptation}

The prototype projects will test a range of Welsh-grown timber species, working with their specific properties and within 4 criteria that have been identified as fundamental to the use of Welsh-grown timber: untreated or 'green', modified to improve durability, engineered to improve structural strength; and standardised to exploit the most efficient sizes and grades available. It should be noted that other species may be used throughout the design studies for property specific purposes, such as flooring, furniture or other bespoke use. These will be highlighted where necessary and considered within the same parameters as these main 6 species. 


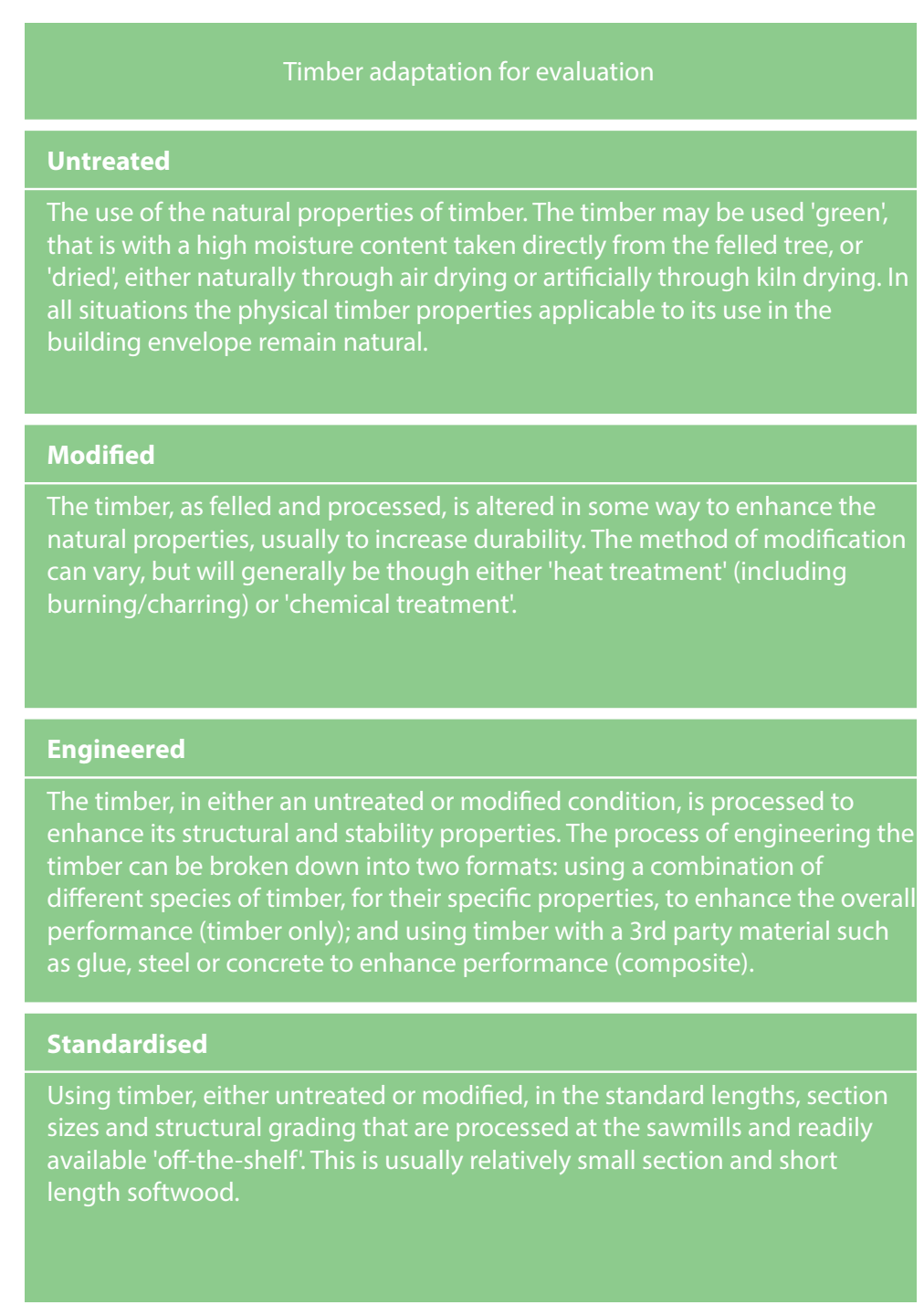

Timber industry criteria for evaluation

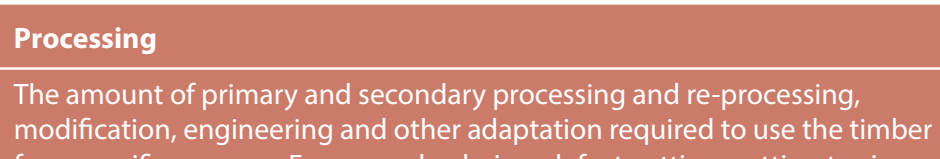

modification, engineering and other adaptation required to use the timber planing, profling, gluing and treatments.

\section{Tools/machinery}

The scale and complexity of tools and machinery used to manufacture the product from hand tools, to operative-controlled machines to large scale

automatic machines in factories.

\section{Fabrication \& construction}

Whether the majority of work is conducted on-site or prefabricated off-site a factory and the scale of prefabrication from on-site construction, elements components and panels to large scale engineering and volumetric modules.
This will reflect the scale and complexity of delivery and assembly on-site This will refiect the scale and complexity of delivery and assembly on-site,
ranging from low-tech elemental traditional hand construction high-skill ranging from low-tech elemental traditional hand construction, high-skill
bespoke construction to general contractor based lifting, moving and fixing

\subsubsection{Building envelope}

The use of Welsh-grown timber will be focused on the architectural building envelope, as providing the greatest demands on the properties of timber. It has been identified that the building envelope must meet a range of demanding performance requirements including 2 significant ongoing movements within construction: smart construction leading to efficient prefabricated systems; and sustainable leading to low-or zero-carbon building performance. ${ }^{3}$ Both of these are highly achievable using timber within the building envelope as demonstrated in precedents from around the World.

\section{Technology and skills}

Furthermore any fabrication, manufacturing and construction with this timber will be considered in light of the barriers and opportunities that have been identified within the timber industry from forest management though processing to the construction industry. This will primarily be focussed on the processing of timber into sawnwood and products and the limitations on technology and skills available to process and construct. The industry is considered as equipped with low-medium technology producing basic prefabricated components and skills ranging from the limited traditional and bespoke to the general carpenter, assembling prefabricated components. Therefore, the following parameters will be used to guide reflections on the designs: the amount and complexity of primary and/ or secondary processing required to modify, engineer and adapt; the scale and complexity of tools and machinery required to manufacture and construct; and the level of onsite construction and/or off-site prefabrication required as well as the scale and complexity of components to assemble.

\section{Tectonic form}

The designs and prototype projects are architectural components, assemblies and buildings. Therefore the implications of using Welsh-grown timber in the building envelope, within the barriers and opportunities of the timber industry will be evaluated against the qualitative parameters of tectonic form. This will lead to a consideration of a 'timber tectonic' initially under the parameters of: context; tradition and innovation; technology; and the corporeal, as detailed in 5.7.1.

Fig 5.1 Timber adaptation for evaluation

Fig 5.2 Timber industry criteria for evaluation
3 HM Government, Industrial Strategy: government and industry in partnership, UK Construction 2025, (London: HMSO 2013) p.4 
The criteria above will be tested, evaluated and reflected on a number of prototype projects. The prototype studies are not divided into projects, chronological order or building typologies, but clustered under four key themes that have emerged from the woodland, industry and building envelope review that cover differing approaches and building envelope components. The themes and following chapters for study are:

Research method
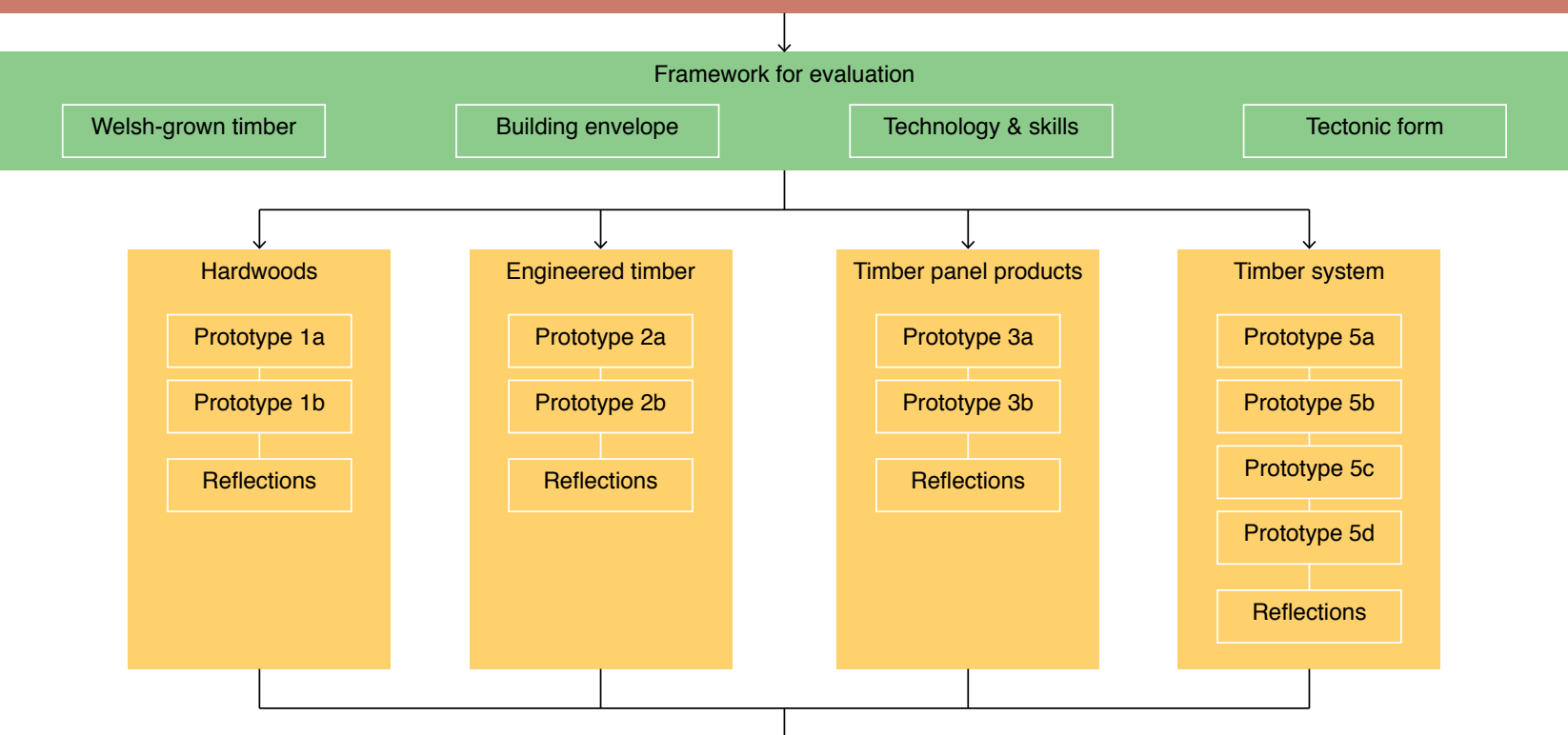

Thesis findings

\section{Hardwoods}

Welsh-grown hardwood is underused and limited in availability despite there being an almost 50:50 split between softwood and hardwood species growing in Wales. In the UK, only $15 \%$ of the round hardwood felled is processed at sawmills contributing to $1 \%$ of the total soft or hard sawnwood produced. $11 \%$ of the hardwood consumed is processed in the UK with the remainder imported. However, the forecast for hardwood availability is expected to increase by up to $934 \%$ between 2013 and $2046^{4}$ potentially resulting in more hardwood available to use, although the longer yield times mean that care needs to be taken in selecting timber to ensure longer term availability and the sustainability of the, often indigenous, woodlands. The hardwoods also offer beneficial properties in terms of strength and durability for use in the building envelope. It is for these reasons that the use of hardwood, within these limitations, will be explored.

\section{Engineered timber}

The vast majority of timber felled, processed, imported and used within the timber and construction industries is softwood. This is predominantly spruce, larch and Douglas fir. Within Wales, the significant species for use in construction is Sitka spruce with limited structural grading, poor durability properties, high levels of moisture movement and limited range of sizes. The precedents identified that the majority of innovative, contemporary timber architecture in mainland Europe uses engineered timber to improve performance, efficiency and push the building envelope further than possible with solid softwood. Currently, in Wales, there are no means to manufacture engineered timber components on a commercial and cost effective scale, resulting in increasing levels of importation. This study will evaluate the use of engineered timber in Wales. 


\section{OBJECTIVE}

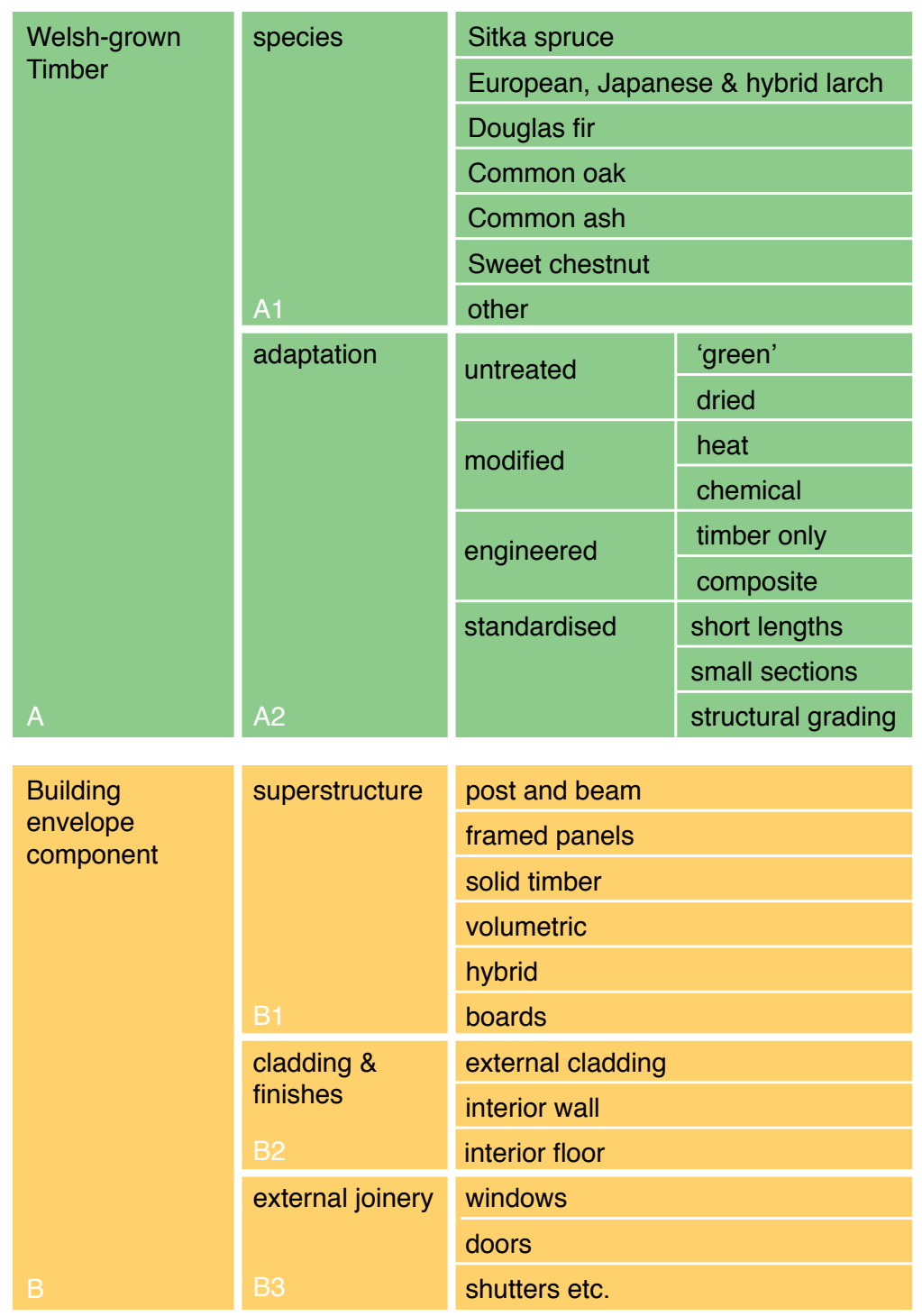

\begin{tabular}{|c|c|c|}
\hline \multirow{10}{*}{$\begin{array}{l}\text { Technology \& } \\
\text { Skills }\end{array}$} & \multirow{3}{*}{$\begin{array}{l}\text { processing } \\
\text { C1 }\end{array}$} & general manipulation \\
\hline & & primary \\
\hline & & secondary \\
\hline & \multirow[t]{2}{*}{ fabrication } & hand crafted/ hand tools \\
\hline & & operative controlled \\
\hline & $\mathrm{C} 2$ & automatic machines \\
\hline & \multirow[t]{4}{*}{ construction } & on-site \\
\hline & & off-site \\
\hline & & low-tech (DIY) \\
\hline & & high-skill (bespoke) \\
\hline C & $\mathrm{C} 3$ & contractor (general) \\
\hline
\end{tabular}

Tectonic
form

Tectonic
form

\begin{tabular}{|l|l|}
\hline context & \\
\hline tradition \& & materials \\
\hline innovation & detail \\
\hline technology & construction \\
\hline & sustainability \\
\hline the corporeal & \\
\hline
\end{tabular}

\section{Timber panel products}

Timber panel, or board, products were identified in the Jaakko Poyry report ${ }^{5}$ to be of interest to the Welsh processing industries. MDF and particleboard are made in Wales with OSB made in Scotland, but no plywood is manufactured in the UK. There could be potential for the primary and secondary processing industries to consider the manufacture of panels as a value added product that could make use of the readily available Sitka spruce pulp and chips for OSB. There is enormous potential for the integration of panel products directly into the current market for timber frame construction, although there may be further innovative uses within the building envelope to consider.

\section{Complete timber system}

This study evaluates the use of Welsh-grown timber as a complete timber building system integrated with tectonic form. The focus of the above studies are incorporated into the design of a prefabricated, domestic-scale construction system that includes the use of soft- and hardwood for their property specific uses. All elements of the building envelope are considered from structure and infill, external and internal finishes and external joinery. Of particular concern is the use of the low-valued, under-used, low-yield and poor quality species and how these can be incorporated into high-value and durable solutions.

\section{Matrix}

The above criteria and study themes have been incorporated into the following framework for evaluation. Each design study chapter will have its own findings, using this matrix, based on the focus of the study and in relation to the overall aim and objectives. This overall matrix, including all projects, will be used in the findings to the thesis to evaluate the use of Welsh-grown timber in the design and construction of components of the building envelope. 


\subsection{Research method}

To address the aim and objectives, the studies, in the following chapters, will involve a range of research approaches. The thesis engages primarily with practice-based design research through the construction of prototype components, assemblies and buildings. These designs and prototypes are then reflected on against the quantitative and qualitative framework for evaluation established from the review of the woodlands, timber properties and timber industry in Wales and the author's approach to design. However, the thesis prototypes do not attempt to resolve these problems by finding direct solutions. Instead bottom-up material experiments alongside top-down architectural design will demonstrate ways of working and using Welsh-grown timber within the context of both the problems and opportunities. As such the research approach will be a hybrid of methods, ${ }^{6}$ engaging with interpretive research on the one hand and performative and reflective research on the other. In this section the research method and structure of the themed design studies is explained and contextualised.

As it is intended to evaluate designed and built prototype projects against the framework, initially the role of the author in the design process will be explained to highlight the role of practice and the author's design approach that has influenced design decisions. This is followed by an overview of the format of the design study chapters before providing context on research methods, justification of the design and prototype process, selection of design projects and the structure of the design study chapters.

The final section highlights the process by which the projects are reflected on and findings presented.

\subsubsection{The role of the author}

The author, as an architect, has been a member of the Design Research Unit Wales (DRU-w) at the Welsh School of Architecture since 2002. DRU-w was established, in 1999, to implement architectural, urban design and landscape projects with the aim of founding the creative activities of the design studio on a sound research-based approach. Although a relatively young organisation, DRUw has attracted a number of commissions in which research-based design is married to notions of sustainability, tectonics, material innovation, environmental and functional performance, and economy. The aim was to make architecture of simple, elemental forms, constructed in a logical, legible and resourceful way from local materials.

6 Linda Groat and David Wang, Architectural Research Methods, (New York: John Wiley \& Sons, Inc, 2002) 
Working mainly in Wales, projects have required a carefully considered response to the sensitive landscapes or industrial and urban contexts, which are typical of Wales. Schemes are pursued through collective and collaborative endeavour in partnership with other consultants and the shared interests of the members of DRU-w. This shaped each project through rigorous and critical analysis of all parameters informing the conceptualisation, development and solution of the project.

A key field of interest of the author is 'tectonic form', inspired essentially by context and materiality. Inspiration is drawn from two established architectural movements: Tectonic form and culture and building simply. These could be described as having many similarities, and as such a number of categories have been identified to explain the design approach used within this thesis and on the prototype projects. Explanations of these themes have been established from two principle sources: An MPhil thesis by a former colleague of DRU-w, Amanda Spence (nee Heal), entitled 'Building Simply: An Investigation into the potential for building simply in the UK', submitted in 2011; and 'Studies in Tectonic Culture: The poetics of Construction in Nineteenth and Twentieth Century Architecture', by Kenneth Frampton, published in 1995.

The definitions of these two terms, as employed by the author in this thesis, are:

Building Simply - 'To build simply means to design and construct in a direct but refined and artful way, producing buildings of simple form and visual calm often constructed with the appropriate use of a predominant local material. An ethical and economical approach to sensible resource use and a critical approach to site are adopted. Buildings are designed with quiet appropriateness in mind, rather than the louder formal manifestation of other contemporary architecture. Building simply is not concerned with purely visual simplicity; it is concerned with minimisation to give tectonic clarity and not minimalism as an aesthetic style. ${ }^{17}$

Tectonic form - '... a certain expressivity arising from the statical resistance of constructional form in such a way that the resultant expression could not be accounted for in terms of structure and construction alone.8

7 Amanda Heal, 'Building Simply: An Investigation into the potential for building simply in the UK' (unpublished MPhil thesis, Cardiff University, 2011), p.4

Eduard Sekler's definition from the 1973 essay 'Structure, Construction and Tectonics', cited in Kenneth Frampton, Studies in Tectonic Culture: The Poetics of Construction in Nineteenth and Twentieth Century Architecture, (Cambridge: MIT Press 1997), p.19 and printed in Gyorgy Kepes, ed. Structure in Art and Science, (New York: Braziller) pg. 89-95 

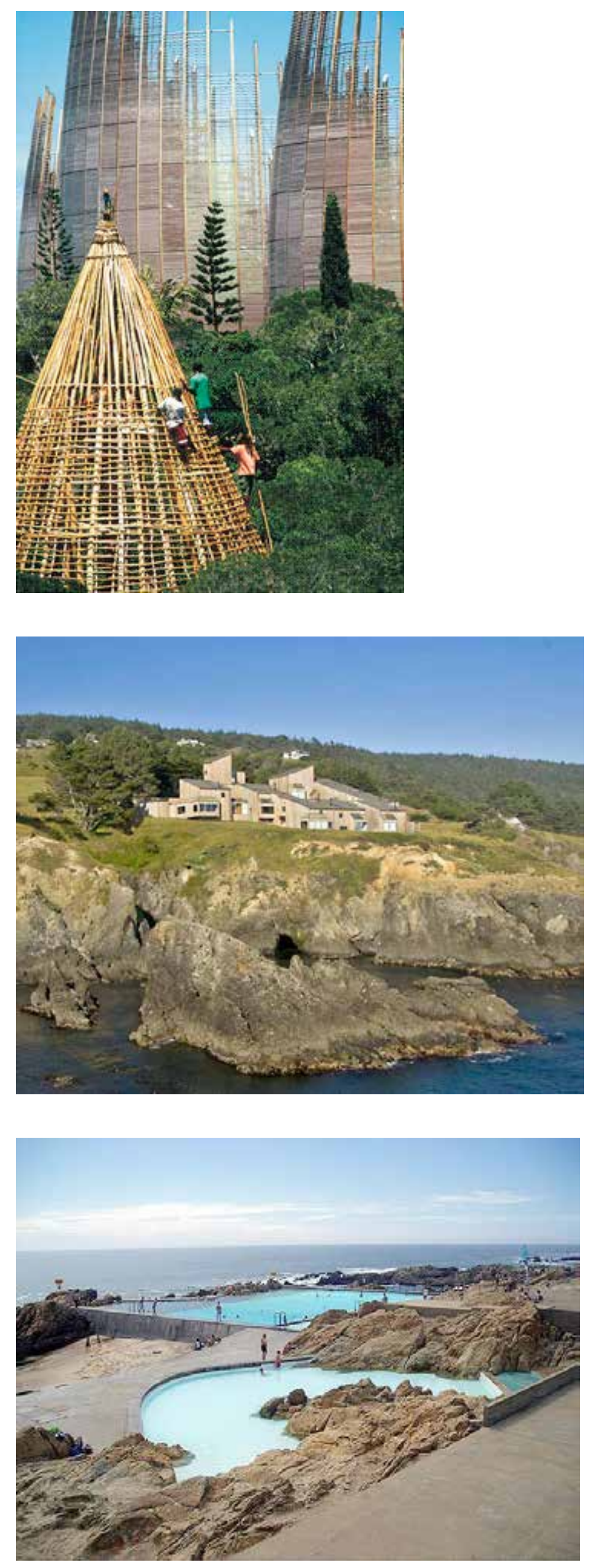

TOP

Fig 5.5 Tradition and Innovation, Tjibaou

Cultural Centre, Noumea, Renzo Piano

MDDLE

Fig 5.6 Originally conceived as a new

community that harmonized with

its environment, The Sea Ranch,

California, Charles Moore

BOTTOM

Fig 5.7 Concrete walls extend into the sea and around existing rock formation context, Leça Swimming Pools, Po Alvaro Siza

\section{Context}

'...Through the concept of the site and the principle of settlement, the environment becomes [on the contrary] the essence of architectural production. From this vantage point, new principles and methods can be seen for design.'

Designing for, with and on site involves a thorough analysis of the landscape and surrounding context at the start of any project. Landscape is used in its broadest terms to be any geographical context, whether rural or urban, that provides inspiration from topography, interventions and human interaction. The analysis may be drawn, interpretative or modelled studies, but will be used to ensure that any proposal is socially and culturally connected to the context through form, material, detail and employing appropriate environmental strategies to reduce energy consumption that when combined generates a sense of that place.

\section{Tradition and innovation: material \& detail}

Kenneth Frampton describes this notion of tradition and innovation as: 'Material constraints aside, innovation is...contingent upon a self-conscious rereading, remaking, and re-collection of tradition, including the tradition of the new, just as tradition can only be revitalized through innovation! ${ }^{10}$

The tectonic form of a building is determined by the choice and use of materials and the resultant details and joints between them. This requires an understanding of material properties and construction detailing. To build simply, materials are to be expressed honestly with only the natural rules of the material determining construction. Materials should provide a connection between the building occupants, the construction process and material origins. Ideally, materials will be sourced local to the site, to maintain cultural significance and lower embodied energy.

\section{Making}

Designs and construction process are simultaneously explored through the act of making, with 1:20 modelling or larger scale prototyping, crafting drawings, developing designs through section and an understanding of the construction process evoke sensory engagement, in collaboration with local industries and suppliers. Models are often crafted in individual components or elements that can be assembled in a similar sequence to the on-site

9 Vittorio Gregotti cited in Kenneth Frampton, Studies in Tectonic Culture: The Poetics of Construction in Nineteenth and Twentieth Century Architecture, (Cambridge: MIT Press 1997), p.8

10 Frampton, p.25 
construction. Such studies embody a curiosity with the expressive potential of materials, technologies, juxtapositions, connections and detail as a formative move in designing architecture.

\section{Technology: construction}

The author is interested in the benefits of tectonic prefabrication, that celebrate production as a means to build, leading to an architecture informed by a systems based approach but remaining site specific. This could be seen as a large scale, elemental or additive form of construction as proposed by Jorn Utzon, in 1970, where 'A consistent utilisation of industrially produced building components can only be achieved if these components can be added to the buildings without having to be cut to measure or adapted in any way.' (Jorn Utzon, Additive Architecture, Arkitektur 1, 1970) Designed within rules means that the design and construction philosophy of prefabricated components can be the same as bespoke site made architecture.

\section{Technology: sustainability}

An assumption that the projects are designed to be 'sustainable' and climate responsive is at the core of all projects. Economic and environmental sustainability means to design within an economy of means and in particular a concern for the consumption of energy and resources. 'By reduction of needs and consumption, the disruption potential of buildings with regard to equilibrium in the environment can be reduced. The law of economy should lead to a specific (passive) architecture that uses resources sparingly. Technical systems are simplified or omitted.' ${ }^{11}$

\section{The corporeal}

The culmination of and connection between architectural form, space, culture and the construction process reveals the corporeal experience. Tectonics, as the art and poetics of construction, is founded in possibilities for emotional contact between an individual and a building. The ontology of building fabric - the tangible presence which derives from a crafted structure - has the potential to evoke a deep sensory response. Textures, smells, shadows and feelings of a building have real potential to enrich human life. It is this level of construction which is a critical process through which projects are interrogated as an aesthetic of the built form rather than just a technological category.

Fig 5.9 The act of making and craft, Tom Kundig

воттом

Fig 5.10 The corporeal experience, Swiss Pavilion, Peter Zumthor

11 Florian Musso, 'Simply Good' in Building Simply, ed. by Christian Schittich (Birkhauser Architecture, 2001) pp.10-25 (p.16) 
The analysis of each design study and prototype will follow a similar structure. The purpose, as already discussed, is to provide a structure which enables the process of design and prototyping to become a method of research, and incorporates reflection as a means to evaluate the process and output.

Each study starts with an introduction on the prototype projects that will form the study, including a tabulated overview of the project(s) and design team details and the specific research aim, objectives and limitations. This is followed by a literature and precedent review to provide the context of focus on each study. Precedents are considered to reflect the best of contemporary design and construction from around the world and at the forefront of innovation in timber architecture and therefore based on a wider cycle of reflection and action from previous research and development. In some cases the context has directly informed the prototype study through design, detailing or construction. In others the literature is provided to contextualise the research behind the prototype study.

The context and structure of the design, prototype and reflection stages are now described.

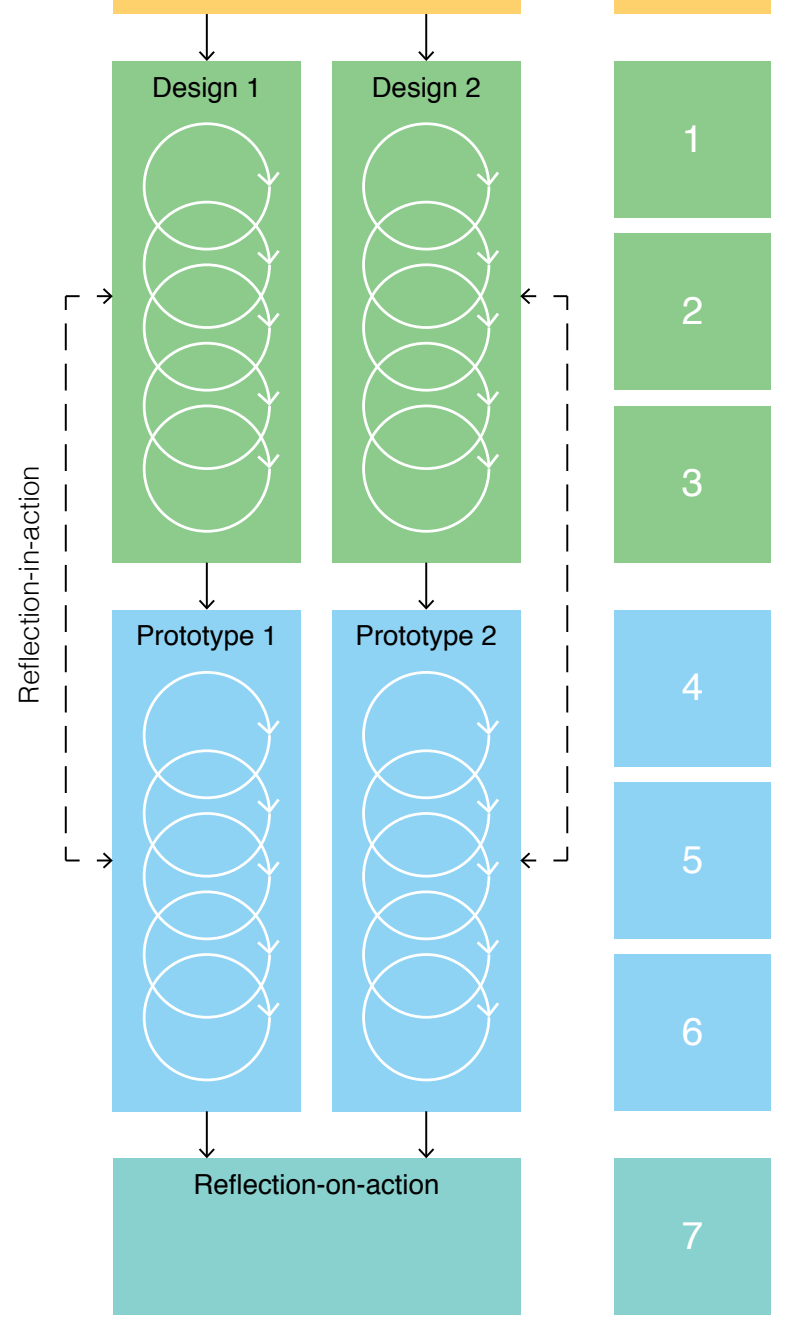


Performative research

introduced by Brad Haseman as a development of qualitative research, with the main difference being through the expression of a symbolic form or could be equivalent to text or numbers in that 'It not only expresses the research, but in that expression becomes the research itself

\section{Design-oriented research}

IIn design-oriented research, the knowledge that comes from studying the designed artefact in use or from the process of bringing the product into being should be seen as the main contrib thio

\section{Research-oriented design \\ IIn research-oriented design, the artefact is the product or primary outcome; it is regarded as the result of their efforts... Here the artefact takes on a much clearer research-oriented design is the level of completeness and stylling of the resulting artefact Here the artefacts often come in the shape of final 'products' rather than as sketches and prototypes. \\ Practice-based research \\ Linda Candy at the University of Technology, Sydney, in a guide for research- in order to gain new knowledge partly by means of practice and the outcomes that practice. In a doctoral thesis, claims of originality and contribution to know edge may be demonstrated through creative outcomes in the form of designs, music, diginal media, performances and exhibitions. Whilst he significance and erstanding can only be \\ Constructive-oriented research \\ '... design research in which construction - be it product, system, space or media specific purpose of this method is to merge the interests, processes and skills of practitioners into the realities of an actual output, whereby the experime tal 'thing' embodies the nature of the research. \\ Source: 1 Brad Haseman,'A Manifesto for Performative Research', Media \\ and Policy, no. 118 (2006) pp. 98-106 2 Daniel Fallman, 'Design-oriented Human-Computer Interaction', Proceedings of (New York, NY: ACM Press), pp. 225-232 (p.231)

\subsubsection{Design research}

The framework criteria are to be tested through two creative forms of research by doing: designing and prototyping. This section provides context behind research by design and application in this thesis.

\subsubsection{Practice-based research}

The design process has divided opinion as to the validity, means and outputs of design as research. Since the 1990's the processes of design, research and design research have become more focused, leading to a number of design research centres in Australia, USA and UK each with slightly differing models. The models opposite have been identified as relevant methods of research through design for this thesis.

While these methodologies each have a slightly different approach to design research and the means to deliver, analyse and produce through practice, they share a common agenda that puts an emphasis on the roles of design, practice and physical outputs within the research. In this thesis, the design of innovative Welsh-grown timber buildings would not in itself constitute research and would not generally be accepted as rigorous enough to produce empirical subject matter However, the notion of practice as the means to conduct the research and that all material outputs from practice are representations and/ or the results of research findings, highlights that the processes involved with practice and designing can provide a legitimate method for conducting research.

It is therefore proposed that this thesis is situated within the practice-based research ${ }^{12}$ methodology established at the University of Technology, Sydney, although there will be an increased emphasis on the 'artefact' as a means to test, analyse and demonstrate research aims, objectives and generate findings. In this sense, it is seen that the performative aspect of design and construction (making) can lead to physical artefacts and prototypes that are both the process of research and primary outcomes as hinted at in research-oriented and constructive-oriented research. method definitions
12 Linda Candy, 'Practice Based Research: A Guide', Creativity \& Cognition Studios 1 (Sydney: niversity of Technology, 2006), p.1 


\begin{tabular}{|c|c|c|c|c|c|c|c|}
\hline & \multicolumn{7}{|c|}{ Study project details } \\
\hline & Project & Year & Location & Client & Design team & & Cost \\
\hline 1 & Beach Hut & 2002 & $\begin{array}{l}\text { Port Eynon } \\
\text { Gower Peninsula }\end{array}$ & $\begin{array}{l}\text { City and Council of } \\
\text { Swansea }\end{array}$ & $\begin{array}{l}\text { Architect: } \\
\text { Engineer: } \\
\text { Timber advice: }\end{array}$ & $\begin{array}{l}\text { Design Research Unit Wales } \\
\text { Arup } \\
\text { Coed Cymru }\end{array}$ & $£ 50 \mathrm{k}$ \\
\hline 2 & $\begin{array}{l}\text { Social housing } \\
\text { (SHIP) }\end{array}$ & 2002 & $\begin{array}{l}\text { Fford Eira } \\
\text { Gorseinon }\end{array}$ & $\begin{array}{l}\text { Gwalia Housing } \\
\text { Association, Social } \\
\text { Housing Innovation } \\
\text { Programme }\end{array}$ & $\begin{array}{l}\text { Architect: } \\
\text { QS/ PM: } \\
\text { Contractor: }\end{array}$ & $\begin{array}{l}\text { Design Research Unit Wales } \\
\text { PCKO Architects } \\
\text { ER Brown } \\
\text { Tycroes }\end{array}$ & f1.2M \\
\hline 3 & $\begin{array}{l}\text { Eisteddfod } \\
\text { pavilion }\end{array}$ & 2004 & $\begin{array}{l}\text { Tredegar Park } \\
\text { Newport }\end{array}$ & Cardiff University & $\begin{array}{l}\text { Architect: } \\
\text { Engineer: } \\
\text { Construction: }\end{array}$ & $\begin{array}{l}\text { Design Research Unit Wales } \\
\text { lan Jones } \\
\text { WSA staff \& graduates }\end{array}$ & $£ 15 \mathrm{k}$ \\
\hline 4 & $\begin{array}{l}\text { Mezzanine } \\
\text { floors }\end{array}$ & 2004 & $\begin{array}{l}\text { Bute Building } \\
\text { Welsh School of } \\
\text { Architecture }\end{array}$ & Cardiff University & $\begin{array}{l}\text { Architect: } \\
\text { Enginieer: } \\
\text { MEE: } \\
\text { Contractor: }\end{array}$ & $\begin{array}{l}\text { Design Research Unit Wales } \\
\text { Veryards Opus Ltd } \\
\text { Cardiff University Estates } \\
\text { Cartwright Construction }\end{array}$ & £250k \\
\hline 5 & $\begin{array}{l}\text { Stress-lam } \\
\text { refectory } \\
\text { table }\end{array}$ & 2004 & $\begin{array}{l}\text { Bute Building } \\
\text { Welsh School of } \\
\text { Architecture }\end{array}$ & $\begin{array}{l}\text { Welsh School of } \\
\text { Architecture }\end{array}$ & $\begin{array}{l}\text { Architect: } \\
\text { Engineer: } \\
\text { Joiner: }\end{array}$ & $\begin{array}{l}\text { Design Research Unit Wales } \\
\text { Nicholson Jones } \\
\text { Dainis Dauksta }\end{array}$ & $£ 2 k$ \\
\hline 6 & Social housing & 2008 & St Athan & $\begin{array}{l}\text { Wales and West } \\
\text { Housing Association }\end{array}$ & $\begin{array}{l}\text { Architect: } \\
\text { Engineer: } \\
\text { Contractor: }\end{array}$ & $\begin{array}{l}\text { Design Research Unit Wales } \\
\text { Powell Dobson Architects } \\
\text { Blackuurn Griffths } \\
\text { Lovell }\end{array}$ & £2.25M \\
\hline 7 & $\begin{array}{l}\text { Margam } \\
\text { Discovery } \\
\text { Centre }\end{array}$ & $\begin{array}{l}2008- \\
2010\end{array}$ & $\begin{array}{l}\text { Margam Country } \\
\text { Park }\end{array}$ & $\begin{array}{l}\text { Neath Port Talbot } \\
\text { Borough Council, } \\
\text { Field Studies Council }\end{array}$ & $\begin{array}{l}\text { Architect: } \\
\text { QS, PM, CDM: } \\
\text { Engineer: } \\
\text { M\&E: } \\
\text { Contractor: }\end{array}$ & $\begin{array}{l}\text { Design Research Unit Wales } \\
\text { Loyn and Co Architects } \\
\text { EC Harris } \\
\text { Faber Maunsell } \\
\text { Faber Maunsell } \\
\text { WRWConstruction }\end{array}$ & E4.9M \\
\hline 8 & $\begin{array}{l}\text { Ty Unnos } \\
\text { system }\end{array}$ & $\begin{array}{l}2008- \\
2014\end{array}$ & & $\begin{array}{l}\text { Coed Cymru } \\
\text { Forestry Commission Wales } \\
\text { Countryside Council Wales } \\
\text { Environment Agency Wales } \\
\text { Technology Strategy Board }\end{array}$ & $\begin{array}{l}\text { Architect: } \\
\text { Engineer: } \\
\text { Consultant: } \\
\text { Specialists: } \\
\text { Testing/ } \\
\text { certification: }\end{array}$ & $\begin{array}{l}\text { Design Research Unit Wales } \\
\text { Burroughs } \\
\text { The Biocomposites Centre, } \\
\text { Bangor University } \\
\text { Cowley Timberwork, Kenton } \\
\text { Jones Ltd, Coed Cymru } \\
\text { BRE Wales, TRADA }\end{array}$ & f500k \\
\hline 9 & $\begin{array}{l}\text { Smithsonian } \\
\text { Folklife Festival } \\
\text { Pavilion }\end{array}$ & 2009 & $\begin{array}{l}\text { The Mall, } \\
\text { Washington DC, } \\
\text { USA }\end{array}$ & Welsh Government & $\begin{array}{l}\text { Architect: } \\
\text { Engineer: } \\
\text { Contractor: }\end{array}$ & $\begin{array}{l}\text { Design Research Unit Wales } \\
\text { Burroughs } \\
\text { Elements Europe, Kenton } \\
\text { Jones Lttd, Coed Cymru }\end{array}$ & $£ 40 \mathrm{k}$ \\
\hline 10 & $\begin{array}{l}\text { Environmental } \\
\text { Resource } \\
\text { Centre (ERC) }\end{array}$ & 2010 & $\begin{array}{l}\text { Steelworks Road } \\
\text { Ebbw Vale }\end{array}$ & $\begin{array}{l}\text { Blaenau Gwent County } \\
\text { Borough } \\
\text { Council, Gwent Wildlife } \\
\text { Trust }\end{array}$ & $\begin{array}{l}\text { Architect: } \\
\text { Engineer: } \\
\text { M\&E: } \\
\text { Specialists: } \\
\text { Contractor: }\end{array}$ & $\begin{array}{l}\text { Design Research Unit Wales } \\
\text { Cowley Timberwork \& } \\
\text { Halcrow (now CH2M) } \\
\text { Halcrow (now CH2M) } \\
\text { Cowley Timberwork, } \\
\text { Coed Cymru } \\
\text { G Adams Construction Ltd }\end{array}$ & f315k \\
\hline 11 & Longhouse & 2010 & $\begin{array}{l}\text { Lime Avenue } \\
\text { Ebbw Vale }\end{array}$ & $\begin{array}{l}\text { Blaenau Gwent County } \\
\text { Borough }\end{array}$ & $\begin{array}{l}\text { Architect: } \\
\text { Engineer: } \\
\text { M\&E: } \\
\text { Specialists: } \\
\text { Contractor: }\end{array}$ & $\begin{array}{l}\text { Design Research Unit Wales } \\
\text { Burroughs } \\
\text { WSA \& BRE Wales } \\
\text { Kenton Jones Ltd, } \\
\text { Coed Cymru } \\
\text { G Adams Construction Ltd }\end{array}$ & $£ 250 \mathrm{k}$ \\
\hline
\end{tabular}

Fig 5.13 Prototype study project details

\subsubsection{Selection of design projects}

The projects have been selected from within the Design Research Unit Wales between 2002 and 2012, and have been worked on by the author as lead architect and researcher. The projects have been chosen in relation to their sustainability, use of local material and consideration of tectonic form in the design process, as discussed in section 5.7.1. Many of the projects were conducted in parallel to this thesis and therefore provided an opportunity to integrate the shared research aims into the design and construction process in collaboration with the clients and wider design team. However, while it was the intention to follow a research by design approach as part of the design process for each project, the specific research outcomes are based on the way they are revisited within this thesis and not necessarily on the original aims of each individual project. The 'real-world' situations that have provided the opportunity, have given parameters to the research that ensure the design and prototype solutions are feasible propositions in the use of Welsh-grown timber.

The table opposite provides details of the prototype projects considered in this thesis. Most of the projects have been built, but each project varies in scale, complexity and number of prototype stages.

Each project has been designed within the Design Research Unit Wales, influenced by the author's design and following the RIBA Plan of Work ${ }^{13}$. As part of the design process, projects have been reviewed by colleagues (architects), design consultants, clients and other specialists and responded to in a continual cycle of development to ensure the design meets both the client aims, legislative requirements and the research aim. The design stages will be reported primarily in a chronological sequence, highlighting key decisions and actions in relation to the research aims and objectives. In reality these stages were cyclical and spiral, overlapping with other decisions and design parameters, towards the end result. For example ideas were proposed, discussed with team, developed, researched, changed, subjected to further consultations and legislation, costed, tested and specified. This can be seen as reflection-in-action informed, influenced and justified by a mix of client requirements, expert opinion and design testing.

The projects vary in their location, client, function and typology, scale and complexity from unbuilt designs and furniture to temporary exhibition pavilions and permanent publicly accessible buildings. As such each project will be reported in the same format to maintain continuity and provide the details required to evaluate against the aims of each prototype study and the overall thesis objectives as highlighted in

13 Dale Sinclair (ed.), RIBA Plan of Work 2013, (London: RIBA Publications 2013) 
Presentation of design

- Project/ client brief

The details of the client and their design aspirations as provided to or developed with the design team.

- $\quad$ Site and context

A description of the site and its macro and micro location,

a site analysis including opportunities and constraints and climatic

considerations and an appraisal of historic, social or cultural

contexts relevant to the project.

- Architectural concepts/vision

A description of the design concepts and how they will influence the project.

- Design development

A description and illustration of key design development stages and iterations.

- Final design drawings and models

The final design drawings or planning application drawings and models will be illustrated. the framework for evaluation. Each design study is purpose designed for the clients needs, considering context and site conditions. They all comply with technical and legislative requirements, relevant at the time they were designed and built, including planning approval, quality standards and the building regulations. Reflection on the design process will highlight how timber is incorporated, detailed and the influences that design aspirations and/ or Welsh-grown timber have on tectonic form.

This part of the study will focus on the project stages 0-3, from RIBA Plan of Work $2013^{14}$ (Stages A-D from the 2007 Plan of Work), from project inception to developed design and/ or a detailed planning application. Annotated drawings, diagrams and model photographs will be used as much as descriptive text to explain the design intentions, layout and performance. The design will be reported under headings appropriate to the project, such as those opposite, without bias so as to test and reflect on the use of timber as designed and specified rather than predetermined or post rationalised.

\subsubsection{Prototype}

This section provides context on the importance of making and research through prototyping to establish a model by which to categorise and reflect on different types of prototype and how they will be used to evaluate the research objectives. The physical making process is discussed as a process by which timber use will be tested and evaluated.

The main focus of the prototype studies will be on the detailing, manufacture and construction although not all the designs have been built, with some stopping at detailed design and production information for tender. As with the design section, the focus will be on reporting the prototype stages without bias towards the research aim. Reflection on this section will highlight species performance, technology and skills in relation to manufacture and construction as well as the implications on tectonic form that were not necessarily expected at design stage.

This section will focus on the project stages 4-6, from RIBA Plan of Work 2013 (Stages E-K from the 2007 Plan of Work), from technical design to project completion and handover including production information, tender and off- and on-site construction. First hand experience, annotated drawings, calculations and 


\section{Presentation of prototypes}

Detailed design and models

The translation of the design and planning drawings into production information and a specification for tender and construction will be reported in relation to design development and alterations of the use of Welsh grown timber. The drawings will vary in detail from general arrangement drawings highlighting the overall layout to fabrication drawings with every component detailed and specified for fabrication. In some cases physical and digital models were also developed to aid the design process and used to show the design team, manufacturers and contractors.

Design team consultation

Where relevant, details of the collaboration and decisions with other design consultants will be reported. These may include structural engineers, timber specialists, mechanical and electrical (M\&E) engineers, manufacturers as well as Building Control.

\section{- Off-site fabrication}

A description of the process of off-site fabrication, where relevant will focus on the technology, skills and process of manufacturing timber components of the design. This will predominantly be conducted through annotated photographs and drawings.

- On-site construction sequence

A report on general site construction and the erection and assembly of components using annotated photographs.

- Completed prototype

The final prototype will be presented in photographic for highlighting the integration of the research aims and use of Welsh grown timber.

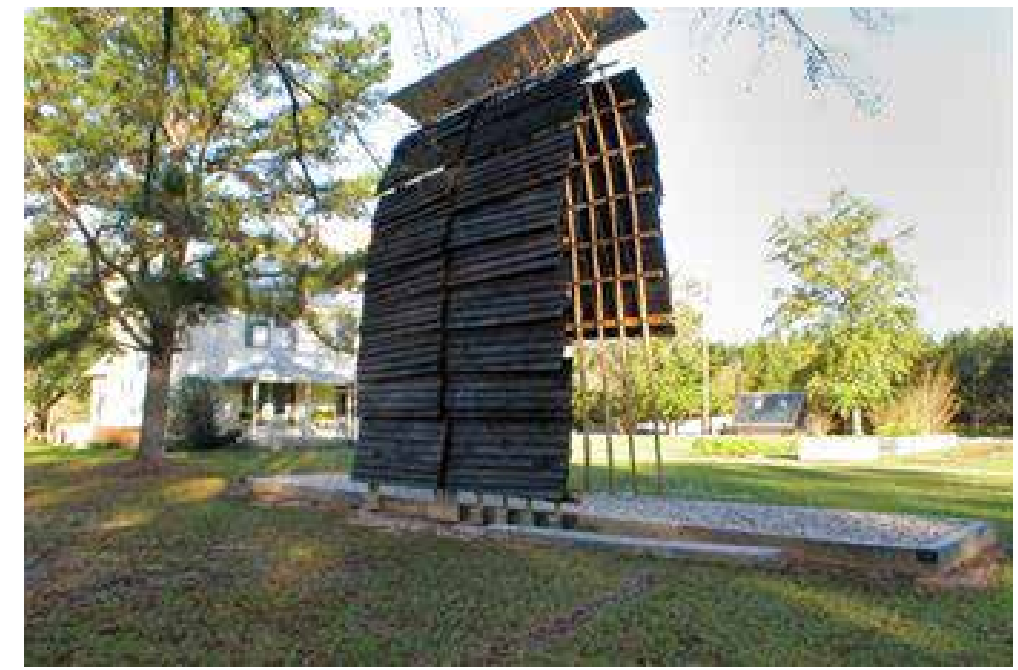

photographs of the fabrication, construction and erection sequences will be used to highlight the key aspects of the prototyping process and outcome. Each prototype will be reported in the same format, using the headings opposite, as appropriate to the study.

\subsubsection{Design through making}

The making of prototypes is critical to this thesis and result from a series of 'conversations with materials' ${ }^{\prime \prime 6}$ where the 'conversations' are interactions between the designer and the design medium. The production of prototypes affords unexpected realisations that a designer could not have arrived at without producing an artefact. It is, therefore, through the creation of prototypes that designers learn about the problem they are trying to solve. Donald Schon summaries that 'Design knowledge is knowing in action, revealed in and by actual designing. It is mainly tacit, in several sense of the word: designers know more than they can say, they tend to give inaccurate descriptions of what they know, and they can best (or only) gain access to their knowledge in action by putting themselves into the mode of doing... ${ }^{17}$

The terms, 'knowing in action,' and 'mode of doing' are critical to the justification of making, modelling, fabrication, construction, installation and assembly as forms of both designing and prototyping. This could also be referred to as design through making. In this thesis the author has, wherever possible, actively engaged in the physical making processes either at early modelling or component testing stages or in the construction of an entire structure. Where it has not been possible to become hands-on, the author, as architect, has worked closely with the joiners, carpenters and builders to continue to understand, develop and respond to the design through making. It is this engagement with timber, that Schon has observed as providing different appreciations of material ability and allowing designs to develop through a combination of design thinking and building. ${ }^{18}$

This concept of design through making is not new. Architects were once at the top of the design and construction process, and often master masons, working on design, form, composition, detailing, material science and construction. The distance between the architect and fabrication is now further apart than it has ever been as Bob Sheil comments, 'Most architects do not make buildings - they make information for buildings. ${ }^{19}$ This interest in the tacit and physical of making has not, however,

16 Donald Schon, 'Designing as Reflective Conversation with the Materials of a Design Situation' Keynote talk for the Edinburgh Conference on Artificial Intelligence in Design, 25th June 1991 in Research in Engineering Design, Vol 3, Issue 3, (USA: Springer-Verlag, 1991) pp.131-147 (p.131) 17 Ibid, p.131

18 Ibid, p.141

19 Bob Sheil,'Design Through Making: An Introduction', Design Through Making, Architectural Design vol.75, No.4 (London: Wiley-Academy, 2005), pp.5-12 (p.6) 

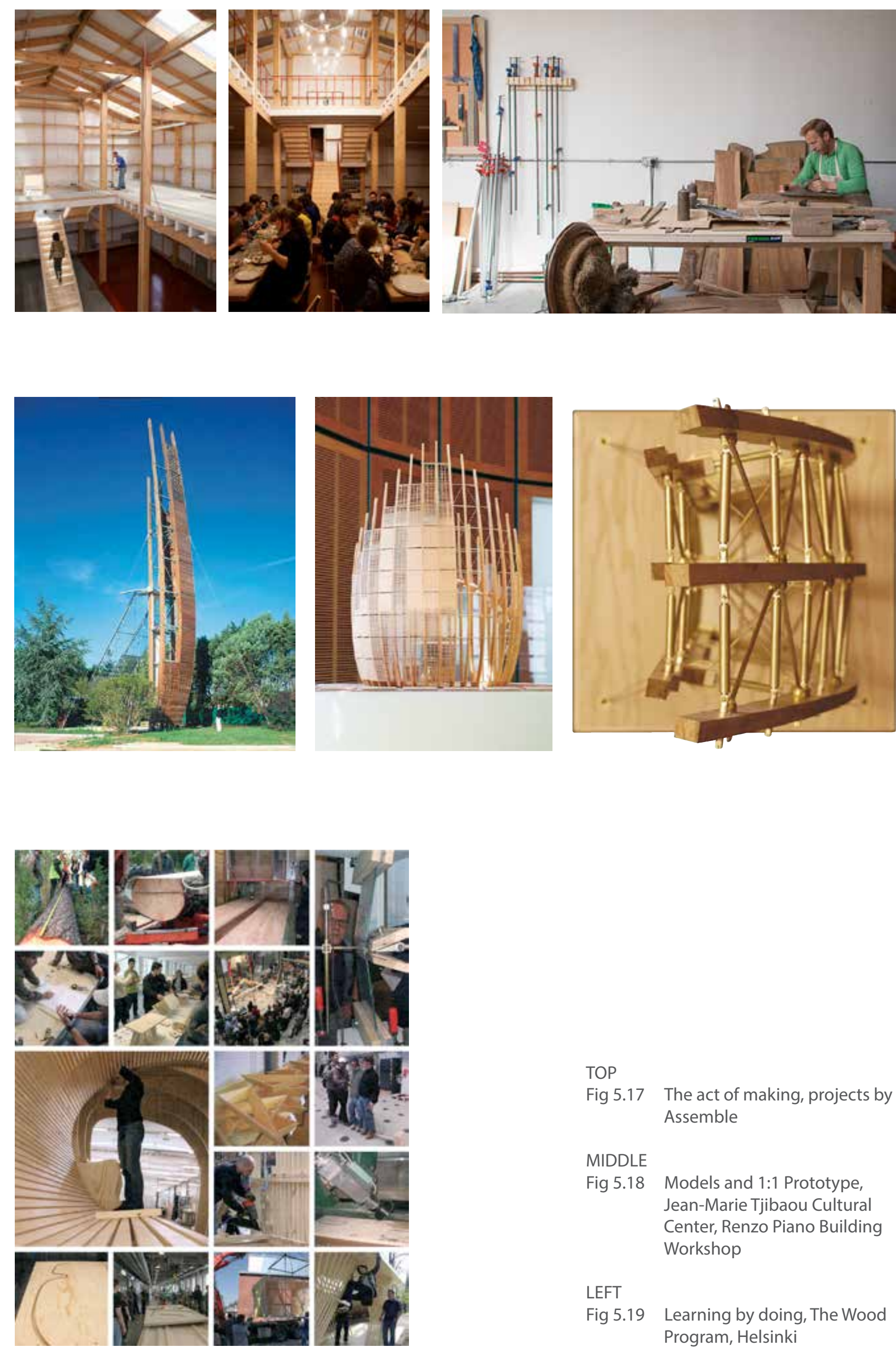

TOP

Fig 5.17 The act of making, projects by Assemble

MIDDLE

Fig 5.18 Models and 1:1 Prototype, Jean-Marie Tjibaou Cultural Center, Renzo Piano Building Workshop

LEFT

Fig 5.19 Learning by doing, The Wood Program, Helsink faded with many new practices established on the basis of a direct connection between design and construction. Many of these exploit the opportunities of digital fabrication from laser cutting, to rapid prototyping and robotic manufacture, while others, such as the author, are enthusiastic about craft and an in-depth understanding of material to design and work with. Some architects, such as the members of Rural Studio in Alabama, USA and Assemble Studio, London, make buildings with communities. Their processes are not dependant on conventional design information, but involve finding opportunities from available materials and working with the users to develop a building through the act of making. The Renzo Piano Building Workshop (RPBW), on the other hand, operates with an understanding of making and detail at its core using physical models and one-to-one scale mockups to test and develop design concepts in collaboration with the client, design team and other specialists.

The Wood Program (formerly Wood Studio) was established by Professor Jan Soderlund and Professor Bengt Lundsten, in 1994, at the Department of Architecture Helsinki University of Technology, on 2 principles: ${ }^{20}$

1. To increase an awareness of wood as a building material in Finland; and that

2. Learning by doing was the best way of teaching.

The aim is to design and erect a small public building in one academic year. The Program '...explores the ecological, technical and architectural properties of wood, providing a thorough and all-round view on the whole chain of wood construction, beginning with the tree in the forest and ending up with an experimental wooden building.21 The program provides students with the opportunity to design timber structures with a full understanding of the properties and both traditional and innovative techniques studied in Finland and around Europe. Modules include studying Finnish tree species and their properties, the history of Finnish timber architecture and industrial wood construction working with foresters and carpenters. ${ }^{22}$

In the Wood Program, students 'learn by doing',23 guided by timber design researchers, with the built outcome providing valuable new skills to the students and new informative research and development for the wider industry. Without the making element, the course would be purely hypothetical and would not

20 Jan Söderlund, 'Wood Studio - the early years 1994-2001 in Puusta Tehty: Wood Works, eds. by Pekka Heikkinen, Jari Laiho, Jussi Tiainen, (Tampere: Parvs Publishing, 2007), p.7

21 Wood Program, Introduction, (Aalto University School of Arts, Design and Architecture)

$<$ http://woodprogram.fi/introduction/> [Accessed 20th July 2015]

22 Jaakko Keppo, 'Wooden Architecture at a scale of 1:1', in Puusta Tehty: Wood Works, p.13

23 Hannu Hirsi, 'Excitement and innovation' in Puusta Tehty: Wood Works, p.9 
provide the research 'proof'. This is similar to the way industry conducts research and development programs, understanding the properties of their material and the problems faced and then developing new products through physical testing. Coed Cymru have been doing this, with the main aim to improve the quality and management of native woodlands in Wales. As part of their R\&D process, Coed Cymru have developed the Welsh Angle; end grain flooring; and prototype windows. The common theme in all these projects, has developed from understanding the industry, to use small section, low cost timber and keep manufacturing simple.

This thesis follows the same method of making prototypes, as the Wood Program and Coed Cymru, to physically test the design of components, the performance and worka-bility of Welsh-grown timber species. Without the doing, or making, the research would only go as far as to suggest hypothetical designs to be future tested and would not lead to any understanding of whether Welsh-grown timber species can be used effectively.

\subsubsection{Prototyping as research}

'There are circumstances where the best or only way to shed light on a proposition, a principle, a material, a process or a function is to attempt to construct something, or to enact something, calculated to explore, embody or test it.' ${ }^{24}$

The role of prototyping will be a vital process to experiment or simulate ${ }^{25}$ ways of using Welsh-grown timber in the building envelope. As a result, some of what are described as prototypes may be completed buildings used by the owners, end users and general public. It is still the view that these are regarded as an output of research and therefore an artefact or prototype, even if they are regarded as a completed building or the final product. The Pocket Oxford Dictionary definitions of output, artefact, product and prototype reveals that all four words can be interchanged as an outcome and process of the design research methodology. A prototype, as a first version, is therefore the best description of each artefact produced as part of and as a result of this research.

The processes and production of prototyping within this thesis provide an essential outcome of the research, as similar to the constructive design research method. In this model, a research prototype is seen as a culmination of theory, senses, aesthetics and quality distilled during the design process. Pieter Jan Stappers has commented that 'Prototypes and other types of expressions such as sketches, diagrams and scenarios,

n. 'a first or preliminary version of a device or vehicle from which other forms are developed';

n. 'the first, original, or typical form of something; an archetype.

24 Bruce Archer, 'The Nature of Research', Co-design: Interdisciplinary Journal of Design, January 1995 pp.6-13 (p.11)

25 Linda Groat and David Wang. p.275 
Lab research

Lab researchers use logical experimentation through design and prototyping for concept testing and selection that leads to an evaluation phase. The prototypes are tested against controlled variables, usually a relationship leading to causality.

\section{Field research}

Field researchers work in and with context as their approach to design.

Rather than experimenting within controlled conditions, such as a labo

tory', field researchers experiment within the natural setting, where the

design is to be used, and follow the design in that context.

\section{: Ilpo Koskinen, John Zimmerman, et al, Dess
lab, field and showroom, Elsevier, 2011)}

Firmitas

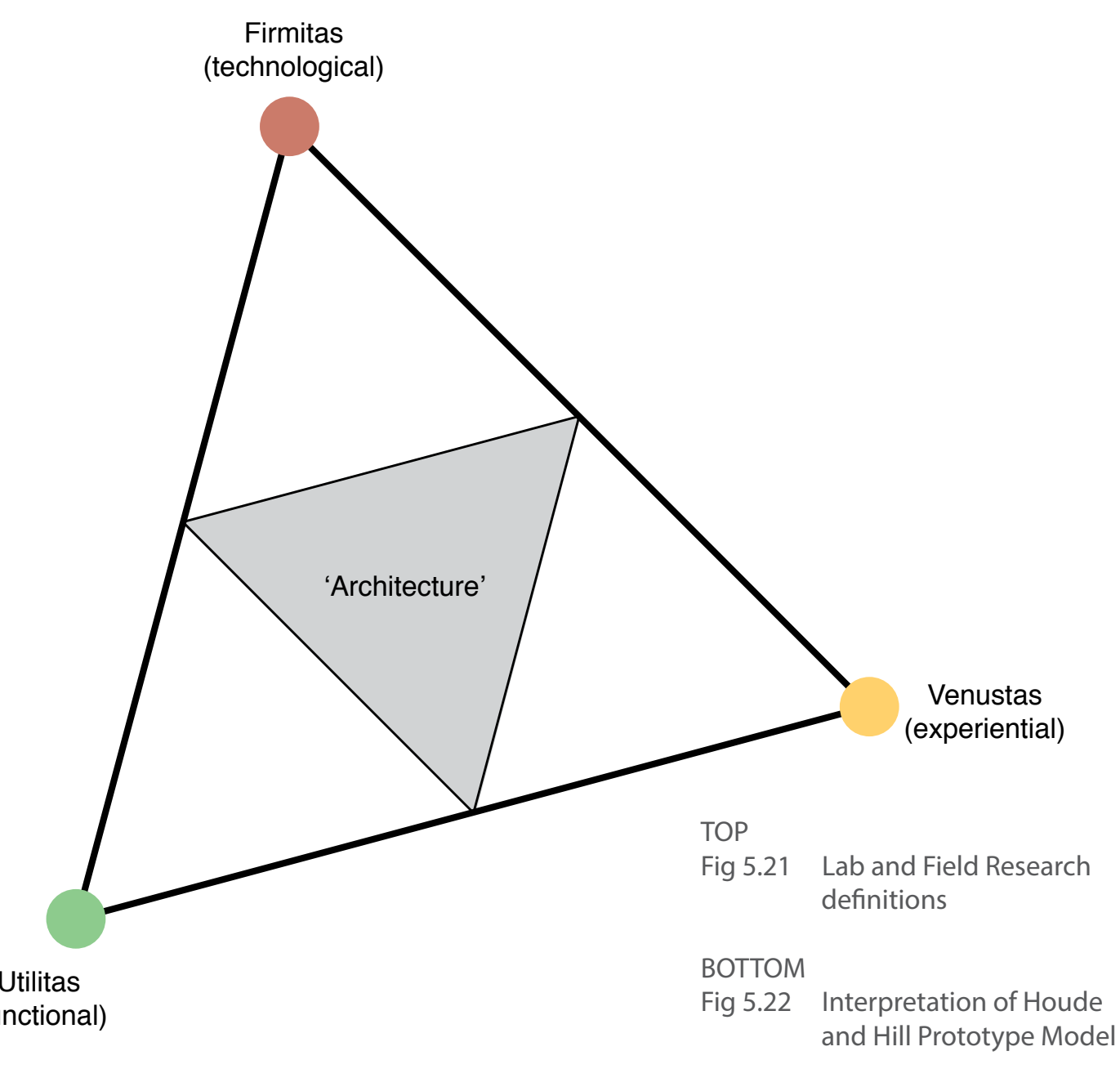

are the core means by which the designer builds the connection between fields of knowledge and progresses toward a product. ${ }^{26}$ The prototype therefore becomes a test of theory, or a 'physical hypothesis', a test of design and a test of the research aims.

Two types of prototyping through research scenario have been identified as metaphors to describe the process by which design research is undertaken with prototypes: Lab research and field research. ${ }^{27}$ In this thesis it could be interpreted that the 'lab' is akin to the timber workshop. The prototypes made in the workshop are informed by theory interpreted from prior quantitative investigations into the crop and industry as well as informed by the qualitative design approach of the author and design team. A further aspect of 'laboratory' experimentation occurs in the early stages of design development, where either scale models or 1:1 prototypes are made for research purposes. Sometimes these are to evaluate proportion, material, texture, weight and sometimes to be tested by third party researchers for structural capacity or thermal performance.

It is also anticipated that the prototypes produced for this thesis contribute towards field research, in that the design and prototype are in the form of a finished building, or element of, in a real-world context, for a real client in collaboration with a multidisciplinary team. The difference with field research is on the evaluation of the prototype in the field. This will be more specifically evaluated against the aims and objectives of this thesis and those of the clients brief, the design intentions and reflection-on-action.

\subsubsection{A Prototype model}

Prototypes in research are generally used in Information Technology, engineering and product design with a prototype often described by different disciplines to mean varying things. Often a prototype is described in terms of the tools or processes used to create it or on how finished it is. These characterisations can be confusing because the parties reviewing the prototype can often misinterpret the significance of what is shown. In response to this, Houde and Hill proposed a triangular model to describe different types of prototype based on a three-type categorisation: ${ }^{28}$

- $\quad$ Role - relates to prototypes that address the purpose of the intended artefact and how it will be useful;

26 Pieter Jan Stappers, 'Doing design as a part of doing research' in Design research now ed by R. Michel (Basel: Birkhäuser, 2007), pp. 81-91 (p.87)

27 Ilpo Koskinen, John Zimmerman, et al, Design Research Through Practice: From the lab, field and showroom, (Elsevier, 2011)

28 Stephanie Houde and Charles Hill, 'What do Prototypes Prototype?' in Handbook of Human-Computer Interaction (2nd Ed.), by M. Helander, T.Ê Landauer, and P. Prabhu (eds.) (Amsterdam: Elsevier Science B.V, 1997), p.3 


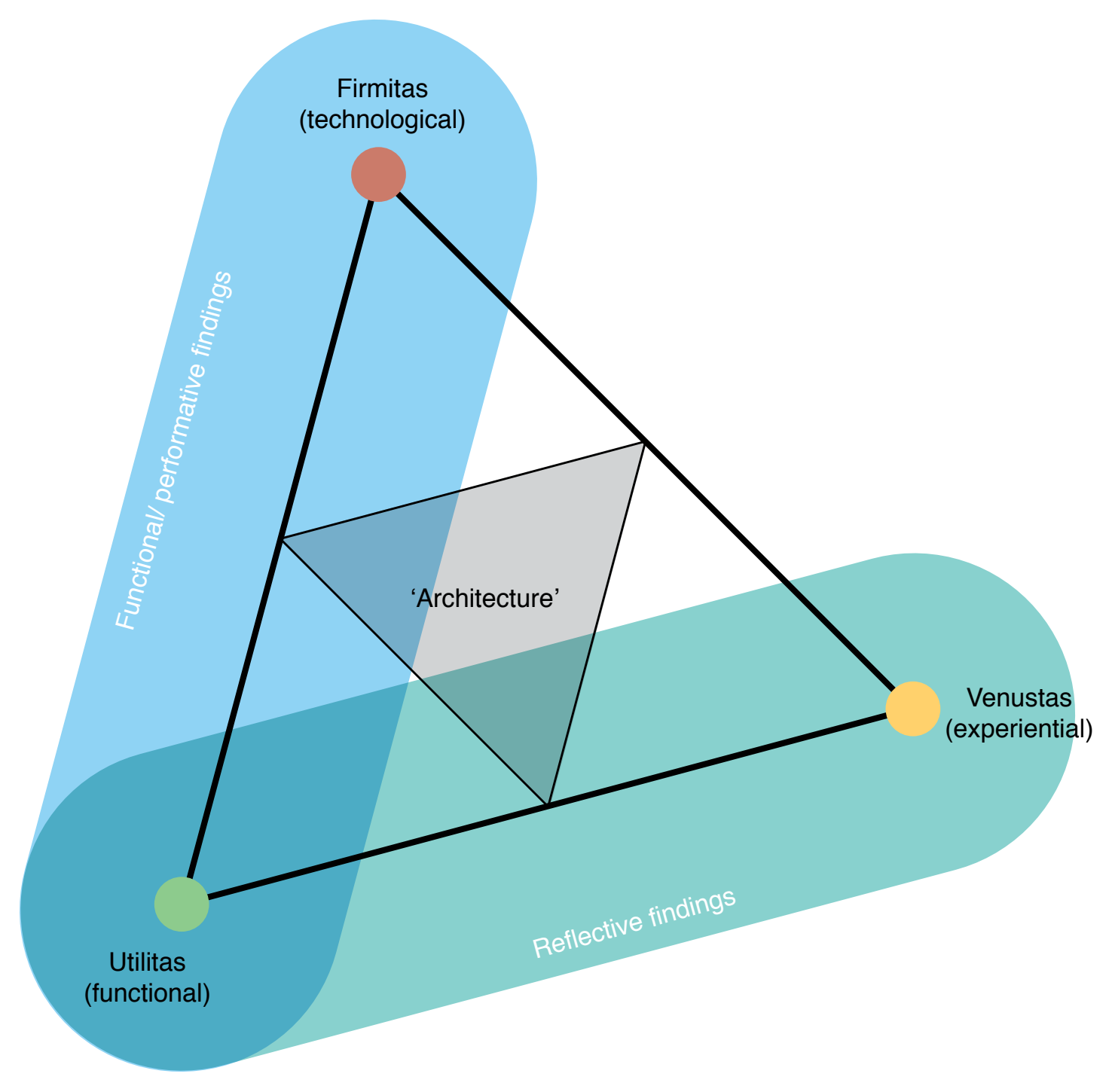

- Look and feel - relates to prototypes that focus on the sensory experience of using the artefact; and

- Implementation (function) - relates to prototypes that highlight the physical techniques and components of the intended artefact.

While Houde and Hill are approaching this subject from a human-computer interaction $(\mathrm{HCl})$ point of view, the terms could be adopted for use in architectural prototyping, as follows:

- Utilitas (or functional) - prototypes that focus on the function and spatial arrangement of the intended building;

- Venustas (or experiential) - prototypes that focus on the experiential aspects of architecture such as proportion, scale, light, texture, culture, context, form - Firmitas (or technological) - prototypes addressing the physical materials, details, construction techniques of the structure and envelope that support and enclose the intended building.

This has been based on Vitruvius' criteria for a good building in De Architectura, for two reasons: the close fit to the Houde and Hill model; and that these terms could still be seen as relevant to contemporary architecture. It is not intended that prototypes must fit one of these categories, instead a prototype is likely to address all three. Houde and Hill refer to this as an integration prototype ${ }^{29}$ to verify that the design is complete and coherent. In the context of this thesis, this could be referred to as architecture, where the complete building is prototyped with all the complexities and costs of any building project. Although it may encompass elements of experimentation that may be developed further if components of the project are used again. The emphasis, of this model, is on understanding the limitations of the prototype for evaluation and therefore how the findings are formulated.

It is not a direct aim of this thesis to analyse the function and spatial arrangements (Utilitas) of the designs, although this is fundamental to the success of the projects, as buildings, for the clients. Instead, Firmitas will likely be the focus of the prototypes, in terms of the incorporation of Welsh-grown timber in the building envelope and the processes of fabrication and construction. While, Venustas, will be the focus in response to the resultant tectonic form. The evaluation of the research objectives in relation to these criteria are likely to reveal findings in different ways. 


\subsubsection{Reflection}

Critical in demonstrating that the processes of designing and making and understanding the results of the physical prototype as research, is the ability to reflect on what is and has been done at regular intervals during the process, and in turn, acting on this reflection. These processes of action and reflection are therefore vital to the success of generating knowledge from practice-based constructive research.

Action research describes a study of examining a situation in terms of how factors within the situation relate to each other as the process develops towards the intended objectives. It is a tool that often uses '... a spiral of steps, each of which is composed of a circle of planning, action and fact-finding about the result of the action. ${ }^{30}$ In other words theoretical knowledge and practical knowledge must inform each other to establish an effective field of study. This is often evident in the design process as described above.

Important to this thesis are Donald Schon's reflection-in-action and reflection-onaction. In his book'The Reflective Practitioner' Schon uses the phrase'design as a reflective conversation with the situation' ${ }^{\prime 31}$ calling this process 'back talk'. Schon proposes that design activity is an example of reflection-in-action, in that to design involves reflection on a number of parameters that will influence the outcome, from material, technical and physical to social, environmental and cultural. He proposes reflection-on-action as occurring after the outcome as a process of critical reflection of what was done, how well it was done and whether changes would be made that could have resulted in a different outcome.

The process by which the timber prototypes are produced is based on a design and making process involving cyclical reflection of the state of the crop, industry, building envelope, client and design team requirements, legislative approvals and on any prototyping that came before. This will involve reflection-in-action leading to quantitative and performative ${ }^{32}$ findings of the functional and technological aspects as having worked or not in the physical outcome of the prototype.

However, while the prototypes may be seen as the outcome of the research it is the subjective and qualitative 'back talk' resulting from the process and final built

30 Lewin, K. (1948) Resolving social conflicts: selected papers on group dynamics ed. by Gertrude W. Lewin (New York: Harper \& Row, 1948), p.202-203

31 Donald Schon, The Reflective Practitioner: How Professionals Think in Action, (New York: Basic Books, 1983), p.76

32 Brad Haseman, 'A Manifesto for Performative Research', Media International Australia incorporating Culture and Policy, no. 118 (2006) pp. 98-106 (p.104) 
prototype, that will provide findings on the integration of Welsh-grown timber in the building envelope and, therefore, the resultant tectonic form. This is reflection-onaction leading to reflective findings.

Both the prototype, as output, and prototype as process of the research will be reviewed as described, against the 4 criteria that form the research objectives and the framework for evaluation to review the successes, failures, opportunities and lessons learnt. This will be incorporated into an operational framework matrix presented at the end of each study to highlight the criteria incorporated or studied in each prototype. All matrix summaries are brought together in the thesis findings to reflect on the use of Welsh-grown timber for the final prototypes.

This section will consider RIBA Plan of Work 2013 project stage $7^{33}$ (Stage L from the 2007 Plan of Work), for the in-use evaluation of the completed prototype as well as a review of the previous 7 work stages. As part of this evaluation the projects, where relevant, have been submitted for awards or publication and subject to peer review, and in some cases as a built output are occupied by clients and end users or open to the public to use, engage with and experience.

The design study chapters end with a presentation of the findings in relation to the specific aim and objectives of that study.

\subsubsection{Next steps}

The following 5 chapters focus on the topics identified in 5.6 .5 for using the DRU-w projects as highlighted in the table opposite.

The final chapter pulls together all the observations and reflections form these chapters into thesis findings focused on the 4 objectives.
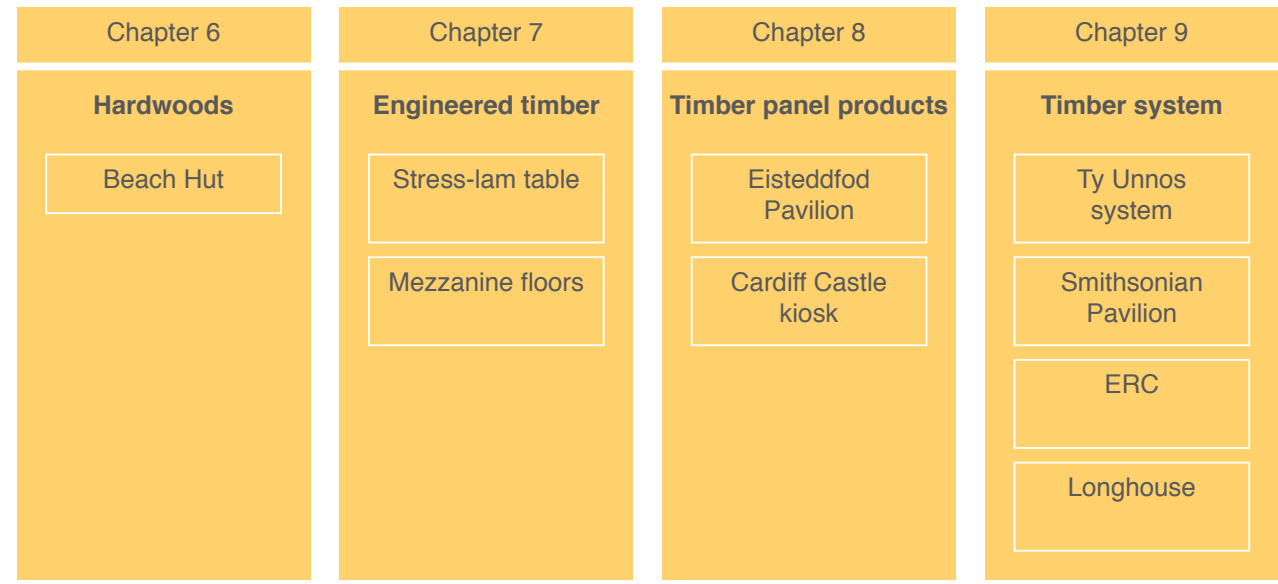

33 RIBA Plan of Work 2013, p.26 


\section{CHAPTER 6}

Hardwoods 
With $49 \%$ of Welsh woodland comprised of broadleaf trees providing hardwood, improving woodland management techniques to harvest hardwood efficiently and sustainably and a potential increase in supply over the next 2 decades, this study will focus on the use of hardwoods in the building envelope.

The first study will focus on a single project for an, as yet, unbuilt beach safety hut at Port Eynon, on the Gower peninsula, designed by the Design Research Unit Wales, in 1999, for the City and Council of Swansea in collaboration with Coed Cymru and Arup.

In this chapter, context and precedents on the use of hardwood in the building envelope are examined to provide background and detail, particularly focussed on green hardwoods. The study begins with the design intentions before describing the prototype as a set of detailed construction drawings and structural engineering calculations. Observations and reflections on the design and structural testing of the project, based on the framework for evaluation conclude the prototype evaluation before presenting overall findings on the use of Welsh-grown hardwoods.

\subsubsection{Research aim}

The aim of this prototype study is to integrate and test the use of Welsh-grown hardwoods in the structure, envelope and finishes of a small building on a sensitive and exposed site.

The following objectives were established to guide this:

- utilise small sections and short lengths of Welsh-grown hardwoods.

use green hardwood for both structure and finishes.

- develop a tectonic form appropriate for the Gower whilst accommodating the building users needs.

6.1 .2

\section{Limitations}

The following limitations are noted in the context of this study:

- The project has not been built and is limited to design, models and structural analysis and testing with Arup.

- The design was proposed in 1999, but much of the research and intent has not altered over the 15 years. (At the time of writing, there is a possibility of resurrecting the essence of this project as a nature reserve look out on a new site) 
In the late 1990's, there had been a renaissance in the use of timber in architecture in Germany, Austria and Switzerland which had been filtering into UK contemporary architecture. Many of the European examples were using innovative, engineered developments with timber or timber based products that are not available with Welsh-grown timber or even manufactured in the UK. It was therefore the intention of this study to work with the standard 'stock' of timber promoted by Coed Cymru and available to use in Wales. ${ }^{1}$ The following precedents have therefore been identified as relevant to the context of this study, that use small section and short length timber, use 'green' timber and are used for principle structure and rainscreens as two of the most demanding components of the building envelope.

\subsubsection{Rainscreen claddings}

Rainscreen cladding is an external finish to a building that has a non-load bearing skin of panels separated from an insulated and airtight backing wall by a cavity. The outer skin is designed to protect the inner layer from the majority of direct rain. Rain can penetrate cladding through five processes:

- Kinetic energy - wind-driven through gaps and joints between cladding elements;

- Surface tension - water 'sticks' to horizontal surfaces and runs inside;

- Gravity - rainwater is pulled down through openings which lead inwards and downwards;

- Capillary action - water is drawn into narrow passages which are bounded by porous materials;

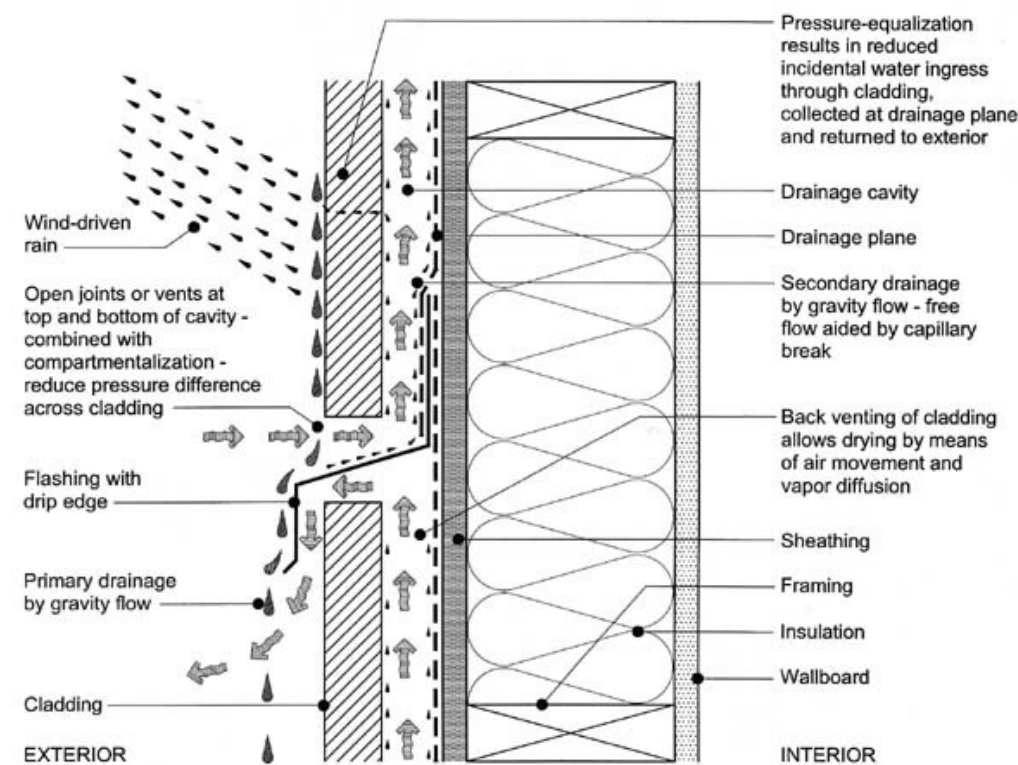

Fig 6.1 Pressure equalised rainscreen cladding 

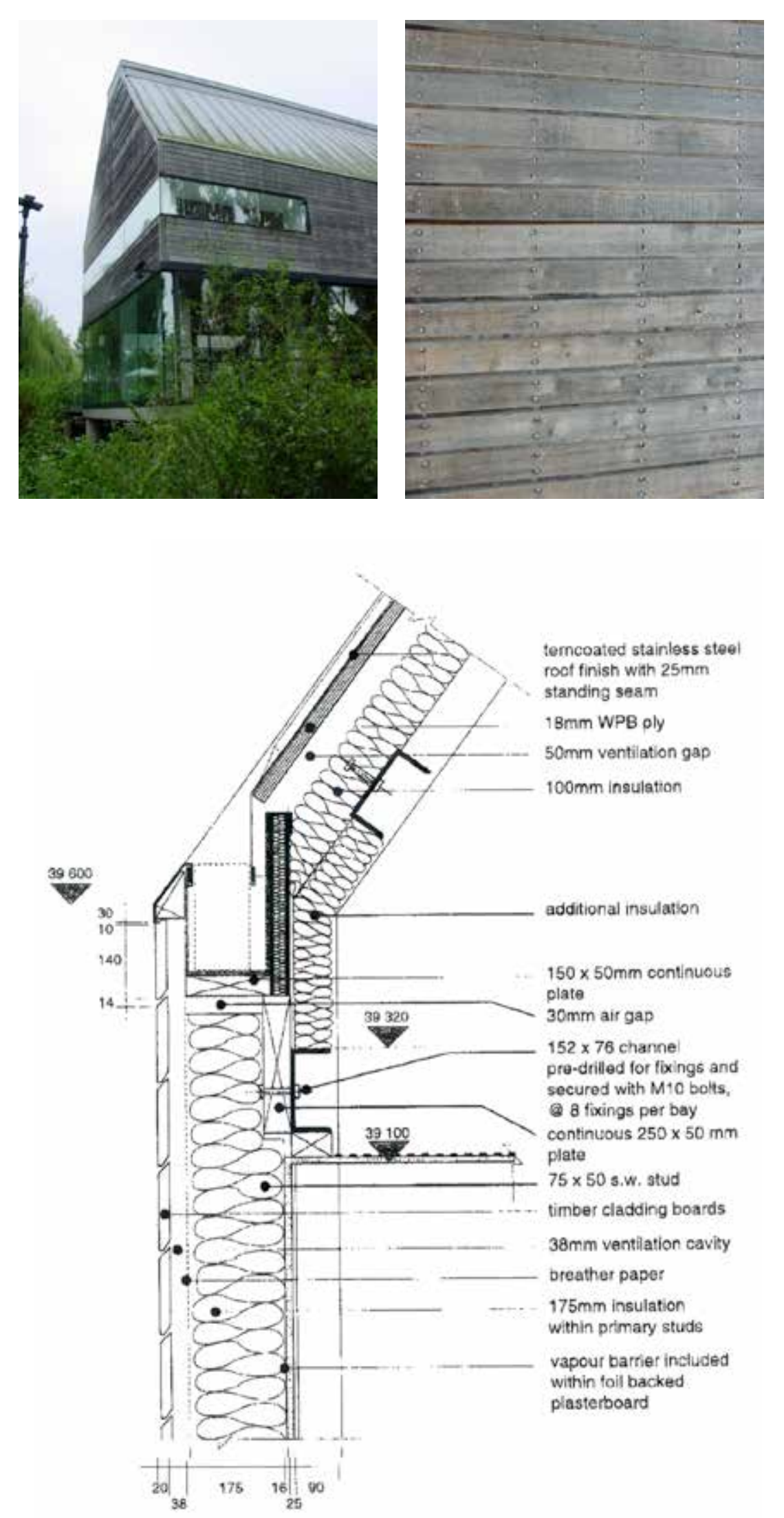

TOP - BOTTOM

Fig 6.2 Green oak cladding, River and Rowing

Museum, Henley-on-Thames, David

Chipperfield

Fig 6.3 Cladding detail, River and Rowing Museum therefore ventilated at top and bottom, detailed to allow moisture to escape and prevented from penetrating the inner layer, usually with a breather membrane.

Over the last 15 years there has been a resurgence in the use of timber in the external building envelope, and in particular as rainscreen claddings. The use of green oak cladding on the River and Rowing Museum, in Henley-on-Thames, designed by David Chipperfield in 1998 is a significant exemplar.

The River and Rowing Museum is located on the Henley river meadows to the south of the river Thames. It contains examples of rowing boats, racing shells and other river craft to explain the history of the sport. It was the context, programme and planning constraints that led Chipperfield to consider the external form as the starting point of the design. With a concrete deck on piloti, concrete frame, glazed ground floor and timber clad upper floor with pitched roof the form resembles that of upturned boat hulls, Oxfordshire barns or even regatta tents. However, the timber cladding also evokes images of the traditional curtain timber wall translated into an innovative external wall.

Initially western red cedar was specified as a ship-lap cladding. However after collaborating with Patrick Hislop at TRADA, green oak was proposed due to its durability and hardening over time, unlike soft cedar, that no treatment or maintenance would be required and that it could be sourced locally. A specification was developed to consider the quality, appearance, performance and fixings. This included that no sap or splay knots were permitted and that all knots were to be no more than one-fifth of the board width and to be a minimum of $15 \mathrm{~mm}$ from the edge.

It was expected that the green oak would shrink, potentially causing warping, bowing or springing of the boards, although there would be negligible movement longitudinally. With changes in relative humidity over time, it was estimated that the change in moisture content could cause up to $2.5 \%$ tangential and $1.5 \%$ radial movement. To control this, a $144 \mathrm{~mm} \times 22 \mathrm{~mm}$ board was chosen and double fixed at $80 \mathrm{~mm}$ vertical centres with elongated $20 \mathrm{~mm}$ diameter washers in a $25 \mathrm{~mm}$ rebate, allowing a fixing tolerance of $+/-2 \mathrm{~mm}$, to $38 \mathrm{~mm}$ Douglas fir vertical battens and a softwood stud frame. Due to the leaching of tannins that will corrode ferrous metals, stainless steel screws and washers were used. To reduce water ingress and prevent visibility through the horizontal open joints from below, the boards were splayed at different angles on the top and bottom edges. 


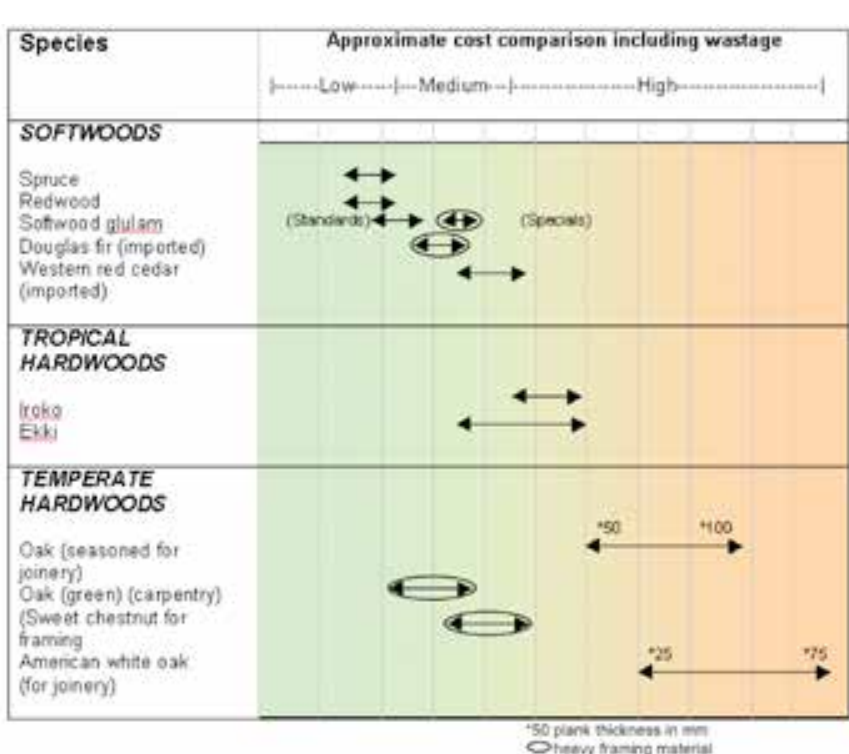

TOP

Fig 6.4 Green oak hardwood costs table

BELOW (Clockwise)

Fig 6.5 Great Coxwell Barn, Oxfordshire

Fig 6.6 Little Moreton Hall, Cheshire

Fig 6.7 Greenstead-juxta-Ongar church, Essex

Fig 6.8 Weobley, Hertfordshire
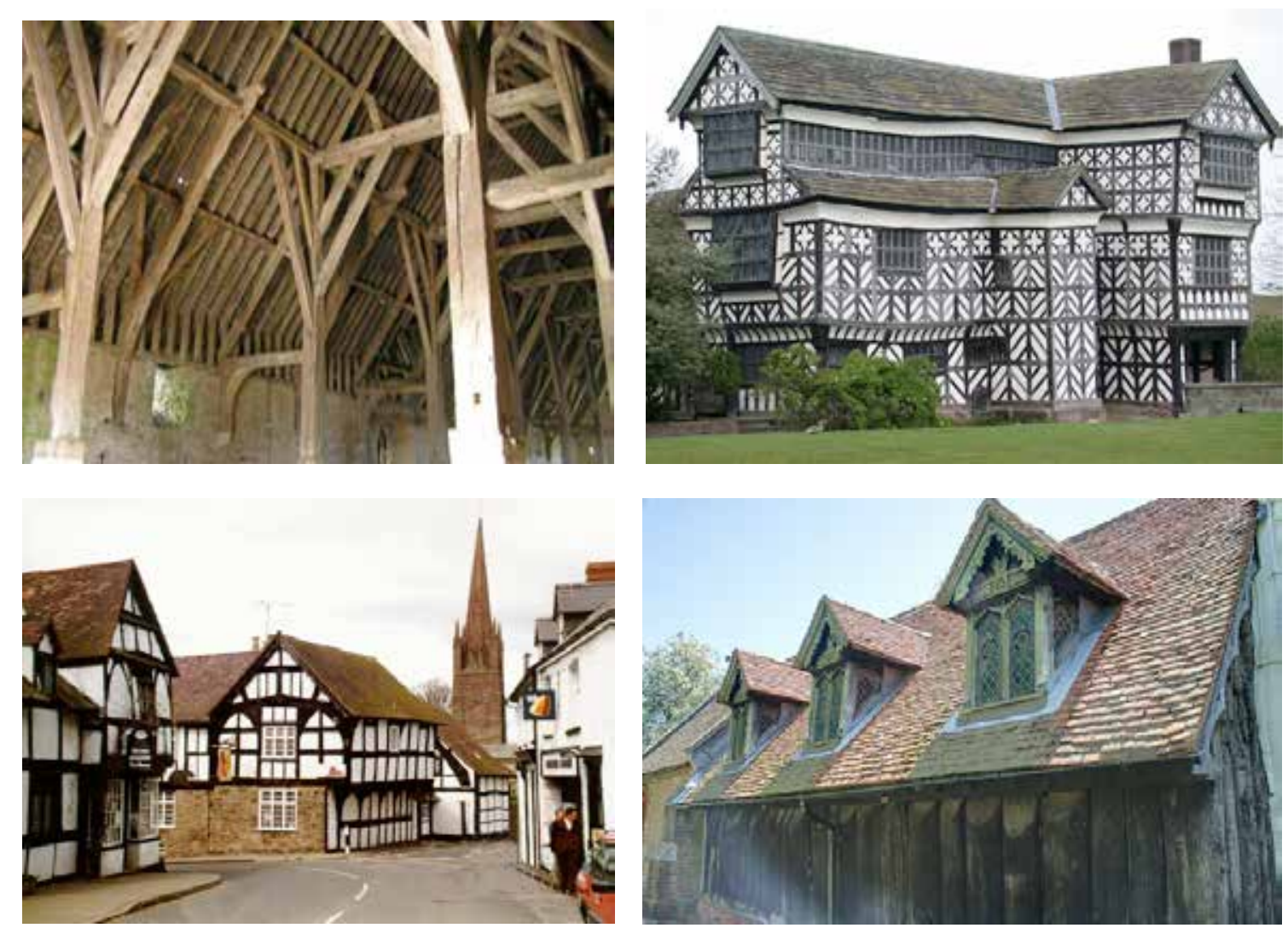

As the tannins leached from the boards, the cladding has weathered from a natural dark golden colour to a silver grey. As this occurred it was anticipated that up to $10 \%$ of the cladding would need to be replaced and so extra boards were stored on site to weather at the same rate as the building.

\section{‘Green’ structures}

Green structures are essentially built from freshly cut timber, often from a specifically selected tree, with a high moisture content. In the UK and Wales, there are two primary timber species for use in green structures: oak and sweet chestnut. When green, both are cost comparative to the higher structural grade local softwoods and imported tropical hardwoods, such as Iroko and Ekki. ${ }^{2}$ The primary use for both is in joinery work, although both also have good structural properties. However, as sweet chestnut is less stable and more expensive, due to a lower standing volume (see tables chapter 2), oak is typically the preferred Welsh-grown temperate hardwood for structures. Green oak has been used in construction and lasted for hundreds of years as seen in the cruck frames of Weobley in Herefordshire, the ninth-century Greenstead-juxta-Ongar church in Essex to the fourteenth-century Great Coxwell Barn, in Oxfordshire, and the sixteenth-century Little Moreton Hall in Cheshire.

The advantages of using green oak are best described by highlighting the problems of using seasoned oak:

- Drying time - oak dries very slowly, $150 \mathrm{~mm}-200 \mathrm{~mm}$ thickness can take between six to eight years to be seasoned with kiln drying having little effect;

- Drying movement - oak moves slowly, but significantly over a long period of time while drying. Seasoned timber would require second cutting/ planing to provide square edges;

- Hardness - seasoned oak is difficult to cut and shape;

- Fissures - oak has a tendency to fissure making joints complicated to construct accurately. ${ }^{3}$ 


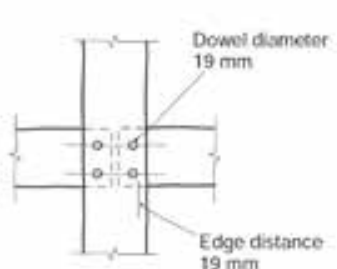

wow boring 步
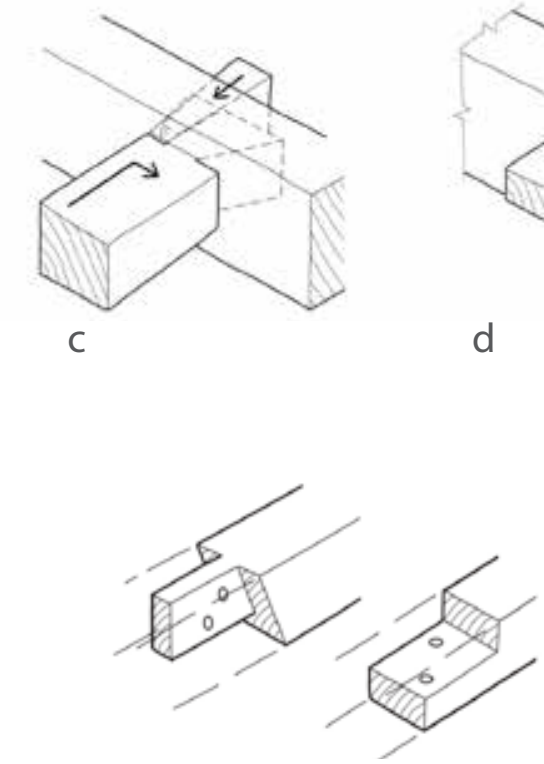

$f$
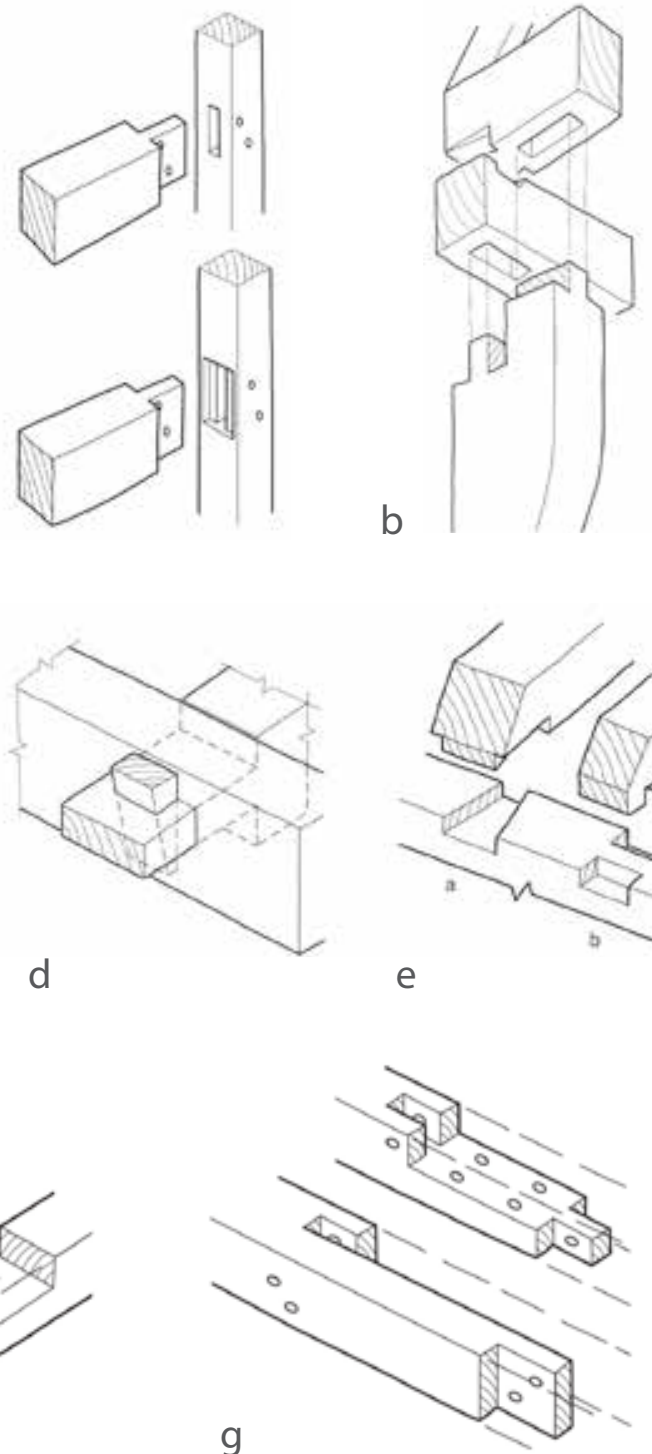

ABOVE CLOCKWISE

Fig 6.9 Traditional framing joints

a. Mortise and tenon

b. Tie beam lap dovetail assembly

c. Wedged dovetail

d. Wedged through tenon

e. dovetail and cog tie beam detail

Bridle and side halved scarf

g. Edge-halved and face-halved scarf
With green oak, apart from hardness, these characteristics are identified after construction and during the early years of use which need to be understood to ensure the integrity of the structure. As such, the following observations have been summarised from 'Green Oak in Construction' by Peter Ross, Christopher Mettem and Andrew Holloway as significant in the design, detailing and construction of green oak structures:

- The strength of green oak is significantly lower than its dry strength, which must therefore be taken into account in the sizing and as a result the dry oak structure will have a greater structural capacity than the green. ${ }^{4}$

- Timber creep (permanent deflection generated in use) is greater in the green timber than seasoned, meaning that structures should be designed: to limit large spans or ambitious span/ depth ratios; to utilise triangulated bracing and/or other jointing methods to allow movement; consider the deformation against other finishes and components; and to consider the appearance.

- The high moisture content of green oak will cause movement as it dries. As oak dries to approx $10 \%$ moisture content it is expected that the radial movement will be $4.5 \%$ and the tangential movement $7 \%$ which is greater than for softwoods. ${ }^{5}$

- This shrinkage will lead to deformed shaped components, as discussed in chapter 2, and often large fissures extending to the pith. These signs of movement are to be accepted and limited, controlled or designed into the structure. For example, stairs, windows, doors and other fitted furniture will need to allow for the structure to move around them or move with it. ${ }^{6}$

- $\quad$ Large posts and beams will take years to dry. The carpenters rule of thumb for drying is: 'a year for every inch thickness ${ }^{17}$ therefore a $100 \mathrm{~mm} \times 100 \mathrm{~mm}$ section might take four years to dry, whereas a $100 \times 200 \mathrm{~mm}$ section may take up to eight years. The typical stabilisation period of a green oak structure is between three to four years.

- When exposed externally, such as for cladding, the tannins in the oak structure will leach out at different rates depending on exposure and corrode ferrous metals, so fixings, brackets, flitch plates etc should be fabricated from stainless steel.

- The architecture of green oak buildings is usually highly tectonic and dominated by large structural oak elements. These are jointed by a wide range of details, but common to both traditional construction and hybrid 
contemporary construction are the following timber joints: Mortice and

tenon, wedged dovetail tenons, wedged through tenons, dovetail and cog lap joints, various scarf joints, pegged joints and lapped dovetail assemblies.
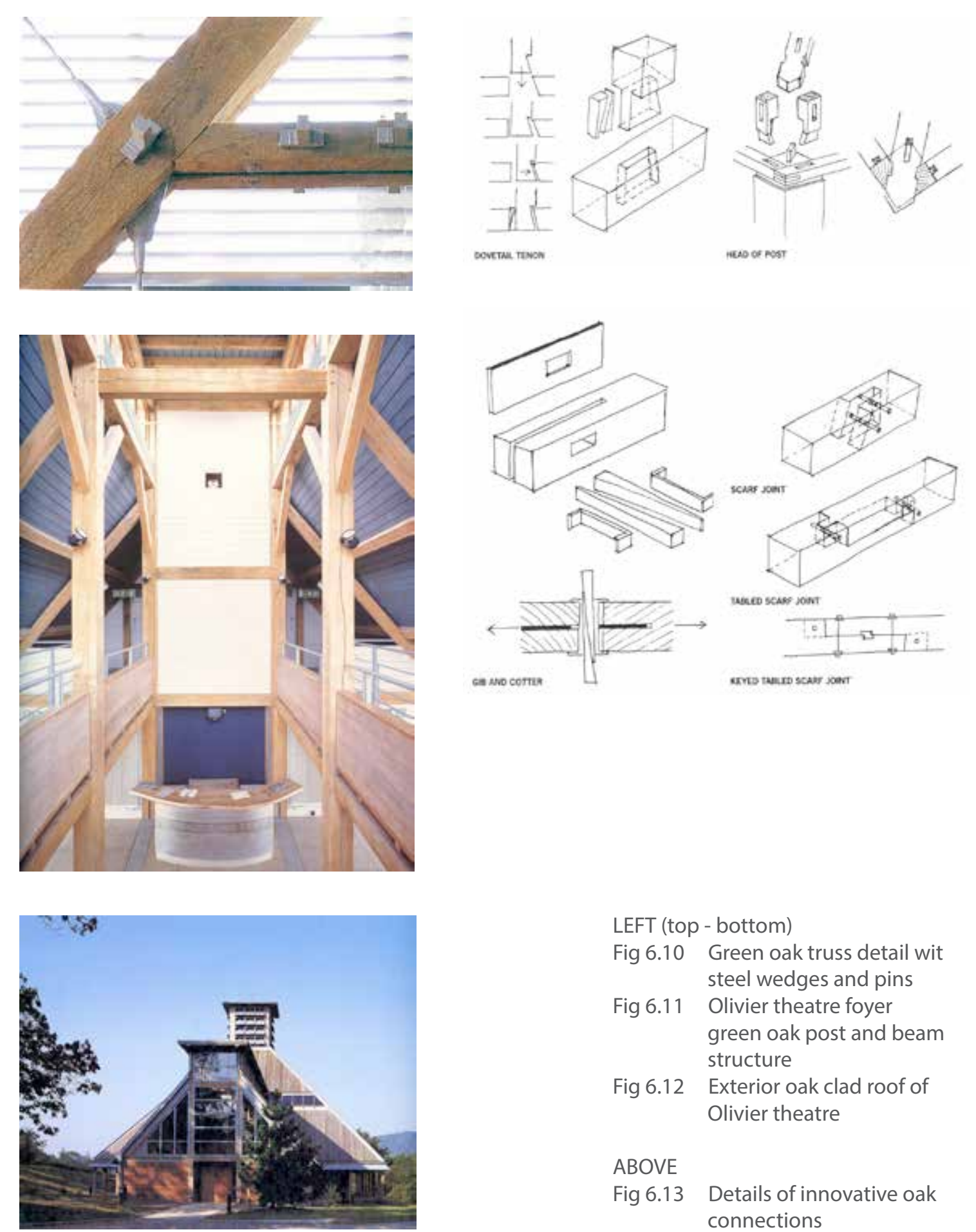

246

LEFT (top - bottom)

Fig 6.10 Green oak truss detail wit steel wedges and pins

Fig 6.11 Olivier theatre foyer green oak post and beam

Fig 6.12 Extructure oak clad roof of Olivier theatre

ABOVE

Fig 6.13 Details of innovative oak connections
6.2 .3

\section{Bedales School Oliver Theatre}

The Olivier Theatre at Bedales School incorporated an innovative approach to green oak timber framing whilst acknowledging long-established traditions. The project was designed and constructed by the Oak Design Group, a collaboration of: Feilden Clegg Architects, Roderick James \& Company and Carpenter Oak \& Woodland. The design approach adopted was that 'The oak frame will be simple, powerful and very dominant... but the joints will be structurally explicit using steel bolts, plates and wedges where necessary to strengthen the oak framing rather than depending solely on traditional joints which are not appropriate to the span and the loading required.'

The principle structural elements of the frame were $4 \mathrm{no} .400 \times 400 \mathrm{~mm}$ green oak corner posts tied at their heads by trusses fabricated on-site from chamfered oak sections varying from $175 \times 250 \mathrm{~mm}$ to $150 \times 150 \mathrm{~mm}$. $90 \%$ of the frame joints use timber pegs for their fixings although stainless steel flitch plates and fixing devices were used at critical tension joints. Wind uplift at the corners of the auditorium, on the boards that line the roof and walls of the theatre could shear traditional oak pegs of mortise and tenon joints. Instead dovetail tenons were used with the tenon dovetailed to one side with the mortise undercut to match and wedges used to hold in place and allow for future adjustment.

A further bespoke detail was developed for the joints between truss components. Instead of a typical flitch plate detail the design team explored solutions using fewer bolts. A variation on a gib and cotter joint was developed with the benefit allowing the wedges to be tightened as the timber dries and shrinks, meaning that the joints could be kept tight. ${ }^{9}$ Allowing for shrinkage was a major challenge with the green oak frame resulting in a number of details related to the glazing and external wall panels developed to allow for significant movement. ${ }^{10}$
8 Barrie Evans, 'Theatre in the frame', Architect's Journal, 1 (1996), pp.35-44 (p.38) 9 Ibid, p.40 

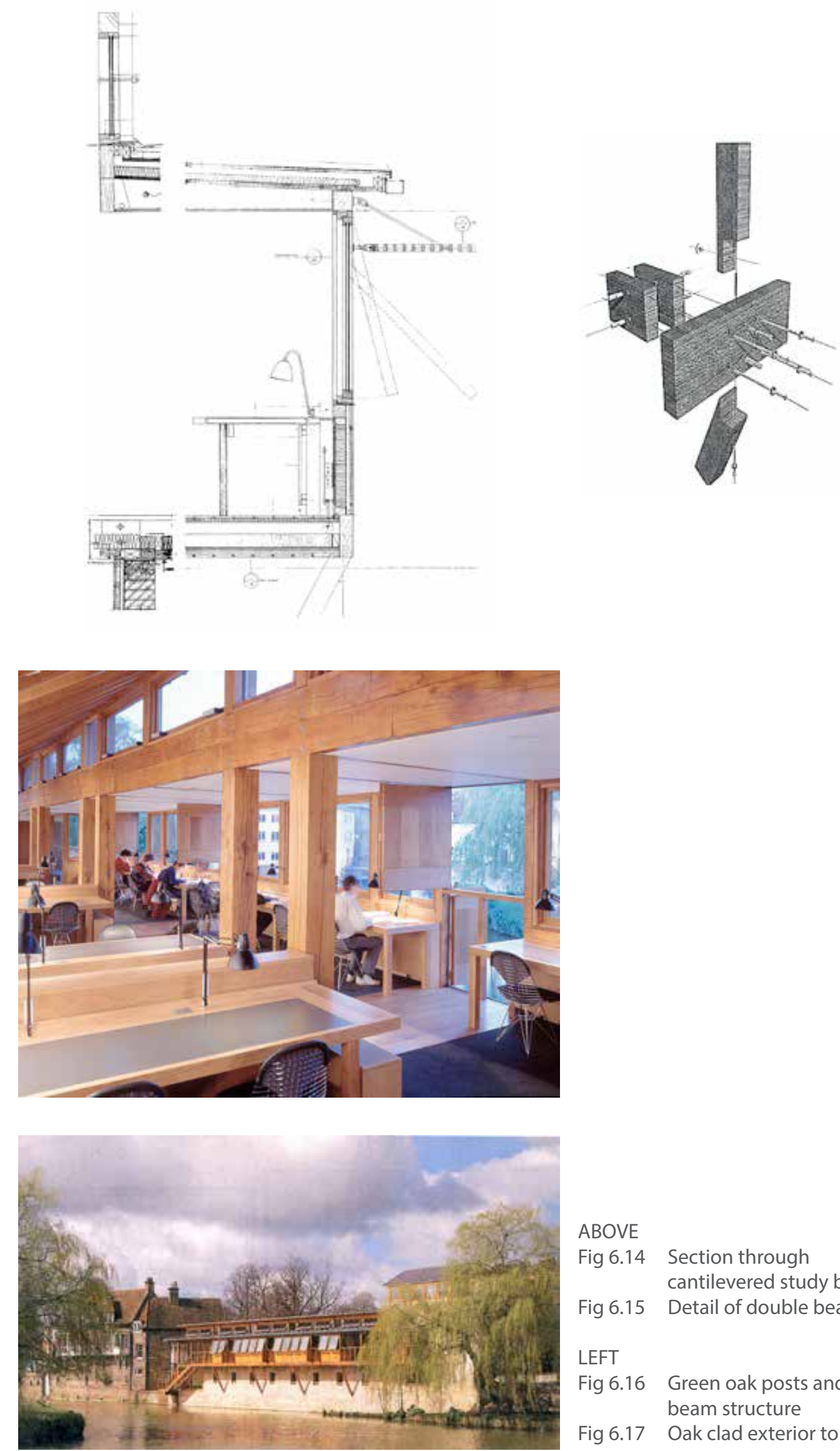

ABOVE

Fig 6.14 Section through cantilevered study bay

Fig 6.15 Detail of double beam bolts LEFT

Fig 6.16 Green oak posts and double beam structure

Fig 6.17 Oak clad exterior to river
The Darwin College Study Centre in Cambridge, designed by Dixon Jones Architects with Ove Arup \& Partners provides a new college building with a choice of study environments for students to use.

The structure is masonry at ground level with a green oak frame above. Home-grown oak was used for the load bearing timber structure as it provided the most economic solution to meet the spans required. ${ }^{11}$ The programme however, only allowed for a 5-6 months drying out period and so the connections in the timber structure had to allow for adjustment and tightening as the drying out took place. ${ }^{12}$ The primary 250 $\times 250 \mathrm{~mm}$ posts are fixed to the precast concrete floor using stainless steel T-section flitch plates. To the waterside, cantilevered beams are anchored back to the main posts, creating a suspended reading area over the water with a flat roof and strip of clerestory, kiln dried oak framed windows above. A mono-pitch roof spans from above the clerestory, over the northern side of the building, running down to sit atop the masonry wall, with another strip of clerestory lights between.

The deep spine beam which runs above the main posts is a composite section of two $250 \times 100 \mathrm{~mm}$ beams connected to each other and the posts with stainless steel screwed bolts, locknuts and anchor bolts in order to overcome the movement of the timber. Isolated rafters forming the pitched roof structure are fixed through to the double skin ply deck above, in order to accommodate any shearing stresses and transfer the lateral loads back to the end walls. ${ }^{13}$

This approach to the green oak joints show'... that solid wood cross-sections do not require hand-crafted or industrial nail-and-plate connections and that with the aid of modern technical methods novel and eye-appealing design details can be achieved. ${ }^{14}$

11 Götz Gutdeutsch, Building in Wood: Construction and Details (Basel: Birkhäuser, 1996) p.17

12 Peter Carolin,'Natural selection: Jeremy Dixon in Cambridge', Architecture Today, 49 (1994), $24-29$ (p.29)

14 Götz Gutdeutsch, p.17 
Prior to this design, the City and Council of Swansea had already designed and obtained planning permission for a beach safety facility to be located in the sand dunes of Port Eynon. The City and Council had a preference for a Welsh-grown timber building and had begun conversations with Coed Cymru, before agreeing to reconsider the design to achieve the following objectives:

- Provide a demonstration of the creative use of Welsh hardwoods in the building structure, envelope and finishes.

\section{Port Eynon Beach Hut}

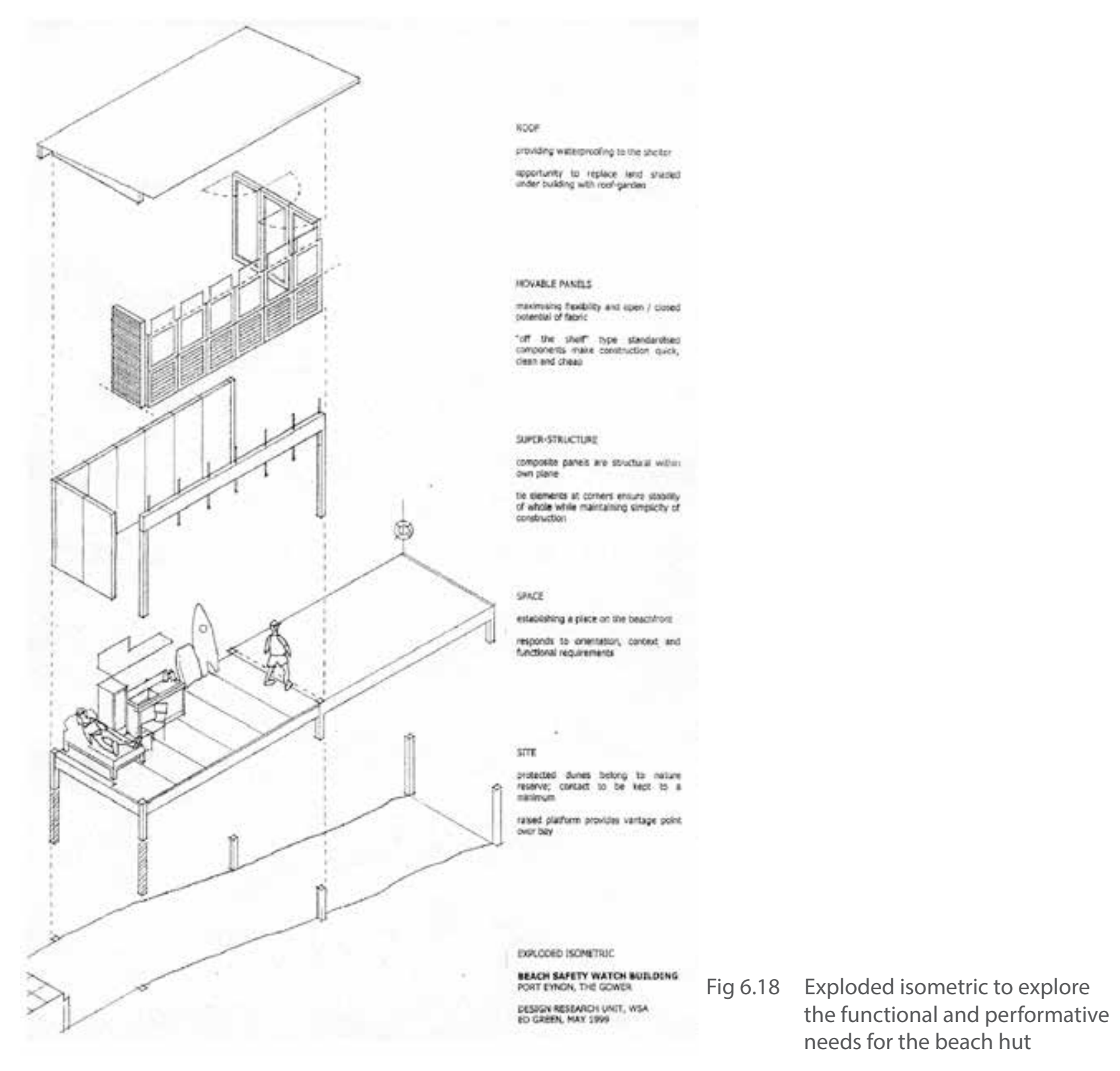

Acknowledge the current best practices of sustainable design and development.

- Provide a possible generic 'type' for similar structures in the Gower whilst accommodating the prospective building users needs.

The beach safety hut was designed to meet the following functional and performative needs:

- $\quad$ Look-out - providing all-round views when the public are on the beach and in the water;

- $\quad$ Access - the building should be easy to access from the car park and beach alike;

- $\quad$ First-aid - The building must cater for first-aid for a range of situations from stings to spinal injuries. It should therefore include a bed, spinal board/ stretcher, blankets and a first aid box;

- Public awareness and information - the building is likely to be a focal point for information about the beach and environment. The structure may act as a weather/ water forecast in the future;

- Occupant comfort - the building is to be used every day between April September from 9am - 7pm. The local life saving club may also use it as a base out of season. The building must therefore provide protection from the extreme climatic conditions including driving rain, wind, solar shade and temperature;

- $\quad$ Security - The building must be secure and robust from vandalism;

- Services - telephone, clean potable water, a water-heater and waste water drainage are required. 

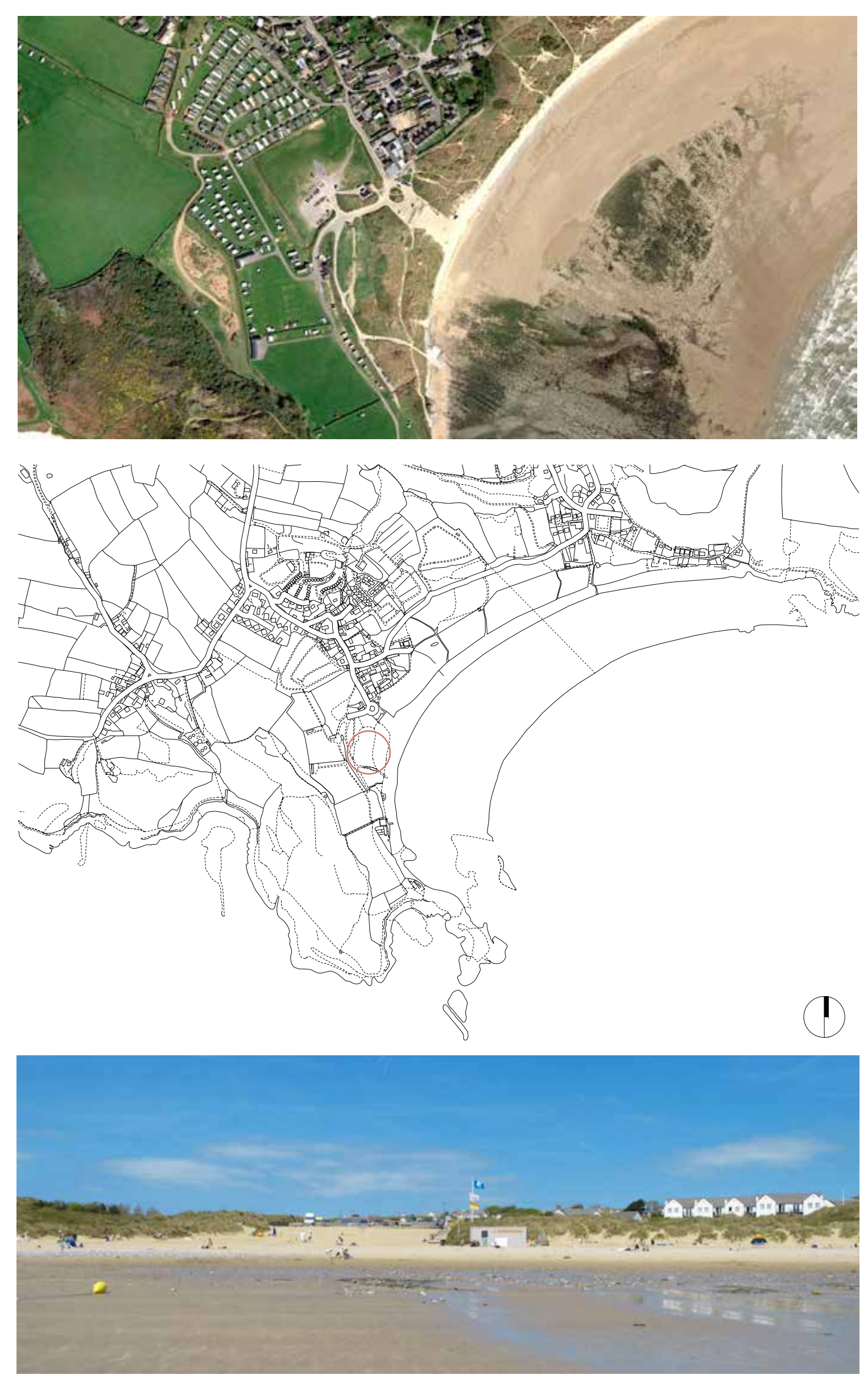

Fig 6.19 Aerial view of Port Eynon $\begin{array}{ll}\text { Fig } 6.20 & \text { Port Eynon Site Plan } \\ \text { Fig } 6.21 & \text { View of Port Eynon }\end{array}$

\subsubsection{Site/ location}

The Gower peninsula is located on the South Wales Coast to the west of Swansea. From Oxwich Bay, in the east, rocky cliffs fade into wide stony bays towards the quiet villages of Horton and Port Eynon. The main bay is bordered on the landward side with a margin of sand dunes with a unique ecology, stabilised by lichens and grasses that are home to reptiles and other animals. To the east is a wide expanse of white sand and to the west are a number of cottages on the edge of the beach as well as the ruins of an old shoreline salt house and oyster pools. The dunes are only breached in two places, Horton and Port Eynon where access to the beach has been constructed.

The site is located in the area of dunes to the south-west of the car park with the existing public convenience to the north due to be extended and improved providing secure storage for the beach safety personnel and would direct visual and pedestrian connections to the beach safety hut.

The exposed location, of Port Eynon beach, is subject to a sometimes harsh, saline but warm south-west prevailing wind in the spring and summer with no obstacles to provide shelter. In the winter the site is protected from the colder north-easterly winds and climate by the coalfield plateau and high scarp of the Carmarthen Fans. ${ }^{15}$ The site is subject to an average UK rainfall which is slightly higher between October and January, however when coupled with the wind means the site can be subject to harsh wind driven rains. Due to the coastal location, the site experiences low snowfall. Good direct solar access with no overshadowing means the site is exposed to the full variations in temperature and UV but with many days of low cloud cover. The siting offers 180 degree views of the crescent shaped beach.

\subsubsection{Design strategy}

The County and City of Swansea proposal was for a single storey, square plan building. To decide on an appropriate location a square footprint was assumed as the basis of a revised design. Four siting and orientation options were considered within the small area adjacent to the car park to predominantly consider different look-out and access arrangements, however each also had an impact on the ecology, services, connection with the beach and spatial configuration. Two were in the dunes and adjacent to existing footways but isolated from the existing buildings and public beach. The other two are on or adjacent to existing public routes to the beach. The chosen site, to the south-west of the disabled car parking, occupies and defines

15 Explore Gower, Weather and Climate (Explore Gower 2015) <http://www.explore-gower co.uk> [Accessed 20th June 2015] 

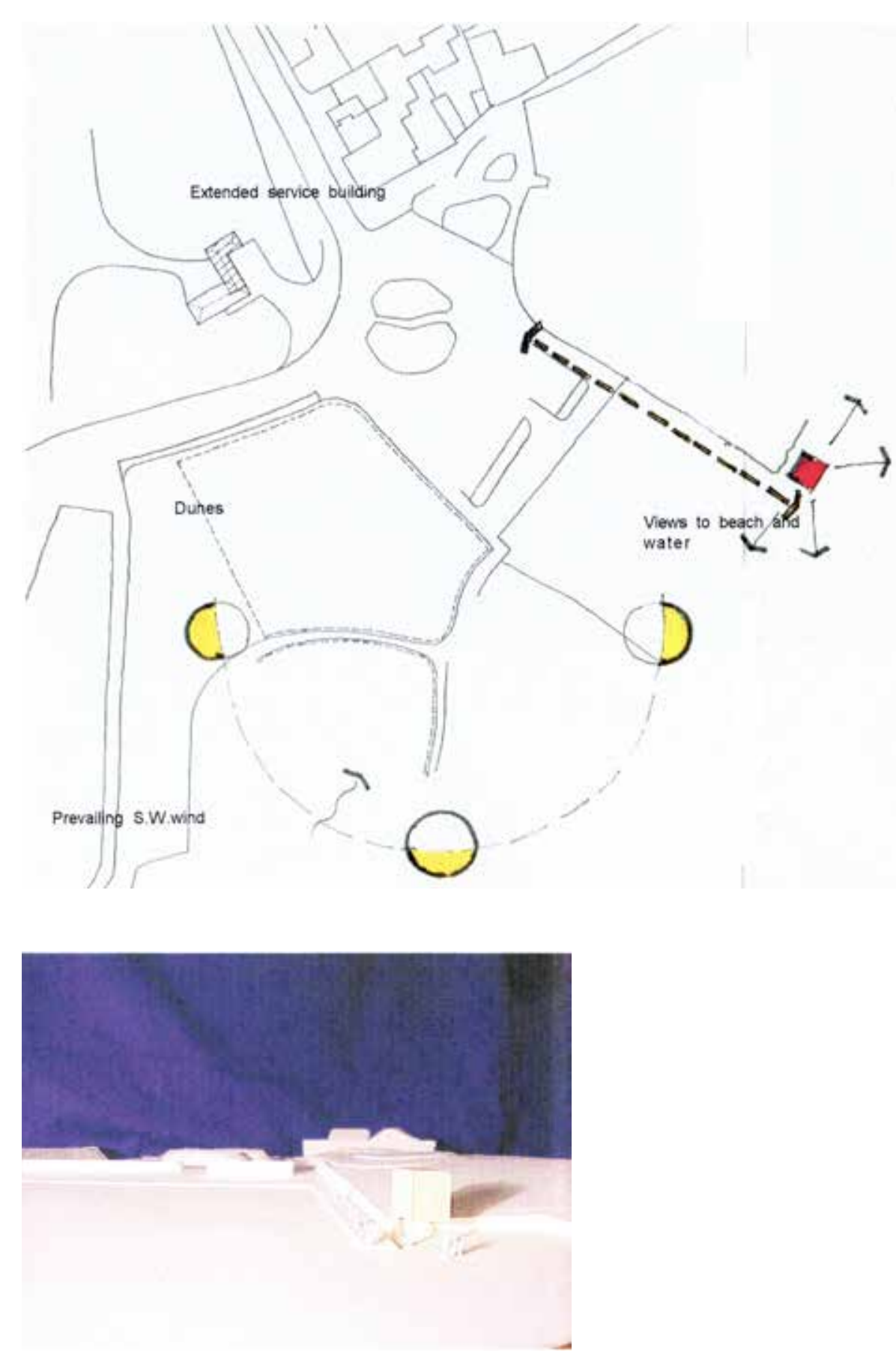

the boundary between the beach and eastern sand dunes with the boundary also providing a logical access and services route. A rectilinear plan would also allow look-out views from three facades and would enable a simple logic to the internal arrangement of viewing, storage, access and first-aid: open toward the beach, closed service zone towards the rear. In relation to the use of timber, the following aspects of orientation are of consideration:

- $\quad$ access decking - the chosen site is along an existing path that drops rapidly away to the beach. A new access decking is required between the path and the raised location of the building. The decking must be durable to resist extreme high-tides, a constant wetting and drying scenario and decay;

- ground conditions - The foundations will be bed into deep sand and at risk of extreme high-tide flooding. Any connections between ground and timber should be minimised to avoid an increased potential of decay;

- climate - The building is in a very exposed location and therefore subject to direct and permanent solar access, high winds, rain, snow, hail and the saline atmosphere on all facades all year round. While the building will be able to utilise natural light and ventilation, the combination of all these climatic conditions will accelerate the bleaching of the tannin and therefore the colour of timber. In some species the combination of wind, wetting and drying, UV and the salty air will rapidly cause deterioration of exposed untreated timber;

- views - The building will provide 180degree surveillance of the beach and water. The introduction of large areas of glazing and openable panels will require careful consideration of joints and seals.

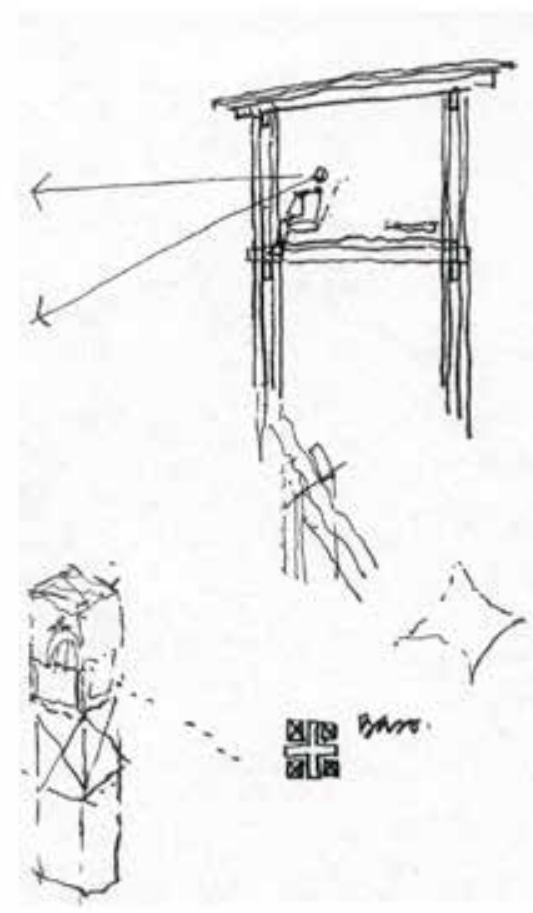

ABOVE

Fig 6.22 Preferred option plan and model for site location

Fig 6.23 Sketches investigating function and form 

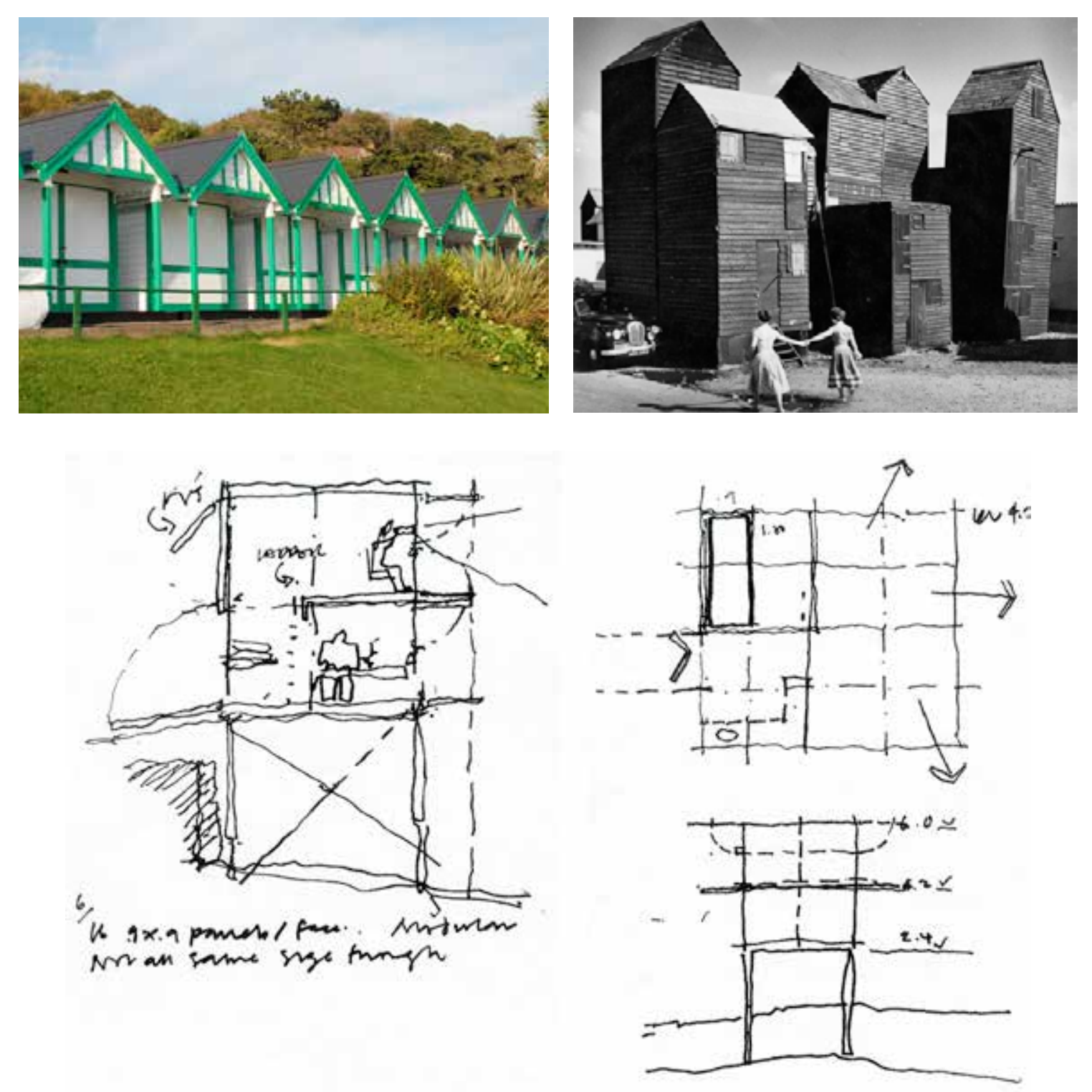

ABOVE

Fig 6.24 Langland Bay beach huts

Fig 6.25 Working fisherman huts in Rye,

Fig 6.26 Modular development sketches of a flexible timber 'cube'.

BELOW

Fig 6.27 Various configurations of the GucklHupf, in Mondsee, Austria

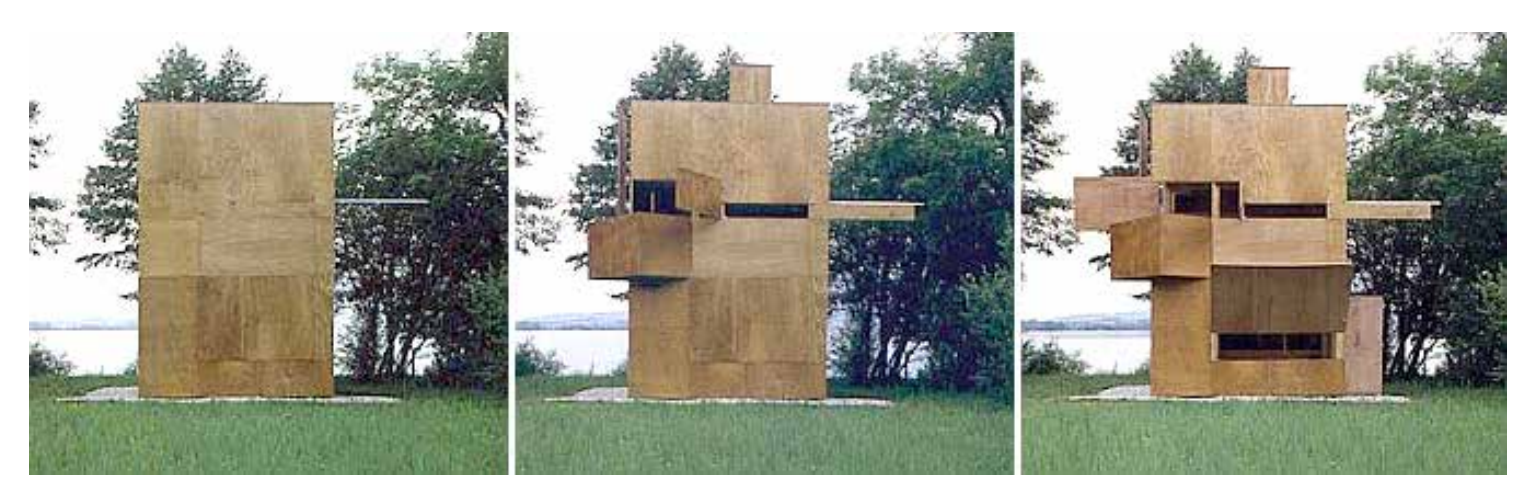

\section{Design development}

The overall form of the building was determined by an intention to create an architecture that 'belongs' to the seaside and a contextual response to the landscape, climate and vernacular of The Gower. It was not to be a kitsch beach hut as seen on Miami beach or a pastiche of a traditional beach hut, although the development of seaside architecture from industrial working buildings through the golden age of the Victorian bathing machines and twentieth century beach holidaying were taken into account. The vernacular green and white beach huts further east along the Gower coast at Langland Bay, built in the 1920s and 1960s, were considered as having achieved this sense of belonging to the seaside in form, function and public opinion.

As well as the seaside image, an appropriate form and composition was explored, informed by the the needs of the buildings users, the function and, potentially more significantly, the properties of the timber species used:

- The structure and skin were to be made of Welsh-grown indigenous hardwood, with the sizes and properties determining scale and use;

- The building envelope would be required to withstand the climatic conditions which over time may resemble the beautifully weathered 'working' fisherman's storage huts in Rye, Sussex, described by J.M. Richards and photographed by Eric de Mare in 'The Functional Tradition';

- The design needed to be capable of meeting the changing occupancy and climatic factors and would therefore likely involve movable panels to facilitate change. The adaptable form of the GucklHupf, designed by Hans Peter Wörndl,1992, in Mondsee, Austria was seen as a playful but direct response between form and function.

The final square plan design was composed over 2 levels. The 'ground' level is $750 \mathrm{~mm}$ above the slatted timber beach deck accommodating the key functions of first aid, information and observation. The upper 'loft' level, $2400 \mathrm{~mm}$ above entry level, is accessed by a fixed ladder for storage and further observation. The building is entered from the south-west by a single glazed door. All four elevations are composed to respond to the views for look-out and the climate but follow the same simple modular proportion determined by the timber properties. 


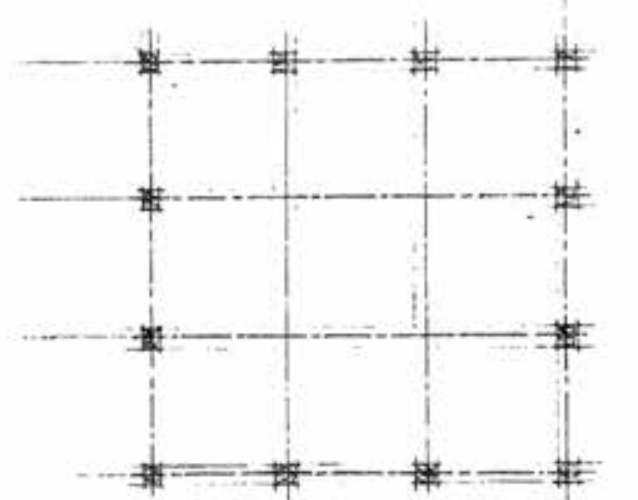

1.Plal at plattorm
simpie $1200 \mathrm{~mm} \times 1200 \mathrm{~mm}$ grid with $150 \mathrm{~mm} \times 150 \mathrm{~mm}$ structure
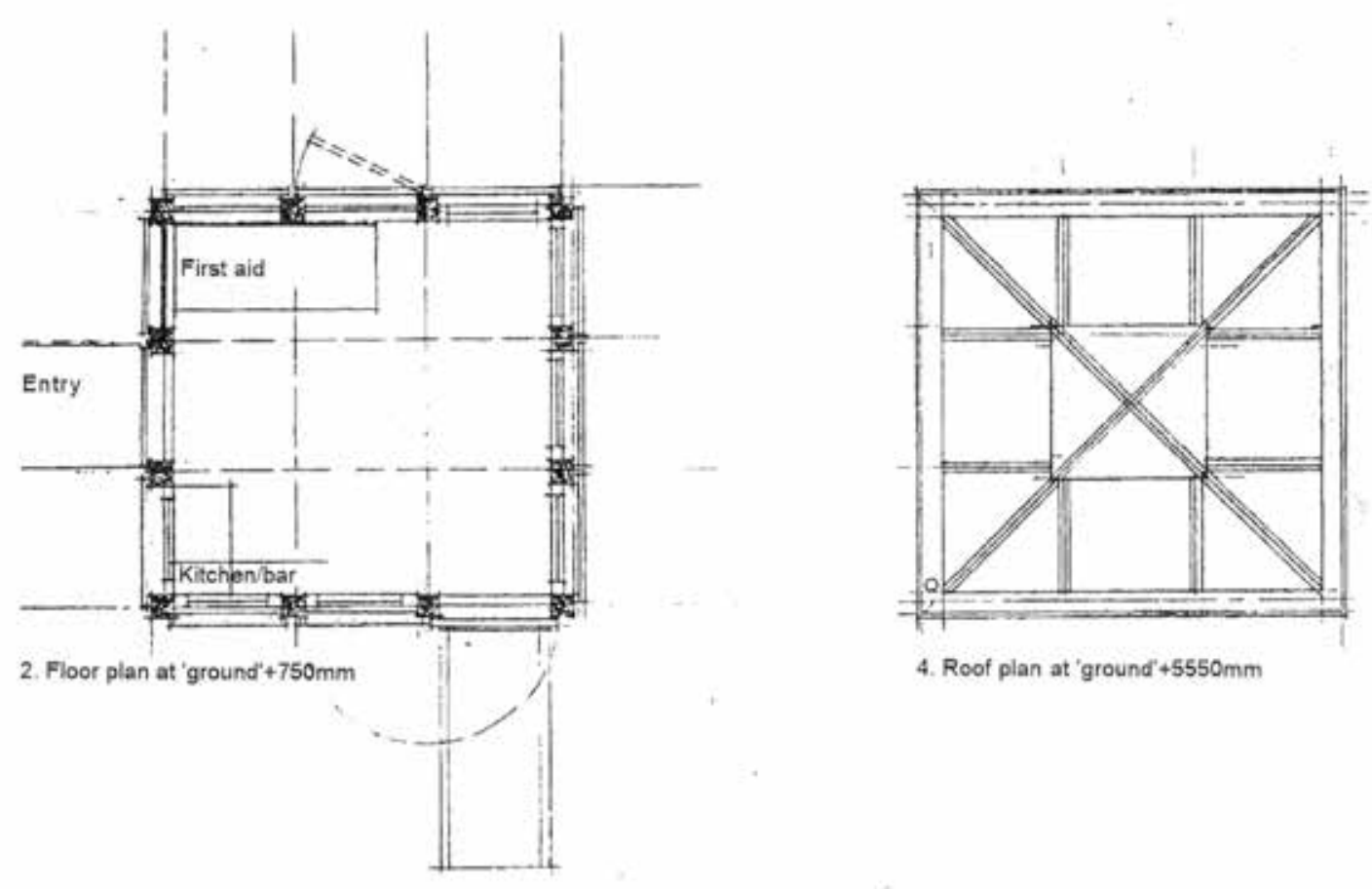

4. Roof plan at' 'ground' $55550 \mathrm{~mm}$

\section{Design drawings}

The following drawings and model show the first proposal for a $3.6 \times 3.6 \times 4.8 \mathrm{~m}$ beach hut, as presented to the City and County of Swansea:

- open chestnut clad 'cube' informed by short lengths of Welsh-grown hardwoods

- $\quad$ separate entrance and beach access ramp with first-aid and basic kitchen at entry level

- a 1st floor'loft' deck for look-out

flexible and adaptable facade that could be opened up entirely
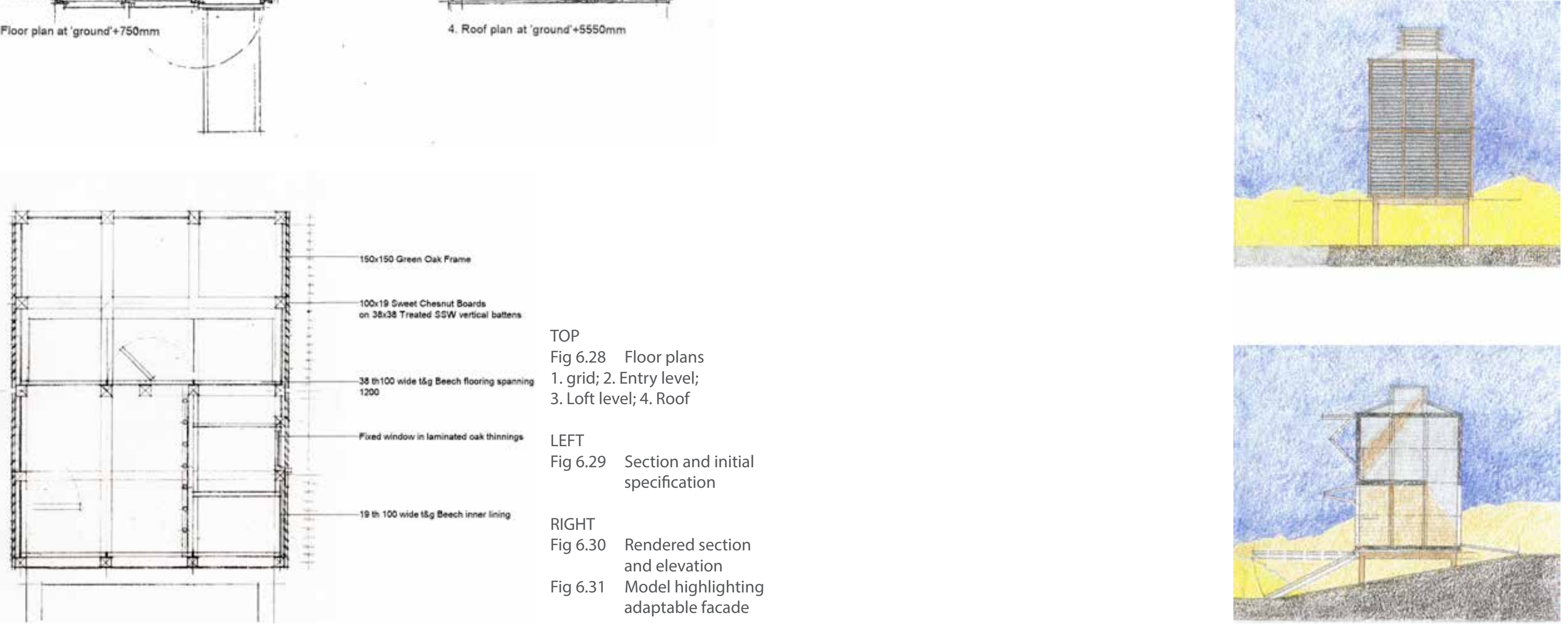
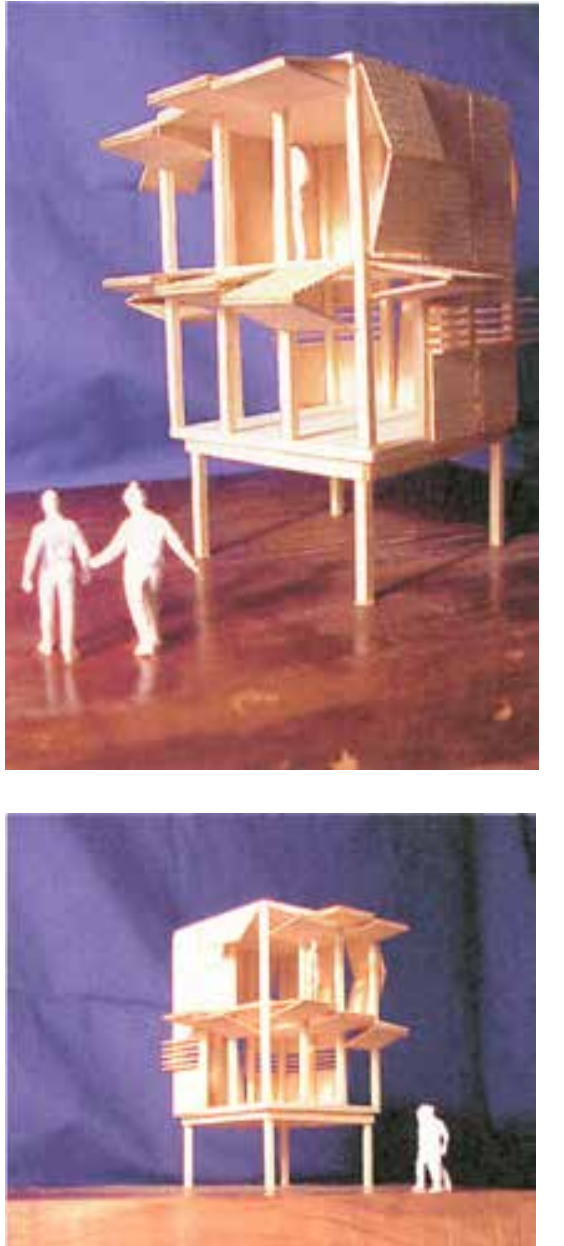


\subsubsection{Prototype}

The proposal was further revised following technical refinement on the material, structural frame and envelope design as illustrated opposite and discussed below with a focus on the overall tectonic form in response to hardwood use and detail.

\subsubsection{Detailed design}
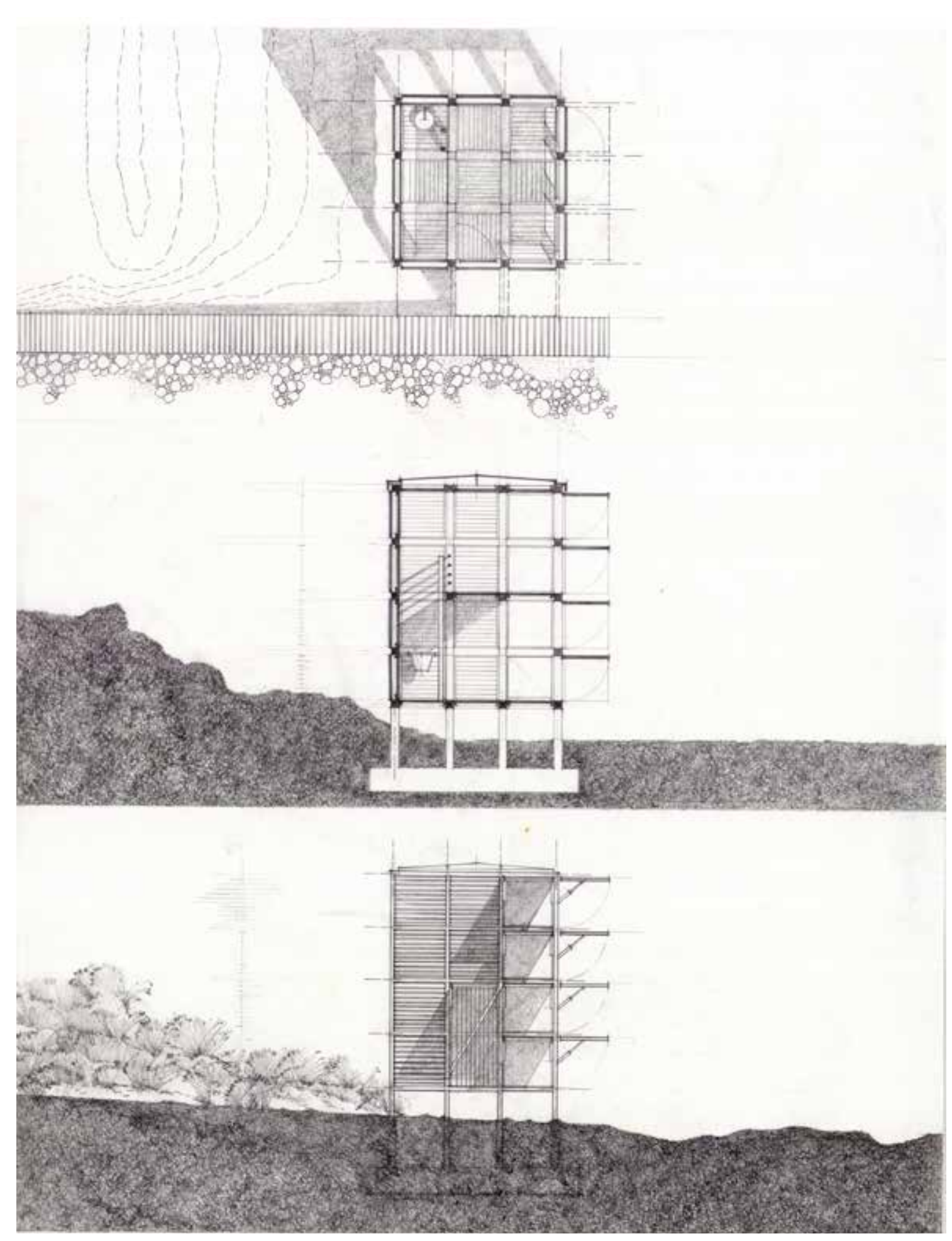

Fig 6.32 Revised designs for planning approval
As well as a functional, seaside building, the beach hut was designed to be a didactic expression in the use of Welsh-grown hardwoods. As discussed in the precedents, there is a lot of potential for the use of homegrown hardwoods as low-maintenance structure and cladding. However, at the time of designing this building, there was little written design advice about the use of green oak and green sweet chestnut, especially in contemporary design. Instead the knowledge was available through specific craftspeople and foresters. Therefore, Coed Cymru were instrumental in the specification and understanding of the timber available to use for this project. As previously discussed the woodland tradition in Wales has been resurrected through organisations such as Coed Cymru who have actively promoted the use of local hardwoods produced from managed woodlands. Continuous Cover Forestry is a system of gradual and selective felling and thinning, distributed continuously over the entire woodland to achieve an uneven-aged structure over time. As mature stem are removed, the gaps created are filled by natural regeneration therefore benefiting the woodland diversity and ecology.

This system of woodland re-generation is not based on the wholesale felling of mature broadleaved forest, but on preserving the best trees, with the trees considered unsuitable for use in construction, harvested. The resultant crop, is therefore based on short length, small to medium diameter timber. Inspired by this approach the following hardwood species were specifically chosen for different parts of the beach hut for their properties in relation to availability, strength and durability:

- Structural frame - green oak:

- External joinery - kiln dried oak

- External rainscreen cladding - green sweet chestnut; and

- Flooring and wall panel linings - kiln dried beech.

As well as hardwood, the beach hut design also incorporated kiln dried Douglas fir (softwood) for window and panel carcassing.

Furthermore, Coed Cymru had developed a conversion process which minimises waste, producing standard sections sizes up to $1200 \mathrm{~mm}$ long. It was these lengths 
and section sizes that were utilised in the design of the beach hut, therefore forming a principle module and bay size of $1200 \mathrm{~mm}$. The grid was, therefore, based on a 1200 $x 1200 \mathrm{~mm}$ centre to centre arrangement in plan, section and elevation.

Based on the required accommodation, 3 modules formed the basis of a $3600 \mathrm{x}$ $3600 \mathrm{~mm}$ plan. The need for an entrance level with first aid and information and a first floor look out level led to a 2 module floor-floor height of $2400 \mathrm{~mm}$ and a total beach hut height of $4800 \mathrm{~mm}$ which was finished with a 10 degree pitched pyramidal hip roof over.

The frame would be infilled with prefabricated panels between the $1200 \mathrm{~mm}$ structural grid frame using a range of timber products that had been developed by Coed Cymru using the small sections and short lengths of hardwood, trademarked as the 'Welsh Angle'. Two of them - a high performance oak framed window and a beech floor cassette were specified for the interior of the beach hut.

\section{Specification of principal elements:}

- $\quad$ structural frame - $150 \times 150 \times 1200 / 4800 \mathrm{~mm}$ oak

- cladding boards $-19 \times 100 \times 1200 \mathrm{~mm}$ sweet chestnut

- floor boards $-38 \times 100 \times 1200 \mathrm{~mm}$ beech
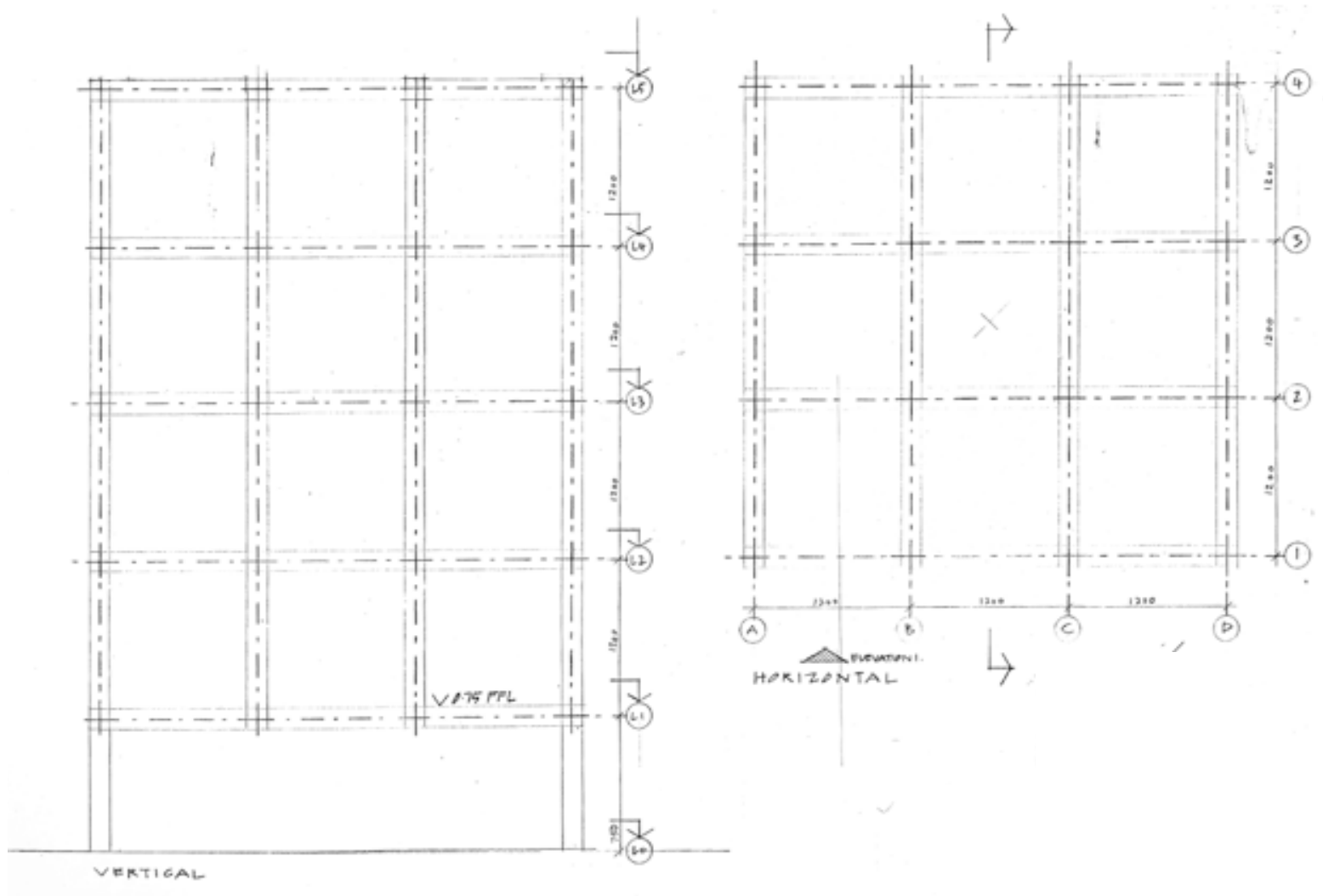

\subsubsection{Structural frame}

The frame was developed as a rigid 'crate' using $150 \times 150 \mathrm{~mm}$ square section, green oak posts on a $1200 \mathrm{~mm}$ centre - centre grid, as specified by the structural engineer. This module of $1200 \times 150 \times 150 \mathrm{~mm}$ was based on the readily available green oak crop that is drawn from medium growth trees.

As the beach hut would be unheated and the oak frame would be exposed to a high relative humidity and extreme saline conditions on a regular basis, it would be expected that the moisture content of the oak would not dry below $20 \%$ and would vary throughout the seasons. To air dry a $150 \times 150 \mathrm{~mm}$ oak section to approximately $20 \%$ may take 6 years or more. ${ }^{16}$ On this basis, green oak was the most appropriate material to specify for the exposed frame, although there would still be initial shrinkage during the first few years of use that would require consideration in the structural frame fixings and infill panels.

The structural grade required was typical of Welsh-grown green, ${ }^{17}$ hardwoods with

17 Green timber has a moisture content greater than 20\% 
a section size over $100 \mathrm{~mm}$ and cross-sectional area over 20000 sqmm, for use in a service class 2 or 3 area (climate conditions with relative humidity exceeding $85 \%$ - BS5756:2007). The timber grades and associated strength class (BS EN 338) were therefore specified by the structural engineers as follows:

- $\quad$ Structural frame - THA green oak with a strength class of D40.

- External joinery - kiln dried oak with strength class D30.

- External rainscreen cladding - $\mathrm{TH} 1$ green sweet chestnut with strength class D30.

- Flooring and wall panel linings - kiln dried beech with grade stresses similar to the tropical hardwood iroko in accordance with BS 5268-2.

- Carcassing and roof structure - kiln dried C16 Douglas fir.

Following structural analysis and calculations based on: expected wind, rain and snow loads; imposed loads; and dead loads the frame design was specified as consisting of 4 frames fabricated on-site and lifted on to corresponding concrete pile foundations. The frames were to be fixed to the pile caps with stainless steel post brackets and braced to the adjacent frame with $150 \times 150 \times 1050 \mathrm{~mm}$ green oak beams at $1200 \mathrm{~mm}$ centres at floor, walls and roof. Each frame was detailed with 2 no. $5550 \mathrm{~mm}$ long posts, to provide the $750 \mathrm{~mm}$ raised floor and $4800 \mathrm{~mm}$ beach hut height. The 2 frames that formed the external elevations have $5 \mathrm{no} .3600 \mathrm{~mm}$ beams with $1050 \mathrm{~mm}$ intermediate posts dividing the elevation into $1200 \mathrm{~mm}$ modules for infill panels. The 2 internal frames have 3 no. $3600 \mathrm{~mm}$ beams for entrance level, lookout level and roof structure.

For torsional and racking stability the frame relied on a rigid fixing detail between posts and beams, the Douglas fir framed fixed infill panels with green sweet chestnut cladding and the transfer of these loads into the foundations.

The rigid fixing details between green oak elements were intended to be minimal, without unnecessary brackets and bolts that would detract from the timber 'crate' tectonic. The details must also allow for the predicted shrinkage and swelling of the oak throughout the seasons. Initially it was proposed that the fixing details between $1200 \mathrm{~mm}$ lengths of oak would be timber only developing on traditional joints as tried and tested at Bedales School, by Carpenter Oak. The most complex of the joints was the corner detail where multiple posts and beams connect. To test the making and performance of the detail, carpentry students at Bridgend College prototyped various tusk and tenon joints, often used to join purlins with rafters and in furniture, to join multiple oak sections together without screws or bolts. The prototypes revealed: 

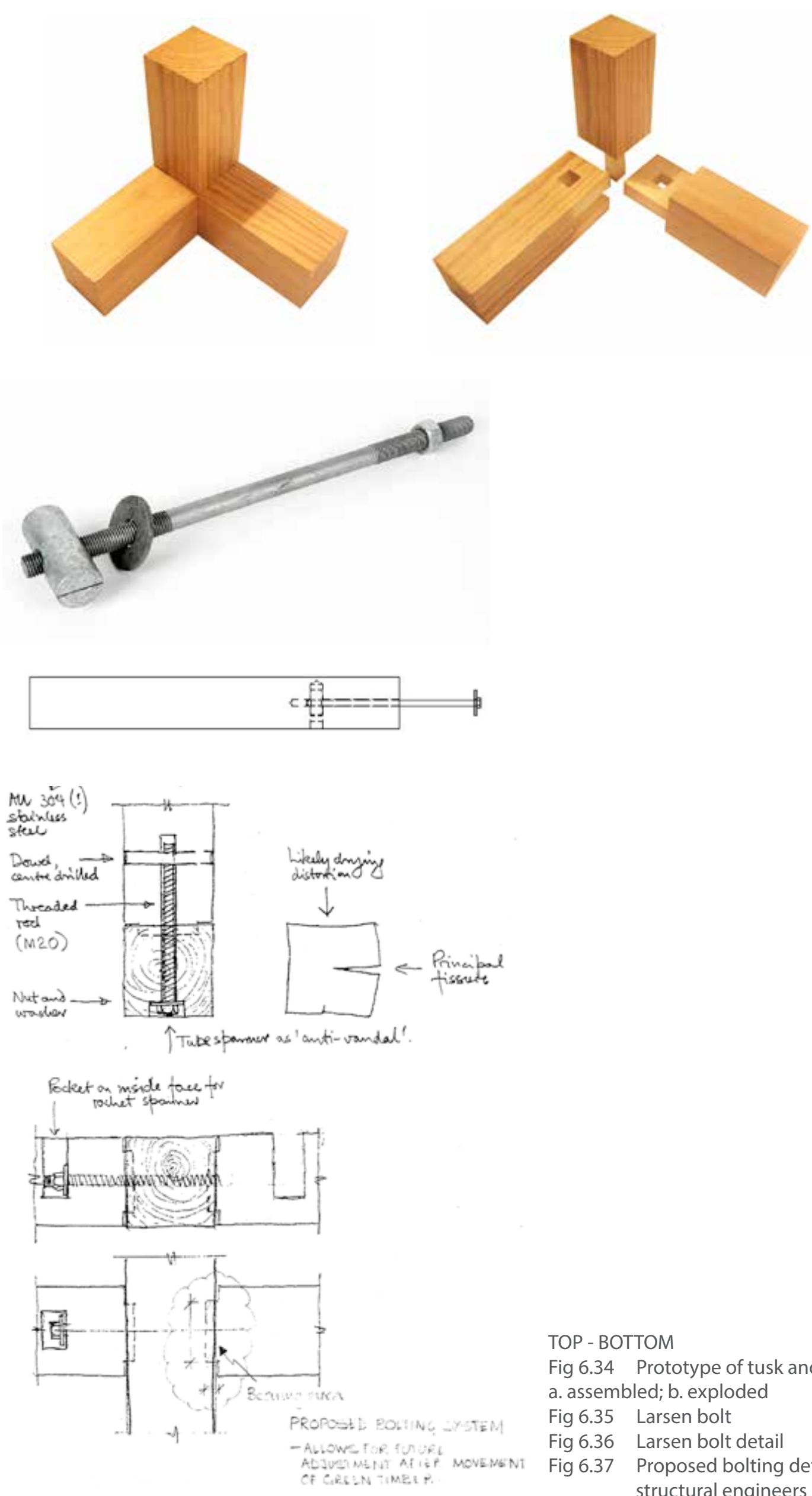

TOP - ВOTTOM

Fig 6.34 Prototype of tusk and tenon joint

a. assembled; b. exploded

Fig 6.35 Larsen bolt

Fig 6.37 Prsen bolt detail

Fig 6.37 Proposed bolting details by
- there were structural difficulties with the sectional area of timber on the corner posts

- the details would likely require ongoing maintenance of wedges and cramps as the structure shrinks.

- that the significant labour involved in hand-crafting each connection would be prohibitive on a small-scale, low-budget project.

As an alternative the structural engineers suggested the use of a Larsen bolt. Much the same as the fixings employed in DIY furniture, the bolt would be invisible but could deal with the complex geometries of the joints and enable easy adjustment of the joint-post connection. The bolts were specified as A4 or 316 marine grade stainless steel to resist corrosion from the tannic acid leeching from the green oak and saline conditions.

\subsubsection{Envelope}

The unheated beach hut was designed to principally provide basic first-aid, storage and shelter from the sun and rain for the beach safety staff. However, the building envelope must function in a number of ways. For the majority of the time the building will be uninhabited and therefore must be able to be closed and secured. In the summer, the building will be opened up to allow prospects to and from the building and the public areas at Port Eynon. The building envelope must therefore provide the following performance requirements:

- $\quad$ structural bracing of the frame;

- allow access for all;

- allow views out at both levels;

- $\quad$ protect from solar gains and glare;

- $\quad$ protect from rain, wind and snow; and

- be secure when uninhabited. 

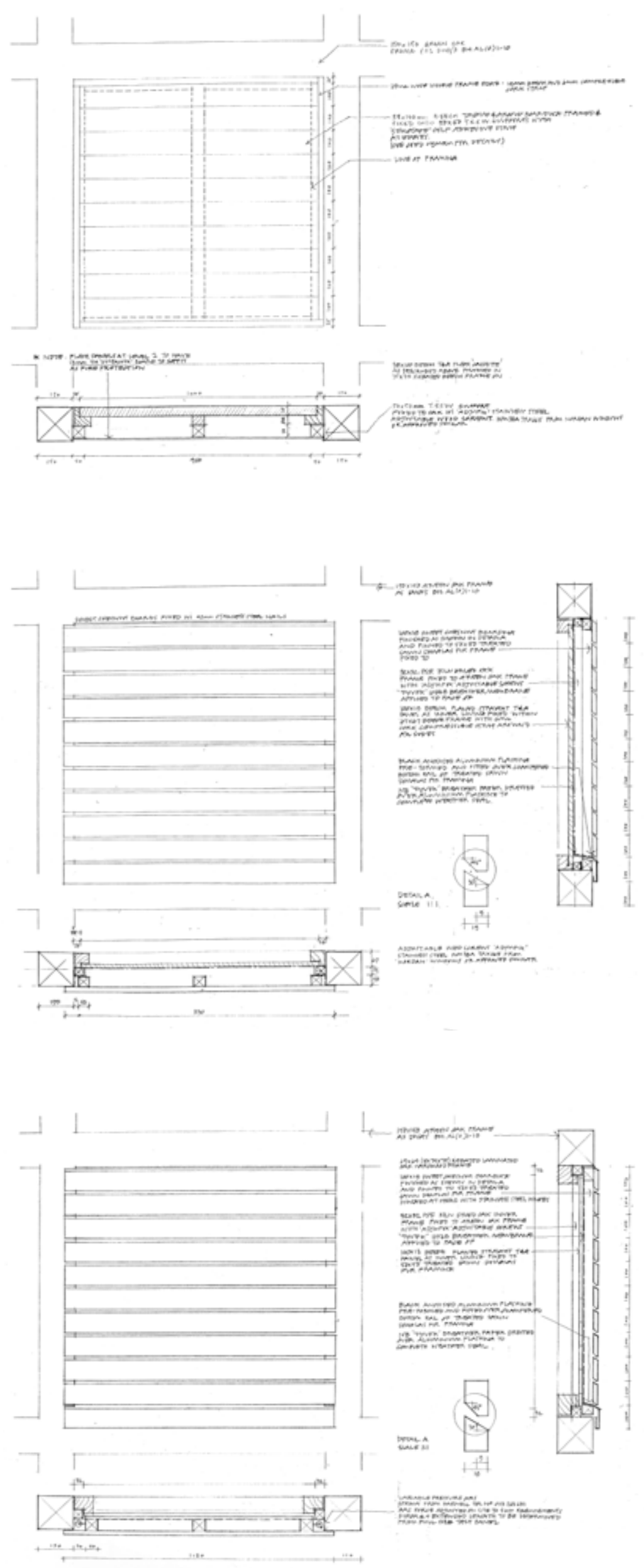

All of the above are incorporated into the infill panels, designed to fit into the $1050 \mathrm{x}$ $1050 \mathrm{~mm}$ frame openings in both plan and elevation. These panels were developed to have both fixed and moveable components providing the flexible and varied control required. While the details vary slightly, the prefabricated panels can be divided into 3 types:

- Fixed floor or wall - The fixed panels provide the structural rigidity to the oak frame with Douglas fir frames, beech t\&g internal finish for both floor levels and walls and sweet chestnut open boarded horizontal external cladding to the walls.

- Openable opaque wall - These panels are positioned in the lower $1200 \mathrm{~mm}$ zone of both levels to provide ventilation on the beach side of the building. Similar to the fixed wall panel, they have a beech $\mathrm{t} \& \mathrm{~g}$ inside finish and a sweet chestnut external cladding, except the beech and sweet chestnut are both fixed to a $50 \times 50 \mathrm{~mm}$ Douglas fir hinged frame with variable pressure gas spring stays. 

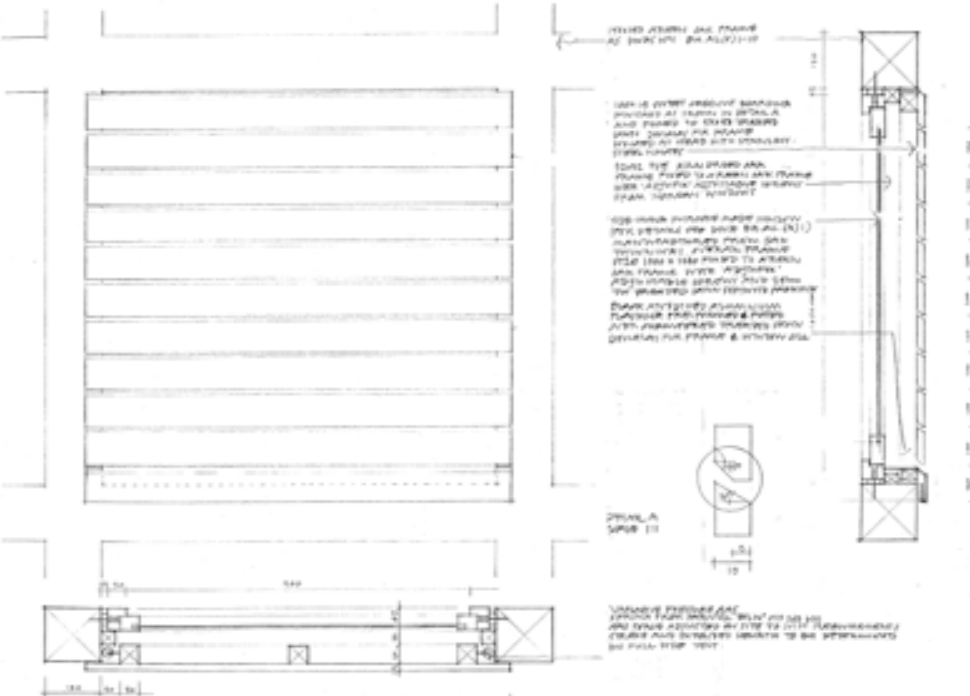

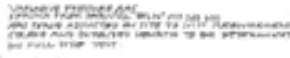
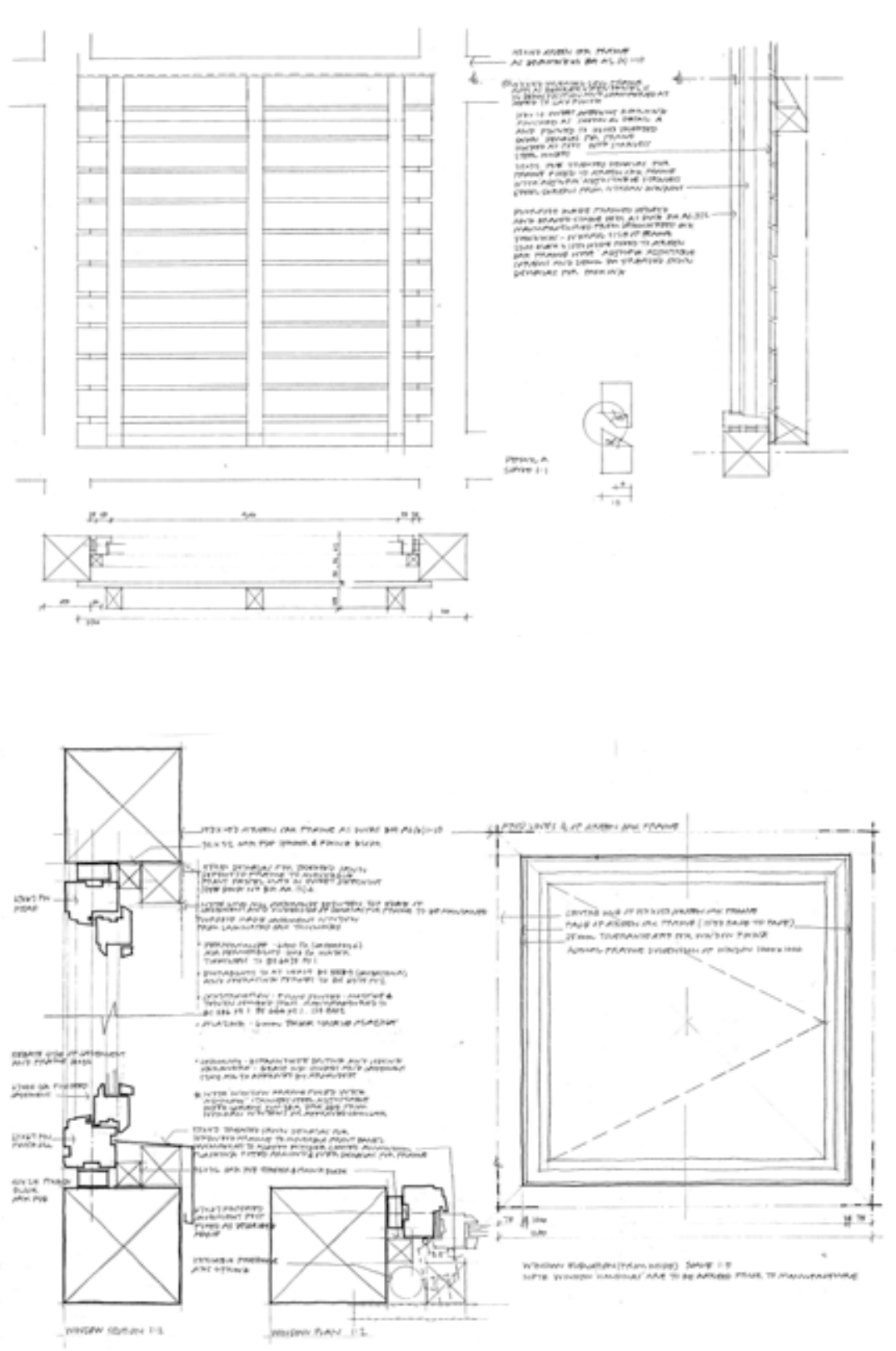

Openable window/ door - The moveable panels have both an inner and an outer skin. The outer skin provides secure protection and top-hung to provide solar shading but also reveals the secondary inner window for views. The side-hung casement window is fabricated using the laminated oak profile developed by Coed Cymru with $6 \mathrm{~mm}$ toughened single glazing. The window frame allows for a $25 \mathrm{~mm}$ tolerance gap accommodating the movement of the green oak frame. At the entrance a $900 \times 2050 \mathrm{~mm}$ framed, braced and ledged laminated oak door and frame replaces the openable window with the top half protected by a top-hung sweet chestnut panel and the bottom half protected by a bottom-hung sweet chestnut panel with external Douglas fir bearers opening to provide a level threshold connecting the entrance ramp with building.
LEFT (top - bottom)

Fig 6.41 Openable panel over window assembly detail

Fig 6.42 Openable bi-panel over door assembly detail

Fig 6.43 Laminated hardwood casement window

assembly detail 

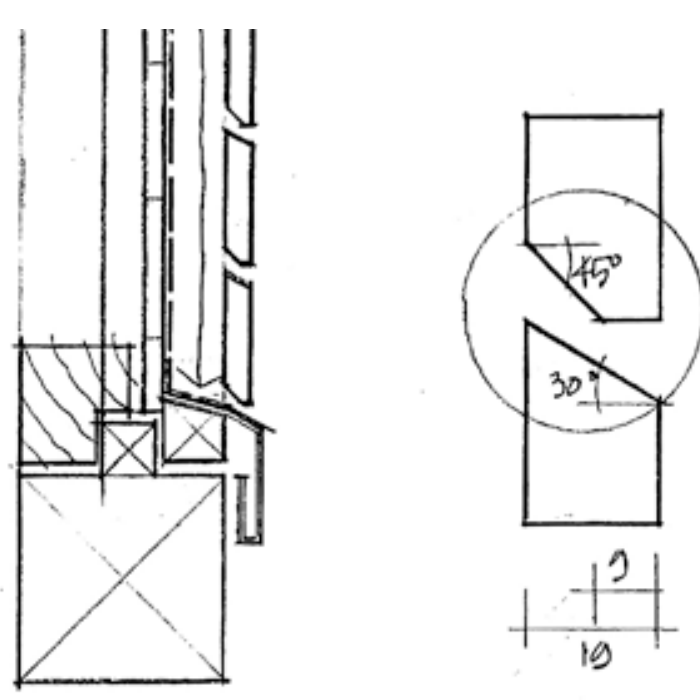

$+\frac{t^{9}}{19} \mid$
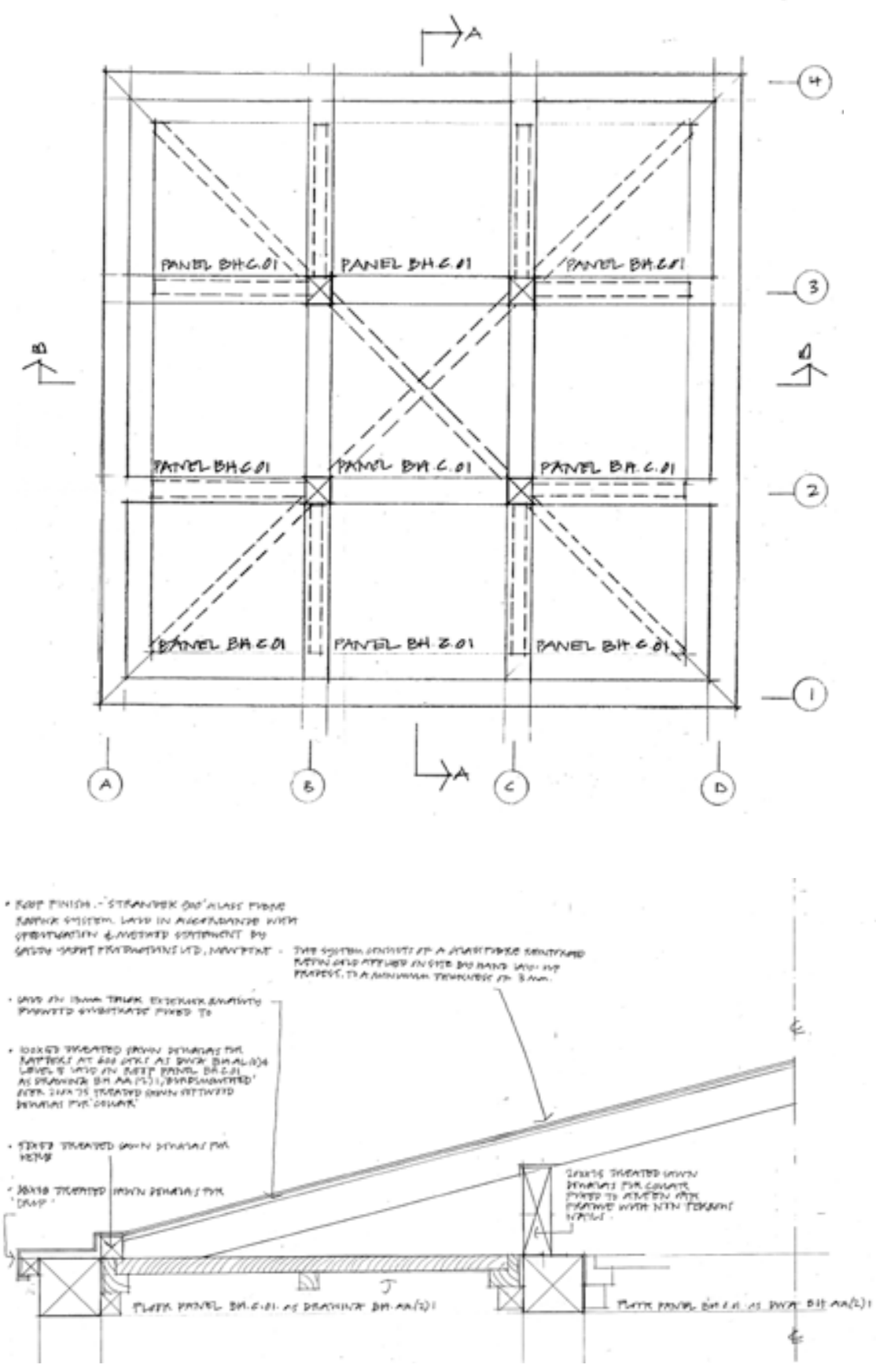

The external cladding of the panels was inspired by the oak cladding of the Henley River and Rowing Museum by David Chipperfield Architects. In all panels, the outer $19 \times 100 \mathrm{~mm}$ sweet chestnut cladding was detailed as an open-jointed, drained and back ventilated rainscreen and brise-soleil fixed to a $50 \times 50 \mathrm{~mm}$ Douglas fir frame. Each board is planed and profiled with a differently angled splay at the top and bottom of the board to prevent visibility through the joint but maintain the rainscreen properties. The opaque panels behind are lined with a breather membrane that laps the bottom aluminium flashing.

The roof was detailed as a simple pyramidal rainscreen to sit on top of the flat structural frame and floor infill panels providing rigidity. $100 \times 50 \mathrm{~mm}$ Douglas fir rafters at $600 \mathrm{~mm}$ centres rest on top of the frame and 'birdsmouthed' over $200 \mathrm{x}$ $75 \mathrm{~mm}$ Douglas fir collar beams. A $3 \mathrm{~mm}$ thick glassfibre roof is laid over $12.5 \mathrm{~mm}$ marine grade plywood and bonded with a glassfibre reinforced resin to form the waterproof layer and drip flashing over the $150 \times 150 \mathrm{~mm}$ oak beams. ig 6.44 Chestnut cladding splay details

Fig 6.46 Roof structural section (half) 


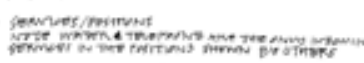

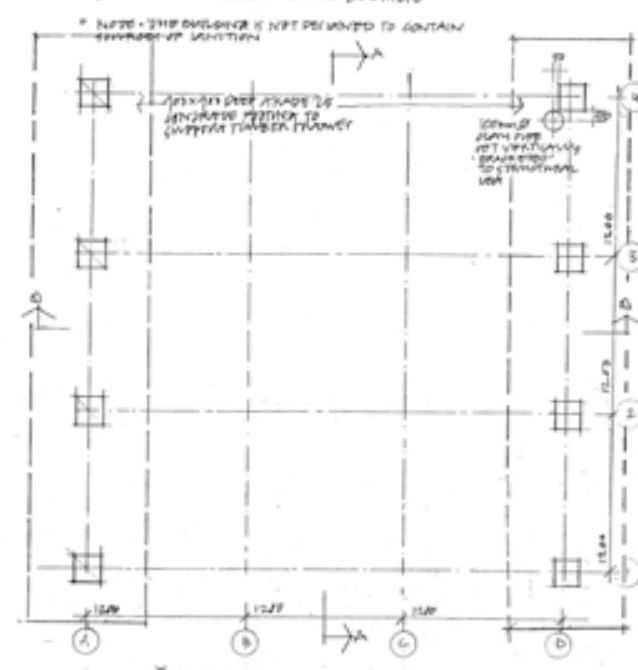

(의)

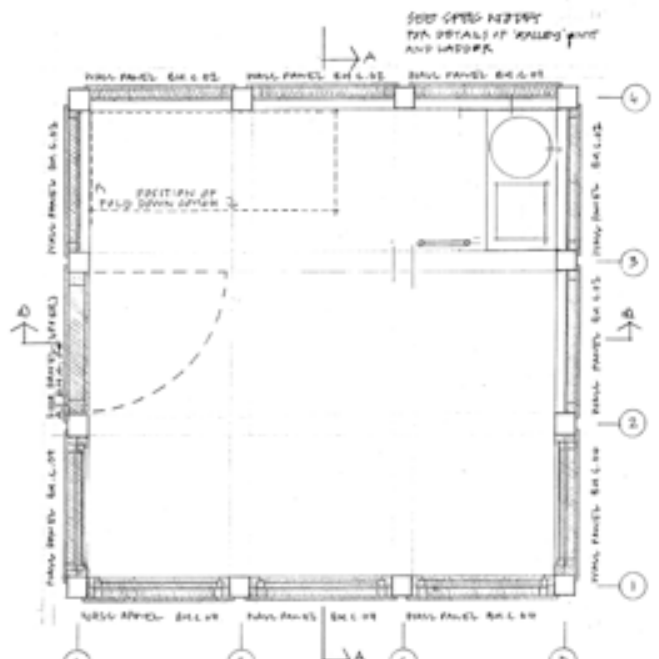$$
\text { (1) }
$$

(12)

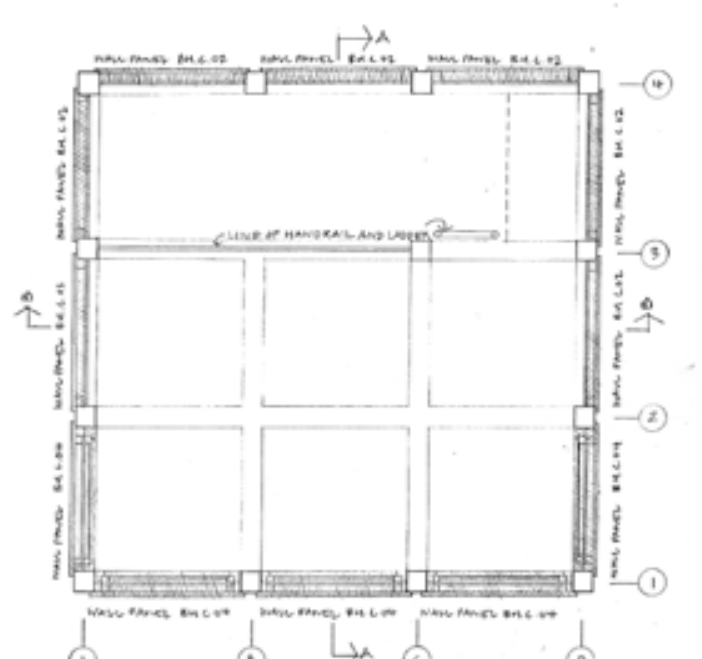$$
\text { (14) }
$$

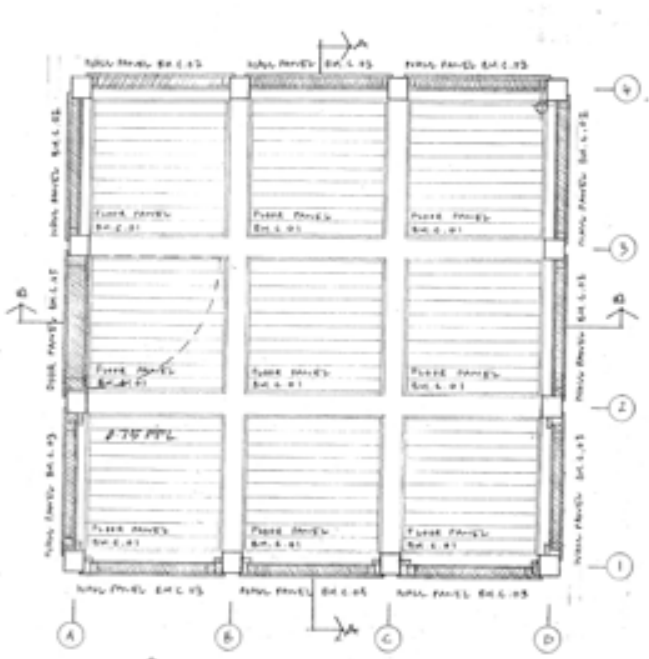

(Li)

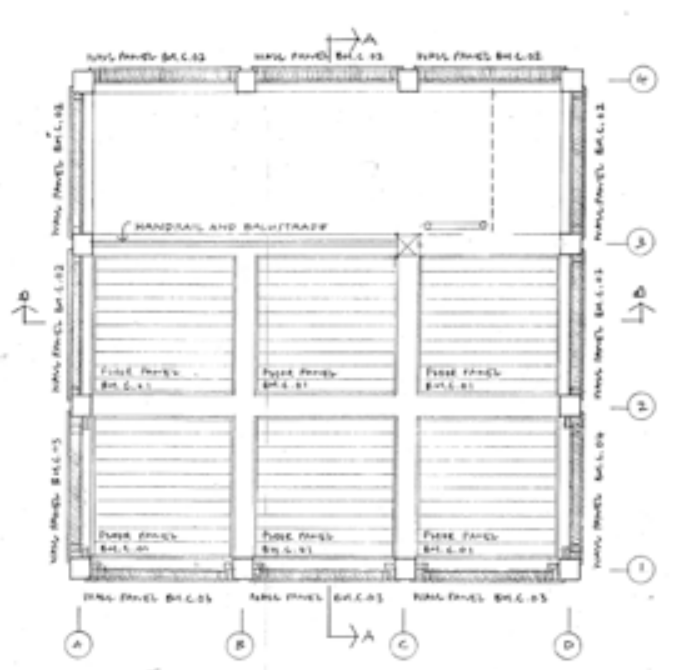

(13)

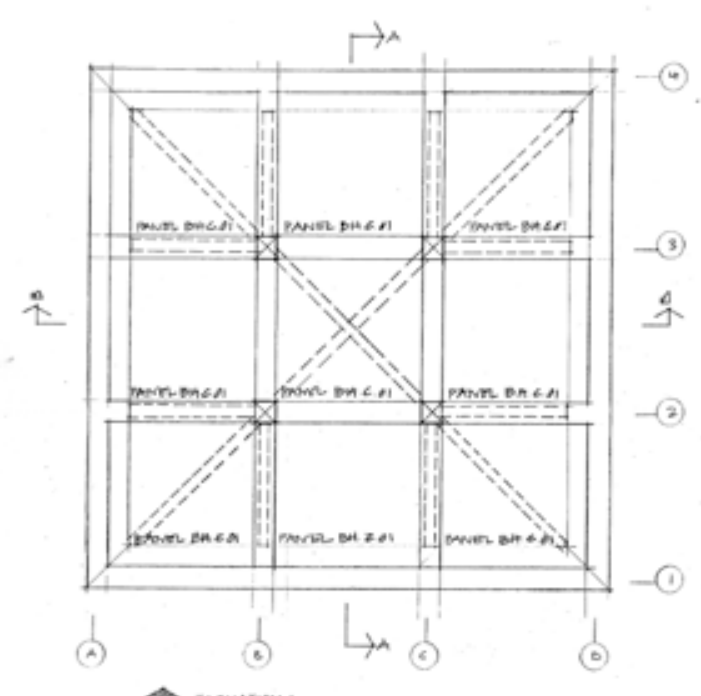

(15)
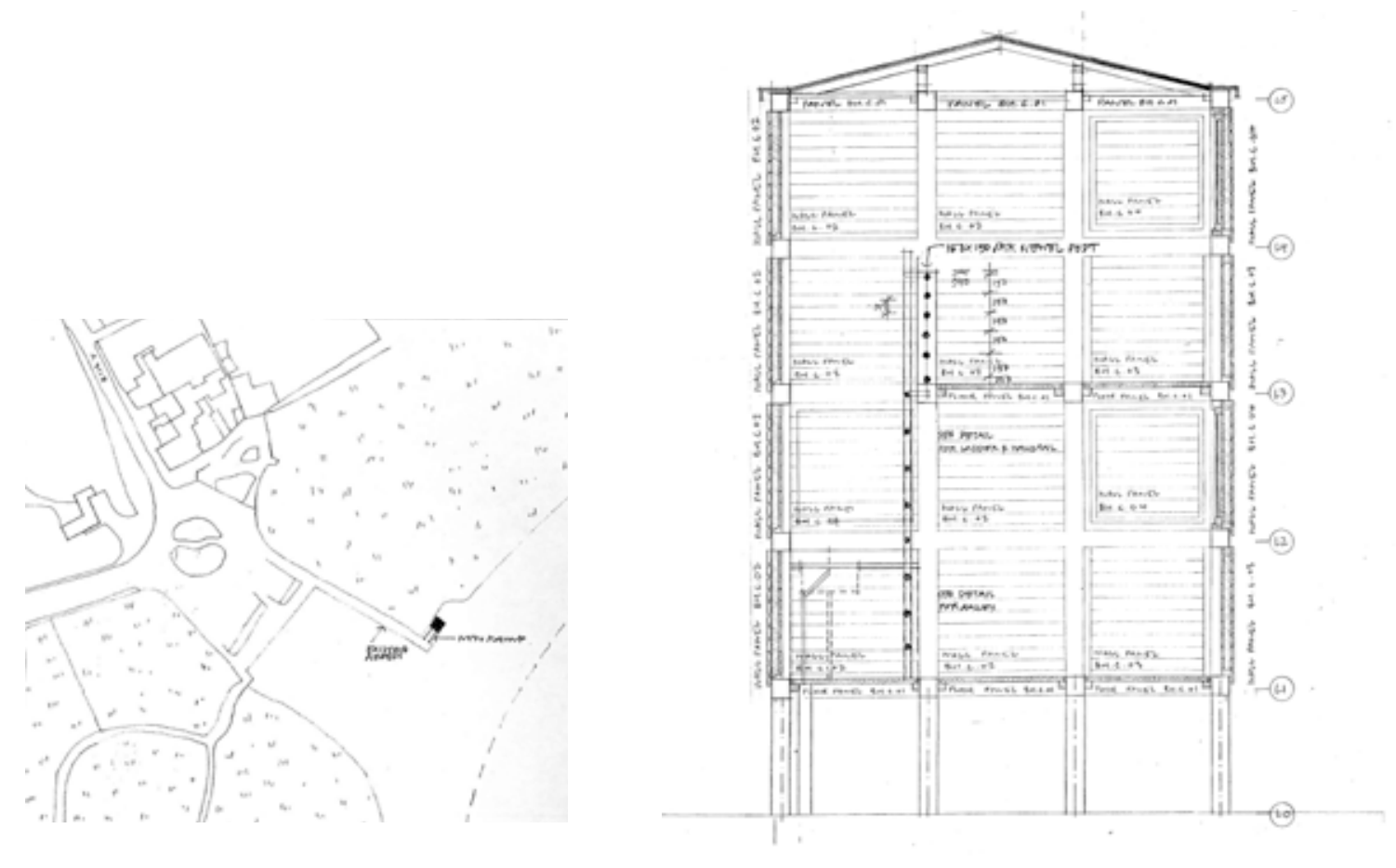

LEFT (top - bottom)

Fig 6.47 General arrangement plans

LO. Setting out plan

L1. Floor cassette arrangement

L2. Entry level plan

L.

L5. Roof structure pla

ABOVE

Fig 6.48 Proposed site plan

RIGHT

Fig 6.49 Proposed Section AA (top)

Fig 6.50 Proposed Section BB (bottom) 

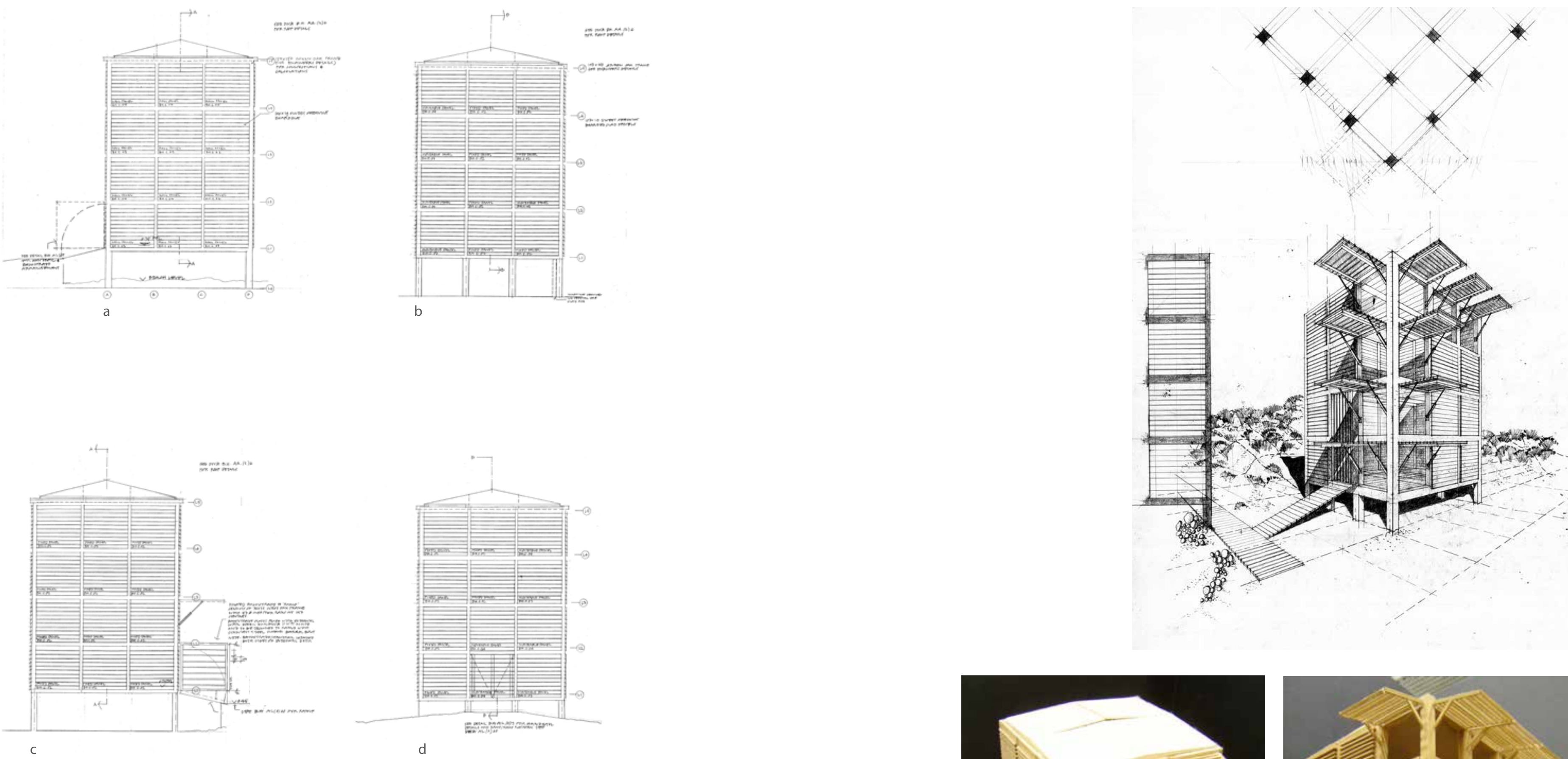

detailed elevations

a. South-east elevation

b.North-east elevation

d. South-west elevation

RIGHT

Fig 6.52 Perspective

Fig 6.53 Tectonic mode
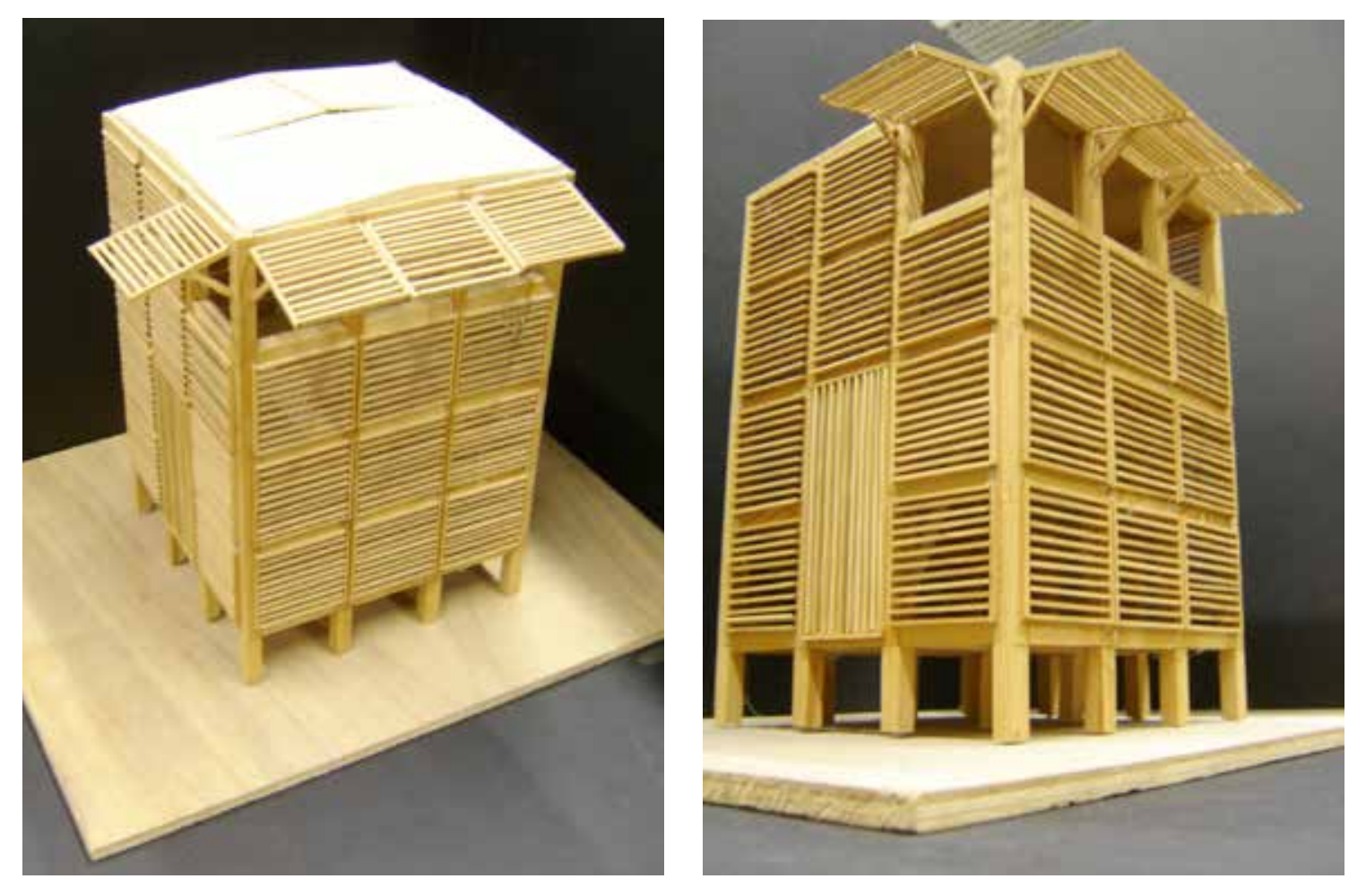


\subsubsection{Observations and reflections}

As the beach hut has not been built, it is not possible to give a full reflection of the performance of Welsh-grown timber in action. As such the following thesis objectives are evaluated against the design intentions/ expectations and limited testing.

\subsubsection{Species performance and adaptation}

\section{SPECIES}

- The Beach Hut incorporated green oak and sweet chestnut and kiln dried beech and Douglas fir for specific purposes related to their individual properties and how they would perform together in a challenging climate. Ash was also considered, as a hardwood almost as abundant as oak, although its durability, performance and availability excluded it from use in this prototype. As highlighted in chapter 2, oak and sweet chestnut are the only durable timbers growing in Wales, with sweet chestnut accounting for only $0.2 \%$ of Welsh woodlands. This poses questions over the use of sweet chestnut in construction for anything other than one-off, bespoke projects. Further research is required to evaluate the sourcing and use of sweet chestnut in action.

- The detailed design and structural engineering revealed that the use of green hardwood requires a thorough understanding of the properties and performance by all members of the design team, including client. The posts and beams proposed will take between 4 and 6 years to dry, to match ambient conditions, past the usual defects liability or rectification period of 6 - 12 months. Connections and junctions between elements and components of the envelope must allow for contraction without allowing moisture or air to penetrate. Specialist timber framing companies offer lifetime warranties on the structural frame ${ }^{18}$, although clients must be aware of the fissures and gaps that may occur over time. In bespoke projects, the full design team and client will need to consider any ongoing maintenance requirements to tighten and adjust any fixings on a regular basis.

- The hardwood required would typically be sourced direct from a sawmill and or timber store. Care would be needed in ensuring that the timber supplied was sourced from woodlands practising continuous cover forestry, rather than being cut down from larger boards at a sawmill. This ensures the timber was sustainably sourced (although not necessarily certified) and that the beach hut is a product of the design principle. The issue of source verification is either not commonly known by clients or practised by architects and 
contractors other than requiring FSC or PEFC certification, which most privately owned broadleaf woodlands in Wales do not have in place.

Therefore, the practice of using short lengths and small section of hardwood must be connected to forest management practice from woodland, through sawmills and onwards and understood by all in the design team as not just a design decision.

- Green sweet chestnut cladding was proposed in $1050 \times 1050 \mathrm{~mm}$ panels leaving a shadow gap between panels. It would be expected that these panels will shrink, possibly with some twisting and bowing that the shadow gaps may disguise. It would be wise for extra cladding to be supplied and allowed to weather on-site to replace any boards with extreme movement over time.

- It is expected that the tannins in both the oak and sweet chestnut will leach out as the beach hut is exposed to rain, UV light and general saline conditions. This must be considered in relation to the design of other components that rain water will carry the tannins onto at a risk of staining. Care must also be taken during construction to ensure the oak and chestnut do not come into contact with non-ferrous metals that may cause blue staining as a reaction with the tannic acid.

TIMBER ADAPTATION

- The intention was to use short lengths and small sections of hardwood, as being an efficient and sustainable use of deciduous, broadleaf woodlands. However, the engineer's structural calculations were based on the use of $4800 \mathrm{~mm}$ long posts, that require significantly sized and aged trees to source these lengths from. A proposal to scarf joint the $1200 \mathrm{~mm}$ lengths into $4800 \mathrm{~mm}$ posts requires further structural research, although this is a tried and tested method of repairing traditional oak framed buildings and used for the beams at Darwin College Library.

- The windows were proposed to be fabricated from short lengths of kiln dried engineered oak using the Welsh angle method developed by Coed Cymru. Since this prototype, Coed Derwen Joinery began manufacturing laminated timber windows producing'...strong stable sections with minimal machining and waste, therefore enabling high levels of labour and material optimisation'.19 


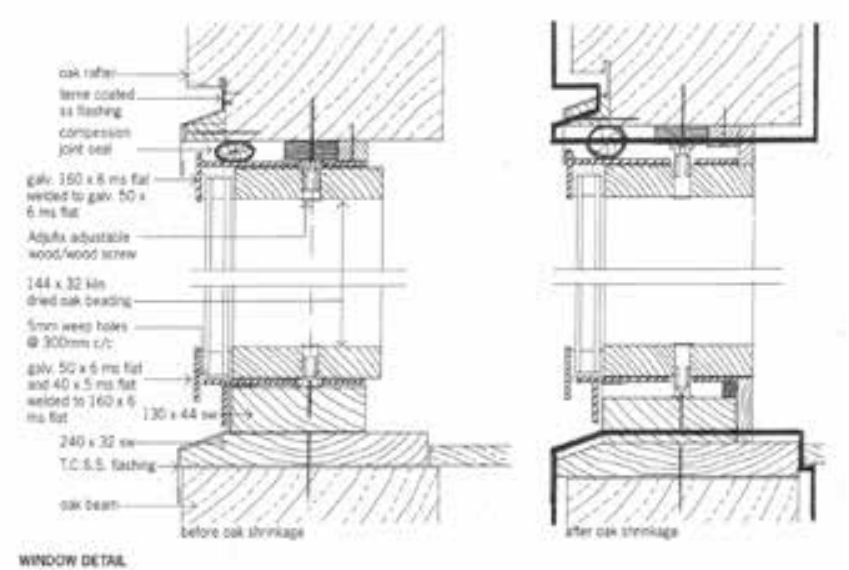

\subsubsection{Building envelope}

\section{SUPERSTRUCTURE}

- The post and beam structure has been structurally assessed with full calculations available to justify sizing of components and joints and as well as for Building Control approval. It can therefore be assumed that the structure would successfully survive the extreme conditions of Port Eynon beach.

- Although, essentially a post and beam structure, the bays are limited to $1200 \mathrm{~mm}$ by the efficient lengths of oak available. These are joined at every node into a similar arrangement to box frame construction of 17th century UK architecture, although adapted, developed and refined for contemporary use to eliminate braces and haunches.

\section{INTEGRATION WITH COMPLETE ENVELOPE}

- The building envelope is defined by the use of green hardwood and a $1200 \mathrm{~mm}$ component for structural frame, infill panel, windows, floor panels and cladding. This has led to an elemental approach to the envelope offering several benefits to the use of green hardwood: the frame is allowed to shrink and move separately to other components; infill panels and windows are fabricated smaller than the $1050 \mathrm{~mm}$ opening to allow for shrinkage with incorporated packing and wedges, similar to the Olivier Theatre details, to take up the increasing gap as the frame shrinks. the cladding is similarly detailed in $1200 \mathrm{~mm}$ bays with a deliberate shadow gap to allow for movement.

- As a beach hut for summer, daytime use only, the proposed envelope does not include insulation, heating, reduced thermal bridging and is not required to meet stringent air permeability tests. Further research would be required to evaluate the thermal performance of a shrinking external structure with integral infill panels for permanent buildings. It would be expected that while the rainscreen will maintain a water tight envelope, the air permeability and thermal bridging may deteriorate. Typically green oak structures are built as an internal frame with an outer envelope meeting environmental performance requirements. Therefore, further modular components may need to be considered as part of the envelope.

- Physical 1:1 prototyping is required to evaluate the performance of the envelope over 4 - 6 years as the green oak posts dry to approximately $18 \%$ moisture content. 
6.3.3.3 Technology and skills

\section{FABRICATION}

- The making of the frame is part of the secondary processing industries, taking place at a joiners workshop. The supply of hardwood would typically come from a small scale sawmill operating in rural locations close to the source woodland. The separated processes can currently cause difficulties in supply, with local sawmills or timber stores not necessarily stocking the timber required when needed, therefore adding considerable lead-in time to source, fell and mill the timber resulting in the use of freshly cut hardwood with very high moisture content. Some carpentry and joinery workshops will source specific trees to supply timber in advance allowing some time for seasoning, although this is a highly bespoke practice to meet specific needs.

- The proposed use of short length and small section timber was intended to simplify the construction to a kit of standard parts assembled into a'crate like' structure. However, the prototype testing of the tusk and tenon joints revealed the labour time and costs involved in making each joint, with approximately 20 joints per frame. Each joint required precision crafting to ensure exact alignment, but also to allow for shrinkage. While these skills are taught at Technical Colleges with competent carpenters and joiners available in Wales, this has become a niche skill compared to the low-skill and technological joints and assembly of prefabricated softwood frame construction therefore attracting premium labour costs to produce.

- Further research may be required to investigate the use of CNC routers and robots to cut basic jointing profiles ready for bolting, such as those used by the large-scale furniture companies to manufacture flat-pack products. Although, this level of technology is limited in Wales to the cutting of timber board products. It is acknowledged that machining green oak can be particularly intensive on cutting heads, blades and drill bits.

\section{CONSTRUCTION}

- The alternative use of larsen bolts, reduced the complexity of the all timber details, the joints still required an element of careful carpentry to align components. However, the number of stainless steel bolts, required to avoid tannic acid corrosion, added considerable material cost.

- To improve quality and accuracy of a frame consisting of multiple, short length elements requires 1:1 prototyping to test: the balance between off-site fabrication with basic on-site assembly; and the use of traditional timber details and/ or bolted connections.

- Collaboration was critical to the success of the beach hut as well as the Olivier Theatre and Darwin College, involving architects, structural engineers, 
timber specialists and carpenters/ joiners. This should be considered best practice to ensure quality of workmanship, design and structural integrity.

\subsubsection{Tectonic form}

CONTEXT

- The overall form of the beach hut was derived from a combination of site context and climate, material properties and technological limitations. The opportunity to explore a hardwood prototype within 'live' architectural parameters meant integrating the vernacular of seaside architecture, material tradition and innovation and an extreme climate has provided a rigorous test of the incorporation of hardwood in the building envelope.

\section{DIMENSIONAL COORDINATION}

- The $1200 \mathrm{~mm}$ timber length defined a module and structural grid of 1200 $x 1200 \mathrm{~mm}$. The choice of $1200 \mathrm{~mm}$ as the basic dimension was developed in collaboration with Coed Cymru as an appropriate length to expect from thinnings and selective felling and a module that would co-ordinate well with other construction industry products.

- An 'honest' approach to construction determined that this grid would inform the design in plan, section and elevation generating an additive 'crate-like' structure of box frames, infill panel and attached cladding/ shutters.

This simple tectonic is similar to a Scandinavian and Swiss approach to timber architecture where details are often carefully considered to avoid unnecessary decoration or detraction from the purity of the guiding module.

- The additive form offers benefits to the performance of green hardwoods as discussed under the building envelope reflections. Although the inclusion of insulation, membranes and internal finishes may need further consideration to maintain a simple, elemental approach to construction and form.

\section{CORPOREAL}

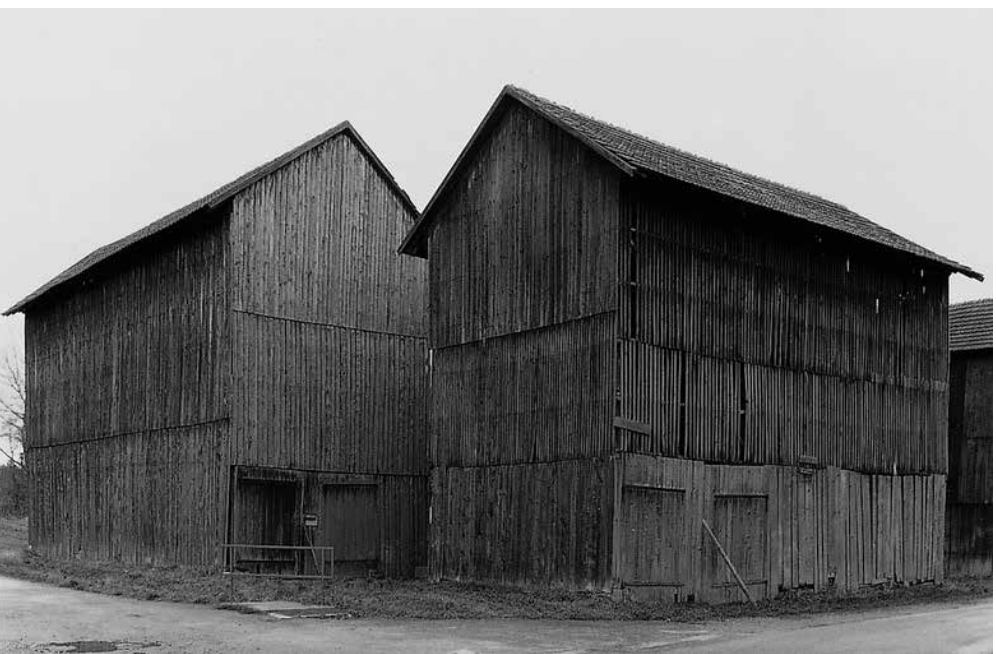

ig 6.57 Modulhaus in Olching

Fig 6.58 Drying sheds of the

- The tectonic expression of connecting multiple elements of oak is critical to the compositional simplicity and elegance of the structure as a whole. The proposed design, engineered details and connection prototypes suggest this may lead to a didactic, but refined, expression of Welsh-grown timber properties and architectural intent. However, 1:1 prototyping is required to test the detailing of $1200 \mathrm{~mm}$ and $4800 \mathrm{~mm}$ posts and the types of connection

- It is expected that the climatic conditions will result in the exposed oak and sweet chestnut turning silver-grey over a couple of years reflecting the site, 


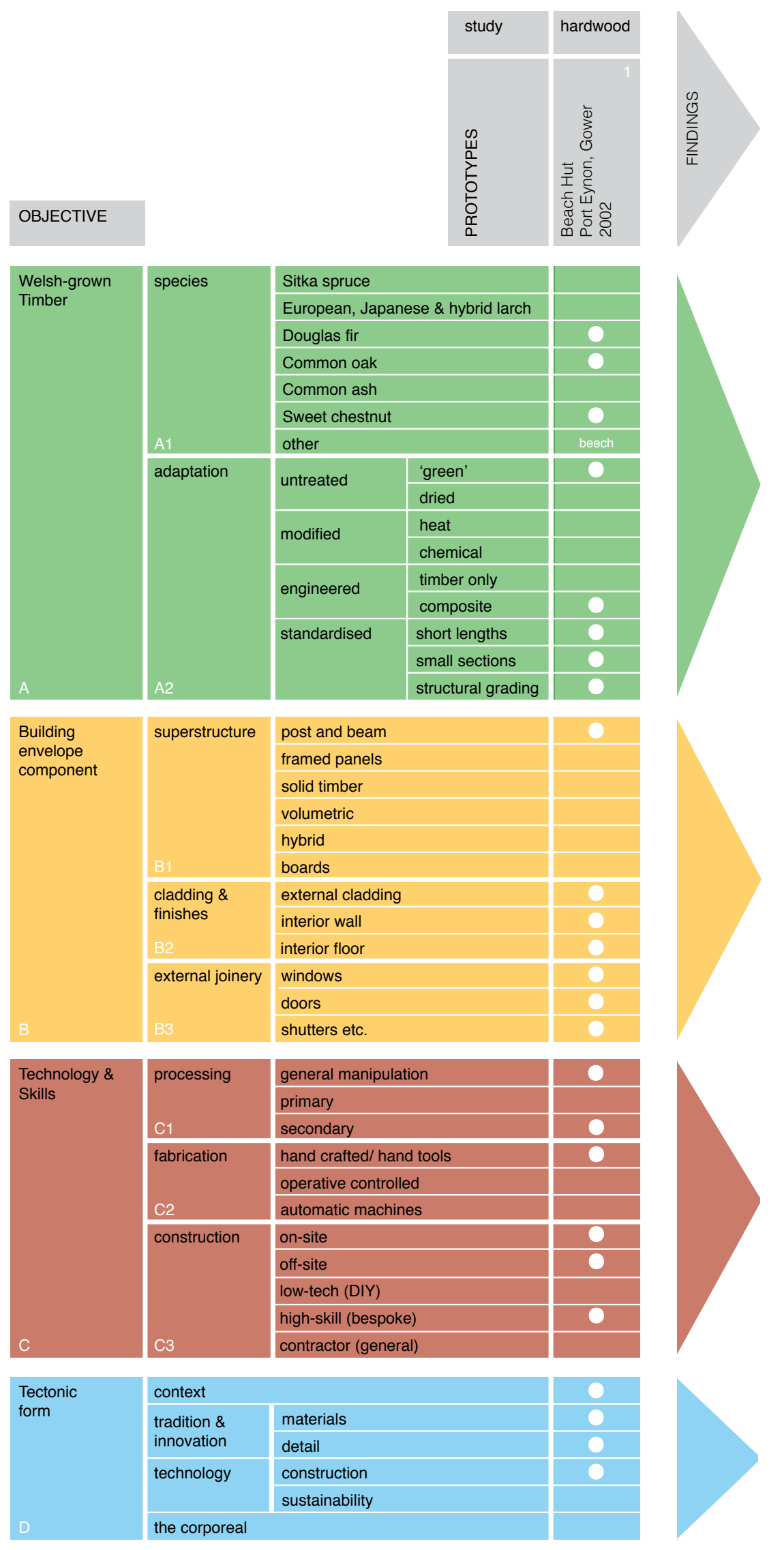

REFLECTION-ON-ACTION climate and building use in the overall appearance. A full prototype is

required to evaluate the qualitative performance of this weathering, impact on moveable windows and panels and overall scale and proportion.

\section{4}

\section{Findings on hardwoods}

- Considerable understanding of the properties of hardwood are required to design, specify and build effectively and efficiently. Particularly in the design of green structures and claddings.

- Short lengths and small section is the most efficient use of Welsh-grown hardwood, but poses questions on detailing and jointing for larger spans and longer lengths. Further research may be required on the use of engineered hardwoods for structural use.

- Engineered, kiln dried hardwood in joinery offers a stable, durable and reliable product for a risk adverse profession.

- Further physical testing is required to evaluate hardwoods in use.

- Since this prototype, knowledge and expertise is widely available through TRADA publications, however the costs, fears of over-using Welsh hardwood and increasing softwood importation have predominantly limited hardwood use to traditional and restoration work. Few best-practice examples exist in the UK for innovative uses of hardwood in structures, joinery or cladding. 
CHAPTER 7

Engineered Timber 
With a large volume of coniferous woodland in Wales, a secondary industry reliant on importation and a primary processing industry focussed on the production of softwood for tried, tested and established markets with limited construction industry potential, the aim of these studies is to evaluate the potential of using engineered Welsh softwood in design and construction.

This pilot study will focus on the application of engineered softwood as identified in the Welsh timber industry review as lacking research, development, investment and application in Wales. The study approaches this subject area from two

directions incorporated into two projects designed and built for the Welsh School of Architecture, Cardiff University in 2004: the use of established glu-laminated timber techniques for the construction of mezzanine floors within existing studios; and the development of a solid timber stress-laminated construction system to build a prototype refectory table. The first considers the application of a widely established structural product manufactured widely in northern and central Europe, the second considers engineered timber the context of the Welsh timber industry.

The study begins with the aims and objectives for each prototype design followed by a contextual study of engineered timber and relevant precedents for design and construction. The design, prototype and reflections are divided into 2 sections focussing on each project separately before presenting findings on the aim of this study.

\subsubsection{Aim \& objectives}

The specific aim of this study is to evaluate the design and construction of engineered timber structures as part of the building envelope, with reflections on the potential of laminating and using Welsh-grown timber.

The objectives are the same as those set out in the Methodology and are used to structure the observations and reflections after each project.

\subsubsection{Limitations}

The following limitations were identified in the design and fabrication of the two study projects:

- The mezzanines use imported glu-lam and therefore do not use Welsh-grown softwood due to lack of technology within industry to fabricate components; softwood for durability and appearance. 
The definition and types of engineered timber and appropriate precedents are reviewed to provide the context and understanding of the use in the building envelope.

\subsubsection{What is engineered timber?}

Engineered timber is the product of a process of enhancing the structural performance characteristics of raw hardwood and softwood through the physical connection of layered timber, veneers, chips, pulp or sawdust. The most common process is through gluing with a variety of different types of petro-chemical based glues, although research is improving on the quality of low-VOC and sustainable glues. However, under a more general title of structural composites, some engineerd products are mechanically assembled using interlocking boards, screws, nails, dowels or other fixings. The most common examples include glulam, cross-laminated timber, laminated veneer lumber, parallel strand lumber and I-joists. These are discussed in further detail in relation to the properties, detail and application.

Adhesives types used in glue laminated manufacturing

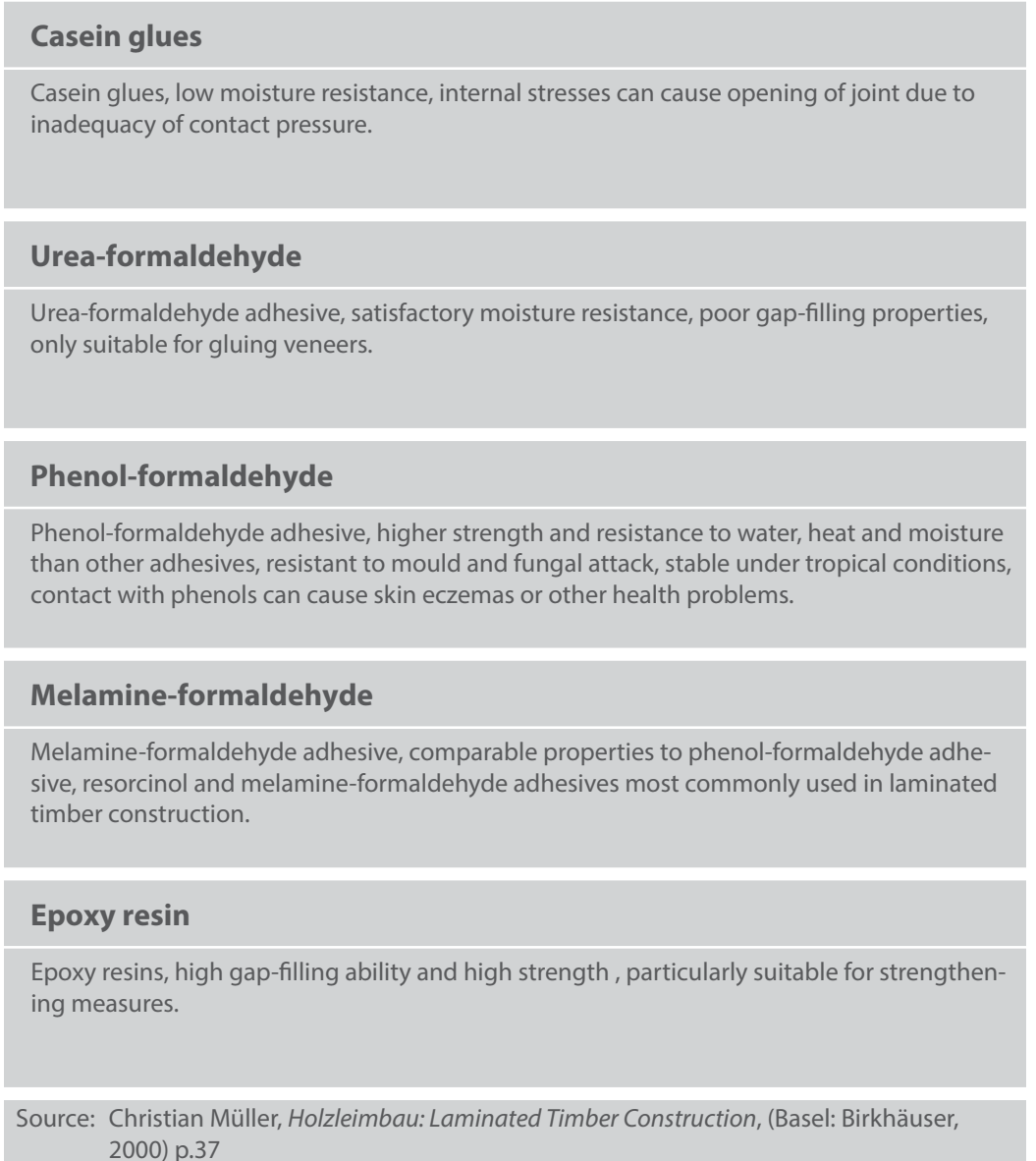

Fig 7.3 Adhesive types used in glue laminated manufacturing

\subsubsection{Glue Laminated Components}

Glue laminated timber has been in use since the start of the twentieth century, with the first patent registered in 1905 by Otto Hetzer. ' Whilst being an early sustainable use of timber, the glues used during the process were not environmentally friendly to produce, use, recycle or dispose of. Recent glues, that satisfy the British Standards such as Phenol Resorcinol, are still created from petro-chemical processes, with the finished glu-lam timber embodying more energy than the equivalent solid section of timber. Life cycle assessment studies do however show that laminated timber products still outperform steel and concrete in terms of embodied energy. ${ }^{2}$

The glu-laminating process can require a large amount of space and considerable time to produce and the finished members need to be planed to remove excess glue squeezed out from between the lamellae during pressing. There are few specialists in Britain, at present, who are able to fabricate such panels due to the size and complexities of the press needed. In Wales, with a large stock of well managed soft- and hardwood identified for use in this way, there are currently no means of commercially producing glu-laminated products.

Laminated veneer lumber (LVL) is manufactured by layering thin strips of wood

1 Christian Müller, Holzleimbau: Laminated Timber Construction, (Basel: Birkhäuser, 2000) p.23 2 Layne Evans, Cross Laminated Timber: Taking Wood buildings to the next level, <http://www rethinkwood.com/sites/default/files/Cross-Laminated-Timber-CEU.pdf> [Accessed 5th September 2015] 

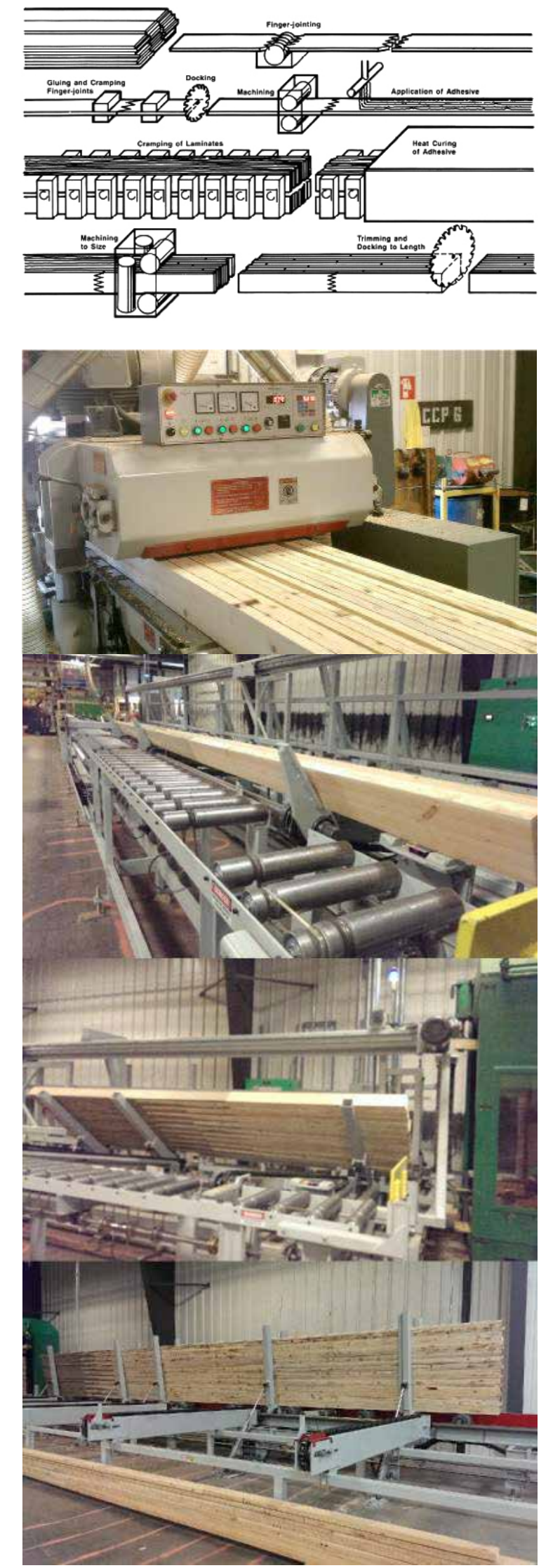

Fig 7.4 The Glu-laminating Process veneer assembled with a moisture resistant adhesive. The layers of wood are bonded with the grain parallel to the length of the board. LVL is generally used as a panel or beam product. ${ }^{3} \mathrm{As} \mathrm{LVL}$ is manufactured in factory conditions it is often stronger, straighter and more uniform than a solid timber component. The lamination process also makes it less prone to distortion that may occur in solid timber beams/boards.

Parallel strand lumber (PSL) is similar to LVL but it uses multiple strips of wood veneer laid horizontally before layering vertically. PSL is generally used in structures with long, free spans. In a continuous press the veneer strips are pressed to form a beam, limited in length only by the maximum that can be handled and transported. As with LVL the fact that knots and other imperfections are dispersed more randomly through the product means that its strength variability is improved when compared to solid timber components. PSL can be made from any wood species, but Douglas fir is most commonly used due to its superior strength. ${ }^{4}$

Laminated strand lumber (LSL) is manufactured by gluing together large flakes of wood to produce structural sections. ${ }^{5}$ As the wood strands become encapsulated within the adhesive LSL is weather-resistant under most conditions. The direction of the strands are either all aligned along the length of the product, or across its width. In the first case the structure produced is suitable for beams and columns whereas the latter is only suitable for walls, floor and ceilings. ${ }^{6}$

\section{Cross-laminated timber (CLT)}

A rapidly increasing timber manufacturing sector in central Europe is the manufacture of cross-laminated timber panels, usually for the private domestic market, due to cost, but also commercial and public buildings. Cross-laminated timber panels used in the UK are currently imported from European factories by Eurban, the main UK agent, supplier, engineer and contractor behind most of these projects or directly through manufacturers such as $\mathrm{KLH}$.

The manufacturing process for CLT panels is relatively complex. Small sections of spruce, larch or Douglas fir are bonded together with adhesives with imperfections in the original timber removed to enhance performance. While C24-grade timber is often used there has been an increase in the use of C16 timber, the latter of which is

3 Michelle Kam-Biron, 'The ABC's of Traditional and Engineered Wood Products' Structure Magazine (2014), <http://www.structuremag.org/?p=7053> [Accessed 4th September 2015]

4 European Wood, Parallel strand lumber (PSL), <http://www.europeanwood.org.cn/en/parallel-strand lumber $>$ [Accessed 4th September 2015]

5 Robin Lancashire and Lewis Taylor, Timber Frame Construction: designing for high performance, (High Wycombe: TRADA Technology Ltd 5th edition, 2011), p.215

6 European Wood [Accessed 5th September 2015] 


\begin{tabular}{|c|c|}
\hline Advantages of CLT construction & Disadvantages of CLT construction \\
\hline Thermal mass of solid timber construction & $\begin{array}{l}\text { size for delivery and lifting although the } \\
\text { panels can be up to } 16 \mathrm{~m} \text { long and } 3 \mathrm{~m} \text { wide }\end{array}$ \\
\hline $\begin{array}{l}\text { Ability to reduce thermal bridging and improve } \\
\text { air-tightness }\end{array}$ & $\begin{array}{l}\text { structural engineering considerations espe- } \\
\text { cially in high-rise buildings }\end{array}$ \\
\hline $\begin{array}{c}\text { Robust surfaces for the simple surface mounting of } \\
\text { services }\end{array}$ & a requirement for accurate groundworks \\
\hline $\begin{array}{l}\text { Available in a range of finishes for non-visible and } \\
\text { exposed locations }\end{array}$ & $\begin{array}{l}\text { requires external cladding or render to protect } \\
\text { the structural adhesive }\end{array}$ \\
\hline $\begin{array}{l}\text { A simple set of screwed and bolted connection } \\
\text { details }\end{array}$ & $\begin{array}{l}\text { must be used } 150 \mathrm{~mm} \text { above DPC, like other } \\
\text { timber frame structures }\end{array}$ \\
\hline A vapour permeable wall construction & \\
\hline
\end{tabular}
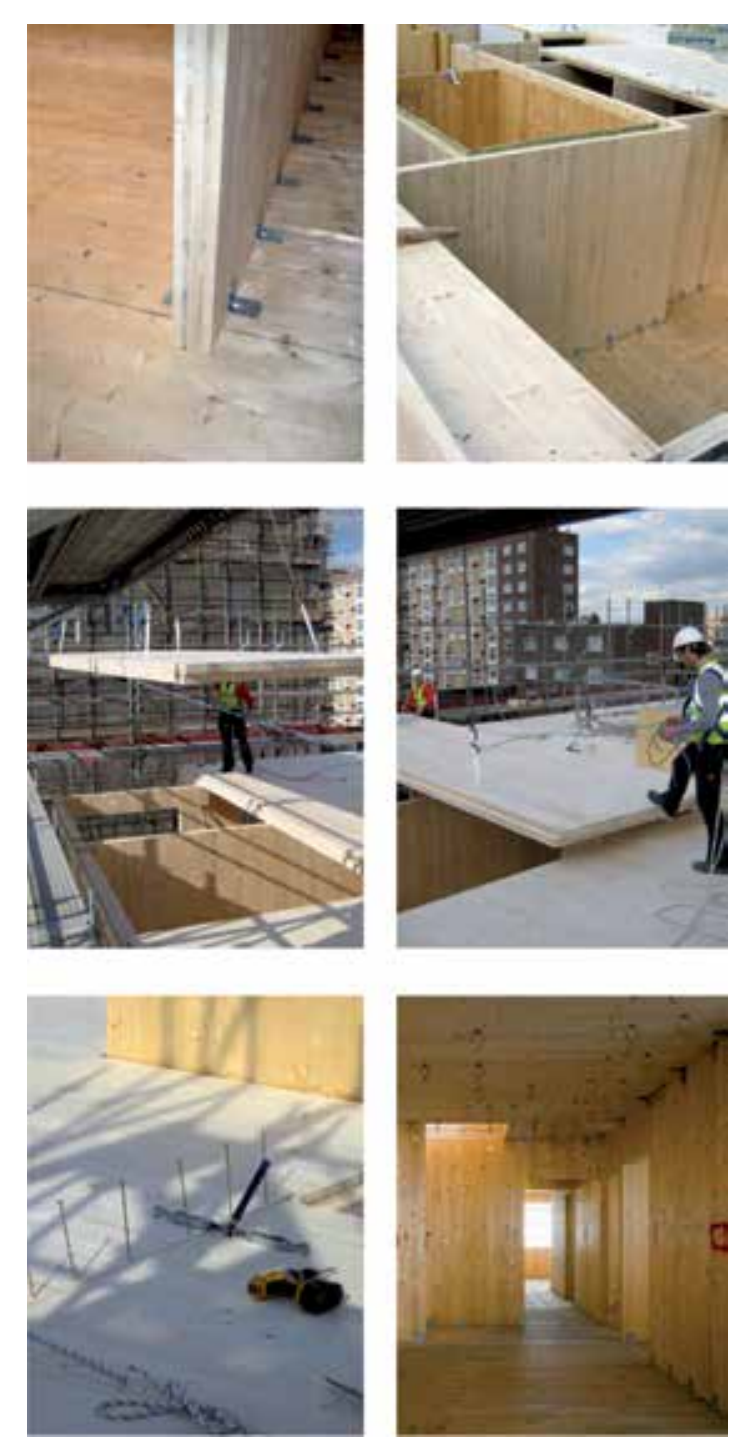

Fig 7.5 Advantages and Disadvantages of CLT construction

LEFT panels

BELOW

Fig 7.7 Simple fixing details

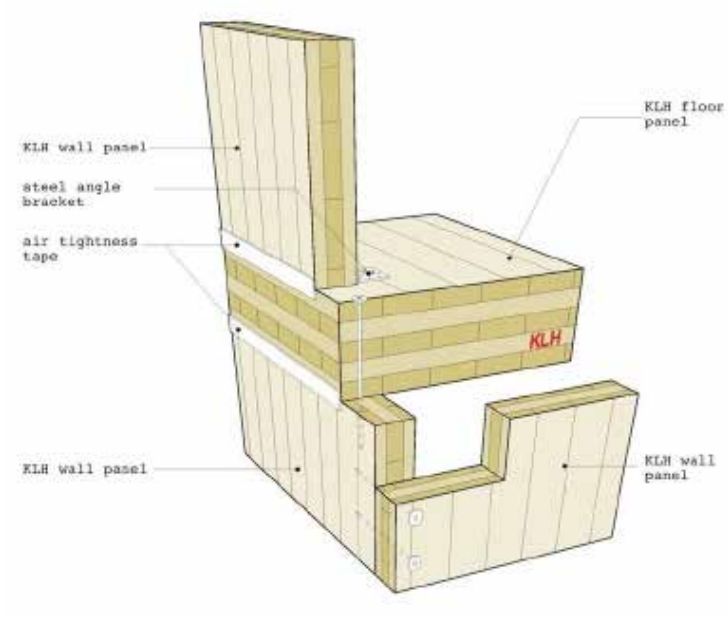

Fig 7.6 Site construction sequence: wall and floor more available in the UK.? Unlike glulam, the small timbers are bonded perpendicular to one another to generate stability in two dimensions. A large-scale automated production line for the planing, sizing, gluing, laying up, and pressing of the panels, is required, with vertical and side pressure applied to each panel. Further finishing and profiling is often required by large, flatbed CNC cutting machines. The manufacture of CLT and similar products also requires considerable quantities of timber with guaranteed supply, on a scale that Wales is unlikely to be able to meet at current rates of productions.

The design of CLT buildings is actually quite simple and flexible although requires a lot of work prior to construction to ensure the accuracy and positions of services. ${ }^{8}$ CLT wall and floor panels are considerably lighter than concrete equivalents with the same load bearing capacities. ${ }^{9}$ Panels can be used for walls, floors and roofs and are typically available in thicknesses from $75 \mathrm{~mm}$ to $500 \mathrm{~mm}$ and spans up to $7 \mathrm{~m}$, although panels can be manufactured up to $16 \mathrm{~m}$ long if appropriately supported and transport and site access permits, therefore allowing the designer to assume the same design principles as a concrete or masonry building. Panels can have openings pre cut for windows, doors and vertical circulation ${ }^{10}$ meaning that construction on-site is reduced to the assembly of prefabricated components rather than onsite fabrication. As CLT is a planar, monolithic construction it is not constructionally constrained to any structural or layout grids and therefore module sizes, although the structure will require coordinating with window and door dimensions and external finish sizes.

\subsubsection{Brettstapel}

Brettstapel is a solid timber construction system fabricated from low-quality small dimension untreated, softwood that may not otherwise be suitable for construction. The softwood lamellae are connected with diagonal hardwood dowels, with a lower moisture content than the posts, that are pushed through pre-drilled holes of a smaller diameter than the dowel. As the timber reaches moisture equilibrium the dowels expand and 'lock' the posts together. ${ }^{11}$ Brettstapel, therefore uses neither glue or nails, unlike other solid core systems such as CLT panels. As with all solid-core construction, brettstapel requires considerable quantities of timber, and although it may be suitable for limited numbers of projects in Wales and across the UK, a largescale implementation will be limited by the supply of domestic timber available.

7 Andy Sutton, Daniel Black, Pete Walker, Cross-laminated Timber: An introduction to low-impact building materials (Watford: BRE Trust, 2011), p.2

$\begin{array}{ll}8 & \text { Ibid, p.4 } \\ 9 & \text { Ibid, p.2 }\end{array}$

10 Robin Lancashire and Lewis Taylor, p.216

11 James Henderson, Sam Foster, Matt Bridgestock, What is Brettstapel? (2012) <http://www brettstapel.org/Brettstapel/What_is_it.html> [Accessed 4th September 2015] 


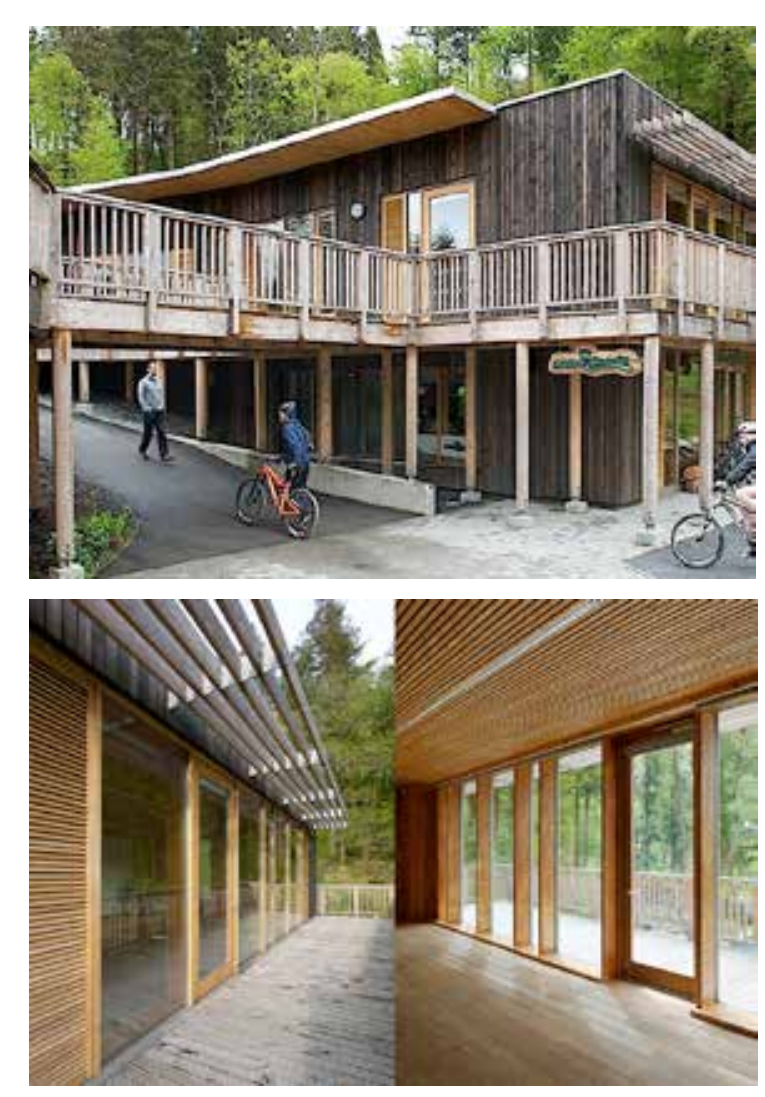

TOP LEFT

Fig 7.8 Welsh made Brettstapel panel, Coed-yBrenin, Architype

BELOW

Fig 7.9 Stress laminated bridge slabs made up of glulam beams on Mattisdammen (top) and Daleråsen bridges (bottom), Norway
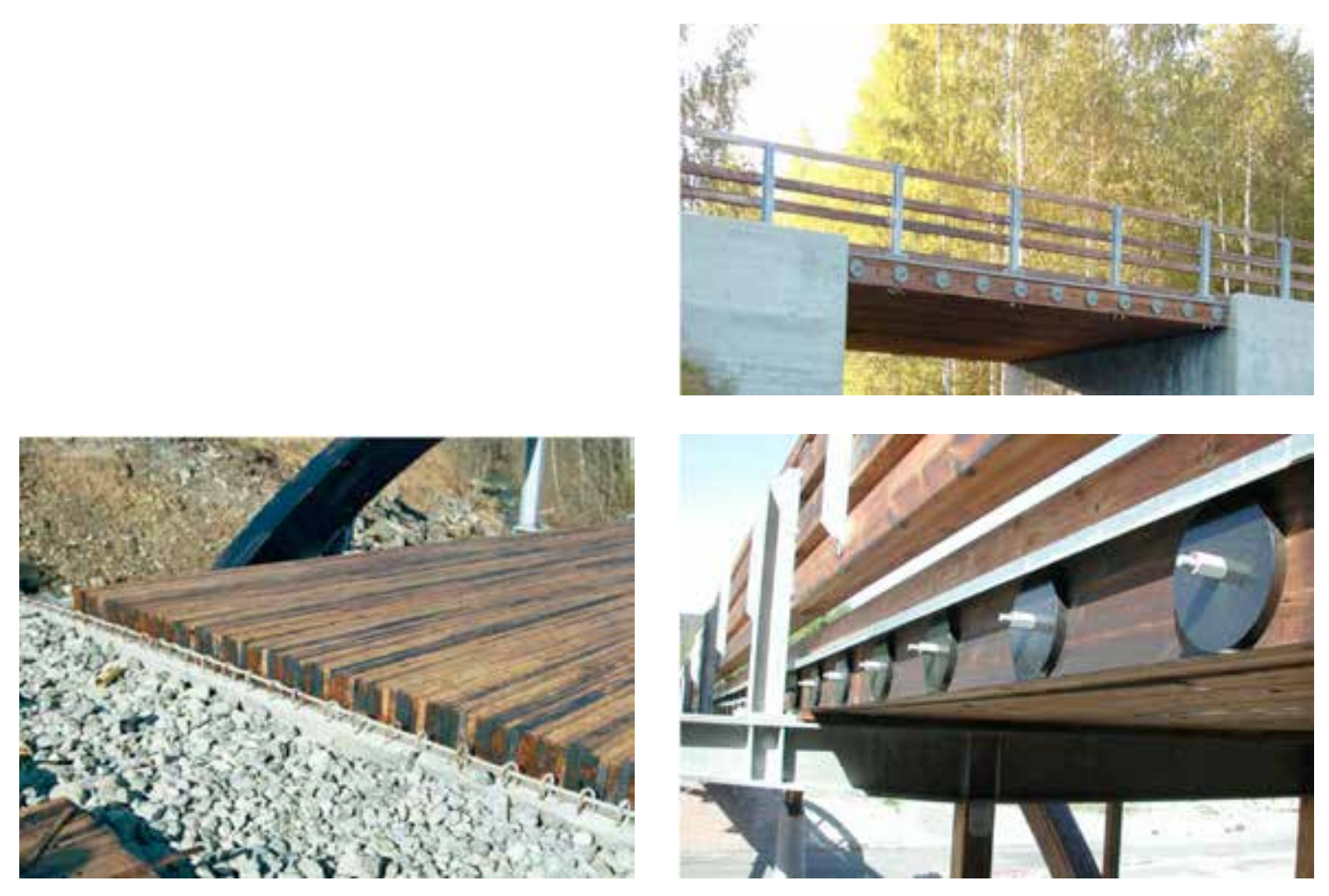

A recent project for a visitor centre at Coed-y-Brenin, designed by Architype, has enabled two joiners to research and test the manufacture of a 'Dowellam' panel ( $A$ Welsh made brettstapel panel) using Sitka spruce, larch, grand fir and beech.

\section{Bridge building}

Structural engineers in Canada, in the 1970's, developed methods of bolting timber together to benefit from the affect of stress acting across the bridge deck from methods of repairing nail-laminated bridge decks that had suffered from movement causing the timbers to separate and from early forms of bolted timber bridges. The research and techniques have since spread to the USA, Australia, New Zealand and Norway. The basic construction of stress-laminated bridge decks involves prestressing a timber panel or deck with high-tensile steel rods at approximately $1200 \mathrm{~mm}$ centres across the width of a timber deck that is tightened at either side with the use of bearing plates to generate friction/ stress between each timber element. The resultant deck may span greater distances than the individual timbers since the lamellae are spliced together by friction generating compressive stress and a transfer of vertical shear between each element. Usually using solid timber beams, stress-laminating research in bridge design has developed further to consider the benefits of stress-laminating trusses and box sections to increase spans and stability. Canada and the United States now have design procedures to guide the design specification and performance. ${ }^{12}$

The main problems experienced with stress-lamination were related to movement caused by high initial moisture content, vertical creep under loading and crushing at stressing-rod anchor points. While the design loads expected on a bridge are much higher than those expected in the building envelope the same principles are likely to apply to smaller section sizes of timber and drier internal environments.

12 Michael C Oliva, Al G. Dimakis, Michael Ritter, 'Development and Use of Stress Laminated Timber Deck Bridges' in Bridges and transmission line structures: Proceedings of the sessions at Structures Congress ' 87 related to bridges and transmission line structures, ed. by Lambert Tall (New York: American Society of Civil Engineers, 1987) August 17-20 1987, pp. 249-255 

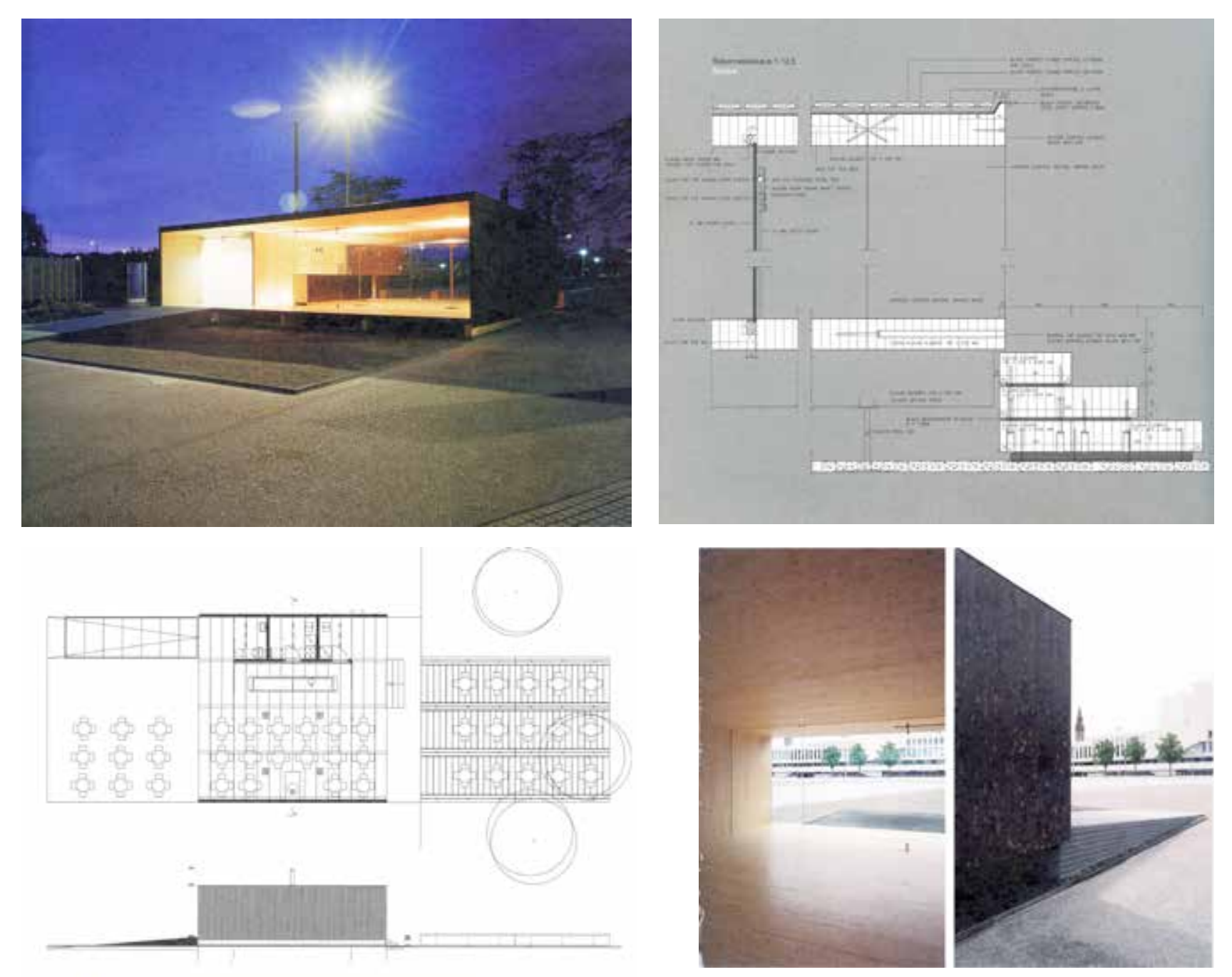

TOP LEFT

Fig 7.10 Hili Cafe, Helsini, Finland constructed from exposed and charred CLT panels.

BELOW (left - right)

Fig 7.11 Reclaimed timber beams with M12mm threaded bars drilled through

Fig 7.12 Plywood table with bolt connection for flexibility of form
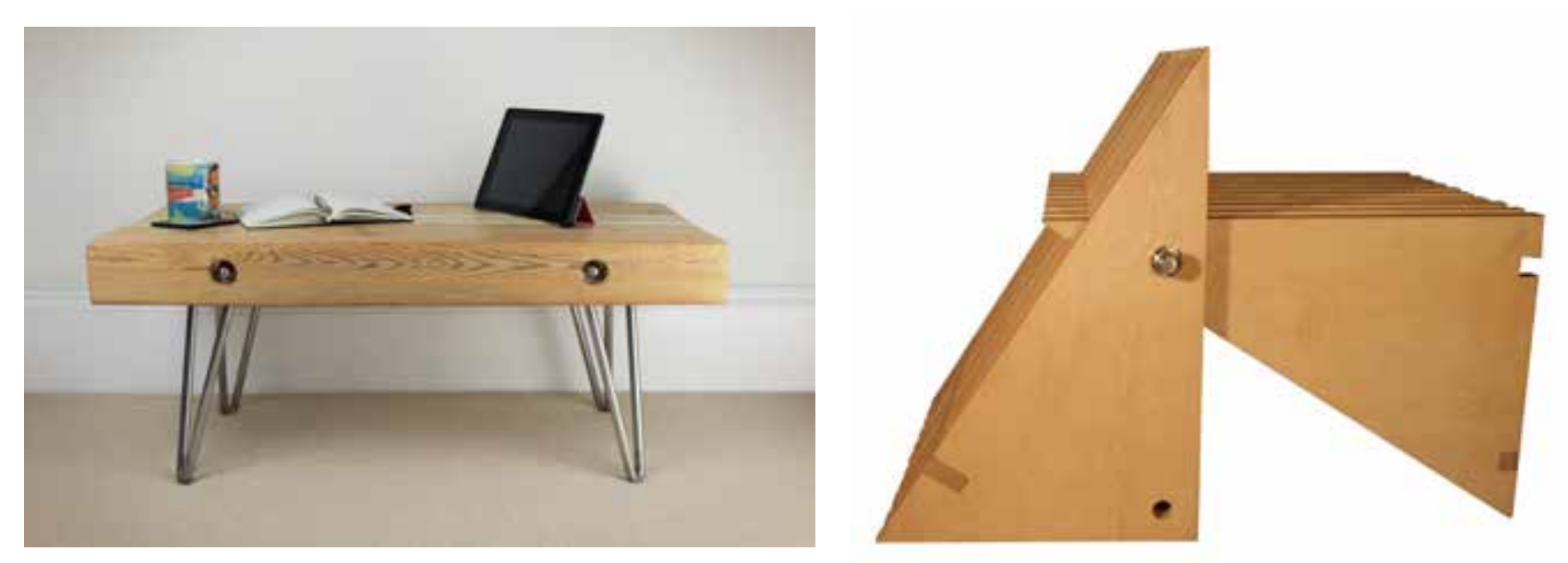

\section{The Hiili Cafe, Helsinki, Finland}

This small summer cafe at Toolonlahti bay, in Helsinki, was the result of a student design competition organised by the University of Technology, the Finnish Timber Council and the city of Helsinki. The pavilion is principally a rectangular timber tube with set-back, sliding glazed screens at either end framing views of the city and providing covered outdoor space. The floor, walls and roof are all constructed from the same $625 \mathrm{~mm} \times 140 \mathrm{~mm}$ cross-laminated timber panels that have been joined with oblique screws and steel dowels. The roof spans $10 \mathrm{~m}$ from wall to wall, while the floor spans $2.5 \mathrm{~m}$ between $145 \mathrm{~mm} \times 260 \mathrm{~mm}$ glu-lam beams as part of the lightweight foundations. The building was prefabricated and erected on-site. ${ }^{13}$

The cafe's name, meaning coal in English, was inspired by the black timber facades that were lightly charred to seal the timber against water ingress and then impregnated with creosote. This leaves the cafe with a simple, elemental and structural form without the need for further cladding layers, although the treatment process is required twice a year to ensure the resistance to rain. The pavilion is only used in the summer and is therefore not insulated. Internally the structure is left as exposed, sanded softwood with all services, where required, hidden under the floor or within the fitted furniture elements of the cafe.

While the plant to fabricate cross-laminated timber panels is not available in Wales, the simple form and construction process combined with screws and coach bolts of this cafe demonstrates potential to create elegant domestic scale spans from relatively small sections and lengths of softwood.

\section{Bolted timber furniture}

Simple furniture designs have been achieved by bolting together individual timber elements to create larger planar elements. The timber elements vary from large section green timber to reclaimed boards and beams but rarely use small section timber. The use of bolts is usually an aesthetic choice behind the connection between timbers or parts such as the legs rather than for structural means with the span of the furniture comfortably achieved by the timber elements themselves or by a supporting structure beneath the surface. However the bolts are often chosen as a low-tech, affordable and robust means to join together individual components of sometimes differing species, quality and size without the complications caused by differing finishes, moisture content or glueing. The bolts effectively hold the pieces in place so that the individual timbers can act effectively as single beams or portals.

13 Pekka Heikkinen, Jari Laiho, Jussi Tiainen, Puusta Tehty: Wood Works, (Tampere: Parvs Publishing, 2007), pp.30-33 
The mezzanine floors were proposed by the Welsh School of Architecture and designed by the Design Research Unit Wales for Cardiff University Estates. The project provided an opportunity to explore, through design and construction, the use of glulaminated timber in structures, with consideration to using Welsh-grown timber and tectonic form.

\subsubsection{Design}

\subsubsection{Brief}

\section{Mezzanine floors}

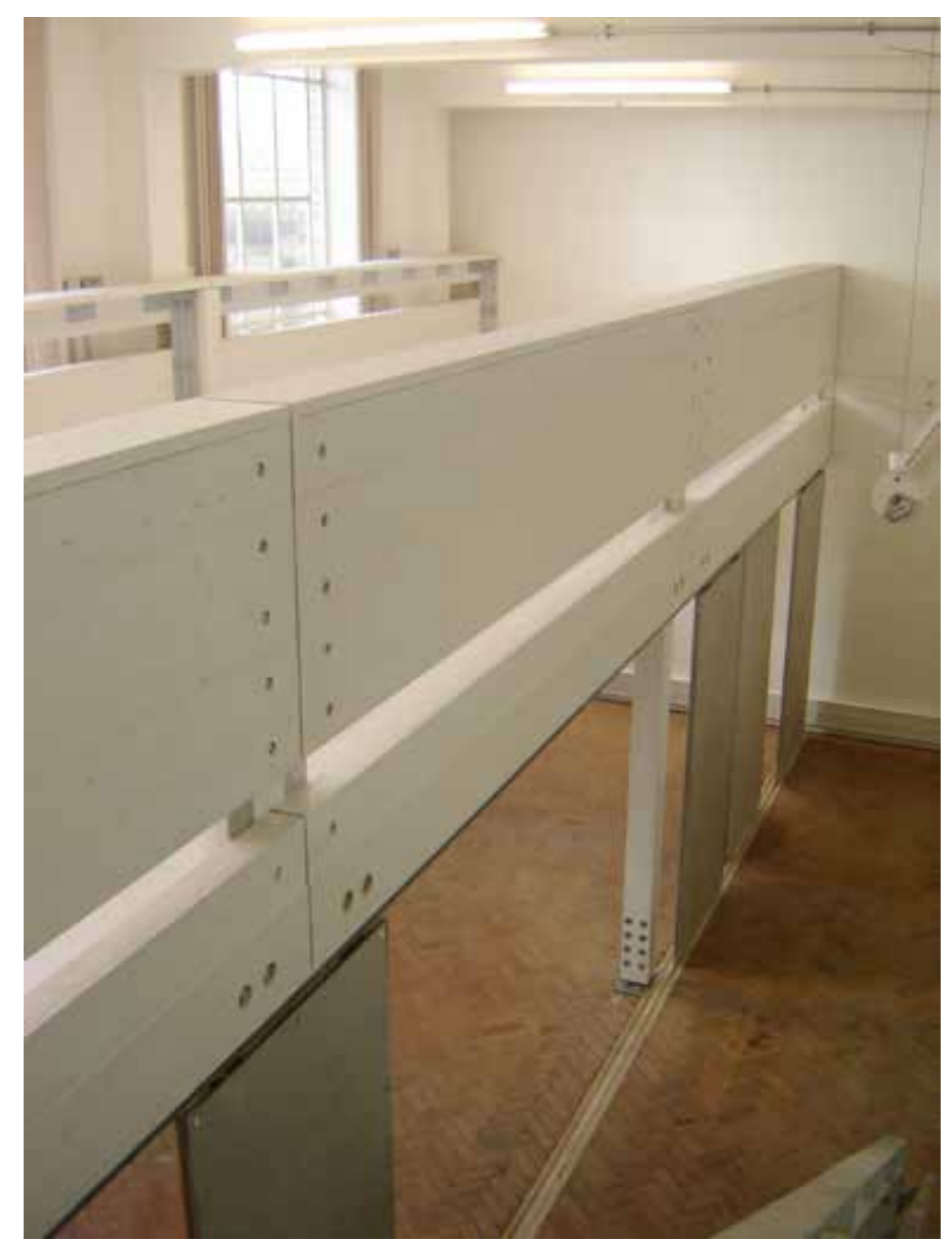

Fig 7.13 Completed Mezzanine
The Welsh School of Architecture is located on the top floor of the Bute Building, Cardiff. Purpose designed studios for 1st, 2nd, 3rd and 5th year students are located around the perimeter of the building. The 2 nd and $3 r d$ year studios were located on the west side of the building and divided across 3no. long, narrow and double height rooms. Since a building refurbishment in 1995, the studio space was becoming tired with improvements required to:

- Respond to the changing working requirements of students;

- Expand and improve desk space needed to accommodate student demand;

- $\quad$ Reflect the creative, research-led ethos of the school; and

- Improve the visual appearance and atmosphere of the school to attract new students.

In response, the Welsh School of Architecture and the Design Research Unit Wales undertook a viability study to appraise strategic options and develop an architectural brief before applying for $£ 250,000$ of funding from Cardiff University Estates. The brief and schedule of accommodation to renovate the west studios was for:

- mezzanine floors;

- 1 no. 2nd year studio, 1 no. 3rd year studio;

- $\quad$ a student 'break out'space;

- a model making workshop;

- 1 no. seminar roomi

- 1 no. meeting room;

- 1 no. MSc studio; and

- to maintain the rooms and functions of the spray room and artificial sky/ heliodon. 

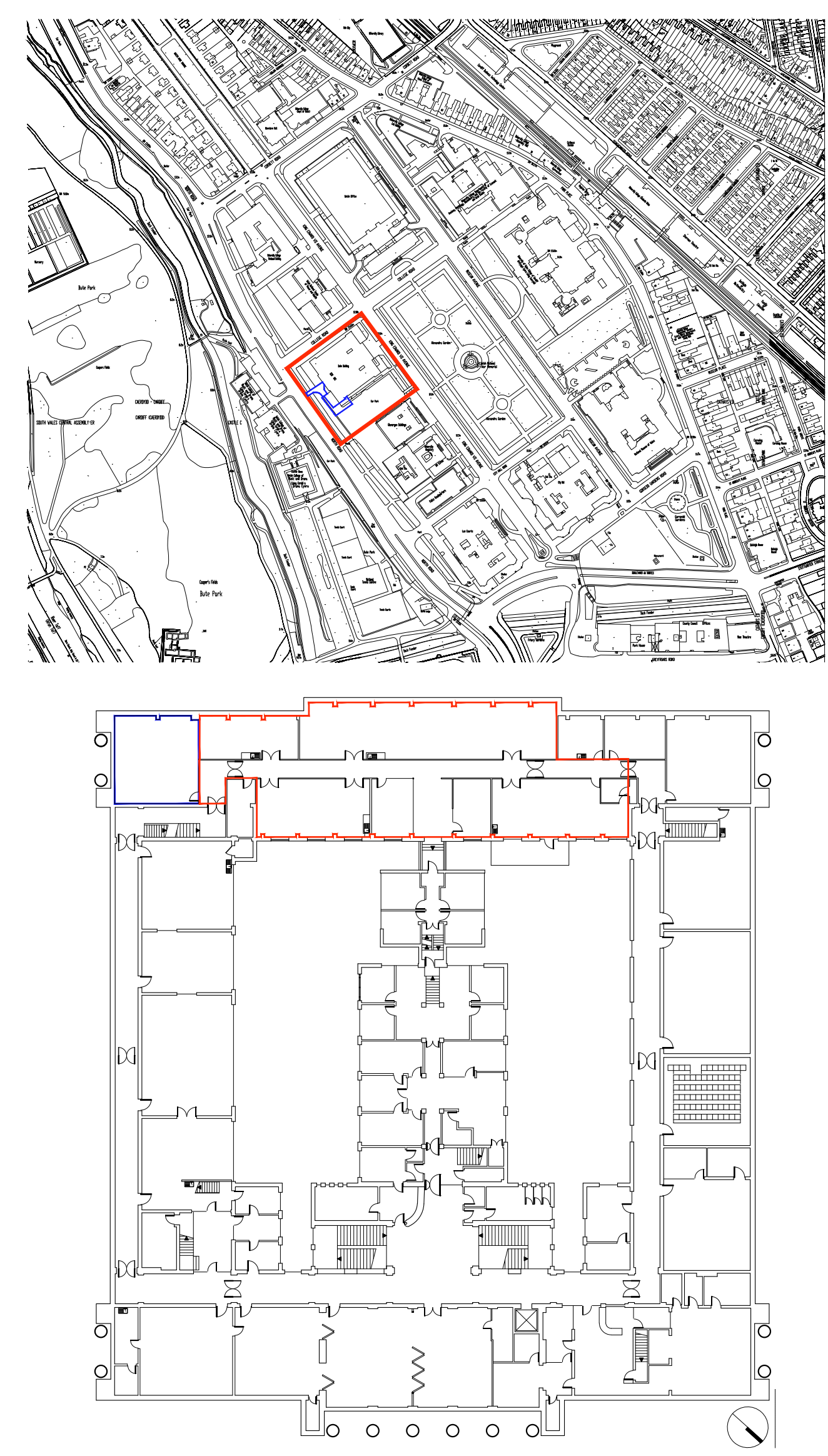

TOP

Fig 7.14 Bute building site location plan BOTTOM

Fig 7.15 Bute building existing floor plan
The focus of this study will be on the design and construction of the mezzanine floors. The requirements of the mezzanines were to:

- $\quad$ provide extra studio desk space

- flexible and adaptable to a range of working methods;

- allow for pin-up reviews and end of year examinations;

- robust to cope with the range of creative activities that will occur on, under and around them; and

- sustainable in terms of material sourcing and recyclability

Furthermore, construction was to take place during the university summer break, following the end of year examinations, between June - September 2004.

\subsubsection{Site/ location}

The Bute building was opened in 1916 in Cathays Park, Cardiff as a Technical College for the University of Wales Institute of Science and Technology (UWIST). The Welsh School of Architecture was established in 1920. As a Grade II listed building, the Bute building was refurbished, in 1995, by the architectural practice Burgess to accommodate more and improved studio space, offices and research facilities. The Welsh School of Architecture is located on the 2nd floor with studios, administrative space and support facilities wrapped around the 4 sides.

The mezzanines were to be located within the existing 2 nd and 3rd year studios either side of the west corridor. Access to the $2 \mathrm{nd}$ floor is via the main staircases and small passenger lift on the east side of the building and via a fire escape stair at either end of west corridor. Deliveries were to be limited to physical lifting and carrying up the north fire escape stairwell from Bute car park.

The Bute building has a hybrid of construction typologies corresponding to the period in which different parts were built. The original, north, south and east externa walls are of Portland stone construction with the inner courtyard walls of brick cavity construction. The west side of the building was added with a steel frame and reinforced concrete floors and outer Portland stone skin. A steel framed 2nd floor mansard roof was added, in 1995, to accommodate the 2nd floor studios. Following an initial structural survey of the Bute building, it was discovered that both the foundations and the 2 nd floor structure only had capacity for extra loading in limited areas. These were limited to both sides of the west corridor as illustrated and that all new loads must be transferred directly into the existing reinforced concrete floor above steel beams and steel columns. The requirement for a workshop at the south 

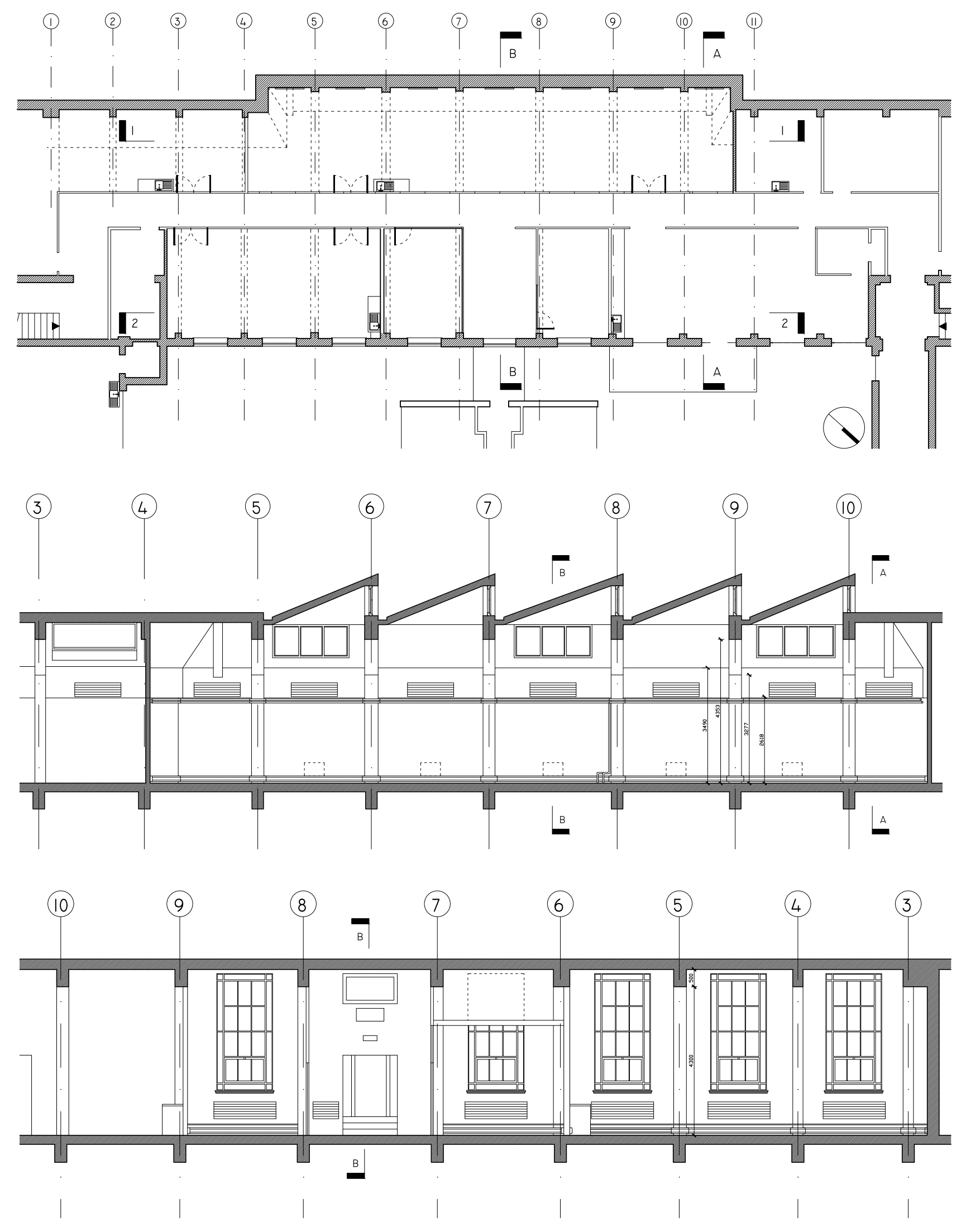

ABOVE (top - bottom)

Fig 7.16 Existing studio plan on 2nd floor of Bute 7.18 Existing studio section $2-2$

RIGHT (top - bottom)

Fig 7.19 Existing studio section A-A

Fig 7.20 Existing studio section B-B end of the the corridor and the width limitations at the northern end determined the mezzanine locations, although if required the mezzanines could be extended into these spaces in the future.

Originally the Bute building was designed to be naturally ventilated using low-level ventilation voids through the external street facing walls and openable windows and centrally heated with cast iron pipes with the thermal mass of the building maintaining even temperatures. During the 1995 refurbishment a gas fired central heating system using radiators and a mechanical ventilation system were added to varying degrees of success. In the west corridor studios, the original wall vents were blocked up, high level radiators were added to clear wall space for studio and remote opening rooflights were provided to aid ventilation. One long studio was naturally lit from north facing sawtooth rooflights, the other two studios were side lit from east facing windows.

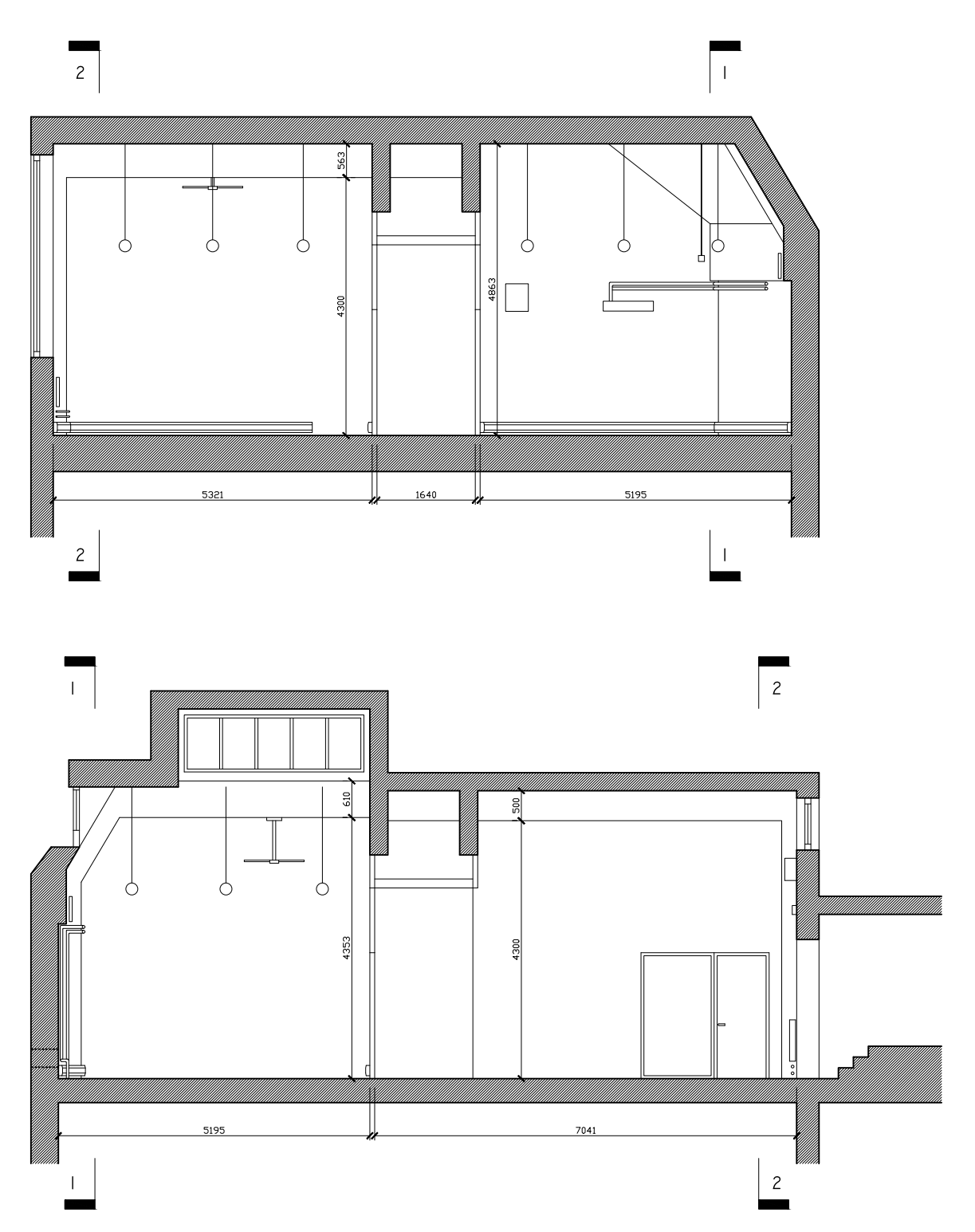



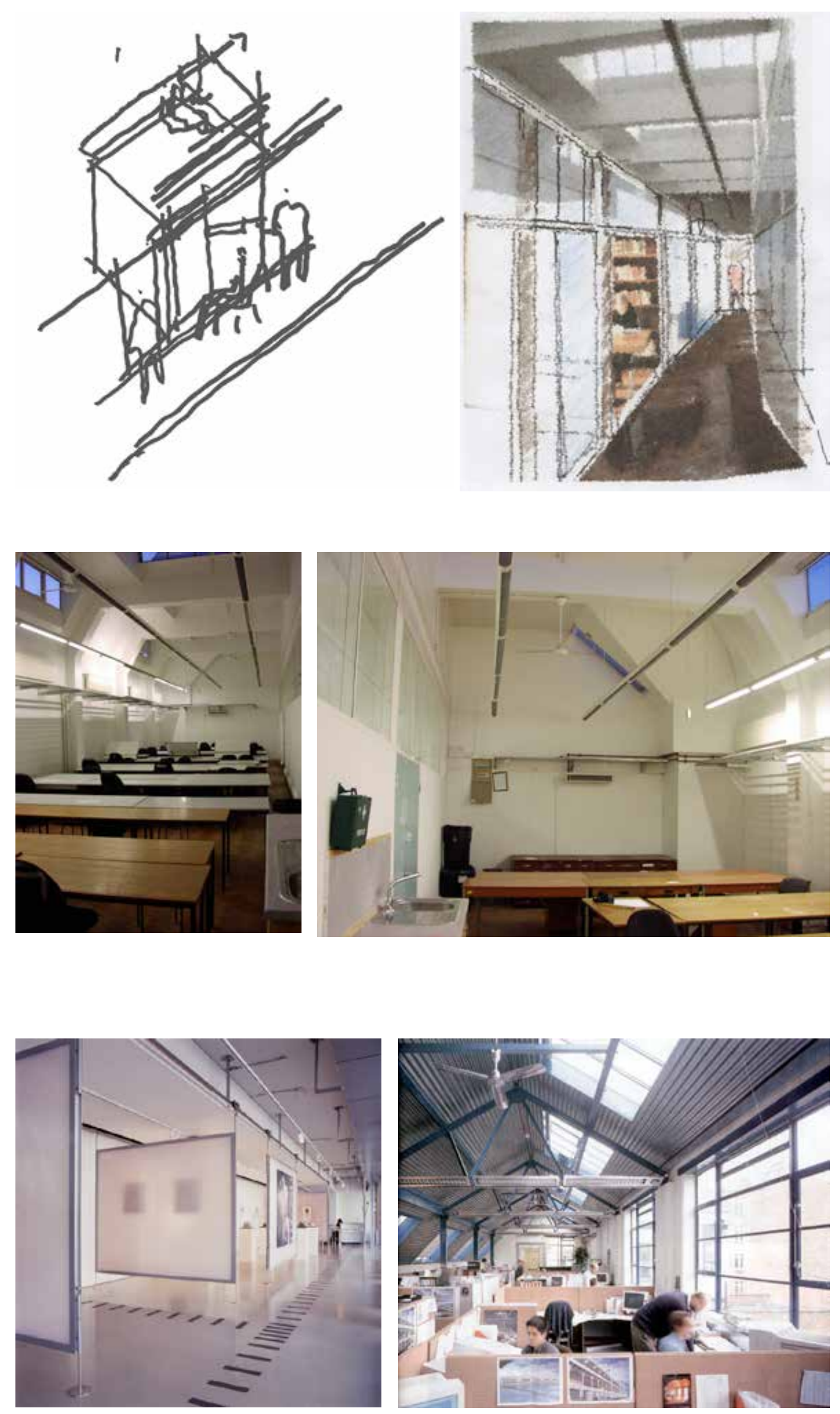

310
7.3.1.3

Concept, vision, strategy

The architectural approach was considered in 2 formats: the spatial and performative vision; and the tectonic strategy. The two were interrelated, influencing the aspiration to technical detail and vice versa. The vision was to create a vibrant, interactive

studio space connecting the mezzanine floors and existing studio level, visually and spatially. The primary means to do this were:

- The mezzanines and studio spaces were informed by the proportion of the existing studio and structure;

- to maintain access to natural light on and under the new mezzanines;

- to maintain natural ventilation in the studios;

- to touch the existing structure lightly, to create an 'object' within the studio rather than be part of the studio;

- to express the clarity in details, structure and construction.

This latter vision was considered in conjunction with the identified studio constraints. The tectonic strategy was therefore to:

- follow a modular design to be repeated across the existing structural bays;

- to use standard sized, 'off-the-shelf' glu-lam sizes to reduce lead in time;

- be simple to install by carpenters who were relatively untrained in the use of glulam;

- allow for replication and extension if needed in the future;

- allow for disassembly and component reuse after the intended lifespan;

- be lightweight physically and in appearance.

Two precedents were identified as appropriate to the above visions: The Buro Happold office, London; and the London print studio exhibition space, by Mikhail Riches.

LEFT (top - bottom)

Fig 7.21 Concept sketch and indicative

Fig 7.22 Photos of existing studio spaces

Fig 7.23 Print Gallery with workshop, London,

Fig 7.24 Buro Happold Offices, London 

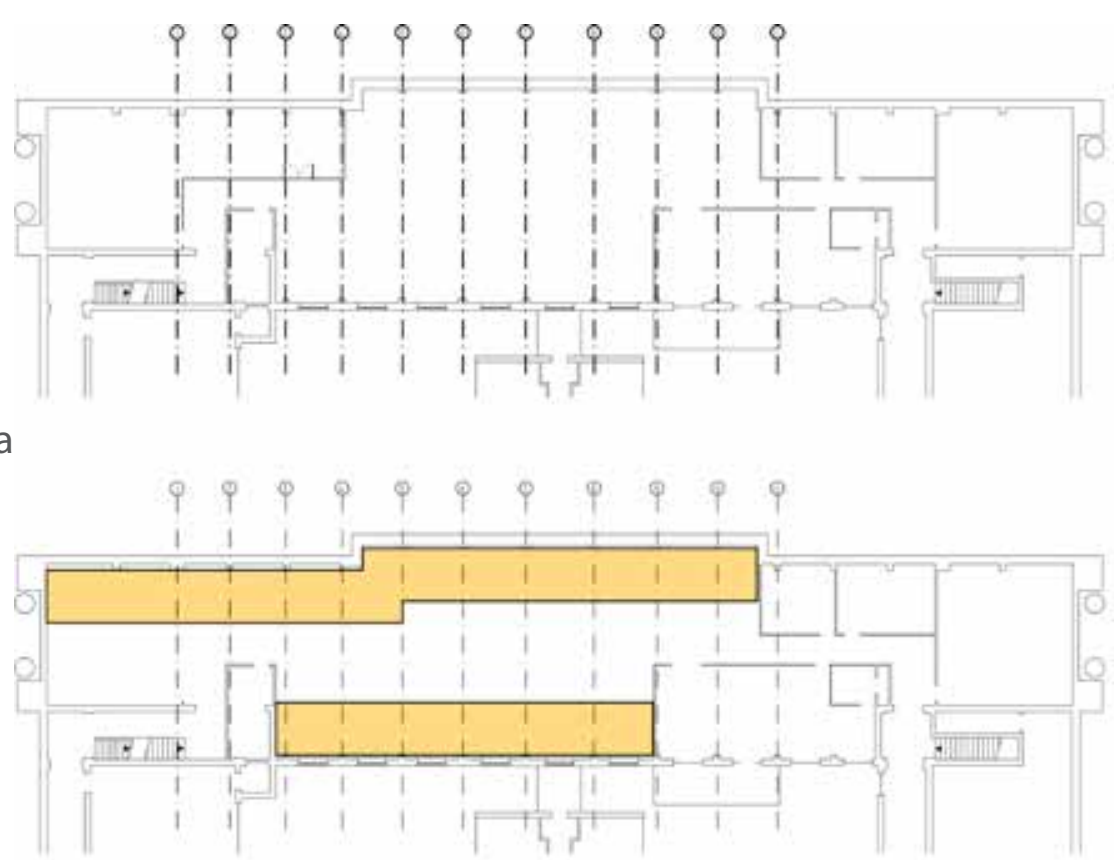

b
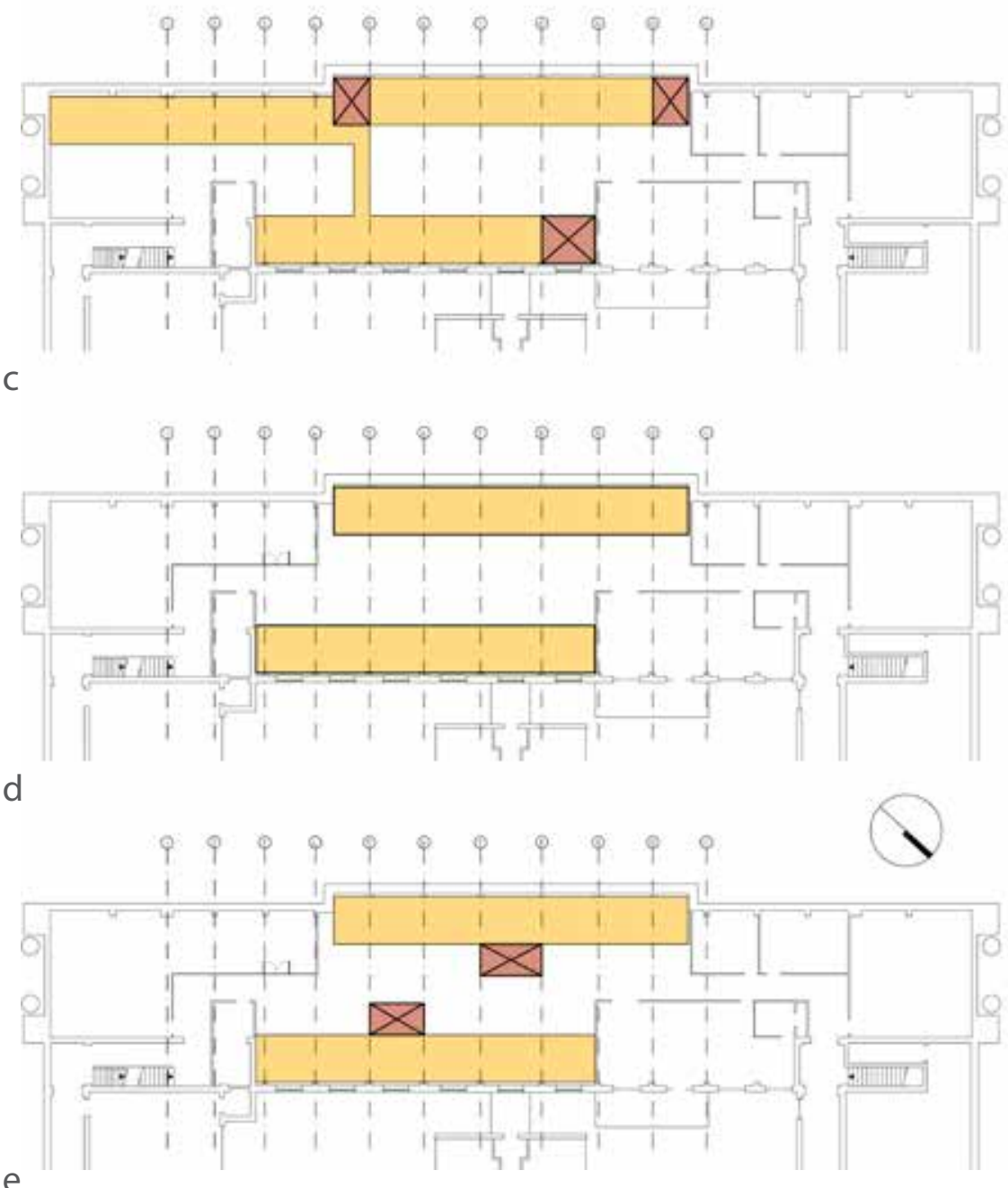

ABOVE (top - bottom)

Fig 7.25 Mezzanine floor layout options

a. Existing structural grid

RIGHT (left - right)

b. Maximum extent of mezzanine floors

c. 3 stairs positioned in-board of mezzanines

d. Reduced mezzanines extent

e. stairs reduced and positioned out-board

\subsubsection{Design development of a bay}

The design decisions are described through the following drawings, diagrams, model photographs and associated annotations and descriptions to illustrate key decisions that relate to the design of the mezzanines, the aims of this study and thesis.

- The existing structural grid determined the zoning and alignment of the mezzanine bays that varied from $3000 \mathrm{~mm}$ to $3900 \mathrm{~mm}$.

- Options were reviewed to extend the mezzanines the full length of the corridor with a bridge link between mezzanine to share staircases.

- The bridge link and full length of western mezzanine was limited due to costs and need for separation between studio spaces and seminar rooms.

- Staircases were initially located in board of the mezzanines as 1 bay of the structure but were moved outboard to become separate elements that service the mezzanine deck and to allow for a repetitive mezzanine structure across all bays.

- The mezzanine width was determined by the spatial requirements needed for desks, chairs and circulation at mezzanine level. Initially two $1800 \mathrm{~mm}$ desks were proposed, per bay, with a $900 \mathrm{~mm}$ walkway along one edge. Below the mezzanines, desks were arranged in a' $U$ ' configuration with strip lighting integrated into the structure above each desk.

- The design was revised to stand-alone from the Bute building structure reducing the width by $300 \mathrm{~mm}$. 2 further desk layouts were proposed below.
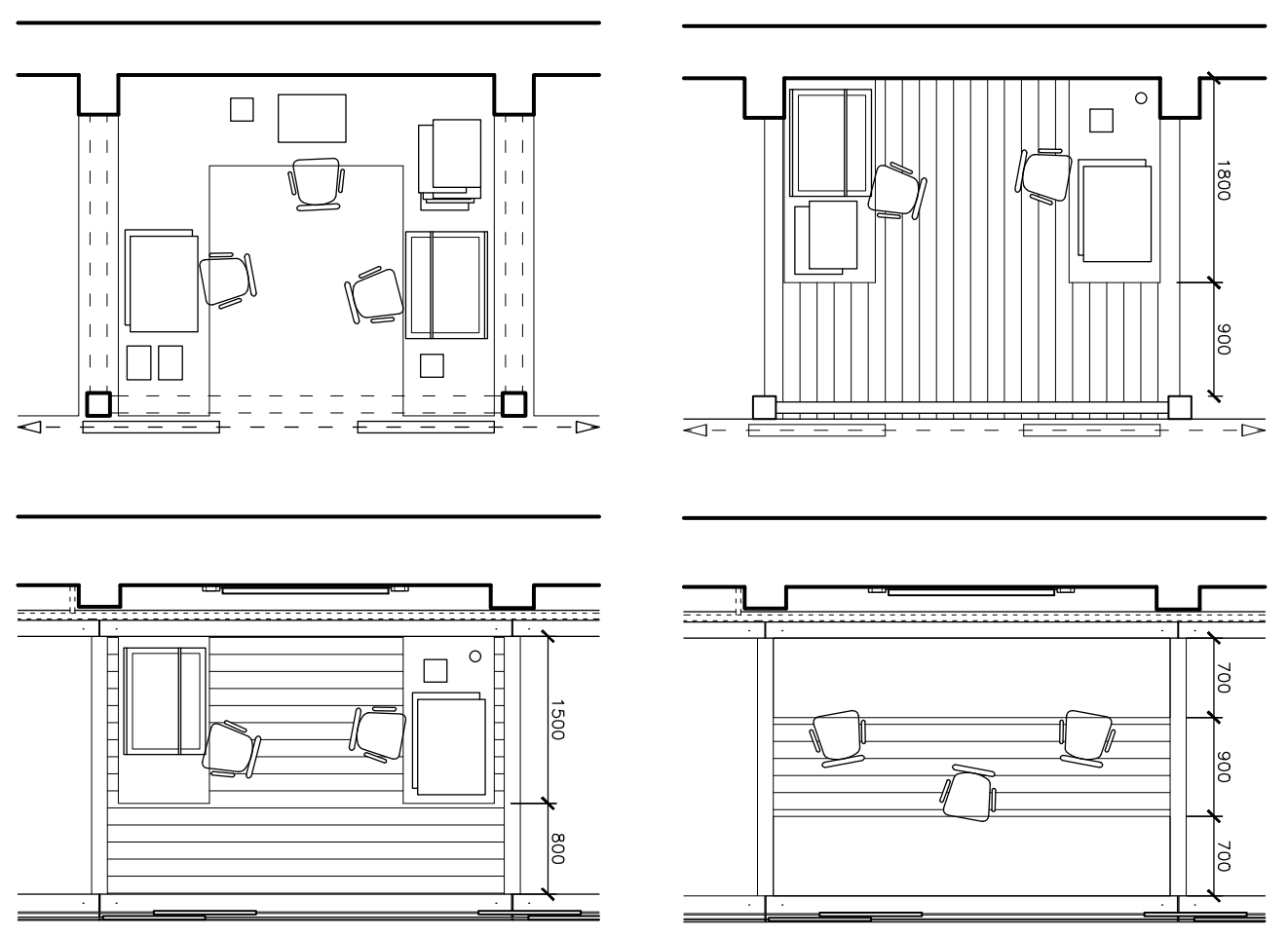

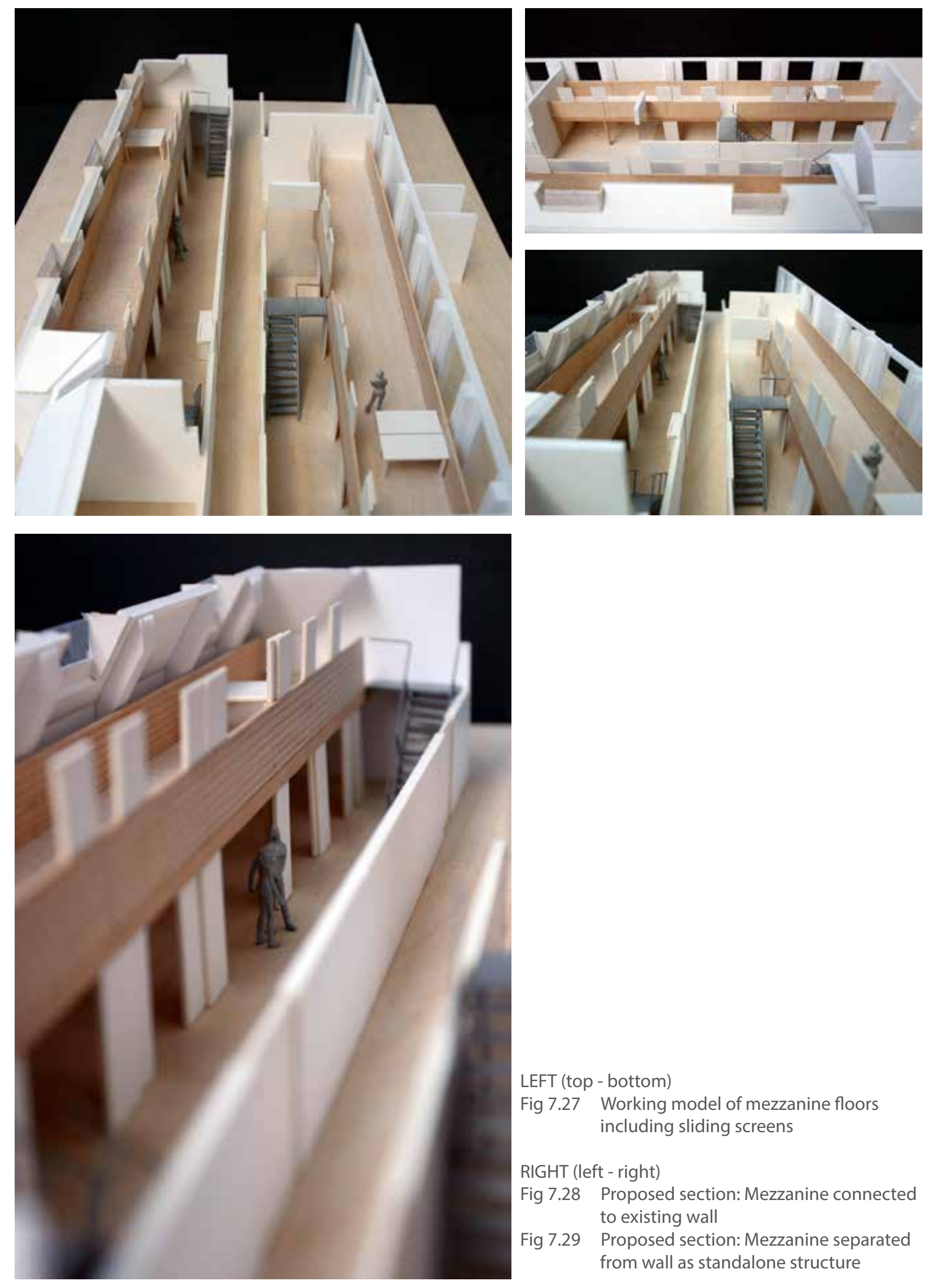

LEFT (top - bottom) including sliding screens

RIGHT (left - right)

Fig 7.28 Proposed section: Mezzanine connected to existing wall

ig 7.29 Proposed section: Mezzanine separated from wall as standalone structure
- The mezzanines were separated from the walls to provide air circulation, even heating and to bounce natural daylight, from the north-facing studio rooflights, off the white walls down to the lower level.

- The section was determined by the limited $4.3 \mathrm{~m}$ height between floor and underside of existing beams. With a $300 \mathrm{~mm}$ floor zone this left a minimum $2 \mathrm{~m}$ floor-ceiling height both under and on the mezzanine. It was essential that the structure appeared lightweight and well lit to counteract the low ceiling.

- The proposed design was for an elemental and additive post and beam structure with standard section and lengths of glulam timber bolted and screwed to allow for ease of disassembly and aid future recycling.

- Sliding screens were proposed for both under the mezzanine and along the top of the balustrade, although the top screens were later omitted to improve visual connections and natural daylighting to under the mezzanines.
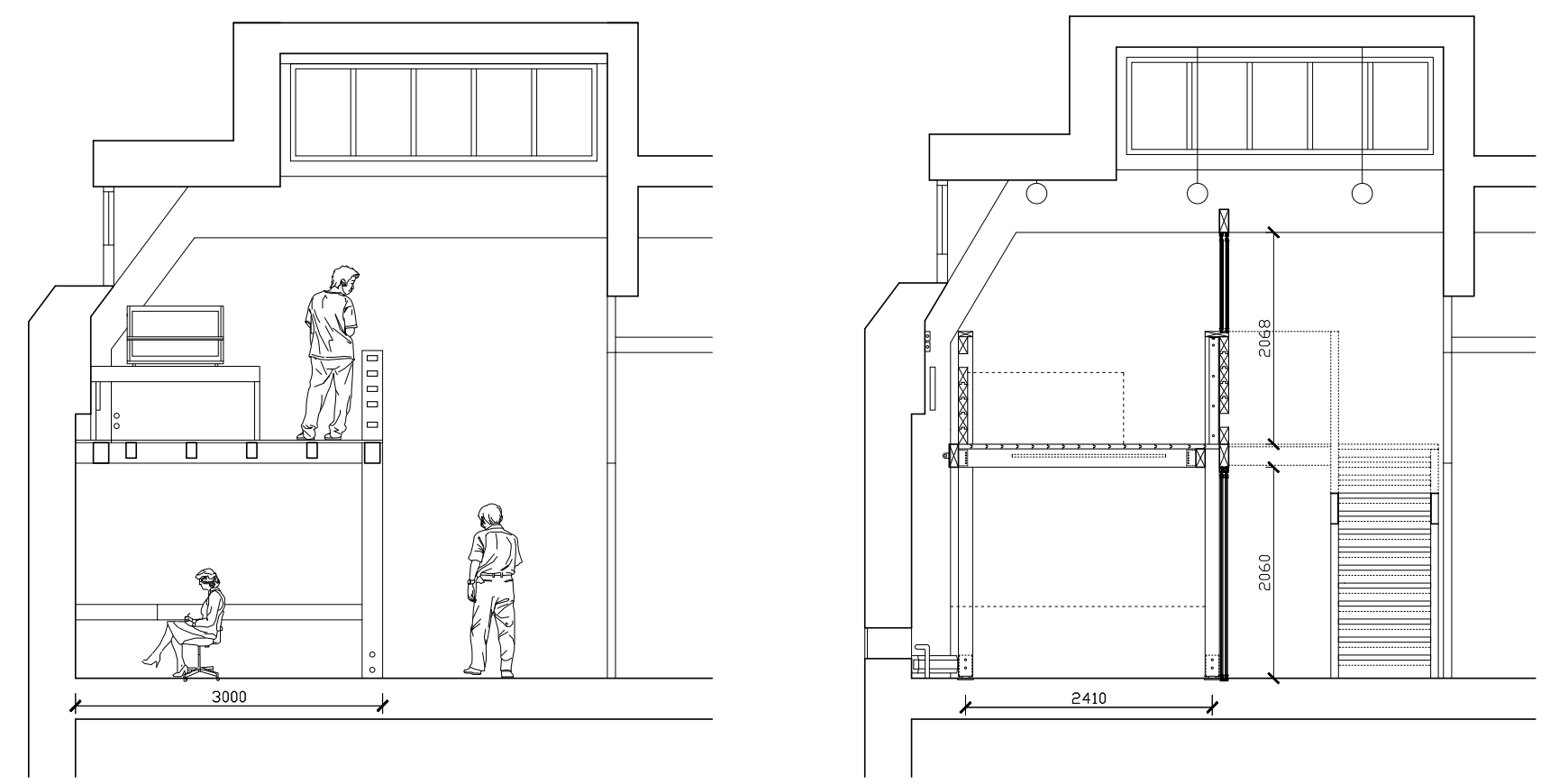


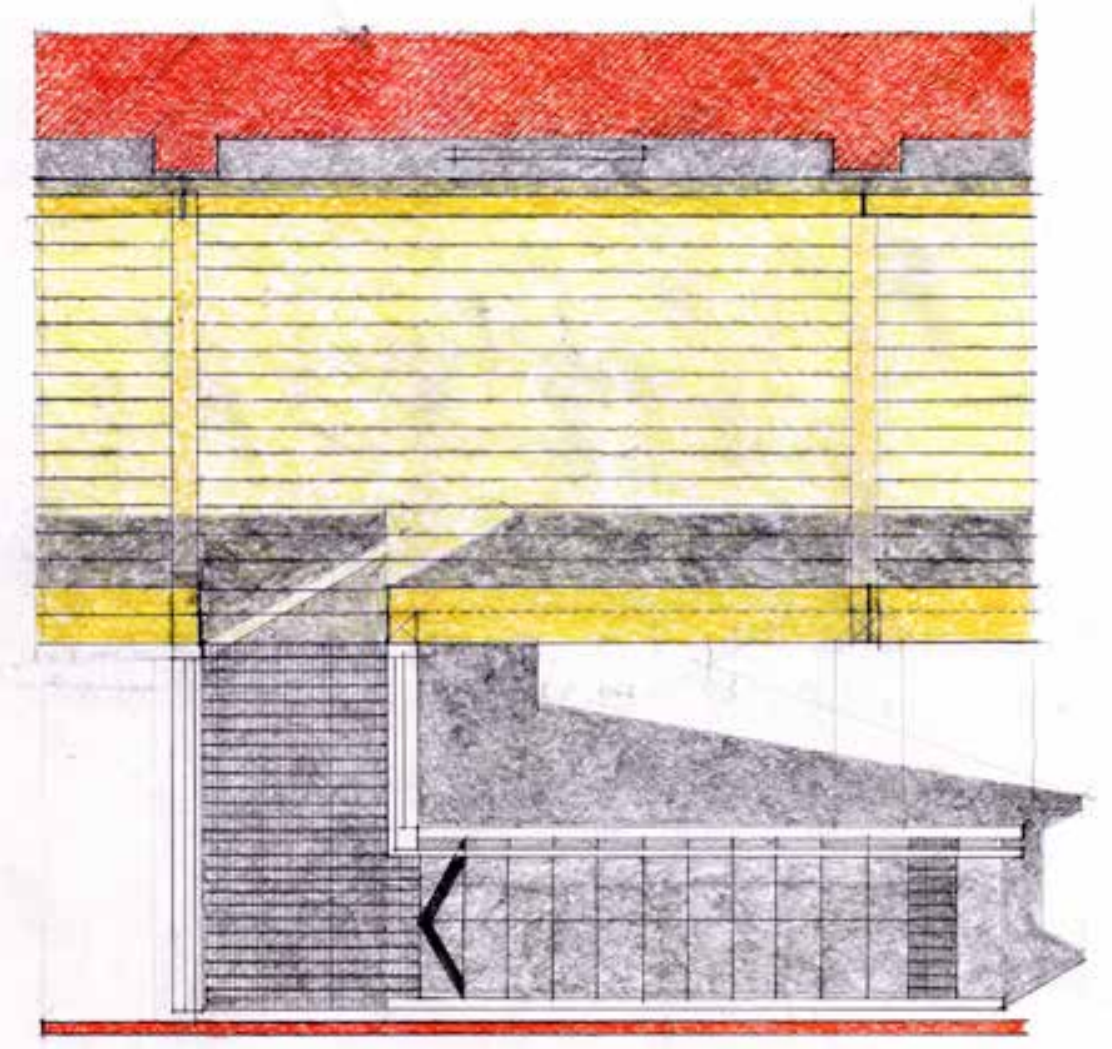

\subsubsection{Final design}

The final design, was proposed as a series of bays, as shown, with an out-board stair in the middle of each mezzanine. The mezzanine is composed as a stand-alone glulam structure held off from the existing walls and structure to be a separate structure within the studios rather than part of the studios.

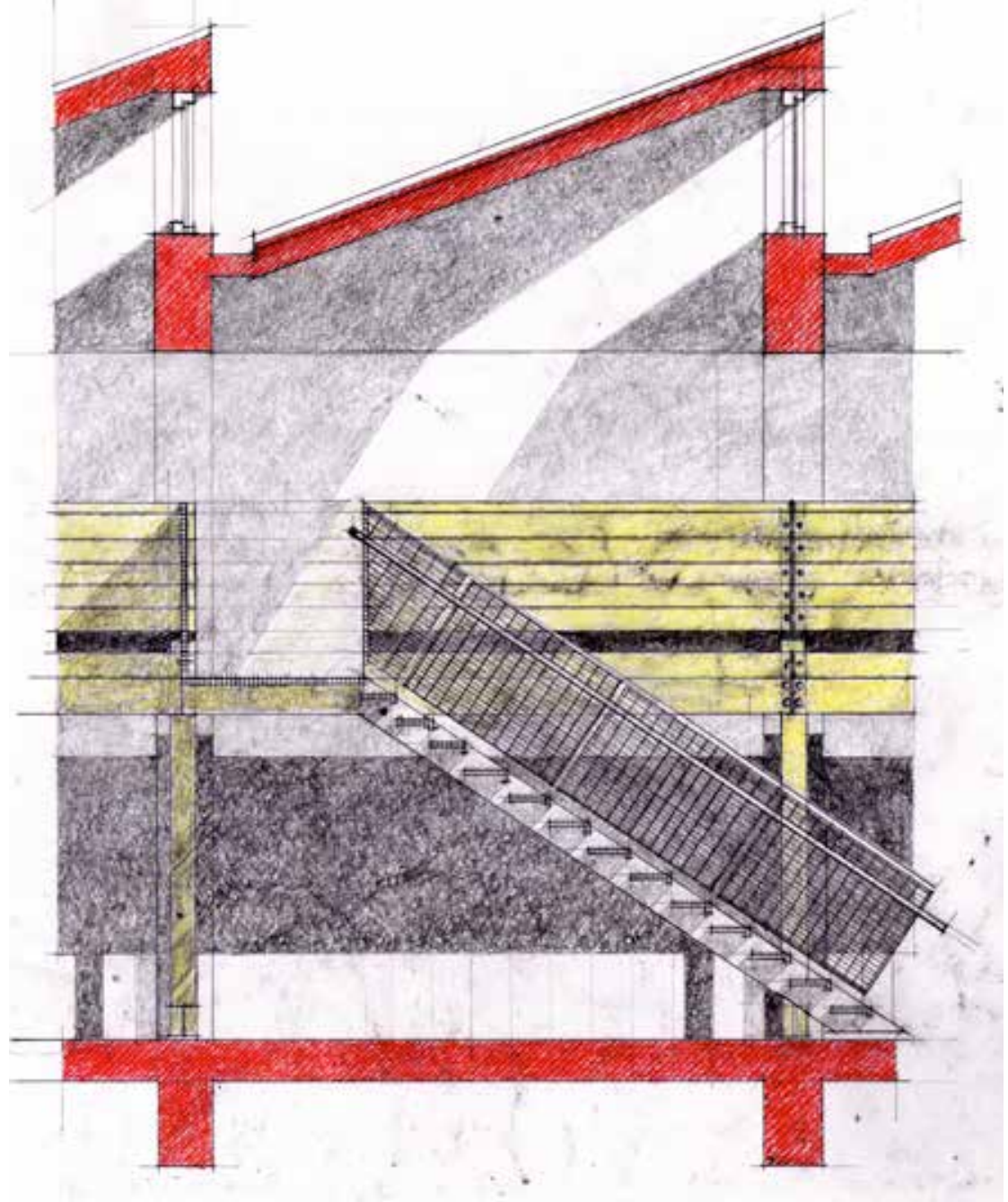

LEFT (top - bottom)

Fig 7.30 Plan of proposed generic

Fig 7.31 bleva mezzanine leve tlevation of proposed mezzanines

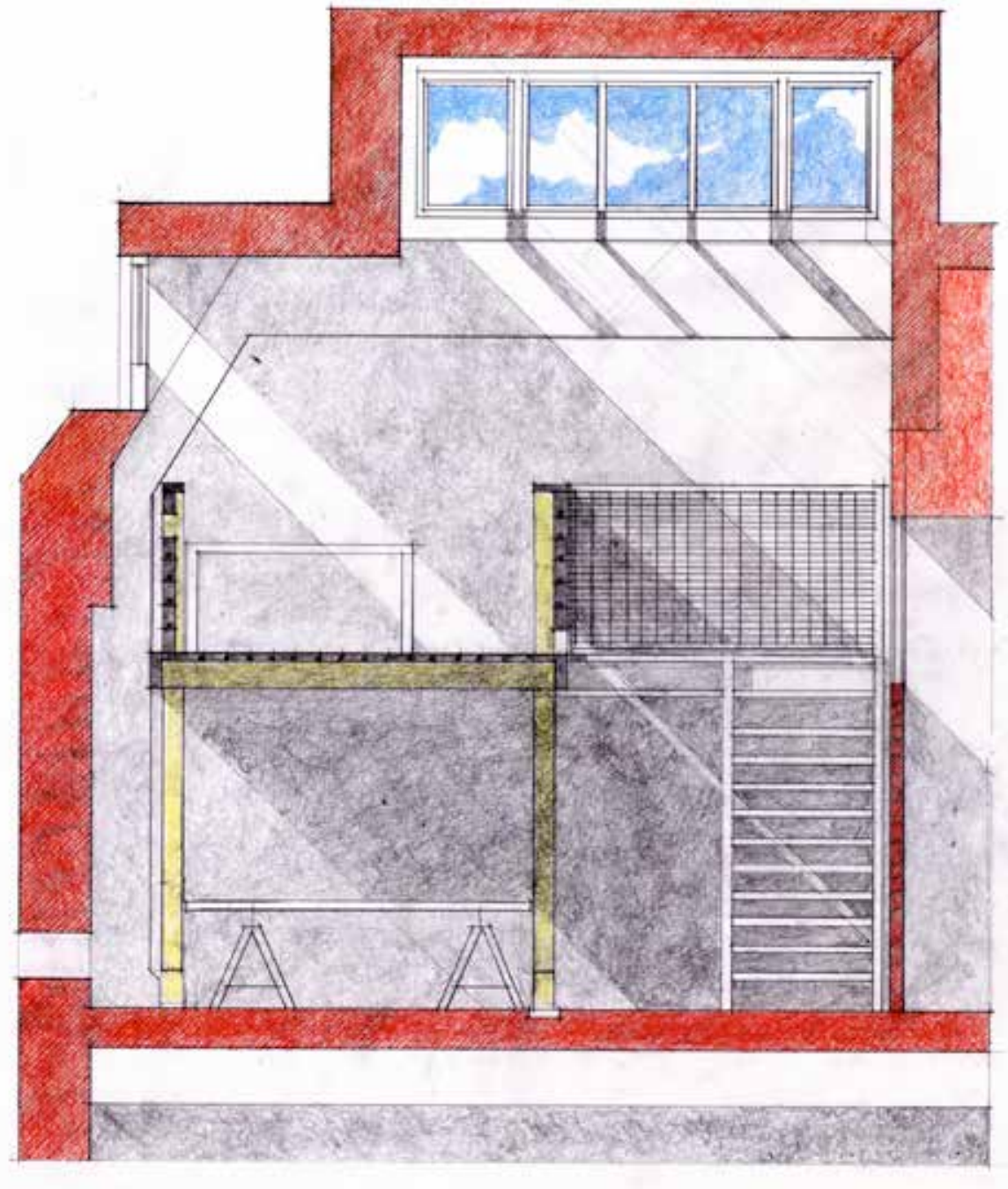




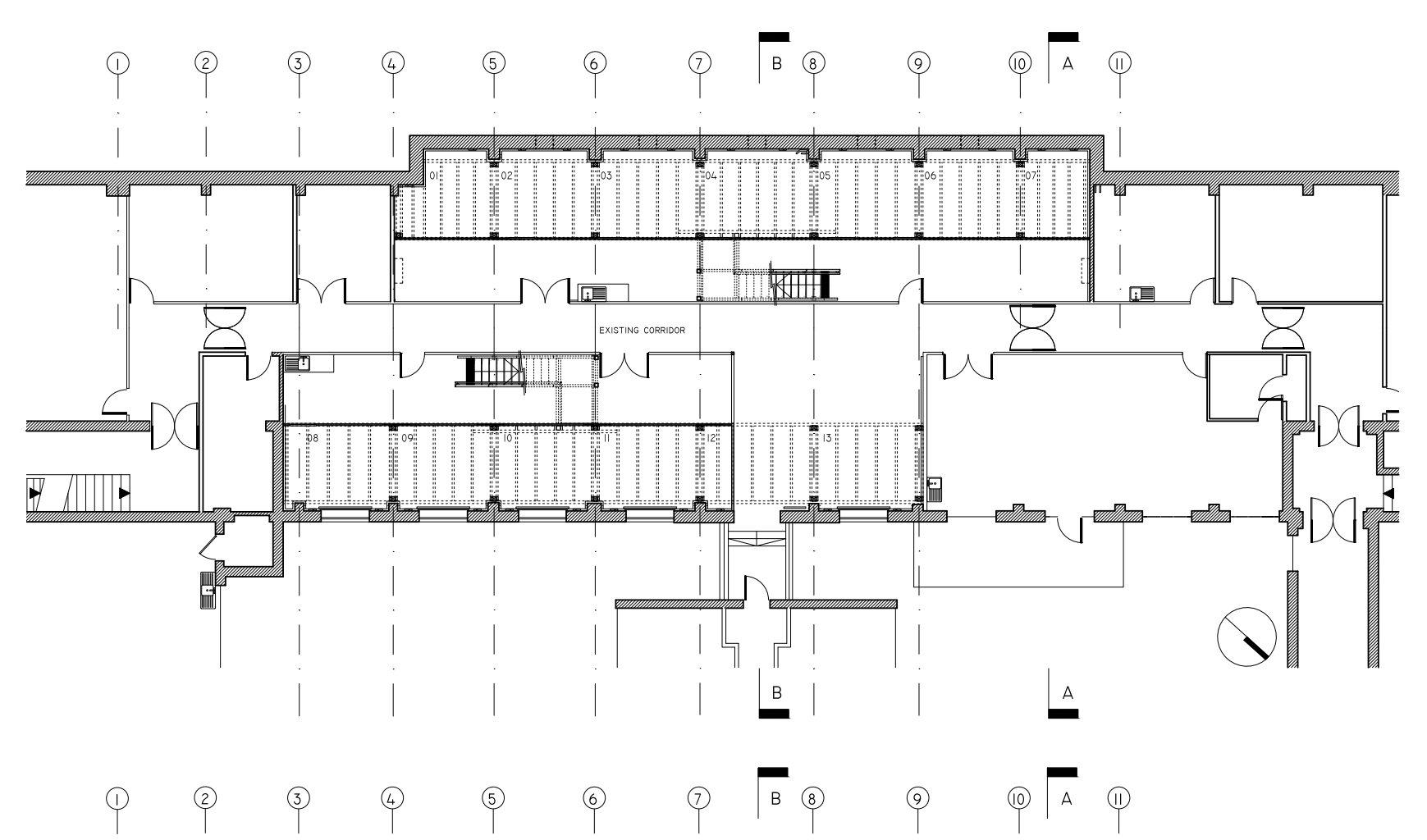

\subsubsection{Prototype}

7.3.2.1 Detailed design

Due to the nature of the mezzanine design and structural constraints the preparation of production information for tender was conducted in collaboration with a structura engineer. The following is therefore a combination of the detailed design as prepared by both the Design Research Unit Wales and Veryard Opus Ltd. To clarify, the role of DRUw was to coordinate the overall design vision, proportions, spatial arrangement and dimensions with the engineer providing structural sizing and connection details, to meet the architectural intentions.

The design detailed for tender was based on two separate mezzanine floor structures on either side of the corridor. The western mezzanine was $23.7 \mathrm{~m}$ long with 7 bays,

the eastern mezzanine was $21.8 \mathrm{~m}$ long with 6 bays. Both had the same cross section width of $2.3 \mathrm{~m}$ internally with the two minor differences with the western mezzanine:

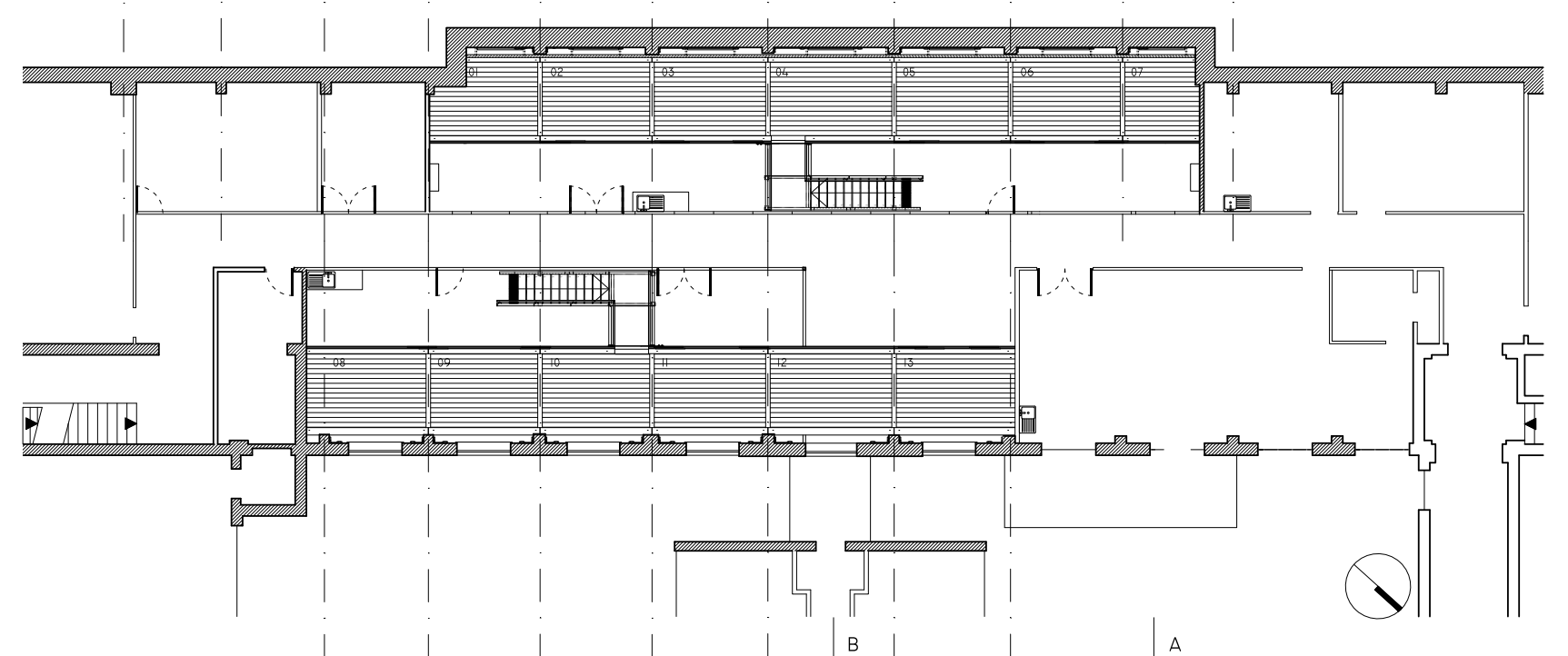

- the rear balustrade was set in between the posts rather than on the outside to allow for the roof pitch; and

- bay 1 was detailed to fit around the external wall return and roof hip above.
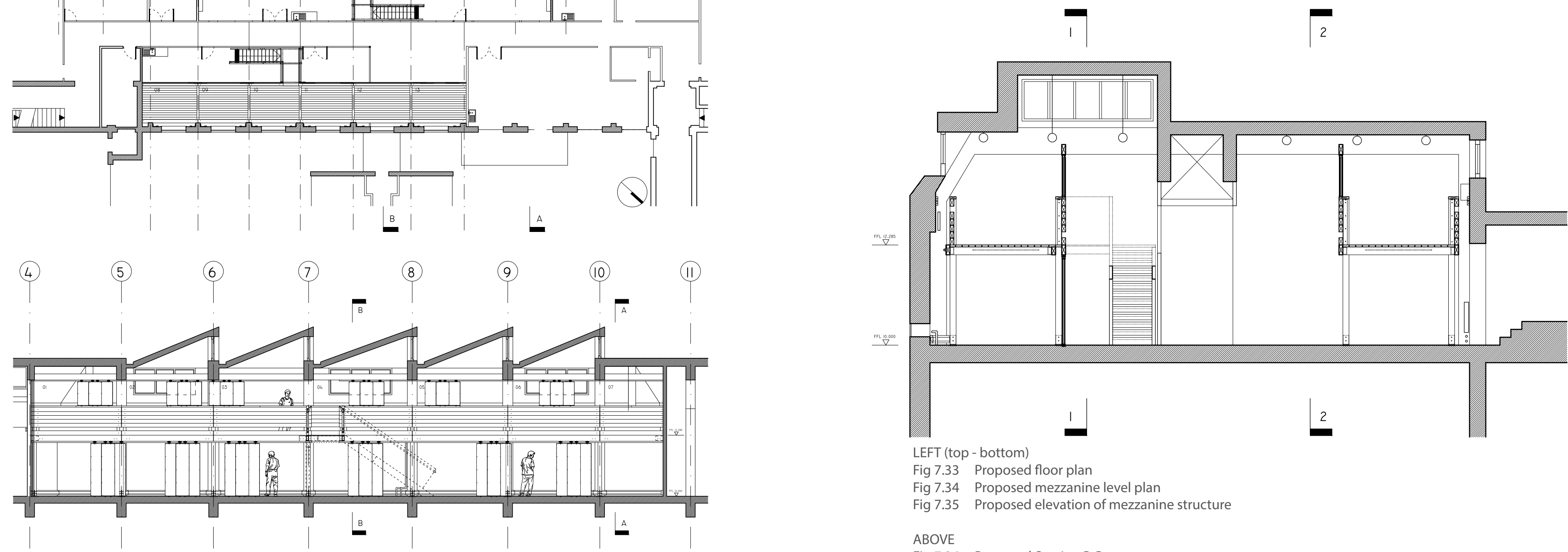

LEFT (top - bottom)

Fig 7.33 Proposed floor plan

Fig 7.34 Proposed mezzanine level plan

Fig 7.35 Proposed elevation of mezzanine structure

ABOVE

Fig 7.36 Proposed Section B-B 
While each structural bay alters in length, the principal of the cross section, timber sizing and detailing was the same in all bays. Each bay consisted of:
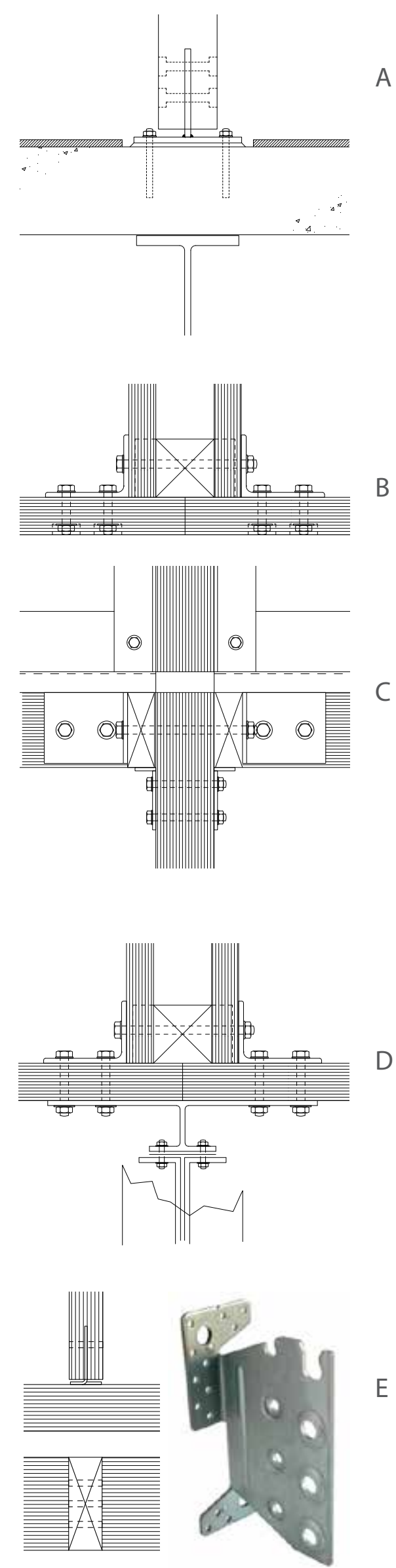

4 no. $140 \times 140 \mathrm{~mm}$ glulam corner posts bolted to the concrete floor on the centre line of the existing Bute building structure using a galvanised steel flitch plate, 4no. M20 galvanised steel bolts and 4no. Hilti HIT HY 150 resin anchors with galvanised M16 threaded rods.

2no. $180 \times 65 \mathrm{~mm}$ glulam floor joists fixed to either side of the posts with galvanised steel supporting brackets with 4no. M16 bolts and a galvanised steel angle bracket with an M20 bolt.

2 no. primary $225 \times 90 \mathrm{~mm}$ glulam beams span the length of the bay and fixed to the floor joists and post with 2 no. M20 bolts to the angle bracket.

The rear $225 \times 90 \mathrm{~mm}$ beams to be jointly fixed to the existing steel columns using a bespoke I-beam bracket and M20 bolts.

E $\quad 180 \times 90 \mathrm{~mm}$ glulam floor joists span between the primary beams from front to back fixed with Simpson Strong-tie TU16 concealed beam hangers evenly spaced at approximately $650 \mathrm{~mm}$ centres depending on bay length
RIGHT

Fig 7.38 Structural details of typical bay connections
Exploded detail axonometric of 1 bay of the mezzanine structure 

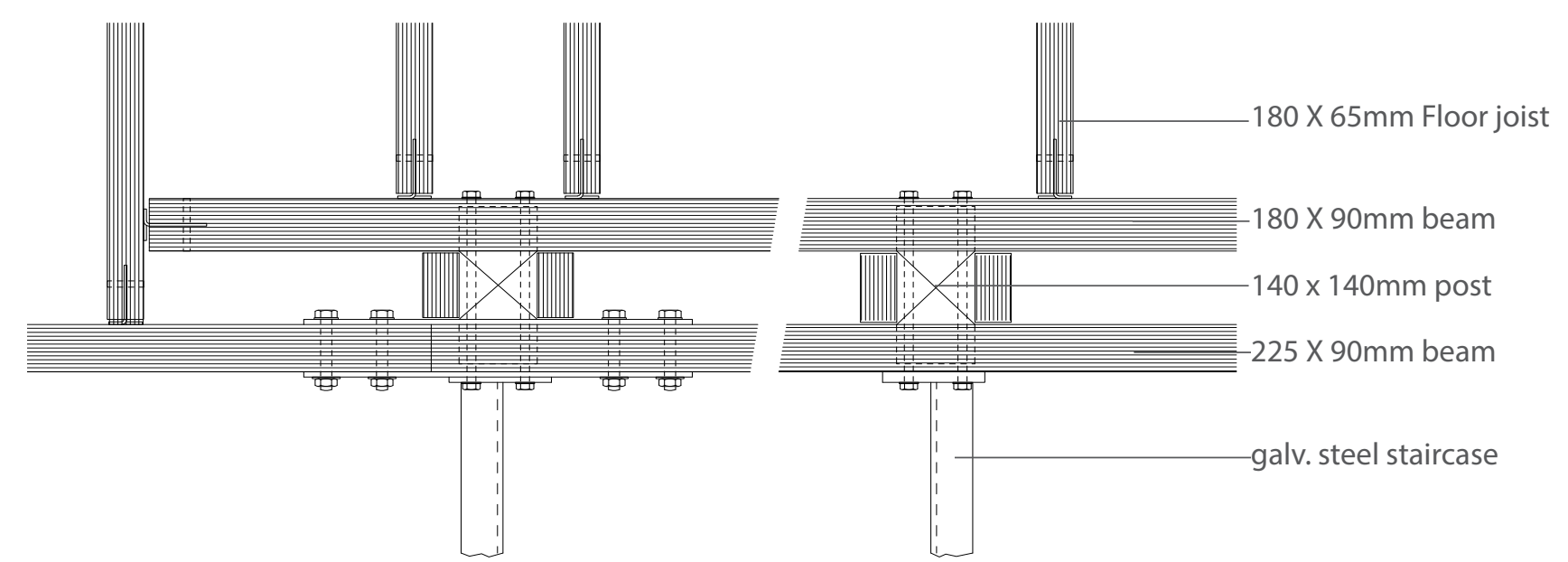

(o)
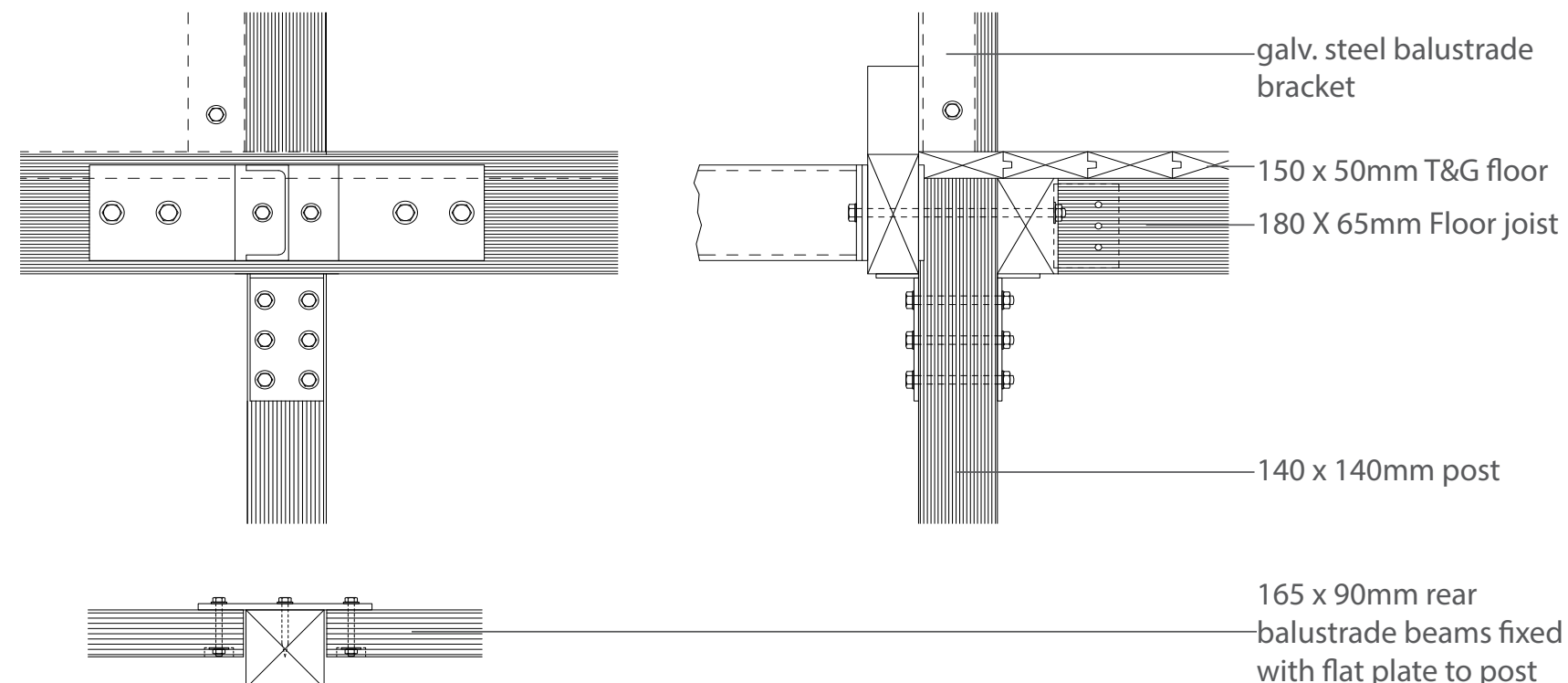

$165 \times 90 \mathrm{~mm}$ rear balustrade beams fixed with flat plate to post

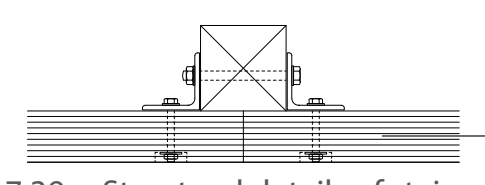

$165 \times 90 \mathrm{~mm}$ fron balustrade beams fixed

Fig 7.39 Structural details of stair connection
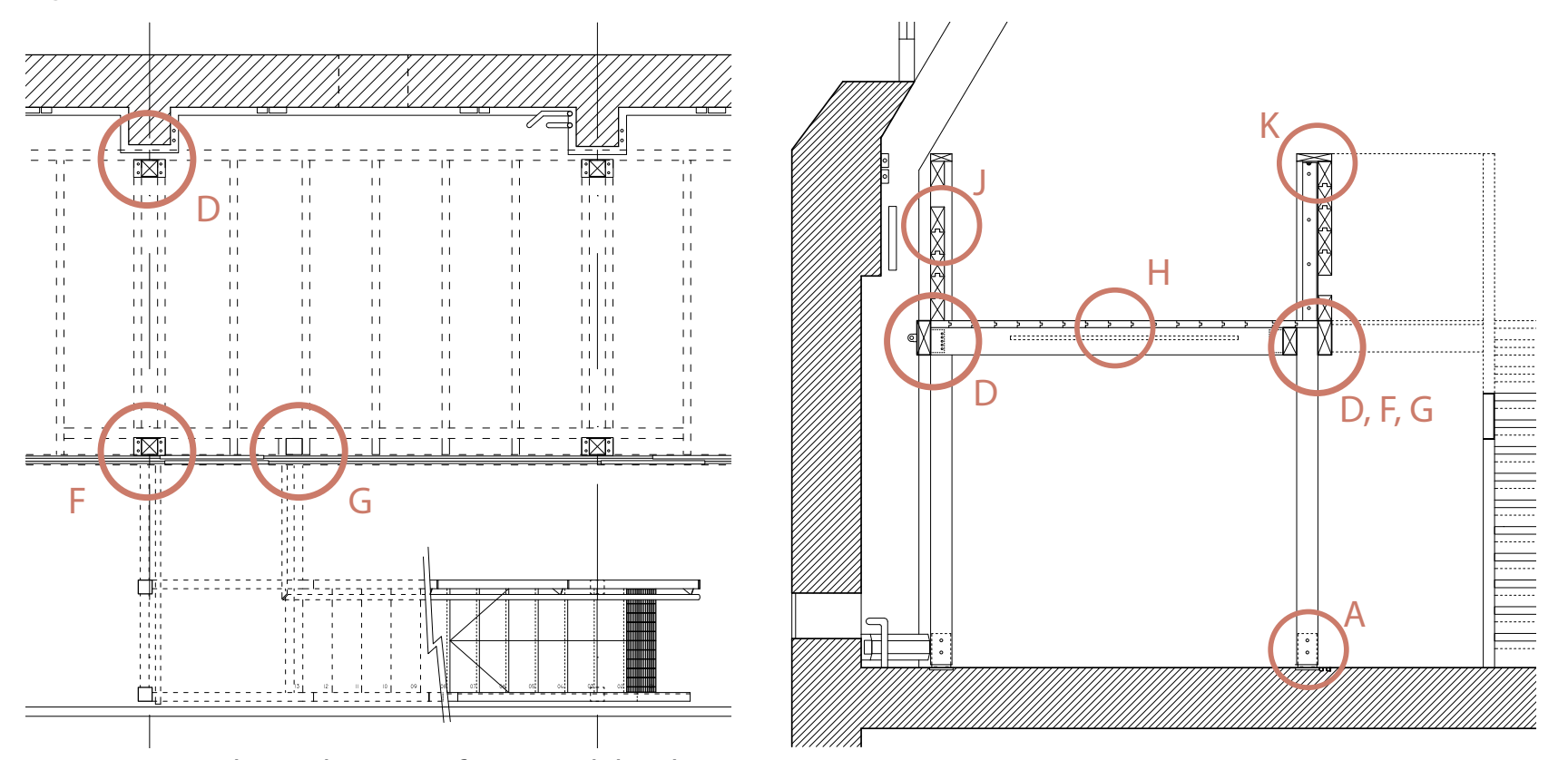

F, G Where the staircase meets and is fixed to the mezzanine, the primary beams are to be pre-cambered $10 \mathrm{~mm}$ with a secondary $180 \times 90 \mathrm{~mm}$ glulam beam bolted behind the front posts and supported underneath with a galvanised steel bracket secured by 6 no. M16 bolts.

H $\quad 150 \times 50 \mathrm{~mm}$ tongue and groove solid spruce floor boards secret screwed to the floor joists through the tongue span the length of each bay. $150 \times 50 \mathrm{~mm}$ spruce cover boards run between the posts at each bay screw fixed to the floor joists.

J 6 no. $165 \times 90 \mathrm{~mm}$ tongue and groove glulam beams span length of bay bolted to an angle bracket with $\mathrm{M} 12$ bolts that is bolted to the posts using M16 galvanised steel bolts. Each beam effectively spans on its own with the $t \& g$ used to align the surface.

$\mathrm{K}$ a $230 \times 50 \mathrm{~mm}$ spruce board is screw fixed to the top balustrade beam as a handrail using galvanised steel brackets.

- $\quad$ This construction repeats along the mezzanine length with a $10 \mathrm{~mm}$ shadow gap between primary beams and balustrade panels of each bay.

- all bolts to the front elevation of primary beams and balustrade are counterbored and recessed.

- The structural engineer specified that all timberwork was to be GL24 comprised of C24 graded whitewood (spruce, larch and Douglas fir).

- The galvanised steel staircases were detailed to be prefabricated as small components that could be lifted by 1 or 2 people and carried into position before being bolted together on-site.

- Exposed galvanised steel electrical conduit was to be surface fixed to the timberwork running along the rear primary beam and branching out to T5 fluorescent tube light fittings in between each structural bay.

It was intended for all glulam components to be sourced off-the-shelf within the UK to reduce costs and lead-in times. However, the design intentions combined with the structural requirements resulted in a number of bespoke components including: precambered glu-lam beams, $180 \times 90 \mathrm{~mm}$ beams, $\mathrm{t} \& \mathrm{~g}$ profiled balustrade beams and the bespoke galvanised steel brackets adding cost and complexity to the modular, standardised design. Some components could be sourced off-the-shelf from different suppliers, others were to be fabricated bespoke for the mezzanines. Furthermore, all timberwork was required to meet the Building Regulations surface spread of flames rating of Class 0 . This was achieved by sending the timber to Arch Timber Protection, in Yorkshire, be impregnated with Dricon, a water-based fire retardant, adding 8 weeks to the lead-in time.

Fig 7.40 Key plan and section of structural details 
The following photographs storyboard the construction and assembly of the glu-
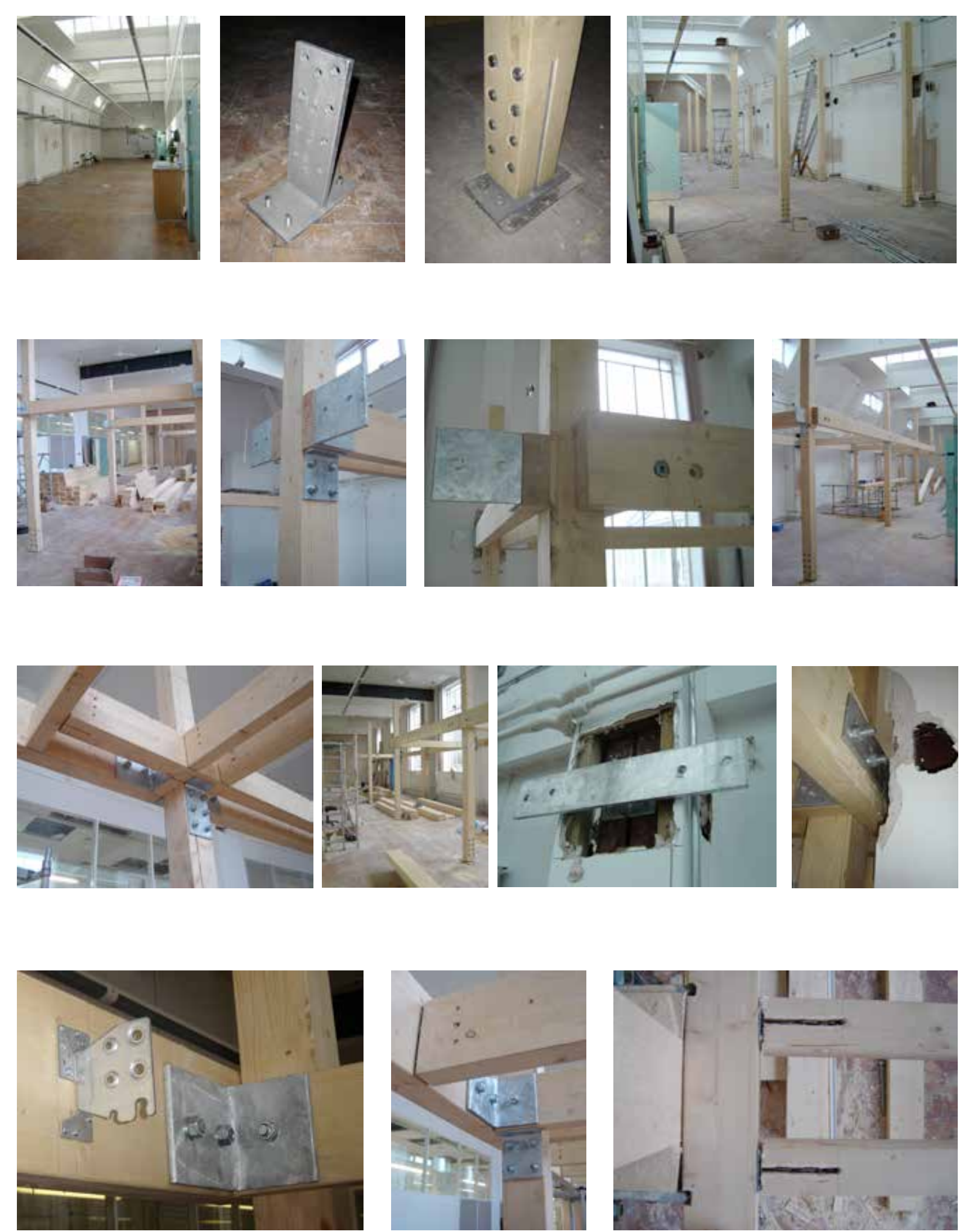
Fig 7.41 Photos of mezzanine construction
Row 1 sequence
Cleared existing studio space; Galvanised steel
flange brackets are bolted to the floor - holes
were originally incorrectly drilled for 4 bolts; 140
$\mathrm{x} 140 \mathrm{~mm}$ glu-lam posts are routed on-site and
bolted to bracket; Freestanding posts in studio.
Row 2
$180 \times 65 \mathrm{~mm}$ floor joists are bolted to either
side of posts; Support brackets are bolted
underneath beams; Detail of fixing brackets for
primary beams with counterboard bolts; 225
x $90 \mathrm{~mm}$ primary beams are bolted to brackets
cross front and back of frame.
Row 3
Detail of post, primary beams and floor joists at stair connection; Structural frame in studio Bespoke galvanised steel fixing bracket
connected to existing Bute steel columns;
to misalignment betws notched onsite due to misalignment between posts and existing
Row 4
Simpson Strong-tie TU16 concealed joists
hanger initially fixed upside-down Floor joists fixed to steel dowels. Floor joists were notched to ass joist hanger on-site with hand chisels.



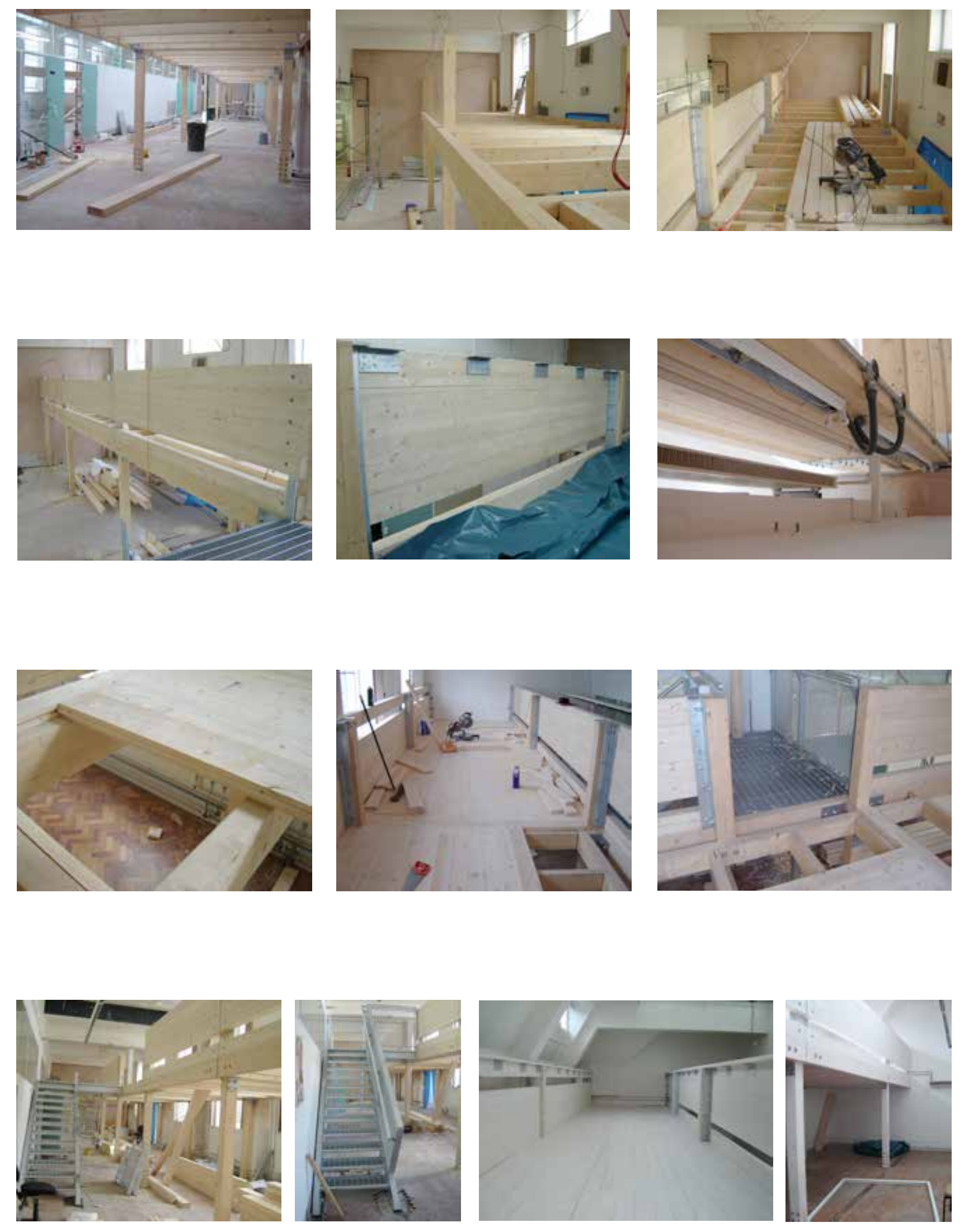

Fig 7.42 Photos of mezzanine construction

Row 5

Floor joists within structural frame; Upper

mezzanine posts extended up to provide fixing

for balustrade beams; $165 \times 90 \mathrm{~mm}$ glu-lam

beams bolted to galvanised steel brackets on

posts to create balustrade.

Row 6

Balustrade fixed across bays with $10 \mathrm{~mm}$ shadow

gap on centre line of posts, between bays. The

lower gap provides visibility to maintain visual

connection between studio floor and mezzanine

level; Short galvanised steel brackets screwed to

balustrade to support $230 \times 50 \mathrm{~mm}$ top board;

Exposed conduit fixed to rear of balustrade for

fluorescent tube light fittings.

Row 7

$1509 \times 50 \mathrm{~mm}$ T\&G spruce floorboards are

secret screwed through tongue to floor joists;

floorboards laid longitudinally with transverse

board between bays; Connection of stair with

mezzanines.

Row 8

Stair case installed in prefabricated pieces;

Mezzanines were finished with a coat of white

OSMO oil on all surfaces. 

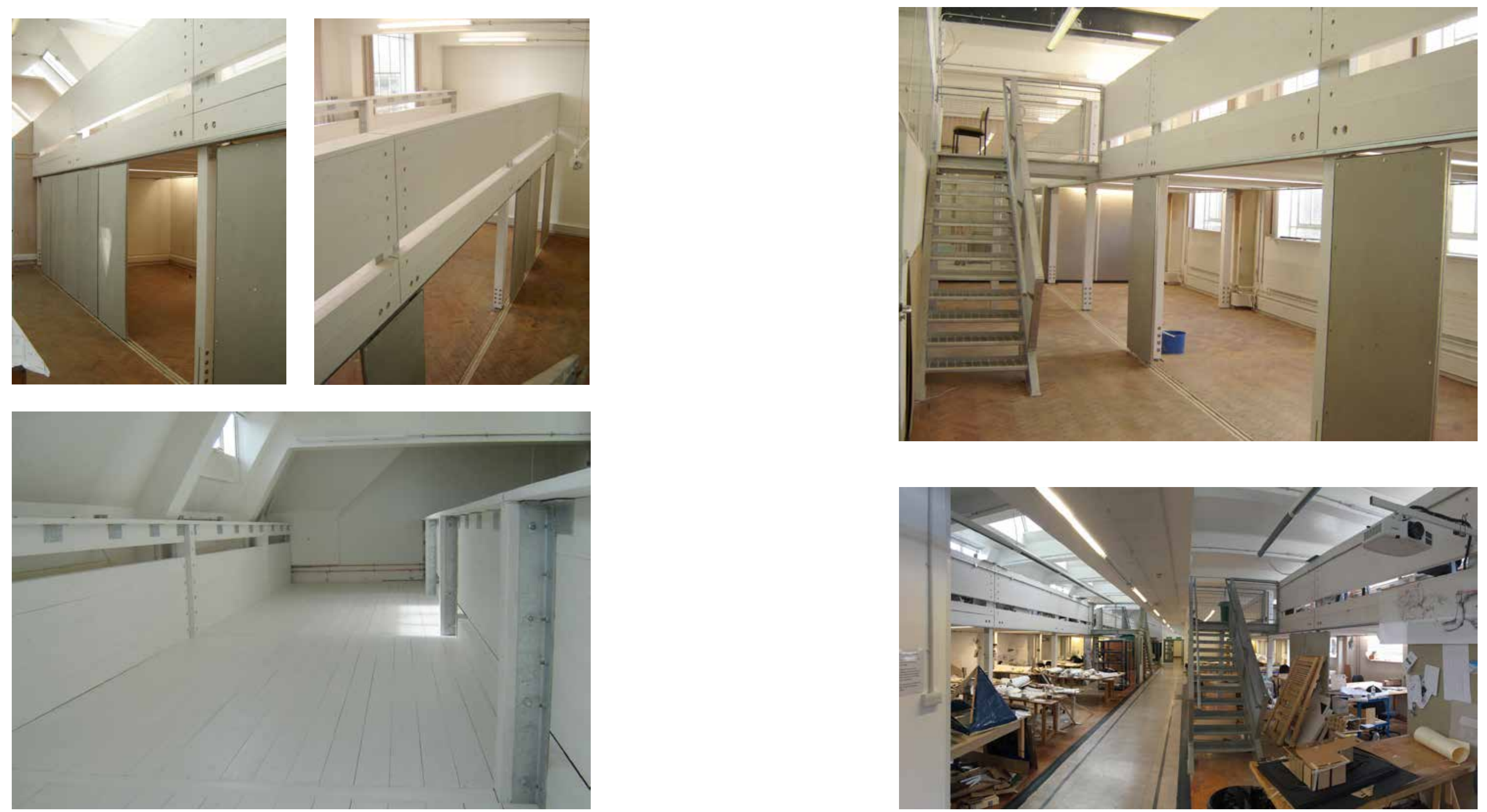

Fig 7.43 Views of completed mezzanines, 2005

a. Sliding screens under mezzanines
b. Balustrade glulam spans from post to post

c. White oiled $t \& g$ floor and multiple steel brackets

TOP

Fig 7.44 Completed mezzanine and stair, 2005

BOTTOM

Fig 7.45 Panoramic view for mezzanines, 2015 


\subsubsection{Observations and reflections}

The mezzanines have been in use, since 2004, with favourable feedback from students and staff promoting the school's studio culture and ethos of learning by doing. Over the last decade only minor maintenance and alterations have been required, with the most significant being the addition of extra plug sockets and the opening up of the studios into one large space containing both mezzanines. However, a 2015 general studio inspection revealed items of wear and tear, minor structural significance, timber movement and design limitations to consider.

The following reflections have been generated from end user feedback and observations on the design and physical prototype as both a structure and as a studio space in use:

\subsubsection{Species performance and adaptation}

\section{SPECIES}

- The mezzanines were not constructed using Welsh-grown timber. Instead the glulam posts and beams were imported from central Europe via a glulam importer and stockist in the UK as chosen by the main contractor increasing lead-in time, transportation costs and embodied energy.

- The imported glulam beams are specified as being fabricated from whitewood - a general term for a collection of pale coloured softwood species including spruce, hemlock, fir and pine of which all are found in Welsh woodlands. The variety means that the manufacturer can select from a wider range of species that meet the required physical properties as well as cost. With all these species grown in central and northern Europe, exhibiting better durability, less movement and achieving higher stress grades than in Wales.

- It would be worth the Welsh industry considering mono species glulam components that are appropriate to the timber species. To achieve a C24 grade this would likely be limited to larch or Douglas fir in limited volume and bespoke purposes. It would also be beneficial to consider alternatives to the solid glulam approach that may be better suited to Norway and Sitka spruce and Western hemlock.

\section{TIMBER ADAPTATION}

- The purpose of engineered timber is generally to increase the structural performance of solid timber. In the case of the mezzanines, required to support high live loads, the glulam components are significantly smaller than raw timber equivalents reducing weight and volume of timber used. Moreover they use small section and lengths of timber from smaller and 

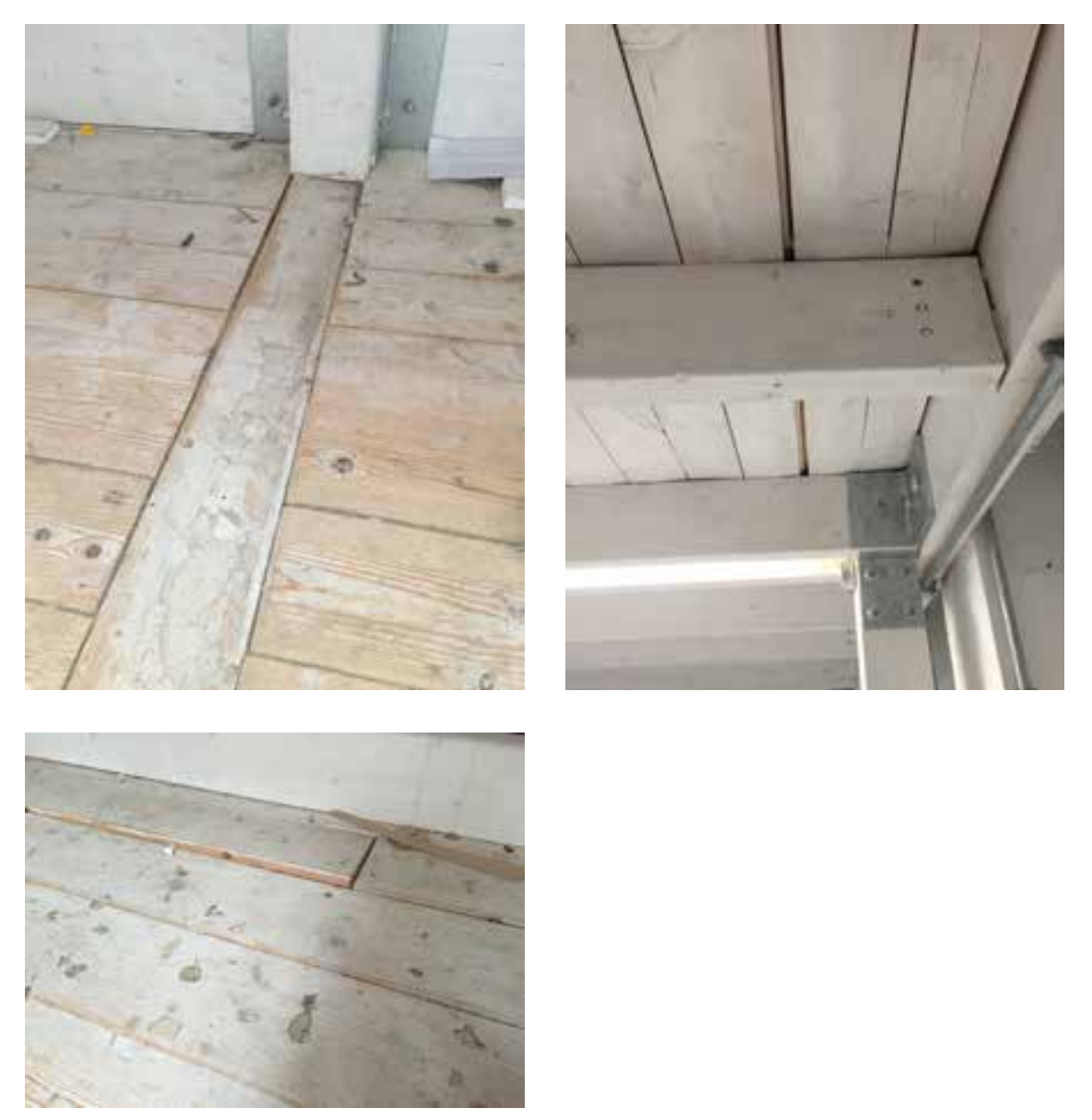

Fig 7.46 Shrinkage has caused gaps between boards and a warping of the end of unsupported boards, April 2015 younger trees to make larger components.

- The structural engineer specified that the glulam be stress graded as $\mathrm{C} 24^{14}$ meaning that the whitewood laminations meet at least a minimum grade of C24. This is one of the biggest difficulties in manufacturing Welsh grown glulam as the major sawmills do not currently grade higher than C16 and to select only C24 graded softwood would result in significant wastage through defect cutting and rejection. The process would also require significant industry processing change starting at the woodland selection and through primary processing before the timber arrives at secondary processing to manufacture glulam.

- The glue used to laminate the whitewood was a WBP melamine glue and therefore not containing formaldehyde that would be required for external lamination. The properties are such that the fire performance of glulam is improved over solid timber due to the Nitrogen that is released when burnt or charred that extinguishes flames.

- Of the 2 parts of the mezzanines that were not specified as engineered timber the solid t\&g whitewood floor has shown significant movement over 10 years that would highlight the benefits of engineered floors. The specification required the moisture content of timber in generally heated spaces to be $20 \%$ or less. At this moisture content, shrinkage would be expected and has happened, leaving gaps between boards and a warping of the end unsupported boards.

\subsubsection{Building envelope}

Overall, the structure demonstrates potential for the use of Welsh-grown timber in glu-laminated components as part of the building envelope, although consideration of scale and complexity will be required as further discussed below.

\section{SUPERSTRUCTURE}

- The mezzanines are a successful demonstration of a structurally efficient post and beam structure with slender columns and an intermediate floor thickness of $225 \mathrm{~mm}$ spanning an area of up to $2.4 \times 3.9 \mathrm{~m}$. However, the structure was braced to the existing Bute building structure eliminating the need for extra cross bracing and shear resistance between the bay posts that may be required in a stand alone structure.

- As a high-value product, glulam is generally used in medium to large span expressive structures for the tactility and warmth that it offers over other material options, and where solid timber would not meet the necessary performance requirements. This has been achieved in the design of the

14 Also known as GL24h to meet BS EN 1194 or DIN 1052 
mezzanines as a small scale structure working within the limited dimensions of the existing studios and could be directly translated into domestic scale construction. However its use would be more beneficial to incorporating Welsh-grown timber into school design and other medium-span public buildings that require uninterrupted open spaces.

\section{INTEGRATION OF COMPLETE ENVELOPE}

- As an internal structure, the mezzanines only demonstrate a structural approach to the use of timber in the building envelope. It could be assumed that this structure could form part of a complete external building envelope like any other post and beam system, although concealing the glulam within the multiple layers of the contemporary building envelope may undermine the qualities of the product and even duplicate the performance of alternative panelised construction systems.

- The building regulations requirement to provide fire protection for both combustibility and surface spread of flames means that a glulam structure either needs to be impregnated, coated or wrapped in a fire retardant or finish. This is despite the known, and extensively researched, predictable performance of structural timber and glulam products in fire and extreme temperatures. As part of a building envelope, glulam will always require an intumescent finish or be hidden behind low value plasterboard or equivalents.

\subsubsection{Technology and skills}

The means to carry out this prototype relied on the use of glulam with timber sourced and fabricated in mainland Europe before importing to the UK. Therefore the technology and skills of the Welsh timber industry were not utilised for reflection. However, the technology and skills required to manufacture glulam can be

hypothetically appraised:

\section{PROCESSING}

- The biggest issues facing the Welsh industry are the supply of appropriate quality softwood, as discussed above, and the scale and costs of the required plant to plane, joint, laminate, press and post-plane components for mass market consumption capable of competing with imported equivalents. This becomes even more complex for any non-standard straight post or beam such as the pre-cambered mezzanine beams.

- As indicated by the Poyry report, the primary industry may be in a position to manufacture glulam to extend their ranges of structural products from C16 CLS, fencing and pallet making. However this would require a significant restructuring of their business plans, supply chains, target markets and 


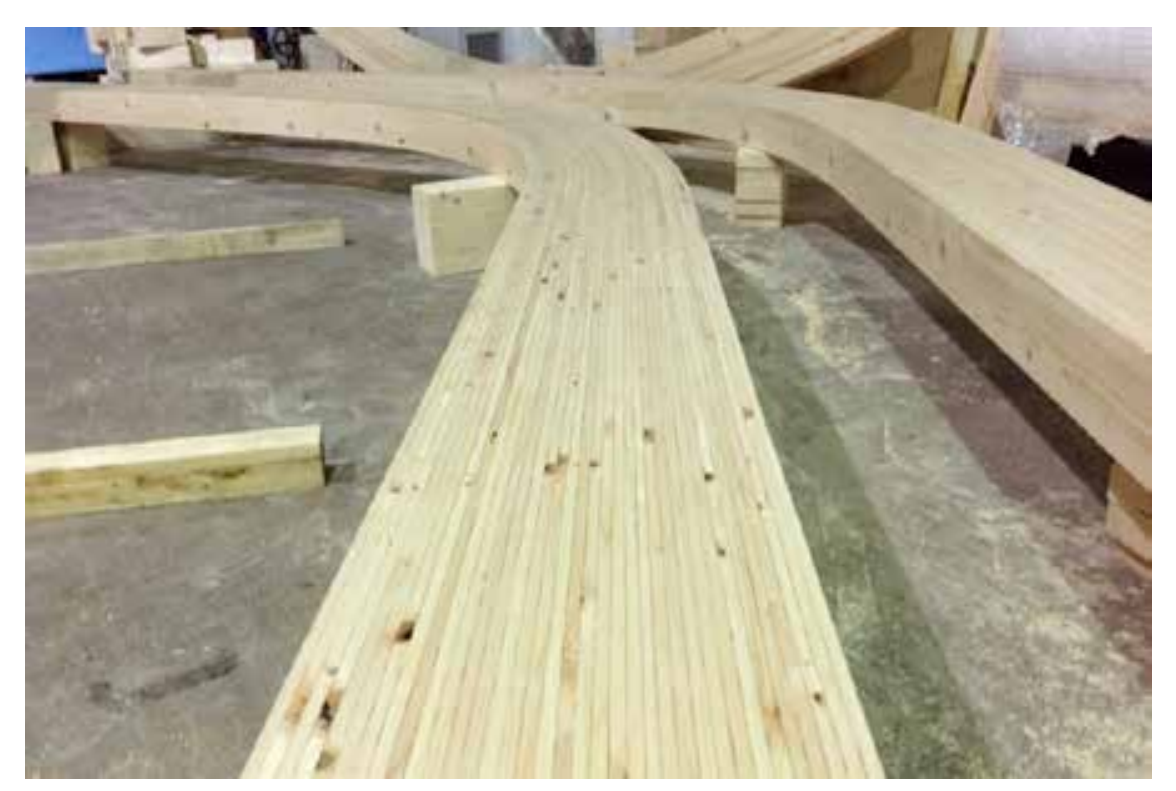

sawmill equipment which currently are highly successful in the largest sawmills across Wales.

- This leaves the smaller sawmills and specialist woodworkers who have the will, ingenuity and basic equipment to manufacture bespoke glulam on an individual basis.

- The mezzanines required fire protection that involved another specialist process that is not available in Wales - the impregnation of fire protection (Dricon). The complexity and specialist nature of this process adds further restrictions on the ability to source timber, manufacture and treat glulam all in Wales. The industry may need to be seen as regional clusters rather than a national Welsh industry that would keep transport costs and energy consumption low but utilise and share a wider range of processes available across the UK, thereby allowing for the manufacture of English, Scottish and Welsh glulam.

FABRICATION

- At the time of designing this prototype, there were only a handful of small-scale specialists, in the UK, with the ability to manufacture small volumes of bespoke glulam at high cost. Since completion of the project a larger scale specialist ${ }^{15}$ began manufacturing standard sizes of glulam with locally grown softwood. They, therefore, demonstrate that it is possible to manufacture homegrown glulam but currently remain the only commercial scale business to compete with the import market of glulam.

- While a Welsh glulam is feasible and would be beneficial, it is unlikely that the Welsh timber industry will establish a glulam manufacturing industry that would be capable of competing with the import market.

\section{CONSTRUCTION}

- The main contractor used their own 'in-house' carpenters to assemble the mezzanines. The contractor chose to order a mix of glulam components pre cut to size, such as the columns, and others slightly longer than required due to the unknown dimensions of bay centres lines at time of ordering. This meant on-site processing would be required.

- The glulam was carried to the 2 nd floor and stacked in appropriate sizes in order. No protection was allowed for what would be the finished surface. It was assumed incorrectly by the contractor that the timber would be planed and sanded where required before being oiled.

- All carpentry work was conducted on-site in the studio environment using relatively low-tech hand power tools, including cutting to length, notches

15 Buckland Timber Ltd, in Devon, in 2012 
for flitch plates and concealed joist hangers and pre-drilling of bolt holes. While the carpenters were trained and skilled with traditional timberwork, they had not worked with glulam and struggled with the expressive nature of the design. This required many site inspections and instructions to describe method statements or to rectify unacceptable workmanship. This included the process of counterboring and recessing bolts and using the concealed joist hangers. With limited contingency glulam available, the level of craftsmanship needed to be high to avoid costly mistakes and delays or exposed errors.

- The final white oiled finish was applied with paintbrushes rather than rubbed in with a lint free cloth, leaving a heavy, thick coat of oil that took longer to

TOP ROW

Fig 7.48 Relationship between

mezzanines and existing

fabric

BOTTOM ROW

Fig 7.49 Bolt intensive connections
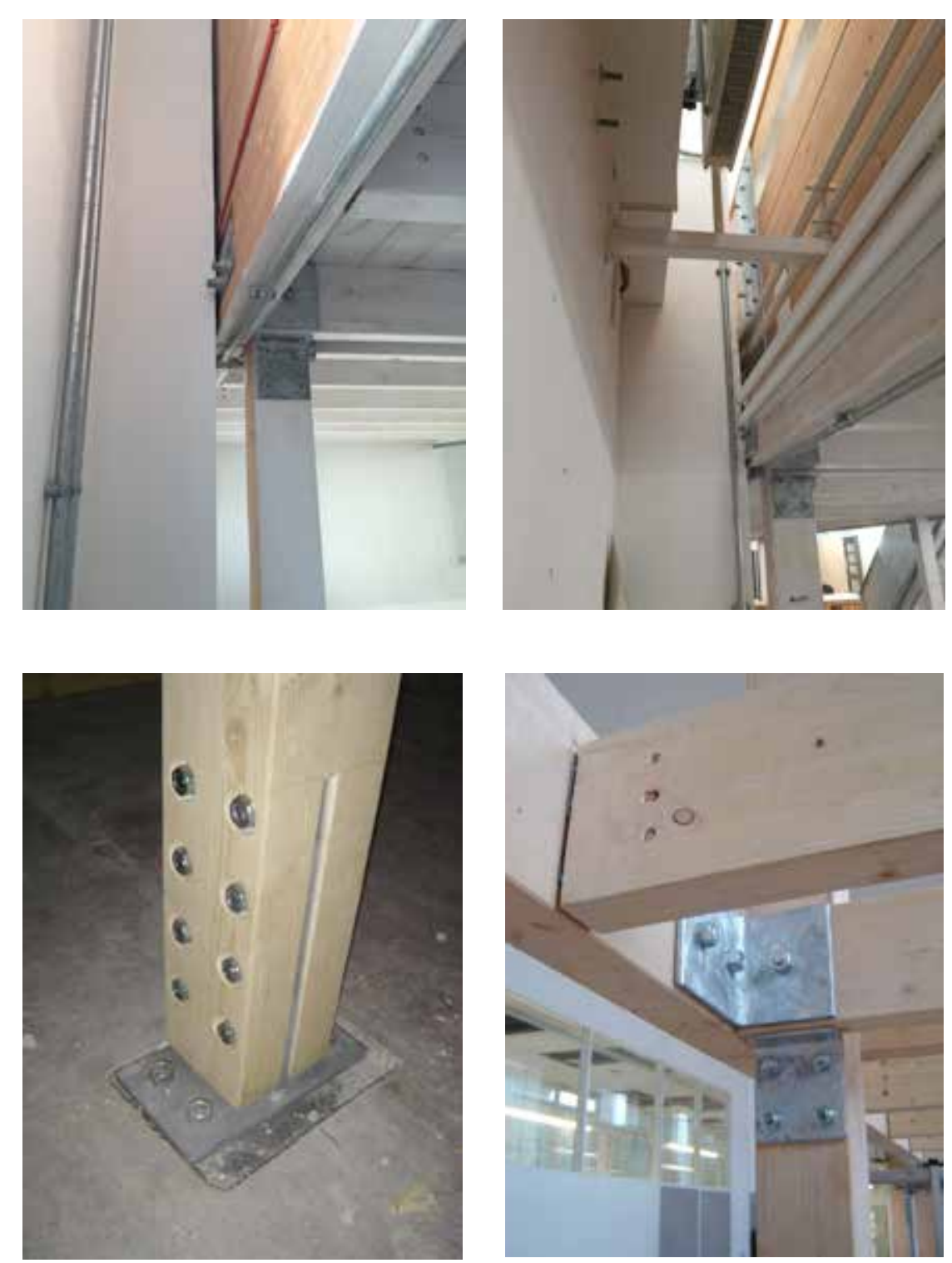

dry and masked the properties of the timber.

\subsubsection{Tectonic form}

CONTEXT

- The grade II listed context of the Bute building resulted in an intention to touch the existing fabric lightly with minimal disruption to existing finishes. The mezzanines sit very close to the external studio columns with an awkward connection between glulam and plasterboard clad steel columns that provides the bracing that allows the structure to appear stand alone without visual triangulation, straps or infilled bays. Together with the expressive, didactic constructive form and detail, this generates a confusing and mis-leading tectonic - on the one hand a simple, lightweight, bolted post and beam structure and on the other a heavy, robust and structurally ambiguous insertion.

DETAIL

- The number of galvanised brackets and bolts between glulam elements are generally heavy and a visually distracting scale. For example, each post is connected to the floor with 4no. M16 floor anchor bolts and 8no. M20 through the flitch plate; and the post to beam details incorporates $4 \mathrm{no} .10 \mathrm{~mm}$ thick galvanised steel brackets and 9no. M20 bolts.

\section{DIMENSIONAL COORDINATION}

- Due to the irregularity of the existing structure the compositional layout grid was set only by the $2.4 \mathrm{~m}$ structural width with the bay length allowed to stretch and shrink according to the needs while following an identical section and construction principle. This has been enhanced by the versatility of glulam to meet varying section sizes and lengths, but manufactured to the same specification, which would require significant sourcing, processing 


\section{MODULAR}

- The construction is elemental and additive allowing for: simple construction and low-tech, on-site carpentry skills; ease of disassembly; reuse or recycling of glulam components; and allowing for simple future extension with standard, off-the-shelf components.

\section{CORPOREAL}

- The creative and casual use of the mezzanines by students would suggest that the mezzanine structure feels robust and over engineered permitting students to abuse, add and amend in a way that may not happen in a lightweight, delicate structure.

- The narrow $2.4 \mathrm{~m}$ width; $225 \mathrm{~mm}$ floor zone; void between mezzanine and walli white oiled finish; and wide spacing of floor joists have provided an increased sense of volume that have created personal studio spaces without compromising light and openness. 
This stress-lam prototype project was established between the Design Research Unit Wales and a forester, carpenter and joiner, ${ }^{16}$ working in Builth Wells. The collaborative research project targeted a number of the technological, performance and design questions posed by the industry - how to design a modular, low-tech, solid construction solution using Welsh-grown timber.

\subsubsection{Design}

7.4.1.1 Brief

\section{Stress-lam construction}

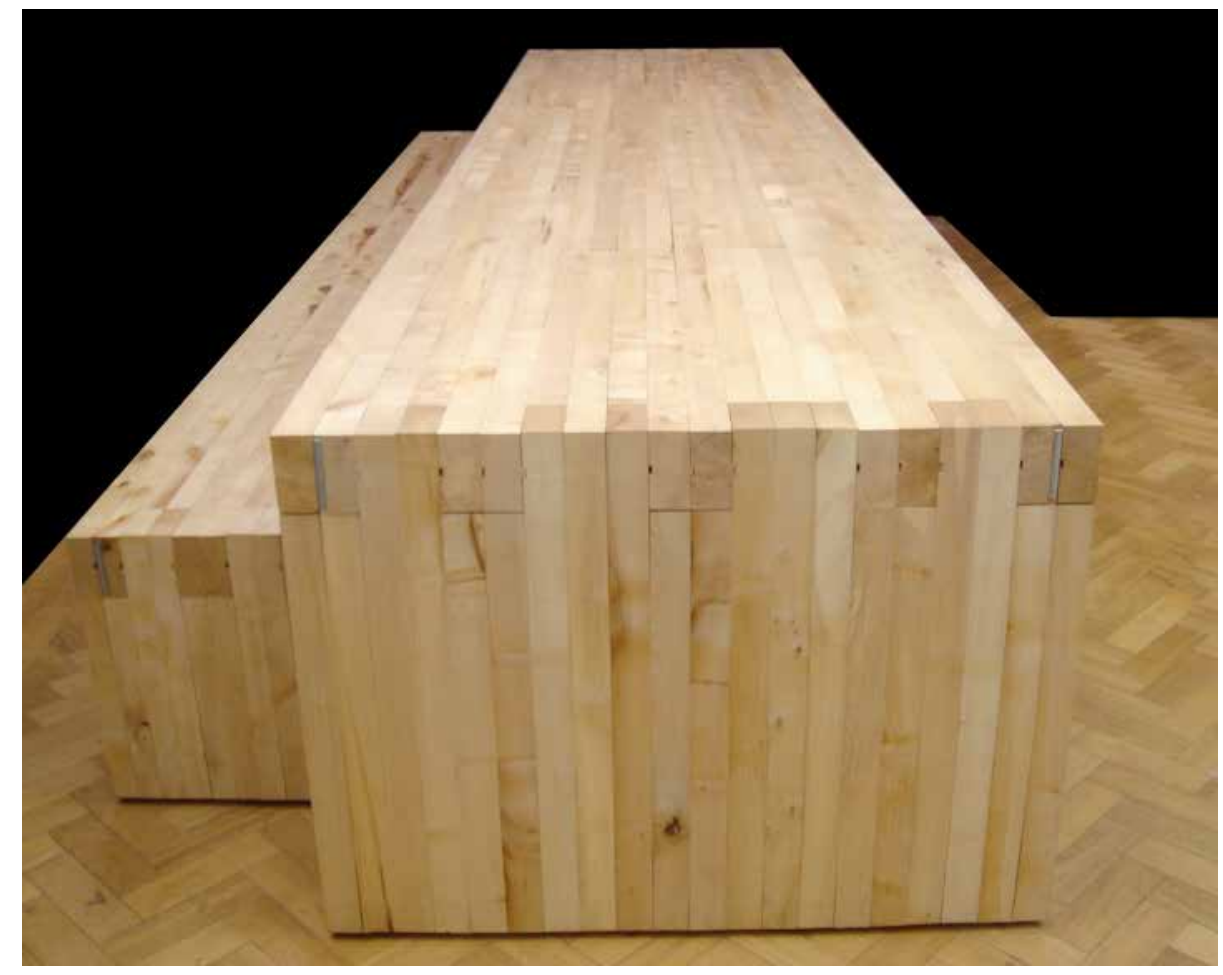

The brief was established as a culmination of the initial principle of timber panels, thoughts amongst the design team about affordable housing and the precedents.

It was clear from the precedent studies that the principles of a solid laminated timber construction system could benefit architectural design, construction and the Welsh timber industry through prefabrication and increased stability of timber. Initial development suggested that it may be possible to create a glue free, structural, solid core timber panel using a number of glue alternatives to generate friction between timber sections. It was therefore the intention that this prototype design study explore the following principles extracted from the precedents:

- Use the stress-laminated construction method of bridges as the basis of the construction;

- Use the design, detailing and on-site construction methods of CLT and brettstapel systems to inspire the architectural form and detail of the design;

- Use the Hiili Cafe's simple envelope to provide a conceptual architectural form or the design of the system; and

- Use the tectonic form and detail of the furniture examples as well as posing the possibility of using reclaimed/ recycled timber within the system.

Based on these criteria, the design brief emerged to explore the design and fabrication of a prototype refectory table and bench as a basic structural form that would closest resemble a domestic building envelope of walls and floors without the complications and costs of a 1:1 building mock-up. The table would be exhibited and used at the Welsh School of Architecture by staff and monitored to evaluate its design, structural and movement stability performance. 
The table was proposed for the staff meeting and refectory area for the Welsh School of Architecture, on the 2nd floor of the Bute Building. As a piece of furniture the location for installation provided the following practical parameters:

- The length of the table would be limited to $4.5 \mathrm{~m}$ in length;

- Access for delivery is via a small passenger lift, staircase and limited door widths

The wider intention was for the system to be used in the design of affordable housing in Wales, predominantly rural Wales. At the time of designing a site had not been identified to study the context, so it was the intention to consider the context of a remote location, considering the simple forms of traditional longhouses, terraced housing, agricultural and industrial buildings.

\subsubsection{Architectural intentions}

The design of the table as a prototype of the stress-lam construction system was initially based on the following principles:

- a simple generic form, inspired by CLT, that would form the structural basis of a building envelope;

- $\quad$ be tectonically honest in its materiality and construction;

- use Welsh-grown Douglas fir or larch, due to the better stability and higher strength performance than Sitka spruce, although spruce could also be considered;

- be a dry, mechanical, prefabricated panel system to construct building components, such as walls, floors and roofs; and

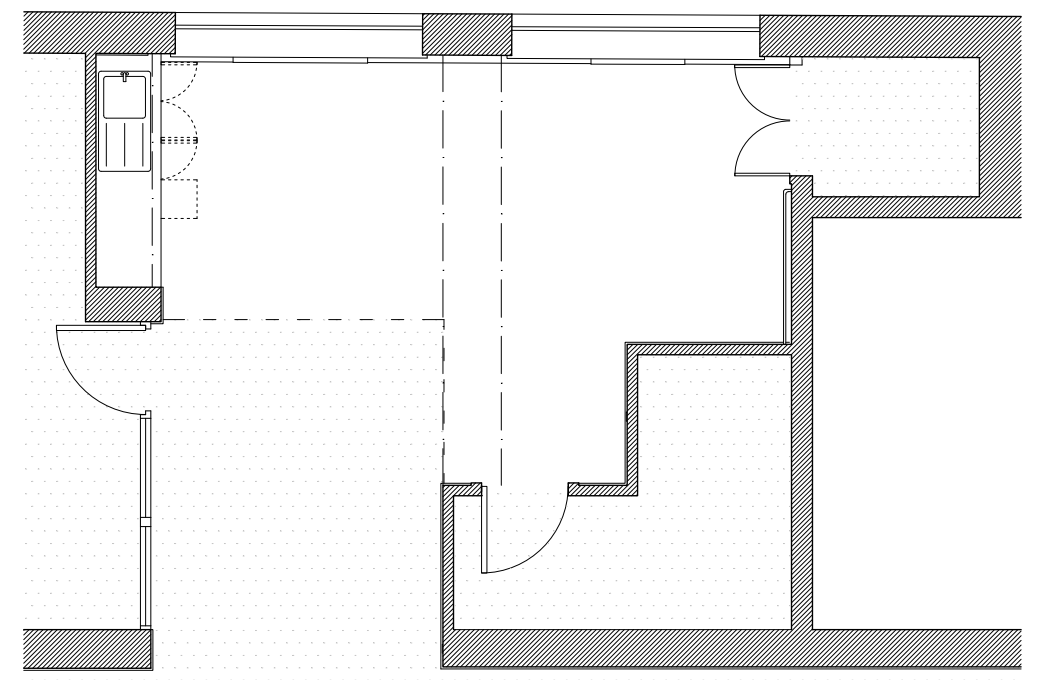

be easily produced using local, unskilled labour, and could therefore be used in remote, rural areas where access to machinery is not available.

As the project developed further, as a refectory table, aspects of ergonomics, functionalism and practicality inspired by an aspiration to keep all details, finishes and forms as rational as possible influenced the final design. Inspired by the mono material, personal scale, rectilinear forms of the traditional Welsh vernacular the table was designed to maximise the qualities of the chosen timber species combined with a rational logic without distractions or decoration. 

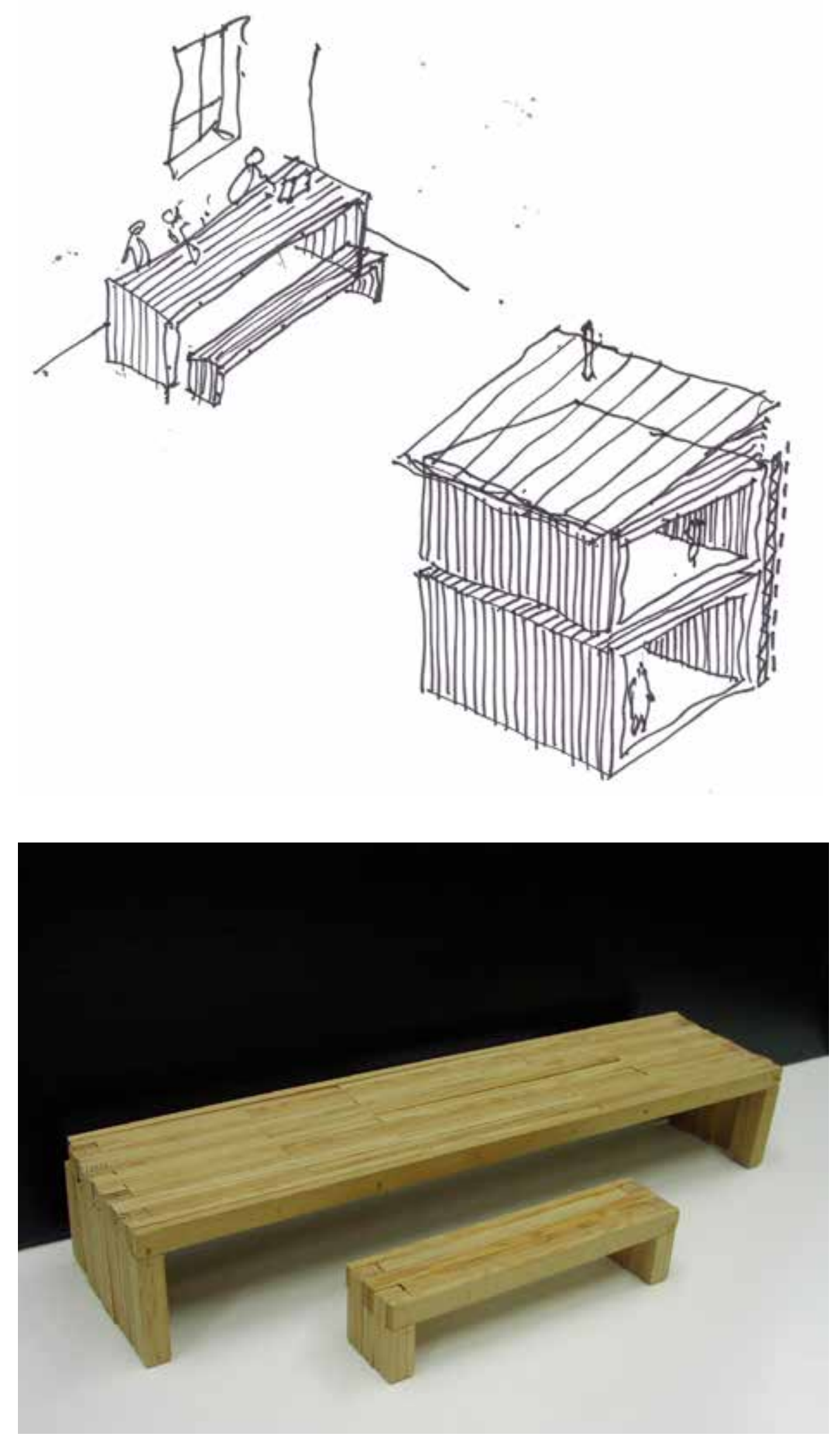

Fig 7.53 Concept sketches of table and stress-lam construction system Fig 7.54 Early development model
The design is essentially a generic building section, comprising two short walls and a roof - or two legs and a table top. The corners were detailed to express the intersection of the two planes by interlocking the lamella of the legs with the lamella of the table top. The principle would be that a fourth plane to represent ground or intermediate floor would be constructed in the same way as the table top or roof, but would not be constructed as part of the table.

As a table, the priority was principally with the structural performance and finish, however the intention was to consider stress-lam as a superstructure system within the building envelope. Based on an appraisal of affordable housing precedents and the Welsh Government's pattern book it was decided that the table prototype should be designed for an appropriate clear span for residential construction. This would be approximately $5 \mathrm{~m}$ for a terraced house spanning between party walls and would likely provide for the widest span required for a living room or master bedroom in semi- or detached dwellings.

The final design was limited to $4.3 \mathrm{~m}$ due to space limitations in the intended location. The proportions of the table were determined by a $300 \mathrm{~mm}$ layout and structural grid that would benefit the design of a building superstructure to coordinate with joinery and finishes. It was the initial intention that the grid would be used to both set the lengths of timber used for each lamella and also the spacing of the bolts.

Furthermore, it was the intention of this design to contribute towards a low energy building fabric prior to the inclusion of renewable technologies. The following principles were identified in the precedent studies as being directly influenced by the design and manufacture of stress-lam panels. While they will not necessarily be incorporated into the table design, consideration was given to how the structural design would integrate and meet these performance characteristics:

- Thermal mass and thermal bridging - The increased volume of timber in solid timber panels over lightweight stud framed panels provides a better thermal store and improved thermal stability providing the entire structure is externally insulated. While still some way off the performance of the thermal mass of heavy concrete and masonry construction, KLH market their product as a 'middleweight' providing a limited thermal buffer, but that solar orientation and air tightness are more important. However, solid timber construction does provide thermal bridging performance at junctions between elements. CLT panels by Crosslam and KLH have a thermal conductivity of $0.13 \mathrm{~W} / \mathrm{mK}$, combined with good insulation U-values of 0.20 
$\mathrm{W} / \mathrm{m} 2 \mathrm{~K}$ and below are achievable in wall thicknesses of $200 \mathrm{~mm}$ and greater. ${ }^{17}$ However the steel bolts in stress-lam will pose a significant thermal bridging effect that may require extra external insulation to minimise the risks of interstitial condensation especially where the ends of the bolts meet the external envelope.

- Air tightness - The factory controlled manufacture of CLT panels with glue sealing gaps between lamella means that the panels are inherently air tight although the fabric is still breathable. Stress-lam panels do not have the glue, however the introduction of a small tongue and groove between timbers may help to ensure that when compressed the air permeability of the joints should be as good as CLT. Consideration may be needed between bolt positions, as over time movement may lead to the opening up of hairline gaps between lamella. This could be reduced through the use of smaller panels taped and sealed at the joints and around openings rather than large wall, floor and roof sized panels. Air tightness levels of $3 \mathrm{~m} 3 / \mathrm{h} . \mathrm{m} 2$ should be achievable with good detailing at joints and an outer coverage of insulation without the need for specialist membranes.

-Woodfibre insulation - Insulating solid timber panel systems externally will reduce thermal bridging and improve air tightness. Standard, cost effective and thermally efficient products are expanded (EPS) and/ or extruded (XPS) polystyrene boards. However these boards are synthetic and would not allow the overall wall construction to breath. Alternatively mineral or glass fibre boards would provide the breathability although the poor compression ability of these boards creates difficulties in fixing battens and external cladding. However, it could be possible to use the waste timber from sawmills, defect cutting, planing and production of stress-lam panels to generate an integral woodfibre insulation product that could be pre-bonded to the stresslam panel.

- Embodied energy and carbon sequestration - Eurban estimate that a solid timber home contains 30 - 40m3 of timber. Welsh timber sourced, felled and processed local to market will have a low embodied energy compared to alternative masonry building materials. The stainless steel bolts will however have a significantly higher embodied energy than the timber, but in comparison to a steel frame building or the continuous cover of PVA glue between layers of CLT, the stress-lam method is likely to remain low in 

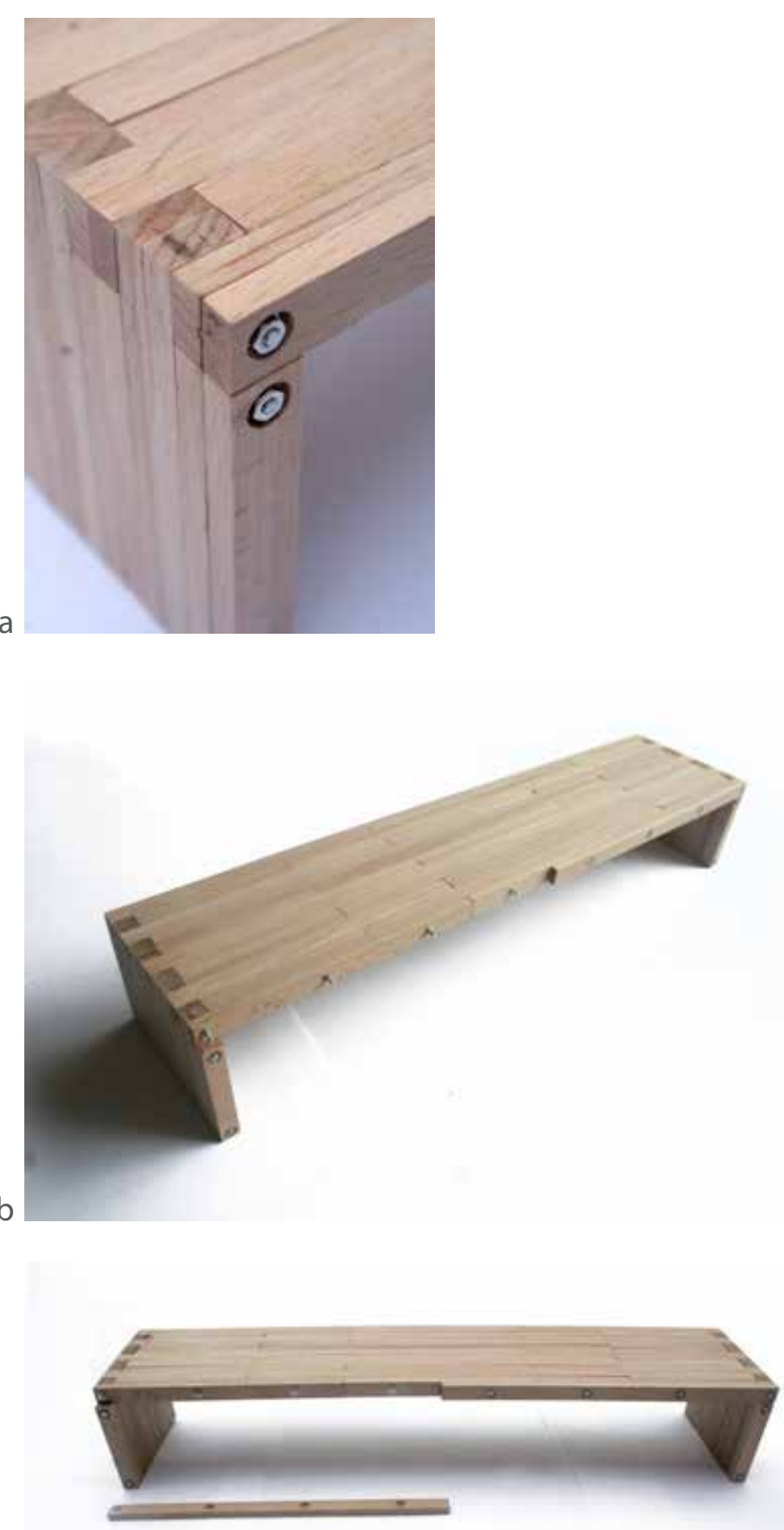

Fig 7.56 Final tectonic

model

a. Corner detail of bolt arrangement

b \& c. complete table model

with part of outer lamella

removed

d. Plan view of model and

lamella alignment comparison. Furthermore when considered in relation to the carbon taken out of the atmosphere by the tree and then stored in the timber structure, the overall stress-lam structure will be carbon negative to a greater degree than even a standard timber stud frame panel system with $60 \%$ more timber in a solid timber frame panel. KLH claim that $1 \mathrm{~m} 3$ of their panels will remove approximately 0.8 tonnes of carbon dioxide from the atmosphere equating to $240-250 \mathrm{Kg}$ of locked in carbon. ${ }^{18}$

\subsubsection{Final design}
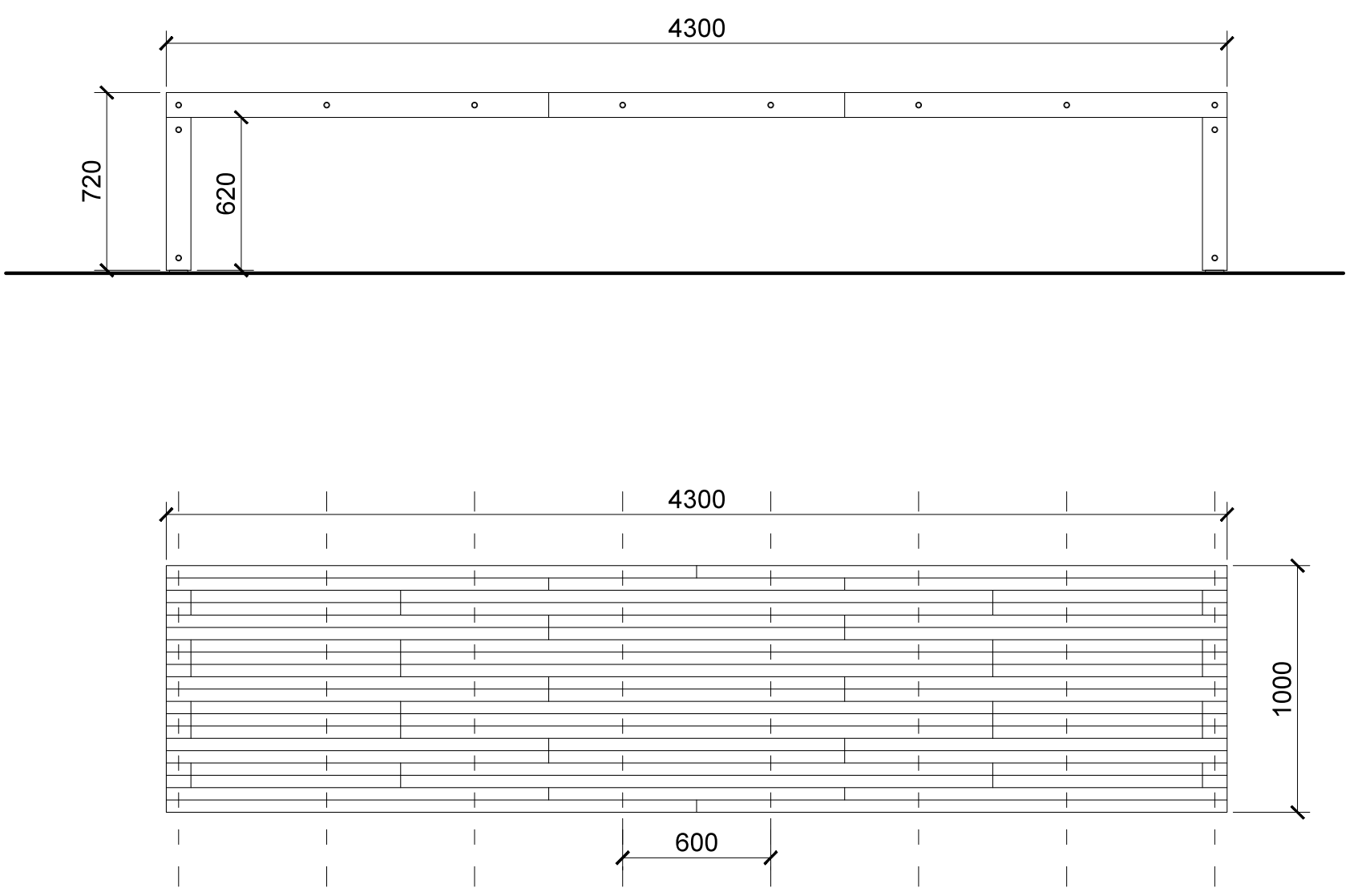

Fig 7.57 General arrangement plan and elevation highlighting bolting positions

18 KLH UK, Sustainability, (London: KLH UK), <http://www.klhuk.com/sustainability.aspx> [Accessed 15th July 2015] 

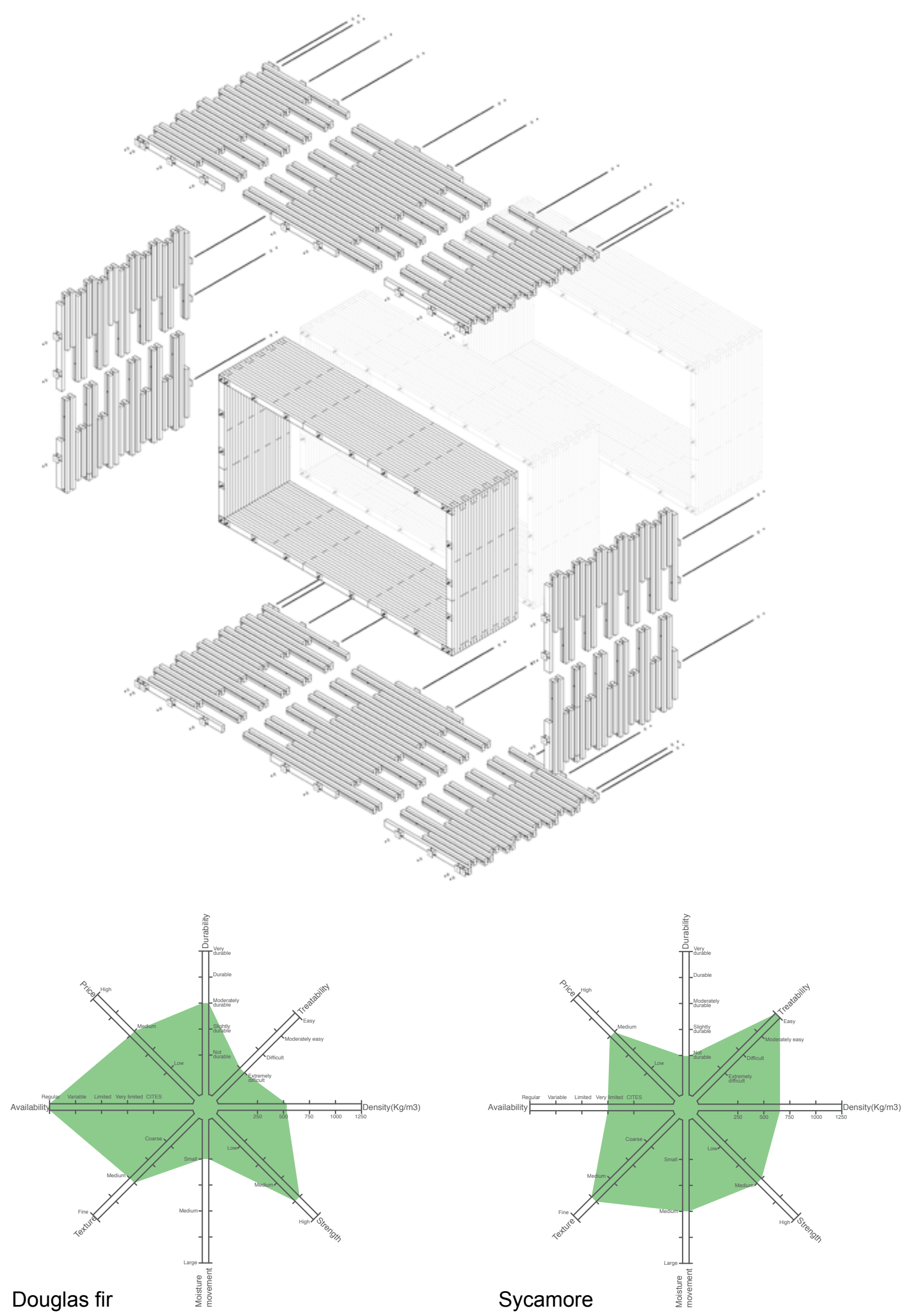

Fig 7.58 Exploded axonometric of stress-lam construction Fig 7.59 Timber species: Douglas fir and Sycamore

\subsubsection{Prototype}

\subsubsection{Detailed design}

The principle of stress-lam construction is simple: where CLT uses glue to hold the timber together and distribute loads across the panel; stress-lam uses friction generated through compression to counterbalance the level of compression on the top and tension on the underside of the panel. This cross panel compression could be achieved by using screws or nails connecting each lamella together and cables or rope post tensioned across the full width of the panel, however it was decided on the basis of the bridge designs that M12, A4 stainless steel threaded rod would be used at $600 \mathrm{~mm}$ centres. The mechanical fixings would enable a relatively unskilled, dry fabrication process that reduces the need for post-press planing to remove excess glue. It also allows for ease of disassembly, if required, which would not be possible by using screws, coach bolts or nails. The no-glue, minimal machinery and elemental processes mean that fabrication is limited to cutting, planing and drilling while assembly and construction on-site is limited to manual labour and bolting. This notion of building simply and low-tech approach is in keeping with the skills and plant available in Wales. It allows the system to be made by a wider audience with basic carpentry skills to low costs, adding value to the forest products, and potentially in 'flying factories' that are set up and relocated as and where they are required.

During an early consultation with the joiner at the workshop and sawmill, it was decided to replace Douglas fir with Welsh grown sycamore for the prototype table. The uniform colour and grain across both the tangential and longitudinal surfaces as well as the surface hardness were decided as more appropriate for interior joinery that would be used several times a day, every week for many years. However a further consideration of the properties of sycamore and Douglas fir revealed that while this prototype would use hardwood, the performance of the table as an example of a softwood construction system would not be too different. While sycamore has a higher strength performance, similar to oak, the sycamore is also $100 \mathrm{Kg} / \mathrm{m} 3$ more dense than Douglas fir. Douglas fir, on the other hand, has the potential for the highest strength grades of the Welsh-grown softwoods at C24. On a weight strength ratio the two species would not necessarily differ that much in the sizing and structural performance of the table. Issues related to differences in durability, grain and treatability would not be of relevance to this design, however the most significant difference between the species that would affect the table was with moisture movement. Sycamore is more susceptible to movement on drying than Douglas fir. It could therefore be assumed that a Douglas fir version of the table with the same moisture content may fare better than the sycamore table during use. 

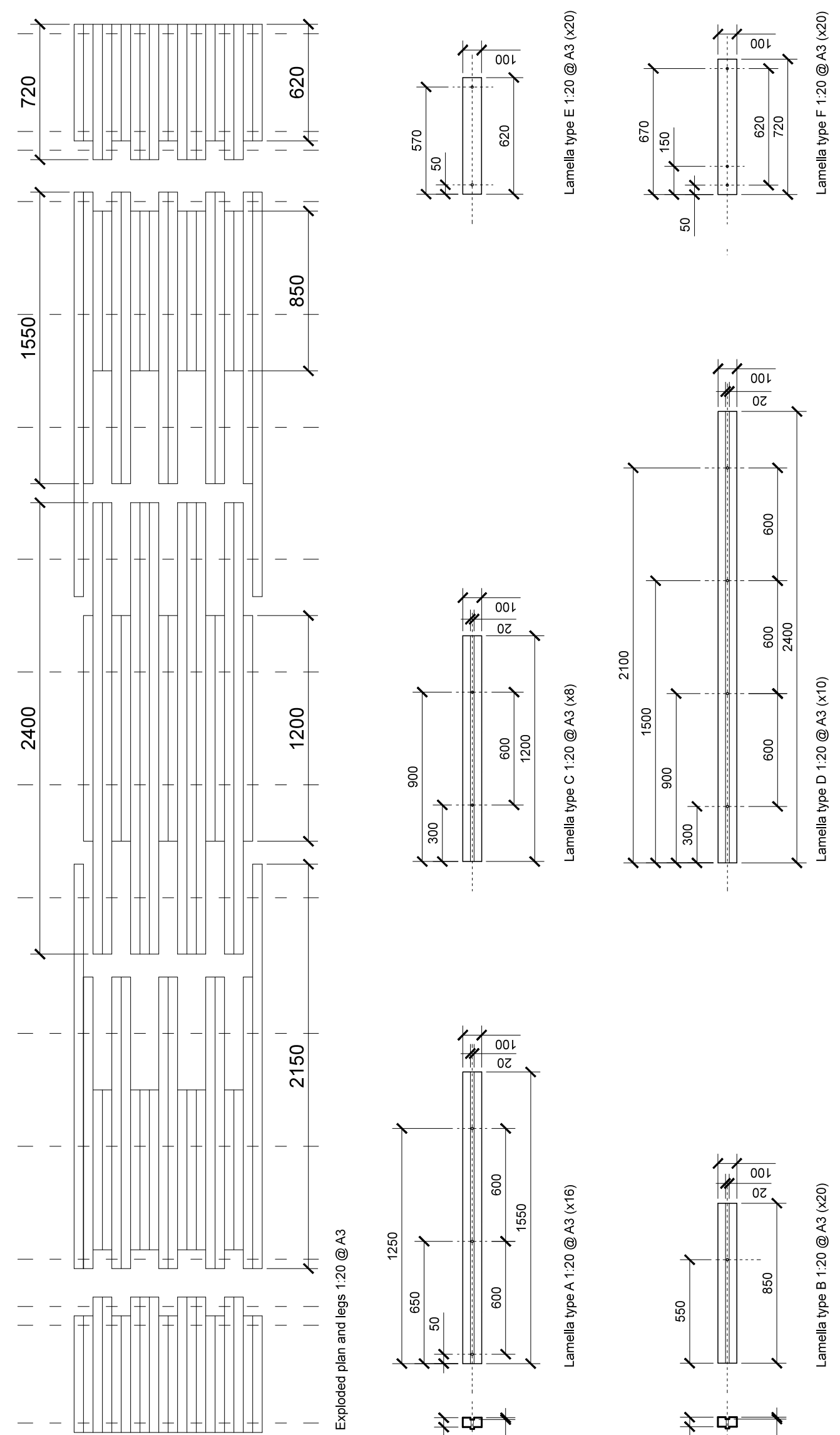

이
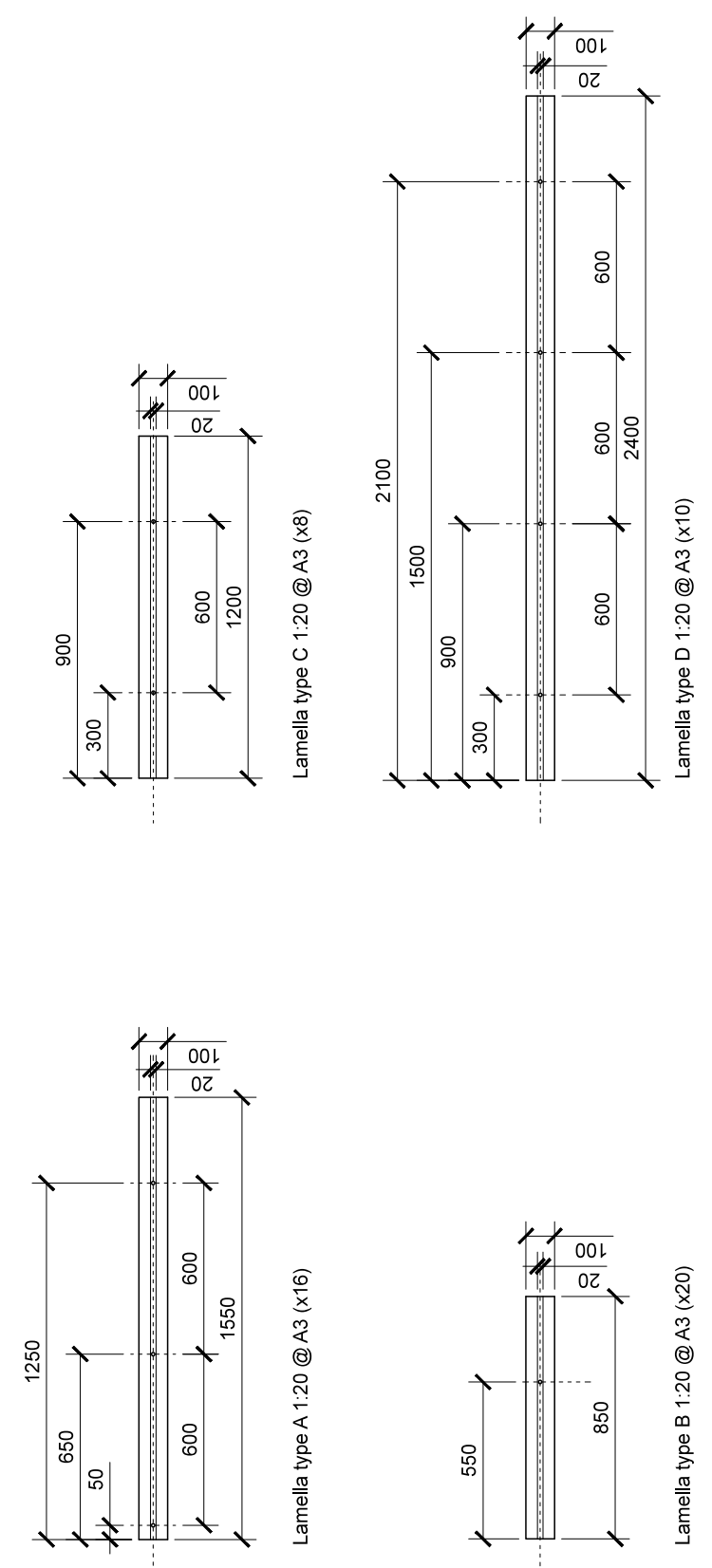

\%

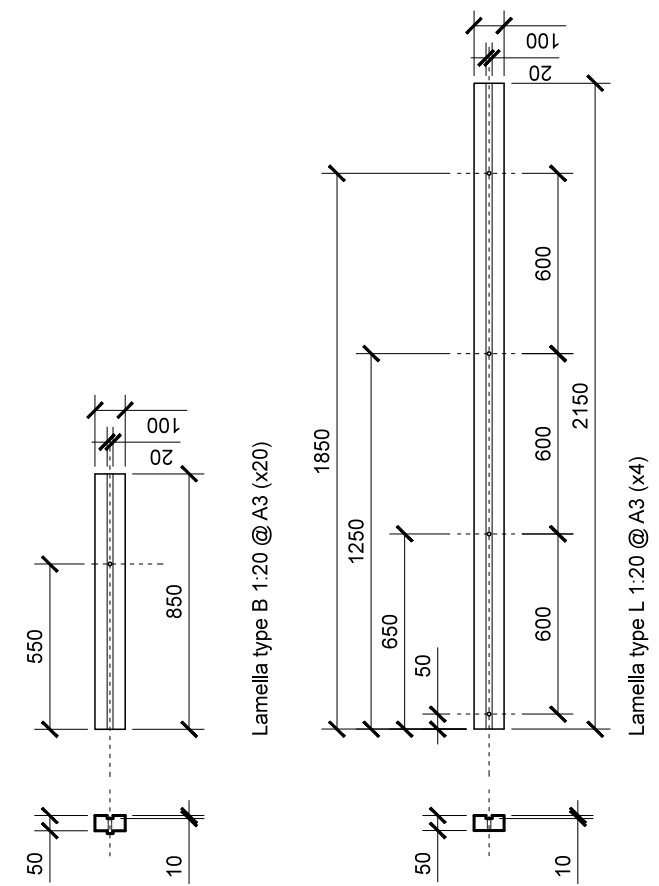

Fig 7.60 Fabrication drawing of lamella types
The final design uses $18 \mathrm{no} .50 \mathrm{~mm} \times 100 \mathrm{~mm}$ timber lamella bolted together over a $900 \mathrm{~mm}$ width at $600 \mathrm{~mm}$ centres with the lamellae arranged in a finger jointed arrangement across the surface. As the span of the table top is made up from three lengths of timber, it was possible to use $1200 \mathrm{~mm}$ and $2400 \mathrm{~mm}$ lengths within the central section of the table, while the timber that engaged with the legs would be $1550 \mathrm{~mm}$ and $850 \mathrm{~mm}$ long. The leg timbers would be $620 \mathrm{~mm}$ and $720 \mathrm{~mm}$ high.

This primarily took into account the proportions of the room that the table was to be located and the need for a minimum of $50 \mathrm{~mm}$ between a bolt and the edge of the timber. To compare the performance of the composite table with the majority of timber held in suspension over the floor, it was also decided to fabricate a bench with the top made from continuous $3600 \mathrm{~mm}$ lengths of timber spanning the entire length between $450 \mathrm{~mm}$ legs rather than many shorter lengths.

The table and bench would be finished using a low-VOC content, clear OSMO oil for surface protection of the table. As a superstructure for residential construction the panels would require fire protection. This could be achieved in one of two ways:

- a single or double layer of $12.5 \mathrm{~mm}$ plasterboard on the internal face to provide 30 or 60 minutes of fire protection as required; or

- to be impregnated with a flame retardant or surface treated with an intumescent varnish or paint to reduce the internal spread of flames and slow the rate of burning of the structure.

Either are viable options, however it was the design intention to maintain an elemental, layer free, tectonically 'honest' approach to construction while expressing the aesthetic and tactile qualities of timber as experienced in the timber architecture of the Vorarlberg, Austria.

\subsubsection{Engineering}

The sizing of components was developed in collaboration with a structural engineer and the joiner. It was not possible for the structural engineers to fully calculate and predict the performance of the structure without 1:1 physical modelling and destructive testing under various loading conditions. As this was not possible within budget and timescales, the engineers provided sizes based on a required compression force needed to create enough friction between the lamellae to support the dead weight of the table plus extra for limited live loads. With this in mind, informed decisions were made by the joiners' knowledge of timber and judgement on the appropriate sizing based on proportion and the spanning distance of the timber in normal use. 

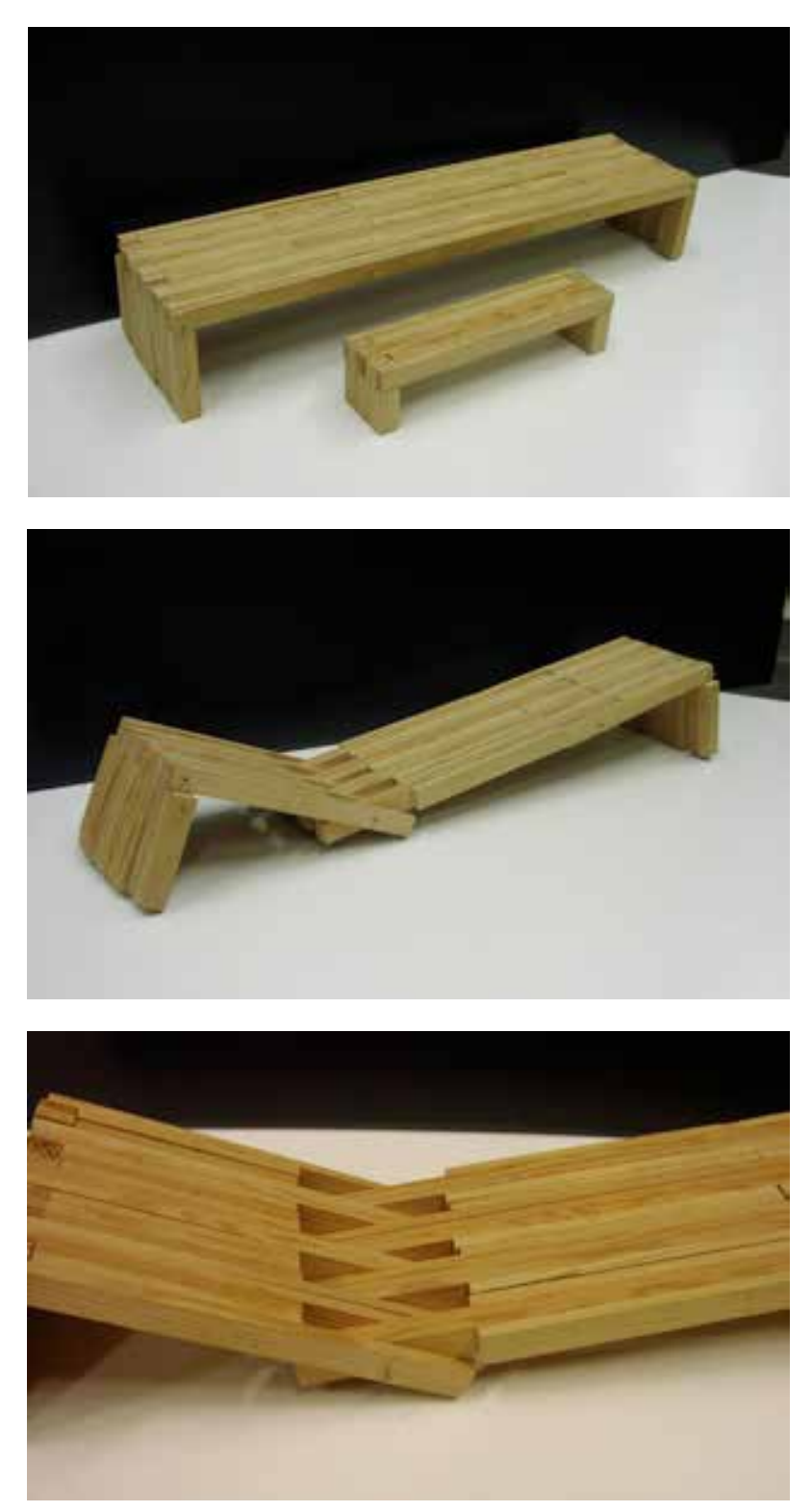

LEFT

Fig 7.61 Model to test rotational movement around single bolt through finger jointed lamella

BELOW

Fig 7.62 Dogtooth washer

Fig 7.63 Dogtooth washer between lamella to

provide rotation resistance

RIGHT

Fig 7.64 Exploded section through lamella
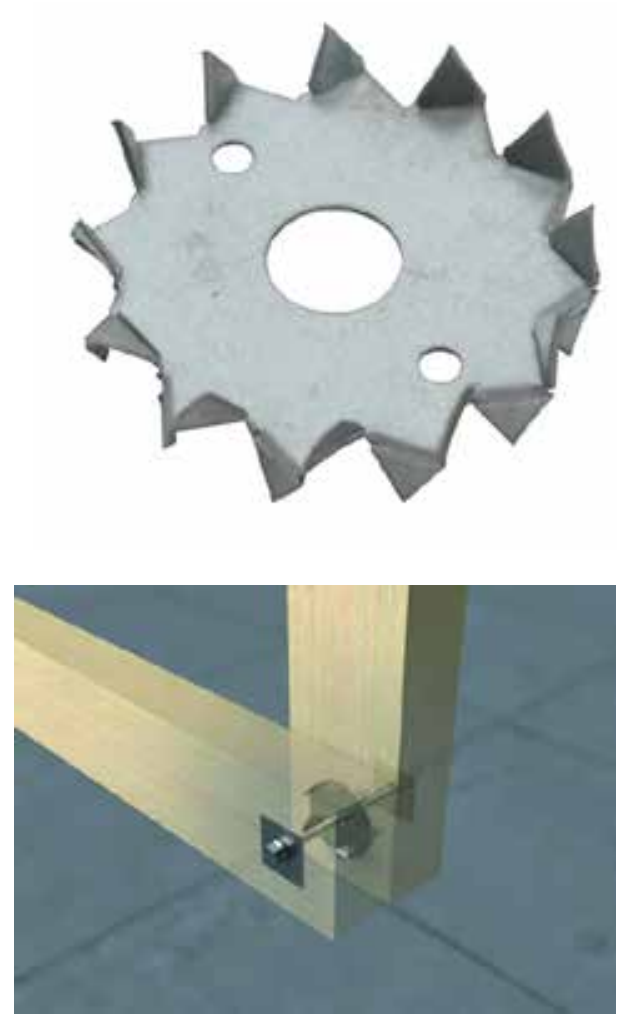

M12 stainless steel threaded rod, penny washers and nuts were chosen to pass

through the $900 \mathrm{~mm}$ width of the panel and tightened. However, two problems were realised:

1. The compression required would risk localised crushing of the outer lamella. This was avoided by the use of $90 \mathrm{~mm} \times 90 \mathrm{~mm} \times 10 \mathrm{~mm}$ stainless steel bearing plates rebated into the outer lamella on both sides of the table. The bearing plate also helped to distribute the compression through a wider zone of the table than just the bolt and washer would have done.

2. There was a significant risk that rotational movement would occur around the bolt that connected two separate lamella across the table surface as it was intended for only one bolt to pass through the arrangement of finger jointed lamellae to maintain the $600 \mathrm{~mm}$ bolt spacing. The first suggestion was to introduce a locating rod $200 \mathrm{~mm}$ from the bolt to lock the timbers and stop the rotation. The structural engineers suggested the use of double-sided 'dog tooth' washers between the lamella that would change the simplicity of the design and fabrication process and that the table should be fabricated with a shallow tongue and groove, for locating purposes, offering rotational resistance along with the compression of the bolts.

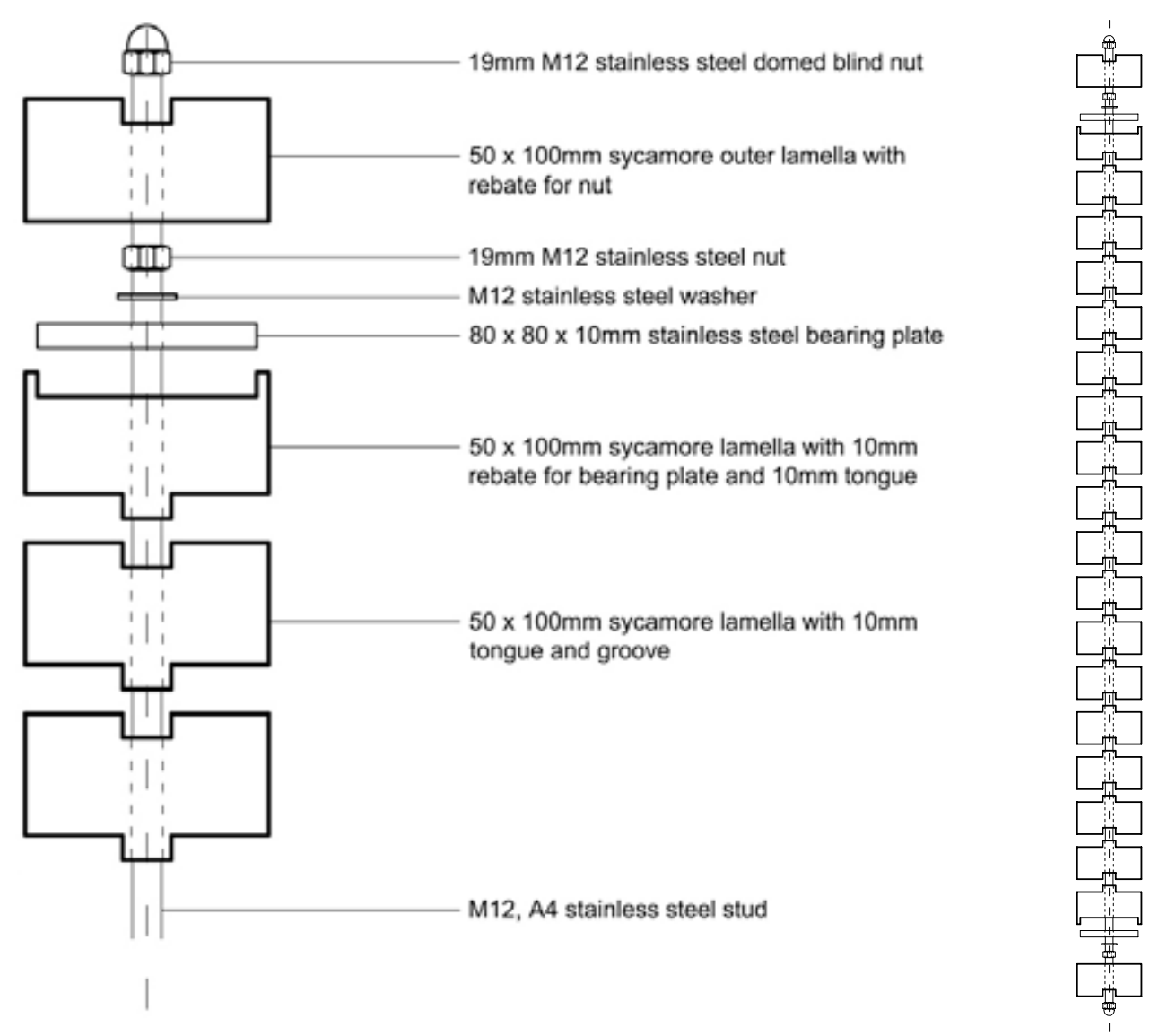



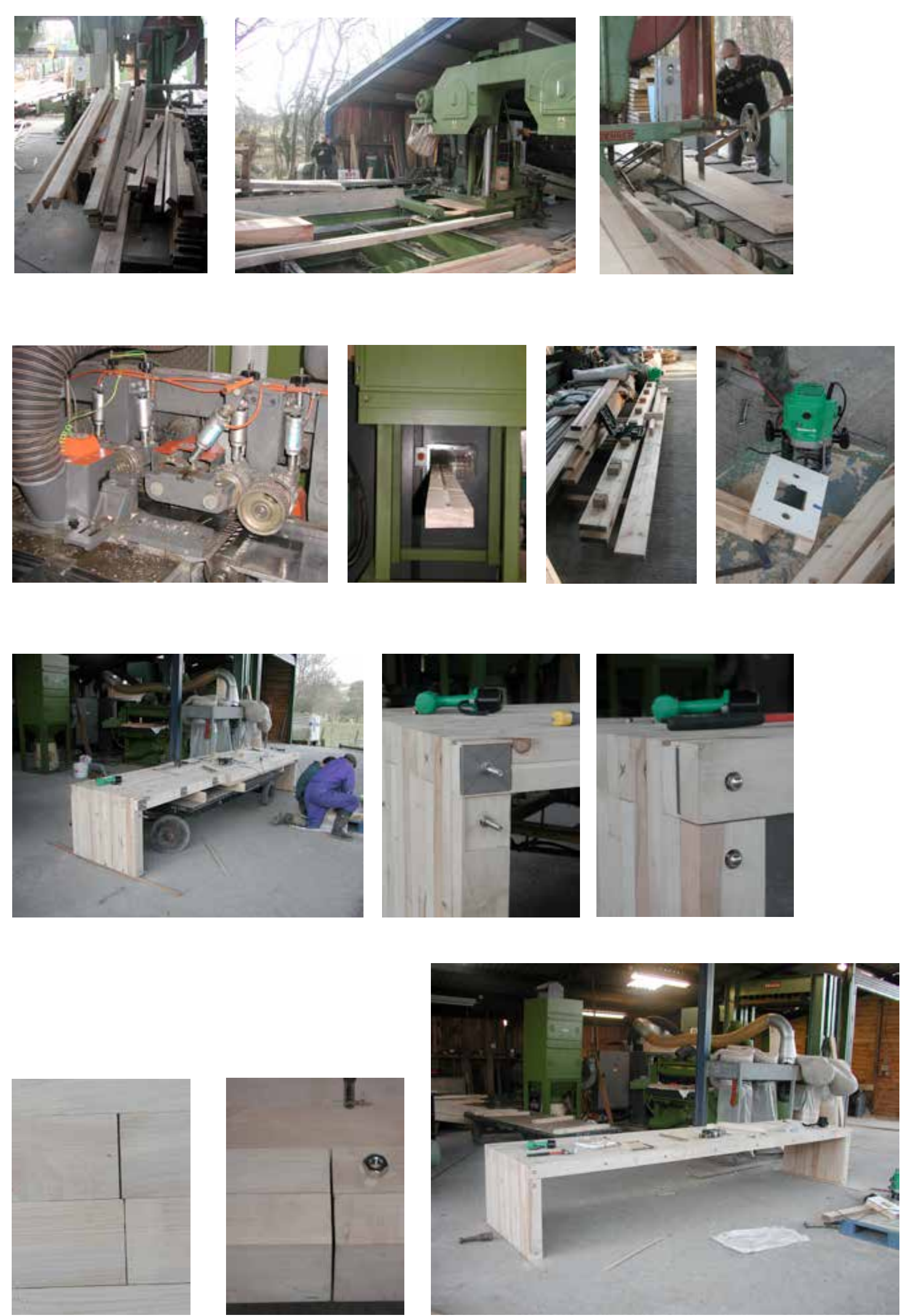

Fig 7.65 Fabrication process photos at workshop in Builth Wells

\section{Fabrication}

The table was fabricated at a small sawmill and joinery workshop near Builth Wells, before being transported to Cardiff for installation. The following photographs and captions describe a low-tech fabrication process:

- The sycamore roundwood was plain sawn into large boards approximately 50 $60 \mathrm{~mm}$ thick and air dried to a moisture content of approximately $18 \%$.

- The boards were cut on an industrial band saw to just over $100 \mathrm{~mm}$ width. Wastage was minimised wherever possible, with offcuts used as fuel for the workshop and adjoining house.

- The slightly oversized boards were passed through a combined thicknesser, planer and moulder to reduce the timber to the exact $50 \mathrm{~mm} \times 100 \mathrm{~mm}$ section size and profile the $5 \mathrm{~mm} \times 10 \mathrm{~mm}$ tongue and groove in one action.

- Jigs were prepared from spruce and oak for the drilling of the threaded rod holes at $600 \mathrm{~mm}$ centres. Each lamella was positioned in the jig using a common datum to ensure the holes were accurately positioned. A timber jig was used for this project to keep costs down but it was acknowledged that a steel jig would be better for larger and more regular use. A further jig was fabricated from plastic for the routing of the bearing plate rebates.

- Once the timber had been planed and profiled the lamella were cut to length, drilled and routed as per drawings of each lamella type.

- The table was constructed at the workshop to test the tolerances and structural performance. A trolley was positioned underneath the table to support and maintain a level surface during assembly prior to the post stressing of the bolts.

- It was decided during fabrication that the exposed threaded rod and nuts posed a risk to snagging clothing and arms while being used as a table. Cover lamella were positioned over the excess threaded rod and fixed using blind domed nuts thus increasing the overall table width to $1000 \mathrm{~mm}$. It would not be the intention to use cover lamella as a superstructure system.

- The first assembly revealed some tolerance issues between lengths of lamella. Gaps and differing alignments were highlighted at the butt joints across the surface. While this was more problematic for the appearance of a table than for a superstructure panel it was acknowledged that it may be an air tightness problem. However, following further adjustment, re positioning of specific lamellae and tightening, the gaps were significantly reduced.

- The table was dismantled at the workshop into 5 pieces: 2 no. legs and 3 no. table top pieces with the $\mathrm{t} \& \mathrm{~g}$ used to help keep the separated panels together while not bolted top one another 

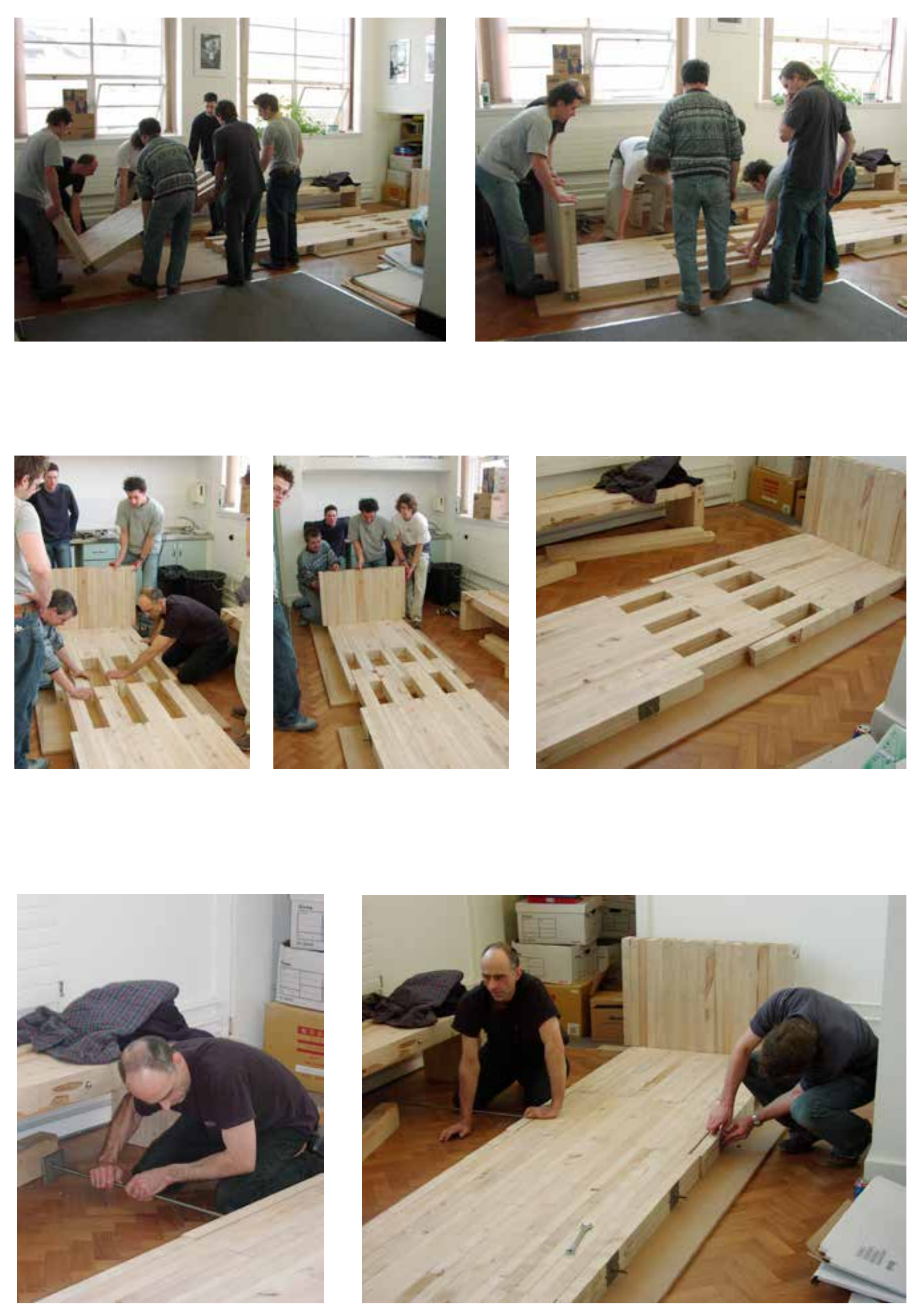

Fig 7.66 Installation sequence photos in Bute building

\section{Installation}

The table was delivered to the Bute Building, Cardiff in the 5 pieces and assembled as the finished refectory table in the following sequence:

- Each table piece was manually carried up to the 2 nd floor of the Bute building and positioned upside-down in the staff kitchen area by 4 members of staff and students of the Welsh School of Architecture.

- The legs were slotted into the appropriate table top ends, bolted and tightened.

- The two ends of the table were aligned on sheets of MDF, to allow the pieces to slide easily and without risk of damage, slotted together with the middle panel.

- Threaded rods were pushed through the two aligned holes and tightened with the bearing plates, washers and nuts.

- The assembled $400 \mathrm{Kg}$ table was turned over by 10 members of staff and students.

- The cover lamella and blind domed nuts were attached.

- The table was planed to create a smooth surface.

- During installation, it was decided that the table should be raised from the parquet flooring, of the WSA staff kitchen area, by $10 \mathrm{~mm}$ to separate materials but also allow the legs to appear as an extrusion that would continue if not limited by the ergonomics of a table.
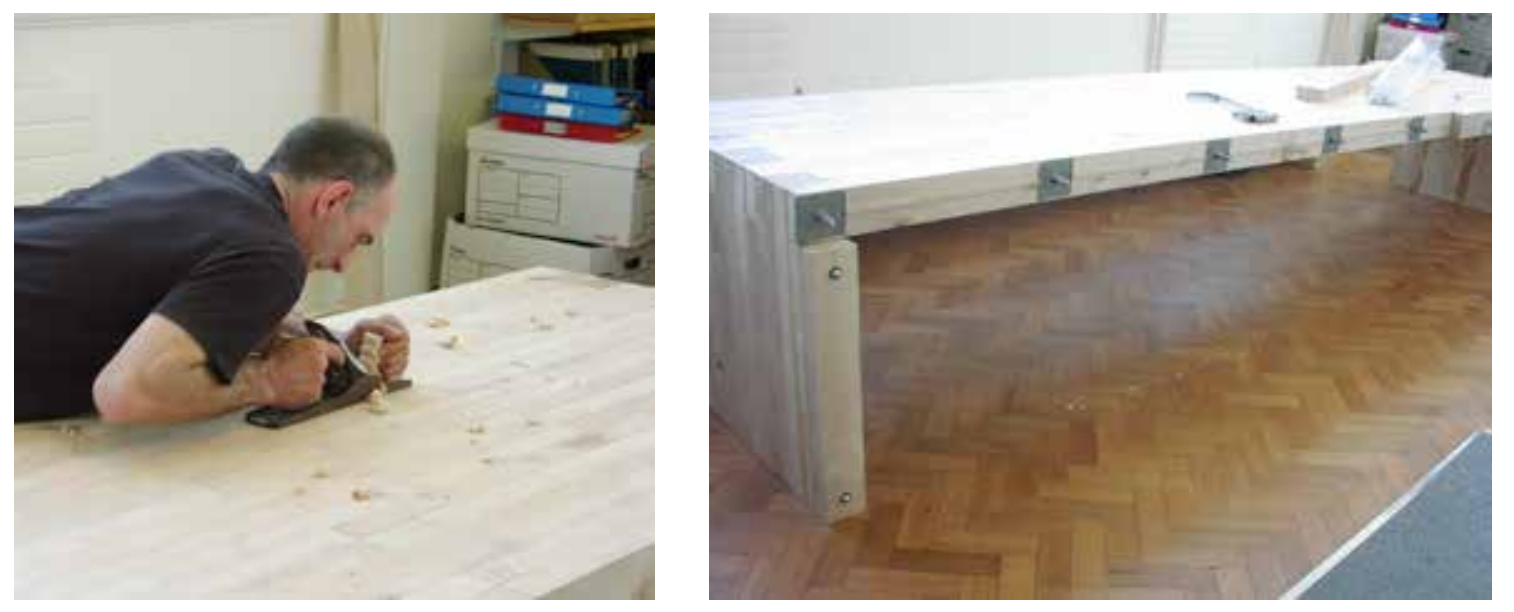

Fig 7.67 Post assembly finishing details 

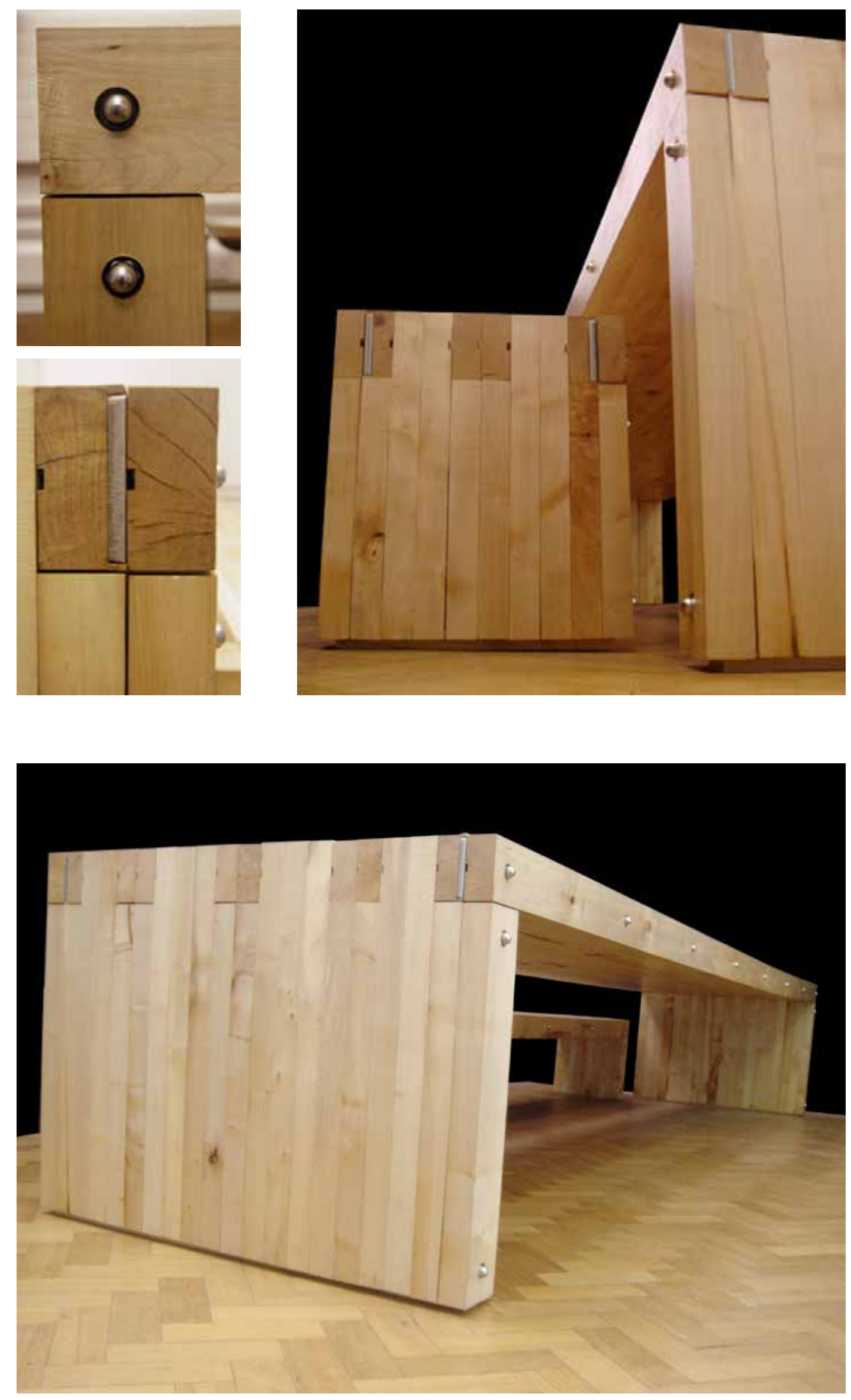

The table was completed in February 2004. The table was recorded and submitted for the Wood Awards 2004, published as a short paper in the MADE at Welsh Schoo of Architecture annual journal and presented at the Tectonics Making Meaning conference, in Eindhoven 2007, as part of a paper on Timber Tectonics.
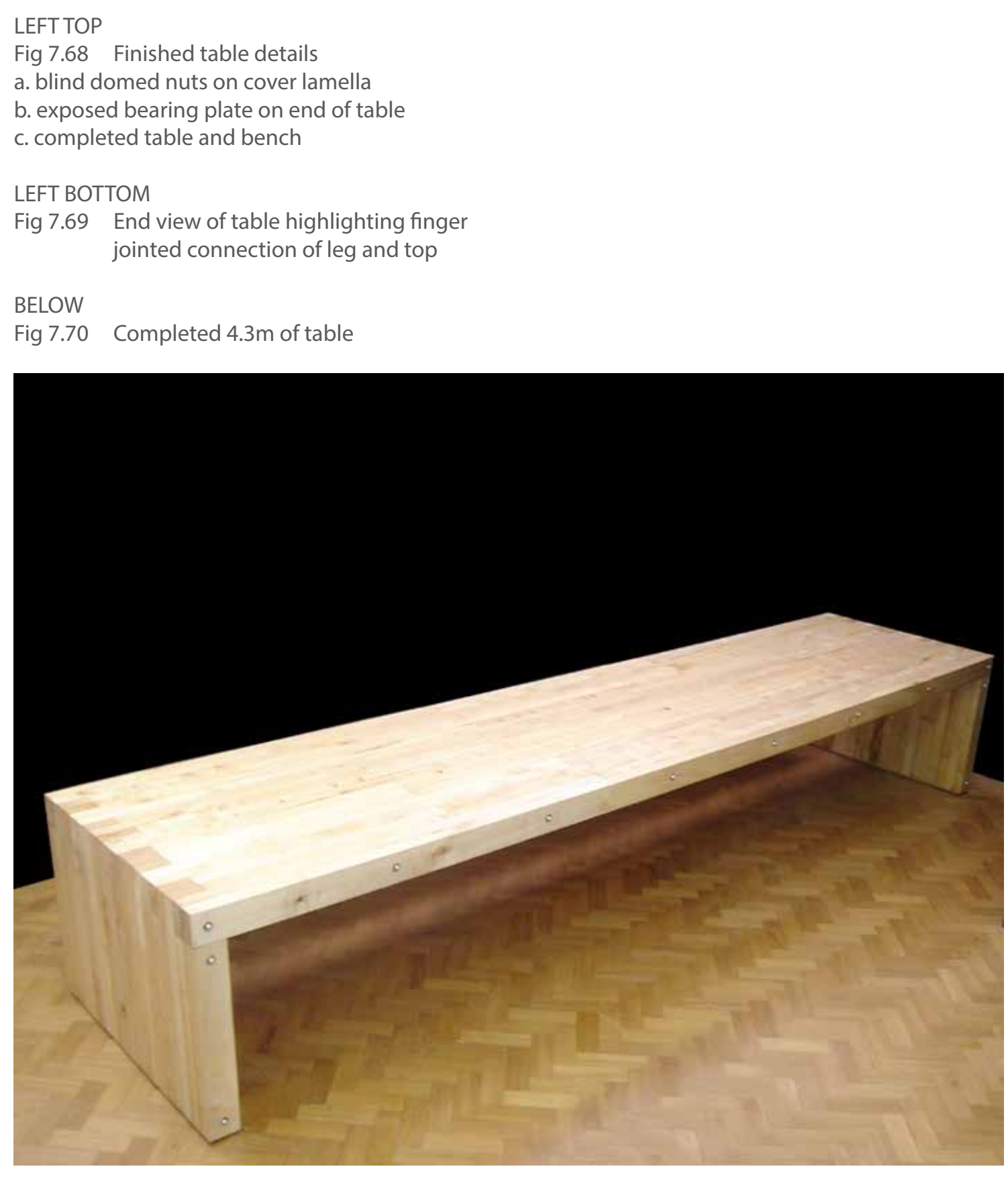

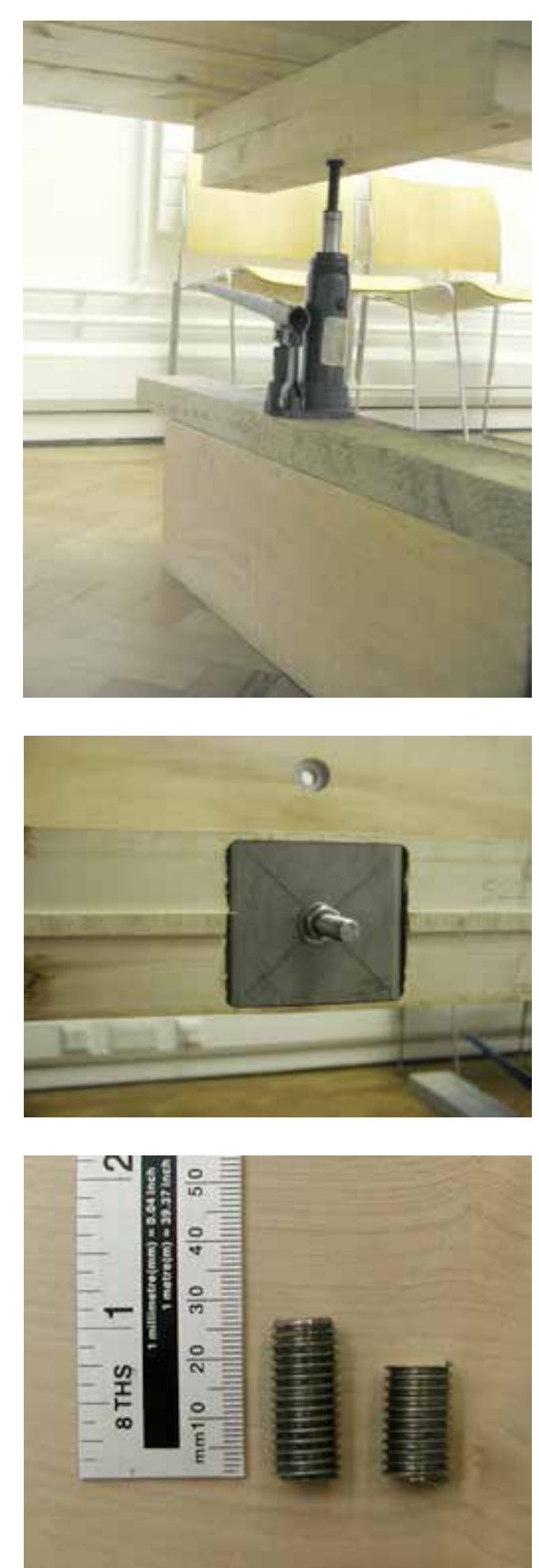

Fig 7.71 Table supported while the bolts were re-tightened, cut to the new length and the top re-planed to take out unevenness created by the movement.

\subsubsection{Observations and reflections}

The stress-laminated table has been used every day since 2004. It has been a success in terms of its required function as a refectory table bringing staff together for informal meetings and lunches. It has also provoked conversation, debate and awareness of timber design within the Welsh School of Architecture and amongst external critics as they visit the school.

The table was installed during the winter near to occupied offices with the building central heating on during working hours. As the table had been installed adjacent to 2 radiators, the table was subjected to uniform heat and therefore artificial and accelerated drying from one side. This resulted in the sycamore drying from approximately $18 \%$ moisture content to approximately $10-12 \%$ moisture content in a short period of time. A month after installation it was recorded that the sycamore lamella had shrunk by up to $2 \mathrm{~mm}$ each across the width resulting in an overall shrinkage of up to $30 \mathrm{~mm}$, this caused some lamella to bow and twist along the length resulting in a visual sag. To rectify this, the table was jacked up and supported while the bolts were re-tightened, cut to the new length and the top re-planed to take out unevenness created by the movement. Following this initial settlement and adjustment, further movement has resulted in a permanent 'sag', although structurally the table has required little maintenance over 11 years.

It is worth noting in relation to this that stress laminated bridge decks are often re-tightened during routine maintenance, although this would not normally be expected after 1 month. In Europe the technique adopted has been to install the laminates at a moisture content lower than the mean ambient conditions. The subsequent swelling of the wood due to hygroscopicity then counteracts the creep losses in clamping force. This makes it possible to re-tighten within the first year after installation and then not for another 4-6 years before further re-tightening becomes necessary.

The design and fabrication process, use, performance and critical opinion of the table is now reflected on as both a piece of furniture and in the wider context of a construction system for affordable housing. The reflections are made against the overall thesis objectives, set out in the methodology, and tabulated.

\subsubsection{Species performance and adaptation}

\section{SPECIES}

- The table was built from sycamore rather than a softwood such as Douglas fir or larch. As a result the table is slightly more durable from surface damage, 
but further prototypes would be required from alternative species to test structural capacity, movement stability, weight and appearance.

- The comparisons between the species were highlighted as offering a comparable strength to weight ratio although the significant issue with the table has been related to moisture movement. It should also be noted that Welsh-grown timber does not always perform to expected characteristics.

- The table was fabricated using sycamore with a moisture content appropriate for external use. The movement may therefore not be as significant if used for housing superstructure with time to adjust and settle on site before being subjected to interior heating. The experience of stress-laminated bridge manufacture should also be considered in using timber with a lower moisture content than will be expected in the ambient conditions. $\mathrm{KLH}$, a manufacturer of CLT panels for domestic construction, kiln dry their softwood to $12 \%$ $+/-2 \% .{ }^{19}$

- The nature of the construction system means that Welsh-grown timber could be incorporated by utilising defect cut timber of different lengths, reclaimed timber or even a variety of species.

\section{TIMBER ADAPTATION}

- As a means to utilise more Welsh-grown softwood and the large quantities of strands, pulp and dust produced by the industry it may be possible to consider LVL or PSL as alternatives to the solid timber lengths, these could be manufactured to bespoke lengths that would reduce the number of junctions between standardised lengths although the scale of investment required may be prohibitive.

\subsubsection{Building envelope}

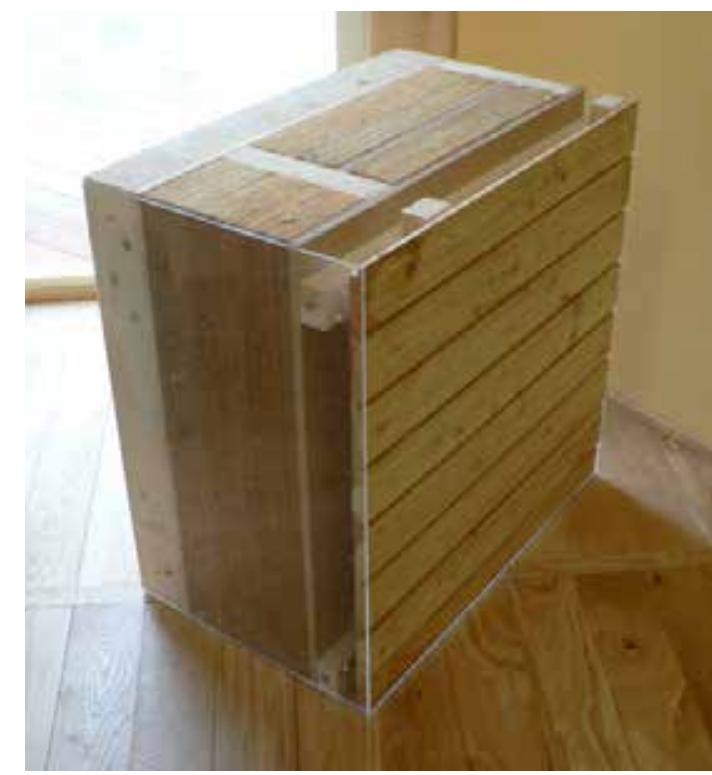

\section{SUPERSTRUCTURE}

- For this prototype, the building envelope is assumed as the table structure of 2 legs or walls and a top, floor or roof. Structurally the system has performed to its design requirements although further structural testing would be required to support residential scale loadings.

- The system may lend itself to panelised construction techniques as the load bearing structure and internal finish in-one, subject to fire protection. 


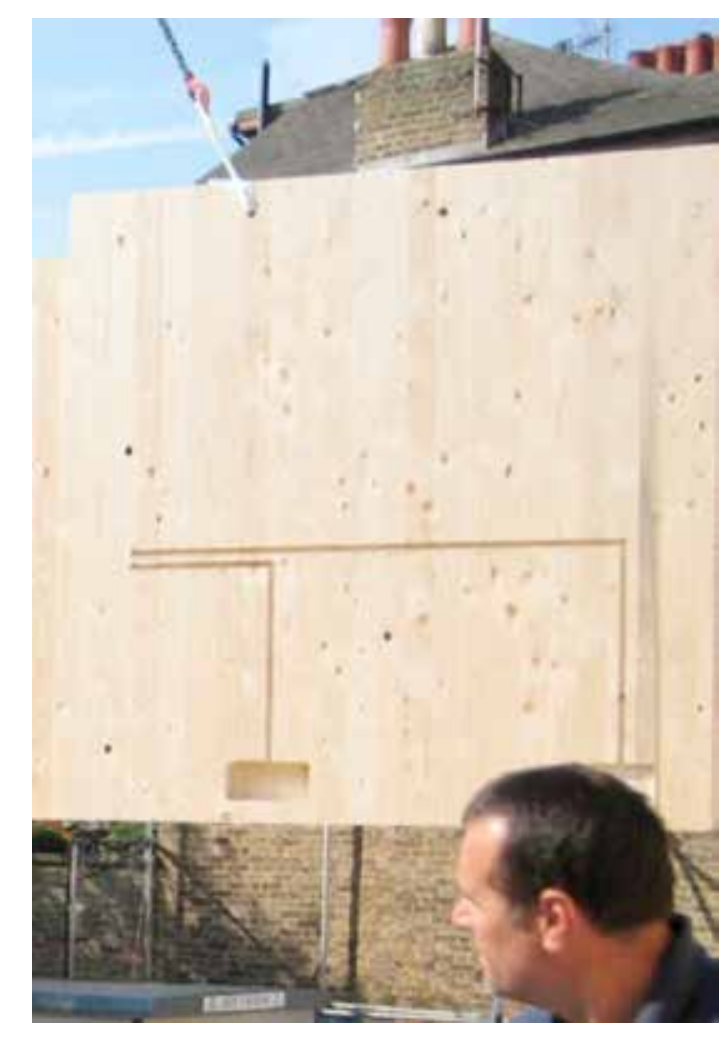

7.74 KLH board with timber services routed in
INTEGRATION WITH COMPLETE ENVELOPE

- As a housing system, the structure would need to be integrated with other layers of a complete building envelope: services, insulation, vapour barriers, breather membranes and internal and external finishes. The expected approach would be akin to that of CLT or brettstapel manufacturing where woodfibre insulation is pre-bonded to the panel, however further testing would be required on the performance of the structure and breathability of the fabric with a concern around the thermal bridging effect of the stainless steel within the timber.

- Openings could be cut into the panels on a $300 \mathrm{~mm}$ layout grid which complements standard door and window sizes. In theory the openings could be accommodated around the bolting positions with little affect on the overall structural integrity. Further testing would be required.

- Services could be manually or CNC routed into the interior surface if combined with another internal finish otherwise they would need to run in alternative voids or be surface mounted.

- The prototype table stands alone from other structural panels which would be fixed to it as a construction system. CLT and brettstapel panels are fixed using simple steel brackets and screws, however the integrated bolts of stress lam may cause problems when butt jointing and at corners. This would also make future maintenance difficult. Further research is required to investigate panel - panel configurations.

- There are questions over the stability, fixing and maintenance requirements of this form of system for use as superstructure within the building envelope. It does however, have potential for furniture or purely structural applications, such as bridges. It would be worth considering the development of CLT or brettstapel panels as a tried and tested alternative.

\section{PERFORMANCE REQUIREMENTS}

- The movement, due to a high moisture content on installation would be of concern in construction due to the impact this would have on other finishes, air tightness and insulation.

- $\quad$ Further testing and modelling would be required to consider the therma mass potential offered by an exposed solid timber panel, although it is possible that the system would be able to include other materials, either in wall or floor panels, to provide thermal mass as part of a complete autonomous house. 


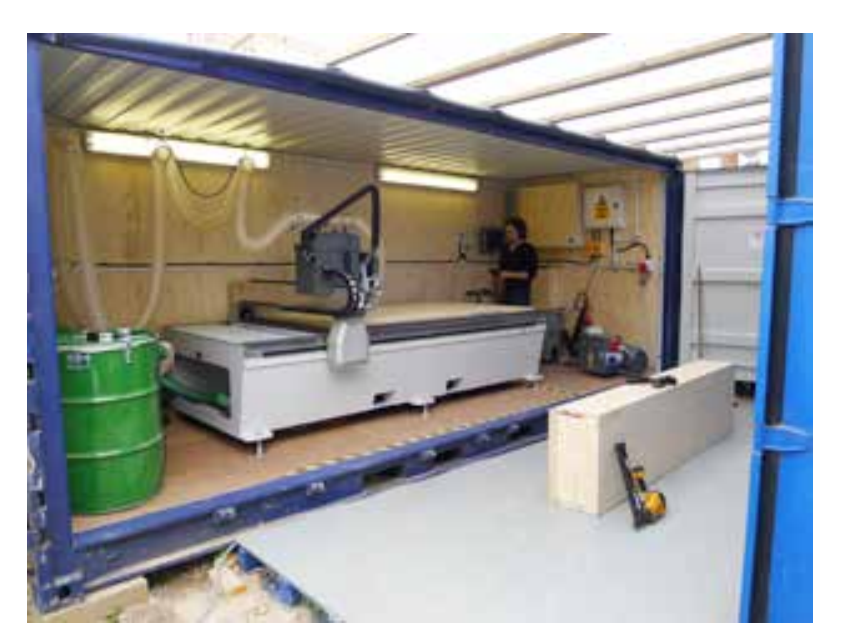

\subsubsection{Technology and skills}

Overall the level of technology and skills required suggest a potential for manufacturing stress-lam, but requires considerable research and development on the on-site construction process of larger scale prototypes, as observed:

\section{FABRICATION}

- The fabrication process was low-tech as intended, with limited skills and machinery required. This means the system could successfully be manufactured in the typical sawmill or workshop operating in Wales. A number of options are available to procure the components needed for even smaller workshops, such as ordering lengths of profiled, planed and square edged softwood ready for drilling and assembling.

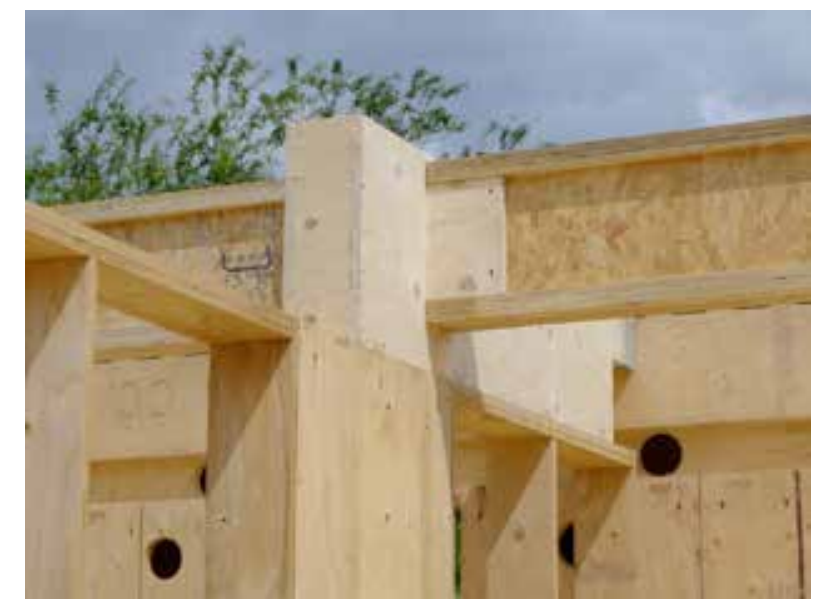

- The complexity was primarily limited to the accuracy required in cutting and drilling lamella to ensure precise tolerances when assembled. These tolerances were limited to the careful production of jigs and the use of a thicknesser, which are both standard processes in a carpenters or joiners wood workshop.

- The pre-drilled holes for the threaded rod were accurate to $+/-2 \mathrm{~mm}$, however over $18 \mathrm{no}$. lamella this produced an uneven top surface that required sanding and planing. This was a problem for a piece of furniture but may also lead to complications in applying other layers of the building envelope and fixing finishes. CLT panels are post planed after lamination using large-scale, specialist, flatbed machinery.

- The plant and skills required allows a simple on-site, temporary production line to be established for large scale production reducing overheads and eliminating transport limitations. Similar processes have been established by specialist CNC and laser cutting fabricators, such as Facit Homes.

- It was proposed by the structural engineers and evidenced during the adjustment of the table that the tongue and groove profiling has provided structural rigidity as well as alignment. This adds an extra process of manufacture requiring specialist machinery to profile the lamella, that may limit the application of a standardised, low-tech fabrication process. Further research is required to test the structural performance with and without the tongue and groove.

- The development of the design to consider lamella length and bolt hole centres meant that a standard jig could be produced to drill all lamella types for table or bench. The spruce and oak jig was worn beyond acceptable tolerances on completion of the prototype however it could be simply made more durable for large quantities, if the panels were to be fabricated on a components, FACIT Homes 
CONSTRUCTION

- Installation of the table was complex, due to its location on the 2nd floor and lack of lifting equipment. The process of prefabricating the table in 5 pieces meant that the table could be lifted by 6 people but the panels then needed to be slotted back together and bolted on-site before turning the table over. This would not be feasible for larger scale residential construction due to weight. Instead panels are more likely to be manufactured as complete wall or floor panels and limited to mechanical lifting requiring significant on site plant.

\subsubsection{Tectonic form}

The prototype table's simple form was inspired by the beauty of the sycamore in its straightforward sawn format, the basic efficiency of the bolted construction and the practicality and ergonomics of a piece of furniture.
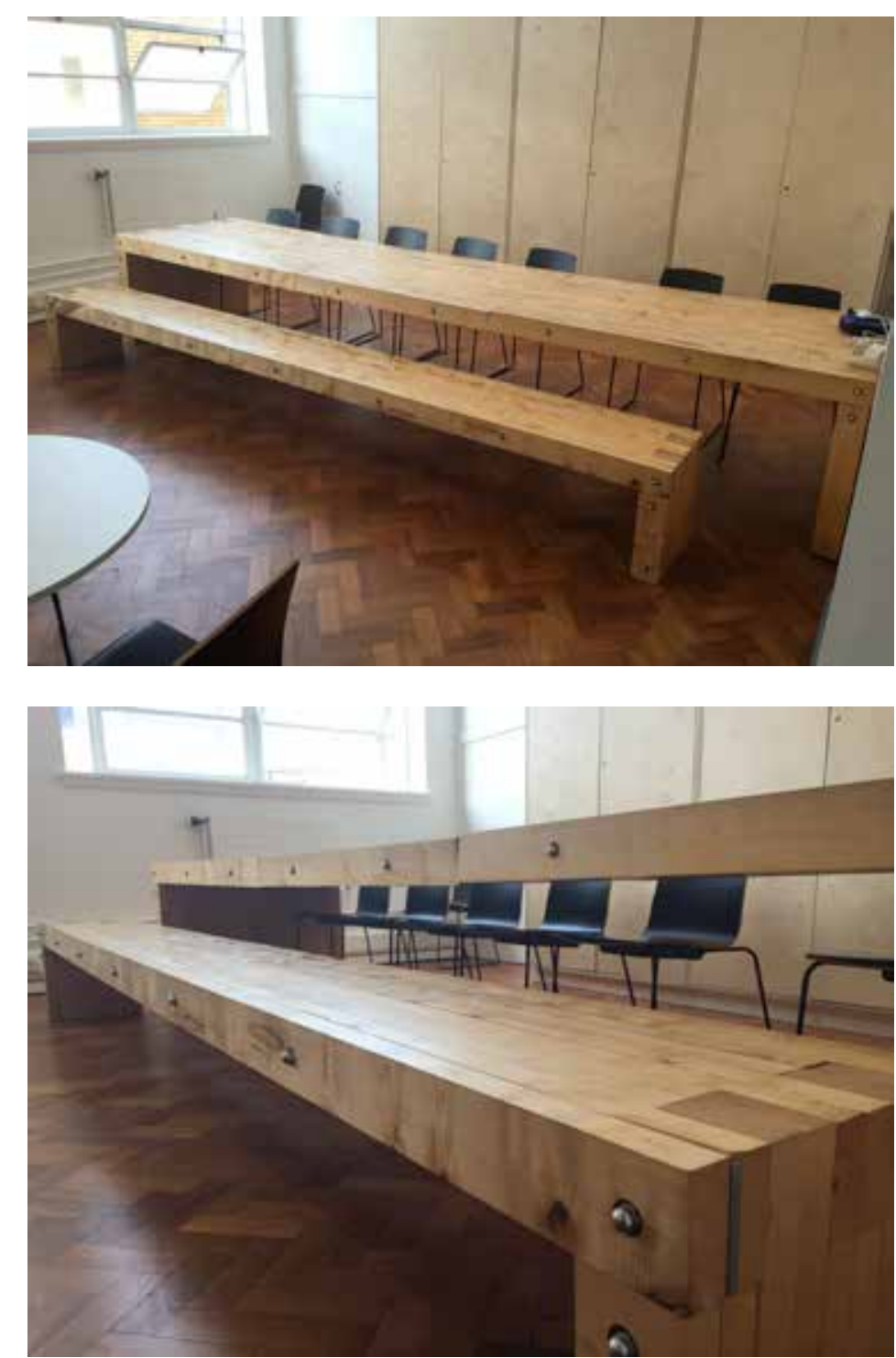

Fig 7.77 Photos of table in 2015
DETAIL

- A number of details require further tectonic refining: the bearing plate, bolting detail and butt joint between lamellae as detailed below:

- The bearing plates were $20 \mathrm{~mm}$ smaller than the timber to conceal them on the top surface of a piece of furniture. This not only made the routing and jig process more complex it also left a $10 \mathrm{~mm}$ piece of timber either side that dried rapidly resulting in warping and splitting. The bearing plate would be better at $100 \mathrm{~mm} \times 100 \mathrm{~mm}$ and exposed on the surface highlighting the tectonic of construction.

- The cover lamella and blind nuts were included to protect users of the table from the exposed threaded rod creating an ambiguous tectonic, although it is not intended to be part of a construction system.

- These details were highlighted by Professor Richard Weston during RIBA Architecture week, 2004 in the 'trial of tectonic deceit'by hiding the bolted connection details that resulted in a mis-understanding of the table structure.

- The butt joints have, over time, become exaggerated by the movement of the sycamore as it dried leaving gaps. Scarf joints may have been better than the butt joints to avoid continuous voids through the structure and maintaining a smooth, even finish.

\section{DIMENSIONAL COORDINATION}

- The $300 \mathrm{~mm}$ layout grid, in the prototype table, had little impact on the overall design with only the central bolting positions determined by this grid with the ends and legs offset by $+/-50 \mathrm{~mm}$. The table proportions were 

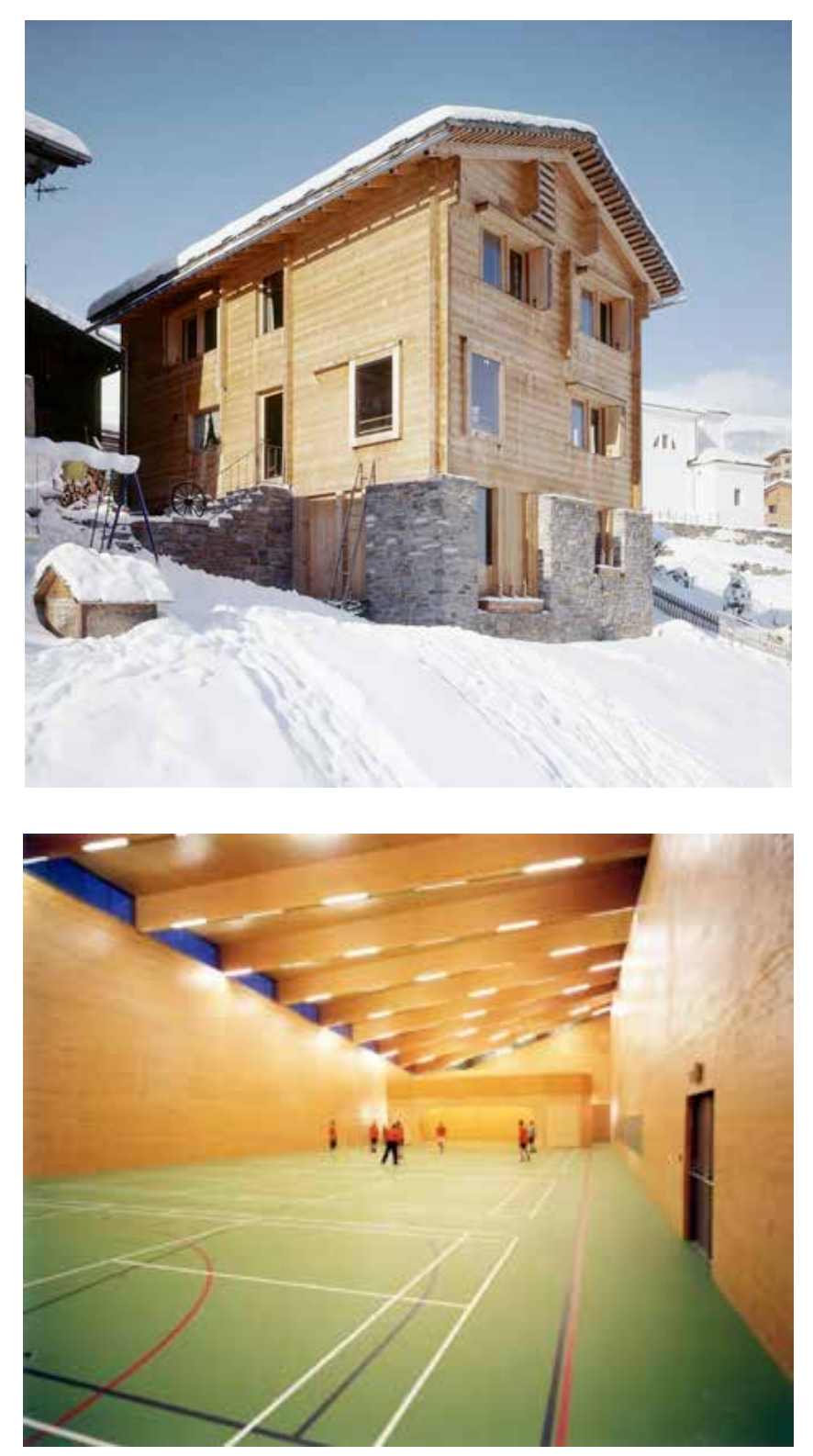

7.5 instead informed by ergonomics for table height, the physical dimensions of the space for length and the tessellated interlocking and bolting of timbers for individual lamella length. Only a few lamella in the middle of the table top were based on a $300 \mathrm{~mm}$ module at $1200 \mathrm{~mm}$ and $2400 \mathrm{~mm}$ long. As a housing construction system, this could be addressed but the prototype highlights the conflict between using a $300 \mathrm{~mm}$ module for spatial configuration, material length and structural rhythm. In terms of timber efficiency it may be best to consider the $300 \mathrm{~mm}$ applying to timber length with the space and bolting determined around this.

\section{MODULAR}

- While the low-tech construction has primarily driven the form, the minimal, right angle corner and planar elements lends itself well to the design of housing to avoid unnecessary detail and articulation. This in turn, may be critical in the success of prefabricated, modular, panelised design allowing for spatial and architectural flexibility and response to context.

- The elemental design and construction process offers flexibility and architectural logic to the proportion and composition of housing designs, however the inclusion of the other components of the complete building envelope could result in the elemental becoming layered with more complex details at connections and around openings than perceived in this prototype.

CORPOREAL

- The minimal, low-tech form is an innovative development of traditional log-on-log construction with simple proportions of modularity and construction. Furthermore, if exposed, stress-lam could provide a tactile, tectonic internal finish without the use of glues, similar to the exposed CLT panels at Kingsdale School by de Rijke Marsh Morgan architects (dRMM).

\section{Findings on engineered timber}

The aim of this study was to evaluate the design and construction of engineered timber structures as part of the building envelope. Observations and reflections on each project have revealed the following overall findings in relation to the use of engineered timber and the possibilities of integrating Welsh-grown timber:

- A post and beam structure and a solid timber panel system have been tested. Both successfully met the design and clients brief and have been 


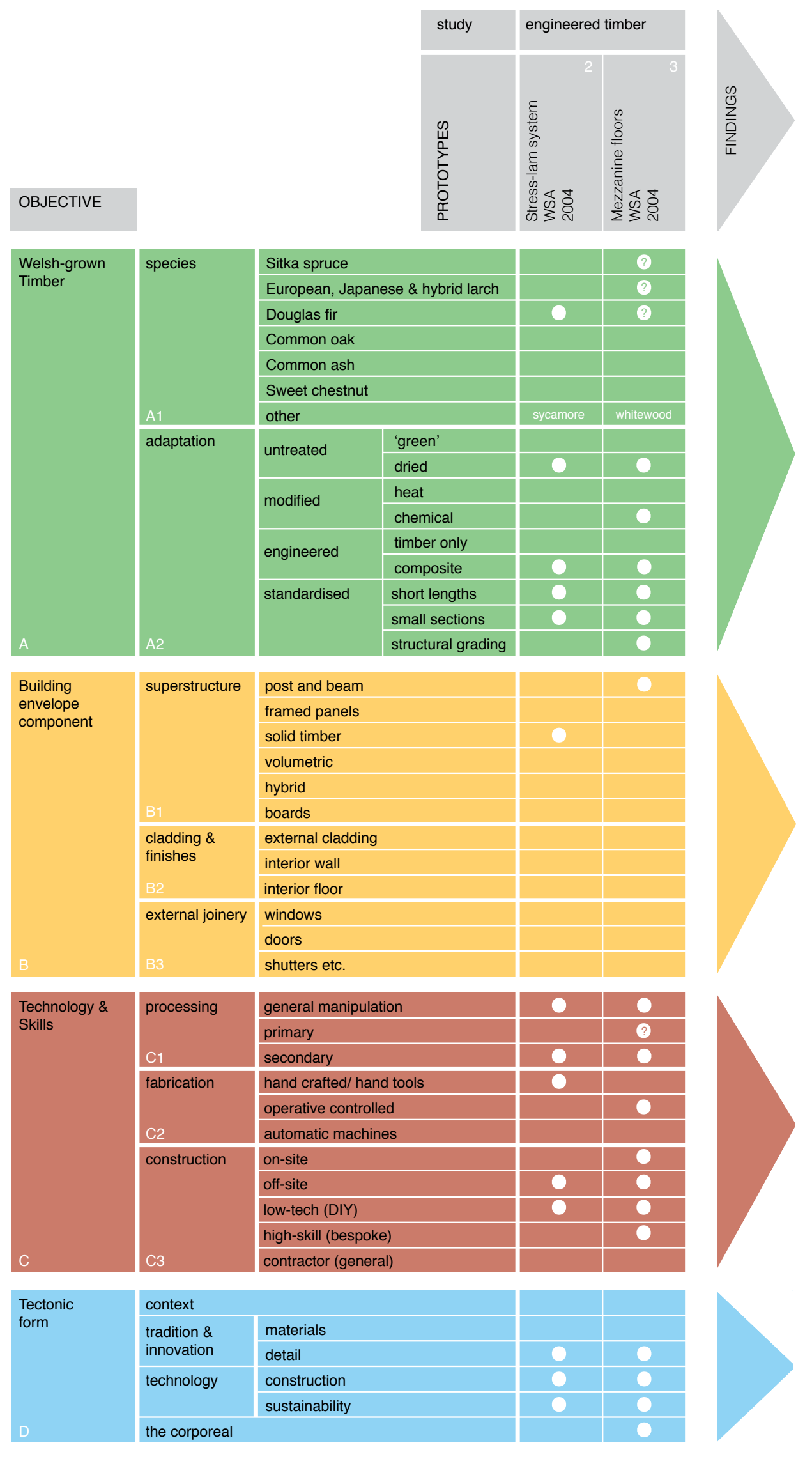

REFLECTION-ON-ACTION in regular use since 2004.

- Both methods could incorporate standard sizes and grades of low quality Welsh-grown softwood, while the stress-lam system has the potential to incorporate irregular sizes as a result of defect cutting or recycled from previous projects. Timber grading may be difficult with Welsh-grown timber, although CLT can be made from $\mathrm{C} 16 .{ }^{20}$

- Glu-lam involves high-tech manufacturing facilities, although on-site post and beams construction has the potential to be low-tech requiring basic assembly and carpentry skills. Other forms of laminated composite lumber require more complex laminating plants that involve veneer production and significant onsite plant to lift and move components.

- The moisture content and stability of most Welsh-grown timber species is likely to pose a problem in this stress-laminated construction, although the cross laminating and grain rotation of small sections of timber in CLT and the diagonal dowelling of brettstapel panels will provide resistance against small amounts of movement.

- The stress-lam system is low-tech to manufacture and in small scales lowtech to assemble, although large scale construction would require on-site lifting equipment.

- The two prototypes have demonstrated the variations in skills within the industry that must be considered - stress-lam was fabricated by a skilled carpenter/ joiner in a small, but unique and bespoke workshop whereas the mezzanines were assembled by a workforce unfamiliar with the materials or the details expected.

- Both systems were designed to follow a structural and spatial layout grid. Both were determined by the parameters of the site constraints but were informed by the sizes of the available material to produce modular, additive replicable and demountable structures.

- Both approaches to engineered timber have the potential to produce a simple tectonic form derived by the material and structural requirements, although the integration of other elements and fire performance of the building envelope must be considered further as the didactic constructions are likely to be lost within multiple layers providing environmental performance requirements, finishes and fire protection. 


\section{CHAPTER 8}

Timber panel products 
The main focus of this study is on a project established between the Design Research Unit Wales, the External Relations Department of Cardiff University and the National Eisteddfod to design and build a pavilion for Cardiff University at the Eisteddfod Festival, Tredegar House, Newport in 2004. The pavilion was to display research and the work of students from all University departments. The pavilion was designed and built by the author with DRU-w and recent WSA graduates assisting in the off-site fabrication and on-site construction and dismantling at the end of the festival. The speed and low level of construction skill available provided an opportunity to explore the use of off-the-shelf timber building materials as standardised and prefabricated components with minimal adjustment. In particular the project focused on the use of timber board products, which have already been identified as being of potential interest to the Welsh timber industry.

Following the reflections and outcomes of this prototype, the design study was further investigated through an un-realised project for a temporary reception kiosk to be located outside Cardiff Castle. The kiosk was designed to provide temporary facilities while a new visitor centre was built inside the castle walls. The project provided an opportunity to carry forward the superstructure ideas demonstrated in the design of the Eisteddfod pavilion into a complete, weather-tight, insulated building envelope.

\subsubsection{Aim and objectives}

The aim of this study was to prototype a low-cost alternative design and construction approach to standard timber board products, readily available from local DIY stores and builders merchants, that may in the future, be manufactured from Welsh-grown timber.

The objectives were to:

- to propose alternative uses for timber board products in the design of the building envelope.

- to involve minimal cutting and wastage and prefabricated to reduce the need for on-site heavy plant;

- Propose and evaluate a tectonic form inspired from standardised material sizes. 

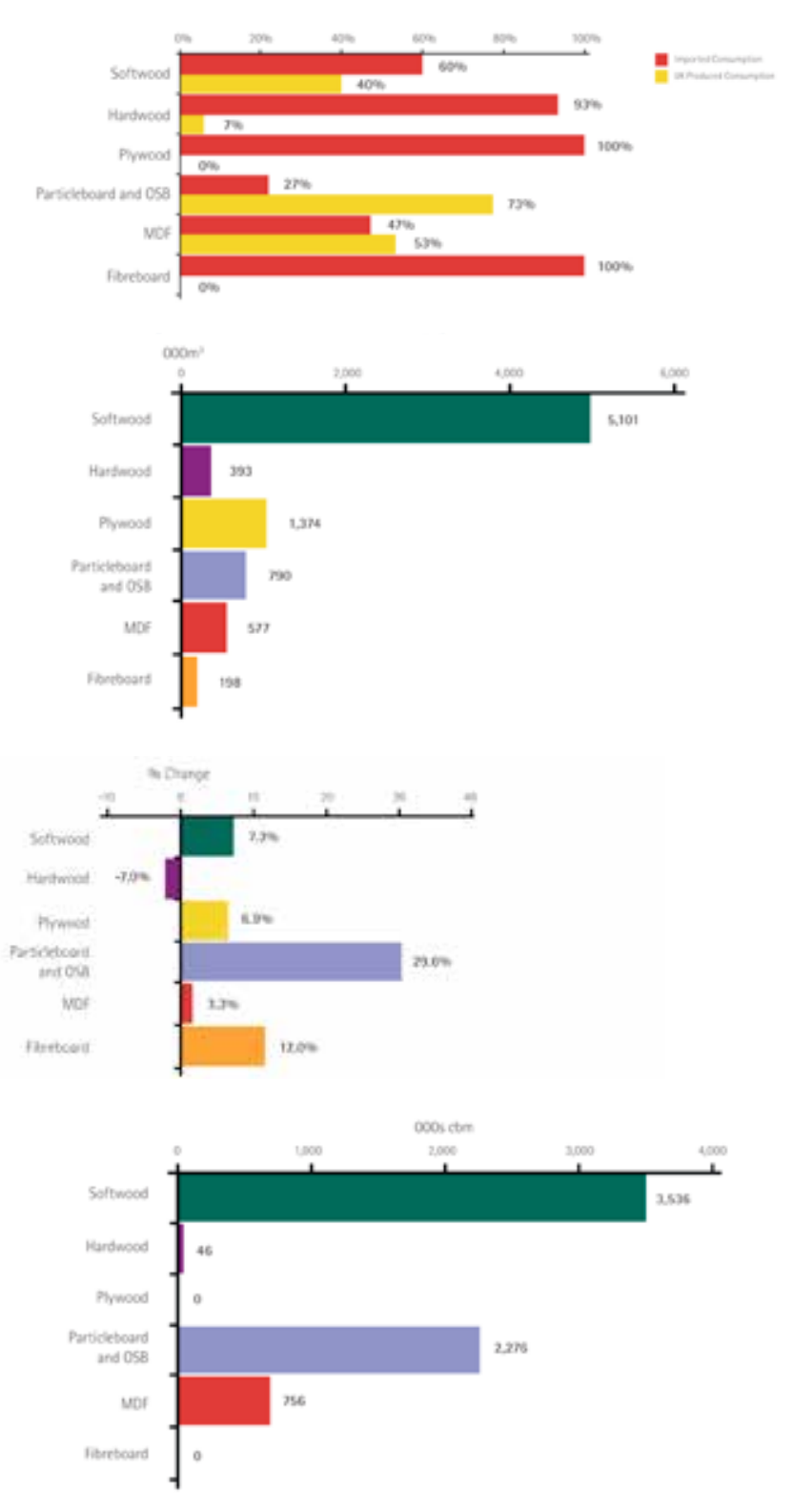

Fig 8.1 UK Consumption by Volume, by Product and Source 2013

Fig 8.2 UK Imports of Timber and Panel Products 2013, by Volume

Fig 8.3 Percentage Volume Change in Timber and Panel Products Imports 2013/2012

Fig 8.4 UK Production of Timber and Panel Products 2013, by Volume
Limitations

For this study, it would not be possible to manufacture sample panels using Welshgrown timber due to the plant required and it would not be possible to send Welsh timber to appropriate factories in Europe to test the manufacture due to the small scale required and costs. Instead either UK manufactured products or imported, sustainably accredited products that use comparable timber species will be used.

\section{Context and precedent}

It was identified in Chapter 3 that the production of timber board products could be of interest to primary and secondary processing industries in Wales as way of adding value to the Welsh-grown crop and current production lines.' It has been established that no plywood is manufactured in the UK, although $73 \%$ of OSB and $53 \%$ of MDF consumed is produced in the UK. ${ }^{2}$ The volume of board product imports is increasing in the UK with a 12\% rise between 2012-2013. The UK imports 1.4 million $\mathrm{m}^{3}$ of plywood, $790000 \mathrm{~m}^{3}$ of particleboard and OSB, which was $29.6 \%$ more than in 2012, and $577000 \mathrm{~m}^{3}$ of MDF while producing a further 2.3 million $\mathrm{m}^{3}$ of OSB and $756000 \mathrm{~m} 3$ of MDF. ${ }^{3}$ The total consumption of timber board products in the UK is the highest since 2007 at 5.5 million $\mathrm{m}^{3}$, valuing almost $£ 1.5$ billion $^{4}$ and contributing to $39 \%$ of all timber and timber products consumed. ${ }^{5}$ This demand and increase in importation, despite UK based manufacturing, is predominantly to meet the needs of the timber frame construction process for sarking, racking resistance and floordecks concealed within the multiple layers of the building envelope. This highlights the potential market to increase UK production, particularly in plywood and OSB, and also whether these products have further tectonic value to offer as exposed finishes.

This review of literature and precedents will focus on the types of timber board products available, their properties and potential, as context to their enhanced use within the building envelope.

\section{Timber board products}

There are numerous types, variations and species of timber based, board product available worldwide. However, no matter what form the board takes they all share

1 Jaakko Poyry Consulting, Welsh Forest Industry: Mapping and Benchmarking the Forest Industry, Final Report (Executive Summary Only), (London, 5th November 2004)

2 Timber Trade Federation, Statistical Review 2014: Industry Facts and Figures for the Year 2013,

(London: TTF 2014), p.8

3 Ibid, p. 15

5 Ibid, p.22 

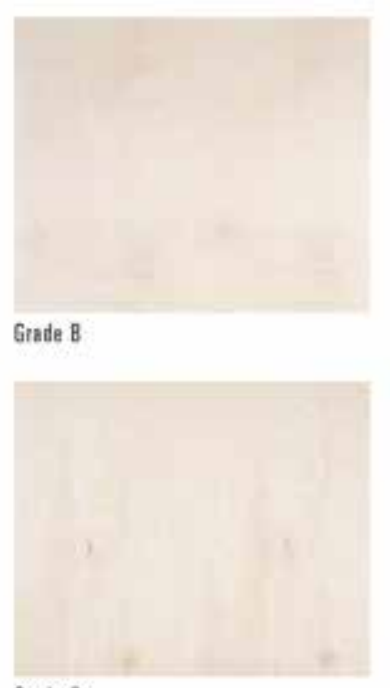

Grate II

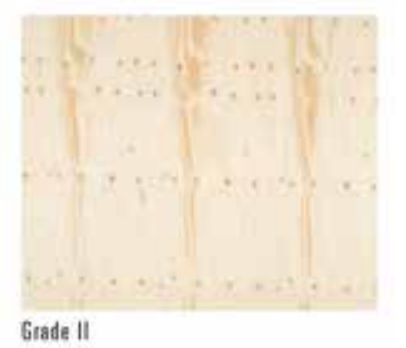

Gindes
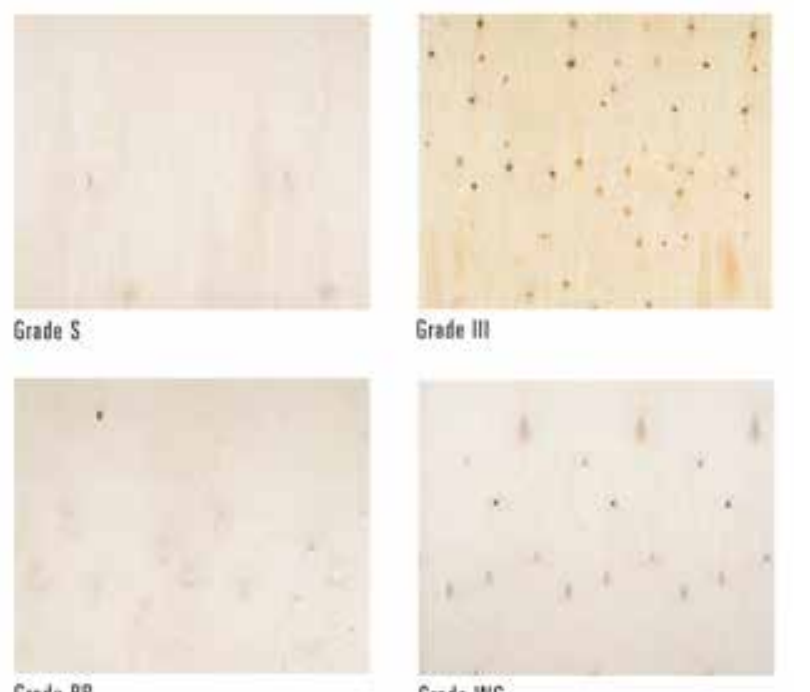

Swatches of different plywood grades

Grade 88 Grade WG

BELOW

Fig 8.6 Thicknesses and layers of plywood Fig 8.7 Table of birch and spruce plywood
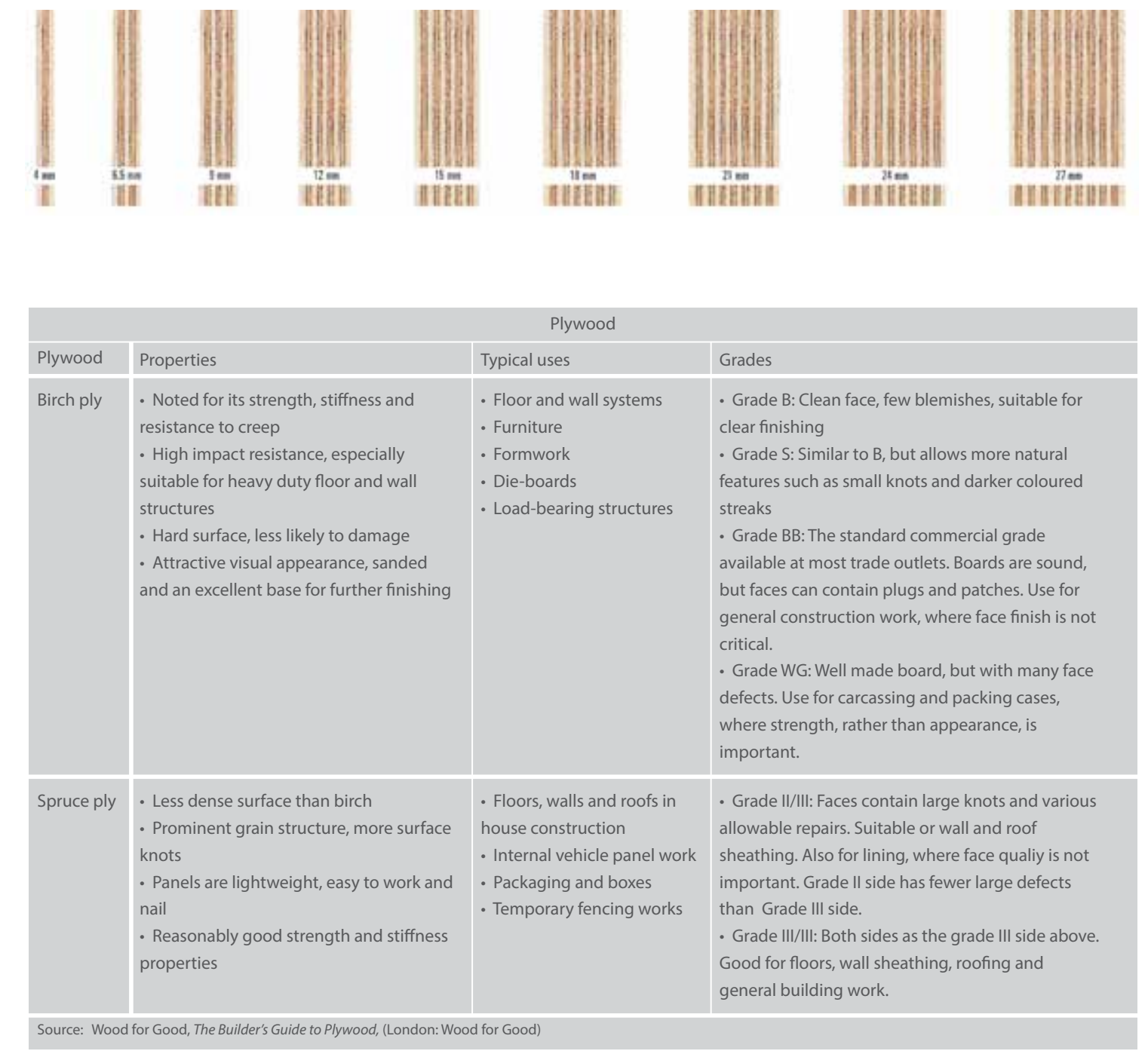

the same basis of composite manufacture - boards, strips, veneers, strands, chips and fibres pressed and bonded together with either synthetic or mineral-based adhesives into boards. ${ }^{6}$ The aim in the production of all these boards is to significantly improve the quality of the source timber species with knots, splits, twists and shakes removed and avoided resulting in a superior strength. ${ }^{7}$ Generally all boards are homogenous products produced with a controlled arrangement of the individual pieces that will determine the direction of load bearing capacity but also minimise the fluctuations in swelling and shrinkage. ${ }^{8}$

Further details will be provided on the following boards used in almost every domestic construction project for either load bearing walls, bracing, flooring, ceilings, furniture, insulation and fire protection all over Wales and the UK:

\section{- Plywood}

Invented in the 19th century by Immanuel Nobel, all plywood is made from an odd number of thin sheets of wood veneer (depending on thickness and quality) glued together with adjacent plies laid at right angles to each other to improve strength and dimensional stability. Plywood is generally easy to work, re-usable and has good resistance to splitting, twisting and warping.

There are three main types of plywood: the most common is softwood made from cedar, Douglas fir, spruce or pine and used for a wide range of construction purposes; hardwood plywood is usually made from birch and used for specialist joinery items where appearance and durability are important, although beech plywood and decorative plywoods with hardwood outer veneers are also available; and tropical plywood made from tropical hardwoods which is usually cheaper with better performance than softwood plywood, however it has been associated with non sustainable sourcing and over harvesting of forests in Malaysia, Indonesia and the Philippines. Other specialist plywoods are also available to increase resistance to heat and humidity, increase resistance to moisture (WBP), reduce weight and allow flexibility. ${ }^{9}$

Plywood surfaces are typically graded as birch B, S, BB, or WG, and spruce I, II or III depending on the quality of finish from free of defects to all defects

6 Borimir Radovic, 'Composite Wood Products and Their Use in Building', Detail, 1 (2000), 91-98 (p. 91$)$ 7 Ibid, p.91

9 Wood For Good, The Builder's Guide to Plywood (London: Wood For Good) <http://www.trada co.uk/publications/download/?id=B98D5D38-C173-4CBD-8046-0FA53B501CBA> [accessed 7 September 2015] 


\section{- Chipboard}

Invented by Max Himmelheber in the 1940s, and also known as particleboard, chipboard is manufactured from birch, beech, alder, pine and spruce pressed wood chips, sawmill shavings and sawdust with a binding adhesive which is then extruded into boards. It is typically the cheapest, lightest and most uniform/ stable of the commonly available boards, used in situations where appearance and strength are not important. However, chipboards are highly prone to expansion when exposed to high levels of moisture when not painted or sealed. Chipboard is commonly bonded to wood or other plastic based veneers to create doors, shelves and other decorative panels.
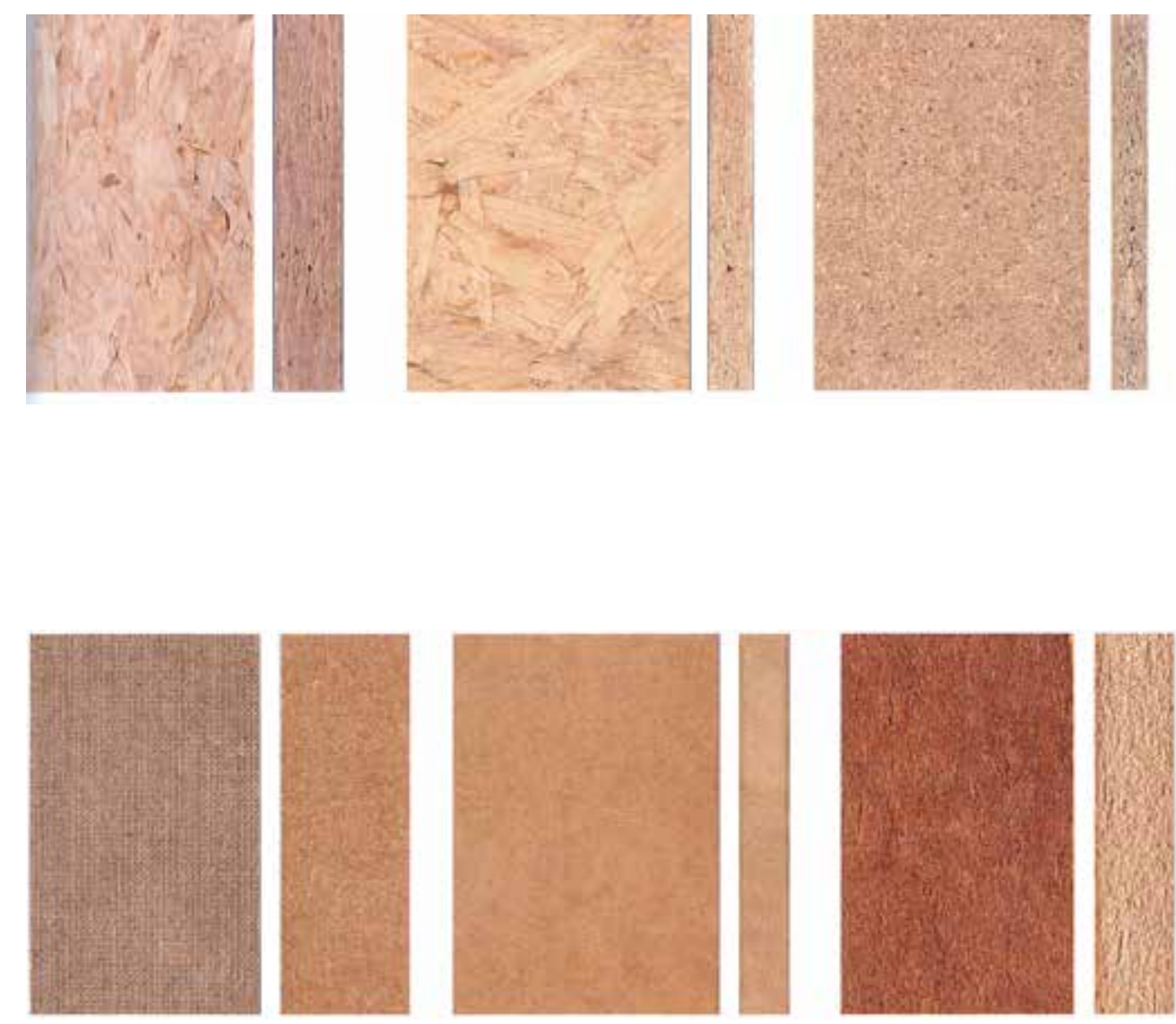

Fig 8.8 Laminated-strand timber, OrientedStrand Board, Chipboard

Fig 8.9 Hardwood fibreboard, Medium-density wood-fibreboard, Soft wood-fibreboard

\section{- Oriented strand board (OSB)}

OSB, also known as Sterling board in the UK, is formed by layering $25 \mathrm{~mm} \mathrm{x}$ $150 \mathrm{~mm}$ strands, or flakes, of wood in specific orientations which are then bonded with wax or synthetic adhesives in a heated press. Similar to the properties of plywood, OSB is cheaper and more uniform and is therefore used as an alternative to plywood in general construction, in particular timber framing. OSB has no internal voids and are usually water-resistant but require protection to achieve impermeability if exposed to external conditions. OSB in the UK is available in 2 grades: OSB/2 for load-bearing dry applications; and $\mathrm{OSB} / 3$ for load bearing humid conditions which is used in construction. ${ }^{10}$

\section{- Medium-density fibreboard (MDF)}

MDF is formed by breaking down both hardwood and softwood residuals into wood fibres which are then combined with wax and a resin adhesive to form panels under high temperature and pressure. MDF can be used for similar purposes in construction as plywood, but its higher density, susceptibility to moisture and inability to be used for racking/ diaphragm resistance means that it is generally used for interior application for finishes and furniture. ${ }^{11}$ MDF is free from knots and other solid wood defects with a hard, flat, smooth surface that is good for veneering and painting. MDF is one of three forms of fibreboard, the others being high density fibreboard usually in thin boards for backing and providing bracing to furniture; and soft wood fibreboard used for thermal and acoustic insulation. ${ }^{12}$

10 Martin P Ansell, Wood Composites, (Cambridge: Woodhead Publishing Limited, 2015), p. 106-109.

$\begin{array}{ll}11 & \text { Radovic, p.98 } \\ 12 & \text { Radovic, p.98 }\end{array}$ 


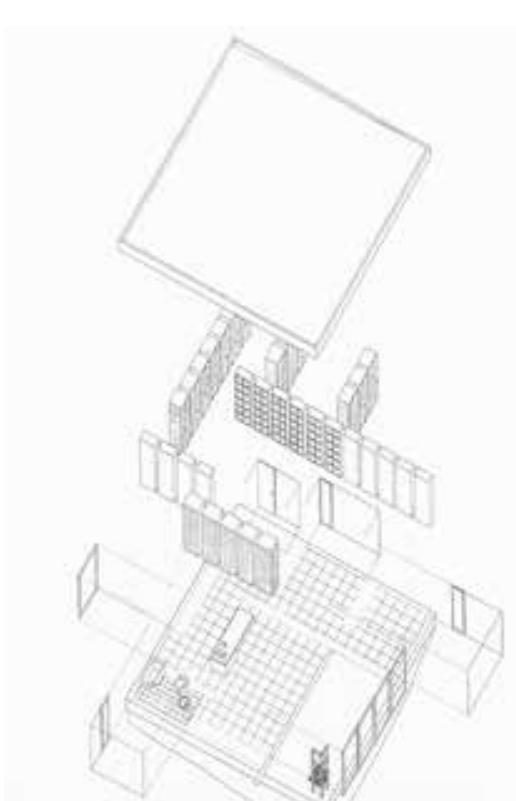

a

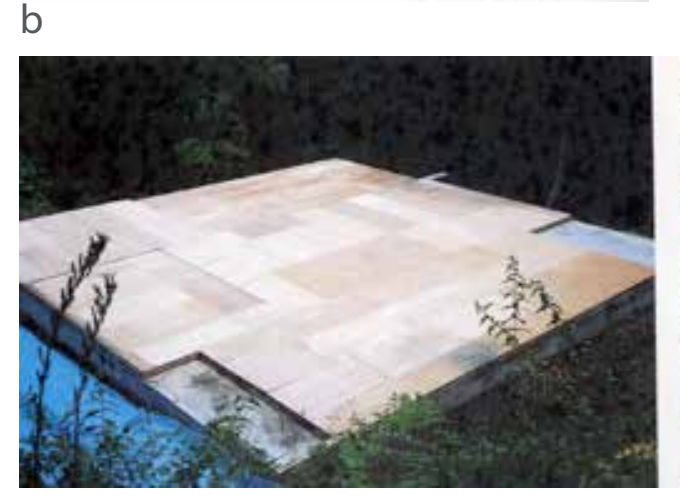

Fig 8.10 Furniture House 1, Lake Yamanaka, Japan Shigeru Ban, 1995

a. Exploded axonometric of principle elements b. exploded constriction of storage unit c. construction sequence of furniture house
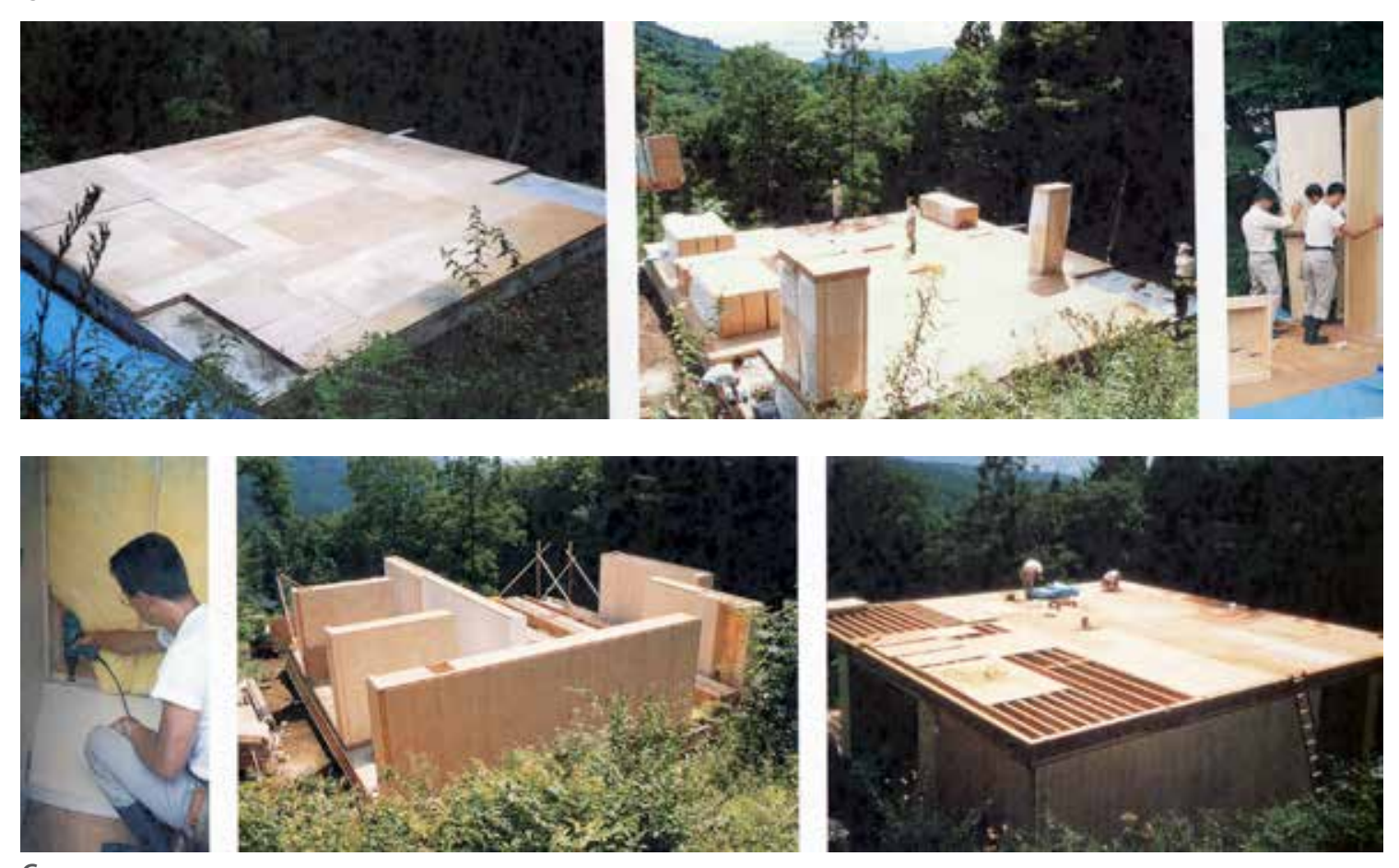

These boards are usually manufactured direct from roundwood. However, all but plywood have the possibility of offsetting the use of unsustainable adhesives, through the use of what could essentially be waste or small sections/ lengths of timber that do not have any practical use or downcycled timber from other projects. This can be taken further in that if mechanically fixed these products can be reused again and again. However the manufacturing process of the boards, in particular chipboard and MDF, poses health risks during processing for construction. As the boards are made from small particles of wood, cutting, sanding and drilling throws dust particles into the air requiring a respirator to be worn. This is made worse as the majority of the adhesives used to bond these boards contain formaldehyde and other volatile organic compounds, which are known to be 'probable human carcinogens.'13 MDF, unless sealed or painted, is also known to slowly release Ureaformaldehyde from the edges and surfaces when in use. Manufacturers are, however, beginning to produce boards now that are formaldehyde free.

All of the above boards are readily available in the UK, in the following sizes:

- thicknesses (mm): 6, 9, 12, 15, 18, 21, 24, 27, 30 and 35. Plywood special sizes are also available between $1-6 \mathrm{~mm}$ and up to $50 \mathrm{~mm}$ thick.

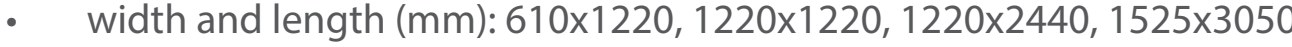

It should be noted that the overall board sizes are a conversion from previous imperial sizes, such as $4^{\prime} \times 8^{\prime}$ and $5^{\prime} \times 10^{\prime}$, although boards are available, on request, from European suppliers in rounded metric dimensions of 1200, 1500, 2400 and $3000 \mathrm{~mm}$.

\section{Furniture Houses, Shigeru Ban}

Shigeru Ban is a Japanese architect, researcher and engineer who experiments with materials to develop new ways of building often in difficult contexts. His experiments often involve textiles, paper and plywood to build temporary pavilions, emergency housing, private houses, churches and museums. Ban has an interest in regional crafts and techniques that leads to experiments with ordinary materials in a variety of architectural interpretation with an aim to allow material to be the sole adornment of his buildings. However this does not mean that material and structure become expressive in a tectonic sense, as often the structure is hidden and part of a construction logic determined by other concepts. The material selection goes hand

13 National Cancer Institute, Formaldehyde and Cancer Risk (2011)

<http://www.cancer.gov/aboutcancer/causesprevention/risk/substances/formaldehyde formaldehyde-fact-sheet> Accessed 30th August 2015] 
An example can be seen in the Furniture House series, where Ban observed the structural integrity of furniture, such as prefabricated bookshelves, wardrobes and storage units, following a series of earthquakes across Japan in 1995. His first experiments used floor-to-ceiling bookshelves to strengthen a cardboard tubular structure against lateral forces (Library of a Poet). ${ }^{15}$ Ban's first furniture houses replaced the usual walls and columns with prefabricated structural shelving that allowed greater off-site quality control and installation of the primary structure onsite in one day, thereby reducing overall time and cost. Furniture House 1 and 2 with timber, and the Bamboo Furniture House, with bamboo, both integrated a structural stud frame into the back of plywood furniture components to provide storage, walls and structure. The frame was insulated and protected with a membrane and external cladding when used on external walls. ${ }^{16}$

Following further research into the wardrobe structure for the Sagaponac House, New York, Ban refined the structural system to provide maximum storage space on the interior while still performing as a load bearing exterior wall element by removing the structural stud frame at the back of the unit. Instead Ban designed the units to rely on a refined construction of maple veneer plywood with the corners reinforced with triangular timber pieces. All units were based on two standardised sizes and types - a box or a panel and exterior or interior. The external units were made $125 \mathrm{~mm}$ deeper to accommodate insulation, weatherproofing and cladding. The roof was structured using a truss I-joist system to span the complete width of the house without being restricted to the furniture wall locations. ${ }^{17}$
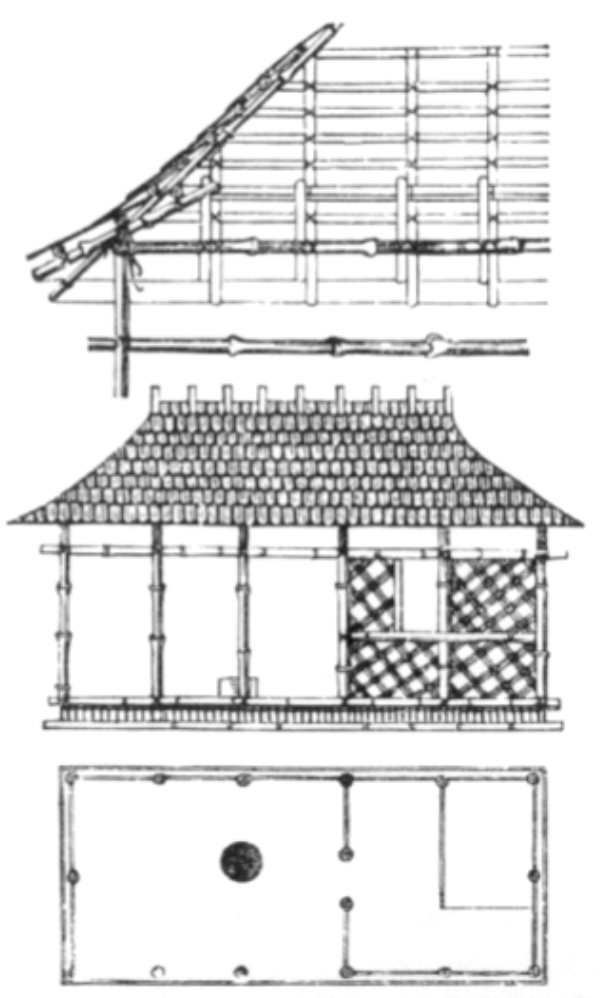

Fig 8.11 Semper's primitive hut model

\subsubsection{Everyday materials}

The tectonic exposure of construction materials, as finished surface, is often seen as an honest and typically purist architectural expression of the construction process allowing the natural quality of materials to be experienced by building occupants

- 'Let brick appear as brick, wood as wood'.18 However, as construction has developed to improve building standards, environmental performance and reduce construction time and costs there has been an increase in the invention and use of man-made and fabricated materials designed to eliminate and improve on the basic, but more costly,

14 Matilda McQuaid, Shigeru Ban, (London: Phaidon, 2003)

15 Ibid, p. 16

16 Ibid, p.134

16 Ibid, p.134

18 Hanno-Walter Kruft, A History of Architectural Theory: From Vitruvius to the Present, (New York: Princeton Architectural Press, 1994) p.311 
natural materials that architecture was founded on, such as stone, timber and earth. The aim of many developers and manufacturers is to deliver architecture as a product in the same way as a cars, mobile phones and computers. This is not to say that these materials are dishonest or inappropriate, as they often exceed the performance characteristics of the natural materials they replace, but to note that they are often hidden away within the building envelope with claddings of natural materials to provide the final, decorative finishes.

However, numerous architects over the last fifty years have embraced new materials and products, as they are developed, as materials in their own right with properties and qualities that are worthy of expression and experience. The following two principles have been identified as of architectural influence in the expression of standardised board and panel products readily available, worldwide:

\subsubsection{Low cost}

The French architectural practice Lacaton and Vassal developed a reputation, in their early years, for designing and delivering experimental low-cost buildings that have since informed the agenda for future projects. Their intentions are not to design cheap buildings but to stretch a clients budget further than would normally be achieved through the use of low-cost standard, off-the-shelf board and sheet materials as structure and finish for the interior and exterior building envelope. As such, the materials are selected on the basis of what they can offer the project, from solar shading and security to architectural composition and performance and not purely on cost. This, in many cases, allows Lacaton and Vassal to design building that provide a spatial added value with more space provided than the brief required to improve a quality of experience and environment that would not be achievable with the given budget. The Latapie house, in Floirac, France, is a 185sqm designed, in 1993, for a couple with two children. The project was the first low-cost house based on a rectangular footprint structured with a white painted steel frame. An insulated timber envelope was inserted into part of the frame to provide the primary living spaces with exposed spruce plywood on walls and ceilings. Extra space was provided through a conservatory created on the garden side to extend the living area of the house, clad in standard polycarbonate sheets. The more defensive street elevation was clad in fibre-cement sheets with the same profile as the polycarbonate that when opened revealed the softer and more warm textures of plywood. 

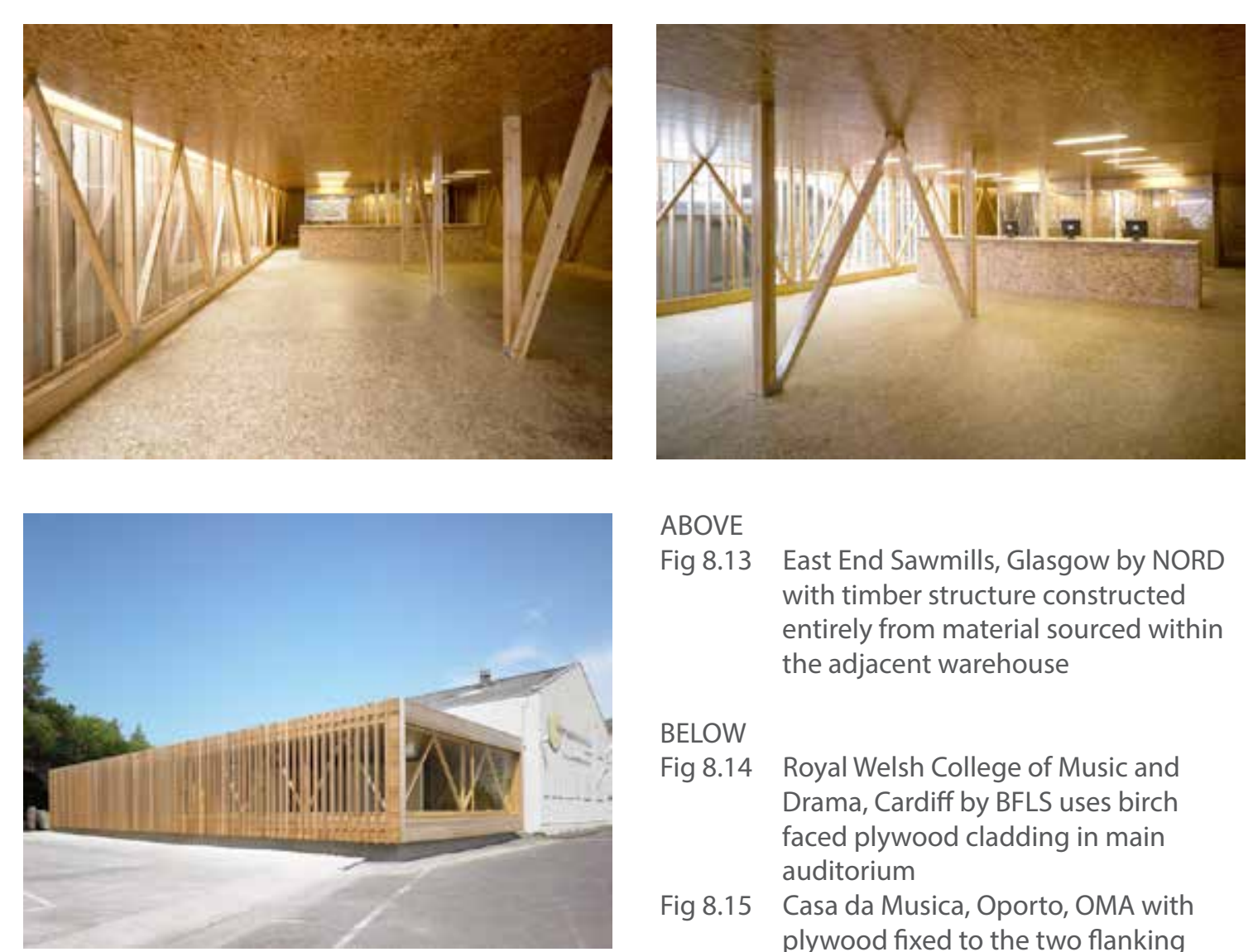

ABOVE

Fig 8.13 East End Sawmills, Glasgow by NORD with timber structure constructed entirely from material sourced withi the adjacent warehouse

BELOW

Fig 8.14 Royal Welsh College of Music and Drama, Cardiff by BFLS uses birch faced plywood cladding in main auditorium

Fig 8.15 Casa da Musica, Oporto, OMA with plywood fixed to the two flanking

requirements of the two glazed ends
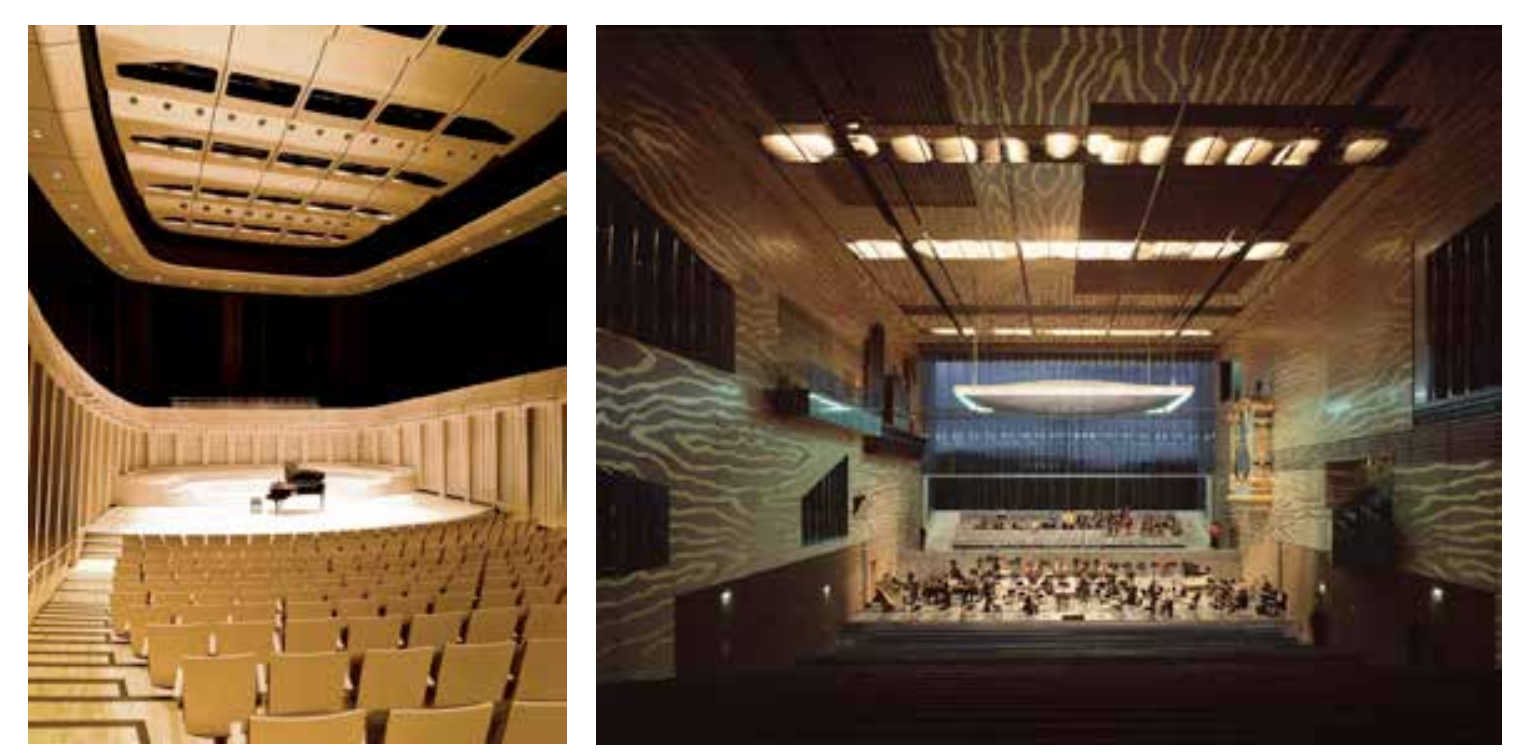

As man-made or re-engineered natural materials are being embraced, architects are using the aesthetic qualities of these products to enhance the experiential quality of the architecture. MDF is commonly used for furniture to provide structure and rigidity, joined by screws, but often hidden behind veneers and coatings that portray another material or a minimalist aesthetic. However, Gigon and Guyer exposed $30 \mathrm{~mm}$ thick varnished MDF in the design of the fitted furniture and staircases in the extension to the Liner Museum in Appenzell, Switzerland. The grain- and scale-less finish of the MDF resulted in blemish free surfaces with a dark brown/ tan colour evoking to the sense of leather and quality. $<$ photos of Liner Museum from El Croquis and Richard Weston book $>$ In contrast, the design of an office and showroom for East End Sawmills in Glasgow, Scotland, by NORD architecture used the materials available from the adjoining warehouse to reduce costs but also to generate a robust, industrial aesthetic that reflected the nature of the business. While the primary structure uses softwood for trusses and joists braced by a skin of OSB on the interior walls, floors and ceilings, the OSB has been sanded and vanished to provide the interior finish. The single use of softwood and OSB has 'heightened the intensity of the material and product ${ }^{\prime \prime 1}$ by using standard construction methods but not as expected.

Unlike MDF and OSB, some types of plywood are manufactured in formats specifically to exploit the quality of the finish for use as an exposed material while at the same time providing structural and other performance properties. Typically grade A plywoods in any species from spruce and Douglas fir to tropical hardwoods can be manufactured with the knots and defects removed and patched to provide a uniform, homogenous surface to exploit visually. In the auditorium of the Casa da Musica in Oporto, Portugal by OMA, full size sheets of plywood have been fixed to the two flanking walls that have then been decorated with a woodgrain of gold leaf to balance the acoustic requirements of the two glazed ends. At the Royal Welsh College of Music and Drama (RWCMD) in Cardiff by Bogle Flanagan Lawrence Silver architects (BFLS) [now known as Flanagan Lawrence] birch faced plywood has been used to clad and construct the entire main auditorium, from seats and balconies to the stage and ceiling to balance reverberation times of a concert orchestra and generate a neutral, uniform tone that provides focus and contrast to the orchestra on stage. Both auditoria could have used solid timber, but would have had far more joints and gaps not ideally suited to acoustic performance. However, the overall effect of the plywood has still been to create a sense of opulence, intimacy and quality while maintaining the corporeal connection with timber grain, texture and smell.

19 Northern Office for Research and Design, East End Sawmills, <http://nordarchitecture.com/projects east-end-sawmills/> [Accessed 6th August 2013] 


\subsection{Eisteddfod pavilion}

8.3.1 Design

8.3.1.1 Brief

The brief was developed with the External Relations Department (now called the Communications and Marketing Department) for an exhibition pavilion to represent Cardiff University, and the different schools, at the National Eisteddfod festival.

Typically Cardiff University would hire a standard rectangular aluminium framed, white fabric pavilion from the Eisteddfod for approximately $£ 3000$. Therefore this purpose built pavilion had to be built to a similar budget.

\section{Eisteddfod Pavilion}

A specific schedule of accommodation was not provided as the Design Research Unit Wales were given freedom to explore the design and means of exhibiting the schools as part of the representation of the Welsh School of Architecture and the use of timber board products. However the following requirements formed the basis of a brief and required facilities:

- Exhibition space for student and research work from all 27 academic schools at Cardiff University;

- The exhibition was to include posters, models, artefacts and demonstrations;

- An approachable staff area to ask questions and obtain information;

- Include an AV space to show the Cardiff University promotional video;

- Include a private staff area for tea and coffee making as well as storage of personal belongings and PR material;

- The exterior of the pavilion to be clearly branded as Cardiff University;

- Accessible to all;

- Simple to open up, close and maintain; and

- Be directly accessible from the main path around the Eisteddfod.

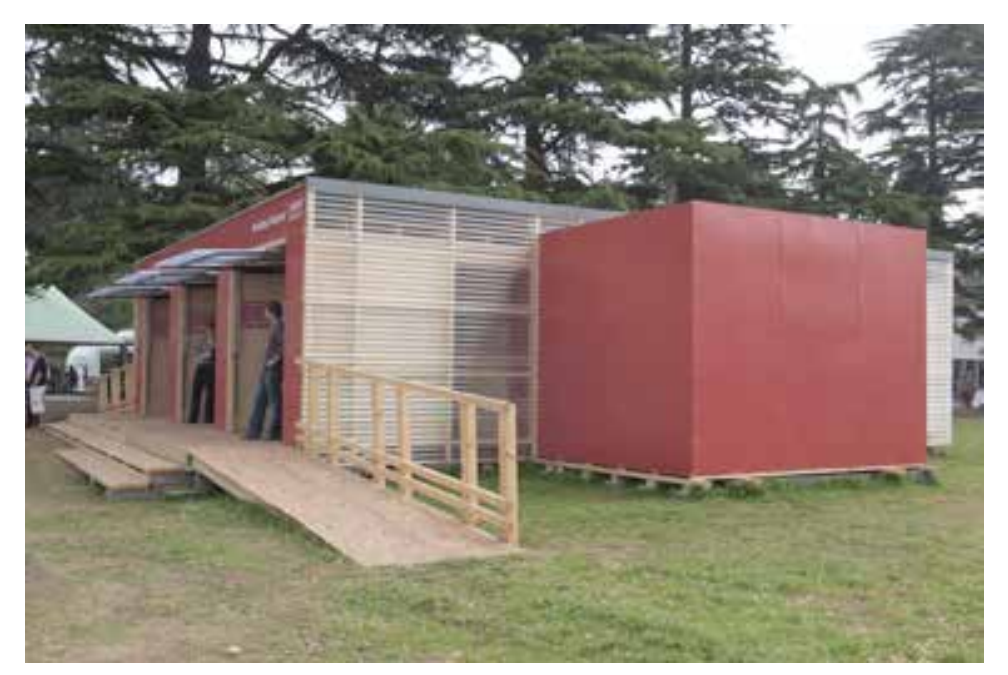

Further to the functional brief and the low budget, the timing meant that the pavilion was to be designed, fabricated and constructed in three months prior to the opening of the festival on 31st July 2004. This resulted in the following technical requirements:

- A prefabricated structure to be manufactured in the workshop at the Welsh School of Architecture using basic hand powered tools;

- $\quad$ Lightweight to allow for 2 people to lift and move components;

- To be constructed from a limited set of materials to reduce consumption, costs, transport and construction time;

- Source locally supplied, off-the-shelf materials to reduce costs and lead-in time. 


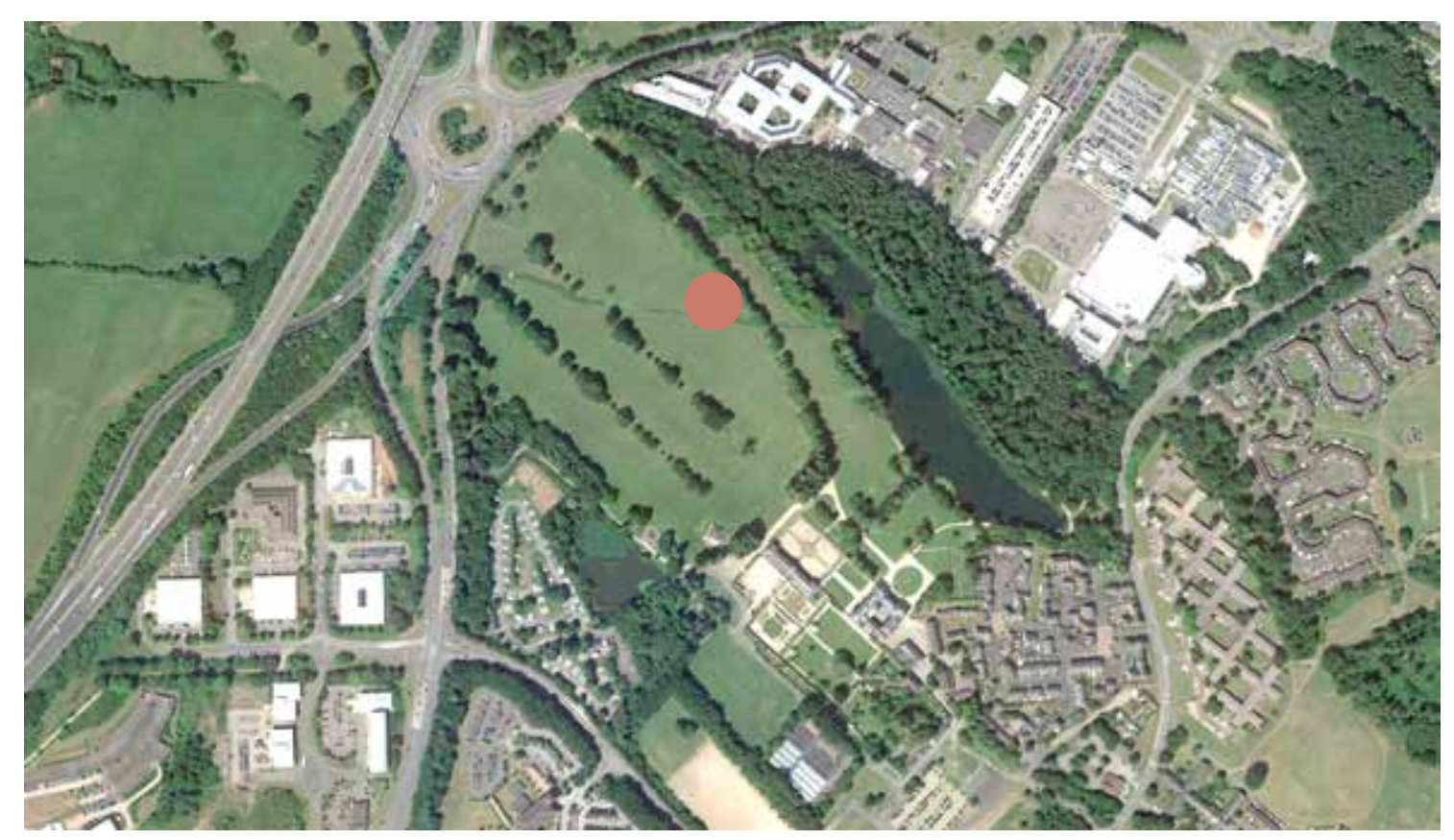

ABOVE

Aerial view of site, Tredegar Park

BELOW

Fig 8.18 Eisteddfod Site Plan - site marked with red boundary

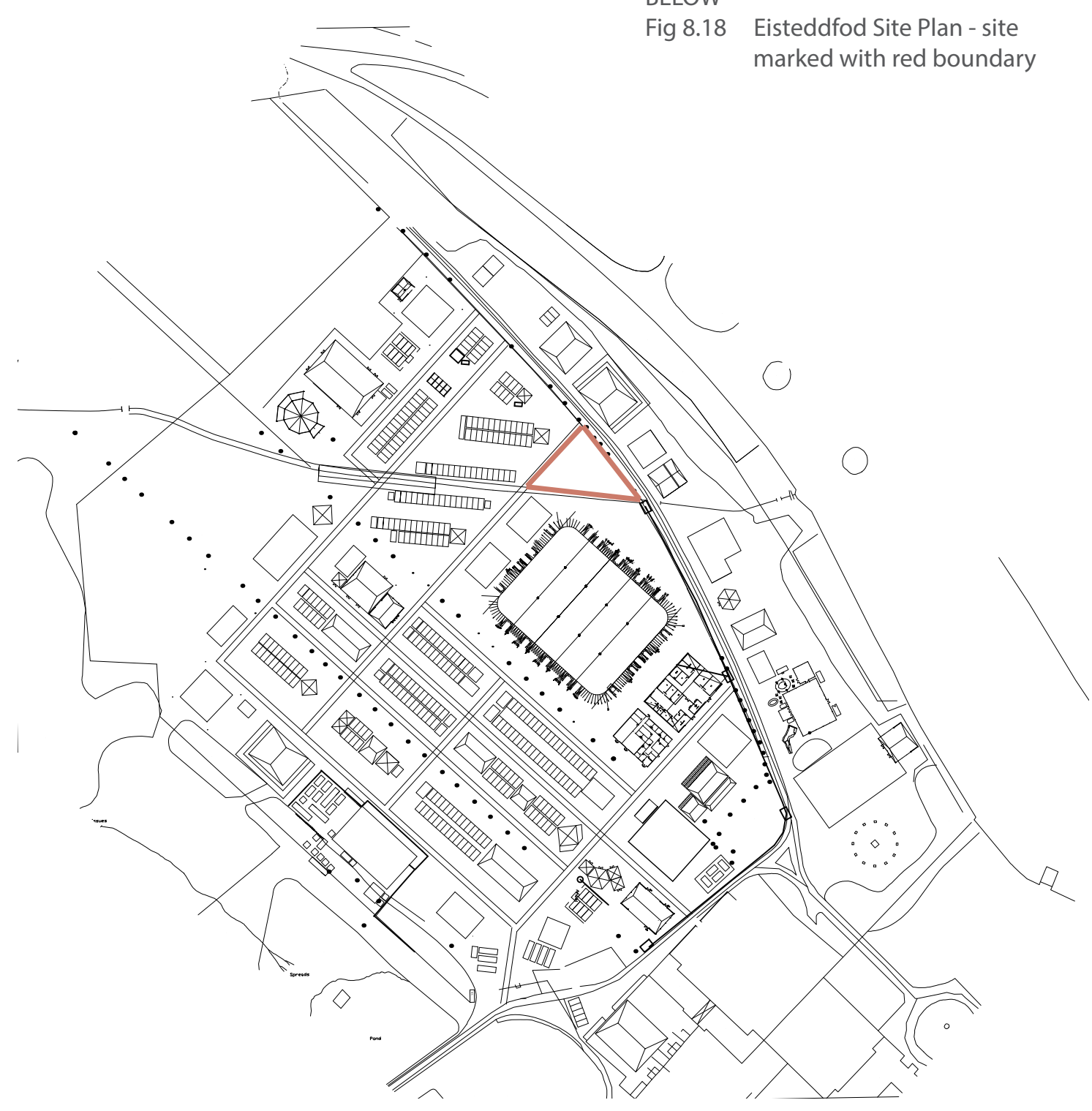

\subsubsection{Site/ location}

The Eisteddfod festival is held annually, in the first week of August, alternating between north and south Wales each year. In 2004, the Eisteddfod was held at Tredegar Park, Newport, south Wales.

Tredegar Park is part of the 90 acres of gardens and parkland of the 17th century, grade I listed Tredegar House, owned by Newport City Council and managed by the National Trust since 2012. The Eisteddfod festival was located in the parkland to the north-west of the house in and around an avenue of mature oak trees extending from the house and formal gardens. The original park is now crossed and bounded by the A48 and M4 to the north, but once extended twice as far. To the south-west is the visitor car park and housing, to the north-east is a business park.

The Eisteddfod had prepared a masterplan for the layout of the festival focussed on the main pavilion with a network of aluminium track footpaths connecting the different zones of pavilions. Normally Cardiff University would be located in one of the cluster of supplied pavilions, but as this was to be a purpose built pavilion, the site for Cardiff University was located on its own plot adjacent to a major path. The site was a triangular, level plot of grassland to the north of the main pavilion, bounded by a row of large oak trees overhanging the site and a parkland track to the east, the Eisteddfod path to the west and a drainage ditch to the south. This provided good access for construction deliveries and on-site storage and fabrication without disruption.

As part of a listed landscape and a public park, the site was to be returned to its original condition following the festival. Therefore the Eisteddfod requested that the pavilion touched the ground lightly with no permanent foundations and all materials removable after the festival.

The parkland had no electricity, water or drainage services that would be required by this pavilion and others. The Eisteddfod provide temporary electricity and water facilities for the duration of the festival from generators and water bowsers. The electricity cable and water pipe were supplied to the pavilion following the aluminium track paths. Waste water was to be disposed of directly into the ground around the pavilion, or collected and disposed of in designated waste tanks if it contained any potential pollutants. 


\subsubsection{Design strategy}

The constraints of time, skills and cost presented DRUw with an opportunity to demonstrate sustainable timber building through a lightweight, modular, demountable, prefabricated construction system. It was based on the standardised boards and timbers readily available at DIY stores and used in almost every domestic construction project for flooring, wall finishes, stud walls, ceilings, furniture, shelving etc. in Wales. This use of timber echoes Konrad Wachsmann, who believed that 'Wood simply as lumber - as traditionally used by the carpenter - is no longer able to meet today's requirements. But as a standardised, machine-produced, pre-fabricated product wood can compete in terms of cost and utility with any other building material. ${ }^{20}$

In this case, a kit of parts from imported machine produced materials were the focus such as chipboard; plywood; oriented strand board (OSB); hard wood-fibreboard and medium-density fibreboard (MDF). These have the advantage of offsetting the use of synthetic-resin or mineral-based adhesives. In this way what are essentially waste or small sections/ lengths of timber that do not have any practical use or downcycled timber from other projects are able to be used. This can be taken further in that if mechanically fixed, these products can be reused again and again.

The vision was therefore for a simple, modular pavilion that could be fabricated and assembled by unskilled labour, of staff and recent graduates of the Welsh School of Architecture, in approximately 2 months that exploits the qualities and adds architectural value to timber board products for use in the building envelope. While adopting a similar constructional approach to the furniture houses by Shigeru Ban, the aim of this pavilion was to build a structure that had the potential to be reused, reconfigured or recycled while minimising wastage, using low-tech processes and the use of appropriate and ultimately flexible passive and active design techniques to provide light and ventilation.

The pavilion was designed to the following concepts:

- Develop a pavilion based on the tectonic principle of platform, storage/ display walls and enclosure.

- Designed to maximise the use of a modular structure as storage and display units.

- The plan and section based on a grid directly informed by the timber board sizes of $1220 \mathrm{~mm} \times 2440 \mathrm{~mm}\left(4^{\prime} \times 8^{\prime}\right)$.

- The natural finish of the board products and modular composition to be

20 Wachsmann, Konrad, Building the Wooden House, (Basel: Birkhauser Verlag, 1995) (first published in German 1930 under the title Holzhausbau - Technik und Gestaltung). 
exposed on all surfaces of components to work as an exhibition space and tectonic experience.

- Use a range of standardised, modular sheet materials from local DIY stores and builders merchants to provide weather protection and cladding.

- Be demountable, reusable and/ or recyclable for future use.

- To be naturally lit and ventilated.

- To be open and inviting to members of the public at the Eisteddfod to experience the Cardiff University work and provoke conversation about the alternative pavilion design.

\subsubsection{Design development}

Board materials, that may be manufactured in Wales from Welsh-grown timber in the future, could obviously be used for the same applications that the imported boards are currently used for. However, it was important that if the Eisteddfod pavilion was to demonstrate a way of working with Welsh boards, the design would need to acknowledge the state of the industry and market that would exist around this. The primary inspiration for the design of this prototype came from the furniture houses by Shigeru Ban, to prefabricate volumetric components that provide the three primary requirements of the pavilion - structure, storage and display, while minimising requirements for finishing treatments.

It was not the intention to merely replicate the designs of the furniture houses, but for the design of the volumetric modules, and therefore the overall pavilion, to be informed by the following considerations that would be specific to this design and the Welsh timber industry:

- the functional performance of different types of board;

- the dimensional opportunities and constraints of board products;

- the physical and sensual properties of different types of boards;

- the likely species used to make the board products; and

- $\quad$ the construction process that unites the above criteria.

Only chipboard and MDF are currently manufactured in Wales, but it has been identified that these two products are the worst in terms of structural performance, durability and moisture resistance as well as having the highest health risks associated with the glues and dust when processing. It was decided that this design would instead focus on the use of plywood and OSB that are commonly imported and used in Welsh construction: 

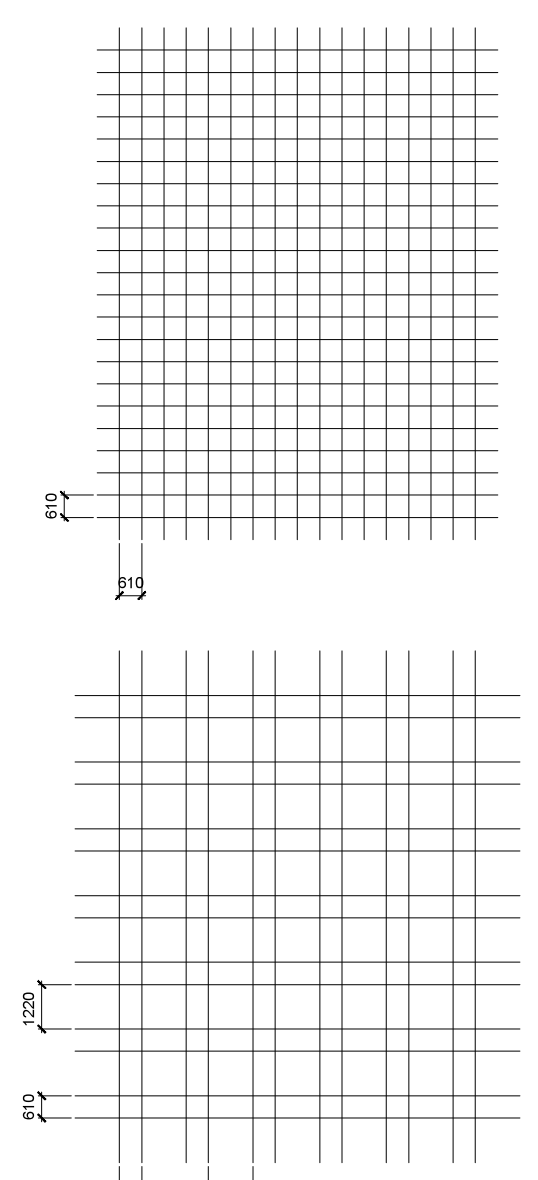

19.1220,
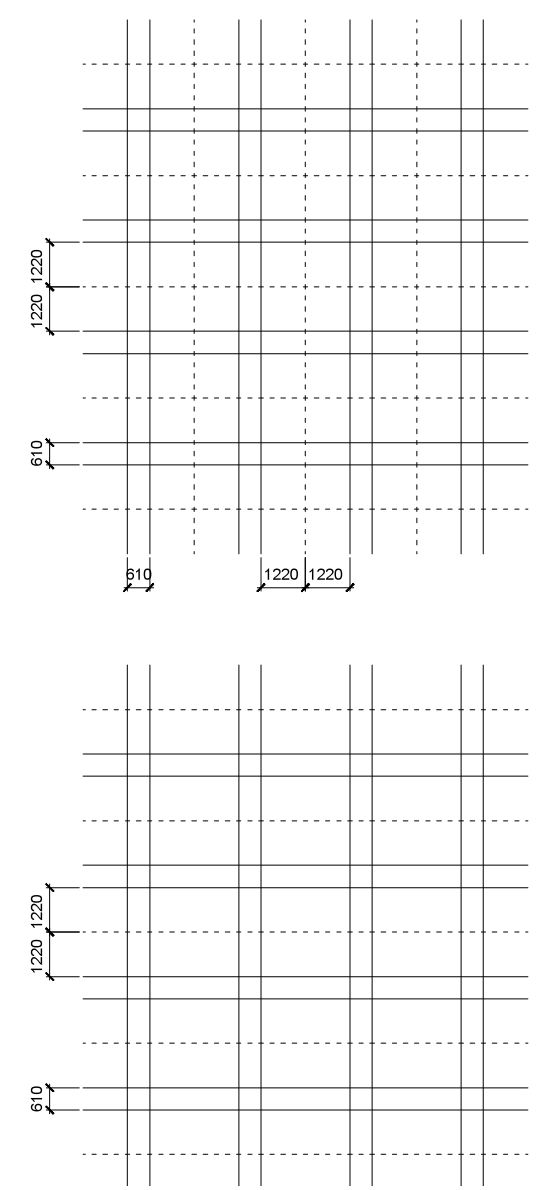

LEFT

Fig 8.20 Grid options to explore standard timber board arrangements

\section{BELOW}

Fig 8.21 Final floor layout grid arrangement yellow - structural zones blue - spatial modules

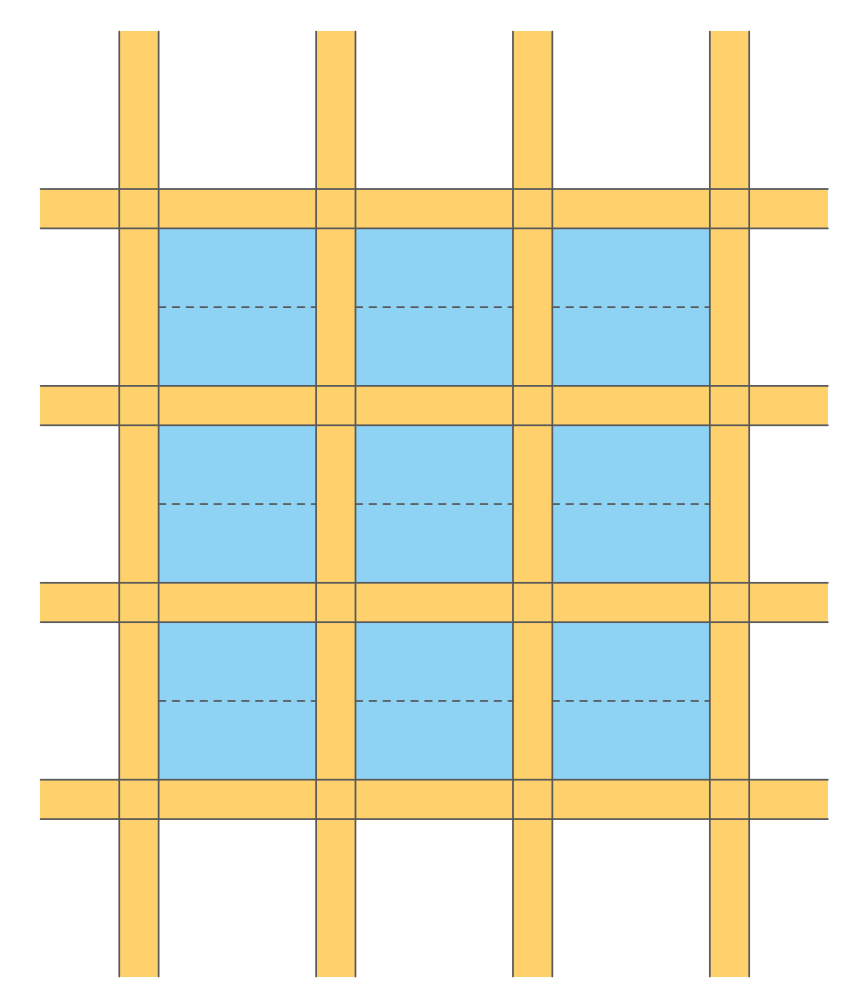

- Wisa spruce and birch plywood, from UPM in Finland, to minimise transport distances and to use boards made from species that are available to use in Wales; and

- OSB/3, from Norbord in Scotland, that is as local as possible to source, thereby also reducing transport and that these boards are made from the same quality spruce, pine and larch that is available to use in Wales.

The design principle was simple and directly informed by the material selection. The standard module and therefore layout and structural grid was based on the standard board sizes of $2440 \times 1220 \mathrm{~mm}\left(8^{\prime} \times 4^{\prime}\right)$. The layout grid was formed on the following principles:

- storage cabinets would be half a board width deep - $610 \mathrm{~mm}$.

- therefore the structural zone on plan was $610 \mathrm{~mm}$.

- Floor and roof spans would be limited to $2440 \mathrm{~mm}$, as the longest length of a standard board product.

- in order to allow for walls in both rectilinear directions a square tartan grid was formed of $2440 \times 2440 \mathrm{~mm}$ bounded by a structural zone of $610 \mathrm{~mm}$.

- This resulted in a floor and roof panel of one board long and 2 wide resulting in a layout and structural grid of A-B-A-B (2440 - $610-2440-610)$ along the length of a board and A-A-B-A-A-B (1220 - $1220-610$ - 1220 - 1220 - 610) across the width.

- This grid was reflected in section and elevation with a full $2440 \mathrm{~mm}$ board for floor - ceiling height.

The resultant grid meant that zones for space and structure were clearly defined and that no span would be larger than $2440 \mathrm{~mm}$. The grid also determined 2 different floor and roof cassette sizes: $2440 \times 1220 \mathrm{~mm}$ and $2440 \times 610 \mathrm{~mm}$ using full or half sheets of OSB/3; and 2 wall unit sizes: W610 x D610 x H2440mm and W1220 x D610 x $\mathrm{H} 2440 \mathrm{~mm}$ using full, half or quarter proportions of a full sheet of birch plywood. This principle provided freedom to locate wall units anywhere within the $610 \mathrm{~mm}$ zone on plan. 


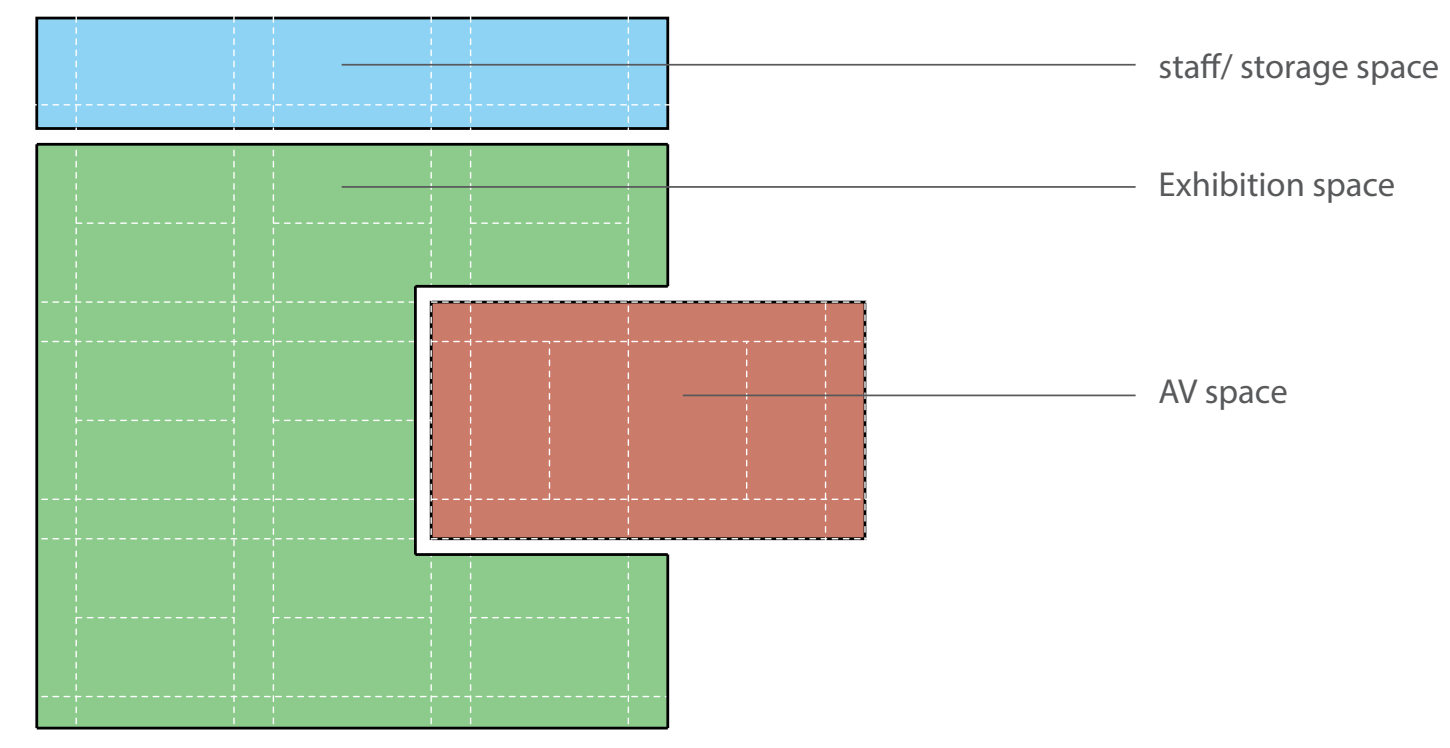

The final plan arrangement was based on the need for 3 activity zones:

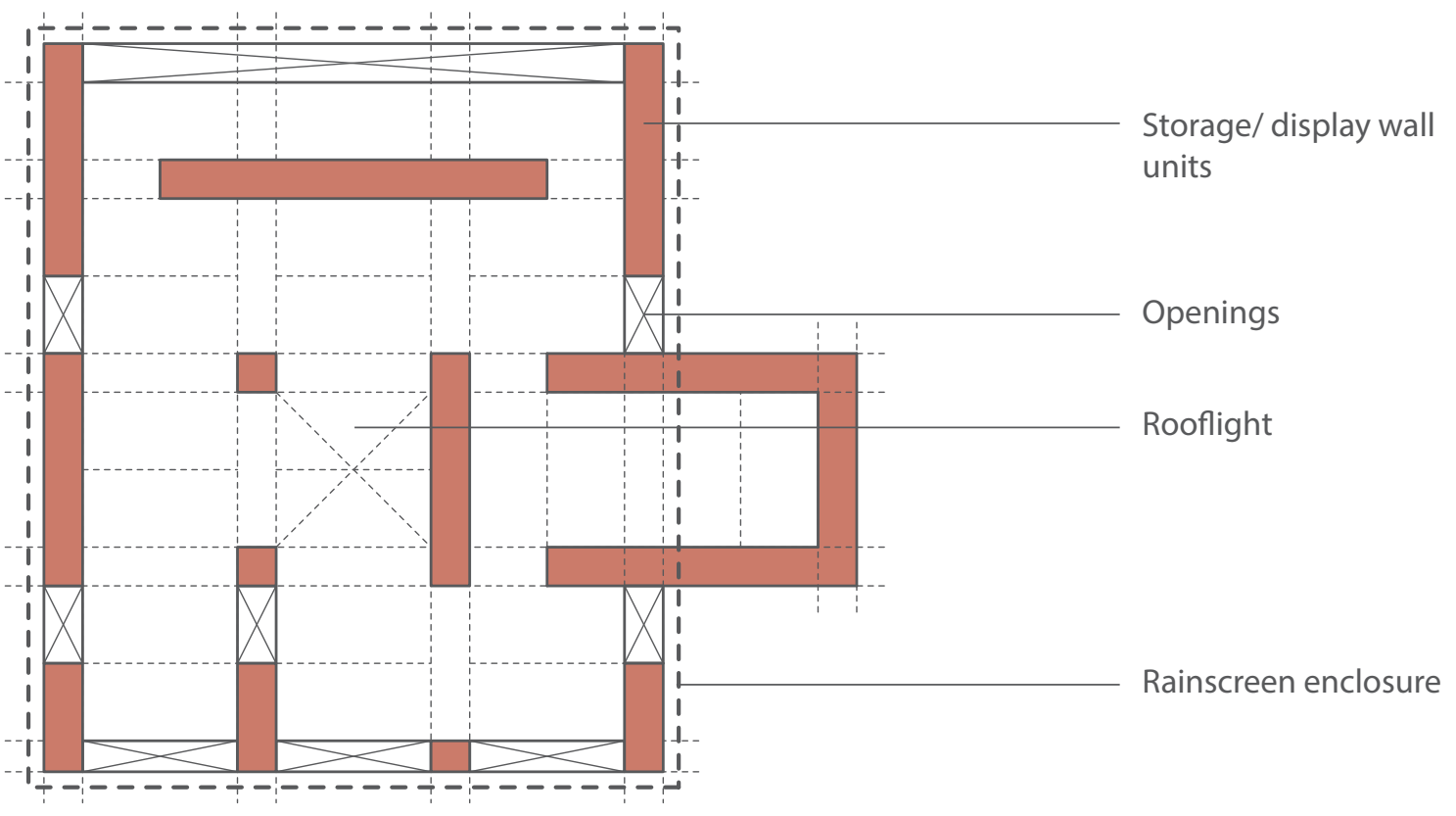

- an exhibition space;

- $\quad$ a dark, AV space for video projection; and

- a private staff space for storage and drinks.

A variety of arrangements were explored balancing quality of natural light, flow of space and openness to the public resulting in the final plan. The entrance was opened up to the main Eisteddfod path to maximise entry and invitation, while the staff area was located to the rear south elevation. It was the intention that every wall unit would provide an opportunity to exhibit work on the wall or inside depending on the requirements of the school. To avoid breaking the flow of the exhibition

floor space, the AV zone was conceived as a 'box' that would protrude from the west elevation, facing the main approach that visitors would experience.

To maintain the simple notion of platform, wall and enclosure and provide natural daylight into the pavilion, the structural exhibition walls were to be clad with translucent sinusoidal GRP sheets following the same rhythm of the layout grid. The elevations of the AV 'box' and northern entrance elevation were to be branded with the University red and logo using powder coated flat steel sheets.

As a temporary pavilion for summer use, it was not the intention to fully seal and insulate the building envelope, but to use passive design techniques to provide light, heat and ventilation to create a comfortable environment. The following were incorporated into the building envelope, manipulating and further enhancing the design strategy:

- no window units were included, instead to enhance the strategy of walls and enclosure units were omitted to create a $1220 \mathrm{~mm}$ wide voids for side lighting and entrance.

- the south elevation was to be exploited for natural solar gains to provide a thermal buffer to the rear of the pavilion.

- the rainscreen enclosure would not be airtight, providing intentional gaps at the bottom of the cladding below floor level and at top of the rainscreen providing natural ventilation to control solar gain and encourage air flow on warm days.

- A roof light as part of the rainscreen roof was located in the centre of the plan to naturally light the exhibition space but also provide a central focus and depth when viewed from outside. 


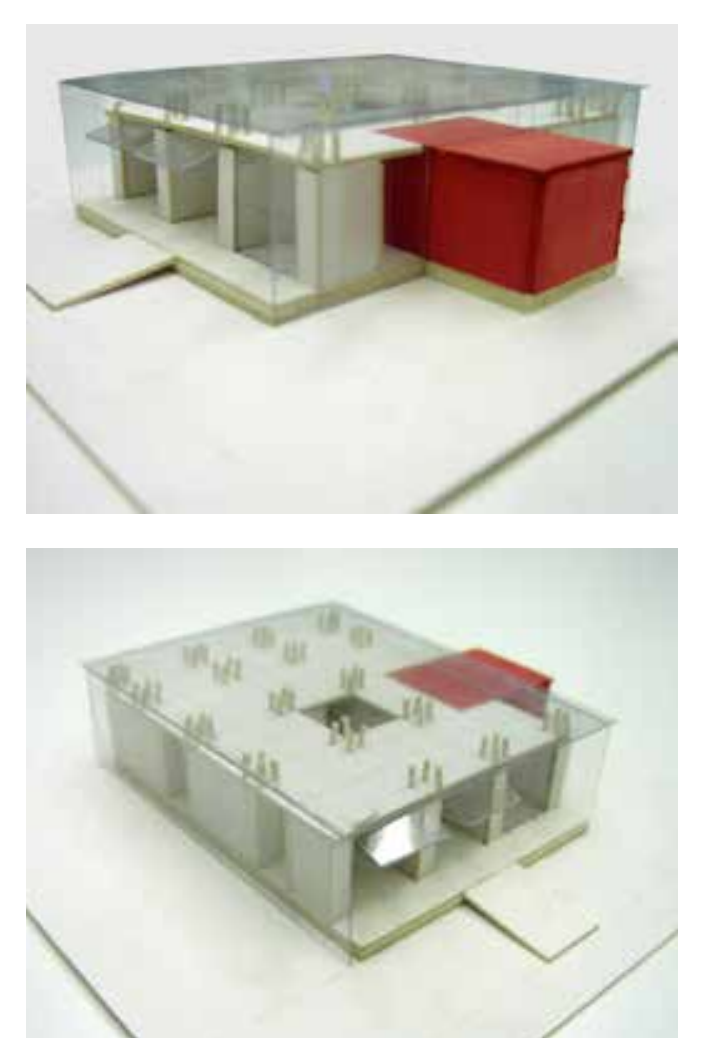

LEFT 8.24 Early concept model with separated structure and enclosure

BELOW

Fig 8.25 Proposed section BB

Fig 8.26 Proposed section AA

RIGHT

Fig 8.27 Proposed floor plan

Fig 8.28 Proposed front elevation
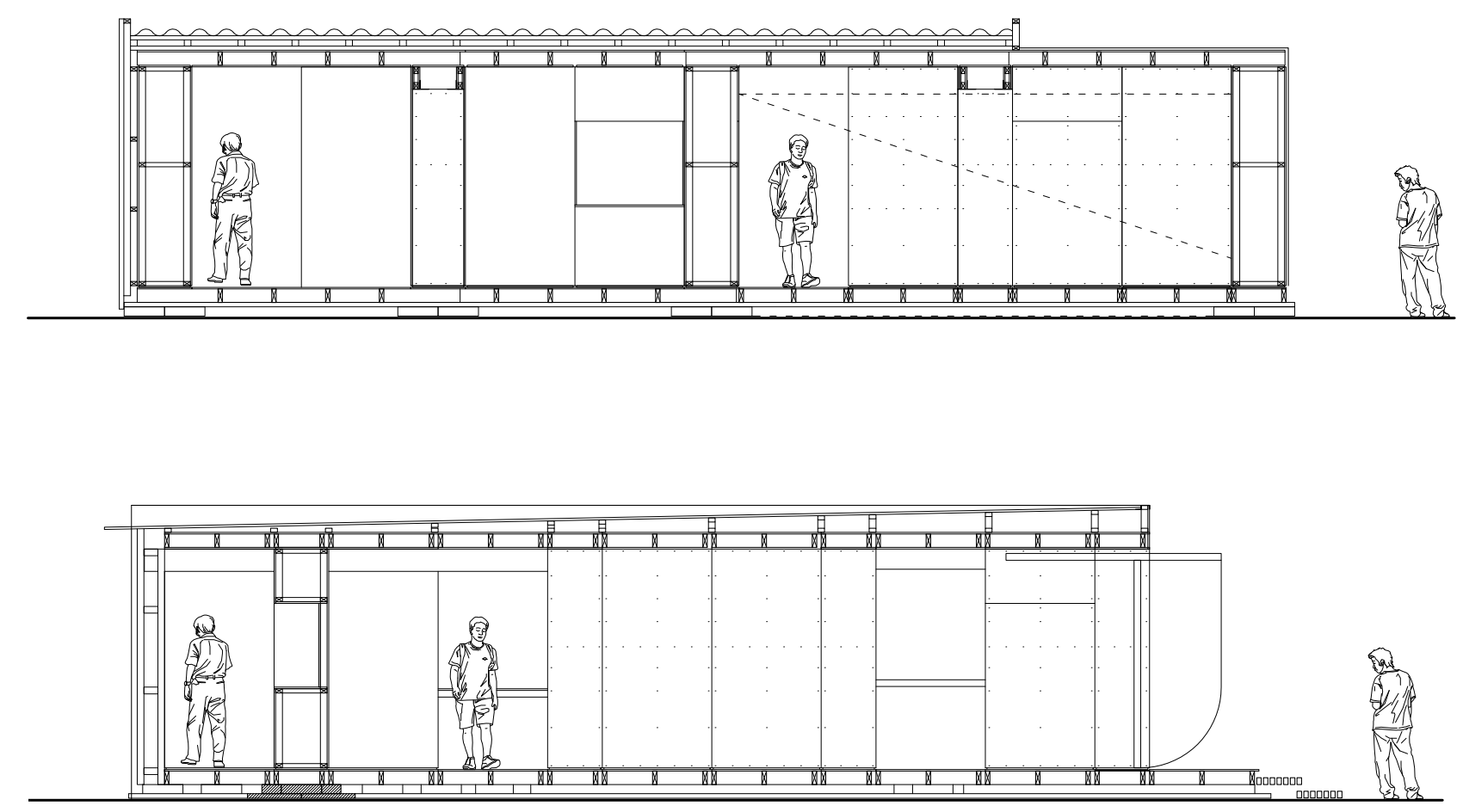

\section{Design drawings/ model}

The following basic arrangement drawings and conceptual model were prepared as the basis of the intended design. These drawings were continually evolving as the fabrication, construction and material sourcing developed the design.
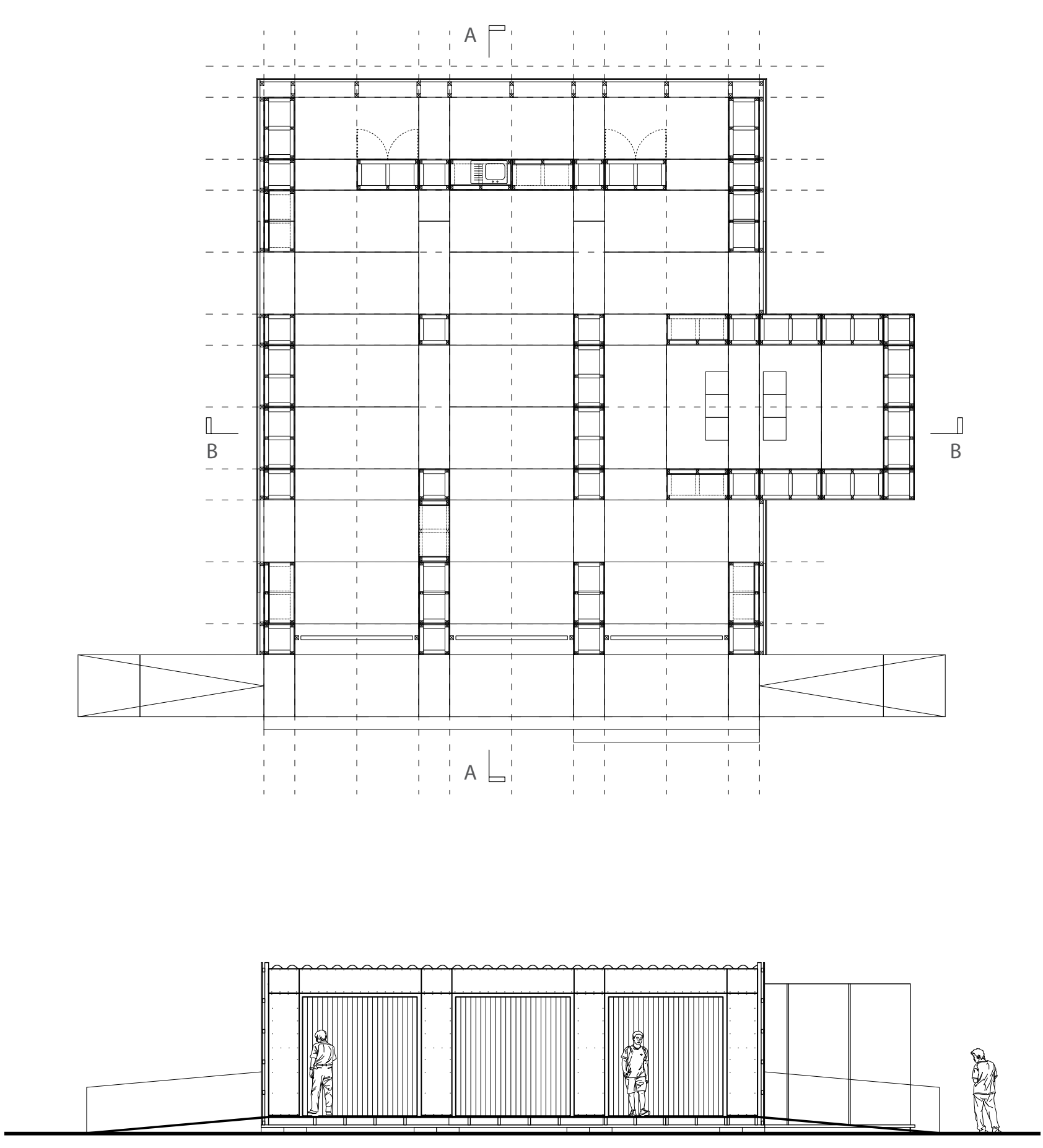


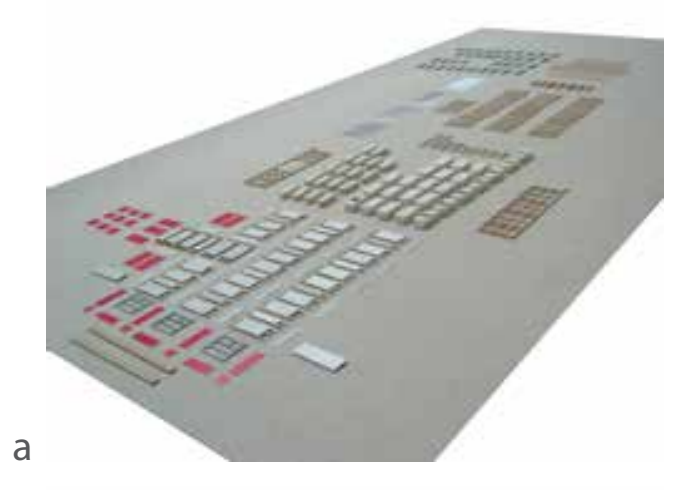

\subsubsection{Prototype}

The timeframe in which to deliver the pavilion meant that the typical sequential processes of design, fabrication and assembly did not always occur in a chronological sequence and were at times happening simultaneously. 'Desktop' detail design drawings were prepared ready for each stage, but were often refined and altered in the workshop while fabricating components. The processes, techniques and details of fabrication and assembly were continually reflected upon as the project developed, feeding back into the overall tectonic. However, for ease of critical reflection and relevance to this study the key prototype stages influencing the final tectonic have been identified as the sequential detail design including structural engineering and fabrication and assembly.

\subsubsection{Detailed design}

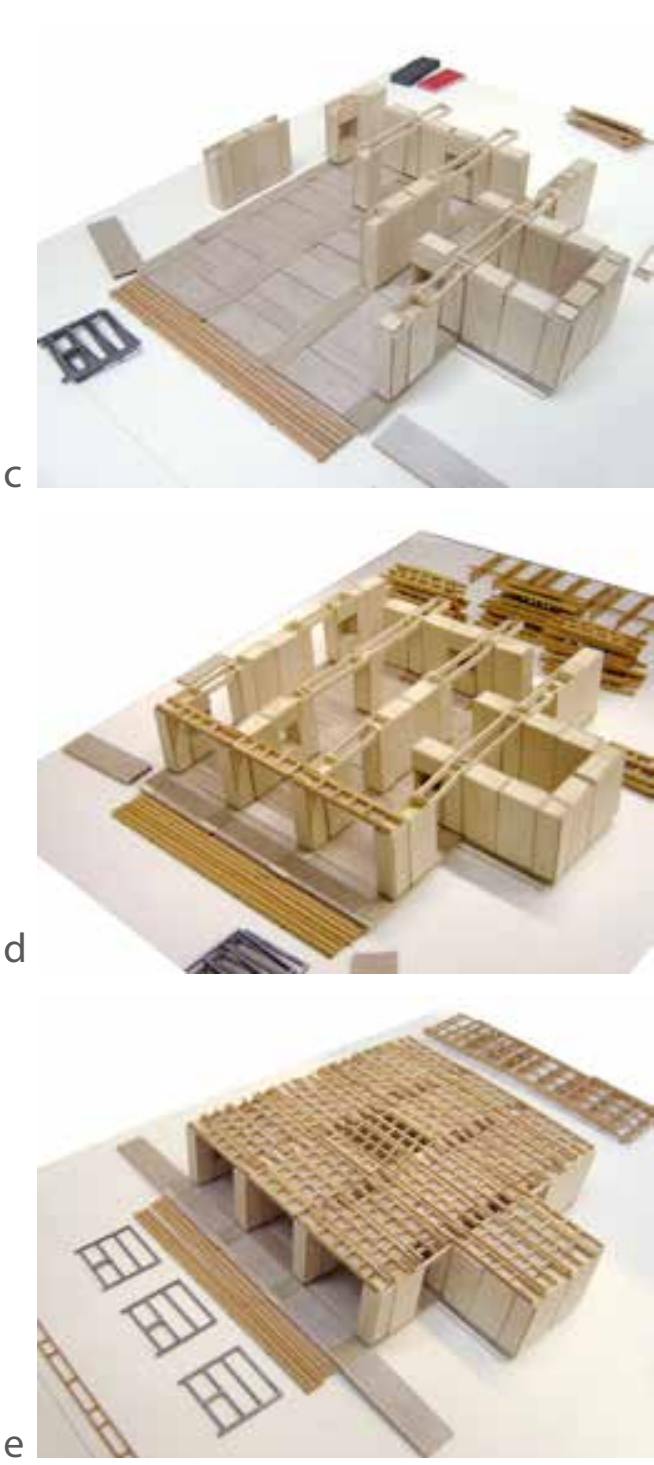

Fig 8.29 Sequence of construction demonstrated using a 1:20 tectonic model

a. all prefabricated parts laid out prior to assembly

b. floor cassettes and AV bay

c. wall units added

d. box beams positioned over wall units

completed roof cassette structure

The need to keep costs low and the speed of the detailed design and fabrication stages meant that material specification and sourcing was opportunistic. Materials were sourced locally and to be available immediately, with adaptation required to accommodate any differences between sourced material and design intention. This complemented the aim to use standard DIY materials, including any timber products, that would be available to any local consumer or contractor in south Wales. The materials would therefore, not necessarily be manufactured in Wales but would be supplied off-the-shelf.

It was the intention that all aspects of the construction, from timber boards to the standardised sheet sizes of profiled steel roofing and cladding, avoided the need for any site cutting with every effort taken to use the materials as bought off-the-shelf. All the fixings were to be mechanical, through the use of screws or bolts to enhance the ability to reuse, recycle and downcycle the components at a later date. The detailing eliminated the need for nails and wet trades that would hinder the ability to dismantle the pavilion.

The preparation of production information including building regulations and structural engineering are described in the following sections.

\section{Building control}

As a publicly accessible temporary structure, the pavilion was required to comply with building regulations to maintain the safety of the public. This primarily required meeting the 2004 regulations relevant to maintaining safety and access dealt with under the Approved Documents, Part A: structural safety, Part B: fire safety, Part K: 

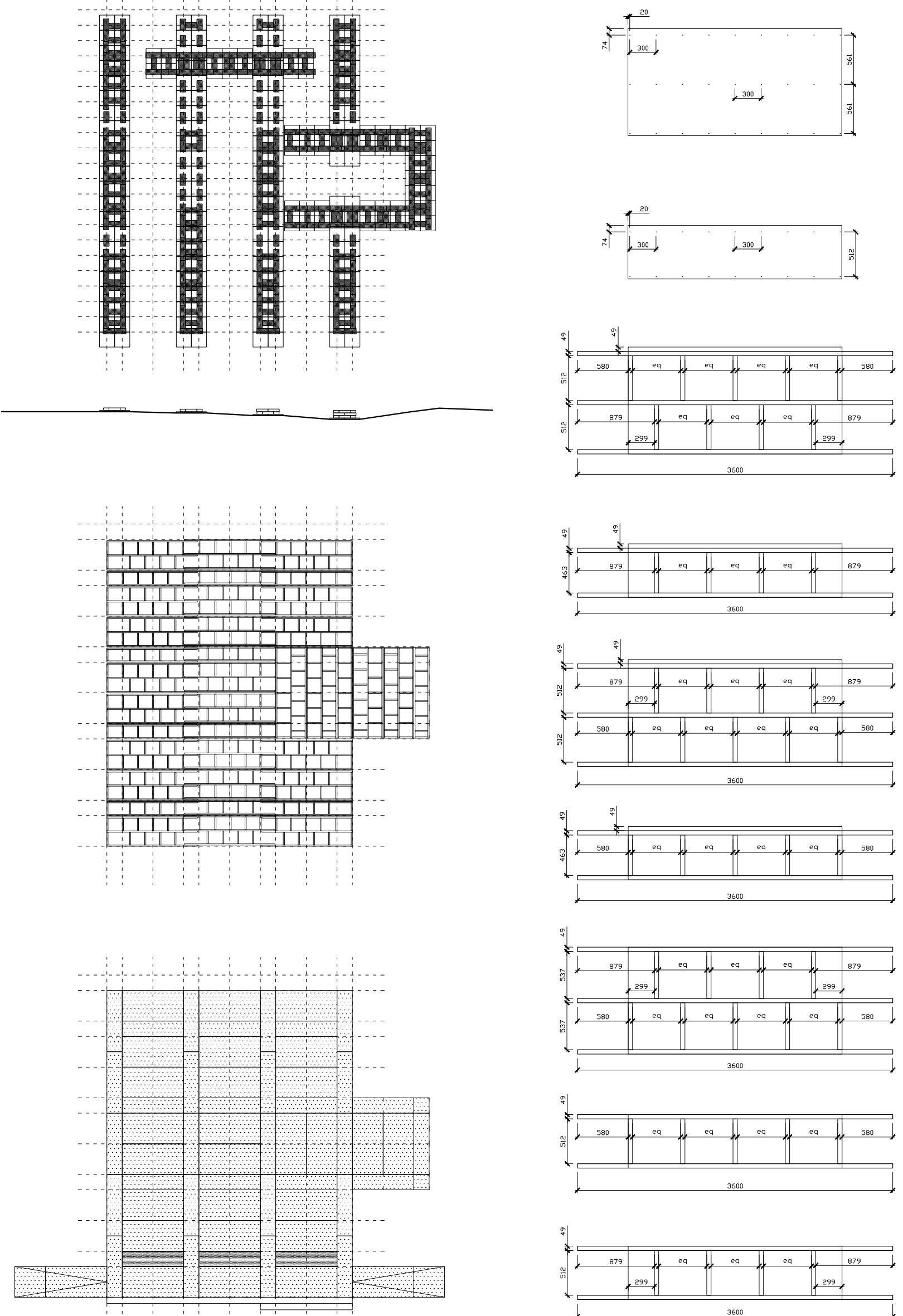

Fig 8.30 Foundation GA plan Fig 8.31 Floor cassette GA plan Fig 8.32 Floor deck GA plan
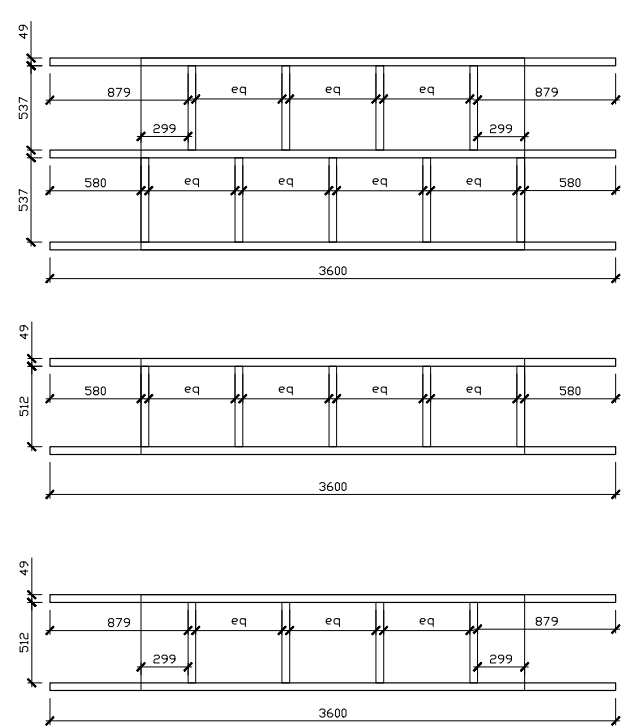

Fig 8.33 Floor cassette fabrication drawings for each type protection from falling and Part M: access. These will be discussed as appropriate below.

\section{Structural engineering}

The structure was required to meet Approved Document Part A. The primary concerns were:

- no foundations meant that the pavilion could be at risk of differential settlement or susceptible to movement from wind loading and wind uplift.

The engineer confirmed that as a summer pavilion standing for approximately 1 month from assembly to dismantling that the platform floor would distribute relatively lightweight loads evenly without risk of extreme settlement. However, the weight of all components fixed to each other would counteract expected wind loadings.

- To resist racking and torsional movement due to wind loads, the perpendicular walls of the storage wall and AV box were essential to brace against the predominantly parallel walls.

- Due to the numerous, independent prefabricated components, the pavilion floor and roof were required to act as diaphragms distributing wind loads into perpendicular walls. All wall components must therefore be connected to each other, the floor and roof to act as one structure.

The sizing and structure of components, were either specified using timber span tables to size joists for floor and roof for a domestic project, or by the structural engineer for wall structure and quantity and positioning of fixings.

\section{Foundations}

The site was relatively level with a $300 \mathrm{~mm}$ difference in level across the footprint. To ensure a level platform, concrete paving slabs and dense concrete blocks were to be laid and stacked as strip foundations under all wall positions to distribute loads evenly. To accommodate any minor differences in level 150 x 50 x 3600mm (6" x 2") softwood joists laid on their side as bearers were to distribute loads further.

\section{Floor cassette details}

The plan was based on $26 \mathrm{no} .2440 \times 1220 \mathrm{~mm}$ and $12 \mathrm{no} .2440 \times 610 \mathrm{~mm}$ floor cassettes, using a full or half width sheet of $18 \mathrm{~mm} \mathrm{OSB} / 3$ with $150 \times 50 \times 3600 \mathrm{~mm}$ (6" $x 2^{\prime \prime}$ ) floor joists and noggins screwed to the underside. The OSB was to be fixed to the joists at maximum $300 \mathrm{~mm}$ centres, with staggered noggins at maximum $600 \mathrm{~mm}$ centres. The joists would protrude $600 \mathrm{~mm}$ either side so as when positioned in rows they would interlock with one another over the foundations and under where the 

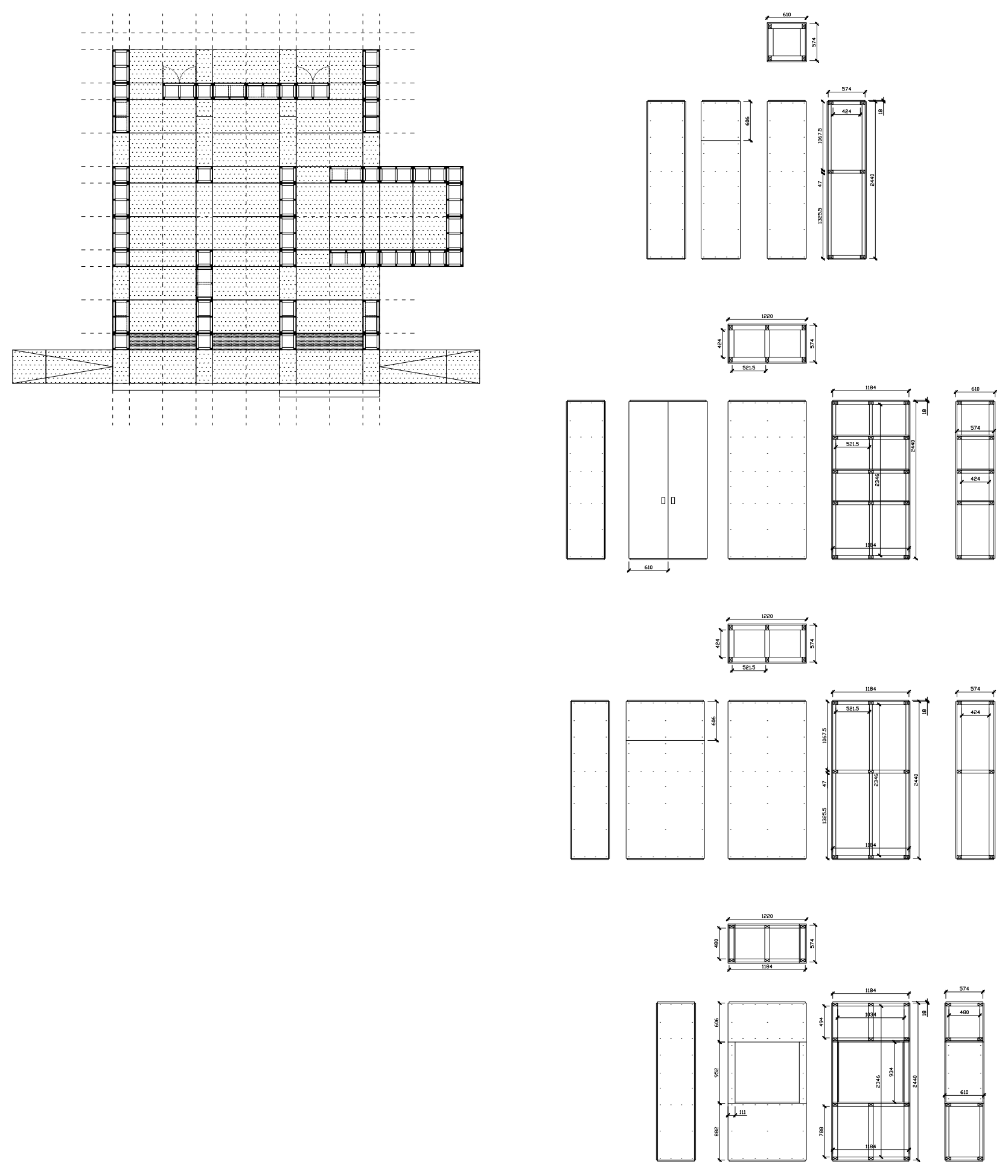

ABOVE

Fig 8.34 Wall units GA plan

RIGHT

Fig 8.35 Wall unit fabrication drawings of different types highlighting stud frame, plywood sizes and screw positions wall units would be fixed. Loose 2440 x $610 \times 18 \mathrm{~mm}$ OSB/3 sheets were laid over the interlocking zone, offset with the gird to join all cassettes into one platform.

The floor and access ramps were to meet Approved Document Parts K \& M. The entrance ramps were designed to a 1:12 gradient for a $300 \mathrm{~mm}$ change in level from path to pavilion with appropriate handrails. The main floor was level throughout with openings wide enough for wheelchair access and turning circles.

\section{Wall unit details}

After considering the types of display and locations for exhibits, the walls were detailed to include five types of unit to be used for display space, shelving, storage and structure all based on the two module sizes as determined by the layout grid:

- 18 no. $610 \times 610 \times 2440 \mathrm{~mm}$ structural units;

- 15 no. $1220 \times 610 \times 2440 \mathrm{~mm}$ structural units:

- 7 no. $1220 \times 610 \times 2440 \mathrm{~mm}$ units with display space;

- 2 no. $1220 \times 610 \times 2440 \mathrm{~mm}$ cupboards; and

- 1 no. $1220 \times 610 \times 2440 \mathrm{~mm}$ unit with void through

All units were to be fabricated from sheets of $18 \mathrm{~mm}$ birch plywood. However the need for wall space to display posters and only limited storage requirements meant that the majority were to be structural without using the enclosed volume. Unlike the Shigeru Ban furniture houses, the units were all designed to incorporate a volumetric framed carcass using $75 \times 50 \mathrm{~mm}\left(3^{\prime \prime} \times 2^{\prime \prime}\right)$ softwood studwork. The $18 \mathrm{~mm}$ plywood was to be screwed to this frame on all 4 side faces, top and base to brace the frame, provide finished wall surfaces and generate an $18 \mathrm{~mm}$ shadow gap at floor and ceiling.

All wall units were specified to be left unfinished with exposed, countersunk screw heads allowing the birch plywood to breath, expressing its properties and internal structural carcass. Screws were detailed to be at maximum $300 \mathrm{~mm}$ centres and to align across all unit types, to maintain design continuity across internal elevations.

\section{Ply box beams}

As natural lighting was to be provided by omitting wall units and allowing light to filter through the translucent cladding, beams were required to: support the roof cassettes over the side openings; to create the $1220 \mathrm{~mm}$ cantilevered roof to the southern staff area; and where wall units had been omitted to open up the exhibition space and AV box. To standardise the palette of materials and tectonic language these $250 \mathrm{~mm}$ deep beams were fabricated as ply box beams using a $75 \times 50 \mathrm{~mm}$ 

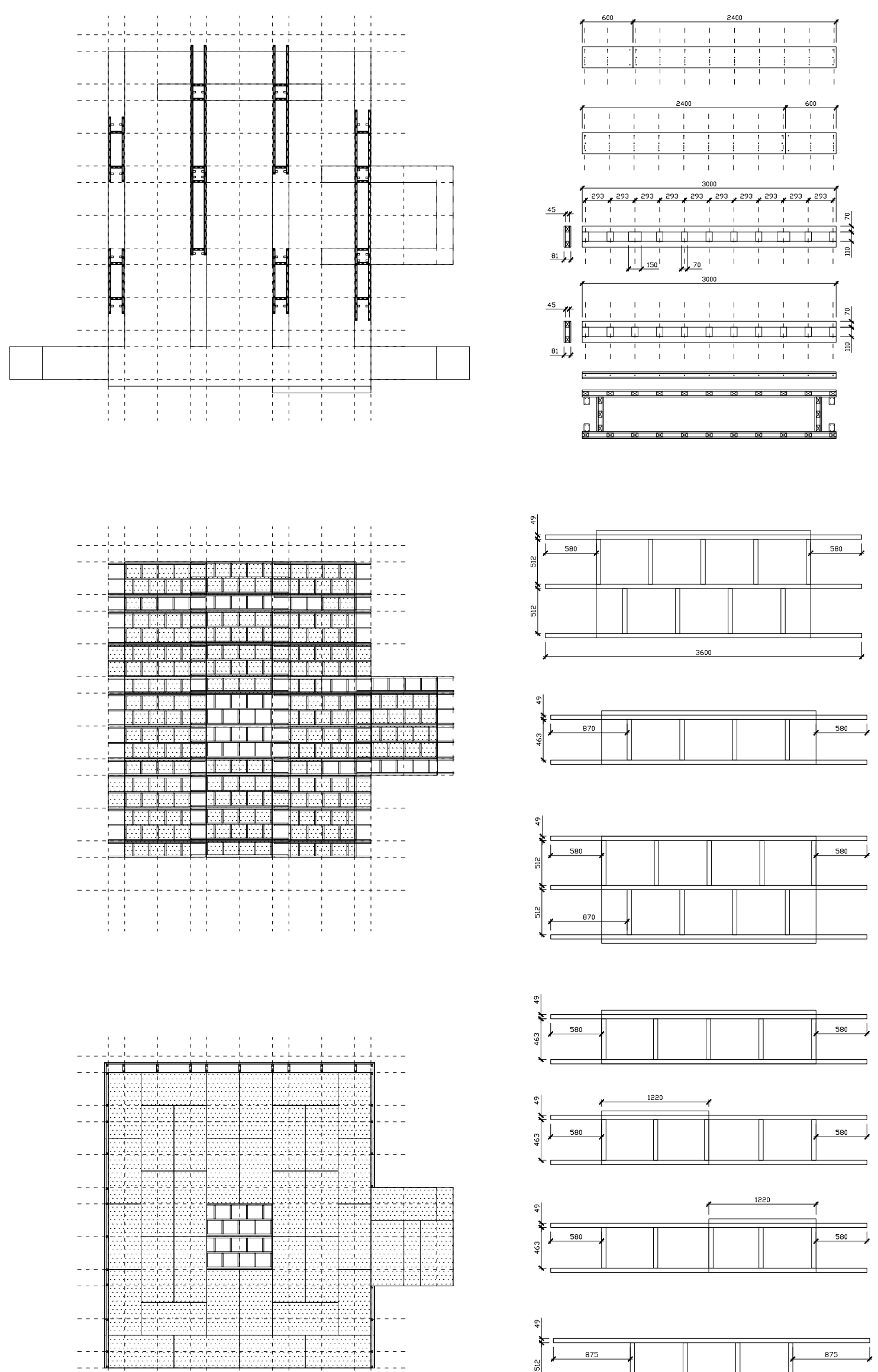

Fig 8.36 Box beam arrangement plan

Fig 8.37 Roof cassette GA plan

Fig 8.38 Diaphragm roof deck GA plan

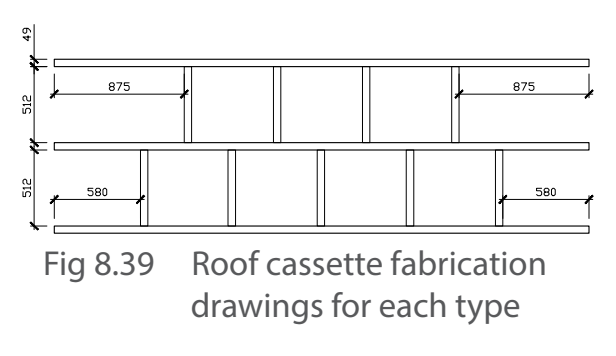

$\left(3^{\prime \prime} \times 2^{\prime \prime}\right)$ softwood frame and $250 \mathrm{~mm}$ plywood strips screwed at $300 \mathrm{~mm}$ centres to the frame. 3 beam lengths were required: 2400, 3600 and $4800 \mathrm{~mm}$ that would be bracketed with screws to the tops of the wall units.

\section{Roof cassette details}

Essentially the roof structure was a mirror image of the floor cassettes with 2 sizes and 3 different types interlocking over the wall units or beams, with the OSB facing down to provide the ceiling finish and bracketed and screwed to the top of the wall units:

- $14 \mathrm{no} .610 \times 2440 \mathrm{~mm}^{-}$

- 21 no. $1220 \times 2440 \mathrm{~mm}$; and

- 2no. $1220 \times 2440 \mathrm{~mm}$ units without OSB/3 for the rooflight opening;

To ensure the roof acted as a diaphragm and to meet Part $\mathrm{A}$ of the building regulations, full or half sheets of $18 \mathrm{~mm}$ OSB/3 were loose laid in a staggered arrangement over the cassettes and screwed down at $300 \mathrm{~mm}$ centres.

\section{Cladding and roof rainscreen enclosure}

The cladding on the east, west and south elevations was to be supported with $75 \times 50 \mathrm{~mm}$ horizontal battens and vertical counter battens to create a tectonic separation between walls and enclosure and allow for external lighting. 2 standard sizes of translucent sinusoidal GRP sheet 12' x 30" (3656 x 762mm) and 6' x 30" (1828 $x 762 \mathrm{~mm}$ ) were to be overlapped as required to fit the proportions of the pavilion. The AV box was clad in red powder coated flat steel sheets 600 and $1200 \mathrm{~mm}$ wide, screwed to the units with a breather membrane in between, reflecting the layout grid behind. 8' x 30" $(2440 \times 762 \mathrm{~mm})$ GRP sheets were fixed to up and over garage door frames on the north elevation to create 3 fully openable entrances.

The roof was finished with Euroclad 32/1000F trapezoidal sheets $1060 \mathrm{~mm}$ wide by $3300 \mathrm{~mm}$ long with a 2 degree pitch, falling $300 \mathrm{~mm}$ along the length of the pavilion from north to south. 2 no. $1060 \times 3300 \mathrm{~mm}$ translucent GRP sheets to match the steel profile were laid over the central roof light. The fall was created with $75 \times 50 \mathrm{~mm}$ softwood purlins spaced to match the vertical wall battens and layout grid. 

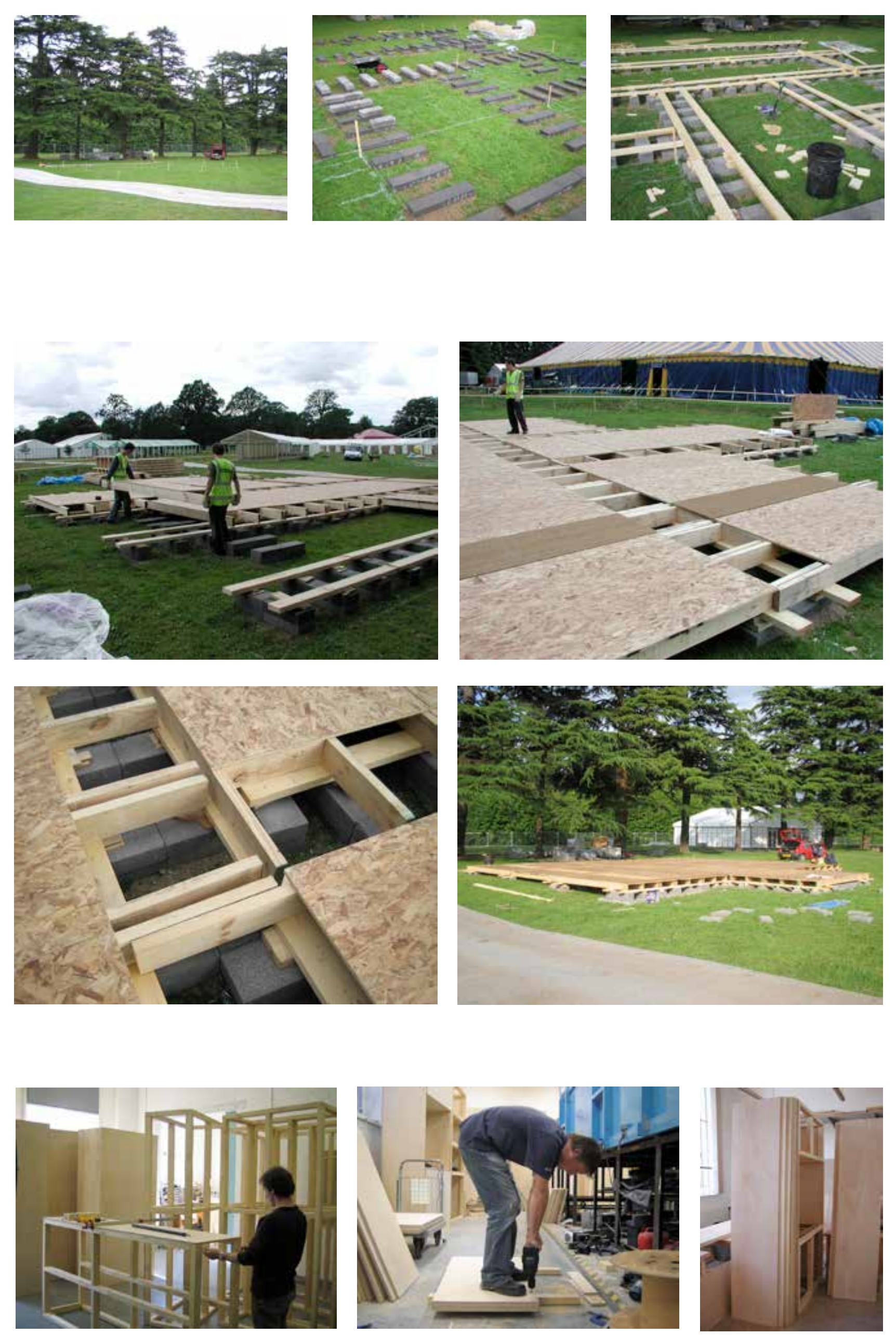

\subsubsection{Fabrication and assembly}

The pavilion was prefabricated in a small wood workshop, within the Welsh School of Architecture, with limited hand and power tools before being transported to site and assembled in concurrent phases over 2 months prior to the start of the festival. The following photographs and annotations represent the significant stages of the fabrication and on-site assembly sequence, presented as a sequence from start to completion.
TOP LEFT

Fig 8.40 Setting out and foundations

a. the site was marked out; b. concrete block and

paving slabs were laid on the grass with sand

binding; c. $150 \times 50 \mathrm{~mm}$ sw joists were used as

bearers.

MIDDLE LEFT

Fig 8.41 Floor cassettes assembly

a. floor cassettes were moveable by 2 people;

b. cassettes were laid directly onto bearers

without brackets with the $610 \mathrm{~mm}$ interlocking

slot left to be covered by loose $610 \times 2440 \mathrm{~mm}$

$\mathrm{OSB} / 3$ sheets. c. twisting movement in the

joists resulted in larger gaps than allowed for; $d$.

finished floor deck.

BOTTOM LEFT

Fig 8.42 Wall unit fabrication

a. $75 \times 50 \mathrm{~mm}$ softwood carcass; b. pilot

holes were drilled through multiple sheets in

preparation for screwing to frames; $c$. wall unit with sink 

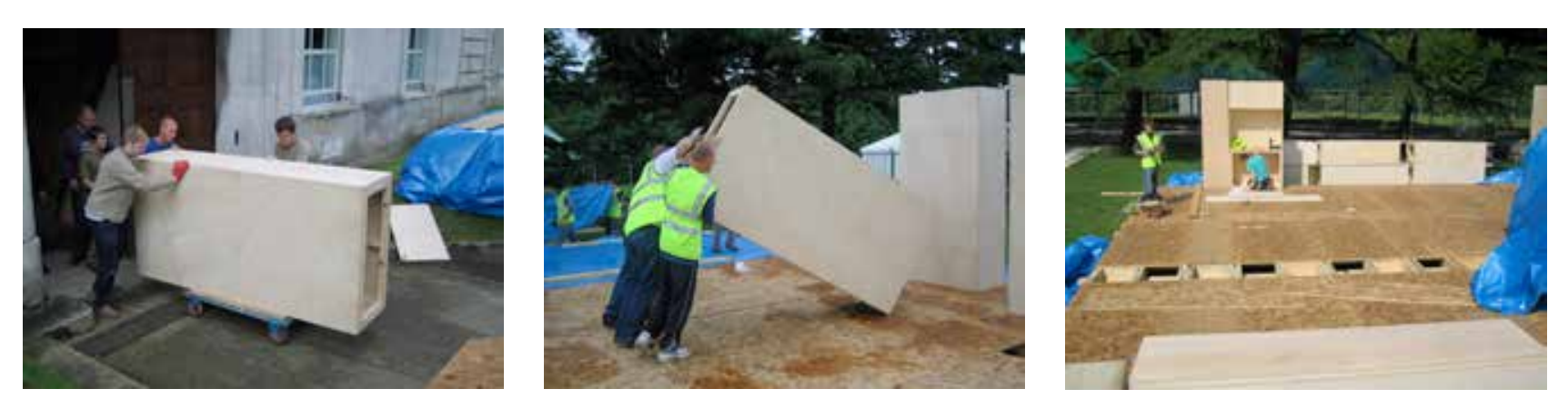
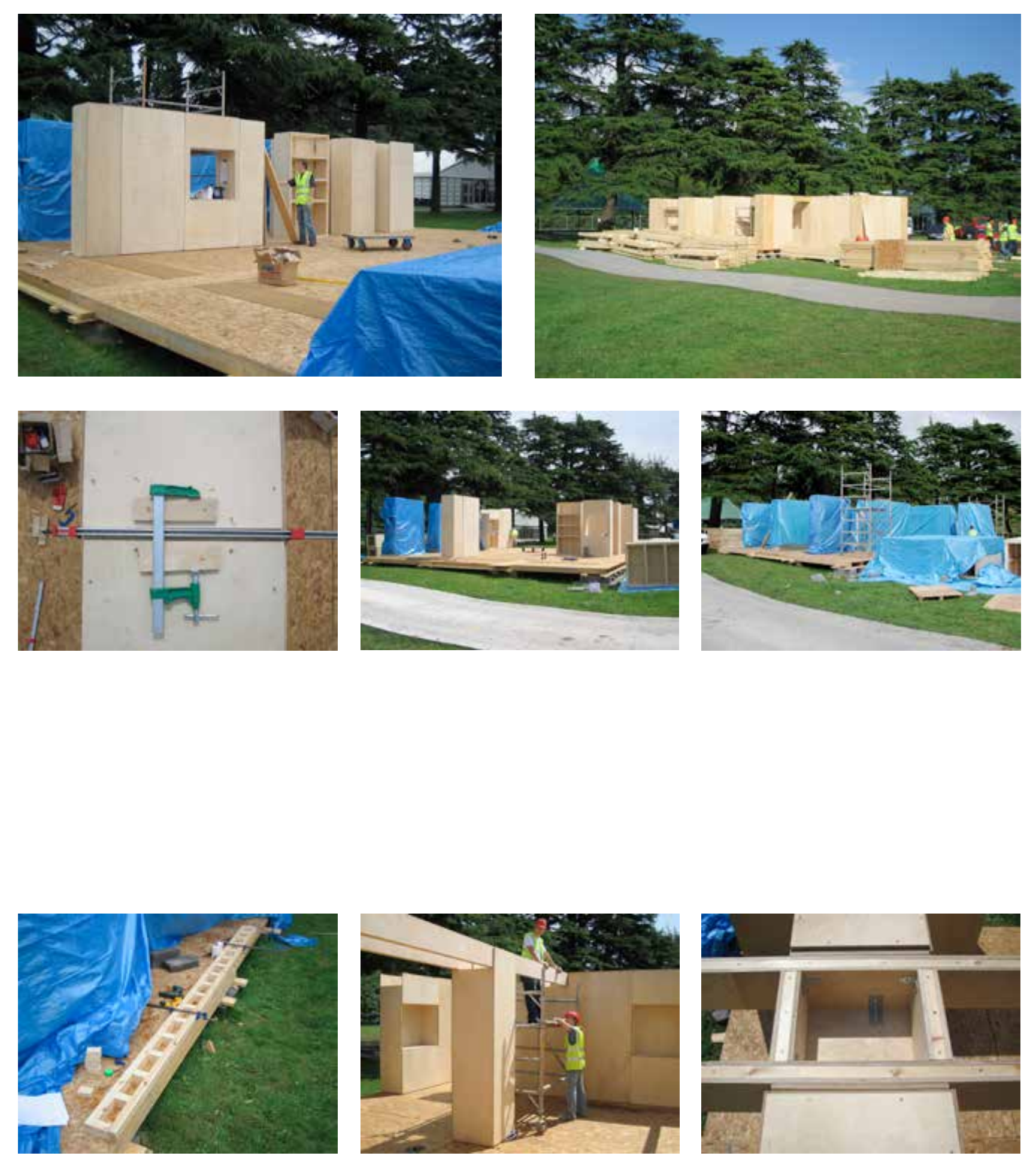

TOP LEFT

Fig 8.43 Wall unit delivery

a. Wall units transported by trolley and removal

lorry; b. Wall units lifted and rotated into place

by 4 people; c. Fronts removed to allow wall

units to be screwed down to deck and to each

other

MIDDLE LEFT

Fig 8.44 Wall unit assembly

a. wall units initially sorted and moved into

location; b. clamps and packing required to align

the units with each other due to slightly uneven

floor and twisting of wall modules; c. birch

plywood of wall units required protection from

moisture to protect final finish; d. All wall units in

position.

BOTTOM LEFT

fabrication and installation

a. ply beams fabricated from $75 \times 50 \mathrm{~mm}$

softwood; $b$. beams installed into notches in top of wall units; c. beams bracketed/ screwed to top of wall units with noggins between.

RIGHT

Fig 8.46 Roof cassettes assembly sequence a. roof cassettes were sorted and stacked ready to be lifed, b. an extencable forkift truck was used to lift all the roof cassettes into position due to Health and Safety risks; c. roof cassettes in position with centre left clear for roonght, d. roof cassettes bracketed to tops of wall units; e. OSB/S sheets loose laid and screwed to provide diaphragm action.
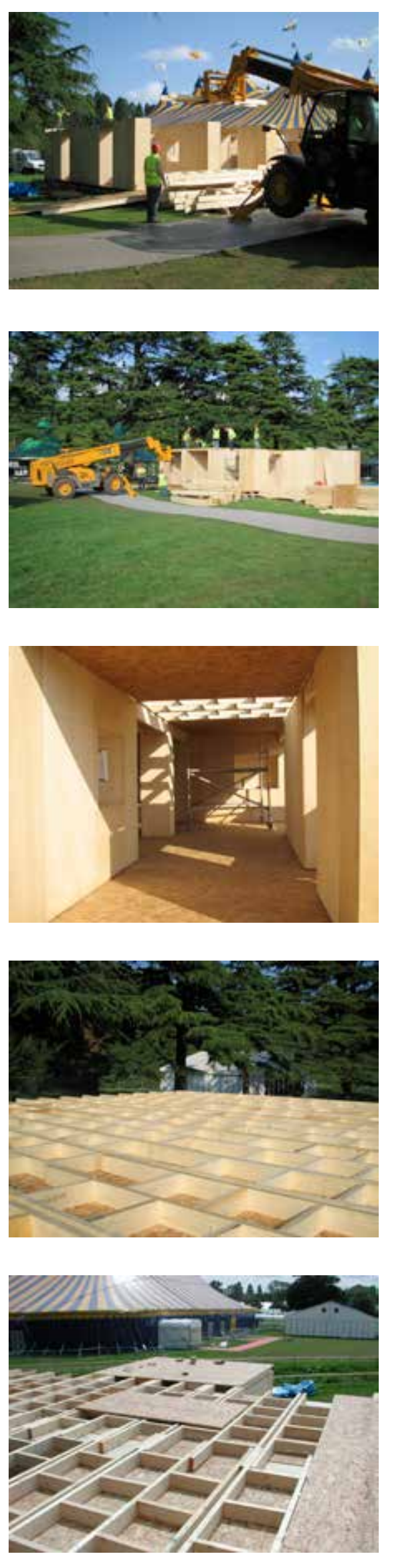

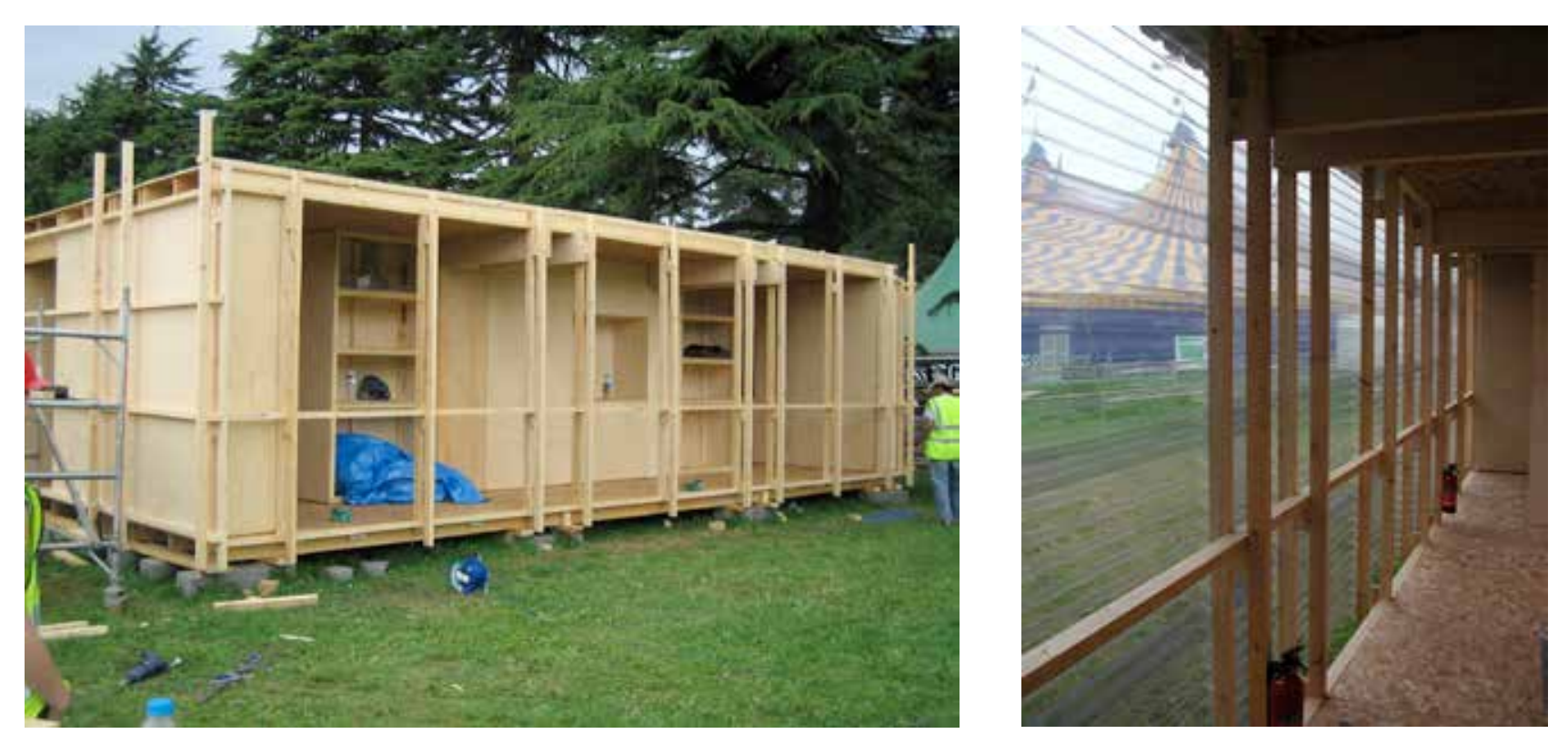
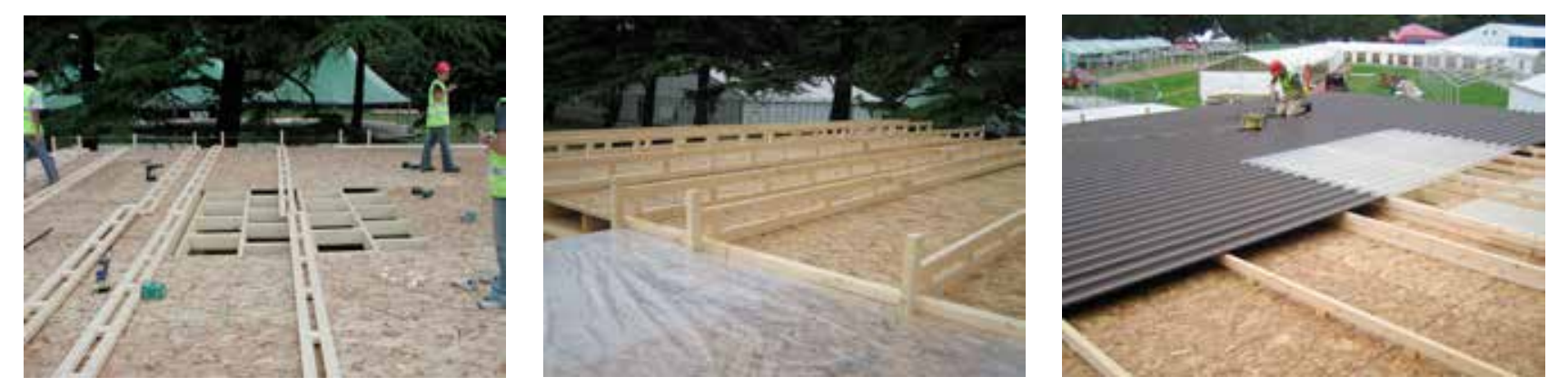

TOP LEFT

Fig 8.47 Installation of wall cladding rails

a. $75 \times 50 \mathrm{~mm}$ PSE softwood battens and counte

battens screwed to wall units on same 610/1200

rangement grid: $b$. the open south

provide rigidity for cladding and handrai.

MIDDLE LEFT

Fig 8.48 Installation of roof firring and rainscreen

$.75 \times 50 \mathrm{~mm}$ PSE softwood truss firrings fabricated

across width of pavilion; b trussed firring screwed

to roof diaphragm: $c$. EuroClad trapezoidal roof

sheets laid and screwed to firring.
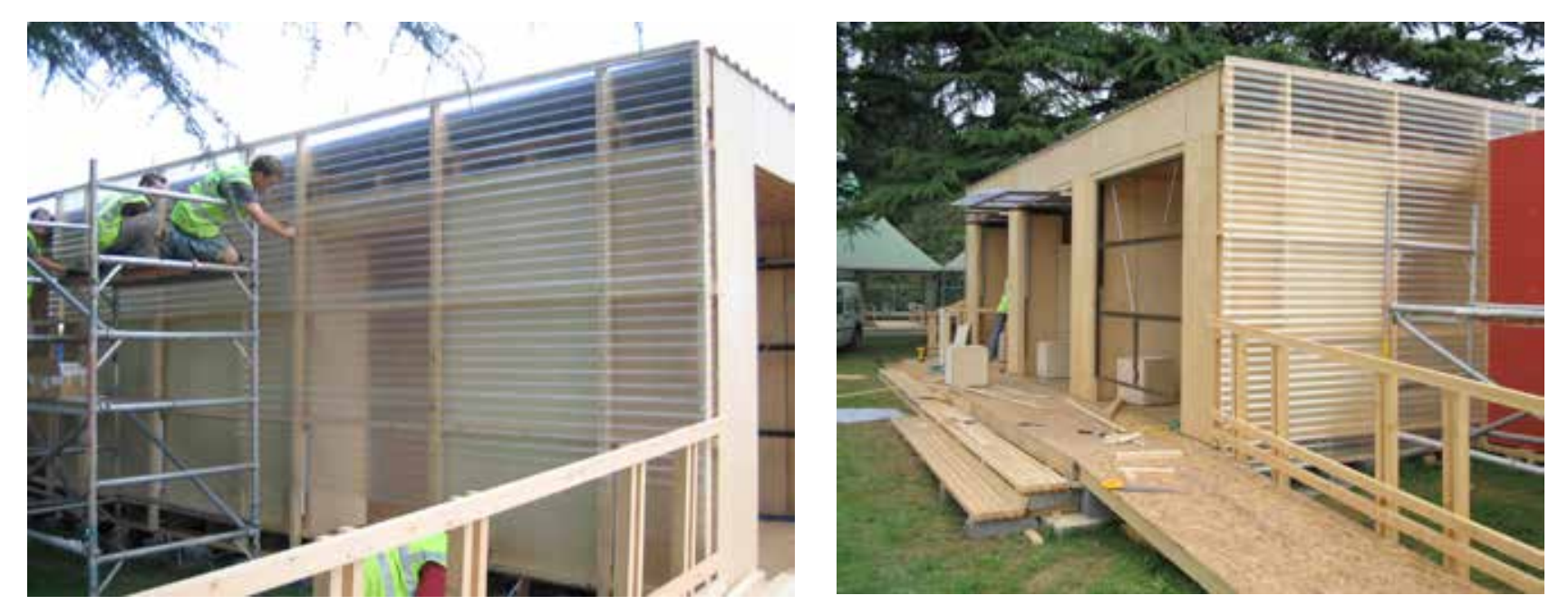

BOTTOM LEFT

Fig 8.49 Cladding installation

a. standard sheets of frosted sinusoidal sheets

screwed horizontally to battens; b. clear sinusoid

sheets fixed vertically to garage door frame in 3

bays of entrance elevation.

RIGHT

Fig 8.50 Completed pavilion

a. red polyester powder coated steel sheets fixed

to AV box and front of pavilion and branded with

Cardiff University logo. b. pavilion finished at night with fluorescent tube lighting behind cladding.
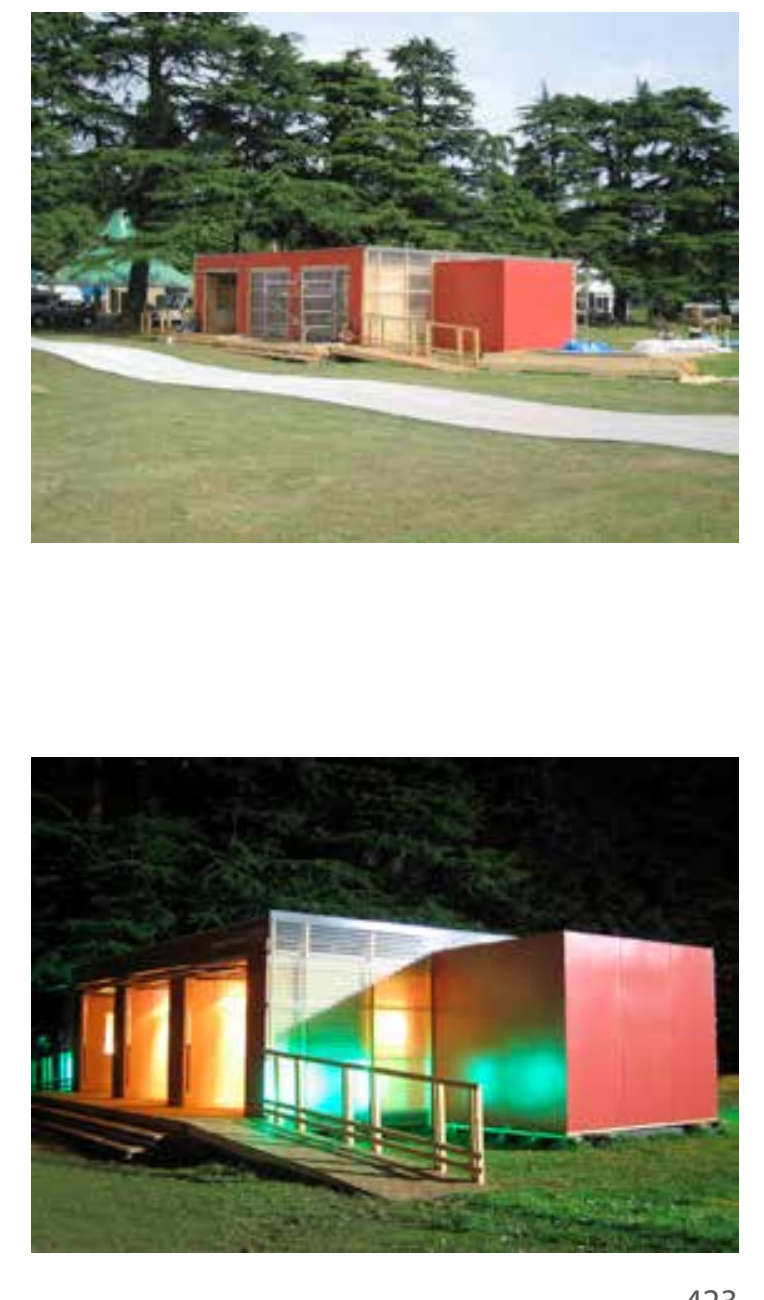

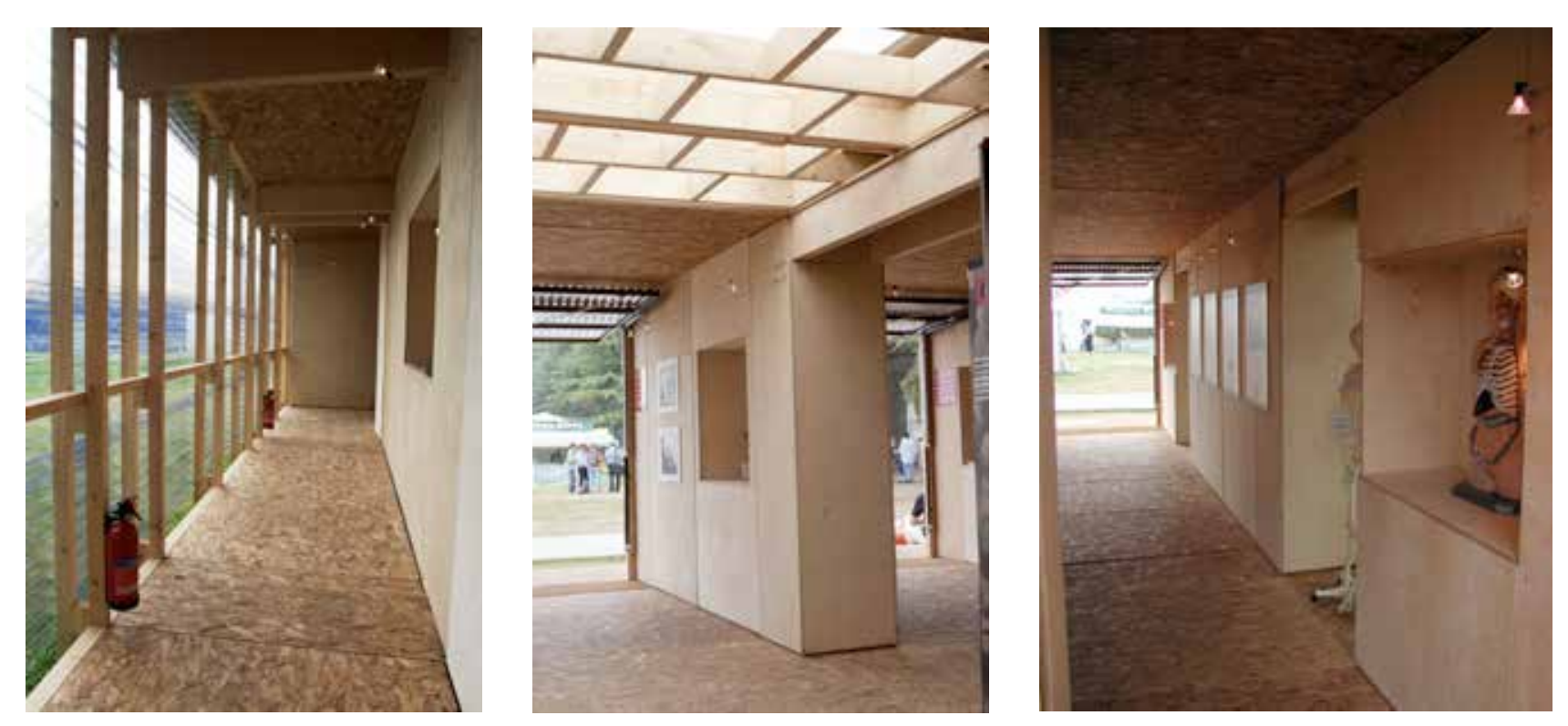

The pavilion was open to visitors from 9am until $6 \mathrm{pm}$ daily during the Eisteddfod festival. Following the festival it was dismantled and transported to storage in Cardiff.
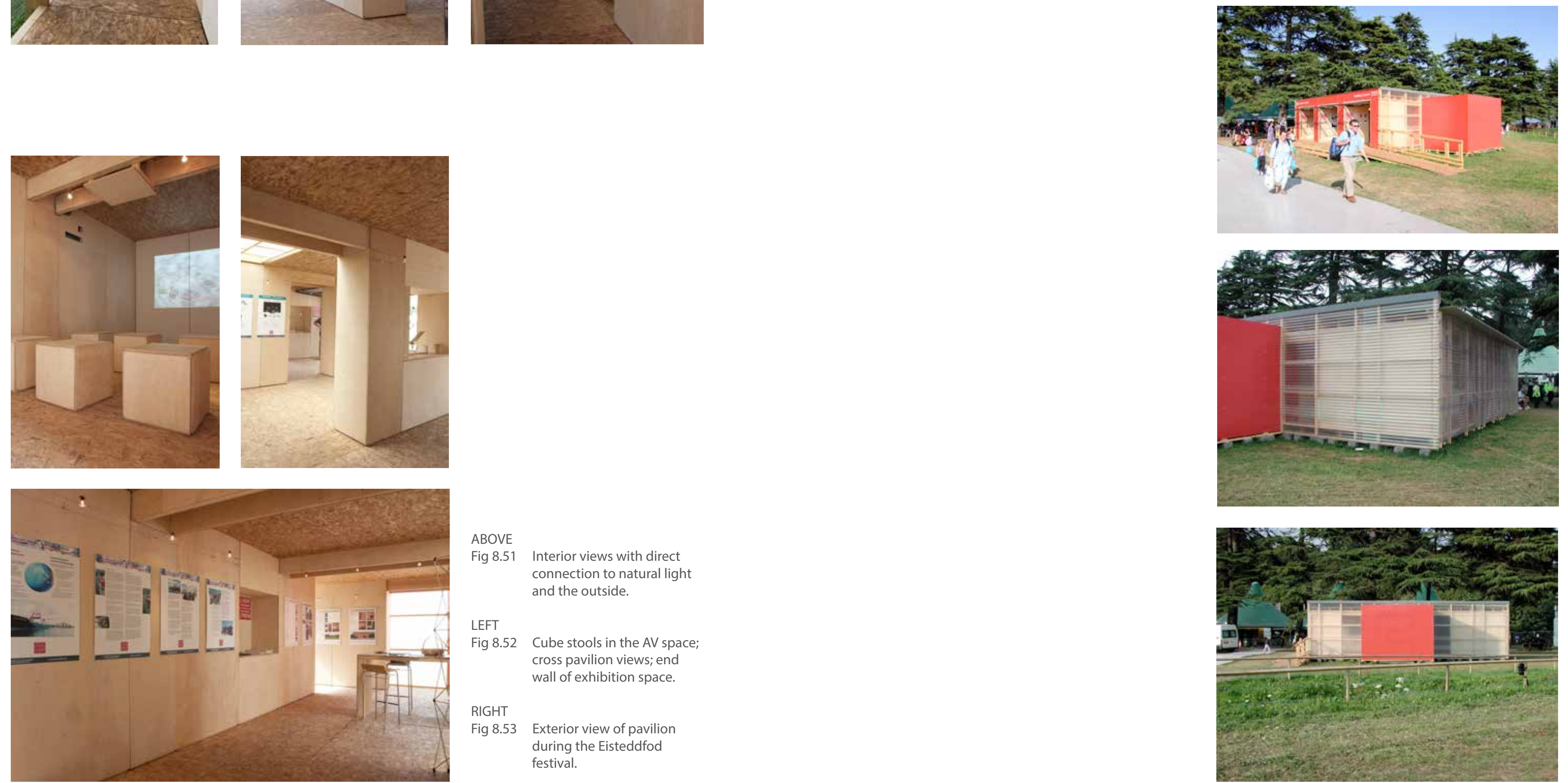

ABOVE

Fig 8.51 Interior views with direct connection to natural light and the outside.

LEFT Cube stools in the AV space cross pavilion views; end

$\mathrm{RIGHT}$

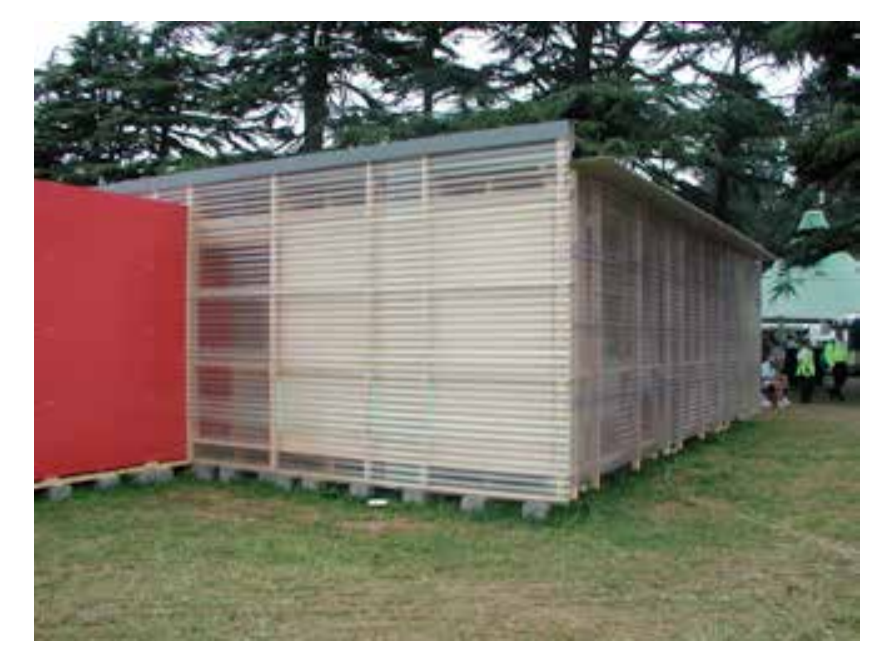

Exterior view of pavilio during the Eisteddfod

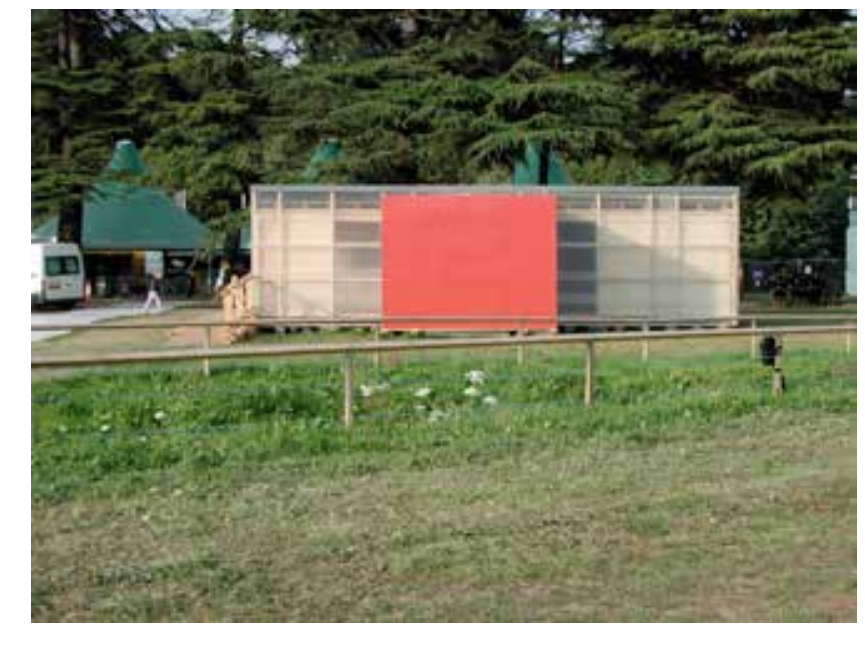




\section{Introduction}

Following the Eisteddfod festival and the dismantling of the pavilion DRUw were approached, in mid-2005, by Cardiff Castle and the City of Cardiff Council about a temporary visitor centre and kiosk outside Cardiff Castle. A temporary kiosk was required outside the Castle within 6 months to coincide with the closure, demolition and remodelling of the existing ticket office and shop within the castle wall. The client was aware of the Eisteddfod pavilion and interested in the possibility of reusing the structure for 2 years.

The following sections and accompanying drawings aim to briefly highlight the development of the prototype Eisteddfod pavilion into a semi-permanent structure with a complete building envelope for reflection.

\section{Cardiff Castle kiosk}

\begin{tabular}{|l|l|l|l|l|l|l|}
\hline Project & Year & Location & Client & Design team & & Cost \\
\hline $\begin{array}{l}\text { Cardiff Castle } \\
\text { kiosk }\end{array}$ & 2006 & Cardiff Castle & $\begin{array}{l}\text { The City of Cardiff Council } \\
\text { and Cardiff Castle }\end{array}$ & $\begin{array}{l}\text { Architect: } \\
\text { Engineer: } \\
\text { Carpenters/ } \\
\text { joiners: } \\
\text { Contractor: }\end{array}$ & $\begin{array}{l}\text { Design Research Unit Wales } \\
\text { Mann Williams }\end{array}$ & $\begin{array}{l}\text { GE Carpentry } \\
\text { OPCO Construction }\end{array}$ \\
\hline
\end{tabular}

Cardiff Castle's brief and requirements were for:

- a semi-permanent structure for a temporary gift shop and ticket office;

- the shop to be the temporary entrance and exit for all visitors to the castle;

- to provide a clear identity that the castle is still open during the building works;

- to maintain the Christmas tree location;

- to sit on the surface of the moat without any deep foundations:

- quick to erect outside the castle to minimise disruption to visitors and the public; and

- for a budget of approximately $£ 50000$ excluding fit-out.

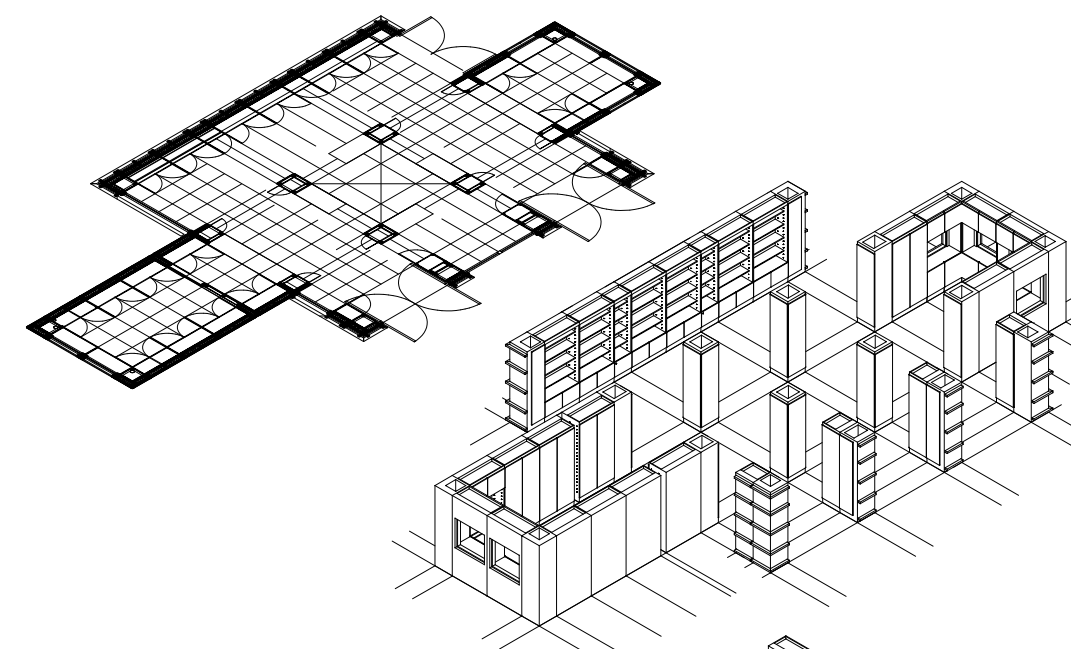

The schedule of accommodation was for:

- $\quad$ an internal ticket desk for private, individuals;

- an external group gathering area and external ticket/ check-in desk

- to accommodate the gift shop:

- a shop counter;

- a ticket office for 3 staff:

- a stock room for the shop; and

- a staff room with lockers for staff personal storage.

- The kiosk would not require a water supply and toilets and therefore a waste water connection.

The design required a 2 year temporary planning approval; temporary listed building 

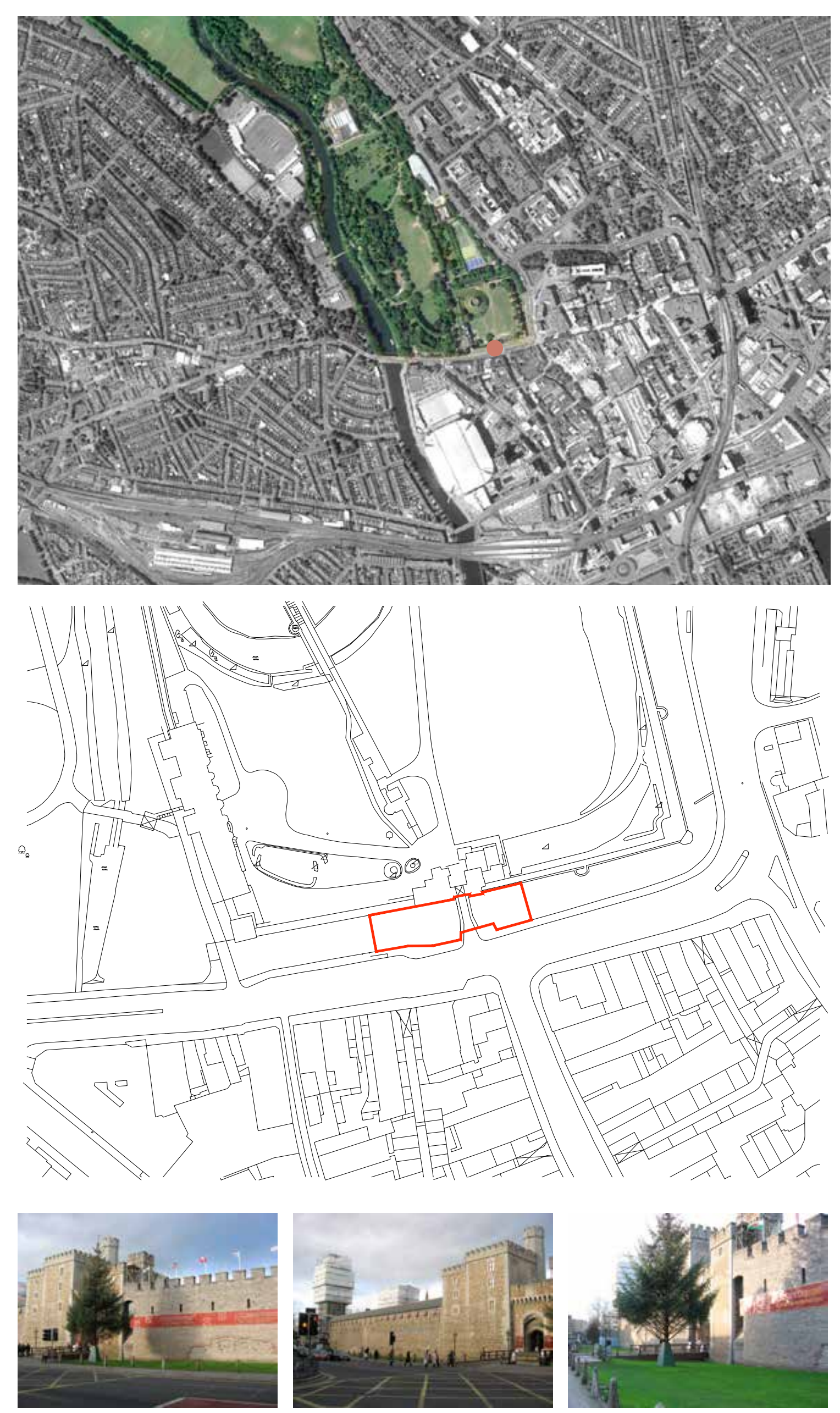

consent to include conditions of engagement with the landscape of the moat and castle wall; and building control approval for a fully heated and insulated structure.

Initially DRUw reviewed the rebuilding of the Eisteddfod pavilion as originally designed in the moat, but these brief and legislative requirements were beyond the capability of the Eisteddfod pavilion with many components not fit for purpose.

The temporary kiosk was to be located in the moat of the grade I listed and scheduled ancient monument of Cardiff Castle. Built on the foundations of a Roman fort, the castle dates from the Norman period to the late 19th-century with the majority of the current fabric remodelled, constructed and redecorated by William Burges for the Earls and Marquises of Bute between 1778 and 1890. The castle and the moat have been altered numerous times through its history leaving layers of history and archaeological remains that are not to be disturbed.

The south facing, $15 \mathrm{~m} \times 30 \mathrm{~m}$ plot to the left of the drawbridge entrance was directly in front of the Military museum and castle wall with arrow slots and sheltered walkway on top of wall. To the south, the pavement on Castle street was $1 \mathrm{~m}$ higher than the moat.

LEFT (top - bottom)

Fig 8.56 Aerial photo of site, Cardiff Castle and Bute Park

Fig 8.57 Existing location plan with site

Fig 8.58 Photos of the moat and Castle wall prior to installation

RIGHT

Fig 8.59 Montage of Eisteddfod pavilion in moat to the east of the main Castle entrance

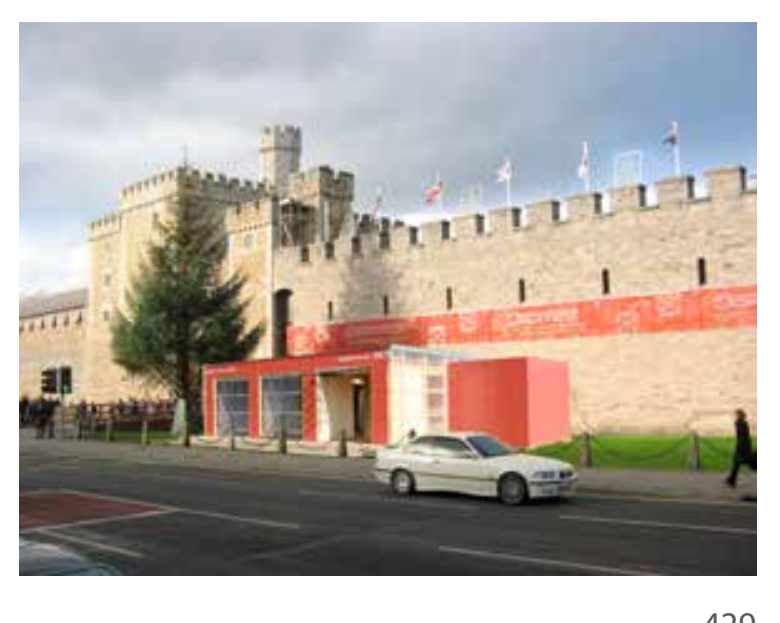



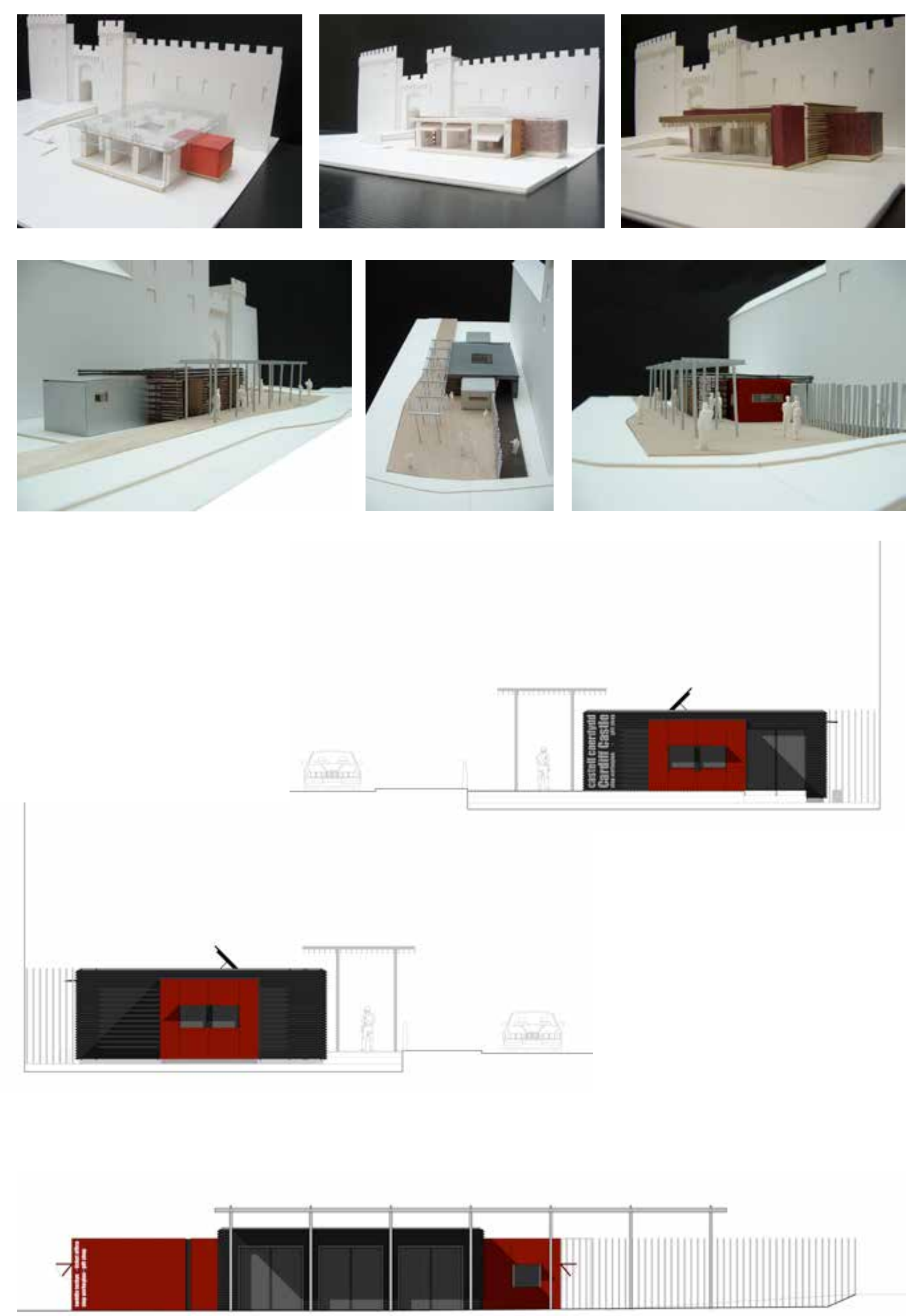

\section{Planning}

Although the Eisteddfod structure was no longer fit for purpose, the intention was to follow the same storage wall and enclosure concept to provide a modular, lightweight, prefabricated building with the wall structure and shop storage/ display combined as individual components. The revised design was submitted for planning approval in January 2006. This kiosk incorporated the following design amendments from the Eisteddfod pavilion:

- The structural grid remained the same using standard $2440 \times 1220 \mathrm{~mm}$ plywood and OSB boards as the guiding module, although a layout grid of $610 \times 610 \mathrm{~mm}$ was used for spatial configuration

- A second 'box' was added to the west elevation to provide storage and shop counter space. Both were to be clad in a burgundy red steel panel to match the red castle shutters and branding.

- The main building was to be clad in a charred softwood louvred rainscreen with breather membrane behind to provide a durable, low cost cladding. This was inspired by the rainscreen cladding of the Mount Stuart Visitor Centre on the Isle of Bute and to provide a robust, durable cladding from low-cost, Welsh-grown softwood.

- A white painted cold formed steel brise soleil canopy was to identify the entrance and provide solar shading to the 3 glazed front bays.

TOP LEFT

Fig 8.60 Development models:

a. Original Eisteddfod pavilion on right hand sid

of moat;

b. 1st design option Ten steel clad box;

c. Revised to incorporate entrance canopy' d-f. The proposal was moved to the LHS of the moat to leave space for the Christmas tree. Final design with charred louvred cladding and large entrance gathering space for groups.

BOTTOM LEFT

Fig 8.61 Proposed elevations

a. East elevation incorporating signt

charred softwood cladding;

b. West elevation with 'storage' box projection

c. South, entrance elevation.

RIGHT

Fig 8.62 Proposed site plan
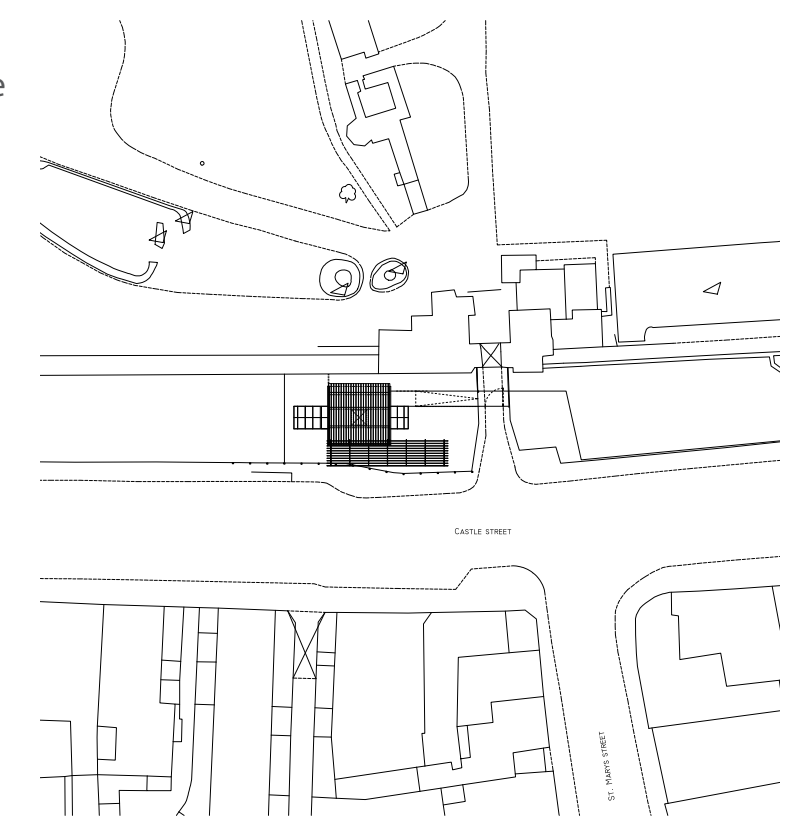


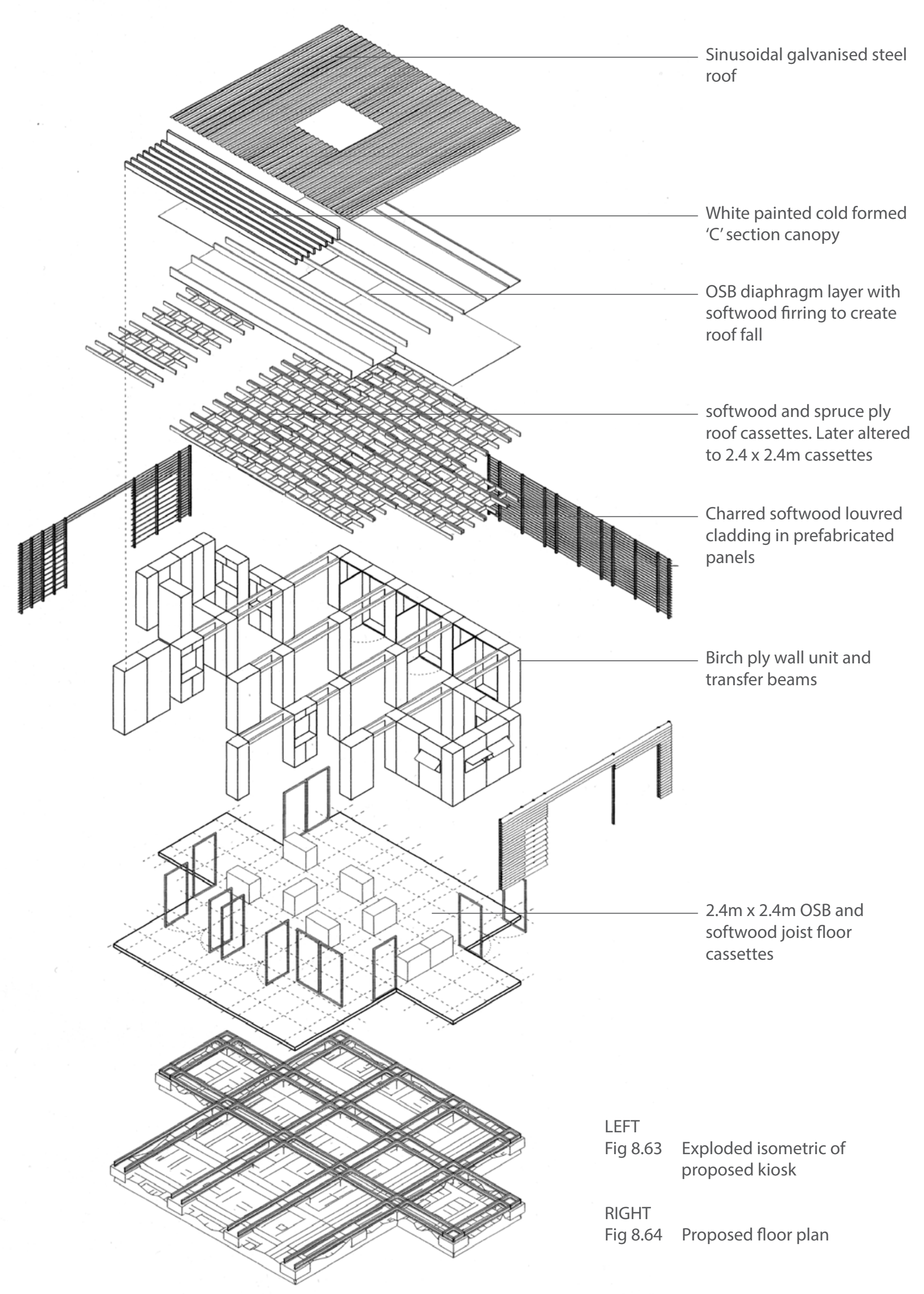

\section{Detailed design}

While awaiting a planning decision (approved in April 2006) the floor, wall and roof components were detailed for pricing purposes with the main contractors subcontractors and supply chain. the following drawings and annotations highlight the detailed design and significant variations from the Eisteddfod prototype.

Following accurate pricing from the appropriate sub-contractors, the costs were deemed too high to proceed with the design. An alternative kiosk was constructed from adapted Portakabins and clad to resemble the planning approved design. I do not have the tender costs!

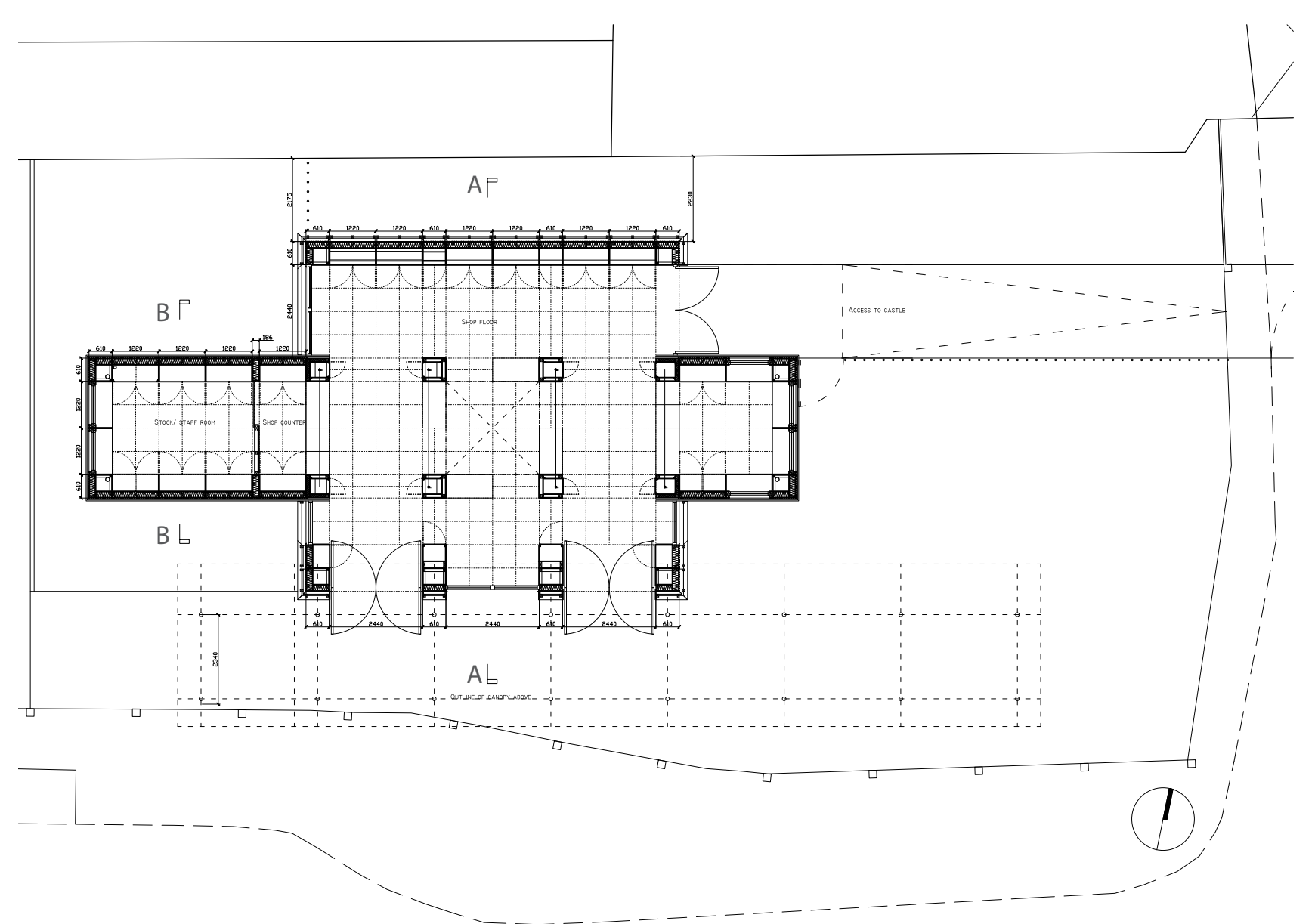



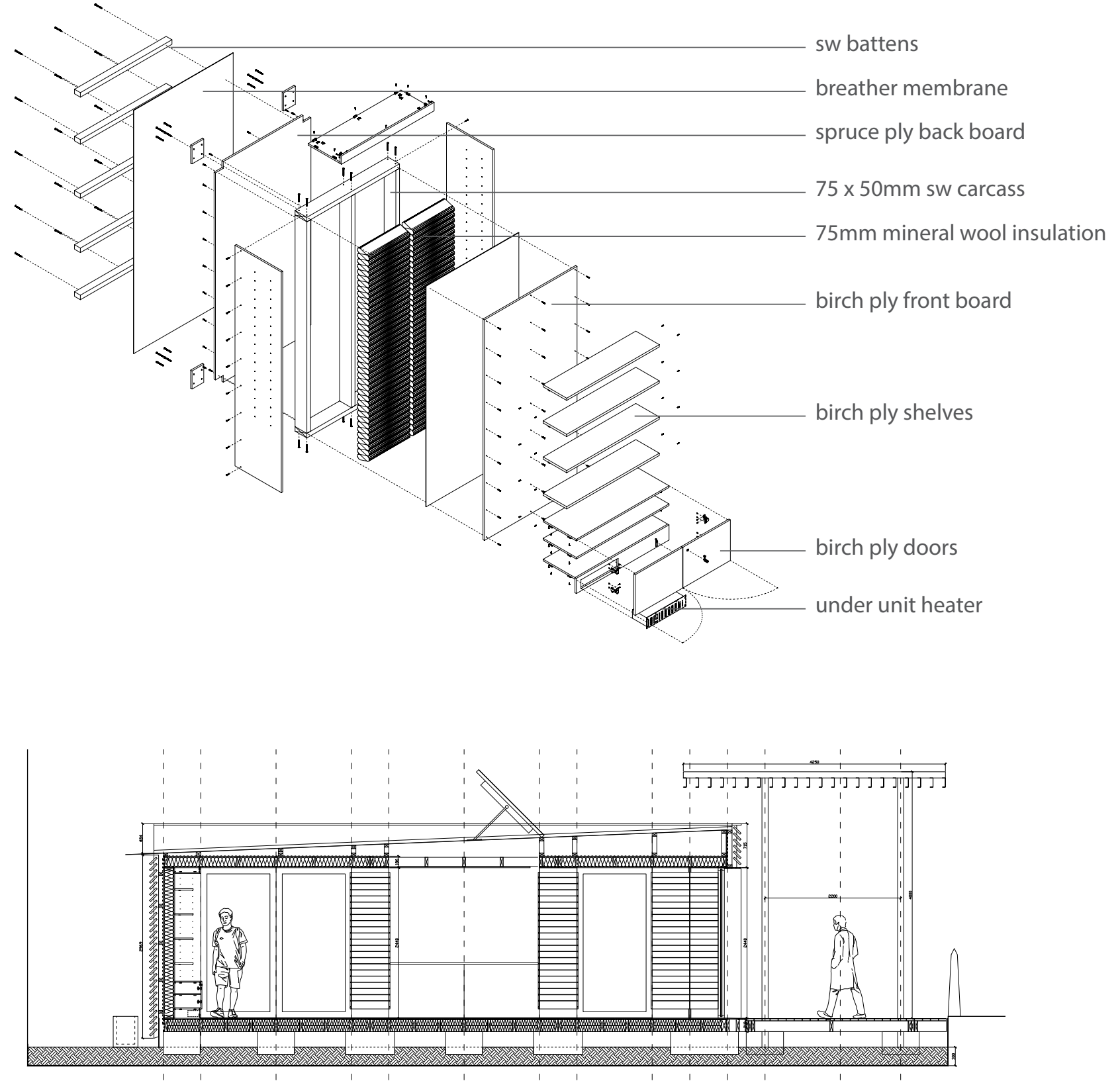

TOP LEFT
Fig 8.65 Exploded isometric of a typical $1220 x$

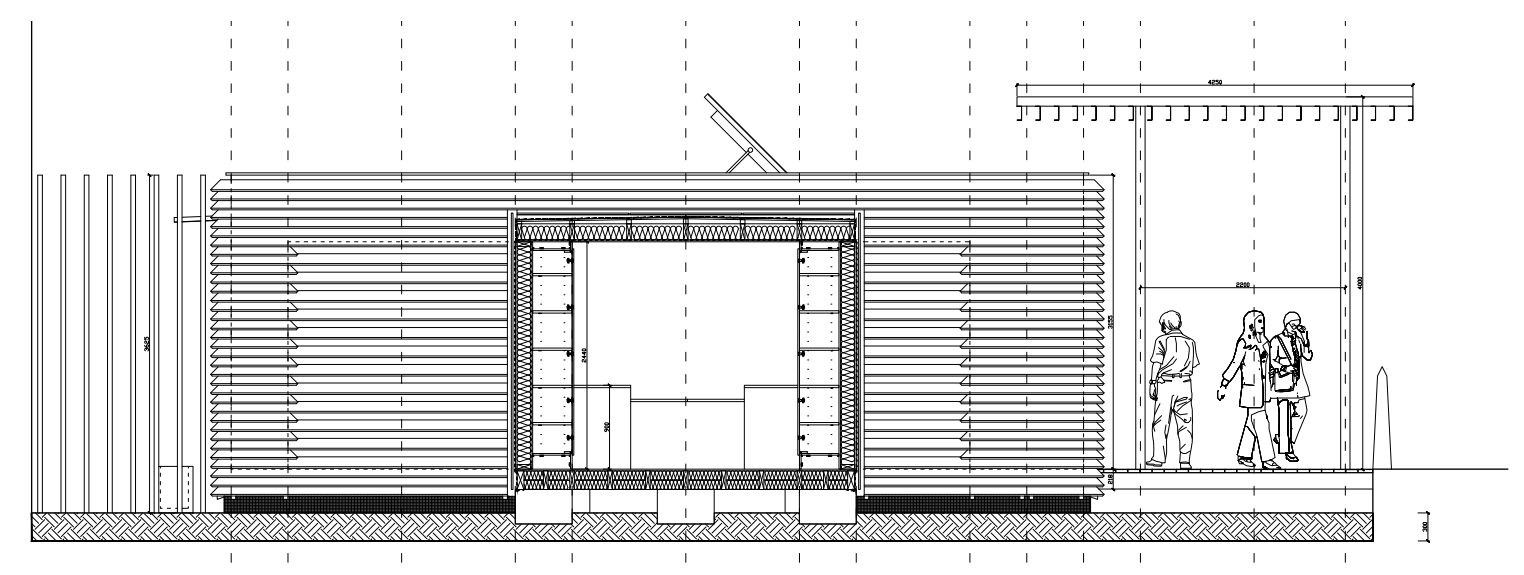
$610 \times 2440 \mathrm{~mm}$ wall unit with display shelving

BOTTOM LEFT

(n)

Fig 8.67 Proposed Section BB

RIGHT

Fig 8.68 Sample exploded isometric modules:

a. Floor cassette

b. $1220 \times 610 \times 2440 \mathrm{~mm}$ Wall unit incorporating

windows for ticket office

c. $610 \times 610 \times 2440 \mathrm{~mm}$ wall unit with shelving

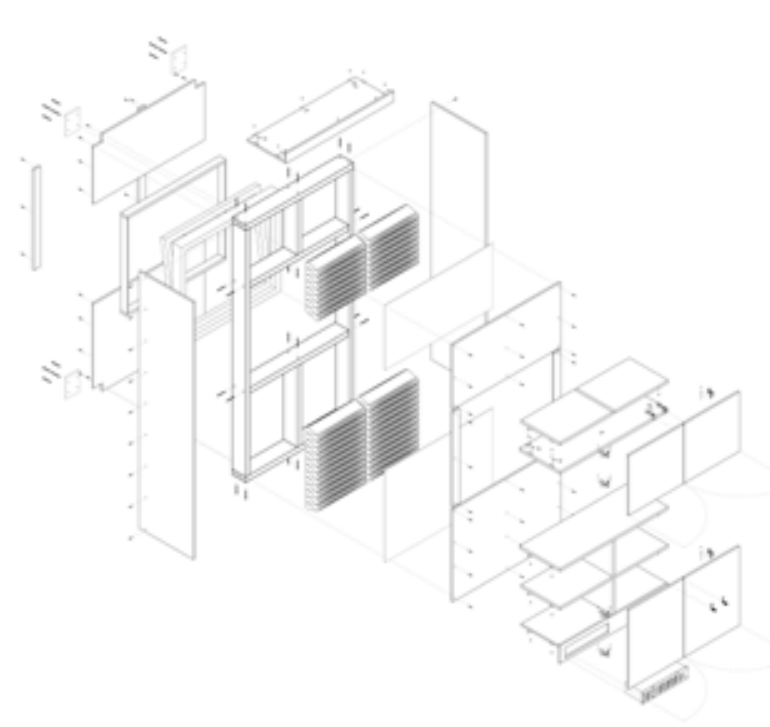




\subsection{Observations and reflections}

The Eisteddfod pavilion was completed one day before the Eisteddfod festival opened to the public. Cardiff University displayed the work of different schools through posters, interactive artefacts, exhibits such as the school of engineering racing car and leaflets. The pavilion was well visited with a comments book recording the opinions of visitors on the pavilion design. Visitors were polarised in their opinions either congratulating the 'innovative design' or questioning the look, form and use of 'unfinished' materials.

Following the festival the pavilion was dismantled, stored with the potential to be reconfigured or re-built. The Castle kiosk was un-realised with an alternative structure built to resemble the proposed design.

The following observations and reflections-on-action have therefore been based on a post-completion review of the design, fabrication and construction processes of both prototypes.

\subsubsection{Species performance and adaptation}

SPECIES

The Eisteddfod pavilion used the following timber species and timber products that are now reflected on:

- Welsh-grown $C 16$ whitewood (spruce, Douglas fir) $(75 \times 50 \mathrm{~mm}, 150 \times 50 \mathrm{~mm})$

- B/BB grade $18 \mathrm{~mm} 8^{\prime} \times 4^{\prime}$ Finnish birch plywood

- $18 \mathrm{~mm} 8^{\prime} \times 4^{\prime}$ Sterling OSB/3 manufactured by Norbord in Scotland.

- The prototyping of units and cassettes, identified that there can be significant differences in stability between the softwood and board products resulting, in some cases, in the warping and twisting of the entire modular component. Twisted floor joists created difficulties in aligning floor and roof cassettes and wall units were required to be clamped, packed and forced into position. Higher tolerances may be required in the future to allow for the softwood movement or greater dependency on the more stable board products.

\section{TIMBER ADAPTATION}

- Plywood and OSB are engineered timber products, therefore enhancing the original low value species properties by increasing structural performance and improving stability. Consideration is rarely focussed on the aesthetic and tectonic qualities of board products as given incorporated in this prototype and dividing the opinions of visitors. If considered differently, the 
boards offer versatility through a variety of performance, functional and experiential qualities that may add further value when incorporated into a secondary processing industry. This is partially evident in SIPs

manufacturing, although often the board is still hidden within the wall make up.

- The process and product of plywood and OSB relies on glues to add strength and rigidity to the veneers, chips and strands. Both products use phenol-formaldehyde glues that off-gases formaldehyde at a slow rate but for a long time. The exposed OSB and plywood was well ventilated in the Eisteddfod prototype. However, the Castle kiosk proposal to incorporate exposed boards within an insulated and air-tight envelope considered the use of formaldehyde free glues to reduce the toxicity of the internal environment.

- There is potential to integrate Welsh-grown timber into the manufacture of timber board products. MDF is already made in Wales and OSB made in

Scotland. Plywood offers the highest quality of finish and has the major share of the board product market. Both the soft- and hardwood species offer potential to provide veneer. Further research, and investment is required to establish whether a Welsh plywood is possible, for example utilising a softwood veneer core and hardwood outer veneers.

\subsubsection{Building envelope}

The Eisteddfod pavilion was successfully built in 1 month prior to the start of the festival, meeting temporary building control approval for structure, fire escape and access and opened to the public. However, the bespoke construction typology of the Castle kiosk resulted in increased costs for fabrication and assembly that, for a temporary building, were prohibitive.

\section{SUPERSTRUCTURE}

- Despite the wall units having a similar construction typology to panelised timber frame construction, the majority of the Eisteddfod units were framed as volumetric modules, reducing the possibility of using the inside for storage or display and adding considerable weight. The Castle pavilion proposal was to reduce the timber frame to a stud frame at the rear of the units. Research by Shigeru Ban demonstrates that it may be possible to reduce this frame further or even eliminate it using robust fillet connections between timber boards.

- The modular and elemental approach to the design and construction of building envelope components allows for flexibility in the arrangement of wall units and floor/ roof cassettes during initial design. Once installed, however, there is limited flexibility in altering the layout as every component 

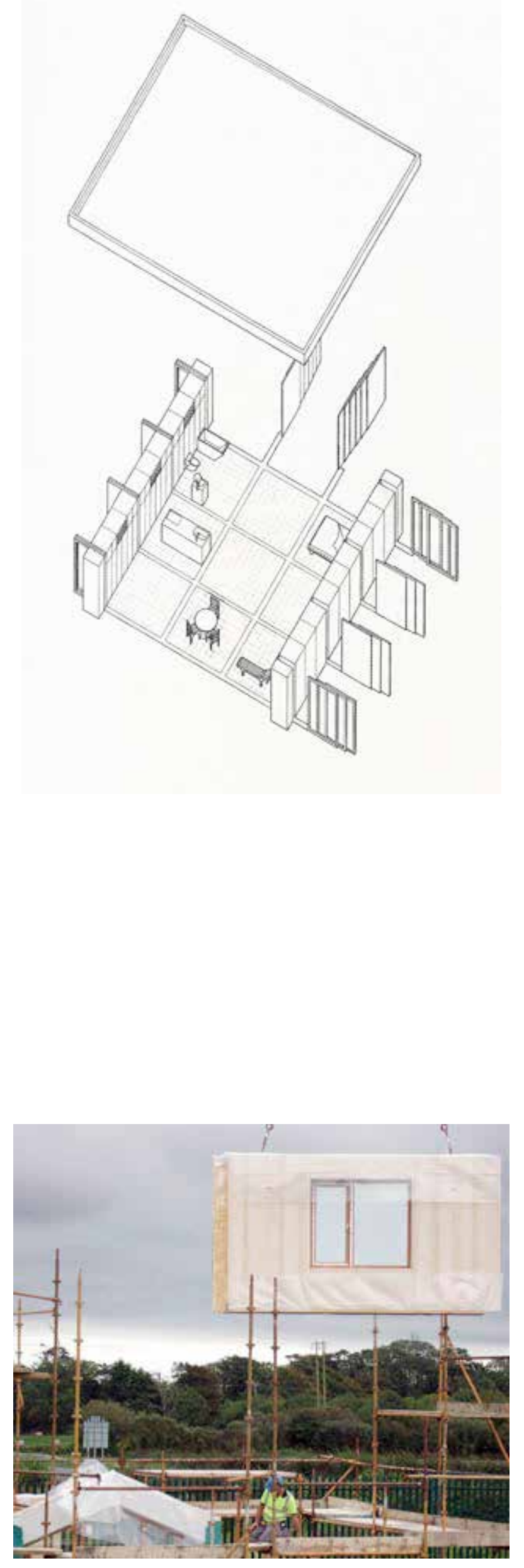

Fig 8.70 Axonometric of Nine-square grid house, Hadano, Japan by Shigeru Ban demonstrating the fexibility of the open plan arrangement with furniture houses

Fig 8.71 Closed timber panel construction complete with external joinery
and membranes is both furniture and structure combined. Early design stages would be critical in establishing long-term design intentions. This may be the reason the furniture houses, by Shigeru Ban, are generally open plan, sometimes with separate moveable walls to allow for flexibility. This requires the roof components to be fabricated in larger modules, possibly integrating engineered timber for larger spans, that would require mechanical lifting.

\section{INTEGRATION WITH COMPLETE ENVELOPE}

- Although the Eisteddfod pavilion did not have a complete building envelope meeting all performance requirements, the intentions of the Castle kiosk demonstrate how this would have been achieved. The principle of insulating and providing modular sections of breather membrane to be lapped on-site is commonly integrated into open and closed timber frame panel construction and explored by Shigeru Ban as furniture modules demonstrating that the Castle kiosk intentions would be possible.

- Following prefabrication, the assembly of the superstructure took 10 days to provide a watertight envelope. If the structure had incorporated insulation, window and door components, the envelope would have been fully weathertight in the same period of time. This is, again, comparable to timber frame panel construction, but with the added benefit of incorporating internal finishes.

- The untreated and unprotected OSB/3 was durable for a 1 week temporary pavilion floor surface, although would require a hard wearing varnish for long term exposure. The OSB may be better suited to the ceiling, sanded smooth and lightly oiled.

- Environmentally the elemental components offer potential to incorporate high levels of insulation and servicing within the units, plinths or heads, following a fabric first approach. However this method has little potential for the inclusion of thermal mass to balance temperature fluctuations which are likely and experienced in the Eisteddfod pavilion during 1 week in the summer.

\section{Technology and skills}

The board products used in the pavilion, were not manufactured in Wales or using Welsh-grown timber, although the OSB was manufactured in Scotland using UKgrown spruce, Douglas fir and larch. It is, therefore not possible to evaluate the technology and skills of the processing industry other than a large-scale investment would be required on the back of a proven market demand and supply of

roundwood. The Kronospan MDF plant in Chirk, Wales and the Norbord OSB plant in Cowie, Scotland make it unlikely that there is space within the limited scale of the UK 
and Welsh timber industries for a further MDF, particleboard or OSB plant in Wales. There would, however, appear to be a market and an opportunity to manufacture plywood, although can the industry compete with the northern European and Asian import markets?

The following reflections are based on the construction industry technology and skills:

\section{PROCESSING}

- The Eisteddfod pavilion was prefabricated and assembled by un-skilled postgraduate students and staff from WSA using low-tech hand power tools for approximately $£ 15000$ in 3 weeks. Due in part to the minimal cutting and standardisation of material components, straight off-the-shelf, resulted in the pavilion being built on time, to a tight programme, with few difficulties, mistakes and, critically, no injuries.

\section{FABRICATION}

- The fabrication processes of both prototypes, highlighted the need for early design decisions and upfront supply of construction information. In the case of the self-build Eisteddfod pavilion this involved cutting lists, screwing position layouts, fabrication and assembly drawings. The Castle kiosk also required drawings to explain the approach to a sceptical audience. As a result, a considerable number of drawings were prepared before it was decided that the project was not going to proceed.

- The Castle kiosk original budget was $£ 100000$ for essentially the same structure as the Eisteddfod pavilion, with additional insulation, breather membranes and windows. Fit-out had a separate budget. The carpenters considered the design as 'bespoke' allocating a considerably longer lead in time and a bespoke production line. This resulted in increased overhead costs, compared to the low-tech Eisteddfod pavilion and even a standard timber frame panel, that pushed the project over budget and time.

- To reduce fabrication time and wastage, in a low-tech workshop by un skilled labour, the pavilion was designed to use a minimal variety of products in a limited range of sizes available off-the-shelf. Timber lengths were sourced in lengths of $2400 \mathrm{~mm}$ or $3600 \mathrm{~mm}$ and all boards were $8^{\prime} \times 4^{\prime}(2440 \times 1220 \mathrm{~mm})$ Cutting diagrams were prepared to use boards effectively limiting wastage to thin slices that were then used for packing where required. Cutting lists were prepared to order specific quantities of softwood that were cut to maximise useable timber. This was incorporated into the construction detailing, as highlighted in the drawings, that determined the overall 
proportion sizes.

- However, a discrepancy appeared between the metric softwood sizes of the unit frames and the imperial board sizes. It was decided to use the board sizes as the determining module size creating proportions of $2440 \mathrm{~mm}$

$1220 \mathrm{~mm}$ and $610 \mathrm{~mm}$. This resulted in excess softwood wastage, for example $2400 \mathrm{~mm}$ lengths were either too short to use as a length or not long enough to cut into 4 no $610 \mathrm{~mm}$ lengths. Metric sized boards could have been ordered, as often used by the timber frame industry (particularly in mainland Europe), although these are not commonly available off-the-shelf. The wasted softwood has the potential to be chipped for use as fuel or in the manufacture of MDF, particleboard or more OSB.

SKILLS

- The industry is set-up to operate within definable roles and risks: a site carpenter, a workshop carpenter, a joiner, a cabinet-maker, fit-out specialists etc. The units for the Castle kiosk combined these roles, both off- and on-site, without the specific skills in any single business to offer the complete package. On reflection, it may have been better to consider a timber frame panel specialist to fabricate the modules along their current production line sequence with a final stage to integrate unit sides, top and shelving.

- This type of construction, or other variations, may complement the processes of an existing secondary industry to offer a diverse range of products to market.

\section{CONSTRUCTION}

- The Eisteddfod pavilion was assembled on-site during the summer. However, the risk of rain and damage that this would cause to the exposed birch faced plywood or performance and integrity of the OSB/ 3 floor deck resulted in constant protection of components as they were assembled. Further consideration would be required for larger scale or permanent structures built with prefabricated and pre-finished components, such as temporary scaffold enclosures.

- The preferred contractor approach to the Castle kiosk, was to build a timber frame box and fit-out internally with storage, display and wall cabinets to match the intended modular proportions. This would increase the scale of on-site work, reduce the benefits of off-site quality control and result in numerous different components and trades. On the other hand the fit-out elements could be recycled later, without being attached to the structure. 
Much of the thinking behind both pavilions is not new but is generally resisted in main stream construction which produces in excess of 120 million tonnes of waste ${ }^{21}$ each year. Walter Segal was an early pioneer of this approach to designing and building houses in a similar way in the 1960s. These were primarily aimed at a limited niche self-build market. Despite the success and proven delivery of these houses, the approach did not gain wide-scale momentum. The difficulties of change within established expectations and demands means that without client or political will, the industry is unlikely to provide alternative processes, products or systems.

A tectonic approach of both pavilions was to use standardised components and be completely recyclable. The 'dry' no nail construction of plywood boards is demountable, therefore when the functional life of the building has expired it can be re-used, reconfigured, become storage cabinets or downcycled with the site returned, unharmed to its natural state.

\section{CONTEXT}

- In both prototypes, the context of the site became secondary to the means to build. The proportion, composition and form were dictated by the modules, detailing and construction sequence which in turn were determined by the standardised material palette. On a temporary site, at the Eisteddfod, this could be acceptable as a demonstrable pavilion. However, outside Cardiff Castle, the proposed tectonic form was primarily inspired by the original pavilion details, with a gesture to the branding and historic landscape through the choice of cladding, rather than the context of the Castle and the city. Further consideration may be required to integrate context and technology, allowing traditions to inform innovation and vice versa.

\section{COMPOSITION AND FORM}

- The design intention was for a 'box' generated from platform, storage walls and a roof wrapped with a rainscreen enclosure. This created a tectonic contradiction between the design and detailing of the roof and enclosure: the need to close openings and control ventilation; the requirement to provide diaphragm action in the roof; the intention to fabricate simple, flat roof components but provide a fall to the main roof finish; and avoid leaks on the flat roof over the AV box. Further development work is required to integrate tectonic clarity with structural performance of the cassette design, prefabrication of extra firring layers and possibly wrapping the

21 Davies Langdon LLP, Designing Out Waste: A Design Team Guide for Buildings (Oxon: Waste \& Resource Action Programme), p.7 
structure in a rubber membrane to provide a watertight layer before applying the rainscreen.

- The built prototype was a physical manifestation of the tectonic strategy of design and building with timber board products. The didactic pavilion envelope clearly presented proportion, fixings, details, modules and enhanced value of board products as finished surfaces. Visitors responded well to the experience of natural lighting and ventilation coupled with robust standardised materials, with some asking what the materials were and others enquiring about the re-use of the structure as a home or classroom.

\section{DIMENSIONAL COORDINATION}

- The detail of the units was to be determined by the sizing of $8^{\prime} \times 4^{\prime}$ timber boards generating a basic grid of $610 \times 610 \mathrm{~mm}$. However, to achieve an enclosed unit with square corners resulted in a basic $610 \mathrm{~mm}$ square unit being fabricated from 2 no. $610 \times 2440 \mathrm{~mm}$ and 2 no. 574 × $2440 \mathrm{~mm}$ sides leaving a $36 \mathrm{~mm}$ wasted strip. On reflection, the tectonic could have been adjusted to respond to the proportions of the product and exacerbate this detail through either slightly rectangular units or a shadow gap between each module.

- The tartan grid was informed directly by the material proportions. This worked well for a small-scale public pavilion, although the $2440 \mathrm{~mm}$ span limit maybe restrictive in domestic scale construction. However the grid and limited number of small module sizes creates arrangement flexibility within defined that is only limited by roof span that may be overcome if larger engineered I-joists were considered.

- The grid provided a clear and logical layout for both prototypes that combined tectonic form with construction sensibility and timber industry standards. If board products are to be used efficiently within the building envelope, the tectonic form of low-tech architecture is likely to reflect these module sizes or generate wastage.

\section{MODULAR}

- The elemental Eisteddfod pavilion was a demonstration of sustainable low-tech design through a lightweight, modular, demountable, prefabricated construction method using off-the-shelf, low-cost sawnwood and timber board products. The Castle kiosk demonstrated the inclusion of the ful building envelope.

- The integration of structure and fit-out, traditionally seen as separate trades and processes, caused difficulties in presenting the design to clients, end users, contractors and specialists. The assumption that the units would 


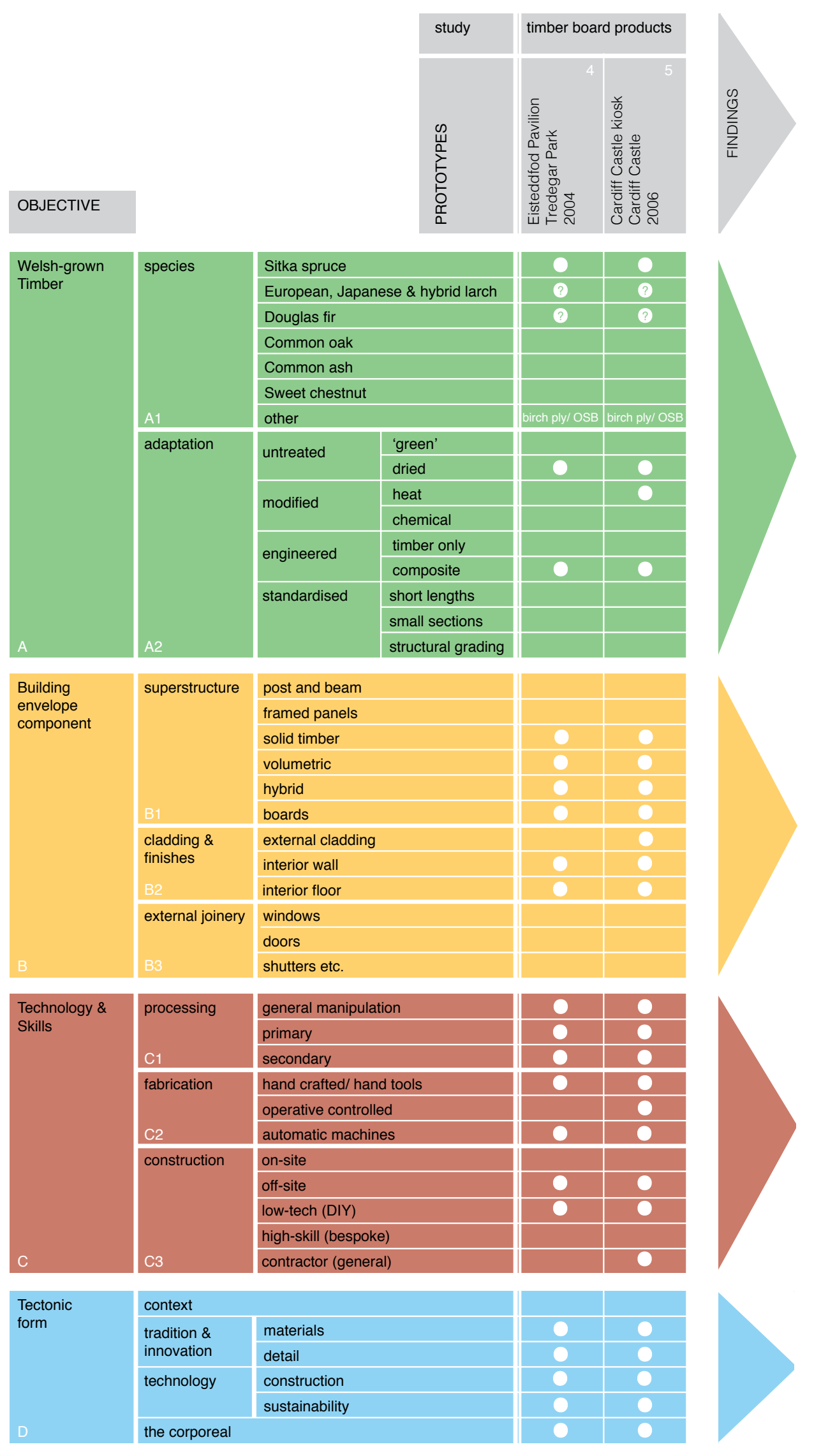

REFLECTION-ON-ACTION provide the building structure, enclosure and fit out challenged the status quo possibly too far within budgets and timescale. The proposed hybrid, elemental approach appears to have limitations, in terms of on-site construction, in comparison to complete volumetric modules.

\section{TRADITION AND INNOVATION}

- Plywood and OSB are generally used, in established construction methods, to provide racking resistance to a softwood stud frame hidden within layers of the building envelope. The pavilion wall, floor and roof modules provided an opportunity to remove further layers of plasterboard and service voids and exploit the benefits of the birch ply finish and OSB for floor and ceiling. The plywood and OSB were therefore upgraded in value and quality from a structural application to an aesthetic finish.

\subsection{Findings on timber board products}

- Possibility of manufacturing plywood is low, due to scale of investment and need for a regular supply of appropriate logs to extract veneer from. If this was to be successful with Welsh-grown timber, other markets may suffer, the woodlands may be over harvested with an increase in clear-felled plantation woodland needed, or importation of roundwood may increase.

- As a high-value product, plywood offers the greatest potential of all the board products for inclusion within the building envelope as an exposed finish.

- OSB is already incorporated into most timber frame constructions in Wales. Its use as an internal finish requires careful composition with other materials and due to the nature of the product, careful maintenance to maintain the integrity of the strands and protection from moisture.

- Integration of board products into a structural and functional module to be wrapped with a breather membrane and rainscreen offers added-value as a finished product and integrated, standardised construction module. 


\section{CHAPTER 9}

Complete timber envelope 
This study considers the use of Welsh-grown timber in the entire building envelope, including structures, the thermal envelope, external joinery and cladding/ finishes, incorporating and developing on the findings from the previous four studies, as appropriate for the prototype designs. Hardwood, engineered timber, timber board products, approaches to prefabrication and their overall integration into the tectonic form are tested and evaluated through a series of progressive prototypes.

Initial research and development, led by Coed Cymru, suggested that Sitka spruce as an underused and undervalued species could be used more productively within the construction industry. Based on industry studies, some of which are included in this thesis, on the use of Welsh-grown timber, affordable housing and Modern Methods of Construction, by the author and Coed Cymru a research project was established, in 2007 , to develop a superstructure system with a focus on domestic scale architecture. The project was led by Coed Cymru with the Design Research Unit Wales, in collaboration with the School of the Environment and Natural Resources, University of Wales, Bangor and Cowley Timberwork Ltd funded by the Countryside Council for Wales (CCW) and the Wales Forest Business Partnership. The output of a feasibility study entitled 'Ty Unnos: Sitka spruce housing,' generated wide interest from the timber and construction industries to potential clients. This led to a successful application, in 2009, with Coed Cymru and Burroughs ${ }^{2}$ for Technology Strategy Board funding for a further 2 years of research, development and prototyping to establish an affordable housing construction system.

While the funded research projects focussed on the primary use of Welsh-grown Sitka spruce, the prototype projects provided opportunities to incorporate and test wider uses of Welsh-grown timber in the building envelope as part of a complete timber envelope as often seen in the architecture of Scandinavia, the Graubunden, Switzerland and the Vorarlberg, Austria.

This study begins with the initial development of a Sitka spruce construction system, before testing and evaluating the use of the system and other timber uses through 3 prototype projects of differing scales, typologies and building envelope completeness:

1. The development of the construction system through prototyping components at scale model and 1:1, as well as structural testing, small scale test structures and hypothetical designs;

1 Ty Unnos translates from Welsh into English as 'House in one night'

2 Burroughs were appointed structural engineers as part of the Technology Strategy Board bid. 
2. The construction of a temporary pavilion, for the Smithsonian Folklife Festival in Washington DC;

3. The design, fabrication and construction of an Environmental Resource Classroom in Ebbw Vale; and

4. The design, fabrication and construction of a a 2-storey, 2 bed, 4 person demonstration, low energy longhouse in Ebbw Vale.

Observation and reflections are presented on each study, before the study ends with findings on the complete timber envelope.

\subsubsection{Aim and objectives}

The aim of this study is to evaluate the use of Welsh-grown timber in the complete timber building envelope through the design, fabrication and construction of 4 sequential prototype projects utilising Sitka spruce in an engineered structural system and other timber components as appropriate to each project.

The following objectives are aligned to the overall thesis objectives:

- Propose and test uses for Welsh-grown timber in the complete building envelope.

- To evaluate the performance of Welsh Sitka spruce in an engineered construction system.

- To test and evaluate the technology and skills required in relation to the use of Welsh-grown timber.

- To reflect on the tectonic form of the prototype building envelopes as an integration of context, clients requirements, architectural response and use of timber.

\subsubsection{Limitations}

The research was conducted as a series of live prototypes in a number of significant stages relating to the the development of the Sitka spruce construction system that continued to develop and provide further studies as the project exposure and funding increased. This study is, therefore, presented in the same sequential format as the Ty Unnos research, highlighting the development of the system alongside other uses of Welsh-grown timber as inspired by the previous research prototypes in this thesis.

This study does not present the full research and development on the Ty Unnos 
system, which has been conducted and reported by Coed Cymru, Burroughs and the Design Research Unit Wales in full. This study focusses on the application of all timber species used in relation to the building envelope element, technologies and skills required and the tectonic form.

\section{Context and precedent}

This study draws on the findings of chapters 2, 3 and 4 as well as the context, precedents and observations from the previous prototype study chapters. The prototype projects will therefore incorporate and innovate with forms of engineered timber with both soft- and hardwood for structures and joinery, timber board products within a prefabricated and modular envelope. The following context provides a summary of the key parameters and further detail, not already provided, that influenced the development of the Ty Unnos research and prototype projects.

\section{Sitka spruce}

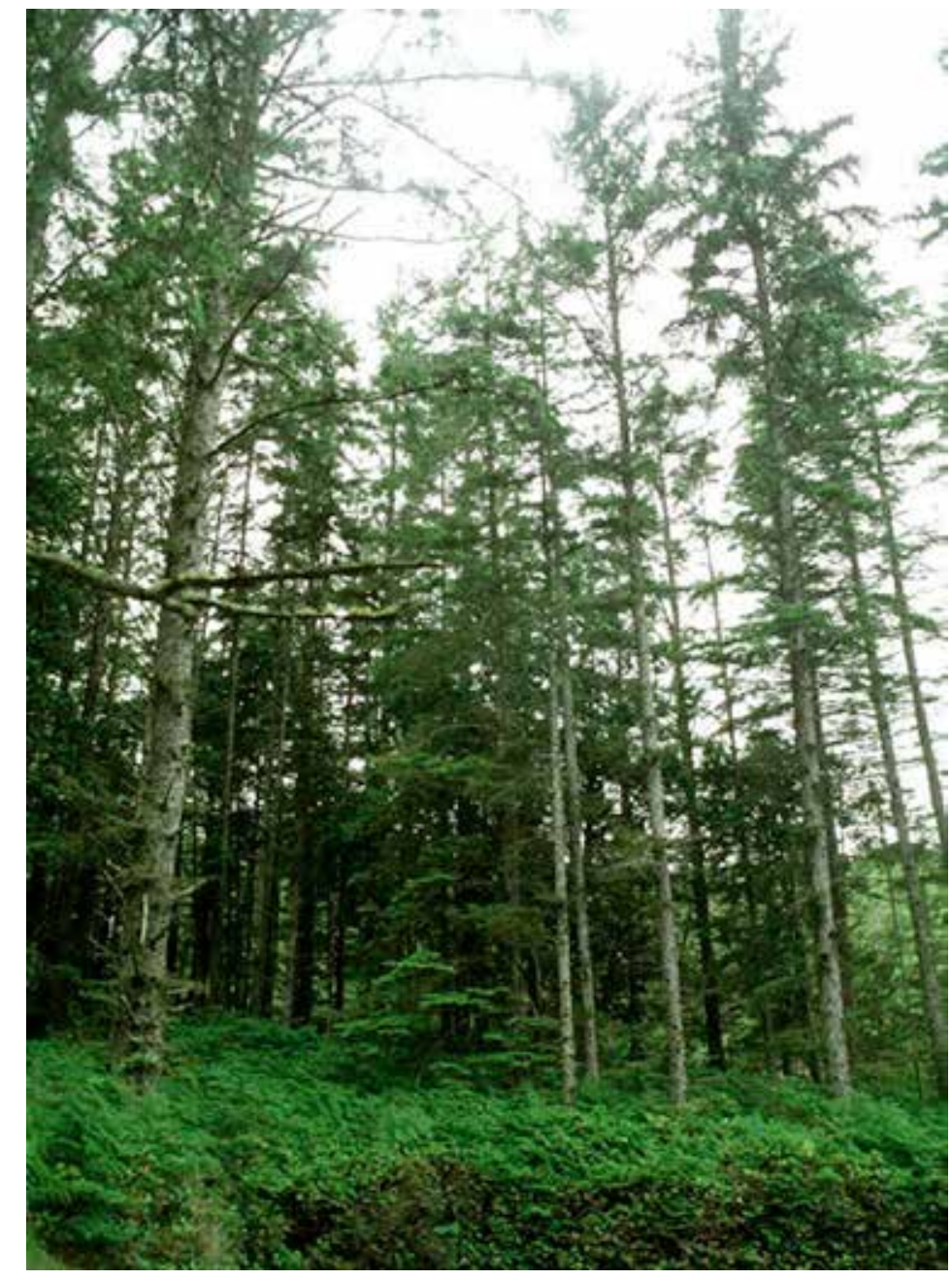

Sitka spruce was planted, following clear felling over 50 years ago, to provide a fast growing timber to produce pit props for the thriving mining industry. Wales now has 131,200 hectares (Chapter 2) of coniferous plantations which produce around a million tonnes of softwood in the round per annum. 59\% of the coniferous plantations and over $70 \%$ of current production is Sitka spruce, a native of the Pacific coast of North America. It has become the predominant species in Welsh plantations because of its liking for a mild and wet climate and its ability to establish in peaty upland soils.

In its native range, Sitka spruce grows slowly to a great age. These old growth stands produce a pale coloured timber with exceptional strength to weight ratio, which led to its use in aircraft frames. Welsh spruce grows much faster producing timber of lower density with heavier branching and larger knots. It is processed for a number of markets including fencing, woodfuel, chipboard and pallets but the most important commodity produced is carcassing timber which is machine graded to a maximum strength of $\mathrm{C} 16$, the lowest strength class in general use. This is widely sold through builders' merchants for use in general carpentry. Welsh grown C16 spruce is readily available in a range of standard lengths upto $4.8 \mathrm{~m}$, a standard thickness of $47 \mathrm{~mm}$ and widths from $75 \mathrm{~mm}$ to $250 \mathrm{~mm}$. As highlighted in chapter 3 , it is seldom used in modern timber frame construction which normally utilises higher grades of imported C24 softwood. Although Welsh spruce has poorer structural properties 


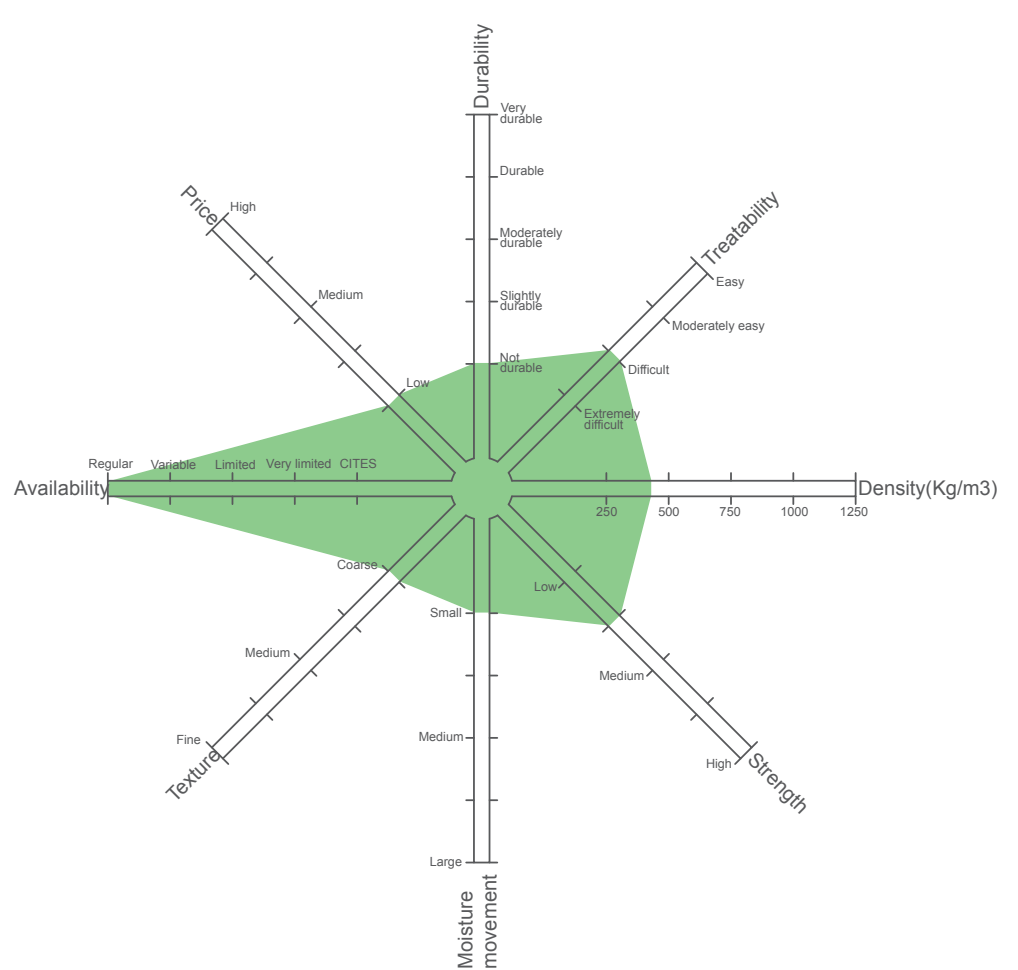

than imported softwoods, it is its tendency to twist during drying that timber frame manufacturers cite as their main reason for not using it.

The significant properties of Sitka spruce are

- High frequency of small knots ${ }^{3}$

- $\quad$ Not durable. ${ }^{4}$

- Low density due to speed of growth. ${ }^{5}$

- Yield class of between 14-20 cubic metres per hectare per year ${ }^{6}$ with rotation length between 35 and 45 years with trees reaching to between $16-23 \mathrm{~m}$ tall with diameter between 250 and $400 \mathrm{~mm}^{7}$

- Can produce $\mathrm{C} 24$ but commonly C16.8

- Low compressive strength in longitudinal and lateral directions and a hardness $25-50 \%$ lower than alternative softwoods. ${ }^{9}$

\subsubsection{Affordable housing in rural Wales}

The development of the Ty Unnos system, in 2007, was based on an identified need for more affordable housing in rural contexts.

The Joseph Rowntree Foundation have identified that there is an acute need for affordable housing in rural Wales due to an increasing population, a significant shift in the demographic and increase in poverty within rural communities and significantly increasing house prices. This has resulted in a net migration of 15-29 year olds and increasing homelessness. ${ }^{10}$ In 2007, the Welsh Assembly Government published the 'One Wales' agenda making proposals to ease the housing shortage, including a commitment to increase the supply of affordable housing by 6,500

homes between 2007 and 2011, by making more publicly owned land available and identifying sites specifically for affordable housing

Affordable housing is defined in Planning Policy Wales as '...housing where there are

3 Cedric Wilkins, Comparison of home grown and imported softwood for Timber Frame market - Fina Report (Watford: Building Research Establishment, 2004), p. 15.

4 John Moore, Wood properties and uses of Sitka Spruce in Britain, (Edinburgh: Forestry Commission,

5 Ibid, p. 11 .

6 lbid, p.2

7 A.L Tyler. D.C. MacMillan, J. Dutch, Models to Predict the General Yield Class of Douglas fir, Japanese Larch and Scots Pine on Better Land in Scotland (Edinburgh: Institute of Chartered Foresters, 1996), p.3 8 John Moore, p.30

9 Ibid, p.20

10 Joseph Rowntree Foundation, Rural Housing in Wales: Final Report (York: Joseph Rowntree

Foundation, 2008) 
secure mechanisms in place to ensure that it is accessible to those who cannot afford market housing.11 Mechanisms vary from affordability, house prices, income, rent and availability with two categories of affordable housing: Social rented housing provided by Local Authorities or Registered Social Landlords (RSLs); and Intermediate housing aimed at prices in-between social rented housing and market rents.

The development of Ty Unnos focussed predominantly on social rented housing, working collaboratively with housing associations across rural Wales for guidance on spatial requirements, technical performance and maintenance. As such, the following spatial, quality, technical and construction standards were required ${ }^{12}$ to be met to ensure value for money, long-term flexibility, adaptability and warranties for publiclyfunded affordable housing:

- Welsh Housing Quality Standards (WHQS) - '...everyone in Wales should have the opportunity to live in a good quality home within a safe an secure community. ${ }^{13}$

- Development Quality Requirements (DQR) - 'Dwellings provided by housing associations should be of good quality and suitable for the needs of the intended tenants.' 14

- Lifetime Homes - There are 16 standards based on 5 principles to ensure 'The Lifetime Homes Standard seeks to enable 'general needs' housing to provide. design solutions that meet the existing and changing needs of diverse households.15

- $\quad$ Building Regulations

- Code for Sustainable Homes

- National House Building Council (NHBC) standards and warranties

\section{Timber prefabrication}

In parallel with the need for more affordable housing, and discussed in chapter 4, the UK Government set increasing standards for low-energy housing and increasing targets for levels of Modern Methods of Construction (MMC). The Welsh assembly also promoted increased use of MMC in Wales in line with an identified need for

11 Planning Policy Wales, Technical Advice Note 2: Planning and affordable housing, (Cardiff: National Assembly for Wales, 2006) 1.4

12 correct at the time of conducting the research.

13 Welsh Government, Welsh Housing Quality Standard, (2014) <http://gov.wales/topics/housing and-regeneration/housing-quality/welsh-standard/?lang=en> [Accessed 2nd September 2015]

14 Welsh Assembly Government, Development Quality Requirements: Design Standards and Guidance (Cardiff: Welsh Assembly Government, 2005), p.2

15 Lifetime Homes, Lifetime Homes Principles, <http://www.lifetimehomes.org.uk/pages/lifetime homes-principles.html> [Accessed 2nd September 2015] 
affordable housing to improve the quality of life for all. The Welsh Assembly's Better homes for the people of Wales states, 'We want everyone in Wales to have the opportunity to live in good quality, affordable, housing; to be able to choose where they live and decide whether buying or renting is best for them and their families.' ${ }^{16}$

The Welsh MMC supply chain is immature compared to that in the rest of the UK. Many of the Welsh MMC manufacturers are receiving larger orders from hotel and fast food retailers outside Wales than from construction and housing companies within Wales. With the correct input, many of the current MMC suppliers have the potential to develop more focussed and advanced construction systems.
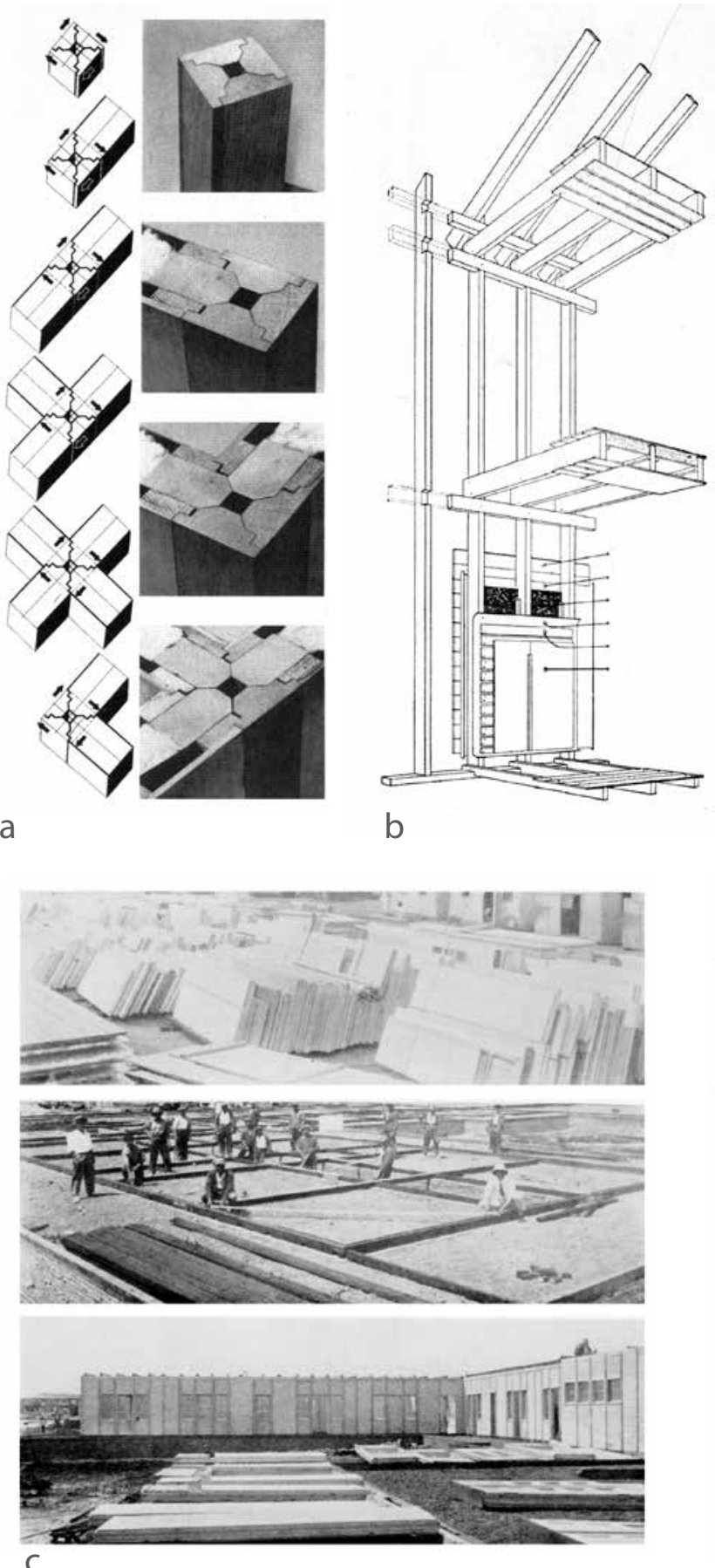

Fig 9.3 The General Panel System

a. multiple post and wall connection detail b. balloon frame type construction process c. manufacturing and assembly of prefabricated panels

d. cut-a-way perspective of assembly

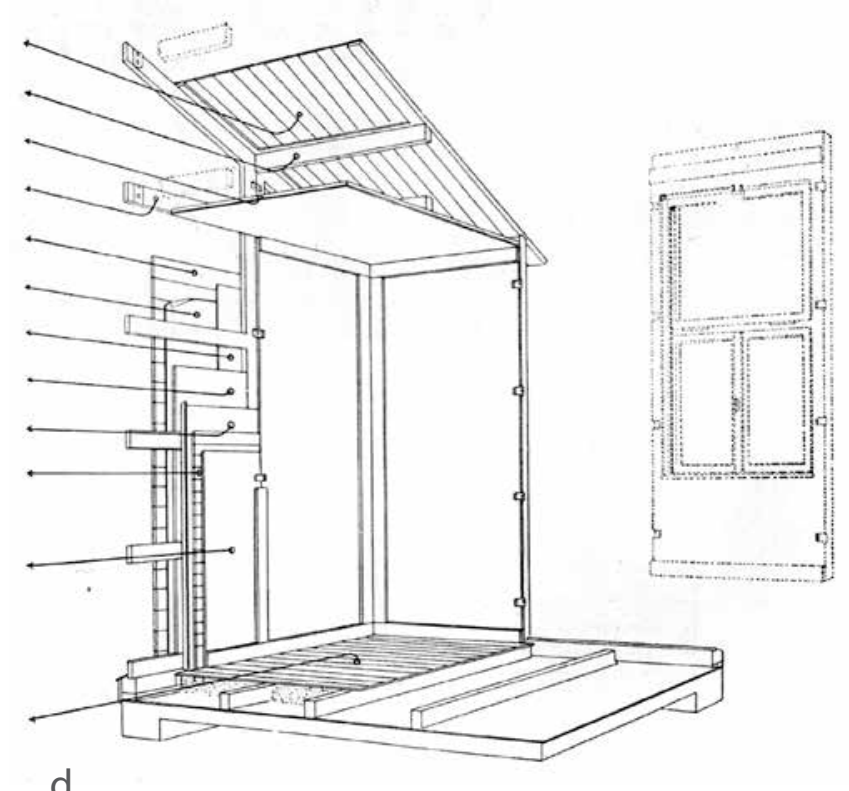

At present all of the modern timber frame manufacturers in Wales (and the UK) use imported softwoods because of the greater stability and superior strength of slow grown softwood from cooler and drier climates. It was recognised that simple substitution with home-grown softwood was not an option for these prototype projects. If a system was to be adopted generally it would need to stabilise the main structural components and eliminate the need for conventional trussed rafters. This would require a radical departure from existing practice.

\section{Precedents}

Three precedent studies revealed different design approaches that would meet the tectonic aims of a simple, low-tech construction system, complementing the properties of Sitka spruce and the available skills and technology:

- The General Panel System by Konrad Wachsmann and Walter Gropius 'A universal system of industrialised components' ${ }^{17}$ The general panel system was proposed to be an industrialised housing system which Konrad Wachsmann and Walter Gropius referred to as 'the packaged house'

The system was a method similar to the American platform frame. Its premise was that all of the building planes, internal and external walls, floor and roof would all use the same panel. The dimensions of supporting cross sections matched the boards used but were laid horizontally rather than vertically to frame the supporting walls. Top and bottom plates provided stability to the panel. These are then joined to form a wall frame using clamps at the corners to provide stability.

16 The National Assembly for Wales, Better Homes for People in Wales: A National Housing Strategy for Wales, (Cardiff: National Assembly for Wales, 2001)

17 Alicia Imperiale, 'An American Wartime Dream: The Packaged House system of Konrad Wachsmann and Walter Gropius' (ACSA Fall Conference, Temple University, 2012), p.41 


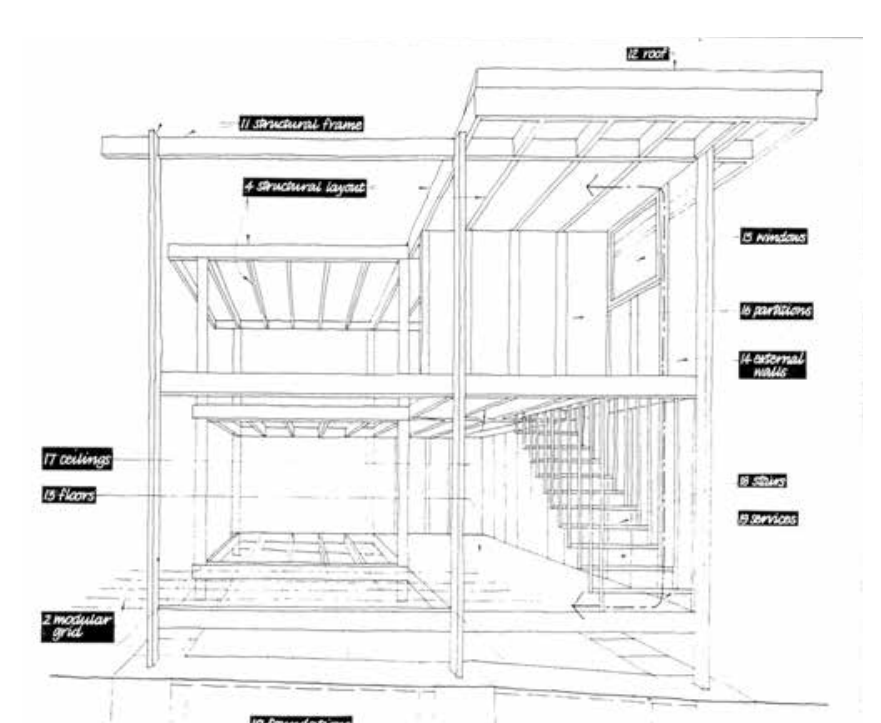

and
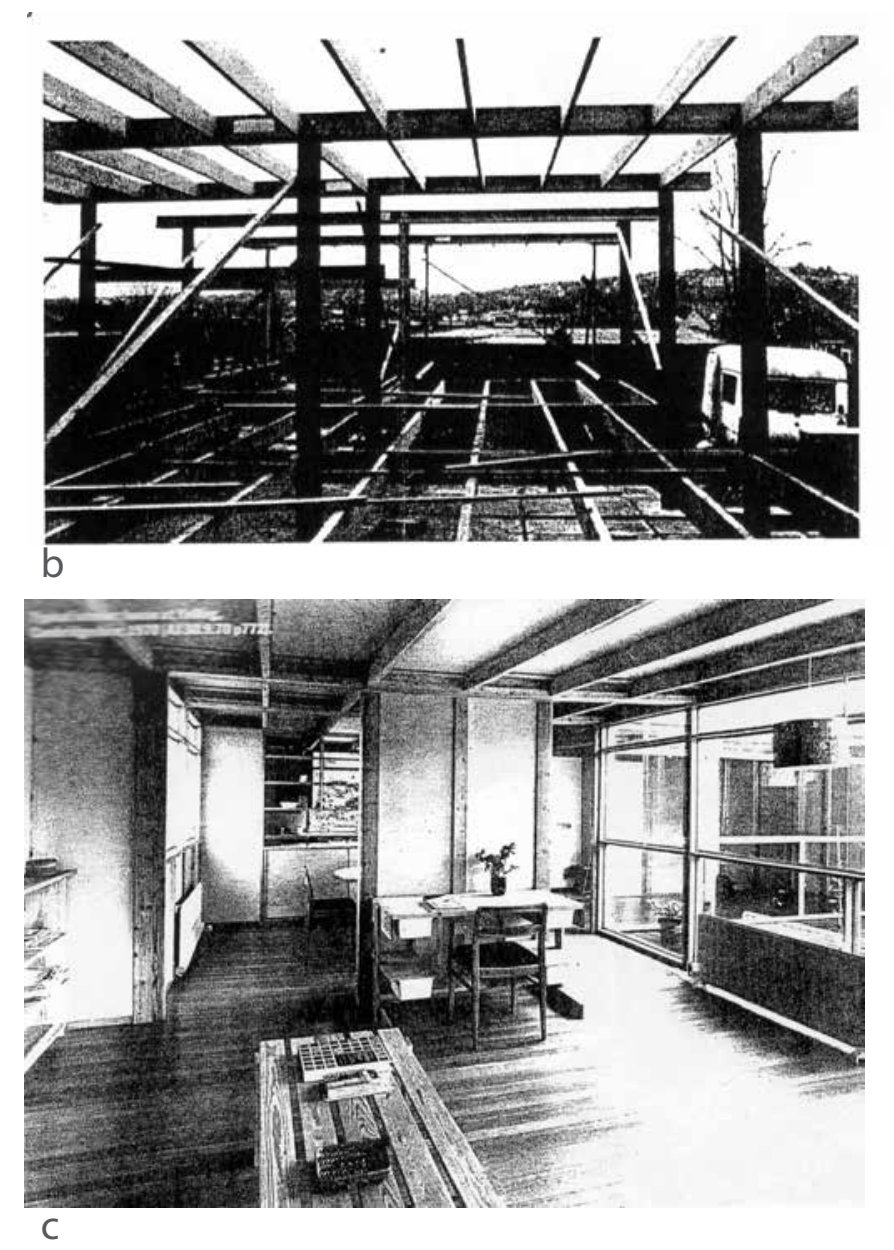

Fig 9.4 The Segal system

a. perspective drawing of standardised frame

b. photo of frame under construction c. photo of finished internal space with exposed standardised components as part of the tectonic expression
It was the connector between panels that was most praised for its innovation. It enabled, 2, 3 or 4 way connections between panels; a three dimensional iron joint could be used for all connections. This innovative jointing system was based on asymmetrical wooden wedges that created an angled three dimensional joint, joined on the inside of the frame with an iron joint. The panels were erected to create building bays which could then be added to each other to create the overall building. ${ }^{18}$

- The Segal Method by Walter Segal

'Using widely available timber put together in an open ended way'" The Segal method is an approach to construction based on reducing the individual building elements to a kit of parts which are readily available and can be obtained off the shelf. The method is based on the assumption that the

skills required to erect these parts into the building envelope are commonly known, i.e. basic carpentry skills. The only exception is in relation to services and roofing where some more specialized skills may be required.

Ideally the individual elements are then assembled in the market sizes, reducing the need for production processes and wastage on site. The building is therefore organized on a modular grid to suit the standard sizes and length of materials available. The framework of the building is constructed from standard sections of timber with board materials such as plasterboard and timber boards used to enclose it.

The components are assembled using simple dry joints with bolts and screws. The internal and external finishes of the materials are accepted as the finished faces of the building envelope, eliminating any wet trades from site such as plasterers. Foundations and groundworks are kept to a minimum as they would generally require a more specialized skill set.

The production information documents prepared to support the building process are reduced to: freehand diagrams and layouts of the structure; typical junction details; a schedule of materials including a bill of quantities and specification with order list; a set of instructions. This provides the basis for accurate ordering of materials and therefore a greater chance of

18 Barry Bergdoll and Peter Christensen, 'Packaged House by Konrad Wachsmann and Walter Gropius (1941-1952), <http://www.shelterpress.com/categories/homes/prefab-homes/history prefabricated-home/packaged-house-konrad-wachsmann-and-walter-gropius.html> [accessed 16th September 2015]

19 Jon Broome, 'The Segal Method', Architect's Journal, 183 (1986), 31-68 (p.36) 

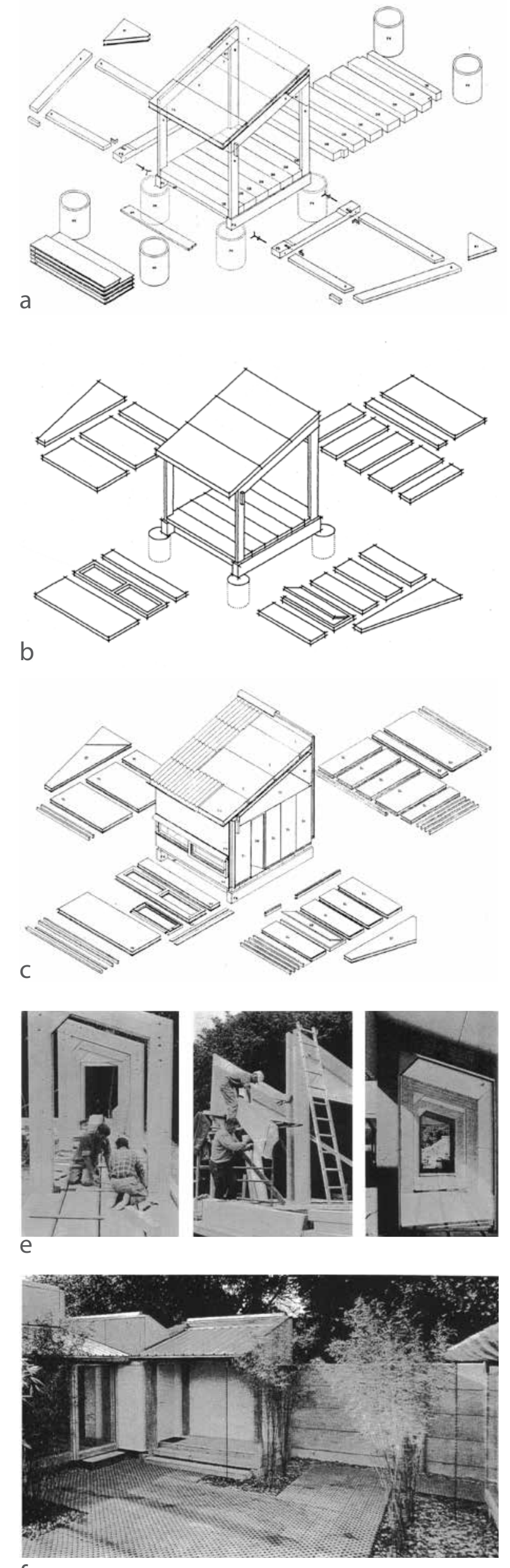
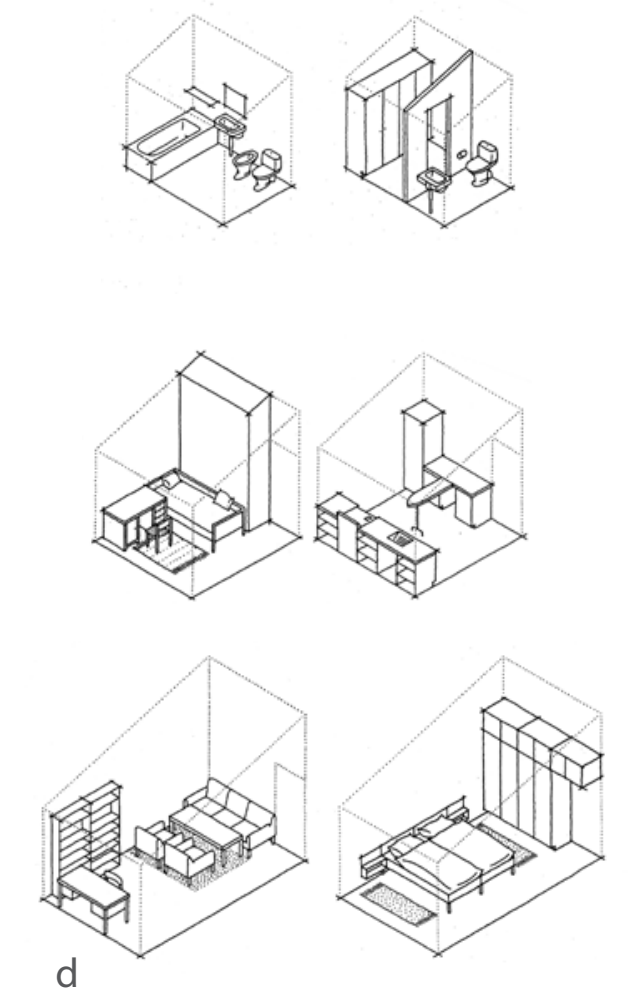

Fig 9.5 The Espansiva System

a. foundation, frame and floor components

b. infill wall and roof panels

c. additive finishes and joinery

d. room module configurations

e. photo of construction sequence

f. photo of prototype courtyard house

g. model of additive configurations based

on one standard spatial module.

Iㅔ
$=1-$

\section{- The Espansiva system by Jørn Utzon}

'Timber was to be the predominant material; the components had to be easy to handle and erect, capable of being produced at competitive prices, and capable of being combined into a great number of design combinations. ${ }^{20}$

The system is based on an additive approach to configuration and structure using a rationale of posts and columns with panelised floor, roof and window components. The external and internal walls therefore become non loadbearing within the frame, leaving the space between columns as flexible.

The system of floor, columns and roof is then arranged into different modules sizes. The module size is set by the function of the room that is planned for that space. Each module has 4 corner posts, joined by a rafter at the head of the post to form a frame that is bolted together on site. The posts and rafters are made from glue laminated timber, with the roof made of stressed skin plywood units with mineral wool insulation between the plywood sheets. The floor is constructed from lightweight concrete units. Once constructed these modules form individual pavilions which can then be arranged and composed into different house type layouts. Different sized modules relate to different room functions, including: circulation and utility space, bedrooms, bathrooms, living, kitchen and dining areas. A gap of $120 \mathrm{~mm}$ is left between each module once laid out together in order to allow for the thickness of the internal partition to fit between. These are typically wall units made from 2 no sheets of plywood with mineral wool insulation between. The walls are then bolted to the posts to be held in place, which makes them easily removable should the space need to be reconfigured. The windows and doors are fixed in the same way and therefore offer the same level of flexibility 

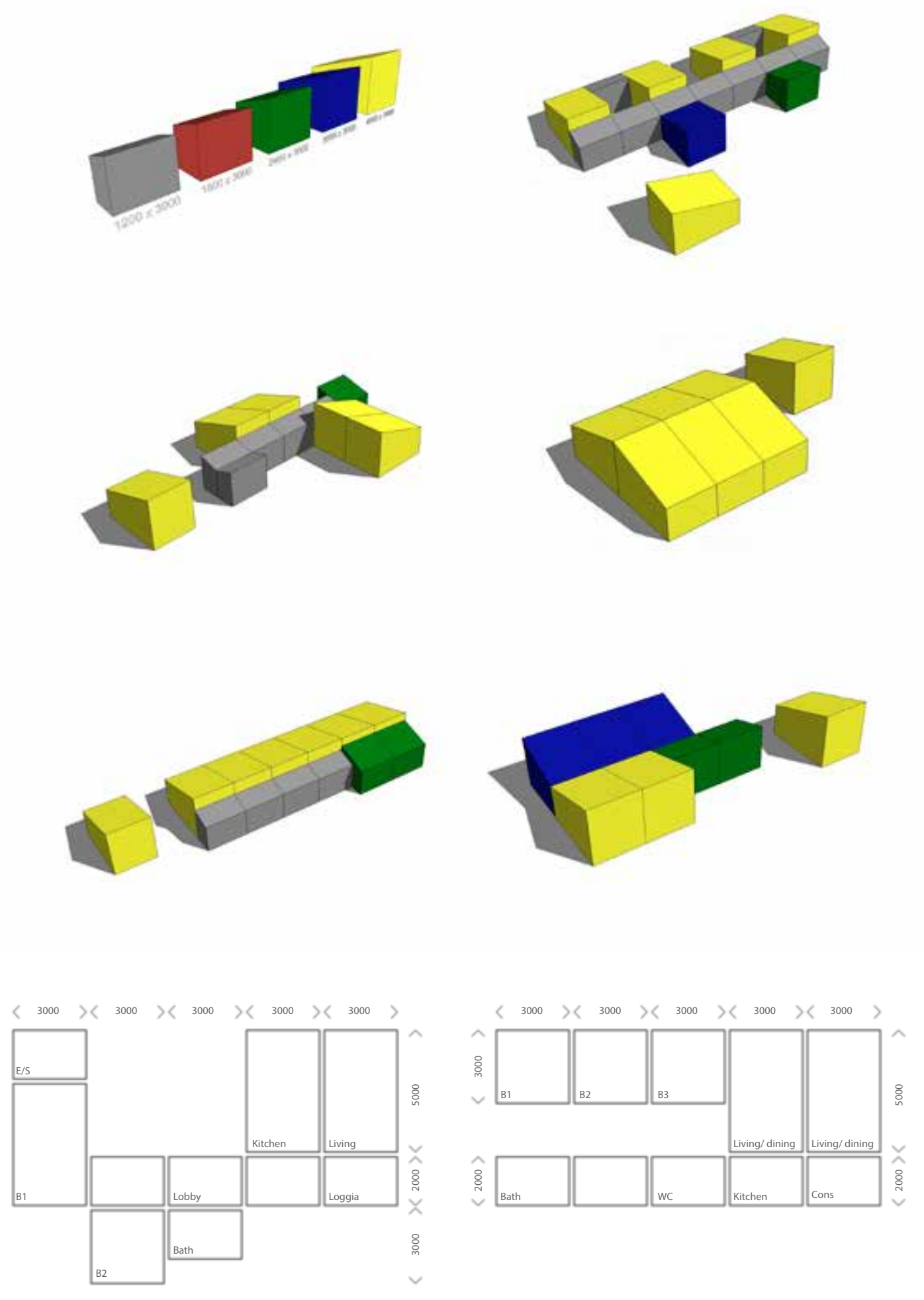

Fig 9.6 Module elements and arrangement types based on Espansiva system

Fig 9.7 Spatial configuration concept of room modules leaving space for circulation
The intention of the first prototype, was to design, fabricate and construct a solution for the use of Welsh-grown Sitka spruce for the construction of affordable housing, known as Ty Unnos, ${ }^{21}$ determined by the following industry and technological factors:

- the use of standardised sizes and sections of Sitka spruce and other softwoods available from local sawmills;

- to use low-tech engineering methods that complement the available skills and plant to reduce costs and enable quick mobilisation; and

- to focus on a domestic scale superstructure system.

\subsubsection{Feasibility}

All 3 precedents demonstrated an additive-based construction approach that would allow for elemental prefabrication of lightweight components for simple on-site assembly by potentially unskilled labour. However, the Espansiva system proved the most influential in the formation of 4 module proportions similar to the framing of traditional Welsh cruck-framed houses. Each corresponded to the standard sizes of timber available, up to $4800 \mathrm{~mm}$ in $600 \mathrm{~mm}$ increments, at larger sawmills and the functions of rooms within a house based on a $600 \mathrm{~mm}$ layout grid:

1. $3000 \times 1200 \mathrm{~mm}$ - Lobby, WC

2. $3000 \times 2400 \mathrm{~mm}-$ Bathroom, small bedroom, study

3. $3000 \times 3600 \mathrm{~mm}$ - Medium bedroom, kitchen, dining room

4. $3000 \times 4800 \mathrm{~mm}$ - Living room, large bedroom

The spatial modules were then combined in a variety of ways to form different house types while using the same sections of post and beam with standard roof pitches of flat, $17.5,25$ or 35 degrees. A further study on an additive construction process was explored with Mogens Prip-Buus, an associate of Jorn Utzon, who worked on the original Espansiva system.

Initial thoughts regarding the timber components were based closely on the precedent studies and therefore to develop:

\section{Repetitive and modular based components;}

21 Ty Unnos translates into English as 'house in a night'. It draws on the ancient tradition of building houses quickly in order to claim common land. The parallel is with the proposed systems speed of construction. 

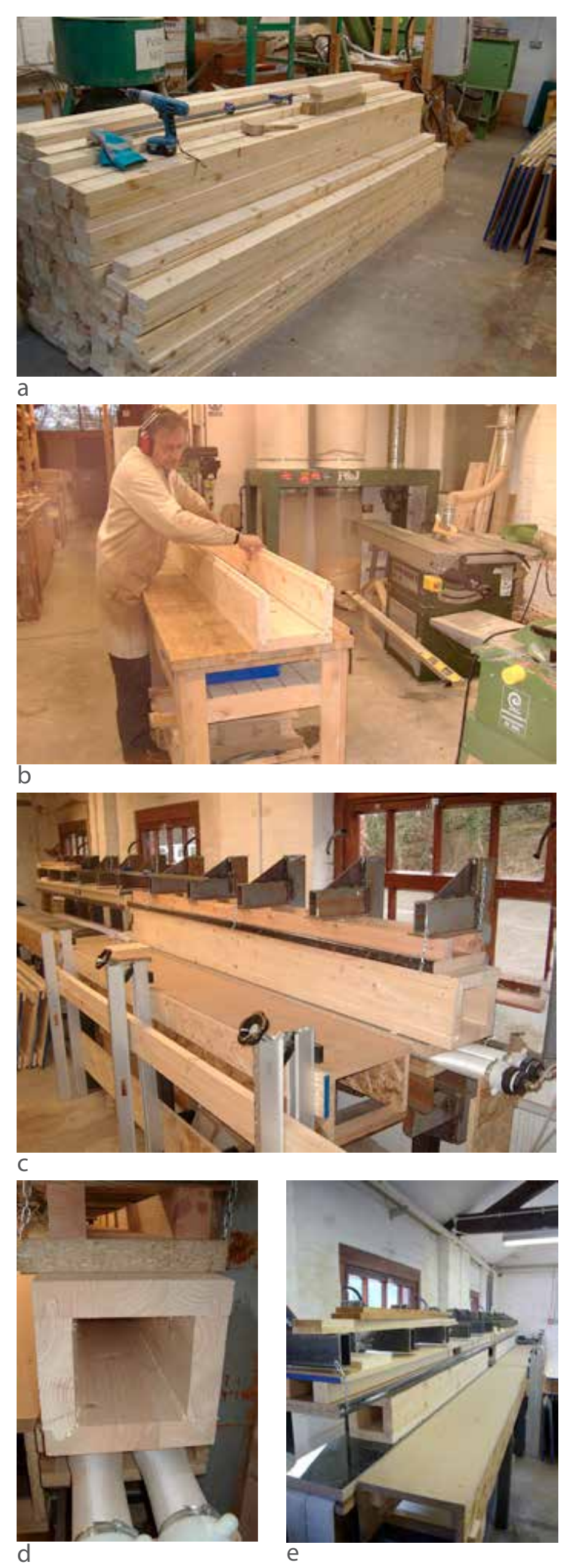

Fig 9.8 Fabricating the box sections a. kiln dried Sitka spruce

b. profiled spruce boards with tongue and groove detail assembled and lued

c. assembled box section located in low-tech press

d. Hoses filled with compressed air pressing the box section

e. box section is held in press for 10

continue drying
- A timber post and beam system with infill panels;

- $\quad$ Components that were lightweight and simple to construct on-site; and

- Provide flexibility in design and future re-use.

However, the solid section sizes needed to support the required spans and loadings of the largest identified spatial module were too large to be cut from Welsh spruce without including the centre of the tree. This invariably causes the spruce to split and warp badly. Glue lamination of thinner sections to form solid engineered posts and beams was feasible but quickly eliminated due to the cost of equipment and slow process that made it prohibitive for small scale manufacture. Therefore, other engineered profiles, such as I-beams, lattice beams and box beams were considered as they can be produced relatively simply by slotting precut spruce boards together using tightly fitting joints which hold while the glue is curing. This reduces the weight and volume of timber required, simplifies the cramping process and increases throughput.

The significant developments on the primary structural frame and secondary structure of the thermal envelope design are highlighted before being incorporated into an early-stage prototype and hypothetical design study to be evaluated.

\subsubsection{Primary Structure}

9.3.2.1 Box section components

The preferred option, to meet the proposed spatial arrangements, was to fabricate box section post and beams with the intention of creating 'portal' frames. The wall thickness and therefore post size was to be determined more by the required $\mathrm{U}$-values, than by structural loading, and by the qualities of sustainable insulation with $200 \mathrm{~mm}$ typically giving $0.2 \mathrm{~W} / \mathrm{m}^{2} \mathrm{~K}$ or better. The box section would use less wood fibre and less labour to fabricate while insulation within the section would reduce the cold bridging effect of solid timber structures. In the majority of locations a $220 \mathrm{~mm}$ square box, comprising 2 no. $50 \mathrm{~mm} \times 225 \mathrm{~mm}\left(2^{\prime \prime} \times 9^{\prime \prime}\right)$, C16 grade plus 2 no. $50 \mathrm{~mm} \times 175 \mathrm{~mm}\left(2^{\prime \prime} \times 7^{\prime \prime}\right)$, was proposed. However, for more highly stressed locations, such as floors and larger spans a $220 \mathrm{~mm} \times 280 \mathrm{~mm}$ box could be used so the whole structural frame could still be built from $50 \mathrm{~mm} \times 225 \mathrm{~mm}$, ordinary quality spruce.

The initial press prepared to manufacture these prototype box sections was intentionally made low-tech, in order to minimise costs and demonstrate how basic the technology can or only needs to be. However, more importantly it demonstrated how simple the manufacturing process is and how easy it would be for other parties to replicate the press and make their own box sections, whether they be self-builders 
or established timber framers moving into a new market without the usual large overheads and risk. The press was fabricated by Coed Cymru from off-the-shelf galvanised steel rectangular hollow sections, softwood, a laminate kitchen worktop and expandable firefighter's water hose. The press and box section profile were designed so that pressure only need be applied for 15 minutes to squeeze the box together and then it could be removed to finish curing elsewhere while another section was pressed.

\subsubsection{Frame connections}

As portal frames, the box section post and beams would provide most of the structural rigidity a house requires. The intention of the portal frame was to simply connect posts with ground floor beam and foundations, and posts with rafters or intermediate floor beams. Two types of connector were proposed:
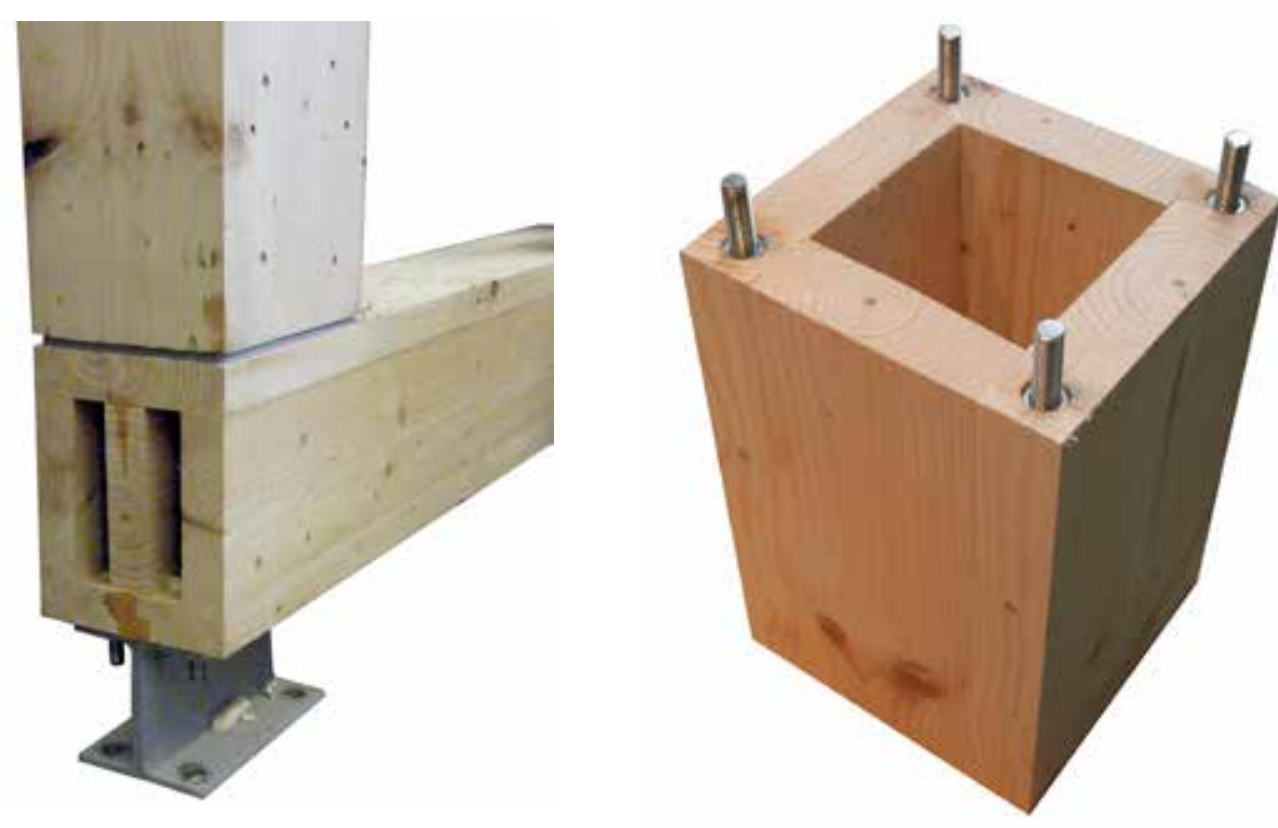

ABOVE

Fig 9.9 End grain bolted connection detail

BELOW

Fig 9.10 'L'shaped insert connectors

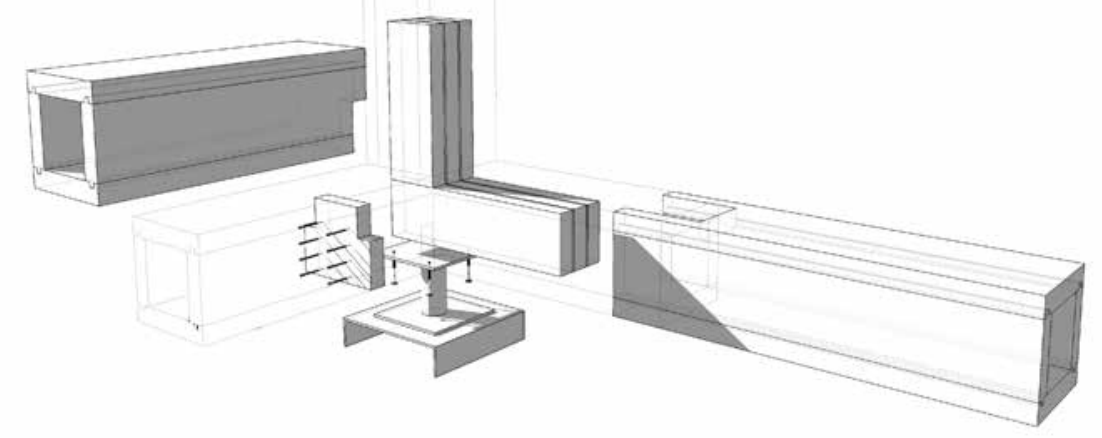

\section{- Threaded end grain bolts}

Developed by Cowley Timberwork, slow setting epoxy resin is used to glue 4 or 6 no. $600 \mathrm{~mm}$ lengths of M16 stainless steel threaded rod into the end grain of a box beam post. The rods are then fed vertically through a bearing plate and corresponded holes in the side of the box beam for floor and roof which is then tightened with washers and nuts. To connect to the foundations, Cowley's extended the length of the bolts through the ground floor beam and through a steel'shoe'. This in turn is bolted to the foundations with resin anchor bolts. Testing by Burroughs revealed that these bolts limited the spacing of frames significantly due in part to crushing of the timber. As a result internal webs were located within the end of the box beam, although reducing the box beam effectively to a solid section. However, the connections still limited frames to single storey structures that would be impractical for domestic use. ${ }^{22}$ This connection was used in the construction of the Environmental Resource Centre in section 10.5.

\section{- ' $L$ ' shaped insert connectors}

Two forms of insert to fit inside each part of the frame were proposed: a preformed, welded, hollow steel section; and a rigid laminated timber or plywood $L$ section, possibly with steel reinforcement. Both could accommodate a number of components meeting from different directions. However structural testing of the portal frame suggested that only primary box section components required rigid connections with any tie or edge beams simply spanning between frames. The preferred option was therefore 
for a laminated 'L' shaped connector using 47 x 150mm sections of Sitka spruce. Testing revealed that the connector would either need to be glued into the box section component; bolted through the full thickness of box section and connector; or screwed from both sides of the box section. A form of this connector was used in the Smithsonian pavilion and the Longhouse detailed later in this chapter.

Further research on the overall frame, infill and assembly sequence revealed that edge beams spanning between the portal frames at intermediate floors and eaves would reduce the structural demands on the infill panels as racking panels. A simple ' $T$ ' shaped timber shear connection was developed to allow edge beams to connect
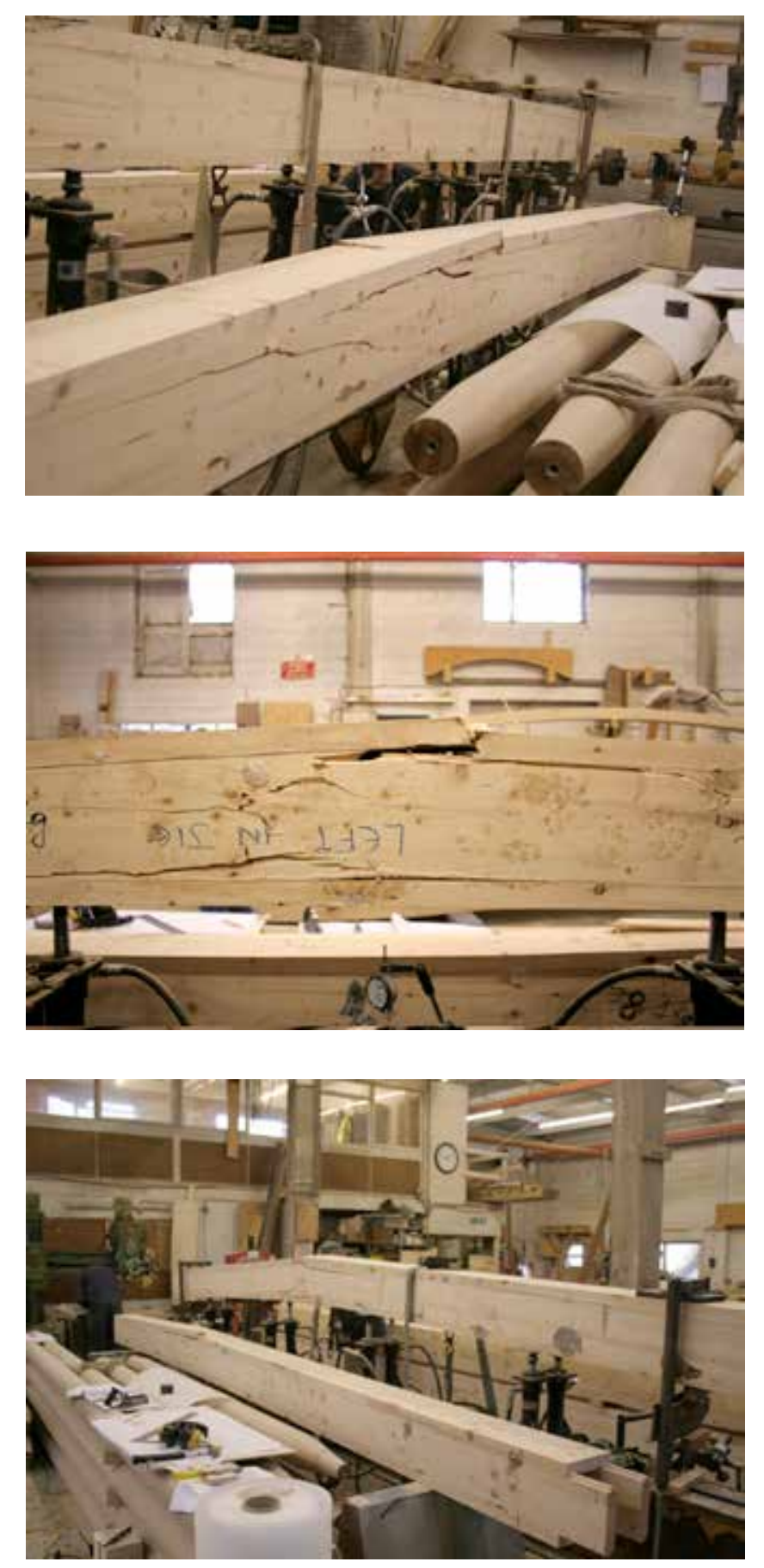

Fig 9.11 Box section beam testing at Cowley Timberwork

\subsubsection{Box frame engineering}

Cowley Timberwork and Burroughs structural engineers undertook structural testing on the Ty Unnos box section in early 2008 , firstly on a simple beam and then in the form of a portal frame. Tests on the box section beam were very promising with consistently high loadings being met with great efficiency.

Five box sections were tested with a section size of $210 \times 270 \mathrm{~mm}^{23}$ based on structural testing procedures set out in BS 5268-2:2002 to evaluate the calculation based assumptions of floor beam spans. The tests involved a series of hydraulic rams used to apply upward loading across 4 locations to a clamped beam set up for a $4.8 \mathrm{~m}$ span. All beams were initially 'bedded in' for 15 minutes, before each beam was taken to the intended design load for 24 hours with the deflection recorded every hour. Finally, three of the beams were then loaded to destruction to evaluate the potential capacity and point of failure. The results were as follows: ${ }^{24}$

- Beams deflected between $12.2-14.5 \mathrm{~mm}$ at design loading.

- When loading was removed the beams returned to within $0-0.3 \mathrm{~mm}$ deflection of original position.

- The three beams failed at $6800 \mathrm{Kg}, 7300 \mathrm{Kg}$ and $8732 \mathrm{Kg}$.

- Testing observations revealed that the beams often responded to sounds of splitting and cracking without noticeable failure. This is noted as a common symptom of timber beams compared to other materials. When the beams failed, this occurred along a weakness such as a knot or split.

$2347 \times 225 \mathrm{~mm}$ boards were to be used to produce a $220 \times 280 \mathrm{~mm}$ beam with $45 \mathrm{~mm}$ thick walls, although the boards required more processing than expected creating a $210 \times 270 \mathrm{~mm}$ beam with $43 \mathrm{~mm}$ walls

24 Cowley Timberwork, Ty Unnos : Prototype Beam Test (Lincoln: Cowley Timberwork, 2007), p. 


\begin{tabular}{c|ccc|cc|cc|}
$\begin{array}{c}\text { Loaded } \\
\text { Width } \\
(\mathrm{m})\end{array}$ & $\begin{array}{c}\text { Maximum } \\
\text { Span }(\mathrm{m})\end{array}$ & $\begin{array}{c}\text { Deflection } \\
(\mathrm{mm})\end{array}$ & $\begin{array}{c}\text { Maximum } \\
\text { Span }(\mathrm{m})\end{array}$ & $\begin{array}{c}\text { Deflection } \\
(\mathrm{mm})\end{array}$ & $\begin{array}{c}\text { Maximum } \\
\text { Span }(\mathrm{m})\end{array}$ & $\begin{array}{c}\text { Deflection } \\
(\mathrm{mm})\end{array}$ \\
\hline & $3.6(\mathrm{M})$ & 10.5 & $4.7(\mathrm{i})$ & 18.3 & $5.6(\mathrm{M})$ & 20.1 \\
\hline 2.4 & $2.7(\mathrm{~V})$ & 6.1 & $3.8(\mathrm{M})$ & 12.9 & $4.4(\mathrm{M})$ & 13.0 \\
\hline 3.6 & $1.9(\mathrm{M})$ & 2.1 & $3.1(\mathrm{M})$ & 8.9 & $3.6(\mathrm{M})$ & 9.0 \\
\hline 4.5 & $1.4(\mathrm{~V})$ & 1.2 & $2.6(\mathrm{~V})$ & 6.3 & $3.2(\mathrm{M})$ & 7.4 \\
\hline
\end{tabular}

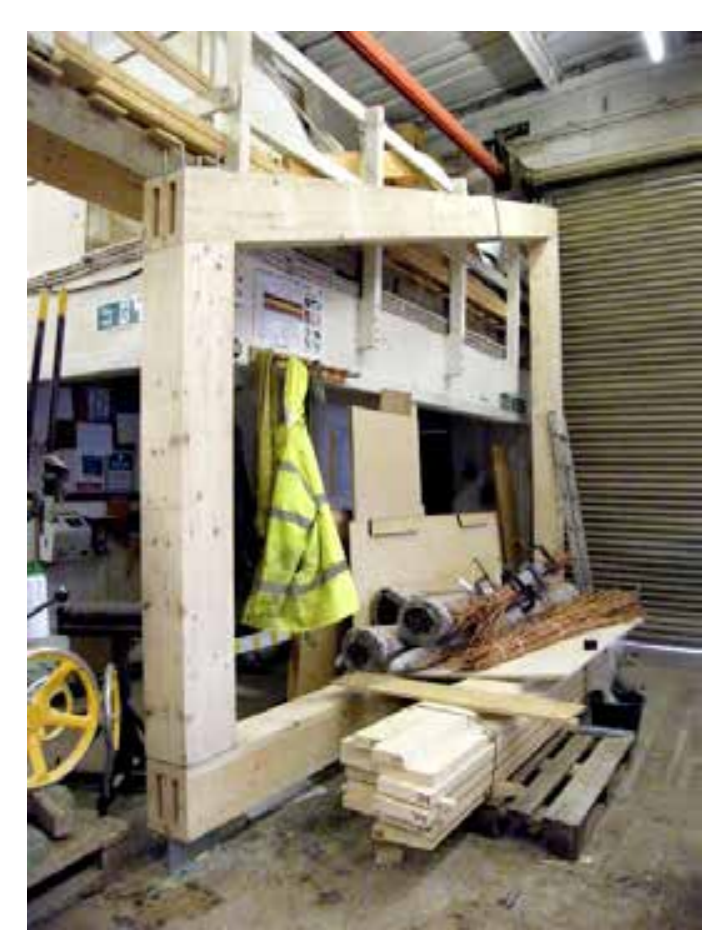

ABOVE

Fig 9.12 Box beam sizes and loadings table prepared by Burroughs

LEFT

Fig 9.13 Completed prototype portal frame using end grain bolting

BELOW

Fig 9.14 Infill panel development studies
This testing and further modeling resulted in a full Technical Assessment of the Ty Unnos system by Burroughs with the span and deflection results of three beam section sizes fabricated with the assumptions that all glued connections are stronger than the wood itself and the timber is graded to $\mathrm{C} 16$. Burroughs conclusions advised that the latter two with $40 \mathrm{~mm}$ thick walls were structurally suitable for use in domestic use.

As well as performing vertically, the box frame structure must also provide resistance to horizontal loadings both parallel and perpendicular to the plane of the frame. The intention was to use portal frames to define the spatial modules, identified in section 10.3.1, that were filled with simply spanning panels to provide the thermal envelope. The portalised performance was physically tested by Cowley Timberwork and CAD simulated by Burroughs.

A simple single storey frame, using $210 \times 270 \mathrm{~mm}$ box components for posts, floor beam and rafter connected using end grain threaded bolts was laid horizontally and bolted to the concrete floor. A hydraulic ram was used to simulate wind loading and resultant deflection of the posts and joints, by applying horizontal force to the highest point of the portal. Under a loading of $950 \mathrm{Kg}$, the frame deflected $22 \mathrm{~mm}$. The CAD simulated test found a deflection of $19 \mathrm{~mm} .{ }^{25}$

Following further tests on rectangular portal frames and alternative frame centres, Burroughs concluded that in general a portal frame structure could perform well up to two storeys.

\subsubsection{Secondary structure}

\subsubsection{Infill panel development}

The initial intention of infill for walls, floor and roof was to create a thermal envelope, embracing much the same philosophy as the frame. Cassettes or boxes using the same $50 \mathrm{~mm} \times 225 \mathrm{~mm}$ re-sawn to $25 \mathrm{~mm}$ boards, for all faces, could be made long enough to span in either direction - influenced by standard sized openings for doors and windows. Although it would be possible to use plywood or OSB infill panels, this would require the importation of non-standard sizes. Instead the lightweight box panels could be pre-filled with hemp fibre (or other natural) insulation and simply slotted into location on-site providing a quick weather tight shell to a very high standard of thermal efficiency, with U-values of $0.15 \mathrm{~W} / \mathrm{m} 2 \mathrm{~K}$.
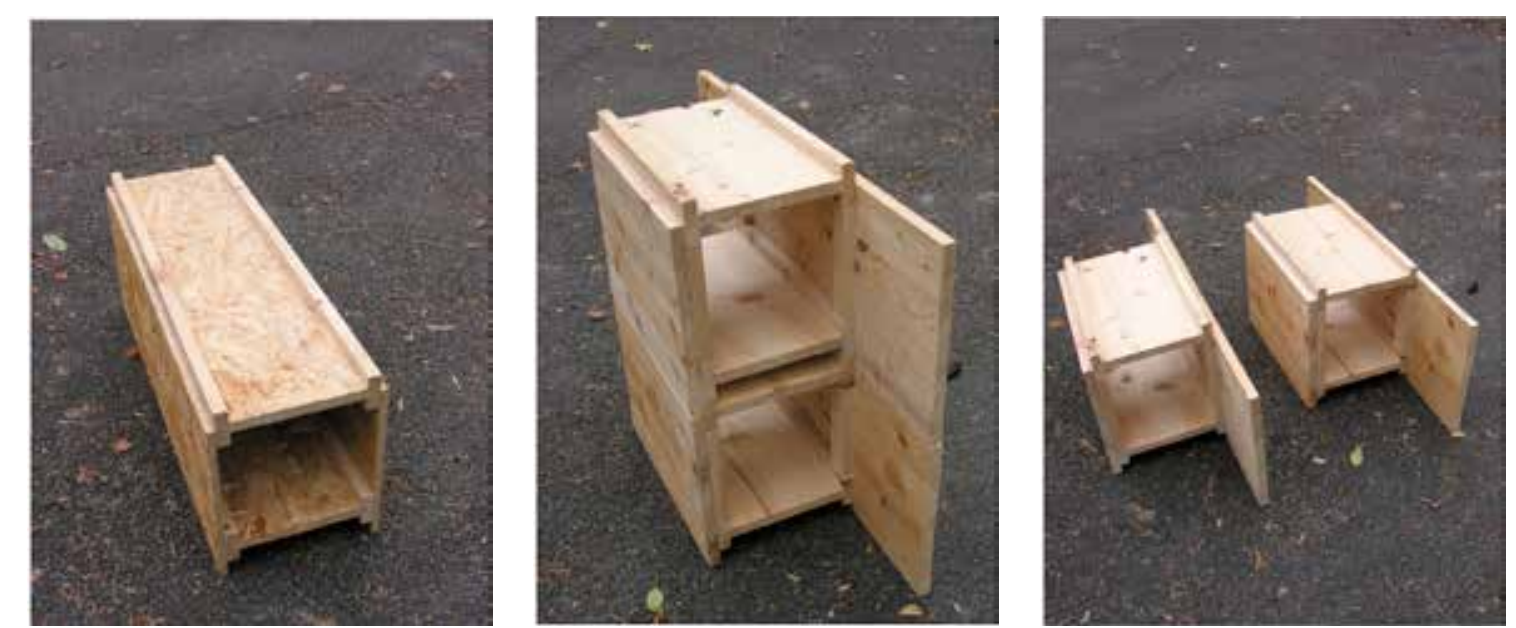

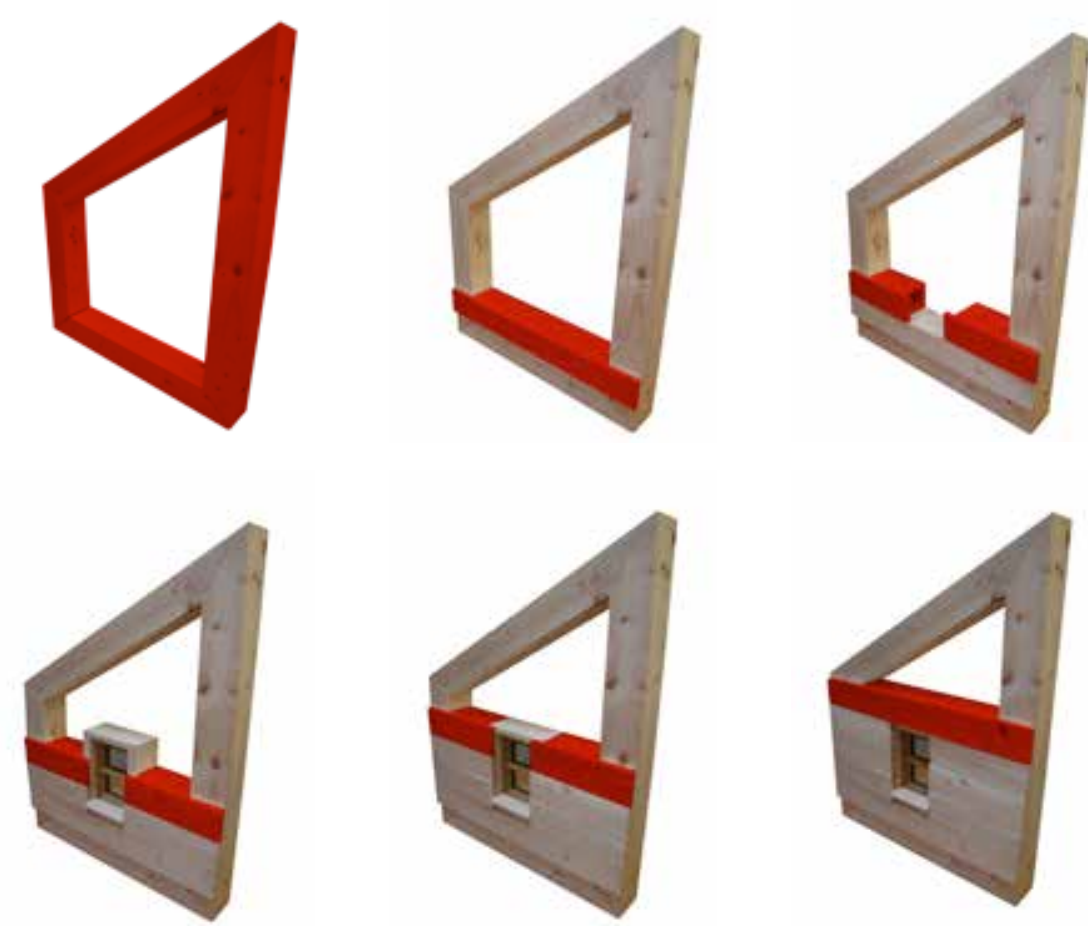

ABOVE

Fig 9.15 Sequence of installing initial proposal for prefabricated infill box sections within a mono pitched portal frame

BELOW

Fig 9.16 Ladder beam panel development
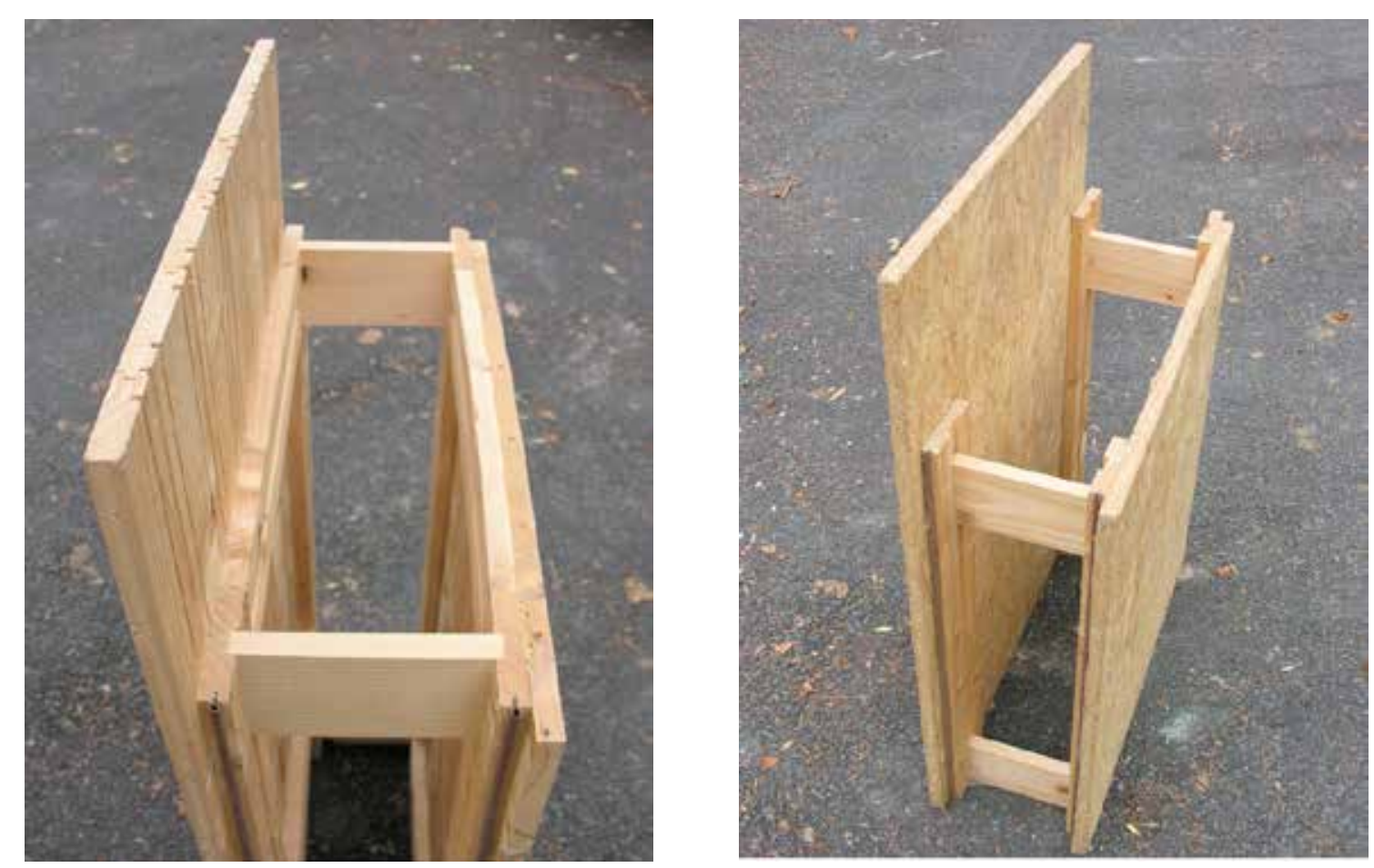

While this elemental method was a good starting point using $100 \%$ Welsh-grown softwood and created a lightweight and strong structure, both model and 1:1 prototyping revealed that the many components needed to build a notional gable wall had the following problems:

- an increased number of individual components rather than repetitive elements;

- more complex details required to reduce the potential for air leakage and thermal bridging; and

- while the box section infill components were individually structurally good, as a whole they were over engineered and working independently to one another.

The system conceived as box section components providing the infill for floor, walls and roof, by simply stacking and spanning between the structural portals, was therefore refined through the development of a larger panel system working on the $600 \mathrm{~mm}$ component and spatial dimension.

\section{Three systems considered included:}

- a whole timber system that uses a small section spruce ladder beam with solid timber planking both internally and externally;

- $\quad$ an OSB system which uses the same small section spruce ladder sandwiched between two layers of Scottish Oriented Strand Board; and

- Structurally Insulated Panels (SIPs).

The first two systems combined low-tech processes, drawing on the local manufacture of pallets, with high insulative values using locally sourced natural insulations. The third option, was to utilise a lightweight, highly insulative and structural prefabricated, 3rd party panel being manufactured by Kingspan in North Wales. However, this would rely on imported plywoods and OSB with less sustainable EPS insulation sandwiched between with glues.

Of the two preferred options, also developed on Coed Cymru's approach to small lengths and sections of hardwood, the ladder beam principle was for a simply connected alternative beam that enabled the use of off-cuts of Sitka spruce from other manufacturing processes. Many types of ladder were fabricated and tested to evaluate the connections, sizing of flanges and webs, tongue and groove joints, glues and screwing positions. These were tested by Coed Cymru, Burroughs and the Centre for Research, Engineering and Environment Applications (CEREA) at Glamorgan 

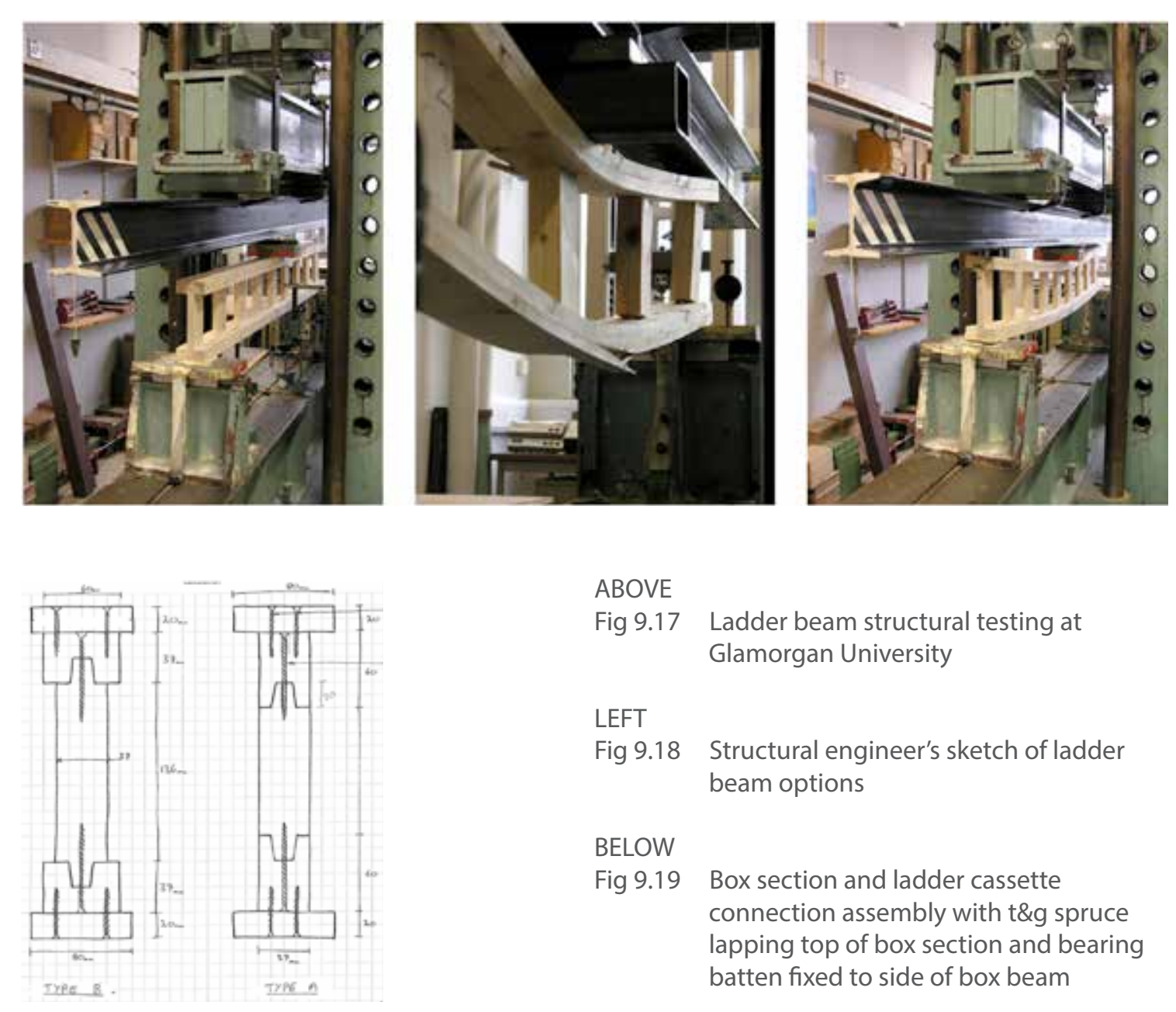

ABOVE

Fig 9.17 Ladder beam structural testing at Glamorgan University

LEFT

Fig 9.18 Structural engineer's sketch of ladder beam options

BELOW

Fig 9.19 Box section and ladder cassette

connection assembly with $t \& g$ spruce lapping top of box section and bearing batten fixed to side of box beam
University. Although requiring further testing, the most successful ladder beams are capable of spanning between $2.2 \mathrm{~m}-3.1 \mathrm{~m}$ depending on spacing at 300,400 or $600 \mathrm{~mm}$ centres. These results were based on testing with an outer flange of $18 \mathrm{~mm}$ $\mathrm{OSB} / 3$ as would be incorporated into the design of full infill panel.

Whilst OSB based components are simpler to manufacture, it was deemed as less sustainable due to the materials involved and the distance required to transport them, and therefore less appropriate to meet increasing demands on low-energy fabrics, reduced carbon emissions and embodied carbon. The use of a whole Sitka spruce infill panel also has the advantage of a greater flexibility in panel span and could provide internal finishes if appropriate. Initial research suggests that all three systems would have an insulation zone of between 200 and $250 \mathrm{~mm}$ and achieve U-values approaching $0.15 \mathrm{~W} / \mathrm{m} 2 \mathrm{~K}$.

In parallel to this research Coed Cymru, in partnership with Coed Derwen, continued to develop additional components such as window and door cassettes, as proposed for use in the beach hut in chapter 6 . The intention was for these to complement the established modules for frame and infill to reduce the number of one-off, bespoke components required. This aimed to integrate a laminated small section hardwood window system as an initiative to add value to Welsh hardwoods, with the infill panel system.
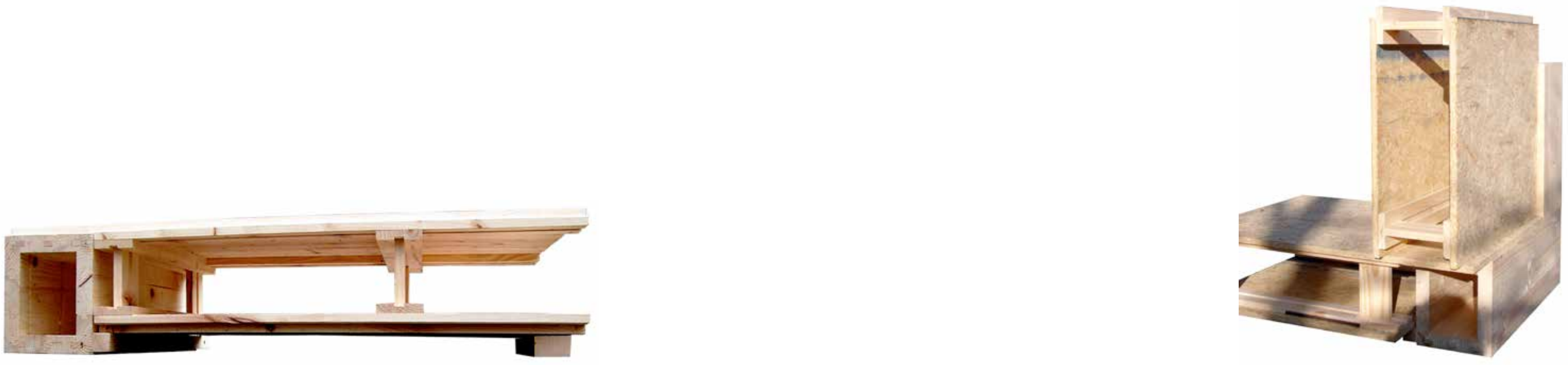

2.4x2.4x2.4m pavilon module with panels

\section{OPPOSITE}

Fig 9.21 Exploded isometric of $2.4 \times 2.4 \times 2.4 \mathrm{~m}$ pavilion module

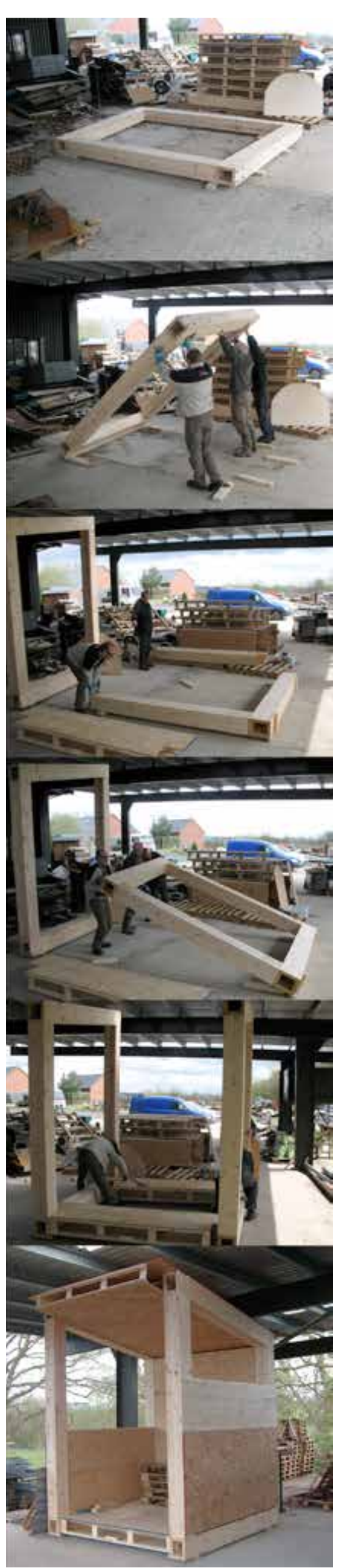

\subsubsection{Prototype structure}

By 2008 , the system described above, had been significantly developed both technically and hypothetically in components and for designs for different room and house types based on module configurations. However, the first test of the system as a prototype module was for a $2.4 \times 2.4 \times 2.4 \mathrm{~m}$ mono pitched pavilion as both test module from a hypothetical house type and a marketing demonstration at the Royal Welsh Show in 2008. The structure was organised on a $600 \mathrm{~mm}$ layout grid using $220 \times 280 \mathrm{~mm}$ box components, end grain bolted connections and a variety of small-scale ladder beam infill panels spanning between frames using spruce and OSB boarding and a $2.4 \mathrm{~m}$ horizontal window module. The sheathing to the infill panels was extended to provide for fixing to the posts.

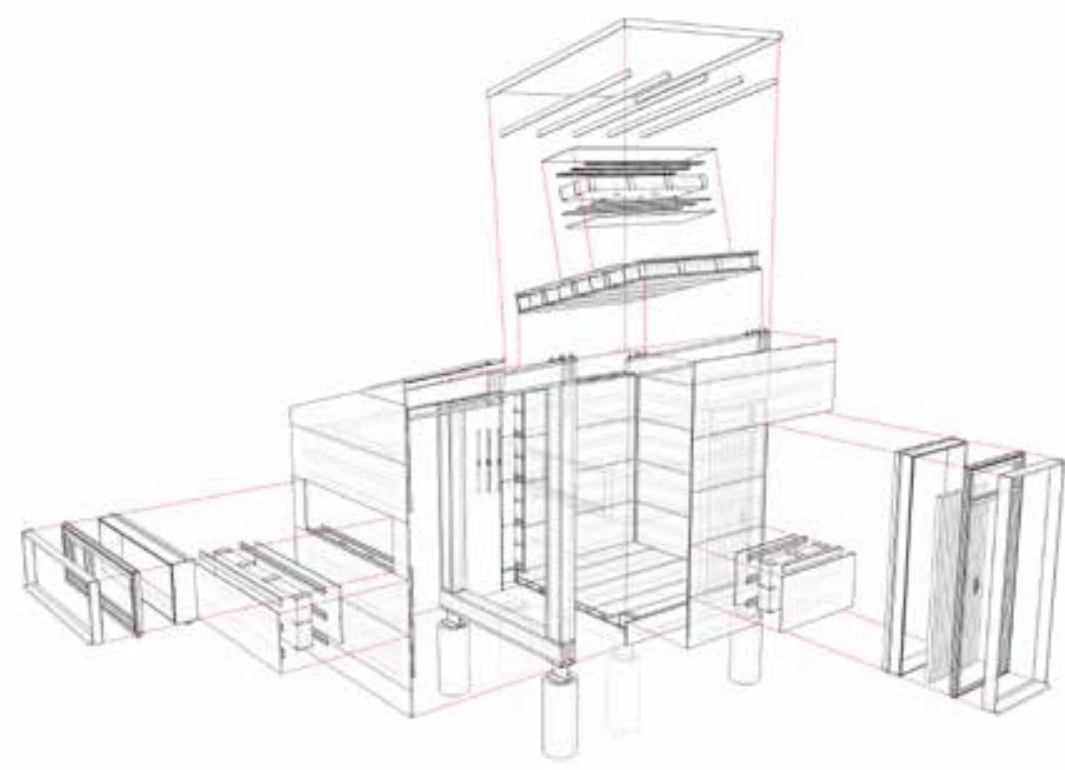



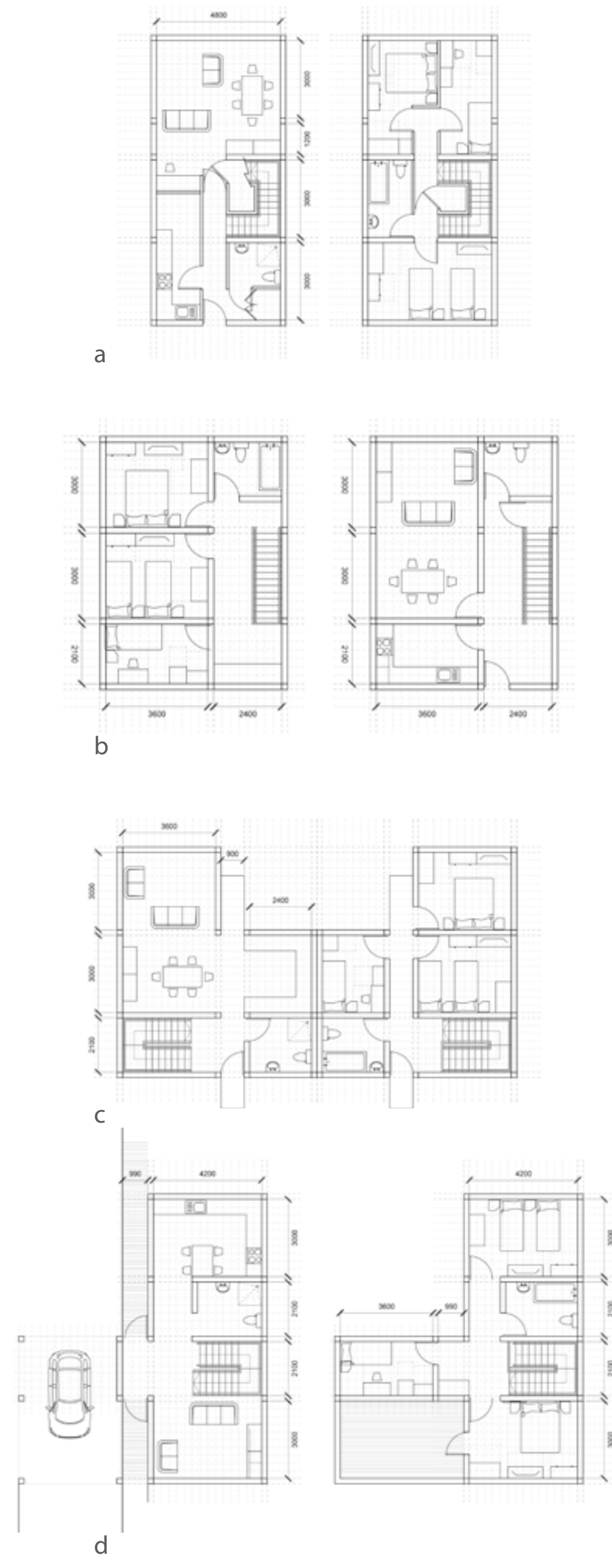

Fig 9.22 Generic house type plans

a. mid-terrace, narrow $3 B 5 \mathrm{P}$ house type

b. mid-trace, wide 3B5P house type

c. L-shaped semi-detached 3B5P house type

droom over carport

RIGHT (top - bottom)

Fig 9.23 Single storey'slipped plan' house

type for rural Wales as 3B6P and

Fig 9.24 Proposed perspective of rural

house type
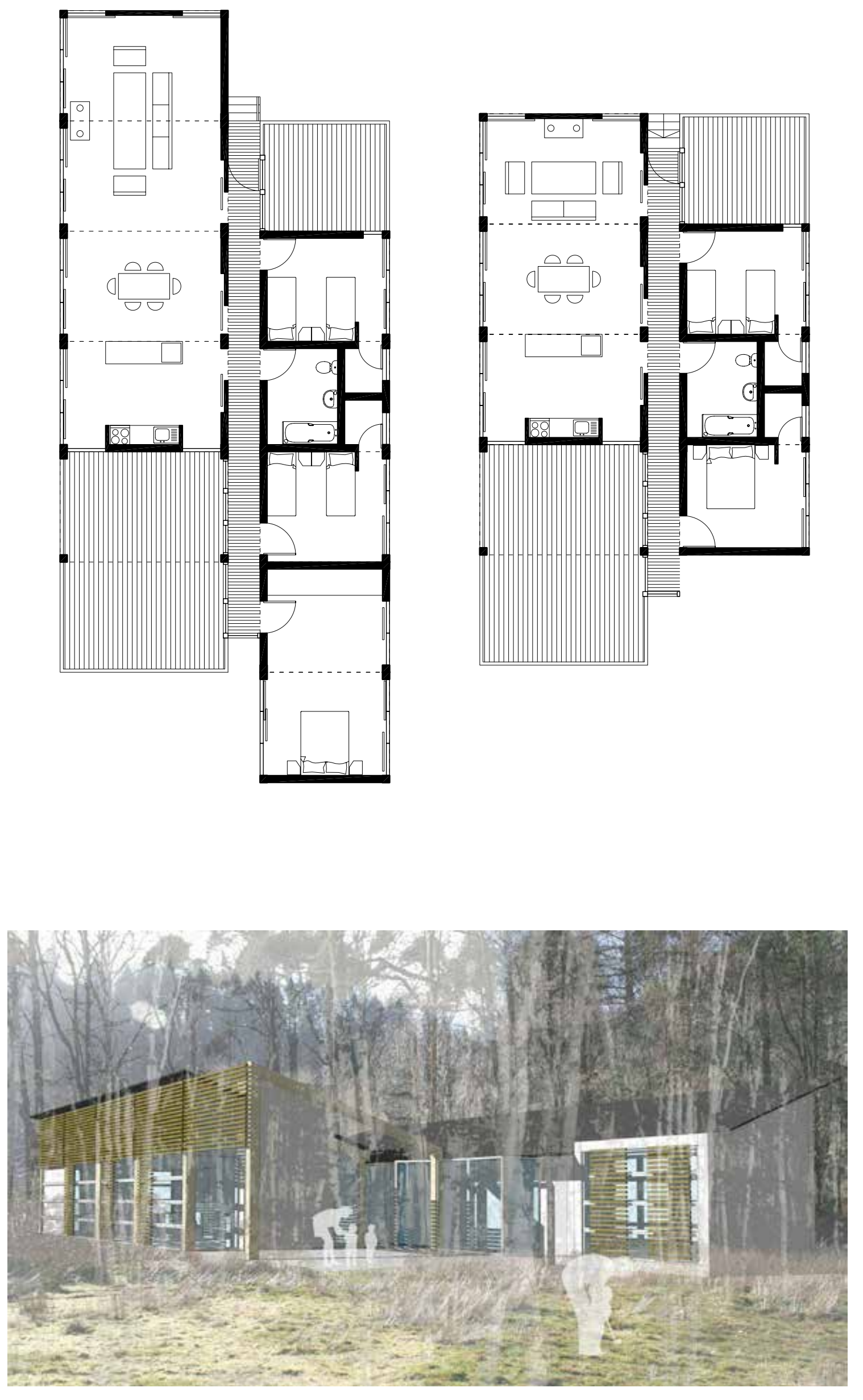


\subsubsection{Observations and reflections}
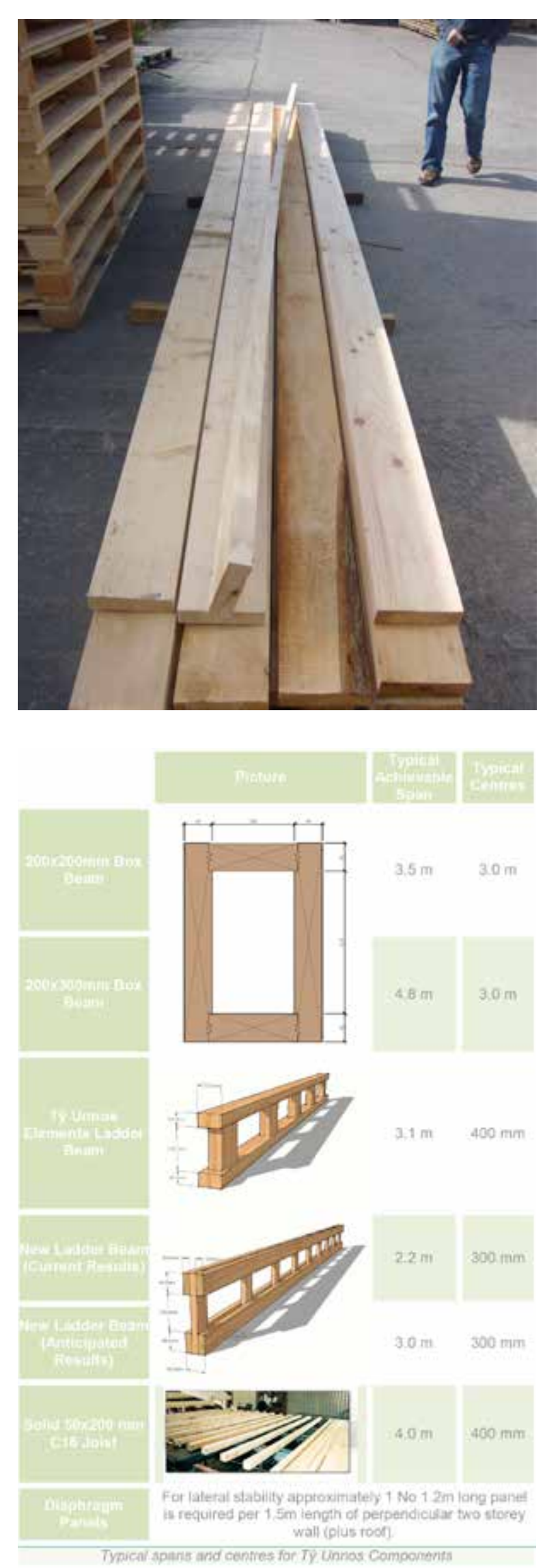

Fig 9.25 Twisted $47 \times 225 \mathrm{~mm}$ Sitka spruce boards prior to drying highlighting typical properties of Welsh spruce Fig 9.26 Typical spans and centres for the principal Ty Unnos components
The development described above has not followed a linear timeframe, but represents the significant developments in the stages of box section components, ladder beams and infill panels as part of the complete timber envelope. The following observations were prepared during the process of testing and developing while reflections are provided looking back on the process and used as the basis for the following 3 prototype projects.

\subsubsection{Species performance and adaptation} SPECIES

- Welsh-grown Sitka spruce has been successfully tested to comply with structural requirements for a domestic project. Further research is included in the following design prototypes to explore the integration of Sitka spruce and the system in various formats into 'live' design projects.

- The spruce components must be contained within the building envelope to maintain durability.

\section{TIMBER ADAPTATION}

- C16 Sitka spruce has been engineered to provide increased structural and stability performance than equivalent solid section spruce.

- Modification may be required to meet fire performance requirements. This will be explore further in this study.

- The box section components rely on $47 \times 225 \mathrm{~mm}$ spruce boards before being planed and profiled. These $225 \mathrm{~mm}$ wide boards are prone to twisting during processing including kiln drying, storage and machining. The box process provides stability, although considerable processing is required to ensure a good quality finish.

\subsubsection{Building envelope}

SUPERSTRUCTURE

- A kit of parts have been developed for use in the building envelope as illustrated opposite.

- Further research needed on ladder beams and infill panels.

- Solid 200 x 200mm spruce sections are not available and solid lamination would be expensive producing a much stronger component than needed. Therefore box sections provide an efficient compromise that use less wood fibre and less labour to fabricate and allow for insulation to fill the void reducing the thermal bridging effect of solid timber. 
INTEGRATION WITH COMPLETE ENVELOPE

- Subsequent post and beam projects have shown the practical benefits in the detailing of square columns slightly exceeding the wall to allow for services.

- The system only requires pad footings (at column bases only) providing quick and easy foundations suitable for challenging rural sites.

\subsubsection{Technology and skills}

\section{PROCESSING}

- An engineered system has been developed that uses low-tech processes to work with the properties of the timber and the technology, skills and potential investment available within the industry.

- The basic press and tongue and groove glue joints highlight the low-tech approach. While the press may seem crude, it has been working efficiently since 2007. It is acknowledged that if the system was to become commercially successful that it is likely that the press will be refined and developed further as investment allows. This could allow for multiple components, longer components alongside possibly finger jointing of spruce and faster, mechanised processes.

FABRICATION

- Supplies of $47 \times 225 \mathrm{mmSitka}$ spruce have varied in workability. Some batches have been intensive on machinery, resulting in higher fabrication costs and increased rejection of timber and time.

- The processes and limitations, in relation to labour time and skill required of end grain bolting are to be tested further.

\subsubsection{Tectonic form}

The first stage of prototyping proved the ability for the box section post and beams with an all spruce infill panel would successfully work at component level. This, in consultation with the wider timber and construction industry, informed the selection of hypothetical room and house layouts based on the following design rules that would inform the design process of subsequent prototypes:

- A dimensional organisation plan based on a $600 \mathrm{~mm}$ grid, between structure, is employed in plan and elevation to determine the position of primary structure, internal and external walls, floors and openings.

- A maximum primary structural span of $4.8 \mathrm{~m}$.

- A maximum secondary structural span between frames of $3.0 \mathrm{~m}$. 
- A primary post and beam structure is organised around a $210 \times 210 \mathrm{~mm}$ or 210 $x 270 \mathrm{~mm}$ section size

- determining an infill thermal envelope with $210 \mathrm{~mm}$ thickness for internal and external walls.

- Roof pitches are determined by box section rafters integrated into the primary post and beam frame

- set at a standard range of flat, $17.5,25$ or 35 degrees that lend themselves to a variety of material finishes.

- A minimum requirement of diaphragm panels will be dependent on building form and site conditions. However a minimum requirement of two $1.2 \times 2.4 \mathrm{~m}$ unbroken panels per floor will be required. 
Following the initial testing, publications and increasing awareness and support from public bodies including the Welsh Assembly Government, the design team were asked to design an exhibition pavilion for the Welsh Assembly to be part of the Welsh representation at the Smithsonian Folklife Festival in Washington DC, United States of America in 2009. It was designed to exhibit both Ty Unnos through itself and the history and traditions of Welsh forestry and management.

\section{Smithsonian Pavilion}

\begin{tabular}{|l|l|l|l|l|l|l|}
\hline Project & Year & Location & Client & Design team & Cost \\
\hline $\begin{array}{l}\text { Smithsonian } \\
\text { Folklife Festival } \\
\text { Pavilion }\end{array}$ & 2009 & $\begin{array}{l}\text { The Mall, } \\
\text { Washington DC, } \\
\text { USA }\end{array}$ & Welsh Government & $\begin{array}{l}\text { Architect: } \\
\text { Engineer: } \\
\text { Contractor: }\end{array}$ & $\begin{array}{l}\text { Design Research Unit Wales } \\
\text { Burroughs } \\
\text { Elements Europe, Kenton } \\
\text { Jones Ltd, Coed Cymru }\end{array}$ & E40k \\
\hline
\end{tabular}

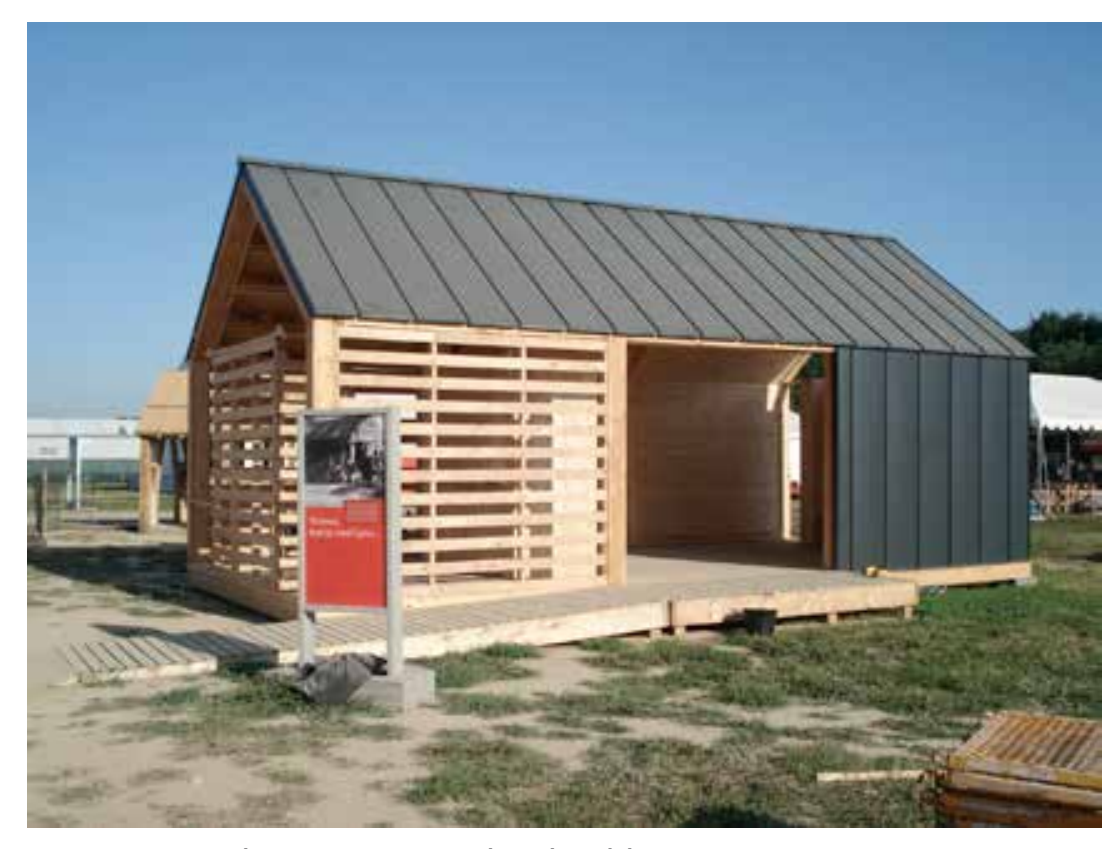

Fig 9.27 Smithsonian project details table

Fig 9.28 Completed Smithsonian Pavilion on the Mall, Washington DC

\subsubsection{Design}

\subsubsection{Brief}

The brief was to provide a small, demountable pavilion that could be flat packed and shipped to the USA at least a month before the festival and re-erected to represent the forestry sector in Wales. The Welsh Assembly Government did not provide guidance on size or the schedule of accommodation, instead leaving the curating of the pavilion structure and exhibition contents to Coed Cymru to propose. A maximum budget of $£ 40000$, partly funded by the Welsh Assembly and other sponsorship, was available to fabricate, ship, assemble and return the pavilion.

As a result the pavilion design, developed in collaboration between Coed Cymru and the Design Research Unit Wales, had two principle design intents. The first to showcase the Ty Unnos Sitka spruce construction system; the second considering the design of housing in rural Wales.

In response to the system, this structure was designed around the principles of the early design concepts and house types to test the structural, spatial and material performance of the components in a non-weathertight, un-insulated exhibition pavilion. It was to be fabricated and initially erected in Chirk, north Wales, before being dismantled, packed into a shipping container and shipped to Washington DC for re-erection by a team in the USA guided by two of the original team.

The principle aims for this structure were focused on the first use of the Ty Unnos system and as such were to:

- Test at 1:1 the use of all box section components in a publicly accessible enclosure;

- Use Sitka spruce 'ladder' beams with t\&g spruce boards as well as some with 

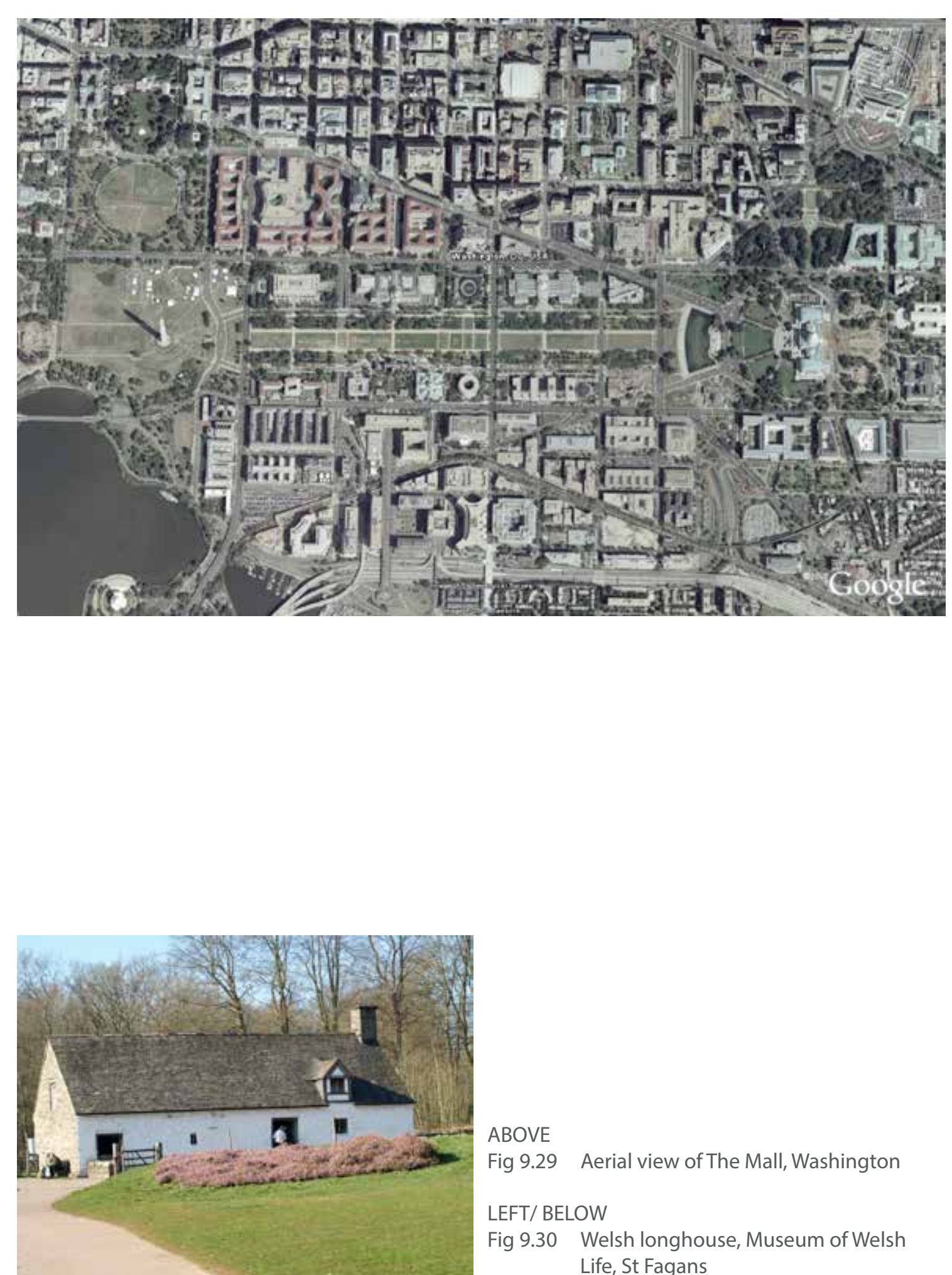

Fig 9.29 Aerial view of The Mall, Washington

LEFT/BELOW

Fig 9.30 Welsh longhouse, Museum of Welsh

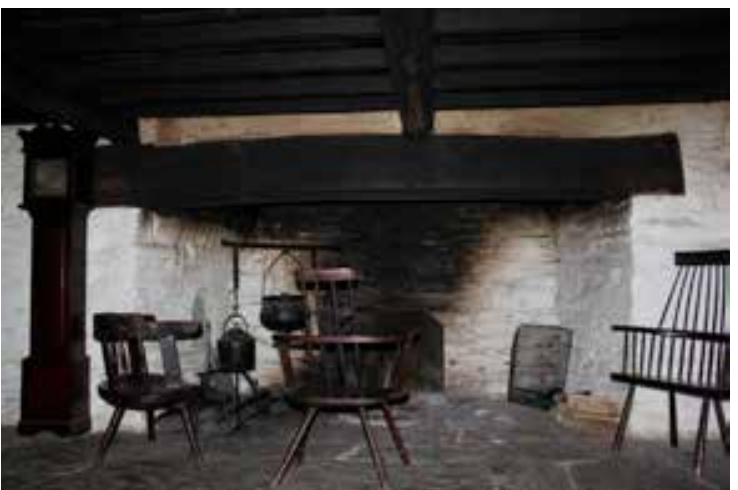

Life, St Fagans

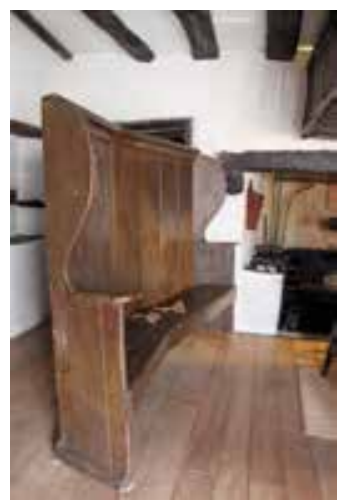

OSB/3 for infill wall, floor and roof panels;

- Test the use and tolerances of internal hardwood junction 'L' shaped sleeves for all portal connections; and

- Test the construction sequence for ease of construction, component weights and practicality.

9.4.1.2

The pavilion design has been based on a consideration of two sites:

- A notional site in rural, woodland Wales of no particular location. The following parameters were assumed for this site: a sensitive brownfield landscape previously occupied with industrial or agricultural buildings, with relatively flat but varying ground conditions, close to mixed woodland, an opportunity to benefit from direct sunlight, direct access from a road, but possibly limited access for large construction vehicles.

- The National Mall outside the Smithsonian Museums in Washington DC as the site for the festival. The position of the pavilion on the mall was unknown until the pavilion had already been shipped.

\subsubsection{Design strategy}

The original proposal for the Smithsonian Festival, entitled 'Learning from the vernacular', was for a two bedroom, single storey, house type inspired by the elemental components of vernacular Welsh rural domestic architecture, such as hearth and zonal separation between spaces. The prefabricated exhibit would be an innovation on the traditional folk culture of Welsh domesticity to generate a contemporary design model encompassing the sustainable concepts of using local resources, recycled materials and low energy design. The vision was to engage with the following traditional design considerations that are all applicable today in contemporary living:

- Rules of siting

- design with climate;

- laws of building

- the use of local material

- form and space use;

- custom;

- furniture;

- artefact. 

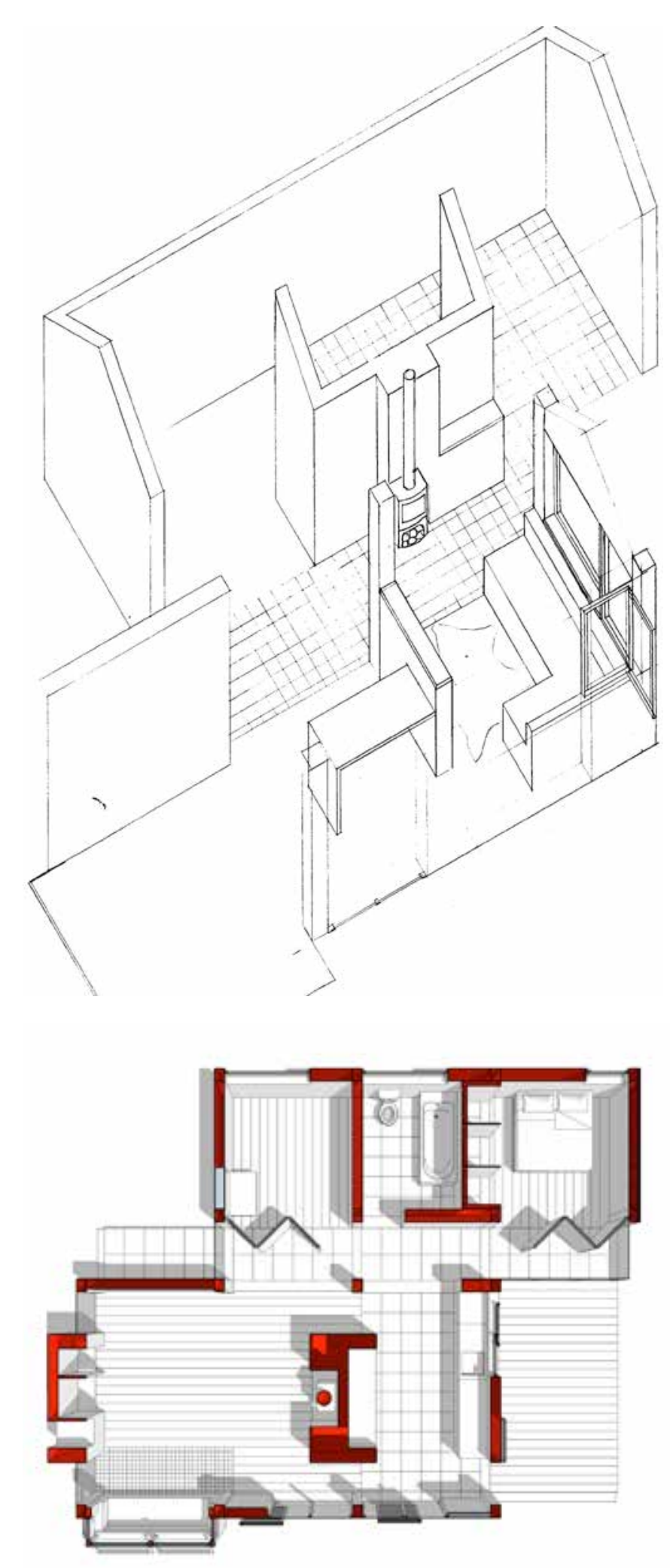

LEFT (top - bottom)

Fig 9.31 Proposed axonometric and plan of demonstration housetype

Marie Short house, New South

Wales, Australia by Glenn Murcutt

RIGHT

Fig 9.33 Reduced pavilion arrangement

to meet budget and limite

prefabricated components
An open plan living, dining and kitchen space are articulated around a central hearth the 'heart of the home' with a bay window in the living room providing a place to sit in the sunlight. A second bay breaks from the gable end to create a storage wall reminiscent of the crockery filled Welsh dresser. Roof spaces are left open to the living areas, but reduce in scale for the central circulation spine, connecting front door to rear sun terrace. Two bedrooms and a bathroom form a second wing opening onto the circulation route finished in durable Welsh slate that would provide thermal mass to the heavily glazed rear sun space.

The components of vernacular Welsh architecture have been incorporated into a plan arrangement based on the hypothetical layout developed to test the arrangement of spatial modules in section 10.3.4 and inspired by the Marie Short house, in New South Wales, Australia by Glenn Murcutt. The slipped plan allows for both a living and sleeping zone, with the central spine allowing access. Both sides of the house are based on 3no. $2.4 \times 3 \mathrm{~m}$ medium sized modules, large enough to provide a master or twin bedroom or be left open plan for the living space.

However, due to budget and time constraints and transport requirements, the pavilion was scaled back as a representation of these concepts in a simple three module form with furniture elements to define hearth, storage and bay seat. The pavilion structure was designed to be predominantly open with a'peeled back' skin to reveal the different Sitka spruce construction components within. 'Hit and miss' screens and a modular standing seam roof, from TATA Steel provided protection from the summer sun and showers.

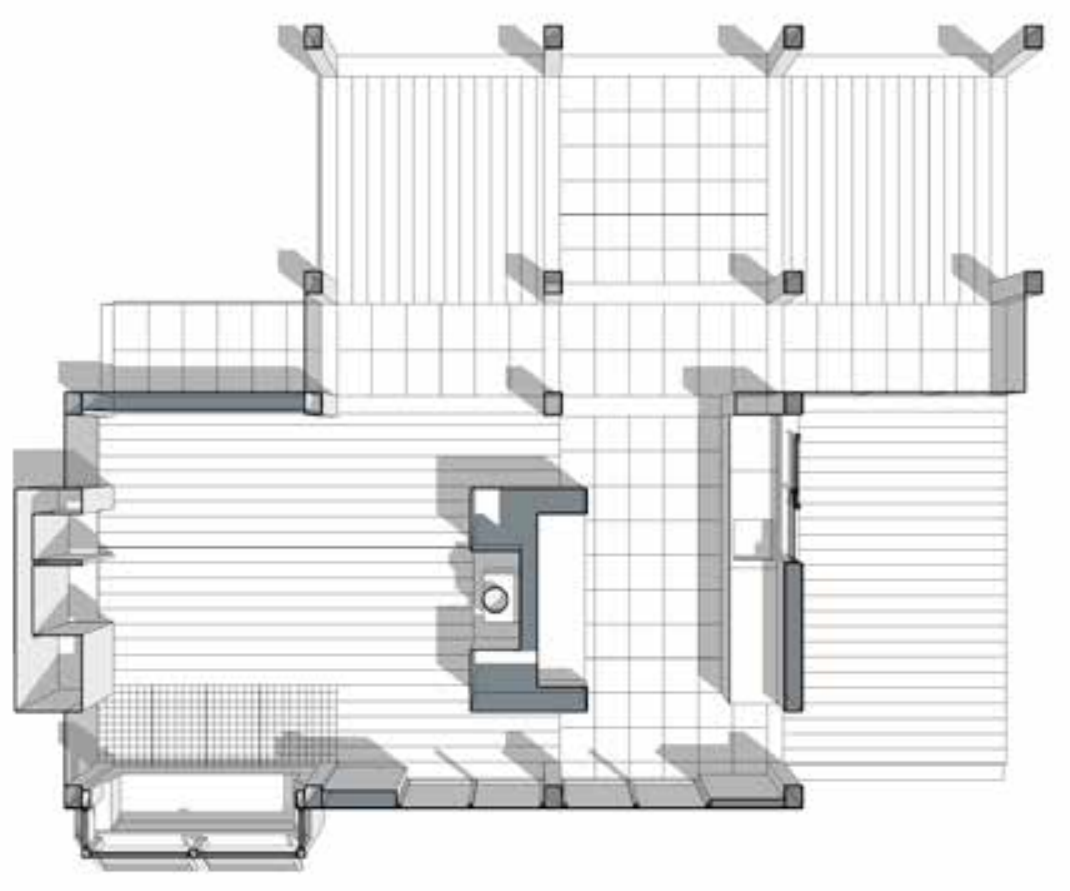



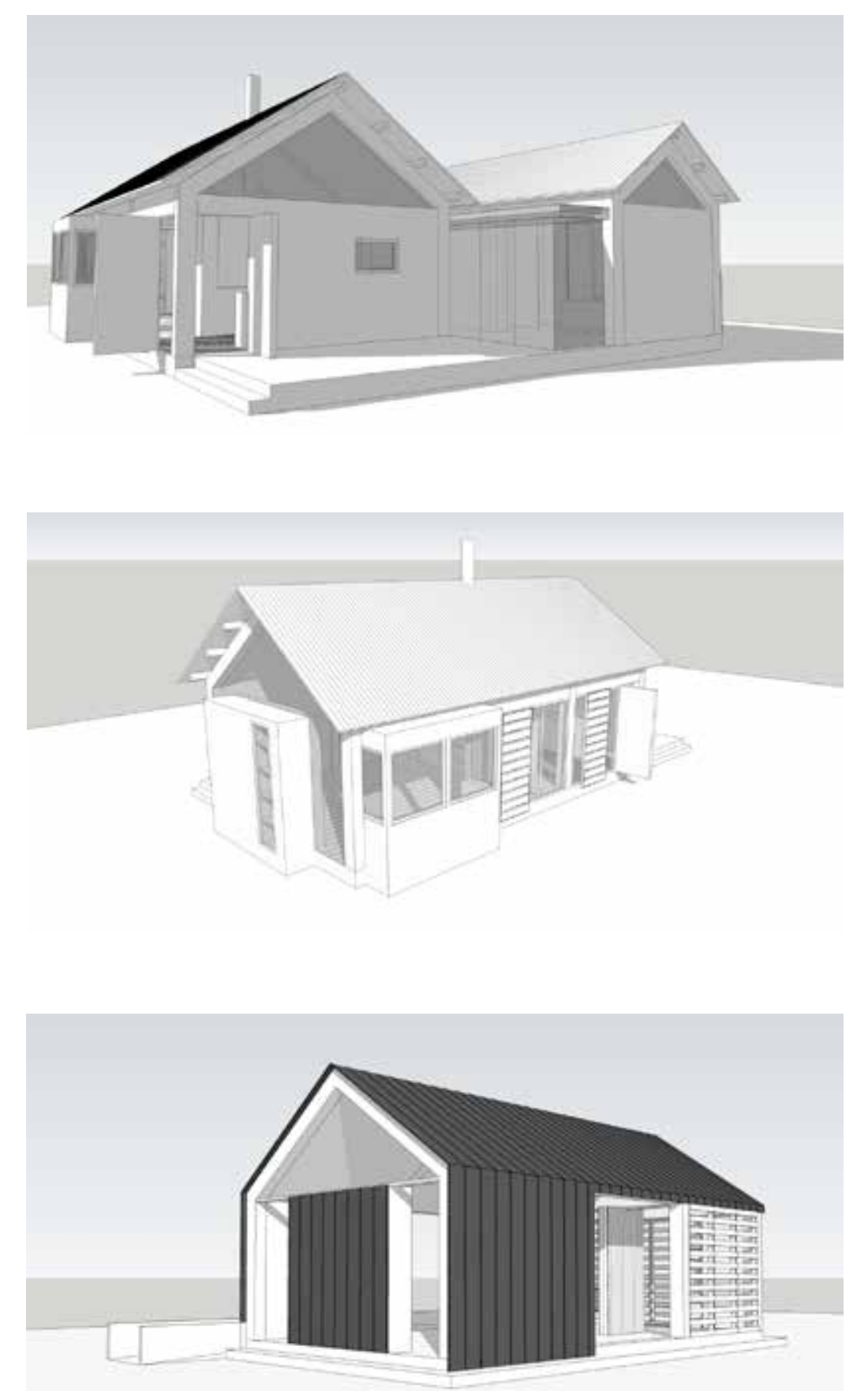

LEFT (top - bottom)

Fig 9.34 Pavilion development models

a. initial pavilion proposal as a house typ

b. reduced proposal to living space only

c. further reduced as an elemental

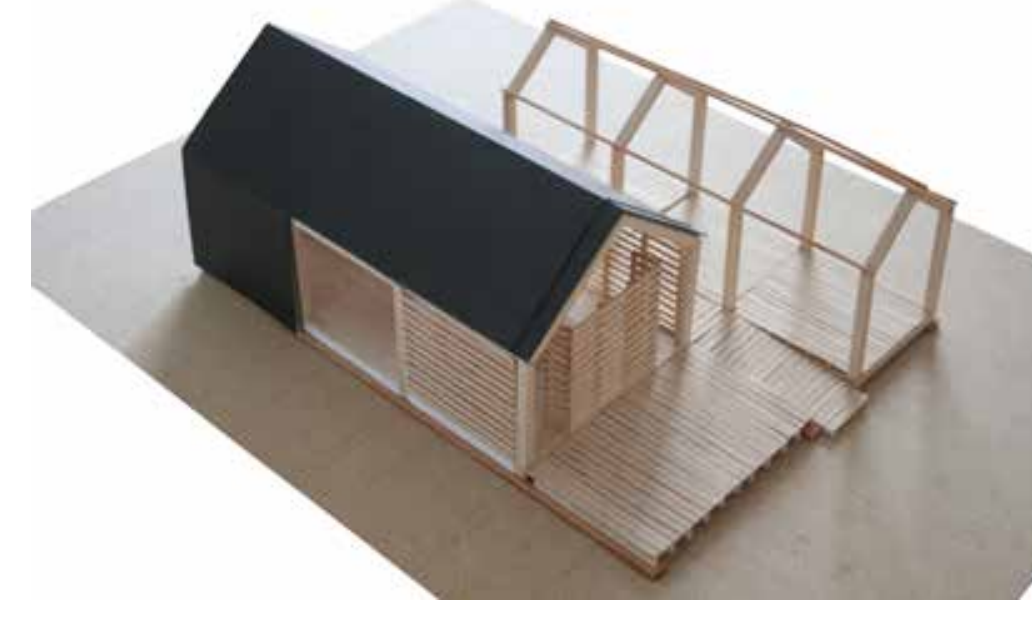

d. physical 1:50 tectonic model to explore

prefabricated construction

RIGHT

Fig 9.35 Original house design for pavilion

1. Snug

2. Dining

3. Kitchen

4. Sun deck

5. bedroom/ exhibition space

6. bathroom/ exhibition kitche

7. Entrance
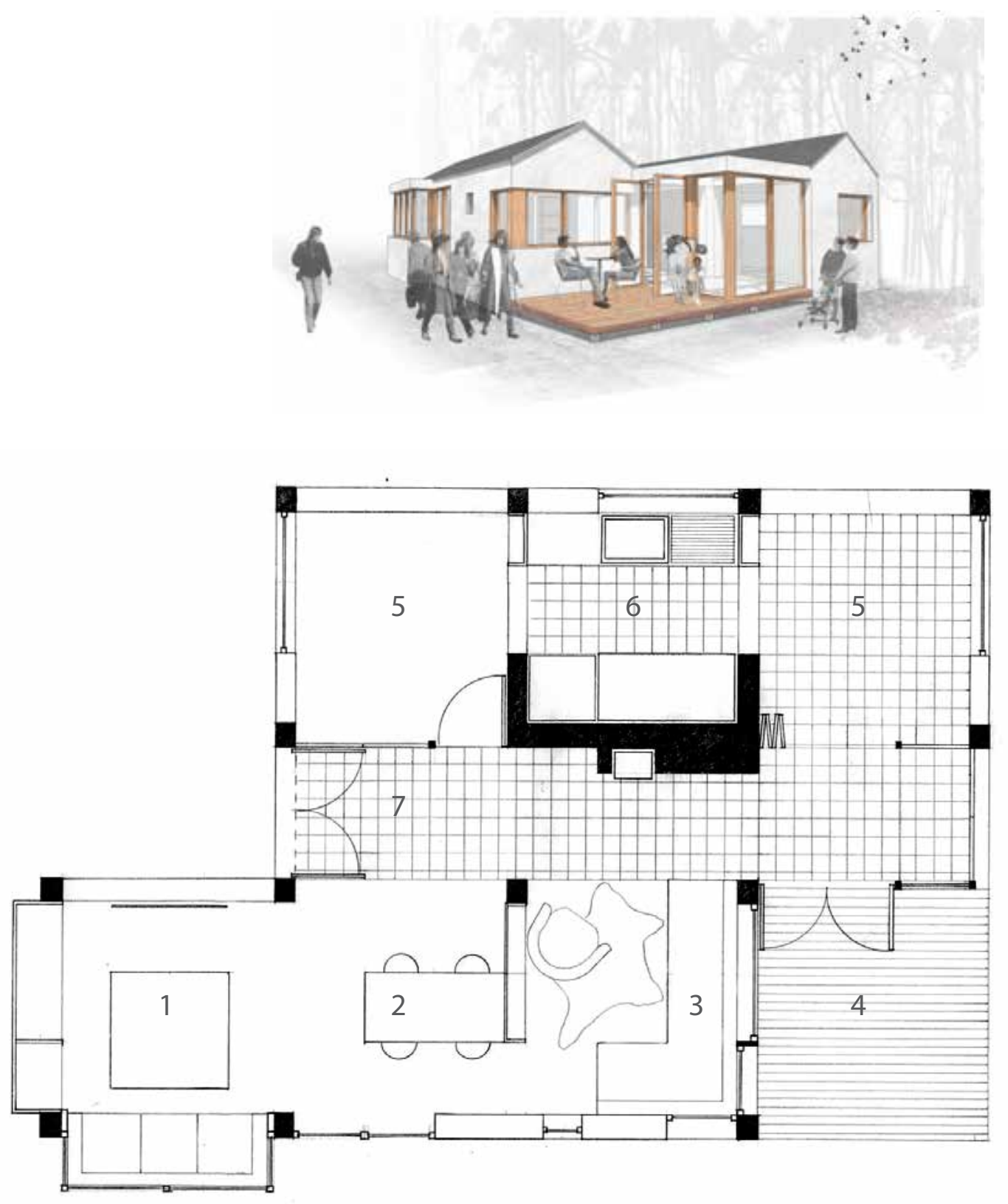


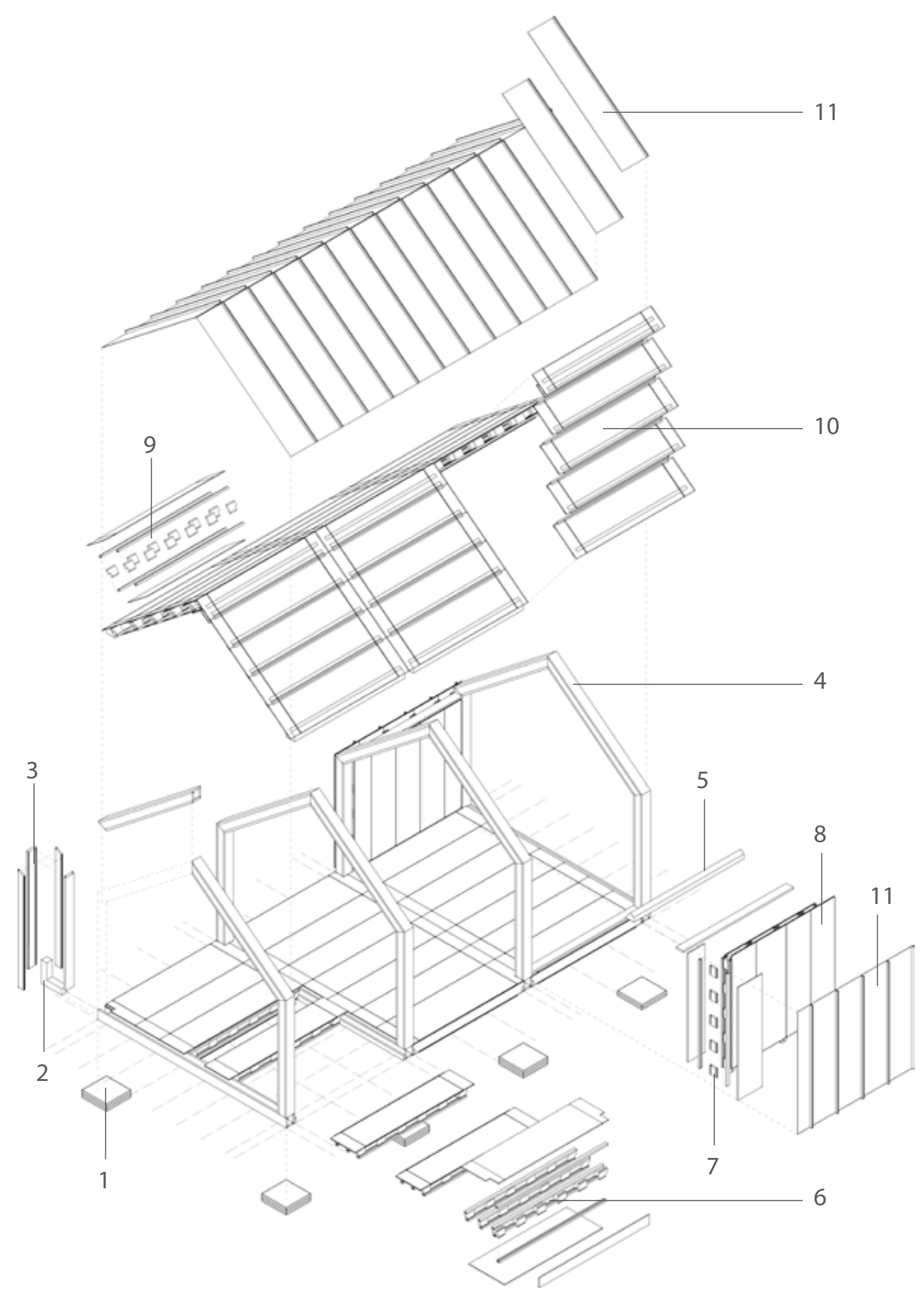

Fig 9.36 Exploded isometric of exhibition pavilion

1. Concrete block foundation pad 2. 'L' shaped insert connector 3. Box section post fabricated from $210 \times 40 \mathrm{~mm}$ Sitka spruce

4. 4 no. complete box section portal frames

5. Wedge shaped edge beam

$6.210 \mathrm{~mm}$ Sitka spruce ladder beam and $18 \mathrm{~mm}$ OSB floor cassettes
$7.210 \mathrm{~mm}$ ladder beam and $18 \mathrm{~mm}$ OSB wall cassettes

8. Complete wall cassettes

$9.210 \mathrm{~mm}$ ladder beam and $18 \mathrm{~mm}$ OSB roo

cassettes

10. Complete roof cassettes roof and walls
11. Colourcoat standing seam cladding for

\subsubsection{Prototype}

\subsubsection{Detailed design}

The pavilion was based on 3 no. internal plan sizes of $4.2 \times 2.7 \mathrm{~m}$ and an internal height of $2.4 \mathrm{~m}$ to eaves. The floors, walls and roof were to use a structural panel system based on the Sitka spruce ladder beams with oriented strand board sheathing. Internally, Welsh spruce tongue and groove and larger section softwood are used to finish surfaces and construct a number of space defining furniture units.

As the construction was bespoke, full general arrangement, assembly and component drawings including all fabrication details, cutting lists and setting out were required by the joiners, who were not specialists in building construction. These following drawings were prepared in collaboration with Burroughs and Kenton Jones Joinery:

\section{Frame design}

The frame is fabricated from $210 \times 210 \mathrm{~mm}$ box section post, floor beam and 38 degree pitched rafters. The frames span $4.2 \mathrm{~m}$ and are positioned at $2910 \mathrm{~mm}$ centres providing a $2.7 \mathrm{~m}$ zone between portal frames. The rafter beams and posts are mitred to meet at the eaves and the ridge. Only a setting out frame drawing was required, as the joiners could work from previous approved drawings for the fabrication of the box components.

The connections are made using solid section connectors of 5 bolted laminations: two $45 \mathrm{~mm}$ cheeks of Sitka spruce, two layers of $10 \mathrm{~mm}$ steel and a $20 \mathrm{~mm}$ spruce core. The steelwork was included to increase weight to counter wind loads rather than for structural performance.

All the floor, wall and roof cassettes use the ladder beam at $300 \mathrm{~mm}$ centres, spanning a maximum $2.7 \mathrm{~m}$ between portals for floor and roof.

\section{Floor panels}

$600 \mathrm{~mm}$ wide floor cassettes were detailed to aid lifting and assembling. Three different types were required for end details lapping with the frame, a standard cassette and a central cassette. There are a total of 7 cassettes spanning the $2.7 \mathrm{~m}$ of each bay. The ladder beams were notched at the ends to allow the cassette to be slotted from above on to a bearing plate fixed to the side of the box section beam. 

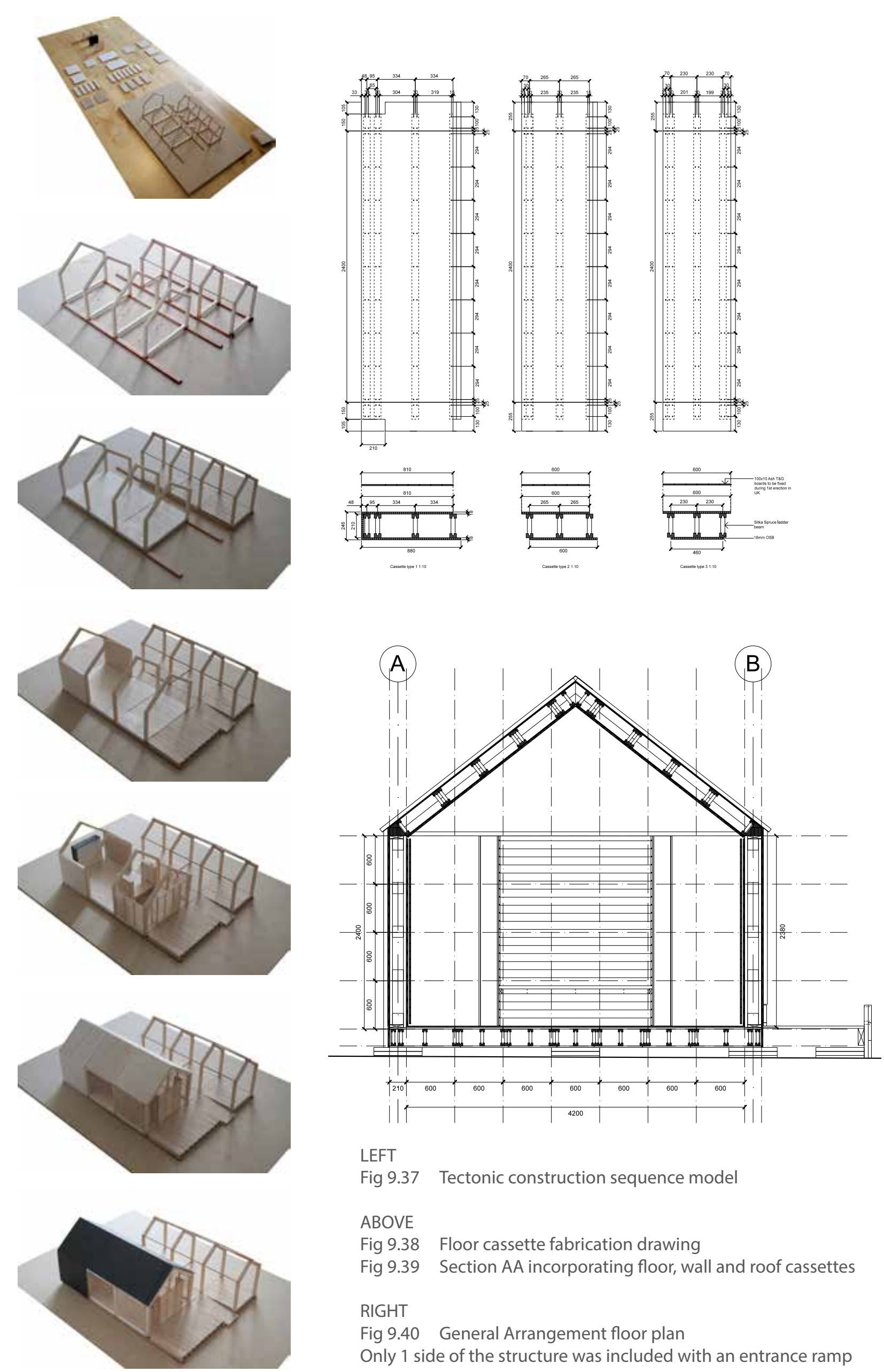

LEFT

Fig 9.37 Tectonic construction sequence model

ABOVE

Fig 9.38 Floor cassette fabrication drawing

Fig 9.39 Section AA incorporating floor, wall and roof cassettes

RIGHT

Fig 9.40 General Arrangement floor plan

Only 1 side of the structure was included with an entrance ramp

\section{Wall panels}

Three types of vertical wall cassette made up the five required for each bay, each varying in width depending on location within the wall and assembly sequence. All cassettes were fitted from the outside lapping a sole plate and the wedge shaped edge beams spanning between frames. The end cassettes were detailed to lap the box section posts allowing for fixings directly into the posts.

\section{Roof panels}

The roof cassettes are similar to the floor, slotted in from above and notched to fit over a bearing plate. Again there were three different cassette types based on a $600 \mathrm{~mm}$ width, with unique eaves and ridge cassettes with OSB extending to complete the roof surface ready for the standing seam panels to be laid.

\section{Finishes}

The internal faces of some wall and roof cassettes were lined with tongue and groove spruce boards to represent the potential spruce finish of the all spruce ladder panel.

The roof and one end wall was finished with prefabricated standing seam steel trays as part of the standardised Urban range from Tata Steel.

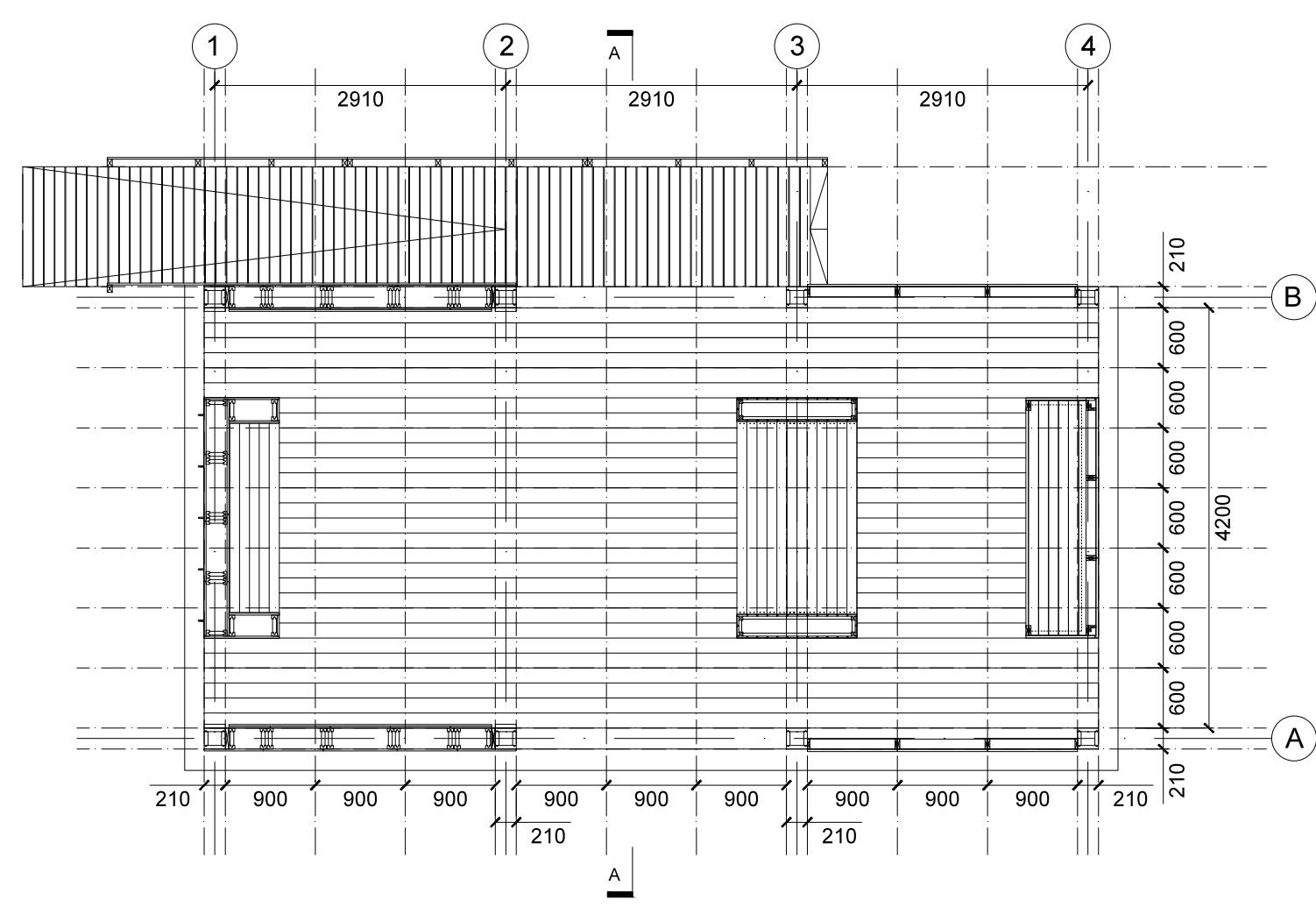



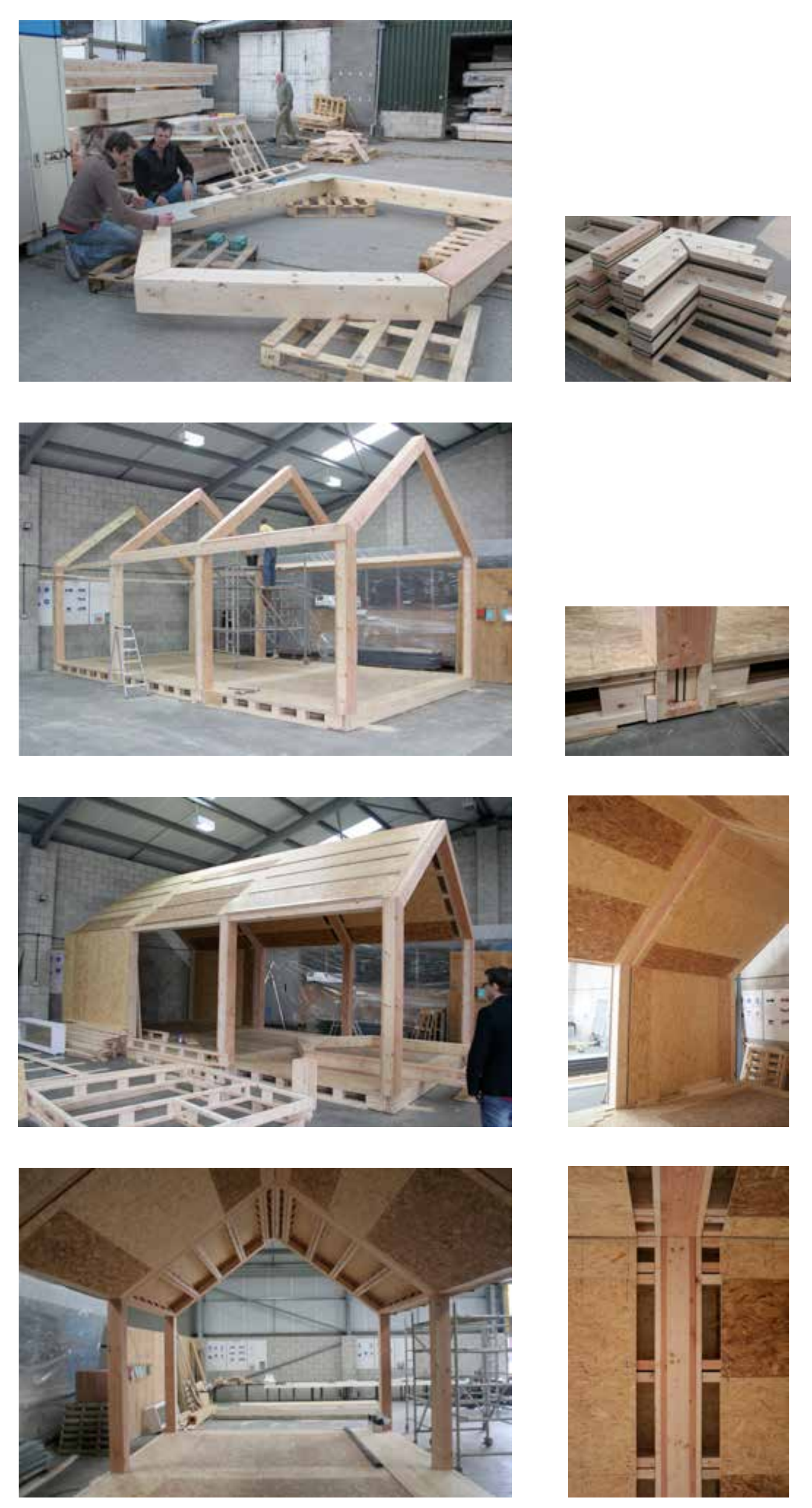

TOP - BOTTOM

Fig 9.41 Box section assembly

a. Portal frame assembled on floor and checked.

b. The beams and columns are jointed using

solid section connectors fabricated of 5

laminations: two $45 \mathrm{~mm}$ cheeks of Sitka spruce

two layers of $10 \mathrm{~mm}$ steel and a $20 \mathrm{~mm}$ spruce

core. The steelwork was included to increase

weight to counter wind loads rather than for

structural performance.

Fig 9.42 Frame assembly in Chirk

a. Frame assembly tested for tolerances.

b. Detail of post connection with floor cassettes

using bearer and notched ladder beams.

Fig 9.43 Infill panel installation

a. Panels manufactured and loose installed on

edge beam to test assembly sequence.

b. The panels finish flush with the box section

frame internally. Loose strips of OS are applied to

cover gaps at edge of panels.

Fig 9.44 Test assembly details

a. The roof panels were left in different states

of completion to highlight the construction

stages. Welsh oak $\mathrm{t} \&$ flooring laid to then

be prefabricated ready for installation in

Washington DC.

b. The entire assembly is fixed by screws. Gaps

are left where roof cassettes lap the bearer. 

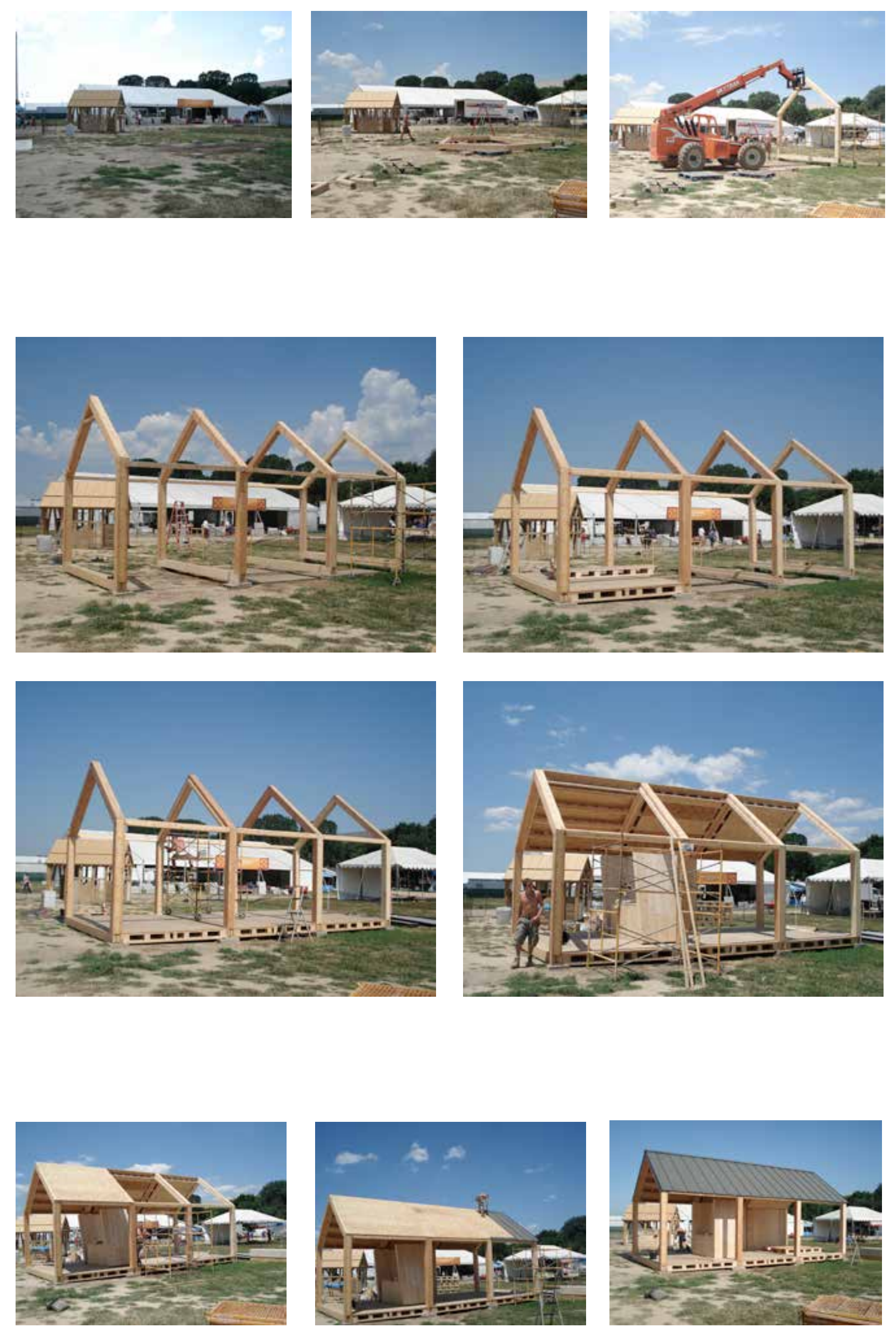

LEFT TOP

Fig 9.45 Smithsonian frame assembly on The Mall, Washington DC

a. Concrete paving slab footings set out: b. The portals were arranged from $210 \times 210 \mathrm{~mm}$ box sections on the flat allowed for angles to be checked using templates adjusted and fixed prior to be rotated and lifted by forklift to a vertical position; c. First portal frame raised into position and supported by scaffolding.

LEFT MIDDLE

Fig 9.46 Infill panel assembly

a. Bespoke wedged shaped edge beams

installed between the portal frames to provide

racking stability in conjunction with infill pane

but also to provide a square edge for roof

cassettes to rest on when lowered from above

b. Three types of floor cassette were required

for seven floor panels per bay using the spruc

ladder beam arranged at $300 \mathrm{~mm}$ centres.

All cassettes are lifted and installed by two

people; c. Completed floor cassettes; d. Five roo

cassettes, installed by hand, made up of three

in place they self support prior to fixing.

LEFT BOTTOM

Fig 9.47 Roof assembly

a. Roof panels continue and the interior furniture items begin; $b$. Polyester coated, modular stee roof sheets with a pre-folded standing seam from Tata Steel hand positioned to align with the $600 \mathrm{~mm}$ building module; c. Completed roof finish.

Fig 9.48 Wall panel and screen assembly a. Three types of $600 \mathrm{~mm}$ wide wall cassette were arranged vertically and installed from outside the frame to a sole and top plate by hand; $b$. Prefabricated hit and miss spruce cladding

panels are hand installed to the north, south and west openings; c. Prefabricated panels of spruce t\&g boards are applied as a surface finish to the solid walls. A bench seat is installed into both the east and west gable ends, a spruce 'hearth' is fitted in the centre of the plan and a Welsh oak floor is installed.
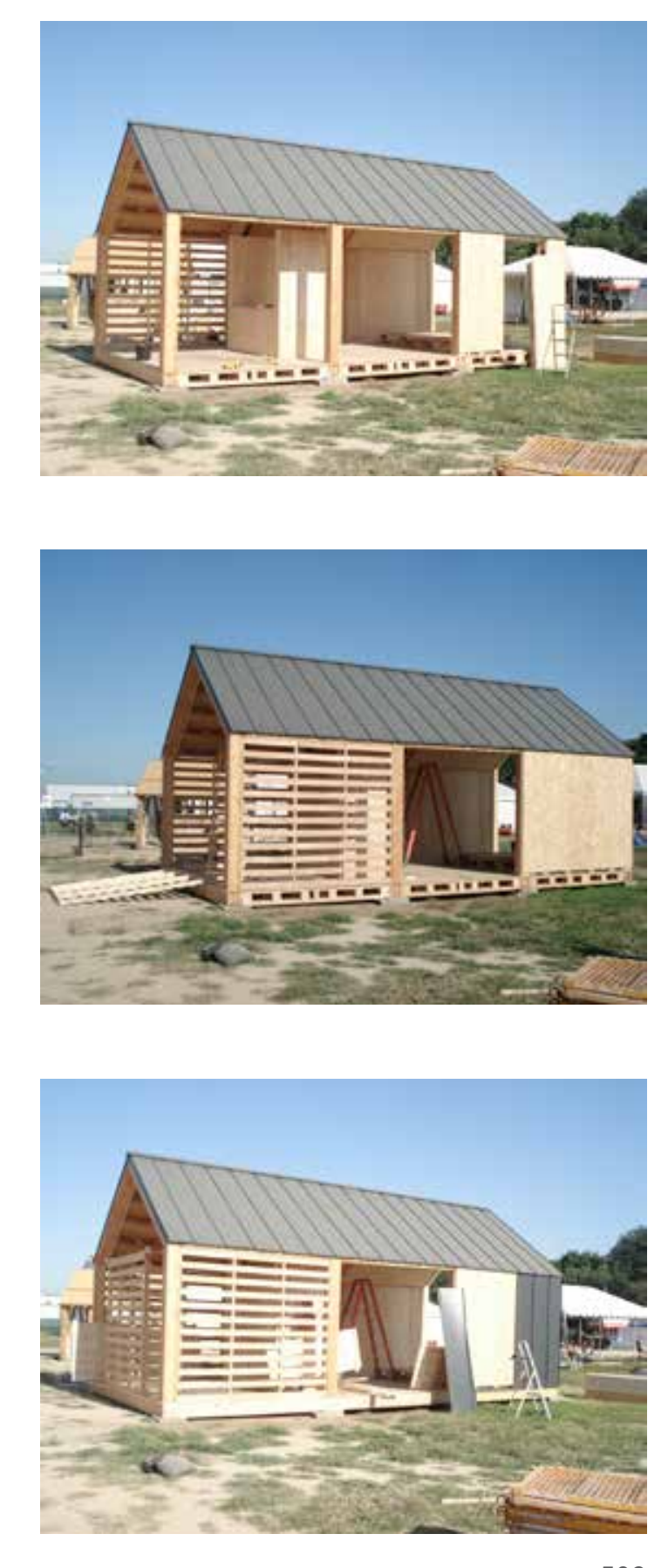

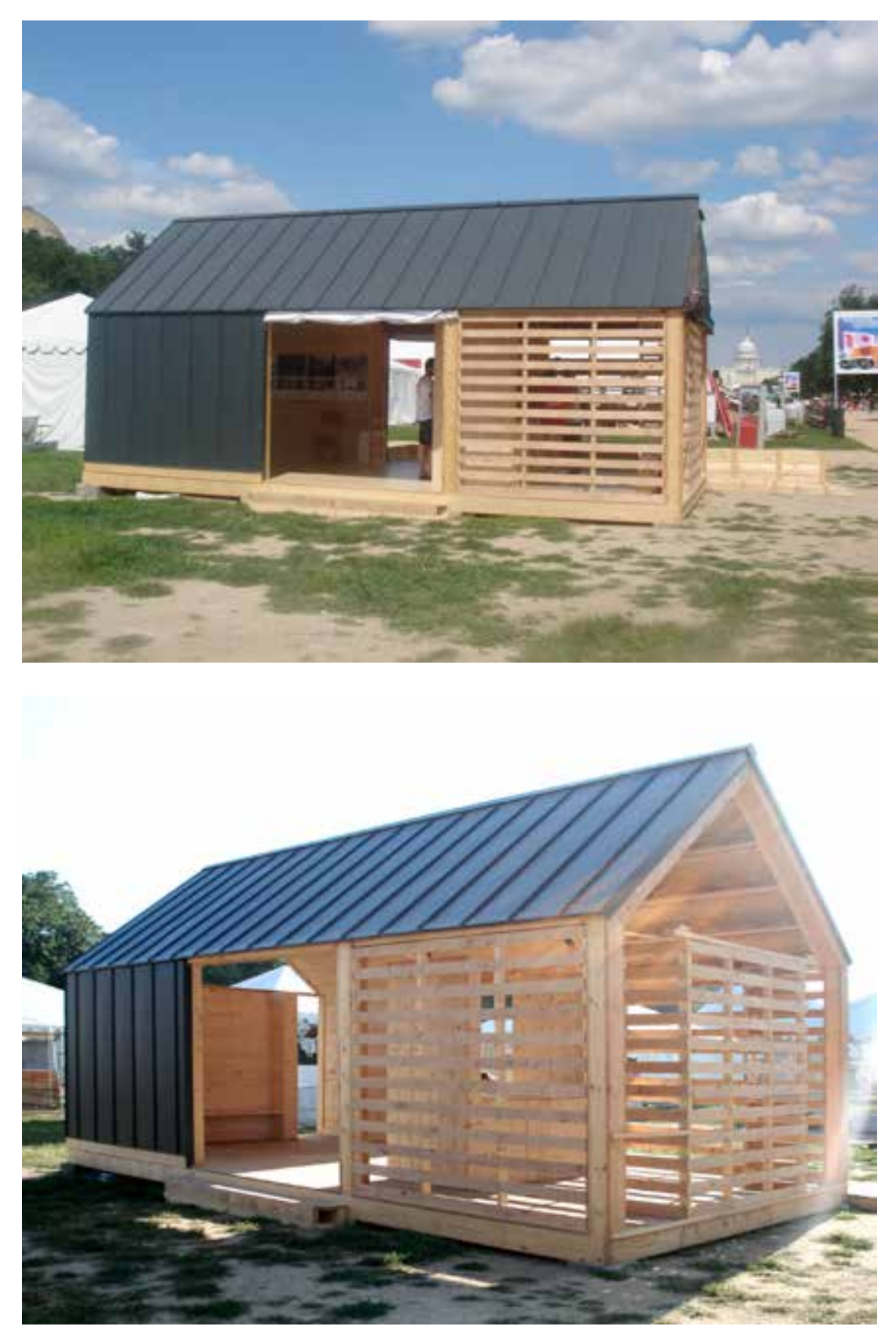

LEFT
Fig 9.49 Exterior of completed pavilion a. Pavilon with exhibition during exhibition ventilated during the hot USA summer. c. Entrance ramp follows the line of the ciculation spine from originat desigh

RIGHT

Fig 9.50 Interior of completed pavilion a. Detail of hit and miss cladding $b$ \&c. The central 'hearth' of the pavilion
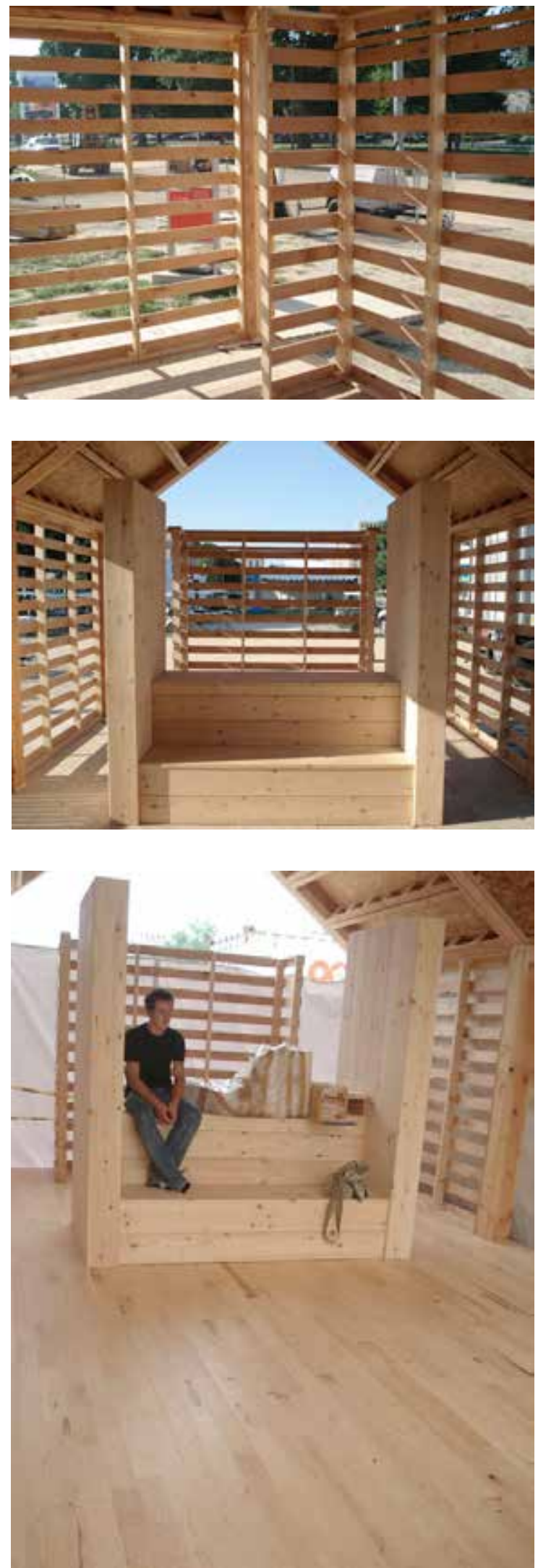
The Smithsonian structure provided the first publicly accessible Ty Unnos structure that integrated the design intentions with the realities of the construction system. The modular and spatial arrangement demonstrated an ability to produce versatile and simple designs with the principles of the system proved under'real' manufacture, transport and erection conditions. The following observations are therefore based on the evolution of the system, previously discussed, and its application into a fully accessible pavilion.

\subsubsection{Species performance and adaptation}

- Sitka spruce has continued to work successfully in a large scale, demountable structure. Following the return of the pavilion to Wales, it has been rebuilt twice at the Royal Welsh Showground as a permanent pavilion for Coed Cymru. However, the overall system continues to rely on OSB/3, further highlighting the importance of these board products to the construction industry.

- The ladder beam panels appear to provide a viable solution to constructing infill panels with reduced thermal bridging although the connections and number of panels require further design detailing and prototyping.

- The use of OSB/ 3 as the racking and diaphragm panel proved to be far more reliable than the $\mathrm{t} \& \mathrm{~g}$ covered panels. While this was to be expected, as this is a primary use of OSB, it further highlights the demand that the timber industry in Wales has on imported OSB. Further research is required into the use of $\mathrm{t} \& \mathrm{~g}$ spruce as part of an infill panel, although the extra processing, labour and costs may always prove to be a prohibitive method.

\subsubsection{Building envelope}

- The level threshold detail and ramp access details were observed as a potential concern for future projects with raised timber floors. The requirement to raise the timber frame $150 \mathrm{~mm}$ above ground may result in the ground floor being a minimum of $420 \mathrm{~mm}$ above ground.

- The hardwood insert connector tolerances were not accurate enough - the frame settled over time due to timber movement and allowable tolerance. (future connectors like this would be designed with a smaller angle to compensate for, and to resist, settlement).

- Assembly resulted in a range of module sizes not related to $600 \mathrm{~mm}$ or $300 \mathrm{~mm}$ spacing for ladder beams. The ladder beams were also doubled up at panel joints, which would be avoided by using larger panels, but this would increase the need for on-site lifting equipment.

- The panels were also sheathed with OSB/3, but the over- and underlapping 
of these boards with each other and the frame resulted in many boards cut to a size that was not an efficient use of the original $2440 \times 1220 \mathrm{~mm}$ board size producing unnecessary wastage.

- The number of joints between components may cause difficulties with air tightness in complete projects. Further research is included in the longhouse prototype in section 10.6.

- Further research is required on the complete timber envelope to incorporate insulation, and air tight envelope and full rainscreen cladding.

\subsubsection{Technology and skills}

- The frame and panel erection demonstrated a successful low-tech approach, without the need for a crane. Components were detailed and fabricated to be lightweight and ease to manhandle. However this increased the number of components which poses problems for differential movement, difficulties in minimising air permeability and the doubling up of structural elements that increases the thermal bridging effect.

- Feedback from the joiners and on-site assembly team reported that the structure was simple to assemble, dismantle, store and rebuild. However, this was a temporary pavilion without the full integration of other building envelope elements.

\subsubsection{Tectonic form}

- The spatial module sizes lent themselves well to the application of other material finishes - such as the Urban Colourcoat roof and wall cladding.

- The $600 \mathrm{~mm}$ module provided an appropriately scaled proportion for domestic scale architecture and low-tech assembly, although this leads to an increased number of components, as already observed, and difficulties in alignment and material efficiency between box frame alignment, panel sizes, timber lengths and board products. The intention was to allow standard timber lengths and boards to fit between frames, however the structural requirements to overlap the box section portal frames resulted in non standard sizing.

- The additive approach to frame and panel design and assembly allows for the simple addition of other modules at a later date for expansion. In theory components can be removed and repositioned within the structural principle of the frame and any other added portals. 


\section{Environmental Resource Centre}
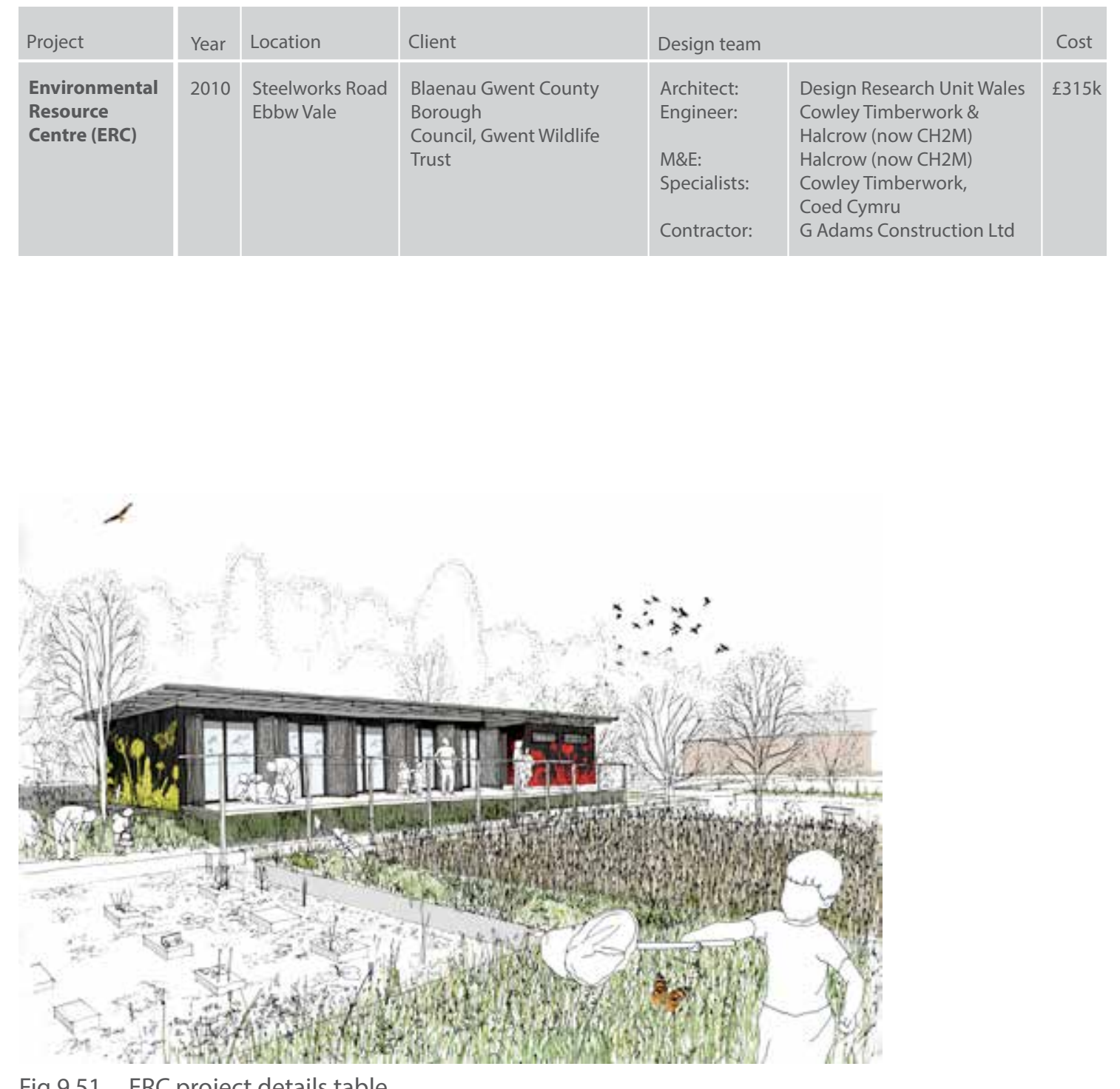

Fig 9.51 ERC project details table

Fig 9.52 Proposed perspective of ERC across reedbeds
The opportunity to design and build an Environmental Resource Classroom in Ebbw Vale provided the first opportunity to utilise the Ty Unnos components in a fully functioning, weathertight building. The classroom was designed for Blaenau Gwent County Borough Council and Gwent Wildlife Trust and was built between November 2009 and May 2010 as a study into simple, modular construction techniques in a post-industrial landscape.

While not a domestic building, the scale of this single classroom project lent itself to the domestic scale components being developed and therefore provided an appropriate prototype for the system. The aims for the development of the Sitka spruce construction system in the design and fabrication of this prototype were:

- to use the standard sized box section components as a simple frame for ground floor, posts and roof with end grain bolting for all frame connections;

- to use Structurally Insulated Panels (SIPs) as the infill for floor, walls and roof that would provide all the necessary racking resistance for the frame;

- to expose the timber surfaces as the final internal finish;

- to use laminated Welsh oak windows as part of the overall modular system;

- use charred Welsh low value softwood as an external rainscreen to demonstrate a growing integration of the system componentry; and

- To achieve low energy and carbon performance primarily through a 'fabric first approach' to the building system.

\subsubsection{Design}

\subsubsection{Brief}

The 140sqm Environmental Resource Centre was to be run by Gwent Wildlife Trust, to allow local school children and community to explore the heritage and ecology of the former steelworks site. The centre provides: Wildlife courses for people of all ages specialist courses for school children linked to the foundation and key stages; a focal point and meeting place for community environmental activities and conservation volunteering. Blaenau Gwent County Borough Council's vision for the project was to:

- Create a high quality educational and cultural facility that celebrates the synergy between heritage, built and natural environments.

- $\quad$ Promote sustainable building and demonstrate low-energy use through passive and renewable design measures for heating and ventilation. 


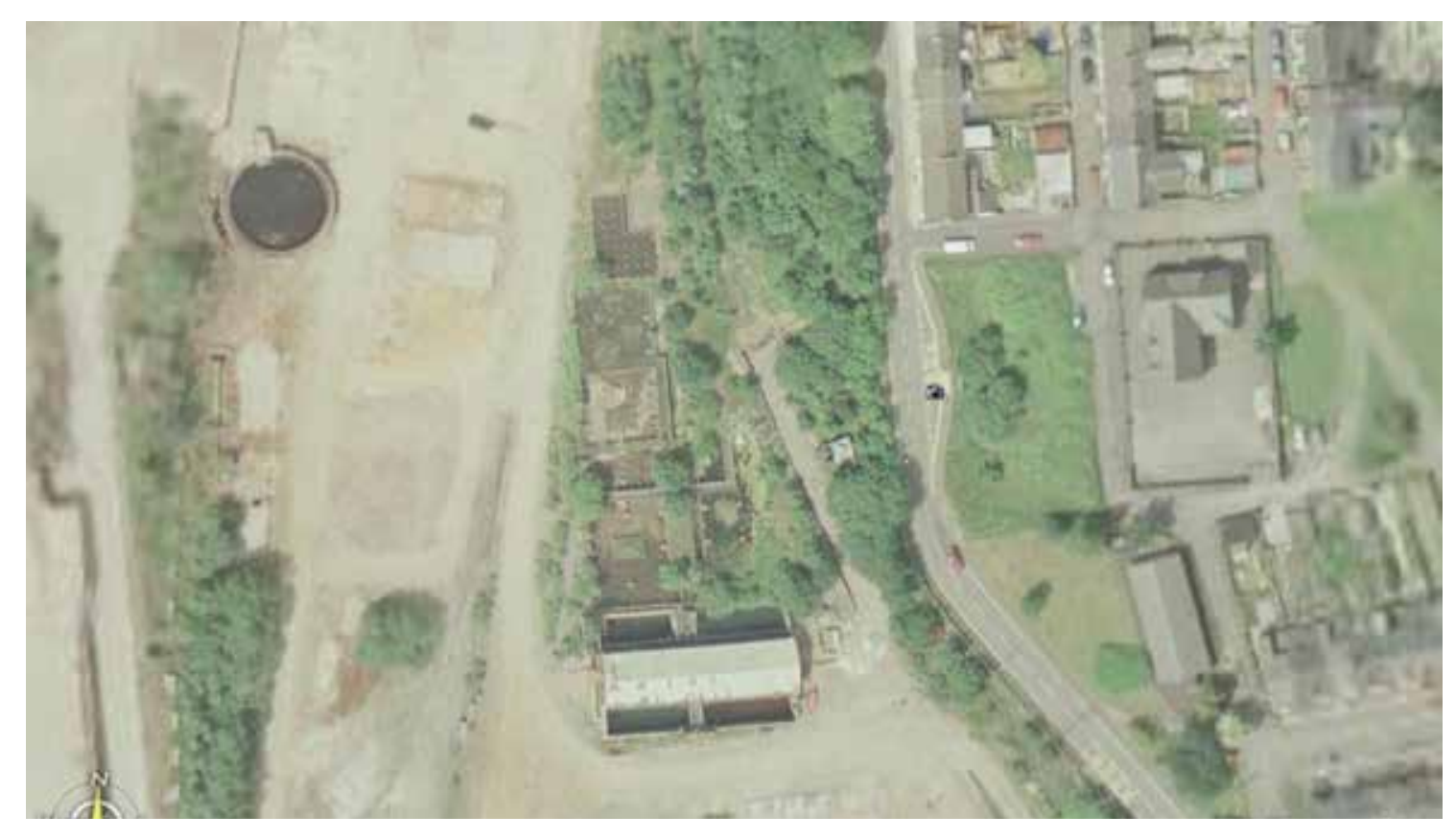

ABOVE

Fig 9.53 Aerial photo of former pumphouse site

LEFT

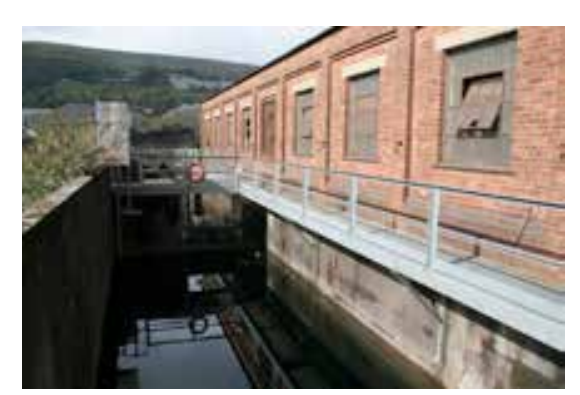

9.54 Existing photos of pumphouse and surrounding site BELOW

Fig 9.55 Site analysis plan of pumphouse site

RIGHT

9.56 Schedule of accommodation table
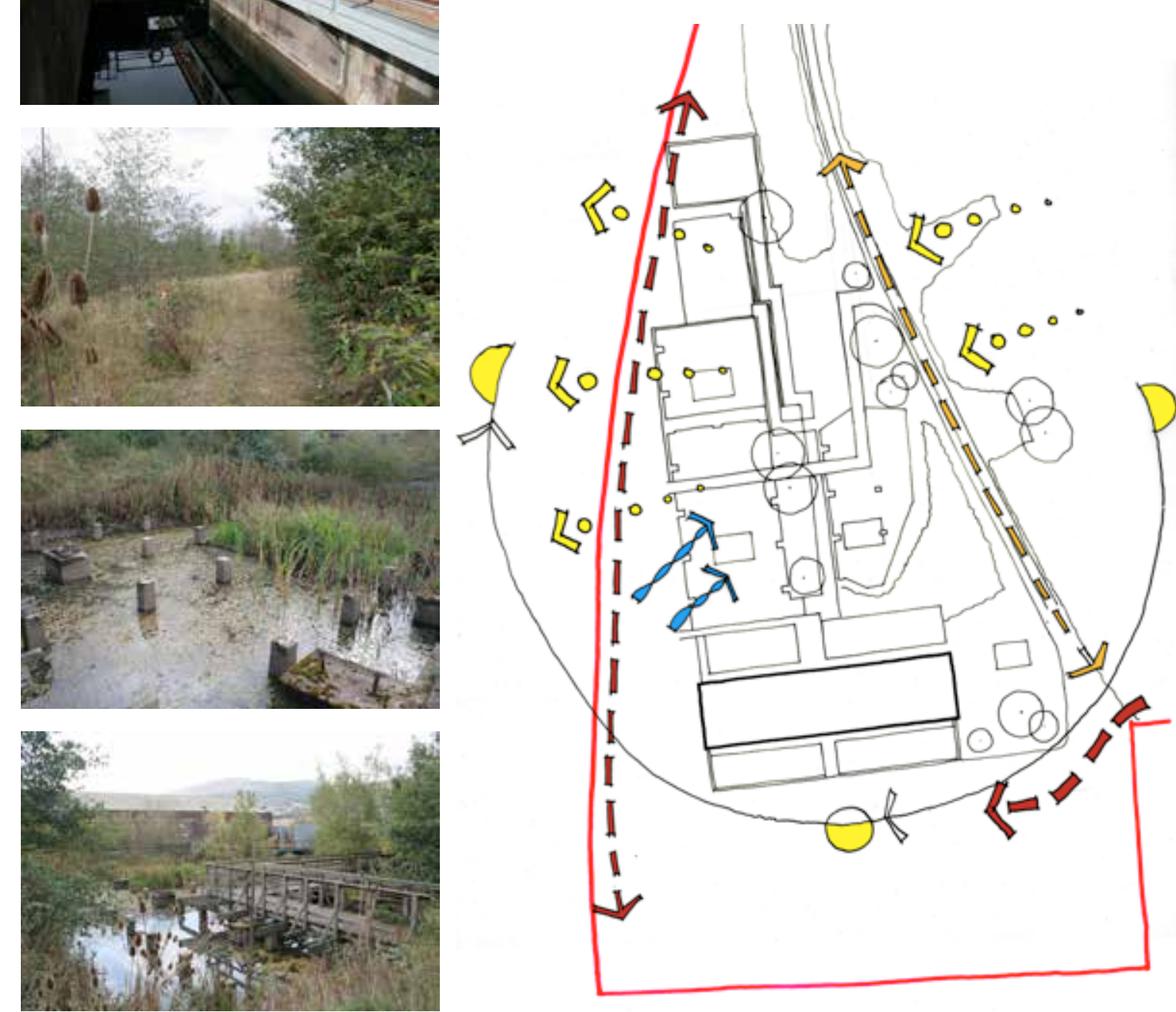

- To be delivered by the end of March 2009 for approx. $£ 150000$

- To be secure from vandalism and theft.

- promote the use of the Ty Unnos system in conjunction with other local materials and suppliers.

\begin{tabular}{|l|l|c|}
\hline Accommodation & Purpose & Approx. area \\
\hline Classroom (with sink) & for max 30 children & $54 \mathrm{~m}^{2}$ \\
\hline Storage & for chairs, desks, equipment & $10 \mathrm{~m}^{3}$ \\
\hline Kitchen & for basic food preparation & $10 \mathrm{~m}^{2}$ \\
\hline Office & & $10 \mathrm{~m}^{2}$ \\
\hline Toilets & 1 unisex disabled, 2 female, male & $20 \mathrm{~m}^{2}$ \\
\hline Wet area/ arrival point & for multi-purpose use & $20 \mathrm{~m}^{2}$ \\
\hline TOTAL & & $120 \mathrm{~m}^{2}$ \\
\hline
\end{tabular}

9.5.1.2 Site

The site is part of the re-development of the steelworks site in Ebbw Vale, known as The Works, with an aim to create a new vision of sustainable community. The overall $£ 300$ million development was to include 720 new homes, a community hospital, learning campus and a business hub. The Environmental Resource Centre is part of the Hot Mill Character Area of the former Steelworks site, which was to include a primary school and residential development.

The site is adjacent to the former steelworks pumphouse, located alongside a proposed PDR corridor between the Hot Mill Character Area and a new Green Bridge forming part of the green link through The Works. As well as the derelict pumphouse, a linear red brick building, there are a series of filtration tanks used to filter water from the steelworks site before returning it to the River Ebbw. Since the closure of the steelworks, the tanks have become a haven for wildlife and an area of high ecological value containing over 100 plant species including amphibians, reptiles and birds.

The site is bounded on two sides by main access routes. To the west, the PDR corridor will bring both vehicular and rail traffic in close proximity to the site eventually cutting across the northern filtration tanks. To the east the ground rises steeply, with a bank of trees, towards Steelworks Road, from which access to the site will be taken. A footpath runs north-south between former rail tracks, which will be used as the main access route to the boardwalks, dipping platforms and the classroom.

The site is overlooked by houses on the valley side to the east of the site, while the pumphouse and filtration tanks benefit from views to the west across the Green Valley of the steelworks site and beyond. 

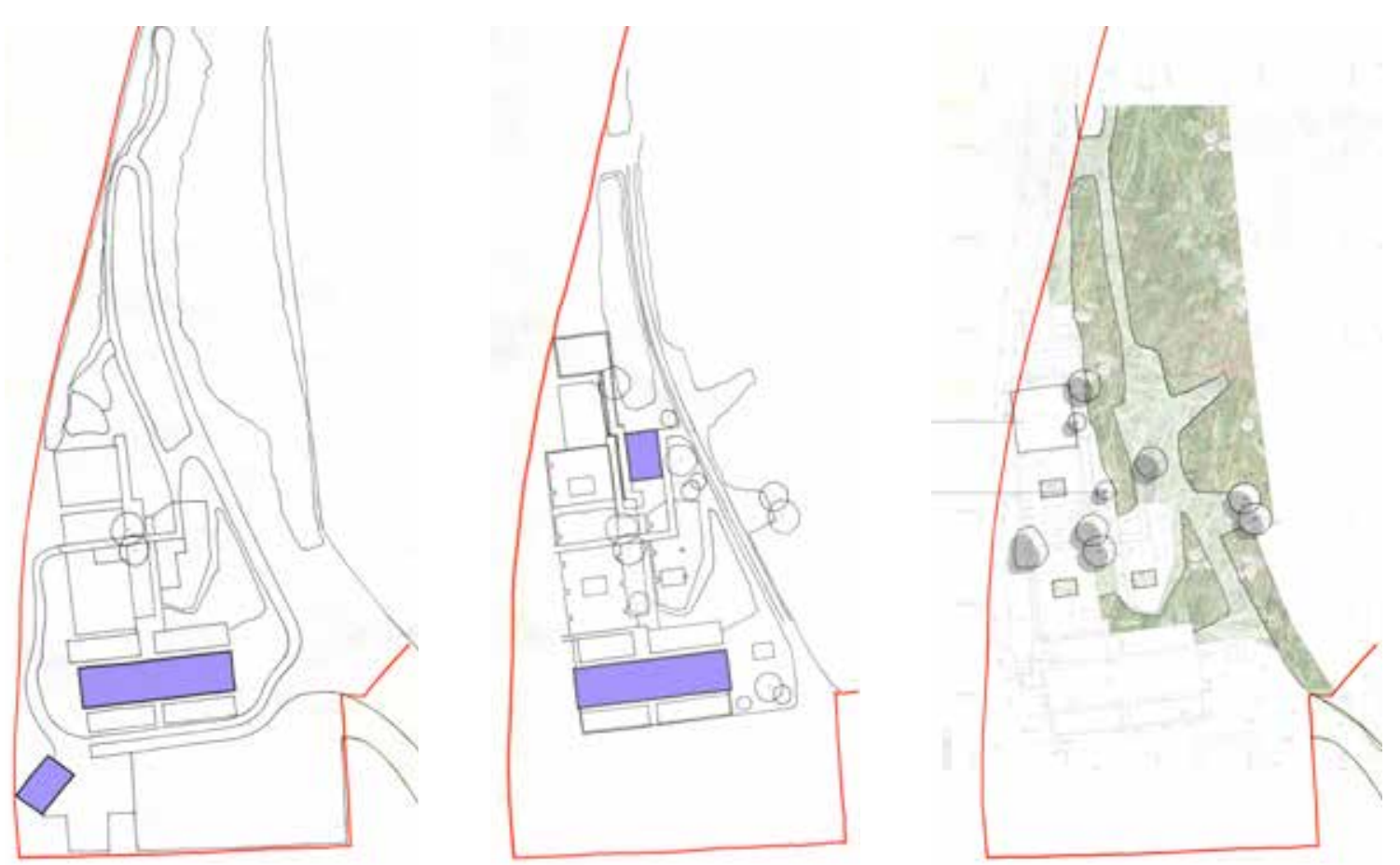

9.5.1.3
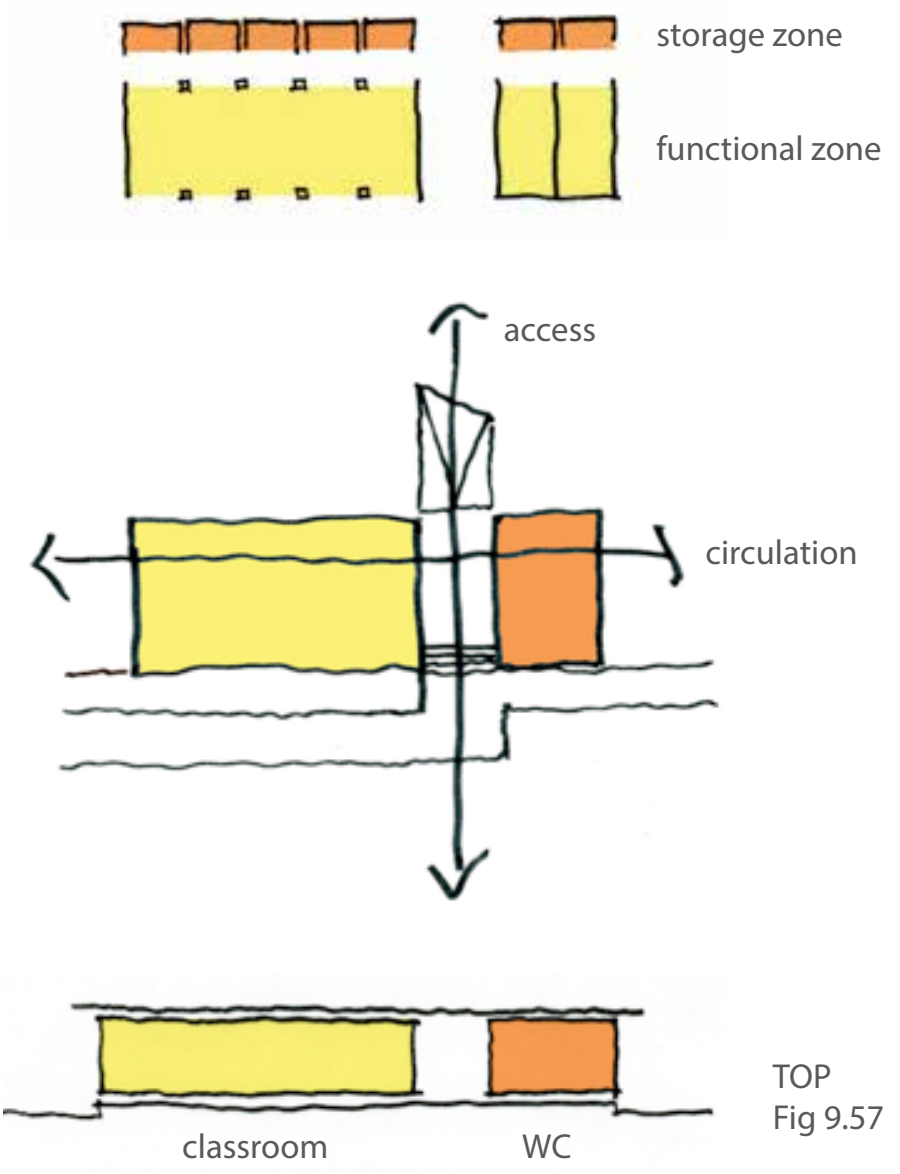

classroom

WC

TOP positioning

LEFT

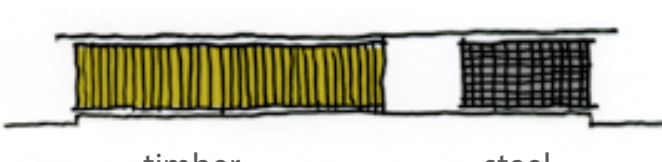

steel

a. simple zoning strategy

b. two axis of circulation and access

timbe

c. two spaces separated by an oversailing roof

\section{ign strategy}

The location of the classroom was originally proposed to the south west of the existing pumphouse. From here a pathway around the west of the pumphouse linked the classroom to the ponds.

The site of the classroom was appraised and different options were examined. It was decided that the best site for the building was in a bank of trees to the east of the site, opposite the reed bed, overlooking the ponds and the valley. This site makes full advantage of the views off the site and places the building in close proximity to the environment it will be used to study. Access to the boardwalks and dipping platforms is from the entrance deck between the two blocks of the building and gives level access.

The building is located to respond to the form and geometry of the former pumphouse and filtration tanks. The immediate context of wildlife and materials has informed the following concepts:

\section{- Simplicity}

A rational, layered simple box that expresses construction and environmental strategies. The classroom has a simple form to reflect the geometry of the site both the rectilinear form of the pumphouse and the regularity of the tanks. The form is derived from an explicit expression of its functional zoning, as occurs in surrounding industrial buildings. Industrial materials will further link the building to its surroundings.

- Zoning

The building is zoned by two key axes. The first links the pathway through the building to the boardwalk. This separates the classroom from the service block and addresses the level change between the path and the boardwalk. A second longitudinal axis separates a service zone along the eastern edge of the building from inhabitable space alongside the ponds and boardwalk. The service zone is created from prefabricated storage units which will contain wet services and storage, while the inhabitable zone has exposed timber beams and columns expressing its post and beam construction system.

\section{- Colour and wildlife}

The building is clad in brightly coloured metal panels to contrast with the surrounding vegetation and with the brick reds and greys of the context. The colour will provide a vibrant learning environment, appealing to both children and adults. Murals across the metal panels will illustrate wildlife 

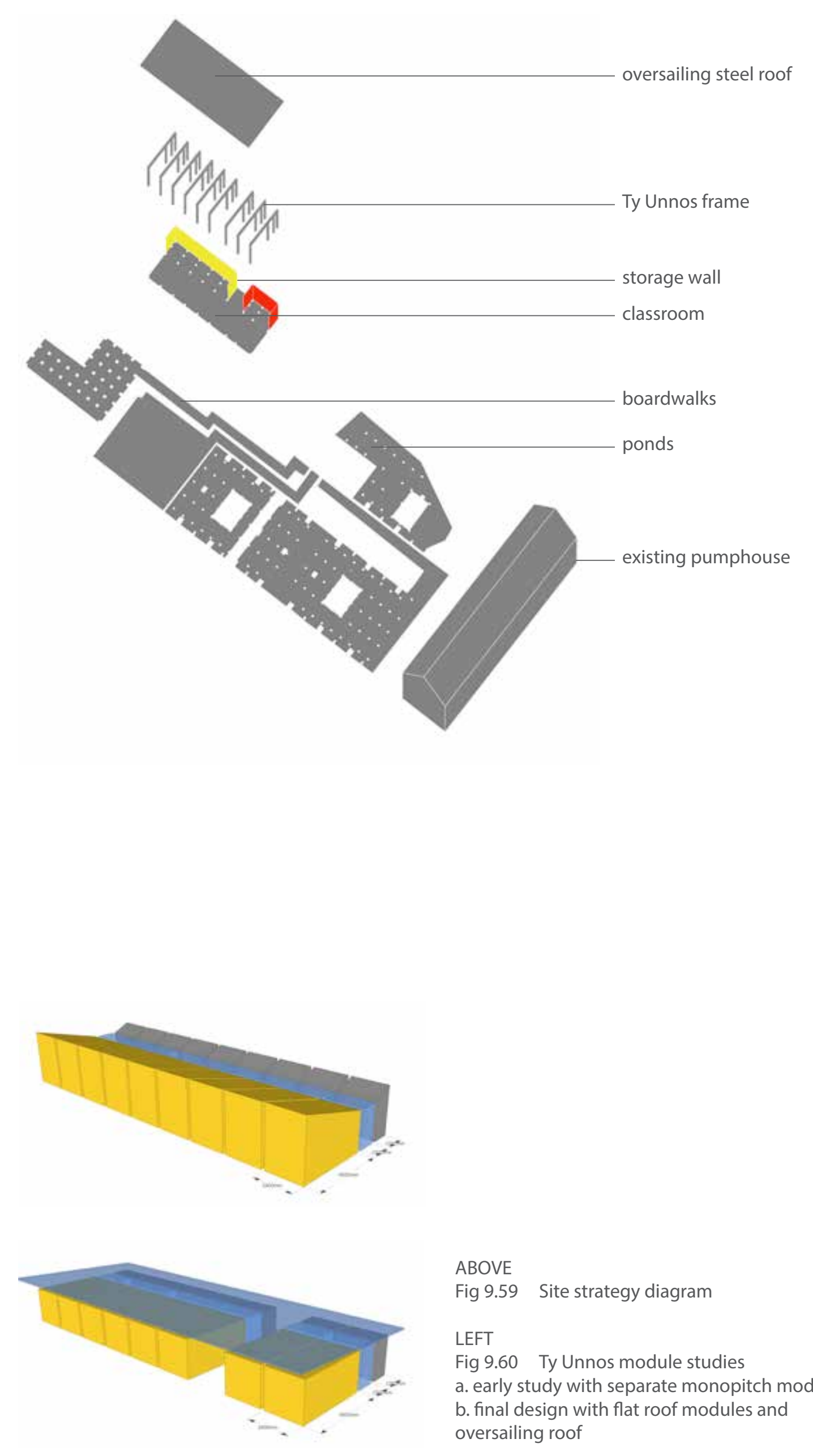

ABOVE

Fig 9.59 Site strategy diagram

LEFT

Fig 9.60 Ty Unnos module studies

a. early study with separate monopitch modules

b. final design with flat roof modules and

oversailing roof as super-graphics, merging with and enhancing the surrounding natural landscaping. Large scale illustrations of plants and animals will be applied across the building to graphically demonstrate its function. Claddings aim to obscure the colour and murals from certain angles and reveal it when viewed from elsewhere. The murals will reveal themselves and disappear as visitors walk up to, past and around the building, akin to nature.

\section{- Materials}

An over sailing sheet metal roof unifies the two blocks. Beneath this the two blocks are clad differently in semi-industrial materials to reflect the industrial heritage of the site. The classroom is clad in charred vertical timber and the service block in metal mesh.

\subsubsection{Design development}

The ERC was designed to respond to the post industrial landscape through the form inspired by the existing linear pumphouse building and the use of industrial materials that evoke the essence of the previous use of the site.

\section{Plan and sectional form}

The plan and section were informed by the following decisions:

- The intention was to test the Ty Unnos components in the first fully enclosed, weathertight building to meet all legislative requirements including Planning approval and Building Control.

- The design was to be a simple linear box providing maximum access and views to the western filtration ponds and boardwalks.

- As a classroom for a maximum 30 children, a 54sqm space would be required although teaching arrangements would be informal and flexible, often in clusters of small groups.

- The conceptual arrangement determined that circulation would be required along the north-south axis with a storage buffer to the east.

- The Sitka spruce box section beams could span a maximum $4.8 \mathrm{~m}$ span, however a $7.2 \mathrm{~m}$ span was required.

- The first design was conceived as a chain of 1 no. $2.4 \times 4.8 \mathrm{~m}$ bay and 1 no. $2.4 \times$ $2.4 \mathrm{~m}$ bay with a $1.2 \mathrm{~m}$ circulation void between.

- To define the spaces of classroom, circulation and storage this was refined to a $7.2 \mathrm{~m}$ beam supported at $4.8 \mathrm{~m}, 6 \mathrm{~m}$ and $7.2 \mathrm{~m}$, in collaboration with the engineers and Cowley Timberwork. This enabled the structurally tested 210 $x 270 \mathrm{~mm}$ beam to be used but propped at either end and at 2 locations along the length. 
$=$
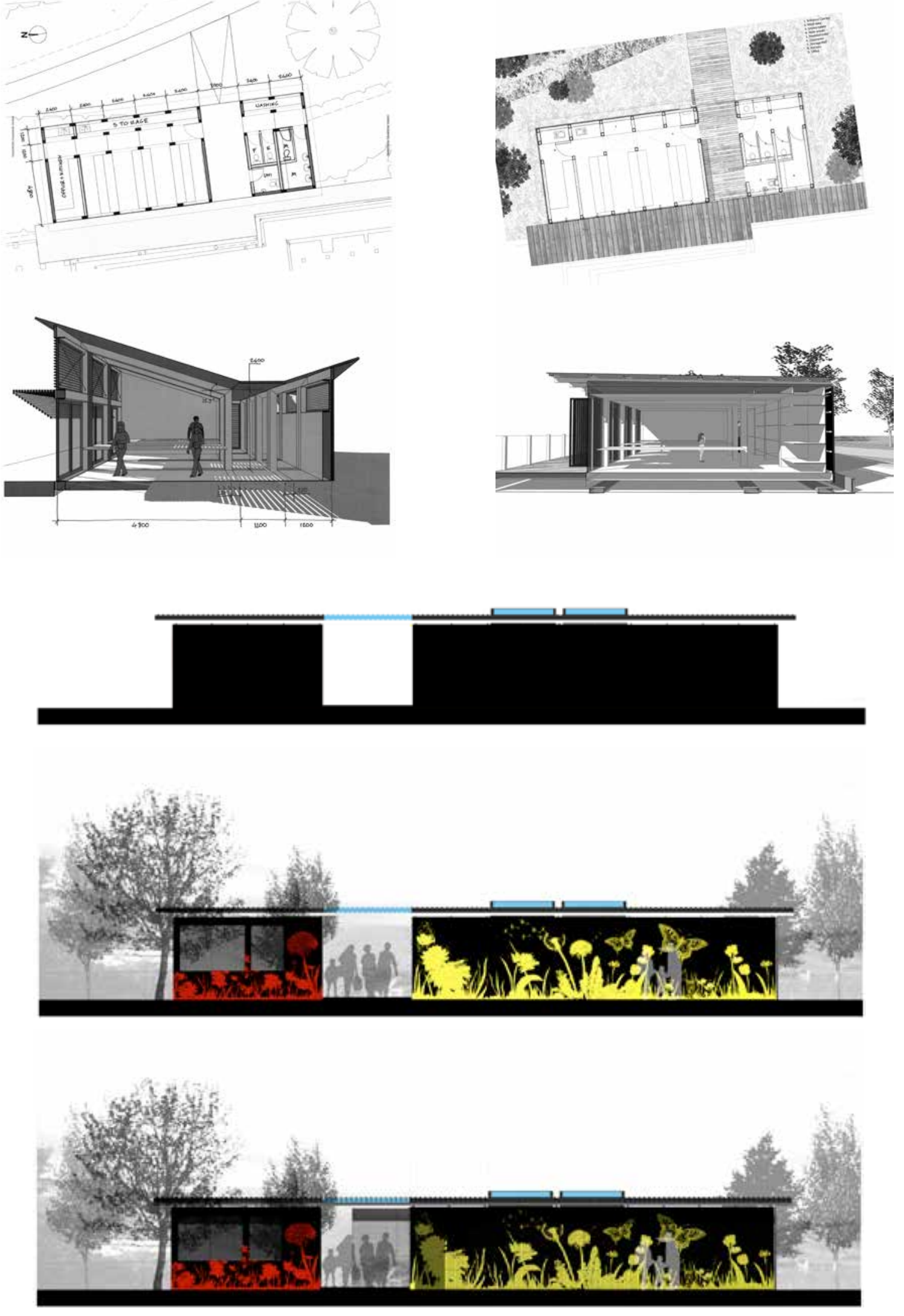

TOP

Fig 9.61 Design development plans and sections

ABOVE

Fig 9.62 Layered murals and cladding a. EPDM watertight membrane; $b$. Coloured murals; c. Charred timber and steel mesh.
RIGHT

Fig 9.63 Charred timber studies

b. charred timber test panel for ERC. a. DSDHA architects timber charring process;
- Initially this was reflected in section as 2 monopitch modules with a flat roof gutter over the circulation. As complications had been identified in the efficiency of fabricating and installing infill panels to fit differing gables along the frame, so a flat roof option was proposed with a separate galvanised steel, shallow mono pitch, rainscreen roof over.

\section{Charred timber cladding}

The murals were developed in collaboration with local school children to identify different habitats and species of wildlife to exhibit on the cladding. On its own this would look bold, bright and not very subtle attracting too much attention to the building in robust, post-industrial landscape, which could attract vandalism. It was, therefore, decided to over clad the murals with a robust hit and miss cladding to blend into the dark and industrial tones of the site, but allow the murals to shine out from behind. This provided an opportunity to re-explore the charred cladding, originally proposed for the Castle kiosk in chapter 8.5:

- Charring timber draws on Japanese traditions of charring posts before placing them in the ground as foundations, the known properties of heat treating wood to reduce its susceptibility to insect attack and rot (Thermawood) and the fire resistance offered as timber burns to the reduce the risks of arson attacks.

- No specifications exist to prescribe levels of charring. It was decided that a dark chocolate colour was required, with loose debris brushed off. The elevations were separated from visitors, so there was low risk of soot being transferred to clothing, although the charred timber was sealed with a water based, low VOC sealant in the entrance space where visitors would sit and hang coats.
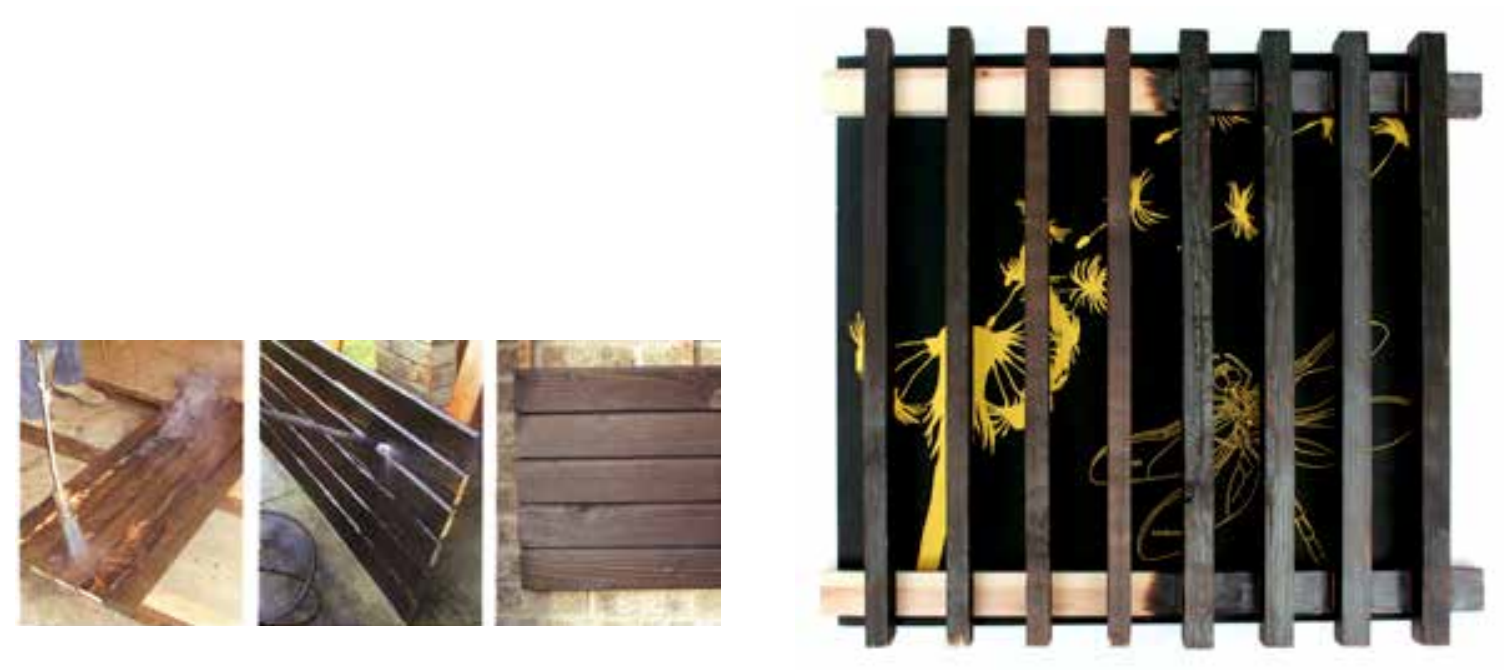
BELOW

Fig 9.64 Exploded environmental strategy

RIGHT

Fig 9.65 Seasonal environmental strategy sections

a. Winter - west afternoon sun allowed deep into classroom

space benefiting from solar gains. Rainwater collected

in perimeter drainage channel and directed to filtration

ponds. Air source heat pump to heat space quickly. Trickl

ventilation through windows and rooflights. Solar hot

water pan

b. Summer - Solar shading from $1200 \mathrm{~mm}$ eaves and vertical louvres on west elevation to reduce solar gains. Openable low level vents and roonights for cross ventlan. Opor

ter panels provide hot water

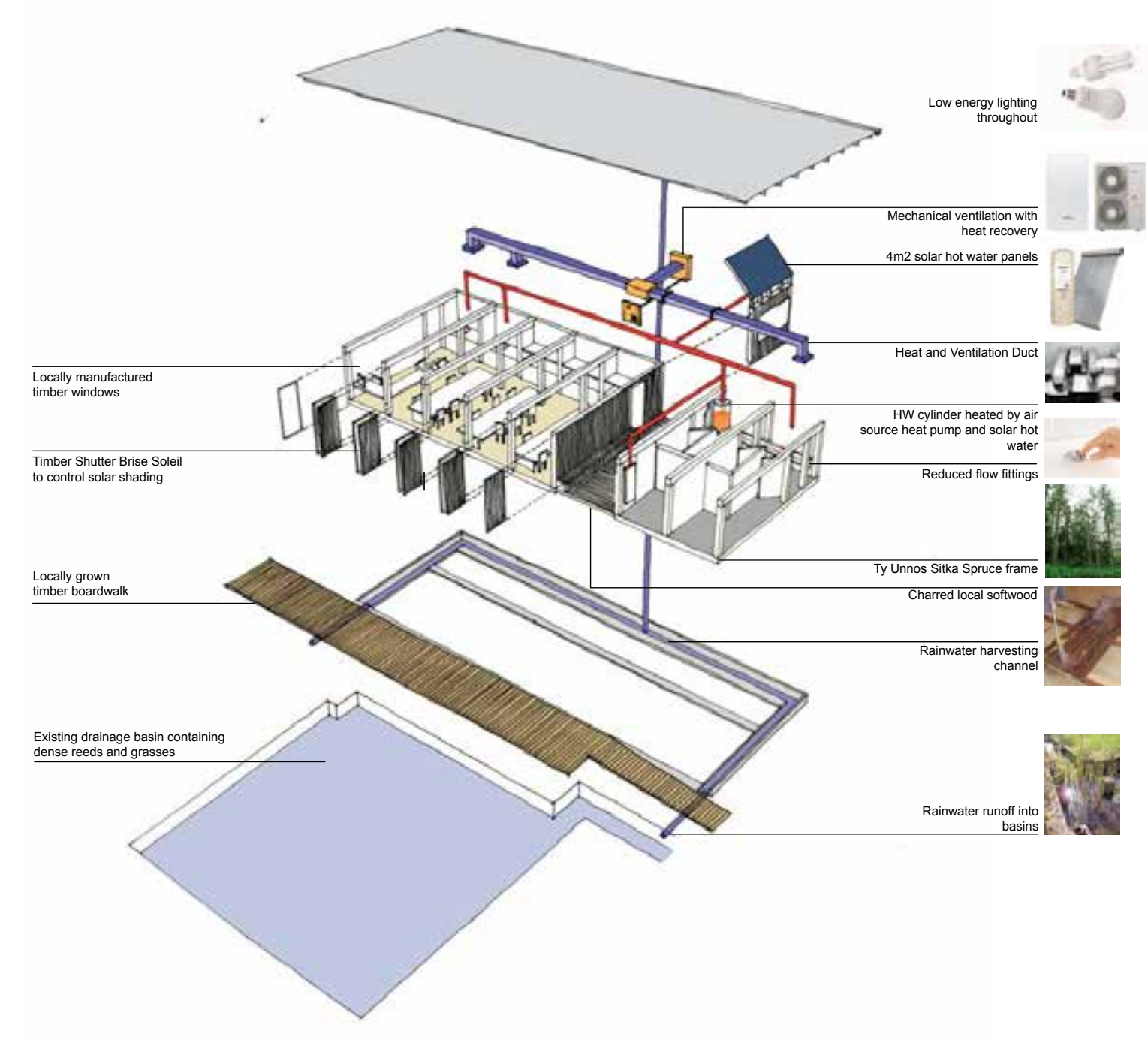

\section{Environmental performance}

The centre is designed to achieve a 60\% reduction over Building Regulations (2006 regulations). This is achieved through the design of a building envelope which provides high U-values and air tightness in parallel with an intelligent response to site encouraging solar gains during winter and natural daylighting. The environmental

performance was to be didactic through the exposure and demonstration of passive and active design measures such as:

- natural ventilation via low level openable panels and rooflights;

- an air source heat pump to provide on demand heating in a flexible environment;

- $\quad 4$ sqm solar hot water to meet hot water demands;

- solar control via a $1200 \mathrm{~mm}$ roof overhang on the west elevation;

collection of rainwater and storage in the existing wildlife ponds; and

exposed M\&E linking systems together.
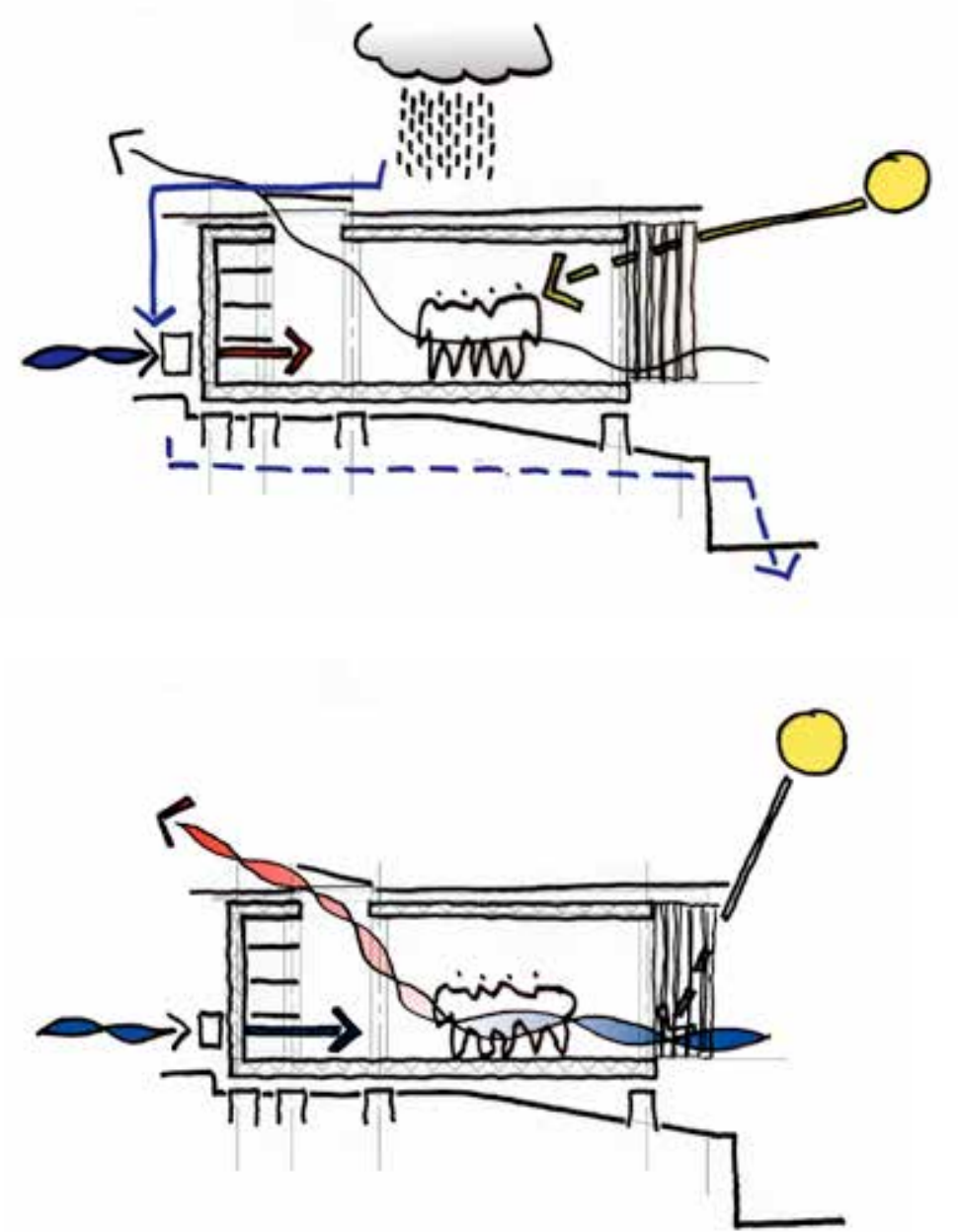
The following drawings and models formed the basis of a successful planning application in September 2008
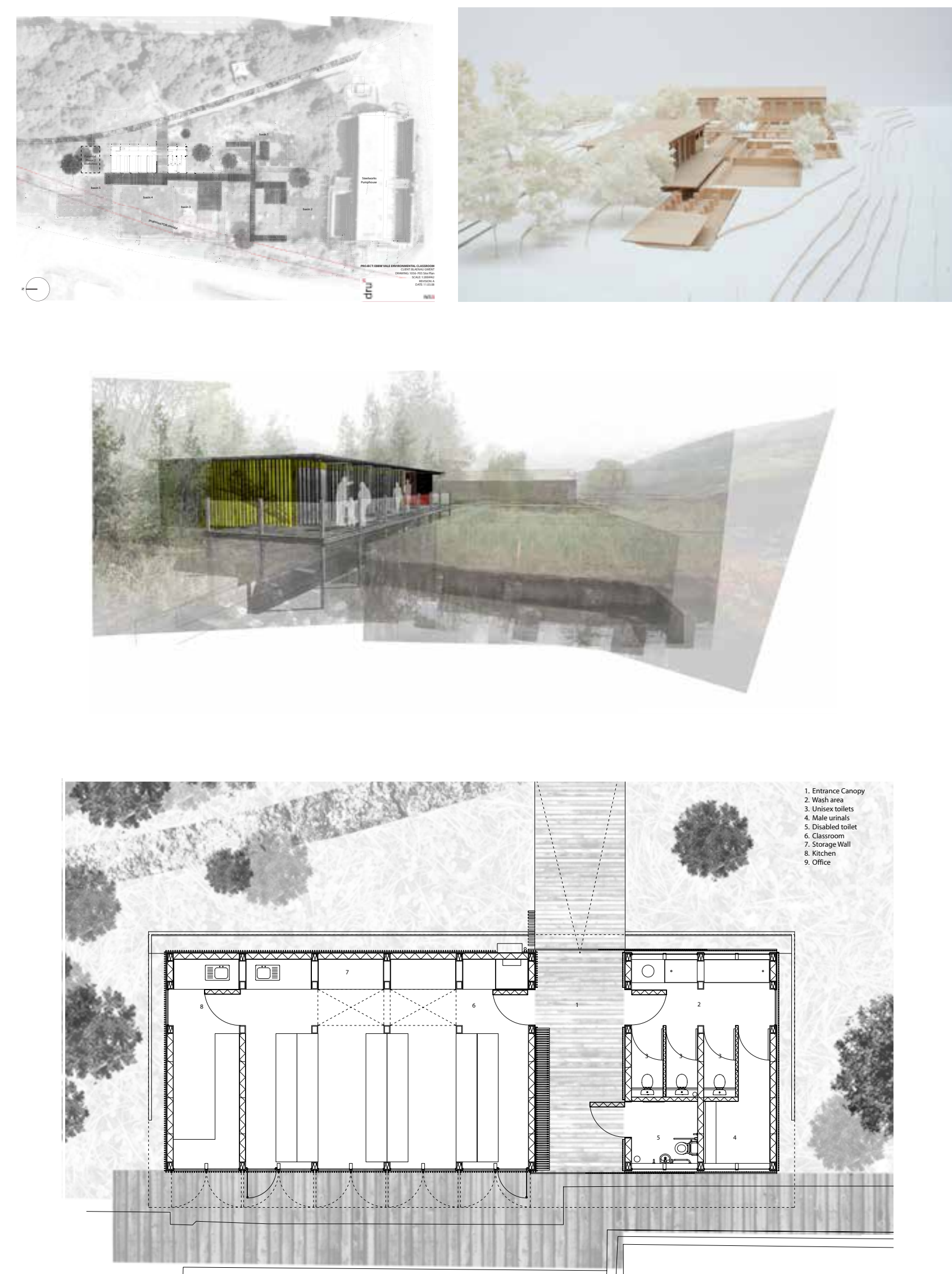

LEFT

Fig $9.67 \quad$ 1:200 site study model of ERC adjacent to ponds

Fig 9.68 Proposed ERC perspective across ponds Fig 9.69 Proposed ERC floor plan

BELOW - RIGHT

Fig 9.70 1:20 exploded ERC model highlighting conceptual elements: spaces, murals, cladding, storage wall, oversailing roof Fig 9.71 ERC east elevation
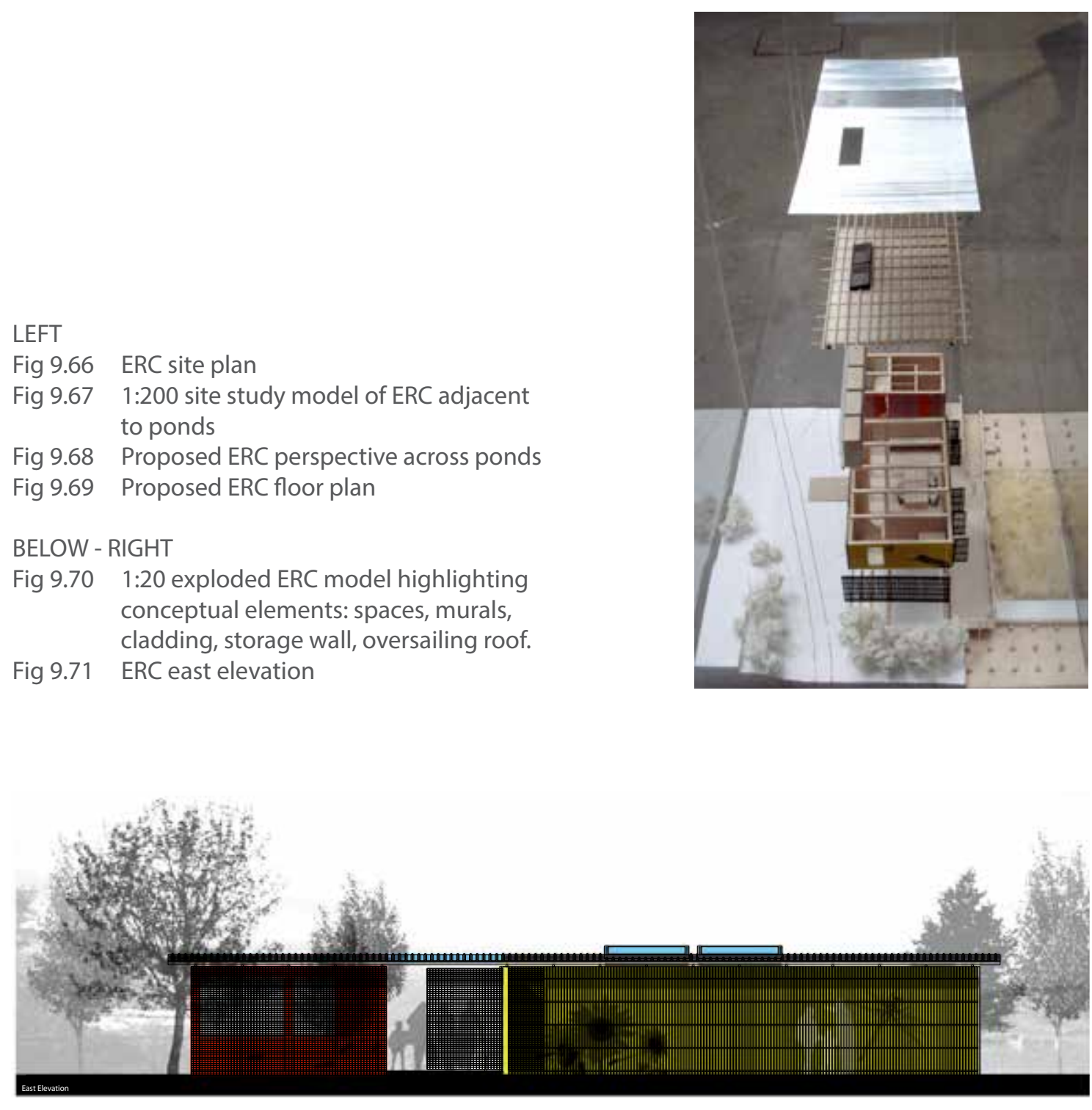


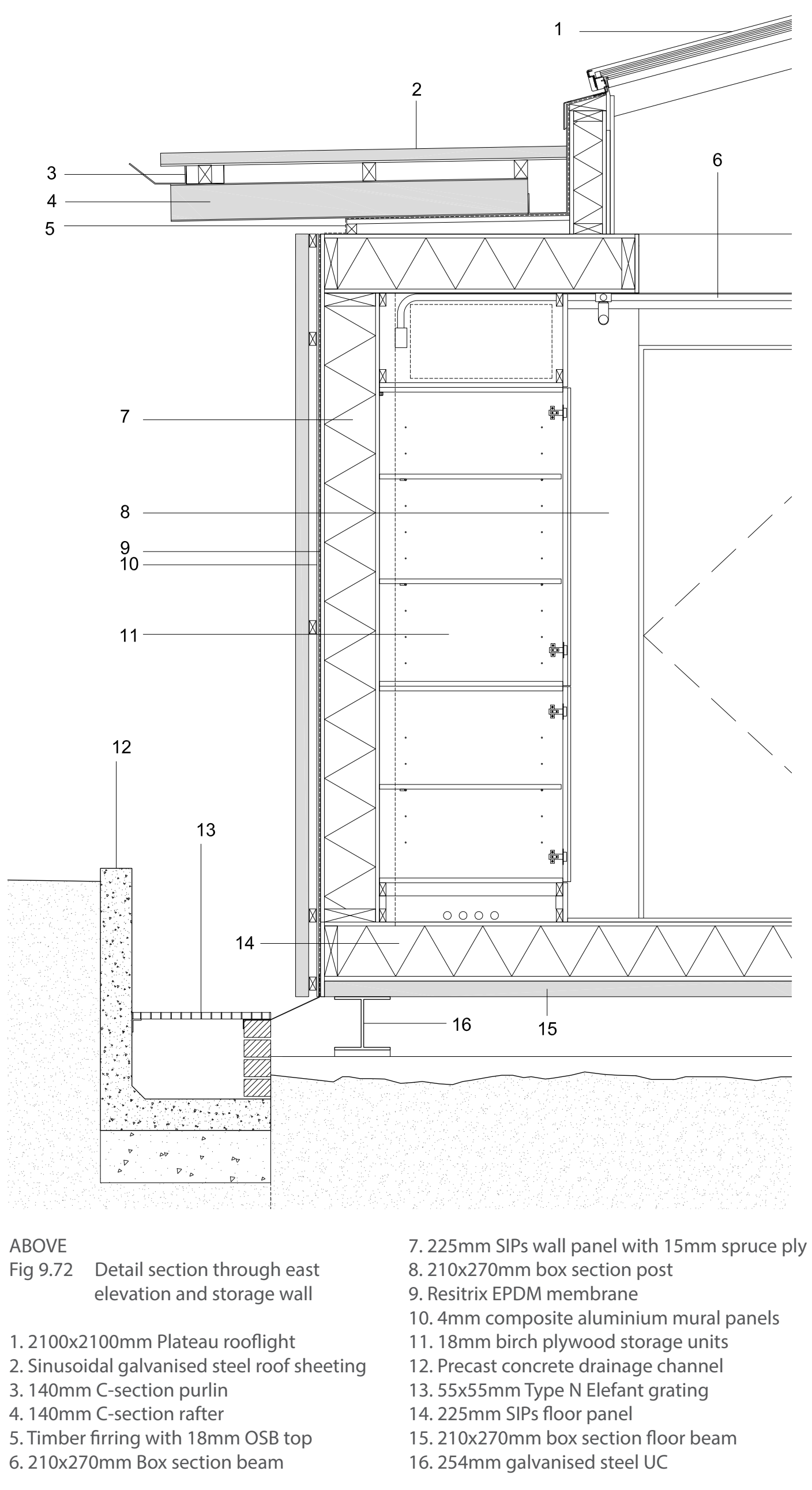

\subsubsection{Prototype}

\subsubsection{Detailed design}

With an aim to improve fabrication and construction efficiency, clearly define the building envelope performance requirements and minimise environmental impact a layered, but elemental construction approach was adopted as shown in the detailed section. From inside to out: Ty Unnos frame, plywood SIPs with surface mounted services, EPDM rubber membrane, aluminium composite graphic panels, charred softwood or galvanised steel grating and rainscreen roof. Each component was specified to facilitate easy man-handling on-site and a quick erection programme to minimise any damage to the exposed internal timber surfaces. The principle elements of the building envelope detail follow, highlighting the use of Welsh-grown timber as part of the complete timber envelope:

\section{Ty Unnos - frame and SIPs}

- Cowley Timberwork were appointed manufacturer for the ERC superstructure following the testing of the box section components and with the experience and knowledge of the construction system. Cowley's had their own in-house design department who were able to translate and convert general arrangement drawings into fabrication and component drawings.

- The ERC was comprised of 9 frames, using $210 \times 270 \mathrm{~mm}$ box section components, creating 8 spatial bays: 1 office, 4 for the classroom, 1 entrance deck and 2 for the WCs. Each portal frame had a 2 no. $7.2 \mathrm{~m}$ beams for ground floor and roof, using non-standard lengths of spruce, and 4 no. $2.4 \mathrm{~m}$ posts that were connected using the end grain bolting system for all joints.

- The frames are located at $2.4 \mathrm{~m}$ centres to allow for $2.4 \mathrm{~m}$ infill panels.

- Inspired by the exposed tectonic use of board products in the Eisteddfod pavilion, chapter 8, Structurally Insulated Panels were chosen due to the limitations of the ladder beam cassettes, the flexibility and lightweight nature of the SIPs panels and that the plywood finish could be exposed as the internal finish. $9 \mathrm{~mm}$ and $12 \mathrm{~mm}$ B-grade birch plywood was used for walls, with $15 \mathrm{~mm}$ grade II spruce ply used for floor and ceiling. $15 \mathrm{~mm}$ Grade III spruce ply was used where it would not be exposed.

- $225 \mathrm{~mm}$ thick SIPs panels span between frames for floor and roof with $210 \mathrm{~mm}$ panels sitting vertically between the floor and roof panels. Both provided a U-value of $0.15 \mathrm{~W} / \mathrm{m} 2 \mathrm{~K}$

- The internal plywood surfaces were treated with Envirograf, a matt finished and transparent, intumescent fire retardant to meet Building Regulation Approved Document Part B surface spread of flame requirements.

- Panels were connected to the frame by screwing through a lapped edge of 

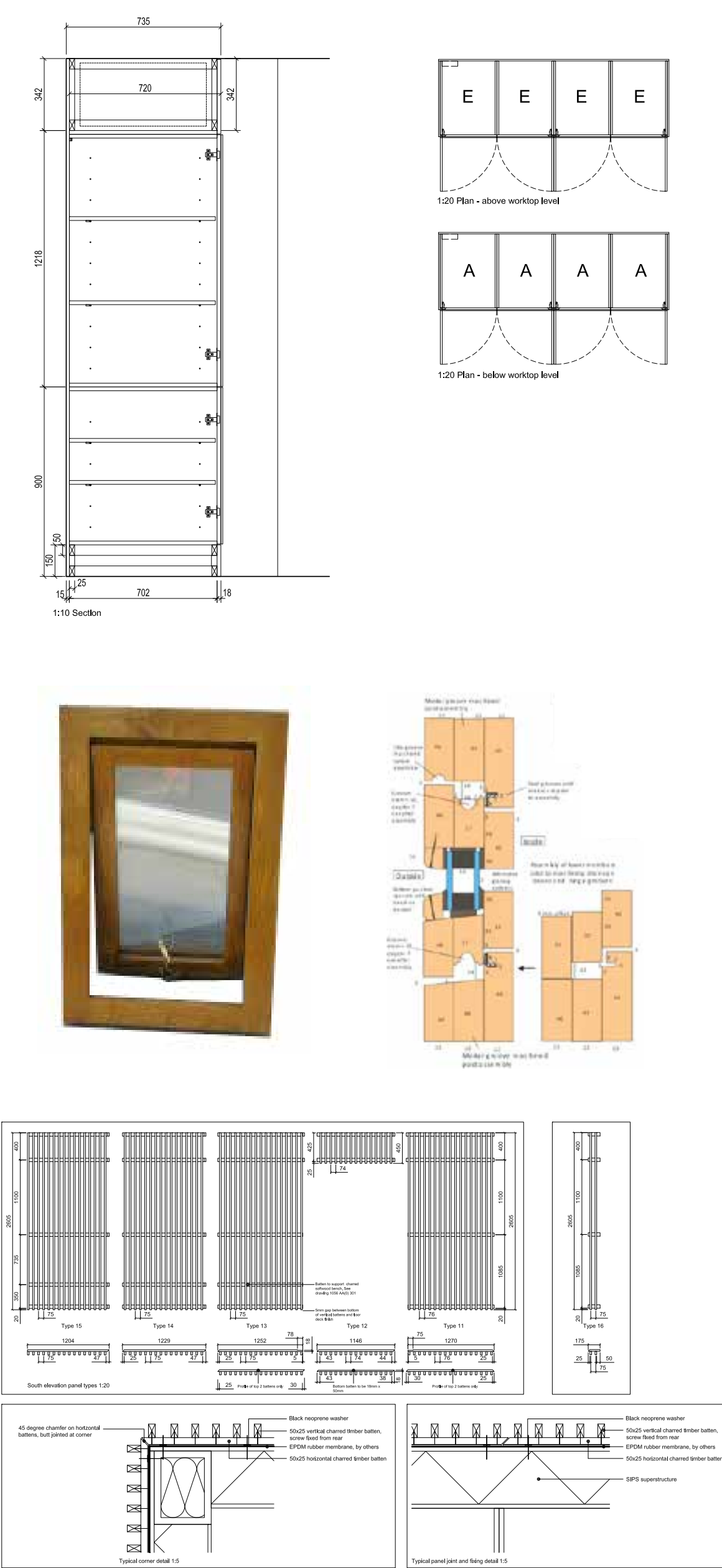

plywood over the posts and beams. All panels were joined to each other using $45 \times 190 \mathrm{~mm}$ spruce edge runners with a tongue and groove joint to locate and align panels.

\section{Prefabricated storage units}

$5 \mathrm{no} .1200 \times 2400 \times 2400 \mathrm{~mm}$ bays of storage cabinets were proposed along the eastern external wall. These were proposed at tender to be prefabricated, structural modules combined with the SIPs wall panels as a development of the units prototyped for the Eisteddfod pavilion in chapter 8. However, following tender, it was not possible to integrate the SIPs panels and the chosen joinery company preferred to fabricate them on-site around the M\&E fit-out to ensure a good fit and finish.

\section{Laminated oak windows}

The initial Ty Unnos studies included a standardised window component to be inserted into openings left either between box sections or between infill panels. The Coed Cymru and Coed Derwen Joinery laminated Welsh oak window was specified to be incorporated into the $2.4 \times 2.4 \mathrm{~m}$ openings on the west elevation, with doors at either end. The lower 'kick-plate' panel incorporated a bottom-hung, inward opening ventilation panel.

\section{Charred cladding panels}

Cowley Timberwork undertook the charring process using a blowtorch to char the $750 \mathrm{~m}$ of $25 \times 50 \mathrm{~mm}$ ungraded spruce battens and vertical cladding. To ease on-site construction the charred timber cladding was to be prefabricated into approximately $1200 \times 2900 \mathrm{~mm}$ panels to be fixed directly to the mural cladding boards.

\section{Construction sequence}

The Proposed construction sequence was digitally modelled to assist the explanation to the design team, client and chosen contractor, G Adams Construction Ltd.

LEFT TOP

Fig 9.73 Sample birch plywood storage cabinet details

LEFT MIDDLE

Fig 9.74 Coed Derwen Joinery top-hung, outward opening window

Fig 9.75 Coed Cymru laminated window details

LEFT BOTTOM

Fig 9.76 Sample charred cladding prefabricated panel drawing 

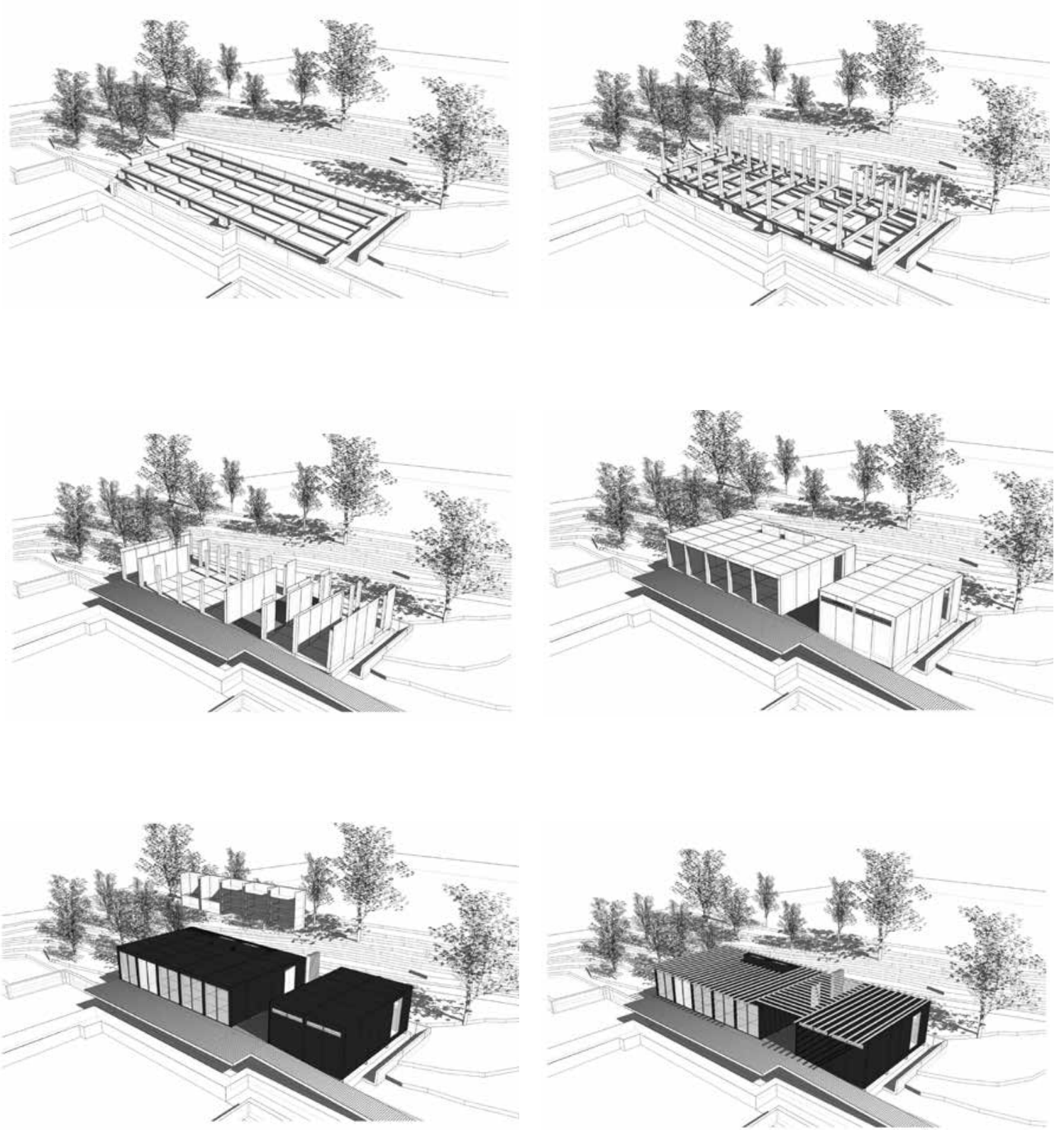

ABOVE (left - right)

Fig 9.77 ERC proposed construction sequence

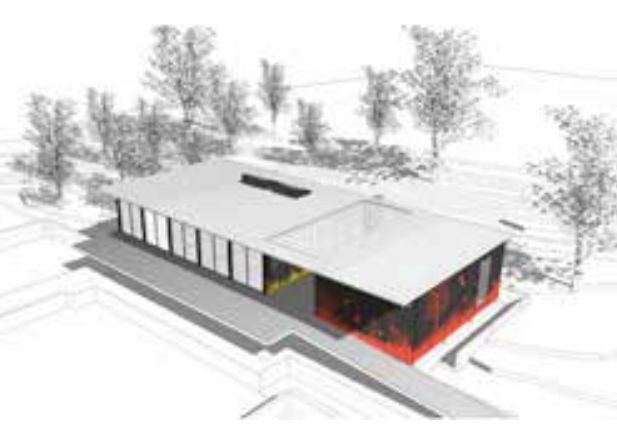

a. $254 \mathrm{~mm}$ UC steel bearers bolted to strip foundations b. $270 \times 210 \mathrm{~mm}$ box section frame erected.

CIPs eft for windows betwen frums. A seconday fing deck is instaws between frames. A secondary firing deck is installed on top.

to frame and SIPs Srefabricated storage units installed terally.

med galvanised steel roof structure installed. screw fixings will self-seal around EPDM rubber. g. mural panels and sinusoidal roof sheet installed.

RIGHT

Fig 9.78 General arrangement floor plan Fig 9.79 General arrangement short section
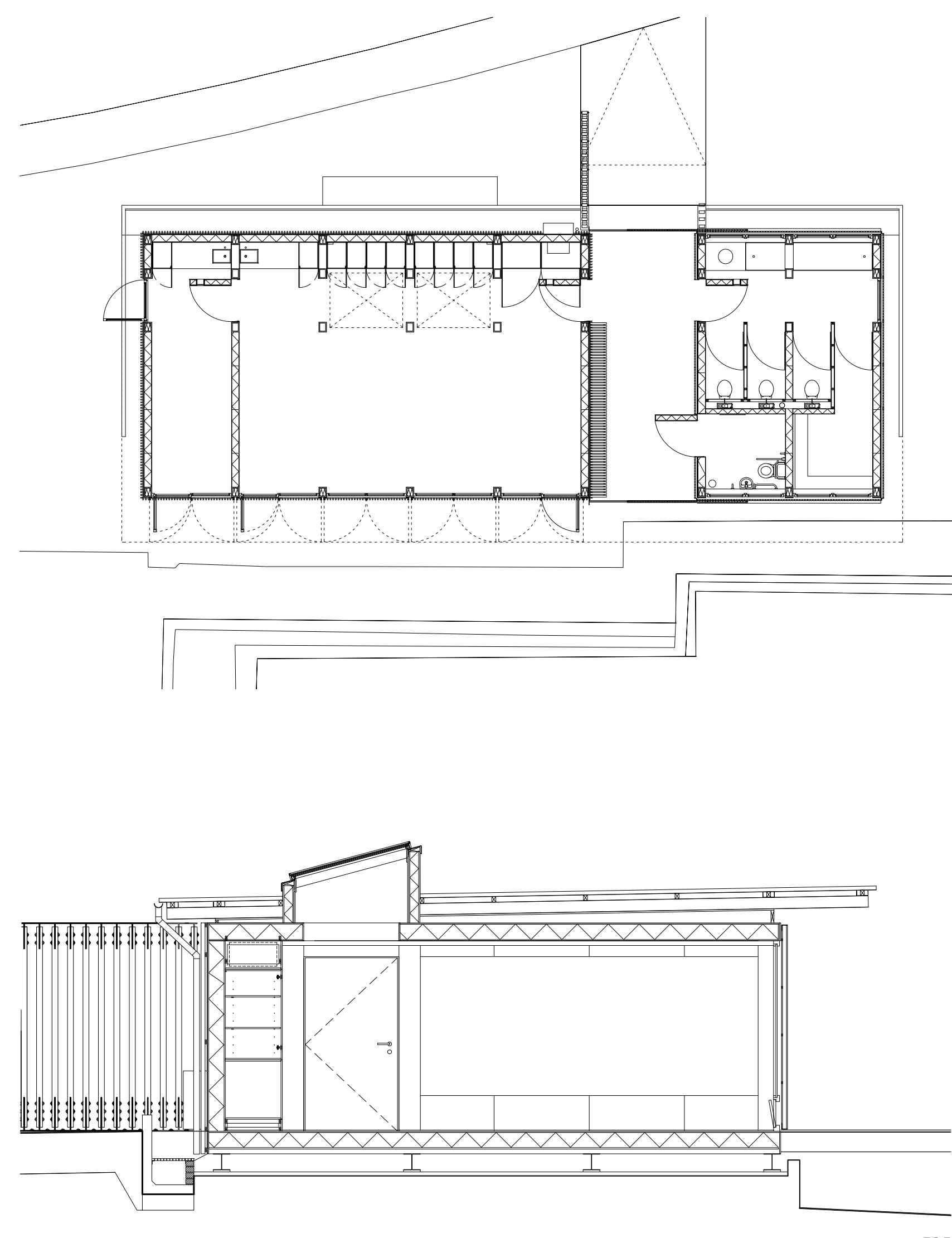

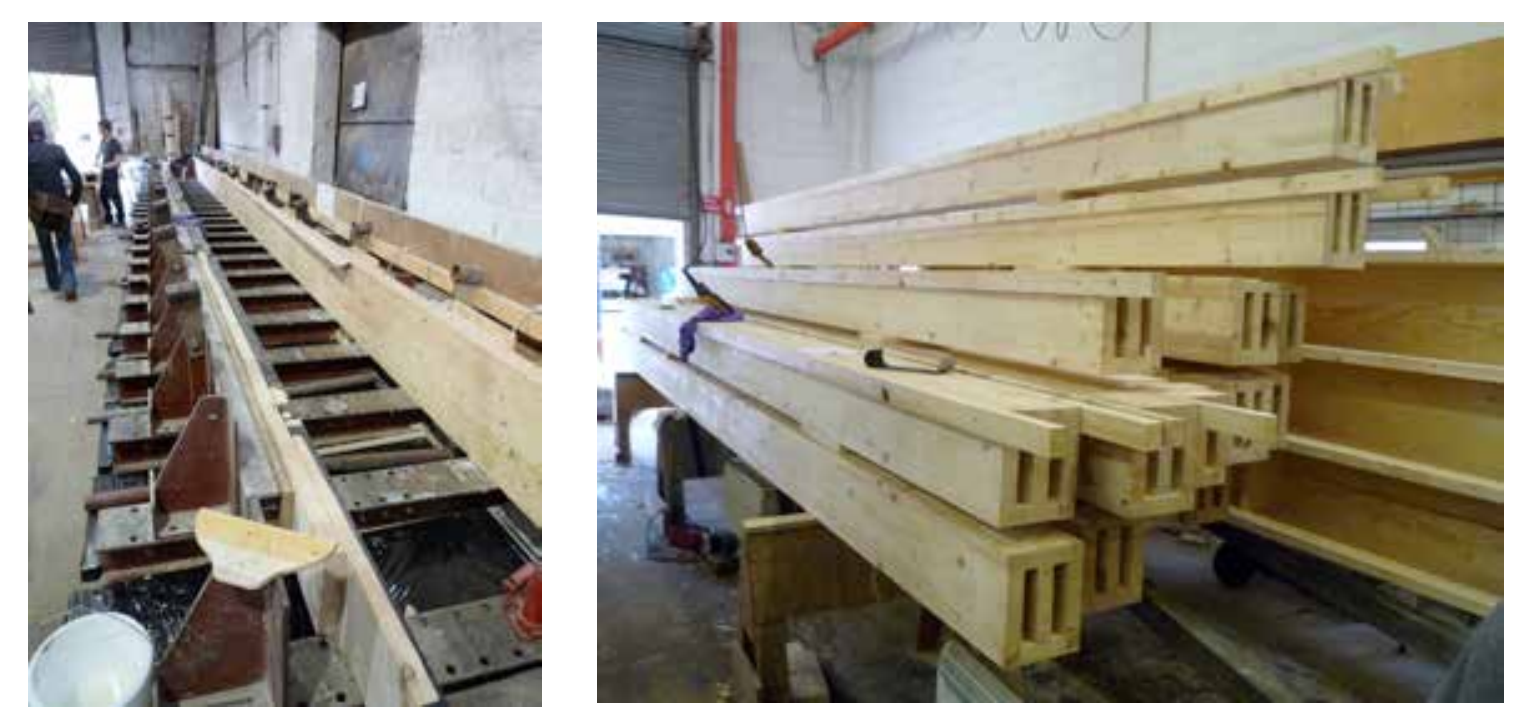

\subsubsection{Fabrication and construction}

The ERC superstructure and charred cladding were fabricated by Cowley Timberwork in Lincoln before being delivered to site in phases and assembled by G Adams Construction. The fabrication and construction processes are illustrated and annotated in the following sequence:
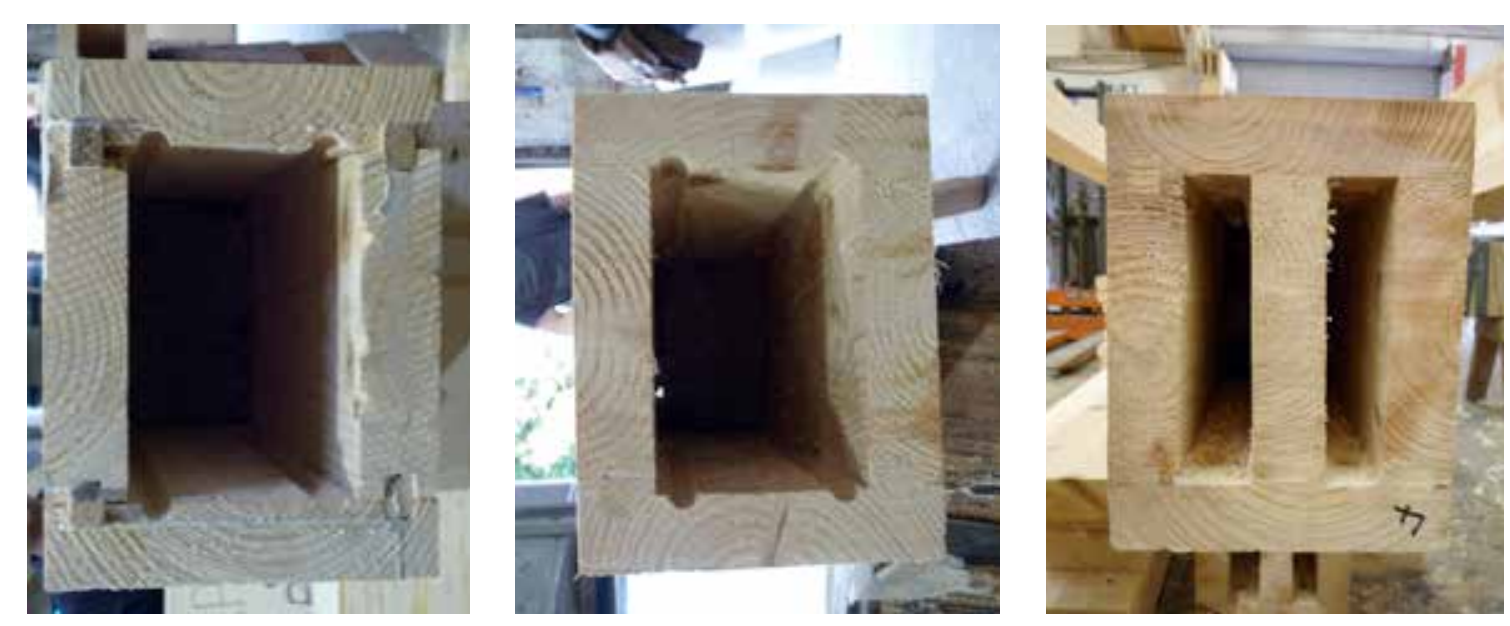

ABOVETOP

Fig 9.80 Laminating $7.2 \mathrm{~m}$ long box section beams a. specialist press for laminating bespoke components b. Stack of $7.2 \mathrm{~m}$ beams with bearers for floor cassettes pre-attached.

ABOVE

Fig $9.81210 \times 270 \mathrm{~mm}$ box sections

a. Loose tongues glued into corner joints instead of

profiling the boards with a tongue and groove

b. End of box section planed to remove excess glue

and to adjust length of beam Beams filled with

sheeps wool insulation to within $300 \mathrm{~mm}$ of ends.

c. Central webs added to middle of beam at ends to

reinforce the end grain bolting.

RIGHT

Fig 9.82 SIPs manufacturing sequence

a. 3 or $4210 \mathrm{~mm}$ SIPs panels pressed at a time in a wide

format press.

b. SIPs passed through table saw to cut to size and

shape.

c. SIPs routed to remove insulation on tongues that

lap box section posts

d. Detail of applied tongue to locate SIPs panels

e. SIPs loaded onto trailer as they are finished.
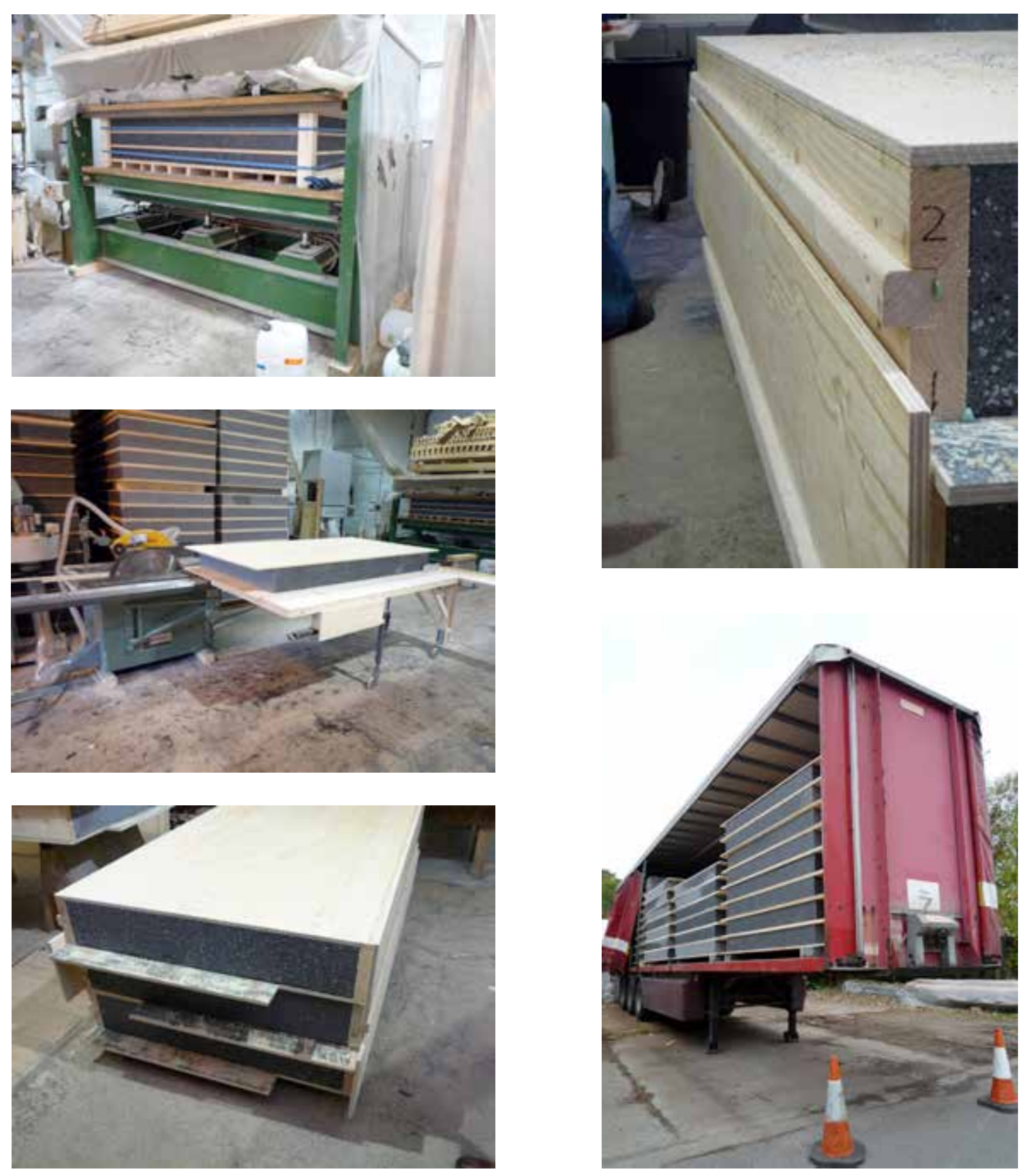

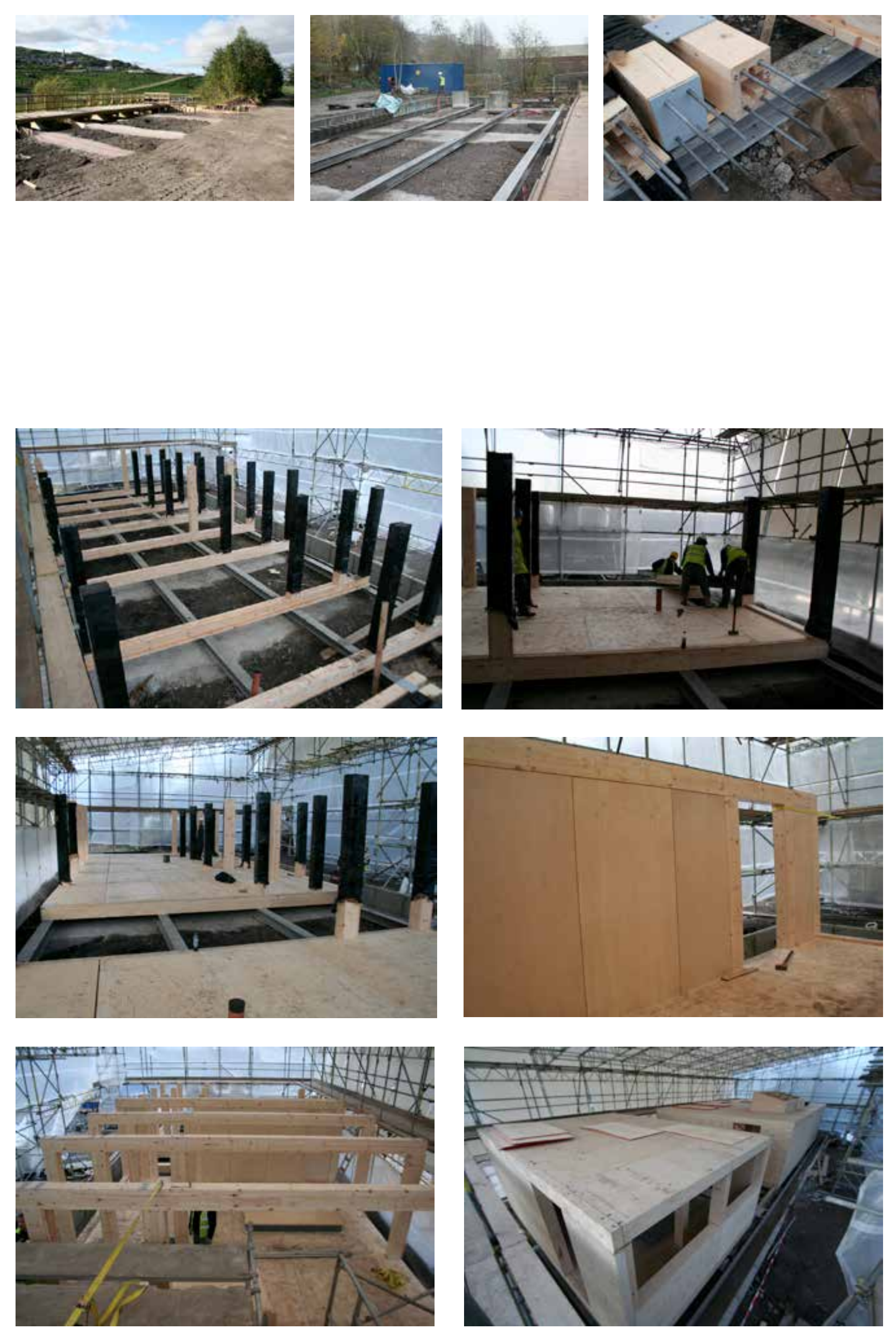

LEFT TOP

Fig 9.83 Foundations and bearer construction

a. Concrete strip foundations were poured with b. Stee

l-sections to reate the tased floric Box section posts

prepared with threaded rod and bearing plates.

LEFT BOTTOM

Fig 9.84 Frame and SIPs infill assembly

a. The $270 \times 210 \mathrm{~mm}$ box section posts and beams and

SIPs panels were pre coded prior to delivery to match the

construction methodology. The box section floor beams and

posts were bolted to the steel bearess and each other using

end grin bolting the sassembled in

10 days by a team of 4 carpenters;

to site in reverse

construction sequence, stored in the correct order adjacent to the site and manually lifted into position;

c. Completed floor assembly;

d. $225 \mathrm{~mm}$ wall SIPs panels installed with shims to maintain

shadow gap around each plywood board:

270x210 mm box section rof beams re end grin bolted to the posts and used to align the frame;

f. Completed frame and SIPs envelope with openings left

between posts for windows and doors.

RIGHT

Fig 9.85 Wall assembly details

a. Top of post with end grain threaded socketsi

b. $225 \mathrm{~mm}$ thick SIPs walls panel are hand positioned by

inserting externally to lap the posts and screwed, providing

and internally flush finish between SIPs and frame.

BELOW (LEFT-RIGHT)

Fig 9.86 Roof SIPs installation sequence

$225 \mathrm{~mm}$ thick SIPs roof cassettes were hand lifted, aligned and

screwed to the frame.
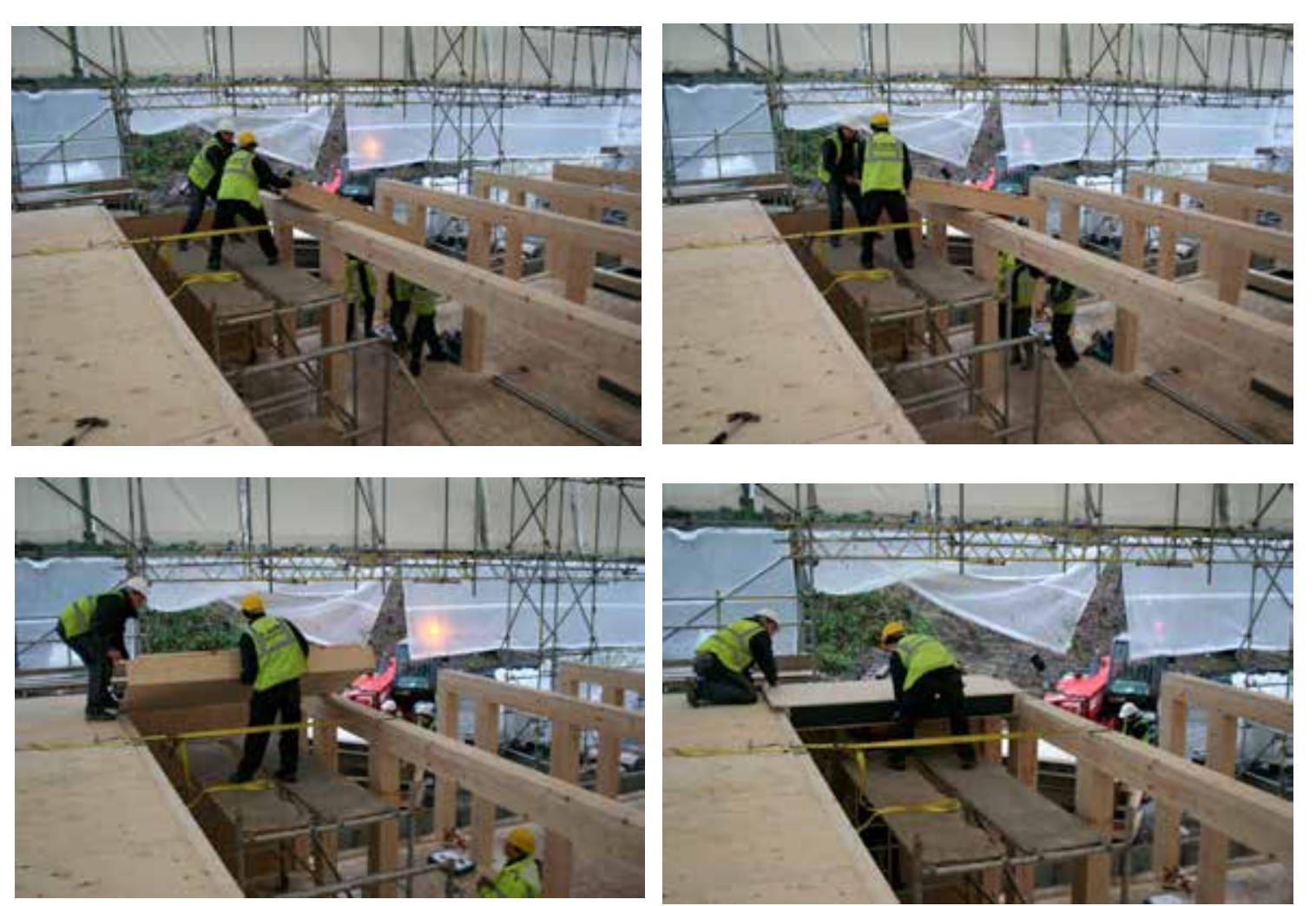

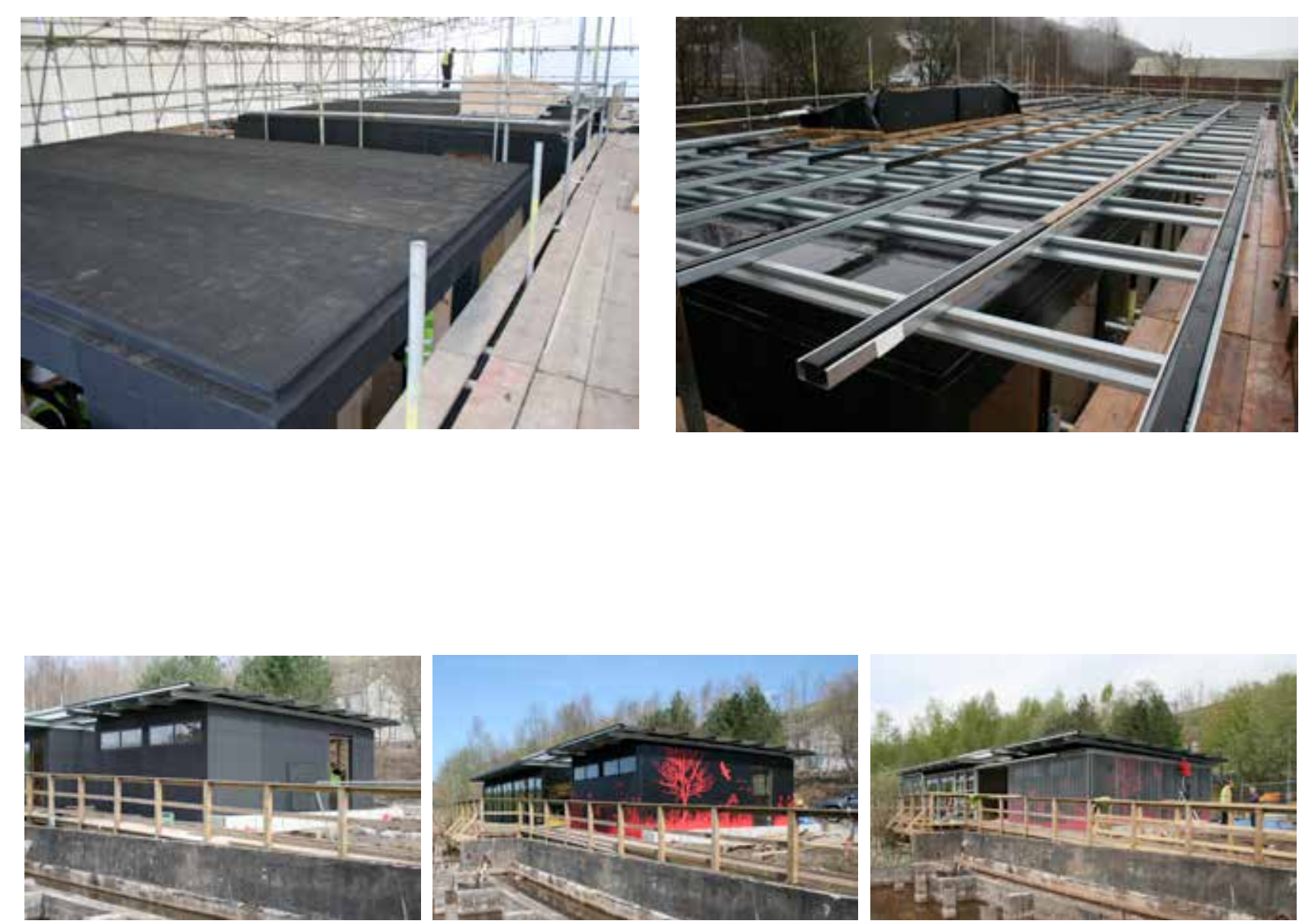

LEFT TOP

Waterproofing of envelope a. The entre uber membrane to provide the watertight layer.

Recessed roof firing zone evident on roof;

b. A floating galvanised steel roof structure and

finish and rooflights are installed.

LEFT MIDDLE

Fig 9.88 Outer cladding installation

a. Watertight envelope with windows, EPDM rubber

and galvanised steel roof;

b. The mural graphic panels are bonded to the

EPDM membrane without breaching the rubber;

c. Galvanised steel mesh fitted over murals on WCs:

$d$ - e. Charred timber cladding fixed over mura

panels on classroom envelope.

LEFT BOTTOM

Fig 9.89 Interior fit-out

(nt

open bays between box section posts;

b. Ventilation panels at bottom of windows;

c. Galvanised steel conduit, sockets and light fittings

are surface fixed internally to sides of box section
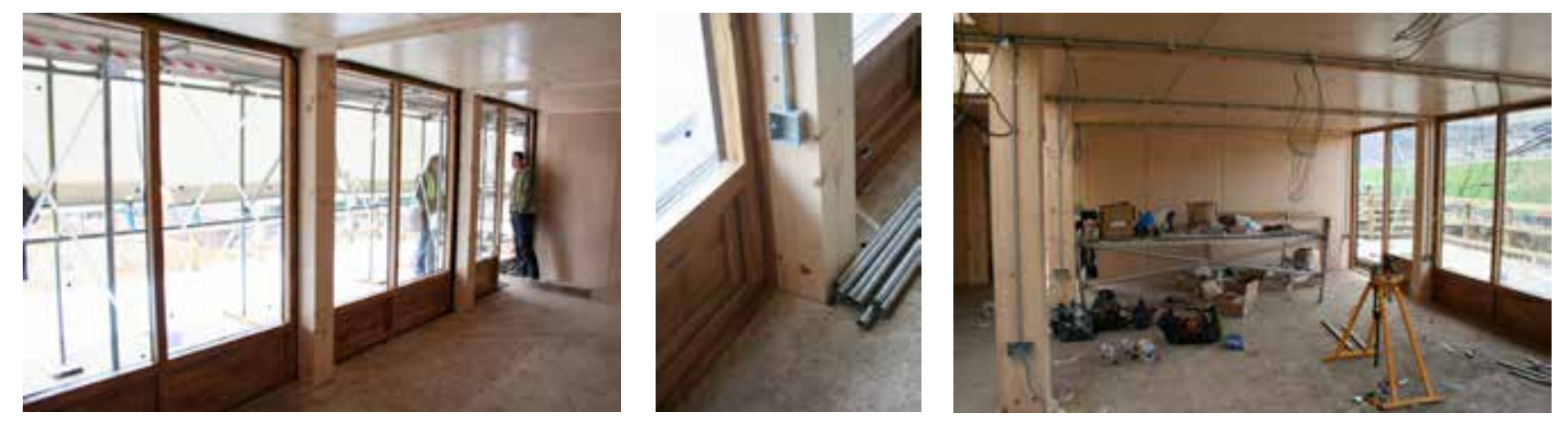

storage wall.

RIGHT

Fig 9.90 Furniture and fittings

a. SIPs doors with viewing panes hung between office and classroom.

b. Birch plywood storage wall is fitted along the back wall;

c. Storage wall is fitted with Sundeala board clad (ns a pin board

d. Birch plywood desk installed in office.
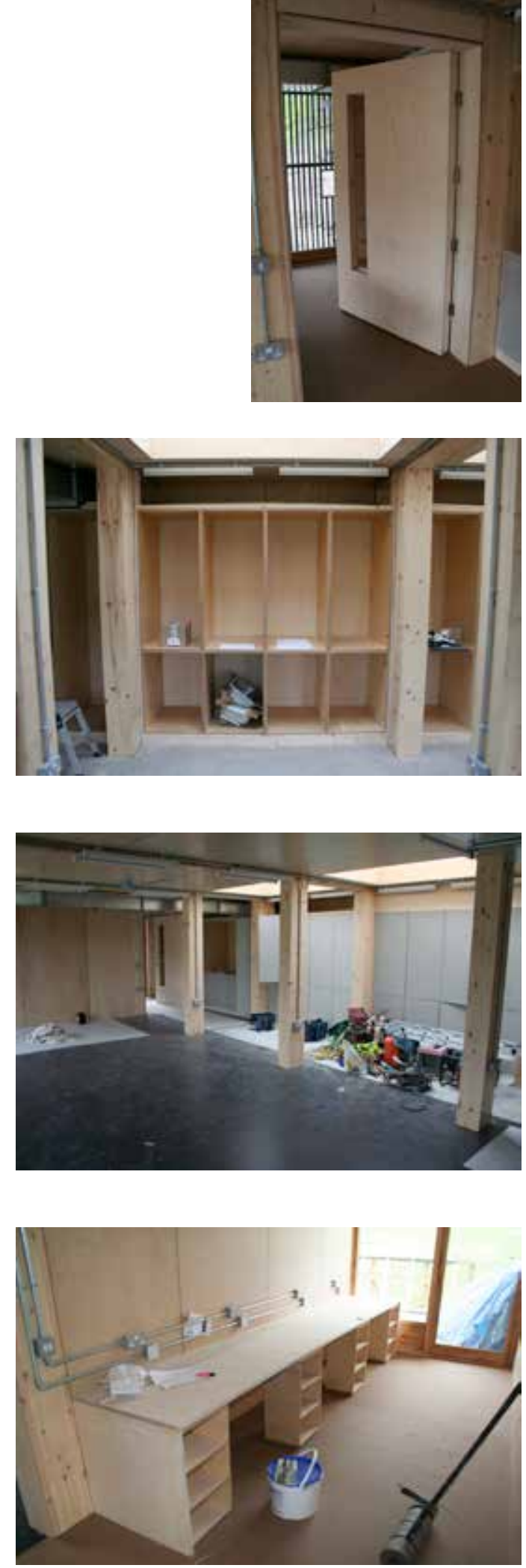

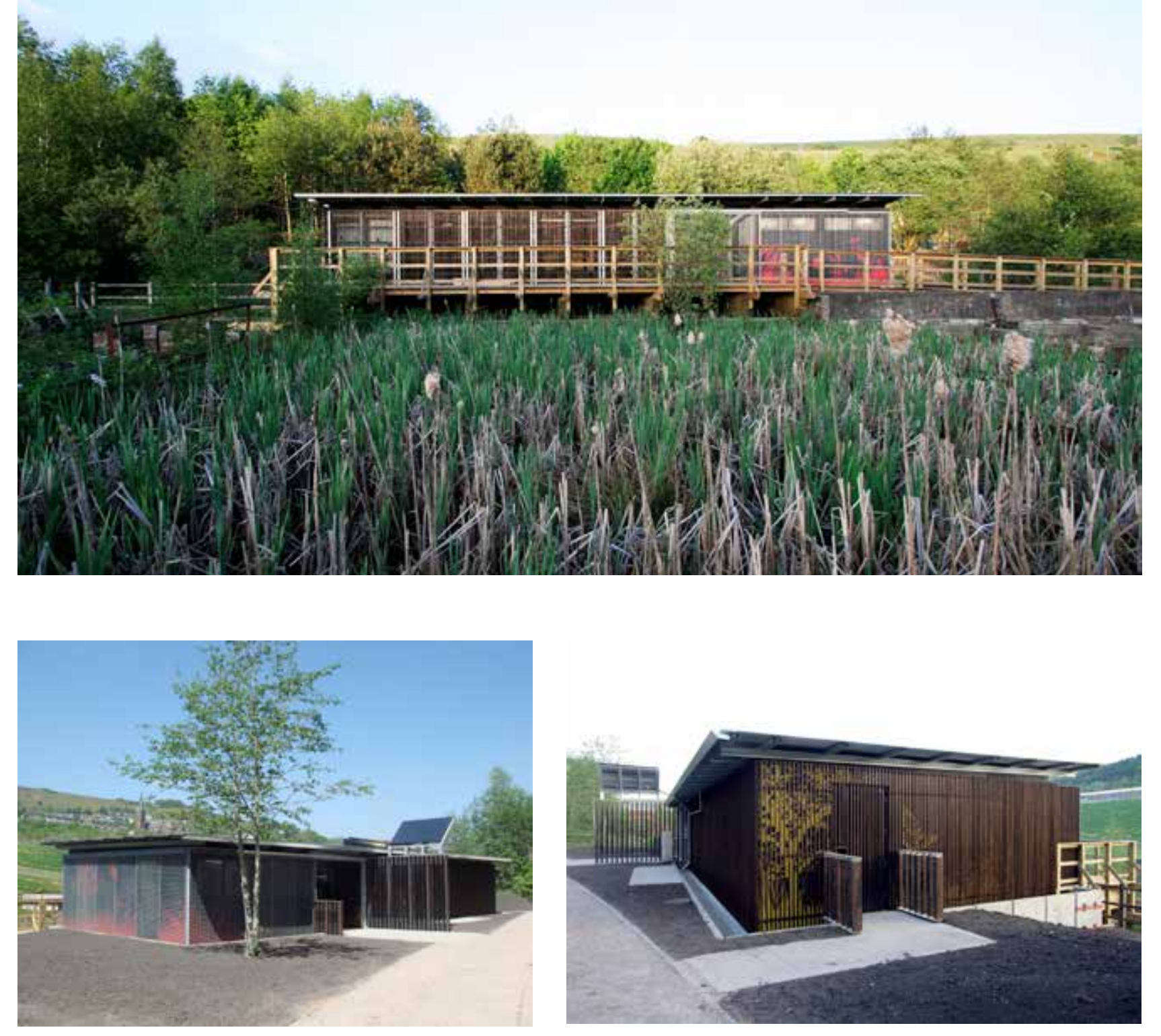

LEFT (top - bottom)

Fig 9.91 View across filtration ponds to

west elevation

Fig 9.92 View on arrival from southpanel entrance screen.

Fig 9.93 Northern view of charred cladding over murals and hidden door to office.

Fig 9.94 View of boardwalk and vertical charred timber shutters at night.

Fig 9.95 Entrance view at night. Fig 9.96 View from entrance deck down circulation spine.
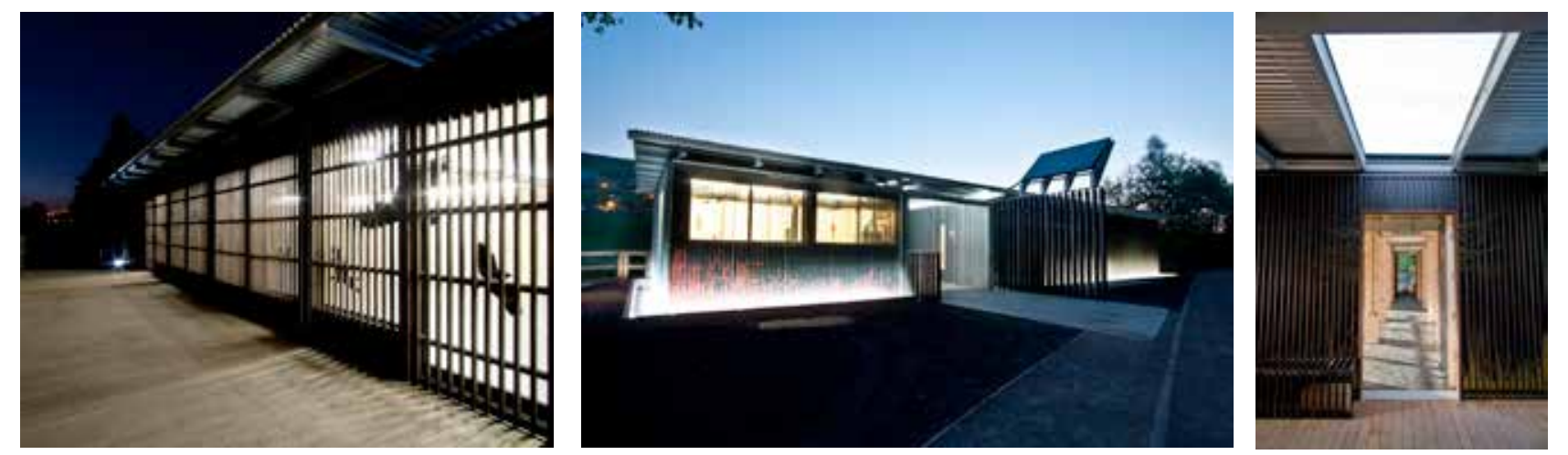

RIGHT TOP-BOTTOM

Fig 9.97 View of glazed screen looking across reed beds and Green Valley.

Fig 9.98 Rear storag board doors across empty classroom.

Fig 9.99 Birch plywood toilet doors Fig 9.100 Detail of charred cladding
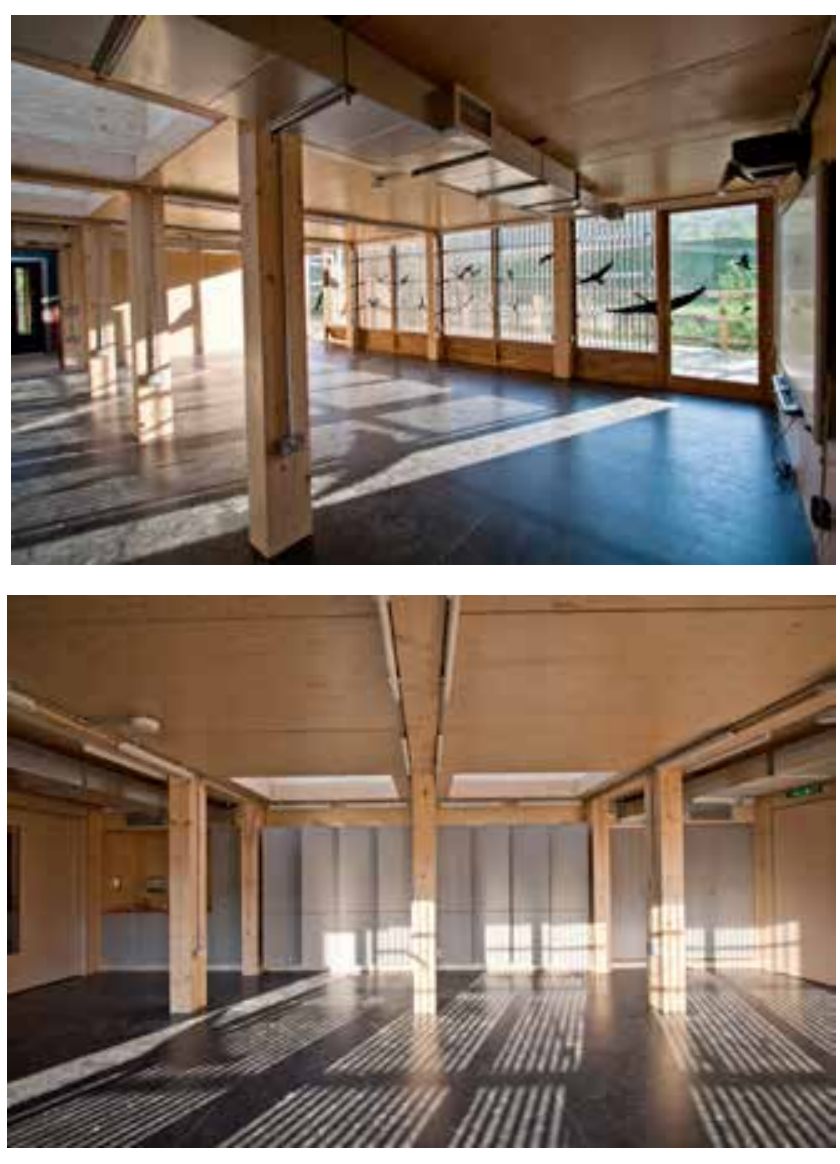
with murals behind.
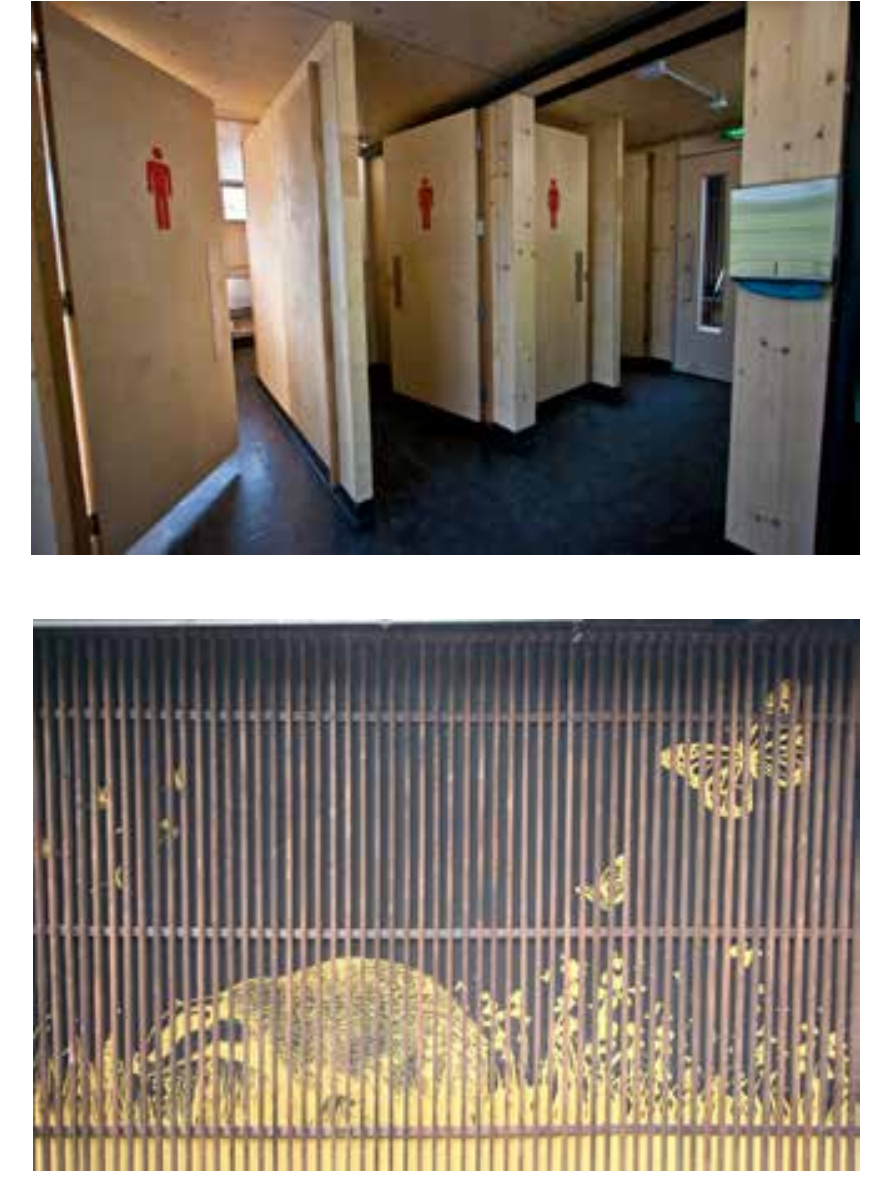


\subsubsection{Observations and reflections}

The ERC successfully integrated a complementary range of components to work together to create a simple layered, but elemental construction that evoked the history and wildlife of the site. The SIPs panels were lightweight and complementary to the box section components but the bespoke fabrication, plywood glues and EPS insulation manufacturing leaves questions about the sustainability and replicability as a low-tech construction solution. Further technical outcomes were revealed during this prototype for consideration in the design of future Ty Unnos buildings:

\subsubsection{Species performance and adaptation}

\section{SPECIES}

- The ERC incorporated the following timber species and timber products:

- Welsh-grown Sitka spruce - box section post and beam structure, charred cladding.

- Welsh-grown oak - laminated small sections for the windows, entrance decking.

- Imported birch and spruce plywood - SIPs panels for floor, walls, roof and doors and storage units.

- Oak laminated windows successfully re-implemented previous research into Welsh wood windows using small sections and lengths of local hardwoods.

- The Welsh-grown Sitka spruce was found to be difficult and time consuming to machine causing extremely high machine and tool wear due to the hardness of knots causing cutters to break. This led to delays in delivering the components to site.

- Consideration is needed when using non durable timber species, such as Sitka spruce and birch plywood, as prefabricated primary structure and exposed final finish to avoid water marks and staining. This either limits the window of construction or, as in the case of the ERC, requires enclosed storage containers and a fully enclosed scaffolding tent over the construction site to protect all the exposed finishes and allow construction to continue, subject to deliveries and access.

\section{TIMBER ADAPTATION}

- The largest, tested size of box section posts and beams were used, and increased in length to $7.2 \mathrm{~m}$ to reduce the number of components and for ease of construction and transportation. Beams were propped at the $4.8 \mathrm{~m}$ point by box section posts.

- Charred timber used ungraded, low value spruce. The building was completed in 2009 and the cladding is still protected by its charred finish, although after 
a year the rain had continued to wash away more of the loose surface leaving the cladding a lighter brown than had originally been intended.

- Since the ERC was completed and published, there has been interest, from other practices, about the use of charred timber as a durable, low-cost cladding, although difficulties exist with the lack of specification details and warranties.

\subsubsection{Building envelope}

The ERC met planning and building control approval and the clients and end users requirements. Feedback since its completion has been positive, generating increased awareness of Welsh forestry and sustainable building methods.

\section{INTEGRATION WITH COMPLETE ENVELOPE}

- Welsh-grown timber has been incorporated into all aspects of the building envelope: superstructure for frame, walls, floor and roof, external joinery, claddings and internal finishes. Furthermore, the prefabricated and low energy building system has been exposed and celebrated as part of the educational programme of the centre.

- While services were exposed in this building, the construction has highlighted potential problems with services integration on other types of building where exposed services would not be desirable or practical. The exposed galvanised steel conduit has also added cost that is traditionally lost in service voids.

- Pre-applying the EPDM rubber to SIPs panels was explored, but the trade cross-over between off-site and on-site and the number of joints to seal made this complex and costly. The EPDM rubber was therefore applied on-site as the watertight barrier.

- The use of EPDM was acceptable with a thermal envelope made from impermeable insulation, but this would not allow a structure with mineral wool insulation to breath. Alternative, lower embodied carbon approaches may need to be considered.

- The level threshold was detailed by using the natural fall to the site, but a large cutting was required to allow for underfloor ventilation - this would need refinement for future projects.

\section{PERFORMANCE REQUIREMENTS}

- The ERC successfully met the $60 \%$ reduction over Part $L 2006$, partly due to the $225 \mathrm{~mm}$ thick SIPs panels achieving a U-value of $0.15 \mathrm{~W} / \mathrm{m} 2 \mathrm{~K}$ and the EPDM rubber eliminating air leakage around components.

- The ERC has not been environmentally monitored, although there have 
been problems with fluctuating temperatures. This was partly related to

the unfamiliar heating system (the air-source heat pump) but also down to a lack of thermal mass within a very lightweight construction system. Further research is required on the incorporation of thermal mass into the complete timber envelope.

- The use of Envirograf, a fire retardant combined with hard wearing varnish for the internal finish has offered a resolution to the concerns raised in the findings from the Mezzanines, stress-lam system and Eisteddfod pavilion. Although questions about the need for the fire protection, especially in a small single-storey structure, are raised when compared to equivalent timber structures in the Vorarlberg that do not have any applied fire protection. Instead the charring properties of the timber are used to predict and understand the effects of fire.

\section{CLADDINGS \& FINISHES}

- The charred cladding is predominantly decorative, with the mural panels providing the rainscreen and the EPDM rubber providing the water tight barrier. This was sensible for a first prototype of this form of treatment and acknowledging the risk the clients have taken. Further research is required on the performance of charred softwood in a full rainscreen cladding system.

\subsubsection{Technology and skills}

\section{FABRICATION}

- The completed system was not manufactured locally, although it used spruce sourced from BSW sawmill in Wales. At the time of construction, only Cowley Timberwork, based in Lincoln, were in a position to fabricate the box section components.

- Cowley Timberwork are a well established, award winning joinery business that have worked on some of the most innovative timber projects in the UK. However there were 2 difficulties that would likely cause significant problems with manufacturing in an equivalent Welsh workshop: The accuracy of machining the spruce boards for lamination due to twisting along the board and the SIPs panels were a non-standard size resulting in multiple processes to cut, plane and profile a $225 \mathrm{~mm}$ panel. Both problems were overcome, however as a low-tech system, these difficulties will need to be resolved. Cowley Timberwork were confident that these problems could be resolved. 
CONSTRUCTION

- The choice of end-grain bolting was successful and aided the simple, no crane construction process. The frames and panels were erected in 10 days with the rubber membrane, M\&E, fit-out and bad weather adding considerable time to the programme. However, each connection was still relatively time consuming requiring careful consideration of torque settings to avoid over-tightening and compression of the spruce and careful alignment to ensure all components fitted within small tolerances. The ' $L$ ' shaped connector has the potential to reduce this on-site accuracy to just assembly.

- Exposing internal finishes creates a difficult time consuming and costly construction process to protect from rain, snow and accidental site-work damage. The soft and compressible spruce posts in particular were vulnerable and showed signs of strap marks and other indentations.

- As illustrated in section 10.5.2.2, the components could be easily lifted and moved into location by $2-4$ people.

\subsubsection{Tectonic form}

The project was presented to the Design Commission for Wales (DCfW) during the planning process, receiving a positive response to the primary objective of using

locally sourced Sitka spruce as a sustainable approach to construction.

\section{COMPOSITION AND FORM}

- The principle of a simple, elemental, component based construction worked well to provide a didactic building envelope that expresses the prefabricated, panelised construction and also responds to the context of the site. The expressed Ty Unnos structure, services and renewable technologies are used as part of the overall environmental awareness within the activities of the centre.

- However, the elemental construction is slightly lost in the external cladding layers of EPDM rubber, mural graphics and over cladding of charred timber and steel mesh. This is partially a result of the design intentions for ghosted super-graphics of wildlife. The roof is more successful as a separated galvanised steel rainscreen.

DETAIL

- Internally, the tectonic intention was to eliminate unnecessary layered finishes and expose where possible the materials of construction. This posed a few problems, including: protecting the finishes during construction and a 


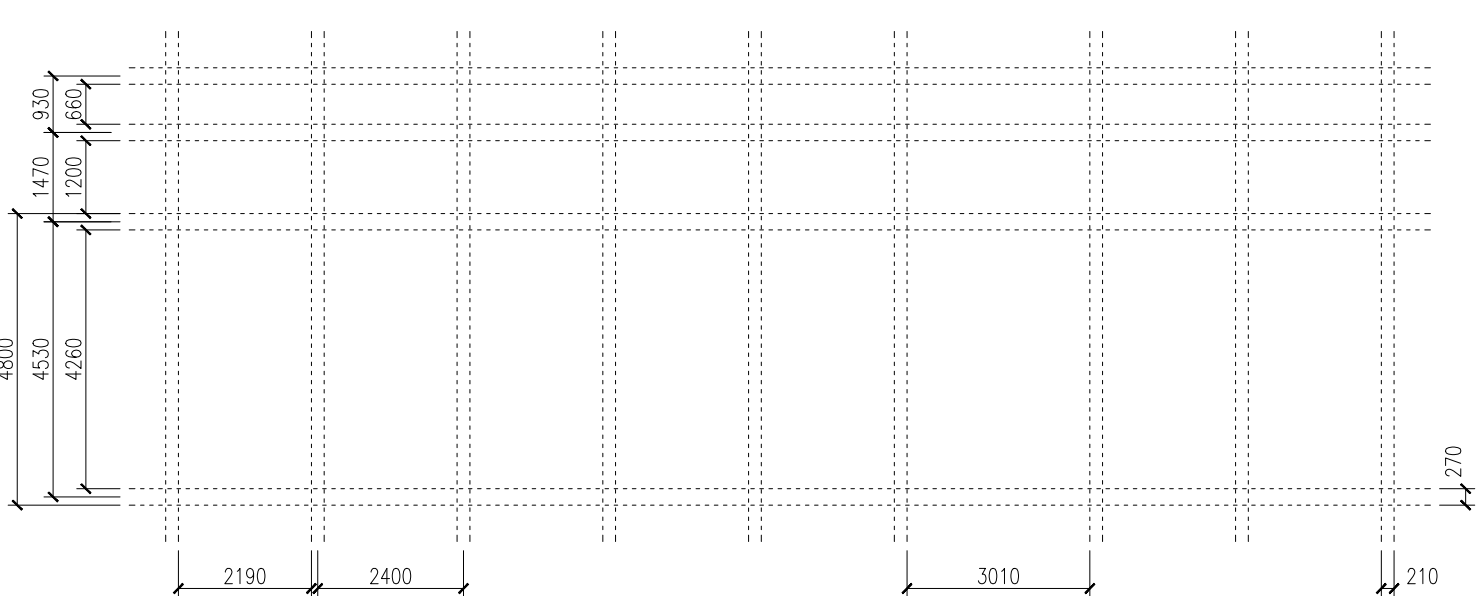

harsh winter; maintaining regular shadow gap tolerances between the connection of primary structural components, that in other forms of construction would be hidden; and the upfront design detailing to coordinate hidden fixing details to maintain a visually minimal surface. These processes are costly and likely to be bespoke to each project. A system build approach would likely result in more internal layers with less accuracy required to the quality of the structural system.

\section{DIMENSIONAL COORDINATION}

- The ERC was designed on a tartan layout grid of $1200 \mathrm{~mm}$ spatial zones and 210 or $270 \mathrm{~mm}$ structural zones dependant on direction and alignment with the box section posts. The grid is directly informed by the plywood board size limitations of the superstructure components $-2400 \times 1200 \mathrm{~mm}$. As observed in the Eisteddfod pavilion, the span limitations do not always lend themselves to spatial requirements.

- The $2400 \mathrm{~mm}$ plywood dimension limited the floor-ceiling height. This is acceptable for children but may be on the limit for adults especially with the surface mounted air ducts lowering the effective ceiling height further.

\section{CORPOREAL}

- The vast area of exposed timber, creates a warm and soft environment for education. This has been particularly commented on by visitors as a pleasant calm and natural, but robust environment for children. 
Following the funding secured through the Technology Strategy Board (TSB) bid for low impact building systems, in 2009, a fully developed and regulatory compliant 2 bedroom, 4 person house was designed and built as the focal point for testing the complete integrated system using a local supply chain. The commission was won through an open design competition conducted by the Welsh Future Homes project partners and was opened by the Welsh Minister for the Environment in August 2010.

This was the final prototype in the series of Ty Unnos constructions to test the refined Sitka spruce components. The primary focus was on the construction of an affordable dwelling using a completely integrated timber system entirely from the local supply chain:

\section{Welsh Longhouse}
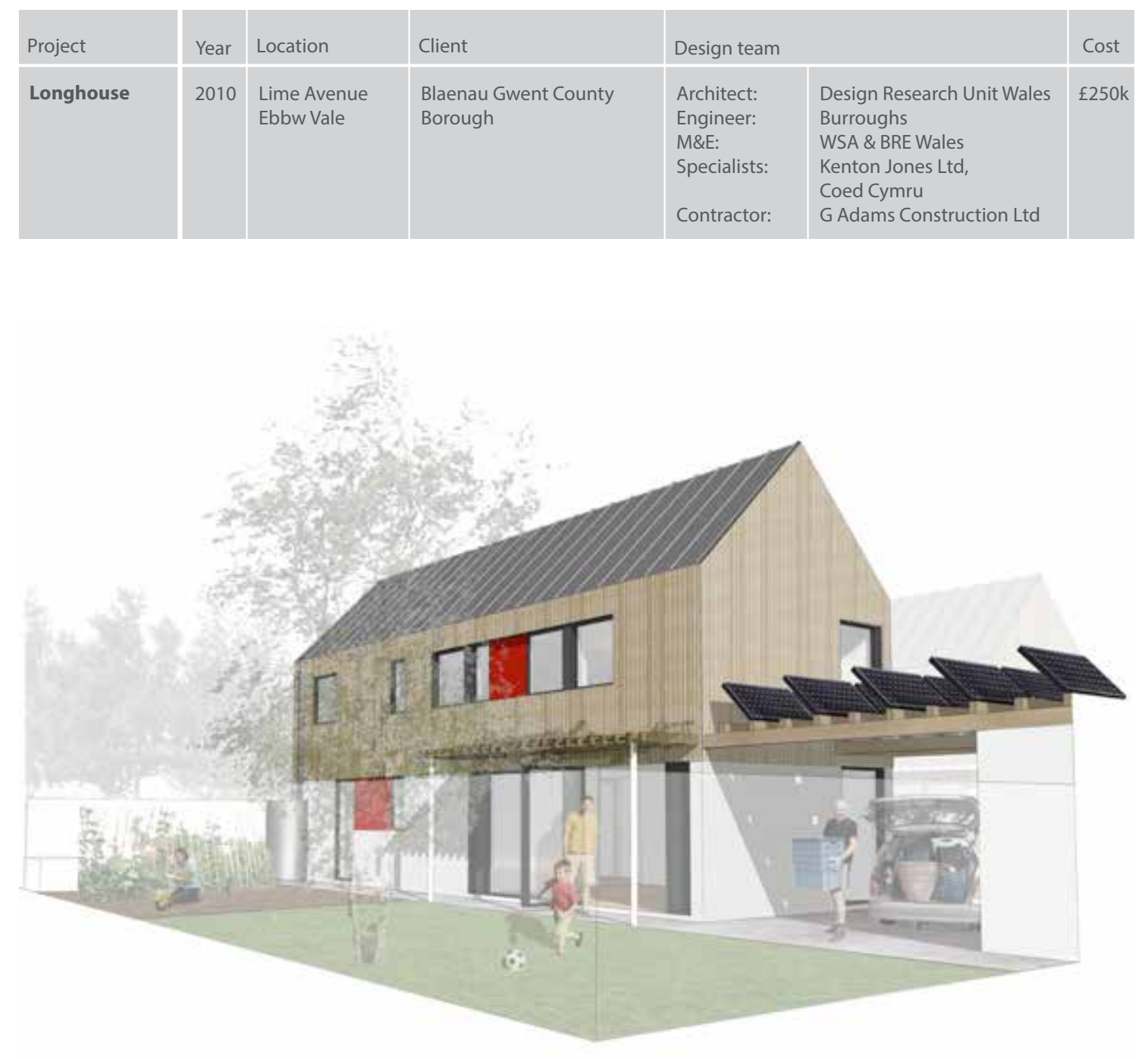

Fig 9.103 Longhouse project details table

Fig 9.104 Proposed perspective of Longhouse south elevation
- An affordable house meeting Welsh Government Design Quality standards

- a raft foundation and minimum $150 \mathrm{~mm}$ requirement of timber structure above ground level;

- a 2-storey structure with loft;

- infill panels with ground to roof OSB racking resistance;

- $\quad$ softwood and steel inner connecting sleeves with steel brackets and plates;

- Welsh chestnut low energy windows; and

- green Welsh chestnut cladding.

- Longhouse principles of form and space

\subsubsection{Design}

9.6.1.1 Brief

The development is the result of a partnership between BRE Wales, the Welsh Assembly Government, The Works at Blaenau Gwent County Borough Council and United Welsh Housing Association. The overall aim of the project was to stimulate the development of a low carbon built environment in Wales but also to kick-start a 'green' economy. Funded by the Heads of the Valleys Programme and The Works, this longhouse was designed as part of a 'mini community' comprising three other sustainable homes.

The original competition brief was for either an affordable 2 bedroom starter home and/ or a 3 bedroom family home on adjacent plots. Proposals were to showcase the latest developments in low energy design while meeting all the statutory requirements of an affordable home to be owned and rented by United Welsh Housing Association (UWHA). The houses were to be opened to the public for 2 years 

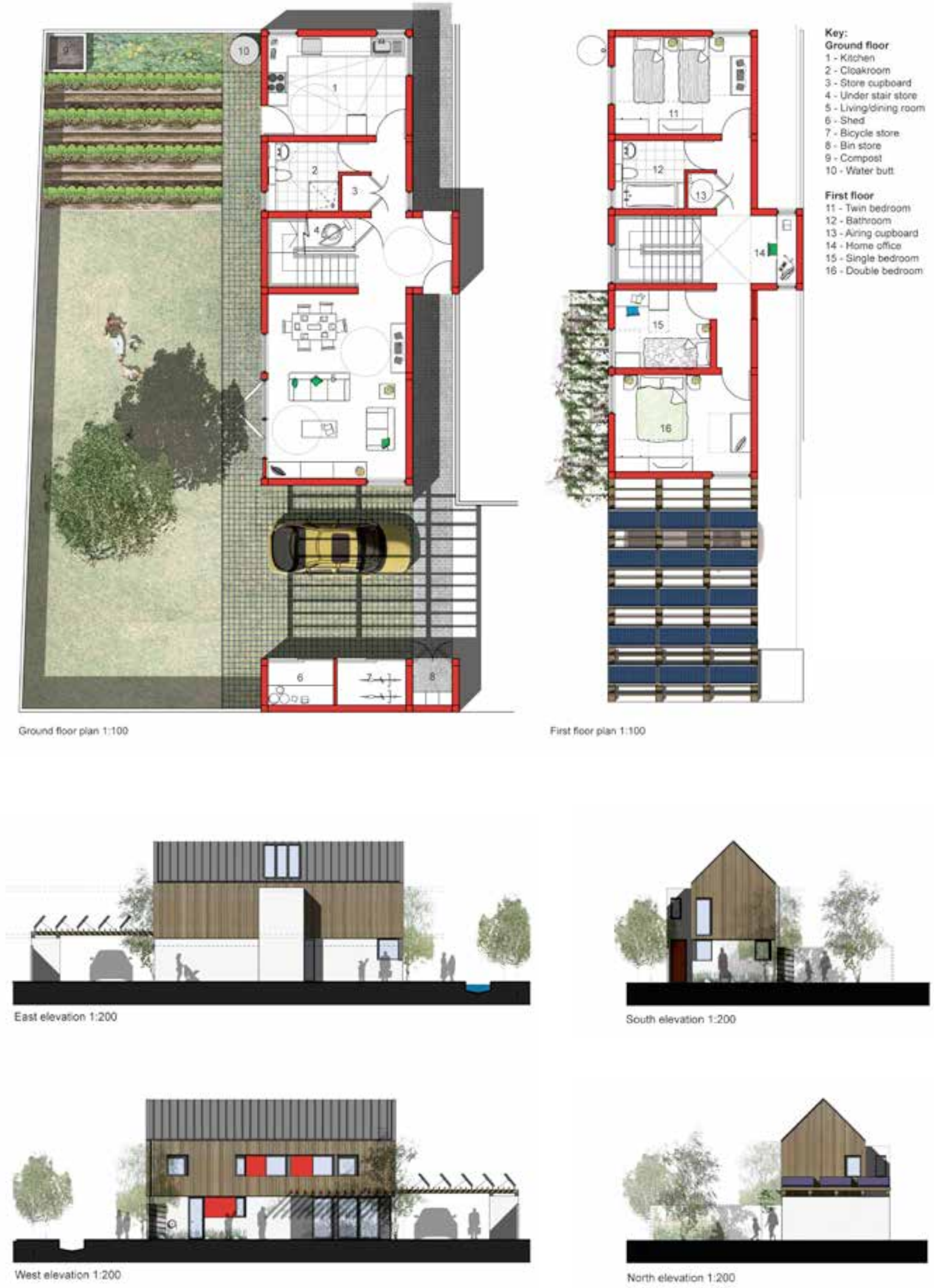

LEFT

Fig 9.105 Original 3bedroom, 5 person, competition design proposal as demonstration homes before being made available for monitored living for a year and then part of UWHA social housing. This design brief included:

- The house must be between 2 and 4 storeys

- Houses must fit within the site boundaries for each house and be compliant with the DQR standards and Lifetime Homes for internal and external space requirements.

- Comply with The Works Design Code to source local, sustainable materials including a $100 \%$ sourcing of materials with a Green guide rating of B or above.

- Achieve Code for Sustainable Homes Level 5 and meet the Passivhaus space heating standard of less than $15 \mathrm{kWh} / \mathrm{m} 2 /$ year.

- To be within the budget of $£ 1200 / \mathrm{m} 2$ excluding renewable technologies and land cost. This was comparable with current social housing construction costs.

- To be delivered in time for the opening of the Eisteddfod Festival, being hosted in Ebbw Vale, in August 2010.

Following the competition, the design team were offered the opportunity to build on a 3rd site to provide an initial visitor centre for the Works, that would be later converted to a house for the open market. The revised brief was for a 2 bedroom, 4 person house to meet the original brief specification with the following differences:

- All materials and labour to be sourced locally, wherever possible.

- The building to initially provide an exhibition space and a meeting room.

- To use and showcase the Ty Unnos construction system

- To be built and owned by Blaenau Gwent County Borough Council with a revised budget of $£ 250000$. 

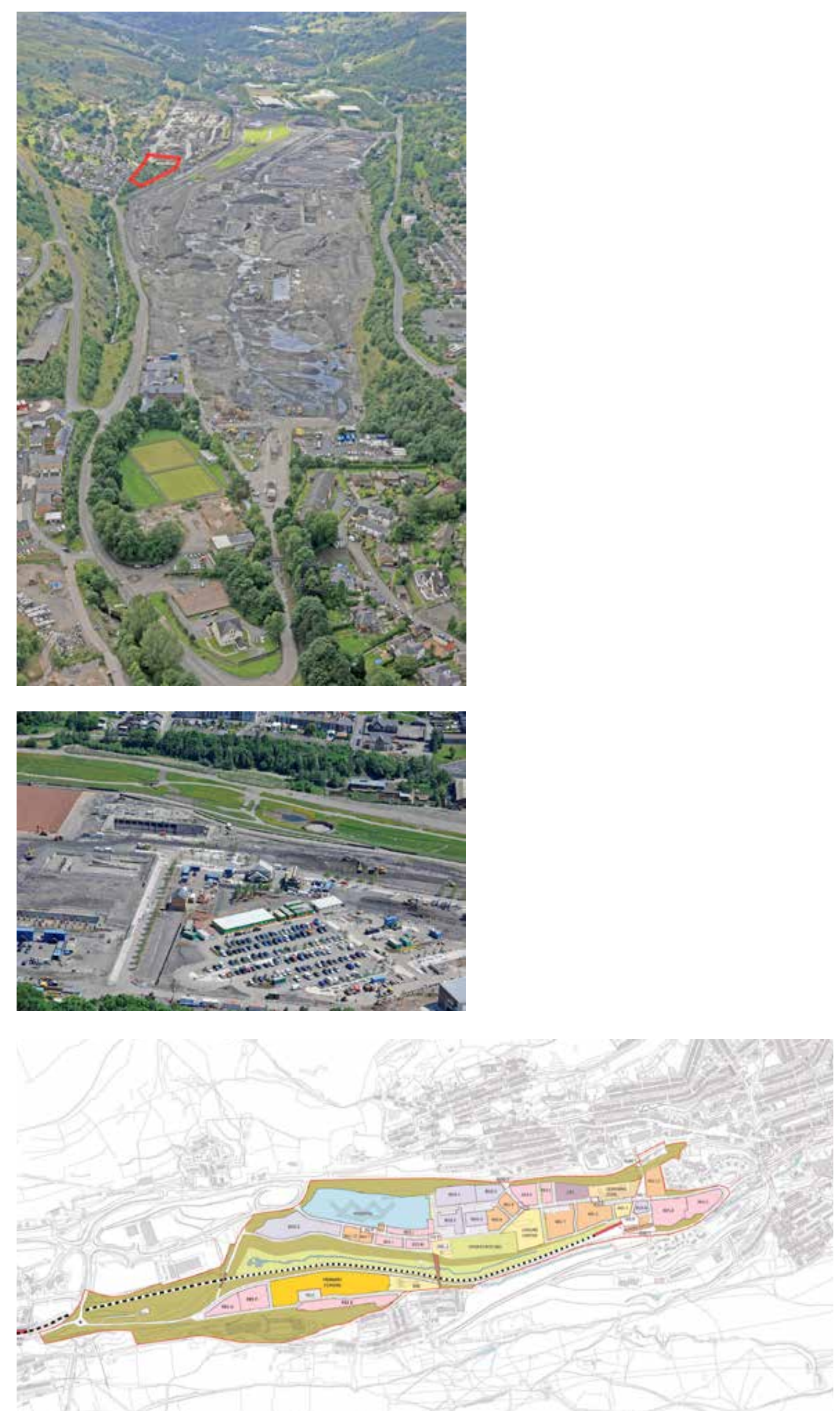

\subsubsection{Site}

The site for the house was to the west of the Environmental Resource Centre but divided by the Green valley. As such, the site is on the same remediated postindustrial landscape of the former steelworks. This particular area of The Works is surrounded by many retained basement structures to be re-used as part of future development works.

The plot was located within area $1 \mathrm{~F}$ of The Works masterplan, in Ebbw Vale. At the time of entering the Welsh Future Homes competition, the only context was the

Ysbyty Aneurin Bevan Hospital to the south-west and the recently landscaped and planted Green valley to the east. The rest of the site including the access road was under construction.

As part of the masterplan, to the east of the plot is Main Street South, later to be named as Lime Avenue. To the west of the plot is an internal access road and beyond that lies area 1B which contains the hospital and its grounds. An access road is immediately to the north of the plot, followed by plots 1-5 to contain other demonstration houses. To the south is a vacant strip of land to be developed for housing in the future.

The overall steelworks site is a large regeneration area which will be a comprehensive mixed use development delivered over the next decade having good public transport links. Specifically, land has been allocated for a rail extension onto the site from the existing Ebbw Vale Parkway Station which already provides rail access to the major employment centre of Cardiff and beyond. It was, therefore expected that the site would be well provided with bus services and have good links with Ebbw Vale town centre. The site will develop over the next few years and it is anticipated that the plot will be well served by amenities and green spaces.

LEFT

Fig 9.106 Aerial photograph of The Works during land remediation

Fig 9.107 Oblique aerial photo of Welsh Future Homes site during construction

Fig 9.108 The Works masterplan. The housing site is labelled RES J. 

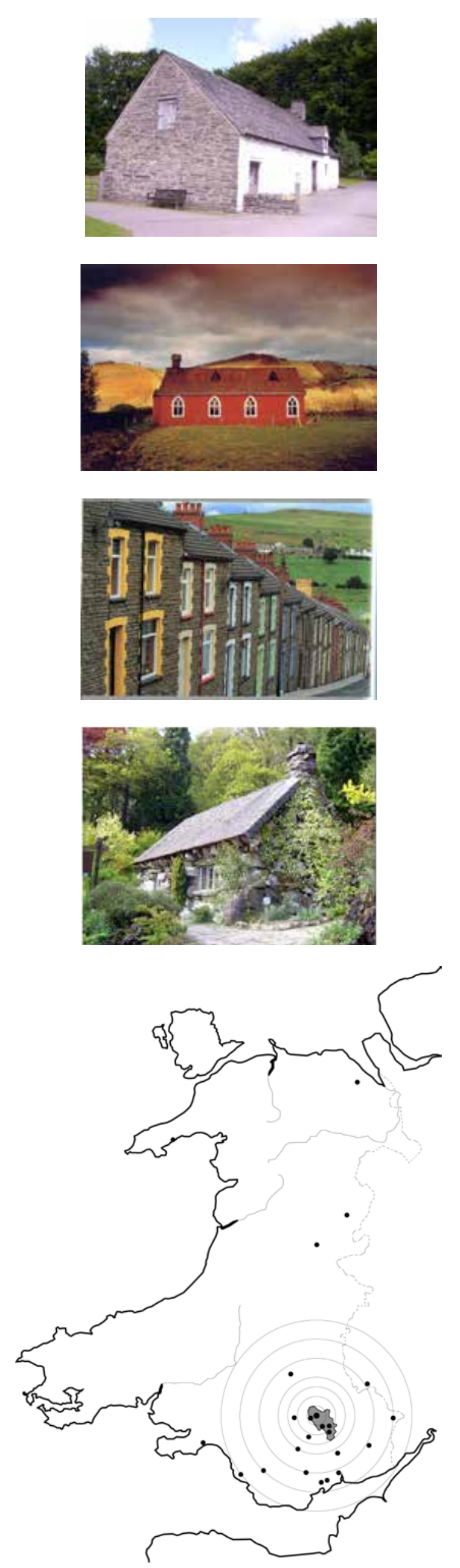

ABOVE

Fig 9.109 Longhouse concept strategy

LEFT TOP

Fig 9.110 Vernacular longhouse - Cilewen Farmhouse

Fig 9.111 Simple forms - St David's Church, Gaufron, Powys

Fig 9.112 Composition

Fig 9.113 Traditional Ty Unnos - The 'Ugly' house near Betws y Coed.

FOTTOM

Fig 9.114 Map of material sources and suppliers in Wales used in the Longhouse construction.

\section{Design strategy}

This proposal was a development on an initial prototype house type, in section10.3, and the Smithsonian pavilion design while inspired by the local context of Ebbw Vale and the wider context of Wales. It was to provide a model of economic, social and environmental sustainable housing for The Works site. The primary concepts were inspired by a reinterpretation of the Welsh vernacular:

\section{- The longhouse}

The house is a re-interpretation of the traditional Welsh longhouse vernacular for the 21st century. The linear house looks south across its garden to the hills beyond with both access and internal circulation along this edge. Ground and first floor primary rooms are located along this edge at either ends of this axis with WC and bathroom in the centre on the north elevation.

\section{- Simple forms}

Drawing on the simple forms of Welsh barns, longhouses and farm buildings, the house aims for a simplicity of planning, materials and detailing. A restrained but elegant palette of vertical timber cladding, white render and standing seam roof are used to develop a contemporary interpretation of traditional vernacular buildings.

- Composition

The addition of colour to a terraced house is a common way of personalising Welsh Valleys housing, with examples close to the site in Ebbw Vale. The houses will use colour to add personalisation, in this case coloured panels will be used on the elevations of the dwellings themselves. Different shades of colours could be used on different dwellings to add individuality.

\section{- Ty Unnos}

As well as the construction system being prototyped the design evoked the sense of the Welsh tradition of building 'a house in one night' with several original Ty Unnos houses existing in the Ebbw Vale area.

\section{- Materials}

It was agreed early on between DRUw and Blaenau Gwent County Borough Council that the design would aim to be a locally made house using local supply chains from within the Ebbw Vale or Blaenau Gwent area and then progressively looking wider as required. Approximately $80 \%$ of materials, suppliers, manufacturers and products were sourced successfully within a 40 mile radius of Ebbw Vale. 


\subsubsection{Design development}

The design of the longhouse was influenced by the following decisions that either influenced the use of Welsh-grown timber in the complete timber building envelope or affected the resultant design:
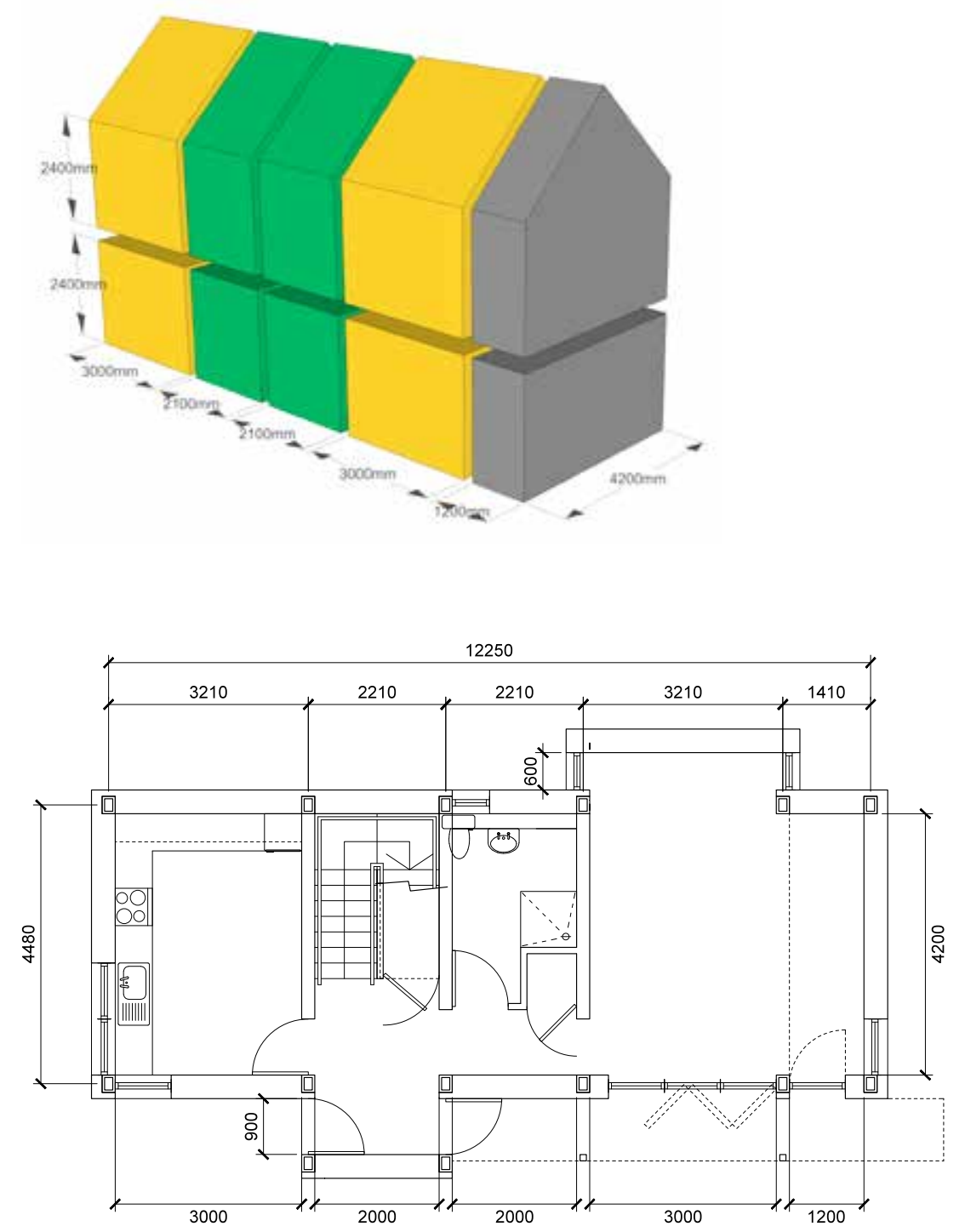

Fig 9.115 Ty Unnos modules arranged as a 2-storey longhouse.

BOTTOM

Fig 9.116 Ground floor plan

highlighted frame centres and bay sizes.

\section{Plan and sectional form}

- The house plan is determined by the longhouse orientation and span limitations of the box section components and intermediate floor cassettes.

- The intention was to test the system as originally intended - spatial modules defined by the structural bays with flexible infill panels to allow for wall, window and door positions. Internal room divisions determine the sizing of the structural bays so that walls align with the structural grid.

- The intention was to use a proposed $600 \mathrm{~mm}$ layout grid to complement module and component sizes.

- As a 2-storey Ty Unnos structure, the house width was limited to a maximum portal span of $4.5 \mathrm{~m}$, centre to centre, leaving a $4.2 \mathrm{~m}$ spatial width. Longitudinally the modules were limited to a maximum $3 \mathrm{~m}$ spatial span due to the floor structure. The rooms are divided into the following longitudinal spatial zones: $3 \mathrm{~m}$ for kitchen and twin bedroom, $2 \mathrm{~m}$ for entrance and stairs, $2 \mathrm{~m}$ for WC, bathroom, storage and services, $3 \mathrm{~m}$ and $1.2 \mathrm{~m}$ for the master bedroom and living/ dining room. The small $1.2 \mathrm{~m}$ module was a result of maximising internal space within the site constraints.

- The straightforward longhouse is broken by two flat roof bays: one $600 \mathrm{~mm}$ deep, single-storey dining bay to provide more space to the living area and a connection with the northern elevation; and a 900 mm deep, 2-storey entrance bay and home-office space above.

- The sectional form was determined by the standard timber board sizes,used to sheath the wall cassettes, timber sizes and layered finishes. Therefore a ground floor - ceiling height of $2.3 \mathrm{~m}$ was achieved. This was okay for the ground floor, but the design team were concerned that the first floor would feel limited if restricted. The two bedrooms were opened to the ridge within the $4.2 \times 3 \mathrm{~m}$ modules. The stair, landing and bathroom were limited to $2.2 \mathrm{~m}$ with a vernacular inspired 'crog' loft above for extra storage and space for mechanical ventilation ducts.

- As a demonstration house, it was decided that the $1.2 \mathrm{~m}$ end bay would not have an intermediate floor and be left open as a master bedroom mezzanine to the living room below.

- The design incorporated natural and modular material finishes wherever possible: board and taped plasterboard finishes to reduce wet trades and drying times, Welsh slate ground floor, Welsh-grown sycamore first floor 
and stair, oak internal window sills, sweet chestnut cladding, laminated chestnut windows, Urban Colourcoat standing seam roof.

\section{Environmental performance}

The longhouse principle exploits a fabric first approach, wrapping up to the north and facing south with all principle rooms having south facing windows, and a south facing garden. This is combined with a high performance thermal envelope influenced by Passivhaus energy performance standards, but adapted to use local products and suppliers. The resultant design proposed the following energy performance measures to reach a Code for Sustainable Homes Level 5 with an emphasis on a fabric first approach:

- Walls and floor $\mathrm{U}$ values $0.12 \mathrm{~W} / \mathrm{m} 2 \mathrm{~K}$, roof $\mathrm{U}$ value $0.10 \mathrm{~W} / \mathrm{m} 2 \mathrm{~K}$.

$0.8 \mathrm{~W} / \mathrm{m} 2 \mathrm{~K}$ triple glazed composite windows.

- Total energy demand for space heating and cooling $<15 \mathrm{kWh} / \mathrm{m} 2 / \mathrm{yr}$.

- Mechanical ventilation with air source heat recovery and solar hot water for water heating demand.

- Ty Unnos system details are designed to achieve air permeability of $1 \mathrm{~m} 3 / \mathrm{hr} / \mathrm{m} 2$ at $50 \mathrm{~Pa}$ as well as reducing thermal bridging.

- Lighting: $100 \%$ low energy fittings throughout.

- A++ labelled white goods.

- Cycle storage for 2 bikes.

- Designated home office.

- $\quad 20 \mathrm{~m} 2$ Photovoltaic array

- $4 \mathrm{~m} 2$ Solar hot water array
LEFT TOP

Fig 9.117 Environmental concept - wrap-up warm and face south

Fig 9.118 Exploded diagram of competition house design and intended environmental strategy. 


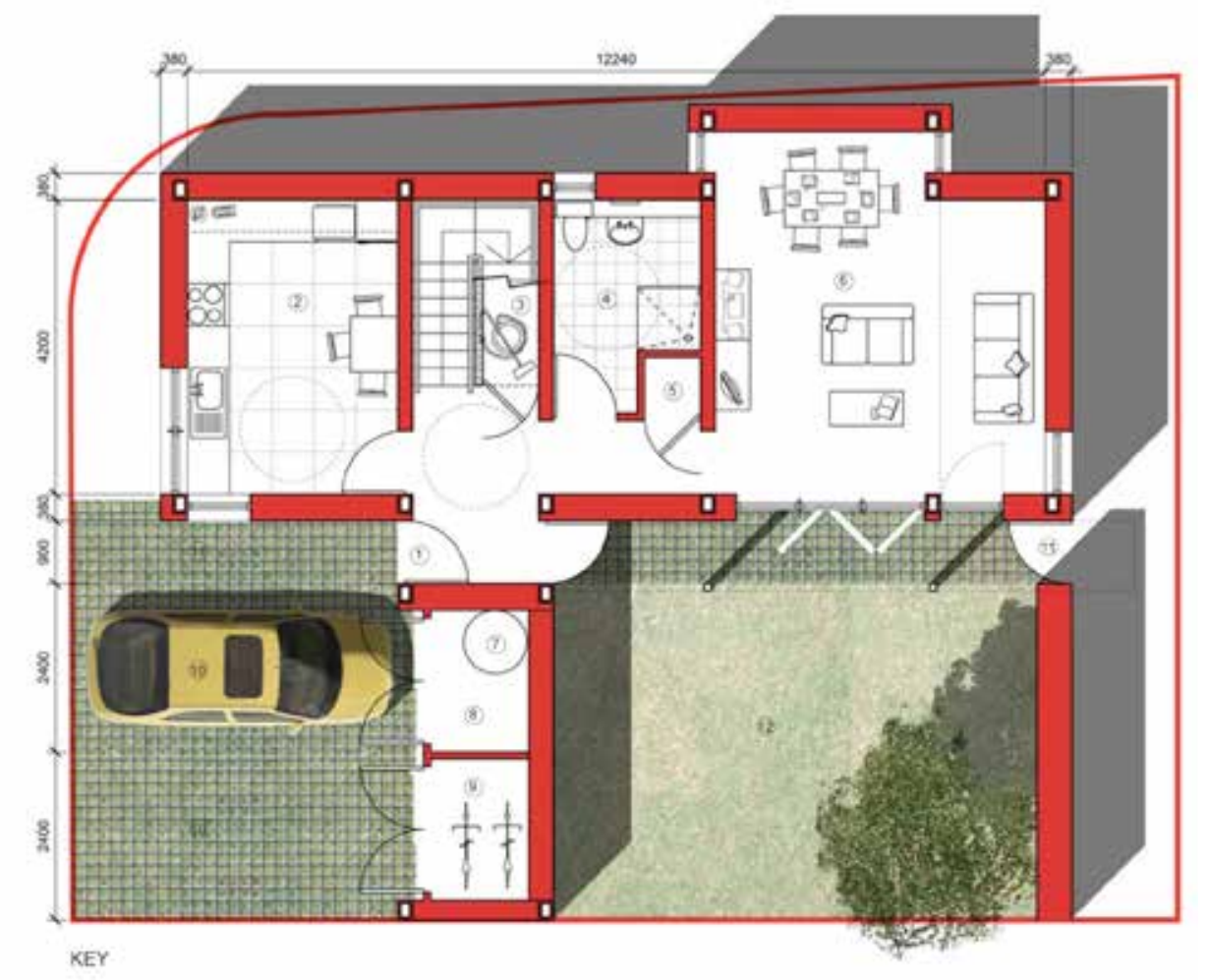

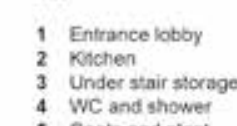

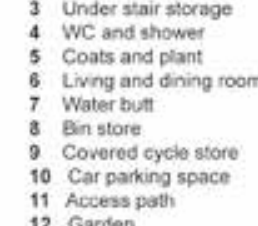

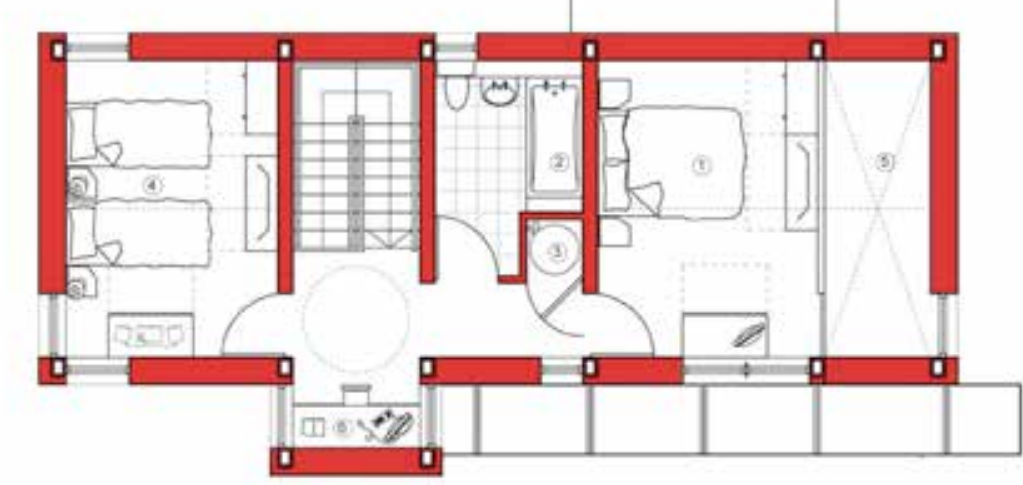

1 Master bediocm

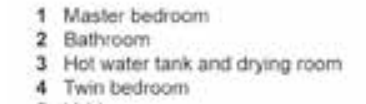

4
5
6
6
6 Hodere ontrice

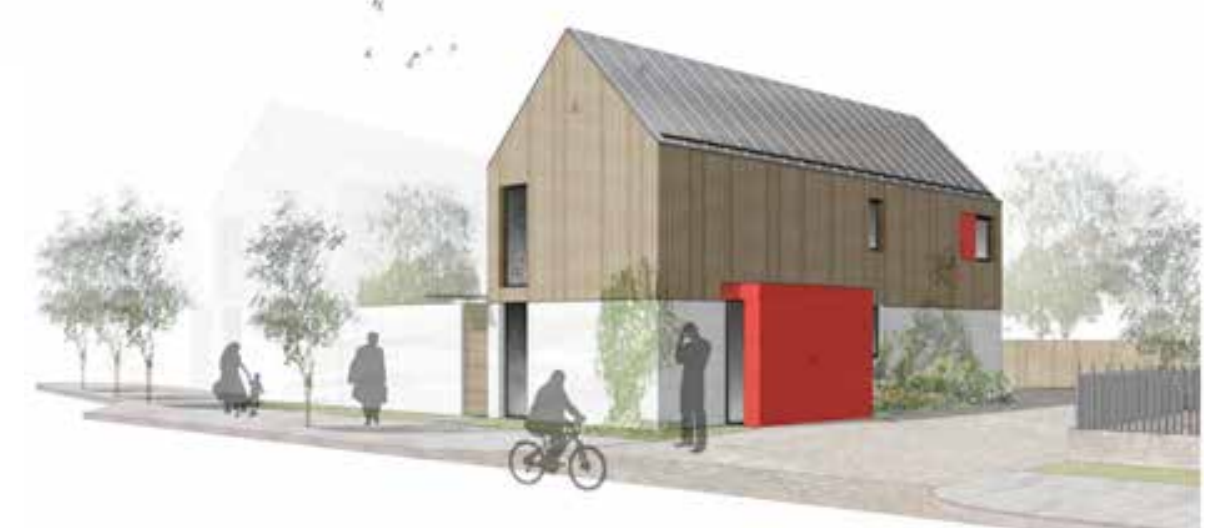

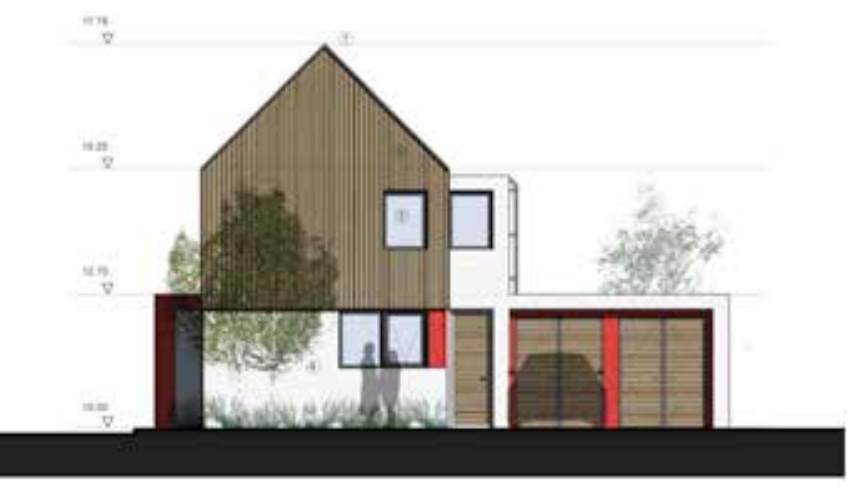

LEFT

Fig 9.119 Floor plans

a. Ground floor

b. Fist foor

Fig 9.120 Perspective of longhouse from

RIGHT

Fig 9.121 Proposed elevations

a. West elevation

b. East elevation

c. North elevation with reduced

number of openings.

d. South elevation

BELOW

Fig 9.122 1:50 Model of

proposed design.

This model was

made to explore the

construction $\mathrm{p}$
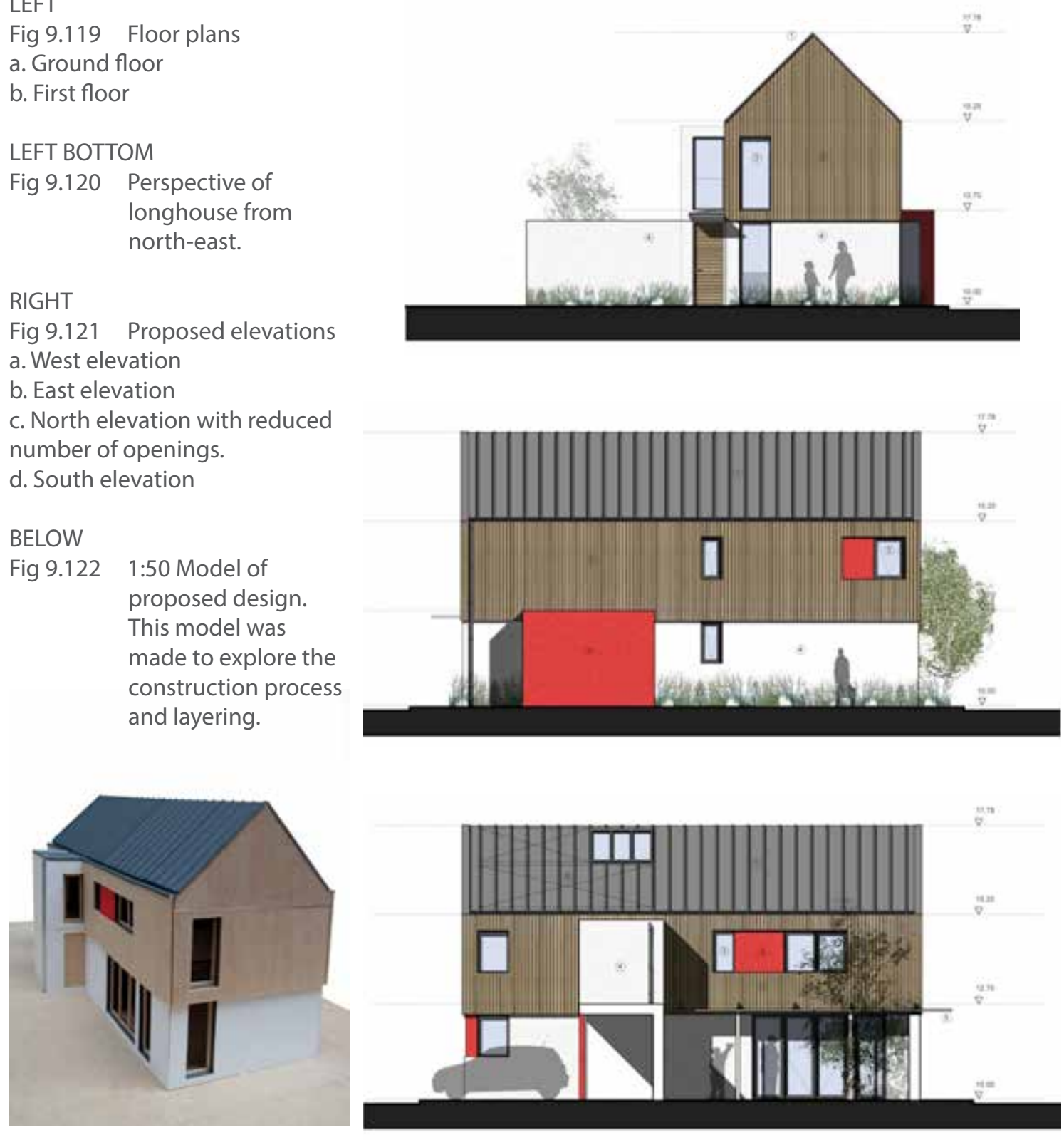


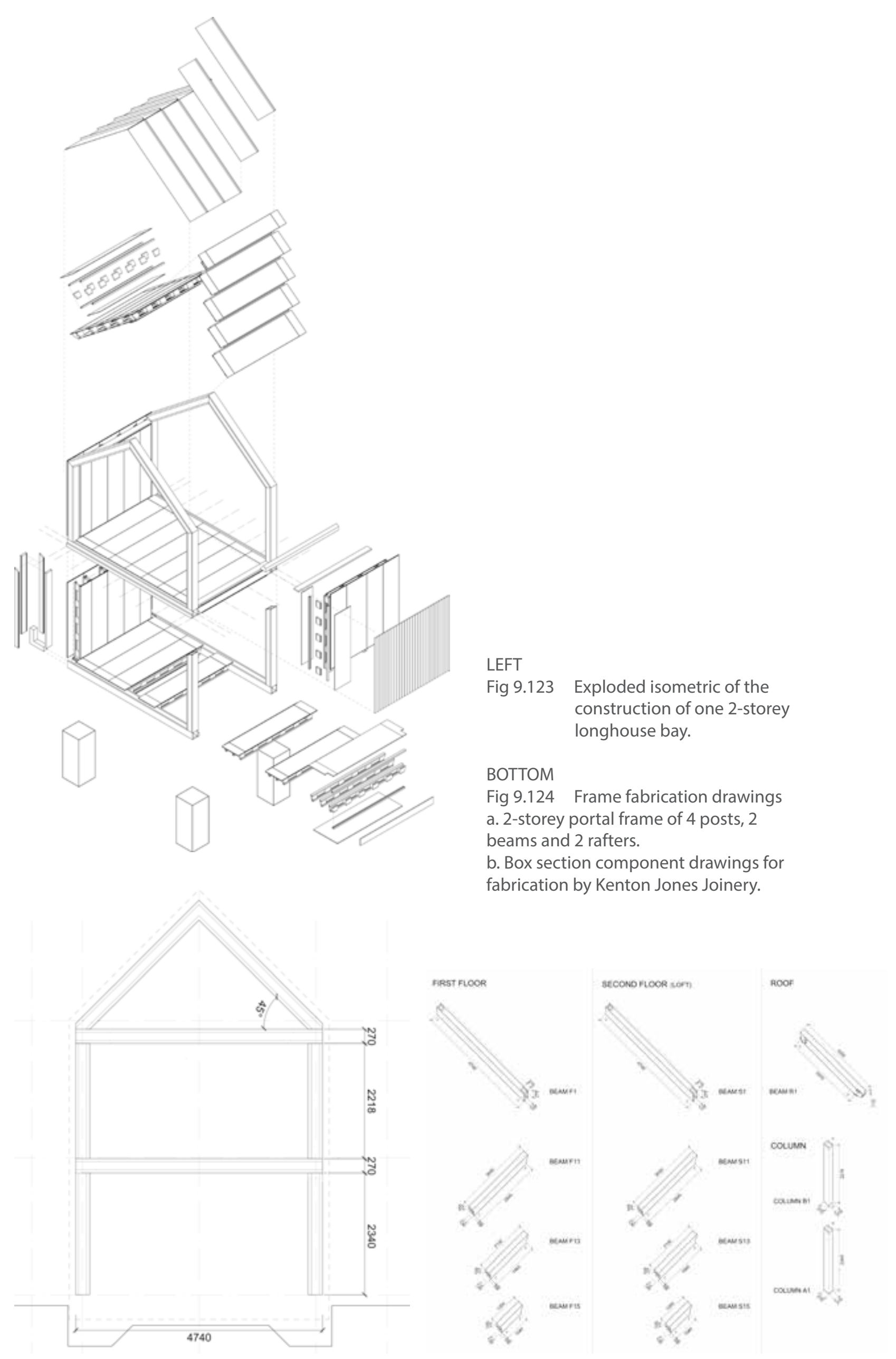

\subsubsection{Prototype}

\subsubsection{Detailed design}

Following planning approval in March 2010, the design team began preparing detailed construction drawings for tender. As time was tight to deliver the house by August 2010, it was agreed with the client that the contractor, G Adams Construction, on the ERC would be asked to continue working with the system as an extension of the ERC contract. As a progression of the system and to work with local and Welsh based organisations, Kenton Jones Joinery (KJJ), was named as the Ty Unnos supplier. KJJ had been gifted the low-tech press (section 10.3.2) from Coed Cymru and begun fabricating box section and ladder beams for testing and for other projects, outside the scope of this thesis. Burroughs continued as structural engineers and BRE Wales provided environmental and M\&E advice.

The principle stages and decisions taken during detailed design are discussed with a focus on the tectonic form and use of Welsh-grown timber in the complete building envelope.

\section{Superstructure}

The Ty Unnos construction system was ideally suited to the simple longhouse form, allowing an optimum configuration of Sitka spruce frames to create a linear 'tube'.

The exploded drawing opposite highlights the primary elements and components of the superstructure of a 2-storey bay of the longhouse.

- The longhouse consisted of 6 no. identical 2-storey frames spaced at different intervals of $1.41 \mathrm{~m}, 2.31 \mathrm{~m}$ and $3.21 \mathrm{~m}$ corresponding to the design and room positions.

- The portal frames were each detailed as $210 \times 270 \mathrm{~mm}$ box sections as a form of platform frame construction with ground floor posts, intermediate beams, first floor posts, tie beam and rafter beams. The post and rafter box sections were to be pre-filled with sheeps wool insulation.

- Edge beams were detailed between each frame at intermediate floor and eaves connected with simple ' $T$ ' plate spruce connectors, to provide racking support and to provide support for the wall panels.

- A significant detail to resolve in order to meet NHBC standards for the timber structure to be a minimum $150 \mathrm{~mm}$ above external ground. This meant that it would not be possible to incorporate a raised suspended ground floor due to the need for level threshold access. A concrete raft foundation was proposed with a $150 \mathrm{~mm}$ high kerb around the perimeter. The slab was insulated underneath with $250 \mathrm{~mm}$ of XPS insulation and above with $100 \mathrm{~mm}$ 

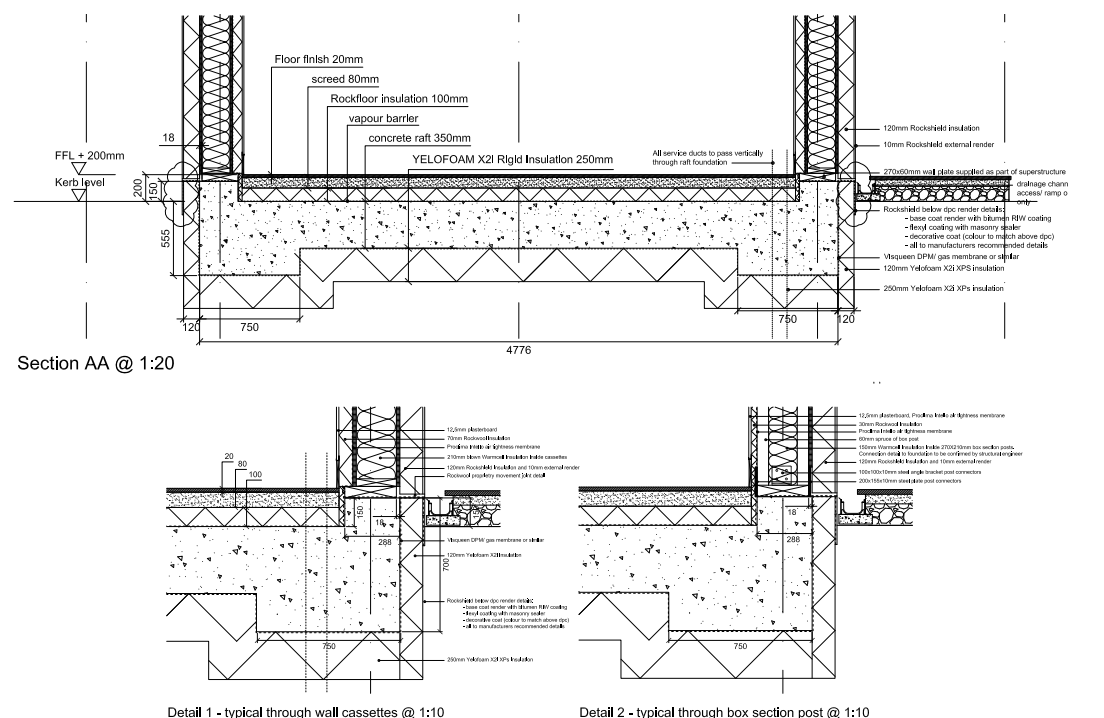

ABOVE

Fig 9.125 Typical foundation construction section details

BELOW

Fig 9.126 Sample frame panel fabrication drawing
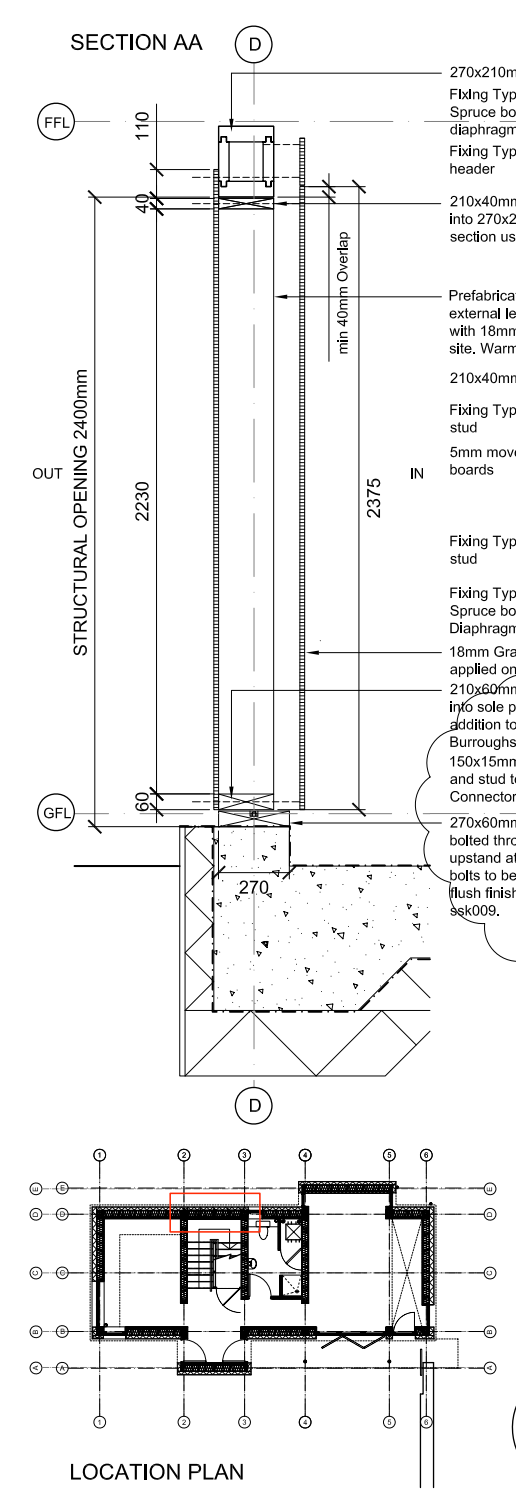

LOCATION PLAN

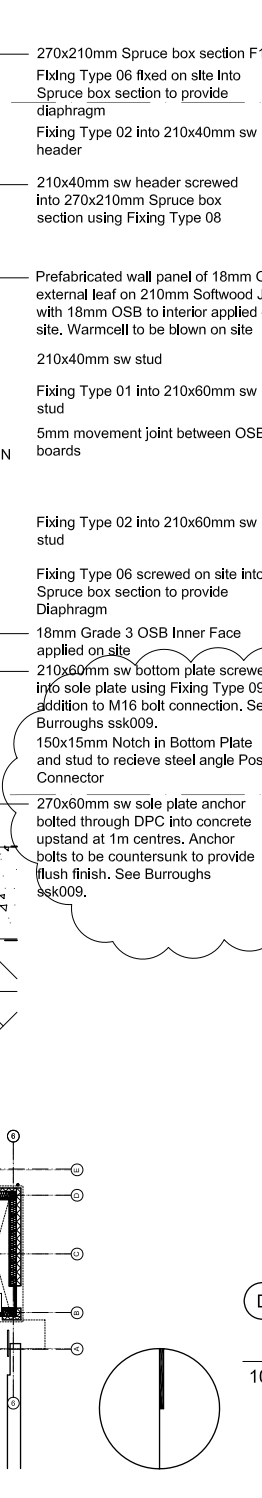

(3) EXTernal elevation

(2)

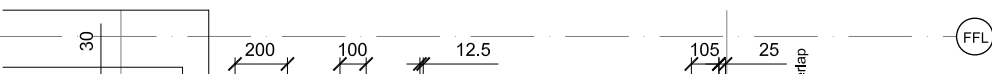

C:

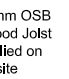

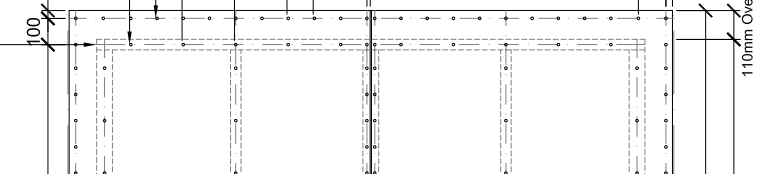

(D)

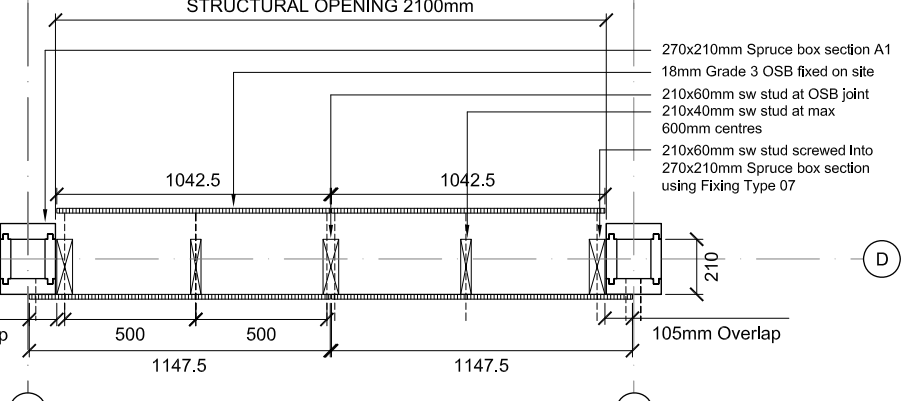

(3) PLAN of Rockfloor insulation and a 80mm screed to reduce thermal bridges and improve U-values.

- The frame posts were to be bracketed with $200 \times 150 \times 10 \mathrm{~mm}$ galvanised steel angle and screwed to $270 \times 60 \mathrm{~mm}$ spruce sole plates that in turn had been resin anchor bolted to the concrete kerb.

- Fist floor beams and posts were connected using a ' $T$ ' shaped steel and solid spruce connector.

- $\quad$ First floor posts, tie-beam and rafters were connected with a similarly shaped steel and spruce inserted connector.

- As the structural testing on the ladder cassettes was not finalised and cost modelling had revealed that the ladder components cost considerably more than other commercial engineered joists such as I-joists, it was decided to use solid C16 spruce joists for all framing elements as a test of the Welsh grown $\mathrm{C} 16$ spruce compared to the feedback from timber frame manufacturers.

- To aid tolerances, reduce the number of components and minimise risks of air leakage, full bay panels were detailed for walls and roof. Each panel was constructed as an open frame panel with $210 \times 40 \mathrm{~mm}$ solid spruce studs at maximum $600 \mathrm{~mm}$ centres. $18 \mathrm{~mm}$ OSB/3 boards lapped the box section frame externally by $40 \mathrm{~mm}$ for fixing on all edges. An internal sheathing of $18 \mathrm{~mm} \mathrm{OSB} / 3$ was applied on-site in staggered arrangements to ensure direct connection between panels and frame from foundation sole plate to eaves beam. This provided the diaphragm resistance required of a tall, thin and long structure.

- The intermediate floor was detailed from loose 210 x $40 \mathrm{~mm}$ C16 spruce joists connected through the $\mathrm{OSB} / 3$ diaphragm sheathing to the box beams with standard joist hangers at $450 \mathrm{~mm}$ centres.

- As a bespoke structure with an inexperienced fabricator, each part of the frame and infill panels required full detailing in collaboration with Burroughs. Close to 50 fabrication drawings were produced to detail each unique frame and panel arrangement.

\section{Thermal envelope}

SAP and Passivhaus modelling conducted by BRE Wales revealed the large proportion of external wall, in particular the north-facing wall, coupled with lower sunlight hours in the Ebbw Vale climate would cause difficulties in achieving the Passivhaus space heating and cooling demand.

The primary focus of the design team, was to aim for as close to Passivhaus standard and achieve CfSH Level 5, by adopting a fabric first approach providing an energy 


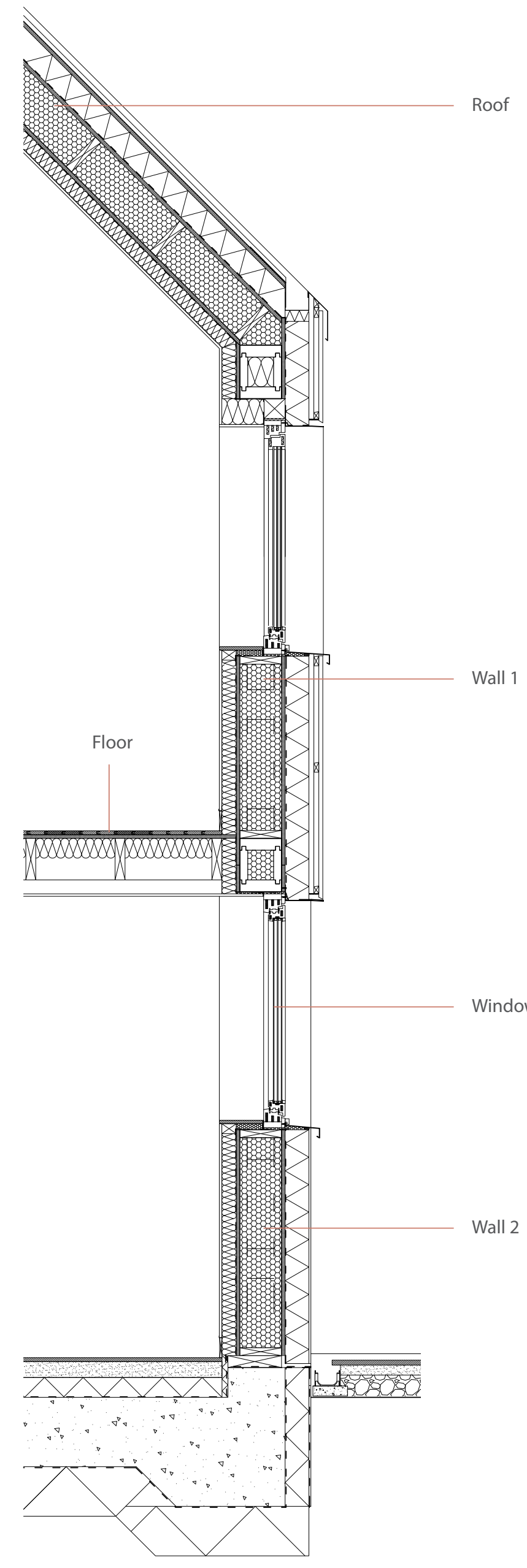

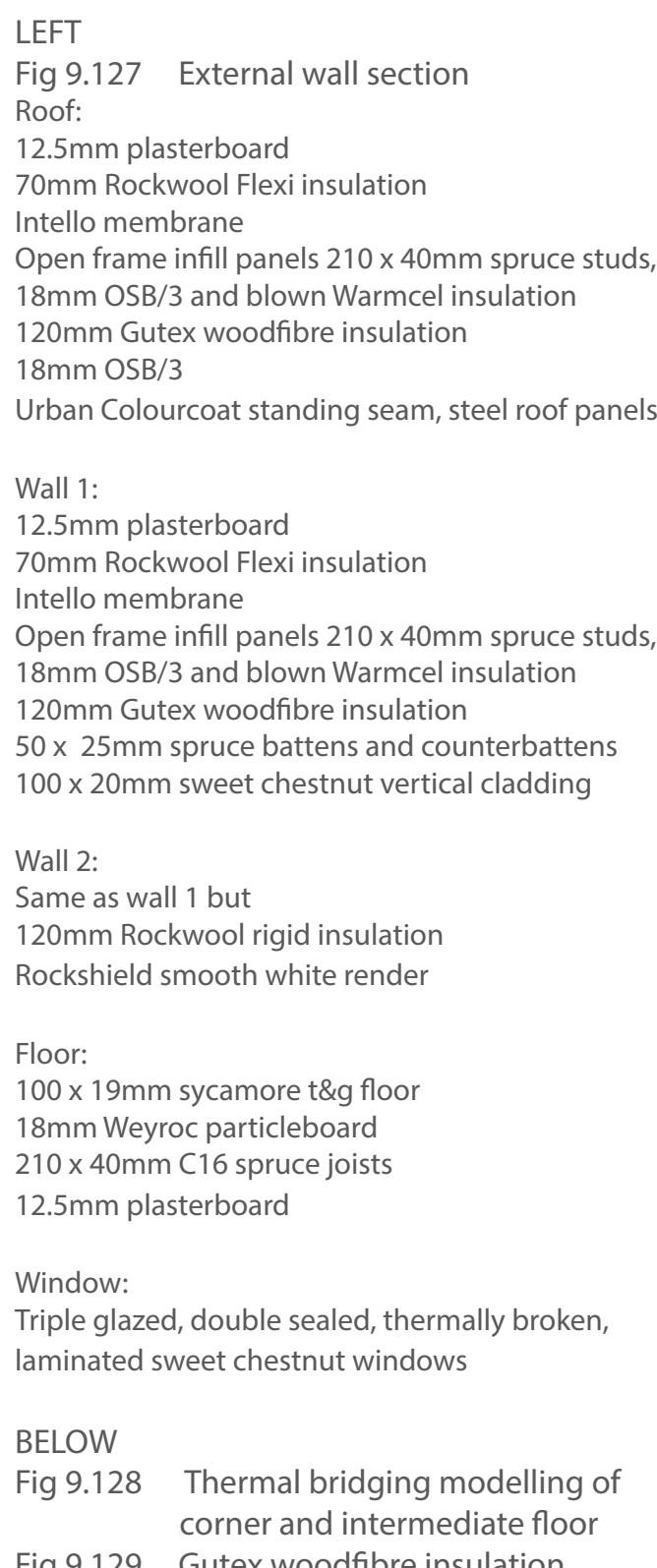

Fig 9.127 External wall sectio Roof:

$12.5 \mathrm{~mm}$ plasterboard

$70 \mathrm{~mm}$ Rockwool Flexi insulation

Intello membrane

O

$20 \mathrm{~mm}$ Gutex woodfibre

$18 \mathrm{~mm} \mathrm{OSB} / 3$

Urban Colourcoat standing seam, steel roof panels

Wall 1:

$12.5 \mathrm{~mm}$ plasterboard

Tomm Rockwool Flexi insulation

Open frame infll

$18 \mathrm{~mm}$ OSB $/ 3$ and

(20mm Gutex woodfibre Warmcel insulatio

$50 \times 25 \mathrm{~mm}$ spruce battens and counterbatten

$100 \times 20 \mathrm{~mm}$ sweet chestnut vertical cladding

Wall 2:

Same as wall 1 but

促

Floor:

$100 \times 19 \mathrm{~mm}$ sycamore t\&g floo

$18 \mathrm{~mm}$ Weyroc particleboard

$210 \times 40 \mathrm{~mm}$ C16 spruce joists

$12.5 \mathrm{~mm}$ plasterboard

Window:

Triple glazed, double sealed, thermally broken,

laminated sweet chestnut windows

BELOW

Fig 9.128 Thermal bridging modelling of

corner and intermediate floor
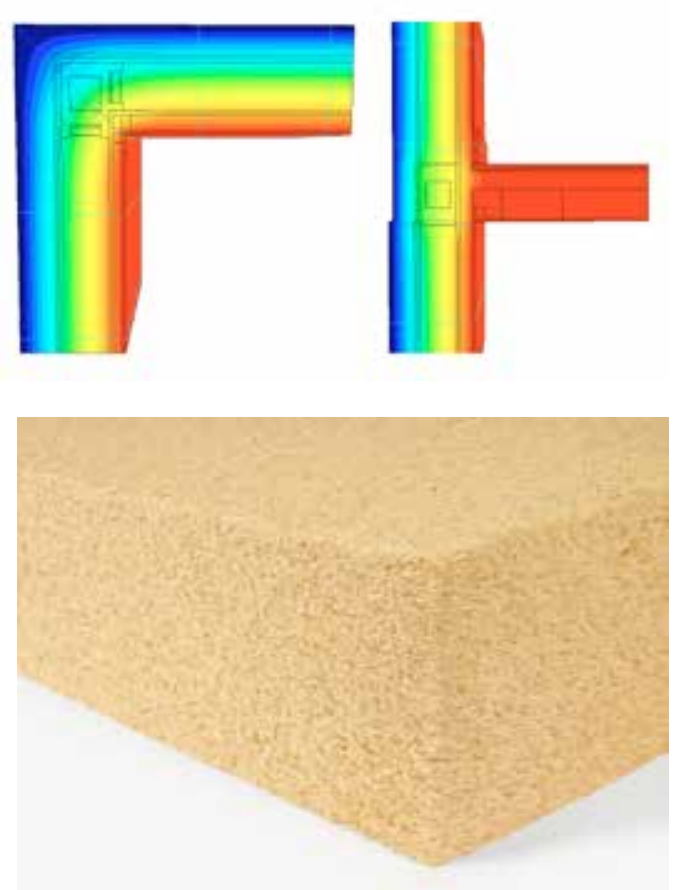

efficient fabric working within the opportunities of the Ty Unnos superstructure.

Renewable and mechanical ventilation systems were considered secondary and as a result of the increased envelope performance.

Due to the extremely low U-values and air tightness requirements, the construction detailing was more complex than the other prototypes, in this thesis, with significantly more layers to floor, walls and roof sandwiching the structure deep within the $425 \mathrm{~mm}$ total envelope thickness. A typical section through the external envelope is detailed opposite that achieved the following performance:

- Ground floor $\mathrm{U}$ value $0.07 \mathrm{~W} / \mathrm{m} 2 \mathrm{~K}$, wall U values $0.1 \mathrm{~W} / \mathrm{m} 2 \mathrm{~K}$, roof $\mathrm{U}$ value $0.11 \mathrm{~W} / \mathrm{m} 2 \mathrm{~K}$.

- Ty Unnos system details designed to be airtight by using Intello membrane to achieve an air permeability less than $0.6 \mathrm{~m} 3 / \mathrm{hr} / \mathrm{m} 2 @ 50$ Pa. Pressure testing during construction revealed that the fabric achieved 0.3m3/hr/m2 @ $50 \mathrm{~Pa}$.

- As a result of the low air permeability, mechanical ventilation with heat recovery (MVHR) was required to maintain air quality.

- Overall thermal bridging modelling performed far above Energy Savings Trust approved details and Part $L$ requirements, although not quite meeting Passivhaus standard around opening and intermediate floor details.

- Total energy demand for space heating and cooling was predicted to be approximately $21 \mathrm{kWh} / \mathrm{m} 2 / \mathrm{yr}$.

\section{Woodfibre insulation}

As part of exploring the complete timber envelope, early research had begun between Coed Cymru and Bangor University on the possibility of manufacturing woodfibre insulation using the waste from processing and defect cutting Sitka spruce. Swiss woodfibre insulation was incorporated in two layers of $60 \mathrm{~mm}$ and $120 \mathrm{~mm}$ to the first floor and roof as an in-use test of this form of insulation. Woodfibre could not be used on the ground floor as it was not currently compatible with an insulated render system. The advantages of woodfibre for the first floor were:

- The rigid boards would allow for battens, counter battens and cladding to be fixed back to the frame behind with minimal penetrations ensuring a continuous thermal covering.

- A waxed finish to the outer board protected the insulation and envelope from rain during construction.

- The woodfibre potentially makes use of waste products from primary and secondary processing industries that is currently used for fuel or to make paper. Low quantities of greener glues are used than in the manufacture of 


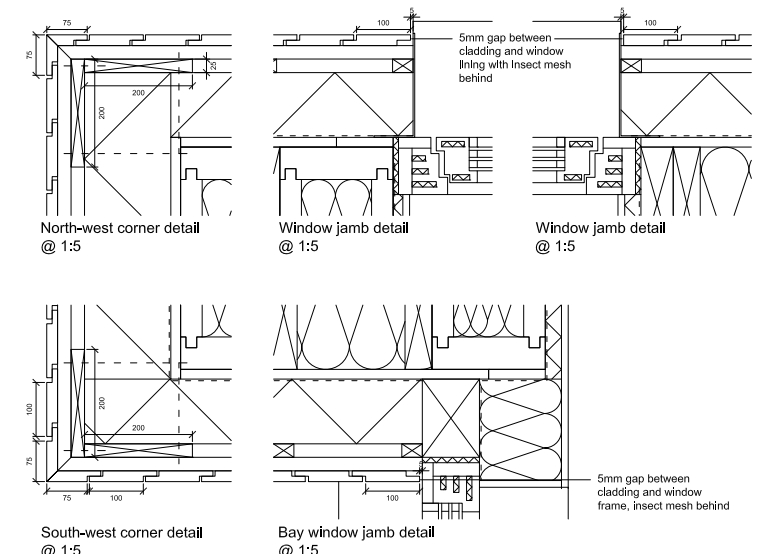

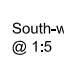

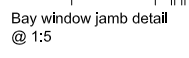
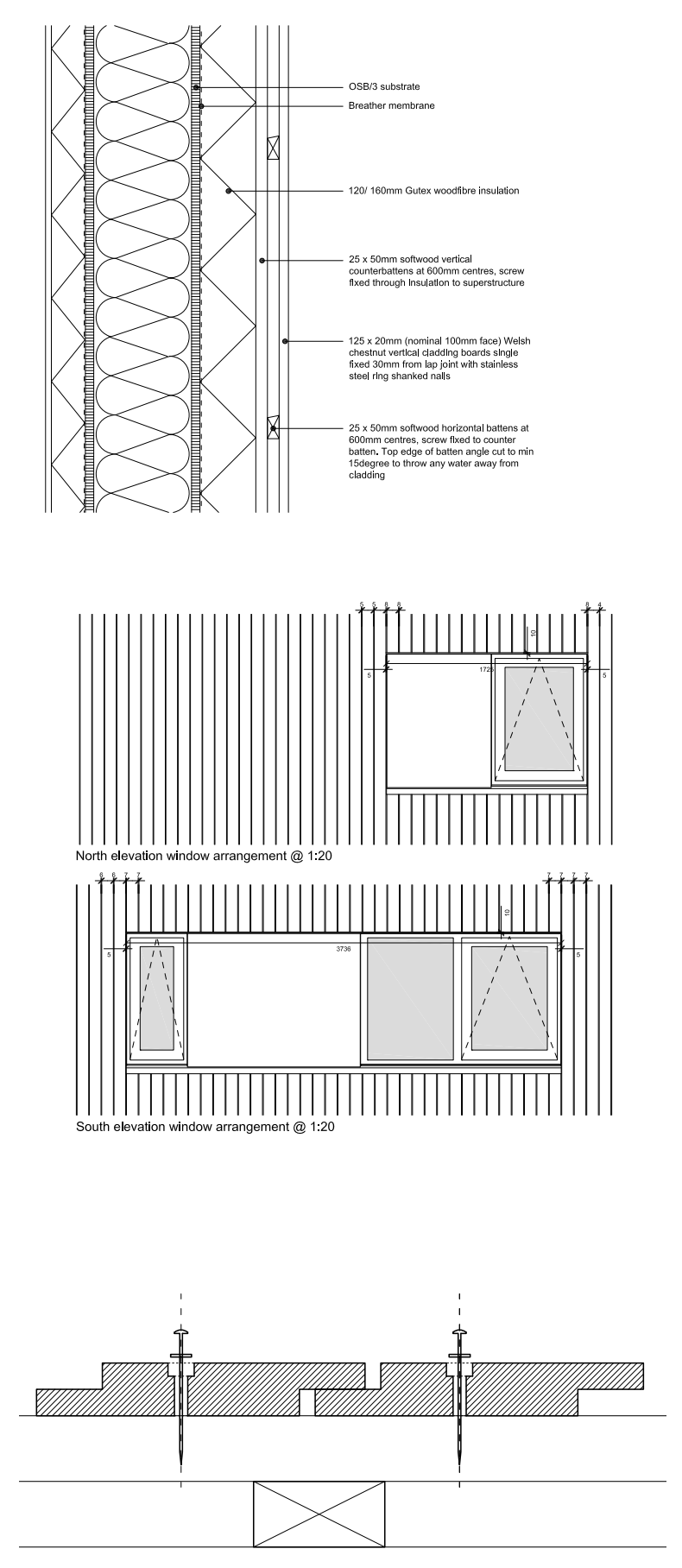

LEFT TOP

Fig 9.130 Sweet chestnut cladding details LEFT

Fig 9.131 Cladding arrangement around windows

BOTTOM

Fig 9.132 Cladding fixing details

a. $100 \times 20 \mathrm{~mm}$ sweet chestnut boards, single

fixed to $50 \times 25 \mathrm{~mm}$ spruce battens and

counter battens

b. Corner detail with $10 \mathrm{~mm}$ shadow gap to

allow for ventilation

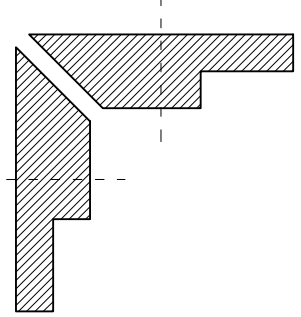

MDF and other board products

\section{Green chestnut cladding}

Following the design development of green hardwood cladding on the beach hut (Chapter 6) and the use of English sweet chestnut on Margam Discovery Centre, it was decided in response for a durable, low maintenance Welsh-grown cladding to use vertical green sweet chestnut on the first floor of the house.

In collaboration with Coed Cymru, and following best-practice guidance from the TRADA External Timber Cladding book by Patrick Hislop, the following assumptions and decisions were made and incorporated into the design drawings for fabrication and installation:

- Open vertical board would not be an option due to the prevailing southerly winds up the valley that would bring wind-driven rain. The breather membrane and woodfibre insulation behind are not designed to regularly cope with heavy wetting.

- The $100 \times 20 \mathrm{~mm}$ boards would need to allow for drying from green to approximately $18 \%$ MC. Any tongue and groove would need to be large enough to allow for this shrinkage.

- It was feared that a tongue and groove detail would collect moisture in the groove via capillary action that would dry slowly, thus creating a risk that some boards may twist, bow or spring slightly as they dry which would cause undue stress through other boards.

- It was therefore decided to profile the boards with a $25 \mathrm{~mm}$ half lap detail with an approximate 4-6mm shadow gap between boards when installed, allowing for ample shrinkage and for the boards to move without applying stress to the neighbouring board.

- Each board was to be single fixed through the centre with stainless steel screws to softwood battens and counter battens. The horizontal batten was to have the top edge profiled at 15 degree to throw water away from the cladding.

- The top end grain of boards was protected by a flashing detail combined with the concealed gutter and under window sills. Insect meshes were detailed at the bottom of boards at the minimum $10 \mathrm{~mm}$ gap for moisture to escape. 
Low-energy chestnut windows

Passivhaus standards require all parts of the building envelope to achieve the highest possible environmental performance. Windows are required to achieve an overall

$\mathrm{U}$-value, for frame and glass of $0.8 \mathrm{~W} / \mathrm{m} 2 \mathrm{~K}$. This means the frames must be thermally broken, the casements double sealed to reduce air permeability and the glass tripleglazed.

Within the timescale of the project, the contractors' joiners developed a bespoke low-energy window using laminated Welsh-grown sweet chestnut as a test of manufacturing processes, cost and performance. The proposed window detail was developed from the Coed Cymru window design, used on the ERC. The frame and casement were thickened to allow for a triple-glazed pane and for the pre-laminating profiling of three voids into which spray polyurethane foam (SPF) insulation could be inserted. Double seals were incorporated onto the frame and casement, with a tripleglazed pane.

BRE Wales, thermally tested the window after completion of the project, achieving an overall U-value of $0.95 \mathrm{~W} / \mathrm{m} 2 \mathrm{~K}$.
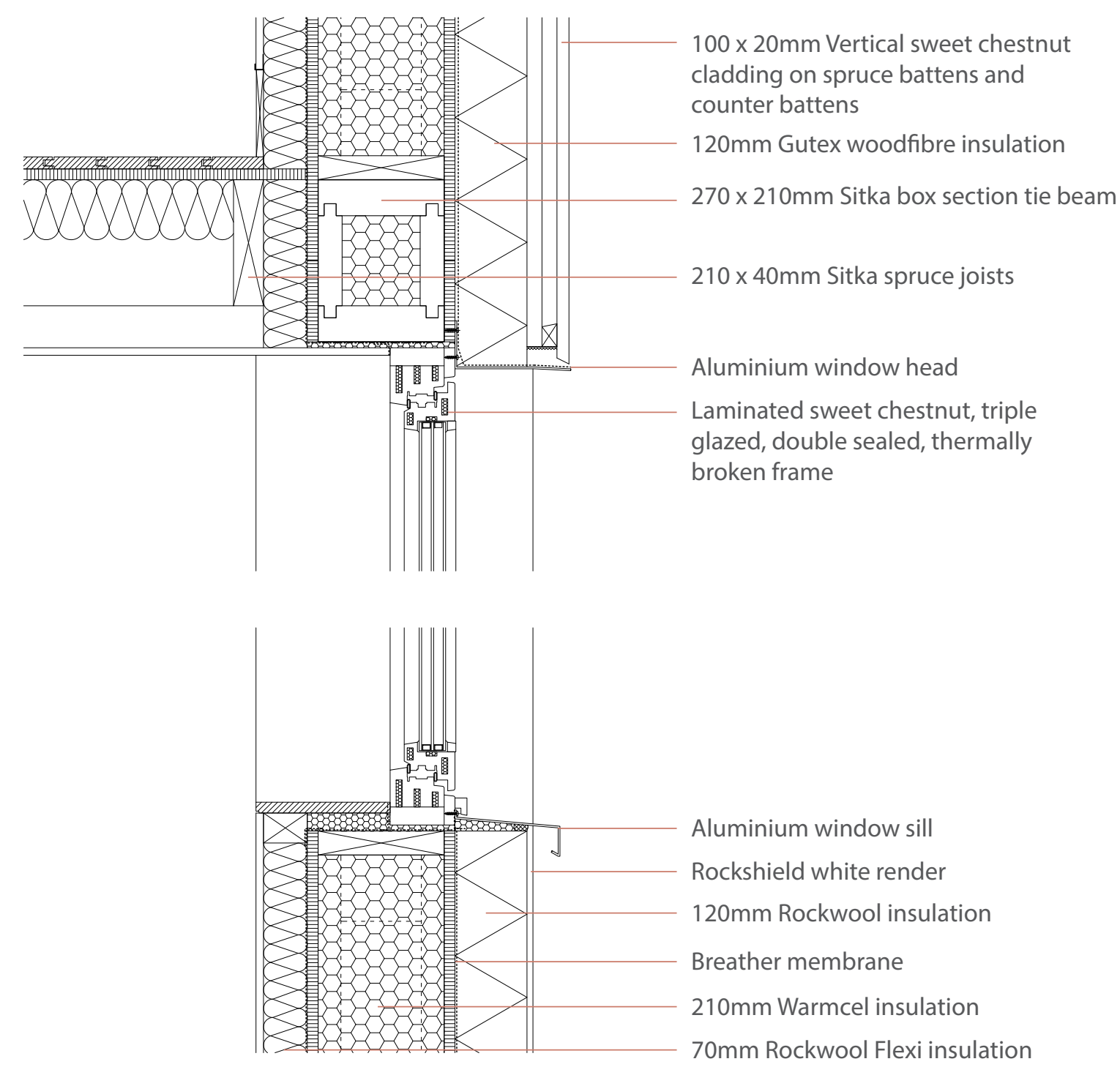

LEFT TOP

Fig 9.133 Details of bespoke low-energy window developed by Vintage Joinery

LEFT BOTTOM

Fig 9.134 Detail section through window 
LEFT TOP-BOTTOM

Fig 9.135 General arrangement south elevation

Fig 9.136 General arrangement section through dining bay

Fig 9.137 General arrangement section through kitchen

BELOW

Fig 9.138 Ground floor plan

Fig 9.139 First floor pla
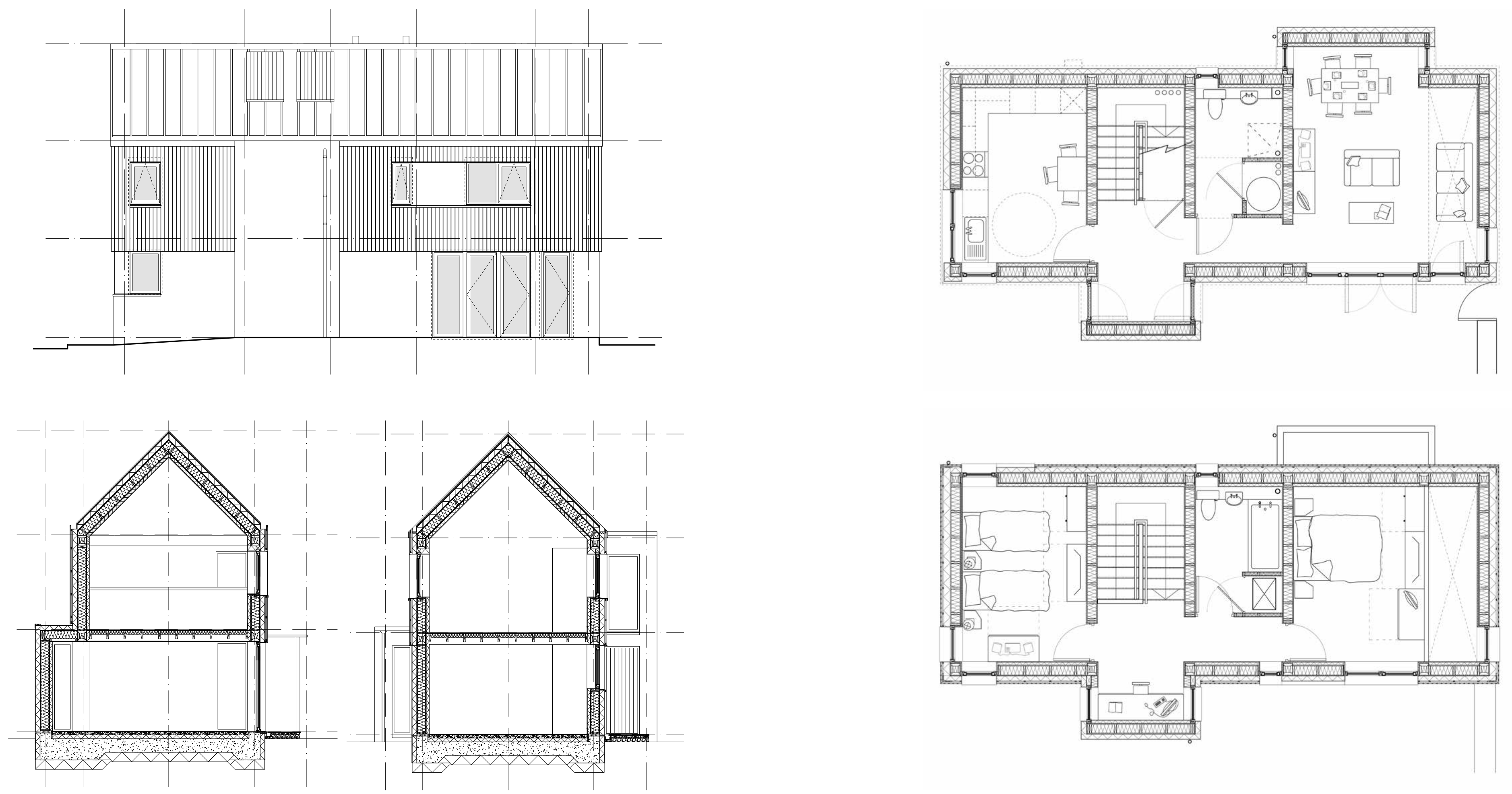

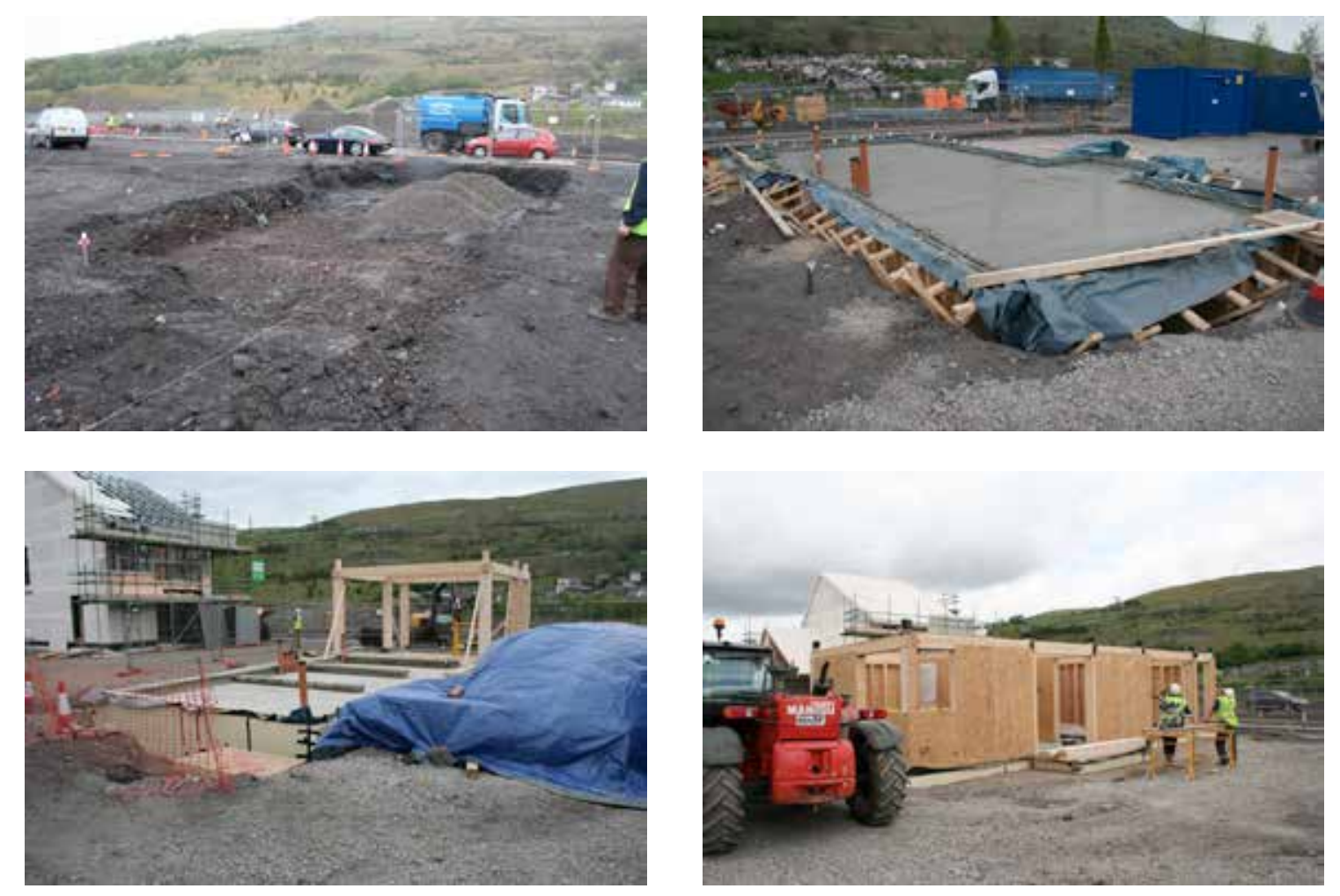

The following photographs and annotations highlight the key stages of the longhouse construction:
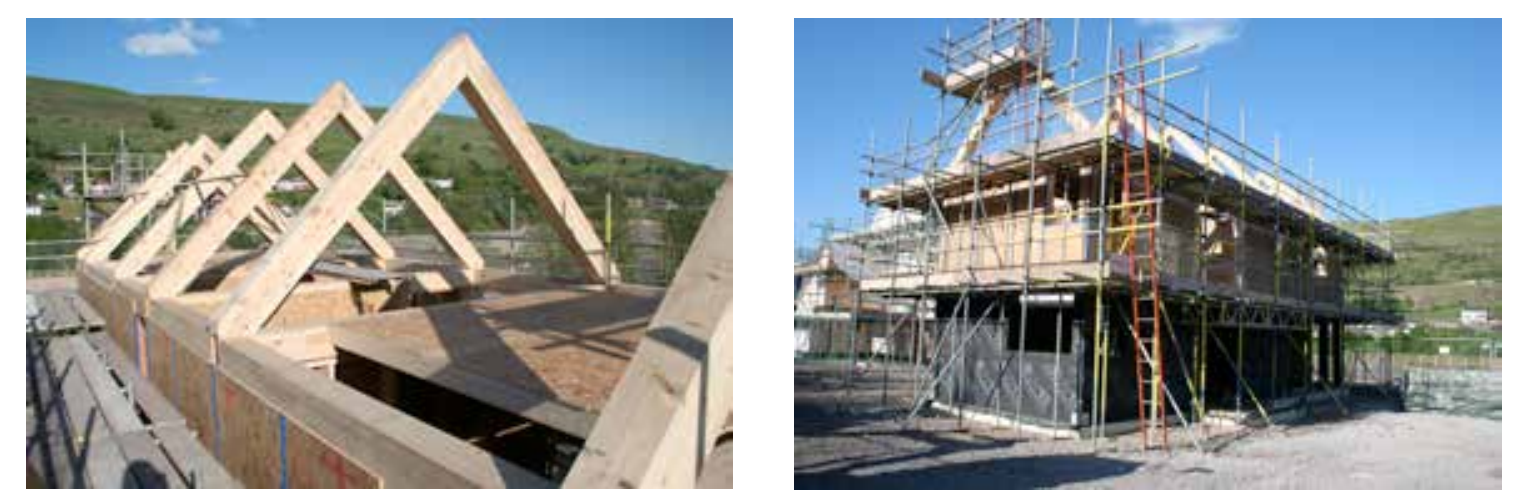

LEFT TOP - BOTTOM

Fig 9.140 Longhouse construction sequence
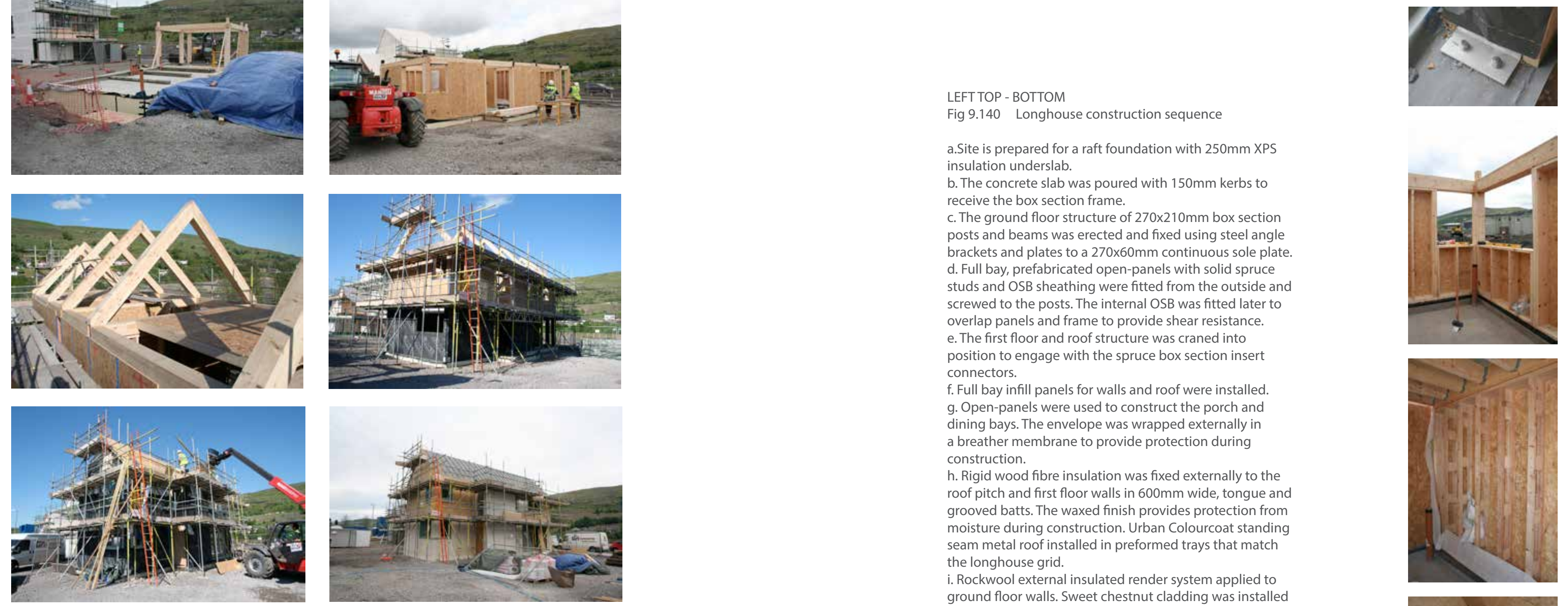

a.Site is prepared for a raft foundation with $250 \mathrm{~mm}$ XPS insulation underslab.

b. The concrete slab was poured with $150 \mathrm{~mm}$ kerbs to

receive the box section frame.

c. The ground floor structure of $270 \times 210 \mathrm{~mm}$ box section posts and beams was erected and fixed using steel angle brackets and plates to a $270 \times 60 \mathrm{~mm}$ continuous sole plate. d. Full bay, prefabricated open-panels with solid spruce studs and OSB sheathing were fitted from the outside and screwed to the posts. The internal OSB was fitted later to overlap panels and frame to provide shear resistance. e. The first floor and roof structure was craned into position to engage with the spruce box section insert connectors.

f. Full bay infill panels for walls and roof were installed. g. Open-panels were used to construct the porch and dining bays. The envelope was wrapped externally in a breather membrane to provide protection during

construction.
h. Rigid wood fibre insulation was fixed externally to the roof pitch and first floor walls in $600 \mathrm{~mm}$ wide, tongue and grooved batts. The waxed finish provides protection from moisture duning construction. Urban Colourcoat standing seam metal roof istatedin prefom the longhouse grid.

i. Rockwool external insulated render system applied to ground floor walls. Sweet chestnut cladding was installed

j. Rainwater goods, $4 \mathrm{~m} 2$ of solar hot water panels and
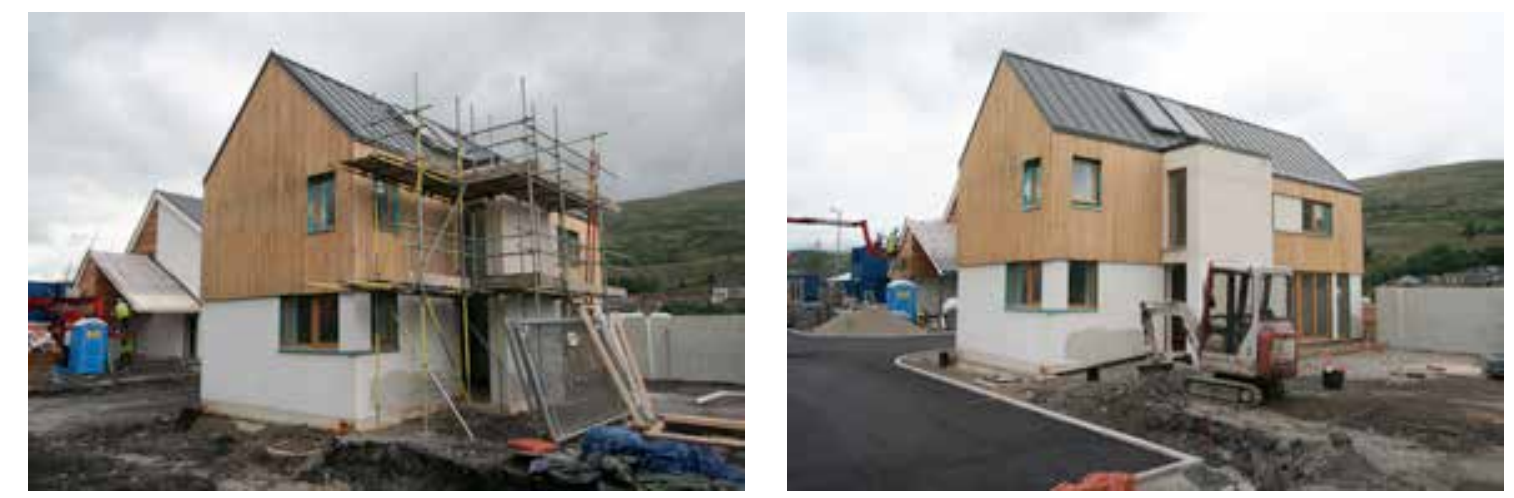

RIGHT

Fig 9.141 Galvanised steel angle bracket fixing box

section post to concrete kerb.

Fig 9.142 Open frame panels were installed from the exterior and sheathed internally with OSB/3.

Fig 9.143 Ladder beam panels were tested internally to use more poor quality spruce.

Fig 9.144 Exposed tie-beam across master bedroom.
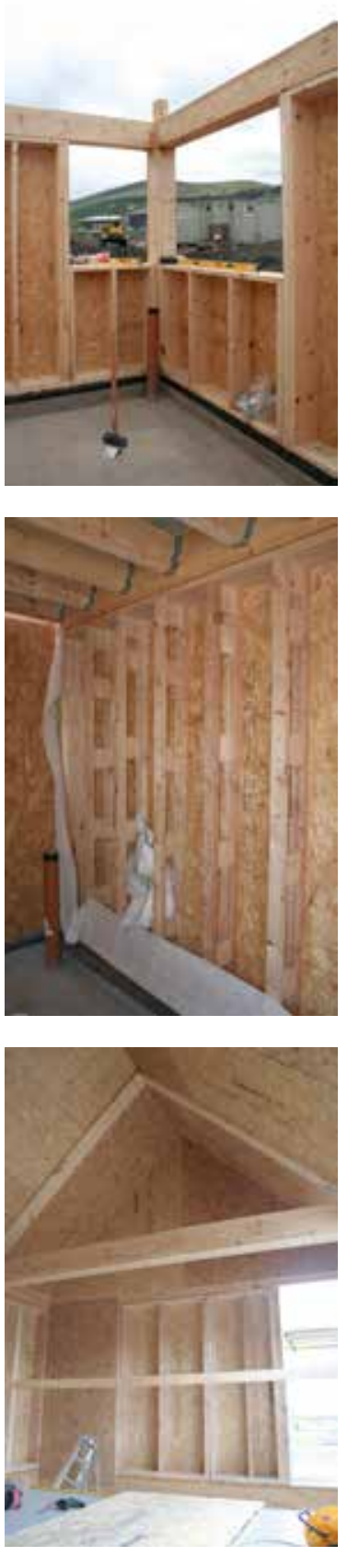

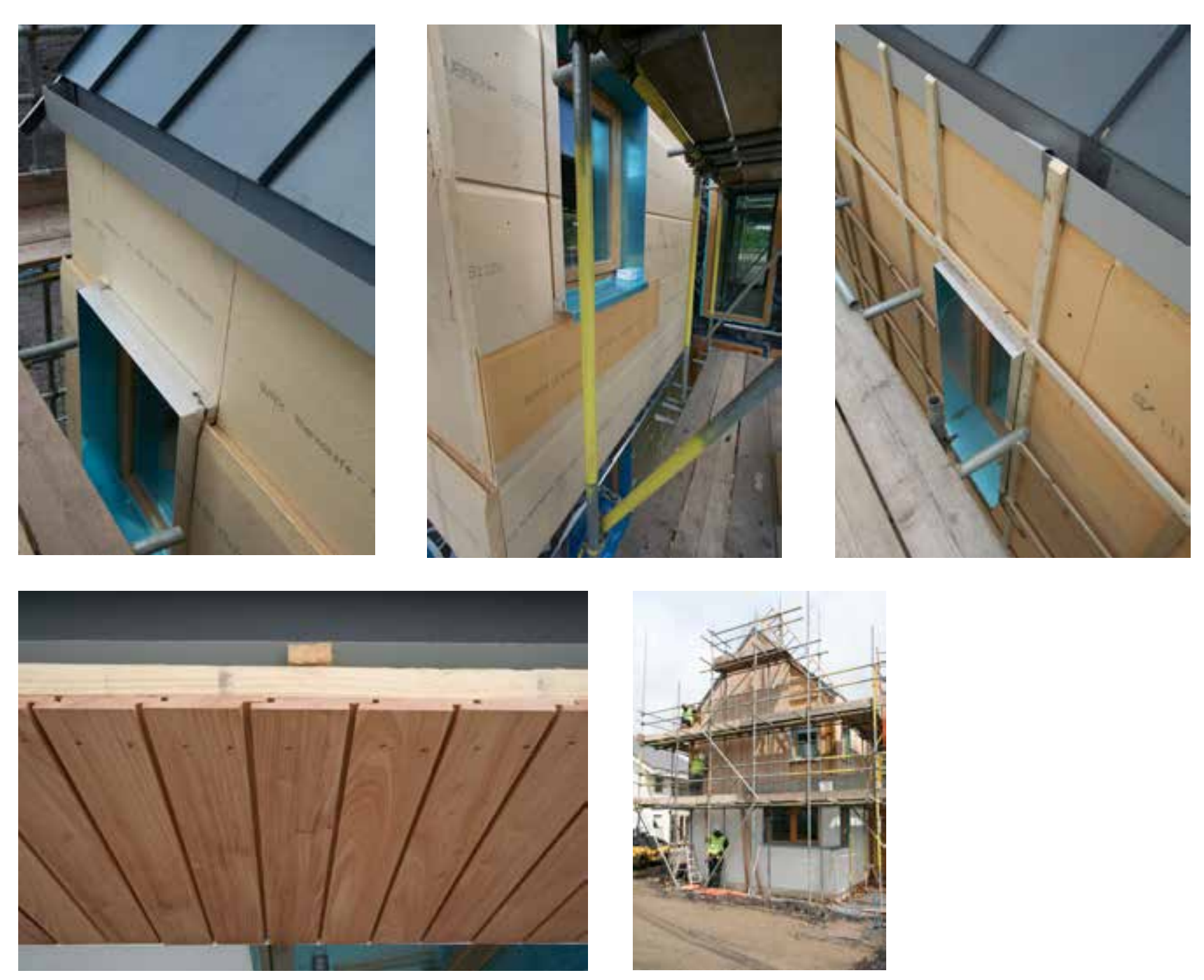

\begin{abstract}
LEFT TOP
Fig 9.145 External finishes

a. Aluminium window linings were installed before the first $60 \mathrm{~mm}$ layer of woodfibre board.

b. The second layer of $60 \mathrm{~mm}$ woodfibre

board was installed to lap the previous layer joints. The outer layer included a waxed finish providing moisture protection during construction.

c. $50 \times 25 \mathrm{~mm}$ spruce battens and

counterbattens fixed through woodfibre

insulation to superstructure.

d. $100 \times 20 \mathrm{~mm}$ vertical sweet chestnut boards were half lapped and fixed with stan screws. The specification required single fixing although the carpenters double fixed with self countersinking screws.

e. The vertical cladding is aligned to fit exactly between window openings and corners.
\end{abstract}

LEFT BOTTOM

Fig 9.146 Welsh chestnut low energy windows and doors are installed, lapped and taped with the Intello membrane.

RIGHT

Fig 9.147 Internal layering of envelope

a. Ties beams between principle portal frames are connected at intermediate floor level and eaves. Warmcel insulation was blown into pre cut holes in all external wall and roof panels. b. Internally the superstructure was lined with a Proclima Intello membrane and taped to improve air tightness. Air pressure tests achieved 0.3m3/hr/m2 @ 50 Pa. All sockets and switches are faced fixed to the membrane and sealed rather than penetrating the membrane.

c.The walls and roof were battened out over the Intello membrane to create a service void before being filled with Rockwool Flex

d. The interior was finished with taped and piled plasterboard to provide 30 minutes fire protection.
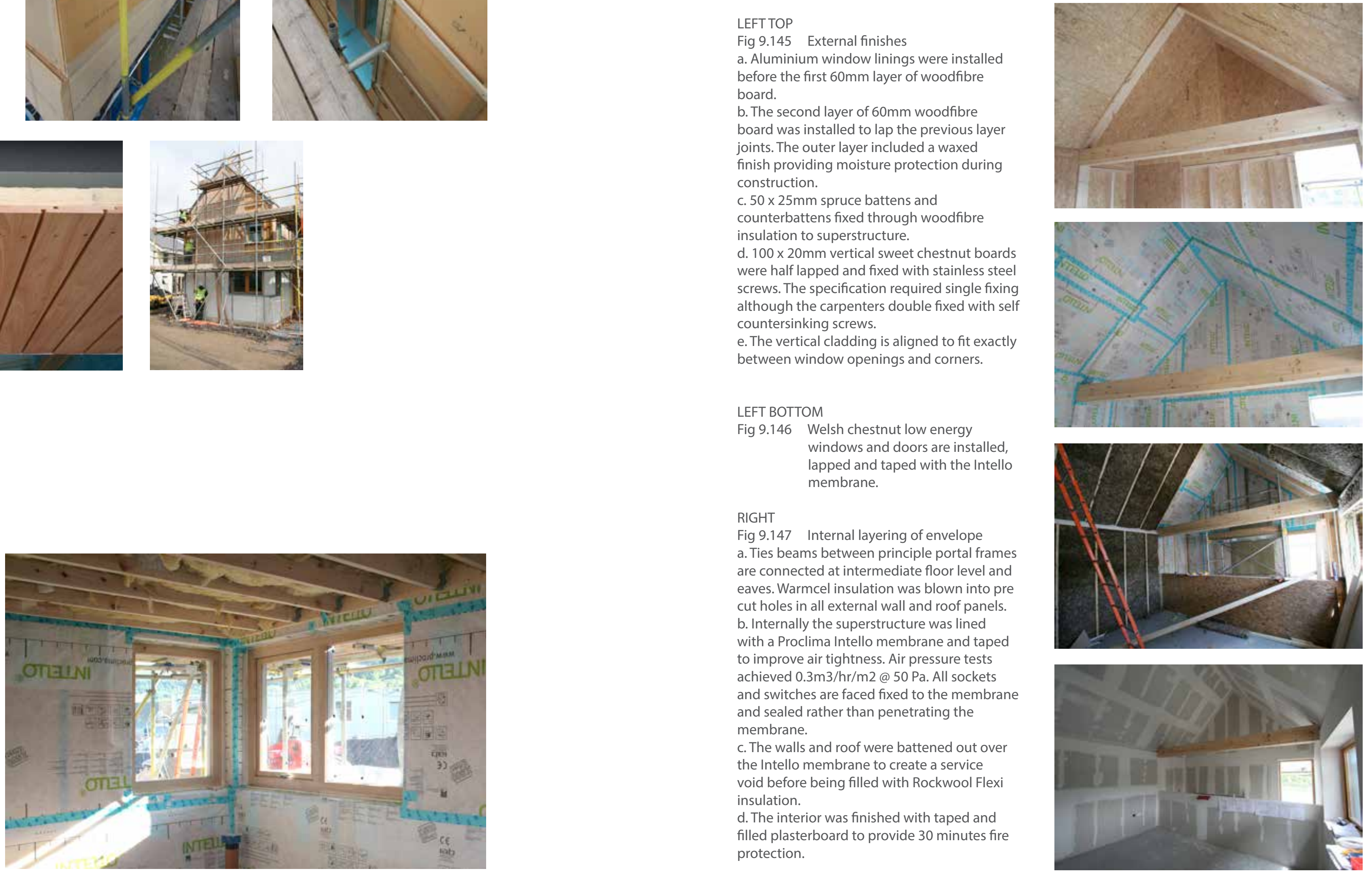

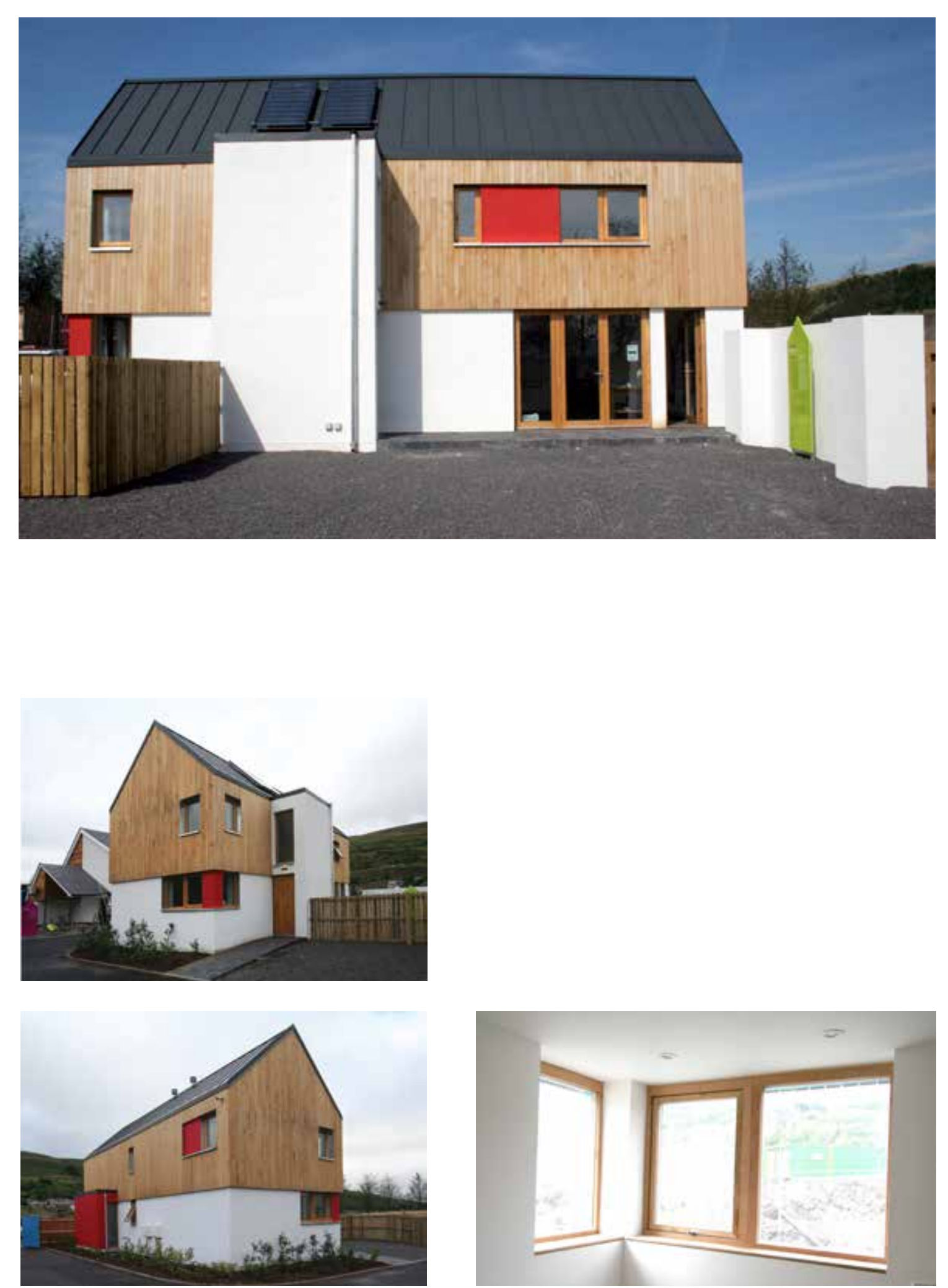

LEFT TOP-BOTTOM

Fig 9.148 South garden elevation

Fig 9.149 West elevation with entrance and drive

Fig 9.150 North elevation with dining bay

Fig 9.151 Detail of south wevation bedroom windows
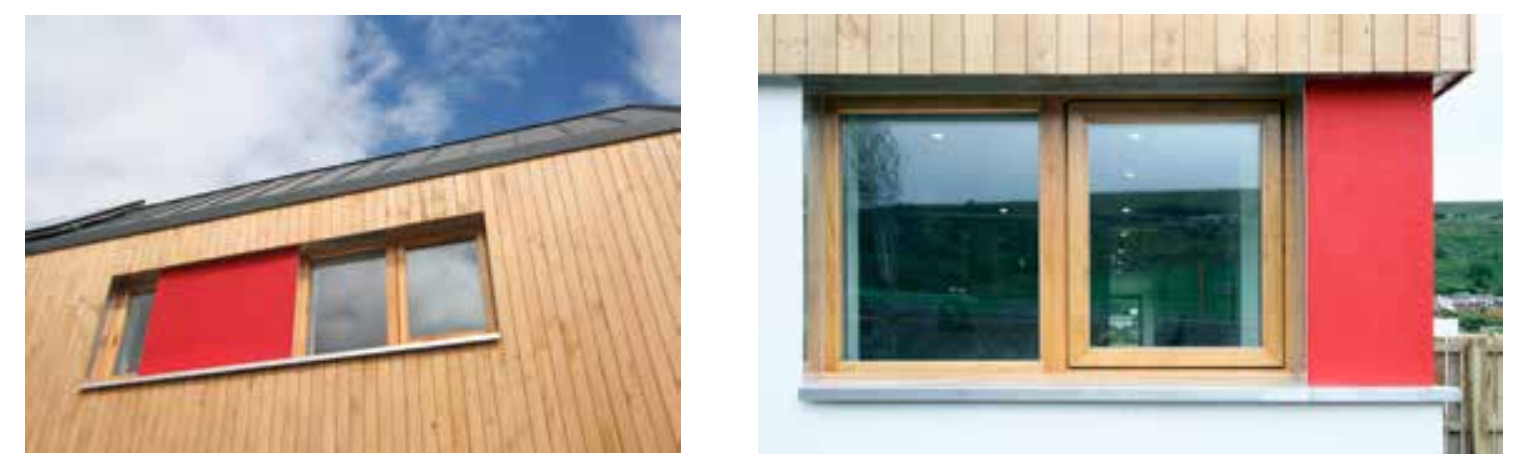

Fig 9.152 Kitchen corner windows interior

Fig 9.153 Kitchen corner windows exterior

RIGHT

Fig 9.154 Living room

Fig 9.155 Master bedroom with exposed

tie-beam

Fig 9.156 Master bedroom with mezzanine void to living room below
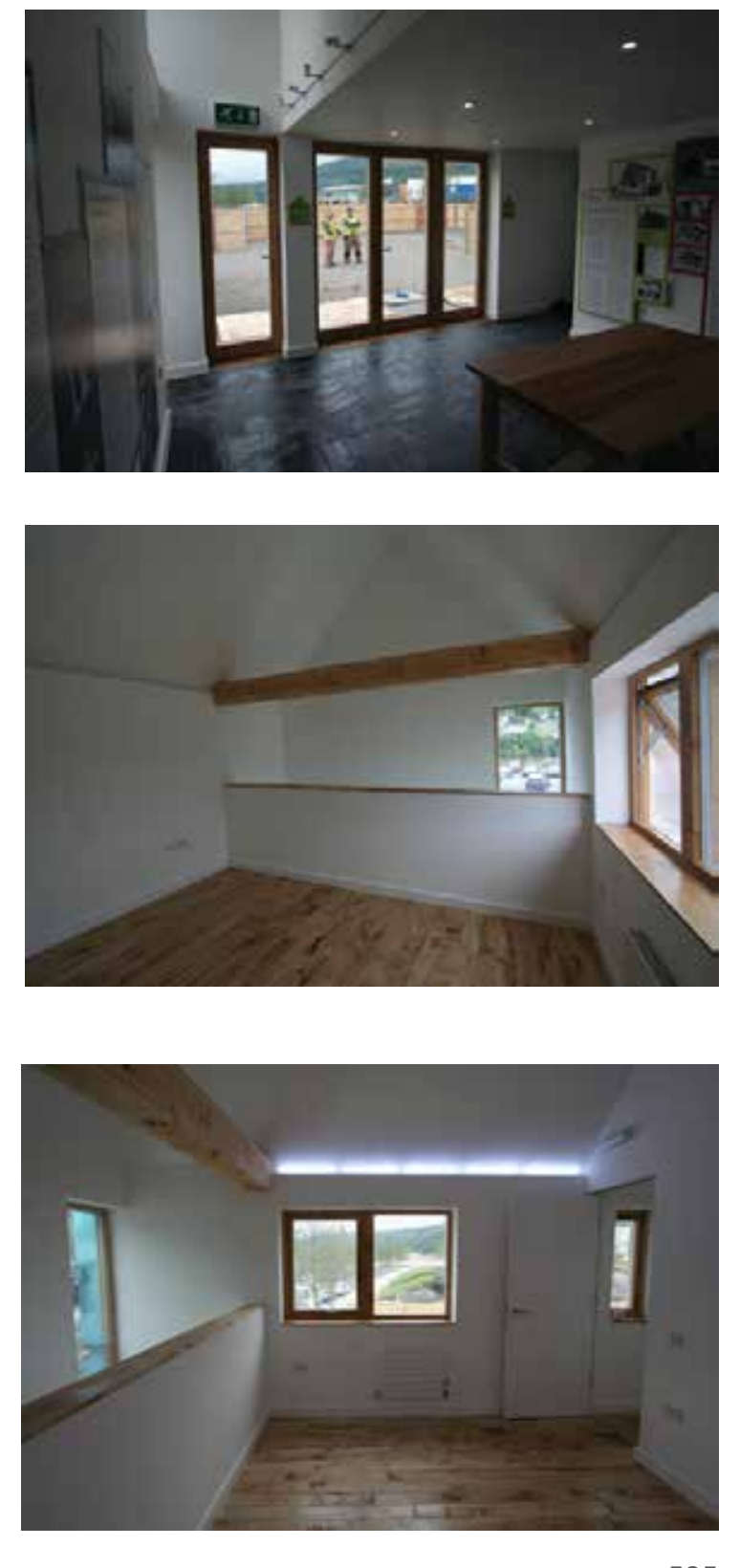


\subsubsection{Observations and reflections}

This was the last of the complete timber envelope prototypes using the Sitka spruce, Ty Unnos, construction system. The Sitka spruce components and construction sequence reflected the intended simple contemporary longhouse form, although the environmental requirements potentially suffocate the timber components behind a white painted plasterboard lining. This was the first construction of a 2-storey structure using the Sitka spruce components, although the limitations of the structure, fabrication process and costs led to a hybrid of systems combining box section frame with open panel construction. This suggests that either the frame or panels alone would suffice. Construction was quick and efficient with the frame and panels erected in 5 days with the remaining construction only extended by the number of layers required to meet the energy performance requirements. Other observations and reflections under the framework for evaluation headings are:

\subsubsection{Species performance and adaptation}

\section{SPECIES}

- The longhouse used the follow timber and timber products in the building envelope:

- Welsh-grown Sitka spruce primary and secondary structures

- Scottish OSB/ 3 for sheathing, racking and diaphragm action

- Sweet chestnut vertical cladding

- Laminated, thermally broken sweet chestnut windows

- Welsh-grown sycamore floor boards

- Welsh-grown oak window sills

- Imported spruce woodfibre insulation

- Green chestnut cladding was sourced from two separate timber stores in

south-east and south-west Wales due to low quantities and short turn around time.

- There are no further reflections or observations on the sourcing, supply, properties or adaptation of Sitka spruce for the box section or infill superstructure that have not already been covered under the previous prototypes.

\subsubsection{Building envelope}

\section{SUPERSTRUCTURE}

- Built on a raft rather than pad or strip foundations - worked well, but excessive amount of concrete and slightly awkward kerb details to create $150 \mathrm{~mm}$ 
Building Regulation requirement.

- Softwood and steel insert connectors developed from hardwood connectors on Smithsonian worked well seemingly with very little settlement, but not good with thermal bridging or filling box beams with insulation at each junction.

- The beams between frames separating each room and the OSB bracing from ground floor to eaves were time consuming and prohibited services running within the floor zones across the house

- Develop the ladder beam further to replace solid stud and reduce weight and thermal bridging effect.

- If the infill panels had used ladder beams, as intended, this would have limited their structural capacity to just infill, thereby necessitating the frame.

However, further research may be beneficial on the development of the ladder beams as a replacement for solid studs in platform frame construction to reduce weight and thermal bridging and eliminate the frame all together.

\section{EXTERNAL CLADDING}

- Green Welsh chestnut cladding has performed well, but initial problems with workmanship and non-ferrous fixings needed to be rectified. Initially the tannins washed out of the chestnut staining the white render below. This resolved itself over time requiring no remedial works.

- The boards installed had been seasoned for at least a year, by the time they were installed thereby reducing the moisture content significantly from green. The carpenters installing the cladding chose to single fix with self countersinking screws, against specification as the risk of severe moisture movement had been reduced. Some boards were accidentally fixed with galvanised screws which almost instantaneously caused blue streaking as the tannic acid attacked the screws when wet. These were promptly replaced with the streaking fading over several months.

- Some boards had come into contact with non-ferrous metals causing lines of blue streaking. The spray affect suggests it may have been caused from iron fillings from an angle grinder. Care must be taken during construction to ensure green oak and chestnut are not exposed to non-ferrous metals to preserve the appearance.

- After 5 years the boards have weathered to a dark grey, with all boards performing as expected, with none needing replacement.

\section{PERFORMANCE REQUIREMENTS}

- The low energy building performance requirements pushed the innovative system to its limits. This was to be expected as the first 2-storey house 

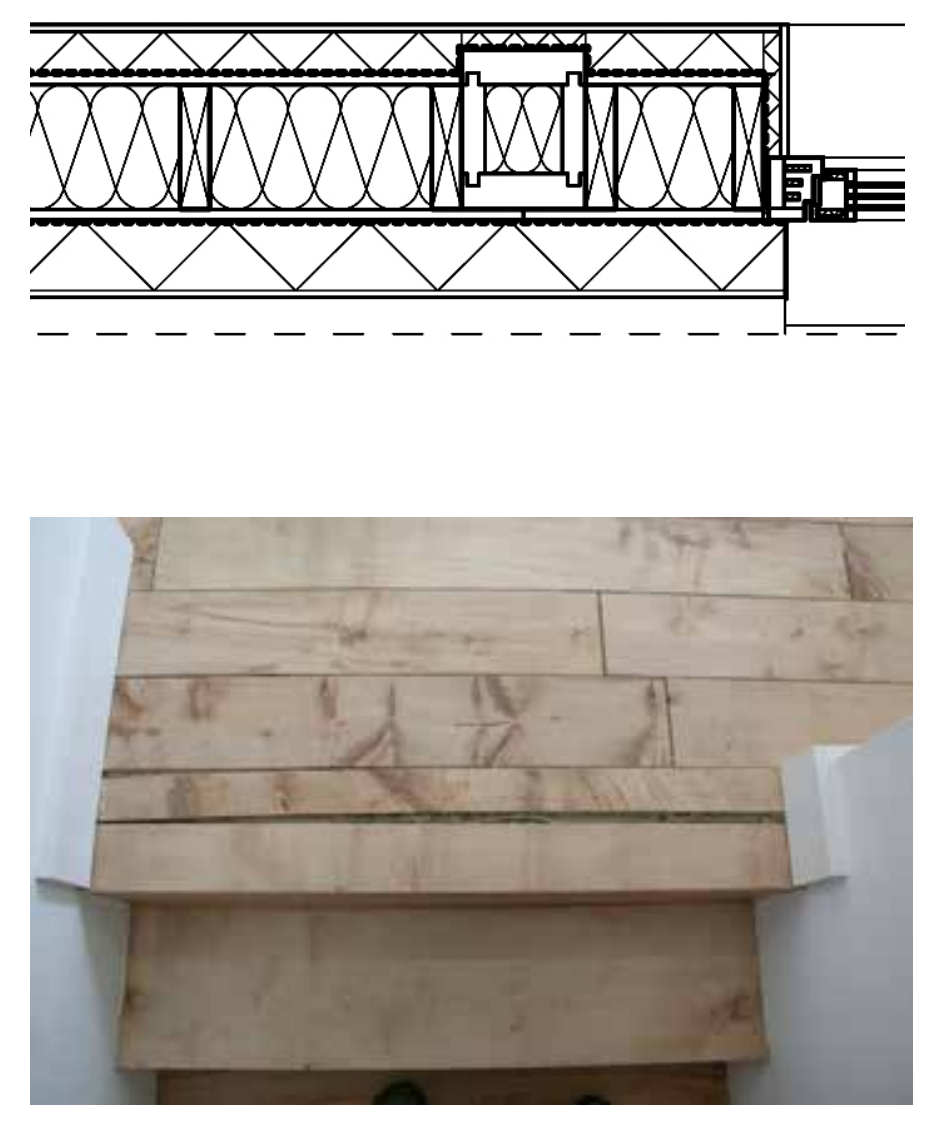

Fig 9.158 Detail of wall panel and box section post prototype that had previously not aimed for Passivhaus levels of insulation and air tightness.

- Thermal bridging was identified as not to Passivhaus standard due to the repetitive box section posts and beams. And the large volume of timber within the wall make-up at these points.

\section{INTEGRATION WITH COMPLETE ENVELOPE}

- The $70 \mathrm{~mm}$ difference between box section size and infill panel lent itself well to creating a service void that avoided punching through the air tightness membrane - but only per room, as the path blocked at each post or beam location.

- MVHR system maintains air quality but reduces humidity, especially when occupied irregularly. This resulted in the extreme drying of the sycamore floor despite being kiln dried to $10 \%$ MC. As was discovered on the stress-lam system, sycamore is prone to high levels of moisture movement, especially when drying below $10 \%$. Cupping, twisting and even significant longitudinal movement of the sycamore floorboards was evident.

\section{EXTERNAL JOINERY}

- Windows were a good, and rapid response, to achieve a low-energy performance using Welsh-grown hardwood. Concerns were raised by BRE Wales during the thermal testing about the long-term performance in relation to drainage of moisture from within the frame and the thin profiles of chestnut left after profiling. 2 years after completion, the external clear oil coating had started to wear away on the exposed southern elevation windows and doors. This is to be expected, although maybe not in such a short time-scale. The use of exposed timber for external joinery will always require maintenance. Further development of the window may include an aluminium outer cover for use in exposed locations.

- The performance of laminated hardwood windows in low humidity environments, such as a Passivhaus (particularly while unoccupied), require further testing. The low internal humidity of the Longhouse caused the inside of the windows and doors to shrink more than the external faces causing problems with warping and twisting.

\subsubsection{Technology and skills}

\section{PROCESSING}

- Open frame panels were manufactured for the infill. These are essentially standard products, already produced by the Welsh industry. If this had been known in advance, a specialist could have prepared the drawings and 


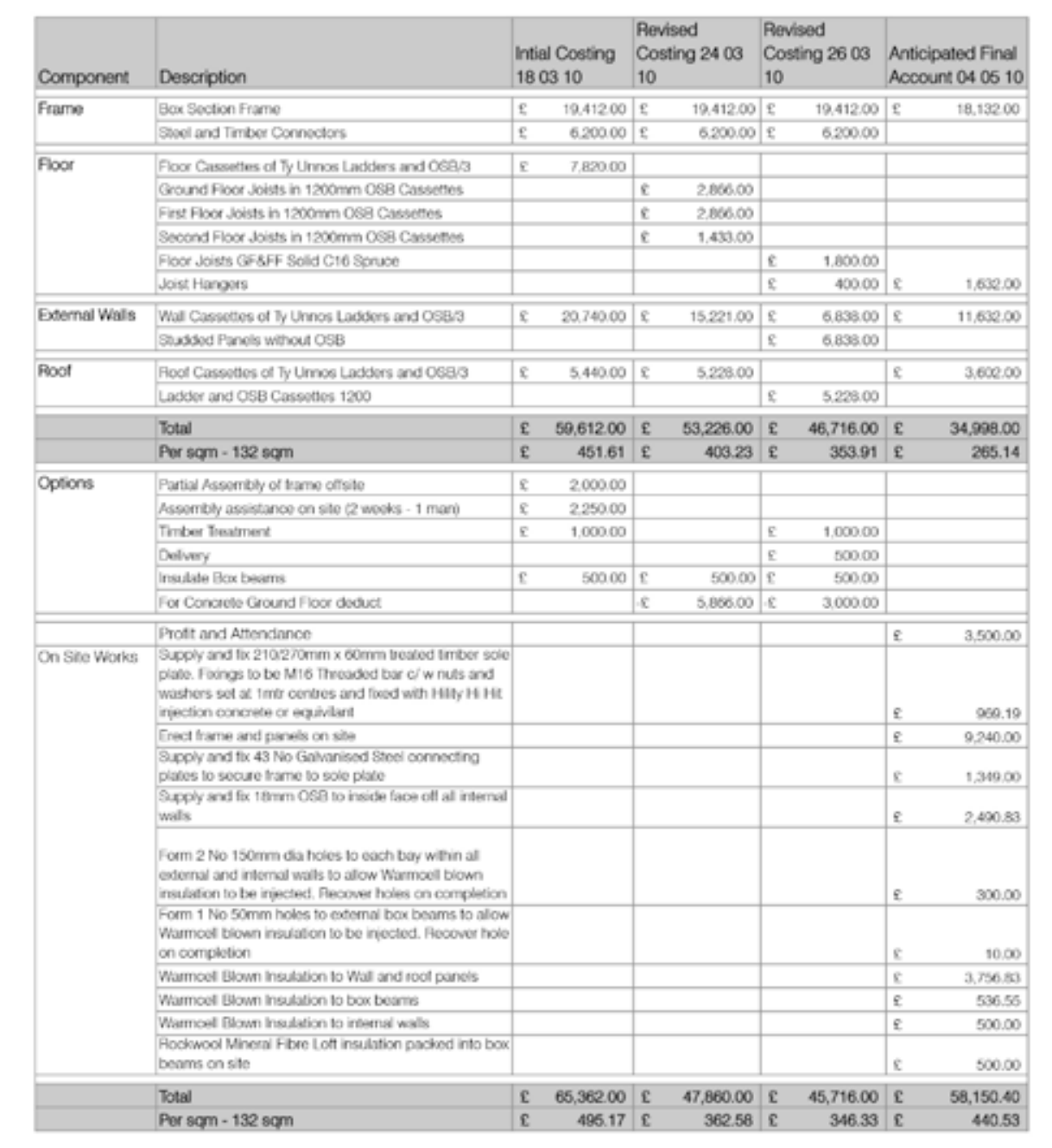

Fig 9.160 Cost appraisal of Longhouse project fabricated quicker than DRUw and KJJ.

\section{FABRICATION}

- A significant quantity of $210 \times 40 \mathrm{~mm} \mathrm{C16} \mathrm{spruce} \mathrm{was} \mathrm{rejected} \mathrm{during} \mathrm{the}$ manufacture of infill panels by Kenton Jones Joinery. This was typically due to distortion, with planing and further processing taking the timber below what could be accepted as $\mathrm{C} 16$ grade. $\mathrm{KJJ}$ also reported difficulties in sourcing the required quantities within the tight timescale, possibly highlighting the primary processing industry focus on production of specific sizes of softwood for specific markets. This resulted in KJJ manufacturing some ladder beam panels for internal walls as an efficient use of smaller section, rejected spruce from longer twisted and warped boards.

- The manufacturing costs of the components must be reviewed. The initial tender costs from $\mathrm{KJJ}$ for the frame an envelope were $£ 450 / \mathrm{m} 2$ which was eventually reduced to $£ 265 / \mathrm{m} 2$ by not using ladder beams and manufacturing floor cassettes. This, however, increased on-site contractor costs by over $£ 23000$ or $£ 175 / \mathrm{m} 2$. An overall reduction from the initial tender of $£ 7000$. This total superstructure costs equated to $23 \%$ of the total contract value.

\section{CONSTRUCTION}

- The contractor would have preferred to use closed panels to reduce time on-site and the need for on-site blown insulation that stopped other work from progressing while this happened. Limitations in the engineering of the system need to be overcome.

- The roof structure was delivered already prefabricated as a 'truss' of tie beam and rafters. This greatly helped construction and reduced craning time and requirements.

- 14 different types of fixing types were required for the assembly and installation of panels. While the contractor followed the drawings closely, this requires refinement, to avoid potential mistakes and simplify the assembly process.

- The tight construction programme caused difficulties and multiple trades working simultaneously, but proved a real test for the bespoke system and entire construction team who were new to fabricating and assembly.

\subsubsection{Tectonic form}

The longhouse was a successful translation of the vernacular precedents and concepts into a contemporary form and composition. The long, slender form and 
south facing orientation evoke the identity of a Welsh longhouse carefully located into the landscape. The two bays and coloured render panels provide personalisation that would vary slightly across a larger development. Internally Welsh slate across the ground floor helps as a thermal store in an otherwise lightweight structure while the Welsh sycamore softens the first floor bedrooms.

However, while the conceptual design intentions have been successfully incorporated and delivered, the expression and evidence of Welsh-grown timber has been limited to the cladding, external joinery and internal finishes. One box beam was exposed, and fire treated with intumescent varnish, to reveal part of the structure for exhibition, the rest is lost within the external walls. The following observations have been identified in relation to this tectonic:

\section{COMPOSITION AND FORM}

- The overall tectonic is not elemental or additive. Instead the external envelope is comprised of 9 layers from plasterboard to chestnut cladding that obscure any understanding of the construction within. Unlike the Environmental Resource Centre, the clients required a 'standard' internal finish with white painted walls and concealed services for affordable housing. Therefore a service void was required to avoid penetrating the infill panels and Intello membrane. Externally the extra layers of insulation created deep window reveals, akin to vernacular masonry construction, and provided summer solar shading reducing the benefits of solar gain.

- Two tectonic construction approaches are combined in the structure of the longhouse: frame with lightweight non-loadbearing enclosure; and panelised platform frame construction with layered finishes. Both the box section frame and open timber infill panel elements are capable of structuring a house of this size and proportion. In this case, it could be seen that the frame is superfluous as the solid stud, open frame panels provide the majority of the enclosure and could be structural adding little to the costs, in comparison to the frame. The difficulty with the frame and lightweight infil enclosure occurs when the envelope requires a U-value close to, or lower than, $0.15 \mathrm{~W} / \mathrm{m} 2 \mathrm{~K}$. The thickness of the insulation begins to match, or exceed, the thickness of a structural framed panel therefore making it more efficient to combine the two.

- Using lightweight green sweet chestnut and laminated hardwood windows seem to be appropriate timber elements to incorporate into a timber structure to complete the tectonic timber envelope. 
DIMENSIONAL COORDINATION

- Due to stair width and bathroom arrangement standards it was not possible to arrange the two central modules on a $1800 \mathrm{~mm}$ width while $2100 \mathrm{~mm}$ would be too long for the site or reduce the primary rooms in size. It was therefore necessary to break the intended $600 \mathrm{~mm}$ or $300 \mathrm{~mm}$ layout grid for these spaces.

\section{MODULAR}

- The original intentions to use spatial modules to define rooms and tectonic logic are not evident in the Longhouse. Each room is divided by the proportions of the module, however unlike exposed traditional oak frames inside the thermal envelope (such as the beach hut in chapter 6) the box section components are included as part of a $425 \mathrm{~mm}$ thick 'tube'. Furthermore these room divisions are on the minimum limit for DQR standards to

accommodate required furniture. To counter this, either the frames and internal walls need to be positioned independently of each other, thereby obscuring the modular tectonic further, or the floor components must span further. The use of engineered I-joists or refined spruce ladder beams may be a solution.

\section{CORPOREAL}

- The $210 \times 270 \mathrm{~mm}$ box sections are large and heavy, in appearance, when seen as a frame and not a delicate frame with an outer skin as proposed in the beach hut. If the box section frame was exposed internally, this would improve the tectonic connection between material, construction and space but the floor area would need to increase by $8 \mathrm{~m} 2$ per floor to accommodate a $270 \mathrm{~mm}$ wide structural zone around the perimeter to reduce the negative effect of protrusions. On the other hand the thermal bridging effect of the box sections in the wall would be improved.

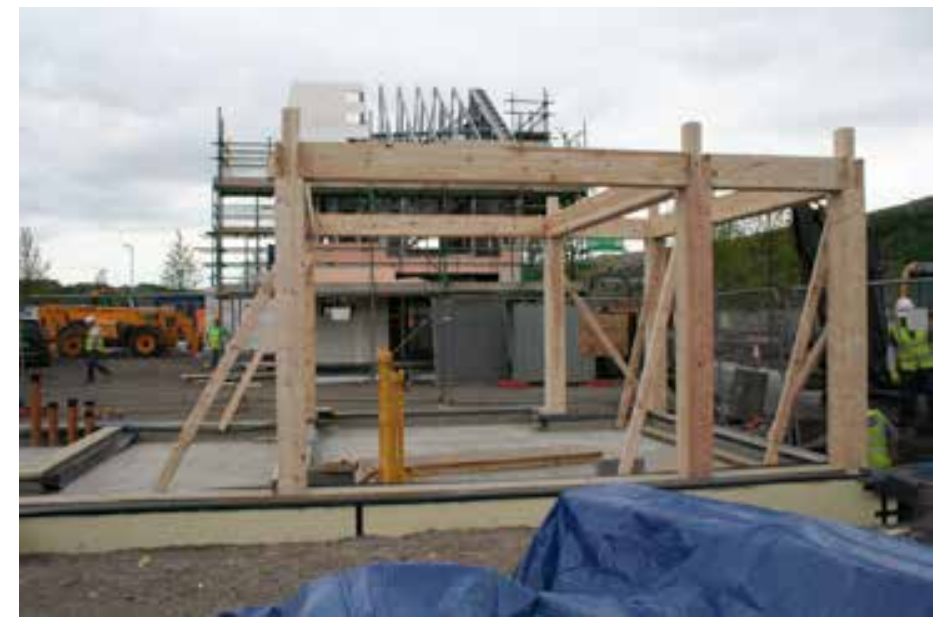

Fig 9.161 The Longhouse structural frame 


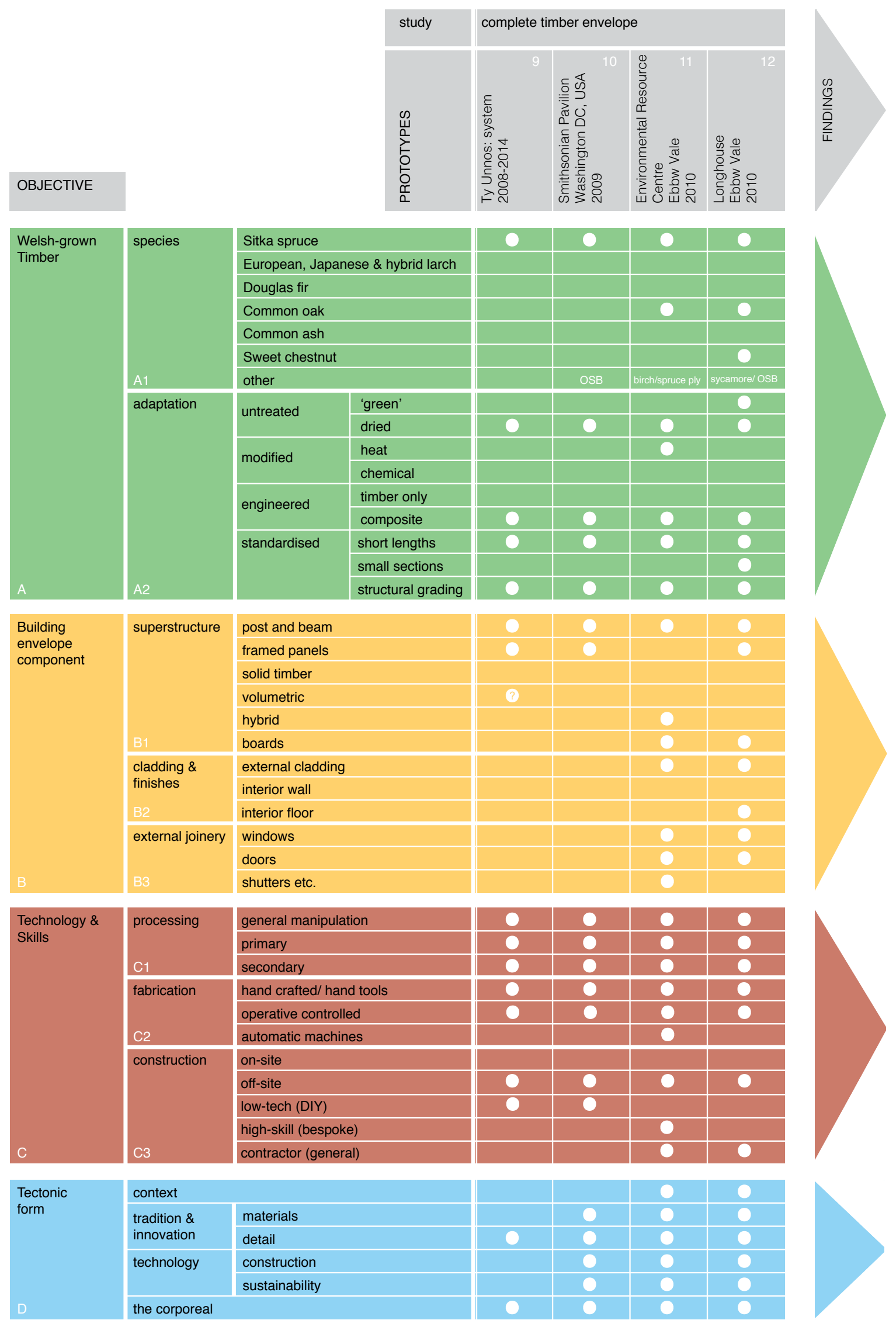

REFLECTION-ON-ACTION

\section{Findings on the complete timber envelope}

The research has shown that local, under utilised, low value Sitka spruce can be used in the design of contemporary and sustainable domestic scale architecture in Wales. Through a re-engineering of the timber, a series of modular responses have been made that show potential to use homegrown Sitka spruce and other softwoods, as an alternative to importing Scandinavian or North American timbers. More specifically, the system has been demonstrated to be efficient, sustainable and simple in the design of small span and domestic scale buildings. The weighting of components, the layering of the building envelope and building design have all contributed to the simplification of the building process eliminating large machinery and reducing the construction time on-site. The system, as demonstrated in this research, is based on:

- a modular glue-laminated post and beam structure, maximising the use of readily available, standard lengths and sections of Sitka spruce;

- a modular panel system based on spruce or other softwoods that can provide flexibility in use and adaptation in the future through wall, window and door positions;

- reduces the need to defect cut any spruce for laminating;

- using basic mechanical fixings such as brackets, plates and screws, to maximise the potential to disassemble and recycle/ downcycle the structure later.

In the three building prototypes, an elemental and additive process to design and manufacture has been observed that begins with local materials in their standard, modular format and contributes with other elements to form the complete building structure and envelope. While each prototype is spatially different, each design reflects the tectonic proportions of the material and modules that have been inspired by the local context and vernacular. The system does, however, have some technical limitations that need to be overcome to reduce cost, improve tolerances and flexibility and refine details for future projects and possible commercialisation:

- the box section frame and panels require further refinement when used together to reduce structural redundancy and repetition;

- the fabrication of the frame connections require less complexity and better thermal performance:

- the manufacturing process should be reviewed to increase production and reduce costs;

- the spatial configuration and distribution of services should be refined to avoid limitations caused by the box section frame. 


\section{CHAPTER 10}

Findings 


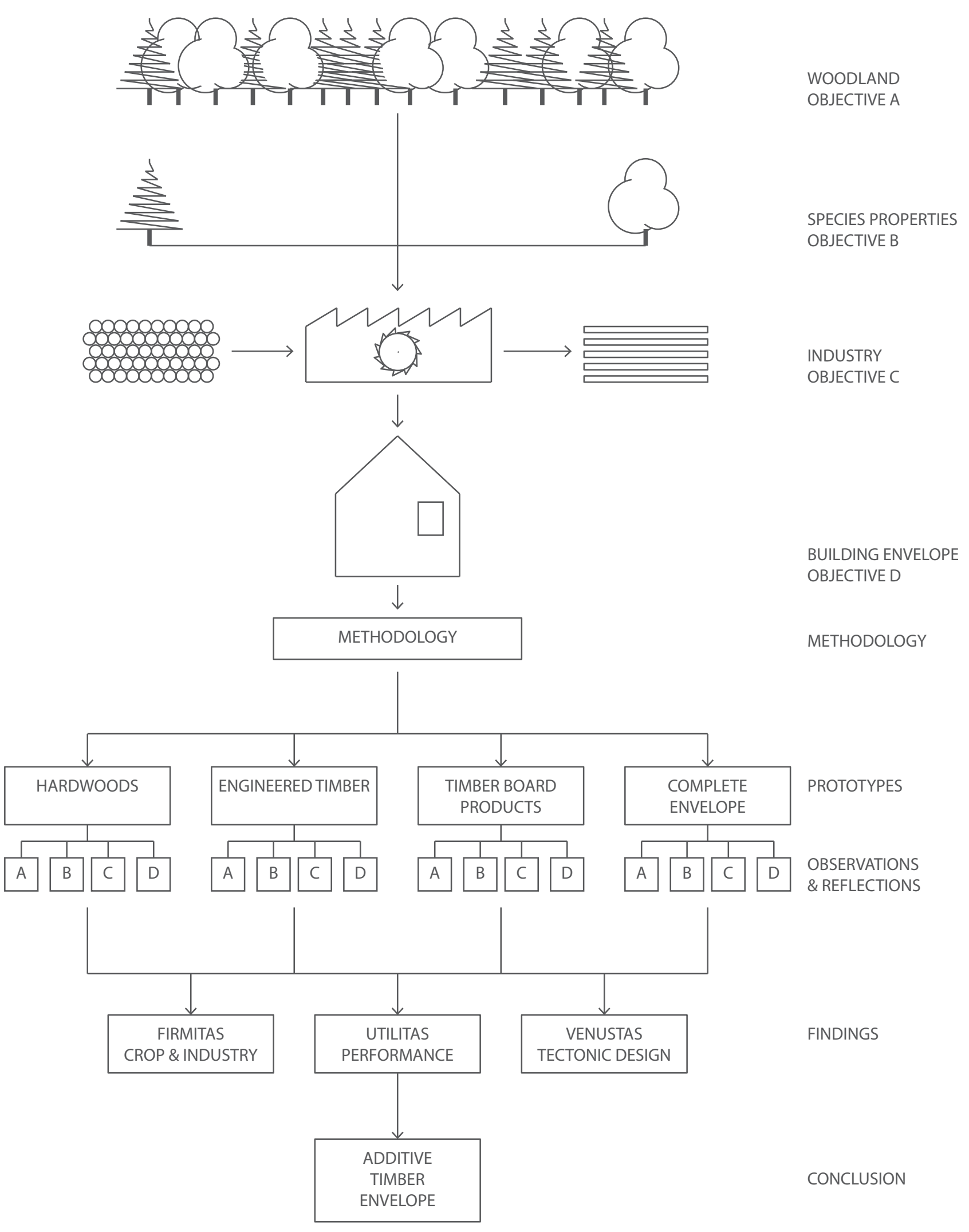

Fig 10.1 Routemap diagram of thesis structure

\section{1 Introduction}

In this chapter, the observations and reflections from the prototype studies are summarised into findings.

The studies reveal that there is potential to exploit the Welsh-grown timber crop in the design and construction of the architectural building envelope.

In chapter 2, six sustainable, Welsh-grown timber species were identified, that had significant potential to be incorporated in the building envelope. It was further identified that the properties of the crop require these species to be used or adapted in one of three ways: naturally, modified or engineered.

In chapter 3, the review of the timber industry and supply chain, from woodland to construction, identified barriers that resulted in large-scale importation of sawnwood and timber products into the Welsh construction industry. Opportunities were, however, recognised for using Welsh-grown timber in the design, fabrication and construction of primary and secondary products. These suggested that consideration must be given to the technology and skills available or required when designing the building envelope.

In chapter 4, the use of timber and timber products in the architectural design of the building envelope was appraised. This identified that timber was ideally suited to the construction of the building envelope in response to two critical agendas facing the wider construction industry: sustainable design, including low embodied carbon and low-energy performance; and construction efficiency, including modern methods of construction. The tectonic potential of this new way of working with timber was also considered.

In the context of these reviews, the research methodology, in chapter 5, posed a series of live design projects leading to physical prototypes as test artefacts focussed on particular elements of the building envelope and/ or complete buildings.

These prototype studies were clustered, and defined, under the following four themes identified from chapters 2, 3 and 4 as of significance in the use, processing manufacturing and construction with Welsh-grown timber:

Ch.6 Hardwoods

Ch.7 Engineered timber

Ch.8 Timber board products

Ch.9 The complete timber envelope. 
Fig 10.2 Completed framework for evaluation as a checklist of teste objectives.

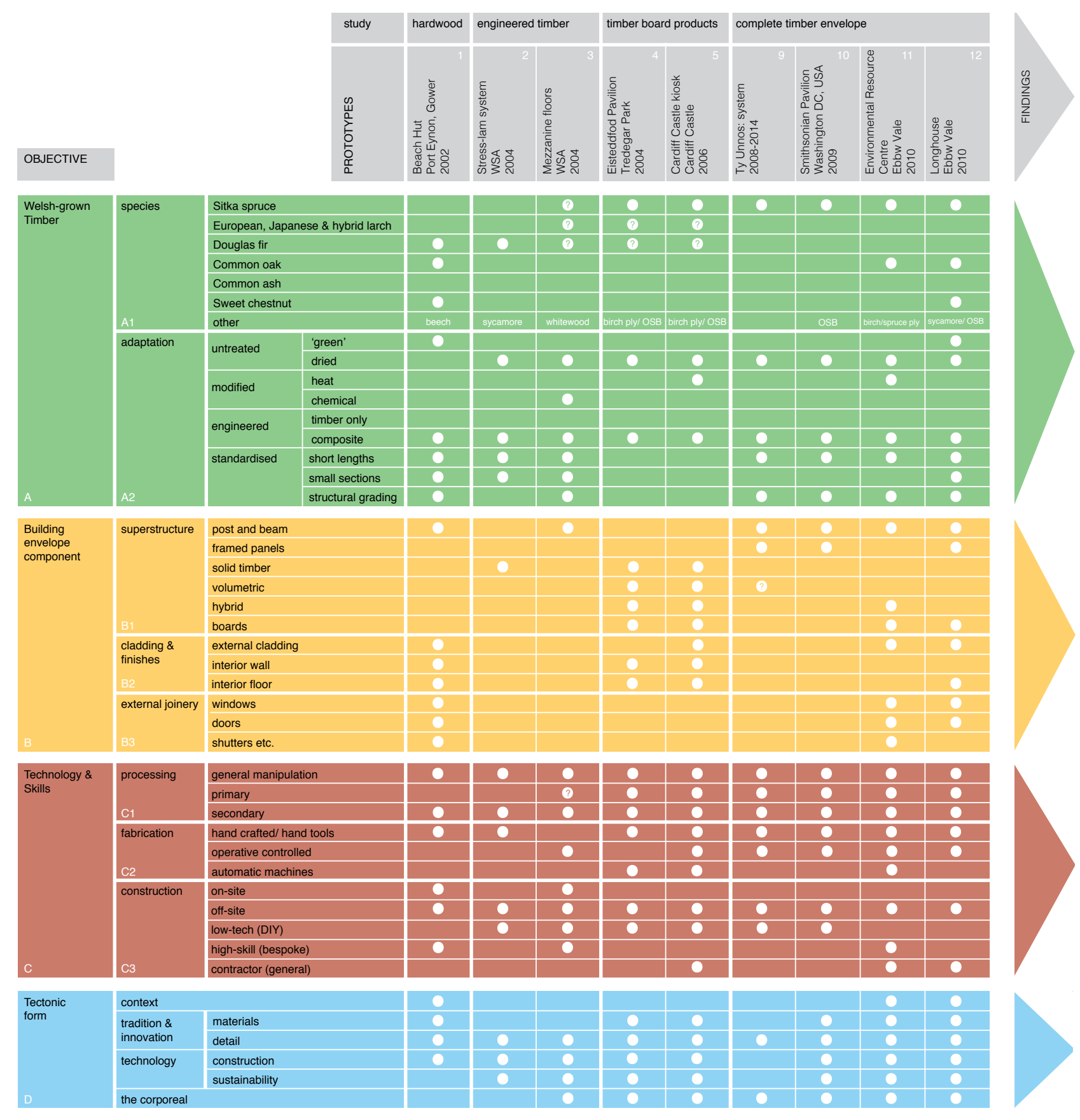

While the prototypes were focused under each of these thematic headings as the primary research objective, overlaps between themes were inevitable in the use of timber within the building envelope. This included the use of hardwoods and engineered timber as part of the complete timber envelope.

Within these themes, each prototype study was evaluated, leading to observations and reflections, against the following research objectives that were revealed in the matrix opposite:

A1 What timber species can be used in relation to the barriers and opportunities of its properties?

A2 Is any adaptation required to enhance the properties of the timber?

B1-3 How well does timber perform in a range of building envelope elements with differing demands on the properties of timber to meet building performance requirements?

C What are the implications on the technology and skills used (local) and/ or required (imported) to:

C1 process the timber?

C2 Manufacture products and components?

C3 Construct/ assemble the prototypes?

D What is the resultant impact of incorporating Welsh-grown timber on tectonic form?

Furthermore, the methodology sets out a model for prototyping based on Vitruvian categories of Firmitas, Utilitas and Venustas, that combine to create an integrated architectural prototype. Each prototype was the means to test the potential use of Welsh-grown timber in the building envelope against all of these categories, to differing amounts:

$\begin{array}{lll}\text { Prototype } & \text { Objective } & \text { Focus } \\ \text { Firmitas } & \text { A \& C } & \text { Crop and industry } \\ \text { Utilitas } & \text { B } & \text { Functional performance } \\ \text { Venustas } & \text { D } & \text { Tectonic design }\end{array}$

The observations and reflections are now collated into these three prototype formats in relation to the thesis aims and objectives: 
10.2 Firmitas (Crop and industry)

The prototype projects have revealed that it is possible to exploit Welsh-grown timber in the design and construction of the building envelope. However the projects revealed a number of species and industry barriers in relation to properties, technology and skills.

There is a political and social desire to use more Welsh-grown timber across all sectors. ${ }^{1}$ However, the woodland cover in Wales, at $13 \%$, is not high enough, with a good balance of timber species, to meet the demands of all sectors. This means, that without a change in forestry policy, there is likely to always be a limited volume of timber available. It was identified in chapter 2 that $22 \%$ of the sawnwood output from sawmills goes into construction, but that this only contributes to $42 \%$ of the total sawnwood consumed in construction. If it is assumed that the industry is operating at a maximum sustainable capacity and that the proportion available for construction will remain approximately $20-25 \%$, then the woodland area in Wales would need to increase by $238 \%$ to $31 \%$ woodland cover to meet $100 \%$ consumption. However, the limited structural grading of Welsh softwood and the higher grades preferred by European counterparts will not have changed. This means that adaptation of the Welsh-grown crop to produce engineered components and products will be essential to meet an increasing demand to reduce construction time, improve quality and environmental performance.

If increased volumes of Welsh-grown timber are to be used in the building envelope, above basic framing methods, there must be considerable changes across the entire timber industry from forestry to architecture. Many of the prototype projects have demonstrated the following barriers in the design process, fabrication or construction:

- timber species performance difficulties;

- $\quad$ problems with timber sourcing and availability;

- a lack of product availability;

- Cheaper or more cost efficient imported timber;

- a lack of, or costly, manufacturing technology or skills; and

- a gap in knowledge in specifying and constructing innovative timber systems.

The difficulties in using Welsh-grown timber in architecture are not entirely related to the weaknesses of the industry. Wales, as with the rest of mainland Europe, was once heavily covered in woodland, with thriving woodland based industries and

1 Forestry Commission Wales, Woodlands for Wales: The Welsh Assembly Government's Strategy for Woodlands and Trees (Cardiff: Welsh Assembly Government, 2009), p.8 
crafts people. However, whereas the industrial revolution and changes in building requirements, in particular after the Great Fire of London, precluded the use of timber in the UK, the culture of using timber in Scandinavia and across Central and Eastern Europe has prevailed. In the Vorarlberg, for example, the forests, wood working skills and designing and manufacturing with timber are parallel to cultural connections with material, craft, sustainability and way of life. ${ }^{2}$

The following findings have emerged, from all prototype studies, as of significance to the architectural designer in the design of the timber, building envelope:

\subsubsection{Welsh-grown timber and adaptation}

- Use only oak and sweet chestnut, as the only durable timbers grown in Wales, or Japanese larch, as moderately durable, in external conditions.

- Limit use of hardwoods to $150 \times 150 \times 1200 \mathrm{~mm}$ lengths as an output of continuous cover forestry, which is becoming increasingly practiced in private woodlands for the medium-term until specific trees reach maturity.

- The larger sections of oak, $150 \times 150 \mathrm{~mm}$, will take up to 6 years to season. These should therefore be used green with careful consideration to the movement details. Since the beach hut design, TRADA and the Forestry Commission have published guidance specifically on the use of green oak structures and green claddings.

- The use of short lengths of solid oak were calculated and detailed as a possible structural system in the beach hut, however the number, complexity and costs of all the connections poses difficulties in this type of application for larger or more integrated building envelopes. The low-tech approach to laminating softwood box sections suggests further research may therefore be required on laminating smaller sections of kiln dried oak into longer posts and beams.

- Smaller section oak and sweet chestnut are ideal for external claddings or kiln dried and laminated for joinery.

- C16 Sitka spruce, larch and Douglas fir have been identified as appropriate for housing construction, although they typically cost more than imported C24 whitewood for an average dwelling. Therefore value must be added to Sitka spruce through engineering, such as the low-tech box section components, to compete with imported equivalents.

- Alternative modification methods, such as charring timber, are successful in improving durability and increasing resistance to fire ignition and spread. This eliminates the need for chemical treatment, instead utilising the natural 
properties of timber.

- There is a large market opportunity to manufacture spruce, birch or other hardwood plywood in Wales, which has been incorporated into two prototypes as an upgraded structure and internal finish. Further research is required on the properties of Welsh-grown spruce, birch and other species to produce veneer., although it is acknowledged that the scale of investment required is significant and that tall, straight trees with even growth and

limited knots are ideally suited to veneering. This on first glance may not suit Welsh grown Sitka spruce, but may be appropriate for other soft and hardwoods.

- It was not possible to test ash or larch in any of the prototypes. Both species have been affected by separate diseases ${ }^{3}$ that has resulted in increased felling and burning of the felled timber, in particular larch, to stop the spread of the diseases. It was intended to use ash in the beach hut prototype (chapter 6) due to its good structural capacity, however its poor durability and tendency to suffer from seasonal moisture movement meant it would be best used within an enclosed building envelope. It is noted that larch has a greater potential to achieve higher structural grading than Sitka spruce, but this would need to be visually graded at extra time and cost than commercial processing of spruce. The resultant exclusion of these species, despite beneficial quantities and properties highlights on the one hand the limitations and difficulties the industry has in being able to rapidly respond and exploit opportunities and on the other the delicate balance of forest management that affects a natural resource. A situation exists at the time of writing where large quantities of healthy larch are potentially becoming available for use in construction. Opportunities exist to conduct further research into the specifics of larch, but with a finite and dwindling supply that will not be available again for, at best, $20-100$ years. ${ }^{4}$

\subsubsection{Material efficiency}

It has been identified in this research that an efficient approach to the Welsh timber resource must be taken. A wide range of industries now relies on timber for packaging, fuel, paper, toys and other products. The volume of timber available does not provide the luxury of just using good straight timber from the main trunk, now the industry must consider using 'everything but the rustle of the leaves in the wind. ${ }^{\prime}$ This is practiced through continuous cover forestry to balance biodiversity

3 Chalara Fraxinea - ash dieback, Phytophthora Ramorum - larch

4 The author has used Welsh-grown ash for internal flooring at his own home that has been susceptible to significant moisture movement throughout the seasons.

5 Interpreted from 'Everything but the squeal' that was attributed to the meat-packing industry from the 1860's and coined in the novel The Jungle, by Upton Sinclairs in 1906. 
and future sustainability with timber production. However, in the production of many of the prototypes it was revealed that processing, fabrication and construction produced significant volumes of wastage. This was not regarded by any as desirable, however the properties of Welsh-grown softwood, in particular, meant that post kiln drying planing and adjustment; defect cutting during structural testing; and general manipulation of sizes during fabrication and construction inevitably resulted in off-cuts, chips and saw dust. These are typically used as biomass to heat workshops or to power kilns, however the prototype studies have highlighted the benefits of a number of imported products that could maximise the use of fast growing, waste timber and add-value in their manufacture such as woodfibre insulation and Oriented Strand Board (OSB). These products do not require structurally graded softwood and with the use of formaldehyde free adhesives will exploit the full potential of Welsh-grown timber in sustainable construction.

Furthermore, the stress-lam, mezzanines, and Ty Unnos prototypes have highlighted an additive process of fabrication that utilises smaller sections and shorter lengths to produce higher performing products.
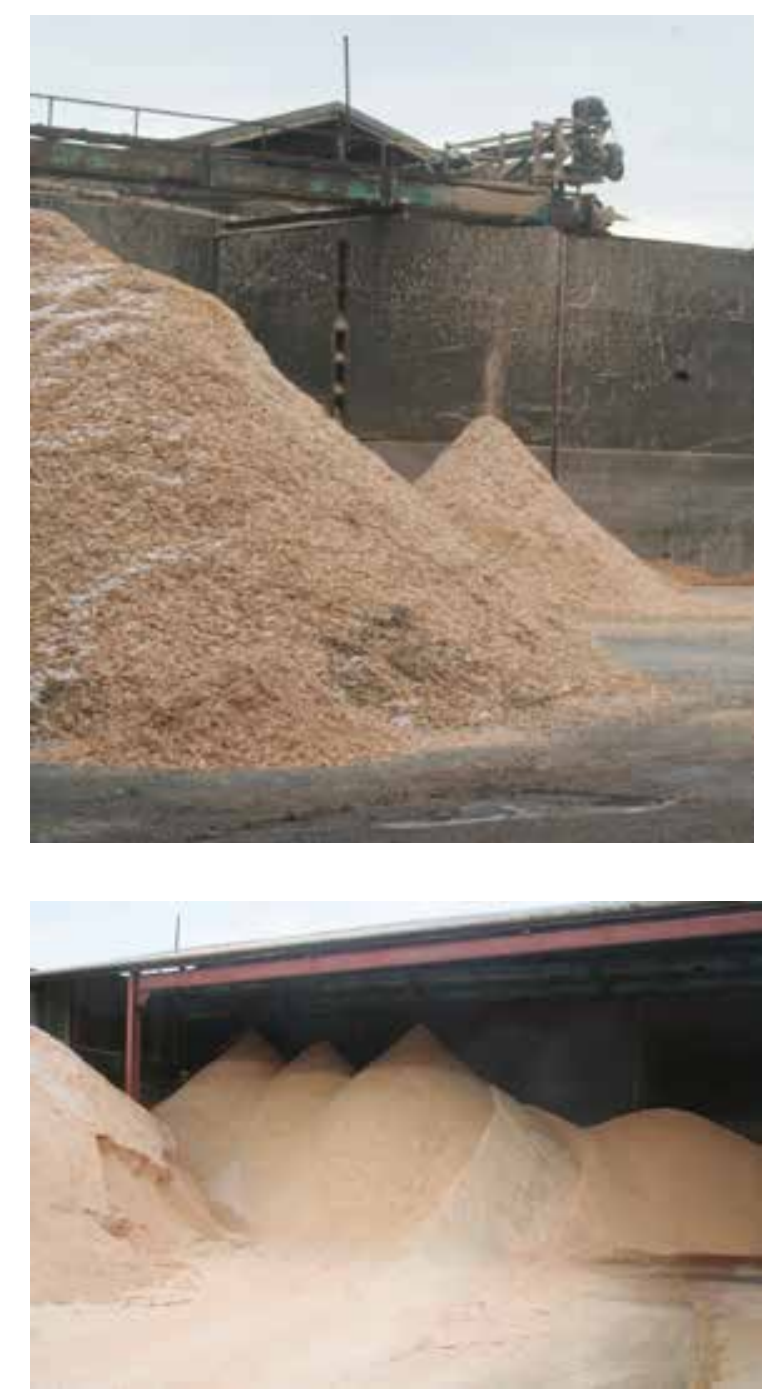

Fig 10.3 Photographs of chippings and sawdust produced during roundwood processing at BSW sawmills at

\subsubsection{Fabrication and construction}

During the period of conducting this research, the primary processing industries have begun to embrace high-tech production lines for the processing of sawnwood at BSW and Pontrilas sawmills and the manufacture of MDF and particleboard by Kronospan in Chirk. However, the technology available in the secondary processing industry remains basic allowing, at most, for pre-cutting timber studs for the manual assembly of open panel frames. These prototypes, and other parallel work to this research, have shown that the industry is favourable and willing to consider alternative technologies, if reliable end markets are identified. This highlights that industry innovation is often limited by market demands. While the clients and designers continue to specify imported timber products, the industry will not be able to grow.

The prototype projects have shown that many of the perceived barriers of using Welsh-grown timber, identified by the secondary processing industries in chapter 4, can be overcome during manufacturing, fabricating and constructing timber components and systems. All prototypes, except the mezzanines, involved aspects of off-site prefabrication to add value, enhance structural capacity and improve stability of structural components, reducing time on-site and improving quality and tolerances of components. 
Difficulties in securing capital investment within SME's, that represent the vast majority of the timber processing industry, has been evident throughout the design and construction of all prototype projects. The multi-dimensional aspect of woodlands, forest industries, the environment and the construction industry means that political support and investment falls under various Welsh Government departments. These have changed and evolved throughout the course of this research, causing difficulties in securing research and development funding for particular projects. ${ }^{6}$ At industry level, businesses from timber frame companies to joiners struggled to secure investment or fully commit to research and development without financial and/ or time support from other parties such as the Design Research Unit Wales, funded by the Technology Strategy Board for the Ty Unnos research, highlighted in chapter 10 . This therefore leads to the further importation of innovative products from outside Wales, and the UK as the most cost effective approach, but further limits opportunities to develop homegrown solutions.

However, the skills and technology available are adequate to manufacture a range of low-tech, off-site prefabricated, elemental components. These include hand crafted hardwood contemporary tusk and tenon joints, framed structural panels, innovative solid timber panels and volumetric timber modules. However, limitations were identified in the crossover between trades to integrate multiple elements such as windows, doors and claddings into complete prefabricated structural modules. This lack of integration, increases time on-site to assemble and apply layers of building envelope that delay the speed at which a watertight shell is provided and therefore the protection of internal finishes.

The industry is at present, reliant on established, tried and tested methods and technology that are increasingly becoming out-dated in other European countries. This has resulted in innovation that works within current low-medium technological parameters, limiting maximum potential. For example, at the time of these prototypes, there was no access to finger jointing machines ${ }^{7}$ or a large-scale press for glue lamination. These could be seen as essentials in the development of new products to exploit the timber crop.

Improved construction efficiency has been demonstrated through an understanding of the current industry technology and skills limitations:

6 In 2014, Natural Resources Wales was formed under one Minister whose portfolio also includes the general categories of planning policy, building control, sustainable development and environment 7 Kenton Jones Joinery invested in a finger jointing machine in summer 2015 to create longer floor and cladding boards as well as utilising shorter lengths of Sitka spruce for Ty Unnos that have been cut from warped and twisted boards. 
- It was found that a low-medium technology approach complements the industry and the available technology and skills. Products and systems that require high-tech manufacturing processes such as brettstapel, CLT, glulam and plywood are not manufactured in Wales and do not use Welsh grown timber. Therefore, if these are specified, they must currently be imported.

- However, it has been demonstrated that low-tech, innovative, construction methods can be successfully manufactured and assembled, such as stress

lam, Ty Unnos box sections and external joinery, in small workshops with the typical tools and machinery available to any carpentry or joinery business in Wales.

- The Ty Unnos box sections and ladder beam cassettes have been certified, with ETAG approvals, and used in component form by other members of the design research team for other projects. The manufacturing processes

presented in the prototype studies are not proposed as the primary means of manufacturing these components, but demonstrate that the potential exists to develop a low-tech process that can be scaled-up, as demand and costs allow, to commercial level production lines. These do not necessarily need to be high-tech, although it is acknowledged from the manufacture of glulam, CLT and brettstapel that greater efficiencies and output are gained from automatic machine based production lines.

\subsubsection{Collaborative design}

The process of conducting and delivering all prototype projects confirmed the importance of collaboration in the designing, specifying, detailing, fabricating and construction of timber architecture. While collaborative and multidisciplinary design teams are common in architectural projects, the successful use of Welshgrown timber extends beyond the usual design team consultants such as project managers, quantity surveyors and engineers. Throughout the prototype projects, the author has worked primarily as lead architect in collaboration with foresters, timber management specialists, timber researchers, carpenters, joiners, timber frame manufacturers, structural engineers and contractors as well as clients and end users. The teams were not the same for each project, but specific to the needs of each to bring independent specialist knowledge and guidance on the growing, physical properties, use, technology and detailing with Welsh-grown timber.

The need to collaborate highlighted a lack of knowledge across the construction industry on the use of Welsh-grown timber including architects, structural engineers and contractors. The prototype projects and research funding therefore provided an opportunity to train specific skills, instead of importing knowledge that would be lost 
as soon as the project ended. This was particularly evident in the Ty Unnos projects, in chapter 10, that allowed the structural engineers to train a newly qualified engineer, who has now become a structural timber specialist.

In all projects the collaborators were external to this thesis bringing an aspect of 'real-world' influence to the prototypes that has been essential to the process and outcomes of this research. Some were co-researching, with different aims and objectives within a different part of the timber or construction industries. Some have directly benefited from the research in relation to manufacturing processes, products, knowledge, commercial opportunities, or from the completed prototype or building.

This need to collaborate was not only the means to be able to conduct the research but has also highlighted a gap in the Welsh timber industry to market timber products simply and efficiently to design teams. The majority of architects do not have the fees or time available to conduct and engage in extended research and development of new products for their projects. This therefore confirms the suggestion in the Jaakko Poyry report, that a 'centre of excellence' for timber research and development be established as both the basis of timber innovation and a 'shop front' to the timber industry.

\section{Utilitas (Functional performance)}

The prototypes demonstrate that Welsh-grown timber can be used innovatively in the design and construction of the complete building envelope. The projects provided successful tests on the complete range of building envelope elements identified in chapter 4, including six superstructure methods, claddings, finishes and external joinery to differing degrees of success as discussed below.

The findings on the performance of timber and timber products within the building envelope are summarised:

\subsubsection{Superstructure}

The prototypes revealed detailing difficulties within the building envelope due to the higher tendency of moisture movement in Welsh-grown timber, across the majority of species tested. This is not only during seasoning or drying, but also in performance, due to the hygroscopic properties. This is most noticeable in the variable shrinkage and expansion corresponding to seasonal and activity related humidity levels. While this is acknowledged and allowed for in claddings, through the detailing of board profile, ventilation and fixings, difficulties are found in the multiple 
element, small section timber, superstructure prototypes, such as the beach hut and stress-lam table. Despite an awareness of the expected shrinkage and designing appropriate fixings between structural components, it is the impact on the other elements of the building envelope that have the most significant effect. The beach hut project demonstrated the hypothetical problems that the movement may cause with the window infill and cladding components. This was witnessed in the stresslam system and non-engineered elements of the mezzanine floors where significant movement resulted in twisting, settlement and gaps. These multi-element systems are likely to result in a separation of structure and envelope to allow for differing movement.

However, the most successful, integrated timber superstructures involved the reduction of moisture movement through engineered solutions as seen in the use of OSB and plywood to provide racking resistance in framed panels and the laminated box and ladder beams. This would further suggest that for reliable, stable, structurally enhanced timber structures, engineered timber solutions such as CLT, brettstapel and glulam should be considered for manufacture with Welsh-grown timber. This is evident in the precedent studies, of projects from around the world, where there is an increasing demand for solid timber systems over framed panels and hybrid glulam post and beam structures combined with other materials for larger spans and number of storeys.

\subsubsection{Claddings, finishes and joinery}

The design and specification of the prototypes confirmed difficulties in the sourcing, supply and manufacturing of Welsh-grown cladding, finishes and external joinery. Welsh joiners and timber merchants often use and supply products manufactured from imported timber including western red cedar, pine and sapele as the default choice, with Welsh-grown timber sometimes offered as a premium product. Alternative modified timber options specified and supplied include Thermowood, using spruce, pine, birch and aspen from Finland and Accoya, processed in the Netherlands using Radiata pine from New Zealand. The prototypes found that oak, sweet chestnut and Japanese larch are ideally suited to external finishes and joinery in the often exposed locations and wet climate across Wales, although larch will only be available for a limited period of time. All other species are appropriate for most internal finishes. Further testing is required on successful initial research, by Bangor University and Coed Cymru, on the heat treatment of larch, Douglas fir, beech and sycamore for cladding and joinery.

The bespoke external joinery included in the prototypes showed varying results that highlights the need for increased research and development: 
- The Coed Cymru window system developed with Coed Derwen successfully laminated small sections of hardwood into low-tech, standardised windows and doors, however the cheaper competition from imported softwood, composite and UPVC windows resulted in low-demand resulting in the closure of Coed Derwen.

- The low-energy window designed and prototyped in the Longhouse has shown signs of de-lamination on the exposed elevations over 5 years. This is partly due to lack of maintenance on the part of the client, highlighting the lack of knowledge on the part of owners, and partly due to detailing problems with the ability to drain and throw water away from the frame.

\subsubsection{Integrated envelope}

It was identified in chapter 4, that timber is ideally suited to prefabricated architecture. All prototypes incorporated differing forms and complexity of prefabrication in response to the limitations and opportunities of industry technology and skills. The off-site fabrication allowed for more efficient uses of standardised timber lengths, sections and products with a greater degree of control allowing for final finishes to be incorporated into components. The full potential has been limited, however, by a lack of complete integration that results in increased onsite care and protection to avoid physical and weather damage while components are assembled into a weathertight envelope.

Low-tech prefabrication has been shown to better suit the Welsh industry with limited integration of the complete building envelope. The handcrafting of oak tusk and tenon joints into prefabricated components for site assembly and the limited component prefabrication of the Longhouse and social housing projects highlight these limitations. Whereas the increased complexities of the castle kiosk and ERC resulted in increased, prohibitive, costs and the use of a non-Welsh manufacturer respectively. Furthermore, the volumetric modules of Margam Discovery Centre were fabricated in Hull, England, although Elements Europe, in Oswestry, Wales, have altered an established light steel frame volumetric pod production line to fabricate volumetric Ty Unnos units for housing construction. Early developments by a timber frame manufacturer, to invest in plant for the production of closed timber panels, were curtailed by fears over market demand, capital costs and the recession of 2008.

Timber prefabrication has the potential to enhance building envelope environmenta performance, as proven in Central Europe. While the renewable, carbon sequestration and thermal benefits of timber are widely known and established; the opportunities to exploit this with Welsh-grown timber are limited. All prototypes were intended to 
push the building envelope beyond Building Regulation requirements, although only the ERC and Longhouse were realised. It was found in these two prototype projects, along with Margam Discovery Centre and the social housing projects, that it is

possible to integrate low energy design into the timber envelope in Wales, within the following parameters:

- The industry is technically limited to prefabricate higher performing solutions, although the industry is willing to innovate, such as the thermally broken,

low-energy Longhouse windows and doors, but lacks the investment, support and knowledge to do so.

- Innovative superstructure systems have the potential to further reduce thermal bridging through prefabrication and replacement of solid timber elements with thermally broken equivalents, such as the box sections and ladder beams.

- The lightweight framing lacks thermal mass to provide thermal stability. If CLT or brettstapel products are not available, further research could consider hybrid solutions with concrete or masonry products that are readily available in Wales.

- The prefabrication of elements must consider broader integration with other components to improve tolerances and therefore reduce thermal bridging and increase air tightness. The fixing of many small components increases the proportion of on-site differential movement and air passages between. These can be resolved on-site but rely on applied membranes, used in the longhouse, that conceal the tectonic, corporeal benefits of timber within the envelope.

- Superstructure methods to achieve low-energy performance tend to point towards a layering of building envelope components that have a dramatic impact on building footprints and wall thickness.

- The prototypes, products available and precedents suggest that it may be possible to build an entirely prefabricated, low-energy timber building

\subsubsection{Fire protection}

A significant difficulty in the use of timber as part of an exposed tectonic structure relates to fire protection. While post and beam structures can be impregnated with water-based fire retardants, this becomes impractical and cost prohibitive the more timber is exposed, such as with solid timber panel systems. This leads to the multilayering of the envelope to encase the timber behind plasterboard providing 30 or 60 minutes of fire protection. This is the standard approach to open timber frame panel construction, however, increased timber product innovation may require alternative approaches to fire protection. 
10.4 Venustas (Tectonic design)

The prototype projects demonstrated the potential for the development of an architectural language specific to the use of Welsh-grown timber, determined by timber properties, technology and design innovation. Design processes and completed prototypes have revealed tectonic successes, opportunities and limitations that have been informed by, integrated with and influenced the technical and performative findings. The findings presented here are therefore the result of the way in which Welsh-grown timber may be incorporated in the architectural design of the building envelope.

The aim of the prototype designs was to create architecture with a clear tectonic language resulting in a comprehensible form. Timber products and components are detailed to be recognisable and exploited for their physical and physiological qualities. The building elements were designed for their functional requirements in conjunction with corporeal experience and not used as applied ornamentation or decoration.

Often the tectonic form was inspired by a juxtaposition of structural typology, elements, language or materiality such as heavyweight and lightweight (stereotomic and tectonic) or solid and filigree. The key tectonic findings are summarised under the following headings:

\subsubsection{Rules, grids and systems}

All prototype projects have been designed, fabricated, constructed or assembled following identified rules, grids and systems for structures and spatial arrangement or composition. These have informed each other in a cyclical process, where spatial rules have informed the development of a system, or an intended system provided a structural grid that generated architectural rules. In each prototype, conceptual rules were established and guided design and making decisions on the use of Welshgrown timber and timber products within a prefabricated, low-energy building envelope. Raimund Abraham highlights this in a study of Alpine timber buildings: 'The elementary function of architecture is to realise building concepts with the simplest of means. The dependence of these means on the development of technology determines the laws which govern any particular way of building.'

The grids have been found to provide a clear spatial ordering, structural and/ or constructional control and logic to plan, section and elevation that are integral to the use of timber. The grids were not always uniform, but often irregular responding 
to the limitations of the system, material sizes or structural capabilities. However, regardless of the format, the grids have been based on either a $300 \mathrm{~mm}$ or $600 \mathrm{~mm}$ dimensional coordination, as is common within the construction industry. The standardisation of building materials generally into lengths and widths of $1200 \mathrm{~mm}$, $2400 \mathrm{~mm}, 3600 \mathrm{~mm}$ and so on, meant that the efficiency of spatial configuration, material usage and construction was always considered, avoiding unnecessary complex details, form and material wastage.

\subsubsection{Composition and form}

The prototype building elements have been incorporated as straight-forward, lowtech modules and components. This was not to eliminate architectural expression, but to consider efficiency in space, repetition, materials, construction and energy that have led to a rational organisation with decoration confined to the composition of the functional.

It has been identified in the prototypes that a tectonic timber architecture is dependent on an 'honest' expression of the building elements, where timber properties, detail and construction can be logically understood and experienced. For the use of timber to be understood and complement the enclosed space and environment each element must be clearly expressed in relation to its function. Where this has not been possible, such as the use of open framed panels and the longhouse superstructure, there has been a disconnection with the essence of the building replaced with generic, non-materially explicit plasterboard and painted finishes.

The conceptual approaches and building envelope form have been developed from a separation of the elements akin to Semper's Four Elements ${ }^{9}$ and Primitive Hut model as: floor, walls, roof and hearth with spatial arrangements derived from lifestyle. This has simultaneously addressed enclosed space, timber properties and environmental performance with a context and climate responsive form.

The prototypes reveal a combination of elemental, modular and layered approaches to manufacturing and construction with differing implications on the tectonic form.

\section{- Elemental}

The separation of building envelope elements or individual timber lengths and products, following a rational geometry and grid, has allowed for each part of the building envelope and the performance requirement implications 

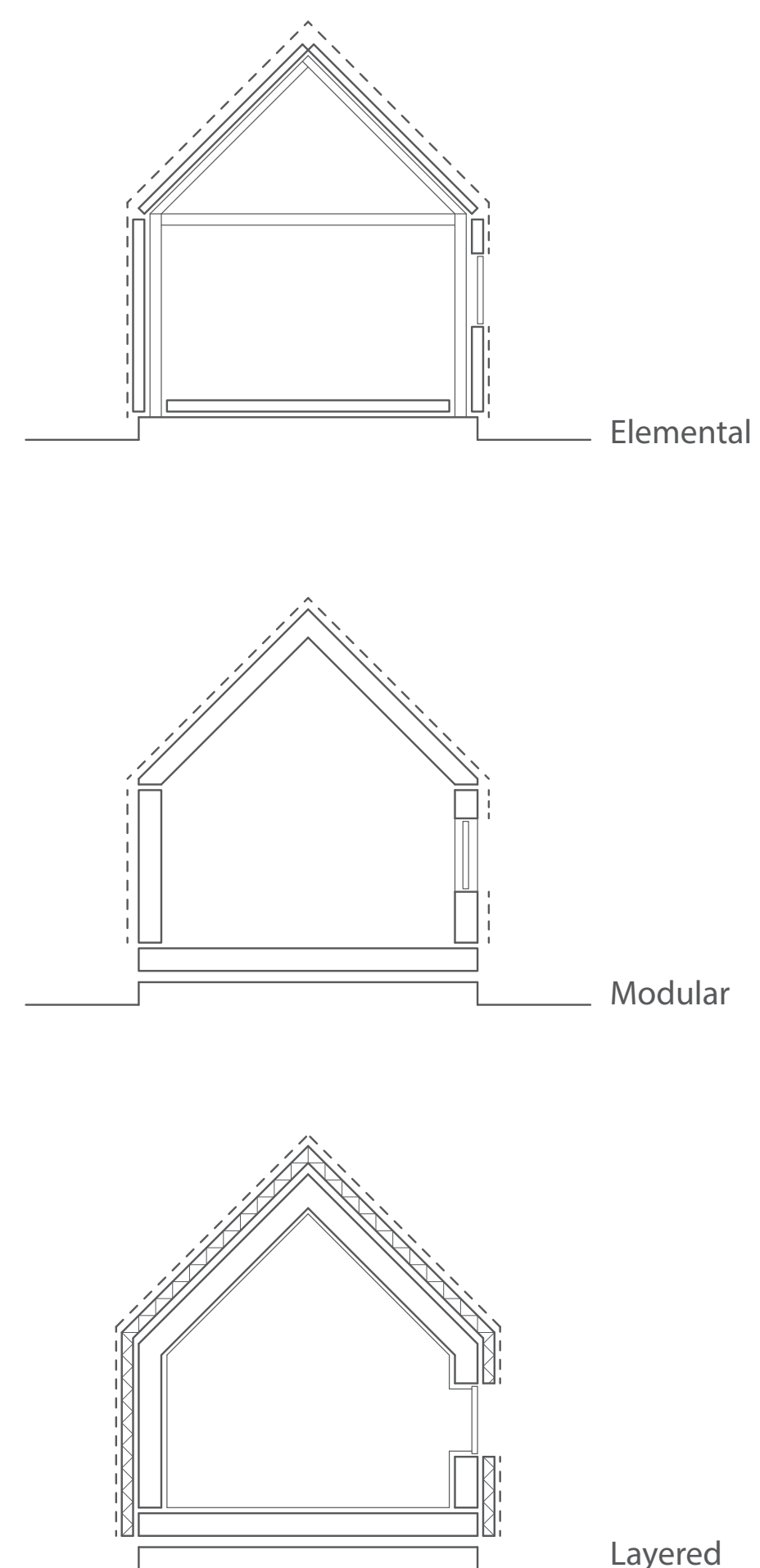

Layered on timber to act independently to one another. This allows for differential shrinkage and expansion, stability, breathability and ease of integration. The resultant form is therefore a didactic expression of timber in architecture.

- Modular

All prototypes used a combination of modular components. The modules were either based on a standardised, off-the-shelf raw material, for example a standard length of timber or board size, or as prefabricated frame, panel and volumetric components. In both cases, the modules are designed to the determining grid, which then becomes the repeated modular grid, thereby resulting in a form based on material sizes that are composed to generate a required spatial arrangement, that is then repeated horizontally and/ or vertically with minor variations.

\section{- Layered}

A layered approach was identified as a means to achieve a low-energy building envelope, although commonly used in open frame panel construction. The superstructure is assembled and then sandwiched with layers of material products, modules and elements to provide diaphragm resistance, water and air tightness membranes, insulation, claddings, service voids and finishes. This is a pragmatic, technical response to successfully meet specific performance targets, although this can be detrimental to the tectonic form and devoid of the poetics of the material, craft and sense of space.

However, layering has also been identified as a means to enhance the performance of Welsh-grown timber. Laminated components such as LVL, glulam, stress-lam,

CLT, plywood and OSB rely on the layering of small section or thin veneers, strands and chips in parallel or perpendicular to one another to provide engineered enhancement to structural and stability limitations.

Separating building elements, modules, enclosures and finishes provided a number of further benefits to construction:

- Touch the ground lightly, requiring minimal ground invasive foundations;

- Prefabrication of panels and volumetric modules for simple on-site assembly;

- Lightweight claddings and components;

- Simple maintenance and adjustment of components

- Allow for disassembly, re-using and recycling of components. 


\subsection{Conclusion: an additive timber tectonic}

In conclusion, this thesis has demonstrated that the unique properties of timber, sustainably grown, managed and processed in Wales can be innovatively fabricated and assembled into prefabricated, components for the design and construction of the low-energy architectural building envelope. Furthermore, the properties, technology and skills available have informed an additive tectonic approach that is specific to Welsh-grown timber.

Having presented the findings of the three aspects of prototyping, it has been possible to identify an approach to the design of an 'integrated timber architecture' that has been equally influenced by: the species available; timber properties and performance; industry technology and skills; and the building envelope performance requirements.

The design and construction of a standardised, prefabricated timber architecture based on repeating species, components, elements and spaces draws inspiration from Jørn Utzon's notion of Additive Architecture: 'A consistent exploitation of industrially produced building elements is only achieved when these elements can be added to buildings without the components in any way needing to be cut or adapted.' ${ }^{10}$ Within the context of this thesis, the additive is seen as both a technical and design process by which the crop is processed and enhanced to add value.

It has been found that the use of Welsh-grown soft and hardwood is best based on standard lengths and section sizes either determined by the process of sustainable woodland management and extraction or processed by sawmills. In both cases, this leads to an efficient production of timber with minimal wastage. Where there is waste, this is reused or recycled for other products and systems. This is the base timber component from which all products and elements are manufactured. It would therefore be the intention to use these lengths and sections as supplied or in exact divisions or multiples of standard lengths to maintain material efficiency. This, in turn, influences the module sizes of elements, panels and volumes to be composed into spatial compositions determined by context, climate and the client. The result is a tectonic expression unique to Welsh-grown timber but flexible to allow for expression and a contextual response.

Five aspects of an additive principle have been identified that incorporate the key findings from the prototype studies and highlight a way of working with Welshgrown timber that is intended to be an approach to understanding and designing 
timber architecture. Specific details and sizes are only provided as a guide in relation to the prototype projects for each stage, but should not be seen as predetermined or the only sizes available. Source, species, sawmill, secondary processing and design decisions all influence sizes and products that may differ from project to project and as technological investment allow.

The following additive principles are listed from woodland to architecture, although this could also be seen as a cycle of influence where grids, systems, material and products influence each other. The additive principle therefore operates simultaneously as a process, technical detail, design tool and expression that does not follow a sequence of stages, but represents both a bottom-up approach to timber use and fabrication and a top-down expression of Welsh-grown timber in the building envelope. The two meet within the timber and construction industries generating a tectonic timber architecture.

\subsubsection{The species}

Woodland management and the extraction of small-medium diameter roundwood of all species, for processing provides the limiting factor by which industry and designers must initially subtract from before adding value. The following table provides an overview of typical Welsh-grown species against appropriate building envelope uses, exposure and suggested enhancement.

\begin{tabular}{|c|c|c|c|c|c|c|c|c|}
\hline & \multicolumn{8}{|c|}{ Standard sawn softwood sizes } \\
\hline & \multicolumn{8}{|c|}{ Welsh-grown species } \\
\hline & \multicolumn{5}{|c|}{ Hardwoods } & \multicolumn{3}{|c|}{ Softwoods } \\
\hline & Oak & $\begin{array}{l}\text { Sweet } \\
\text { chestnut }\end{array}$ & Ash & Beech & Sycamore & $\begin{array}{l}\text { Spruce } \\
\text { Sitka \& Norway }\end{array}$ & Douglas fir & $\begin{array}{l}\text { Larch } \\
\text { European, } \\
\text { Japanese anybrid }\end{array}$ \\
\hline Superstructure & - & & & & & - & - & - \\
\hline External joinery & - & - & & & & & & - \\
\hline Cladding & - & - & & & & & & - \\
\hline Finishes & - & - & - & - & - & & & \\
\hline External & - & • & & & & & & \\
\hline Internal & - & - & - & - & - & - & - & - \\
\hline Green & - & - & & & & & & \\
\hline Kiln dried & - & - & - & - & - & - & - & - \\
\hline Engineered & - & - & & & & - & - & - \\
\hline Modified & & & & & & - & - & - \\
\hline
\end{tabular}

Fig 10.6 Table of potential Welsh-grown species against appropriate uses exposure and enhancement. 
The reduction of roundwood into standardised sizes, for use in construction,

maximises the potential of the roundwood and minimises waste. The sizing is determined by the needs of the construction industry and an efficient exploitation of roundwood that form the basic components or modules to be repeated and multiplied.

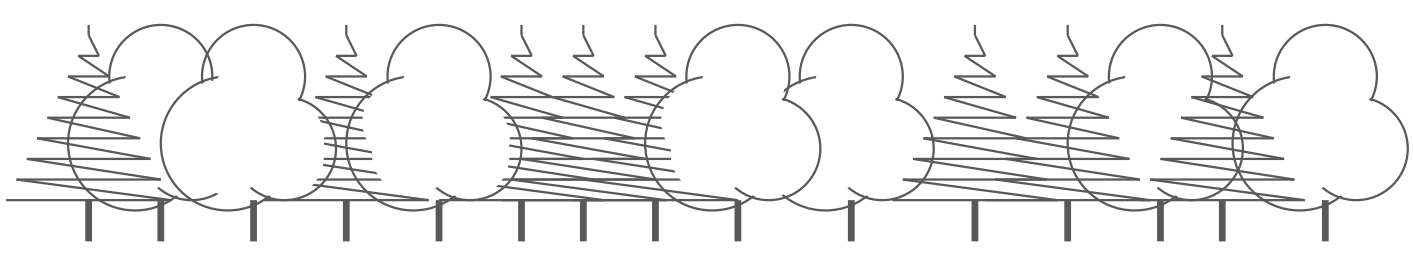

WOODLAND

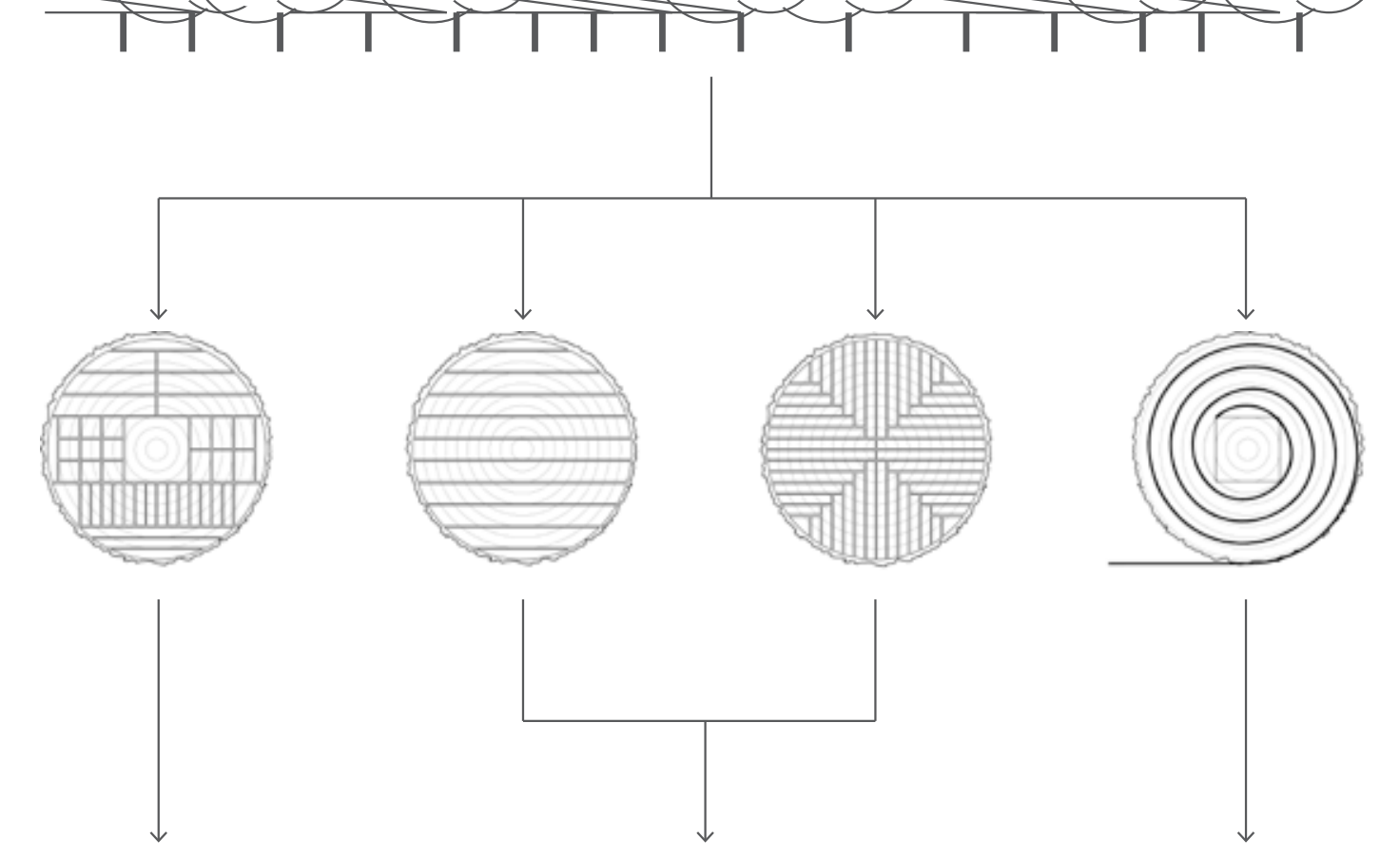

$\underset{\substack{\text { ROUNDWOOD } \\ \text { CUTTING }}}{\text { Con }}$
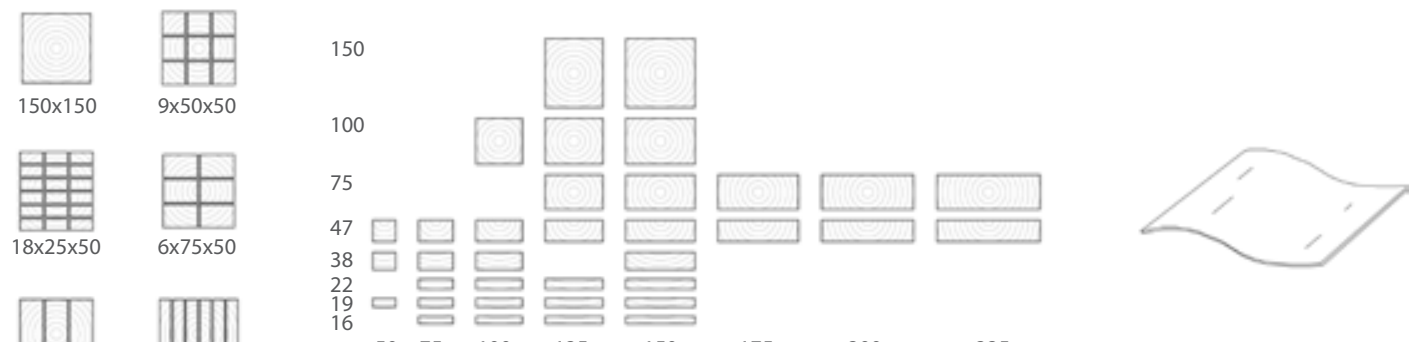

HARDWOOD

$\prod_{3 \times 150 \times 50}||||||$

$5075 \quad \sum_{100}{\underset{125}{150}}_{175}$

SHAVINGS,
CHIPPINGS \&

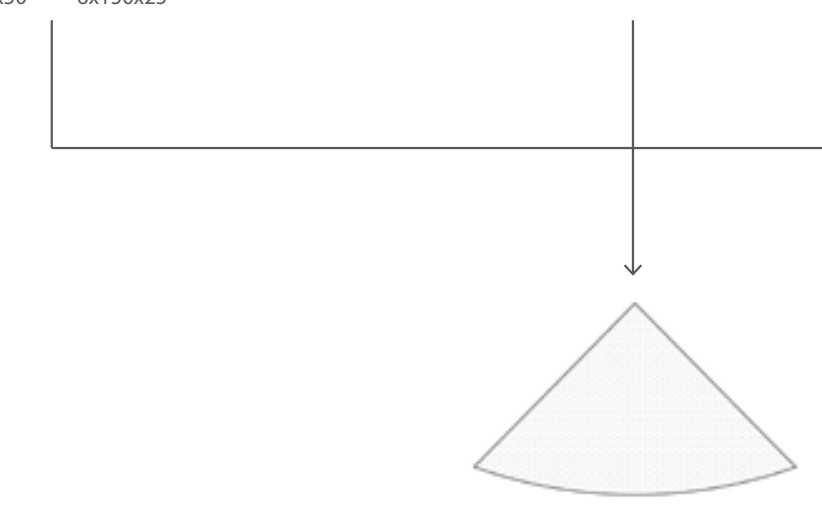




\subsubsection{The engineered component}

Traditionally, timber with specific shapes and sizes, was felled in large sections to carve, for example, cruck frames and stair volutes. Contemporary, equivalent, components are now required to be engineered from multiple short lengths and small sections to manufacture rational, planar and rectilinear products. This additive approach suggests the engineering of all timber species through stacking, aligning, layering, cross-layering, sandwiching, finger-jointing and orienting to enhance the performance of the basic sawnwood, veneers, chips, strands and sawdust.

RIGHT

Fig 10.8 Additive process of engineered timber to exploit the use of Welsh-grown timber

a. Finger jointing to create longer, more stable lengths than available in solid

section.

b. Stacking of standard timber sizes for

glulam components.

c. Bolting, or alternative methods, of

producing solid timber panels.

d. Box section laminating.

e. Cross stacking of standard sized timber

lengths for CLT panels.

f. Potential layering of veneers for plywood

manufacture.

g. Orienting of strands for potential OSB

manufacture.

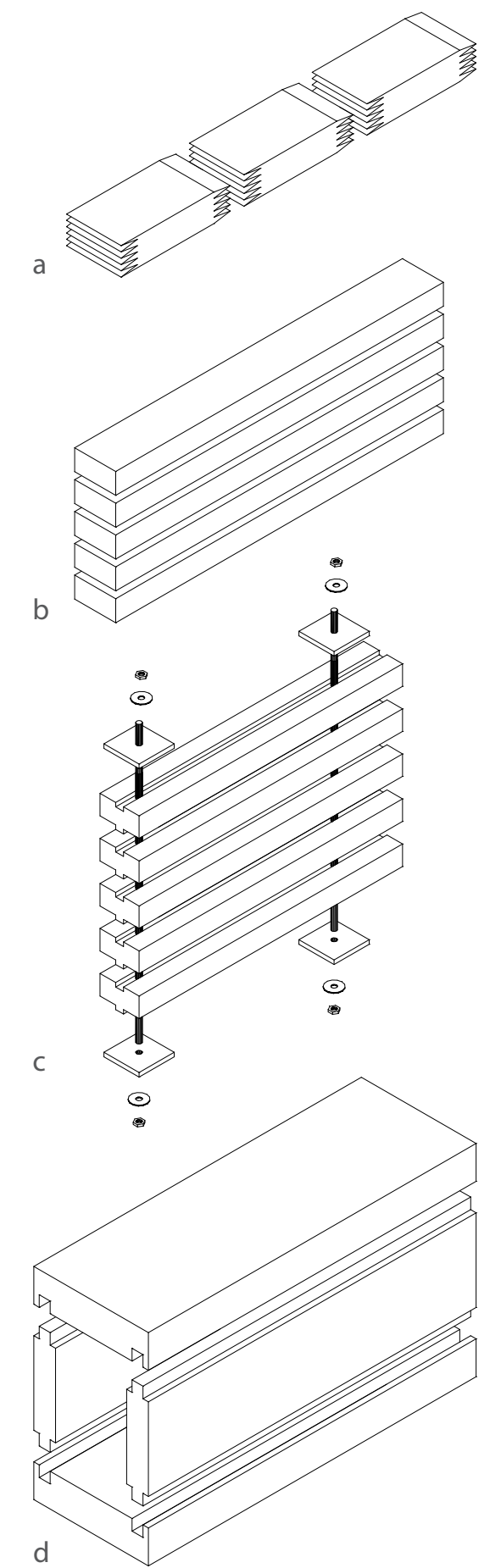

e

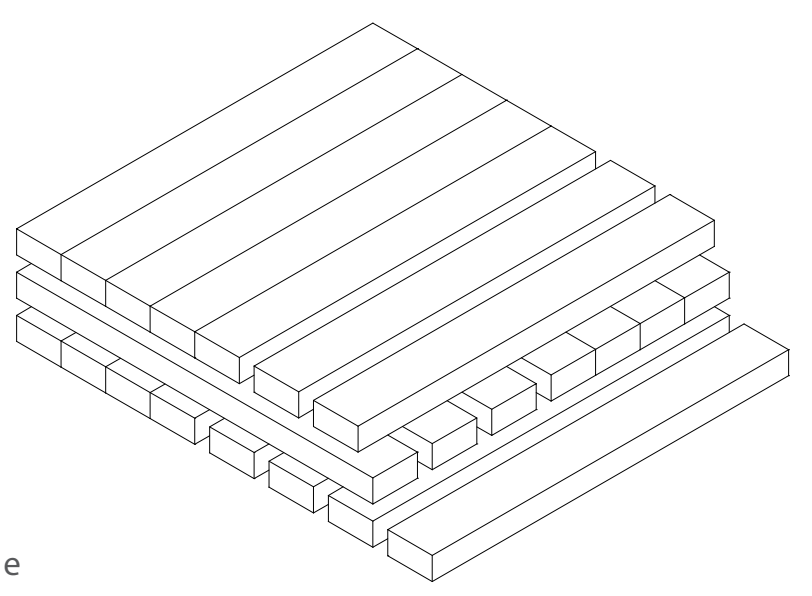

f
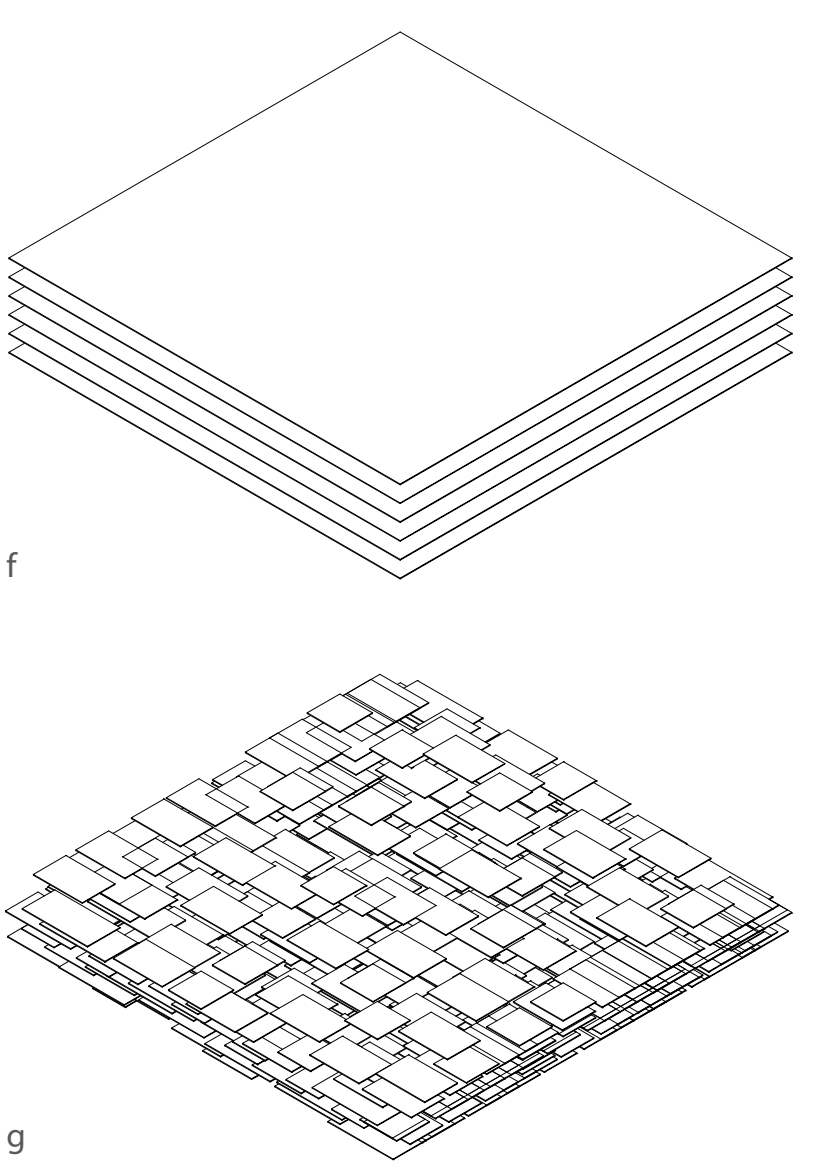


\subsubsection{The building element}

The sawnwood, engineered timber and timber products are manufactured,

fabricated and constructed into a range of modular and/ or prefabricated building envelope elements.
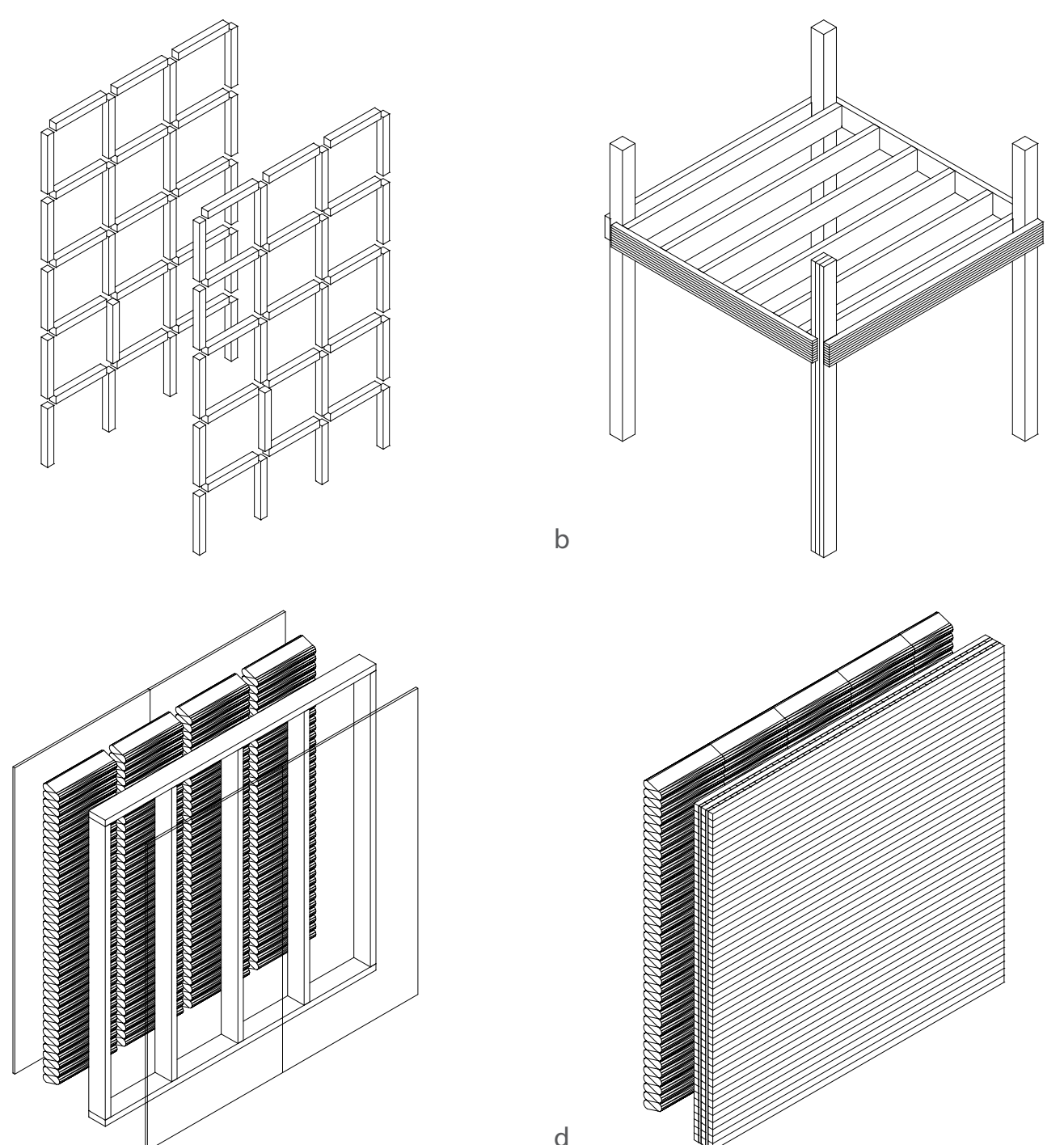

a. Small section and short length post and beam structures

b. Engineered post and beam structure

c. Timber frame, modular panel

d. Solid timber panels.

e. Standard sized components used to

fabricate hybrid volumetric/ panelised

storage units.

Volumetric construction using glulam

and standard sized components.

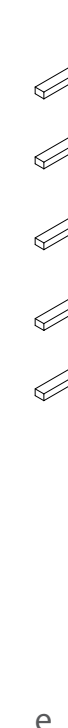
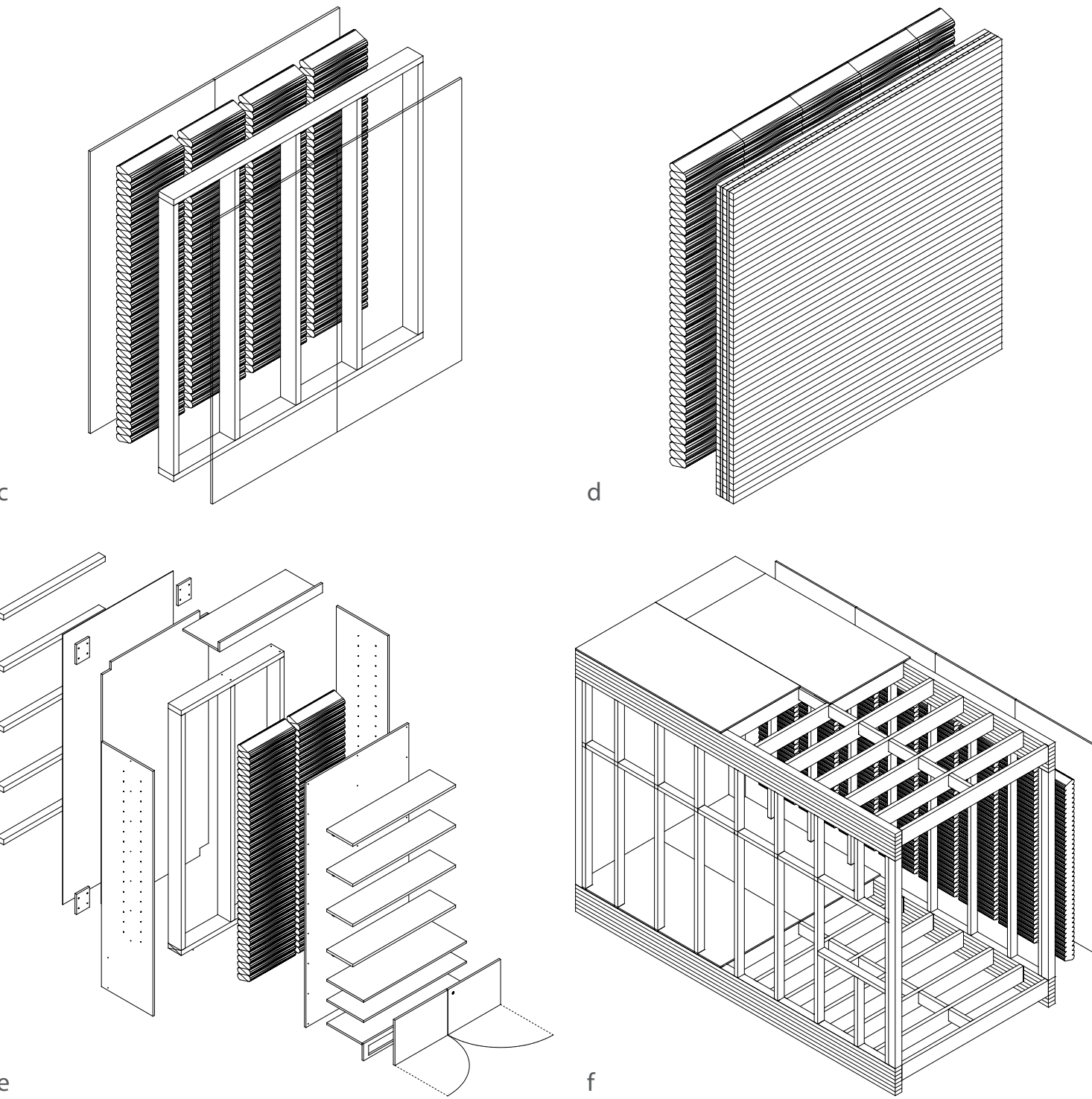


\section{The tectonic module}

The culmination of the additive stacking and layering of timber components and elements is informed by an applied design grid based on $300 / 600 \mathrm{~mm}$ repetitive modules. Modules may be elemental, panelised, volumetric or a hybrid combination but repeated to provide structure, enclosure, finishes and define space. The resultant tectonic is therefore honest to the use of Welsh-grown timber, responding to the species properties and industry technology to provide an efficient, low-energy building envelope. The proportion and composition in plan, section and elevation, determined by layout and structural grids allow for further extension and repetition with the addition of more modules. In a similar approach to Utzon's additive principle, space, composition, form and timber materiality are all expressed and respected as a tectonic timber architecture.
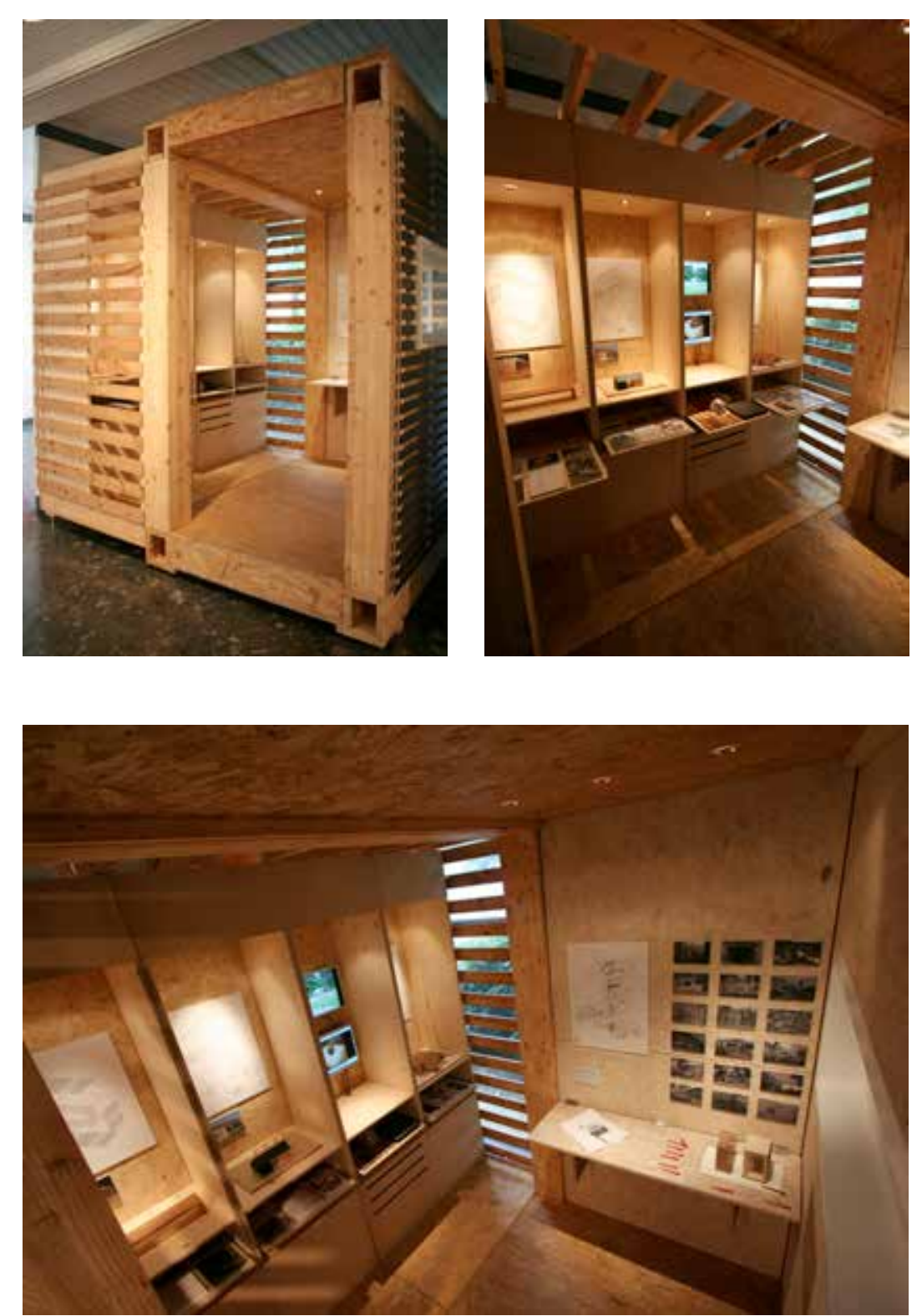

Fig 10.10 Exhibition installation for Reflecting Wales 09:09 The structure provided an opportunity to explore a combination of Welsh timber and manufactured buildin envelope components illustrated opposite based on a $600 \mathrm{~mm}$ layout grid. RIGHT

Fig $10.11600 \mathrm{~mm}$ layout grid coordinated with the a. $150 \times 150 \times 1200 \mathrm{~mm}$ frame b. standardised glulam post and beam structure

c. timber frame panel

d. $1200 \times 600 \mathrm{~m}$ plywood cabinets e. solid timber panels

f. volumetric spatial arrangement and construction

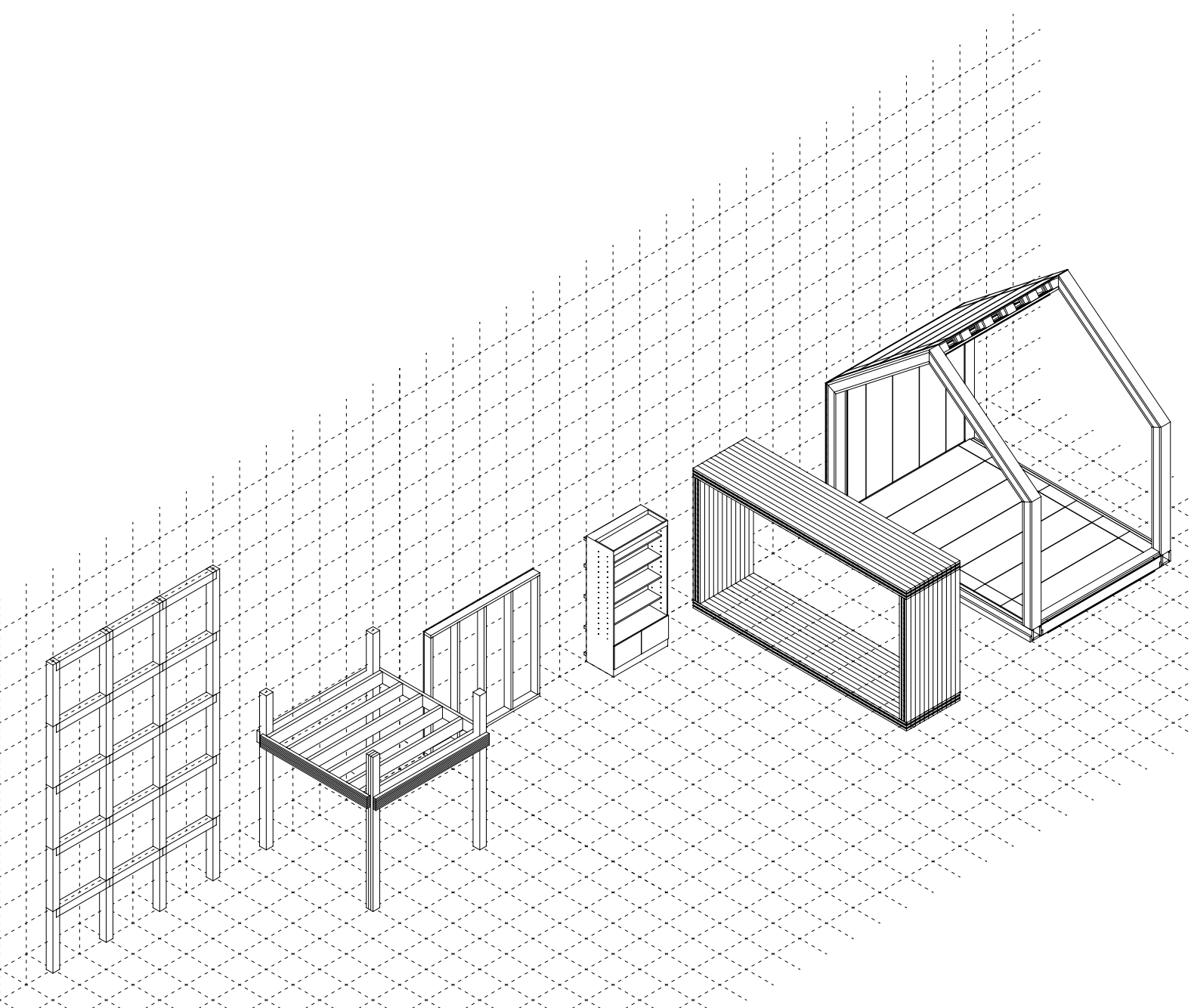




\section{$10.6 \quad$ Further work}

The research has produced findings that have developed the author's approach to designing and constructing with Welsh-grown timber and also produced a number of systems and products that are now being used by the construction industry to further the use of timber. However, the research also highlighted a number of further areas of study and research to develop the use of homegrown timber beyond the scope of this study:

\subsubsection{Timber industry promotion}

The research highlighted a number of areas of difficulty in growing, specifying, fabricating and detailing timber across all sectors of the industry and supply chain. This raises the question, who takes responsibility for the implementation of the findings? While Natural Resources Wales is currently within the same Welsh Government ministerial portfolio as development and construction, a source of decision making and possible funding is potentially more clear than throughout the research, however the many departments within this are diverse, each with a slightly differing focus. On the other hand, the findings are not necessarily all politically driven. There is clearly a need for a better understanding, availability and bestpractice examples with Welsh-grown timber to demonstrate to architects, engineers and consumers/ clients. While incentives and increased research and development is needed within the timber manufacturing sectors.

As a suggestion, the research has indicated that a 'centre of excellence' be established that would be beneficial to the Welsh timber industry representing the interests of the wide diversity of timber industries, attract research funding, support development within the sector and showcase best practice innovations and products. This currently exists in pockets from Coed Cymru, WFBP, WKW and BRE Wales as well as UK wide TRADA, Confor and TTF. This broad range of interests lacks a clear focus that a relatively small-scale industry needs to compete with the masonry and steel sectors. The industry must attract new, young and a diverse range of people for the future.

At an architectural level, it is worth considering a range of guides on the use of Welsh-grown timber that vary from technical performance guides such as for cladding, structures and general timber properties to architectural exemplars that highlight the benefits to construction efficiency and environmental performance that is evident in the Vorarlberg region. A publication such as New Timber Architecture in Scotland ${ }^{11}$, by Peter Wilson would be beneficial.

11 Peter Wilson, New Timber Architecture in Scotland, (Edinburgh: Arcamedia, 2007) 


\subsubsection{Sitka spruce system}

The most commercially successful output of this research was the development of the Sitka spruce construction system - Ty Unnos. The research into the additive use of Sitka spruce in contemporary Welsh architecture continues, with large-scale spans being explored for use in school and public buildings and window and door cassette systems, that are complementary to the current components and allow for simple replacement and maintenance in the future. However, the system approach has been dropped in favour for a range of components to be specified for specific needs and structural solutions.

Further research and development of the Ty Unnos system could be beneficial to a tectonic timber architecture, akin to that seen in the Vorarlberg. Commercialisation of the system or brand, more detailed economic modelling for mass production, ladder beam refinement as a potential replacement for imported C24 solid timber studs and environmental performance modelling and detailing are required.

\subsubsection{Innovation and adaptation}

The research has tested a number of bespoke innovations and experimented with current product availability. This research must continue in collaboration with other specialists to develop low-tech, innovative and cost effective products. This will require further: cost analysis on the use of homegrown timber from roundwood and sawnwood to value added products; and legislative research and testing such as on fire performance of exposed, unprotected timber.

\subsubsection{Design}

From the prototype projects and research into efficient, low-energy building construction it would seem possible to design and construct a $100 \%$ timber building envelope, excluding fixings and possible membranes, from internal finishes to external cladding using specific timber species as appropriate to the function and tectonic detail. This was not achievable within this thesis due to current limitations, but future opportunities would further develop the findings and test the performance of timber for a full range of building envelope uses.

Furthermore, the projects in this thesis were predominantly confined to smallscale, small-medium span, one-off projects that were appropriate for prototype research. However, an opportunity to explore a medium-scale development of 10-20 dwellings or an educational building type would further push the opportunities and efficiencies of innovative timber solutions. Scales of economy may be afforded to CLT, 


\subsubsection{Other sector research}

The research also highlighted a wide range of research within other sectors that would not necessarily be conducted by the author but would contribute significantly to the use of Welsh-grown timber in architecture such as: woodland management techniques to grow and produce appropriate timber species for a range of long-term and established markets; technical innovation and product manufacturing within the processing industries. 
Glossary of terms 


\section{Glossary of terms}

\begin{tabular}{|c|c|}
\hline $\begin{array}{l}\text { BRE: } \\
\text { BS: }\end{array}$ & $\begin{array}{l}\text { Building Research Establishment Wales } \\
\text { British Standard }\end{array}$ \\
\hline $\begin{array}{l}\text { BS: } \\
\text { C: }\end{array}$ & $\begin{array}{l}\text { British Standard } \\
\text { Conifer timber grade }\end{array}$ \\
\hline CCW: & Countryside Council for Wales \\
\hline CEREA: & Centre for Research, Engineering and Environment Application \\
\hline CfSH: & Code for Sustainable Homes \\
\hline CLS: & Canadian Lumber Sizes \\
\hline CLT: & Cross-Laminated Timber \\
\hline D: & Deciduous timber grade \\
\hline DCLG: & Department for Communities and Local Government \\
\hline DQR: & Development Quality Requirements \\
\hline DRU-w: & Design Research Unit Wales \\
\hline EPS: & Expanded polystyrene insulation \\
\hline ERC: & Environmental Resource Centre \\
\hline FAO: & Food and Agricultural Organisation \\
\hline FC: & Forestry Commission \\
\hline FSC: & Forest Stewardship Council \\
\hline GS: & General grade timber \\
\hline $\mathrm{HCl}:$ & Human-Computer-Interaction \\
\hline HS: & Imported tropical hardwood grade \\
\hline KJJ: & Kenton Jones Joinery \\
\hline LCRI: & Low Carbon Research Institute \\
\hline LSL: & Laminated Strand Lumber \\
\hline LVL: & Laminated Veneered Lumber \\
\hline MDF: & Medium-density fibreboard \\
\hline MMC: & Modern Methods of Construction \\
\hline NFI: & National Forest Inventory \\
\hline NHBC: & National House Building Council \\
\hline NIWT: & National Inventory of Woodlands and Trees \\
\hline NRW: & Natural Resources Wales \\
\hline OPDM: & Office of the Deputy Prime Minister \\
\hline OSB: & Oriented Strand Board \\
\hline PEFC: & Pan European Forest Certification \\
\hline PPW: & Planning Policy Wales \\
\hline PSL: & Parallel Strand Lumber \\
\hline RPBW: & Renzo Piano Building Workshop \\
\hline SIPS: & Structurally Insulated Panel System \\
\hline SPF: & Spray polyurethane foam \\
\hline SS: & Structural grade timber \\
\hline STA: & Structural Timber Association \\
\hline TAN: & Technical Advice Note \\
\hline TH1 and TH2: & UK hardwood general structural grade \\
\hline THA and THB: & UK hardwood heavy use grade \\
\hline TRADA: & Timber Research and Development Association \\
\hline TTF: & Timber Trade Federation \\
\hline UKTFA: & UKTimber Frame Association \\
\hline UWHA: & United Welsh Housing Association \\
\hline UWIST: & University of Wales Institute of Science and Technology \\
\hline WG: & Welsh Government previously Welsh Assembly Government \\
\hline WHQS: & Welsh Housing Quality Standards \\
\hline WFBP: & Wales Forest Business Partnership \\
\hline WKW: & Wood Knowledge Wales \\
\hline WSA: & Welsh School of Architecture \\
\hline WSW: & Wood Source Wales \\
\hline
\end{tabular}


Bibliography 


\section{Periodicals/ papers/ conferences/ reports}

Archer, 'Bruce, The Nature of Research', Co-design: Interdisciplinary Journal of Design, (1995) 6-13

Beim, Anne, 'Tectonic Visions in Architecture' (PhD dissertation, The Royal Danish Academy of Fine Arts, 1999)

British Standards Institution, BS 4978:2007+ A1: 2011 Visual strength grading of softwood - specification (London: British Standards Limited, 2011)

British Standards Institution, BS 5756:2007+ A1:2011 Visual strength grading of hardwood - specification (London: British Standards Limited, 2007)

British Standards Institution, BS EN 335: 2013 Durability of Wood and Wood-based products - use classes: definitions, application to solid wood and wood-based products (London: British Standards Limited 2013)

British Standards Institution, BS EN 336: 2003, Structural timber - sizes, permitted deviations (London: British Standards Limited, 2003)

British Standards Institution, BS EN 338: 2009 Structural timber - Strength classes (London: British Standards Limited, 2009)

British Standards Institution, BS EN 350-1: 1994 Durability of wood and wood-based products - Natural durability of solid wood, Part 1: Guide to the principles of testing and classification of the natural durability of wood (London: British Standards Limited, 1994)

British Standards Institution, BS EN 350-2: 1994 Durability of wood and wood-based products - Natural durability of solid wood, Part 2: Guide to the natural durability and treatability of selected wood species of importance in Europe (London: British Standards Limited, 1994)

British Standards Institution, BS EN 460: 1994 Durability of wood and wood-based products - Natural durability of solid wood - Guide to the durability requirements for wood to be used in hazard classes, (London: British Standards Limited, 1994)

British Standards Institution, BS EN 942: 2007 Timber in joinery - General requirements, (London: British Standards Limited, 2007)

British Standards Institution, BS EN 1313-1:2010 Round and sawn timber-Permitted deviations and preferred sizes, Part 1: Softwood sawn timber (London: British Standards Limited, 2010)

British Standards Institution, BS EN 1313-2: 1999 Round and sawn timber - Permitted deviations and preferred sizes, Part 2: Hardwood sawn timber (London: British Standards Limited, 1999)

British Standards Institution, BS EN 14081-1:2005+ A1:2011 Timber structures - Strength graded structura timber with rectangular cross section, Part 1: General requirements (London: British Standards Limited, 2011)

British Standards Institution, BS EN 14081-2:2010+ A1:2012 Timber structures - Strength graded structural timber with rectangular cross section, Part 2: Machine grading; additional requirements for initial type testing (London: British Standards Limited, 2012)

British Standards Institution, BS EN 1995-1:2004+ A1:2008 Eurocode 5: Design of timber structures, Part 1-1: General - Common rules and rules for buildings (London: British Standards Limited, 2008)

Broome, Jon, 'The Segal Method', Architect's Journal, 183 (1986), 31-68

Brundtland Commission, Our Common Future: The World Commission on Environment and Development 1987 (Reading: Oxford University Press, 1987) 
"Building in Timber", Architects' Journal, 172 (1980), 393-421

Building Research Establishment, The Movement of Timbers: Technical Note 38 (Watford: BRE, 1982)

Burroughs, Technical Assessment of the Ty Unnos System (Cardiff: Burroughs, 2009)

Carolin, Peter, 'Natural selection: Jeremy Dixon in Cambridge', Architecture Today, 49 (1994), $24-29$

Candy, Linda, 'Practice Based Research: A Guide', CSS Report (Sydney: University of Technology, 2006)

Cowley Timberwork, Ty Unnos: Prototype Beam Test (Lincoln: Cowley Timberwork, 2007)

Dauksta, Dainis, 'Japanese Larch in Wales: Investigating the potential to grow market share of larch in Wales and the Marches with a view to utilising increased timber production due to Phytophtho ramorum sanitation

Dauksta, Dainis, 'Perceptions of quality in homegrown Douglas fir', WoodKnowledge Wales report (Machynlleth: Wales Forest Business Partnership: 2011)

Davies, Ivor, Sustainable Construction Timber: Sourcing and Specifying Local Timber (Edinburgh: Forestry Commission Scotland, 2009)

Davies, I., B. Walker, J. Pendlebury, Timber Cladding in Scotland (Edinburgh: ARCA Publishing Ltd, 2002)

Davies, I., Watt, G., Making the Grade: A guide to appearance grading UK grown hardwood timber (Edinburgh: ARCA Media 2005)

Davis Langdon LLP, Designing out Waste: A design team guide for buildings (Oxon: Waste \& Resources Action Programme) p.7

Department for Research, Principles of Modern Building (London: HMSO 3rd edition, 1959)

Dyken, Tormod, Otto Kleppe, 'The Norwegian Approach to Modern Timber Bridge Design' (Baltic Road Association 25th Conference, Vilnius, 2003)

Barrie Evans, 'Theatre in the frame', Architect's Journal, 1 (1996) 35-44

Food and Agriculture Organization of the United Nations, State of the World's Forests 2007 (Rome: Electronic Publishing Policy and Support Branch - Communication Division - FAO, 2007)

Food and Agriculture Organization of the United Nations, 'Global Forest Resources Assessment Main Report' (Rome: FAO, 2010) p.224-228

Forestry Commission, Forestry Facts and Figures (UK : Forestry Commission, 2014)

Forestry Commission, Forestry Statistics 2012 (Edinburgh: Forestry Commission 2012)

Forestry Commission, Forestry Statistics 2014 (Edinburgh: Forestry Commission 2014)

Forestry Commission, National Inventory of Woodlands and Trees: Wales (Edinburgh: Forestry Commission, 2002)

Forestry Commission, NFI 2011 Woodland Map Wales: National Forest Inventory Report (Edinburgh: Forestry Commission, 2011)

Forestry Commission Wales, Woodlands for Wales: The Welsh Assembly Government's Strategy for woodlands and Trees (Cardiff:Welsh Assembly Government, 2009)

Haseman, Brad, 'A Manifesto for Performative Research', Media International Australia incorporating Culture and Policy, 118 (2006) 98-106 
Hawkes, Dean, 'Necessity and Poetry: David Lea's Bridge Pottery', ARQ, 6 (2002), 131-143

Heal, Amanda, 'Building Simply: An Investigation into the potential for building simply in the UK' (unpublished MPhil thesis, Cardiff University, 2011)

HM Government, Industrial Strategy: government and industry in partnership, UK Construction 2025 (London: HMSO, 2013)

HM Government, The Building Regulations 2010: Approved Document Part B Volumes 1 \& 2 (London: NBS, 2006)

Imperiale, Alicia, 'An American Wartime Dream: The Packaged House system of Konrad Wachsmann and Walter Gropius' (ACSA Fall Conference, Temple University, 2012)

Jaakko Pöyry Consulting, Welsh Forest Industry: Mapping and Benchmarking the Forest Industry, Final Report (Executive Summary Only) (London: Jaakko Pöyry Consulting, 2004)

Jenkins, Tom, Justin Gilbert, Ewan Mackie, Robert Matthews, Tree Species: A document listing the tree species included in the 2011 Production Forecast (Edinburgh: Forestry Commission, 2011)

Johnson E., British Grown C16 Timber, (Earlston: BSW Timber, 2013)

Jones, Dennis, Timber Cladding in Wales: Timber Cladding in Wales (Machynlleth: Wales Forest Business Partnership: 2010)

Jones, Dennis, Nick Tune, 'Sustainable construction with timber in Wales', WoodKnowledge Wales report (Machynlleth: Wales Forest Business Partnership: 2010)

Jones, Dennis, Information sheet WKW 9-1: Modified Wood - opportunities in Wales Wood Knowledge Wales (Machynlleth: Wales Forest Business Partnership: 2009)

Jones, Dennis, Information sheet WKW 8: Producing energy efficient windows - opportunities for using Welsh grown timber (Machynlleth: Wales Forest Business Partnership: 2008)

Jones, Dennis, Review of the Welsh Timber Resource - Report number 268-534 (Port Talbot: Building Research Establishment Ltd, 2011)

Jones, Dennis, Welsh timber resources and their potential within the construction industry - Report number 236-355 (Port Talbot: BRE Wales for the Forestry Commission, 2007)

Joseph Rowntree Foundation, Rural Housing in Wales: Final Report (York: Joseph Rowntree Foundation 2008)

Kleboe, J, Timber and the Built Environment Conference (Edinburgh: Historic Scotland, 2004)

Marsh, R, Woodland Management in Wales: Recent research and implications for policy, (Wales Forest Business Partnership, 2013)

Mason, Bill, Gary Kerr and James Simpson, What is Continuous Cover Forestry? (Edinburgh: Forestry Commission, 1999)

McCartney, Alan, An evaluation of home grown Sitka spruce for high performance cladding, Thesis (B.Arch.) - Cardiff University, 2006

MCPFE and EfE/PEBLDS ad hoc Working Group, Sustainable Forest Management and the Ecosystem Approach (Warsaw: Ministerial Conference on the Protection of Forests in Europe, 2005)

Moore, John, Wood properties and used of Sitka spruce in Britain (Edinburgh: Forestry Commission, 2011) The National Assembly for Wales, Better Homes for People in Wales: A National Housing Strategy for Wales (Cardiff: National Assembly for Wales, 2001) 
Office of the Deputy Prime Minister, Housing, Planning, Local Government and the Regions Select Committee - Eighth Report, supplementary memorandum by the Office of the Deputy Prime Minister (London: The House of Commons, 2004)

Oliva, Michael C, Al G. Dimakis, Michael Ritter, 'Development and Use of Stress Laminated Timber Deck Bridges' Bridges and transmission line structures: Proceedings of the sessions at Structures Congress '87 related to bridges and transmission line structures (New York: American Society of Civil Engineers, 1987) 249-255

Owen, Julian, Kit and Modern Timber Frame Homes: The Complete Guide (Marlborough: The Crowood Press, 2007)

Papadopoulos, loannis, Glykeria Karagouni, 'European Timber Trade Analysis: An Economical Overview and Regional Market Potential', International Workshop, Larnaka, Cost Action E34 "Bonding of Timber" 2007

Planning Policy Wales, Technical Advice Note 2: Planning and affordable housing (Cardiff: National Assembly for Wales, 2006)

Powell, Kenneth, 'It's a Bute', Architects' Journal, 214 (2001), 30-39

"Review of Architecture: Timber Construction", Detail, January/February 2000

Reynolds, T N, and M Cornwell, Comparison of home grown and imported softwood for Timber frame market - Final report - Report number 215-340 (Port Talbot: Building Research Establishment Ltd, 2004)

Rhodes, Michael, 'Wood Architecture in the 1990's: An analysis of the changing state of wood architecture using case studies from around the world', (unpublished BArch Dissertation, Welsh Schoo of Architecture, 1999)

Ritter, Michael, Earl A Geske, Lola Mason, William McCutcheon, J William, Russell C Moody, James Wacker, James, 'Performance of Stress-Laminated Bridges', Wood Design Focus, 1 (1990), 12-16

Runberger, Jonas, 'Architectural Prototypes II, Reformations, Speculations and Strategies in the Digital Design Field' (Doctoral Thesis, KTH School of Architecture and the Built Environment, 2012)

Sassi, Paola, Recyclable buildings: Environmental, social and economic benefits of recyclable technologies, (London: RIBA Research Trust, 2004)

Secretary of State for Environment, Food and Rural Affairs, The UK Government Sustainable Development Strategy (London: HMSO, 2005)

Sheil, Bob, 'Design Through Making: An Introduction', Architectural Design, 75(2005) 5-12 Sinclair, Dale (ed.), RIBA Plan of Work 2013 (London: RIBA Publications, 2013) Stoney Bryans, Thomas, Integrated Strategies for the Welsh Timber Industry, (Cardiff: LCRI, 2011) Structural Timber Association, Structural Timber Engineering Bulletin : Fire safety in timber buildings (Alloa: Structural Timber Association, 2014)

Sutton, Andy, Daniel Black and Pete Walker, 'Cross-Laminated Timber: An introduction to low-impact building materials', BRE Information Paper, IP 17/11 (Watford: BRE Trust, 2011)

Sutton, Andy, Daniel Black and Pete Walker, 'Natural Fibre Insulation: An introduction to low-impact building materials', BRE Information Paper, IP 18/11 (Bracknell: BRE Publications, 2011)

Tanner, Dafydd, 'How is it possible to use more homegrown timber in Wales as a sustainable option in construction' (unpublished BArch Thesis, Cardiff University, 2006) 
Timber Trade Federation, Statistical Review 2014: Industry Facts and Figures for the Year 2013 (London: TTF, 2014)

Timbertrends, Market Report 2012 (Alloa: Structural Timber Association, 2012)

Trada Technology Ltd, 'Dry graded structural softwood', Trada Wood Information Sheets, 4, 29 (Buckinghamshire: Trada Technology Ltd, 2002)

Tyler A.L., D.C MacMillan and J Dutch, Models to Predict the General Yield Class of Douglas fir, Japanese larch and Scots Pine on Better Quality Land in Scotland (Edinburgh: Institute of Chartered Foresters,

1996)

United Nations Development Programme, United Nations Environment Programme, World Bank, World Resources Institute, A Guide to World Resources 2000-2001: People and Ecosystems: The Fraying Web of Life (Washington: World Resources Institute, 2000)

United Nations Economic Commission for Europe/ Food and Agriculture Organization of the United Nations, European Forest Sector Outlook Study (Geneva: United Nations, 2005)

United Nations General Assembly, Non-Legally Binding Authoritative Statement of Principles for a Global Consensus on the Management, Conservation and Sustainable Development of all Types of Forests (Rio de

Utzon, Jørn, 'Espansiva', Architektur, 14 (1970), 3-12

Vokes, Clare and Jennifer Brennan, Technology and Skills in the Construction Industry: Evidence Report 74 (Rotherham: UKCES, 2013)

Welsh Assembly Government, Development Quality Requirements: Design Standards and Guidance (Cardiff: Welsh Assembly Government, 2005)

Welsh Assembly Government, One Wales: A progressive agenda for the government of Wales, An agreement between the Labour and Plaid Cymru Groups in the National Assembly, 27th June 2007

Welsh Assembly Government, One Wales: One Planet, The Sustainable Development Scheme of the Welsh Assembly Government (Cardiff: Welsh Assembly Government, 2009)

Wilkins, Cedric, Comparison of home grown and imported softwood for Timber Frame market Final Report - report 215-340 (Watford: BRE, 2004)

"Wood", The Architectural Review, vol.1199, January 1997

Wood for good, 'Timber: meeting the demand for sustainable buildings', EcoTech: Sustainable Architecture Today, Issue 10, November 2004

Wright, Frank Lloyd 'In the cause of architecture IV: The meaning of materials - wood', Architectural Record, 63 (1928), 481-488 


\section{Books}

Affentranger, Christian, New Wood Architecture in Scandinavia (Verlag: Birkhäuser, 1997) Allen, William, Envelope Design for Buildings (Oxford: Architectural Press, 1997)

Banham, Reyner, Architecture of the Well-Tempered Environment (London: Architectural Press, 1969) Brunskill, R.W, Timber Building in Britain, 2nd edn (London: Cassell, 1994) Brunskill, R.W, Illustrated Handbook of Vernacular Architecture (London: Faber and Faber, 1971) Charles, F.W.B., Medieval Cruck-building and its Derivatives (London: The Society of Medieval Archaeology, 1967)

Chong, C. V. Y, Properties of Materials (Plymouth: Macdonald and Evans Ltd, 1977) Cross, Nigel, Developments in Design Methodology (Chichester: John Wiley \& Sons Ltd, 1984) Cross, Nigel, Designerly Ways of Knowing (Basel: Birkhauser, 2007)

Deplazes, Andrea (ed.), Constructing Architecture: Materials Processes Structures: A handbook (Basel: Birkhäuser, 2005

Dudley, Nigel, Jean-Paul Jeanrenaud and Frances Sullivan, Bad Harvest: timber trade and the degradation of the world's forests (London, Earthscan Publications Limited, 1996)

Eastwick-Field, John and John Stillman, The Design and Practice of Joinery (London: The Architectural Press, 1958)

Edwards, B and P Hyett, Rough Guide to Sustainability (London: RIBA, 2001)

Edwards, Brian, Sustainable Architecture: European Directives \& Building Design, 2nd edn (Oxford: Architectural Press, 1999)

Everett, Alan, Mitchell's Building Series: Materials (Harlow: Addison Wesley Longman Limited, 1997)

Fiel , Wolfgang (Ed.) Getting Things Done: Evolution of the Built Environment in Vorarlberg (Basel: Birkhauser, 2014)

Findlay, W. P. K., Timber: Properties and Uses (Herts: Granada Publishing Limited,1978)

Fitter, Alastair, Trees (Glasgow: Harper Collins Publishers Limited, 2004)

Frampton, Kenneth, Studies in Tectonic Culture: The Poetics of Construction in Nineteenth and Twentieth Century Architecture (Massachusetts: MIT Press, 2001)

Gibbs, Nick, The Real Wood Bible (London: Firefly Books Ltd, 2005)

Gili, Monica, Lacaton \& Vassal: 2G Libros Books (Barcelona: Editorial Gustavo Gili, SL, 2006) Groak, Steven, The idea of building, (London: E \& FH Spon, 1992)

Groat, Linda and David Wang, Architectural Research Methods (Canada: John Wiley \& Sons, Inc., 2002) Gutdeutsch, Götz, Building in Wood: Construction and Details (Basel: Birkhäuser, 1996)

Haan, Hilde de, Wood Works: architecture in wood | Onix : architectuur in hout (Rotterdam: NAi Uitgevers, 2009) 
Hairstans, Dr Robert, Off-site and modern methods of timber construction: a sustainable approach (High Wycombe: TRADA Technology Ltd, 2010

Hansen, Hans Jèurgen, Architecture in wood: a history of wood building and its techniques in Europe and North America (New York: Viking Press, 1971)

Harris, Cindy and Pat Borer, The Whole House Book: Ecological Building Design and Materials (Machynlleth: Centre for Alternative Technology, 2005)

Harris, Richard, Discovering Timber-Framed Buildings (Aylesbury: Shire Publications Ltd, 1986) Hegger, Manfred, Hans Drexler and Martin Zeumer, Basics: Materials (Basel: Birkhäuser, 2007)

Heikkinen, Pekka, Jari Laiho and Jussi Tiainen, Puusta Tehty: Wood Works (Helsinki: Parvs Publishing, 2007)

Helander, M., T.Ê Landauer and P. Prabhu (eds.), Handbook of Human-Computer Interaction, 2nd edn (Amsterdam: Elsevier Science B. $V$, 1997)

Henrichsen, Christoph, Japan - Culture of Wood: Buildings, Objects, Techniques (Basel: Birkhäuser Architecture, 2004)

Hensel, Michael, Design Innovation for the Built Environment: Research by Design and the Renovation of Practice (Oxon: Routledge, 2012)

Hislop, P.J, External Timber Cladding, 2nd edn (High Wycombe: TRADA Technology, 2007)

Hoffmann Kurt: Griese, Helga, Building with Wood: Form, Structural Design and Preservation, London Iliffe Books Ltd, 1969

Kapfinger, Otto (ed.), Hermann Kaufmann Wood Works (New York: Springer-Wien, 2009)

Kapfinger, Otto; Ulrich Weiler, Riess Wood 3: Modulare Holzbausysteme (Vienna: Springer, 2007)

Kaufmann, Hermann and Winfried Nerdinger, Building with Timber: Paths into the Future (Munich: Prestel Publishing Ltd, 2011)

Kaufmann, Hermann, Spirit of Nature Wood Architecture Award 2010 (Helsinki: Rakennustieto Publishing, 2010)

Koskinen, Ilpo, John Zimmerman, Thomas Binder, Johan Redstrom, Steohan Wensveen, Design Research Through Practice: From the lab, field and showroom (Waltham: Elsevier, 2011)

Lancashire, Robin and Lewis Taylor, Timber Frame Construction: designing for high performance, (High Wycombe: TRADA Technology Ltd 5th edition, 2011)

Latham, Bryan, Timber: A Historical Survey of its Development and Distribution (London: George Harrap,

Law, Ben, The Woodland Way: A Permaculture Approach to Sustainable Woodland Management (Hampshire: Permanent Publications, 2001)

Lawson, Bryan, How Designers Think: The Design Process Demystified (Oxford: Architectural Press, 1980) Lewin, K., Resolving social conflicts: selected papers on group dynamics (New York: Harper \& Row, 1948) Le Cuyer, Annette, Radical Tectonics (London: Thames \& Hudson, 2001)

Lindman, Ake Eison and others, Swedish Architecture in Wood: The 2004 Timber Prize (Stockholm: Arvinius Förlag, 2004) 
Linnard, William, Welsh Woods and Forests: A history (Llandysul: Gomer Press, 2000)

McQuaid, Matilda, Shigeru Ban (London: Phaidon, 2003)

Meyhöter, Dirk, Touch Wood: The rediscovery of a building material (Switzerland: Verlagshaus Braun, 2008)

Michel, R. (ed.), Design research now (Basel: Birkhäuser, 2007)

Ministry of Technology: Forest Products Research, A Handbook of Hardwoods (London: Her Majesty's Stationery Office, 1956

Müller, Christian, Holzeimbau: Laminated Timber Construction (Basel: Birkhäuser, 2000)

Osbourn, Derek, Mitchell's Building Series: Introduction to Building (Harlow: Addison Wesley Longman Limited, 1997)

Parker, Harry and James Ambrose, Simplified Design of Structural Wood (Canada: John Wiley \& Sons, 1998)

Pitts, Geoffrey and Robin Lancashire, Low-energy timber frame buildings: designing for high performance, 2nd edn (High Wycombe: TRADA Technology Ltd, 2011)

Prip-Buus, Mogens (ed.), Jørn Utzon Logbook:v.5 Additive Architecture (Copenhagen: Edition Bløndal 2009)

Rich, Peter and Yvonne Dean, Principles of Element Design (Oxford: Butter- Heinemann,1999)

Richards, J.M., The Functional Tradition in early industrial buildings; with photographs by Eric de Maré (London: Architectural Press, 1958)

Rose, Walter, The Village Carpenter (Ammanford: Stobart Davies, 2009)

Ross, Peter, Christopher Mettem and Andrew Holloway, Green Oak in Construction (High Wycombe: TRADA Technology Ltd, 2007)

Rushke, W, Timber construction for trade, industry, administration: basics and projects (Boston: Birkhäuser, 2004)

Savill, Peter. S, The Silviculture of Trees Used in British Forestry, 2nd edn (Boston: CABI Publishing, 2013)

Schittich, Christian, Best of Detail: Holz/Wood (München: Institut für international ArchitekturDokumentation GmbH \& Co. KG, 2014)

Schittich, Christian (ed.), Building Skins (Basel: Birkhauser Architecture, 2006)

Schittich, Christian (ed.), Building Simply (Basel: Birkhauser Architecture, 2001)

Schon, Donald, The Reflective Practitioner: How Professionals Think in Action (USA: Basic Books, 1983)

Schönbächler, Daniel, Saint Benedict Chapel Architecture and Symbolism: Thoughts and Images (Sumvitg: Cussegl da fundazin, 2013)

Schumacher, E.F, Small is Beautiful: A Study of Economics as if People Mattered (London: Vintage, 1993)

Semper, Gottfried, Four Elements of Architecture and Other Writings, transl. Harry Francis Mallgrave and Wolfgang Herrmann (Cambridge: Cambridge University Press, 1989)

Sheil, Bob, Manufacturing the Bespoke: Making and Prototyping Architecture (West Sussex: John Wiley \& Sons Ltd, 2012)

Slavid, Ruth, Wood Architecture (London: Laurence King Publishing, 2005) 
Van Schaik, Leon and Michael Spooner (eds.), The Practice of Practice 2: Research in the medium of Design (Melbourne: onepointsixone, 2010)

Wachsmann, Konrad, Building the Wooden House (Verlag: Birkhauser, 1995)

West, Trudy, The Timber-frame House in England (Newton Abbott: David and Charles, 1971)

Weston, Richard, Utzon : Inspiration, Vision, Architecture (Copenhagen: Edition Bløndal, 2002)

White, John, Jill White and S. Max Walters, Trees: a field guide to the trees of Britain and Northern Europe (Oxford: Oxford University Press, 2005)

Wilson, Peter, New Timber Architecture in Scotland (Edinburgh: Arcamedia, 2007)

Wirz, Heinz, Konstruktionen/Constructions: Burkhalter and Sumi - Architekten/Architects, Makio Wiederkehr - Holzbauingenieure/ Timber Construction Engineers (Luzern: Quart Verlag, 2005)

Woolley, T and S Kimmins, Green Building Handbook Volume 1: A Guide to Building Products and their Impact on the Environment (London: E \& FN Spon, 1997)

Internet

Activehouse <http://www.activehouse.info $>$ [accessed 5th August 2015]

American Tree Farm System (Washington DC, 2015) <https://www.treefarmsystem.org> [accessed 1st August 2015]

Bergdoll, Barry and Peter Christensen,'Packaged House by Konrad Wachsmann and Walter Gropius (1941-1952)', <http://www.shelterpress.com/categories/homes/prefab-homes/history

prefabricated-home/packaged-house-konrad-wachsmann-and-walter-gropius.html> [accessed 16th September 2015]

BSW Timber Group, Easi-timber, <http://www.easi-timber.co.uk/construction/> [accessed 10th August 2015]

Carpenter, Andrew, Building in Timber, (Heathfield: Architects Datafile, NetMAGMedia, 2014) $<$ http://www.architectsdatafile.co.uk/news/building-in-timber> [accessed 20th August 2015

Cavill, Nancy,'Timber's back in the frame', Issue 31, 1999, <http://www.building.co.uk/ timber8217sback-in-the-frame/4474.article> [accessed 22nd August 2015]

Coed Cymru, Objectives and Targets <http://www.coedcymru.org.uk/objectives.html> [accessed 17th August 2015]

Coed Cymru, Innovation <http://www.coedcymru.org.uk/innovation.html> [accessed 10th July 2015]

Dudley, Nigel, Timber and Certification: Trade incentives for sustainable development, March 1995 $<$ http://www.equilibrium consultants.com/publications/docs/timberandcertification.pdf $>$ [accessed 24th August 2005] 
European Wood, Parallel strand lumber (PSL), <http://www.europeanwood.org.cn/en/parallel-strandlumber> [accessed 4th September 2015]

Evans, Layne, Cross Laminated Timber: Taking Wood buildings to the next level, <http://www. rethinkwood.com/sites/default/files/Cross-Laminated-Timber-CEU.pdf> [accessed 5th September

Explore Gower, Weather and Climate (Explore Gower 2015) <http://www.explore-gower.co.uk> [accessed 20th June 2015]

Forestry Commission, Woodlands for Wales <http://www.forestry.gov.uk/wwstrategy> [accessed 3rd August 2009]

Forest Stewardship Council <http://www.fsc.org/en> [accessed 15th August 2005]

Forest Stewardship Council, Our Mission (FSC) <http://www.fsc-uk.org/our-mission-and vision.8.htm> [accessed 27th June 2013]

Forestry Commission, Sustainable Forestry Management: The International Framework, $2002<\mathrm{http}: / /$ www.forestry.gov.uk/pdf/sfm.pdf/Sfile/sfm.pdf> [accessed 24th August 2005]

Greenpeace <http://www.greenpeace.org/international/campaigns/forests> [accessed 27th August 2005

Halstead, Gary R, Northern European Timber Trade in the Later Middle Ages \& Renaissance <http://www. medievalwoodworking.com/articles/lumber trade.htm $>$ [accessed 15th August 2009]

Henderson, James, Sam Foster, Matt Bridgestock, What is Brettstapel? (2012) <http://www.brettstapel. org/Brettstapel/What is it.html> [accessed 4th September 2015]

Hermann Kaufmann Architects <http://www.hermann-kaufmann.at/pdfs/11_12.pdf> [accessed 12th September 2015]

House of Commons, Environmental Audit Committee 2002, Buying Time for Forests: Timber Trade and Public Procurement <http://www.publications.parliament.uk/pa/cm200102/cmselect/ cmenvaud/792/79202.htm> [accessed 3rd August 2009]

Kam-Biron, Michelle, 'The ABC's of Traditional and Engineered Wood Products' Structure Magazine (2014), <http://www.structuremag.org/?p=7053> [accessed 4th September 2015]

KLH UK, Panel Surface Quality (London: KLH UK) <http://www.klhuk.com/product-/panelsurfacequality.aspx> [accessed 15th July 2015

KLH UK, Sustainability (London: KLH UK) <http://www.klhuk.com/sustainability.aspx> [accessed 15th July 2015]

KLH UK, Technical Characteristics sheet (London: KLH UK) <www.klhuk.com/media/29233/ technical\%2characteristics.pdf> [accessed 15th July 2015]

Lassila, Anssi, Kärsämäki Shingle Church <http://www.architonic.com/aisht/karsamaki-shingle-churchlassila-hirvilammi-architects/5100120> [accessed 12th September 2015]

Lifetime Homes, Lifetime Homes Principles, <http://www.lifetimehomes.org.uk/pages/lifetimehomesprinciples.html> [accessed 2nd September 2015]

Ministry of Agriculture and Forestry <http://www.mmm.fi/en/index/frontpage/forests/legislation. html $>$ [accessed 12th August 2015]

Northern Office for Research and Design, East End Sawmills, <http://nordarchitecture.com/projects/ east-end-sawmills/> [accessed 6th August 2013] 
Pan European Forestry Certification (PEFC), <http://www.pefc.org/internet/html/about_pefc.htm> 1995 [accessed 24th August 2005]

Passivhaus Trust, The UK Passive House Organisation, <http://www.passivhaustrust.org.uk> [accessed on 5th August 2015]

Ross, Peter, Sustainable timber - the designer's options, first published in the Faculty of Building Journal, February $2001<$ http://www.faculty-of-building.co.uk/pubs_tomalin_text.htm> [accessed 14th April 2005]

2005 Serpentine Gallery <http://alvarosizavieira.com/2005-serpentine-gallery> [accessed 13th September 2015]

Smit, Josephine,'20 years after World in Action, Barratt goes back into prefab', 2003

<http://www.building.co.uk/news/finance/20-years-afetr-world-in-action-barratt-goes-back-into prefab/1030087.article> [accessed 22nd August 2015]

Swisher, Shawn. 'What Makes Us Human: Reactions to the Shelters for Roman Archaeological Site.' ArchDaily, $2010<$ <ttp://www.archdaily.com/76796/what-makes-us-human-reactions-to-the-sheltersfor-roman-archaeological-site> [accessed 13th September 2015]

Techniker, Tall Timber Buildings: The Stadthaus, Hoxton, London <http://www.techniker.oi-dev.org/ blog> [accessed 13th September 2015]

The Forestry Commission, Tree species and provenance <http://www.forestry.gov.uk/fr/INFD-8CYJVJ>

Timber Trade Federation, Sustainability (London: Timber Trade Federation 2014) <http://www.ttf. co.uk/sustainability.aspx> [accessed 7th August 2015]

Welsh Government, Welsh Housing Quality Standard, (2014) <http://gov.wales/topics/housing-andregeneration/housing-quality/welsh-standard/?lang=en> [accessed 2nd September 2015]

Wood Program, Introduction, (Aalto University School of Arts, Design and Architecture) <http:// woodprogram.fi/introduction/> [accessed 20th July 2015] 
